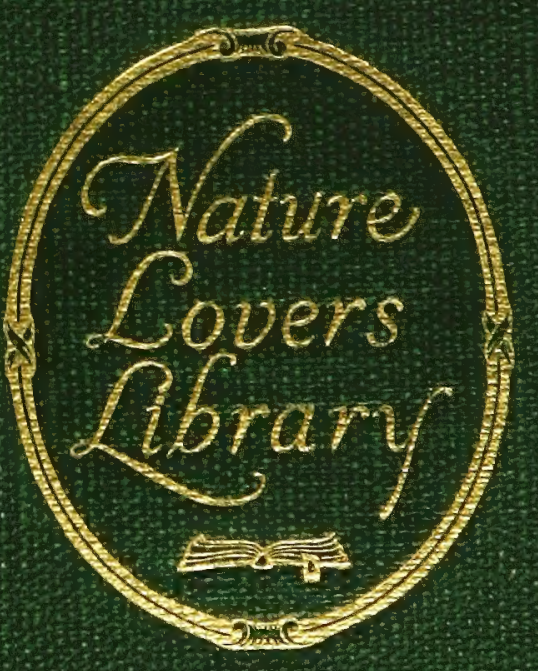




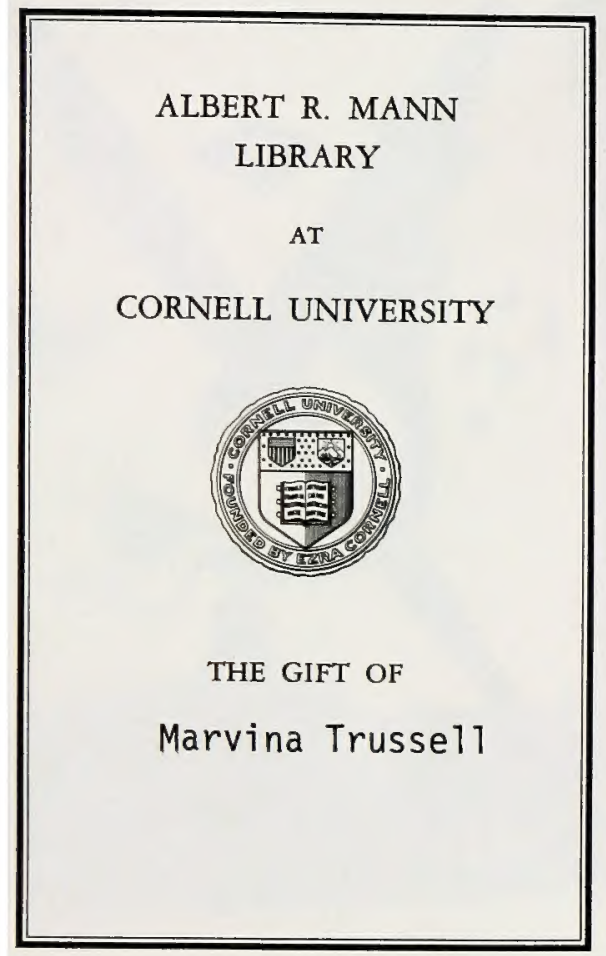




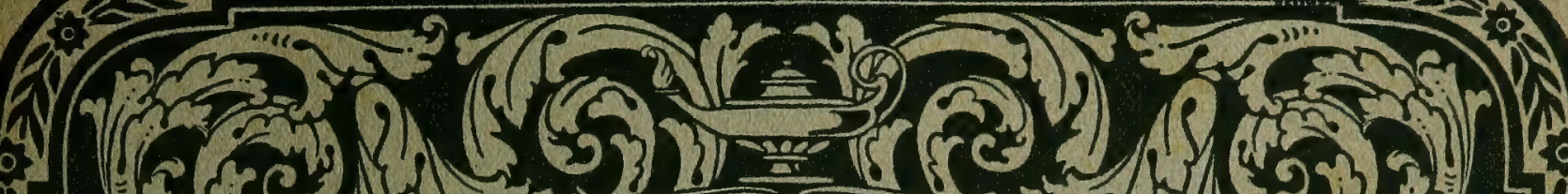

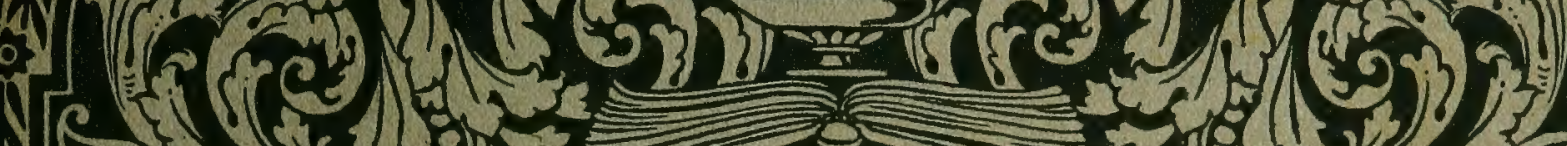

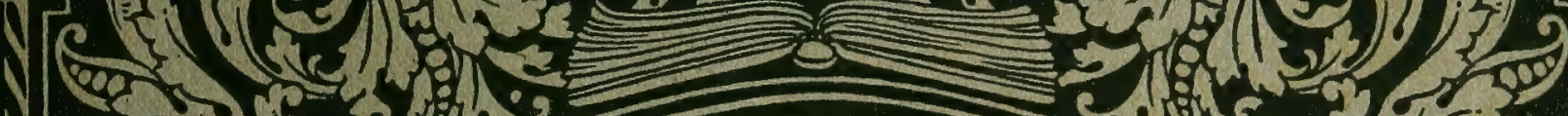

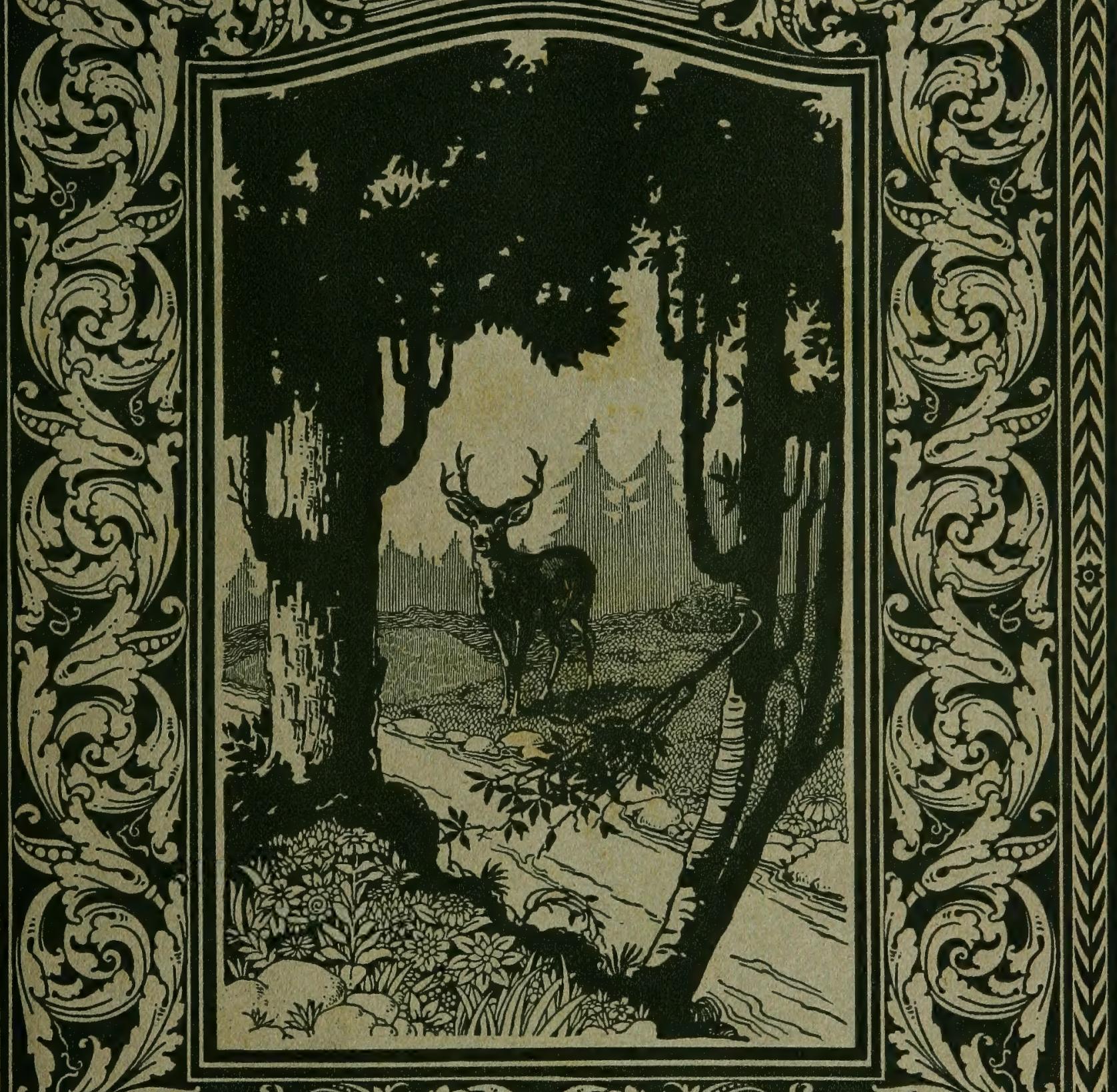

$1 / 2=0$

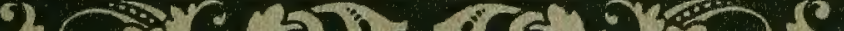

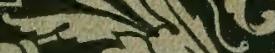

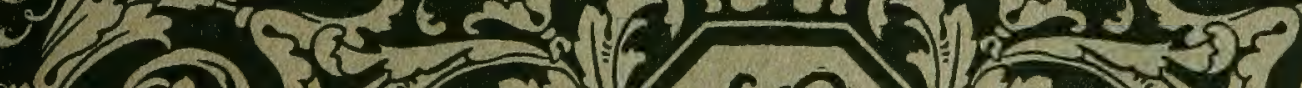

$\left\{\frac{2}{2}\left(\frac{2}{3}\right)\right.$

की

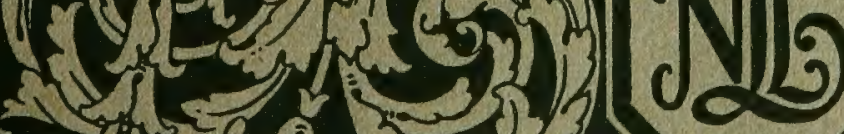

$\sqrt{2}$

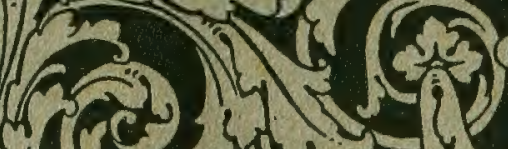




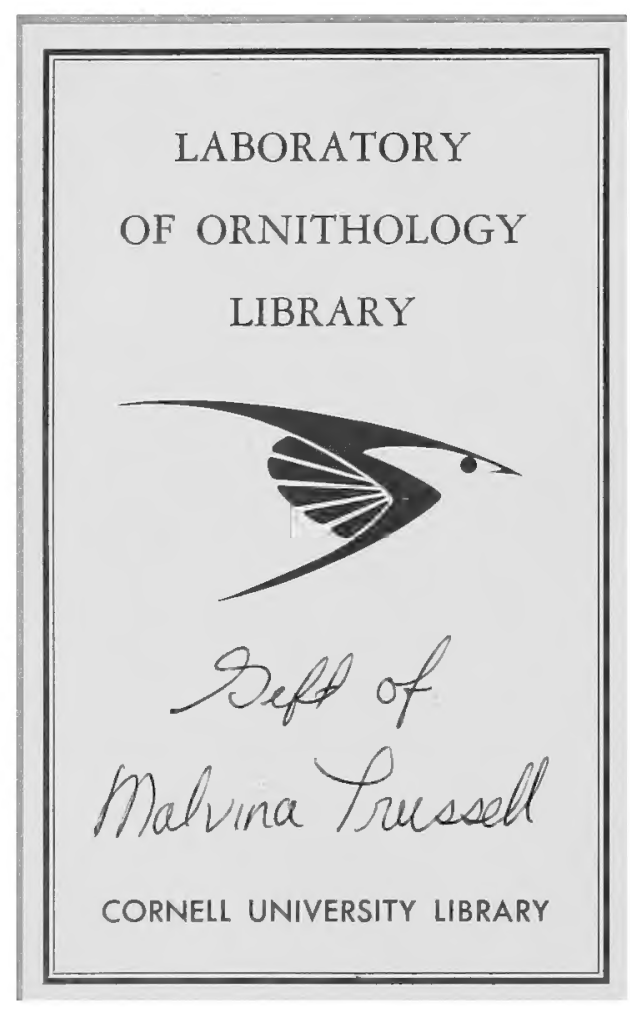




\section{Cornell University Library}

The original of this book is in the Cornell University Library.

There are no known copyright restrictions in the United States on the use of the text.

http://www.archive.org/details/cu31924022566826 
Mammals of other lands;

31924022566826
ormi 



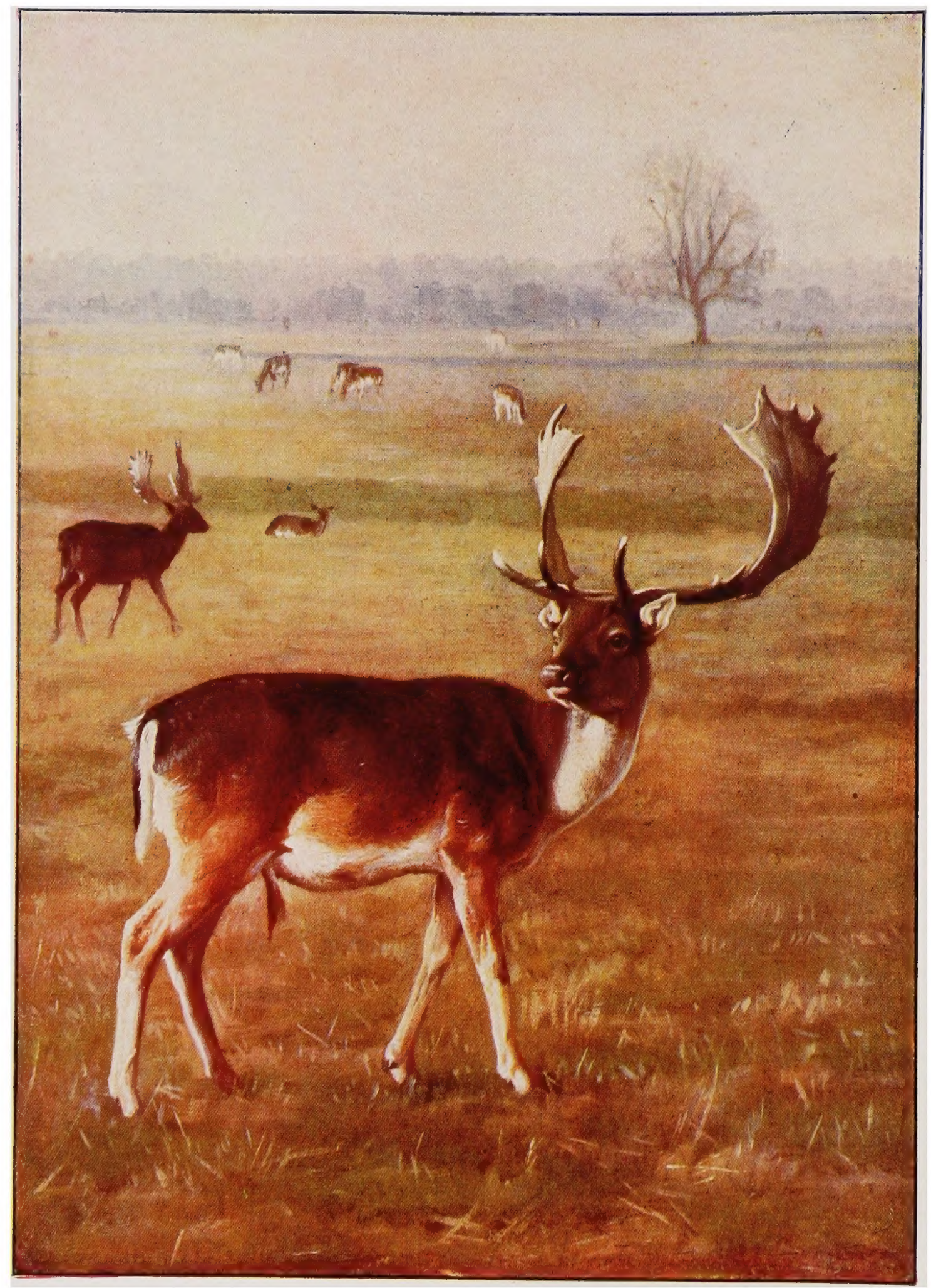

Photo by the Duchess of Bedford, Woburn Abbey.

FALLOW DEER,

There are two breeds of these beautiful deer in the British Isles; in the one the summer coat is fawn dappled with white; in the other the colour is dark brown at all seasonș. 




\section{Mammals \\ of Other Lands}

Editors and Special Contributors

Charles J. Cornish Sir Herbert Maxwell

Ernest Ingersoll Sir Harry Johnston

F. C. Selous H. N. Hutchinson

R. Lydekker J. W. Gregory and many others

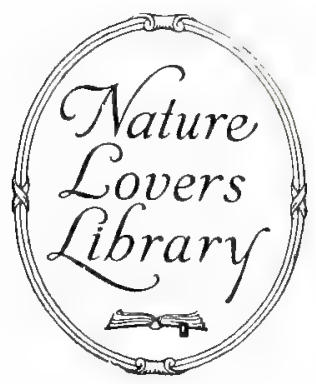

The University Society Inc.

New York

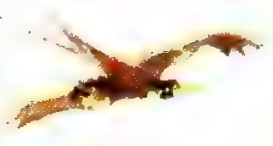




$$
\begin{aligned}
& \text { Mann } \\
& \text { Spec.coll. } \\
& \text { it } \\
& 706 \\
& 1126 \times \\
& 19: 7
\end{aligned}
$$

Copyright, 1917, by

The University Society Inc.

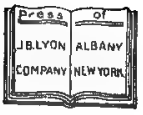




\section{CONTENTS}

\section{MAMMALS OF OTHER LANDS}

Apes, Monkeys, and Lemurs.

PAGES

The Cat Tribe. . . . . . . . . . . . . . . . . . 33

The Fossa, Civets, and Ichneumons . . . . . . . . . . . • . . . 74

The Hyenas and Aard-Wolf . . . . . . . . . . . . . . . . 80

The Dog Family . . . . . . . . . . . . . . . . . . . . . 83

The Bears . . . . . . . . . . . . . . . . . . . . . . . 109

The Smaller Carnivora . . . . . . . . . . . . . . . . . . . . . 115

Marine Carnivora: The Seals, Sea lion, and Walrus . . . • . • . 120

The Rodents, or Gnawing Animals . . . . . . . . . . . . . . 130

The Bats and Insect-Eating Mammals . . . . . . . . . . . . . . 143

The Elephant, Tapir, Hyrax, and Rhinoceros . . . . . . . . . . . 150

The Horse Tribe . . . . . . . . . . . . . . . . . . . 167

The Hollow-Horned Ruminants: Oxen, Bisjn, Buffaloes, and Musk-Oxen . . 185

The Sheep and Goats . . . . . . . . . . . . . . . . 196

The Antelopes . . . . . . . . . . . . . . . . . . . . . . . . . 213

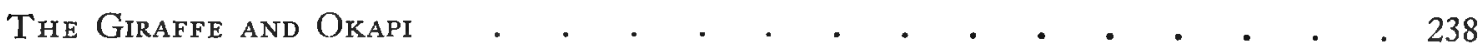

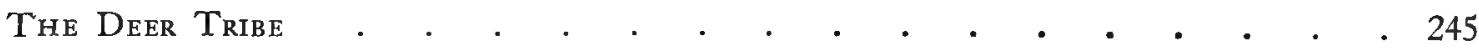

The Camel Tribe and the Chevrotains . . . . . . . . . . . . . . . . . 266

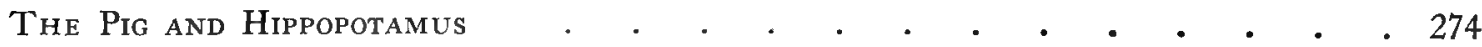

The Dugong, Manatees, Whales, Porpoises, and Dolphins . • . • • . 291

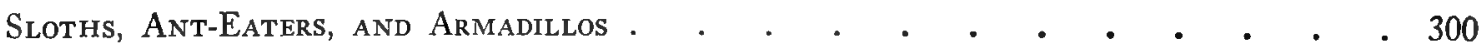

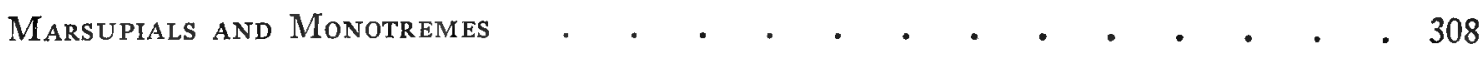





\section{PREFACE}

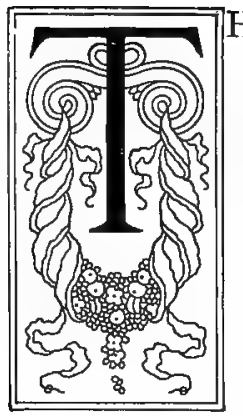

HE concluding sections of this Library, dealing with animals of other lands, are not entirely new, but are revised reprints of an earlier successful work, "The Living Animals of the World." The chief change made in this text has been to eliminate, so far as possible, references to American birds and mammals. Some cutting down in other directions was also necessary, with the result that the cream of five large volumes is here given in two volumes, and none of the matter duplicates what has gone before.

The publishers feel justified in retaining this material from the fact that it has been widely sold and commended in its former shape It contains what is believed to be the finest portrait gallery of wild animals ever collected in the covers of one work. From every page they greet the reader, life and action showing in each pose. The materials, in respect to both pictures and text, have been gathered from the whole world, and represent the latest studies, much of which has never been popularly published heretofore. Specialists of distinction and renowned scientific travelers have contributed photographs and field-notes, often from remote regions where alone many of the most rare and interesting animals may be found. These unique contributions come from the most distant islands of the Southern Ocean, the deserts and coral reefs of Australia, the New Zealand hills, the Indian jungle, the African forest and veldt, and the wilds of tropical and South America. Wherever it has not been possible to get really good pictures of wild creatures in their native haunts, living examples have been sought in the great Zoological Gardens of the world - London, Berlin, Antwerp, Florence, New York, Calcutta, and Sydney.

It is one of the most important functions of out-door photography, to-day, to preserve for posterity a record of passing conditions and of diminishing species; and a work like the present is of permanent interest, and will increase in historical and bibliographical value as time goes on. Such a book, covering in an entertaining style the whole range of zoology, carefully prepared by men of exact knowledge, yet avoiding technicalities, and wholly illustrated by precise reproductions of photographs, many in life colors, is not only novel and beautiful but is also of high value as an educator; and it would seem to be as indispensable a part of the library of every family and school-room as is the dictionary or yearbook, since by its aid all reading may be illuminated, and perchance corrected, and the whole view of nature enlightened and enlarged.

The editors have had the assistance of the most eminent authorities in other lands. Mr. F. C. Selous deals with the African Lion and the Elephants, with which he has had thrilling experiences; and other sportsmen treat of other game animals of the Dark Continent. To Mr. W. Saville-Kent, author of "The Great Barrier Reef," has been assigned the Marsupials of Australia, and also the Reptiles generally. Sir Herbert E. Maxwell writes on the Salmon family, and so on; while Dr. Richard Lydekker, Dr. R. Bower Sharpe, Mr. F. W. Kirby, and other specialists are editorial advisers in regard to the branches in which they stand as authorities 



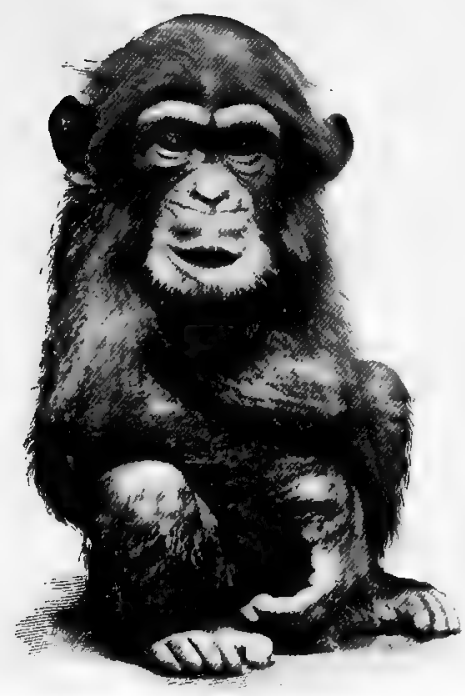

Photo by G. W. Wilson os Co, Ltd.]

Anger

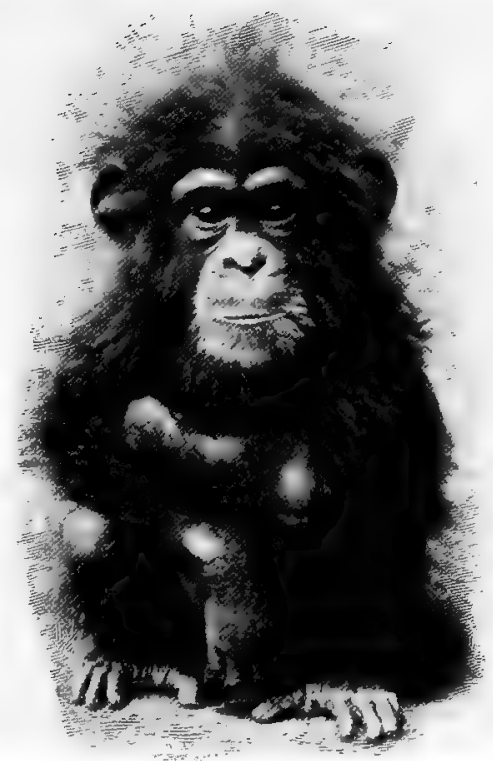

A YOUNG CHIMPANZEE Pleasure

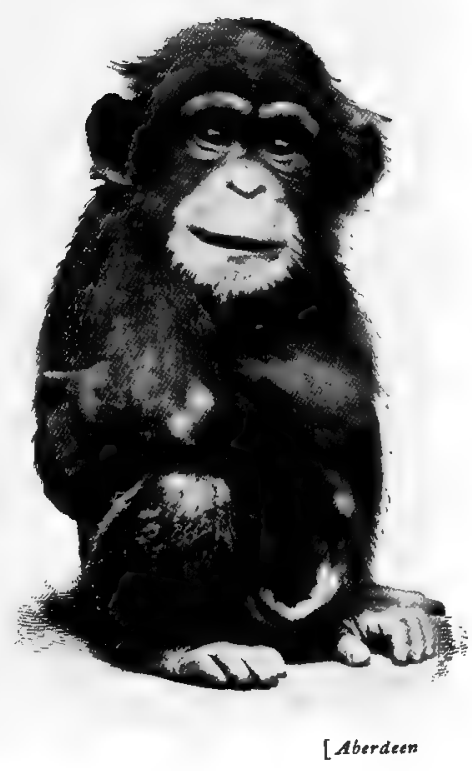

Fear

\section{Mammals of Other Lands}

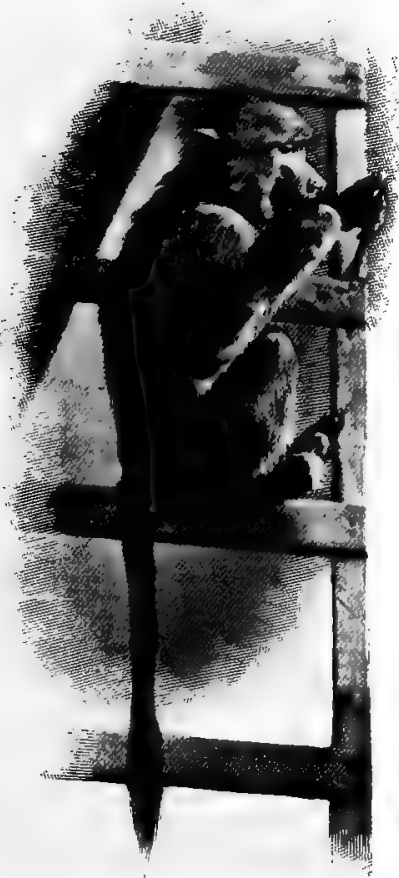

Photo by Frasell Alinari, Florence ARABIAN BABOON
APES, MONKEYS, AND LEMURS

\section{THE MAN-LIKE APES}

\section{The Chimpanzee}

$F$ all the great apes the Chimpanzee most closely approaches man in bodily structure and appearance, although in height it is less near the human standard than the gorilla, 5 feet being probably that of an adult male.

Several races of this ape are known, among them the TRUE Chimpanzee and the Bald Chimpanzee. The varieties also include the Kulo-kamba, described by Du Chaillu, and the Soko, discovered by Livingstone, who confounded it with the gorilla. But the variations in neither of these are sufficiently important to justify their being ranked as species.

The first authentic mention of the chimpanzee is found in "The Strange Adventures of Andrew Battell," an English sailor taken prisoner by the Portuguese in I590, who lived eighteen years near Angola. He speaks of two apes, the Pongo and the Enjocko, of which the former is the gorilla, the latter the chimpanzee. The animal was first seen in Europe in I64I, and described scientifically fifty-eight years later, but we are indebted 


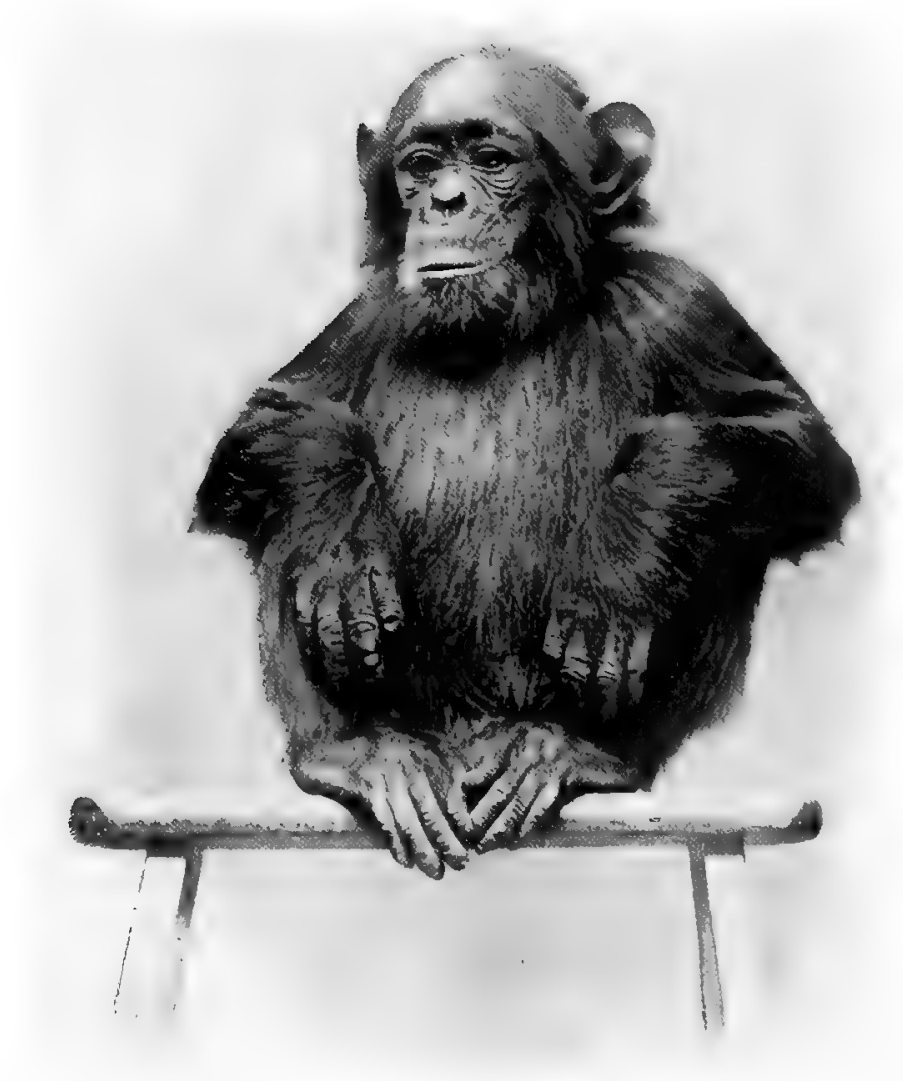

Photo by Schouastic Photo. Co.]

[Parson's Green

"JENNY;" THE WELL-KNOWN CHIMPANZEE A VERY CHARACTERISTIC POSE

In this picture the rounded ear, human-like wrinkles on the forehead, and length of the toes should be noted to Dr. Savage, a missionary, for our first account of its habits, in 1847 .

The chimpanzee, like the gorilla, is found only in Africa. The range includes West and Central Equatorial Africa, from the Gambia in the north to near Angola in the south, while it occurs in the Niam-Niam country to the northwest of the great lakes, and has been discovered recently in Uganda. The new Uganda Railway, which will open out the great lakes to the east, will bring many travelers well within reach of the nearest hauni of these great apes. It is on the likeness and difference of their form and shape to those of man that the attention of the world hàs been mainly fixed.

The chimpanzee is a heavily built animal, with chest and arms of great power. The male is slightly taller than the female. The crown is depressed, the chin receding, the ridges which overhang the eye-sockets more prominent than in man, less so than in the gorilla. The nose has a short bridge, and a flat extremity. The

ear is large, and less human than that of the gorilla. The hands and feet are comparatively long; the digits are, except the thumb and great toe, joined by a web. The arms are short for an ape, reaching only to the knces. The teeth are similar to those of man, and the canines of only moderate size. The chimpanzee has thirteen pairs of ribs, and, like man, has a suggestion at the end of the vertebræ of a rudimentary tail. It walks on all-fours, with the backs of its closed fingers on the ground, and can only stand upright by clasping its hands above its head. The skin is of a reddish or brown flesh-colour, the hair black with white patches on the lower part of the face. The bald chimpanzee has the top, front, and sides of the face bare, exceedingly large ears, thick lips, and black or brown hands and feet.

The chimpanzee's natural home is the thick forest, where tropical vegetation ensures almost total gloom. But near Loango it frequents the mountains near the coast. It is a fruit-feeding animal, said to do much damage to plantations, but the bald race, at all events in captivity, takes readily to flesh, and the famous "Sally " which lived in the Zoo for over six years used to kill and eat pigeons, and caught and killed rats. The male chimpanzee builds a nest in a tree for his family, and sleeps under its shelter; when food becomes scarce in the vicinity, a move is made, and a new nest built. This ape lives either in separate families or communities not exceeding ten in number, and is monogamous.

As to the animal's courage, it is difficult to get accurate information, as the sins of the 
gorilla and baboon have often been laid on its shoulders, and information derived from natives is usually untrustworthy. Apparently the chimpanzee avoids coming into collision with man, although, when attacked, it is a formidable antagonist. Tales of chimpanzees kidnapping women and children need stronger evidence than they have yet obtained. The natives kill this ape by spearing it in the back, or by driving it into nets, where it is entangled and easily dispatched. According to Livingstone, the Soko, as the chimpanzee is called in East Central Africa, kills the leopard by biting its paws, but falls an easy prey to the lion.

In captivity it is docile and intelligent, but usually fails to stand a northern climate for more than a few months. It is easily taught to wear clothes, to eat and drink in civilised fashion, to understand what is said to it, and reply with a limited vocabulary of grunts. Sally learnt to count perfectly up to six, and less perfectly to ten; she could also distinguish white from any colour, but if other colours were presented her she failed, apparently from colour-blindness. Of this ape the late Dr. G. J. Romanes wrote with something more than the enthusiasm of a clever man pursuing a favourite theme: "Her intelligence was conspicuously displayed by the remarkable degree in which she was able to understand the meaning of spoken language-a degree fully equal to that presented by an infant a few months before emerging from infancy, and therefore higher than that which is presented by any brute, so far at least as I have evidence to show." Romanes here speaks only, be it noticed, of ability to understand human speech-not to think and act But this is in itself a great mark of intelligence on human lines. "Having enlisted the cooperation of the keepers, I requested them to ask the ape repeatedly for one straw, two straws, three straws. These she was to pick up and hand out from among the litter of her cage. No constant order was to be observed in making these requests; but whenever she handed a number not asked for her offer was to be refused, while if she gave the proper number her offer was to be accepted, and she was to receive a piece of fruit in payment. In this way the ape had learnt to associate these three numbers with the names. As soon as the animal understood what was required, she never failed to give the number of straws asked for. Her education was then completed in a similar manner from three to four, and from four to five straws. Sally rarely made mistakes up to that number; but above five, and up to ten, to which one of the keepers endeavoured to advance her education, the result is uncertain. It is

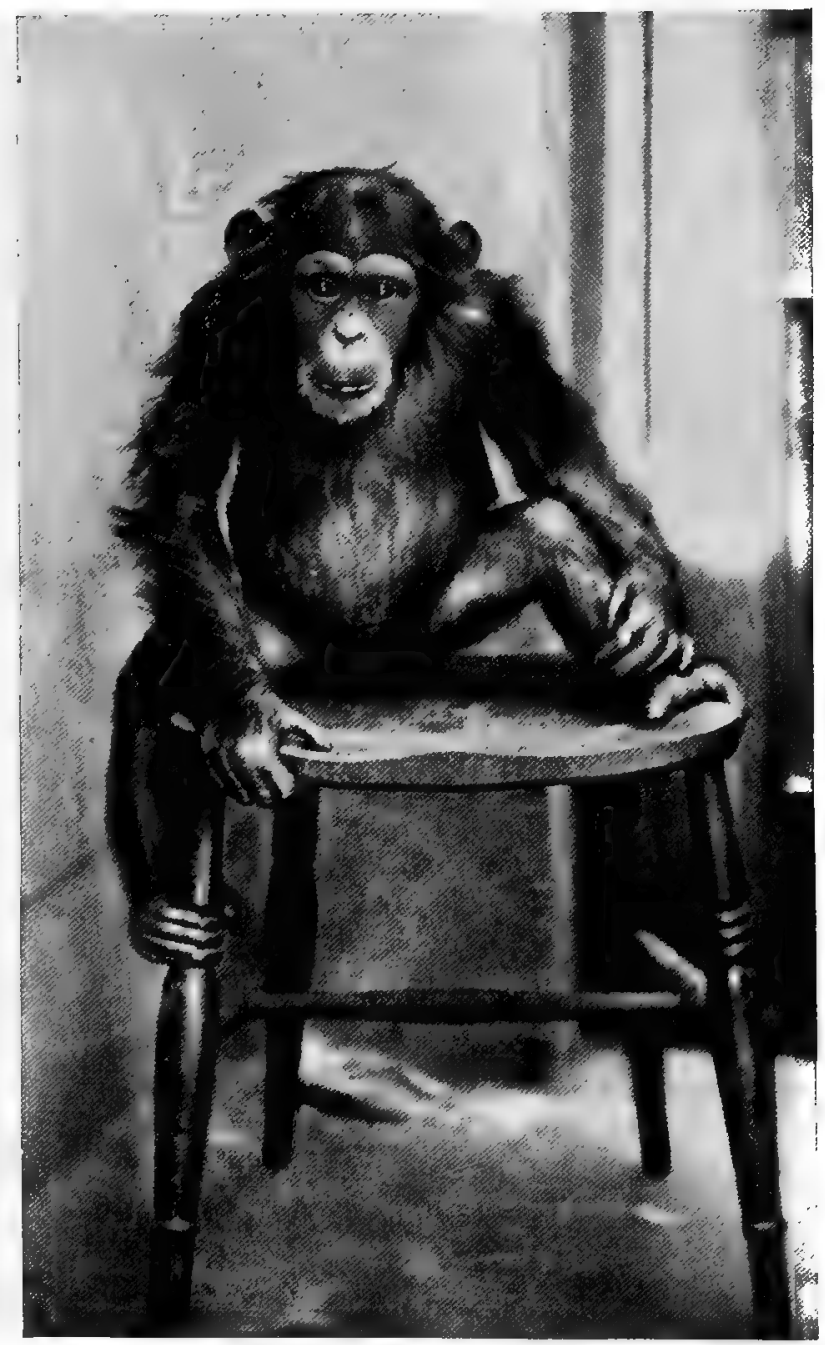

Phato by G. W. Wilson \& Co., Ltd.]

A YOUNG CHIMPANZEE

This excellent photograph, by Major Nott, F.Z.S., is particularly good. as showing the manner in which these animals use their hands and feet 


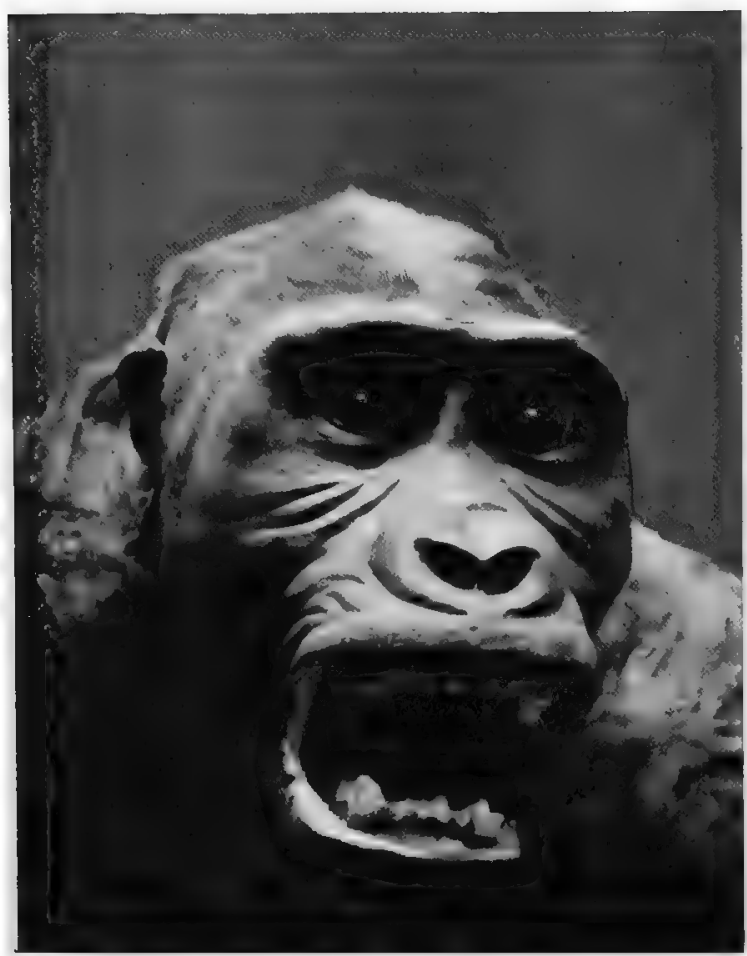

Photo by A. S. Rudland \& Sonts

HEAD OF MALE GORILLA

This is a phutograph of one of the firse gorillas ever brought to England. It was sent by the famous $M$. du Chiaillu evident that she understands the words seven, eight, nine, and ten to betoken numbers highes than those below them. When she was asked for any number above six, she always gave some number over six and under ten She sometimes doubled over a straw to make it present two ends, and was supposed (thus) to hasten the attainment of her task." By no means all the chimpanzees are so patient as Sally. One kept in the Zoological Gardens for some time made an incessant noise by stamping on the back of the box in which it was confined. It struck this with the flat of its foot while hanging to the cross-bar or perch, and made a prodigious din. This seems to bear out the stories of chimpanzees assembling and drumming on logs in the Central African forests.

\section{The Gorilla}

The name of this enormous ape has been known since 450 B. C. Hanno the Carthaginian, when off Sierra Leone, met with wild men and women whom the interpreter called Gorillas. The males escaped and flung stones from the rocks, but several females. were captured. These animals could not have been gorillas, but, were probably baboons. Andrew Battell, already mentioned, described the gorilla under the name of Pongo. He says it is like a. man, but without understanding even to put a $\log$ on a fire; it kills Negroes, and drives off the elephant with clubs; it is never taken alive, but its young are killed with poisoned arrows; it covers its dead with boughs. Dr. Savage described it in I847. Later Du Chaillu visited its haunts, and his well-known book relates how he met and killed several specimens. But Mr. Winwood Reade, who also went in quest of it, declared that Du Chaillu, like himself, never saw a live gorilla. Von Koppenfels, however, saw a family of four feeding, besides shooting others. The late Miss Kingsley met several, one of which was killed by her elephant-men.

The gorilla has a limited range, extending from $2^{\circ}$ north to $5^{\circ}$ south latitude in West Africa, a moist overgrown region including the mouth of the Gaboon River. How far east it is found is uncertain, but it is known in the Sierra del Cristal. In 1851-52 it was seen in considerable numbers on the coast.

The Gorilla is the largest, strongest, and most formidable of the Primates. An adult male is from 5 feet 8 inches to 6 feet high, heavily built, with arms and chest of extraordinary power. The arms reach to the middle of the legs. The hands are clumsy, the thumb short, and the fingers joined by a web. The neck scarcely exists. The leg has a slight calf. The toes are stumpy and thick; the great toe moves like a thumb. The head is large and receding, with enormous ridges above the eyes, which give it a diabolical appearance. The canine teeth are developed into huge tusks. The nose has a long bridge, and the nostrils look downwards. The ear is small and man-like.

In colour the gorilla varies from deep black to iron-gray, with a reddish tinge on the head; old animals become grizzled. The outer hair is ringed gray and brown; beneath it is a woolly growth. The female is smaller-not exceeding 4 feet 6 inches_and less hideous, as the canines 


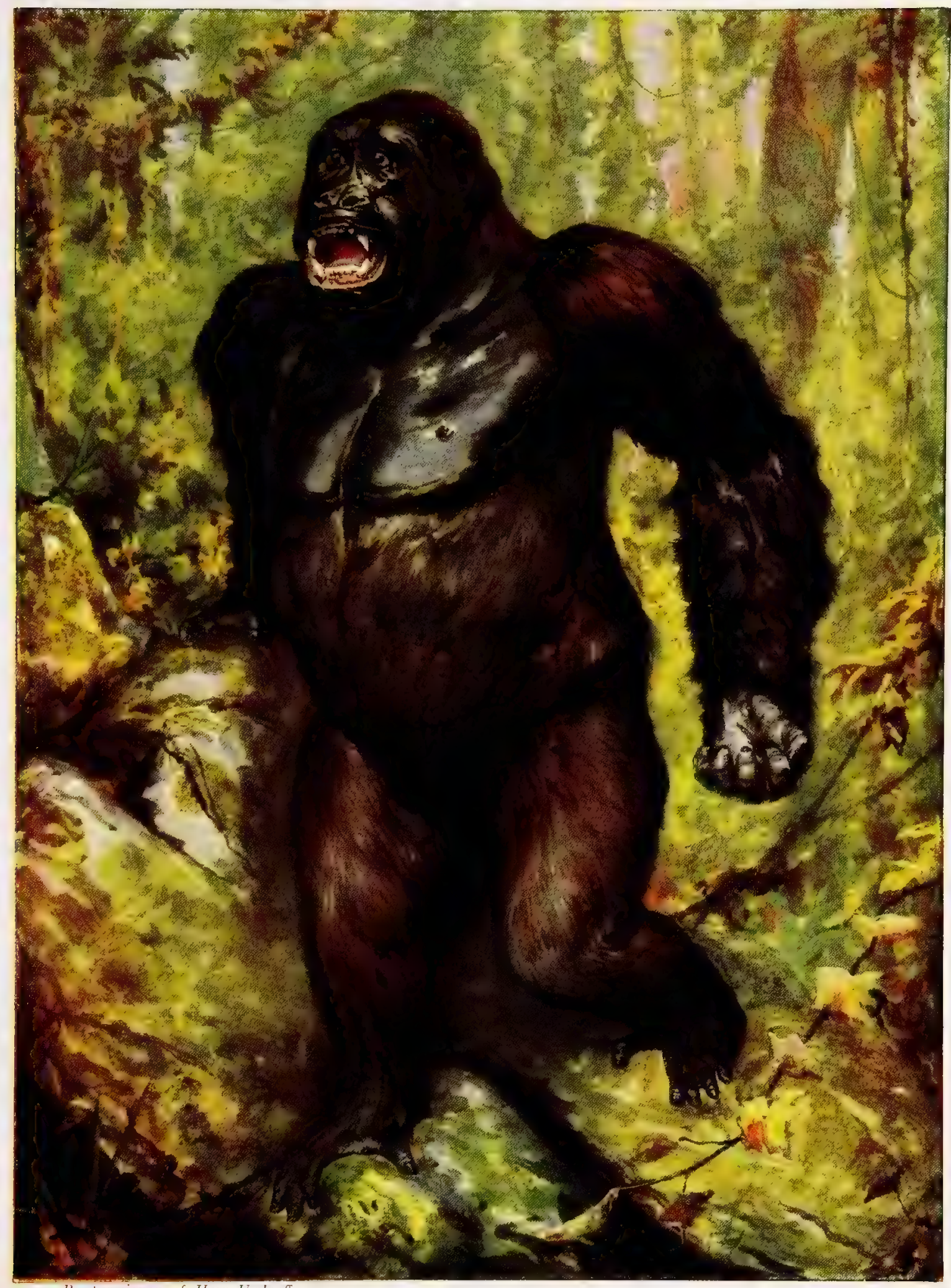

By promission of Herr Umlanff.

THE LARGEST GORILLA EVER CAPTURED.

This huge ape, 5 feet 5 inches high, measures a distance of over 8 feet from finger to finger. 
are much smaller, and the ridges above the eyes are not noticeable, a feature common also to the young.

Timid, superstitious natives and credulous or untrustworthy travelers have left still wrapped in mystery many of the habits of this mighty ape, whose fever-stricken, forest-clad haunts render investigation always difficult, often impossible. Many tales of its ferocity and strength are obviously untrue, but we think that too much has been disbelieved. That a huge arm descends from a tree, draws up and chokes the wayfarer, must be false, for intelligent natives have confessed to knowing no instance of the gorilla attacking man. That it vanquishes the leopard is probable; that it has driven the lion from its haunts requires proof. Nor can we accept tales of the carrying off of Negro women; and the defeat of the elephants, too, must be considered a fiction.

But we must believe that this ape, if provoked or wounded, is a terrible foe, capable of ripping open a man with one stroke of its paw, or of cracking the skull of a hunter as easily as a squirrel cracks a nut. There is a tale of a tribe that kept an enormous gorilla as éxecutioner, which tore its victims to pieces, until an Englishman, doomed to meet it, noticing a large swelling near its. ribs, killed it with a heavy blow or two on the weak spot.

Gorillas live mainly in the trees on whose fruit they subsist; they construct a shelter in the lower: boughs for the family, and as a lying-in place for the female. The male is said to sleep below, with his back against, the tree-a favourite attitude with both sexes-to keep off leopards. On the ground it moves on all-fours, with a curious swinging action, caused by putting its hands with fingers extended on the ground, and bringing its body forward by a half-jump. Having a heel, it can stand better than other apes; but this attitude is not common, and Du Chaillu appears to have been, mistaken when he describes the gorilla as attacking upright.

In captivity only immature specimens have been seen-Barnum's great ape being one of the larger forms of chimpanzee. Accounts vary as to the temper of the gorilla, some describing it as untamable, while others say it is docile and playful when young. There is a wonderful tale that a gorilla over 6 feet high was captured near Tanganyika, but nothing more has reached us about it.

When enraged, a gorilla beats its breast, as the writer was informed by a keeper, who thus confirmed $\mathrm{Du}$ Chaillu's account. Its usual voice is a grunt, which, when the animal is excited, becomes a roar.

\section{The Orang-utan}

This great red ape was mentioned by Linnæus in 1766 , and at the beginning of the last century a specimen living in the Prince of Orange's collection was described by Vosmaer.

There are three varieties of the Orang, called by the Dyaks Mias-

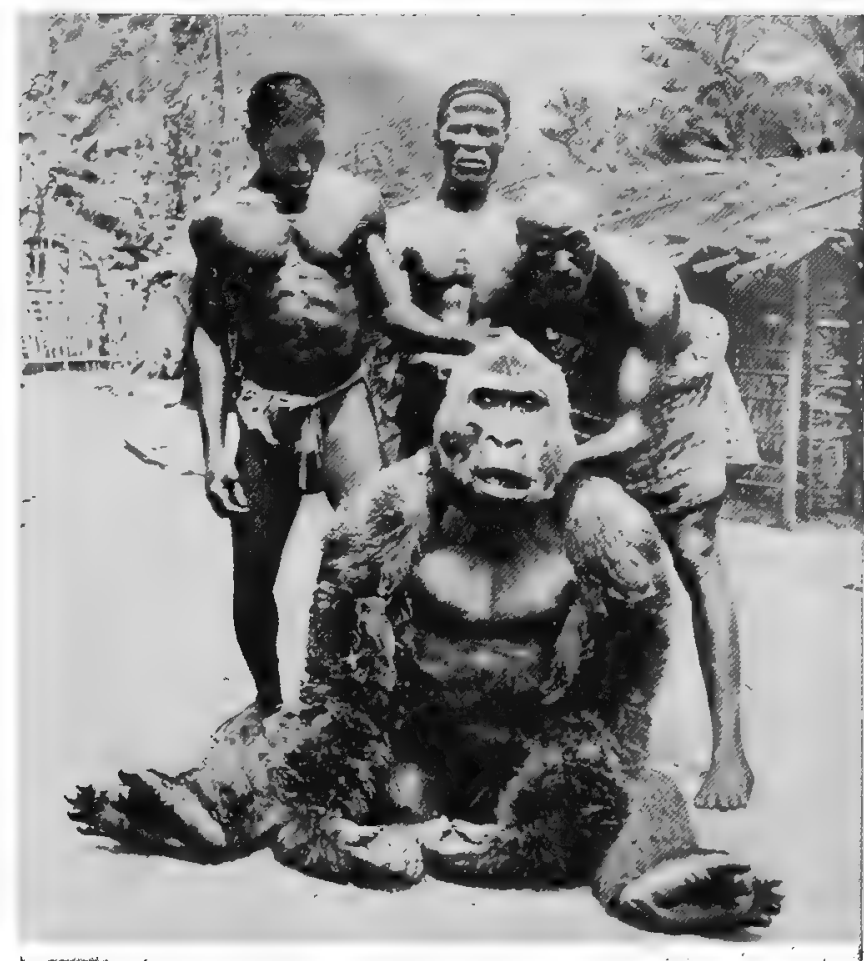

By permission of Herr Omlauf] A MALE GORILLA

This photograph of the largest gorilla known was taken immediately after death by Herr Paschen at Yaunde, and gives an excellent idea of the size of these animals as compared with Negroes. The animal weighed $400 \mathrm{lbs}$. 
PAPpan, Mias-RAmbi, and Mias-kassu, the third of which is smaller, has no cheek-excrescences, and very large teeth. Some naturalists recognise a pale and a dark race.

Most of our information is due to Raja Brooke and Dr. Wallace. The species is confined to Borneo and Sumatra, but fossils have been found in India of this genus, as well as of a chimpanzee. The orang is less man-like than the chimpanzee and gorilla. In height the male varies from 3 feet 10 inches to 4 feet 6 inches, the female being a few inches shorter. It is a heavy creature, with large head-often a foot in breadth_thick neck, powerful arms, which reach nearly to the ankles, and protuberant abdomen. Its legs are short and bowed. The forehead is high, the nose fairly large, the ears very human. The throat is ornamented with large pouches, and there are often callosities on the cheeks. The fingers are webbed, the thumb small, the foot long

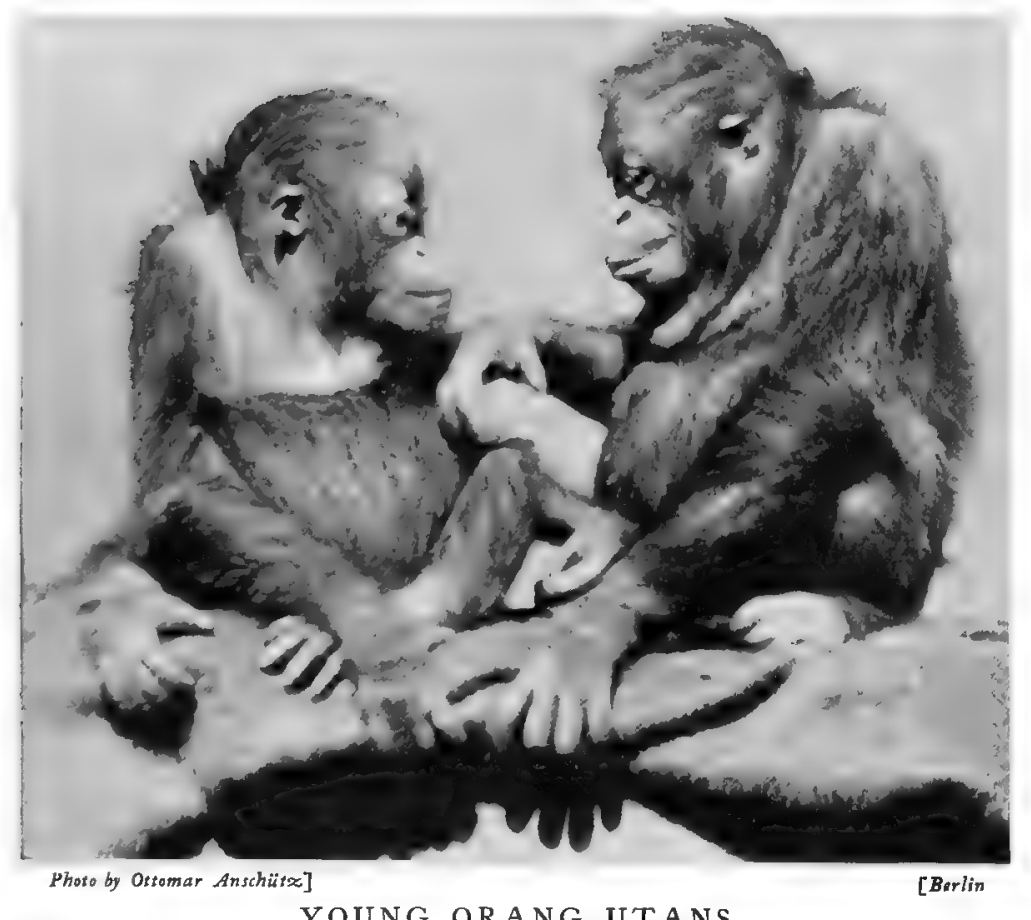

YOUNG ORANG-UTANS

It will be seen here, from the profile, that the young anthropoid ape has only the upper part of the head at all approaching the human type and narrow, the great toe small and often without a nail. The brain is man like, and the ribs agree in number with those of man; but there are nine bones in the wrist, whereas man, the gorilla, and the chimpanzee have but eight. The canine teeth are enormous in the male. The hair, a foot or more long on the shoulders and thighs, is yellowish red: there is a slight beard. The skin is gray or brown, and often, in adults, black.

The orang is entirely a tree-living animal, and is only found in moist districts where there is much virgin forest. On the ground it progresses clumsily on all-fours, using its arms as crutches, and with the side only of its feet on the ground. In trees it travels deliberately but with perfect ease, swinging along underneath the branches, although it also walks along them semi-erect. It lives alone with mate and young, and builds a sleeping place sufficiently low to avoid the wind. Its food is leaves and fruit, especially the durian; its feeding-time, midday.

No animal molests the mias save-so say the Dyaks-the python and crocodile, both of which it kills by tearing with its hands. It never attacks man, but has been known to bite savagely when brought to bay, and it is very tenacious of life, one being found by Mr. Wallace still alive after a fall from a tree, when "both legs had been broken, its hip-joint and the root of the spine shattered, and two bullets flattened in neck and jaws."

In captivity young orangs are playful and docile, but passionate. Less intelligent than chimpanzees, they may be taught to eat and drink nicely, and to obey simple commands. One in the Zoo at present has acquired the rudiments of drill. They will eat meat and eggs, and drink wine, beer, spirits, and tea. An orang described years ago by Dr. Clarke Abel was allowed 


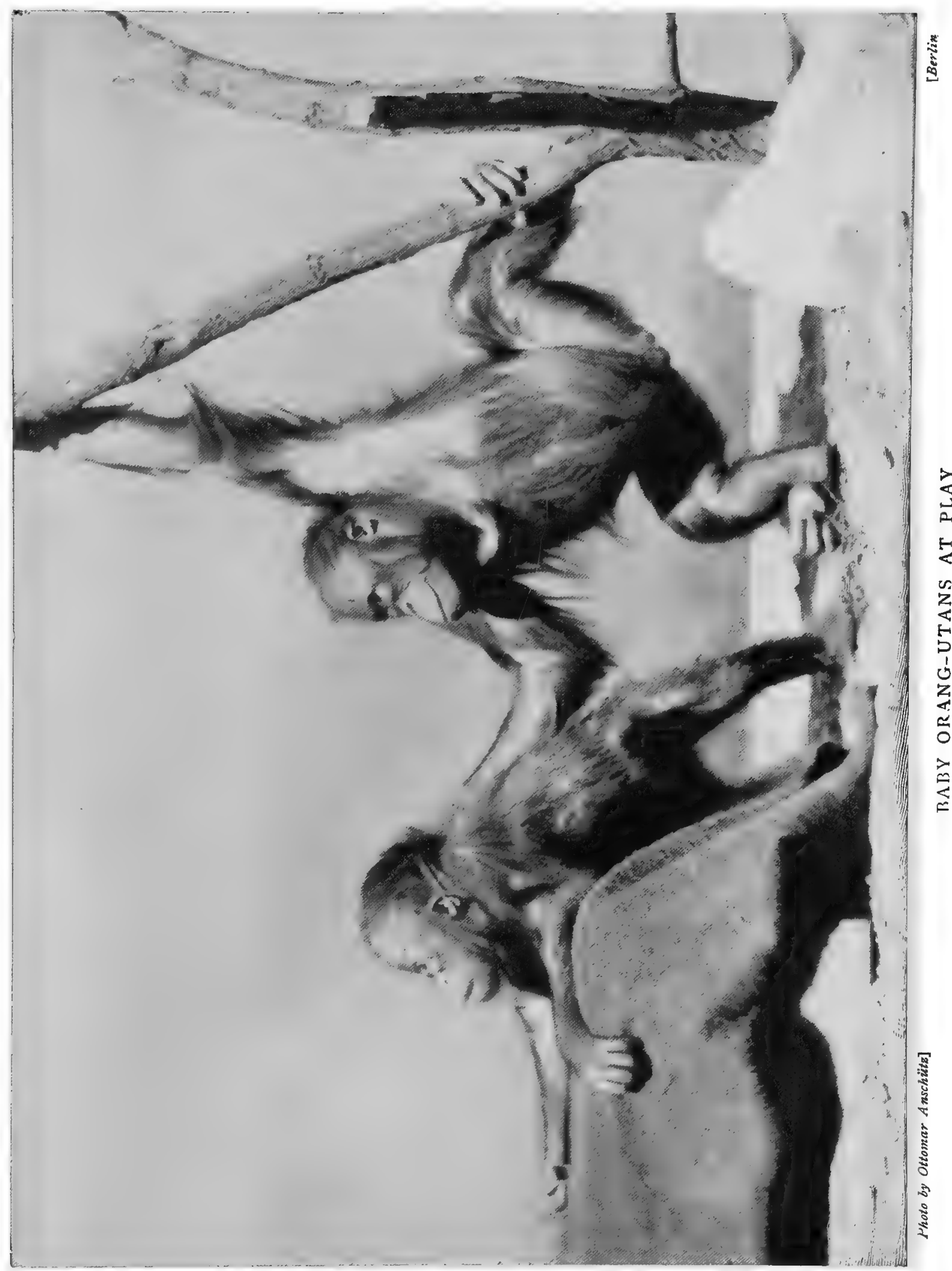


the run of the ship on the voyage to England, and would play with the sailors in the rigging. When refused food he pretended to commit suicide, and rushed over the side, only to be found under the chains.

The orang is the least interesting of the three great apes; he lacks the power and brutality of the gorilla and the intelligence of the chimpanzee. "The orang," said its keeper to the writer, " is a buffoon ; the chimpanzee, a gentleman."

It is worth remark that, although all these apes soon die in menageries, in Calcutta, where they are kept in the open, orangs thrive well.

\section{The GibBons}

Next after the great apes in man-like characters come a few long-armed, tailless apes, known as the Gibions. Like the orang-utan, they live in the great tropical forests of Asia, especially

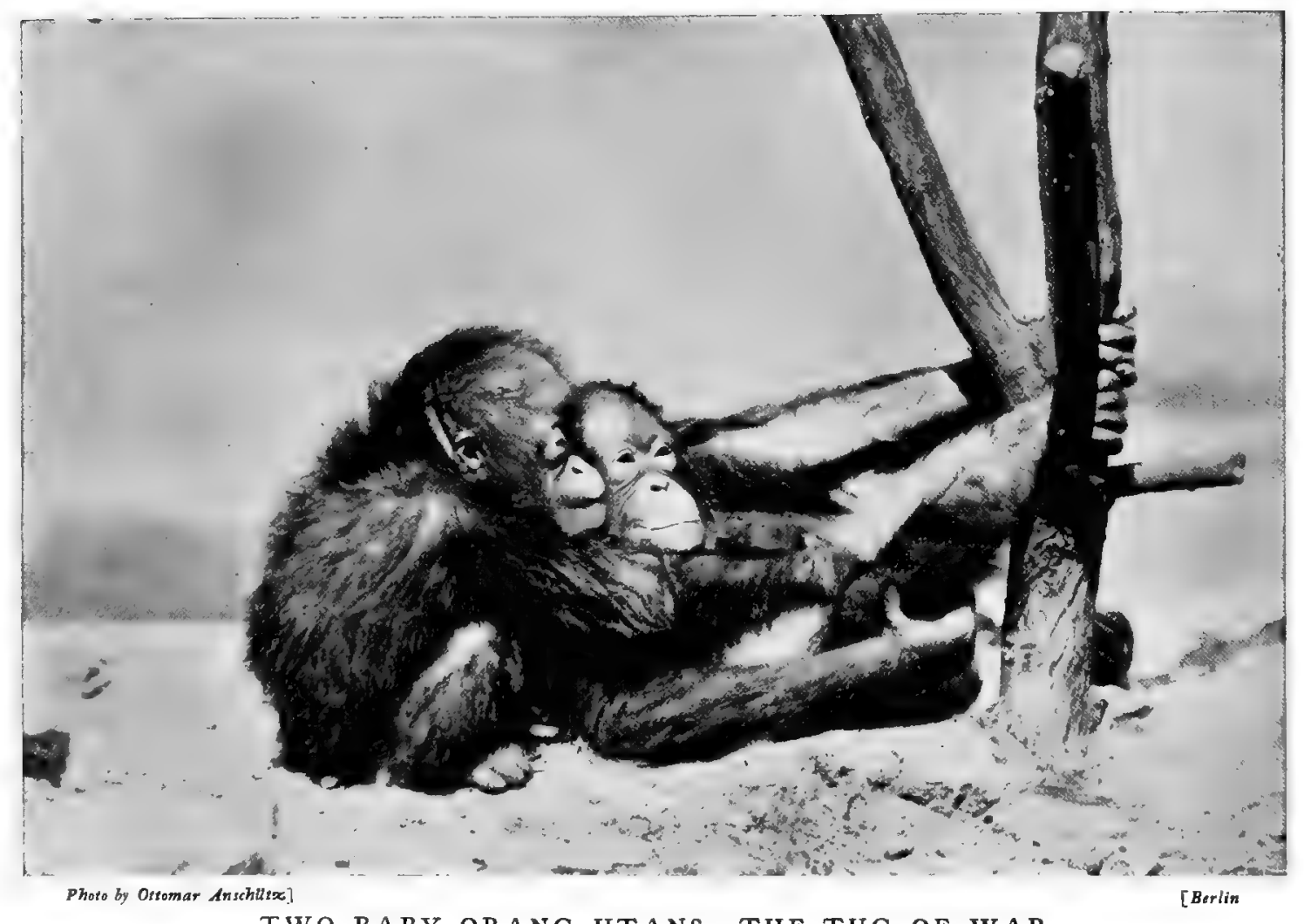

TIVO BABY ORANG-UTANS. THE TUG-OF-WAR

the Indian Archipelago; like the latter, they are gentle, affectionate creatures; and they have also a natural affection for man. But it is in mind and temperament, rather than in skeleton, that the links and differences between men and monkeys must be sought. It will be found that these forest apes differ from other animals and from the true monkeys mainly in this_that they are predisposed to be friendly to man and to obey him, and that they have no bias towards mischief, or " monkey tricks." They are thoughtful, well behaved, and sedate.

The Siamang, one of the largest of the long-armed, tailless gibbons, lives in the Malay Archipelago. The arms of a specimen only 3 feet high measured 5 feet 6 inches across. This, like all the gibbons, makes its way from tree to tree mainly by swinging itself by its arms. But the siamang can walk upright and run. One kept on board ship would walk down the cabin breakfast-table without upsetting the china. The White-Handed GibBon is found in Tenasserim, 
southwest of Burma. This ape has a musical howl, which the whole flock utters in the early mornings on the tree-tops. In Northern India, in the hills beyond the Brahmaputra, lives another gibbon, the Hulock. One of these kept in captivity soon learnt to eat properly at meals, and to drink out of a cup, instead of dipping his fingers in the tea and milk and then sucking them. The Silvery Gibbon kept at the Zoological Gardens was a most amiable pet, and had all the agility of the other gibbons. It is very seldom seen in this country, being a native of Java, where it is said to show the most astonishing activity among the tall cane-groves. One of the first ever brought to England belonged to the great Lord Clive. The A giLe Gibbon is another and darker ape of this group.

The list of the man-like ape closes with this group. All the gibbons are highly specialised for tree-climbing and an entirely arboreal life; but it is undeniable that, apart from the modifications necessary for this, such as the abnormal length of

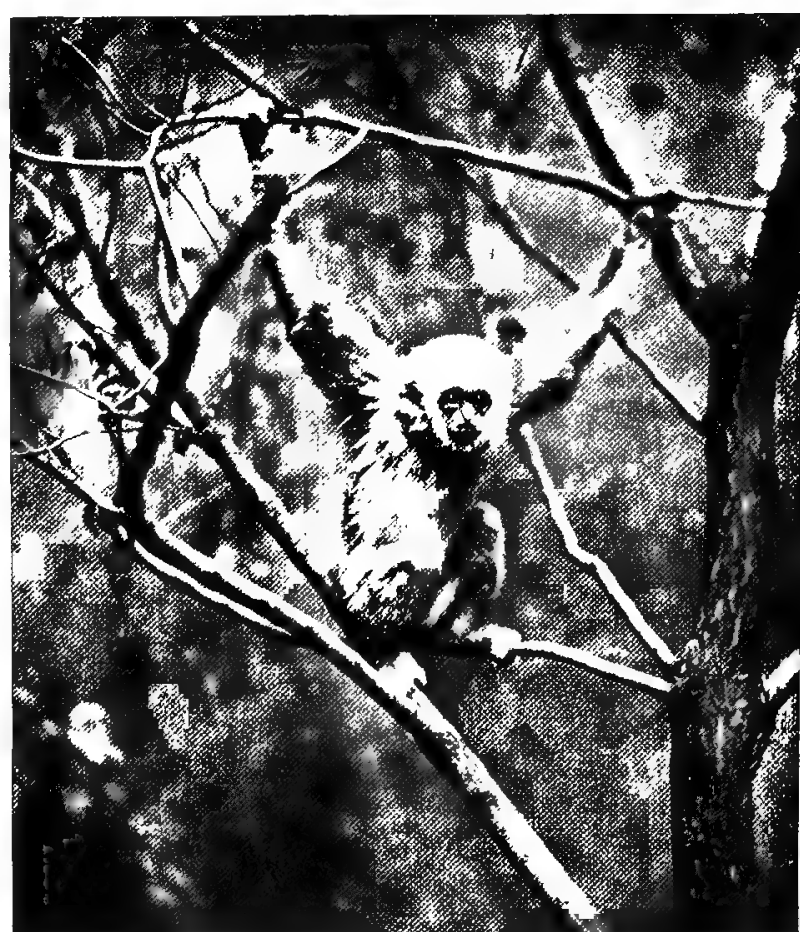

Photo by rork \& Son] [Notting Hill

WHITE-HANDED GIBBON

This gibbon is found th the forests of the Malay Archipelago the arms, the skeleton closely resembles that of the human being. In their habits, when wild, none of these apes show any remarkable degree of intelligence; but their living is gained in so simple a way, by plucking fruits and leaves, that there is nothing in their surroundings to

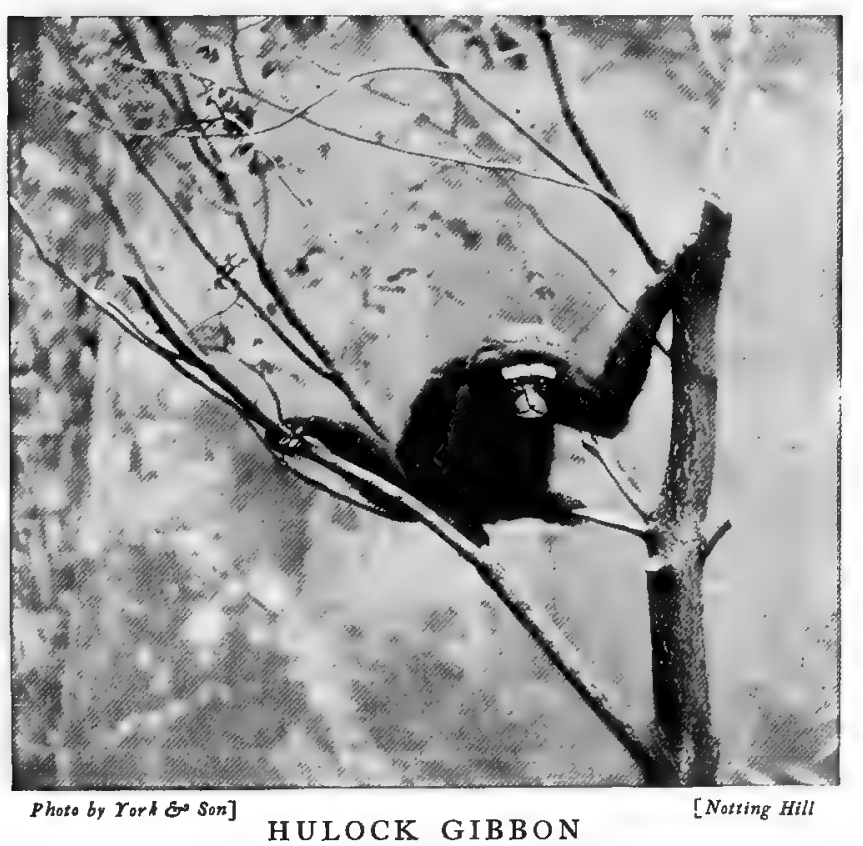

'ze great length of arm in comparison with the body and head should here be stimulate thought. They do not need even to think of a time of famine or winter, or to lay up a stock of food for such a season, because they live in the forests under the Equator.

\section{MONKEYS}

\section{The Dog-shaped Monkeys}

AFTER the gibbons come a vast number of monkeys of every conceivable size, shape, and variety, which naturalists have arranged in consecutive order with fair success Until we reach the Baboons, and go on to the South American Monkeys and the Lemurs, it is not easy to give any idea of what these monkeys do or look like merely by referring to their scientific groups. The usual order of natural histories will here be followed, and the descriptions will, so far as possible, present the 


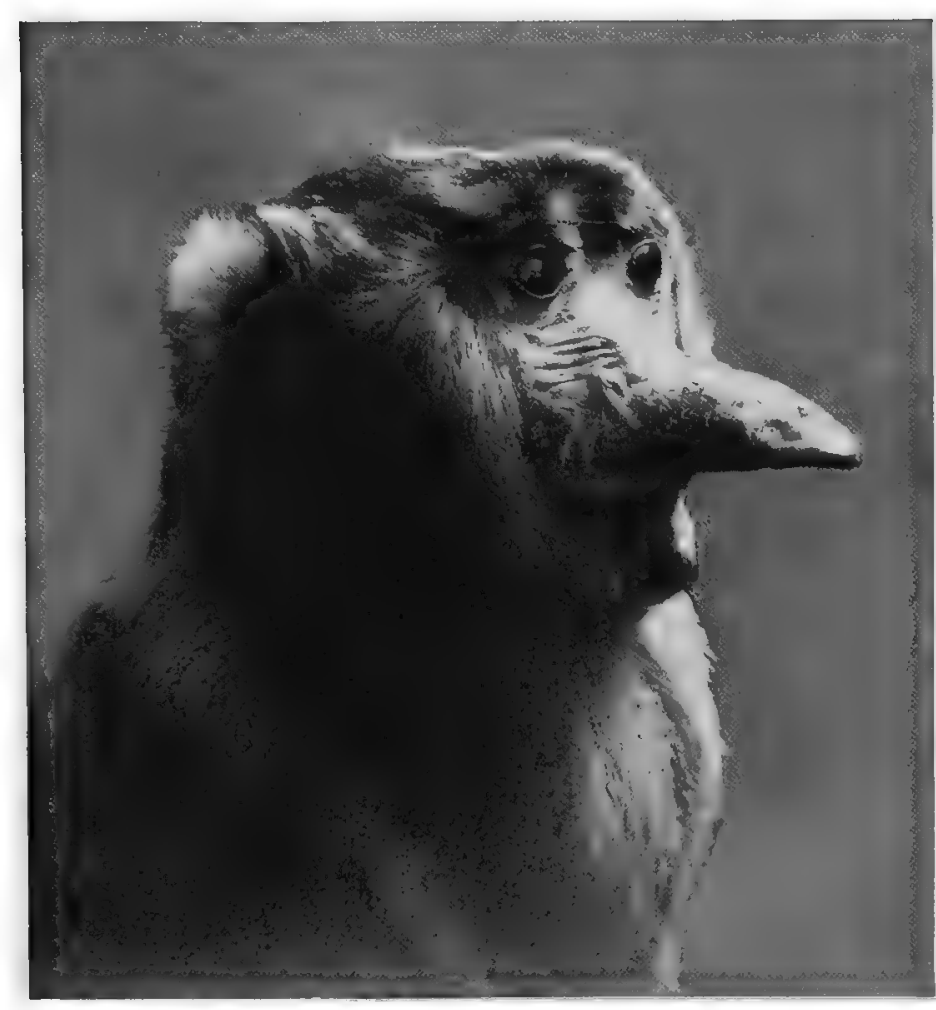

Photo by A. S. Rudland o Sons

HEAD OF PROBOSCIS MONKEY

$A$ nattve of Borneo. Next to the orang-utam, the most striking monkey in the Malay Archipelago habits and appearance of the monkeys specially noticed.

This great family of true monkeys contains. the Sacred Monkeys, or Langurs, of India, the Guerezas and Guenons of Africa, the Mangabeys, Macaques, and Baboons. Most of them have naked, hard patches of skin on the hindquarters, and the partition between the nostrils is narrow. Some have tails, some none, and they exhibit the most astonishing differences of size and shape. Perhaps the most grotesque and astonishing of them all is the Proboscis Monkey. It is allied to the langurs, and is a native of the island of Borneo, to which it is confined; its home is the west bank of the Sarawak River. It is an arboreal creature, living in small companies. Mr. Hose, who saw them in their native haunts, says that the proboscis monkeys kept in the trees overhanging the river, and were most difficult to

shoot. "I saw altogether about 150 of these monkeys, and without a single exception all were in trees over the water, either lake, river, or in submerged forest. As long as they are in sight, they are very conspicuous objects, choosing the most commanding positions on open tree-tops. Once I saw thirteen in one tree, sitting lazily on the branches, as is their habit, sunning themselves, and enjoying the scenery." They are very striking animals in colour, as well as in form. The face is cinnamon-brown, the sides marked with reddish brown and white, the belly white, the back red-brown and dark brown. Next to the orang-utan, these are the most striking monkeys in the Malay Archipelago.

The greater number of the species intermediate between the gibbons and the New World species are called "Dog-Shaped" Monkers. We wonder why? Only the baboon and a few others are in the least like dogs. The various Sacred Monkeys of India are often seen in this country, and are quite representative of the "miscellaneous" monkeys in general. Most of them have cheek-pouches, a useful monkey-pocket. They poke food into their pouches, which unfold to be filled, or lie flat when not wanted; and with a pocketful of nuts or rice on either side of their faces, they can scream, eat, bite, or scold quite comfortably, which they could not do with their mouths full. The pouchless monkeys have only their big stomachs to rely on.

The Entellus Monkey is the most sacred of all in India. It is gray above and nutty brown below, long-legged and active, a thief and an impudent robber. In one of the Indian cities they became such a nuisance that the faithful determined to catch and send away some hundreds. This was done, and the holy monkeys were deported in covered carts, and released many miles off. But the monkeys were too clever. Having thoroughly enjoyed their ride, they all refused to part with the carts, and, hopping and grimacing, came leaping all the way back beside them to the city, grateful for their outing. One city obtained leave to kill the monkeys; 
but the next city then sued them for "killing their deceased ancestors." In these monkeyinfested cities, if one man wishes to spite another, he throws a few handfuls of rice on to the roof of his house about the rainy season. The monkeys come, find the rice, and quietly lift off many of the tiles and throw them away, seeking more rice in the interstices.

This is not the monkey commonly seen in the hills and at Simla. The large long-tailed monkey there is the Himalayan LANGur, one of the common animals of the hills. "The langur," says Mr. Lockwood Kipling in his " Beast and Man in India," “ is, in his way, a king of the jungle, nor is he often met with in captivity. In some parts of India troops of langurs come bounding with a mighty air of interest and curiosity to look at passing trains, their long tails

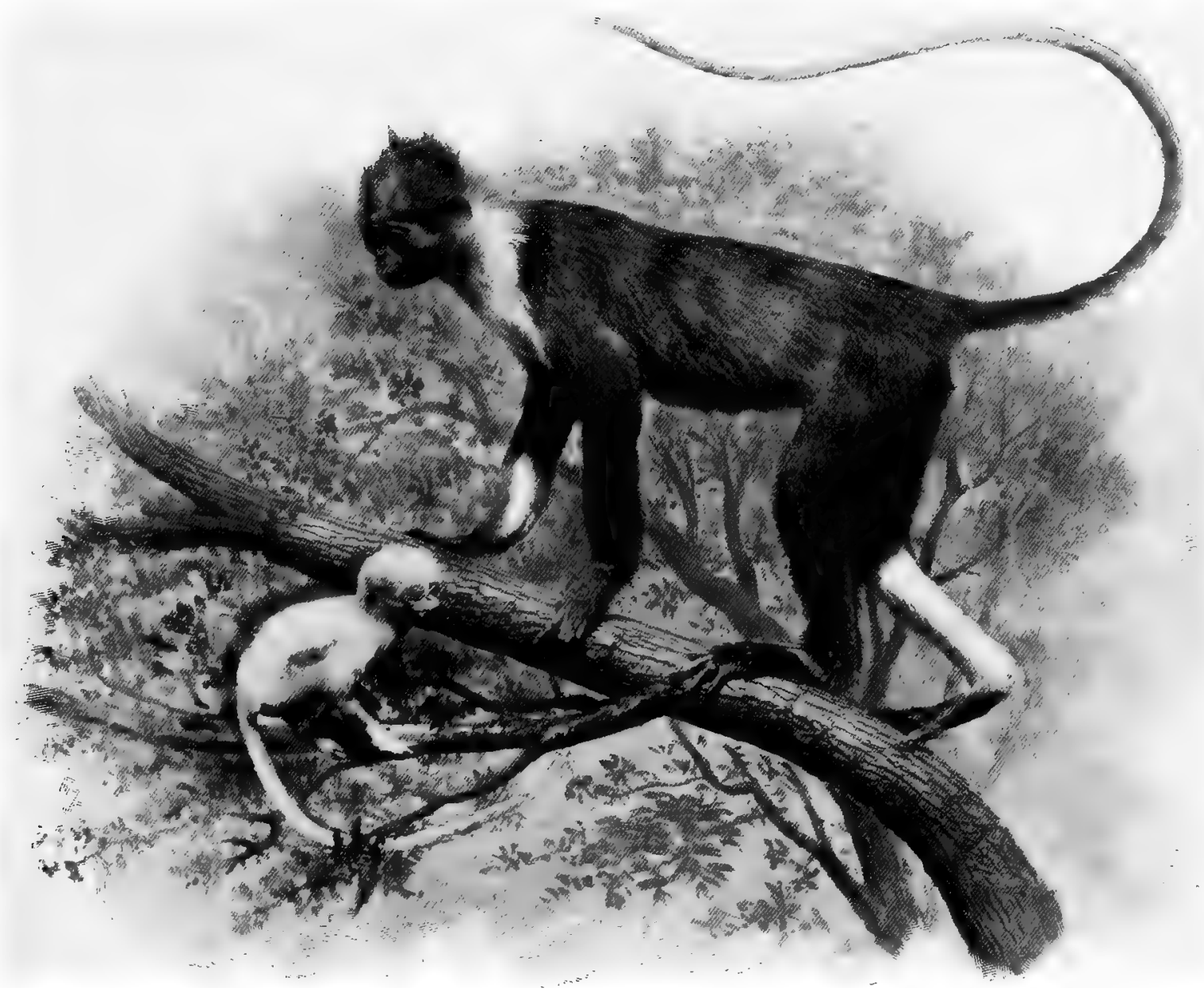

Photo by A. S. Rudland Sons

\section{CROSS-BEARING LANGUR AND YOUNG \\ $A$ forest monkey of Borneo}

lifted like notes of interrogation; but frequently, when fairly perched on a wall or tree alongside, they seem to forget all about it, and avert their heads with an affectation of languid indifference."

In India no distinction is made between monkeys. It is an abominable act of sacrilege to kill one of any kind. In the streets holy bulls, calves, parrakeets, sparrows, and monkeys all rob the shops. One monkey-ridden municipality sent off its inconvenient but holy guests by rail, advising the station-master to let them loose at the place to which they were consigned. The station, Saharanpur, was a kind of Indian Chicago, and the monkeys got into the engine-sheds and workshops among the driving-wheels and bands. One got in the double roof of an inspection- 
car, and thence stole mutton, corkscrews, camp-glasses, and dusters. Among many other interesting and correct monkey stories of Mr. Kipling's is the following: "The chief confectioner of Simla had prepared a most splendid bride-cake, which was safely put by in a locked room, that, like most back rooms in Simla, looked out on the mountainside. It is little use locking the door when the window is left open. When they came to fetch the bride-cake, the last piece of it was being handed out of the window by a chain of monkeys, who whitened the hillside with its fragments."

From India to Ceylon is no great way, yet in the latter island different monkeys are found. The two best known are the White-bearded Wanderoo Monkey and the Great Wanderoo. Both are grave, well-behaved monkeys. The former has white whiskers and a white beard, and looks so wise he is called in Latin Nestor, after the ancient counsellor of the Greeks. Nice, clean little monkeys are these, and pretty pets. The great wanderoo is rarer. It lives in the hills. "A flock of them," says Mr. Dallas, "will take possession of a palm-grove, and so well can they conceal themselves in the leaves that the whole party become invisible. The presence of a dog excites their irresistible curiosity, and in order to watch his movements they never fail to betray themselves. They may be seen congregated on the roof of a native hut. Some years ago the child of a European clergyman, having been left on the ground by a nurse, was bitten and teased to death by them. These monkeys have only one wife." Near relatives of the langurs are the two species of Snub-nosed Monkeys, one of which (see figure on page I8) inhabits Eastern Tibet and Northwestern China, and the other the valley of the Mekong.

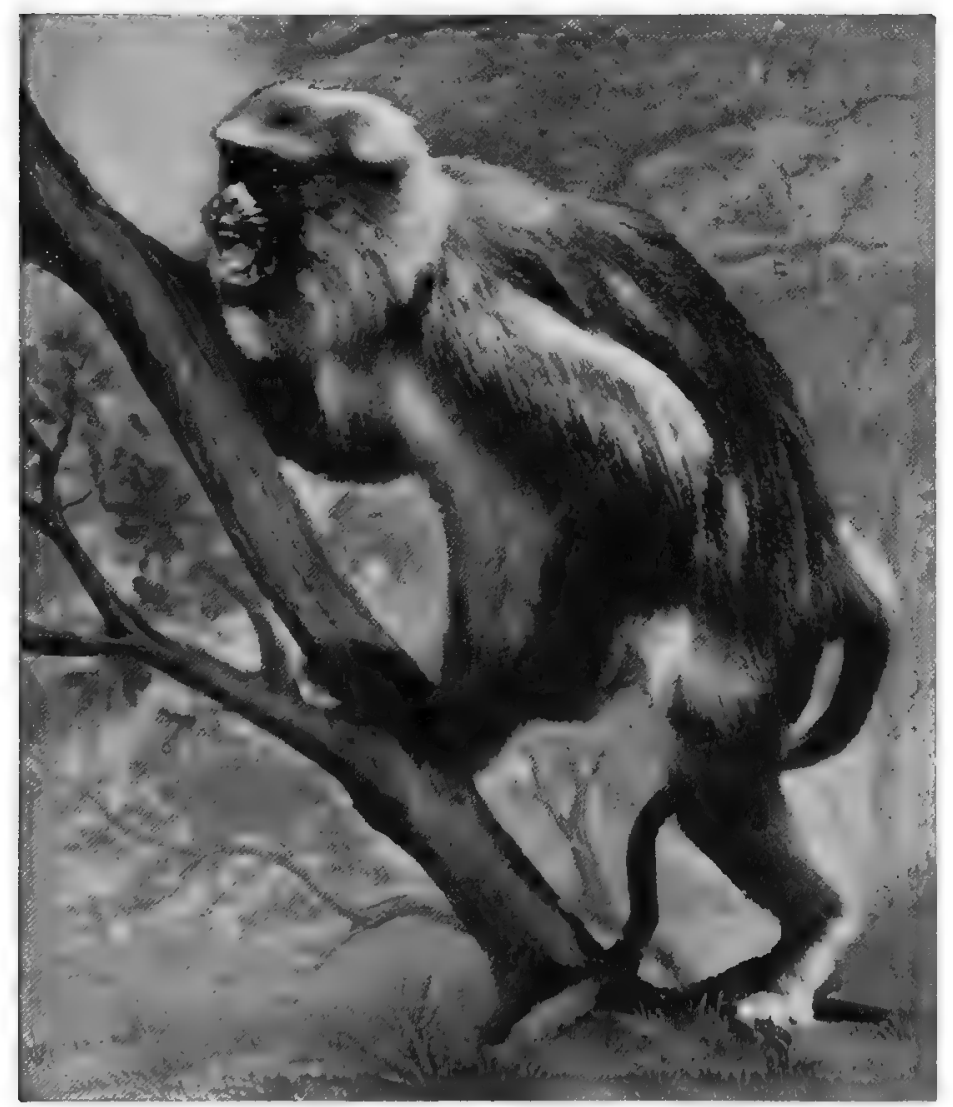

Phosoby A. S. Rudland of sons

MALE HIMALAYAN LANGUR

A king of the jungle, not often met with in captivity

\section{The Guerezas and Guenons}

Among the ordinary monkeys of the Old World are some with very striking hair and colours. The Guereza of Abyssinia has bright white and black fur, with long white fringes on the sides. This is the black-and-white skin fastened by the Abyssinians to their shields, and, if we are not wrong, by the Kaffirs also. Among the Guenons, a large tribe of monkeys living in the African forests, many of which find their way here as "organ monkeys," is the Diana, a most beautiful creature, living on the Guinea Coast. It has a white crescent on its forehead, bluishgray fur, a white beard, and a patch of brilliant chestnut on the back, the belly white and orange. A lady, Mrs. Bowditch, gives the following account of a Diana monkey on board ship. It jumped on to her shoulder, stared into her face, and then made friends, seated itself on her knees, and carefully examined her 


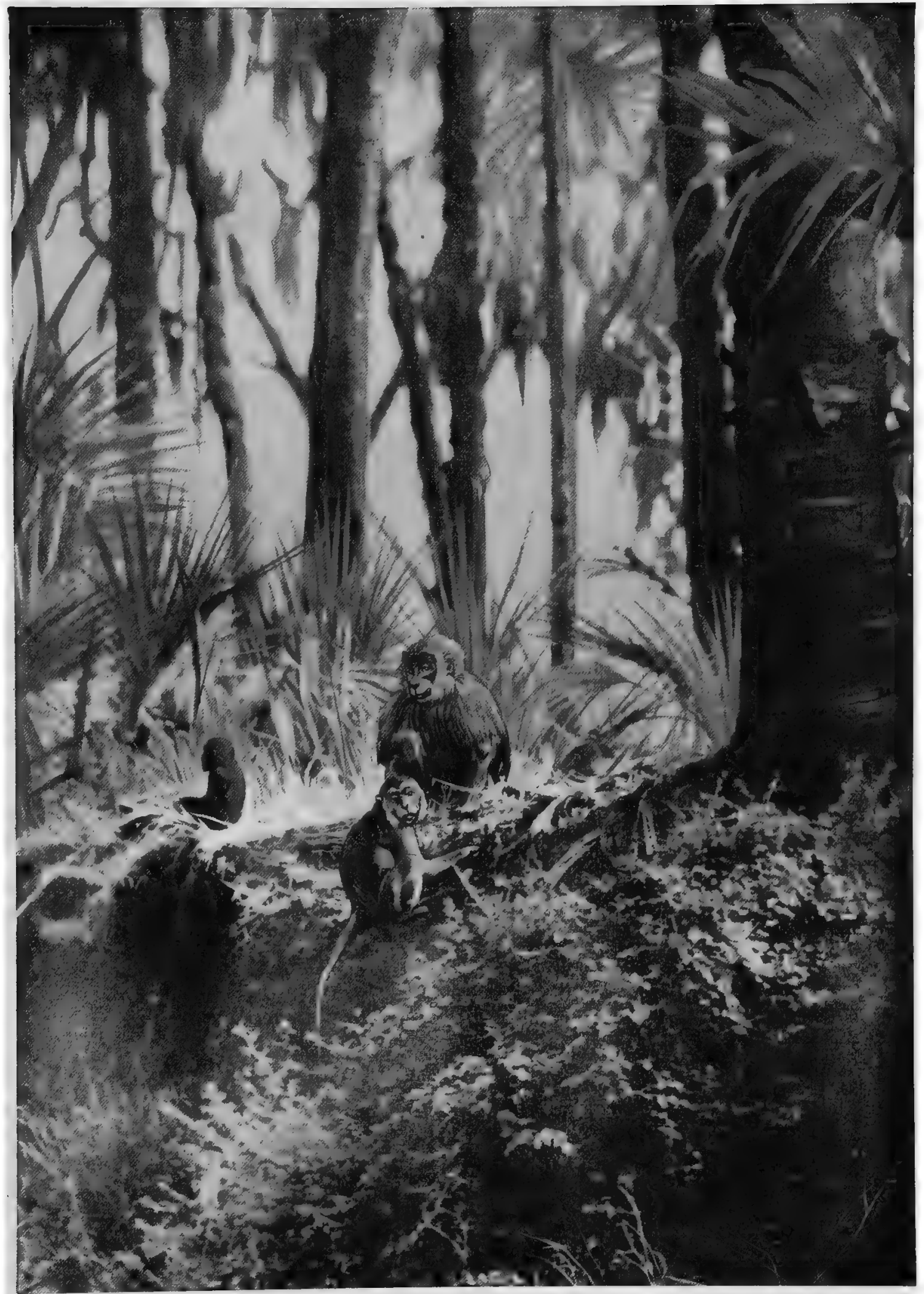

GELADA BABOONS AT HOME

This photograph is probably unique, as a gelada baboon has been rarely seen. It shows them at home looking for food on the ground under the bamboos and palms. It was taken by Lord Delamere in the East African jungle 


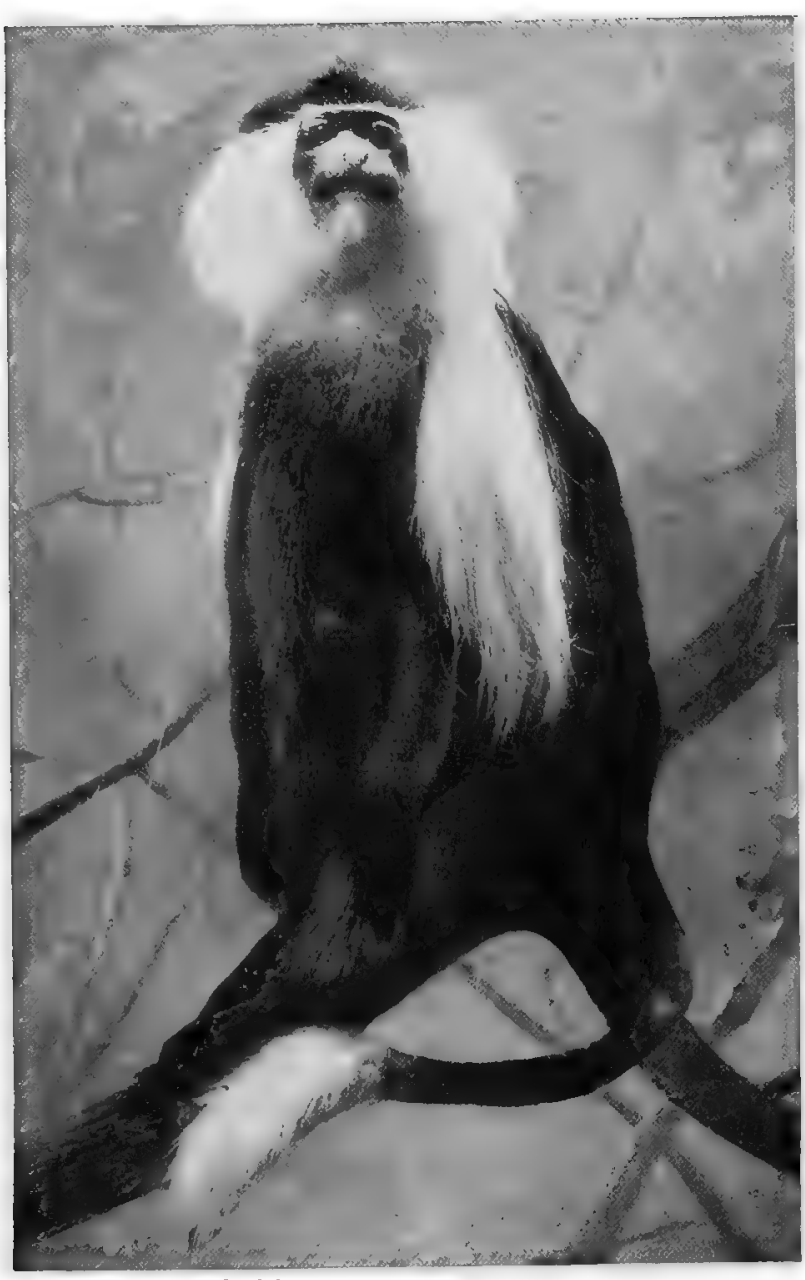

Phote by A. S. Rudland \&s Sons

MANTLED GUEREZA

This group of monkeys supplies the "monkey muffs" once very fashionable. The species with white plumes is used to decorate the Kaffir shields hands. " $\mathrm{He}$ then tried to pull off my rings, when I gave him some biscuits, and making a bed for him with my handkerchief he then settled himself comfortably to sleep; and from that moment we were sworn allies. When mischievous, he was often banished to a hen-coop. Much more effect was produced by taking him in sight of the panther, who always seemed most willing to devour him. On these occasions I held him by the tail before the cage; but long before I reached it, knowing where he was going, he pretended to be dead. His eyes were closed quite fast, and every limb was as stiff as though there were no life in him. When taken away, he would open one eye a little, to see whereabouts he might be; but if he caught sight of the panther's cage it was instantly closed, and he became as stiff as before." This monkey stole the men's knives, tools, and handkerchiefs, and even their caps, which he threw into the sea. He would carefully feed the parrots, chewing up biscuit and presenting them the bits; and he caught another small monkey and painted it black! Altogether, he must have enlivened the voyage. The Grivet Monkey, the Green Monkey, the Mona Monkey, and the MANGABEY are other commonly seen African species.

\section{The Macaques}

The Macaques, of which there are many kinds, from the Rock of Gibraltar to far Japan, occupy the catalogue between the guenon and the baboon. The Common MACAQUE and many others have tails. Those of Japan, and some of those of China, notably the TCHeli Monkey, kept outside the monkey-house at the Zoo, and the JAPANESE MACAQUE, at the other entrance, are tailless, and much more like anthropoid apes. The Tcheli monkey is large and powerful, but other macaques are of all sizes down to little creatures no bigger than a kitten. Some live in the nottest plains, others in the mountains. The Common MACAQue, found in the Malay Archipelago, is a strong, medium-sized monkey. The Formosan MACAQUE is a rock-living creature; those of Japan inhabit the pine-groves, and are fond of pelting any one who passes with stones and fir-cones. The BONNET MACAQUE is an amusing little beast, very fond of hugging and nursing others in captivity. The BANDAR or RHESUS MONKEY, a common species, also belongs to this group. But the most interesting to Europeans is the MAGOT, or BARBARY ApE. It is the last monkey left in Europe. There it only lives on the Rock of Gibraltar. It was the monkey which Galen is said to have dissected, because he was not permitted to dissect a human body. These monkeys are carefully preserved upon the Rock. Formerly, when they were more com- 


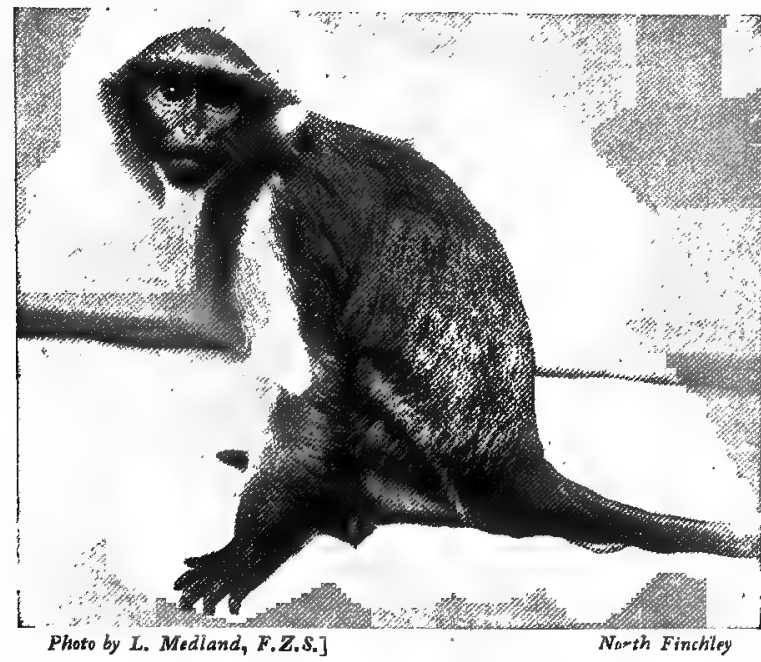

DIANA MONKEY

One of the most gaily coloured monkeys of Africa

The Baboons

Far the most interesting of the apes in the wild state are the Baboons. Their doglike heads (which in some are so large and hideous that they look like a cross between an ill-tempered dog and a pig), short bodies, enormously strong arms, and loud barking cry distinguish them from all other creatures. The greater number-for there are many kinds-live in the hot, dry, stony parts of Africa. They are familiar figures from the cliffs of Abyssinia to the Cape, where their bold and predatory bands still occupy Table Mountain. They are almost the only animals which the high-contracting Powers of Africa have resolved not to protect at any season, so mischievous are they to crops, and recently to the flocks. They kill the suckling lambs, and tear them to pieces for the sake of the milk contained in their bodies.

One of the best-known baboons is the Chacma of South Africa. The old males grow to a great size, and are most formidable creatures. Naturally, they are very seldom caught; but one very large one is in the Zoological Gardens, Regent's Park, at the time of writing. The keeper declares he would rather go into a lion's cage than into the den of this beast when angry. Its head is nearly one-third of its total length from nose to the root of the tail. Its jaw-power is immense, and its forearm looks as strong as Sandow's. mon, they were very mischievous. The following story was told by Mr. Bidcup: "The apes of the Rock, led by one particular monkey, were always stealing from the kit of a certain regiment encamped there. At last the soldiers caught the leader, shaved his head and face, and turned him loose. His friends, who had been watching, received him with a shower of sticks and stones. In these desperate circumstances the ape sneaked back to his old enemies, the soldiers, with whom he remained." Lord Heathfield, a former Governor of the Rock, would never let them be hurt; and on one occasion, when the Spaniards were attempting a surprise, the noise made by the apes gave notice of their attempt.

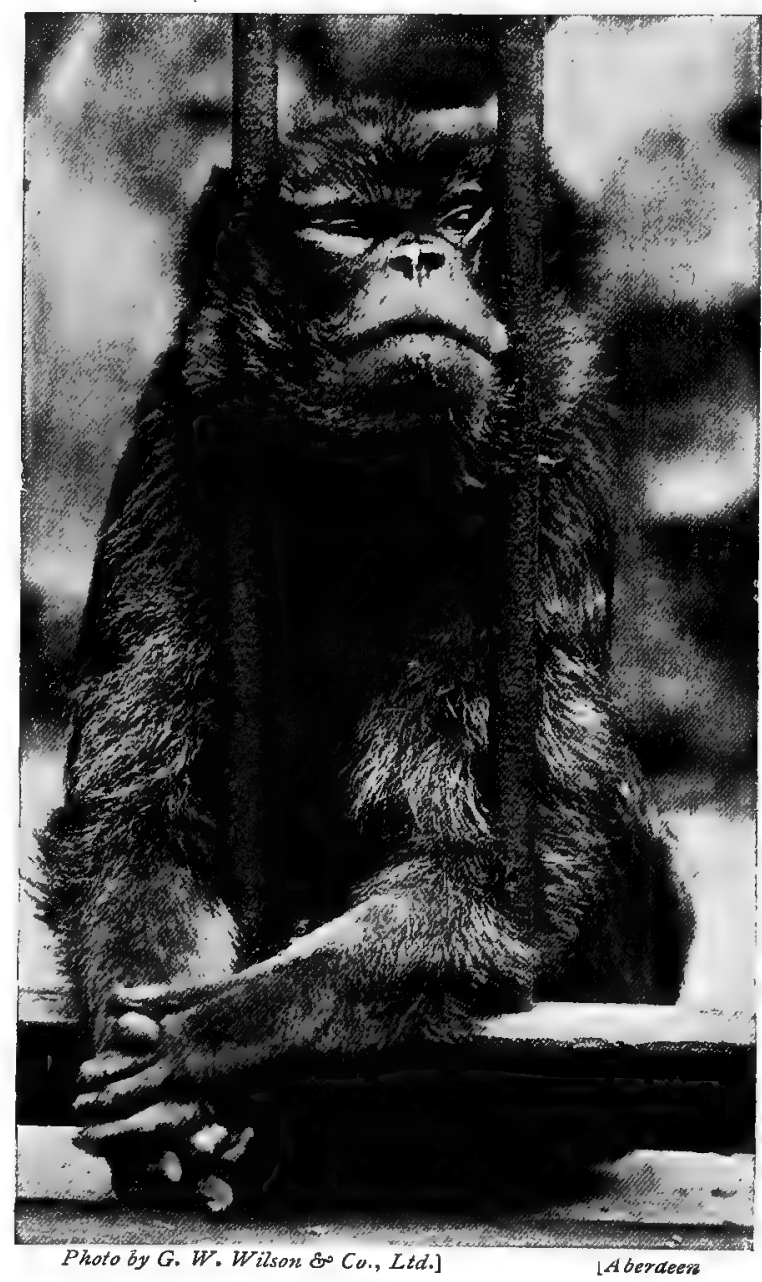

BARBARY APE
The last of the European monkeys on this side of the Mediterranean. and it is only found on the Rock of Gibraltar 


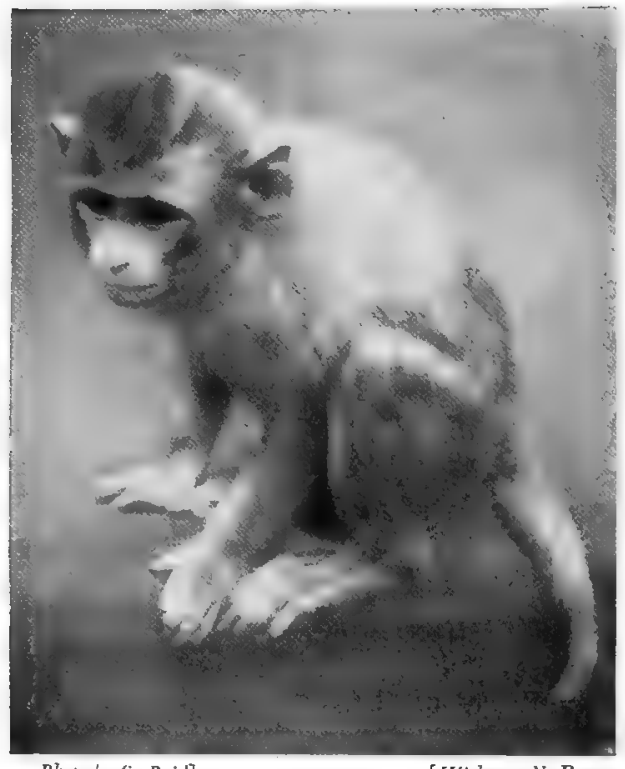

Photo by C: Reid]

Wishaw, N.B.

RHESUS MONKEY

A young specimen of the common Bengal monkey

Like all monkeys, this creature has the power of springing instantaneously from a sitting position; and its bite would cripple anything from a man to a leopard. The chacmas live in companies in the kopjes, whence they descend to forage the mealie-grounds, river-beds, and bush. Thence they come down to steal fruit and pumpkins or corn, turn over the stones and catch beetles, or eat locusts. Their robbing expeditions are organised. Scouts keep a lookout, the females and young are put in the centre, and the retreat is protected by the old males. Children in the Cape Colony are always warned not to go out when the baboons are near. When irritated-and they are very touchy in their tempers-the whole of the males will sometimes charge and attack. The possibility of this is very unpleasant, and renders people cautious.

Not many years ago a well-known sportsman was shooting in Somaliland. On the other side of a rocky ravine was a troop of baboons of a species of which no examples were in the British Museum. Though he knew the danger, he was tempted to shoot and to secure a skin. At 200 yards he killed one dead, which the rest did not notice. Then he hit another and wounded it. The baboon screamed, and instantly the others sat up, saw the malefactor, and charged straight for him. Most fortunately, they had to scramble down the ravine and up again, by which time the sportsman and his servant had put such a distance between them, making "very good time over the flat," that the baboons contented themselves by barking defiance at them when they reached the level ground.

They are the only mammals which thoroughly understand combination for defense as well as attack. But Brehm, the German traveler, gives a charming story of genuine courage and self-sacrifice shown by one. His hunting dogs gave chase to a troop which was retreating to some cliffs, and cut off a very young one, which ran up on to a rock, only just out of reach of the dogs. An old male baboon saw this, and came along to the rescue. Slowly and deliberately he descended, crossed the open space, and stamping his hands on the ground, showing his teeth, and backed by the furious barks of the rest of the baboons, he disconcerted and cowed these savage dogs, climbed on to the rock, picked up the baby, and carried him back safely. If the dogs had attacked the old patriarch, his tribe would probably have helped him. Burchell, the naturalist after whom Burchell's zebra is named, let his dogs chase a troop. The baboons turned on them, killed one on the spot by biting through the great blood-vessels of the neck, and laid bare the ribs of

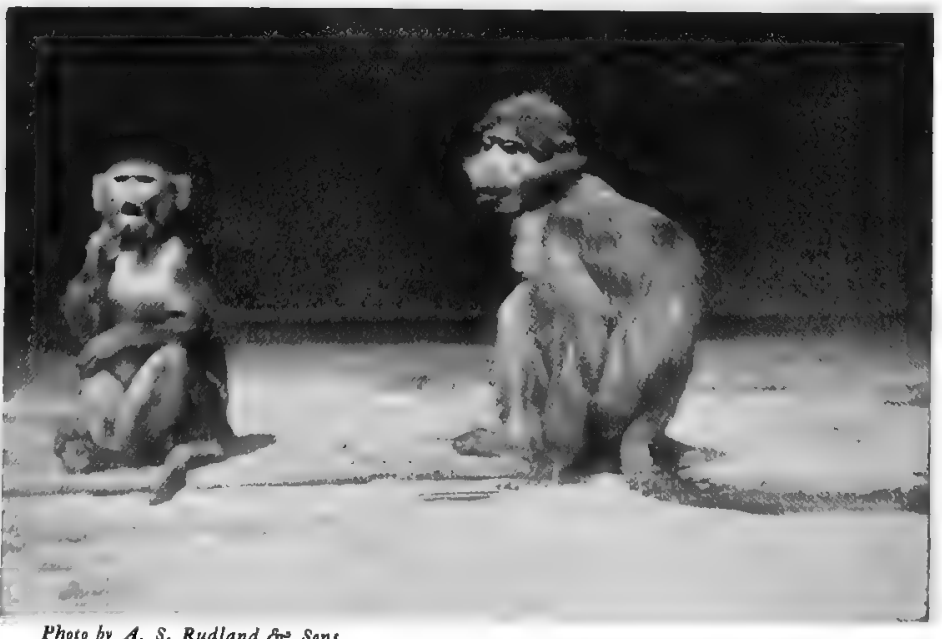

RHESUS MONKEY AND SOOTY MANGABEY The sooty mangabey (to the right of the picture) is gentle and companionable, but petu- 


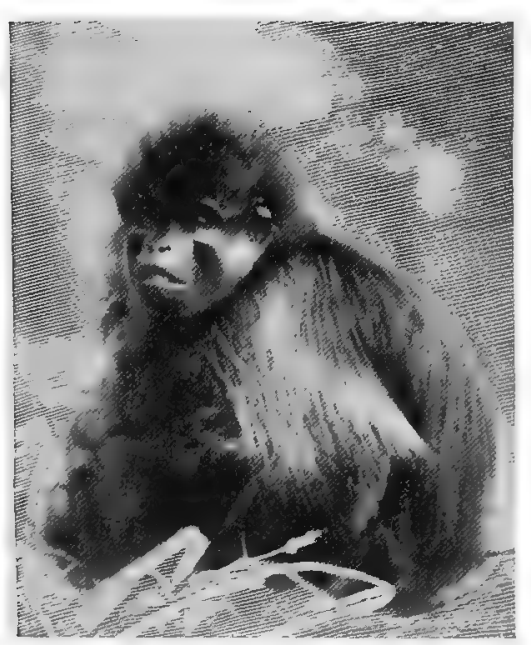

Photo by L. Medland, F.Z. S., North Finchley GREY-CHEEKED NANGABEY

One of the small African monkeys another. The Cape Dutch in the Old Colony would rather let their dogs bait a lion than a troop of baboons. The rescue of the infant chacma which Brehm saw himself is a remarkable, and indeed the most incontestable, instance of the exhibition of courage and self-sacrifice by a male animal.

If the baboons were not generally liable to become bad-tempered when they grow old, they could probably be

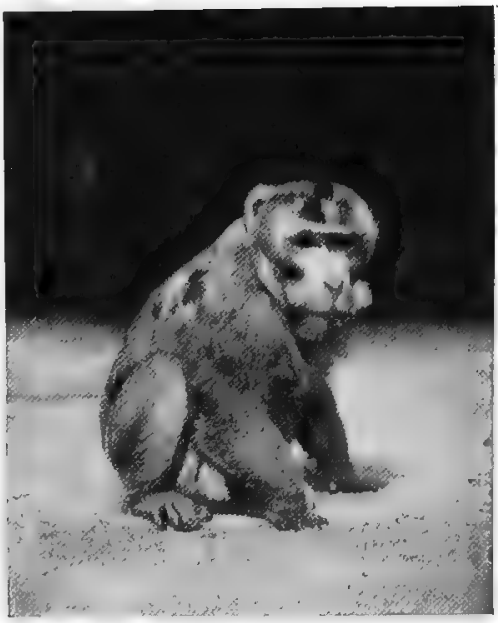

Photo by A. S. Rudland \& Sins

CHINESE MACAQUE

This monkey lives in a climate as cold as ours

trained to be among the most useful of animal helpers and servers; but they are so formidable, and so uncertain in temper, that they are almost too dangerous for attempts at semi-domestication. When experiments have been made, they have had remarkable results. Le Vaillant, one of the early explorers in South Africa, had a chacma baboon which was a better watch than any of his dogs. It gave warning of any creature approaching the camp at night long before the dogs could hear or smell it. He took it out with him when he was shooting, and used to let it collect edible roots for him. The latest example of a trained baboon only died a few years ago. It belonged to a railway signalman at Uitenhage station, about 200 miles up-country from Port Elizabeth, in Cape Colony. The man had the misfortune to undergo an operation in which both his feet were amputated, after being crushed by the wheels of a train. Being an ingenious fellow, he taught his baboon, which was a full-grown one, to pull him along' the line on a trolley to the " distant" signal. There the babóon stopped at the word of command, and the man would work the lever himself. But in time he taught the baboon to do it, while he sat on the trolley, ready to help if any mistake were made.

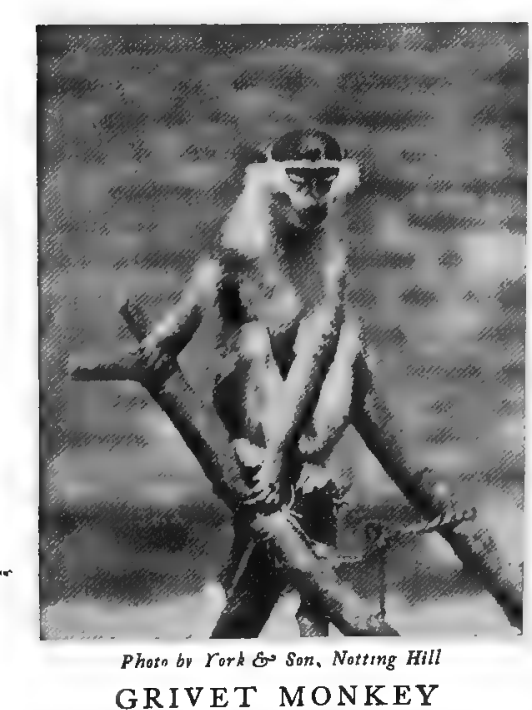

This is the small monkey commonly taken about with street-organs
The chacmas have for relations a number of other baboons in the rocky parts of the African Continent, most of which have almost the same habits, and are not very different in appearance. Among them is the Gelada Baboon, a species very common in the rocky highlands of Abyssinia; another is the Anubis Baboon of the West Coast of Africa. The latter is numerous round the Portuguese settlement of Angola. Whether the socalled Common Baboon of

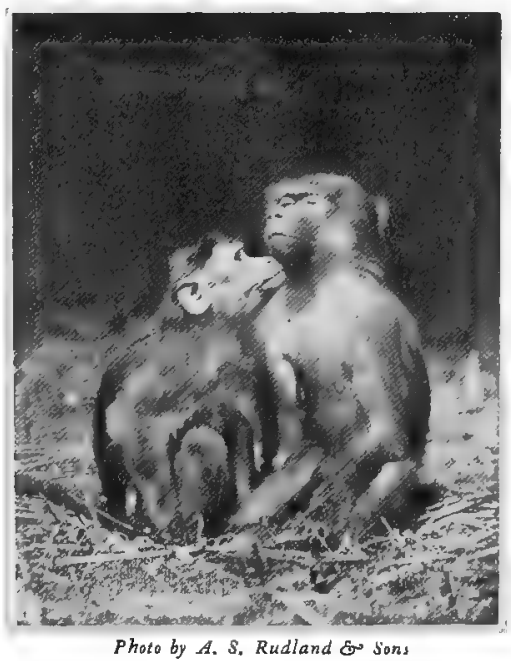

BONNET MONKEY, AND ARA. BIAN BABOON (ON THE RIGHT) 


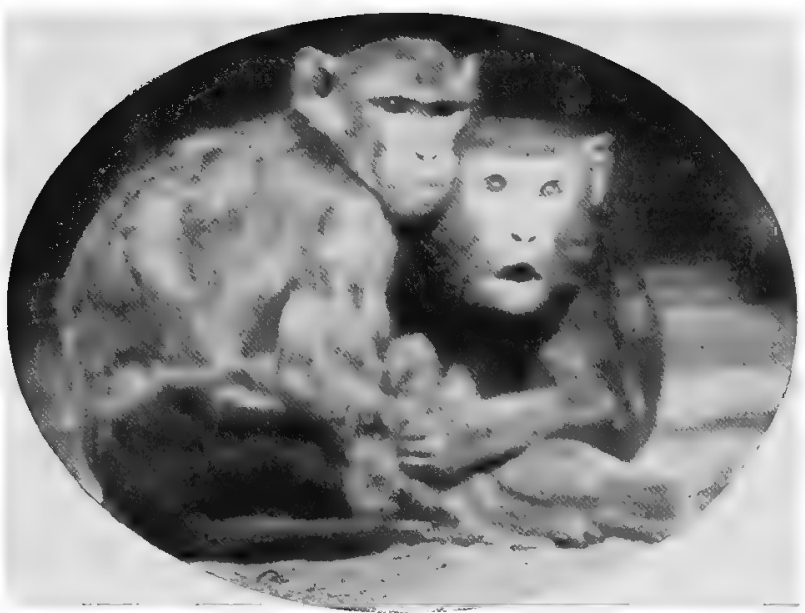

Photo by L. Medland, F.Z.S.]

RHESUS MONKEYS

This photagraph is particularly interesting. It was attually taken by another monkey, which pressed the button of Mr. Medland"s camera size, and are probably the most hideous of all beasts. The frightful nose, high cheek-bones, and pig-like eyes are the basis of the horrible heads of cievils and goblins which Albert Dürer and other German or Dutch mediæval painters sometimes put on canvas. Add to the figure the misplaced bright colours-cobalt-blue on the cheeks, which are scarred, as if by a rake, with scarlet furrows, and scarlet on the buttocks — and it will be admitted that nature has invested this massive, powerful, and ferocious baboon with a repulsiveness equaling in completeness the extremes of grace and beauty manifested in the roe-deer or the bird of paradise.

The natives of Guinea and other parts of West Africa have consistent accounts that the mandrills have tried to carry off females and children. They live in troops like the chacmas, plunder the fields, and, like all baboons, spend much time on the ground walking on all-fours. When doing this, they are quite unlike any other creatures. They walk slowly, with the head bent downwards, like a person walking on hands and knees looking for a pin. With the right hand (usually) they turn over every stick and stone, looking for insects, scorpions, or snails, and these they seize and eat. The writer has seen

the menageries is a separate species or only the young of some one of the abovementioned is not very clear. But about another variety there can be no doubt. It has been separated from the rest since the days of the Pharaohs. It does not differ in habits from the other baboons, but inhabits the rocky parts of the Nile Valley. It appears in Egyptian mythology under the name of Thoth, and is constantly seen in the sculptures and hieroglyphs.

Equally strong and far more repulsive are the two baboons of West Africa-the Drill and the MANDRILl. As young specimens of these beasts are the only ones at all easily caught, and these nearly always die when cutting their second teeth when in captivity, large adult mandrills are seldom seen in Europe. They grow to a great

\section{Prate}

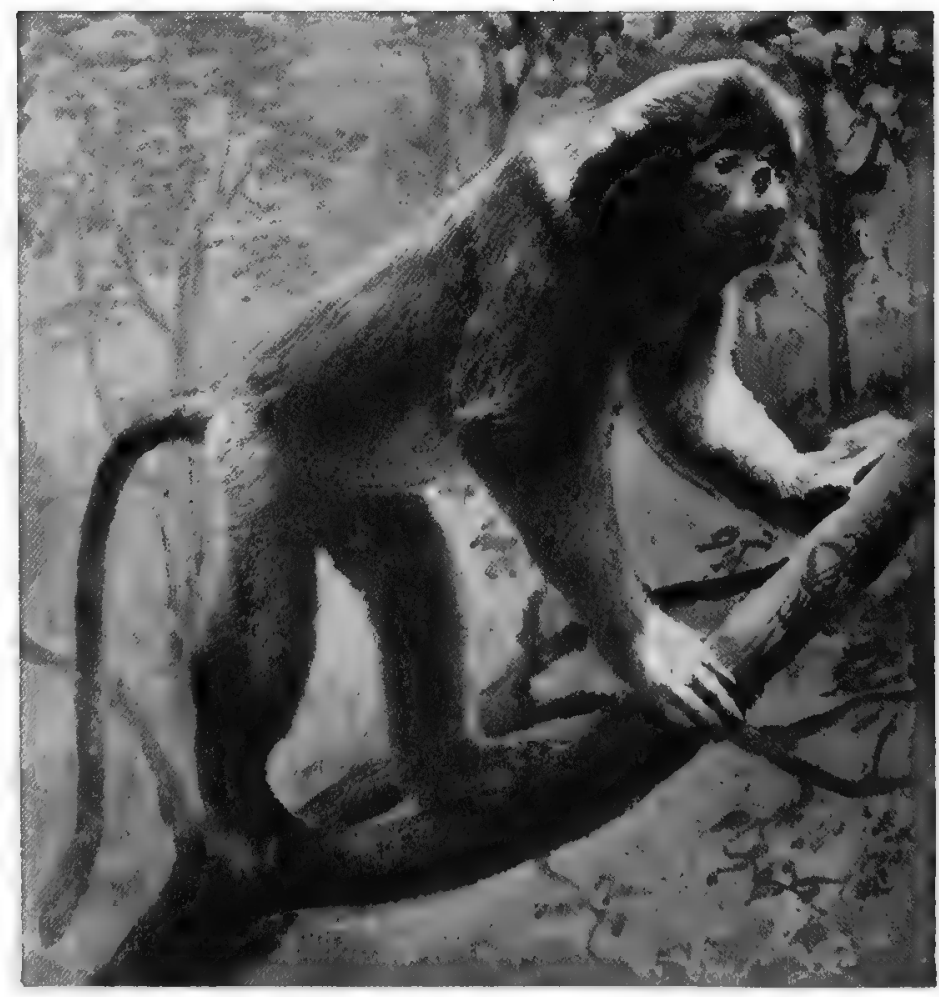

Phowe by A. S. Rudland os Sons

ORANGE SNUB-NOSED MONKEY

This should be contrasted with the Proboscis Monkey 
baboons picking up sand, and straining it through their fingers, to see if there were ants in it. He has also seen one hold up sand in the palm of its hand, and blow the dust away with its breath, and then look again to see if anything edible were left. Mandrills kept in captivity until adult become very savage. One in Wombwell's menagerie killed another monkey and a beagle. Mr. Cross owned one which would sit in an armchair, smoke, and drink porter; but these convivial accomplishments were accompanied by a most ferocious temper.

One of the earliest accounts of the habits of the Abyssinian baboons was given by Ludolf in his "History of Ethiopia." It was translated into quaint, but excellent old English : "Of Apes," he says, "there are infinite flocks up and down in the mountains, a thousand and more together, and they leave no stone unturned. If they meet with one that two or three cannot lift they call for more aid, and all for the sake of the Worms that lye under, a sort of dyet which they relish exceedingly. They are very greedy after Emmets. So that having found an emmet hill, they

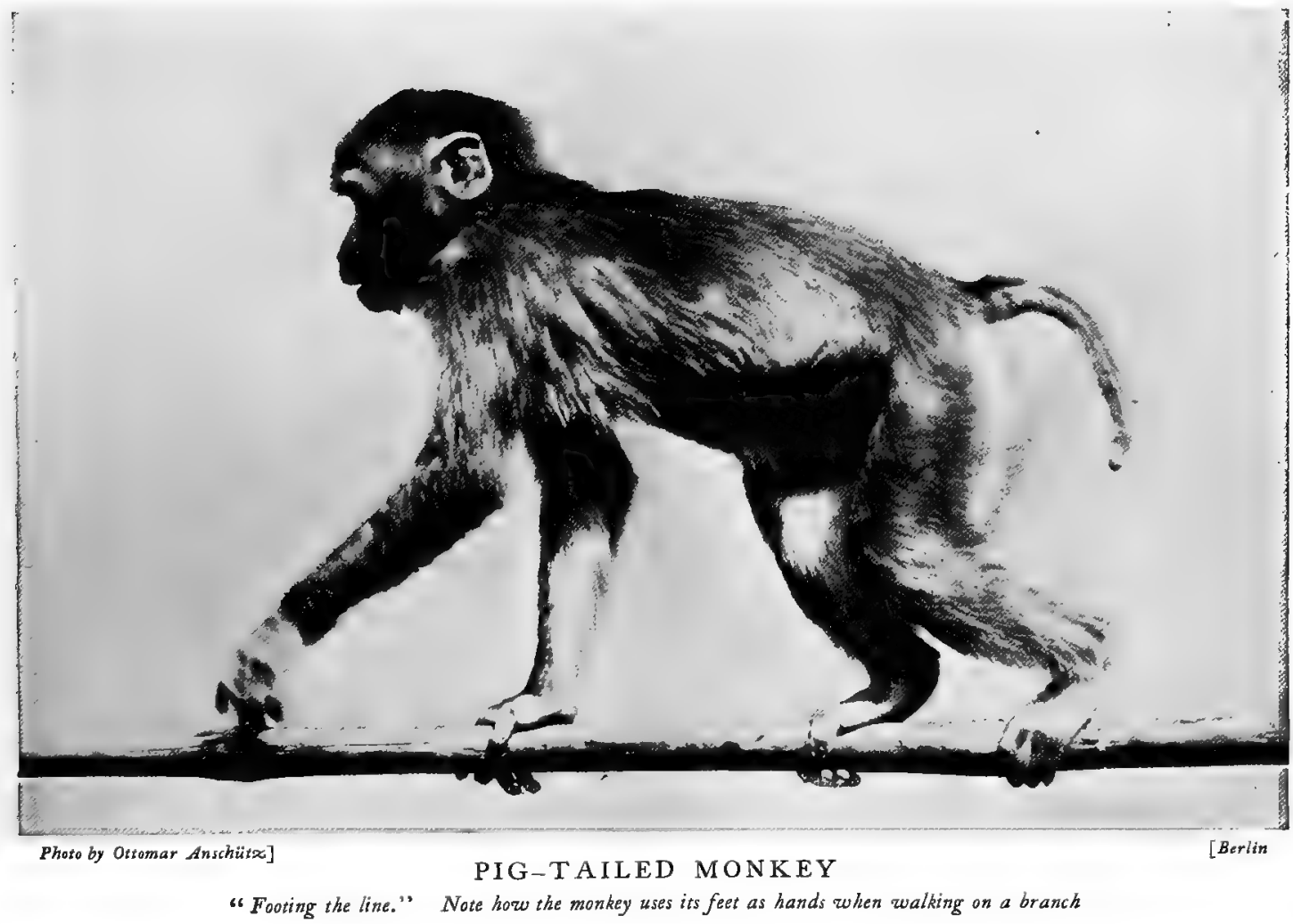

presently surround it, and laying their fore paws with the hollow downward upon the ant heap, as soon as the Emmets creep into their treacherous palms they lick 'em off, with great comfort to their stomachs. And there they will lye till there is not an Emmet left. They are also pernicious to fruits and apples, and will destroy whole fields and gardens unless they be looked after. For they are very cunning, and will never venture in till the return of their spies, which they send always before, who, giving all information that it is safe, in they rush with their whole body and make a quick despatch. Therefore they go very quiet and silent to their prey; and if their young ones chance to make a noise, they chastise them with their fists; but if the coast is clear, then every one has a different noise to express his joy." Ludolf clearly means the baboons by this description.

A more ancient story deals with Alexander's campaigns. He encamped on a mountain on which were numerous bands of monkeys (probably baboons). On the following morning the sentries saw what looked like troops coming to offer them battle. As they had just won a 


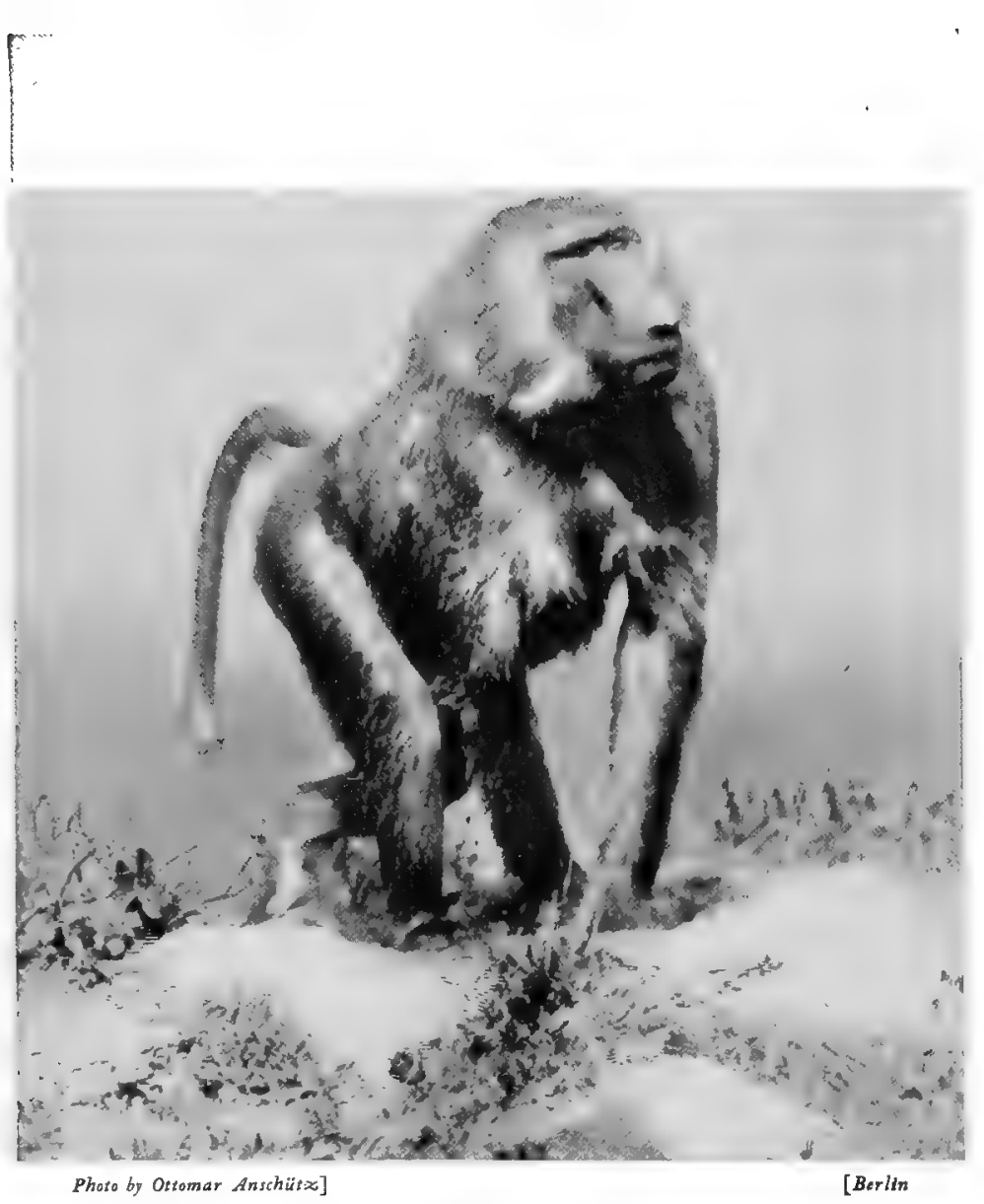

CHACMA BABOON

This photograph shows his attitude when about to make an attack

victory, they were at a loss to guess who these new foes might be. The alarm was given, and the Macedonian troops set out in battle-array. Then through the morning mists they saw that the enemy was an immense troop of monkeys. Their prisoners, who knew what the alarm was caused by, made no small sport of the Macedonians.

\section{The Speech of Monkeys}

Something should be said of the alleged "speech of monkeys" which Professor Garner believed himself to have discovered. He rightly excluded mere sounds showing joy, desire, or sorrow from the faculty of speech, but claimed to have detected special words, one meaning " food," another "drink," another "give me that," another meaning "monkey," or an identification of a second animal or monkey: He used a phonograph to keep permanent record of the sounds, and made an expedition to the West African forests in the hope that he might induce the large anthropoid apes to answer the sounds which are so often uttered by their kind in our menageries. The enterprise ended, as might have been expected, in failure. Nor was it in the least necessary to go and sit in a cage in an African forest in the hope of striking up an acquaintance with the native chimpanzees. The little Capuchin monkeys, whose voices and sounds he had ample opportunity of observing here, give sufficient material for trying experiments in the meaning of monkey sounds. The writer believes that it is highly probable that the cleverer monkeys have a great many notes or sounds which the others do understand, if only because they make the same under similar circumstances, otherwise they would not utter them. They are like the sounds which an intelligent but nearly dumb person might make. Also they have very sharp ears, and some of them can understand musical sounds, so far as to show a very marked attention to them. The following account of an experiment of this kind, when a violin was being played, is related in "Lire at the Zoo": "The Capuchin monkeys, the species selected by Professor Garner for his experiments in monkev language, showed the strangest and most amusing excitement. These pretty little creatures have very expressive and intelligent faces, and the play and mobility of their faces and voices while listening to the music were extraordinarily rapid. The three in the first cage at once rushed up into their box, and then all peeped out, chattering and excited. One by one they came down, and listened to the music witis intense curiosity, shrieking and making faces at a crescendo, shaking the wires angrily at a discord, and 


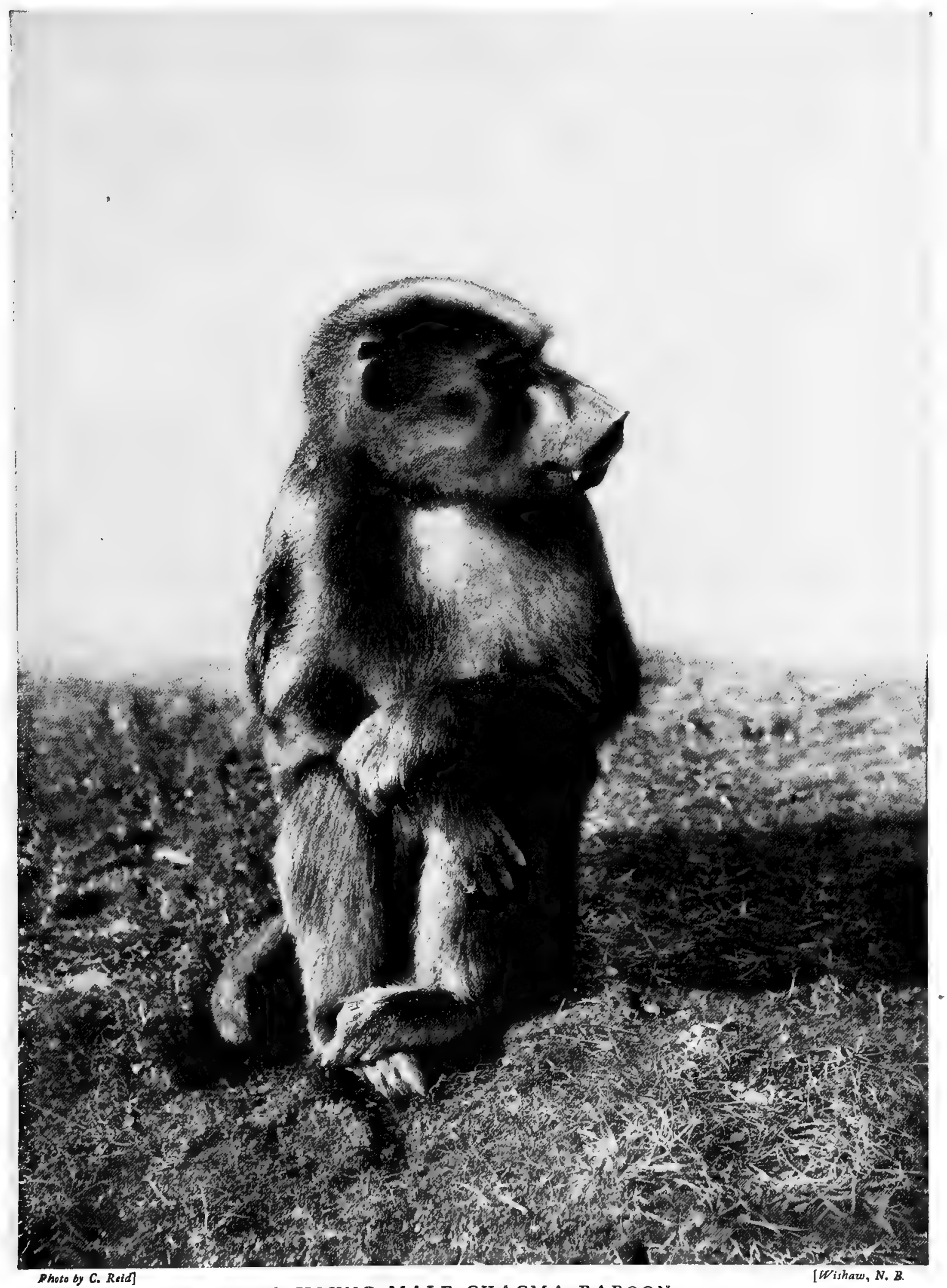

A YOUNG MALE CHACMA BABOON

Note the protruding tusk in the upper jaw. A baboon sitting in this position of rest can instantly leap six or seven feet, and inflict a dangerous bite 


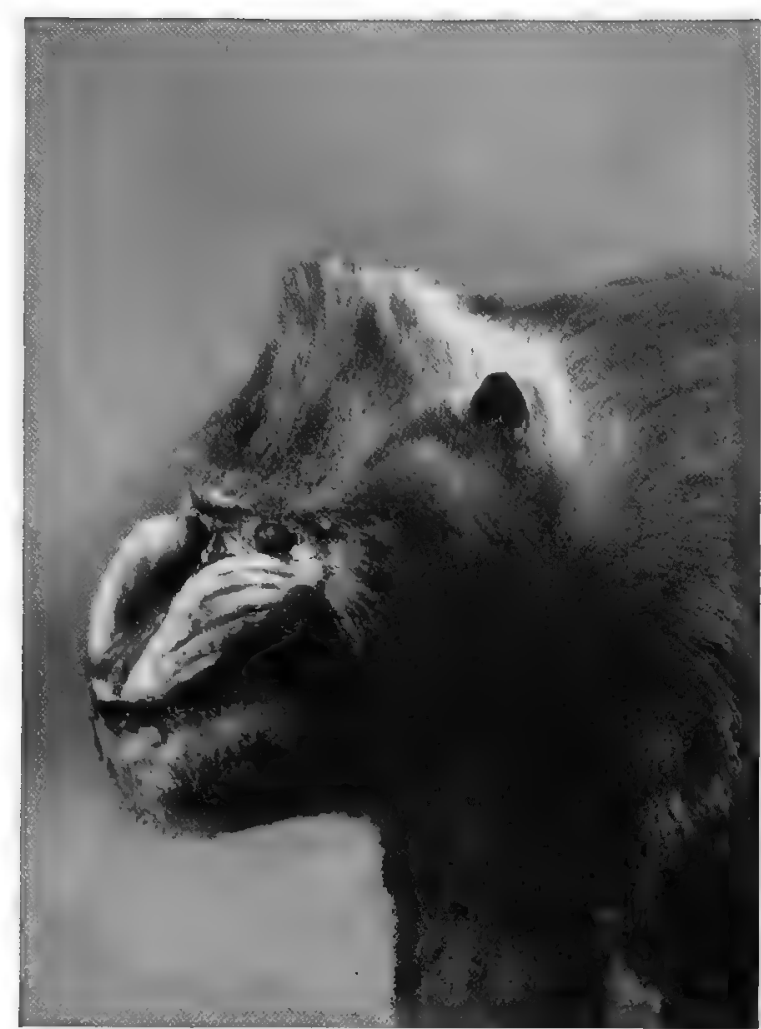

Photo by A. S. Rudland \& Sons]

HEAD OF MALE MANDRILL

This is one of the most hideous of living animals. The natives of West Africa hold it in greater dislike even than the large carnivora, from the mischief it does to their crops trils, which are not mere slits close together, but'like the nostrils of men. They also have human-looking rounded heads. Their noses are of the "cogitative" order, instead of being

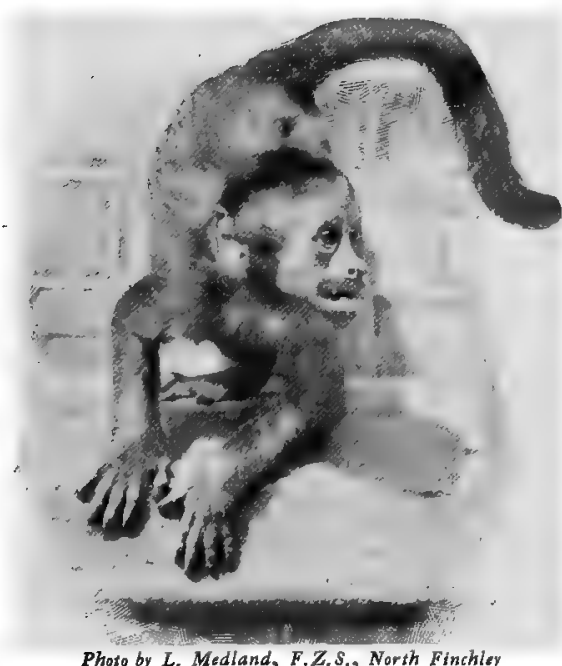

Phoso by L. Medland, F.Z.S., North Finchley BROWN CAPUCHIN

The most intelligent of the common monkeys of America. It uses many sounds to express emotions, and perhaps desires putting their heads almost upside-down in efforts at acute criticism at low and musical passages. Every change of note was marked by some alteration of expression in the faces of the excited little monkeys, and a series of discordant notes roused them to a passion of rage." At the same time a big baboon, chained up near, evidently disliked it. $\mathrm{He}$ walked off in the opposite direction to the farthest limits of his chain.

\section{The American Monkeys}

Mention of the Capuchins takes us to the whole group of the American Monkeys. Nearly all of these live in the tropical forests of Brazil, Guiana, Venezuela, and Mexico. They are all different from the Old World monkeys, and many are far more beautiful. The most attractive of the hardier kinds are the Capuchins; but there are many kinds of rare and delicate little monkeys more beautiful than any squirrel, which would make the most delightful pets in the world, if they were not so delicate. To try to describe the Old World monkeys in separate groups from end to end is rather a hopeless task. But the American monkeys are more manageable by the puzzled amateur. Most of them have a broad and marked division between the nossnouts or snubs with narrow openings in them; and the whole face is in many ways human and intelligent. The Howler Monkeys, which utter the most hideous sounds ever heard in the forests, and the SPIDER MoNkeys are the largest. The latter have the most wonderfully developed limbs and tails for catching and climbing of any living animals. As highly specialised creatures are always interesting, visitors to any zoological garden will find it worth while to watch a spider monkey climbing,

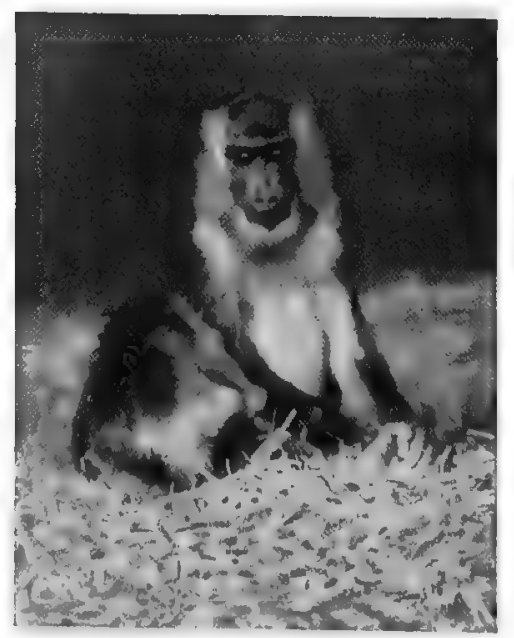

DRILL

Only less ugly than the Mandrill. Its habits an the same
Photo by L, Medland, F.Z.S., North Finchley 


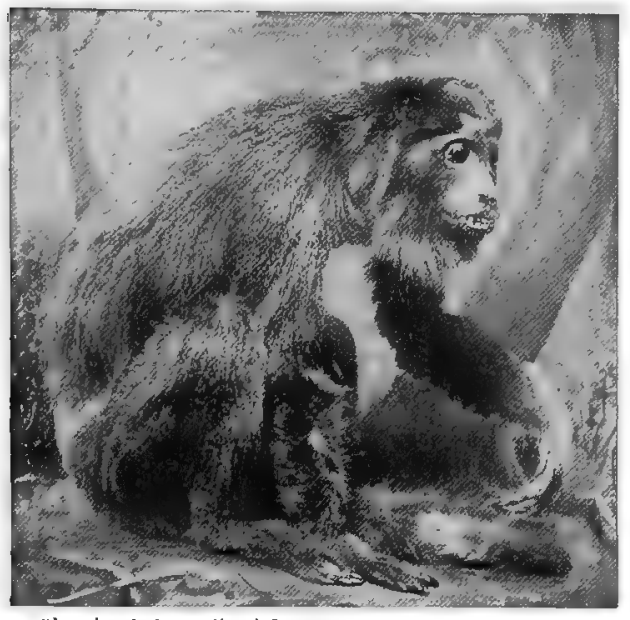

Photo by A. S. Rudland \&s Sons

RED HOWLER MONKEY

The male possesses a most extraordinary voice

just as it is always worth while to watch a great snake on the move. The tail is used as a fifth hand: the Indians of Brazil say they catch fish with it, which is not true. But if you watch a spider monkey moving from tree to tree, his limbs and tail move like the five fingers of a star-fish. Each of the extremities is as sensitive as a hand, far longer in proportion than an ordinary man's arm, and apparently able to work independently of joints. The monkey can do so many things at once that no juggler can equal it. It will hold fruit in one hand, pick more with one foot, place food to the mouth with another hand, and walk and swing from branch to branch with the other foot and tall, all simultaneously. These monkeys have no visible thumb, though dissection shows that they have a rudimentary one; but the limbs are so flexible that they can put one arm round behind their heads over on to the opposite shoulder, and brush the fur on their upper arm. The end of the tail seems always "feeling" the air or surroundings, and has hairs, thin and long, at the end, which aid it in knowing when it is near a leaf or branch. It is almost like the tentacle of some sea zoophyte. Gentle creatures, all of them, are these spider monkeys. One of them, of the species called WAITA, when kept in captivity, wore the fur off its forehead by rubbing its long gaunt arms continually over its brow whenever it was scolded. The spider monkeys differ only in the degree of spidery slenderness in their limbs. In disposition they are always amiable, and in habits tree climbers and fruit-eaters.

The Capuchins are, in the writer's opinion, the nicest of all monkeys. Many species are known, but all have the same round merry faces, bright eyes, pretty fur, and long tails. There is always a fair number at the Zoological Gardens. They are merry, but full of fads. One hates children and loves ladies; another adores one or two other monkeys, and screams at the rest. All are fond of insects as well as of fruit. A friend of the writer kept one in a large house in Leicestershire. It was not very good-tempered, but most amusing, climbing up the blind-cord first, and catching and eating the flies on the window-panes most dexterously, always avoiding the wasps. This monkey was taught to put out a lighted paper (a useful accomplishment) by dashing its hands on to the burning part, or, if the paper were twisted up, by taking the unlighted end and beating the burning part on the ground ; and it was very fond of turning the leaves of any large book. This it did not only by vigorous use of both arms and hands, but by putting its head under too, and "heaving" the leaves over.

In the private room behind the monkeyhouse at the Zoo there are always a number of the

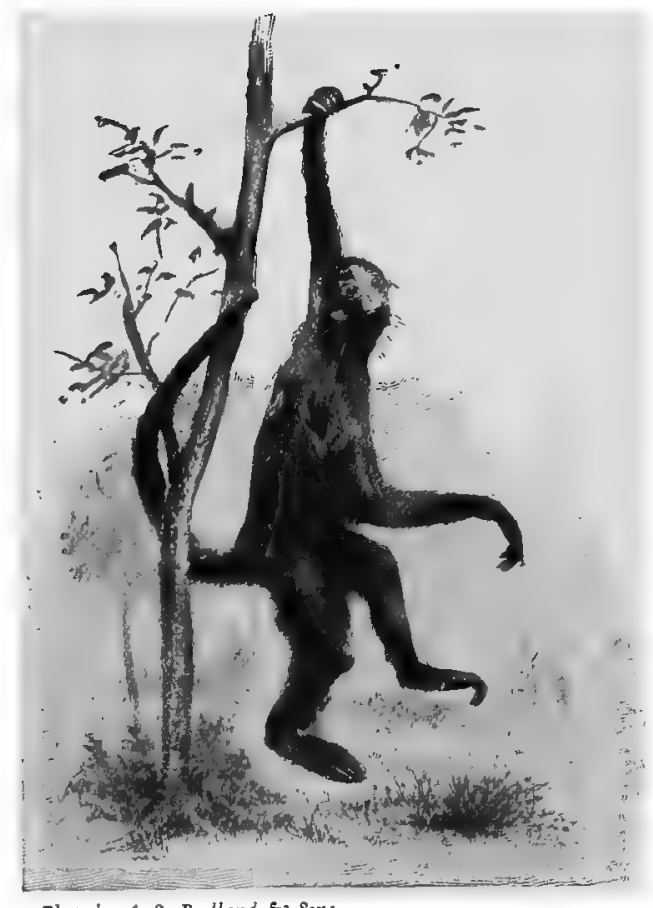

Phoso by A. S. Rudland Es Sons

A SPIDER MONKEY

This monkey is specially adapied for arboreal life. The tail acts as a fifth hand 


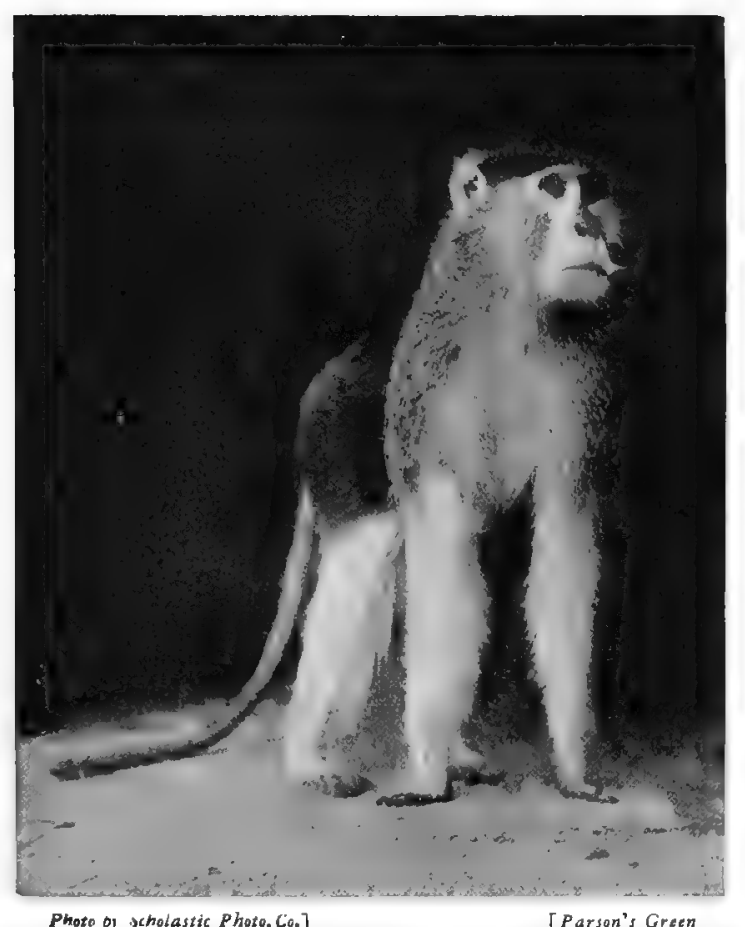

PATAS MONKEY

Found in West Africa. A large and brilliantly coloured species

rare and delicate monkeys from America, which cannot stand the draughts of the outer house, like the Capuchins and spider monkeys. The greater number of these come from tropical America. There, in the mighty forests, so lofty that no man can climb the trees, so dense that there is a kind of upper story on the interlaced tree-tops, where nearly all the birds and many mammals live without descending to earth, furests in which there is neither summer nor winter, but only the changes from hour to hour of the equatorial day, the exquisite MARmosets, whose fur looks like the plumage and whose twittering voices imitate the notes of birds, live and have their being. They are all much alike in shape, except that the Lion Marmoser's mane is like that of a little lion clad in floss silk; and they all have sharp little claws, and feed on insects. The Pinché Marmoset from the Guiana forests has a face like a black Indian chief, with white plumes over his head and neck like those worn by a "brave" in full war-paint. Merchants who do business with Brazil very frequently import marmosets and the closely

allied tamarins as presents for friends at home in England; the Brazilians themselves like to have them as pets also; so there is to some extent a trade demand for them.

Among the most delicate of American monkeys are the OukARIs, which have somewhat human faces, exquisite soft fur, and are as gentle as most of these forest creatures. They seldom live long in captivity, a few months being as much as they will generally endure, even in Brazil. Perhaps the rarest of all is the white-haired SCARLET-FACED OUKARI. This monkey has long white hair from neck to tail, sandy whiskers, and a bright scariet face. It lives in a district of partly flooded forest, and is only obtained by the Indians using blow-pipes and arrows dipped in very diluted urari poison. The WhiteHEADED SAKI is a rare and very pretty little monkey of Brazil; and there are a very large number of other species of this group whose names it would be mere weariness to mention. All these small monkeys are very quick and intelligent, while the rapidity of their movements, their ever-changing expression, and sharp, eager cries heighten the idea of cleverness given by their general appearance. Other little imps of these forests are the Squirrel Monkeys. In the common species the face is like a little furry man's, its arms brilliant yellow (as if dipped in gamboge dye), the cheeks pink, and eyes black. In habits it is a quick-tempered, imperious little creature, carnivorous, and a great devourer of butterflies and beetles.

The most beautiful and entertaining of all monkeys are

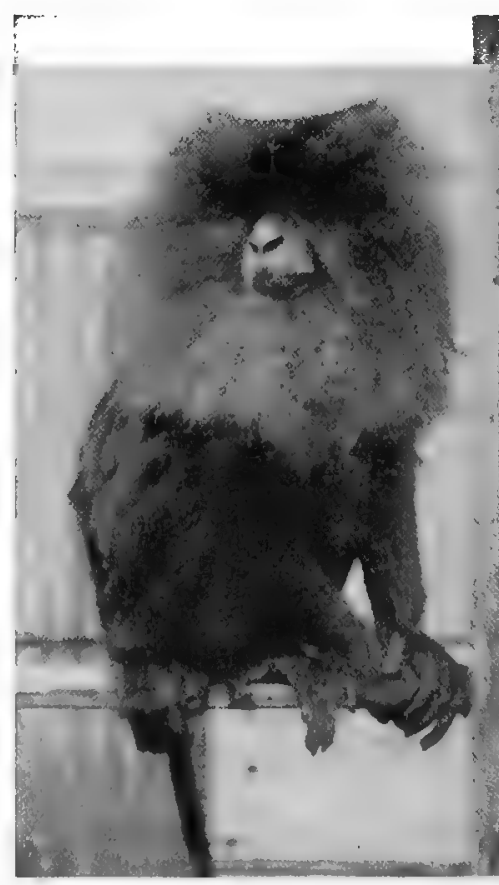

Phato by C. Roid] [Wishaw, N.B.

WANDEROO MONKEY

The number of monkeys wuhich have leonine manes is large. The manes act as capes tr keep the dew and wet from their cheses and shoulders. 


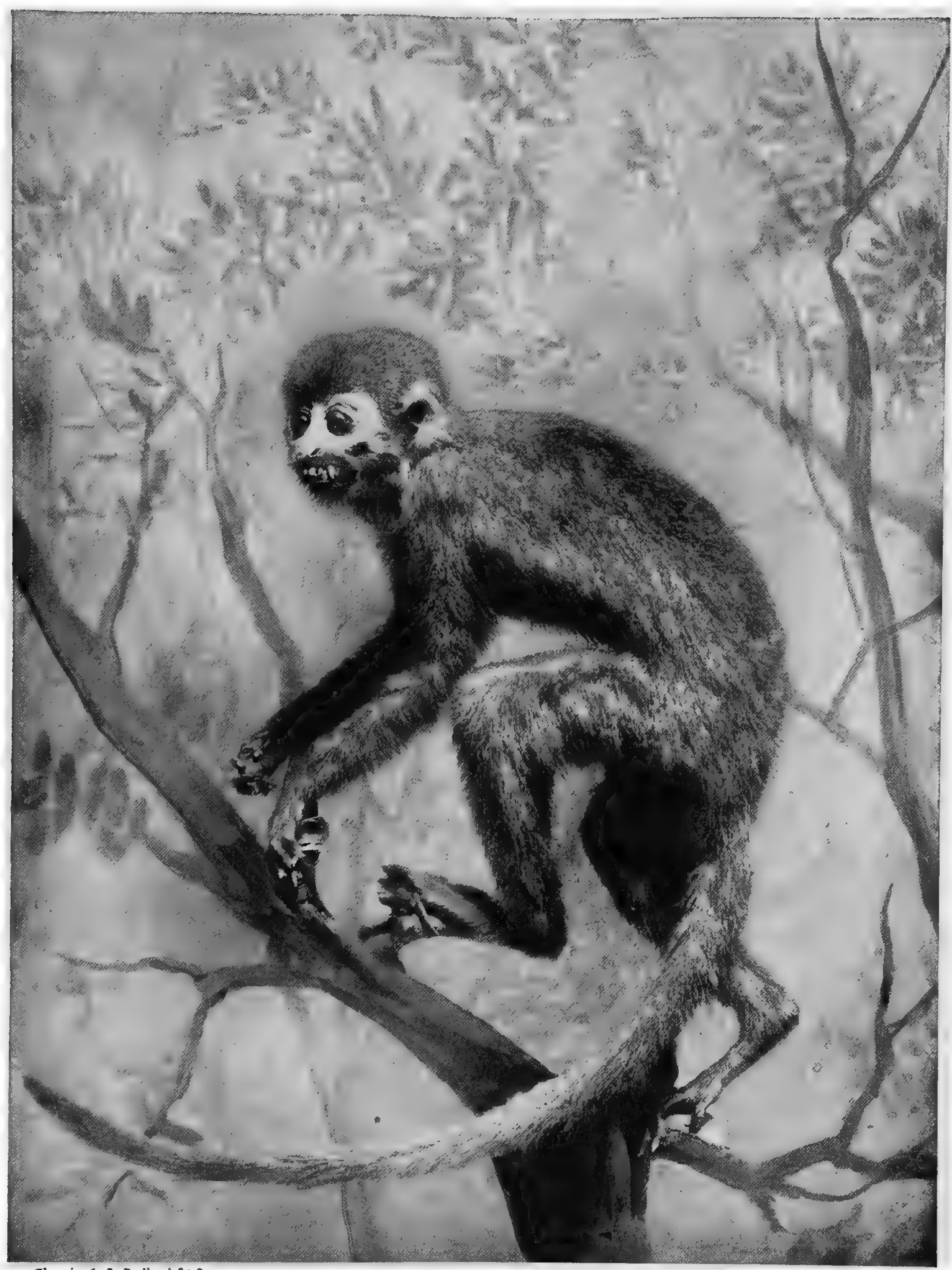

Phats by $A$. S. Rudland \& Sons

COMMON SQUIRREL MONKEY

The squarrel monkeys have soft, bright-coloured fur, and long, hairy tails. They are found from Mexico to Paraguay 
these New World species. No person clever at interpreting the ways of animals would fail to consider them far more clever and sympathetic than the melancholy anthropoid apes, while for appearance they have no equals. Probably the most attractive monkey in Europe is a South American one now in the London Zoological Gardens. It was first mentioned to Europeans by Baron von Humboldt, who saw it in the cabin of an Indian on the Orinoco. These forest Indians of South America are gentle creatures themselves. Among other amiable qualities, they have a passion for keeping pets. One who worked for a friend of the writer, with others of his tribe, was asked what he

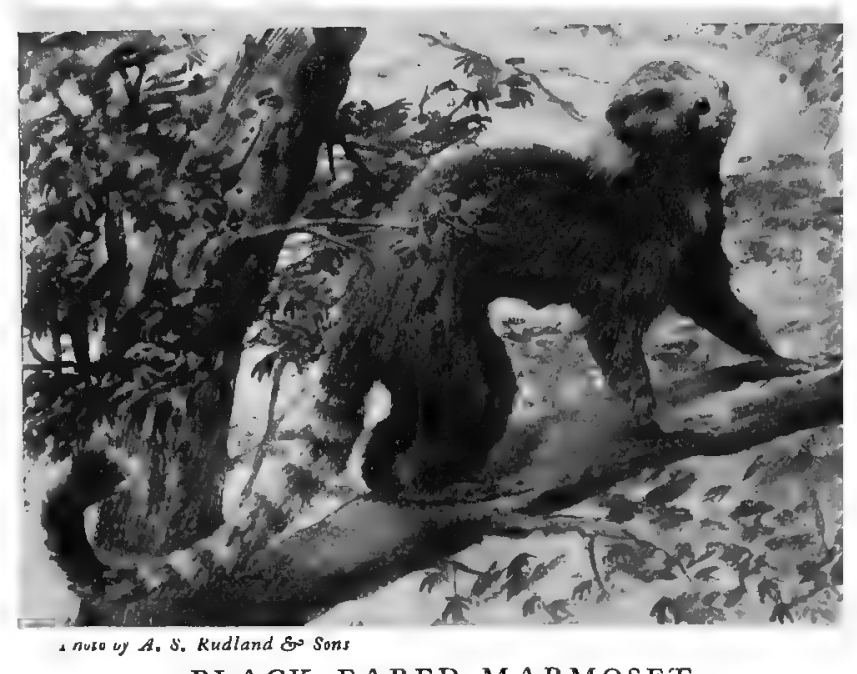

BLACK-EARED MARMOSE'T

These are among the prettiest of small tropical monkeys in America: they are
insect-feeders, and very delicate would take in payment, which was given in kind. The others chose cloth, axes, etc. This Indian said that he did not care for any of these things. He said he wanted a "poosa." No. one knew what he meant. He signed that he wished to go to the house and would show them. Arrived there, he pointed to the cat! "Pussy," to the Arawak Indian, was a " poosa," and that was what he wanted as a month's wages. Humboldt's Indian had something better than a " poosa." It was a monkey, as black as coal, with a round head, long thickly furred tail, and bright vivacious eyes. The explorer called it the LaGothrix, which means Hare-skin Monkey. The fur is not the least like a hare's, but much resembles that of an opossum. The more suitable name is the Woolly Monkey. The one kept at the Gardens is a most friendly and vivacious. creature, ready to embrace, play and make friends with any well-dressed person. It dislikes. people in working-clothes which are dirty or soiled-a not uncommon aversion of clever animals.

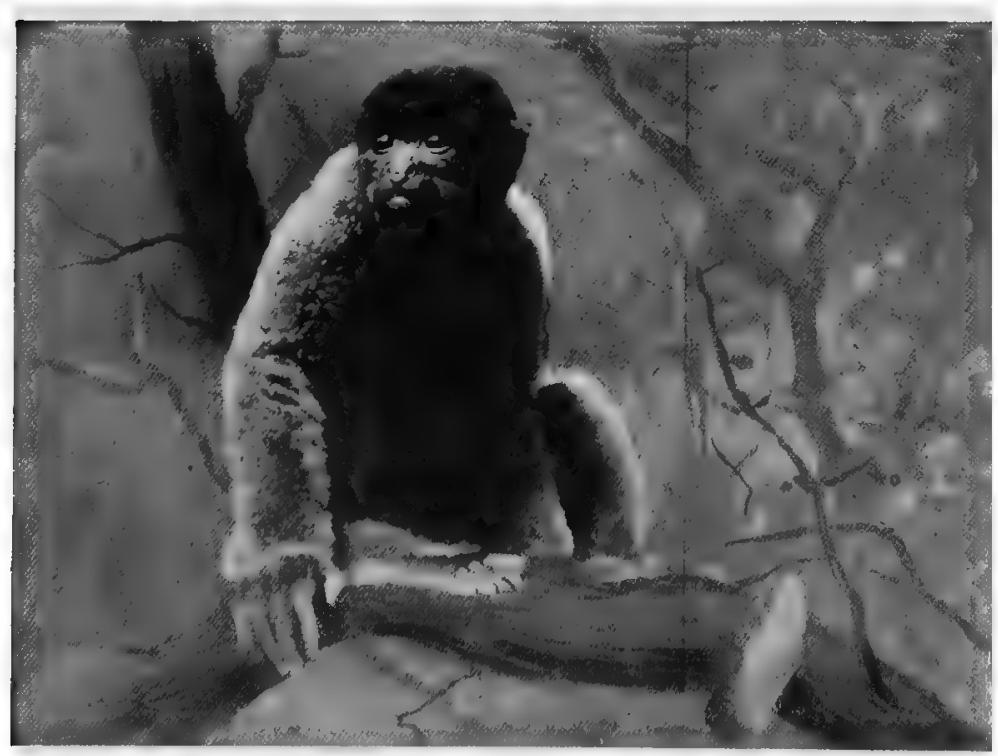

Phoso by L. Madland, F.Z, S.]

HUMBOLDT'S WOOLLY MONKEY

This is the most popular monkey in captivity. He looks for all the world like a Negro, and has a must beautiful, soft, woolly coat. He is very tame. and loves nothing better than being pested
In spite of all the varieties of temperament in the monkey tribe, from the genial little Capuchins to the morose old baboon, they nearly all have one thing in commonthat is, the monkey brain. The same curious restlessness, levity, and want of concentration mark them all, except the large anthropoid apes. Some of these have without doubt powers of reflection and concentration which the other monkeys do not possess. But in all the rest, though the capacity for understanding exists, the wish to please, as a dog does, and the desire: to remember and to retain what it has learnt, seem 
almost entirely wanting. Egoism, which is a sign of humam dementia, is a very leading characteristic of all monkeys. There is no doubt that the baboons might be trained to be useful animals if they always served one master. Le Vaillant and many other travelers have noted this. But they are too clever, and at the bottom too ill-tempered ever to be trustworthy, even regarded as "watches," or to help in minor manual labour. Baboons would make an excellent substitute for dogs as used in Belgium for light draught; but no one could ever rely on their behaving themselves when their master's eye was elsewhere.

Taken as a family, the monkeys are a feeble and by no means likeable race. They are "undeveloped" as a class, full of promise, but with no performance.

\section{THE LEMURS}

THE South American monkeys, with their forms and fur, are followed by a beautiful and of creatures, called the Lemurs, with their Maholis, and Pottos. Their resemblance to their hands and feet. These are real and hands, with proper thumbs. The second always terminates in a long, sharp alist, who kept them as pets nothemselves with. Some of them sensitive disk, full of extra "Unlike the lively squirrels hiding-places till the tropical when they seek their but by ascending to the and again, at the first apthe light in the recesses The Ring-Tailed Lemur most of the race are so the light seems to they turn over same inarticuBut at night they fly from so that the whether they ghosts of their

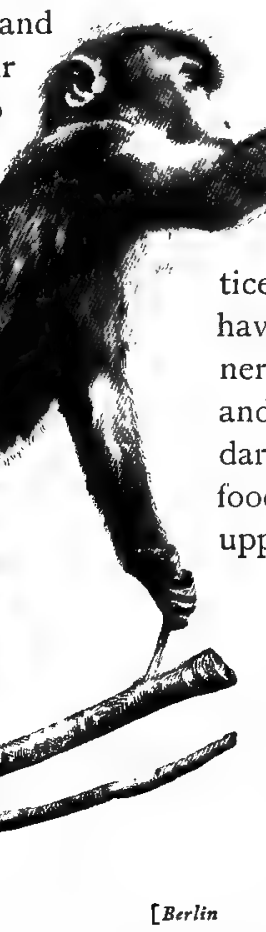

Photo by Ottomar Anschüts] PIG-TAILED MONKEY CATCHING A FLY Most of the smaller monkeys, as zuell as the baboons, are fond of eating. insects. Beetles, white ants, and fies are eagerly sought and devoured

squirrel-like interesting group cousins the Lorises. monkeys is mainly in very highly developed toe on the hind foot nearly claw. "Elia," the Indian naturticed that they used this to scratch have the finger-tips expanded into a nerves. Lemur means "ghost." and monkeys, they do not leave their darkness has fallen on the forest, food, not by descending to the ground, upper surface of the ocean of trees, proach of dawn, seek refuge from of some dark and hollow trunk. is as lively by day as night; but entirely creatures of darkness that stupefy them. When wakened, like sleeping children, with the late cries and deep, uneasy sighs. most are astonishingly active; tree to tree, heard, but invisible; natives of Madagascar doubt are not true leniures, the unquiet departed dead.

Though the lemurs are here treated apart from the other animals of Madagascar, it will be obvious that they are a curious and abnormal tribe. This is true of most of the animals of that great island, which has a fauna differing both from that of the adjacent coast of Africa and from that of India or Australia. In the FossA, a large representative of the Civets, it possesses a species absolutely unlike any other. The Aye-aye is also an abnormal creature. Nor must it be forgotten that Madagascar was until recently the home of some of the gigantic ground-living birds. But, after all, none of its inhabitants are more remarkable than its hosts of lemurs, some of which are to be met with in almost every coppice in the island. There are also many extinct kinds.

Exquisite fur, soft and beautifully tinted, eyes of extraordinary size and colour (for the pupil shuts up to a mere black line by day, and the rest of the eye shows like a polished stone of rich brown or yellow or marble gray), are the marks of most of the lemurs. But there are other lemur-like creatures, or "lemuroids," which, though endowed with the same lovely fur, like 


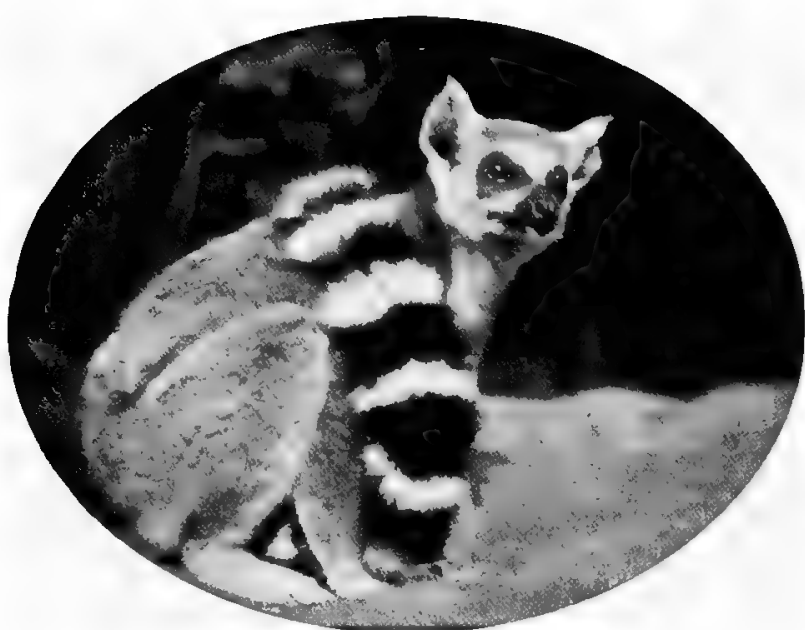

Photo by L. Medland, F.Z.S.]

RING-TAILED LEMUR

This lemur is often kept as a domestic animal, and allowed to run about the house like a cat

softest moss, have no tails. The strangest of all are two creatures called the SLENDER Loris and the SLow Loris. The slender loris, which has the ordinary furry coat of the lemurs, and no tail, moves on the branches exactly as does a chameleon. Each hand or foot is slowly raised, brought. forward, and set down again. The fingers then as slowly close on the branch till its grasp is secure. It is like a slow-working mechanical toy. Probably this is a habit, now instinctive, gained by ages of cautiously approaching insects. But the result is to give the impression that the creature is, almost an automaton.

Madagascar is the main home of the lemurs, though some of the related animals are also found in Africa and in the East Indies. But the dense forests of the great island are full of these curious nocturnal beasts, of which there are so many varieties presenting very slight differences of form and habit, that naturalists have some difficulty in giving even a complete list of their species. Add to this that nearly all of them are intensely and entirely nocturnal, and the scarcity of data as to their habits is easily accounted for. When seen by us, their faces all lack expression-that is to say, the eyes, which mainly give expression, seem entirely vacant and meaningless. But this is due to their special adaptation to seeing in the dark tropical night. By day the pupil of the eye almost disappears. If only we could also see in the dark, the eyes of the lemur might have as much expression as those of a faithful dog. The change which night makes in their general demeanour is simply miraculous. By day many of them are like hibernating animals, almost incapable of movement. When once the curtain of night has fallen, they are as active as squirrels, and as full of play as a family of kittens. The Ring-Tailed Lemur is often kept as a pet, both in Madagascar and in the Mauritius. It is one of the very few which are diurnal in their habits. When in a hurry it jumps along, standing on its hind feet, like a little kangaroo, but holding its tail upright behind its back. It will follow people up-stairs in this way, jumping from step to step, with its front paws outstretched, as if it were addressing an audience. The French call these day lemurs Makis. The ring-tailed lemur lives largely among rocks and precipices. Most of these creatures live upon fruit, the shoots and leaves of trees, and other vegetable food. But, like the squirrel, they have no objection to eggs and nestlings, and also kill and eat any small birds and insects. Some of the smaller kinds are almost entirely insect-feeders. The largest kind of lemur belongs to the group known as the INDRIS. The BIACK-ANDwHITE INDRI measures about two feet in length. It has only a rudimentary tail, large ears, and a sharp-pointed nose. The amount of white colouring varies much in different individuals. This variation in colouring-a very rare feature among wild mammalia, though one of the first changes shown when animals are domesticated-is also found in the next three species, called Sifakas. The Diademed Sifaka, the Wooliy

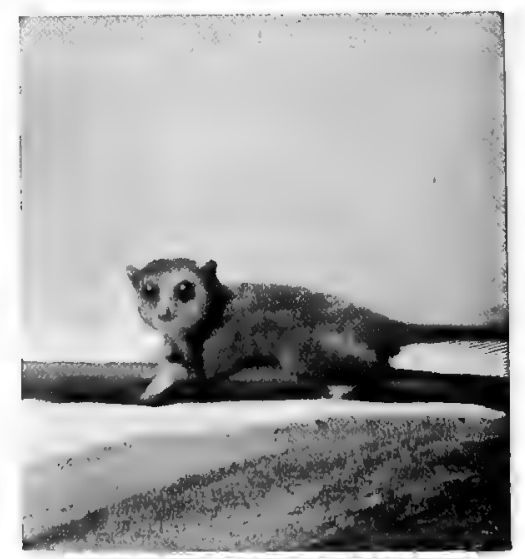

Phoso by L. Medland, F.Z.S., North Finchlay A DWARF I.EMUR

These tiny animals take the place of the dorm mouse in Madagascar 
INDRI, and the BLACK INDRI all belong to this group. The Sifakas, as some of these and the allied forms are called, are venerated by the Malagasys, who never kill one intentionally. Mr. Foster observes that " they live in companies of six or eight, and are very gentle and inoffensive animals, wearing a very melancholy expression, and being as a rule morose, inactive, and more silent than the other lemurs. They rarely live long in captivity. In their native state they are most alert in the morning and evening, as during the day they conceal themselves under the foliage of trees. When asleep or in repose, the head is dropped on the chest and buried between the arms, the tail rolled up on itself and disposed between the hind legs. The sifakas live exclusively on vegetable substances, fruits, leaves, and flowers, their diet not be-

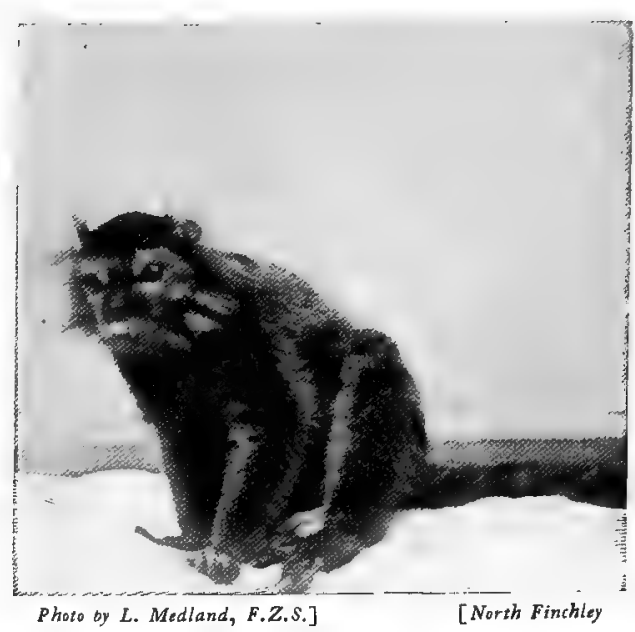

BLACK LEMUR

Found on the coast of Madagascar

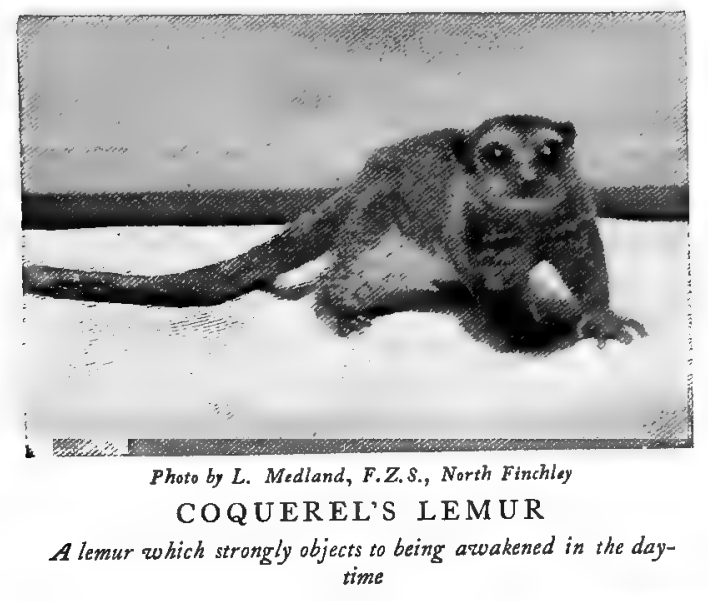

ing varied, as in the other lemurs, by small birds, eggs, or insects. Their life is almost entirely arboreal, for which the muscles of their hands and feet, as well as the parachute-like folds between their arms and bodies, and their peculiar hooked fingers, are well fitted. The young one is carried by the mother on its back, its hands grasping her armpits tightly."

This is not the universal way of carrying the young among lemurs. The Crowned Lemur, a beautiful gray-and-white species, often breeds at the Zoo. The female carries its young one partly on its side. The infant clings tightly with arms and tail round the very slender waist of the

lemur, and pushes out its sharp little face just above the thigh of the mother. The Woolly INDRI has more woolly fur than the others of its tribe, a shorter nose, and a longer tail.

\section{The True Lemurs}

Of these there are several species, all confined to Madagascar and the Comoro Islands. One of the best known is the RING-TAILED LEMUR, mentioned above. It is called Lemur Catta, the Cat Lemur, from being so often kept in domestication. The Weasel Lemur, the Gray Lemur, the Mouse Lemur, the Gentle Lemur, the Sportive Lemur, the

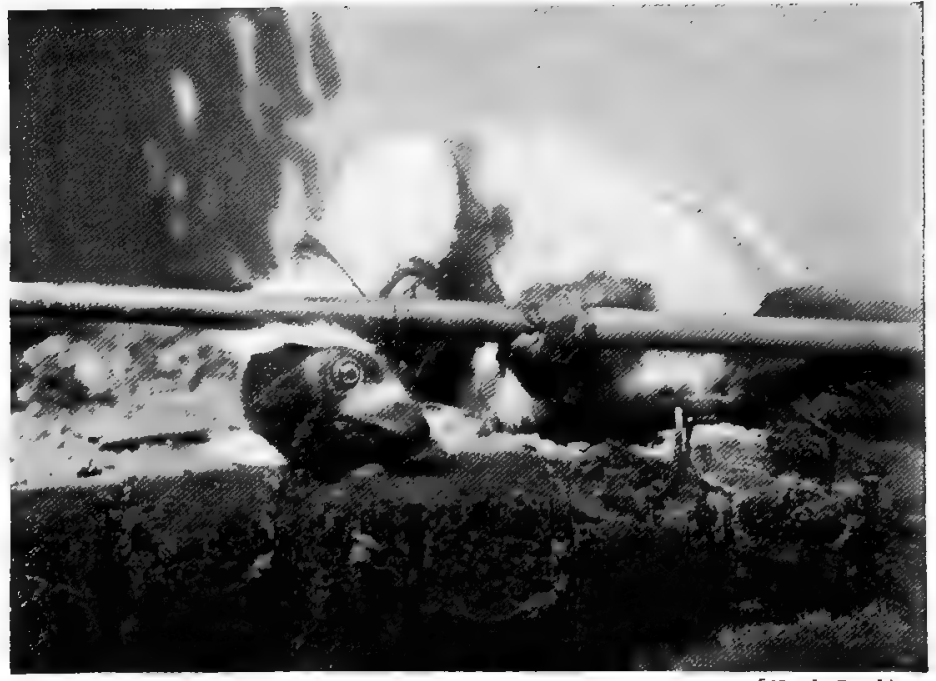

Photo by L. Medland, F.Z.S.] RUFFED LEMUR Another of the nocturnal lemurs. It lives mainly on frut and insects 


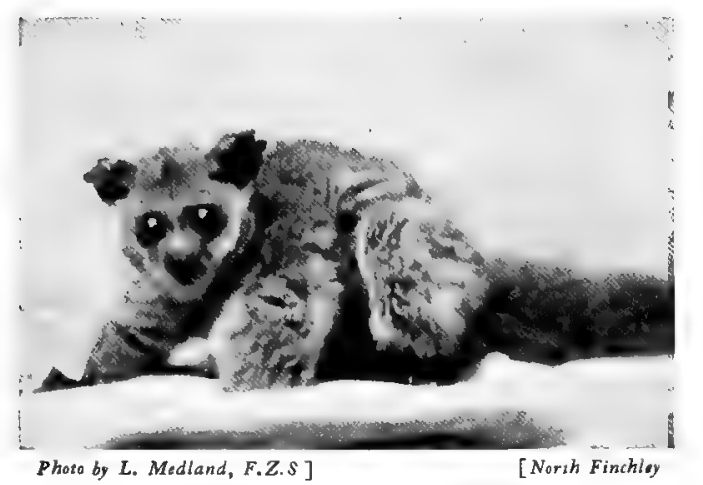

GARNET T'S GALAGO

One of the squirrel-like lemuroids

Crowned Lemur, and Coquerel's Lemur, all represent various small, pretty, and interesting varieties of the group. The BLACK-AND-white LEMUR, one of the larger kinds, is capable of domestication. A specimen kept in a London house, where the present writer saw it, was always called "Pussy" by the children. The other small kinds are very like squirrels, mice, weasels, and other creatures, with which they have no connection. It seems as though the curiously limited and primitive fauna of Madagascar tried to make up for its want of variety by mimicking the forms of other animals, and something of the same kind is seen in Australia, where the marsupials take the place of all kinds of ordinary mammals. There are marsupial rats, marsupial wolves, marsupial squirrels, and even marsupial moles. The small squirrel and rat-like lemurs are calleu Chirogales. Coquerel's Lemur is really a chirogale. It is a quaint and by no means amiable little animal, sleeping obstinately all day, and always ready to growl and bite if disturbed. Its colour is brownish gray and cream-colour. A pair of these, rolled up tightly into balls in a box of hay, will absolutely refuse to move, even when handled. They only feed by night.

\section{The Galagos}

An allied group, confined to tropical Africa, is that of the Galagos. They are most beautiful little creatures, whose nearest relatives are the Malagasy lemurs. Generally speaking, they have even more exquisite fur than the lemurs. It is almost as soft as floss silk, and so close that the hand sinks into it as into a bed of moss. The colour of the fur is rich and pleasing, generally some shade of brown. The head is small, the nose pointed, and the ears thin, hairless, and capable of being folded up, like the wings of a beetle. But the most beautiful feature of the galagos is their eyes. These are of immense size, compared with the head. The eye is of the richest and most beautiful brown, like a cairngorm stone, but not glassy or clear. Though quite translucent, the eye is marked with minute dividing-lines, like the grain in an agate-a truly exquisite object. When handled or taken in the arms, the little galago clasps the fingers or sleeve tightly, as if it thought it was holding a tree, and shows no disposition to escape. A family of three or four young ones, no larger than mice, with their large-eyed mother attending to them, forms an exquisitely dainty little group. The galagos vary from the size of a squirrel to that of a small cat. The kind most often seen in England is the MaHoli GalaGo from East Africa. Another species comes from Senegal, and others from Calabar and the forests of the Gold Coast. GarnetT's Galago, another species, is shown above. They may be regarded as nocturnal tropical lemuroids, analogous to the chirogales of Madagascar. It has been suggested, with great probability, that the intensely drowsy sleep of many of the lemuroid animals corresponds to the hiberna-

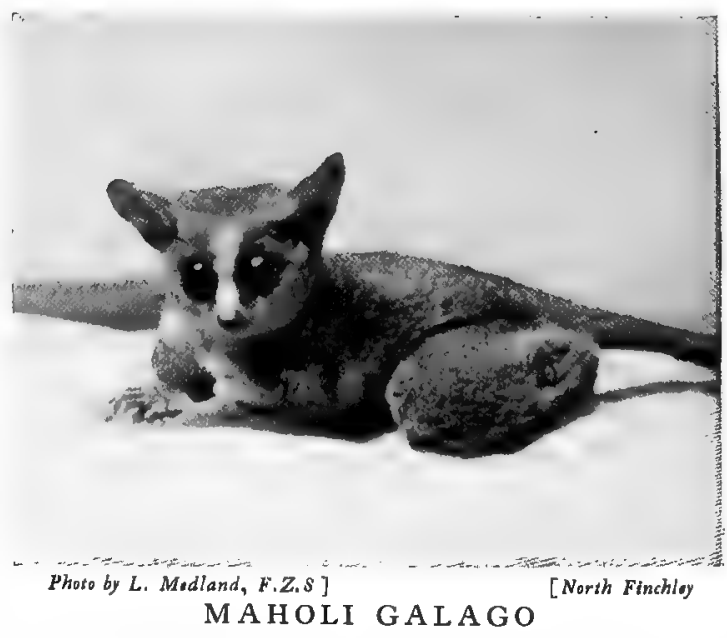

This little animal is a native of East Africa. It has very large ejes, and fur as soft as the chinchilla's 


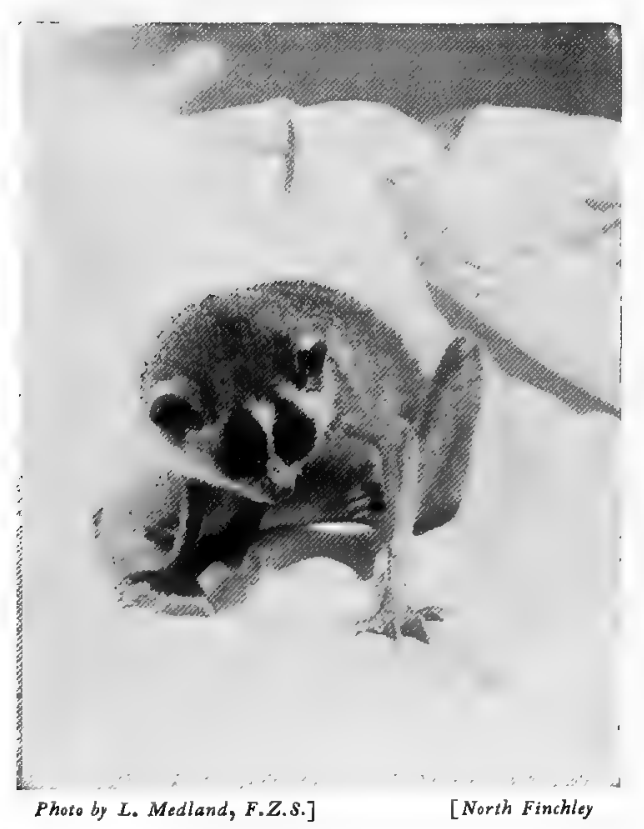

SLENDER LORIS

This extraordinary creature has the habits of a chameleon when seeking insects for food. The photograph is unique tion of many northern mammals. Tropical animals often become torpid to avoid the famine caused by the hot season, just as creatures in cold countries hibernate to avoid the hunger which would otherwise come with winter.

\section{The Slow Lemurs or Lorises, and Tarsiers}

Another group of lemuroids is distinguished from the foregoing by having the second finger of the fore paws either very short or rudimentary. The thumb and great toe are also set very widely apart from the other fingers and toes. A far more striking distinction to the non-scientific eye is their astonishingly deliberate and slow movements. They have no tails, enormous eyes, and very long, slender legs.

The Slow LORIS is found in Eastern India and the Malay countries, where it is fairly common in the forests. The Bengali natives call it sharmindi billi ("bashful cat"), from its slow, solemn, hesitating movements whien in pursuit of insects. Of a slow loris kept by him, Sir William Jones, in the "Asiatic Researches," wrote: "At all times he seemed pleased at being stroked on the head and throat, and he frequently allowed me to touch his extremely sharp teeth. But his temper was always quick, and when he was unseasonably disturbed he expressed a little resentment, by an obscure murmur, like that of a squirrel.

When a grasshopper or any insect alighted within his reach, his eyes, as he fixed them on his prey, glowed with uncommon fire; and having drawn himself back to spring on his prey with greater force, he seized it with both his fore paws, and held it till he had devoured it. He never could have enough grasshoppers, and spent the whole night in prowling for them."

The Slender Loris, an equally curious creature, is only found in Southern India and Ceylon. Its food consists entirely of insects, which it captures by gradual, almost paralysed approach. Its has been described as a "furry-coated chameleon." A group of slow lemurs, living in Western Africa, are known as Porros. They are odd little quadrupeds, in which the "forefinger" never grows to be more than a stump. The tail is also either sharp or rudimentary. They are as slow as the lorises in their movements.

In the Malay islands a distant relative, even more curiously formed, is found in the TARSIER. It has the huge eyes, pointed ears, and beautiful fur of the galagos, but the tail is long, thin and tufted. The fingers are flattened out into disks, like a tree-frog's. These creatures hop from bough to bough in a frog-like manner in search of insects. They are not so large as a good-sized rat. Our photograph does not give an adequate idea of the size of the eyes.

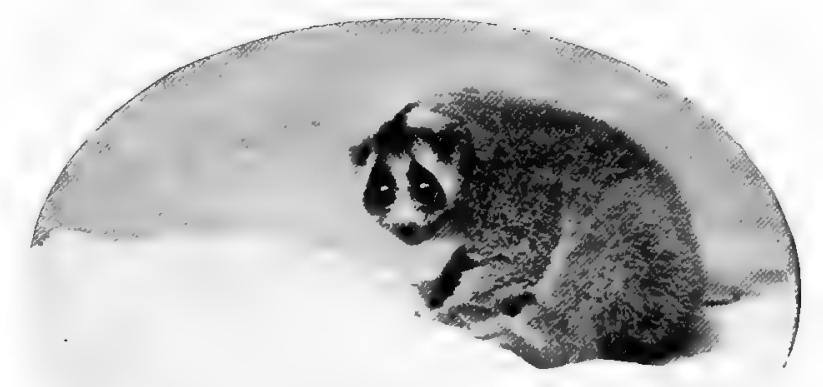

Photo by L. Modland, F.Z.S.] [North Finchley

SLOW LORIS

Another of the slow-moving loris group. These animals are not shown to the general public at the Zoo, but kept in a specially wormed rosm 


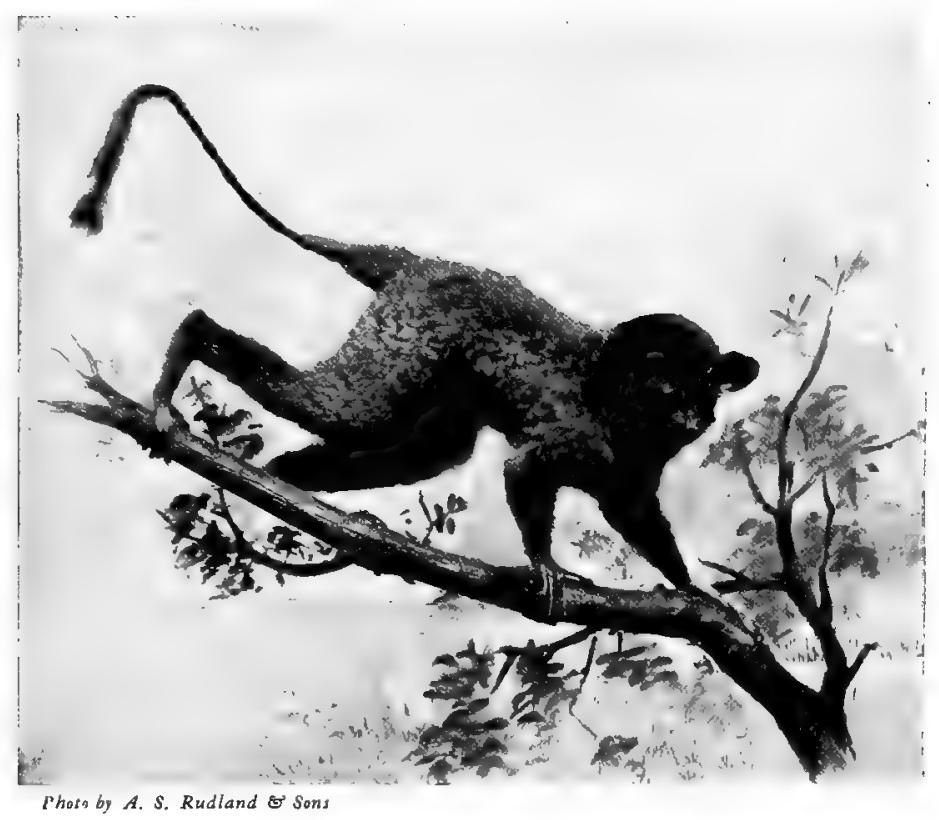

T A RSIER

These little animals hop about in the trees like frogs. They are nocturnal, and seldom

\section{The Aye-Aye}

Last, and most remarkable of all these weird lemuroids, is the AYE-AYE. It is placed in a group by itself, and has teeth like those of the Rodents, a large bushy tail, and most extraordinarily long, slender fingers, which it probably uses for picking caterpillars and grubs out of rotten wood. It is nearly as large as an Arctic fox, but its habits are those of a lemur. In Madagascar it haunts the bamboo forests, feeding on the juice of sugar-cane, grubs, and insects. The fingers of its hands are of different sizes and lengths, though all are abnormally long and slender. The second finger seems to have "wasted," but is said to be of the utmost value to its owner in ex-

tracting grubs and insects from the burrows in which they dwell, or the crannies in which they may have taken refuge. Very seldom is this animal seen alive in captivity. Although commonly called Aye-aye in this country, it is doubtful if this is really its native name. The aye-aye was long a puzzle to naturalists, but is now classed as a lemuroid.

THE living races of animals have thus far been reviewed along the completed list of the first great order-the Primates. Even in that circumscribed group how great is the tendency to depart from the main type, and how wonderful the adaptation to meet the various needs of the creatures' environment! The skeletons, the frames on which these various beings are built up, remain the same in character; but the differences of proportion in the limbs, of the muscles with which they are equipped, and of the weight of the bodies to be moved are astonishing. Compare, for instance, the head of the male Gorilla, with its great ridges of bone, to which are attached the muscles which enable it to devour hard tropical fruits and site off young saplings and bamboos, with the rounded and delicate head of the Insect-eating Monkeys of South Africa; or set side by side the hand of the Chimpanzee with that of the Ayeaye, with its delicate, slender fingers, like those of a skeleton hand. What could be more diverse than the movements of these creatures, whose structure is nevertheless so much alike? Some of the lemuroids are as active as squirrels, flying lightly from branch to branch ; in others, as the Slow Lorises, the power of rapid movement has disappeared, and been replaced by a creeping gait which cannot be accelerated. Already, in a single order, we see the rich diversity of nature, and its steady tendency to make all existing things serviceable by adapting other parts of creation to their use or enjoyment.

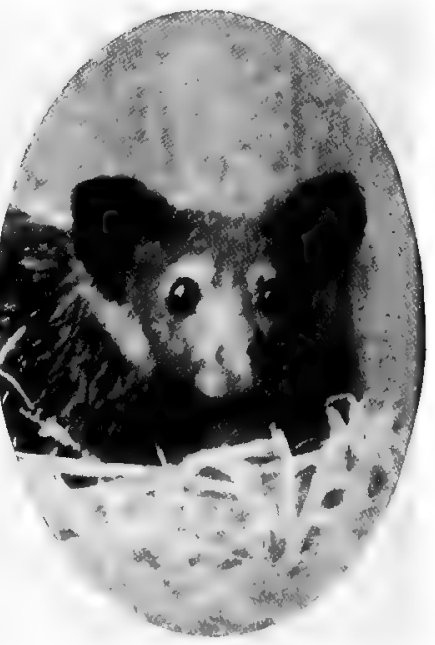

Photo by L. Medland, F, Z, S, N. Finchly HEAD OF AYE-AYE

The aye-aye lives mainly in the wild sugar-cane groves, and feeds on insects and grubs, as well as on the juice of the surar-cane 


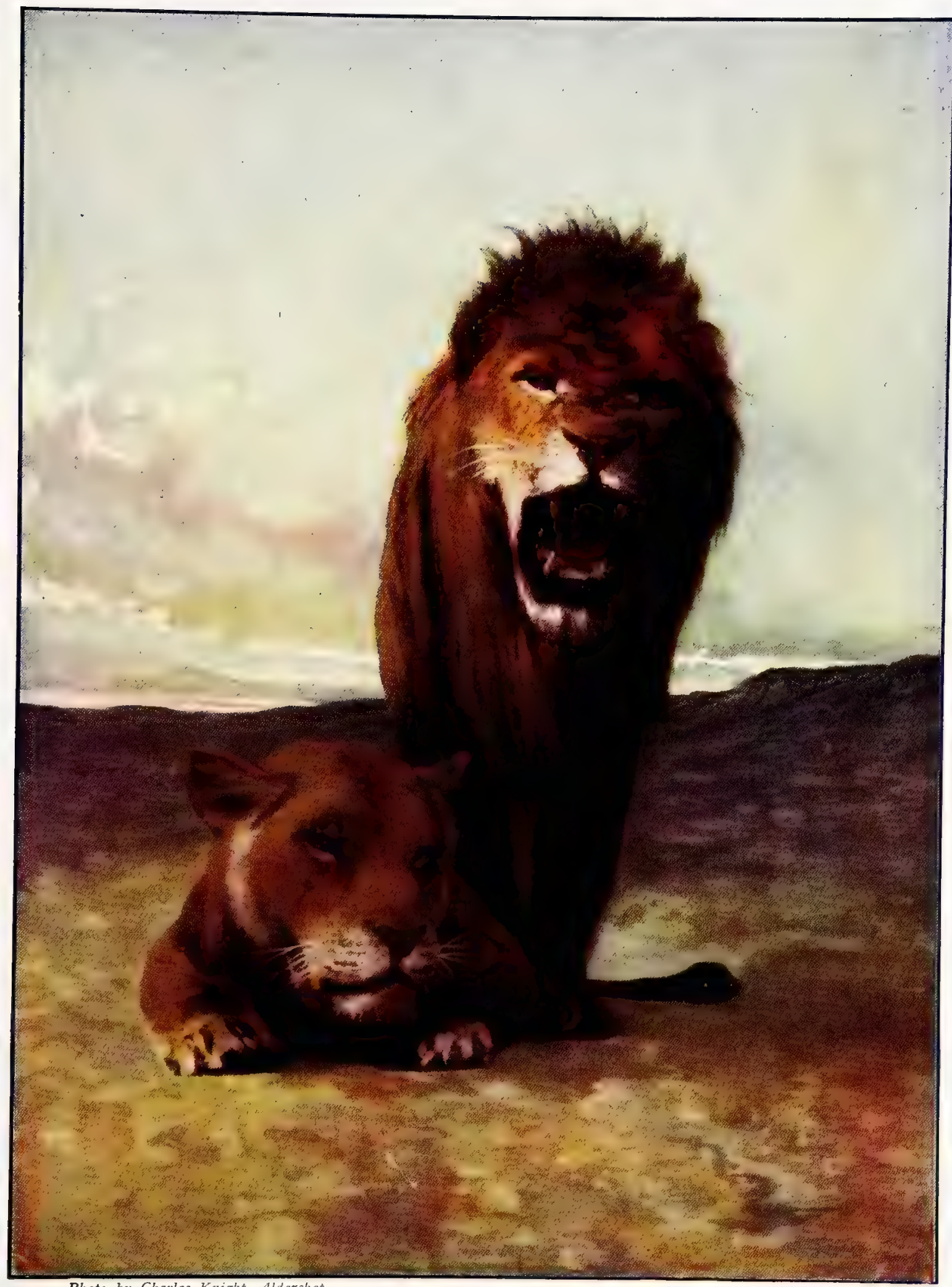

Photo by Charles Knight, Aldershot.

AFRICAN LION AND LIOINESS.

These animals are so numerous in East Africa that they are exempted from protection. 


$$
\text { • }
$$




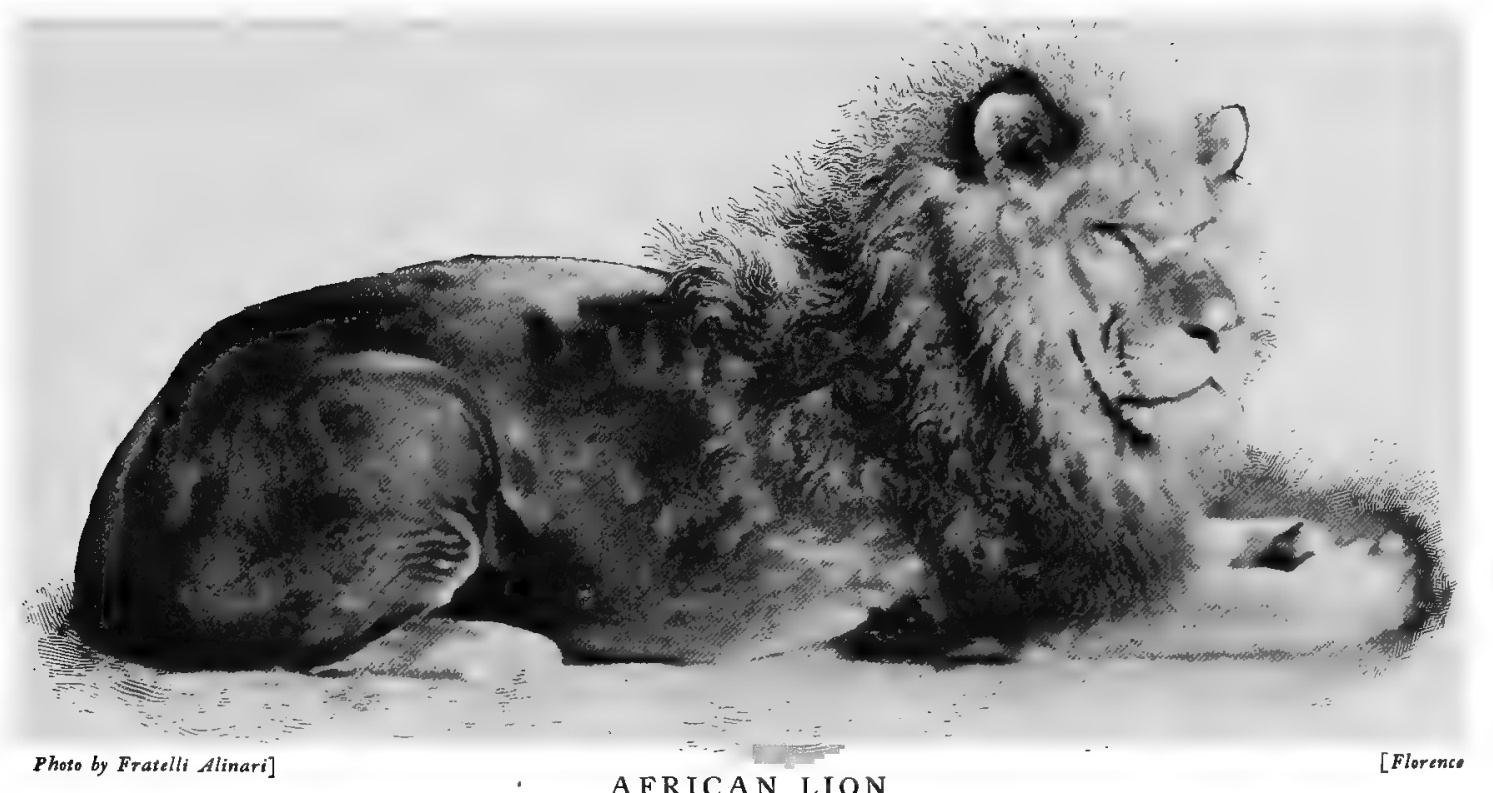

AFRICAN LION

This lion is almost in the attitude of those sculptured by Sir Edwin Landseer for the Nelson Monument, but the feet are turned in, not lying flat

\section{H A P T E R I I}

\section{THE CAT TRIBE}

7 HOUGH only one species is entirely domesticated, and none of the Cats have flesh edible by man, except perhaps the puma, no group of animals has attracted more interest than this. Containing more than forty species, ranging in size from the ox-devouring tiger or

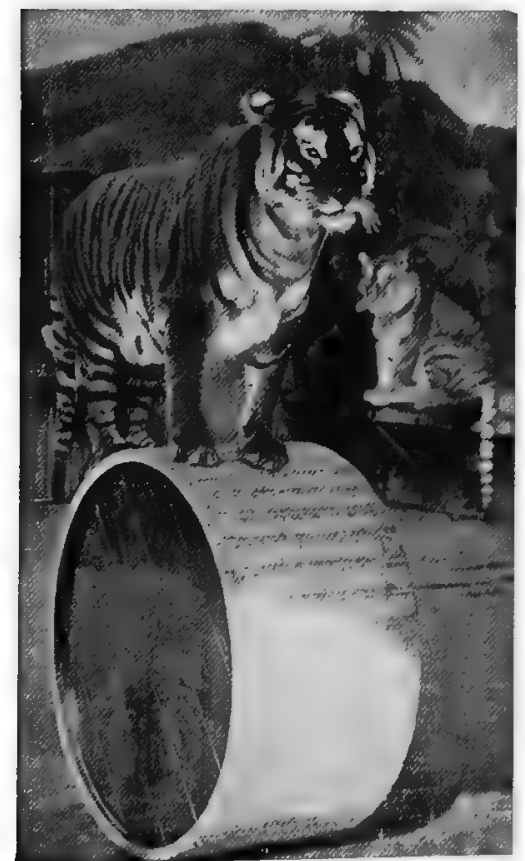

By permission of Herr Larl Hagenbech, Hainburg

AN UNWILLING PUPIL

This is one of Herr Hagenbeck's famous performing tigers

lion to the small wild cats, they are so alike in habit and structure that no one could possibly mistake the type or go far wrong in guessing at the habits of any one of them. They are all flesh-eaters and destroyers of living animals. All have rounded heads, and an extraordinary equipment of teeth and of claws, and of muscles to use them. The blow of the forearm of a lion or tiger is inconceivably powerful, in proportion to its size. A stroke from a tiger's paw has been known to strike off a native's arm from the shoulder and leave it hanging by a piece of skin, and a similar blow from a lion to crush the skull of an ox. The true cats are known by the power to draw back, or "retract," their claws into sheaths of horn, rendering their footsteps noiseless, and keeping these weapons always sharp. The hunting-leopard has only a partial capacity for doing this.

The characteristics of the Cats and their allies are too well known to need description. We will therefore only mention the chief types of the group, and proceed to give, in the fullest detail which space allows, authentic anecdotes of their life and habits. The tribe includes Lions, Tigers, Leopards, Pumas, Jaguars, a large number of so-called Tiger-cats (spotted and striped), Wild Cats, Domestic Cats, and Lynxes. The Hunting-leopard, or Cheeta, stands in a sub-group by itself, as does the Fossa, the only large carnivore of Madagascar, 


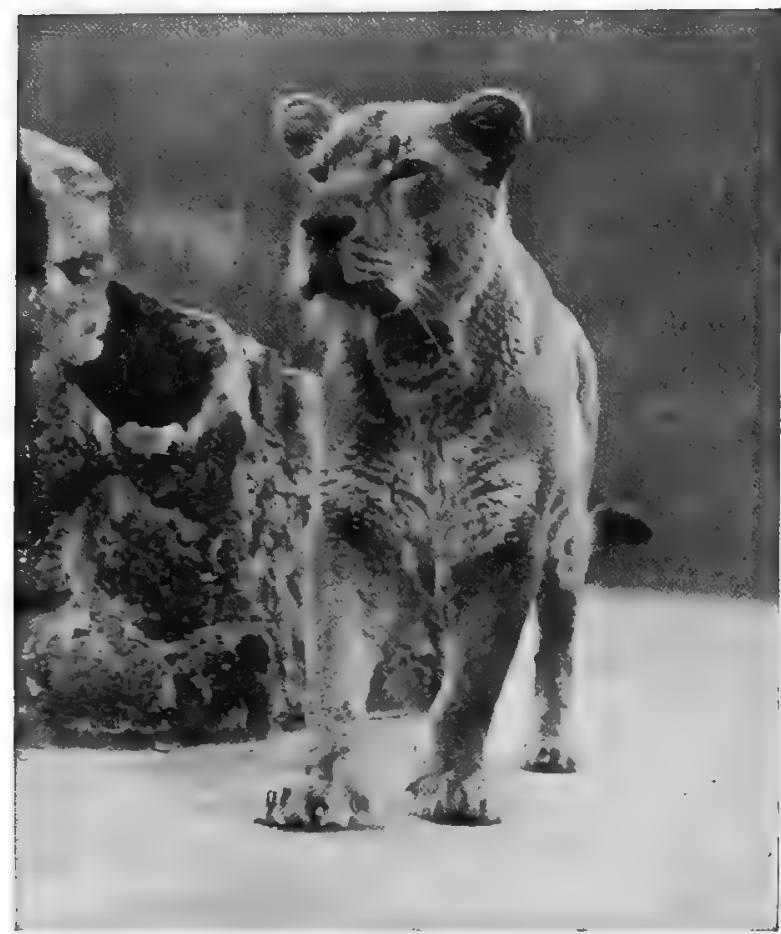

Phote by rark Es Son]

LIONESS AROUSED

The pose of the animal here shows attention, but not anger or fear

This closes the list of the most cat-like animals. The next links in the chain are formed by the Civets and Genets, creatures with more or less retractile claws, and long, bushy tails; the still less cat-like Binturong, a creature with a prehensile tail; and the Mongooses and Ichneumons, more and more nearly resembling the weasel tribe.

\section{THE LION}

RECENT intrusions for railways, sport, discovery, and war into Central and East Africa have opened up new lion countries, and confirmed, in the most striking manner, the stories of the power, the prowess, and the dreadful destructiveness to man and beast of this king of the Carnivora. At present it is found in Persia, on the same rivers where Nimrod and the Assyrian kings made its pursuit their royal sport; in Gujerat, where it is nearly extinct, though in General Price's work on Indian game written before the middle of the last century it is stated that a cavalry officer

killed eighty lions in three years; and in Africa, from Algeria to the Bechuana country. It is especially common in Somaliland, where the modern lion-hunter mainly seeks his sport. On the Uganda Railway, from Mombasa to Lake Victoria, lions are very numerous and dangerous. In Rhodesia and the Northern Transvaal they have killed hunters, railway officials, and even our soldiers near Komati Poort. It has been found that whole tracts of country are still often deserted by their inhabitants from fear of lions, and that the accounts of their ravages contained in the Old Testament, telling how Samaria was almost deserted a second time from this cause, might be paralleled to-day.

\section{The African Lion}

BY F. C. SELOUS

When, in the latter half of the seventeenth century, Europeans first settled at the Cape of Good Hope, the lion's roar was probably to be heard almost nightly on the slopes of Table Mountain, since a quaint entry in the Diary of Van Riebeck, the first Dutch governor of the Cape, runs thus: "This night the lions roared as if they would take the fort by storm "- the said fort being situated on the site of the city now known as Cape Town.

At that date there can be little doubt that, excepting in the waterless deserts and the dense equatorial forests, lions roamed over the whole of the vast continent of Africa from Cape Agulhas to the very shore of the Mediterranean Sea; nor was their range very seriously curtailed until the spread of European settlements in North and South Africa, and the acquisition of firearms by the aboriginal inhabitants of many parts of the country, during the latter half of the nineteenth century, steadily denuded large areas of all wild game.

As the game vanished, the lions disappeared too; for although at first they preyed to a large extent on the domestic flocks and herds which gradually replaced the wild denizens of the 


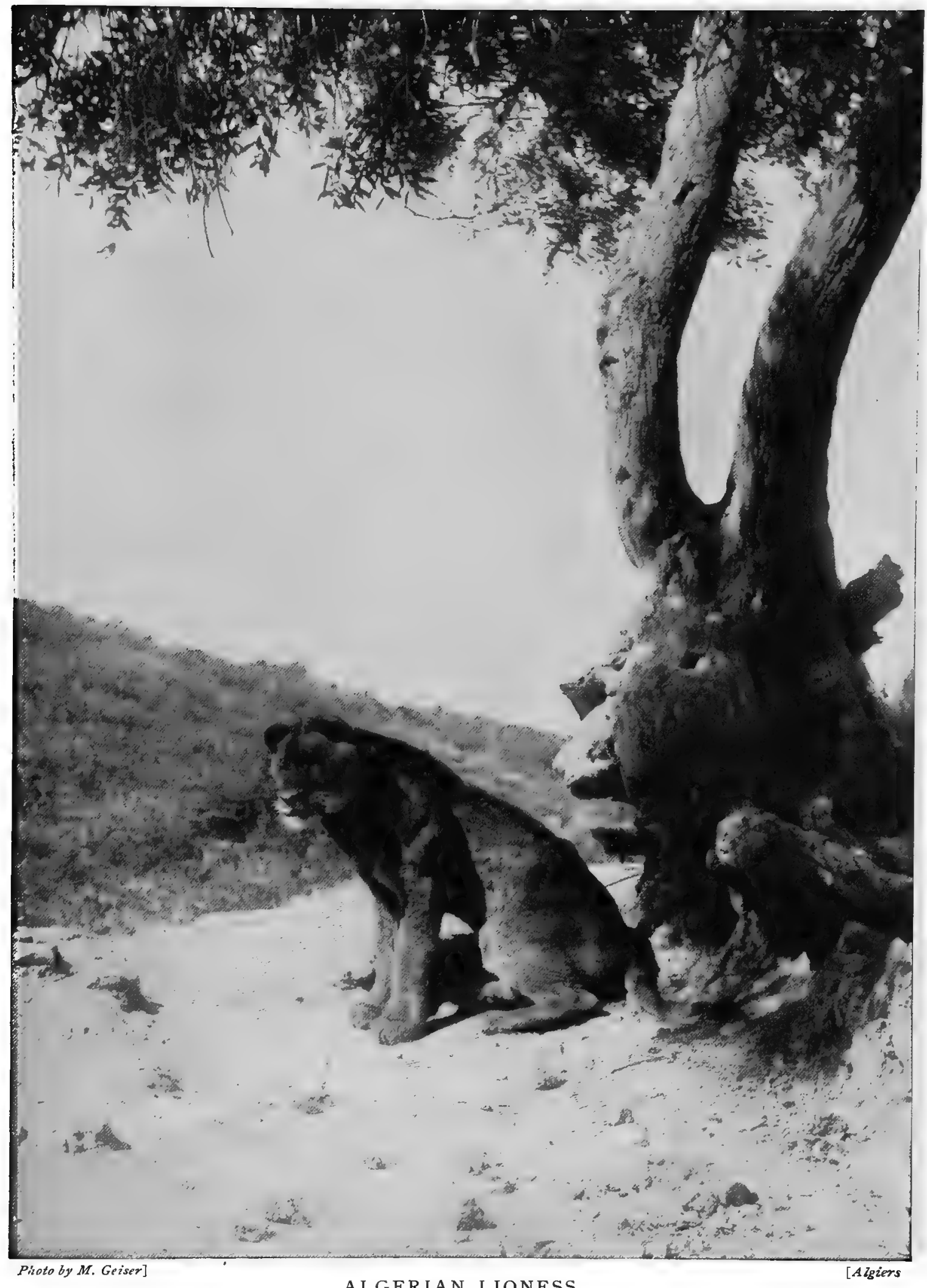

ALGERIAN LIONESS

2his Lioness, sitting under an olive-tree, was actually photographed in the Soudan by the intrepid M. Geiser 


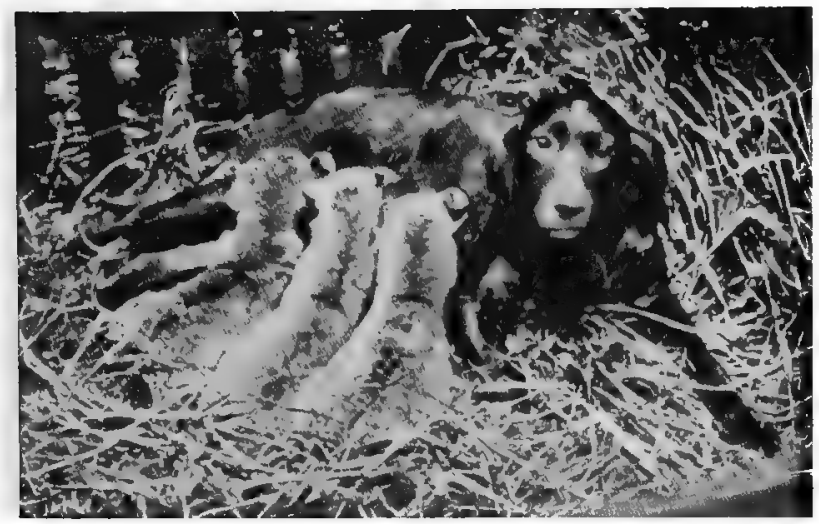

A FOSTER-MOTHER

This is a remarkable photograph of a setter suckling three lion cubs which had lost their mother. It is reproduced here by permission of the Editor of the Irish Field

come so numerous in the sparsely inhabited or altogether uninhabited parts of Africa, that they would first have exterminated all the game on which they had been wont to prey, and would then have had to starve or to have eaten one another. But such a state of things has never been known to occur; and whenever Europeans have entered a previously unexplored and uninhabited tract of country in Africa, and have found it teeming with buffaloes, zebras, and antelopes, they have always found lions in such districts very plentiful indeed, but never in such numbers as to seriously diminish the abundance of the game upon which they depended for food. once-uninhabited plains, this practice brought them into conflict with the white colonists or native herdsmen armed with weapons of precision, before whom they rapidly succumbed.

To-day lions are still to be found wherever game exists in any quantity, and their numbers will be in proportion to those of the wild animals on which they prey.

The indefinite increase of lions must be checked by some unknown law of nature, otherwise they would have be-

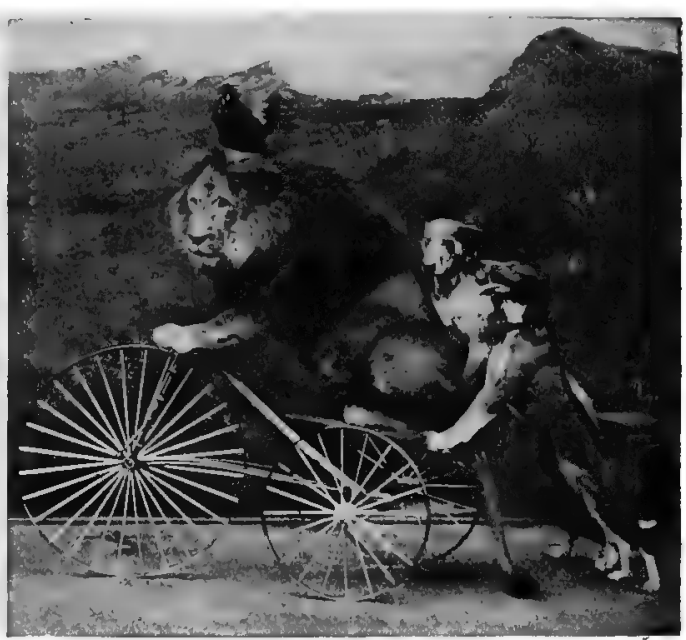

By permisison of Herr Larl Hagenoek]

A PERFORMING LION

Lions, it would seem, are capable of being taught almost anything, even tricycle-riding

It is easy to understand that the increase of a herd of herbivorous animals would be regulated by the amount of the food-supply available, as well as constantly checked by the attacks of the large carnivora, such as lions, leopards, cheetas, hyænas, and wild dogs; but I have never been able to comprehend what has kept within bounds the inordinate increase of lions and other carnivorous animals in countries where for ages past they have had an abundant food-supply, and at the same time, having

Lion cubs thrive both in Dublin and Amsterdam, but not so well at the Lonaon Zoo 
been almost entirely unmolested by human beings, have had no enemies. Perhaps such a state of things does not exist at the present day, but there are many parts of Africa where such conditions have existed from time immemorial up to within quite recent years.

Since lions were once to be found over the greater portion of the vast continent of Africa, it is self-evident that these animals are able to accommodate themselves to great variations of climate and surroundings; and I myself have met with them, close to the sea, in the hot and sultry coastlands of Southeast Africa; on the high plateau of Mashonaland, where at an altitude of 6,000 feet above sea-level the winter nights are cold and frosty; amongst the stony hills to the east of the Victoria Falls of the Zambesi; and in the swamps of the Chobi. In the great reedbeds of the latter river a certain number of lions appeared to live constantly, preying on buffaloes

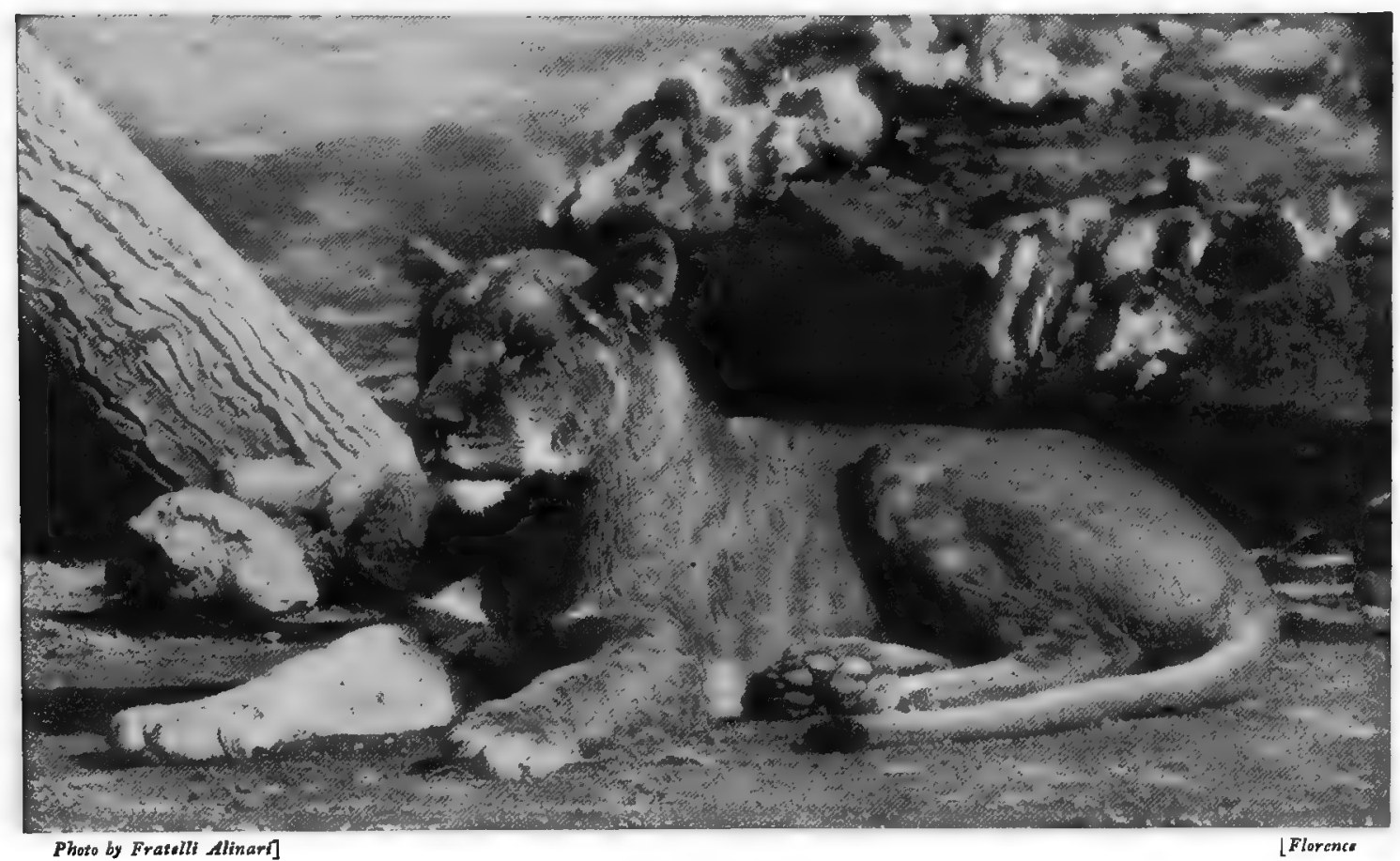

Photo by Fratoll Alinari]

A YOUNG LIONESS

The sole of the hind foot shows the soft pads on which the Cats noiselessly approach their prey

and lechwe antelopes. I often heard them roaring at nights in these swamps, and I once saw two big male lions wading slowly across an open space between two beds of reeds in water nearly a foot in depth.

Although there are great individual differences in lions as regards size, general colour of coat, and more particularly in the length, colour, and profuseness of the mane with which the males are adorned, yet as these differences occur in every part of Africa where lions are met with, and since constant varieties with one fixed type of mane living by themselves and not interbreeding with other varieties do not exist anywhere, modern zoologists are, I think, now agreed that there is only one species of lion, since in any large series of wild lion skins, made in any particular district of Africa or Asia, every gradation will be found between the finest-maned specimens and those which are destitute of any mane at all. Several local races have, however, been recently described by German writers.

In the hot and steamy coastlands of tropical Africa lions usually have short manes, and never, I believe, attain the long silky black manes sometimes met with on the high plateaux of the interior. However, there is, I believe, no part of Africa where all or even the majority 


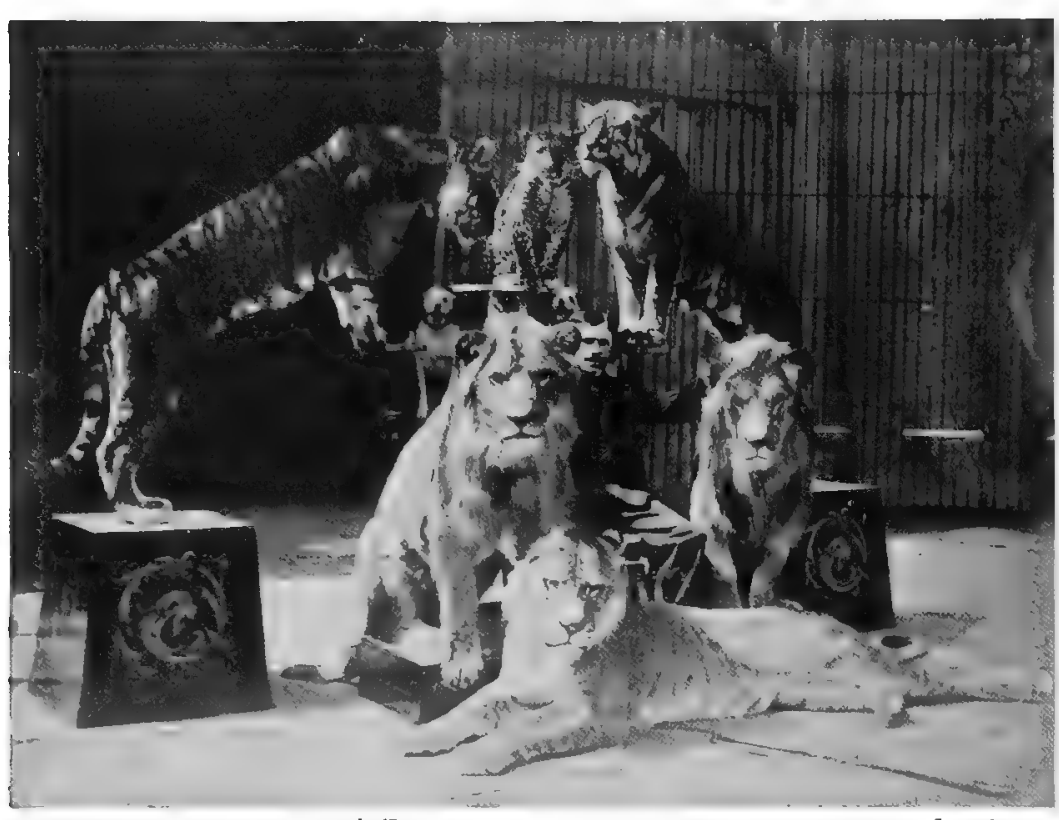

By permission of Herr Carl Hagenbech]

A H APPY FAMILY

Here is a group of animals and their keeper from Herr Hagenbeck's Thierpark. The animal in front is a cross between a lion and a tigress; he lives on quite friendly terms with his keeper, and also with lions, tigers, and leopards, as seen in the photograph

of hair in each flank just where the thighs join the belly; but I have never yet seen the skin of a lion shot within the last thirty years with the whole belly covered with long, thick hair, as may constantly be observed in lions kept in captivity in menageries. There is, however, some evidence to show that, when lions existed on the high plains of the Cape Colony and the Orange River Colony, where the winter nights are much colder than in the countries farther north where lions may still be encountered, certain individuals of the species developed a growth of long hair all over the belly, as well as an extraordinary luxuriance of mane on the neck and shoulders.

From the foregoing remarks it will be seen that wild lions, having as a rule much less luxuriant manes than many examples of their kind to be seen in European menageries, are ordinarily not so majestic and dignified in appearance as many of their caged relatives. On the other hand, the wild lion is a much more alert and active animal than a menagerie specimen, and when in good condition is far better built and more powerful-looking, being free from all appearance of lankiness and weakness in the legs, and having strong, well-formed hindquarters. The eyes of the menagerie lion, too, look brown and usually sleepy, whilst those of the wild animal are yellow, and extraordinarily luminous even after death. When wounded and standing

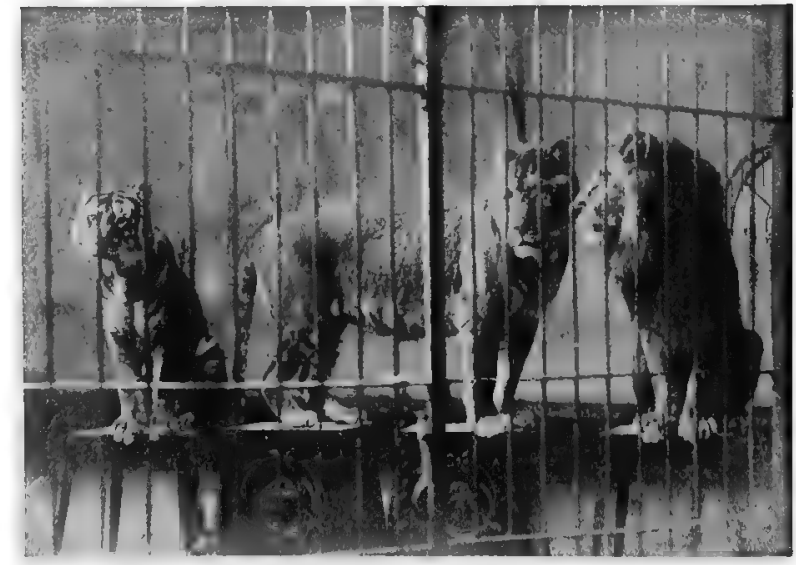

By permission of Herr Carl Hagenbeck]

[Hamburg

A CROSS BETWEEN LION AND TIGRESS

This unique photograph shows a remarkable hybrid and its proud parents. The father (on the right) is a lion, and the mother (on the left) a tigress. The offspring (in the centre) is a fine, large male, now four years old; it is bigger than an average-sized lion o* tiger 


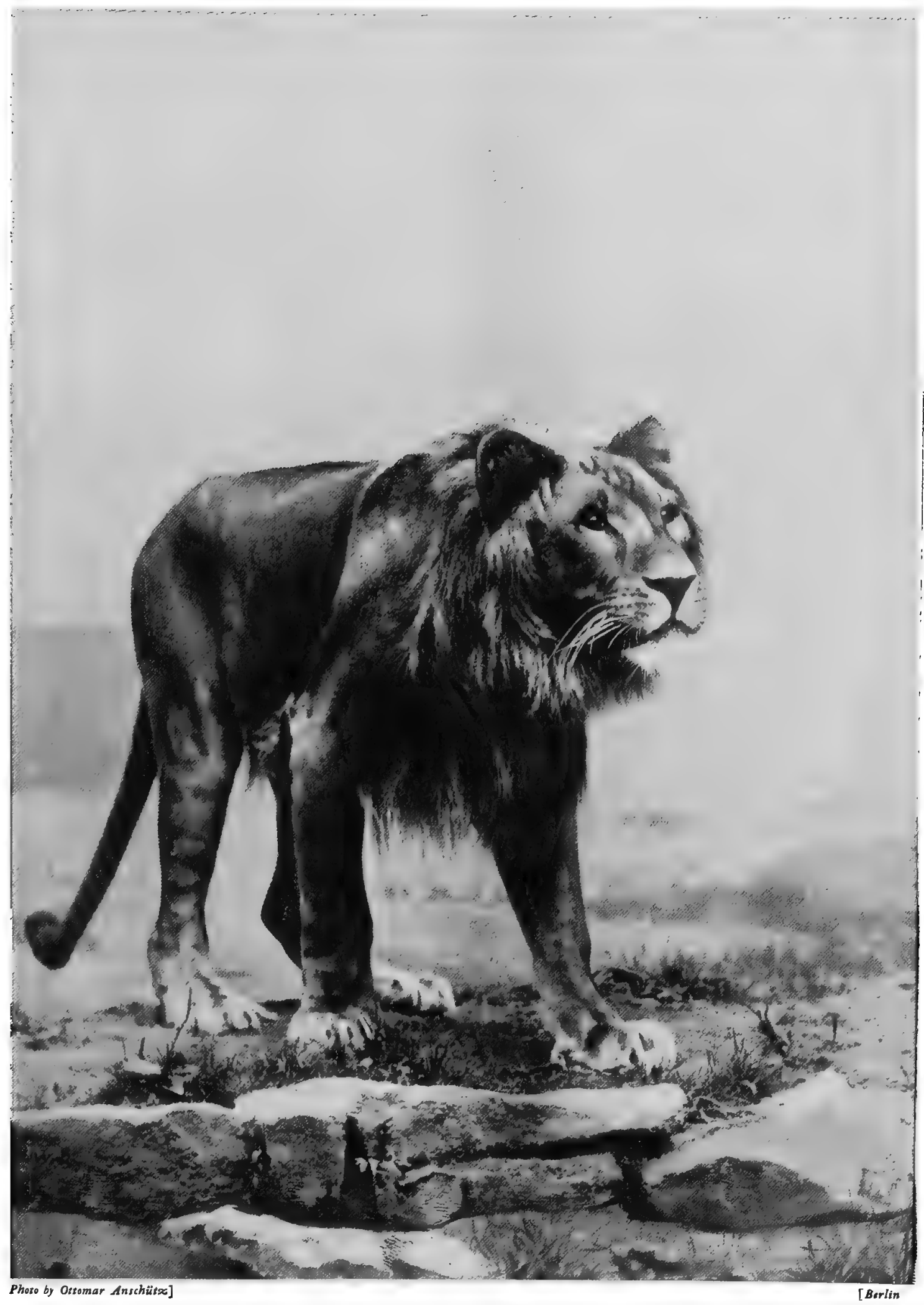

A HUNGRY LION

Notice that the mane, as in most wild lions, is very scanty 


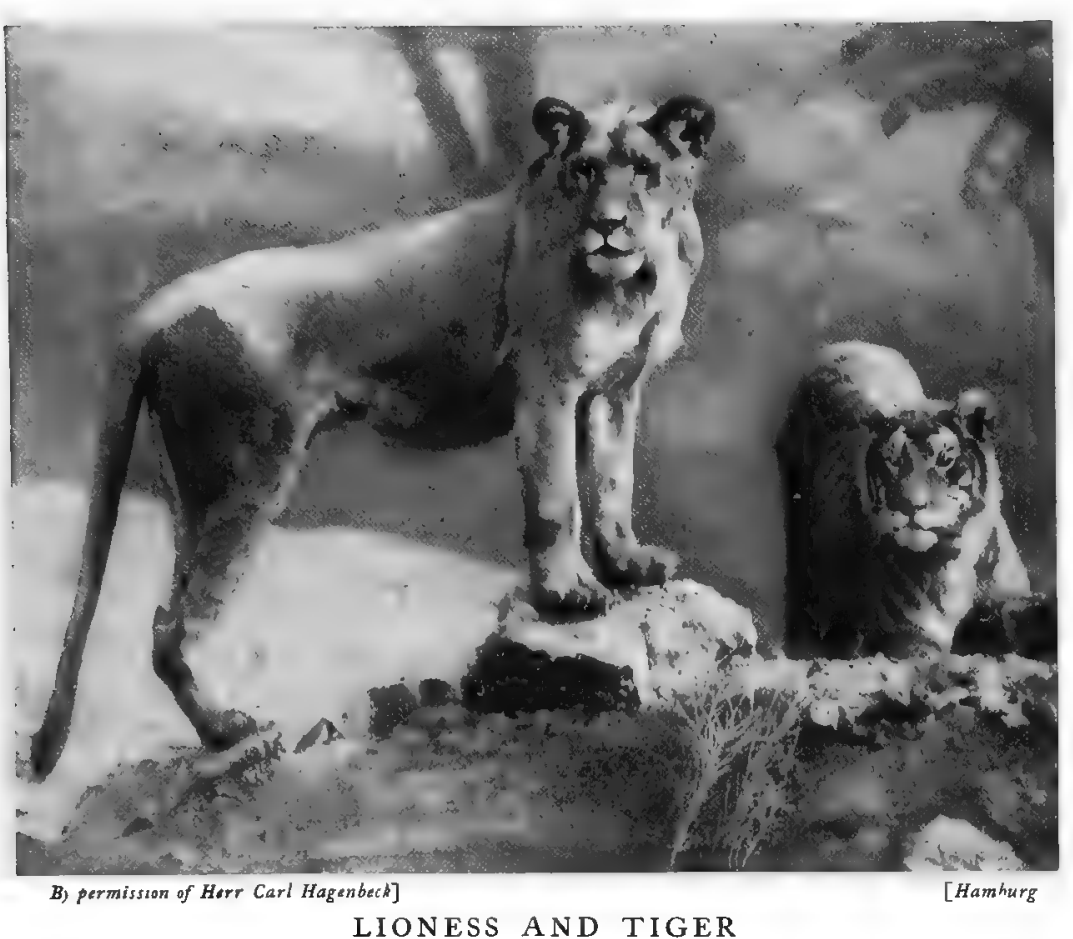

The stratghtness of the sone $\mathrm{s}^{\prime}$ s tail is here shown. It is not in the least like that of the tiger or of the cat at bay, with head held low between his shoulders, growling hoarsely, and with twitching tail, even if he is not near enough to be observed very closely, a lion looks a very savage and dangerous animal; but should he be wounded in such a way as to admit of a near approachperhaps by a shot that has paralyzed his hindquarters - his flaming eyes will seem to throw out sparks of living fire.

Speaking generally, there is little or no danger in meeting a lion or lions in the daytime. Even in parts of the country where firearms are unknown, and

where the natives seldom or never interfere with them, these animals seem to have an instinctive fear of man, and even when encountered at the carcase of an animal freshly killed, and at a time when they may be supposed to be hungry, they will almost invariably retreat before the unwelcome presence, sometimes slowly and sulkily, but in districts where much hunting with firearms has been going on at a very rapid pace. However, I have known of two cases of Europeans mounted on horseback having been attacked by lions in broad daylight, and Dr. Livingstone mentions a third. In one of the instances which came within my own knowledge, a lion sprang at a Boer hunter as he was riding slowly along, carrying an elephant-gun in his right hand and followed by a string of natives on foot. The lion attacked from the left side, and with its right paw seized my friend from behind by the right side of his face and neck, inflicting deep gashes with its sharp claws; one of which cut right through his cheek and tore out one of his teeth. My friend was pulled from his horse, but, clutching the loosely girthed saddle tightly with his knees, it twisted round under the horse's belly before he fell to the ground. Instead of following up its success, the lion, probably scared by the shouting of the Kaffirs, trotted away for a short distance, and then turned and stood looking at the dismounted hunter, who, never having lost his presence of mind, immediately shot it dead with his heavy old muzzle-loading elephant-gun. Besides these three instances of Europeans having been attacked in the daytime by lions, I have known of a certain number of natives having been killed in broad daylight. Such incidents are, however, by no means every-day occurrences, and, speaking generally, it may be said that the risk of molestation by lions in Africa during daylight is very small. It is by night that lions roam abroad with stealthy step in search of prey; and at such times they are often, when hungry, incredibly bold and daring. I have known them upon several occasions to enter a hunter's camp, and, regardless of fires, to seize oxen and horses and human beings.

During the year following the first occupation of Mashonaland in I 890 , a great deal of damage was done by lions, which could not resist the attractions of the settlers' live stock. For the first few months I kept as accurate an account as I could of the number of horses, donkeys, 
oxen, sheep, goats, and pigs which were killed by lions, and it soon mounted up to over 200 head. During the same time several white men were also mauled by lions, and one unfortunate man named Teale was dragged from beneath the cart, where he was sleeping by the side of a native driver, and at once killed and eaten. Several of the horses were killed inside rough shelters serving as stables. In the following year (1891) over 100 pigs were killed in one night by a single lioness. These pigs were in a series of pens, separated one from another, but all under one low thatched roof. The lioness forced her way in between two poles, and apparently was unable, after having satisfied her hunger, to find her way out again, and, becoming angry and frightened, wandered backwards and forwards through the pens, killing, almost all the pigs, each one with a bite at the back of the head or neck. This lioness, which had only eaten portions of two young pigs, made her escape before daylight, but was killed with a set gun the next night by the owner of the pigs.

When lions grow old, they are always liable to become man-eaters. Finding their strength failing them, and being no longer able to hunt and pull down large antelopes or zebras, they are driven by hunger to killing small animals, such as porcupines, and even tortoises, or they may visit a native village and catch a goat, or kill a child or woman going for water; and finding a human being a very easy animal to catch and kill, an old lion which has once tasted human flesh will in all probability continue to be a man-eater until he is killed. On this subject, in his "Missionary Travels," Dr. Livingstone says: "A man-eater is invariably an old lion; and when he overcomes his fear of man so far as to come to villages for goats, the people remark, "His teeth are worn; he will soon kill men.' They at once acknowledge the necessity of instant action, and turn out to kill him." It is the promptness with which measures are taken by the

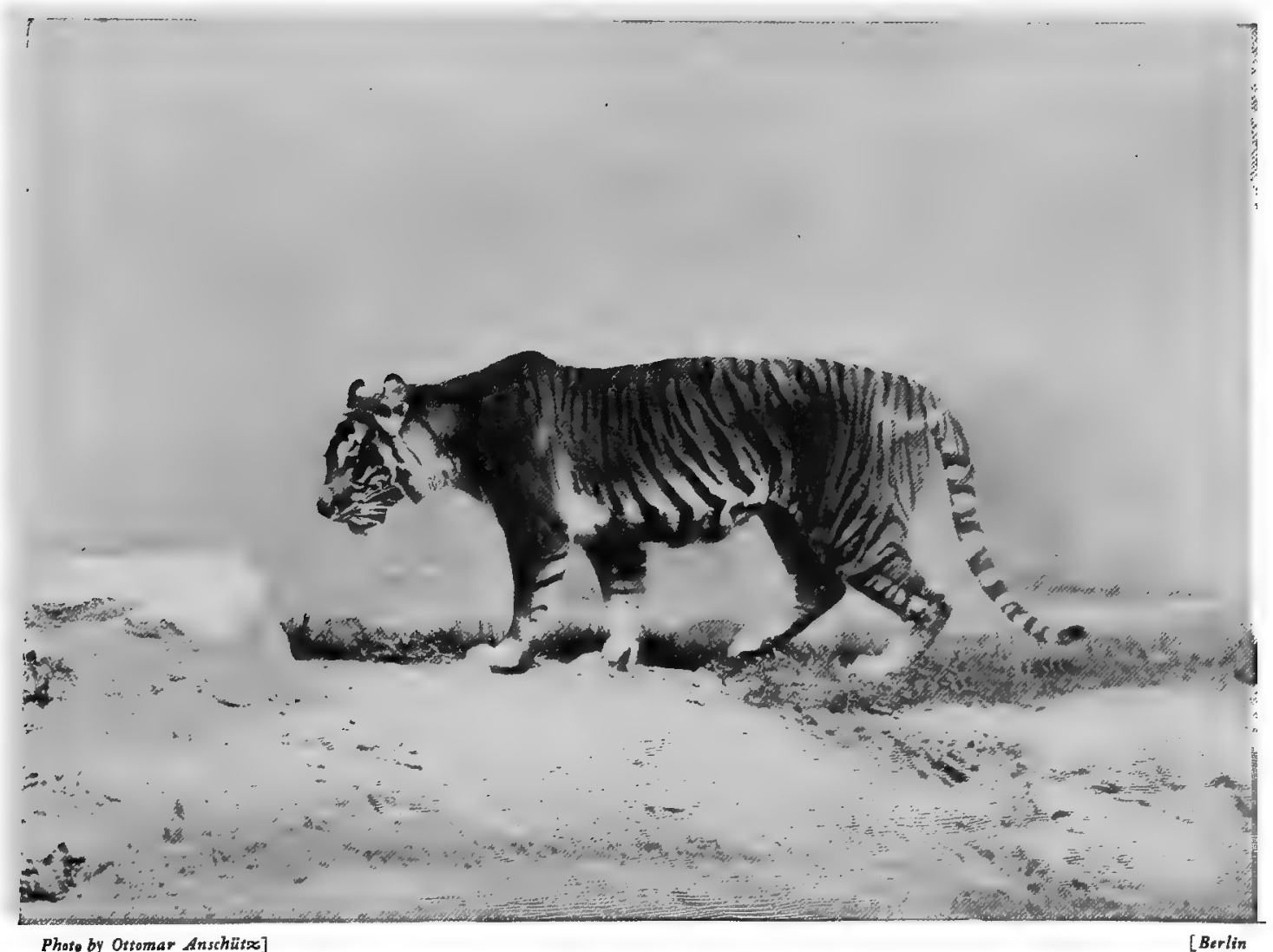

Phoro by Ottomar Ansthititz]

TIGRESS

Were the grass seen here the normal height of that in the Indian jungles, the upright lines would harmonise with the stripes, and render she tiger almost invisible 


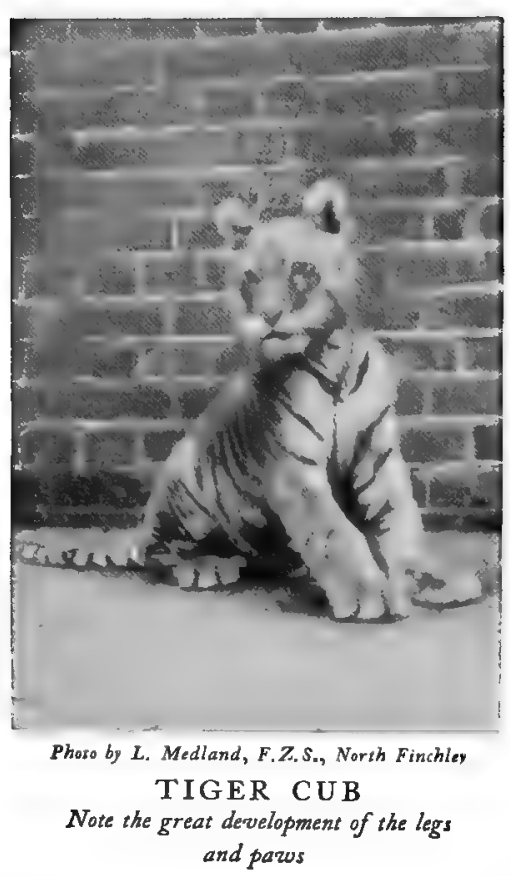

greater part of the natives of Southern Africa to put an end to any lion which may take to eating men that prevents these animals as a rule from becoming the formidable pests which man-eating tigers appear to be in parts of India. But maneating lions in Africa are not invariably old animals. One which killed thirty-seven human beings in 1887 , on the Majili River, to the north-west of the Victoria Falls of the Zambesi, was, when at last he was killed, found to be an animal in the prime of life; whilst the celebrated man-eaters of the Tsavo River, in East Africa, were also apparently strong, healthy animals. These two man-eating lions caused such consternation amongst the Indian workmen on the Uganda Railway that the work of construction was considerably retarded, the helpless coolies refusing to remain any longer in a country where they were liable to be eaten on any night by a maneating lion. Both these lions were at last shot by one of the engineers on the railway (Mr. J. H. Patterson), but not before they had killed and devoured twenty-eight Indian coolies and an unknown number of native Africans.

\section{THE TIGER}

Tigers are the "type animal" of Asia. They are found nowhere else. Lions were inhabitants, even in historic times, of Europe, and are still common on the Euphrates and in parts of Persia, just as they were when the Assyrian kings shot them with arrows from their huntingtchariots. They survived in Greece far later than the days when story says that Hercules slew the Nemean lion in the Peloponnesus, for the baggage-animals of Xerxes' army of invasion were attacked by lions near Mount Athos. But the tiger never comes, and never did come in historic times, nearer to Europe than the Caucasian side of the Caspian Sea. On the other hand, they range very far north. All our tiger-lore is Indian. There is scarcely a story of tigers to be found in English books of sport which deals with the animal north of the line of the Himalaya. These Chinese northern tigers and the Siberian tigers are far larger than those of India. They have long woolly coats, in order to resist the cold. Their skins are brought to market in hundreds every year to the great fur-sales. But the animals themselves we never see. The present writer was informed by a friend that in the Amur

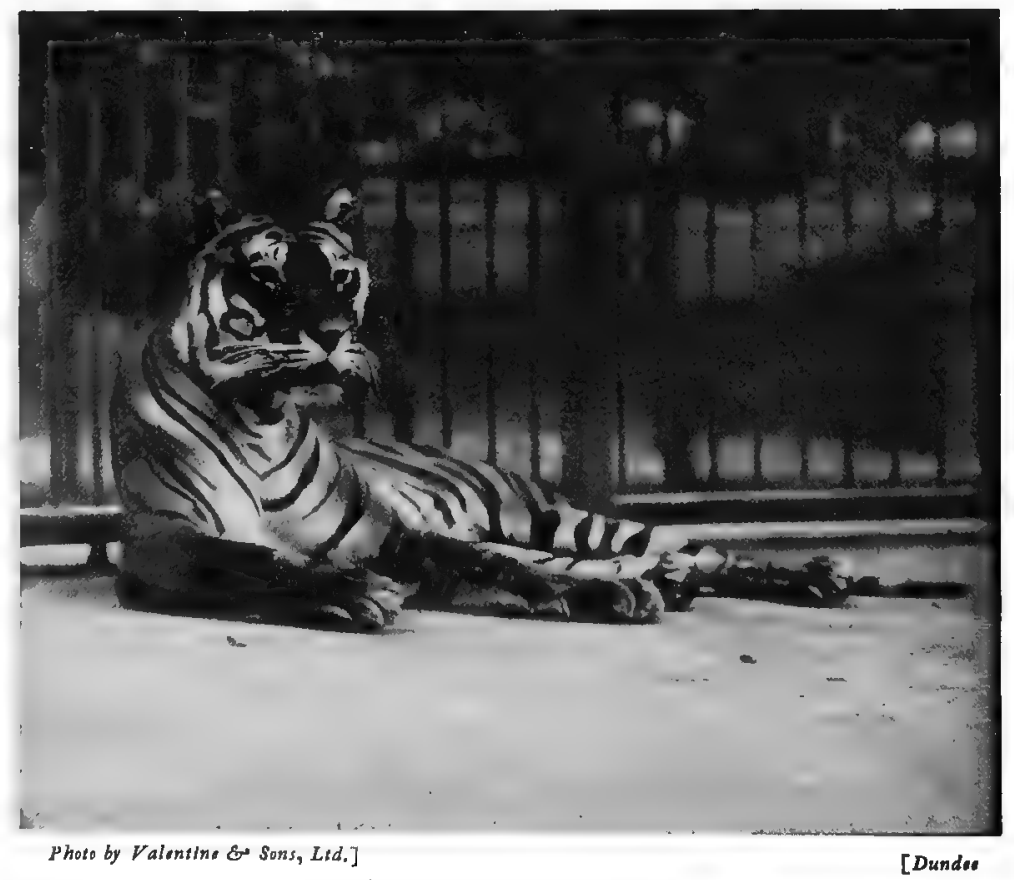

A ROYAL TIGER

This is an old Bengal Tiger. with the smooth. short coat arown in that hot climew 


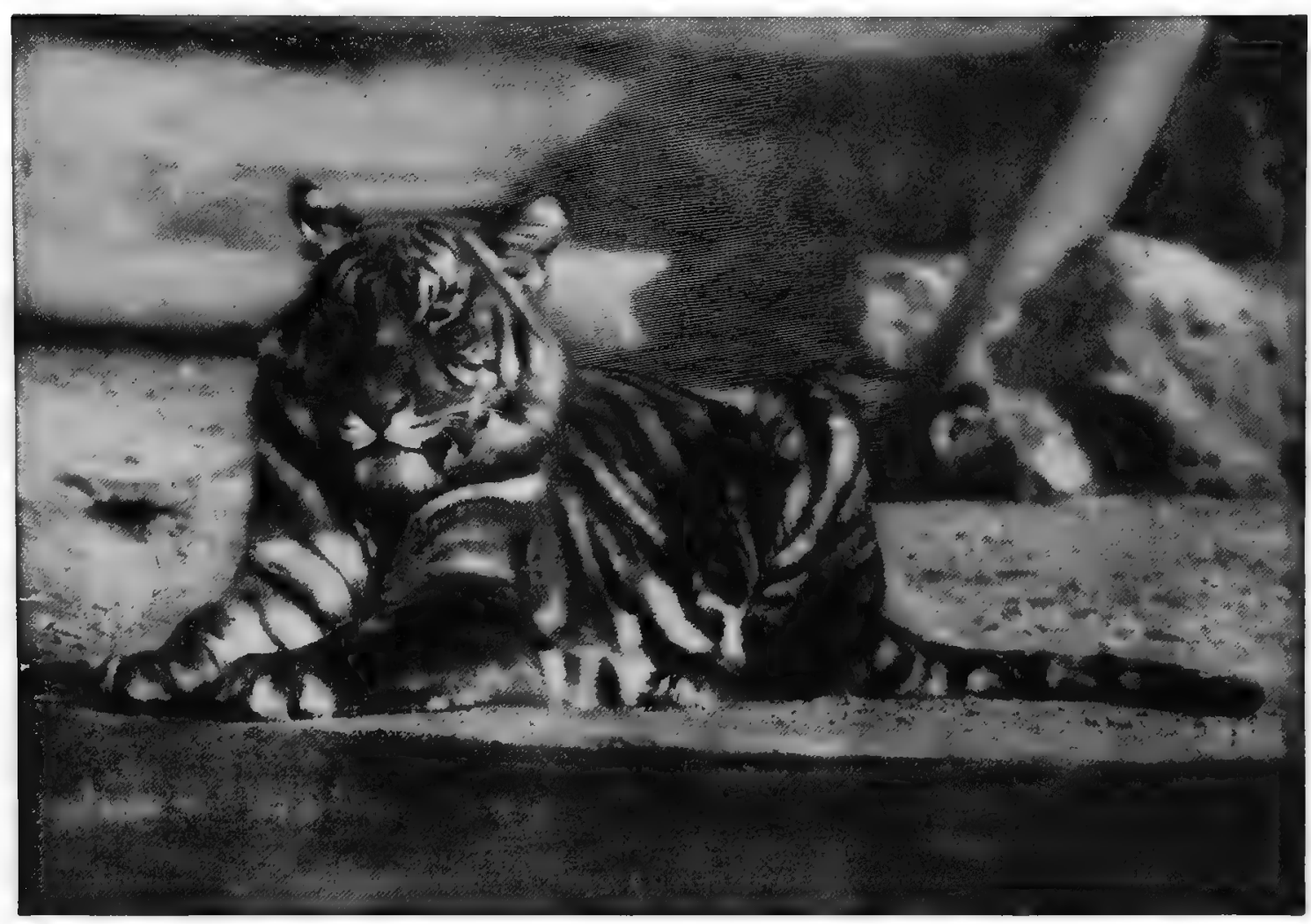

Photo by Fratelli Alinari]

[Florenc;

A TIGER BEFORE SLEEPING

Tigers, when about to sleep, sit in this position; when more drowsy, they lie down or roli over on their backs

Valley he shot three of these tigers in a day, putting them up in thick bush-scrub by the aid of dogs.

The Royal Bengal Tiger, so called, and very properly called in the old books of natural history, is a different and far more savage beast. It is almost invariably a ferocious savage, fierce by nature, never wishing to be otherwise than a destroyer_of beasts mainly, but often of men. Compared with the lion, it is far longer, but rather lighter, for the lion is more massive and compact. "A well-grown tigress," says Sir Samuel Baker, " may weigh on an average 240 lbs. live weight. A very fine tiger may weigh $440 \mathrm{lbs}$., but if fat the same tiger would weigh 500 lbs. There may be tigers which weigh 50 Ibs. more than this; but I speak according to my experience. I have found that a tiger of 9 feet 8 inches is about 2 inches above the average. The same skin may be stretched to measure Io feet. A tiger in the Zoological Gardens is a long, lithe creature with little flesh. Such a specimen affords a poor example of this grand animal in its native jungles, with muscles in their full, ponderous development from continual exertion in nightly travels over long distances, and in mortal struggles when wrestling with its prey. A wellfed tiger is by no means a slim figure. On the contrary, it is exceedingly bulky, broad in the shoulders, back, and loins, and with an extraordinary girth of limbs, especially in the forearms and wrists."

This ponderous, active, and formidably armed creature is, as might be expected, able to hold its own wherever Europeans do not form part of the regular population. In India the peasants are quite helpless even against a cattle-killing tiger in a populous part of the country. In the large jungles, and on the islands at the mouths of the great rivers, the tigers have things all their own way. Things are no better in the Far East. A large peninsula near Singapore is said to 
have been almost abandoned by its cultivators lately, owing to the loss of life caused by the tigers. In the populous parts of India the tiger is far more stealthy than in the out-of-the-way districts. It only hunts by night; and after eating a part of the animal killed, moves off to a distance, and does not return. Otherwise the regular habit is to return to the kill just at or after dusk, and finish the remainder. Its suspicions seem quite lulled to sleep after dark. Quite recently a sportsman sat up to watch for a tiger at a water-hole. It was in the height of the Indian hot season, when very little water was left. All the creatures of that particular neighbourhood were in the habit of coming to drink at one good pool still left in the rocky bed of the river. There the tigers came too. The first night they did not come until all the other creatures - hog, deer, peacocks, and monkeys_had been down to drink. They then came so softly over the sand that the gunner in waiting did not hear them pass. His first knowledge that they were there was due to the splashing they made as they entered the water. It was quite dark, and he felt not a little nervous, for the bush on which he was seated on a small platform was only some 1o feet high. He heard the two tigers pass him, not by their footsteps, but by the dripping of

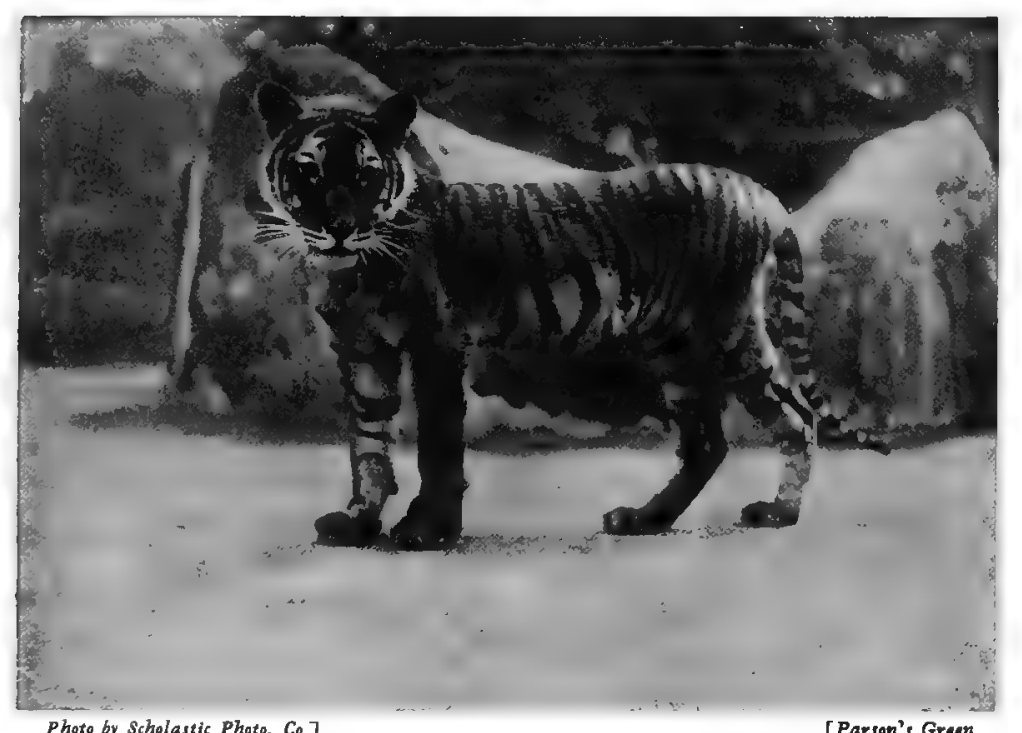

Photo by Scholastic Photo. Co.]

A HALF-GROWN TIGER CUB

Tigers "grow to their head," like children. The head of a half-grown cub is as long, though not so broad, as that of the adult the water as it ran off their bodies on to the sand. Next night they came again. This time, though it was dark, he shot one in a very ingenious manner. The two tigers walked into the water, and apparently lay down or sat down in it, with their heads out. They only moved occasionally, lapping the water, but did not greatly disturb the surface. On this was reflected a bright star from the sky above. The sportsman put the sight of the rifle on the star, and kept it up to his shoulder. Something obliterated the star, and he instantly fired. The "something" was the tiger's head, which the bullet duly hit.

The hill-tigers of India are, or were, much more given to hunting by day than the jungletigers. In the Nilgiri Hills of Southern India the late General Douglas Hamilton said that before night the tigers were already about hunting, and that in the shade of evening it was dangerous to ride on a pony-not because the tigers wished to kill the rider, but because they might mistake the pony and its rider for a sambar deer. He was stalked like this more than once. Often, when stalking sambar deer and ibex by day, he saw the tigers doing the same, or after other prey. "My brother Richard," he writes, "was out after a tiger which the hillmen reported had killed a buffalo about an hour before. He saw the tiger on first getting to the ground, and the tiger had seen him. It was lying out in the open watching the buffalo, and shuffled into the wood, and would not come out again. Next morning, when we got to the ground, the tiger was moving from rock to rock, and had dragged the body into a nullah. . . . We were upon the point of starting home when we observed a number of vultures coming down to the carcase. The vultures began to collect in large numbers on the opposite hill. I soon counted fifty; but they would not go near the buffalo. Then some crows, bolder than the rest, flew down, and 


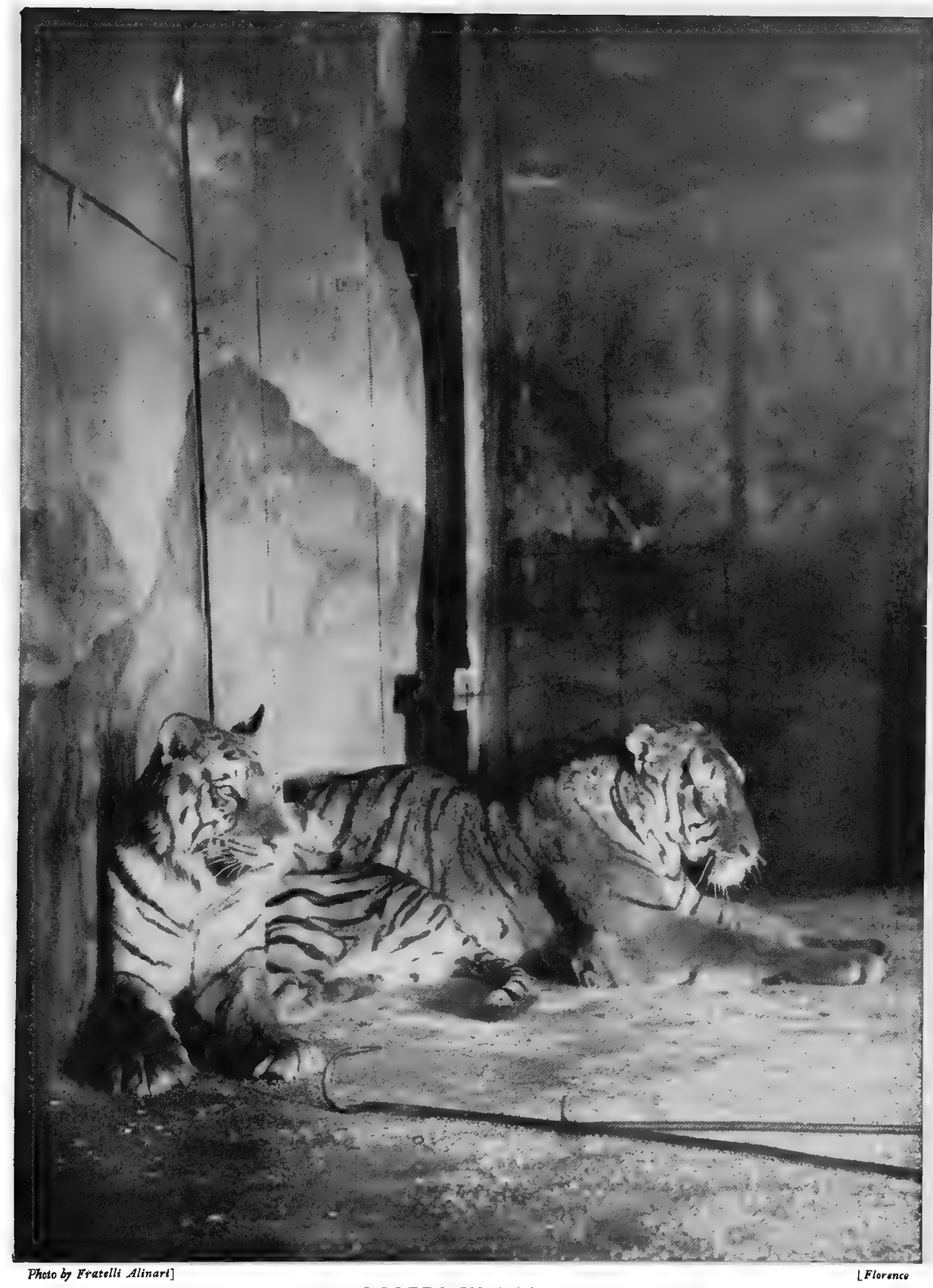

TIGERS IN ITALY

These tigers were photographed in Turin. Italy was the first European country to which these animals were brought from the East 4 
made a great row over their meal. All of a sudden they all flew up, and I made certain it was the tiger. Then my brother fired, and there he was, shot right through the brain, lying just above the buffalo. He had been brought down by the noise the crows were making. Upon driving the sholas (small woods on these hills), tigers were often put out. Sometimes they availed themselves of the drive to secure food for themselves. A wood was being driven, when a tremendous grunting was heard, and out rushed an old boar, bristling and savage. B- was about to raise his rifle, when a growl like thunder stopped him, and a great tiger with one spring cleared the nullah, and alighted on the back of the old boar. Such a battle then took place that, what with the growls of the tiger and the squeals of the boar, one might believe oneself in another world. I thought of nothing but of how to kill one or the other, or both; so, as they were rolling down over and over, about fifty yards from me on the open hillside, I let fly both barrels. For a second or two the noise went on; then the tiger jumped off, and the boar struggled into the nullah close by. The tiger pulled up, and coolly

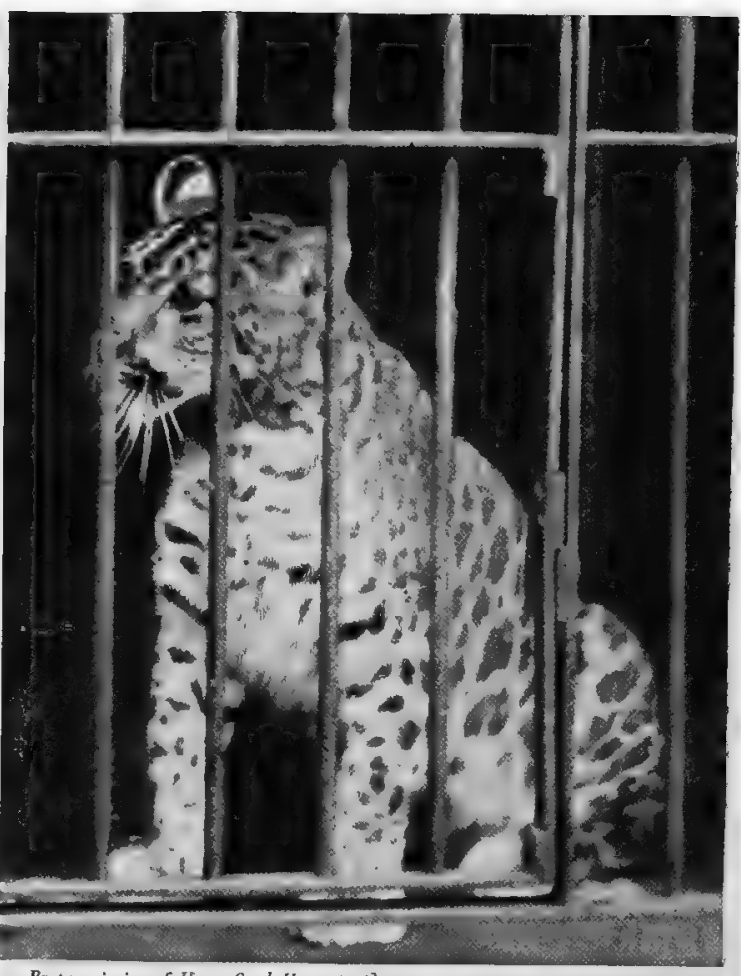

By permission of Herr Carl Hagenbe, $]$

A LEOPARD_PUMA HYBRID

This is a photograph from life of a very rare hybrid. The amimal's father was a puma, its mother a leopard. It is now dead, and may be seen stuffed in Mr. Rothschild's Museum at Tring stared at us without moving; but his courage seemed to fail him, and he sprang into the nullah and disappeared."

In most parts of India tigers are now scarce and shy, except in the preserves of the great rajas, and the dominions of some mighty and pious Hindu potentates, such as the Maharaja of Jeypur, who, being supposed to be descended from a Hindu god, allows no wild animals to be killed. There the deer and pig are so numerous that tigers are welcome to keep them

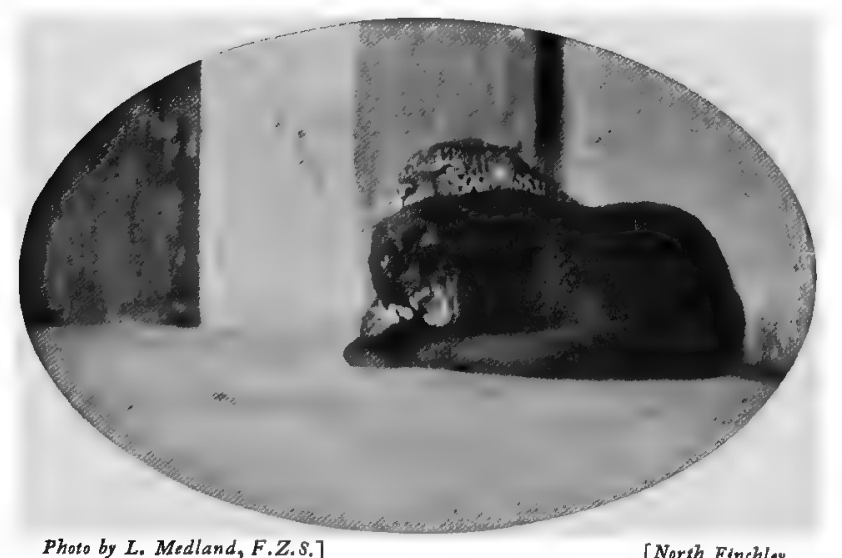

LEOPARDS

A pair of leopards, one spotted, the other black. Black leopards may be the offsping of the ordinary spotted form; they are geverally much more savage down. But the Sunderbunds, unwholesome islands at the Ganges mouth, still swarm with them. So does the Malay Peninsula.

Mr. J. D. Cobbold shot a tiger in. Central Asia in a swamp so deep in snow and so deadly cold that he dared not stay for fear of being frozen to death. Tigers sometimes wander as far west as the Caucasus near the Caspian. The farther north, the larger your tiger, is the rule. The biggest ever seen in Europe was. a Siberian tiger owned by Herr Carl Hagenbeck, of Hamburg, and the largest known skin and skull is from the Far North. The skin is I 3 feet 6 inches from the nose to the end of the tail. The 
largest Indian tiger-skin, from one killed by the Maharaja of Cuch Behar, measures I I feet 7 inches.

\section{LEOPARDS}

LFss in size, but even more ferocious, the LEOPARD has a worse character than the tiger. Living mainly in trees, and very nocturnal, this fierce and dangerous beast is less often seen than far rarer animals. It is widely spread over the world, from the Cape of Good Hope to the Atlas Mountains, and from Southern China to the Black Sea, where it is sometimes met with in the Caucasus. There seems to be no legend of its presence in Greece, Italy, or Spain ; but it was quite common in Asia Minor; and Cicero, when governor of Cilicia, was plagued by an aristocratic young friend in Rome to send him leopards to exhibit in a fête he was giving.

Any one who has frequented the Zoo for any time must have noticed the difference in size and colour between leopards from different parts of the world. On some the ground-colour is almost white, in others a clear nut-brown. Others are jet-black. Wherever they live, they are cattle thieves, sheep thieves, and dog thieves. Though not formidable in appearance, they are immensely strong. Sometimes one will turn man-eater. Both in India and lately in Africa cases have been known where they have "set up" in this line as deliberately as any tiger. They have four or five young at a birth, which may often be kept tame for some time and are amusing pets. But the following plain story shows the danger of such experiments. At Hongkong an English merchant had a tame leopard, which was brought into the room by a coolie for the guests to see at a dinner party. Excited by the smell of food, it refused to go out when one of the ladies, who did not like its looks, wished for it to be removed. The man took hold of its collar and began to haul it out. It seized him by the neck, bit it through, and in a minute the coolie was dying, covered with blood, on the dining-room floor!

The Chinese leopard ranges as far north as the Siberian tiger, and, like the latter, seems to grow larger the farther north it is found. The colour of these northern leopards is very

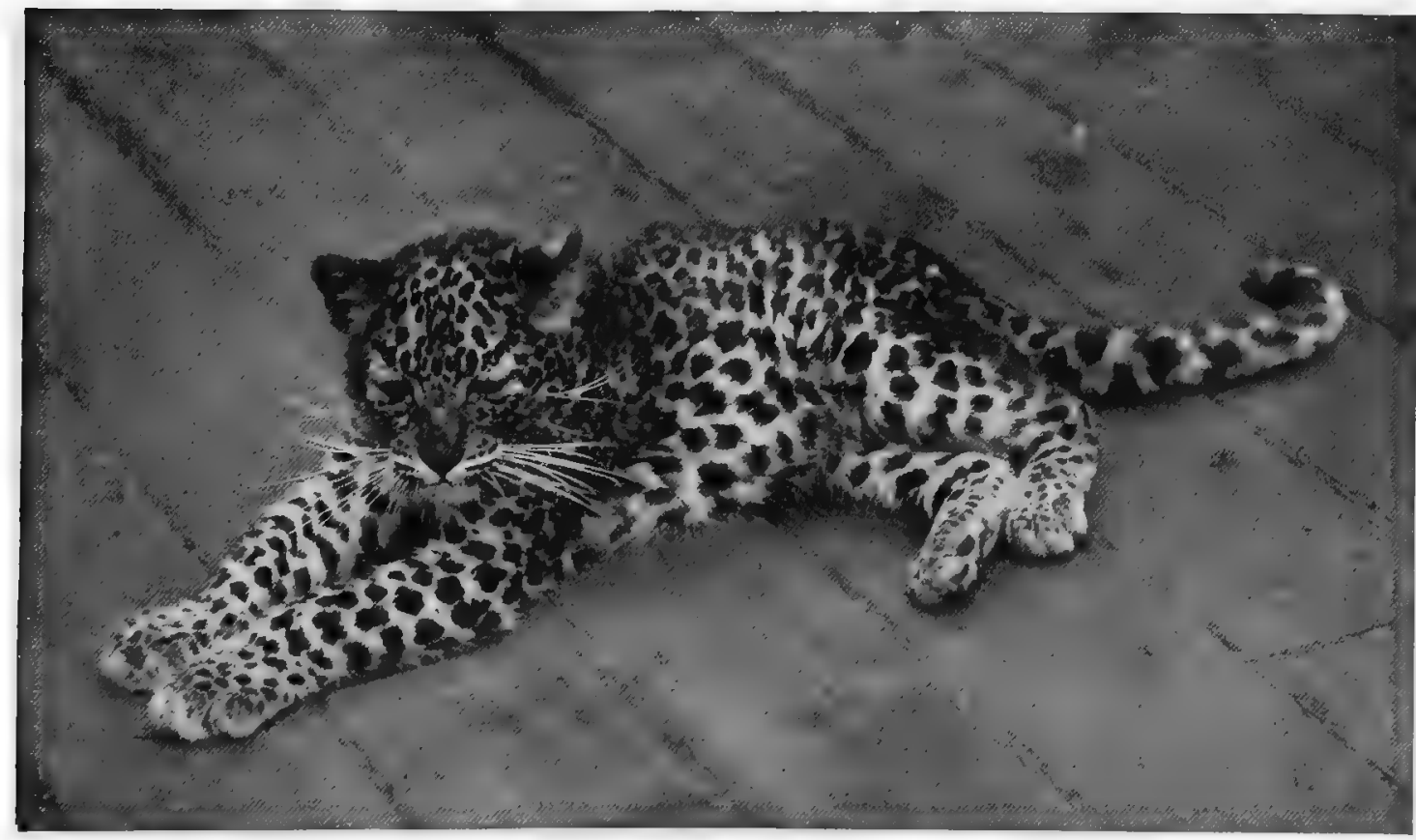

Photo by C. Reid]

A YOUNG LEOPARD

$[$ Wishaw, N. B.

The leopard cub is far more cat-like in appearance than the young tiger or lion 
pale, the spots large, and the fur very long. At the March fur-sales of the present year, held at the stores of Sir Charles Lampson, there were Siberian leopard-skins as large as those of a small tiger.

Leopards are essentially tree-living and nocturnal animals. Sleeping in trees or caves by day, they are seldom disturbed. They do an incredible amount of mischief among cattle, calves, sheep, and dogs, being especially fond of killing and eating the latter. They seize their prey by the throat, and cling with their claws until they succeed in breaking the spine or in strangling the victim. The largest leopards are popularly called Panthers. In India they sometimes become man-eaters, and are always very dangerous. They have a habit of feeding on putrid flesh; this makes wounds inflicted by their teeth or claws liable to blood-poisoning. Nothing in the way of prey comes amiss to them, from a cow in the pasture to a fowl up at roost. "In every country," says Sir Samuel Baker, "the natives are unanimous in saying that the leopard is more dangerous than the lion or tiger.

Wherever I have been in Africa, the natives have declared that they had no fear of a lion, provided they were not hunting, for it would not attack unprovoked, but that a leopard was never to be trusted. I remember when a native boy, accompanied by his grown-up brother, was busily employed with others in firing the reeds on the opposite bank of a small stream. Being

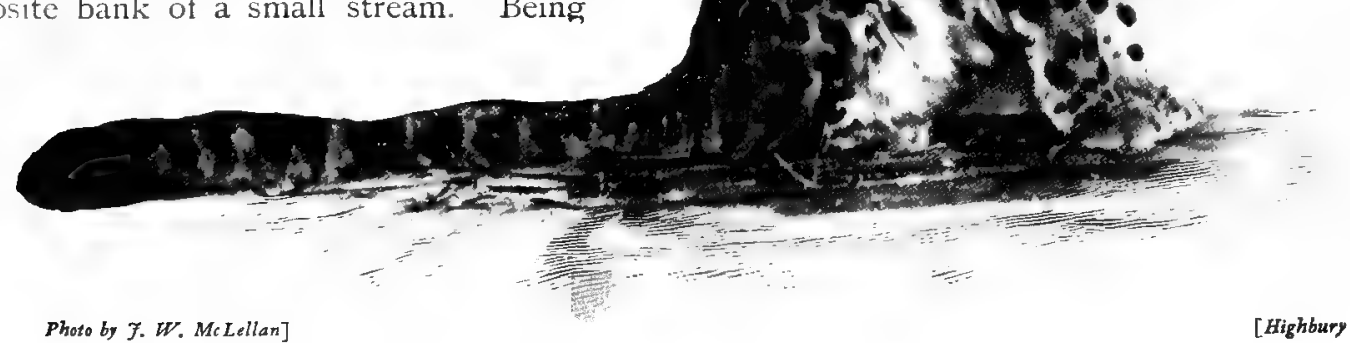

Phote by $\mathcal{F}$ W. McLellan]

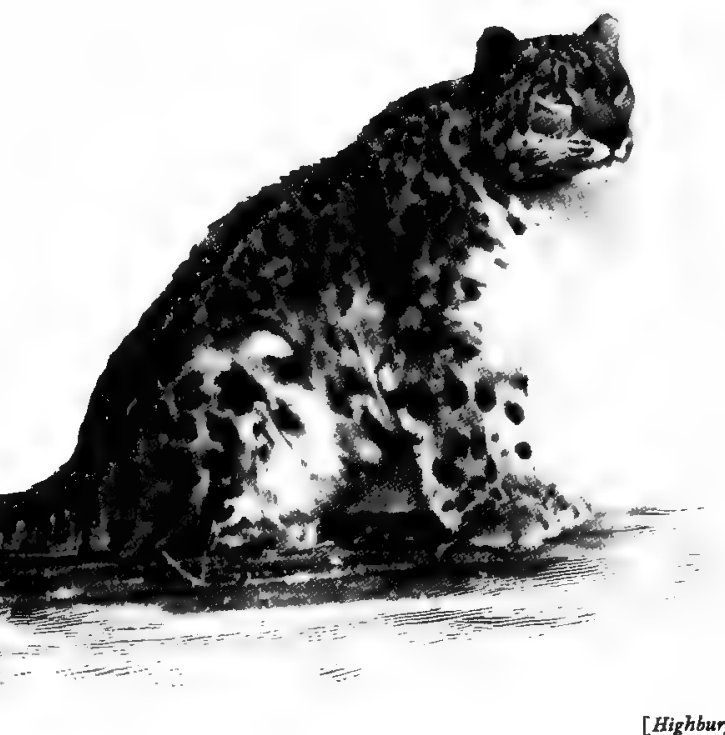

SNOW-LEOPARD, OR OUNCE

This is a striking portrait of a wery beautiful animal. Note the long bushy tail, thick ccat, and iarge eyes

thirsty and hot, the boy stooped down to drink, when he was immediately seized by a leopard. His brother, with admirable aim, hurled his spear at the leopard while the boy was in his jaws. The point separated the vertebræ of the neck, and the leopard fell stone-dead. The boy was carried to my hut, but there was no chance of recovery. The fangs had torn open the chest and injured the lungs. These were exposed to view through the cavity of the ribs. He died the same night."

In the great mountain-ranges of Central Asia the beautiful SNow-LEOPARd is found. It is a large creature, with thick, woolly coat, and a long tail like a fur boa. The colour is white, clouded with beautiful gray, like that of an Angora cat. The edges of the cloudings and spots are marked with black or darker gray. The eyes are very large, bluish gray or smoke-coloured. It lives on the wild sheep, ibex, and other mountain animals. In captivity it is far the tamest and gentlest of the large carnivora, not excepting the puma. Unlike the latter, it is a sleepy, quiet animal, like a domestic cat. The specimen shown here belonged to a lady in India, who kept it for some time as a pet. It was then brought to the Zoological Gardens, where it was more amiable and friendly than most cats. The writer has entered its cage with the keeper, stroked it, and patted its head, witnout in the least ruffling its good-temper. The heat of the lion-house did not suit it, and it died of consumption. 


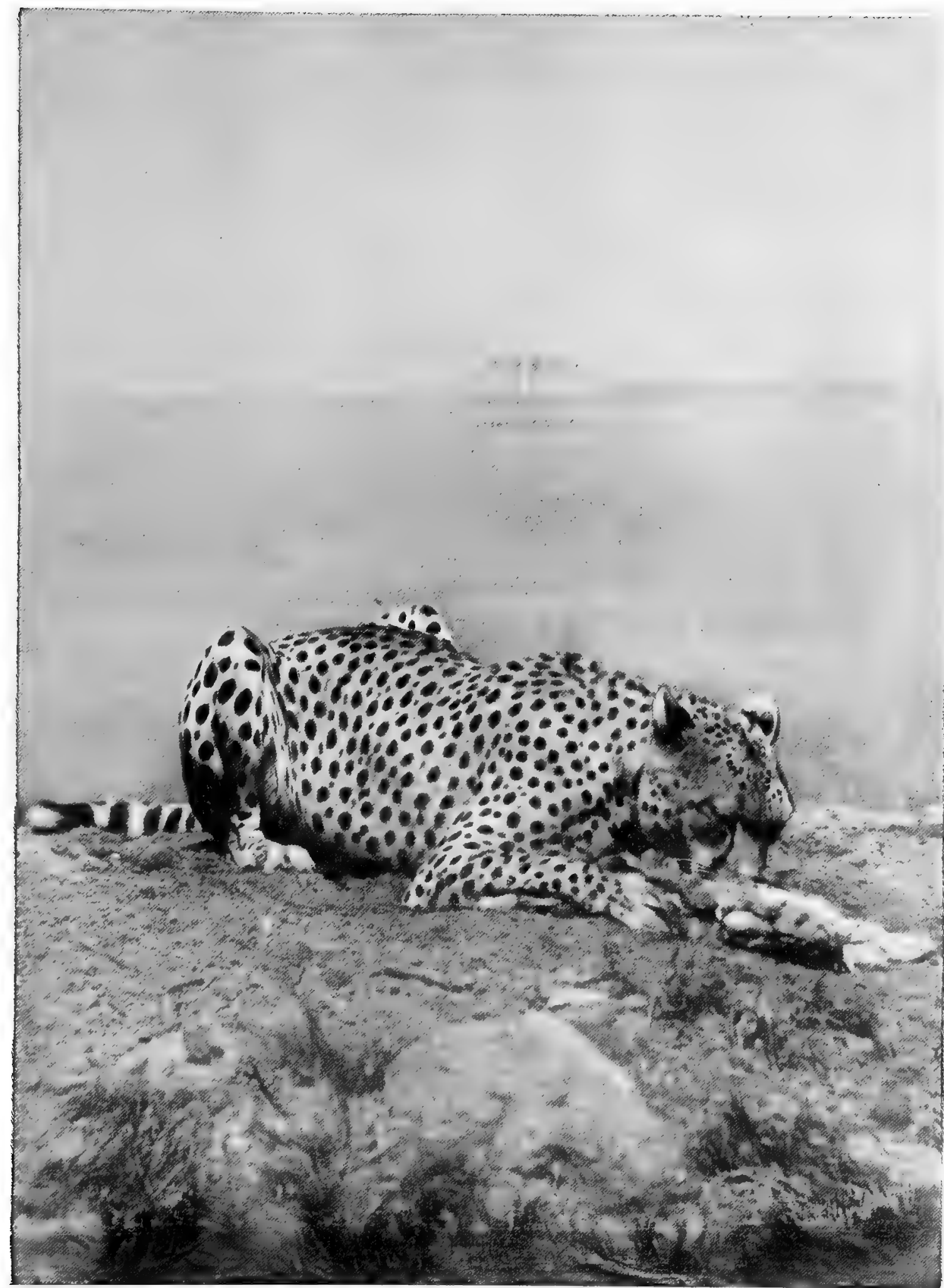

Phoro by Ottomar Anschütz]

CHEETA

L Birisn

A sheeta is a huning-leopard; this one is a particularly large specimen. The cheetas ase dealt with later on in this chapter 


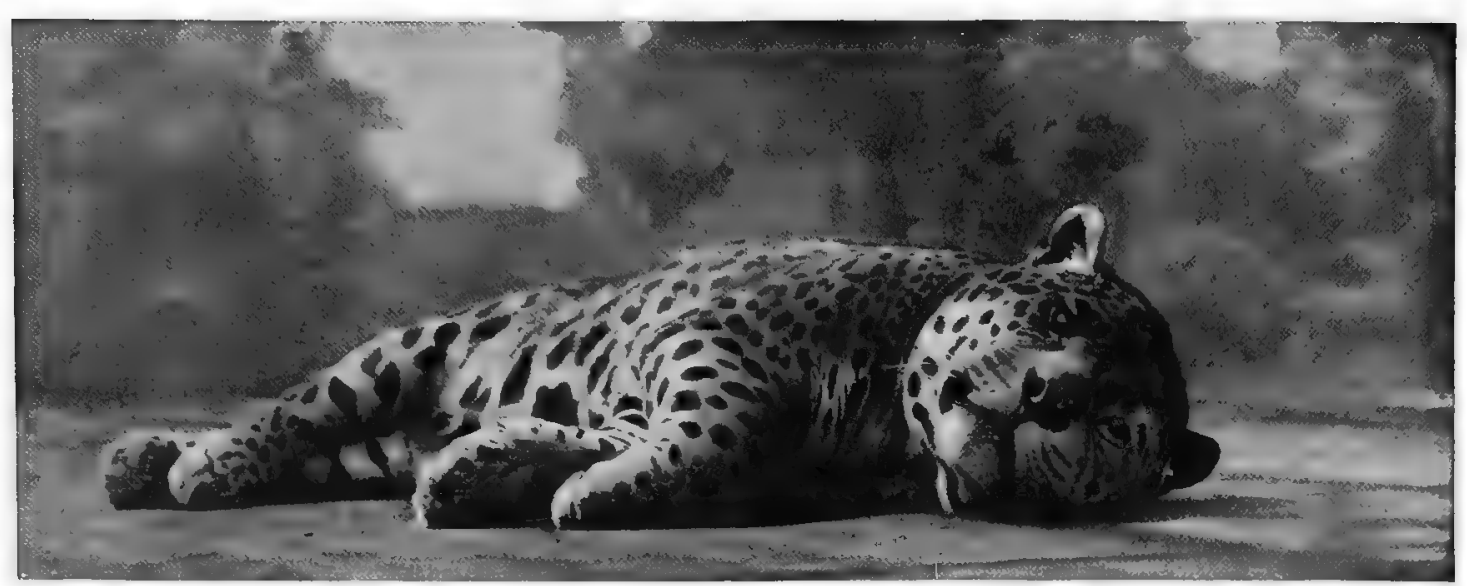

Photo ly G. W. Wilson \& Co., Lsd.?

JAGUAR

[Aberdeest

The largest and strongest of the Cars of America. A South American species

THE AMERICAN CATS

THE cats, great and small, of the New World resemble those of the Old, though not quite so closely as the caribou, wapiti deer, and moose of the northern forests resemble the reindeer, red deer, and elk of Europe. They are like, but with a difference. The Jaguar and the Ocelot are respectively larger and far more beautiful than their counterparts, the leopard and serval cats. But the Puma, the one medium-sized feline animal which is unspotted, is something unique. The jaguar and puma are found very far south in South America; and though the. jaguar is really a forest animal, it seems to have wandered out on to the Pampas of Argentina, perhaps attracted by the immense numbers of cattle, sheep, and horses on these plains.

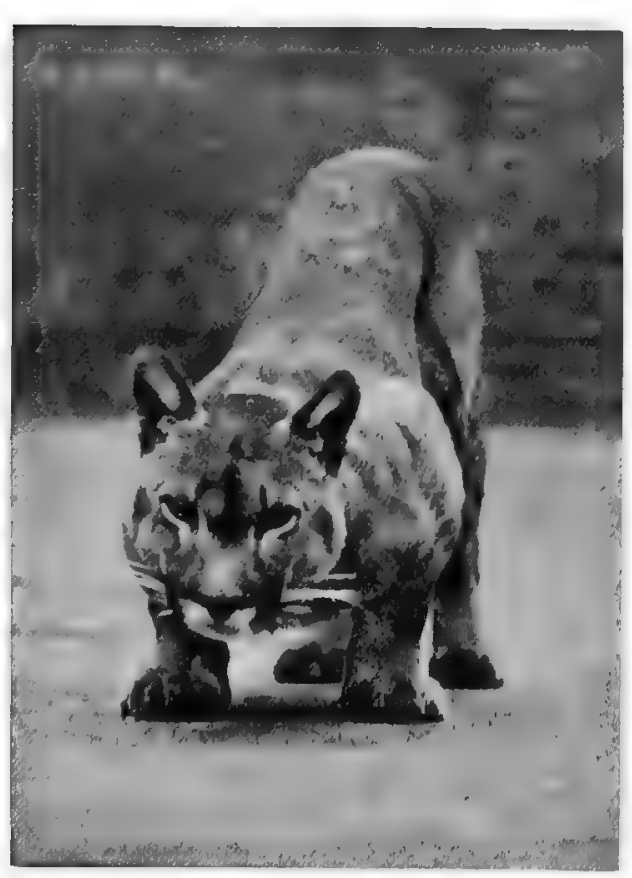

P.hoto by Scholastic Photo. Ce., Parsm's Grean

P U M A

A puma in the act of lying dorwn, like a domestic cat

\section{The Jaguar}

The JAGUAR is as savage as it is formidable, but does not often attack men. Its headquarters are the immense forests running from Central America to Southern Brazil; and as all great forests are little inhabited, the jaguar is seldom encountered by white men. By the banks of the great rivers it is semi-aquatic; it swims and climbs with equal ease, and will attack animals on board boats anchored in the rivers. As there are few animals of great size in these forests, its great strength is not often seen exercised, as is that of the lion; but it is the personification of concentrated force, and its appearance is well worth studying from that point of view. The spots are larger and squarer than in the leopard, the head ponderous, the forearms and feet one mass of muscle, knotted under the velvet skin. On the Amazons it draws its food alike from the highest tree-tops and the river-bed; in the former it catches monkeys in the branches, fish in the shallows of the rivers, and scoops out turtles' eggs from the sand banks. Humboldt, who visited these regions when the white population 
was scarce, declared that 4,000 jaguars were killed annually, and 2,000 skins exported from Buenos Ayres alone. It was clearly common on the Pampas in his day, and made as great havoc among the cattle and horses as it does to-day.

\section{The Puma}

The PUMA is a far more interesting creature. It is found from the mountains in Montana, next the Canadian boundary, to the south of Patagonia. Many stories of its ferocity may have some foundation; but the writer believes there is no recorded instance of the northern puma attacking man unprovoked, though in the few places where it now survives it kills cattlecalves and colts. It is relentlessly hunted with dogs, treed, and shot. As to the puma of the

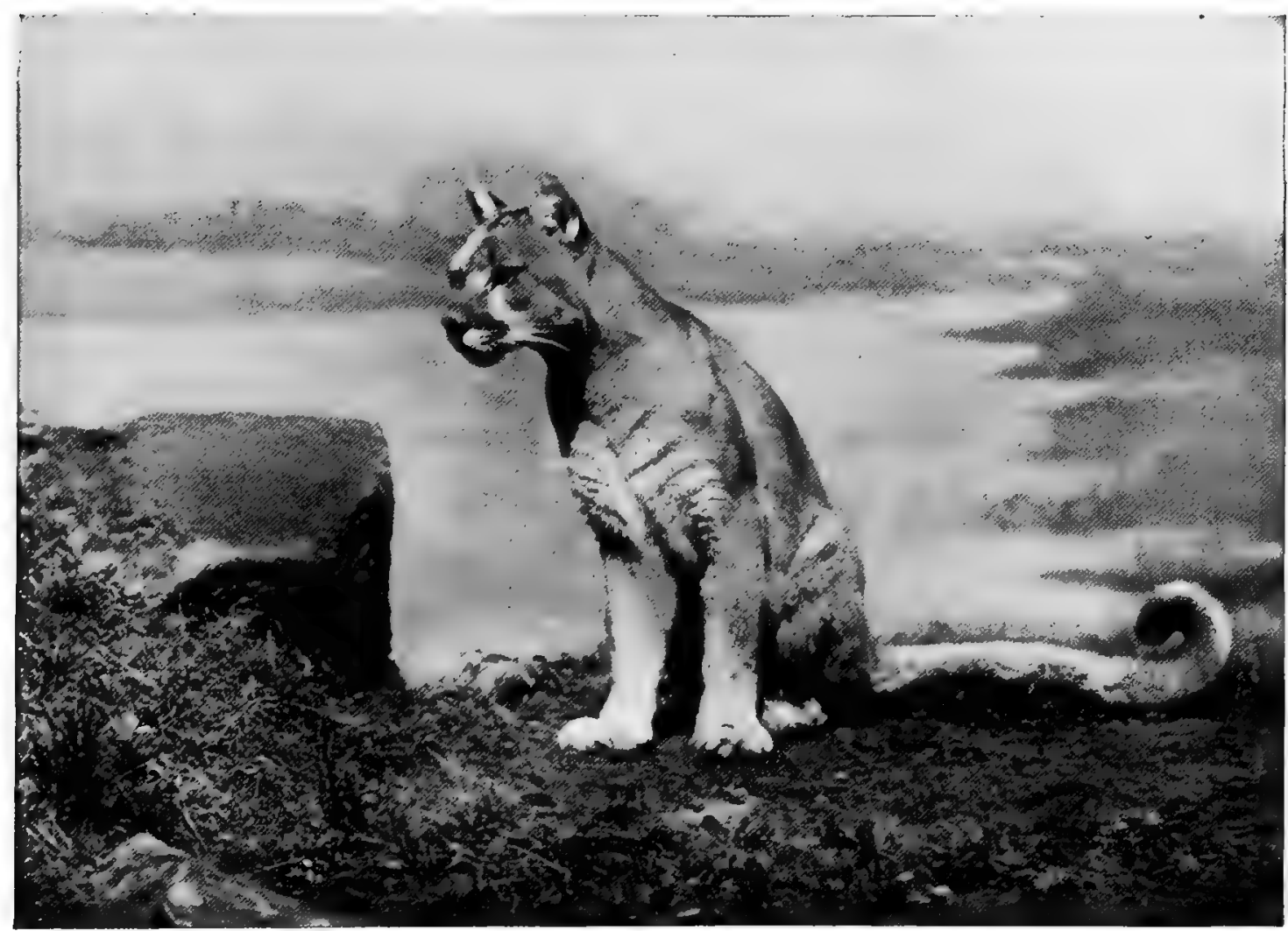

Phaso by Otzamar Anschütsc]

FEMALE PUMA

[Berlin

This shows a puma alert and vigilant, with ears pricked forward

southern plains and central forests, the natives, whether Indians or Gauchos, agree with the belief, steadily handed down from the days of the first Spanish conquest, that the puma is the one wild cat which is naturally friendly to man. The old Spaniards called it amigo del Cristiano (the Christian's friend); and Mr. Hudson, in "The Naturalist in La Plata," gives much evidence of this most curious and interesting tendency: "It is notorious that where the puma is the only large beast of prey it is perfectly safe for a small child to go out and sleep on the plain. . . . The puma is always at heart a kitten, taking unmeasured delight in its frolics; and when, as often happens, one lives alone in the desert, it will amuse itself for hours fighting mock bat. tles or playing hide-and-seek with imaginary companions, or lying in wait and putting all its wonderful strategy in practice to capture a passing butterfly." From Azara downwards these stories have been told too often not to be largely true; and in old natural histories, whose 


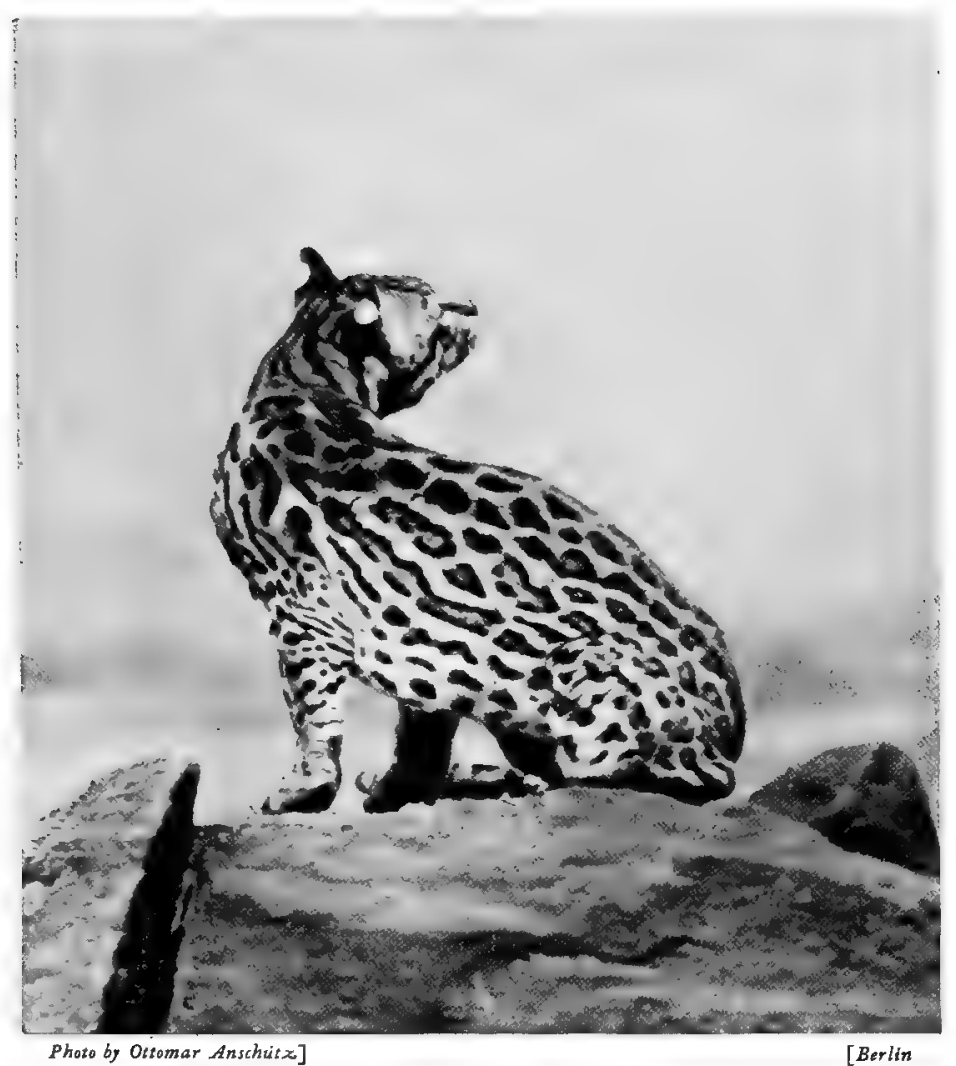

OCELOT

writers believed the puma was a terrible man-eater, they also appear as "wonderful escapes." One tells how a man put his poncho, or cloak, over his back when crawling up to get a shot at some duck, and felt something heavy on the end of it. He crept from under it, and there was a puma sitting on it, which did not offer to hurt him.

As space forbicis further quotation from Mr. Hudson's experiences, which should be read, the writer will only add one anecdote which was told him by Mr. Everard im Thurn, C. B., formerly an official in British Guiana. He was going up one of the big rivers in his steamlaunch, and gave a passage to an elderly and respectable Cornish miner, who wanted to go up to a gold-mine. The visitor had his meals on the boat, but at night went ashore with the men and slung his hammock between two trees, leaving the cabin to his

host. One morning two of the Indian crew brought the miner's hammock on board with a good deal of laughing and taiking. Their master asked what the joke was, whereupon, pointing to the trees whence they had unsiung the hammock, one said, "Tiger sleep with old man last night." They "were quite in earnest, and pointed out a hollow and marks on the leaves, which showed that a puma had been lying just under the man's hammock. When asked if he had noticed anything in the night, he said, "Only the frogs croaking wakened me up." The croaking of the frogs was probably the hoarse purring of the friendly puma enjoying his proximity to a sleeping man." Mr. Hudson quotes a case in which four pumas played round and leapt over a person camping out on the Pampas. He watched them for some time, and then went to sleep! Many of those brought to this country come with their tempers ruined by ill-treatment and hardship; but a large proportion are as tame as cats. Captain Marshall had one at Marlow which used to follow him on a chain and watch the boats full of pleasure-scekers at the lock.

The puma is always a beautiful creature,-the fur cinnamon-coloured, tinged with gold; the belly and chest white; the tail long, full, and round. Though friendly to man, it is a desperate cattle-killer, and particularly fond of horse-flesh, so much so that it has been suggested that the indigenous wild horses of America were destroyed by the puma.

There are two other cats of the Pampas - the Grass-CAT, not unlike our wild cat in appearance and habits, and the WOOD-CAT, or Geoffroy's Cat. It is a tabby, and a most elegant creature, of which there is a specimen, at the time of writing, in the Zoo.

\section{The OCELot}

In the forest region is also found the most beautiful of the medium-sized cats. This is the 
OCELOT, which corresponds somewhat to the servals, but is not the least like a lynx, as the servals are. It is entirely a tree-cat, and lives on birds and monkeys. The following detailed description of its coloration appeared in "Life at the Zoo":-

"Its coat, with the exception perhaps of that of the clouded leopard of Sumatra, marks the highest development of ornament among four-footed animals. The Argus pheasant alone seems to offer a parallel to the beauties of the ocelot's fur, especially in the development of the wonderful ocelli, which, though never reaching in the beast the perfect cup-and-ball ornament seen on the wings of the bird, can be traced in all the early stages of spots and wavy lines, so far as the irregular shell-shaped rim and dot on the feet, sides, and back, just as in the subsidiary ornament of the Argus pheasant's feathers. Most of the ground-tint of the fur is

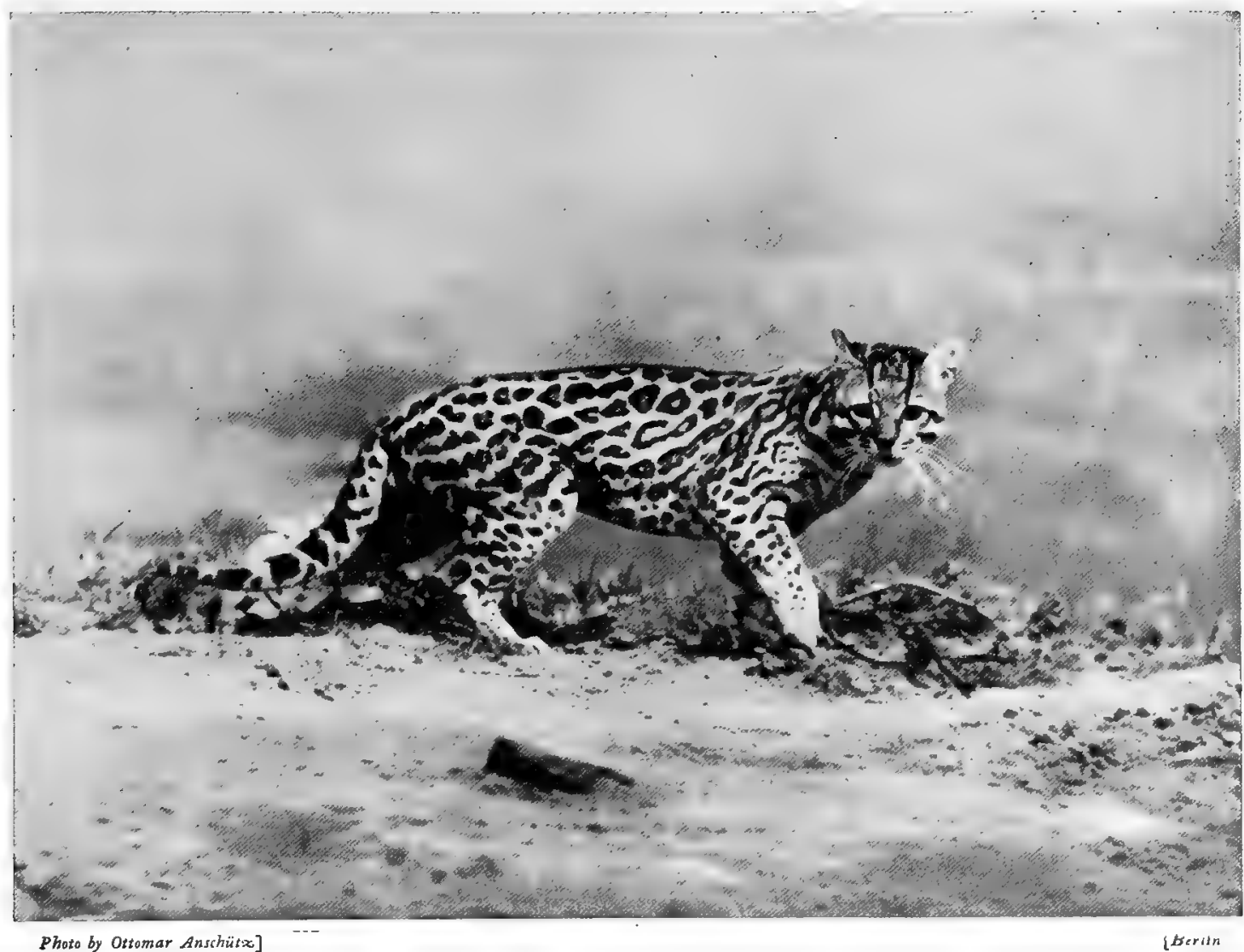

Photo by Ottomar Anschüt:x]

OCELOT FROM CENTRAI AMERICA

The ocelot can be tamed and almost domesticated if taken young, and is cccasionally kept as a pet by the forest Indians

smoky-pearl colour, on which the spots develop from mere dots on the legs and speckles on the feet and toes to large egg-shaped ocelli on the flanks. There are also two beautiful pearl-coloured spots on the back of each ear, like those which form the common ornaments of the wings of many moths."

The nose is pink; the eye large, convex, and translucent.

A tame ocelot described by Wilson, the American naturalist, was most playful and affectionate, but when fed with flesh was less tractable. It jumped on to the back of a horse in the stable, and tried to curl up on its hindquarters. The horse threw the ocelot off and kicked it, curing it of any disposition to ride. On seeing a horse, the ocelot always ran off to its kennel afterwards. When sent to England, it caught hold of and threw down a child of four years old, whom it rolled about with its paws without hurting it. 


\section{OTHER WILD CATS}

A handsome leopard-like animal is the Clouded Leopard. It is the size of a small common leopard, but far gentler in disposition. Its fur is not spotted, but marked with clouded patches, outlined in gray and olive-brown. Its skin is among the most beautiful of the Cats. It is found in the Malay Peninsula, Borneo, Sumatra, Formosa, and along the foot of the Himalaya from Nepal to Assam. Writing of two which he kept, Sir Stamford Raffles said: "No kitten could be more good-tempered. They were always courting intercourse with persons passing by, and in the expression of their countenance showed the greatest delight when noticed, throwing themselves on their backs, and delighting in

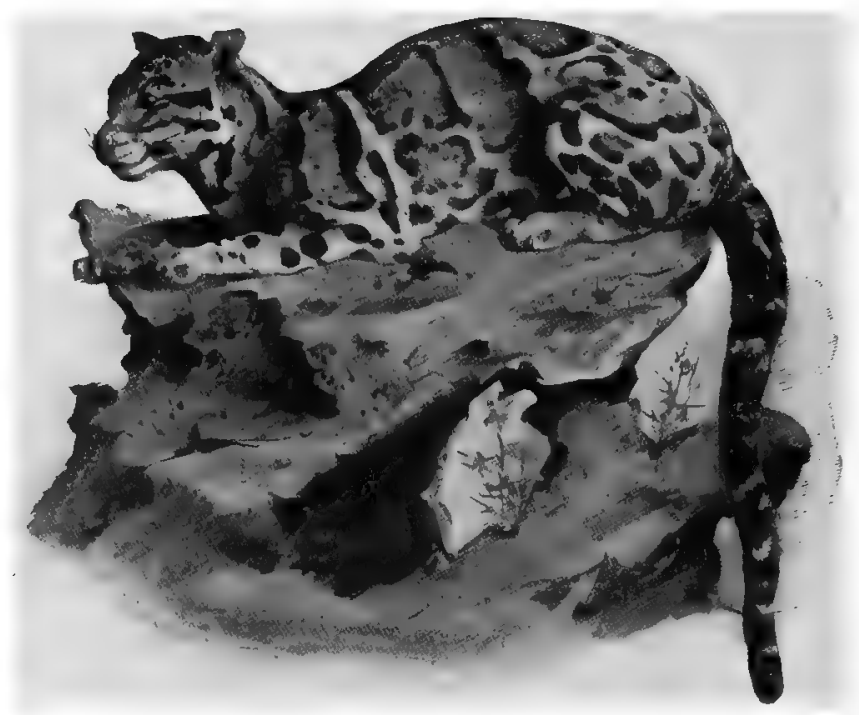

Photo by A. S, Rudland \& Son:

CLOUDED LEOPARD

It shares with the ocelot the first place among the highly ornamented cats

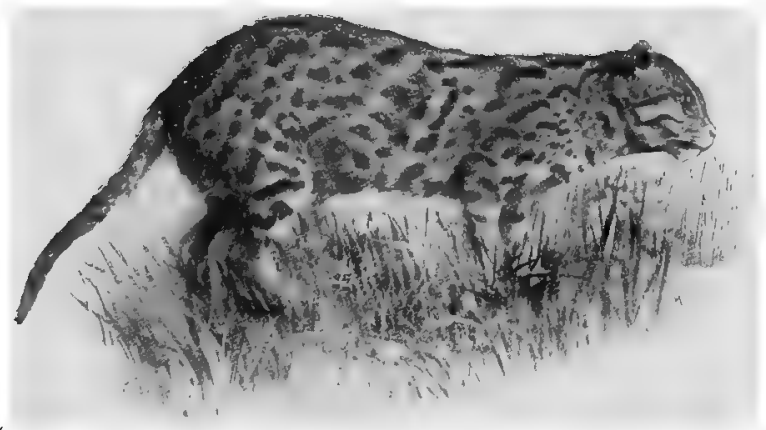

Phoso by A.S. Rudland \& Sons

F IS H ING-CAT

This wild cat haunts the sides of rivers, and is an expert at catching fish

gray and spotted, and those which are gray and striped, or "whole-coloured." There is no wholly gray wild cat, but several sandy-coloured species. All live on birds and small mammals, and probably most share the tame cat's liking for fish. Among the gray-and-spotted cats are the MottleD CAT of the Eastern Himalaya and Straits Settlements and islands; the TIBETAN Tiger-CAT; the Fishing-CAT of India and Ceylon, which is large enough to kill lambs, but lives much on fish and large marsh-snails; Geoffroy's Cat, an American species; the LEOPARD-CAT of Java and Japan, which seems to have gray fur in being tickled and rubbed. On board ship there was a small dog, which used to play around the cage with the animal. It was amusing to watch the tenderness and playfulness with which the latter came in contact with its smaller-sized companion." Both specimens were procured from the banks of the Bencoolin River, in Sumatra. They are generally found near villages, and are not dreaded by the natives, except in so far that they destroy their poultry.

The number of smaller leopard-cats and tiger-cats is very great. They fall, roughly, into three groups: those which are yellow and spotted, those which are

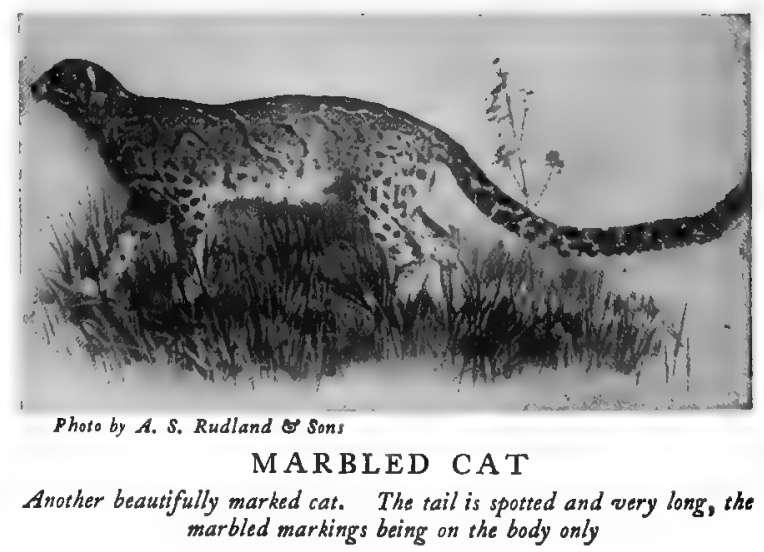




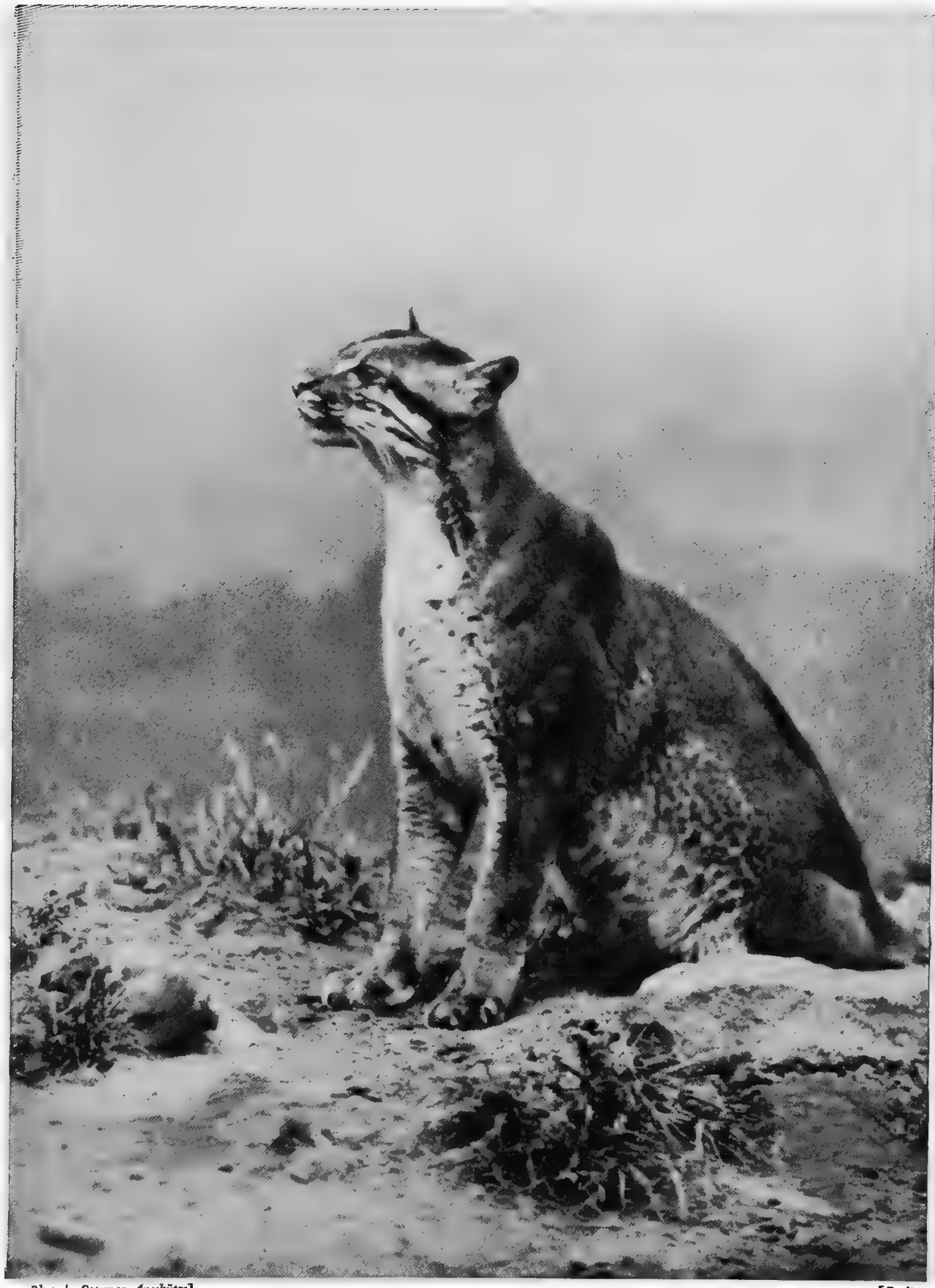

Photo br Ottomar Anschüt:x]

[Barlin

\section{GOLDEN CAT}

Sumatra is the home of this very beautifully coloured cat. The general tint is that of gold-stone. Sometimes the belly is pure wohite 


\section{THE LIVING ANIMALS OF THE WORLD}

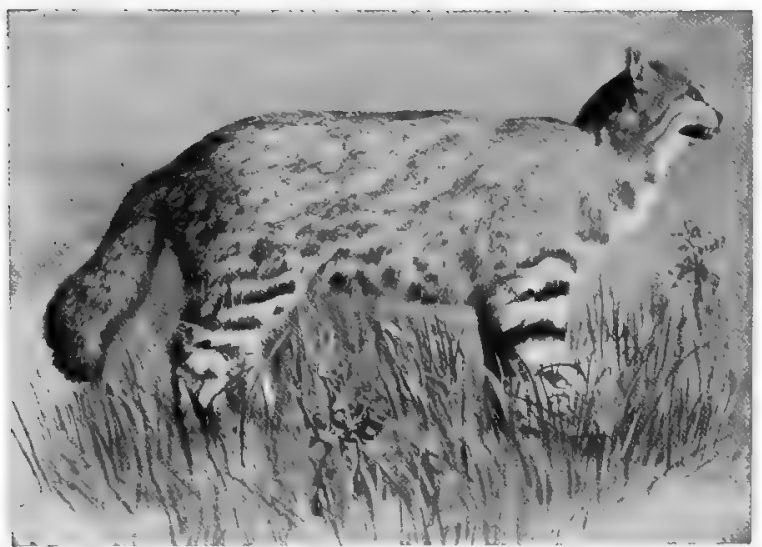

Phoso by A. S. Rudland \& Sons

PAMPAS-CAT

Note the likeness of the thick tail and barred legs to the English wild cat. "Inexpressibly savage in disposition" (Hudson)

Japan and a fulvous leopard-like skin in India, where it is also called the TIGER-CAT; and the smallest of all wild cats, the little Rusty-spotted Cat of India. This has. rusty spots on a gray ground. "I had a kitten brought to me," says Dr. Jerdon. of the species, "when very young. It became quite tame, and was the delight and admiration of all who saw it. When it was about eight months old, I introduced the fawn of a gazelle into the room where it was. The little creature flew at it the moment it saw it, seized it by the nape of the neck, and was with difficulty taken off." Of the whole-coloured wild cats-which include the Bay Cat, the American PampasCAT, PALLAS' CAT of Tibet and India-the

most beautiful is the Golden CAT of Sumatra, one of which is now in the Zoological Gardens. It has a coat the colour of gold-stone. The nose is pink, the eyes large and topazcoloured, the cheeks striped-with white, and ihe underparts and lower part of the tail pure white.

Four kinds of wild cats are known in South Africa, of which the largest is the Serval, a short-tailed, spotted animal, with rather more woolly fur than the leopard's. The length is about 4 feet 2 inches, of which the tail is only $\mathrm{I} 2$ inches. It is found from Algeria to the Cape; but its favourite haunts, like those of all the wild cats of hot countries, are in the reeds by rivers. It kills hares,

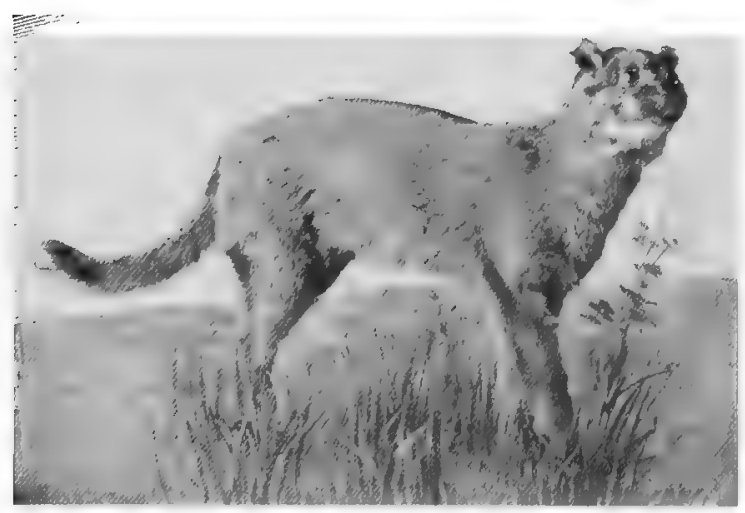

Phoso by A. S. Rudland Es Sions

BAY CAT

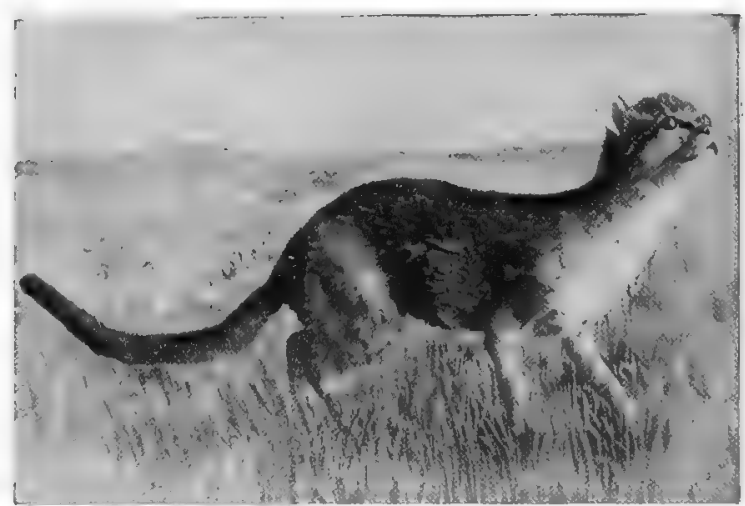

Photo by A. S. Rudland sons

EYRA CAT

The lowest and longest of the cats, shaped more like a civet; it is readily tamed, and makes a charming pet

rats, birds, and small mammals generally.

The BLACK-FOOTED WILd CAT is another African species. It is a beautiful spottedand-lined tabby, the size of a small domestic cat, and as likely as any other to be the origin of our tabby variety, if tame cats came to Europe from Atrica. At present it is only found south in the Kalahari Desert and Bechuanaland.

The Kaffir CAT is the common wild cat of the Cape Colony, and a very interesting animal. It is a whole-coloured tawny, upstanding animal, with all the indifference to man and generally independent character of the domestic tom-cat. 


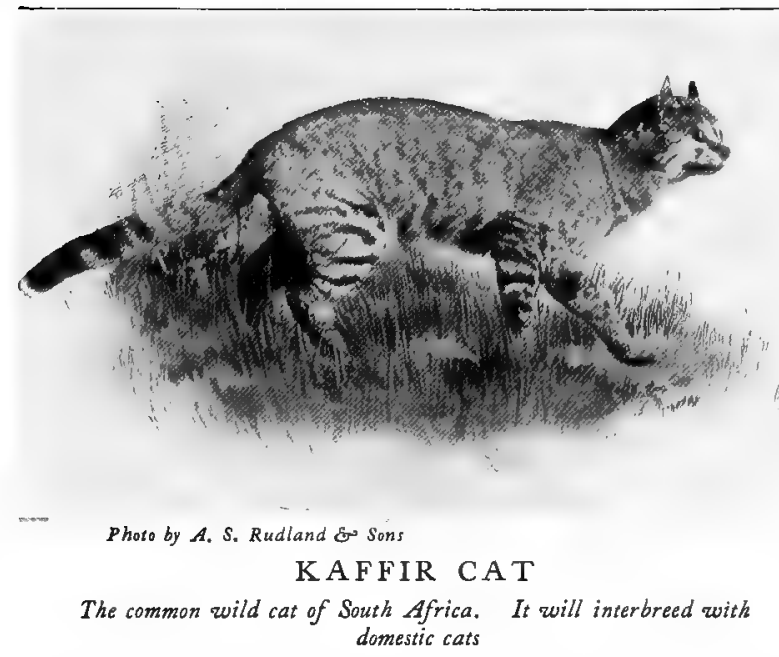

It is, however, much stronger than the tame cats, with which it interbreeds freely. In the Colony it is often difficult to keep male tame cats, for the wild Kaffir cats come down and fight them in the breeding-season. The Egyptian cat is really the same animal, slightly modified by climate. A very distinct species is the Jungle-CAT, ranging from India, through Baluchistan, Syria, and East Africa, and called in Hindustani the Chaus. The European striped wild cat extends to the Himalaya, where the range of the lioncoloured, yellow-eyed chaus begins. The chaus has a few black bars inside the legs, which vary in different regions. The Indian chaus has only one distinctly marked; the Kaffir cat has four or five. The Egyptian FetTERED CAr has been said to be the origin of the domestic and sacred cats of Egypt. A male chaus is most formidable when "cornered." General Hamilton chased one, which had prowled into the cantonments on the lookout for fowls, into a fence. "After a long time I spied the cat squatting in a hedge," he writes, " and called for the dogs. When they came, I knelt down and began clapping my hands and cheering them on. The cat suddenly made a clean spring at my face. I had just time to catch it as one would a cricket-ball, and, giving its ribs a strong squeeze, threw it to the dogs; but not before it had made its teeth meet in my arm just above the wrist. For some weeks I had to carry my arm in a sling, and I shall carry the marks of the bite to my grave."

The chaus, as will be seen from the above, wanders boldly down into the outskirts of large towns, cantonments, and bungalows, on the lookout for chickens and pigeons. Its favourite plan is to lie up at dawn in some piece of thick cover near to where the poultry wander out to scratch, feed, and bask. It then pounces on the nearest unhappy hen and rushes off with it into cover. An acquaintance of the writer once had a number of fine Indian game fowl, of which he was not a little proud. He noticed that one was missing every morning for three days, and, not being able to discover the robber, shut them up in a hen-house. Next morning he heard a great commotion outside, and one of his bearers came running in to say that a leopard was in the henhouse. As this was only built of bamboo or some such light material, it did not seem probable that a leopard would stay there. Getting his rifle, he went out into the compound, and cau. tiously approached the hen-house, in which the fowls were still making loud protests and cries of alarm. The door was shut; but some creature-certainly not a leopard-might have squeezed in through the small entrance used by the hens. He opened the door, and saw at the back of the hen-house a chaus sitting, with all its fur on end, looking almost as large as a small leopard. On the floor was one dead fowl. The impudent jungle-cat rushed for the door, but had the coolness to seize the hen

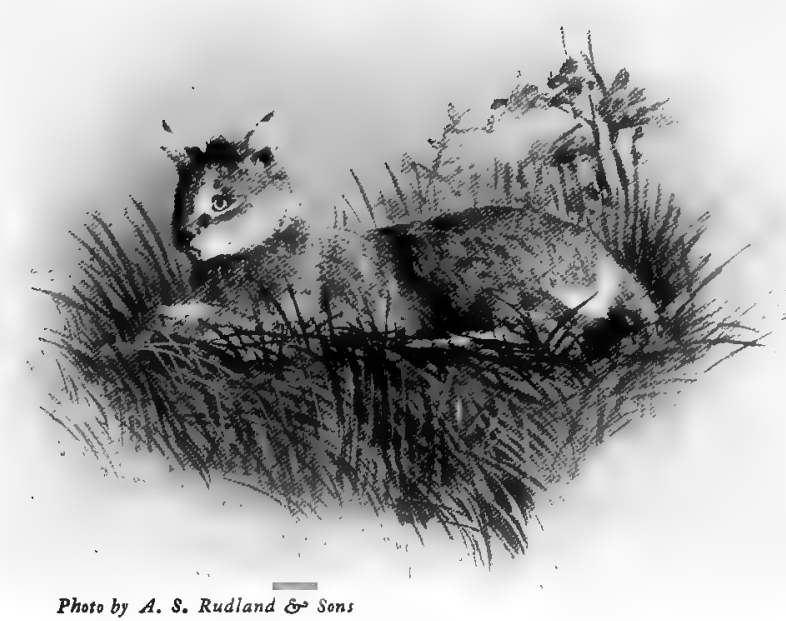

AFRICAN CHAUS, OR JUNGLE-CAT

The chaus is the Indian and African equivalent of our woild cat. It is equally strong and savage 
as it passed, and with this in its mouth rushed past the owner of the hens, his servants and retainers, and reached a piece of thick scrub near with its prize.

As the chaus is common both in India and Africa, a comparison of its habits in both continents is somewhat interesting. Jerdon, the Indian naturalist, writes: "It is the common wild cat from the Himalaya to Cape Comorin, and from the level of the sea to 7,000 or 8,000 feet elevation. It frequents alike the jungles and the open country, and is very partial to long reeds, and grass, sugarcane-fields, and corn-fields. It does much damage to all game, especially to hares and partridges. Quite recently I shot a pea-fowl at the edge of a sugarcane-field. One of these cats sprang out, seized the pea-fowl, and after a short struggle-for the bird was not quite dead-carried it off before my astonished eyes, and, in spite of my running up, made his escape with his booty. It must have been stalking these very birds, so closely did its spring follow my shot. It is said to breed twice a year, and to have three or four young at a birth. I have very often had the young brought to me, but always failed in rearing them; and they always showed a savage and untamable disposition. I have seen numbers of cats about villages in various parts of the country that must have been hybrids between this cat and the tame ones."

The late Sir Oliver St. John was more fortunate with his jungle-cat kittens. He obtained three in Persia. These he reared till they were three months old, by which time they became so tame that they would climb on to his knees at breakfast-time, and behave like ordinary kittens. One was killed by a greyhound, and another by a scorpion-a curious fate for a kitten to meet. The survivor then became morose and ill-tempered, but grew to be a large and strong animal. "Two English bull-terriers of mine, which would make short work of the largest domestic cat, could do nothing against my wild cat," says the same writer. "In their almost daily battles the dogs always got the worst of it."

In Africa the chaus haunts the thick cover bordering the rivers. There it catches not only water-fowl, but also fish. According to Messrs. Nicolls and Eglington, "its spoor may constantly be seen imprinted on the mud surrounding such pools in the periodical watercourses as are constantly being dried up, and in which fish may probably be imprisoned without chance of escape." The chaus has for neighbour in Africa the beautiful Serval, a larger wild cat. This species is reddish in colour, spotted on the body, and striped on the legs. The ears are long, but not tufted, like those of the lynx. The serval is more common in North and Central Africa than in the South. But it is also found south of the Tropic of Capricorn. Messrs. Nicolls and Eglington say of it: "Northward through South Central Africa it is fairly common. It frequents the thick bush in the vicinity of rivers. The karosses, or mantles, made from its skins

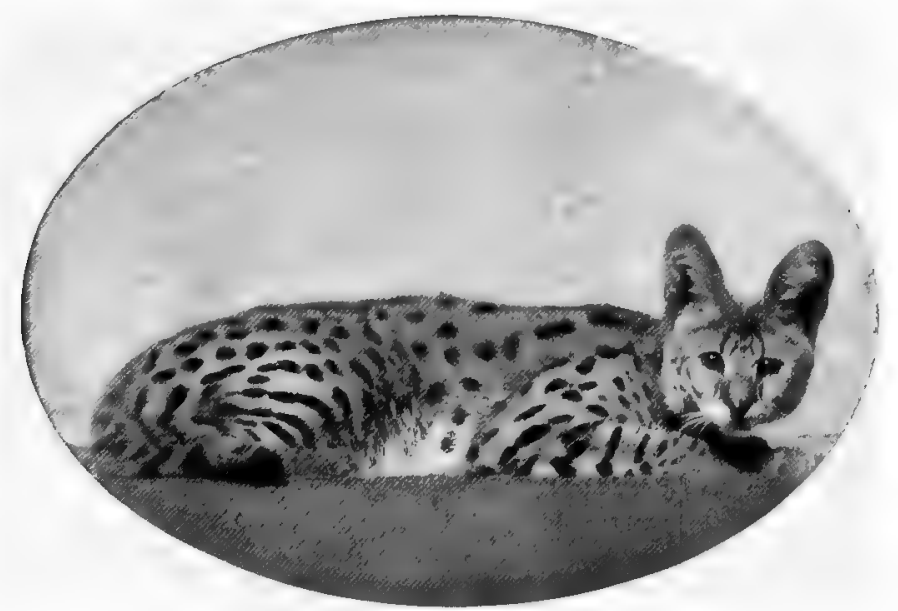

Phoso by L. Medland, F,Z.S.]

SER V A L are only worn by the chiefs and very high dignitaries amongst the native tribes, and are in consequence eagerly sought after, on which account the species runs a risk of rapid extermination. Its usual prey consists of the young of the smaller antelopes, francolins, and wild guinea-fowls, to the latter of which it is a most destructive enemy in the breedingseason. When obtained young, the serval can be tamed with little trouble; but it is difficult to rear, and always shows a singular and almost unaccountable aversion to black men. Its otherwise even temper is always aroused at the sight of a native. 


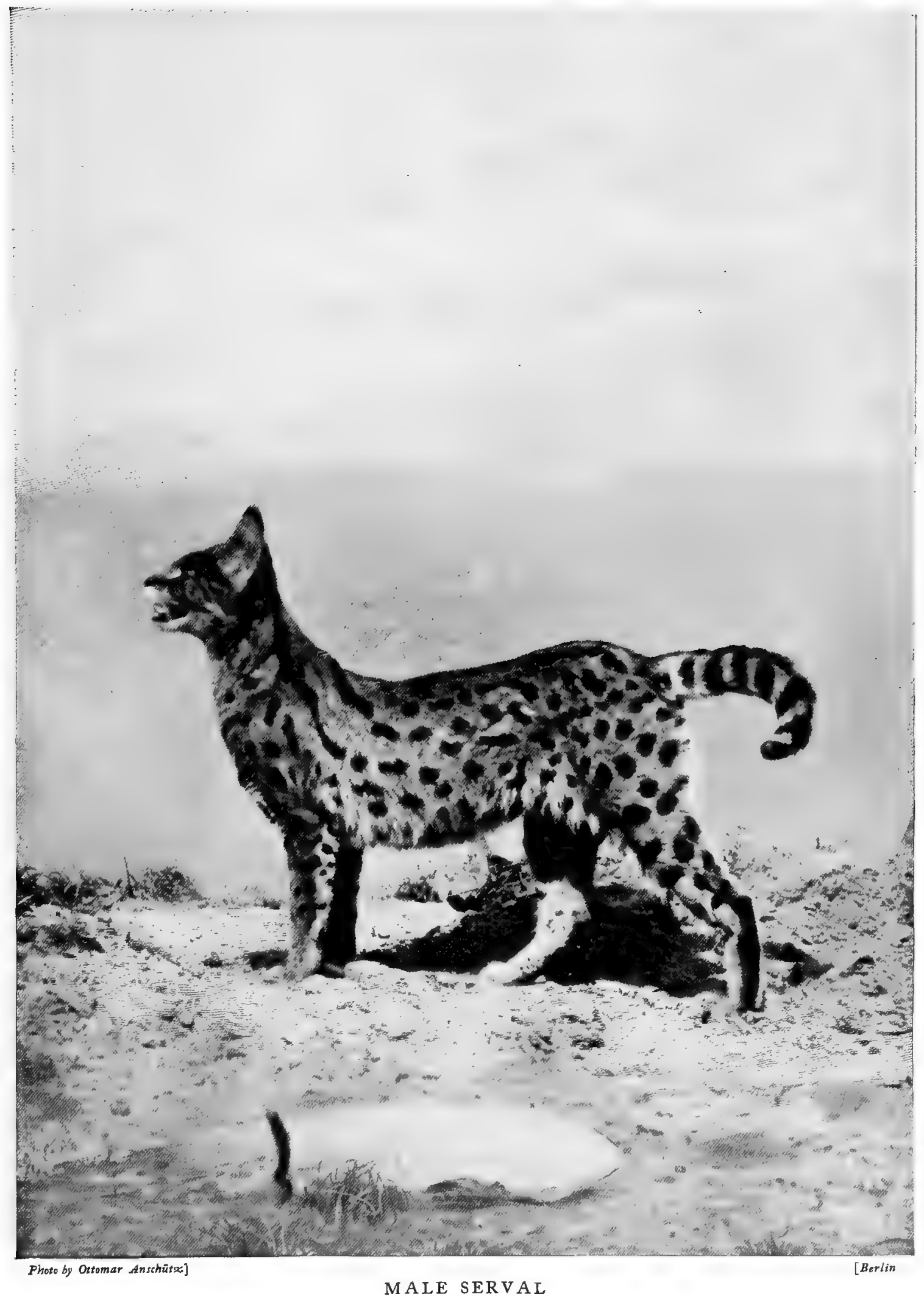

The serval is a link between the leopards and tiger-cats, quite large enough to kill the young of the smaller antelopes 


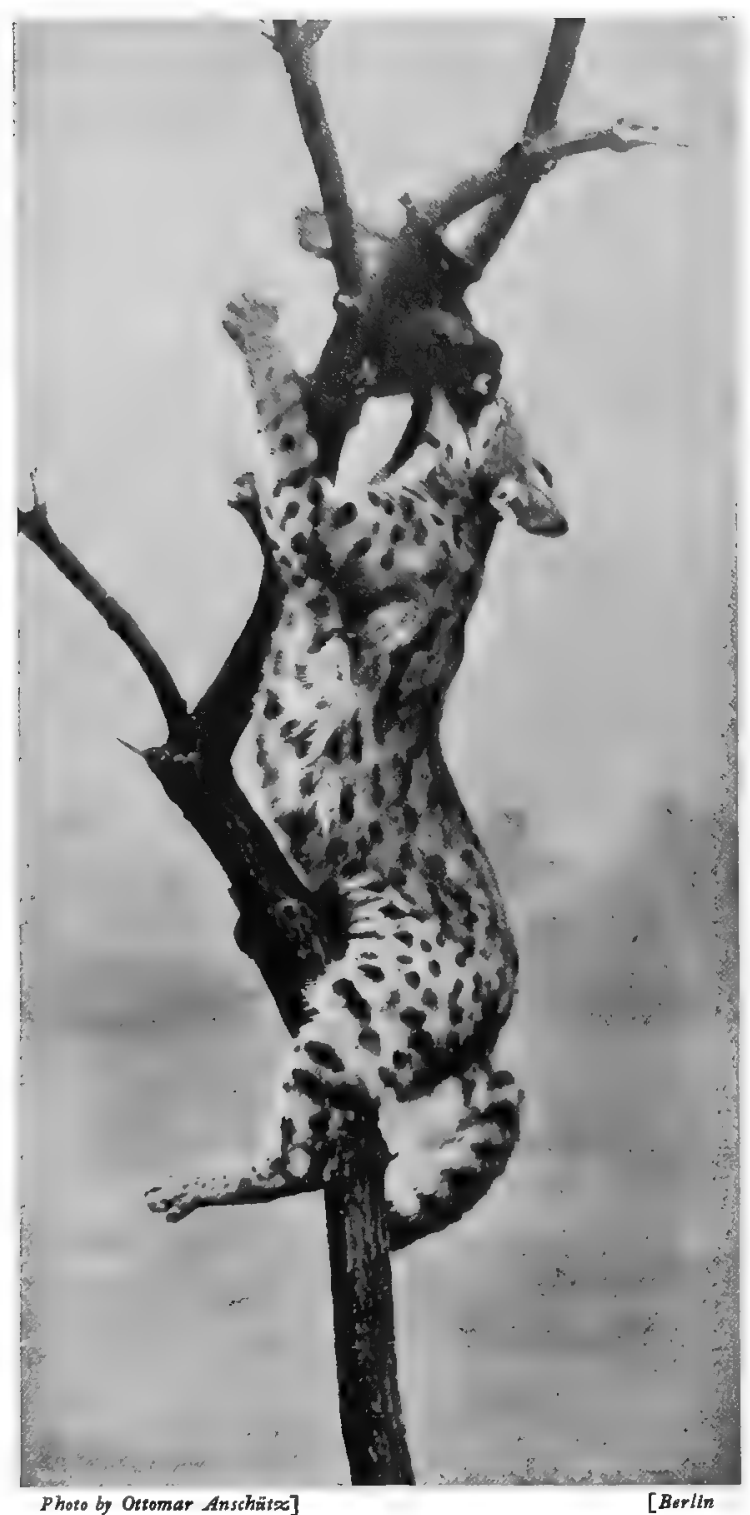

SER VAL CLIMBING

Note the active, cat-like method of climbing
When in anger, it is by no means a despicable antagonist, and very few dogs would like to engage in a combat with one single-handed."

\section{The Common Wild Cat}

The Wild Cat was once fairly common all over England. A curious story, obviously exaggerated, shows that traditions of its ferocity were common at a very early date. The tale is told of the church of Barnborough, in Yorkshire, between Doncaster and Barnsley. It is said that a man and a wild cat met in a wood near and began to fight; that the cat drove the man out of the wood as far as the church, where he took refuge in the porch; and that both the man and cat were so injured that they died. According to Dr. Pearce, the event was formerly commemorated by a rude painting in the cliurch.

Mr. Charles St. John had an experience with a Scotch wild cat very like that which General Douglas Hamilton tells of the junglecat. He heard many stories of their attacking and wounding men when trapped or when their escape was cut off, and before long found out that these were true. "I was fishing in a river in Sutherland," he wrote, "and in passing from one pool to another had to climb over some rocky ground. In doing so, I sank almost up to my knees in some rotten heather and moss, almost upon a wild cat which was concealed under it. I was quite as much startled as the cat itself could be, when I saw the wild-looking beast rush so unexpectedly from between my feet, with every hair on her body on end, making her look twice as large as she really was. I

had three small Skye terriers with me, which immediately gave chase, and pursued her till she took refuge in a corner of the rocks, where, perched in a kind of recess out of reach of her enemies, she stood with her hair bristled out, spitting and growling like a common cat. Having no weapon with me, I laid down my rod, cut a good-sized stick, and proceeded to dislodge her. As soon as I was within six or seven feet of the place, she sprang straight at my face over the dogs' heads. I Jad I not struck her in mid-air as she leaped at me, I should probably have received a severe wound. As it was, she fell with her back half broken among the dogs, who with my assistance dispatched her. I never saw an animal fight so desperately, or one which was so difficult to kill. If a tame cat has nine lives, a wild cat must have a dozen. Sometimes one of these animals will take up its residence at no great distance from a house, and, entering the hen-roosts and outbuildings, will carry off fowls in the most audacious manner, or even lambs. Like other vermin, the wild cat haunts the shores of lakes and rivers. 
and it is therefore easy to know where to set a trap for them. Having caught and killed one of the colony, the rest of them are sure to be taken if the body of their slain relative is left in the same place not far from their usual hunting-ground and surrounded with traps, as every wild cat passing that way will to a certainty come to it."

The wild cat ranges from the far north of Scotland, across Europe and Northern Asia, to the northern slopes of the Himalaya. It has always been known as one of the fiercest and wildest of the cats, large or small. The continual ill-temper of these creatures is remarkable. In the experience of the keepers of menageries there is no other so intractably savage. One presented to the Zoological Gardens by Lord Lilford some eight years ago still snarls and spits at any one who comes near it, even the keeper.

The food of the wild cat is grouse, mountain-hares, rabbits, small birds, and probably fish caught in the shallow waters when chance offers. It is wholly nocturnal; consequently no one ever sees it hunting for prey. Though it has long been confined to the north and nor'hwest of Scotland, it is by no means on the verge of extinction. The deer-forests are saving it to some extent, as they did the golden eagle. Grouse and hares are rather in the way when deer are being stalked; consequently the wild cat and the eagle are not trapped or shot. The limits of its present fastnesses were recently fixed by careful Scotch naturalists at the line of the Caledonian Canal. Mr. Harvie Brown, in I880, said that it only survived in Scotland north of a line running from Oban to the junction of the three counties of Perth, Forfar, and Aberdeen, and thence through Banffshire to Inverness. But the conclusion of a writer in the Edinburgh Review of July, I 898, in a very interesting article on the survival of British mammals, has been happily contradicted. He believed that it only survived in the deer-forests of Inverness and Sutherlandshire. The wild cats shown in the illustrations of these pages were caught a year later as far south as Argyllshire. The father and two kittens were all secured, practically unhurt, and purchased by Mr. Percy Leigh Pemberton for his collection of British mammals at Ashford, in Kent. This gentleman has had great success in preserving his wild cats. They, as weli as others-martens, polecats, and other small carnivora-are fed on fresh wild rabbits killed in a warren near; consequently they are in splendid condition. The old "tom" wild cat, snarling with characteristic ill-humour, was well supported by the wild and savage little kittens, which exhibited all the family temper. Shortly before the capture of these wild cats another

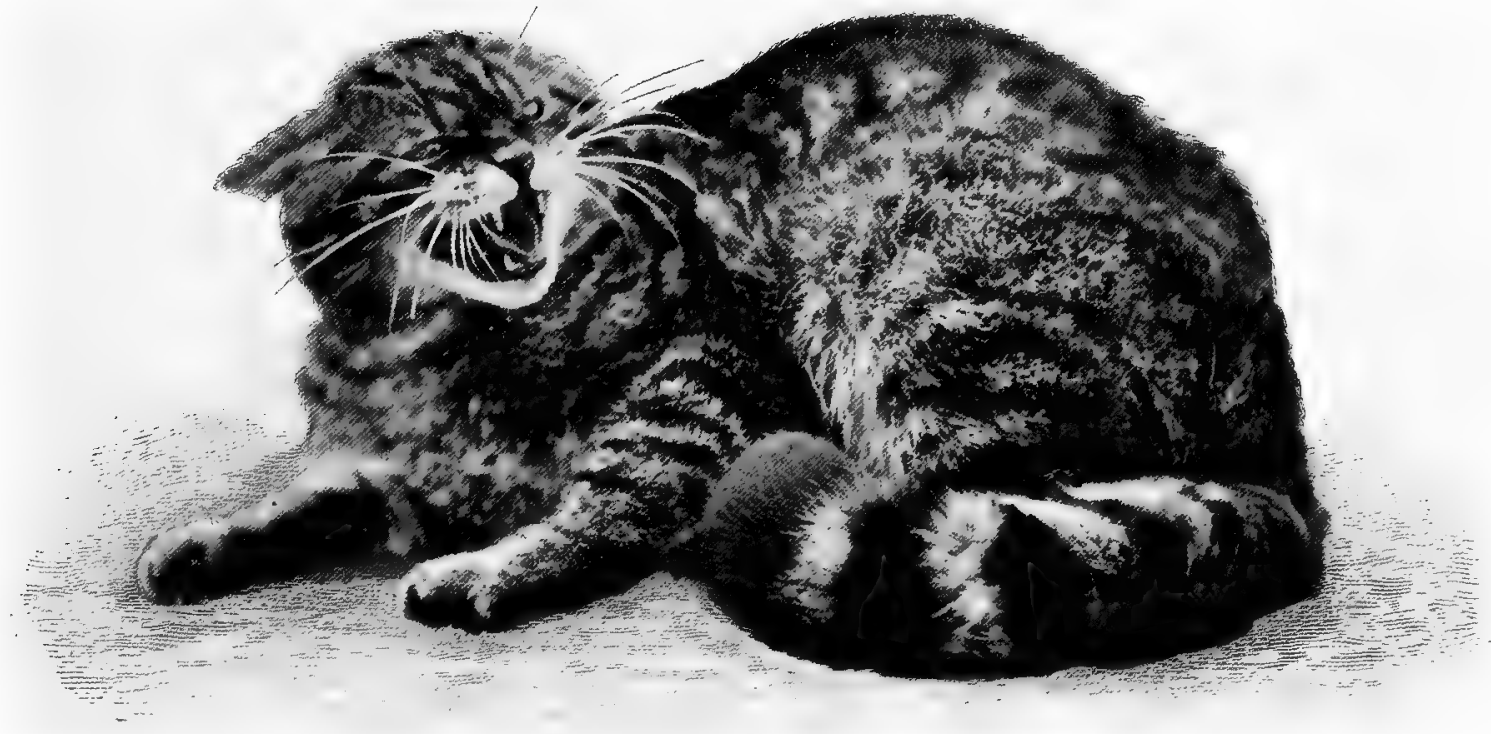

By permassion of Percy Leigh Pemberion, Esq.

EUROPEAN WILD CAT

The British representative of this species is rapidly becnming extinct. The, stecimen wowose portrait is given here zoas caught in Argyllshire 


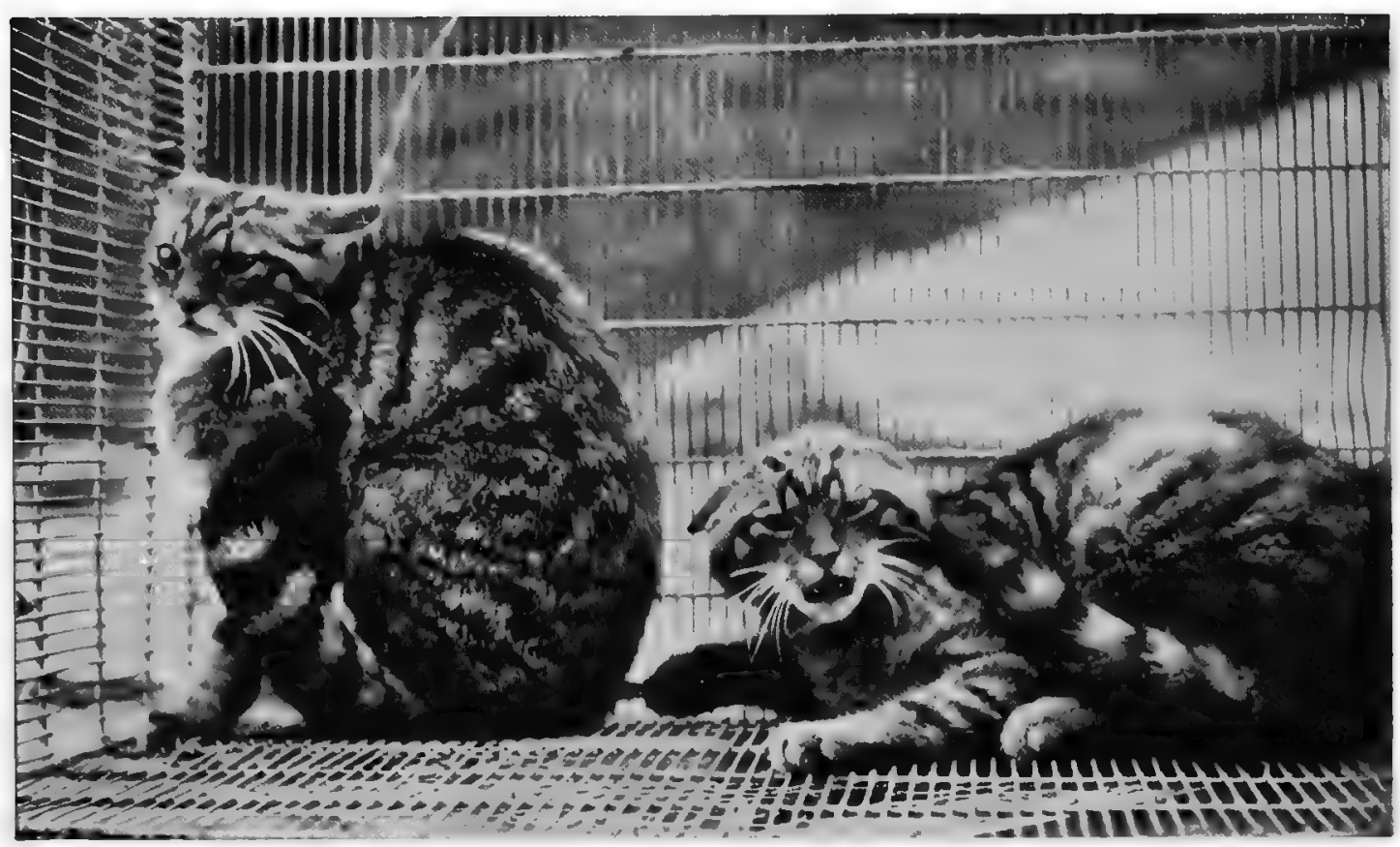

By parmissien of Percy Leigh Pemberton, Esq.

\section{SCO'TCH WILD CATS}

These wild cats, the property of Mr. P. Leigh Pemberton, though regularly fed and well treated, show their natural bad-temper in their faces

family were trapped in Aberdeenshire and brought to the Zoological Gardens. Four kittens, beautiful little savages, with bright green eyes, and uninjured, were safely taken to Regent's Park. But the quarters given them were very small and cold, and they all died. Two other full-grown wild cats brought there a few years earlier were so dreadfully injured by the abominable steel traps in which they were caught that they both died of blood-poisoning.

The real wild cats differ in their markings on the body, some being more clearly striped, while others are only brindled. But they are all alike in the squareness and thickness of head and body, and in the short tail, ringed with black, and growing larger at the tip, which ends off like a shaving-brush.

It may well be asked, Which of the many species of wild cats mentioned above is the ancestor of our domestic cats? Probably different species in different countries. The African Kaffir cat, the Indian leopard-cat, the rusty-spotted cat of India, and the European wild cat all breed with tame cats. It is therefore probable that the spotted, striped, and brindled varieties of tame cats are descended from wild species which had those markings. The so-called red tame cats are doubtless descended from the tiger-coloured wild cats. But it is a curious fact that, though the spotted gray-tabby wild varieties are the least common, that colour is most frequent in the tame species.

\section{THE LYNXES}

In the LynXes we seem to have a less specially cat-like form. They are short-tailed, high in the leg, and broad-faced. Less active than the leopards and tiger-cats, and able to live either in very hot or very cold countries, they are found from the Persian deserts to the far north of Siberia and Canada.

The Caracal is a southern, hot-country lynx. It has a longer tail than the others, but the same tufted ears. It seems a link between the lynxes and the jungle-cats. It is found in India, Palestine, Persia, and Mesopotamia. In India it was trained, like the cheeta, to catch birds, 
gazelles, and hares. The Common Lynx is probably the same animal, whether found in Norway, Russia, the Carpathians, Turkestan, China, or Tibet. The Canadian LynX is also very probably the same, with local differences of colour. The Northern Lynx is the largest feline animal left in Europe, and kills sheep and goats equally with hares and squirrels. The beautiful fur, of pale cinnamon and light gray, is much admired. In some southern districts of America we have the RED Lynx, or so-called "wild cat;" which is distinct from the lynx of Canada. The MediterRANEAN or SPANISH LynX seems likewise entitled to rank as a distinct species.

Of the lynxes the Caracals are perhaps the most interesting, from their capacity for domestication. They are found in Africa in the open desert country, whereas the Serval is found in the thick bush. In Africa it is believed to be the most savage and untamable of the Cats. That is probably because the Negro and the Kaffir never possessed the art of training animals, from the elephant downwards. In India the caracal's natural prey are the fawns of deer and antelope, pea-fowl, hares, and floricans. The caracal is the quickest with its feet of any of the Cats. One of its best-known feats is to spring up and catch birds passing over on the wing at a height of six or eight feet from the ground. A writer, in the Naturalist's Library, notes that, besides being tamed to catch deer, pea-fowl, and cranes, the caracal was used in "pigeon matches." Two caracals were backed one against the other to kill pigeons. The birds were fed on the ground, and the caracals suddenly let loose among them, to strike down as many as each could before the birds escaped. Each would sometimes strike down with its forepaws ten or a dozen pigeons. "Caracal" means in Turkish "Black Ear," in allusion to the colour of the animal's organ of hearing.

The Common Lynx is a thick-set animal, high in the leg, with a square head and very strong paws and forearms. It is found across the whole northern region of Europe and Asia. Although never known in Britain in historic times, it is still occasionally seen in parts of the Alps and in the Carpathians; it is also common in the Caucasus. It is mainly a forest animal, and very largely nocturnal; therefore it is seldom seen, and not often hunted. If any enemy approaches, the lynx lies perfectly still on some branch or rock, and generally succeeds in avoiding notice. The lynx is extremely active; it can leap great distances, and makes its attack usually

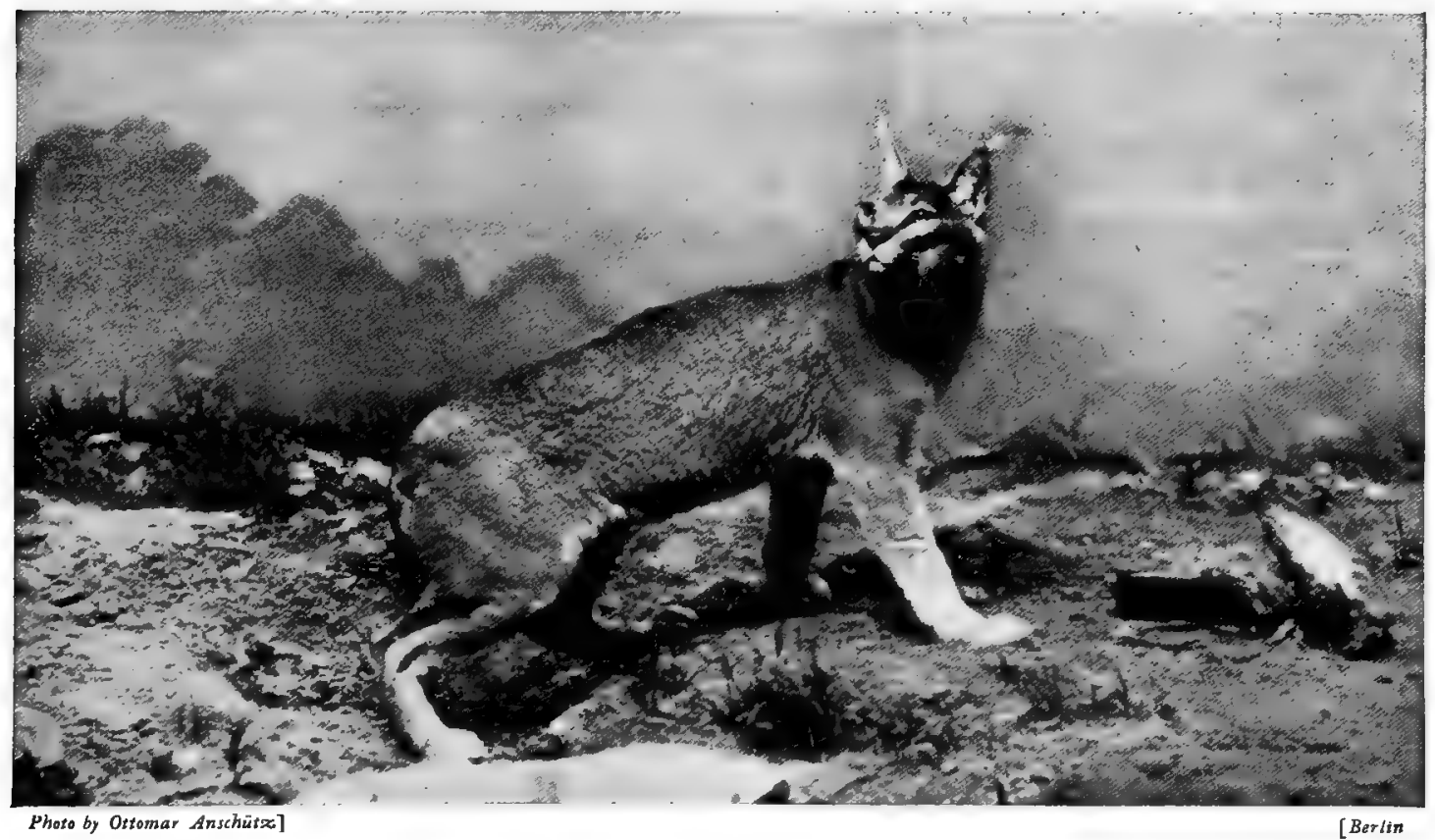

L Y N X

This animal is a uniformly coloured species common to India and Afruca 


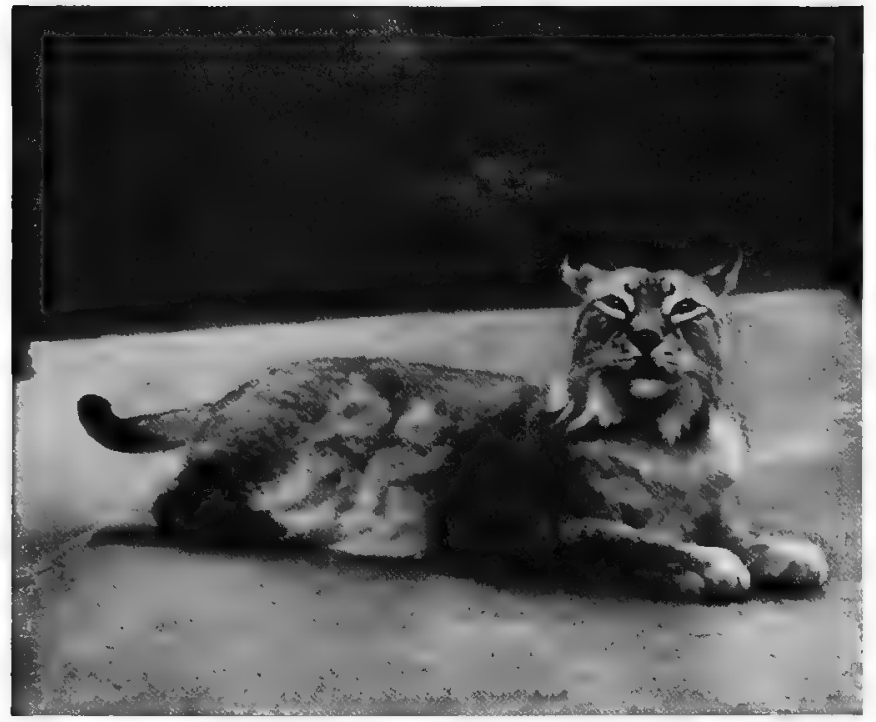

Photo by A. S. Rudland E Sons

EUROPEAN LYNX

The largest of the cat tribe left in Europe in that way. When traveling, it trots or gallops in a very dog-like fashion. Where sheep graze at large on mountains, as in the Balkans and in Greece, the lynx is a great enemy of the flocks. In Norway, where the animal is now very rare, there is a tradition that it is more mischievous than the wolf, and a high price is set on its head.

In Siberia and North Russia most of the lynx-skins taken are sold to the Chinese. The lynx-skins brought here are mainly those of the Canadian species. The fur is dyed, and used for the busbies of the officers in the hussar regiments. These skins vary much in colour, and in length and quality of fur. The price varies correspondingly. The Canadian lynx lives mainly on the wood-hares and on the woodgrouse of the North American forests. The flesh of the lynx is said to be good and tender.

Brehm says of the Siberian lynx: "It is a forest animal in the strictest sense of the word. But in Siberia it occurs only singly, and is rarely captured. Its true home is in the thickest parts in the interior of the woods, and these it probably never leaves except when scarcity of food or the calls of love tempt it to wander to tle outskirts. Both immigrants and natives hold the hunting of the lynx in high esteem. This proud cat's activity, caution and agility, and powers of defense arouse the enthusiasm of every sportsman, and both skin and flesh are valued, the latter not only by the Mongolian tribes, but also by the Russian hunters. The lynx is seldom captured in fall-traps; he often renders them useless by walking along the beam and stepping on the lever, and he usually leaps over the spring-traps in his path. So only the rifle and dogs are left."

The Red Lynx is a small American variety, the coat of which turns tawny in summer, when it much resembles a large cat. It is called in some parts of the United States the Mountain-cat. This lynx is 30 inches long in the body, with a tail 6 inches long. It is found on the eastern or Atlantic side of the continent, and by no means shuns the neighbourhood of settlements.

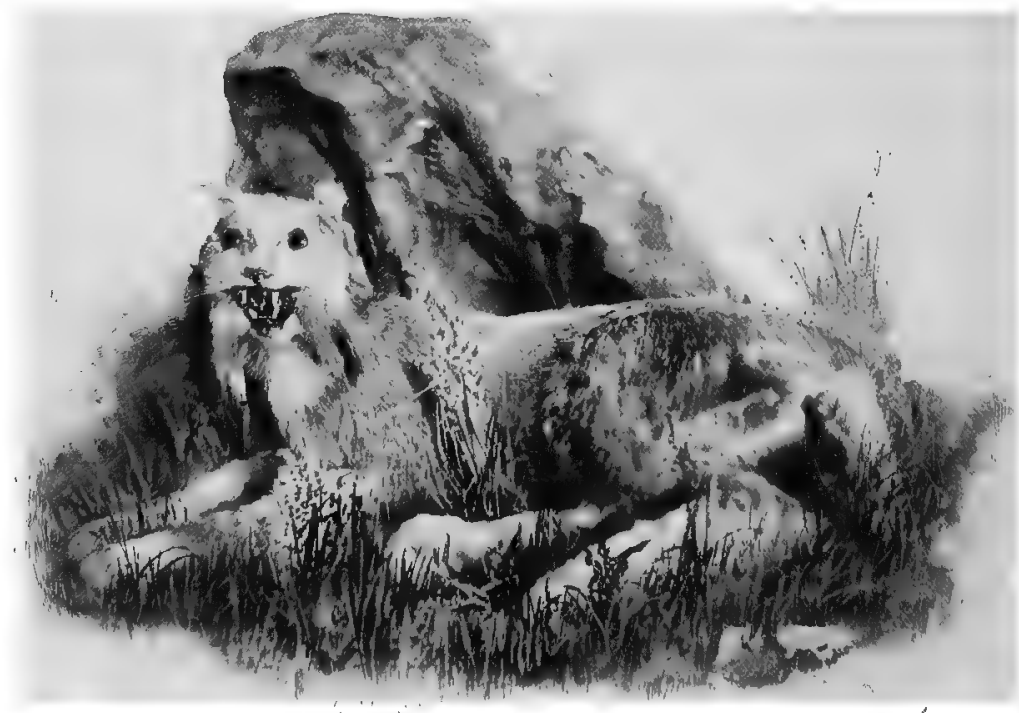

By permission of Mr. S. B. Gundy]

[Torants

CANADIAN IY NX

Griat nitmbers of these are trapped every year for the sake of their fur 


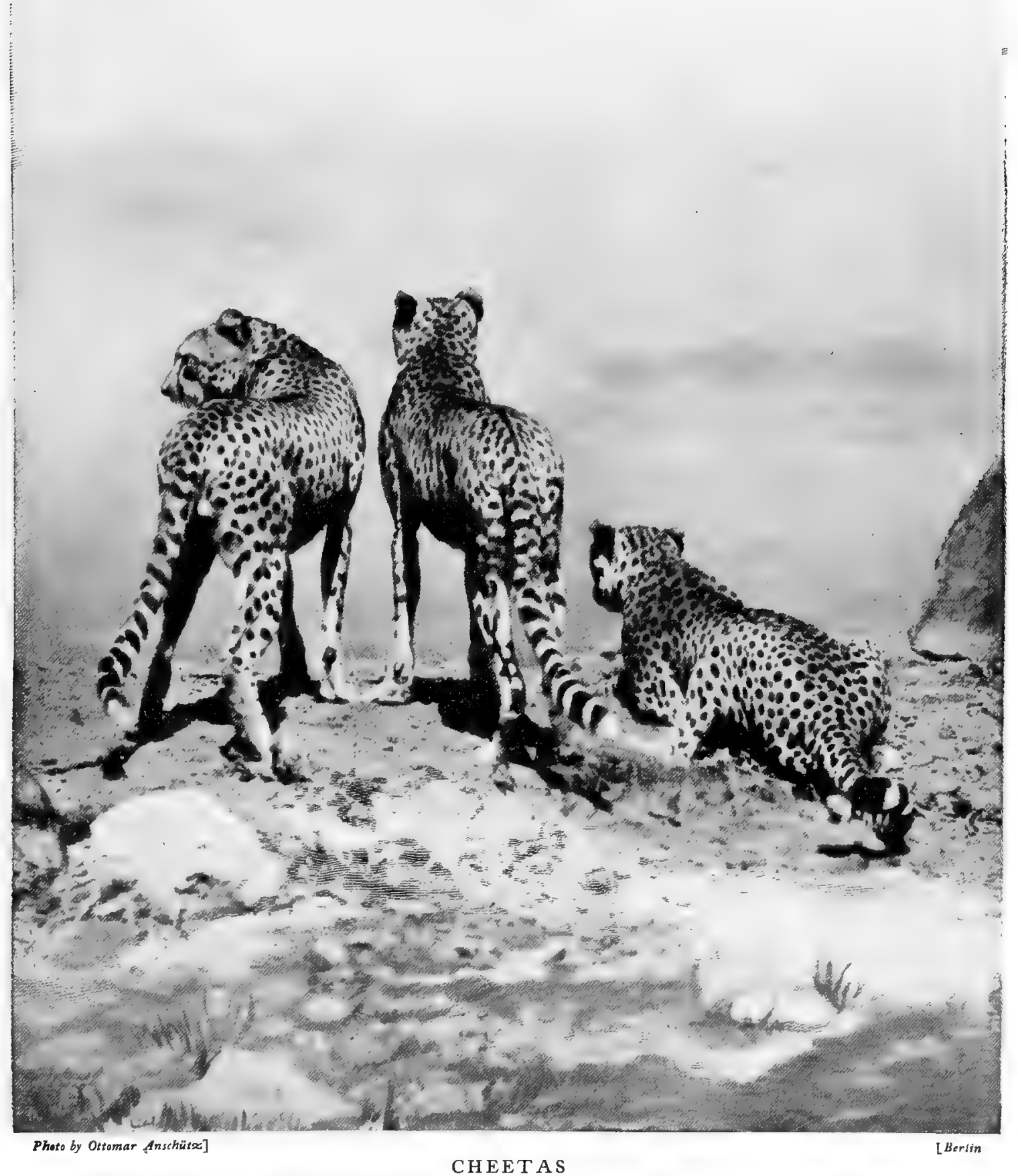

Cheetas can be distinguished at a glance from the ordinary leopards by the solid black spots "pon the back instead of the "rosettes." 
THE CHEETA

\section{The Non-Retractile-Clawed Cat}

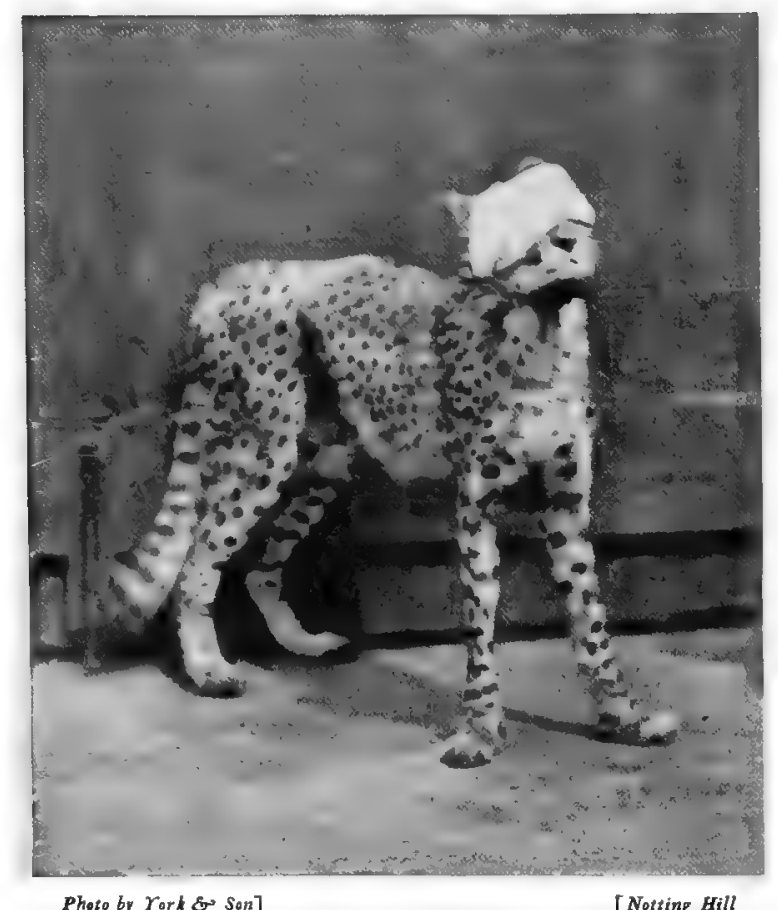

A CHEETA HOODED

The cheeta is not unhooded until fairly near his ouarry, when he is given a sight of the game, and a splendid race ensues

The Cheeta, or Hunting-leopard, is the only example of this particular group, though there was an extinct form, whose remains are found in the Siwalik Hills, in the north of India. It is a very widely dispersed animal, found in Persia, Turkestan, and the countries east of the Caspian, and in India so far as the lower part of the centre of the peninsula. It is also common in Africa, where until recent years it was found in Cape Colony and Natal. Now it is banished to the Kalahari Desert, the Northern Transvaal, and Bechuanaland.

The cheeta is more dog-like than any other cat. It stands high on the leg, and has a short, rounded head. Its fur is short and rather woolly, its feet rounded, and its claws, instead of slipping back into sheaths like a lion's, are only partly retractile.

Mr. Lockwood Kipling gives the following account of the cheeta and its keepers: "The only point where real skill comes into play in dealing with the hunting-leopard is in catching the adult animal when it has already learnt the swift, bounding onset, its one accomplishment. The young cheeta is not worth catching, for it has not yet learnt its trade, nor can it be taught in captivity. . . . There are certain trees where these great dog-cats (for they have some oddly canine characteristics) come to play and whet their claws. The hunters find such a tree, and arrange nooses of deer-sinew round it, and wait the event. The animal comes and is caught by the leg, and it is at this point that the trouble begins. It is no small achievement for two or three naked, ill-fed men to secure so fierce a capture and carry it home tied on a cart. Then his training begins. He is tied in all directions, principally from a thick rope round his loins, while a hood fitted over his head effectually blinds him. He is fastened on a strong cot-bedstead, and the keepers and their wives and families reduce him to submission by starving him and keeping him awake. His head is made to face the village street, and for an hour at a time, several times a day, his keepers make pretended rushes at him, and wave clothes, staves, and other articles in his face. $\mathrm{He}$ is talked to continually, and the women's tongues are believed to be the most effective of things to keep him awake. No created being could withstand the effects of hunger, want of sleep, and feminine scolding; and the poor cheeta becomes piteously, abjectly tame. He is taken out for a walk occasionally - if a slow crawl between four attendants, all holding hard, can be called a walkand his promenades are always through the crowded streets and bazaars, where the keepers' friends are to be found; but the people are rather pleased than otherwise to see the raja's cheetas amongst them." Later, when the creature is tamed, " the cheeta's bedstead is like that of the keeper, and leopard and man are often curled up under the same blanket! When his bedfellow is restless, the keeper lazily stretches out an arm from his end of the coat and dangles a tassel over the animal's head, which seems to soothe him. In the early morning I have seen a cheeta sitting up on his couch, a red blanket half covering him, and his tasseled red hood awry, looking exactly like an elderly gentleman in a nightcap, as he yawns with the irresolute air of one who is in doubt whether to rise or to turn in for another nap." 
This charming and accurate description shows the cheeta at home. In the field he is quite another creature. $\mathrm{He}$ is driven as near as possible to the game, and then unhooded and given a sight of them. Sir Samuel Baker thus describes a hunt in which a cheeta was used: "The chase began after the right-hand buck, which had a start of about I Io yards. It was a magnificent sight to see the extraordinary speed of pursuer and pursued. The buck flew over the level surface, followed by the cheeta, which was laying out at full stretch, with its long, thick tail brandishing in the air. They had run 200 yards, when the keeper gave the word, and away we went as fast as our horses could carry us. The horses could go over this clear ground, where no danger of a fall seemed possible. I never saw anything to equal the speed of the buck and the cheeta ; we were literally nowhere, although we were going as hard as horse-flesh could carry us; but we had a glorious view. The cheeta was gaining in the course, while the buck was exerting every muscle for life or death in its last race. Presently, after a course of about a quarter of a mile, the buck doubled like a hare, and the cheeta lost ground as it shot ahead, instead of turning quickly, being only about thirty yards in rear of the buck. Recovering itself, it turned on extra steam, and the race appeared to recommence at increased speed. The cheeta was determined to win, and at this moment the buck made another double in the hope of shaking off its terrible pursuer; but this time the cheeta ran cunning, and was aware of the former game. It turned as sharply as the buck. Gathering itself together for a final effort, it shot forward like an arrow, picked up the distance which remained between them, and in a cloud of dust we could for one moment distinguish two forms. The next instant the buck was on its back, and the cheeta's fangs were fixed like an iron vice in its throat. The course run was about 600 yards, and it was worth a special voyage to India to see that hunt."

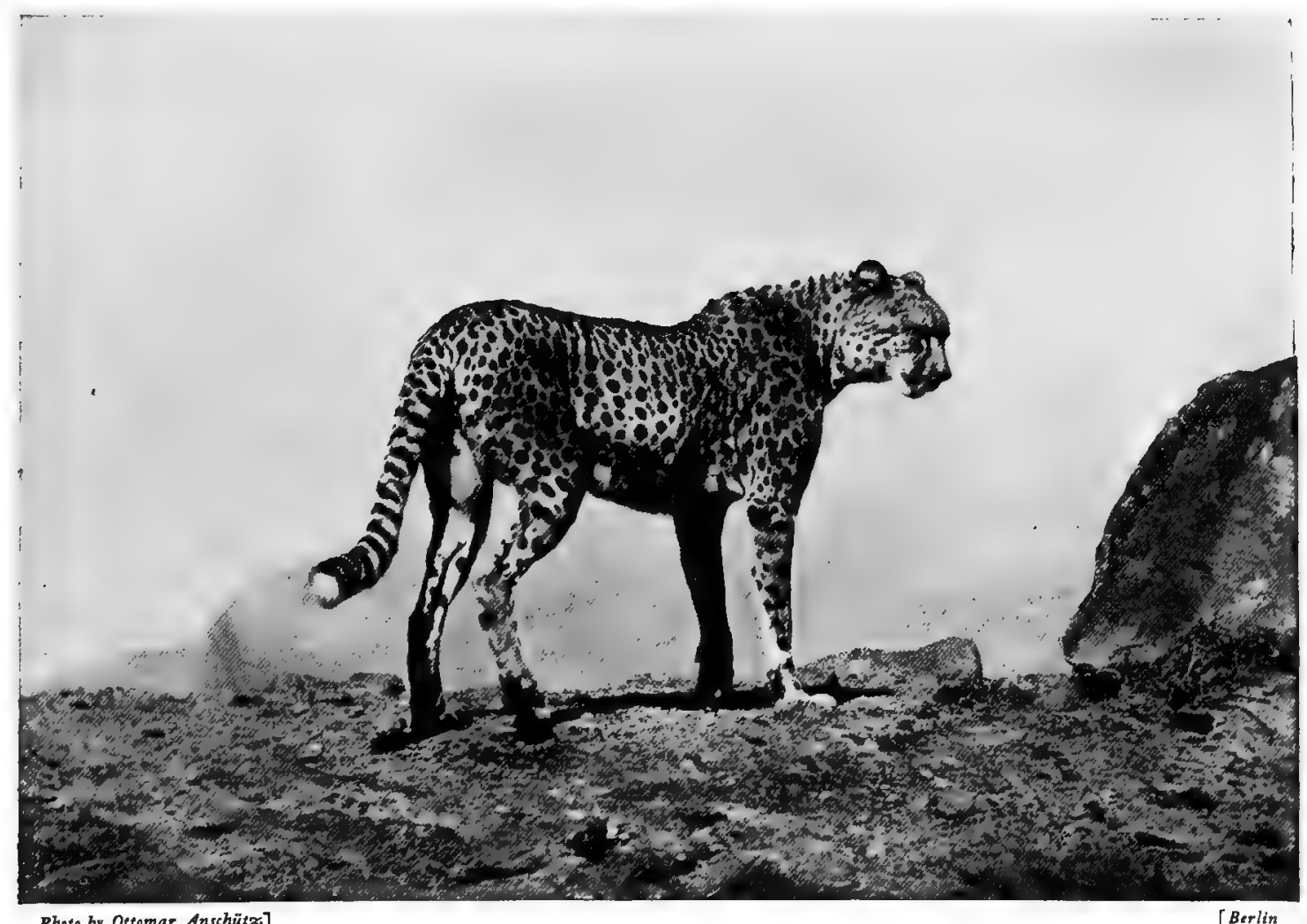

Photo by Ottomar Anschütx]

A CHEETA ON THE LOOK-OUT

Cheetas are common to Africa and India. By the native princes of the latter country they are much used for taking antelope and other game 


\section{THE DOMESTIC CAT}

By Louis WaIN

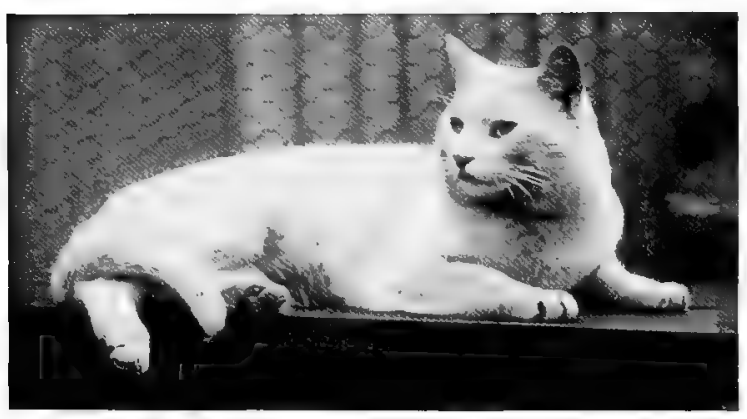

Photo by T. FaIl]

WHITE SHORT-HAIRED

Most white cats are not albinoes - that is to say, they have ordinarily coloured and not red eyes

OF the domestication of the cat we know very little, but it is recorded that a tribe of cats was trained to retrieve-i.e., to fetch and carry game. In our own time I have seen many cats fetch and carry corks and newspapers, and on one occasion pounce upon a small roach at the end of a line and place it at its owner's feet. Gamekeepers whom I have known agree that, for cunning, craftiness, and tenacity in attaining an object, the semi-wild cat of the woods shows far superior intelligence to the rest of the woodland denizens. It is quite a usual thing to hear of farm cats entering upon a snake-hunting expedition with the greatest glee, and showing remarkable readiness in pitching upon their quarry and pinning it down until secured. These farm cats are quite a race by themselves. Of decided sporting proclivities, they roam the countryside with considerable fierceness, and yet revert to the domesticity of the farmhouse fireside as though innocent of roving instincts. They are spasmodic to a degree in their mode of life, and apparently work out one mood before entering upon another. It will be remembered that this spasmodic tendency - the true feline independence, by the bye-is and has been characteristic of the cat throughout its history, and any one who has tried to overcome it has met with failure.

Watch your own cat, and you will see that he will change his sleeping-quarters periodically ; and if he can find a newspaper conveniently placed, he will prefer it to lie upon, before anything perhaps, except a cane-bottomed chair, to which all cats are very partial. If you keep a number of cats, as I do, you will find that they are very imitative, and what one gets in the habit of doing they will all do in time : for instance, one of my cats took to sitting with his front paws inside my tall hat and his body outside, and this has become a catty fashion in the family, whether the object be a hat, cap, bonnet, small basket, box, or tin. If by chance one of the cats is attacked by a dog, a peculiar cry from the aggrieved animal will immediately awaken the others out of their lethargy or sleep, and bring them fiercely to the rescue. They

are, too, particularly kind and nice to the old cat, and are tolerant only of strange baby kittens and very old cats in the garden as long as they do not interfere with the "catty" subject. The same quality obtains in Spain or Portugal, where a race of scavenging cats exists, which go about in droves or families, and are equal to climbing straight walls, big trees, chimneys, and mountainsides. Long, lanky, and thin, they are built more on the lines of a greyhound than the ordinary cat, and are more easily trained in tricks than home cats.

The TorToiseshell has long been looked upon as the national cat of Spain, and in fact that country is overrun with the breed, ranging from a dense

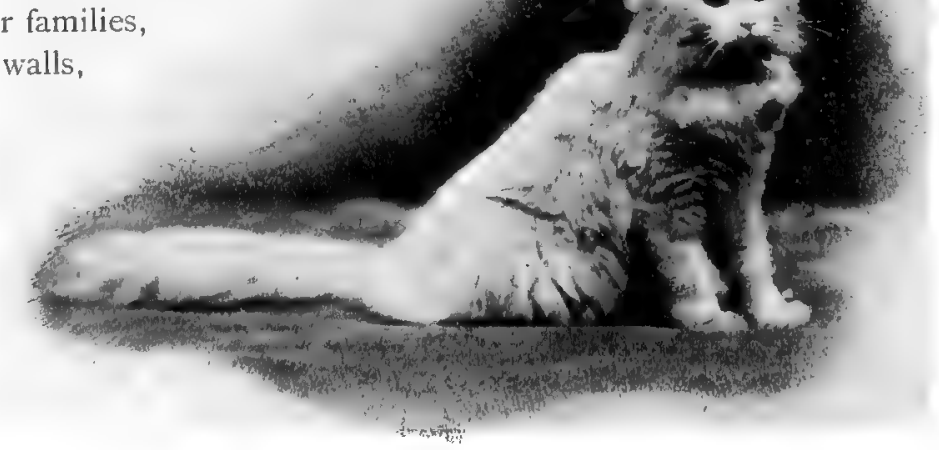

Photo by T, Fall]

LONG-HAIRED WHITE

[Baker Strent

White cats with blue eyes are genterally deaf, or at all events hard of hearing 


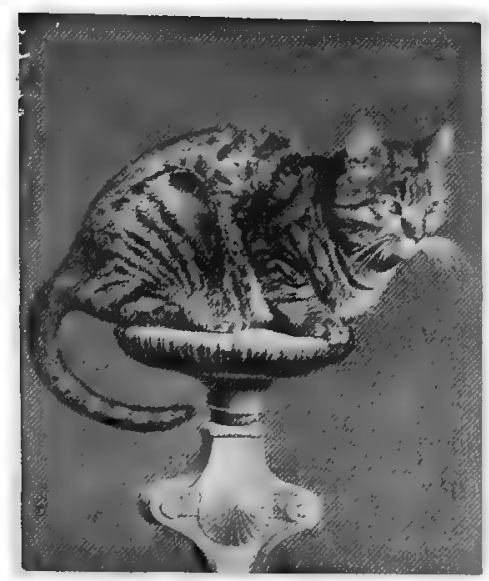

Photo by Fratelli Alinari, Florence

MACKEREL-MARKED TABBY

Tabbies are probably the best known and the commonest cats

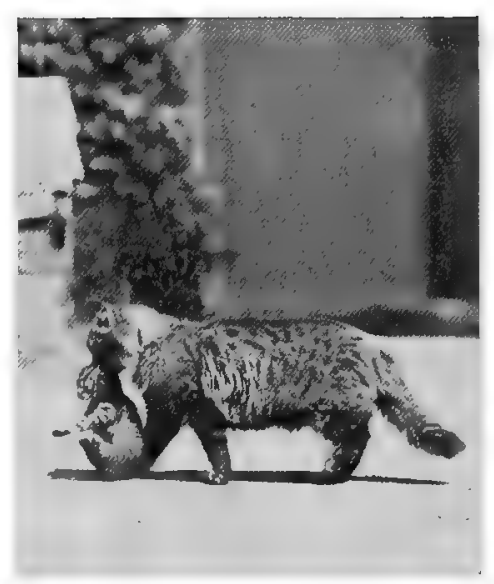

Photo by L. Medland, F.Z.S., North Finchley CAT CARRYING KITTEN $A$ unique photograph, showing the way in which the cat carries its young

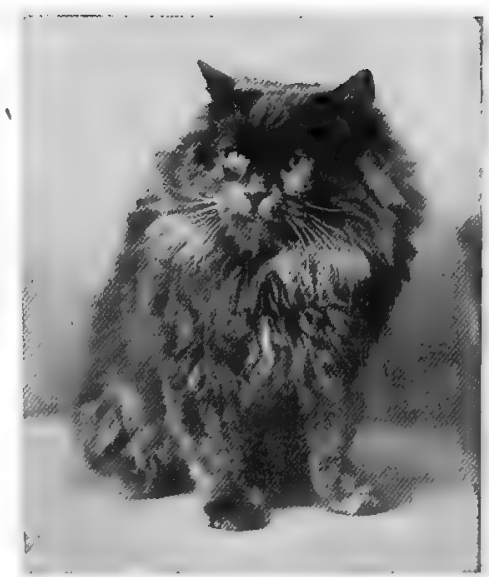

Photo by E. Landor, Ealing

BLUE LONG-HAIRED, OR PERSIAN

Persian or long-haired cats are of various colours; this is one of the least common

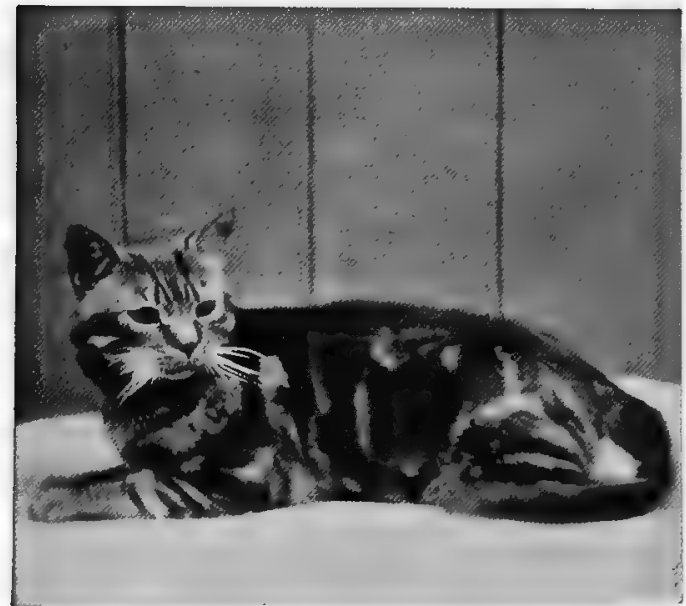

By permission of Lady Alexander ORANGE TABBY A champion winner of 90 first prizes

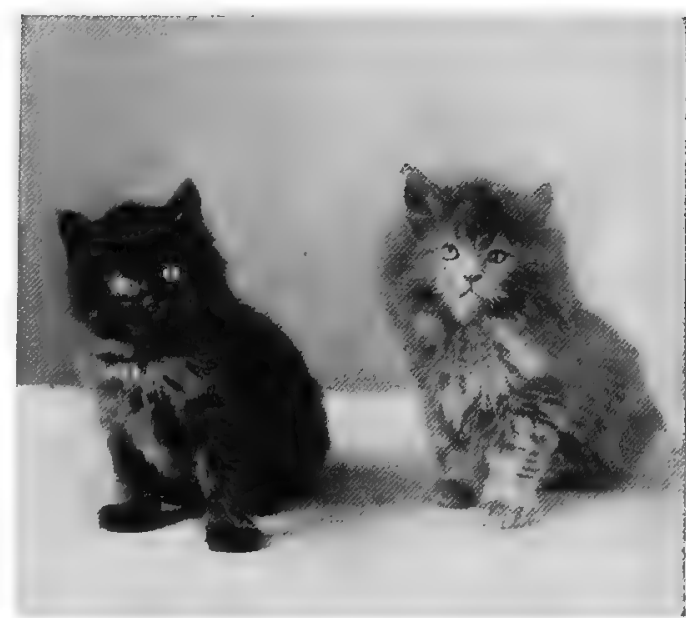

Photo by E. Landor, Ealing

SMOKE AND BLUE LONG-HAIRED

Two pretty and valuable Persian kittens

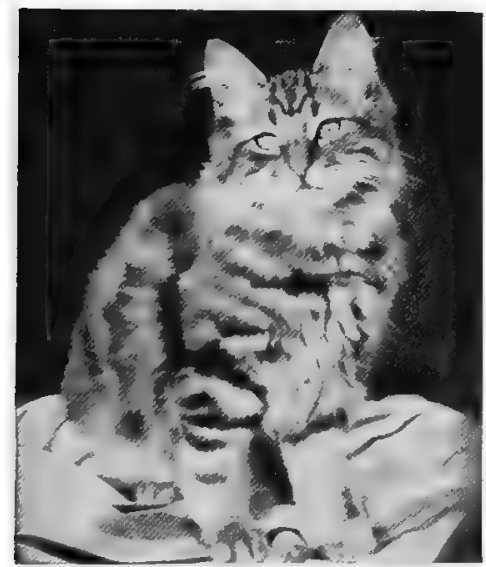

Photo by E. Landor, Ealing

IONG-HAIRED TABBY $A$ pretty pose

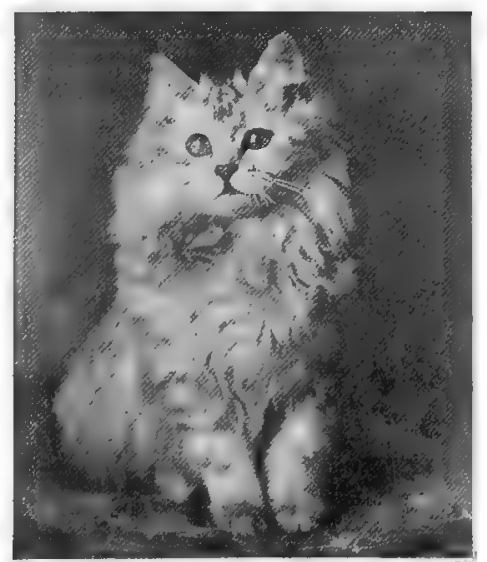

Photo by E. Landor, Ealing SILVER PERSIAN $A$ handsome specimen

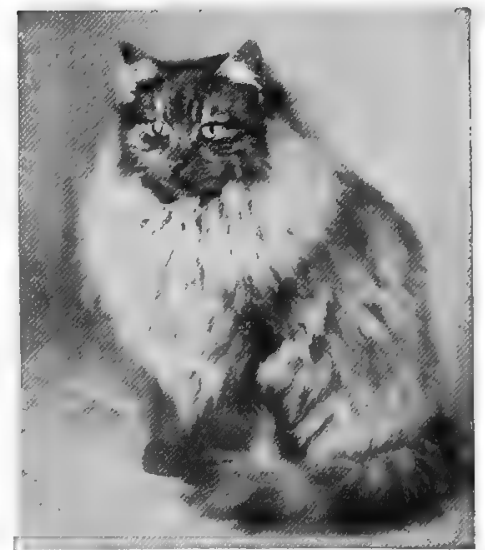

Photo by E. Landor, Ealing

SMOKE LONG-HAIRED, OR PERSIAN

A new breed 
black and brown to lighter shades of orange brown and white. The pure tortoiseshell might be called a black and tan, with no white, streaked like a tortoiseshell comb if possible, and with wonderful amber eyes. It is characteristic of their intelligence that they will invariably find their way home, and will even bring that mysterious instinct to bear which guides them back long distances to the place of their birth; and, with regard to this cat, the stories of almost impossible journeys made are not one bit exaggerated. The tomcats of this breed are very rare in England; I myself have only known of the existence of six in fifteen years, and of these but three are recorded in the catalogues of the cat shows.

The BLACK CAT has many of the characteristics of the tortoiseshell, but is essentially a town cat, and is wont to dream his life away in shady corners, in

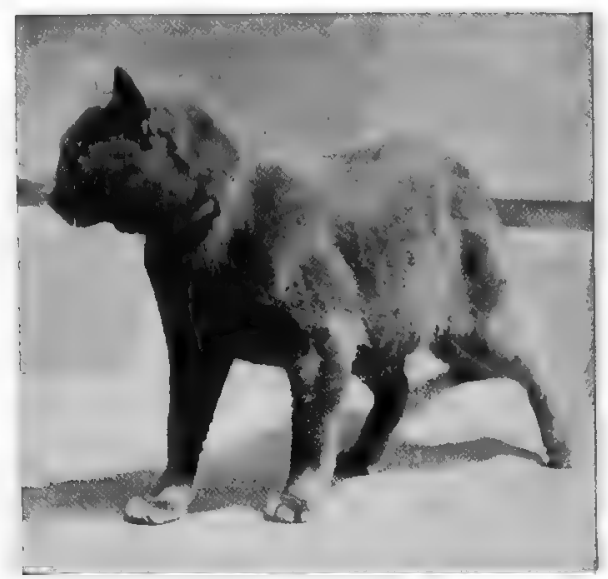

SH ORT-HAIRED BLUE

This champion cat belongs to Lady Alexander, by whose kind permission it is here reproduced underground cellars, in theatres, and in all places where he can, in fact, retire to monastic quiet. The black cat of St. Clement Danes Church was one of the remarkable cats of London. It was his wont to climb on to the top of the organ-pipes and enjoy an occasional musical concert alone. A christening or a wedding was his pride; and many people can vouch for a lucky wedding who had the good-fortune to be patronised by the black cat of St. Clement Danes, which walked solemnly down the aisle of the church in front of the happy couples.

My old pet Peter was a black-and-white cat, and, like most of his kind, was one of the most remarkable cats for intelligence I have ever known. A recital of his accomplishments would, however, have very few believers - a fact I find existing in regard to all really intelligent cats. There are so many cats of an opposite character, and people will rarely take more than a momentary trouble to win the finer nature of an animal into existence. Suffice it to say, that Peter would lie and die, sit up with spectacles on his nose and with a post-card between his paws -a trick I have taught many people's cats to do. He would also mew silent meows when bid, and wait at the door for my home-coming. For a long time, too, it was customary to hear weird footfalls at night outside the bedroom doors, and visitors to the house were a little more superstitious as to their cause than we were ourselves. We set a watch upon the supposed ghost, but sudden opening of the doors discovered only the mystic form of Peter sitting purring on the stairs. He was, however, ultimately caught in the act of lifting the corner of the doorrug and letting it fall back in its place, and he had grown quite expert in his method of raising

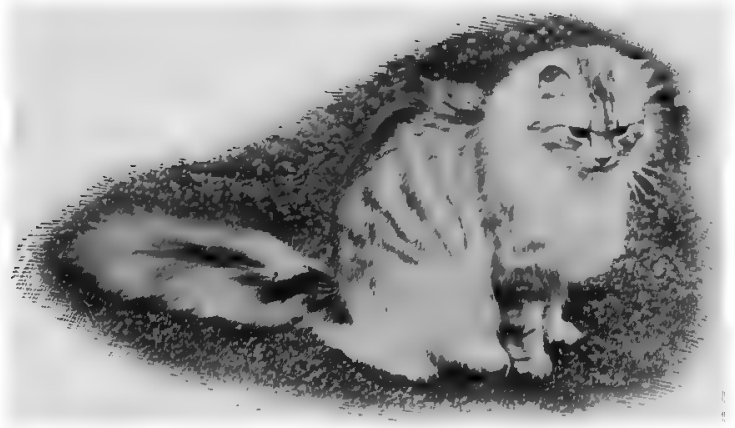

Phoso by T, Fall]

SILVER TABB Y $A$ beautiful wariety of a typical cat and dropping it at regular intervals until he heard that his signals had produced the required effect, and the door was opened to admit him.

White Cats I might call musical cats, for it is quite characteristic of the albinoes that noises rarely startle them out of their simpering, loving moods. The scraping of a violin, which will scare an ordinary cat out of its senses, or the thumping of a piano, which would terrorise even strong-nerved cats, would only incite a white cat to a happier mood. Certainly all white cats are somewhat deaf, or lack acute quality of senses; but this failing rather softens the feline nature than becomes dominant as a weakness. 


\section{THE CAT TRIBE}

The nearest to perfection perhaps, and yet at the same time extremely soft and finely made, is the Blue CAT, rare in England as an English cat, but common in most other countries, and called in America the Maltese Cat-for fashion's sake probably, since it is too widely distributed there to be localised as of foreign origin. It is out in the mining districts and agricultural quarters, right away from the beaten tracks of humanity, where the most wonderful breeds of cats

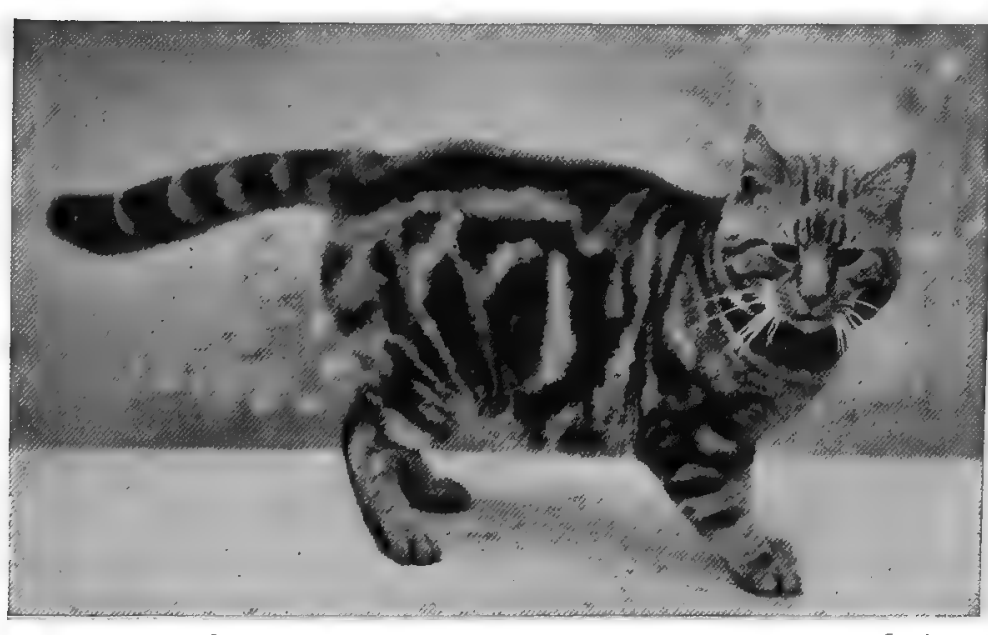

Photo by E. Landor]

SHORT-HAIRED TABBY

This is perhaps the most famous cat now living. It has won no less than 200 prizes develop in America; and

caravan showmen have told me that at one time it was quite a business for them to carry cats into these wildernesses, and sell them to rough, hardy miners, who dealt out death to each other without hesitation in a quarrel, but who softened to the appeal of an animal which reminded them of homelier times.

One man told me that upon one occasion he sold eight cats at an isolated mining township in Colorado, and some six days' journey farther on he was caught up by a man on horseback from the township, who had ridden hard to overtake the menagerie caravan, with the news that one of the cats had climbed a monster pine-tree, and that all the other cats had followed in his wake; food and drink had been placed in plenty at the foot of the tree, but that the cats had been starving, frightened out of their senses, for three days, and despite all attempts to reach them they had only climbed higher and higher out of reach into the uppermost and most

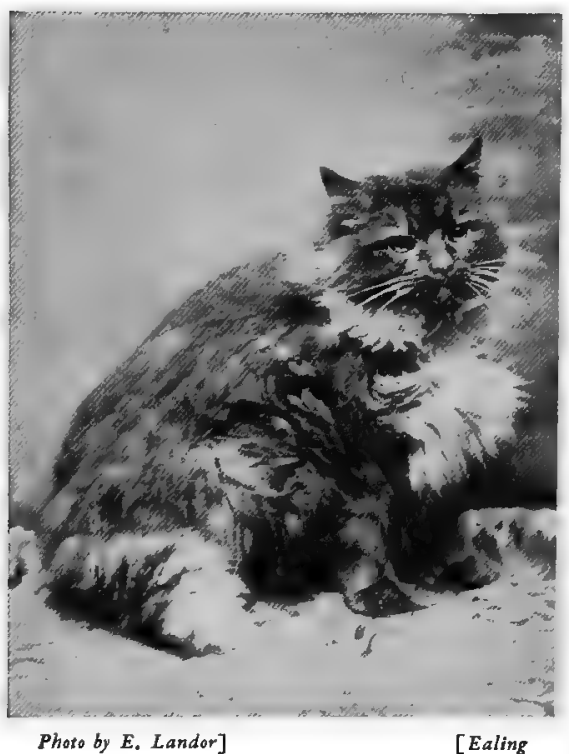

LONG-HAIRED ORANGE

A good. specimen of this variety is always large and finely furred dangerous branches of the pine. The showman hastened with his guide across country to the township, only to find that in the interval one bright specimen of a man belonging to the village had suggested felling the tree and so rescuing the cats from the pangs of absolute starvation, should they survive the ordeal. A dynamite cartridge had been used to blast the roots of the pine, and a rope attached to its trunk had done the rest and brought the monster tree to earth, only, however, at the expense of all the cats, for not one survived the tremendous fall and shaking. A sad and tearful procession followed the remains of the cats to their hastily dug grave, and thereafter a bull mastiff took the place of the cats in the township, an animal more in character with the lives of its inhabitants.

Analogous to this case of the traveling menageries, we have the great variety of blues, silvers, and whites which are characteristic of Russia. There is a vast tableland of many thousands of miles in extent, intersected by caravan routes to all the old countries of the ancients, and it is not astonishing to hear of attempts being made 


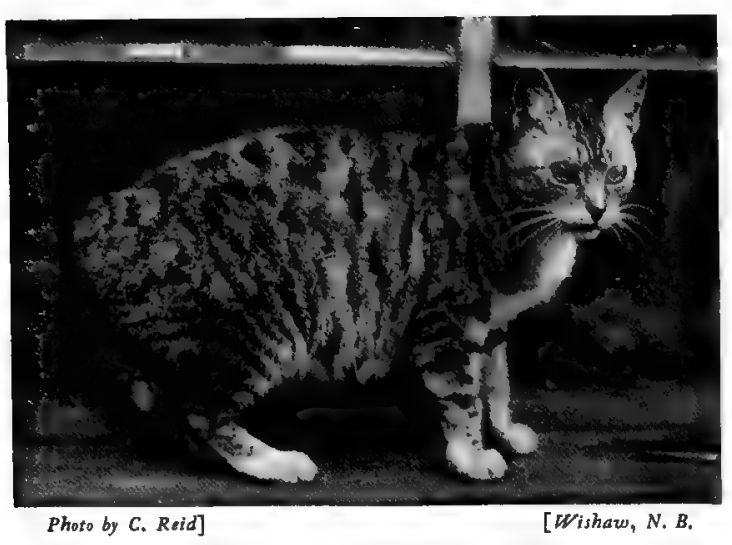

M A N X

These tailless cats are well known; they were formerly called "Cornwall cats." Note the length of the hind legs, which is one of the characteristics of this variety of the domestic cat

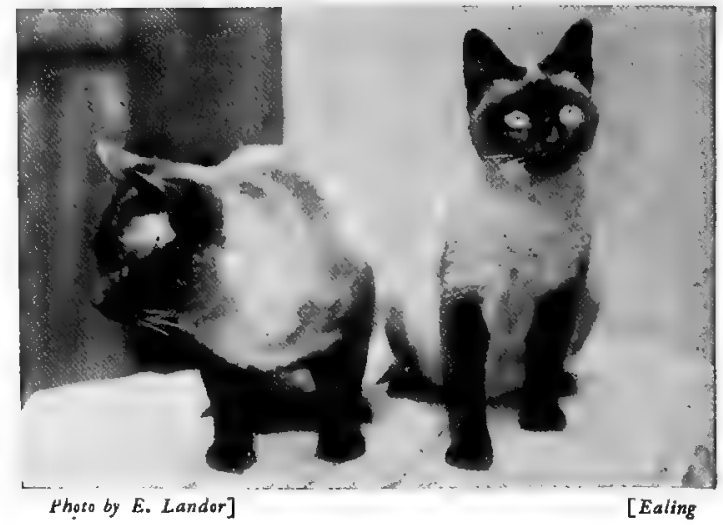

SI A MESE

These strikingly coloured cats are now fairly numerous, but command high prices. They have white kittens, which subsequently become coloured

to steal the wonderful cats of Persia, China, and Northern India, as well as those of the many dependent and independent tribes which bound the Russian kingdom. But it is a remarkable fact that none but the blues can live in the attenuated atmosphere of the higher mountainous districts through which they are taken before arriving in Russian territory. It is no uncommon thing to find a wonderful complexity of blue cats shading to silver and white in most Russian villages, or blue cats of remarkable beauty; but with a dash of tably-marking running through their coats. Their life, too, is lived at the two extremes. In the short Russian summer they roam the woodlands, pestered by a hundred poisonous insects; in the winter they are imprisoned within the four walls of a snow-covered cottage, and are bound down prisoners to domesticity till the thaw sets in again. Many of the beautiful furs which come to us from Russia are really the skins of these cats, the preparation of which for market has grown into a large and thriving industry. The country about Kronstadt, in the Southern Carpathian Mountains of Austria, is famous for its finely developed animals; and here, too, has grown up a colony of sable-coloured cats, said to be of Turkish origin, where the pariahs take the place of cats.

The TABBY is remarkable to us in that it is characteristic of our own country, and no other colour seems to have been popular until our own times. If you ask any one which breed of cat is the real domestic cat, you will be told the tabby, probably because it is so well known to all. The complexity of the tabby is really remarkable, and for shape and variety of colouring it has no equal in any other tribe of cat. It has comprised in its nature all the really great qualities of the feline, and all its worst attributes. You can truthfully say of one of its

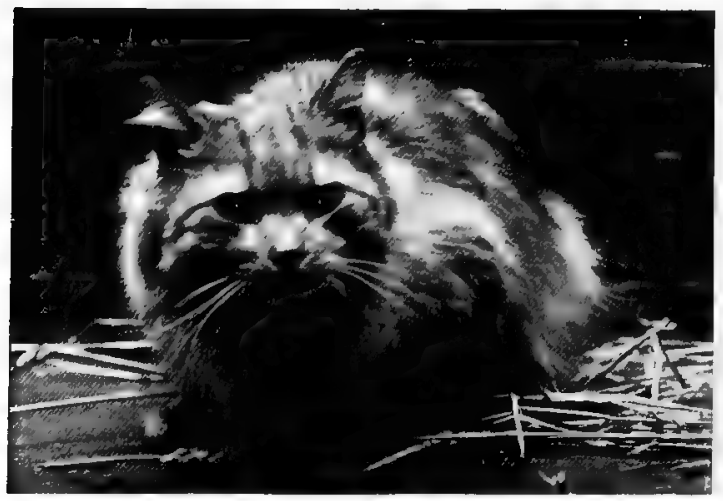

BLUE LONG-HAIRED, OR PERSIAN This cat belonged to Queen Victoria

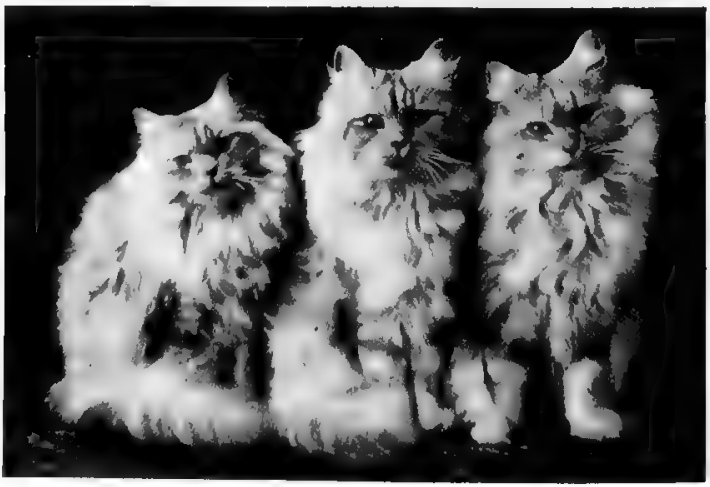

SILVER PERSIANS

Three of Mrs. Champion's celebrated cats 


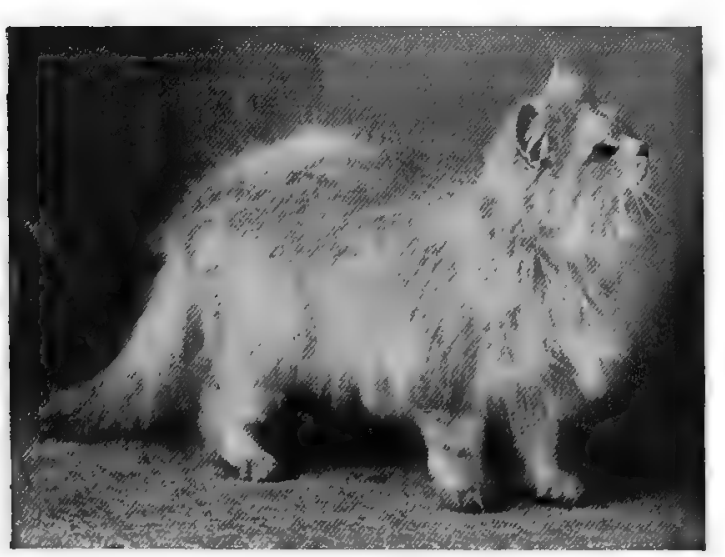

Photo by $E$, Landor]

LONG-HAIRED CHINCHILLA

Note the beautiful "Anffiness" of this cat's fur

specimens that it attaches itself to the individual, while of another in the same litter you will get an element of wildness. A third of the same parents will sober down to the house, but take only a passing notice of people. You can teach it anything if it is tractable, make it follow like a dog, come to whistle, but it will have its independence.

The SAND-Coloured CAT, with a wholecoloured coat like the rabbit, which we know as the Abyssinian or Bunny Cat, is a strong African type. On the Gold Coast it comes down from the inland country with its ears all bitten and torn away in its fights with rivals. It has been acclimatised in England, and Devonshire and Cornwall have both established a new and distinct tribe out of its parentage. The MANX CAT is nearly allied to it, and a hundred years ago the tailless cat was called the Cornwall Cat, not the Manx.

Siam sends us a regal aminal in the SiAmese Royal $\mathrm{CAT}_{\mathrm{A}}$; it has a brown face, legs, and tail, a cream-coloured body, and mauve or blue eyes. The Siamese take great care of their cats, for it is believed that the souls of the departed are transmitted into the bodies of animals, and the cat is a favourite of their creed; consequently the cats are highly cultivated and intelligent, and can think out ways and means to attain an end.

I have tried for years to trace the origin of the Long-HAIRED or PERsian Cats, but I cannot find that they were known to antiquity, and even the records of later times only mention the ShorT-HAIRED. European literature does not give us an insight into the subject; and unless Chinese history holds some hidden lights in its records, we are thrown back upon the myths of Persia to account for the wonderful modern contribution of the long-haired cat, which is gradually breeding out into as many varieties as the shorthaired, with this difference-that greater care and trouble are taken over the long-haired, and they will, as a breed, probably soon surpass the short-haired for intelligence and culture.

One variety is quite new and distinctive-the SMOKE LoNGHAIRED, whose dark brown or black surface-coat, blown aside, shows an under coat of blue and silver, with a light brown frill round its neck. All the other long-haired cats can pair with the short-haired for colouring and marking, but I have not yet seen a BunNy Long-

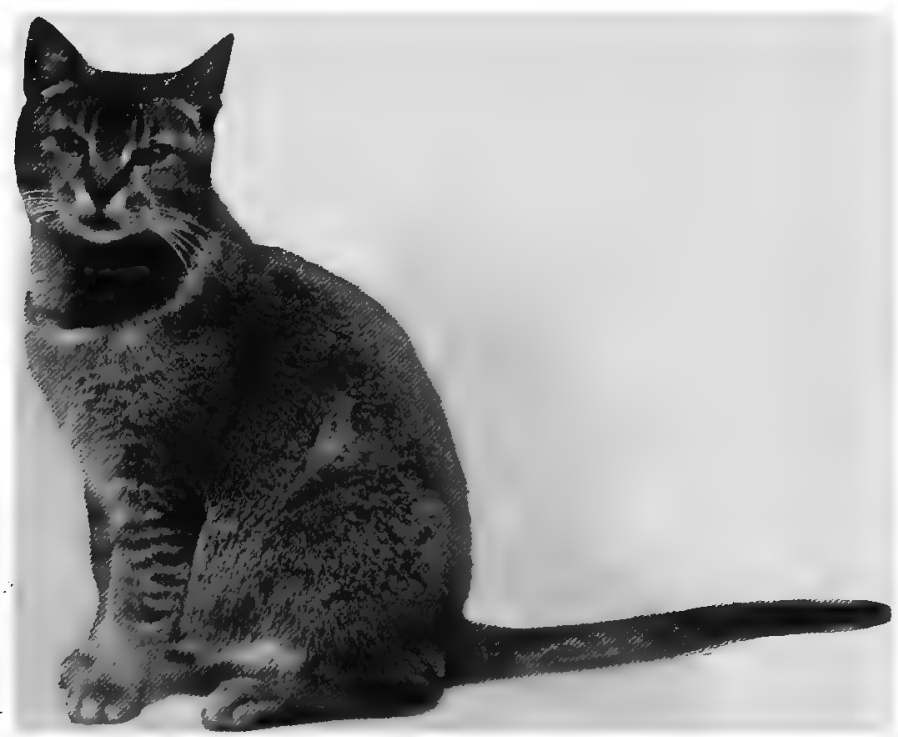

Photo by H. Trevor fessop

THE "BUN" OR "TICKED" SHORT-HAIRED CAT This is one of the rarest of cats. It belongs to Miss $K$. Maud Bennett who has kindly had it photographed for this work HAIRED. 


\section{H A P'TER I I I}

\section{THE FOSSA, CIVETS, AND ICHNEUMONS}

THE FOSSA

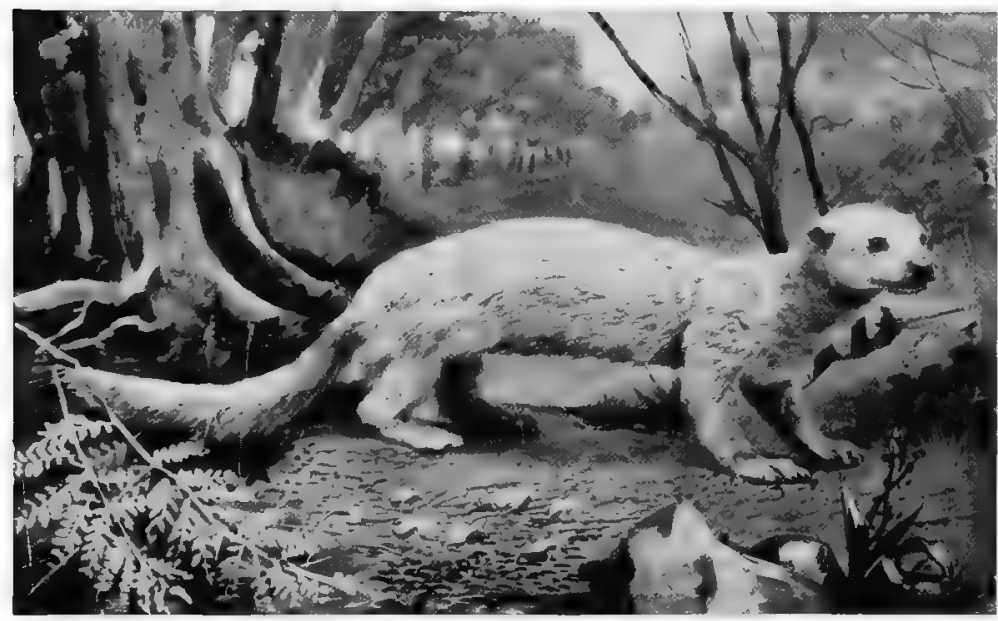

Photo by A. S. Rudland Es Sons

FOSSA

The only feline animal of Madagascar
T $\mathrm{N}$ the Fossa Madagascar possesses an altogether peculiar animal. It is a very slender, active creature, with all its proportions much elongated. It is of a bright bay uniform colour, with thick fur, and has sharp retractile claws. It has been described as the natural connecting link between the Civets and the Cats, anatomically speaking. Thus it has, retractile claws, but does not walk on its toes, like cats, but on the soles of its feet (the hind pair of which is quite naked), like a civet. Very few have been brought

to captivity; indeed, the first time that one was exhibited in the Zoological Gardens was only ten years ago. Formerly stories were told of its ferocity, which was compared to that of the tiger. These tales were naturally the subject of ridicule. The fossa usually attains a length of about 5 feet from snout to tail, and is the largest of the carnivora of Madagascar. A fine young specimen lately brought to London, and in the Zoological Gardens at the time of writing, is now probably full grown. It is about the same length and height as a large ocelot, but with a far longer tail, and is more slenderly built. The extreme activity of the fossa no doubt renders it a very formidable foe to other and weaker creatures. It has been described by a recent writer as being entirely nocturnal, and preying mainly on the lemurs and birds which haunt the forests of Madagascar. The animal kept at the Zoological Gardens has become fairly tame. It is fed mainly on chickens' heads and other refuse from poultererc' shops. Apparently it has no voice of any kind. It neither growls, roars, nor mews, though, when irritated or frightened, it gives a kind of hiss like a cat.

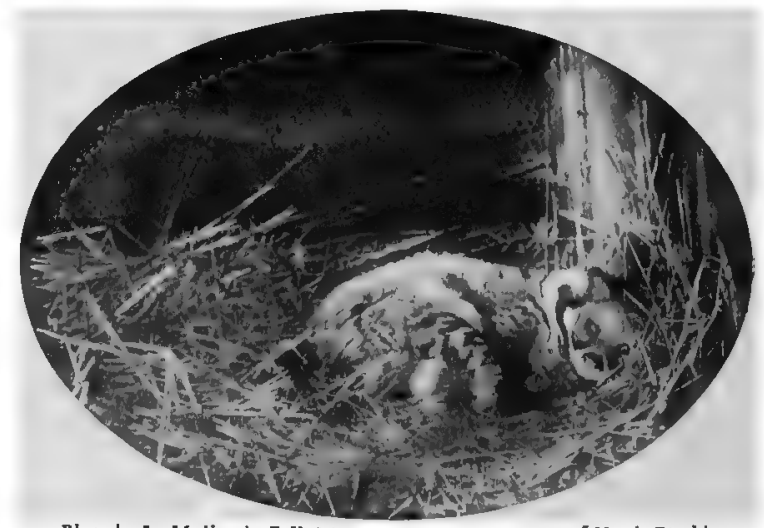

Photo by L. Modland, F.Z.S.J LARGE INDIAN CIVET

Civets are nocturnal in their habits. That shown here has juss awakened in broad daylight 
THE CIVETS AND GENETS

The Civets are the first marked deviation from the Cat Family. Their bodies are elongated, their legs short, their claws only partially retractile. Some of them have glands holding a strong scent, much esteemed in old days in Europe, when "The Civet Cat" was a common inn-sign even in England. The civets are generally beautifully marked with black stripes and bands on gray. But none of them grow to any large size, and the family has never had the importance of those which contain the large carnivora, like the true cats or bears. Many of the tribe and its connections are domesticated. Some scholars have maintained that the cat of the ancient Greeks was one of then-the common genet. The fact is that both this and the domestic cat were kept by the ancients; and the genet is still used as a cat by the peasants of Greece and Southern Italy.

The African Civet and Indian Civet are large species. The former is common almost throughout Africa. Neither of them seems to climb trees, but they find abundance of food by catching small ground-dwelling animals and birds. They are good swimmers. The Indian civet has a handsome skin, of a beautiful gray ground-colour, with black collar and markings. It is from these civets that the civet-scent is obtained. They are kept in cages for this purpose, and the secretion is scooped from the glands with a wooden spoon. They produce three or four kittens in May or June. Several other species very little differing from these are known as the Malabar, Javan, and Burmese Civets.

The RASSE is smaller, has no erectile crest, and its geographical distribution extends from Africa to the Far East. It is commonly kept as a domestic pet. Like all the civets, it will eat fruit and vegetables.

The GENETS, though resembling the civets, have no scent-pouch. They are African creatures, but are found in Italy, Spain, and Greece, and in Palestine, and even in the south of France. Beautifully spotted or striped, they are even longer and lower than the civet-cats, and steal through the grass like weasels.

The Common Genet is black and gray, the latter being the ground-colour. The tail is very long, the length being about 15 inches, while that of the body and head is only I9 inches. Small rodents, snakes, eggs and birds are its principal food. It is kept in Southern Europe for

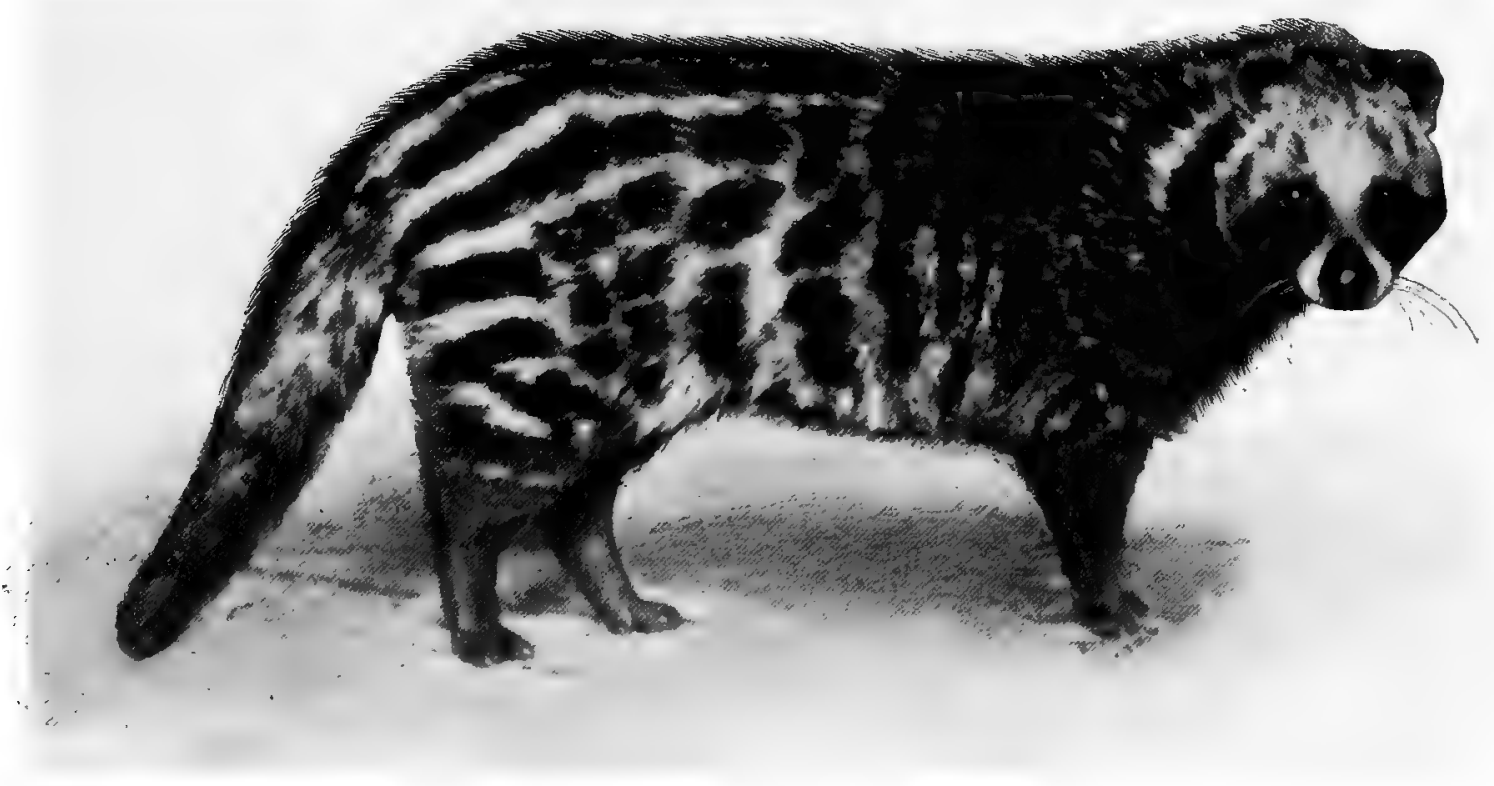

Photo by A. S. Rudland EN Sons

AFRICAN CIVET

This is one of the largest of the Civet Tribe. The perfume known as "civet" ts obtained from it 


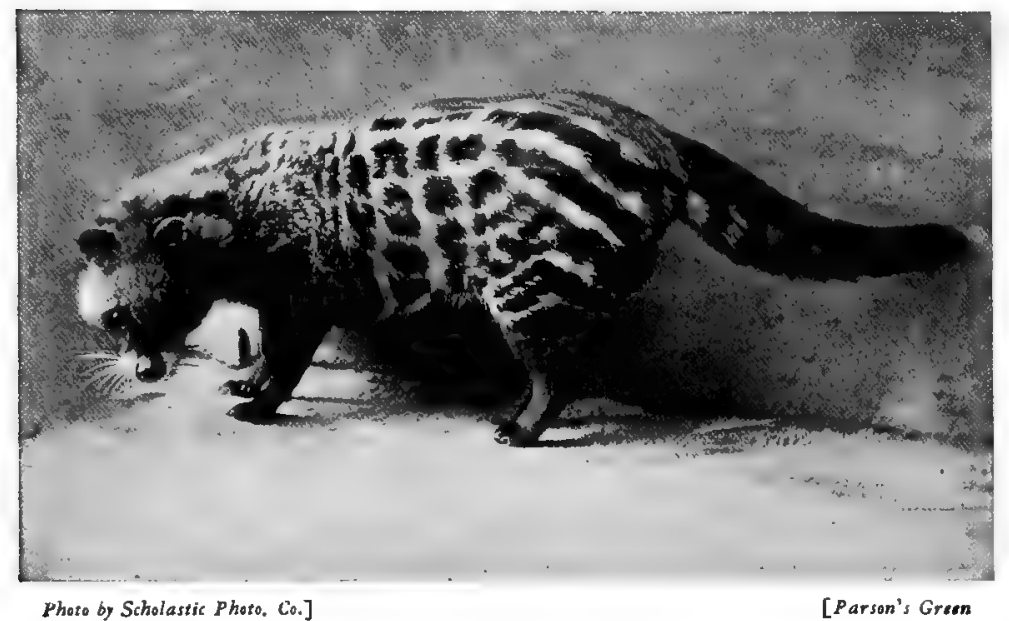

AFRICAN CIVET

This photograph shows the finely murked fur of the species and the front view of the head

killing rats. Several other very similar forms are found in Africa. The hiresence of such a very Oriental-looking animal in Europe is something of a surprise, though many persons forget that our South European animals are very like those of Africa and the East. The porcupine, which is common in Italy and Spain, and the lynx and Barbary ape are instances. A tame genet kept by an acquaintance of the writer in Italy was absolutely domesticated like a tame mongoose. It had very pretty fur, gray, marbled and spotted with black, and no disagreeable odour, except a scent of musk. It was a most active little creature, full of curiosity, and always anxious to explore not only every room, but every cupboard and drawer in the house. Perhaps this was due to its keenness in hunting mice, a sport of which it never tired. It did not play with the mice when caught as a cat does, but ate them at once.

The Linsangs, an allied group, are met with in the East, from India to Borneo and Java. They are more slender than the genets, and more arboreal. Of the NePalese Linsang Hodgson writes: "This animal is equally at home on trees and on the ground. It breeds and dwells in the hollows of decaying trees. It is not gregarious, and preys mainly on living animals." A tame female owned by him is stated to have been wonderfully docile and tractable, very sensitive to cold, and very fond of being petted. There is an allied West African species.

The Palm-Civets and Hemigales still further increase this numerous tribe. Slight differences of skull, of the markings of the tail, which may only have rings on the base, and of the foot and tail, are the naturalist's guide to their separation from the other civets; HARDWICKE's Hemigale has more zebra-like markings. Borneo, Africa, India, and the Himalaya all produce these active little carnivora; but the typical palm-civets are Oriental They are sometimes known as Toddy-cats, because they drink the toddy from the jars fastened to catch the juice. The groves of cocoanut-palm are their favourite haunts; but they will make a home in holes in the thatched roofs of houses, and even in the midst of cities. There are many species in the group.

The Binturong is another omnivorous, treehaunting animal allied to the civets; but it has a prehensile tail, which few other mammals of the Old World possess. It is a blunt-nosed, heavy animal, sometimes called the Bear-cat. Very little is known of its habits. It is found from the Eastern Himalaya to Java.

The last of the Civet Family is Bennetr's Civet, the only instance of a cat-like animal with partly webbed feet. Found in the Malay Peninsula and in

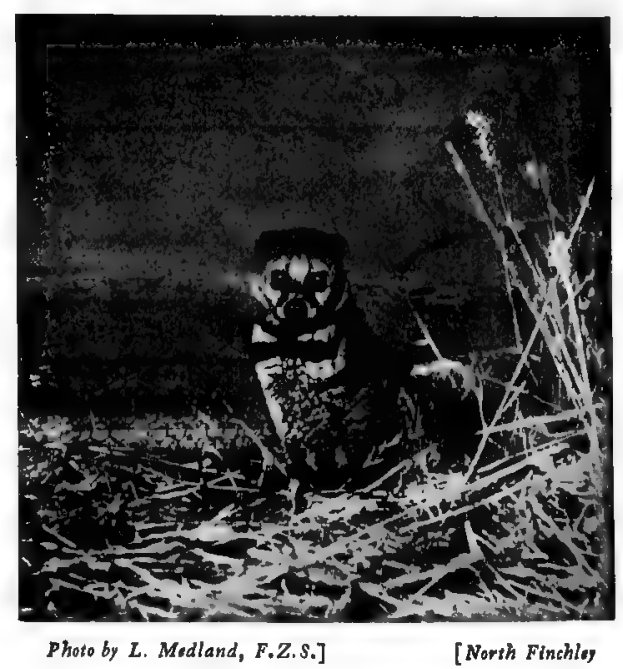

SUMATRAN CIVET

$A$ small and very beautiful member of the Civet Family It feeds largely on fish 
Sumatra and Borneo, it is very rare, but is known to feed on fish and crustacea, and to be semiaquatic. The author of the chapter on the civets in the Naturalist's Library says, "It may be likened to a cimbing otter."

\section{THE MONGOOSE AND ICHNEUMON FAMILY}

THESE are a numerous and useful race of small mammals, feeding mainly on the creatures most annoying to man within tropical countries. Snakes, the eggs of the crocodile, large lizard, rats, mice, and other creatures known generally as " vermin," are their favourite food. " It must be added that, though they are most useful in destroying these, they also kill all kinds of birds, and that their introduction into some of the West India Islands, for the purpose of killing rats, has been fatal to the indigenous bird life.

\section{The Indian Mongoose}

This universal favourite is one of the largest, the head and body being from 15 to 18 inches

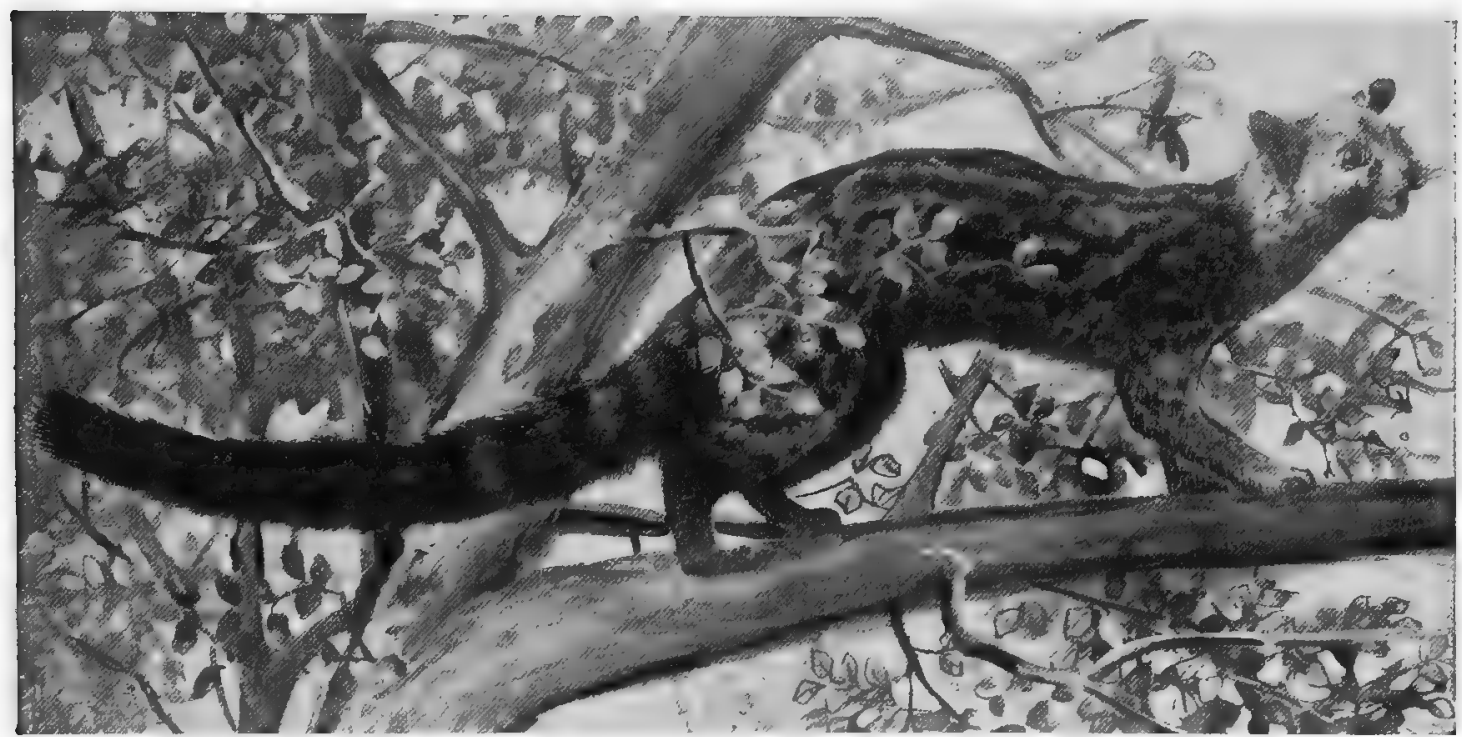

Photo by A. S. Rudland \&ons

GENET

The genets are smaller than some civets, but allied to them. One was anciently dumesticated like a cat

long, and the tail 14 inches. The fur is loose and long, and capable of being erected. As in all the tribe, the tint is a "pepper and salt," the "pepper" colour being sometimes blackish and sometimes red, but a speckled appearance characterises the whole group. This is the animal supposed to be immune from snake-bite. It is possibly so to some extent, for it kills and eats the poisonous snakes, and it is now known that the eating of snake-poison tends to give the same protection as inoculation does against certain diseases. But it is certain that in most cases the mongoose, by its activity, and by setting up the hair on its body, which makes the snake " strike short," saves itself from being bitten.

Many descriptions of the encounters between these brave little animals and the cobra have been written. Here is one of the less known: "One of our officers had a tame mongoose, a charming little pet. Whenever we could procure a cobra-and we had many opportunitieswe used to turn it out in an empty storeroom, which had a window at some height from the ground, so that it was perfectly safe to stand there and look on. The cobra, when dropped from the bag or basket, would wriggle into one of the corners of the room and there coil himself up. The mongoose showed the greatest excitement on being brought to the window, and the moment 


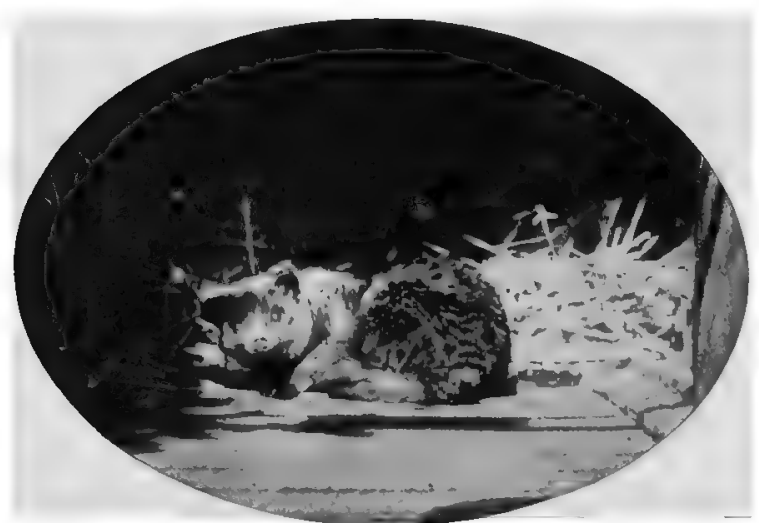

Phoso by L. Medland, F.Z.S.]

TWO-SPOTTED PALM-CIVET

This is a West African species, which, with an allied form from East Africa, represents the palm-civets in the Dark Continent

he was let loose would eagerly jump down into the room, when his behaviour became very curious and interesting. He would instantly see where the snake was, and rounding his back, and making every hair on his body stand out at right angles, which made his body appear twice as large as it really was, he would approach the cobra on tiptoe, making a peculiar humming noise. The snake, in the meantime, would show signs of great anxiety, and I fancy of fear, erecting his head and hood ready to strike when his enemy came near enough. The mongoose kept running backwards and forwards in front of the snake, gradually getting to within what appeared to us to be striking distance. The snake would strike at him repeatedly, and appeared to hit him, but the mongoose continued his comic dance, apparently unconcerned. Suddenly, and with a movement so rapid that the eye could not follow it, he would pin the cobra by the back of the head. One could hear the sharp teeth crunch into the skull, and, when all was over, see the mongoose eating the snake's head and part of his body with great gusto. Our little favourite killed a great many cobras, and, so far as I can see, never was bitten.

The Egyptian Mongoose, or Ichneumon, has an equally great reputation for eating the eggs of the crocodile; and the Kaffir Mongoose, a rather larger South African species, is kept as a domestic animal to kill rats, mice, and snakes, of which, like the Indian kind, it is a deadly foe. There are more than twenty other species, most of much the same appearance and habits.

The smooth-nosed mongoose tribe are closely allied creatures in South Africa, mainly burrowing animals, feeding both on flesh and fruit. The Cusimanses of Abyssinia and West Africa are also allied to them. Their habits are identical with the above.

\section{The Meerkats, or Suricates}

Most people who have read Frank Buckland's Life will remember the suricate which was his chief pet in Albany Street. The Suricates, or Meerkats, burrow all over the South African veldt, especially in the sandy parts, where they sit up outside their holes like prairiedogs, and are seen by day. They are sociable animals, and make most amusing pets. A full-grown one is not much larger than a hedgehog, but more slender. It barks like a prairie-dog, and has many other noises of pleasure or anger. A lady, the owner of one, writes in Country Life: "It gets on well with the dogs and cats, especially the latter, as they are more friendly to her, and allow her to sleep by their side and on the top of them. One old cat brings small birds

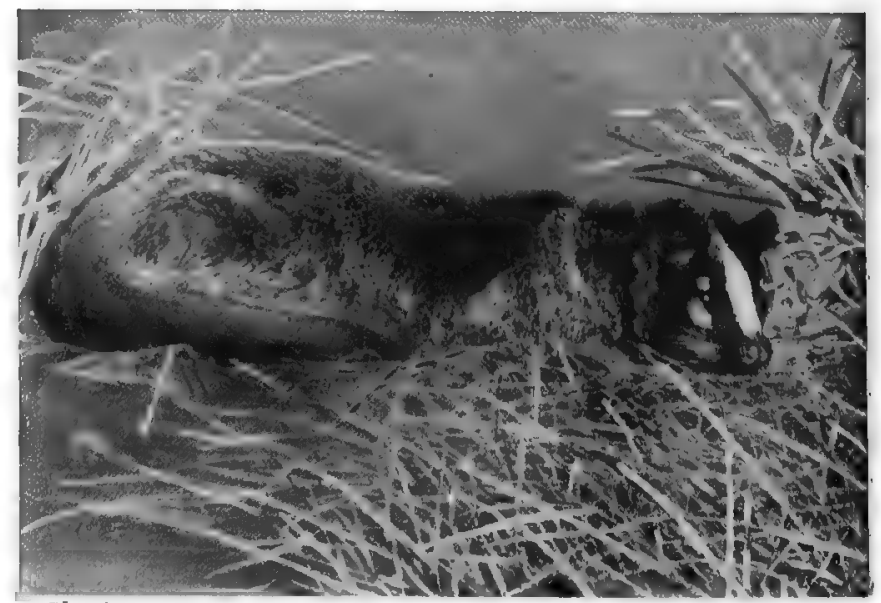

Photo by L. Medland, F.Z.S.]

[North Finchler

MASKED PALM-CIVET

$A$ whole-coloured species of the group 


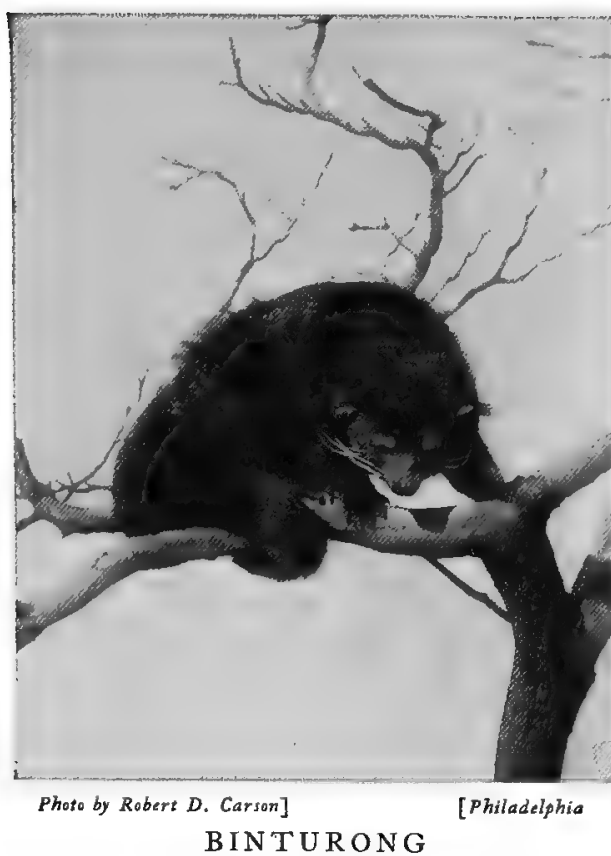

The binturong is placed with the civets. It has a prehensile tail like the kinkajou (see page I27)

to her (her favourite is a sparrow), and makes her usual cry, and Janet runs to her and carries off the bird, which she eats, feathers and all, in a very few minutes, if she is hungry." When near a farm, the meerkats will devour eggs and young chickens. They are also said to eat the eggs of the large leopard-tortoise. The commonest is the SLendertailed Meerkat. It is found all over South Africa, and is very common in the Karroo. It eats insects and grubs as well as small animals, and is commonly kept as a pet throughout the Colony.

WE have now traced the long line of the Carnivora from the lordly Lion, the slayer of man and his flocks and herds, and the Tiger, equally formidable and no less specially developed for a life of rapine on a great scale, to creatures as small and insignificant as the Meerkat, which is at least as much an insectfeeder as a devourer of flesh, and the Ichneumons and Civets. The highest form of specialisation in the group is the delicate mechanism by which the chief weapons of offense, the claws, are enabled to keep

their razor edge by being drawn up into sheaths when the animal walks, but can be instantly thrust out at pleasure, rigid and sharp as sword-blades. The gradual process by which this equipment deteriorates in the Civets and disappears in the Mongoose should be noted. There are many other carnivora, but none so formidable as those possessing the retractile claws. Thus. the Bears, though often larger in bulk than the Lion, are far inferior in the power of inflicting violent injury. At the same time such delicate mechanism is clearly not necessary for the wellbeing of a species. The members of the Weasel Tribe are quite as well able to take care of themselves as the small cats, though they have non-retractile and not very formidable claws.

Such a very abnornal animal as the BinTurong-of which we are able to give an excellent photograph -is doubtless rightly assigned to the place in which modern science has placed it. But it will be found that there are several very anomalous forms quite as detached from any general type as is the binturong. Nature does not make species on any strictly graduated scale. Many of these nondescript animals are so unlike any other group or family that they seem almost freaks of nature. The binturong is certainly one of these.

The next group with which we deal is that of the Hyænas. In these the equipment for catching living prey is very weak. Speed and pursuit are not their métier, but the eating of dead and decaying animal matter, and the consumption of bones. Hence the jaws and teeth are highly developed, while the rest of the body is degenerate.

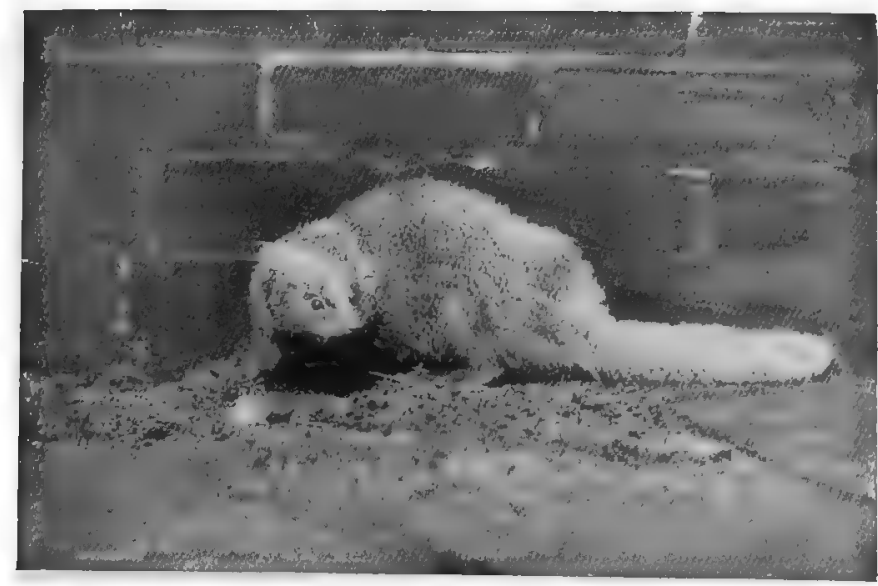

Photo by L. Medland, F.Z.S.]

[North Finchley

MONGOOSE

The Indian mongoose is the great enemy of snakes. Another species eats the eggs of the crocodile 


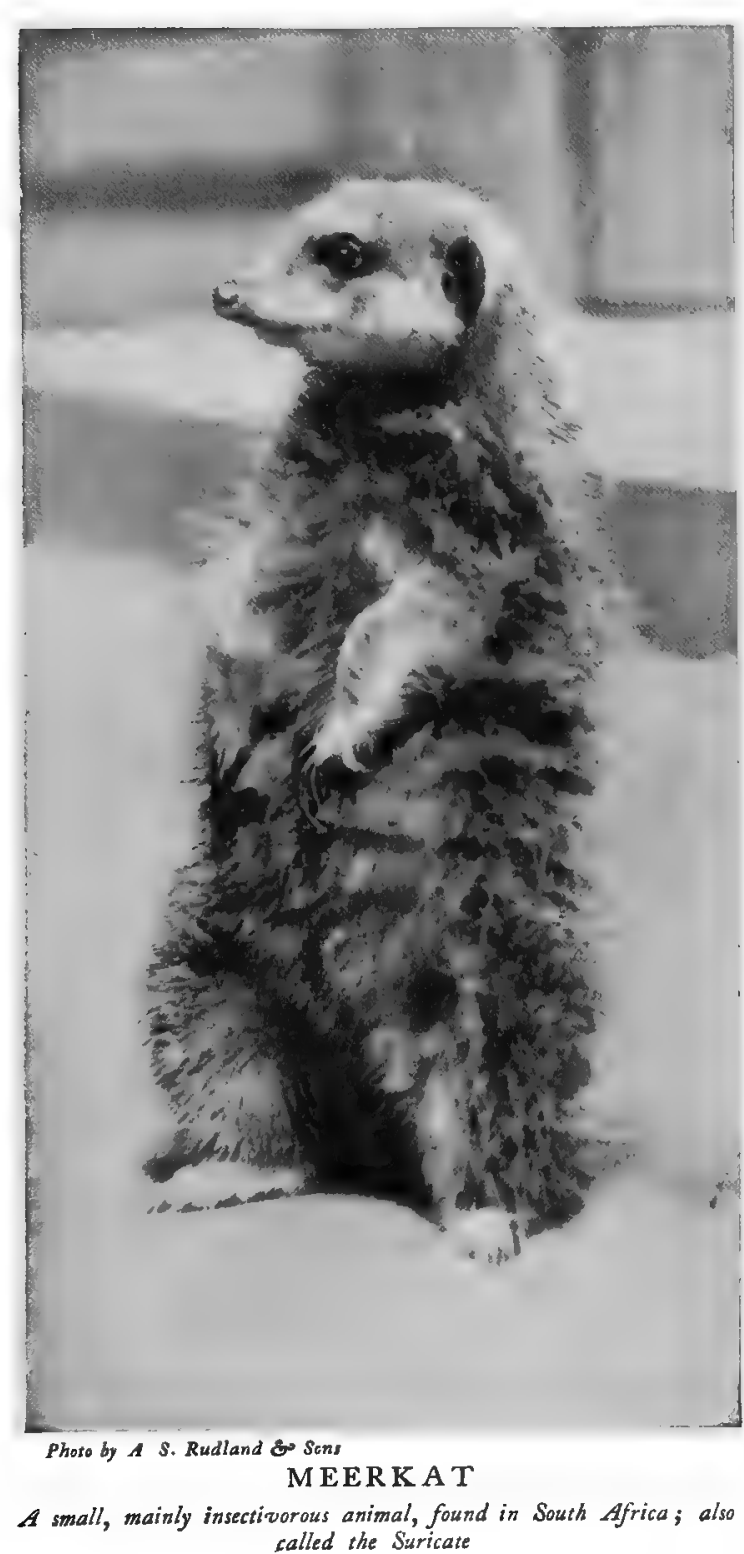

The question of the comparative intelligence of the Apes and Monkeys, and the carnivorous animals subsequently described in these pages, is an interesting one. It would seem at first as if the Cat Tribe and their relations, which have to obtain their prey by constant hunting, and often to make use of considerable reflection and thought to bring their enterprises against other animals to a successful issue, would be more likely to develop intelligence and to improve in brain-power than the great Apes, which find an easy living in the tropical forests, and only seek fruits and vegetables for their food. Yet it is quite certain that this is not the case. The Cat Tribe, with the exception of the domesticated cats, does not show high intelligence. Even the latter are seldom trained to obey man, though they learn to accommodate themselves to his ways of life. There is no evidence that cats have any sense of number, or that any of them in a wild state make any effort to provide shelter for themselves or construct a refuge from their enemies, though the Leopard will make use of a cave as a lair. In matters requiring intelligence and cooperation, such rodents as the Beaver, or even the Squirrel, are far beyond the feline carnivora in sagacity and acquired or inherited ingenuity. Except the Stoat, which sometimes hunts in packs, no species of the carnivora yet dealt with in this work combines to hunt its prey, or for defense against enemies. Each for itself is the rule, and even among the less-specialised flesheating animals of the other groups it is only the Dog Tribe which seems to understand the principles of association for a common object.

\section{H A P T E R I V \\ THE HYENAS AND AARD-WOLF}

$I^{\mathrm{P}}$ F every animal has its place in nature, we nust suppose that the hyæna's business is to clear up the bones and such parts of the animal dead as the vultures and other natural " undertakers" cannot devour. Hyænas have very strong jaws, capable of crushing almost any bone. In prehistoric times they were common in England, and lived in the caves of Derbyshire and Devon. In these caves many bones were found quite smashed up, as if by some very large wild animal. It was supposed that this was done by bears-Dean Buckland said "by hyænas." He procured a hyæna, kept it at his house, and fed it on bones. The smashed fragments he laid on the table at a scientific lecture beside the fragments from the caverns. The resemblance was identical, and the Dean triumphed. 


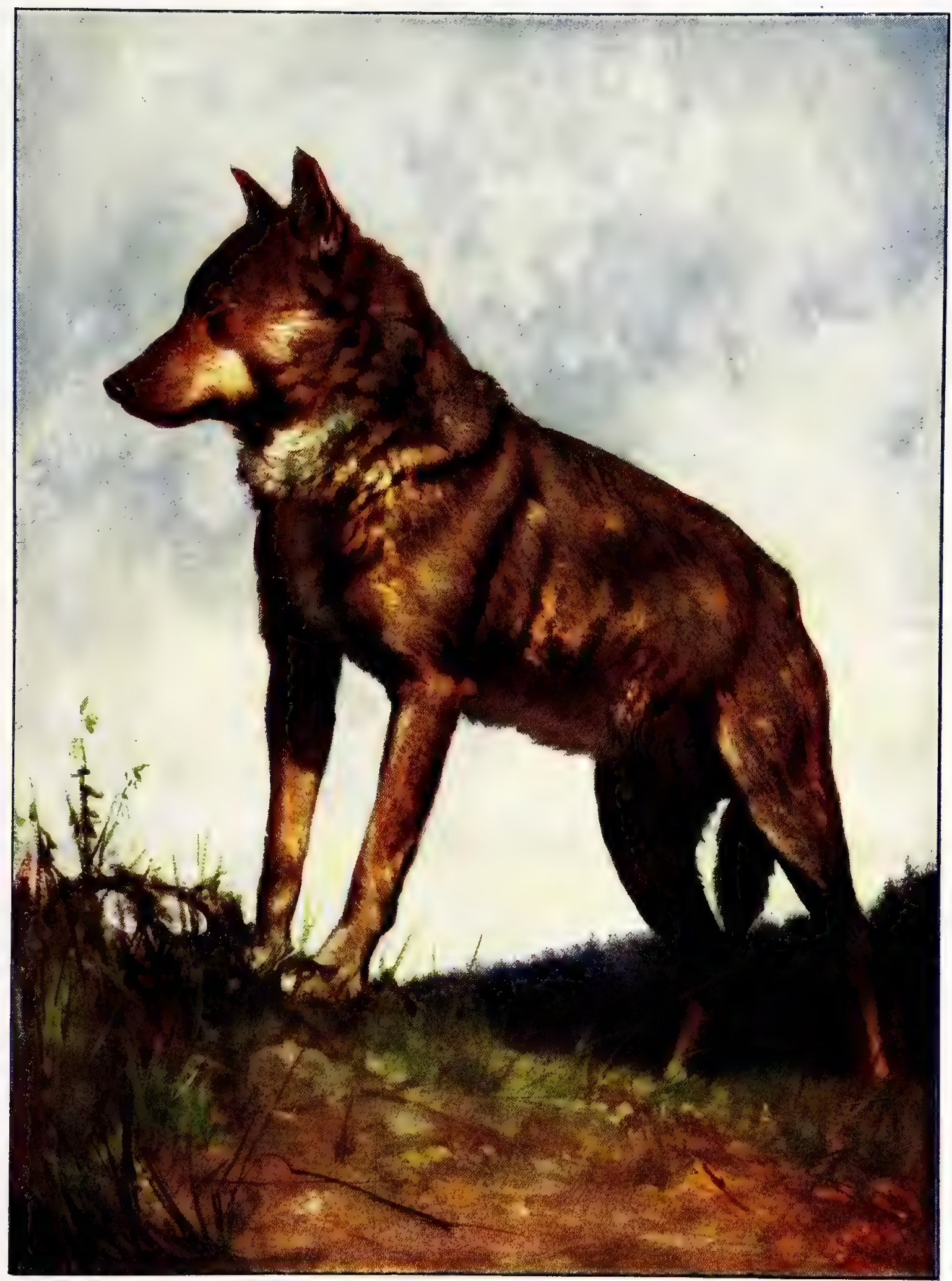

Photo by Utiomur Anscliutz, Berlun.

WOLF FROM CENTRAL EUROFE.

The last persons recorded as killed ly these animals were an artist and his wife travelling in II ungary. 


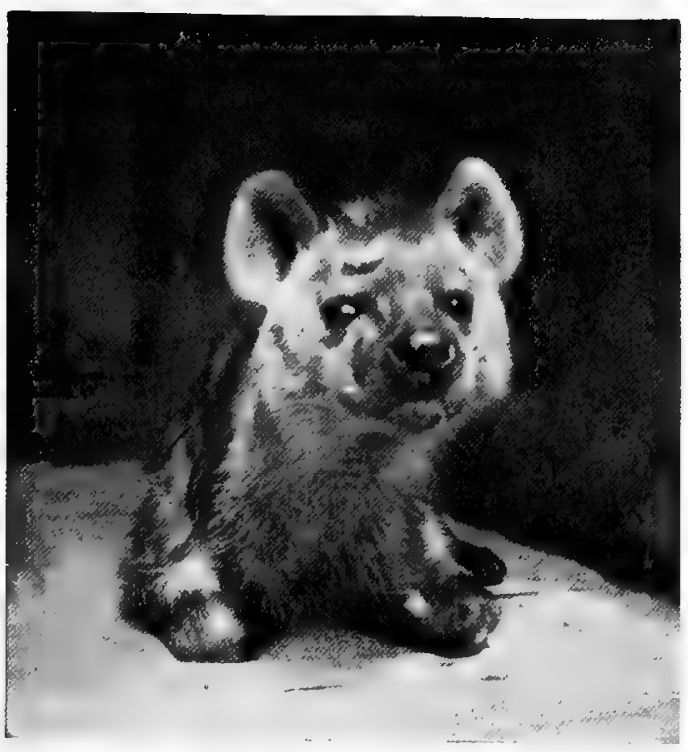

Photo by A. S. Rudland so Sons

SPOTTED HYANA

The largest of the carrion-feeding animals. A South African
species
The hyænas are carnivorous animals, with the front limbs longer than the hind. The tail is short, the colour spotted or brindled, the teeth and jaws of great strength.

The Brown Hyæna, or StrRand-wolf, is an African species, with very long, coarse hair, reaching a length of Io inches on the back. It is not found north of the Zambesi; and it is nocturnal, and fond of wandering along the shore, where it picks up crabs and dead fish. Young cattle, sheep, and lambs are also killed by it, and offal of all kinds devoured.

The Spotted Hyma is a large and massive animal, the head and body being 4 feet 6 inches long without the tail. It is found all over Africa from Abyssinia and Senegal southwards. A few are left in Natal. It is believed to be the same as the cave-hyæna of Europe. By day it lives much in the holes of the aard-vark (ant-bear); by night it goes out, sometimes in small bands, to seek food. It has a loud and mournful howl,

beginning low and ending high. It also utters a horrible maniacal laugh when excited, which gives it the name of Laughing-hyæna. "Its appetite," says Mr. W. I. Sclater in his "South African Mammals," " is boundless. It is entirely carnivorous, but seems to prefer putrid and decaying matter, and never kills an animal unless driven to do so by hunger. Sheep and donkeys are generally attacked at the belly, and the bowels torn out by its sharp teeth. Horses are also frequen objects of attack; but in this case shackling is useful, as the horse, unable to escape, faces the hyæna, which instantly bolts. It is an excellent scavenger, and it has been known to kill and carry off young children, though the least attempt at pursuit will cause it to drop them. Many stories are told, too, of its attacking sleeping natives; in this case it invariably goes for the man's face. Drummond states that he has seen many men who had been thus mutilated, wanting noses, or with the whole mouth and lips torn away. This is confirmed by other authors." Drummond gives an instance of seven cows being mortally injured in a single night by two hyænas, which attacked them and bit off the udders. Poisoned meat is the only means to get rid of this abominable animal.

Sir Samuel Baker says: "I can safely assert that the bone-cracking power of this animal is extraordinary. I cannot say that it exceeds the lion or tiger in the strength

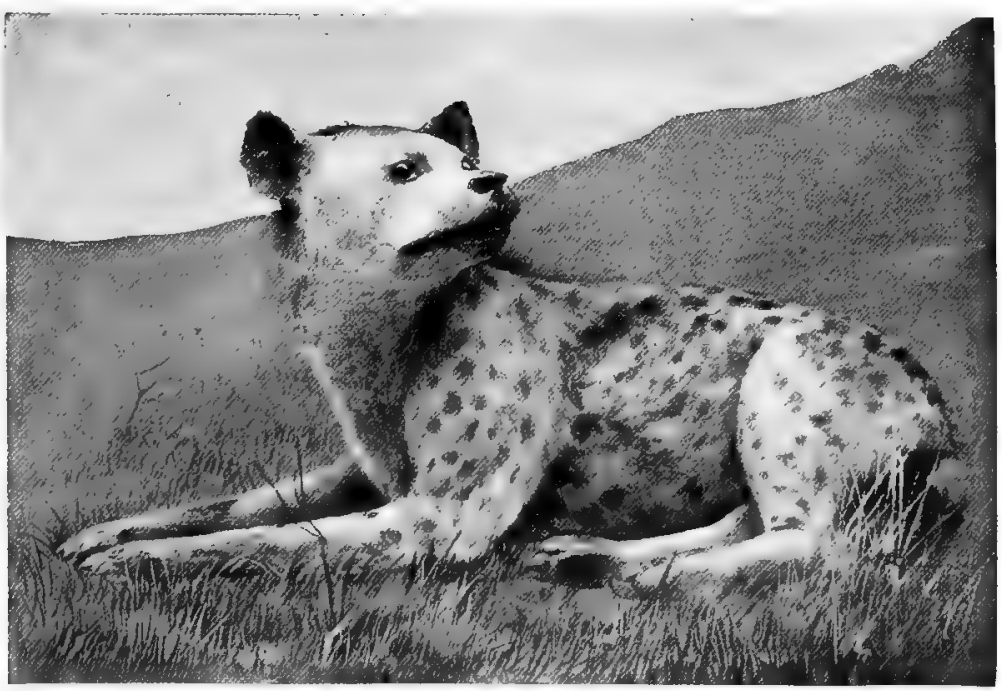

Photo by A. S. Rudland \& Sons

SPOTTED HY ENA

The jaws of the hyoena are specially made for cracking bones. They will smash the thigh-bone of a bufficlo 


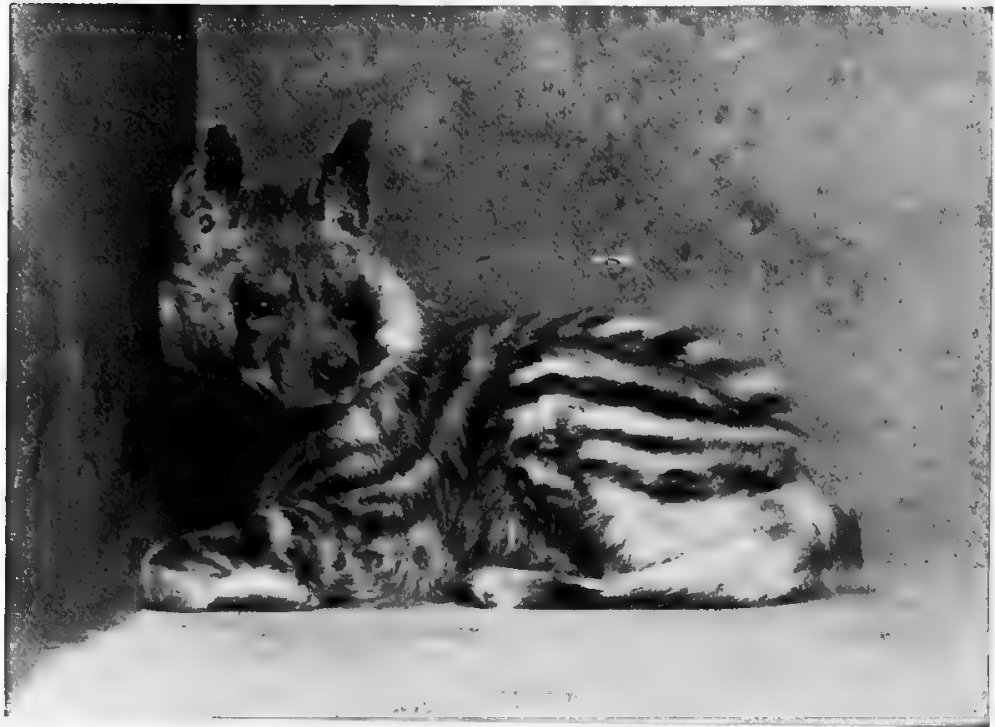

Photo by L. Medland, F.Z.S.]

STRIPED HY ENA

This is the hyona of Northern Africa, Palestine, and India of its jaws; but they will leave bones unbroken which a hyæna will crack in halves. Its powers of digestion are unlimited. It will swallow and digest a knuckle-bone without giving it a crunch, and will crack the thigh-bone of a buffalo to obtain the marrow, and swallow either end immediately after. . . I remember that once a hyæna came into our tent at night. But this was merely a friendly reconnaissance, to see if any delicacy, such as our shoes, or a saddle, or anything that smelt of leather, were lying about. It was bright moonlight, and the air was

calm. There was nothing to disturb the stillness. I was awakened from sleep by a light touch on my sleeve, and my attention was directed by my wife to some object that had just quitted our tent. I took my rifle from beneath the mat on which I lay, and, after waiting for a few minutes sitting up in bed, saw a large form standing in the doorway preparatory to entering. Presently it walked in cautiously, and immediately fell dead, with a bullet between its eyes. It proved to be a very large hyæna, an old and experienced depredator, as it bore countless scars of encounters with other strong biters of its race."

The Striped Hyæna is found in India as well as in Africa. In portions of Abyssinia these animals are so numerous that on the Nile tributaries Sir Samuel Baker used to hear them cracking the bones after supper every night just as they had been thrown by the Arabs within a few feet of the deserted table. In this way they are useful scavengers.

\section{The Aard-ivolf}

This small African hyæna-like creature stands in a family by itself. The animal is like a small striped hyæna, with a pointed muzzle, longer ears, and a kind of mane. It is common all through South and East Africa, where it lives on carrion, white ants, and lambs and kids. It has not the strong jaws and teeth of the dog or hyæna family. The colonists commonly hunt and kill it with fox-terriers.

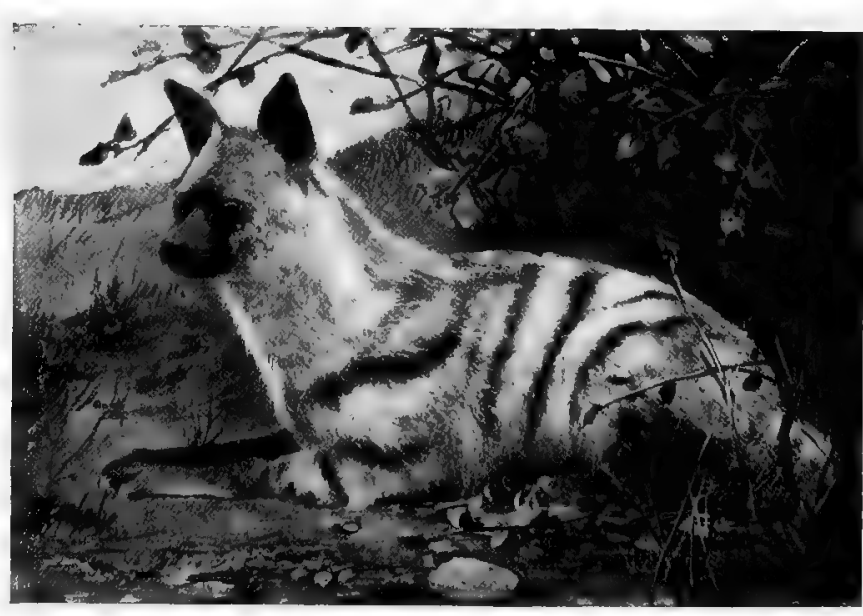

Photo by $A, S$. Kudland Es Sons A ARD-W OLF

The aard-wolf stands in a family by itself. It is allied to the hycenas, but is a row feebler animal 


\section{CHA P T E R V}

\section{THE DOG FAMILY}

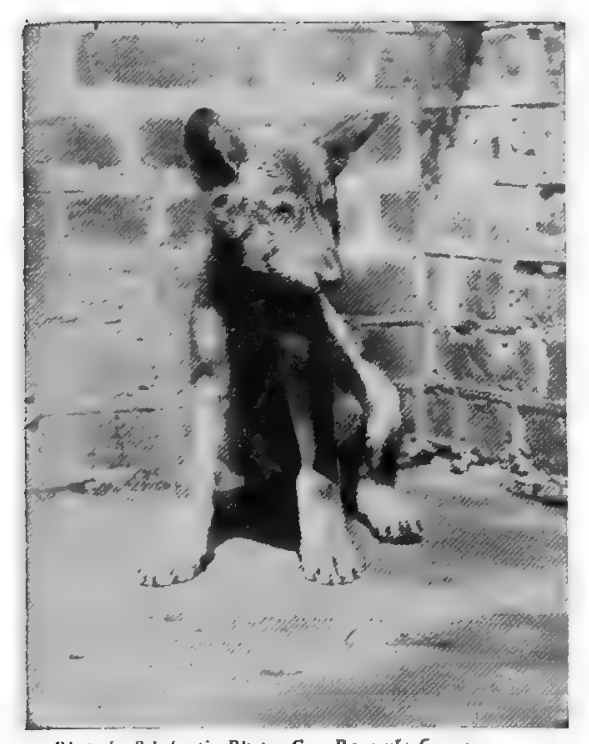

Phoso by Scholatic Photo, Co., Parsonts Green

A GROWING CUB

Note how the wolf cub develops the long pasterns, large feet, and long jow before its body grows in proportion

7 HE tribe now treated is called the Dog Family, and rightly so, for our domestic dogs are included in the group, which comprises the Wolves, Dogs, Jackals, Wild Dogs, and Foxes. Their general characters are too familiar to need description, but it should be noted that the foxes differ from the dogs in having contracting pupils to the eye (which in bright sun closes like a cat's to a mere slit), and some power of climbing. The origin of the domestic dog is still unsettled.

\section{THE WOLF}

This great enemy of man and his dependents-the creature against the ravages of which almost all the early races of Europe had to combine, either in tribes, villages, or principalities, to protect their children, themselves, and their cattle_was formerly found all over the northern hemisphere, both in the Old and New Worlds. In India it is rather smaller, but equally fierce and cunning, though, as there are no long winters, it does not gather in packs. In many lands the popular fear of the wolf has persisted for centuries, a momento of the time when this animal was man's most dreaded enemy. In Switzerland the ancient organisations of wolf clubs in the cantons are still maintained. In Brittany the Grand Louvetier is a government official. Every very hard winter wolves from the Carpathians and Russia move across the frozen rivers of Europe even to the forests of the Ardennes and of Fontainebleau. In Norway they ravage the reindeer herds of the Lapps. Only a few years ago an artist, his wife, and servant were all attacked on their way to Budapest, in Hungary, and the man and his wife killed. The last British wolf was killed in 1680 by Cameron of Lochiel. Wolves are common in Palestine, Persia, and India.

Without going back over the well-known history of the species, we will give some anecdotes of the less commonly known exploits of these fierce and dangerous brutes. Mr. Kipling's "Jungle Book" has given us an "heroic" picture of the life of the Indian wolves. There is a great deal of truth in it. Even the child-stealing by wolves is very probably a fact, for native opinion is unanimous in crediting it. Babies laid down by their mothers when working in the fields are constantly carried off and devoured by them, and stories of their being spared and suckled by the she-wolves are very numerous.

Indian wolves hunt in combination, without assembling in large packs. The following is a remarkable instance, recorded by General Douglas Hamilton: "When returning with a friend from a trip to the mountain caves of Ellora, we saw a herd of antelope near a range of low rocky hills; and as there was a dry nullah, or watercourse, we decided on having a stalk. While creeping up the nullah, we noticed two animals coming across the plain on our left. We took them at first for leopards, but then saw that they were wolves. When they were about 500 yards from 
the antelope, they lay down quietly. After about ten minutes or so, the smaller of the two got up and trotted off to the rocky hills, and suddenly appeared on the ridge, running backwards and forwards like a Scotch collie dog. The larger wolf, as soon as he saw that the antelope were fully occupied in watching his companion, got up and came as hard as he could gallop to the nullah. Unfortunately he saw us and bolted; and his companion, seeing there was something wrong, did the same. Now, it is evident that these

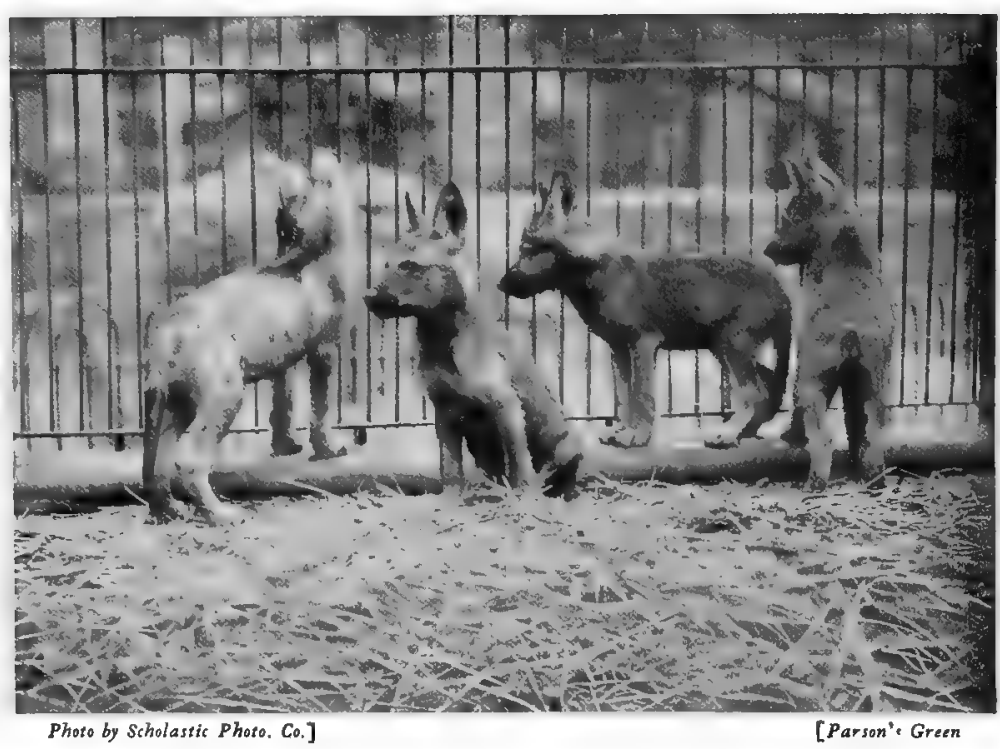

WOLF CUBS wolves had regularly planned this attack. One was to occupy the attention of the antelope, the other to steal up the watercourse and dash into the midst of them. At another time a brother-officer of mine was stalking a herd of antelope which were feeding down a grassy valley, when suddenly a wolf got up before him, and then another and then another, until fourteen wolves rose out of the grass. They were extended right across the valley in the shape of a fishing-net or jelly-bag, so that as soon as the herd had got well into the jelly-bag they would have rushed on the antelope, and some must have fallen victims to their attack." They have been known to join in the chase of antelopes by dogs. Captain Jackson, of the Nizam's service, let his dogs course an antelope fawn. A wolf jumped up, joined the dogs, and all three seized the fawn together. He then came up, whipped off the dogs and the wolf, and secured the fawn, which did not seem hurt. The wolf immediately sat down and began to howl at the loss of his prey, and in a few moments made a dash at the officer, but when within a few yards thought better of it, and reconmenced howling. This brought another wolf to his assistance. Both howled and looked very savage, and seemed inclined to make another dash at the antelope. But the horse-keepers came up, and the wolves retired.

The Indian wolf, if a male, stands about 26 inches high at the shoulder. The length of head and body is 37 inches; tail, 17 inches.

The same species practically haunts the whole of the world north of the Himalaya. It varies in colour from almost black to nearly pure white. In the Hudson Bay fur-sales every variety of colour between these may be seen, but most are of a tawny brindle. The male grows to a very great size. One of the largest ever seen in Europe was for years at the London Zoo. It stood 6 feet high when on its hind legs, and its immense head and jaws seemed to occupy onethird of the space from nose to tail. Horses are the main prey of the NorTHERN Wolf. It will kill any living creature, but horse-flesh is irresistible. It either attacks by seizing the flank and throwing the animal, or bites the hocks. The biting power is immense. It will tear a solid mass of flesh at one grip from the buttock of a cow or horse. In the early days of the United States, when Audubon was making his first trip up the head-waters of the Missouri, flesh of all kinds was astonishingly abundant on the prairies. Buffalo swarmed, and the Indians had any quantity of buffalo meat for the killing. Wolves of very large size used to haunt the forts and villages, and were almost tame, being well fed and comfortable. Far different was the case even near St. Petersburg at the same period. A traveler in 1840 was chased by a pack of wolves so 


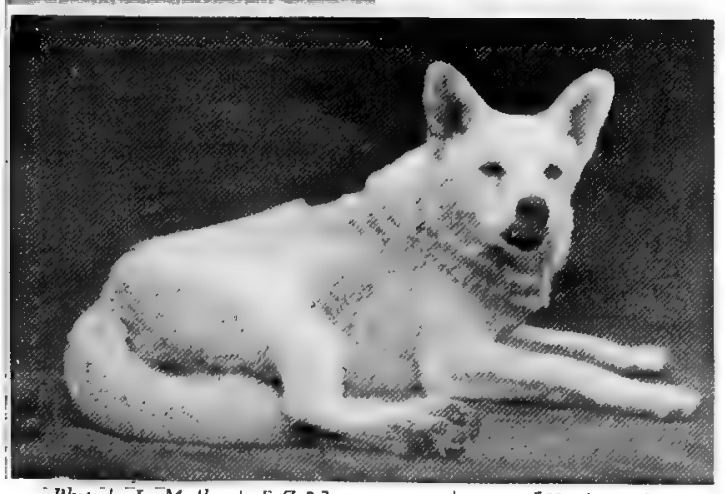

Photo by L. Medland, F.Z.S ]

WHITE WOLF

closely that when the sledge-horses reached the post-house and rushed into the stable, the doors of which were open, seven of the wolves rushed in after them. The driver and traveler leaped from the sledge just as it reached the building, and horses and wolves. rushed past them into it. The men then ran up and closed the doors. Having obtained guns, they opened the roof, expecting to see that the horses had been killed. Instead all seven wolves were slinking about beside the terrified horses. All were killed without resistance.

In Siberia and Russia the wolves in winter are literally starving. Gathering in packs, they haunt the roads, and chase the sledges with their unfaltering gallop. Seldom in these days does a human life fall victim; but in very hard winters sledge-horses are often killed, and now and then a peasant. Rabies is very common among wolves. They then enter the villages, biting and snapping at every one. Numbers of patients are sent yearly from Russia and Hungary to the Pasteur Institutes, after being bitten by rabid wolves. In Livonia, in 1823 , it was stated that the following animals had been killed by wolves: I5,I82 sheep, I,807 oxen, I,84I horses, 3,270 goats, 4, I90 pigs, 703 dogs, and numbers of geese and fowls. They followed the Grand Army from Russia to Germany in 18I2, and restocked the forests of Europe with particularly savage wolves. It is said that in the retreat

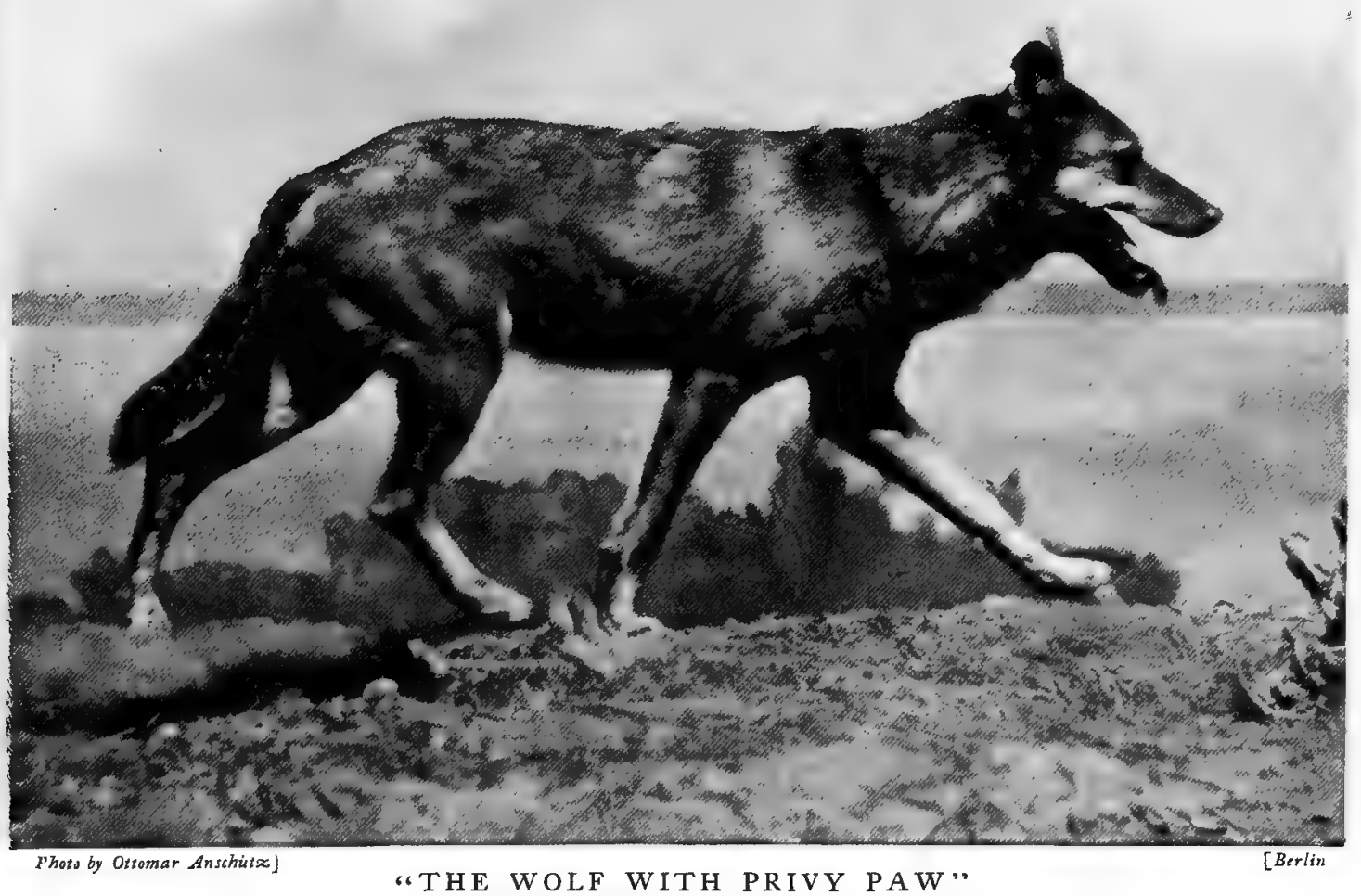

The photograph shows admirably the slinking gate and long stride of the wolf 


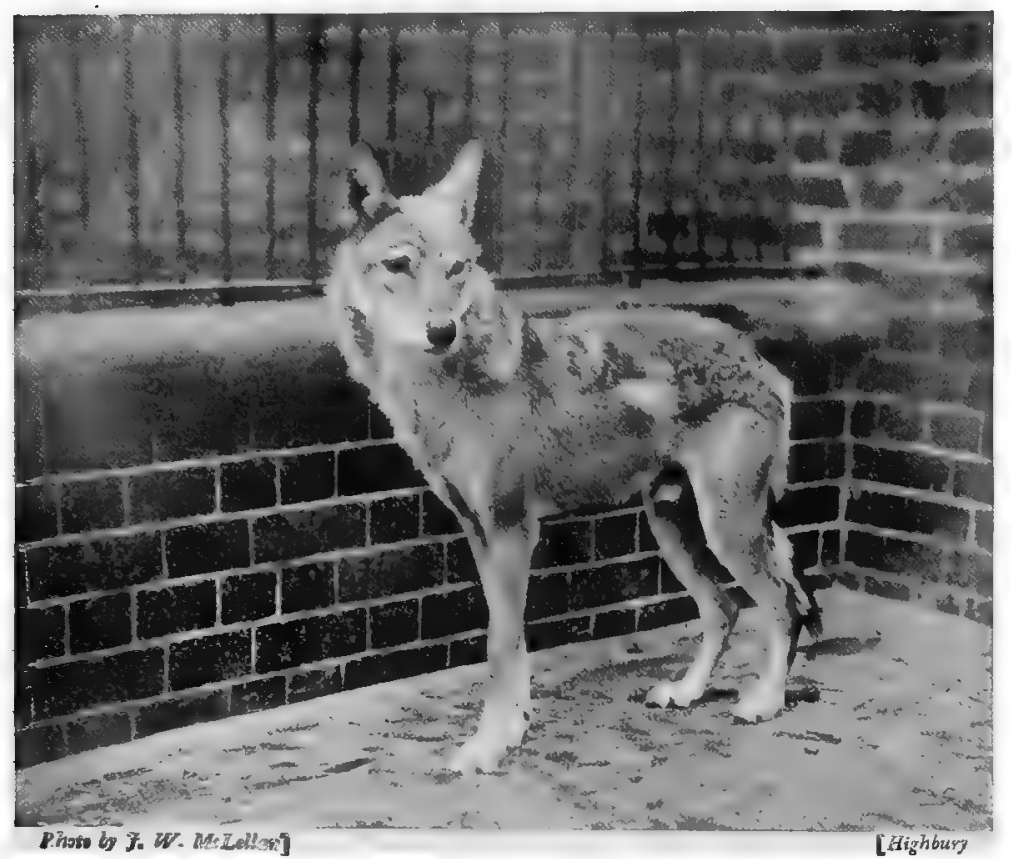

RUSSIAN WOLF

This is a most characieristic garsiggraph of one of the so-calied "greyhound walves" of the Russian forest

wolf-dogs of Tibet, generally called Tibetan Bloodhounds. steppes near the Caucasus also keep a very large and ferocious breed of dog. All these are of the mastiff type, but have long, thick hair. When the shepherds of Albania or Mount Rhodope are driving their flocks along the mountains to the summer pastures, they sometimes travel a distance of 200 miles. During this march the dogs act as flankers and scouts by day and night, and do battle with the wolves, which know quite well the routes along which the sheep usually pass, and are on the lookout to pick up stragglers or raid the flock. The Spanish shepherds employ a large white shaggy breed of dog as guards against wolves. These dogs both lead the sheep and bring up the rear in the annual migration of, the flocks to and from the summer pastures.

Colonel Theodore Roosevelt says of hunting wolves: "In Russia the sport is a science. The princes and great landowners who take part in it have their hunting-equipages equipped perfectly to the smallest detail. Not only do they follow wolves in the open, but they capture them and let them out before dogs, like hares in a closed coursing-meeting. The huntsman follows his hounds on horseback. (These hounds are the Borzoi, white giant greyhounds, now often seen in England.) Those in Russia show signs of reversion to the type of the Irish wolf-hound, dogs weighing something like Ioo lbs., of remarkable power, and of reckless and savage temper. Now three or four dogs are run together. They are not expected to kill the wolf, but merely to hold him. . . . The Borzois can readily overtake and master partly grown wolves, but a full-grown dog-wolf, in good trim, will usually gallop away from them."

Wolf cubs are born in April or May. The litter is from four to nine. There was one of six a few years ago at the Zoological Gardens at The Hague, pretty little creatures like collie puppies, but quarrelsome and rough even in their play. When born, they were covered with reddish-white down; later the coat became woolly and dark.

The European wolf's method of hunting when in chase of deer is by steady pursuit. Its speed is such and its endurance so great that it can overtake any animal. But there is no doubt that the favourite food of the wolf is mutton, which it can always obtain without risk on the wild mountains of the Near East, if once the guardian dogs are avoided. M. Tschudi, the naturalist 
of the Alps, gives a curious account of the assemblage of wolves in Switzerland in I799. They had, as it is mentioned above, followed the armies from Russia. Having tasted human flesh, they preferred it to all other, and even dug up the corpses. The Austrian, French, and Russian troops penetrated in 1799 into the highest mountain valleys of Switzerland, and fought sanguinary battles there. Hundreds of corpses were left on the mountains and in the forests, which acted as bait to the wolves, which were not destroyed for some years.

Wolves will interbreed with dogs readily, which the red fox will not. The progeny do not bark, but howl. The Eskimo cross their dogs with wolves to give them strength.

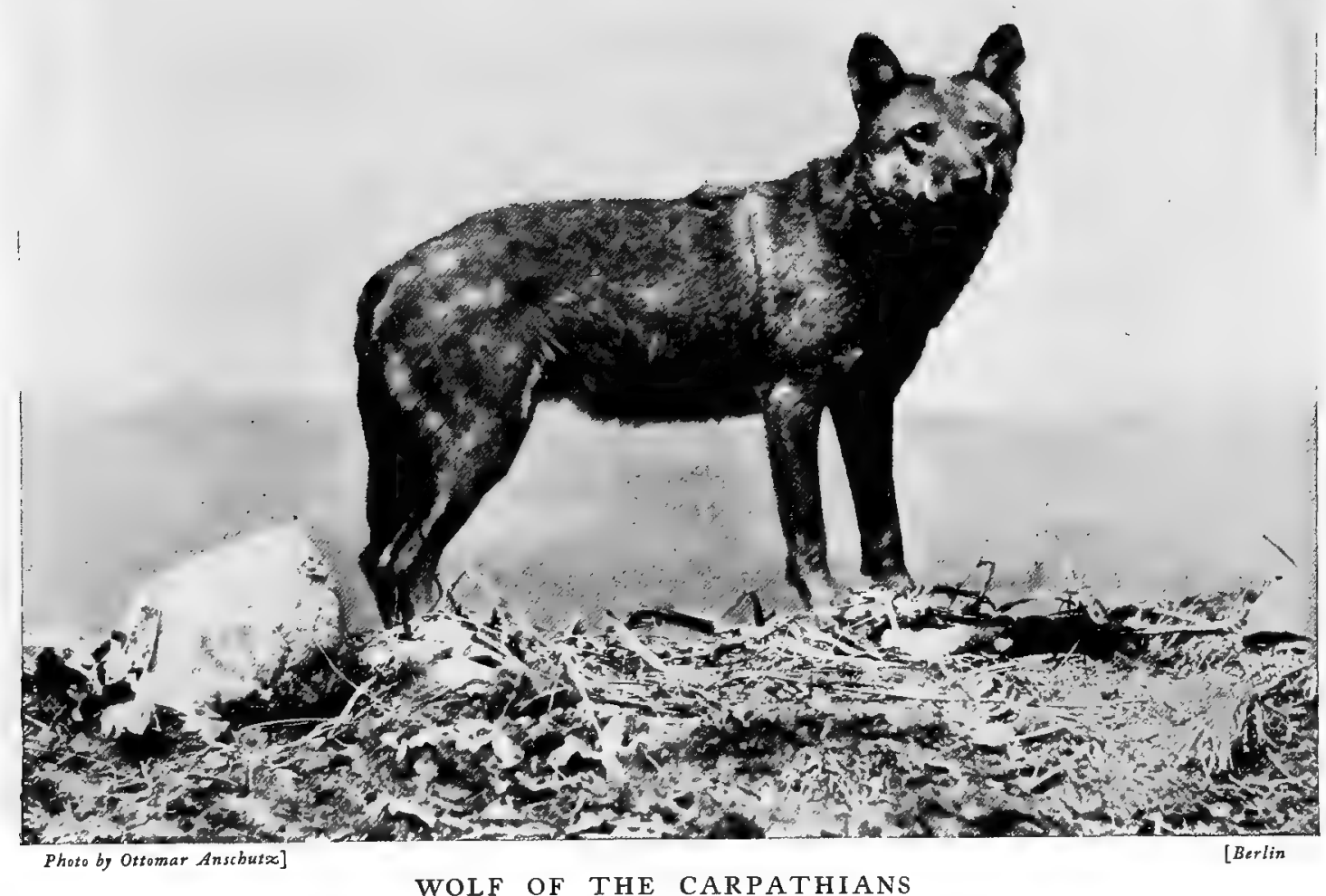

This wolf is a shortor and more heavily built specimen than the Russian wolf on the previous page 


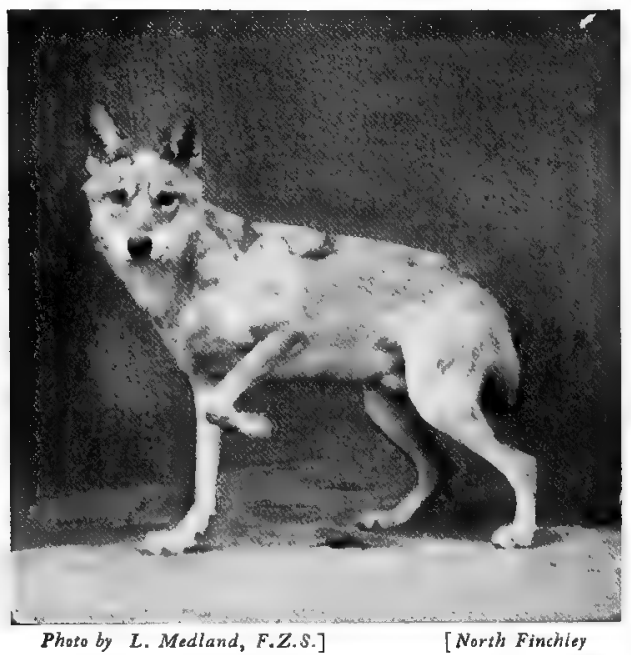

INDIAN WOLF

This photograph shows the Indian zolf alarmed. It has a reputation for stealing children as well as killing cattle

Some years ago experiments were made at the Regent's Park Zoological Gardens to ascertain if there were any foundation for the old legends that wolves feared the sound of stringed instruments such as the violin. Every one will remember the story of the fiddler pursued by wolves. It is said that as the pack overtook him he broke a string of his instrument, and that the sudden noise of the parting cord caused the pack to stand still for a minute, and so enabled him to reach a tree, which he climbed. Further, that when he improved on the hint so given, and played his fiddle, the wolves all sat still; when he left off, they leapt up and tried to reach him. Experiments with the Zoo wolves showed that there was no doubt whatever that the low minor chords played on a violin cause the greatest fear and agitation in wolves, both European and Indian. The instrument was first played behind the den of an Indian wolf, and out of sight. At the first sound the wolf began to tremble, erected its fur, dropped its tail between its legs, and crept. uneasily across its den. As the sound grew louder and more intense, the wolf trembled so violently, and showed such physical evidence of being dominated by excessive fright, that the keeper begged. that the experiment might be discontinued, or the creature would have a fit. A large European wolf is described in "Life at the Zoo" as having exhibited its dislike of the music in a

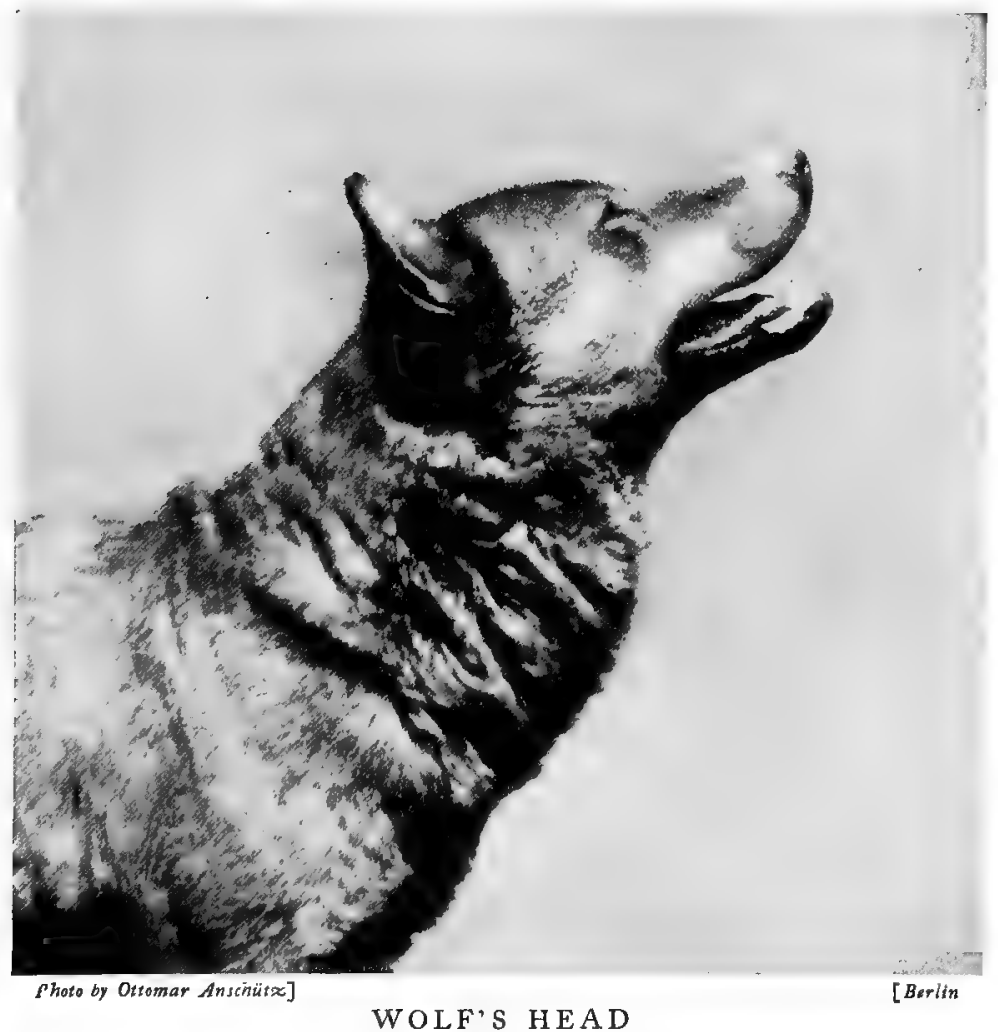

A very fine study of the head, jarws, and teeth of a female wolf. The head of the male is different way. It set up all its. fur till it looked much larger than its ordinary size, and drew back its lips until all the white teeth protruding from the red. gums were shown. It kept. silent till the violin-player approached it; then it flew at: him with a ferocious growl, and tried to seize him.

There are instances of wolves having been quite successfully tamed, and developing great affection for their owners. They are certainly more dog-like than any fox; yet even the fox has been tamed so far as to become a domesticated animal for the lifetime of one particular individual. An extraordinary instance of this was lately given in Country Life, with a photograph of the fox. It. was taken when a cub, and brought up at a large country house with a number of dogs. 
Among these were three terriers, with which it made friends. There were plenty of wild foxes near, some of which occasionally laid up in the laurels in a shrubbery not far from the house. These laurels were, in fact, a fairly safe find for a fox. It was the particular sport of the terriers to be taken to "draw" this bit of cover, and to chase out any fox in it. On these expeditions the tame fox invariably accompanied them, and took an active part in the chase, pursuing the wild fox as far as the terriers were able to maintain the hunt.

In Central Asia the wolves lie out singly on the steppes during the

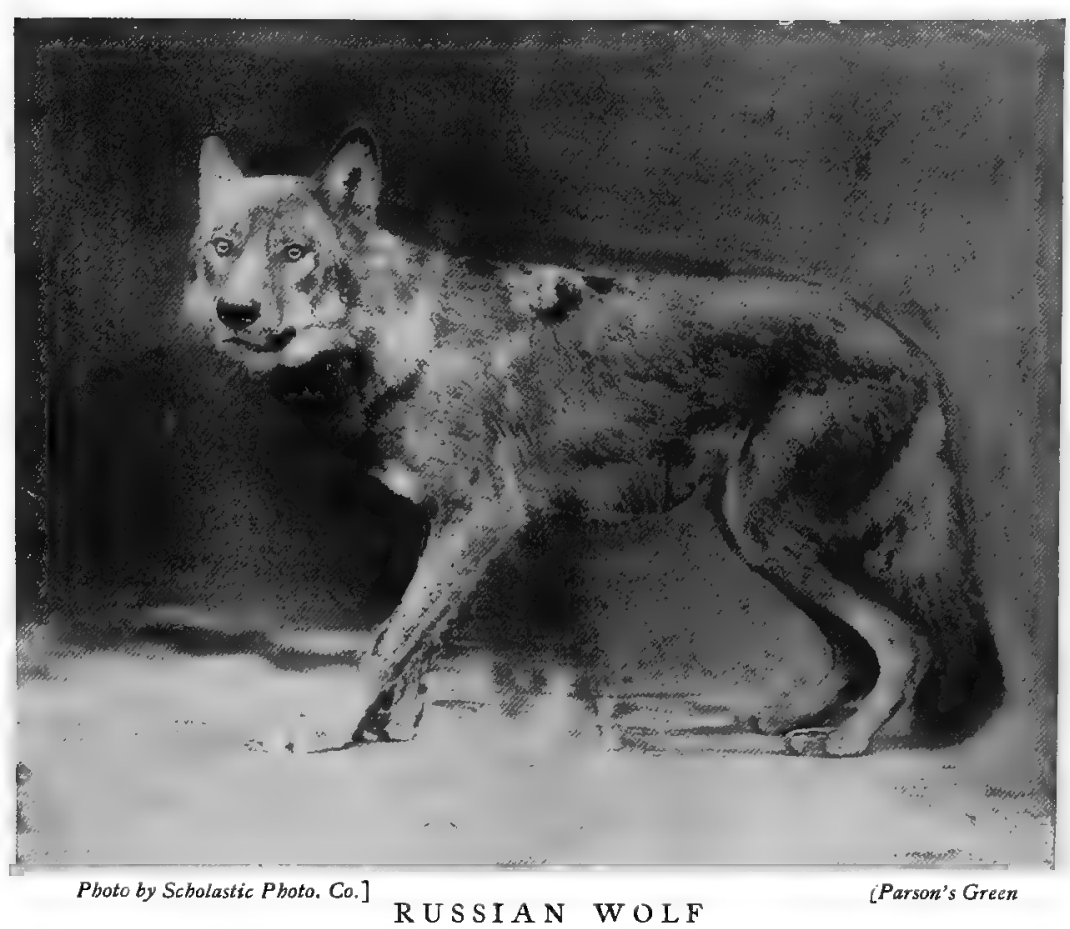

Note the expression of fear and ferocity on the face of tbis wolf; also the enormousiy powerful jaw.

summer, and feed on the young antelopes and the lambs and kids of the Tartar's flocks. The Kirghiz organise wolf-killing parties, to which as many mounted men and dogs come as can be brought together. In order to aid the dogs, the Tartars often employ eagles trained to act like falcons, which sit on the arm of the owner. As the eagle is too heavy to be carried for any time in this way, a crutch is fastened to the left side of the saddle, on which the bearer of the falcon rests his arm. When a wolf is sighted, the eagle is loosed, and at once flies after the wolf, and overtakes it in a short time, striking at its head and eyes with its talons, and buffeting it with its wings. This attack so disconcerts the wolf that it gives time for the dogs to come up and seize it.

The habits of the Siberian wolf are rather different from those in West Russia, and the settlers and nomad Tartars of Siberia are far more adventurous and energetic in defending themselves against its ravages than the peasants of European Russia. Being mounted, they also have a great advantage in the pursuit. The result is that Siberian wolves seldom appear in large packs, and very rarely venture to attack man. Yet the damage they do to the flocks and herds which constitute almost the only property of the nomad tribes is very severe.

Both the Russians and Siberians believe that when a she-wolf is suckling her young she carefully avoids attacking flocks in the neighbourhood of the place where the cubs lie, but that if she be robbed of her whelps she revenges herself by attacking the nearest flock. On this account the Siberian peasants rarely destroy a litter, but hamstring the young wolves and then catch them when partly grown, and kill them for the sake of their fur. Among the ingenious methods used for shooting wolves in Siberia is that of killing them from sledges. A steady horse is harnessed to a sledge, and the driver takes his seat in front as usual. Behind sit two men armed with guns, and provided with a small pig, which is induced to squeak often and loudly. In the rear of the sledge a bag of hay is trailed on a long rope. Any wolf in the forest near which hears the pig concludes that it is a young wild one separated from its mother. Seeing the hay-bag trailing behind the sledge in the dusk, it leaps out to seize it, and is shot by the passengers sitting on the back seat of the sledge. 


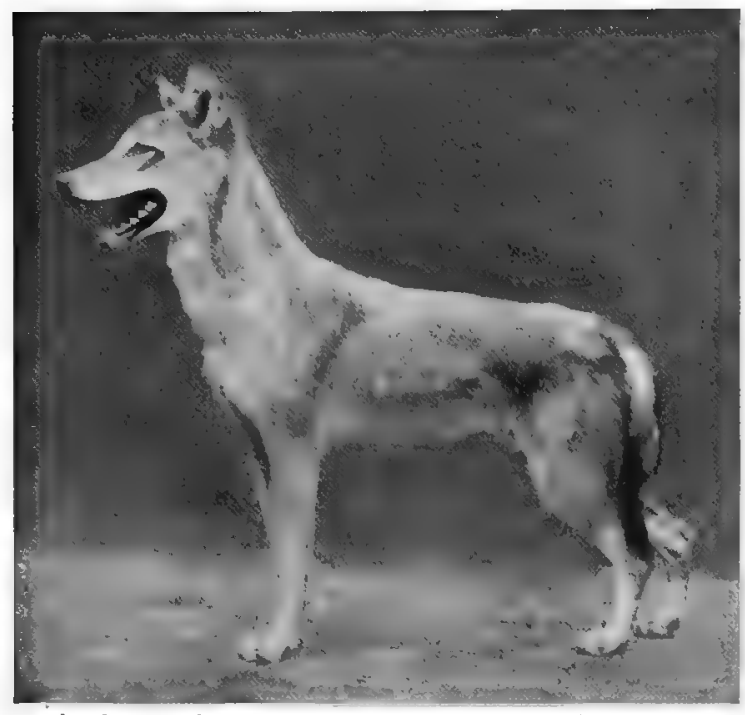

Photo by L. Medland, F.Z.s]

NORTH AFRICAN JACKAL

This is the common jackal of Cairo and Lower Egypt

\section{The Jackal}

Of the Wild Canine Family, the JACKaL is the next in numbers and importance to the wolves. Probably in the East it is the most numerous of any. In India, Egypt, and Syria it regularly haunts the outskirts of cities, and lives on refuse. In the Indian plains wounded animals are also killed by the jackals. At night the creatures assemble in packs, and scour the outskirts of the cities. Horrible are the howlings and weird the cries of these hungry packs. In Ceylon they live in the hills and open country like foxes, and kill the hares. When taken young jackals can be tamed, and have all the manners of a dog. They wag their tails, fawn on their master, roll over and stick up their paws, and could probably be domesticated in a few generations, were it worth while. They eat fruits and vegetables, such as melons and pumpkins, eagerly.

In Africa two species are found-the Black-BACKed Jackal and the Striped JackaL; the rormer is the size of a large English fox. The young jackals are born in holes or earths; six seems to be the usual number of puppies. They have nearly always a back door by which they can escape; this is just large enough for the puppies to squeeze through, whatever their size. When fox-terriers are put into the earth, the jackal puppies fly out of their back doors, through which, as a rule, the terriers are unable to follow them. Should there be no one outside, the puppies race out on to the veldt as hard as they can go. . This jackal is terribly destructive to sheep and lambs in the Colony. A reward of $\$ 1.80$ per tail is paid to the Kaffirs for killing them. The Side-Striped Jackal is a Central African species, said to hunt in packs, to interbreed with domestic dogs, and to be most easily tamed.

Both in India and South Africa the jackal has been found to be of some service to the white man by providing him with a substitute for the fox to hunt. It has quite as remarkable powers of endurance as the fox, though it does not fight in the same determined way when the hounds overtake it. But it is not easy to estimate the courage of a fox when in difficulties. The writer has known one, when coursed by two large greyhounds, to disable both almost instantaneously. One was bitten across the muzzle, the other through the foot. The fox escaped without a bite from either. In India the hounds used are drafts from English packs. The hot weather does not suit them, and they are seldom long-lived; but while they are in health they will run a jackal across the

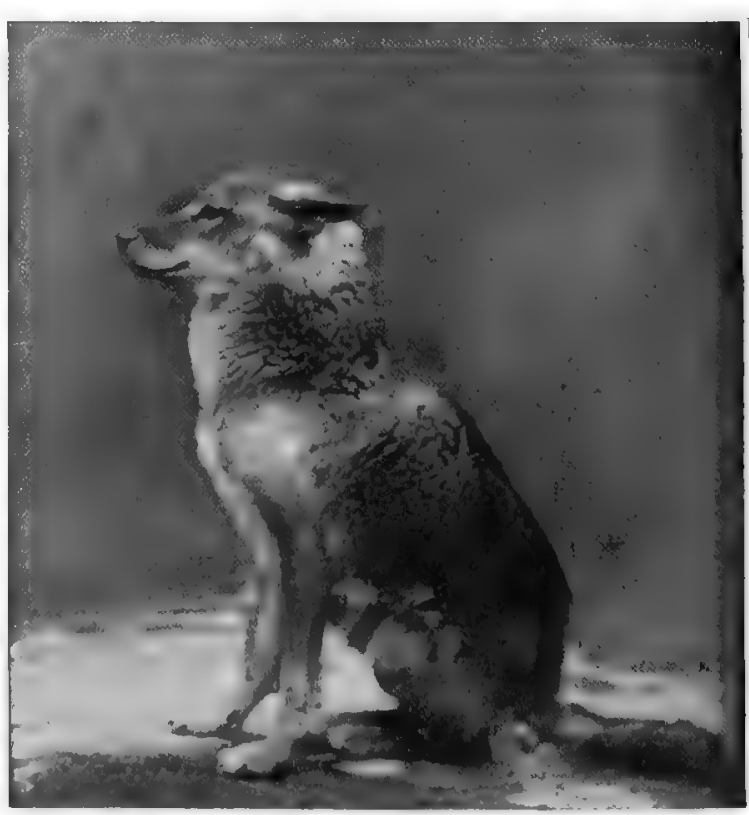

Photo by A. S. Rudland \&s Sont

IN DIAN JACK AL

This Indian jackal might be sitting for his portrait in $M r$. Rudyard Kipling"s sale of the "undertakers" - the jackal, alligaror, and adjutant 
Indian plains as gaily as they would a fox over the Hampshire Downs. The meet is very early in the morning, as the scent then lies, and riding is not too great an exertion. The ground drawn is not the familiar English covert, but fields, watercourses, and old buildings. A strong dog-jackal goes away at a great pace, and as the ground is open the animal is often in view for the greater part of the run; but it keeps well ahead of the hounds often for three or four miles, and if it does not escape into a hole or ruin is usually pulled down by them. Major-General R. S. S. BadenPowell has written and illustrated an amusing account of his days with the fox-hounds of South Africa hunting jackals. The local Boer farmers, rough, unkempt, and in ragged trousers; used to turn up smoking their pipes to enjoy the sport with the smartly got-up English officers. When once the game was found, they were just as excited as the Englishmen, and on their Boer ponies rode just as hard, and with perhaps more judgment.
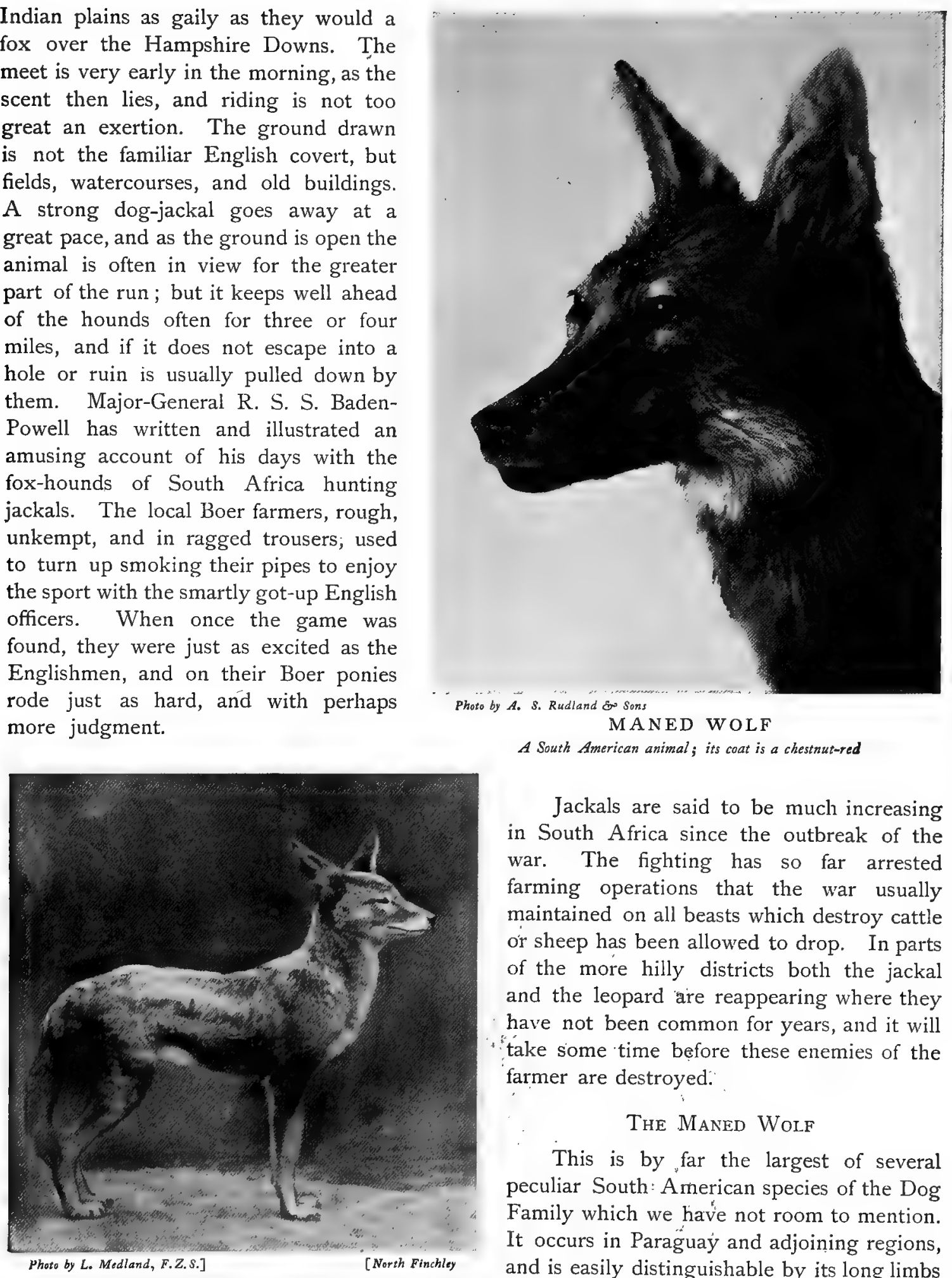

Jackals are said to be much increasing in South Africa since the outbreak of the war. The fighting has so far arrested farming operations that the war usually maintained on all beasts which destroy cattle or sheep has been allowed to drop. In parts of the more hilly districts both the jackal and the leopard are reappearing where they have not been common for years, and it will take some time before these enemies of the farmer are destroyed:

\section{The Maned Wolf}

This is by far the largest of several peculiar South: American species of the Dog Family which we have not room to mention. It occurs in Paraguay and adjoining regions, and is easily distinguishable by its long limbs and large ears. It is chestnut-red in colour, with the lower part of the legs black, and is solitary in its habits.

This fackal is common in both Turkey in Europe and in Asia. Nem Constantinople it feeds largely on the bodies burted in the cemeteries at Scutari 


\section{THE LIVING ANIMALS OF THE WORLD}

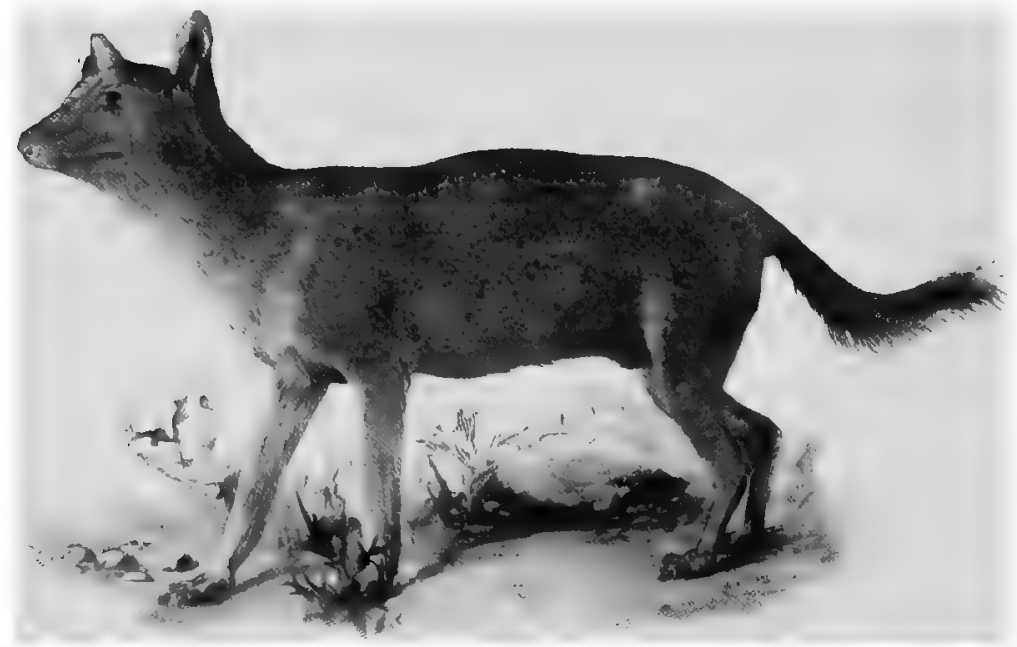

Photo by A. S. Rudland so sins

\section{W ILD DOG}

These animals range from the plains of India and Burma to the Tibetan Plateau and Siberia. They hunt in small packs, usually by day, and are very destructive ro game, but seldom attack domestic animals

kills the farmers' cattle and sheep and the largest antelopes. devour to the last morsel a large buck in fifteen minutes. Drummond says: "It is a marvelous sight to see a pack of them hunting, drawing cover after cover, their sharp bell-like note ringing through the air, while a few of the fastest of their number take up their places along the expected line of the run, the wind, the nature of the ground, and the habits of the game being all taken into consideration with wonderful skill." The same writer says that he has seen them dash into a herd of cattle feeding not a hundred yards from the house, drive out a beast, disappear over a rising ground, kill it, and pick its bones before a horse could be saddled and ridden to the place.

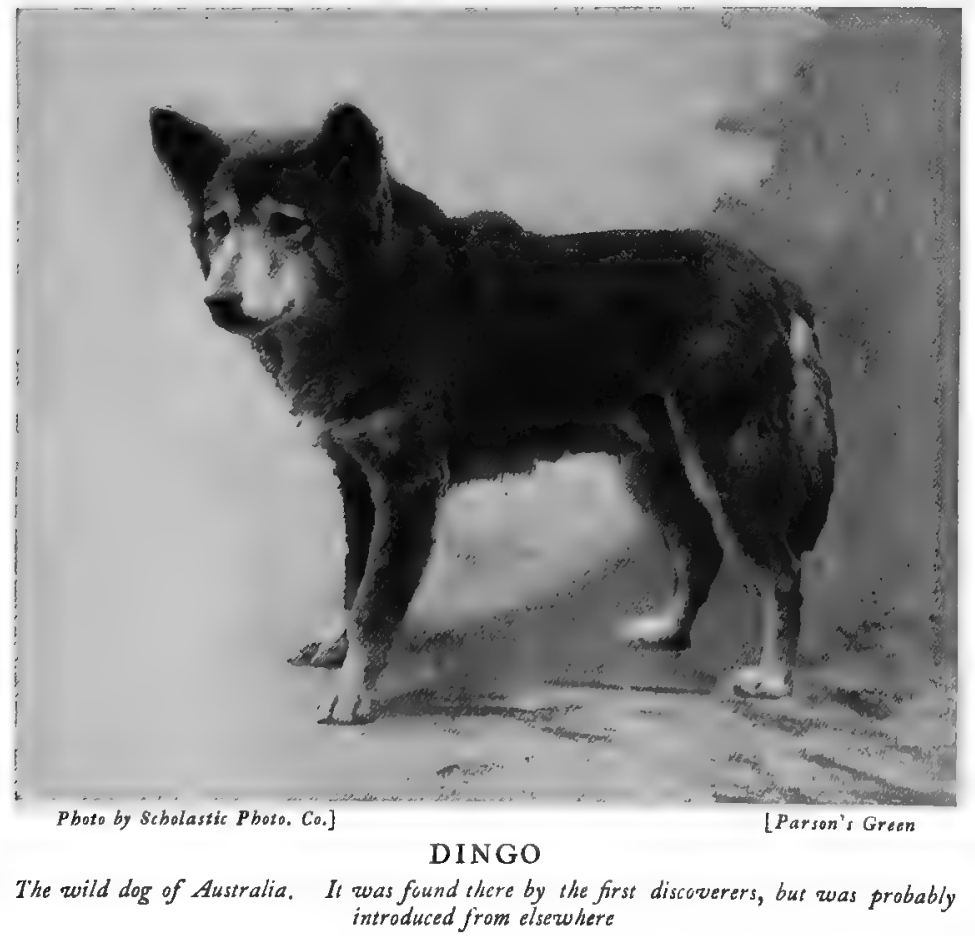

\section{The Indian Wild Dogs}

Mr. Rudyard Kipling's stories of the "Dhole," the red dogs of the Indian jungle, have made the world familiar with these ferocious and wonderfully bold wild dogs. There is very little doubt that they were found in historic times in Asia Minor. Possibly the surviving stories of the "Gabriel hounds" and other ghostly packs driving deer alone in the German and Russian forests, tales which remain even in remote parts of England, are a survival of the days when the wild dogs lived in Europe. At present there is one species of long-haired wild dog in West Central Siberia. These dogs 


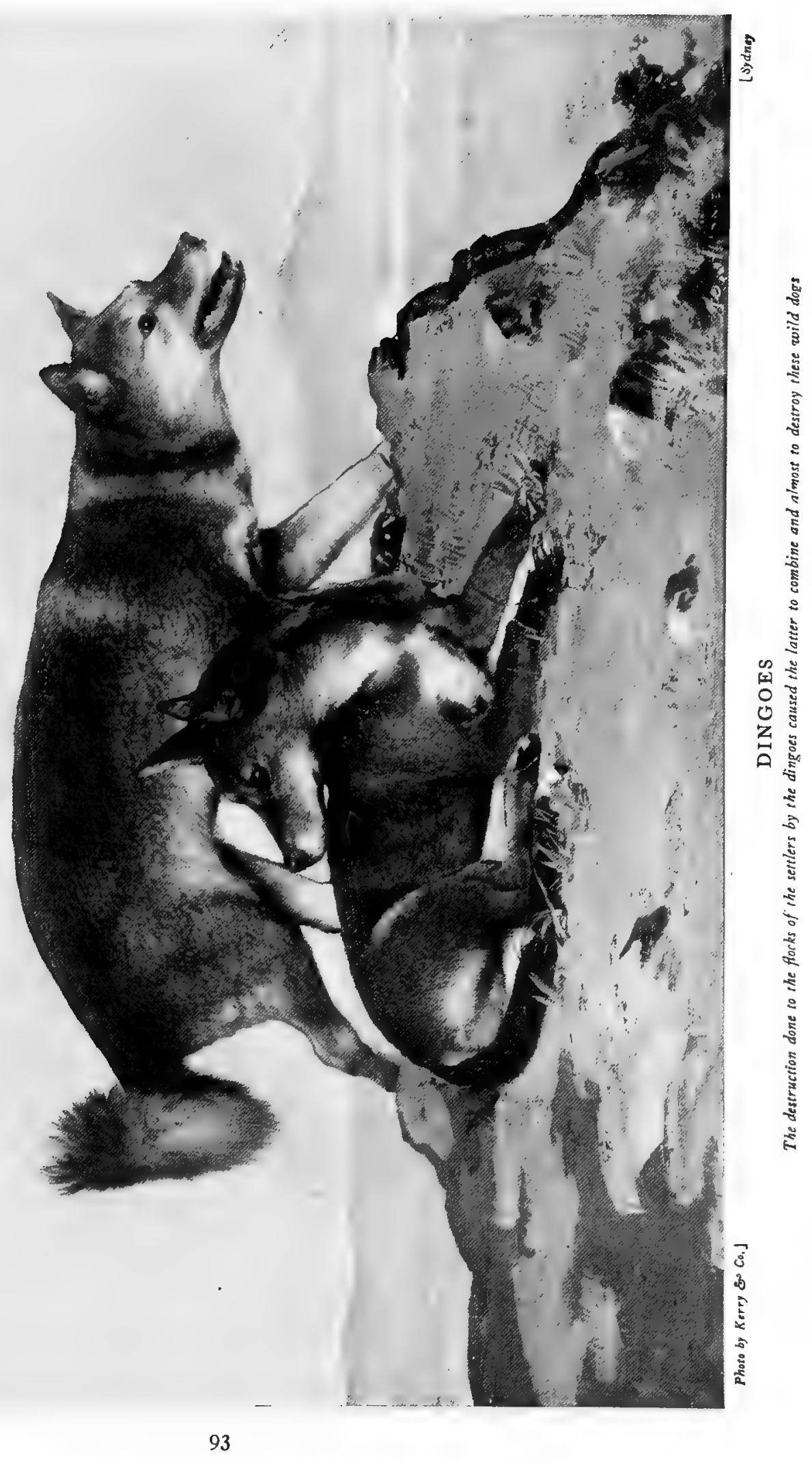




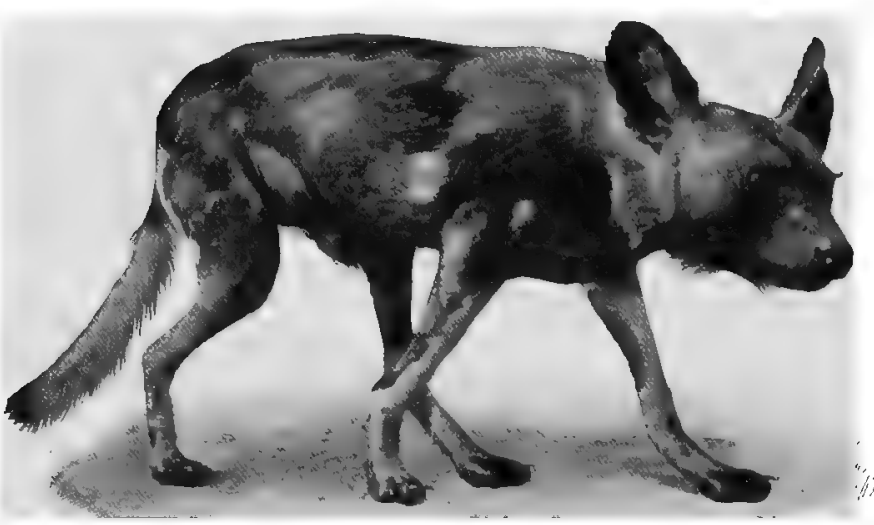

Photo by A. S. Rudland \& Sons

CAPE HUNTING-DOG

This animal hunts in packs. It ss very active and most destructive to large game of many kinds

killed nearly all the deer in the large forests near Omsk some years ago. Across the Himalaya there are several species, one of them as far east as Burma; but the most famous are the Red Dogs of the Deccan. They frequent both the jungles and the hills; but their favourite haunt is the uplands of the Indian Ghats. They are larger than a jackal, much stronger, and hunt in packs. They have only ten teeth on each side, instead of eleven, as in the other dogs and foxes. There is no doubt that these fierce hunting-dogs actually take prey from the tiger's jaws, and probably attack the tiger itself. They will beset a tiger at any time, and the latter seems to have learnt from them an instinctive fear of dogs. Not so the leopard, which, being able to climb, has nothing to fear even from the "dhole." A coffee-planter, inspecting his grounds, heard a curious noise in the forest bordering his estate. On going round the corner of a thick bush, he almost trod on the tail of a tiger standing with his back towards him. He silently retreated, but as he did so he saw that there was a pack of wild dogs a few paces in front of the tiger, yelping at him, and making the peculiar noise which had previously attracted his attention. Having procured a rifle, he returned with some of his men to the spot. The tiger was gone, but they disturbed a large pack of wild dogs feeding on the body of a stag. This, on examination, proved to have been killed by the tiger, for there were the marks of the teeth in its neck. The dogs had clearly driven the tiger from his prey and appropriated it. The dread of the tiger for these wild dogs was discovered by the sportsmen of the Nilgiri Hills, and put to a good use. They used to collect scratch packs, and hunt up tigers in the woods. The tiger, thinking they were the dreaded wild pack, would either leave altogether or scramble into a tree. As tigers never do this ordinarily, it shows how wild dogs get on their nerves.

Several South American wild dogs and foxes are included in the series with the wolves and jackals. Among these are Azara's Dog and the Raccoon-Dog. These are commonly called foxes, though they have wolf-like skulls.

\section{The Dingo}

The only non-marsupial animal of Australia when the continent was discovered was the Wild Dog, or Dingo. Its origin is not known; but as soon as the settlers' flocks and herds began to increase its ravages were most serious, though doubtless some of the havoc with which it was accredited was due in a great measure to runaways from domestication. Anyhow, in the dingo the settlers found the most formidable enemy with which they had to contend, and vigorous measures were taken to reduce their numbers and minimise their ravages, so that by now they are nearly exterminated in Van Diemen's Land and rare on the mainland of Australia.

It is a fine, bold dog, of considerable size, generally long-coated, of a light tan colour, and with pricked-up ears. It is easily tamed, and some of those kept in this country have made affectionate pets. Puppies are regularly bred and sold at the Zoological Gardens. The animal has an elongated, flat head which is carried high; the fur is soft, and the tail bushy. In the wild state it is very muscular and fierce. 


\section{THE FOXES}

Foxes form a very well-marked group. They have very pointed muzzles, strong though slightly built bodies, very fine thick fur, often beautifully coloured and very valuable, bushy tails, pricked-up ears, and eyes with pupils which contract by day into a mere slit. They are quite distinct from dogs (although wolves are not), and will not interbreed, though stories are told to the contrary. The smell of a fox is disgusting to a dog, and quite sufficient to distinguish it.

If the present writer takes a simpler view of the kinds and species of foxes than that adopted by many naturalists, he must plead to a study of the subject on slightly different lines than those usually followed. The skins of all foxes are valuable, some more than others. But they are sent in hundreds of thousands, and from all parts of the northern hemisphere, to London to the great fur-sales. There these differences can be studied as they can be studied

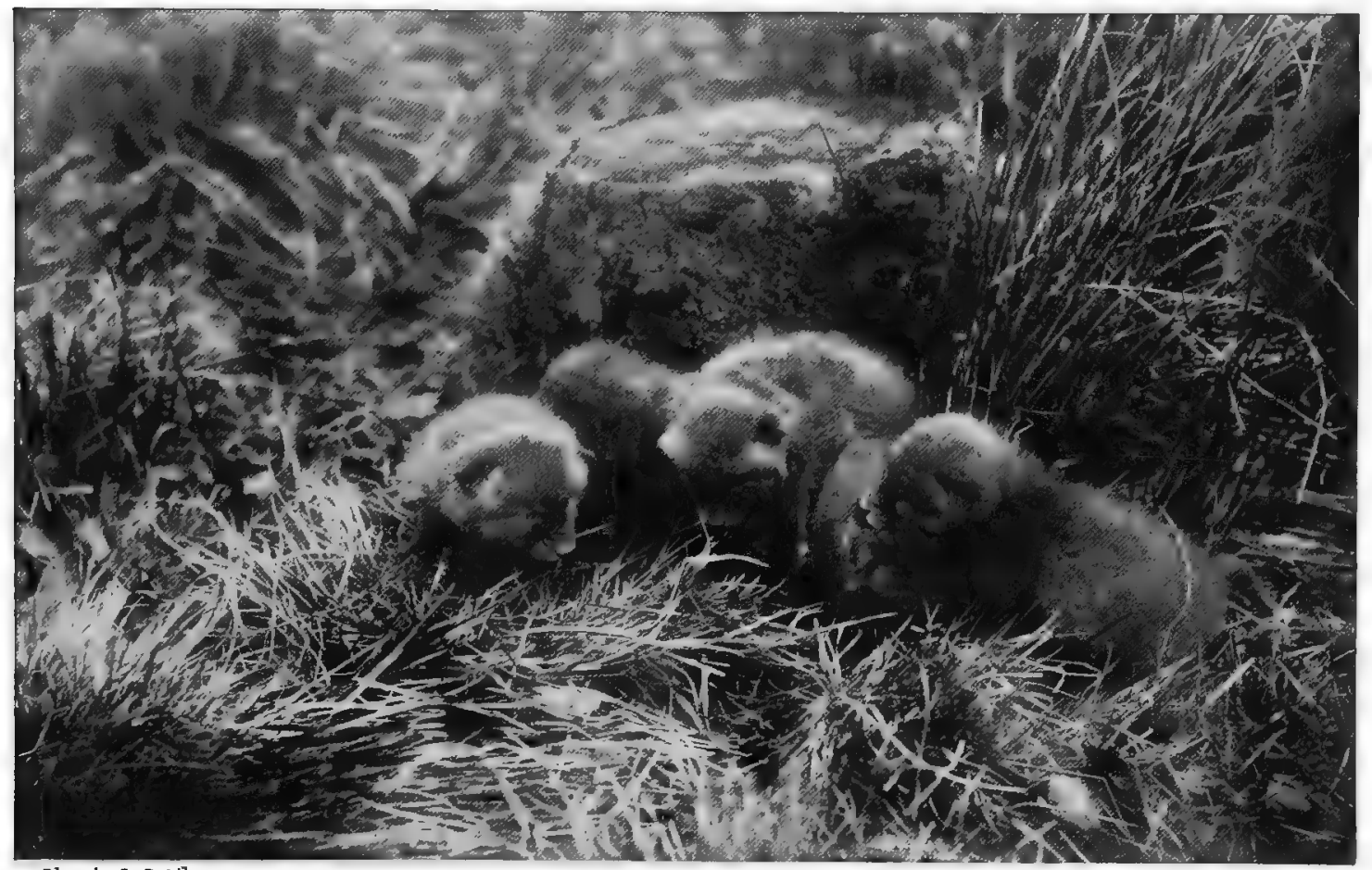

Photo by C. Reid]

FOX CUBS

$[$ Wishaw, N. B.

Fox cubs are born from March 25 till three weeks later, the time when young rabbits, their best food, are most numerous

nowhere else. As the habits and structure of foxes are much alike, allowing for differen:es of climate, and the discrepancies in size, not rnore than can be accounted for by abundance or scarcity of food, it seems pretty certain that these animals are some of the few, almost alone among mammals, showing almost every variety of colouring, from black to white, from splendid chameleon-red to salmon-pink, and many exquisite shades of brown, gray and silver. In the East, from Asia Minor to China, red, gray, and yellow fox skins are the lining of every rich man's winter wraps. Splendid mixed robes are made by the Chinese by inserting portions of cross fox-skins into coats of cut sable, giving the idea that it is the fur of a new animal.

The Common Fox, the foundation or type of all the above, is the best known carnivorous animal in this country. Abroad its habits do not greatly differ, except that, not being hunted much with hounds, it is less completely nocturnal. It drops its young in a dugout early in April. Thither the mother carries food till late in June, when the cubs come out, and often move to a wood or a corn-field. There they are still fed, but learn to do a little on their own account by catching mice and moles. By late September the hounds come cub-hunting, 
partly to kill off superfluous foxes, partly to educate the young hounds, and to teach the foxes to fear them and to make them leave cover easily. Four or five cubs in a litter are commonly seen. The distance which a fox will run is extraordinary. The following is a true account of one of the most remarkable runs ever known. The hounds were those of Mr. Tom Smith, master of the Hambledon Hunt. He was the man of whom another famous sportsman said that if he were a fox he should prefer to be hunted by a pack of hounds rather than by Tom Smith with a stick in his hand. The fox was found in a cover called Markwells, at one o'clock in the afternoon in December, near

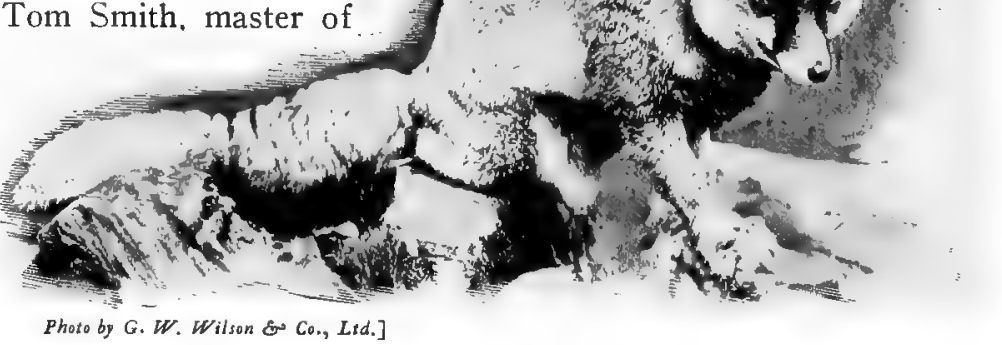

MOUNTAIN-FOX

In billy countries the fox becomes a porverful and destructive animal, killing not only game but lambs

Petersfield. It crossed into Sussex, and ran into an earth in Grafham Hill a little before dark. The fox had gone twenty-seven miles. The hounds had forty miles to go back to kennel that night, and three only found their way home four days afterwards. Dog-foxes assemble in considerable numbers when a vixen is about in spring, and at all times common foxes are sociable creatures, though not actually living in societies. Sometimes as many as five or six are found in a single earth. Two years ago five foxes and a badger were found in one near Romford. They eat mice, beetles, rats, birds, game, poultry, and frogs. Their favourite food is rabbits. If there are plenty of these, they will not touch other game. They hunt along the railway-lines for dead birds killed by the telegraph-wires. In the New Forest they also go down to the shore and pick up dead fish. One in the writer's possession was shot when carrying away a lamb from a sheepfold near the cliffs of Sidmouth, in Devon. The shepherd thought it was a marauding dog, and lay in wait with a gun.

\section{The Fennecs}

Africa has a group of small foxes of its own. They have very large ears and dark eyes. Some of them remind us of the Maholis and other large-eyed lemuroids. Several are not

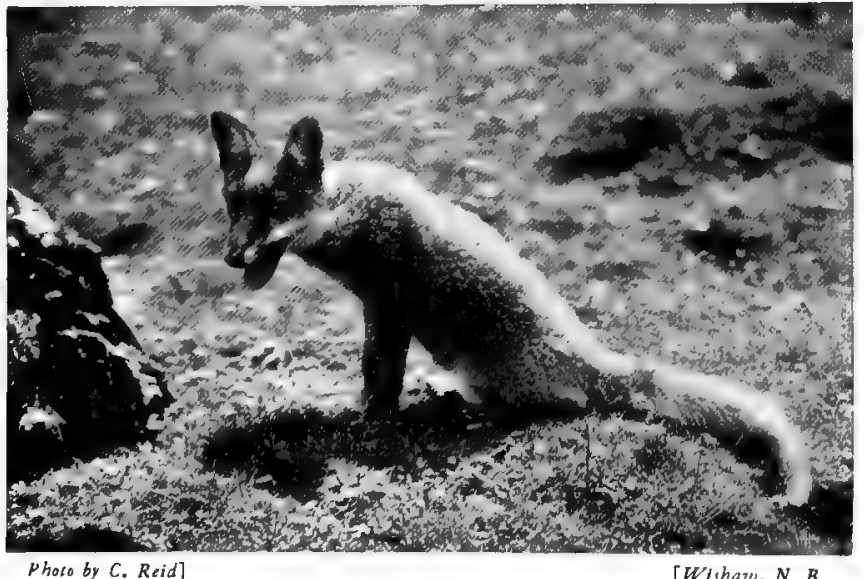

LEICESTERSHIRE FOX more than 9 or Io inches long; they are a whitish-khaki colour, but the eyes are very dark and brilliant.

The Common Fennec is found over the whole of Africa. Its favourite food is dates and any sweet fruit, but it is also fond of eggs, and will eat mice and insects. It is probably the original hero of the story of the fox and the grapes. The large-eared fennec, which is sometimes called the Silver Fox, is found from the Cape to as far north as Abyssinia. It is 23 inches long, and lives mainly on insects and fruit. 


\section{DOMESTIC DOGS}

BY C. H. LANE

The Dog, almost without exception, shows a marked liking for the society of human beings, and adapts itself to their ways more than any other animal.

Fox-, Stag-, and Hare-hounds-the latter better known as Hariers and Beagles-have many points in common, much beauty of shape and colour, and great suitability for their work, though differing in some other particulars.

Another group_Greyhounds, Whippets, Irish Wolf-hounds, Scottish Deer hounds, all of which come under the category of Gaze-hounds, or those which hunt by sight-are built for great speed, to enable them to cope with the fleet game they pursue. In the same group should be included the Bonzor, or Russian Wolf-hound, now very popular in this country, with something of the appearance of the Scottish deer-hound about it as to shape, but with a finer, longer head, deeper body, more muscular limbs, and shaggier in the hair on body and tail.

The OTtER-HOUnd is one of the most picturesque of all the hound tribe. This variety somewhat reminds one of a large and leggy Dandie Dinmont terrier, with a touch of the bloodhound, and is thought to have been originally produced from a cross between these or similar varieties.

The Blood-Hound is another, with much style and beauty of shape, colour, and character about it which cannot fail to favourably impress any beholder. The matches or trials which have of late years been held in different localities have been most interesting in proving its ability for tracking footsteps for long distances, merely following them by scent, some time after the person hunted started on the trail. By the kindness of my friend Mr. E. Brough, I am able to give as an illustration a portrait of what he considers the best blood-hound ever bred.

Much valued by sportsmen with the gun are PoInTERs, so called from their habit of remaining in a fixed position when their quarry is discovered, eagerly pointing in its direction until the arrival of the guns. They are most often white, with liver, lemon, or black markings; but occasionally self-colours, such as liver or black, are met with. They have been largely bred in the

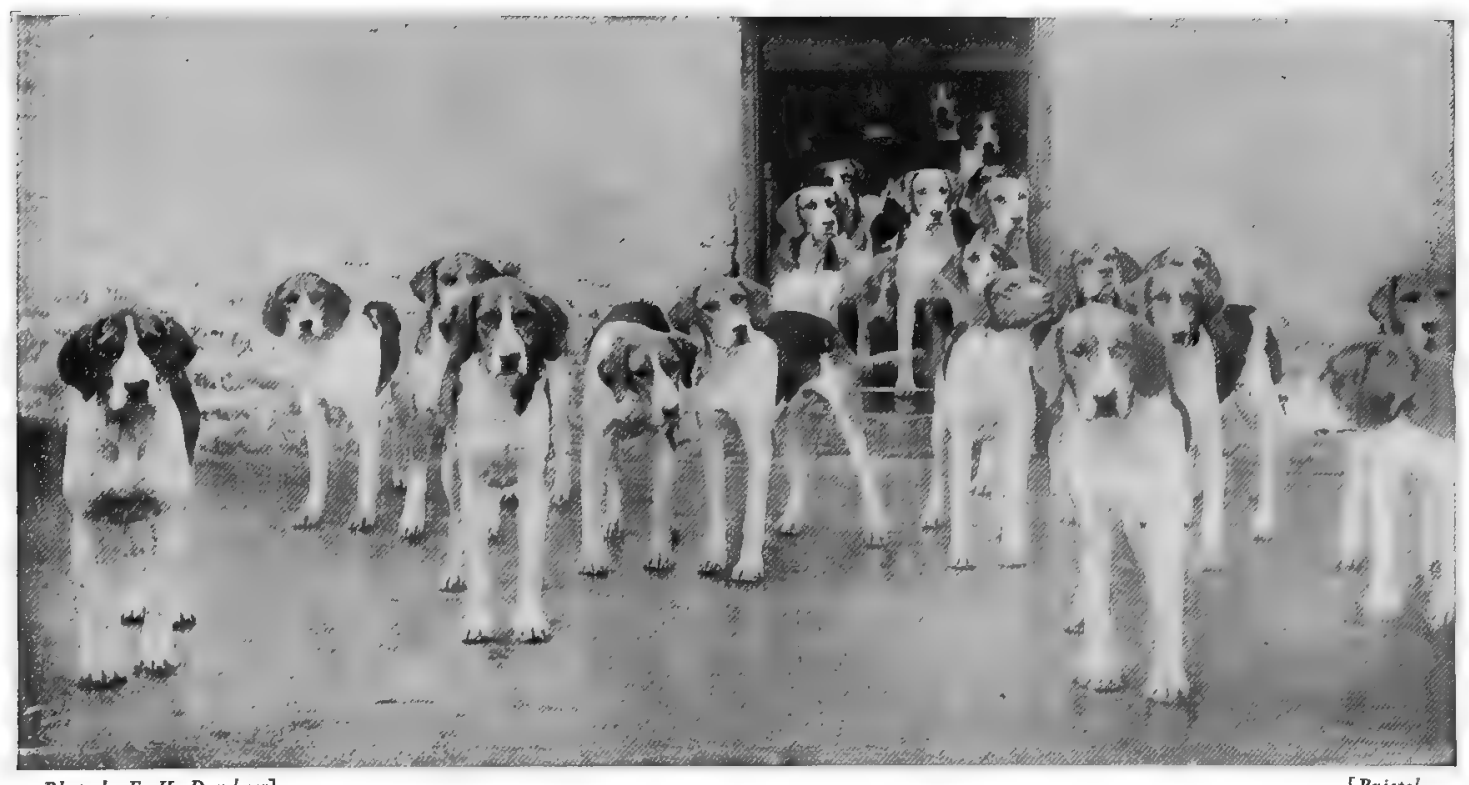

Pboso by F. H. Dembrey]

STAG-HOUND PUPPIES

[Bristol

This gives an interesting group of hounds in kennel 


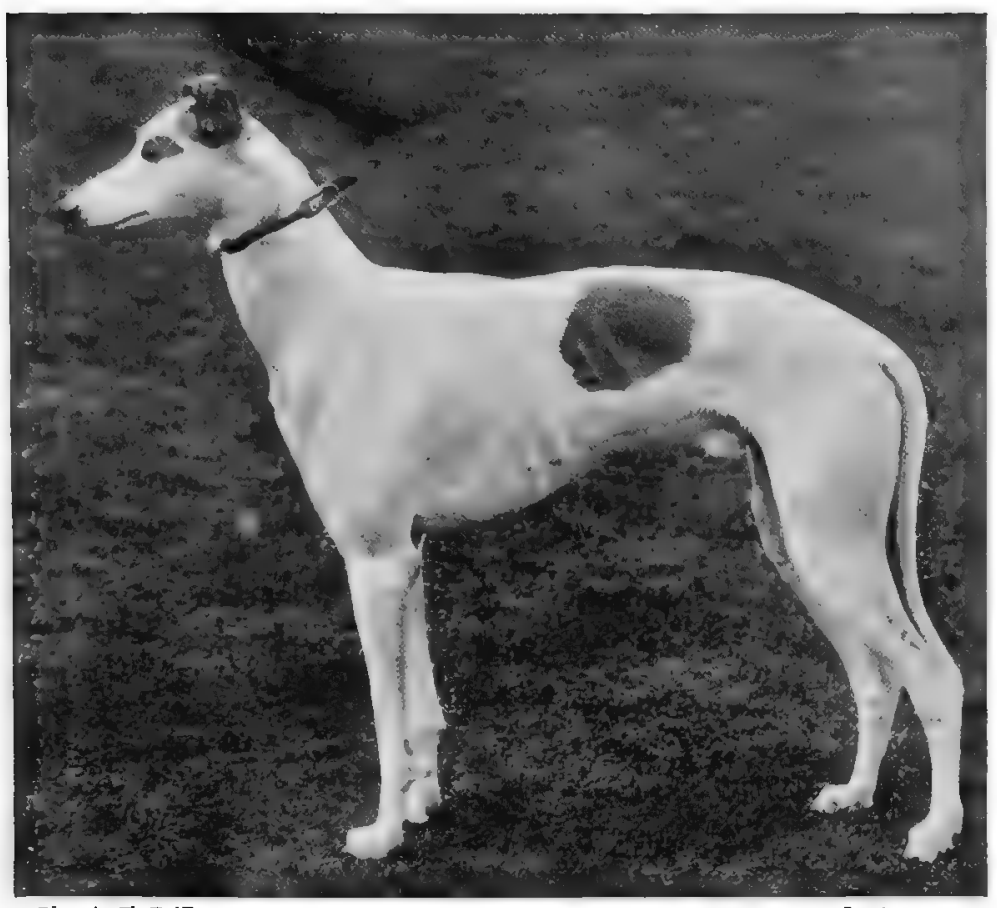

Photo by T. Fall]

GREYHOUND

west of England. I have been fortunate in obtaining one of Mr. E. C. Norrish's celebrated strain as a typical specimen for illustration.

The SETTER group, which comprises three varieties, are all useful and beautiful in their way. The English are usually white, with markings or tickings of blue, lemon, or black; they are rather long and narrow in the head, with bodies and sterns well feathered, and are graceful and active movers. Gordon setters, which are always black and tan in colour, and preferred without any white, are generally larger and stronger in build than the last-named. Irish setters are more on the lines of the English, being a rich tawny A eypical specimen of this elegant variety

red in colour, rather higher on the leg, with narrow skulls, glossy coats, feathered legs and stern, ears set low and lying back, and lustrous, expressive eyes.

Retrievers may be divided into flat-coated and curly-coated. Both are usually black, but other colours are occasionally seen. The coats of the first-named are full, but without curl in them; while the latter have their bodies, heads, legs, thighs, and even tails covered with small close curls. The eyes of both should be dark, and the ears carried closely to the sides of the head. In an article dealing with retrievers, which appeared in the Cornhill Magazine under the title of "Dogs which Earn their Living," the author writes: "There is not the slightest doubt that in the modern retrievers acquired habits, certainly one acquired habit, that of fetching dead and wounded game, are transmitted directly. The puppies sometimes retrieve without being taught, though with this they also combine a greatly improved capacity for further teaching. Recently a retriever was sent after a winged partridge which had run into a ditch. The dog followed it some way down the ditch, and presently came out with an old rusty teakettle, held in its mouth by the handle. The kettle was taken from the dog, amid much laughter; then it was found that inside the kettle was the partridge! The explanation was that the bird, when wounded, ran into the ditch, which was narrow. In the ditch was the old kettle, with no lid on. Into this the bird crept; and as the dog could not get the bird out, it very properly brought out the kettle with the bird in it. Among dogs which earn their living, these good retrievers deserve a place in the front rank." The illustration shows a good flat-coated retriever at work.

The SPAnIel group is rather large, including the English and Irish water-spaniels, the former an old-fashioned, useful sort, often liver or roan, with some white or other markings, and a good deal of curl in the coat and on the ears. His Irish brother is always some shade of liver in colour, larger in the body and higher on the leg, covered with a curly coat, except on the tail, which is nearly bare of hair, with a profusion of hair on the top of the head, often hanging down over the eyes, giving a comical appearance, and increasing his Hibernian expression. They 


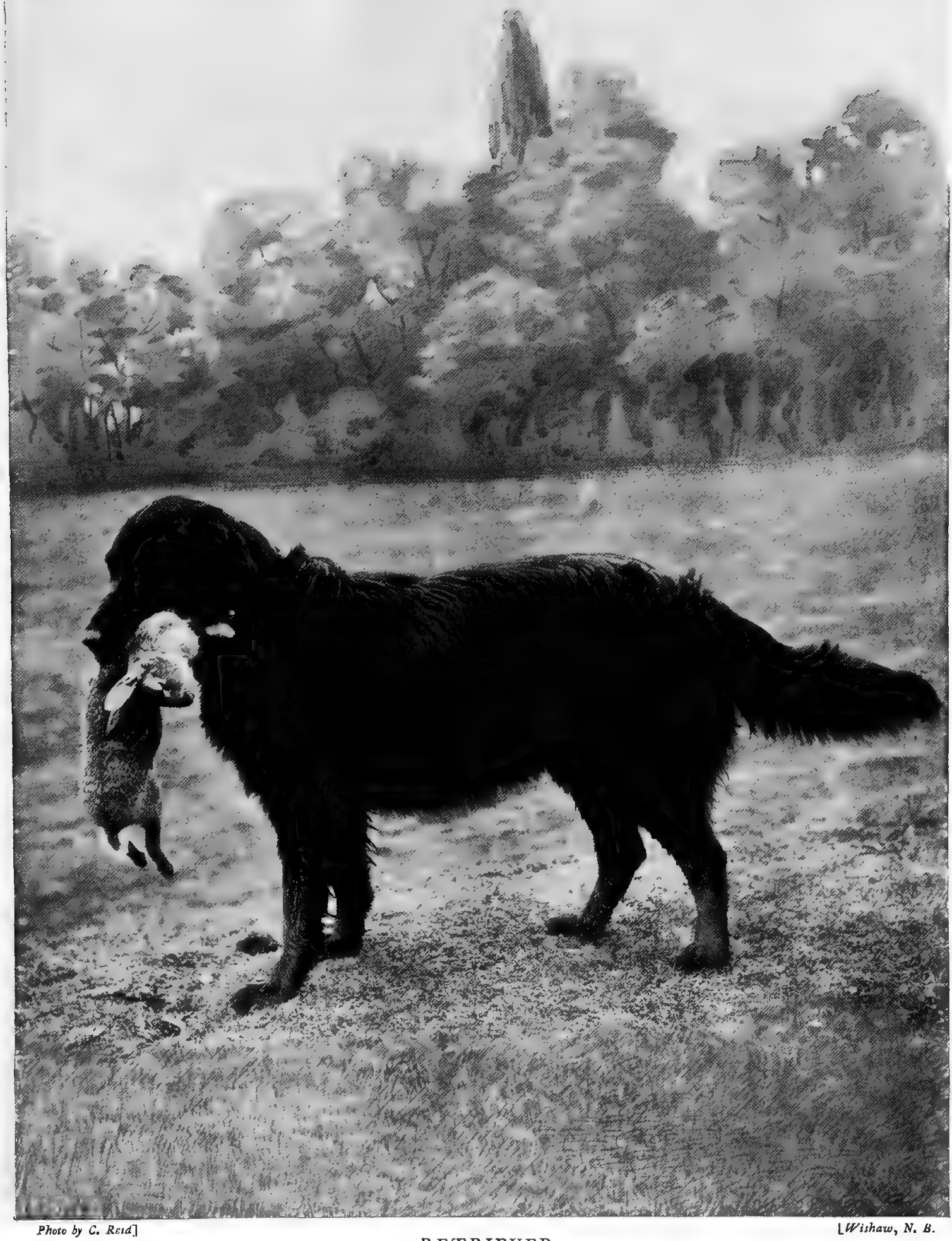

Photo by C. Retd]

RETRIEVER

LWishaw, N. B.

This represents a flat-coated retriever at work, and is remarkably true to life 


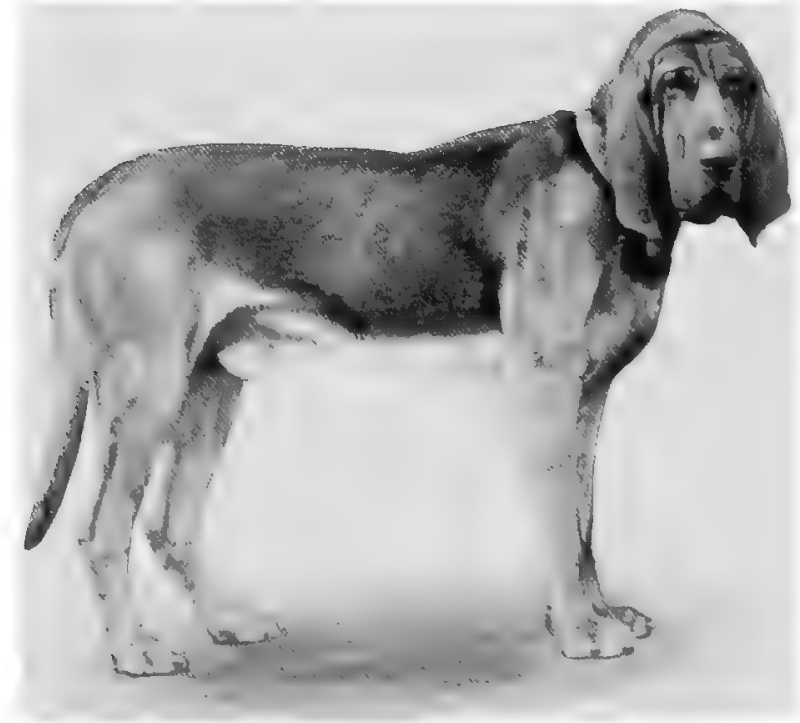

\section{BLOOD-HOUND}

This photograph shows what an almost perfect blood-hound should be like

make lively, affectionate companions and grand assistants at waterfowl-shooting.

Clumber Spaniels are always a creamy white, with lemon or light tan markings, and are rather slow and deliberate in their movements, but have a stylish, high-class look about them.

Sussex Spaniels are also rather heavy in build and of muscular frame, but can do a day's work with most others. They are a rich copper-red in colour, with low short bodies, long feathered ears, full eyes of deep colour, and are very handsome.

Black Spaniels should be glossy raven-black in colour, with strong muscular bodies on strong short legs, long pendulous ears, and expressive eyes. Good specimens are in high favour, and command long prices. I regret I cannot find room for an illustration of this breed, so deservedly popular.

COCKERS, which are shorter in the back, higher on the leg, and lighter in weight, being usually under $25 \mathrm{lbs}$., are very popular, full of life, and very attractive in appearance.

BASSET-HOUNDS, both rough-and smooth-coated, are probably the most muscular dogs in existence of their height, with much dignity about them. In the Sporting Teams at the Royal Agricultural Hall there were some thirteen or fifteen teams of all kinds of sporting dogs, and of these a team each of rough and smooth bassets was in the first four.

DAchshunds are often erroneously treated as Sporting Dogs. There are certainly not so many supporters of the breed as formerly. Their lean heads, with long hanging ears, long low bodies, and crooked fore legs, give them a quaint appearance. The colours are usually shades of chestnut-red or black and tan; but some are seen chocolate and "dappled," which is one shade of reddish brown, with spots and blotches of a darker shade all over it.

GREAT Danes, though mostly classed amongst Non-sporting Dogs, have much of the hound in their bearing and appearance. The whole-coloured are not so popular as the various shades of brindle and harlequin, but I have seen many beautiful fawns, blues, and other whole colours.

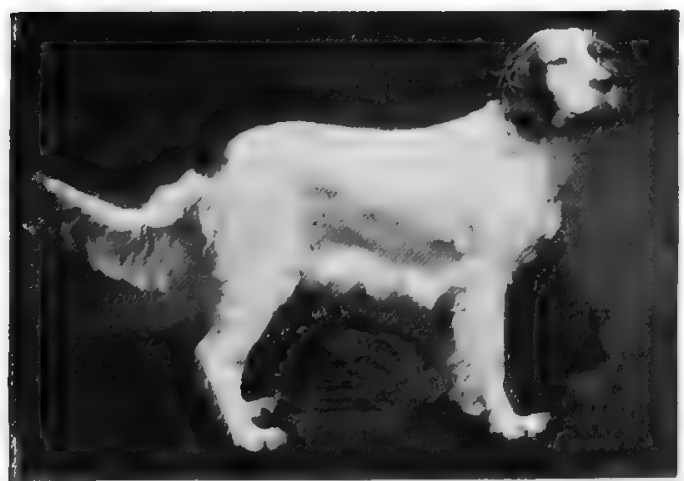

ENGLISH SETTER

A typical but rather coarse specimen of a beautiful variety

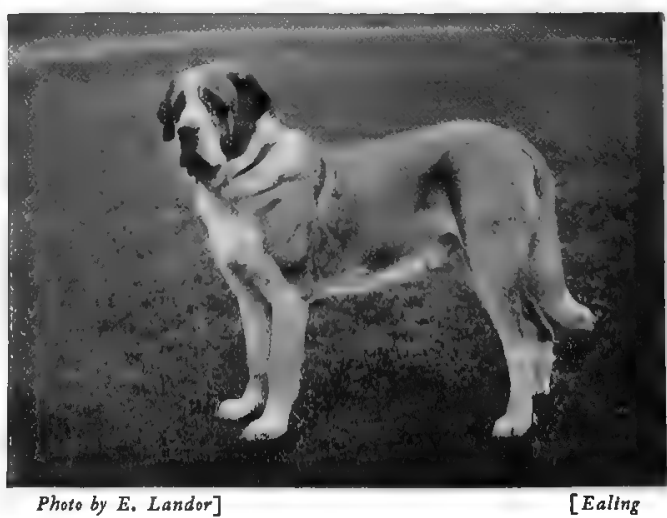

SMOOTH-COATED SAINT BERNARD The illustration gives a capical idea of these handsome dogs 
They are being bred with small natural drooping ears. One of the first I remember seeing exhibited was a large harlequin belonging to the late Mr. Frank Adcock, with the appropriate name of "Satan," as, although always shown muzzled, he required the attentions of three or four keepers to deal with him; and at one show I attended he overpowered his keepers, got one of them on the ground, tore his jacket off, and gave him a rough handling.

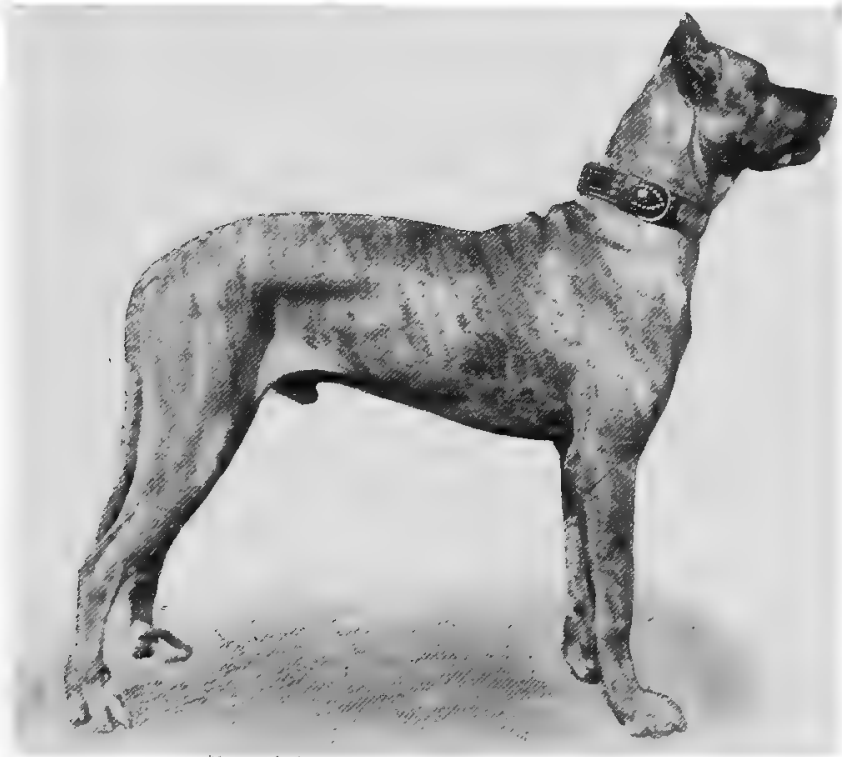

Photo by Fratelli Alinari] GREAT DANE

This shows a typical specimen of this breed, with cropped ears, which will be discontinued in show dogs
Non-SPORTing VARIETies.

SaINT Bernards, although sometimes exceeding 3 feet at the shoulder, are as a rule very docile and good-tempered, and many are owned by ladies. The coat may be rough or smooth, according to taste; but either are splendid animals. They are sometimes seen sti-coloured, but those with markings_-shades of rich red, with white and black, for preference-are the handsomest. They are still used as "first aids" in the snow on the Swiss mountains. So far as I remember, this is the only breed of dog used for stud and exhibition for which as much as $\$ 7,500$ has been paid; and this has occurred on more than one occasion.

NewfoundLands have re-

gained their place in popularity, and many good blacks and black-and-whites can now be seen. Numerous cases. are on record of their rendering aid to persons in danger of drowning, and establishing communication with wrecked vessels and the shore.

MASTIFFs are looked on as one of the national breeds. Their commanding presence and stately manner make them highly suitable as guards, and they are credited with much attachment and devotion to their owners. The colours are mostly shades of fawn with black muzzle, or shades of brindle. I am able to give the portrait of one of the best specimens living, belonging to $\mathrm{Mr}$. R. Leadbeater.

BULI-DOGS are also regarded as a national breed. They are at present in high favour. The sizes and colours are so various that all tastes can be satisfied. Recently there has been a fancy for toy bull-dogs, limited to 22 lbs. in weight, mostly with upright ears of tulip shape. In spite of the many aspersions on their character, bull-dogs are usually easy-going and good-tempered, and are often very fastidious feeders-what fanciers call " bad doers."

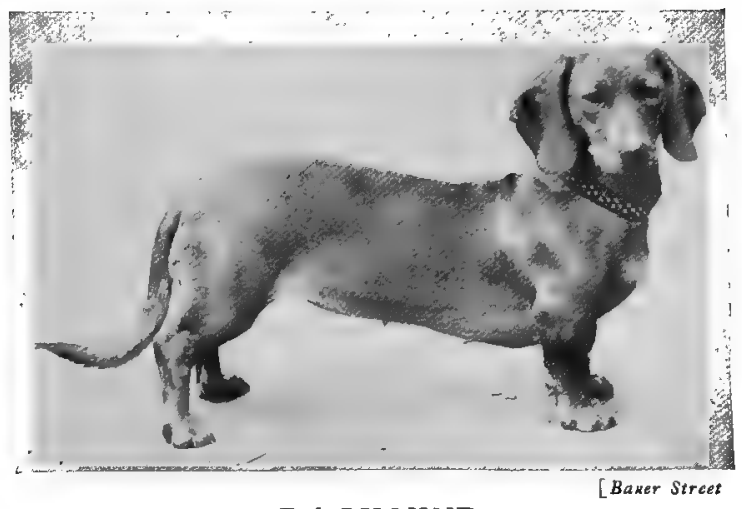

D ACHSUND

The pliotograph conveys a fair idea of these quaint degs 


\section{I02 THE LIVING ANIMALS OF THE WORLD}

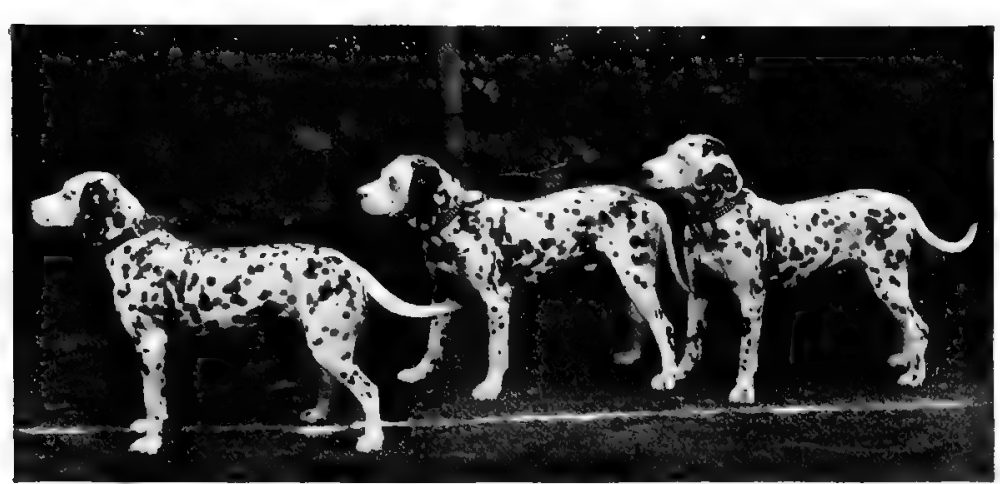

Photo by Kitchener Portrait Co.

\section{A LMATIANS}

All are typical, but the first is the best in quality and marking

Rough Collies are very graceful, interesting creatures, and stand first in intelligence among canines. They are highly popular. Several have been sold for over $\$ 5,000$, and the amounts in prize-money and fees obtained by some of the "cracks" would surprise persons not in " the fancy." A high-bred specimen " in coat" is most beautiful. The colours most favoured are sables with white markings; but black, white, and tans, known as "tricolors," are pleasing and effective. I quite hoped to give a portrait of one of the most perfect of present-day champions, belonging to $\mathrm{H}$. H. the Princess de Montglyon, but could not find room.

Sмоотн Collies are a handsome breed, full of grace, beauty, and intelligence, and very active and lively. A favourite colour is merle, a sort of lavender, with black markings and tan and white in parts, usually associated with one or both eyes china-coloured. Specimens often win in sheep-dog trials; a bitch of mine won many such, and was more intelligent in other ways than many human beings.

Old ENGLish SheEp-dogs are a most fascinating breed, remarkably active, possessed of much endurance and resource, and very faithful and affectionate. I have often made long

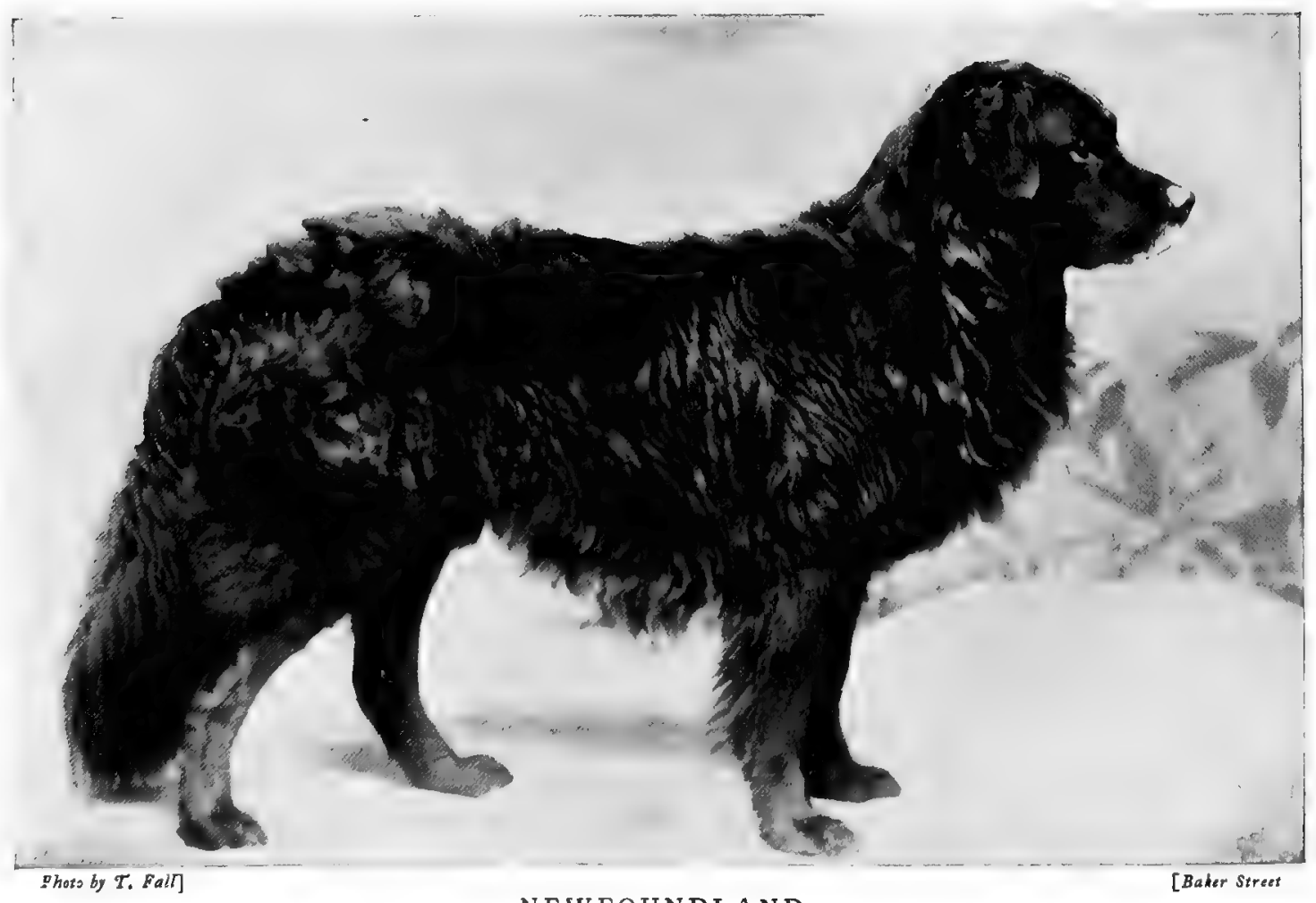

NEW FOUNDLAND

The dog shozsn here gives a good idea of size and character, but is not in best coat 
journeys through cross-country roads accompanied by one or more of them, and never knew them miss me, even on the darkest night or in the crowded streets of a large town. The favourite colour is pigeon-blue, with white collar and markings. The coat should be straight and hard in texture. The illustration is from a portrait of one of the best bitches ever shown, belonging to Sir $\mathrm{H}$. de Trafford.

Dalmatians are always white, with black, liver, or lemon spots, the size of a shilling or less, evenly distributed over the body, head, ears, and even tail, and pure, without mixture of white. There is much of the pointer about this variety, which has long been used for sporting purposes on the continent of Europe. I can testify to their many good qualities as companions and house-dogs. To quote again from the article above mentioned: "It is commonly believed that the spotted carriage-dogs once so frequently kept in stables were about the most useless

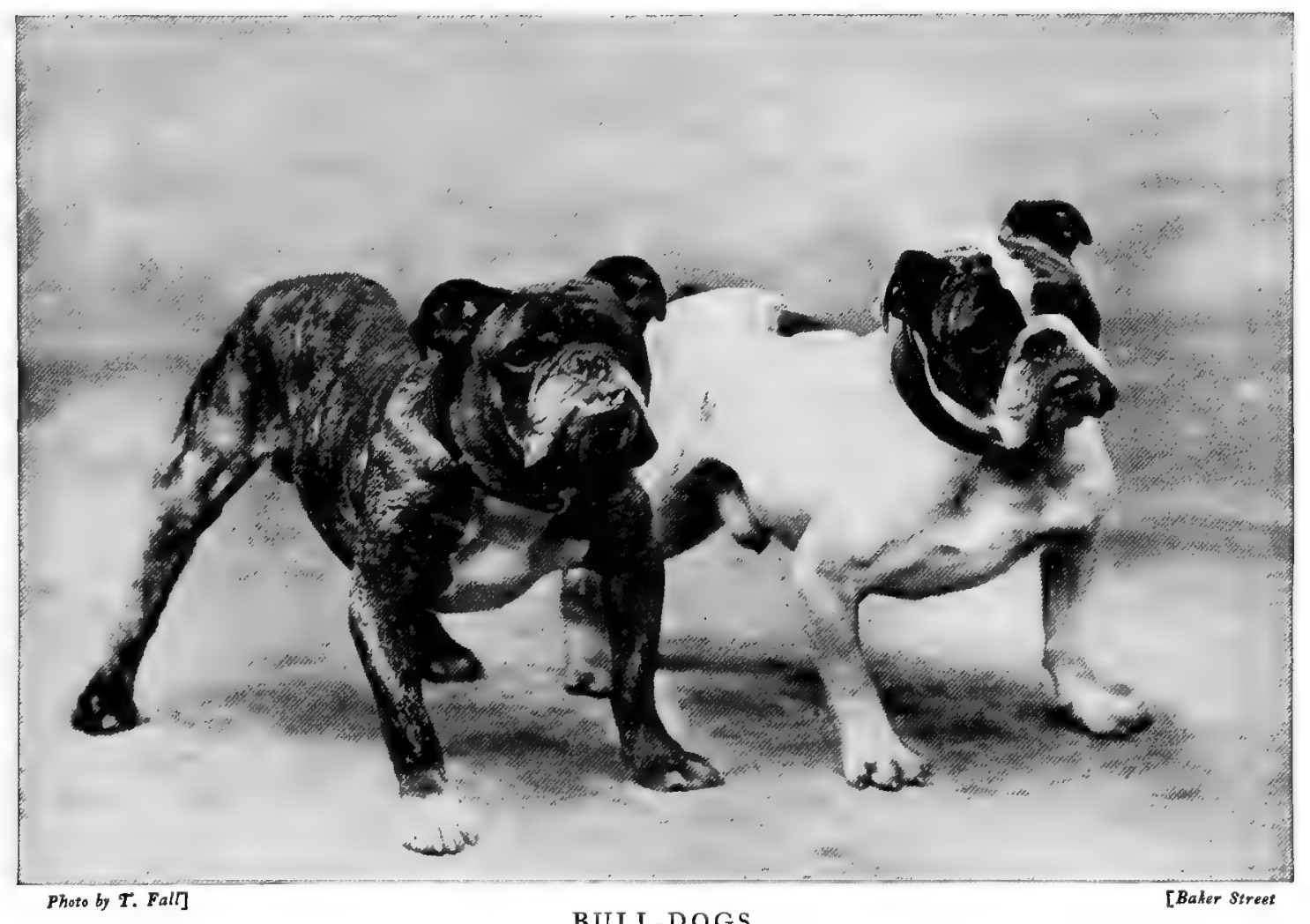

The photograph is remarkably good and characteristic of this variety

creatures of the dog kind, maintained only for show and fashion. This is a mistake. They were used at a time when a traveling-carriage carried, besides its owners, a large amount of valuable property, and the dog watched the carriage at night when the owners were sleeping at country inns. We feel we owe an apology to the race of carriage-dogs. . . . While this dog is becoming extinct, in spite of his useful qualities, other breeds are invading spheres of work in which they had formerly no part." There is only one point in which I differ from the above, and that is contained in the last sentence. There are a number of enthusiastic breeders very keen on reviving interest in this variety, and I have during the last few years had large entries to judge, so that we shall probably see more of them in the future.

POODLES are of many sizes and colours. They are very intelligent, easily taught tricks, and much used as performing dogs. They have various kinds of coats: corded, in which the hair hangs in long strands of ringlets; curly, with a profusion of short curls all over them, something 


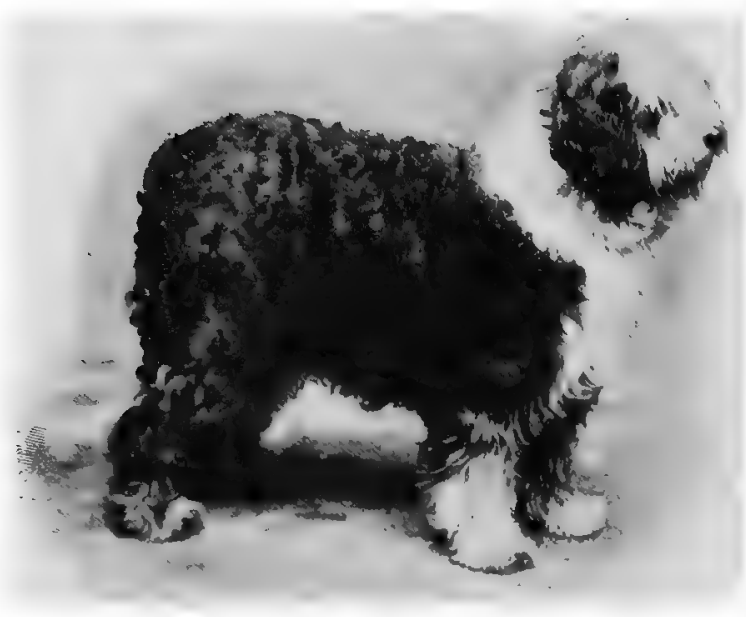

\section{OLD ENGLISH SHLEP-DOG} This is a remarkably fine photograph of a well-known specimen of this
interesting variety like retrievers; and $f$ uffy, when the hair is combed out, to give much the appearance of fleecy wool. A part of the body, legs, head, and tail is usually shorn.

BULL-TERRIERS are now bred with small natural drooping ears, and should have long wedge-shaped heads, fine coats, and long tails. There is also a toy variety, which hitherto has suffered from round skulls and tulip ears, but is rapidly improving. I have bred many as small as 3 lbs. in weight. In each varicty the colour preferred is pure white, without any markings, and with fine tapering tails.

IRISH TERRIERs are very popular, and should be nearly wholly red in colour, with long lean heads, small drooping ears, hard coats, not too much leg, and without coarseness. They make good comrades.

Bedlington Terriers have long been popular in the extreme north of England, and are another fighting breed. It is indeed often difficult to avoid a difference of opinion between show competitors. Their lean long heads, rather domed skulls, with top-knot of lighter hair, long pointed ears, and small dark eyes, give them a peculiar appearance. The coats, which are "linty" in texture, should be shades of blue or liver.

Three breeds, all more or less hard in coat-texture, and grizzled in colour on heads and bodies, while tanned on other parts, are Airedale, Old English, and Welsh Terriers, which may be divided into large, medium, and small. The first-named make very good all round dogs; the Old English, less in number, make useful dogs, and are hardy and companionable; while Welsh terriers are much the size of a small wire-haired fox-terrier, but usually shorter and somewhat thicker in the head. I intended one of Mr. W. S. Glynn's best dogs to illustrate the last-named.

FOX-TERRIERS are both smooth- and wire-haired. Their convenient size and lively temperament make them very popular as pets and companions for both sexes and all ages. The colour is invariably white, with or without markings on head or body, or both.

Black-And-Tan and White English

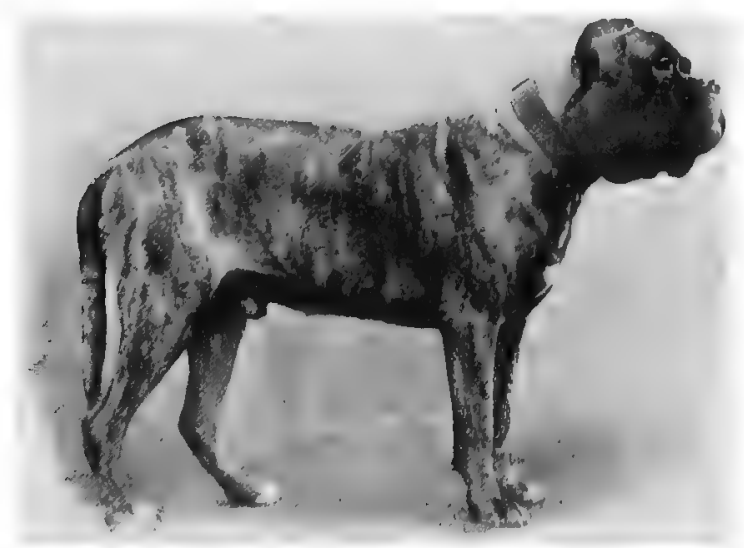

MASTIFF Terriers are built upon the same lines, differing chiefly in colour, the former being raven-black, with tan markings on face, legs, and some lower parts of the body, and the latter pure white all over. Both should have small natural drooping ears, fine glossy coats, and tapering sterns. The toy variety of the former should be a miniature of the larger, and is very difficult to produce of first-class quality.

SCOTTISH TERRIERs are very interesting, often with much "character" about them. The usual colours are black, shades of gray, or brindle, but some are seen fawn, stonecolour, and white. The ears should be carried bolt upright, the coat as hard as a badger's, 


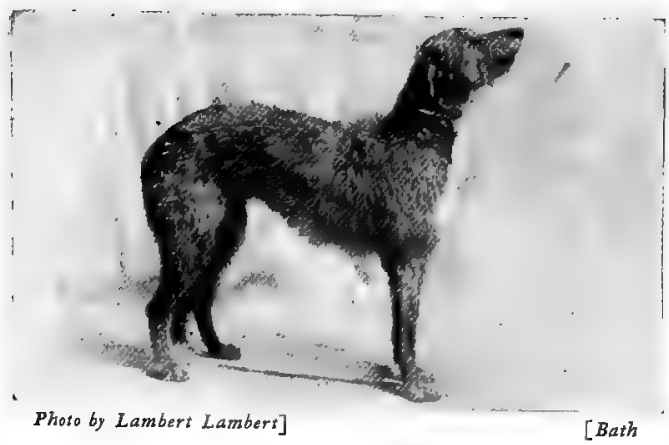

DEER-H O UND

his is a capital portrait of one of the best of this graceful variet

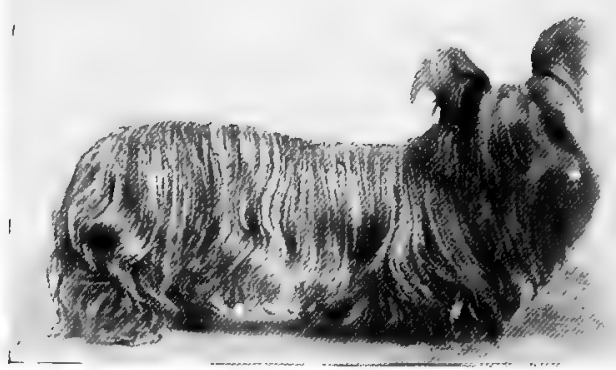

Photo by Villiers $\mathfrak{s}$ Sons]

Newport

SKYE TERRIER

The photograph is of a well-known winner in show form

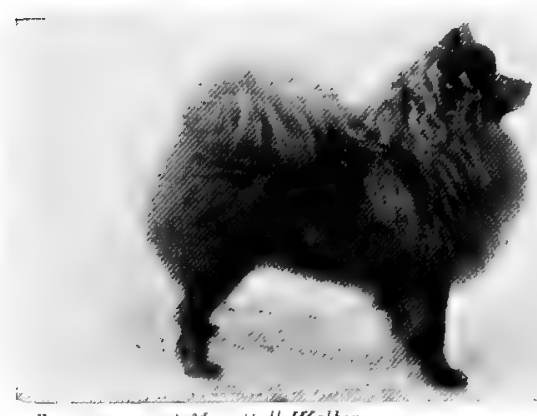

Br permissuen of Mirs. Hall-Walker

POMER A N A N

Probably about the best all-black Toy Pomeranian ever shown

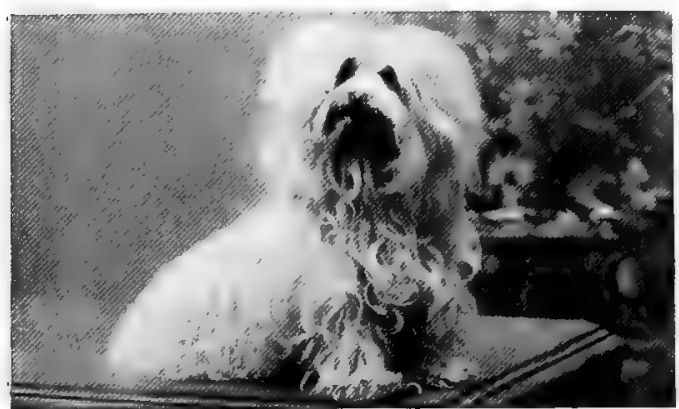

Photo by i. N. Taylor]

[Cowley Road

MALTESE TOY TERRIER

$A$ very excellent representation of one of the best specimens of the present day

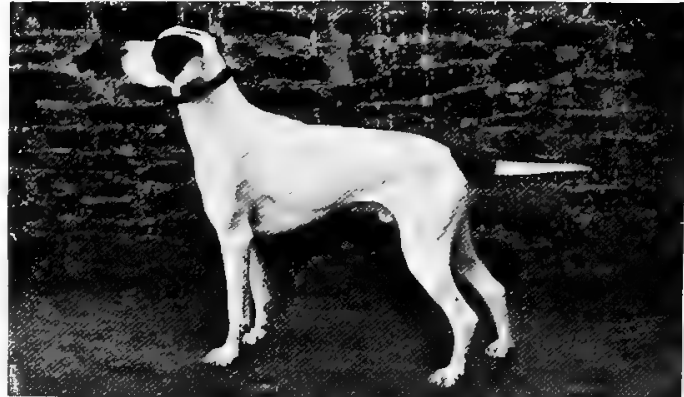

Photo by $H$. Cornish]

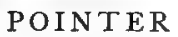

[Croditon

This is a young dog not yet shown, bue full of quality and type

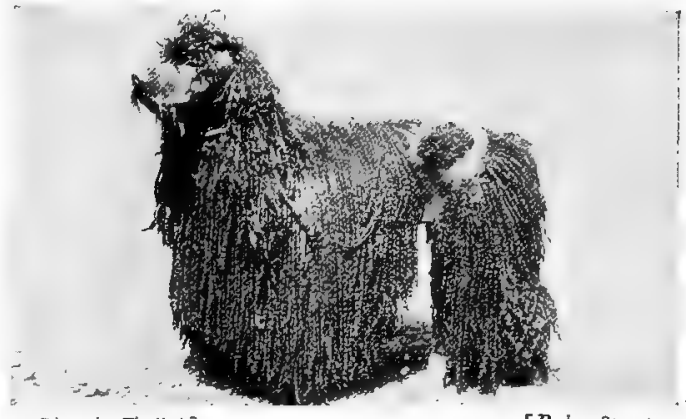

Photo by $T$. Fall]

[Baker Sereet

CORDED POODLE

The length of the cords of which the coat is composed is clearly shown

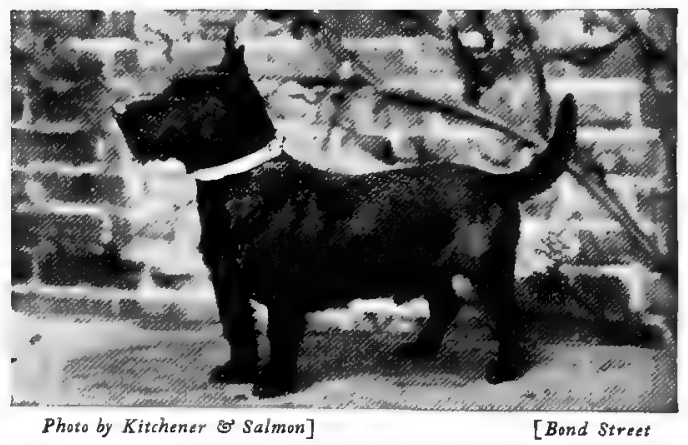

SCOTTISH TERRIER

A smart picture of one of the best of these popular dogs

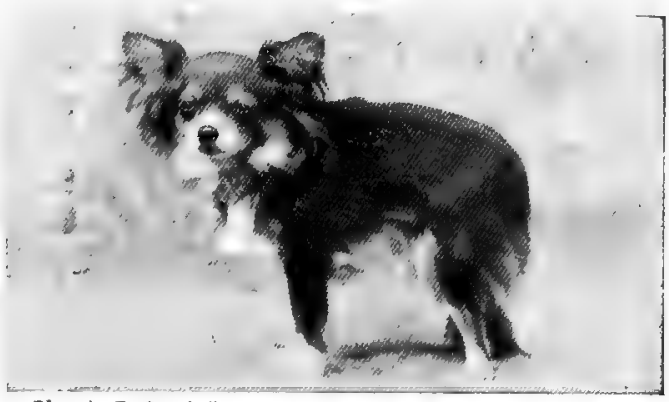

Photo by E. Landor]

B UT T ERFLY-DOG

The photograph gives an excellent ides of this somezuhat rare variety 


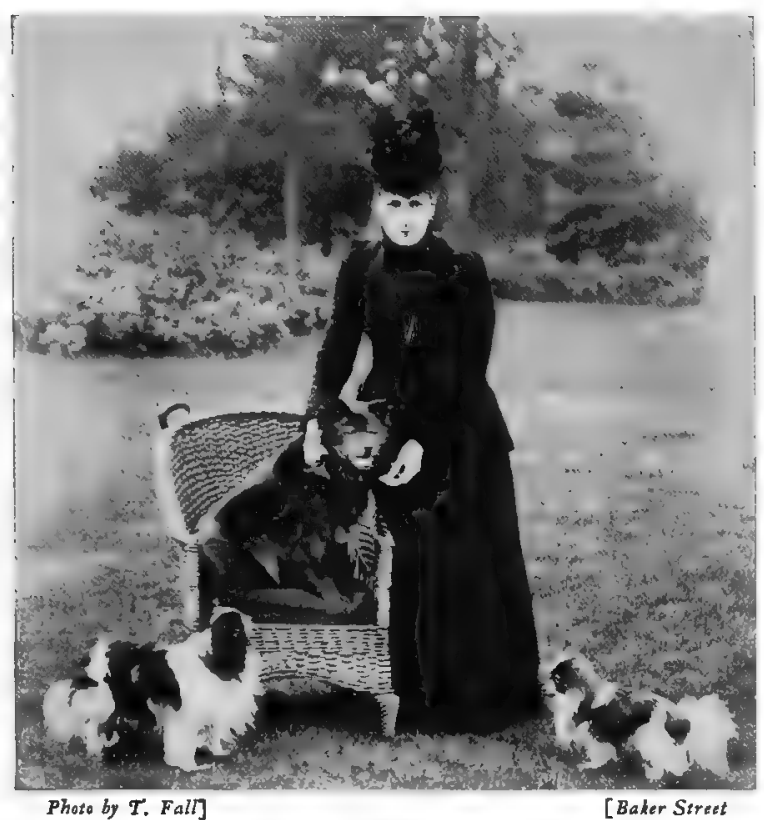

HER MAJESTY QUEEN ALEXANDRA, WITH CHOW AND JAPANESE SPANIELS

teeth even, small dark expressive eyes, fore legs straight, the back short. One I brought from Skye many years since I took with me when driving some miles into the country; coming back by a different route, he missed me; but on nearing my starting-point I found him posted at a juncture of four roads, by one of which I must return. He could not have selected a better position. The illustration is that of a first-rate specimen of the variety, "Champion Balmacron Thistle."

Dandie Dinmont Terriers have many quaint and charming ways. They are very strongly built, being among the most muscular of the terriers, of high courage, devotedly attached to their owners, and admirably adapted for companions, being suitable for indoors or out, and at home anywhere. The colours are pepper (a sort of darkish irongray) and mustard (a yellowish red fawn), both with white silky hair on head, called the top-knot, and lustrous dark eyes, very gipsylike and independent in expression.

Skyes, both Prick - and Drop-EAREd, are another Scottish breed which well deserve their popularity, as they are thorough sporting animals. The colours are chiefly shades of dark or light gray, but sometimes fawn with dark points and whites are seen. The texture of coat should be hard and weather-resisting ; the eyes dark and keen in expression; bodies long, low, and well knit; legs straight in front; even mouths; tails carried gaily, but not curled over the back.

Schipperkes are of Belgian origin. To those who do not know them, they are something like medium-sized Pomeranians, short of coat, but without tails. They are nearly always pure black in colour, with coats of hardish texture, fullest round the neck and shoulders, the ears standing straight up like darts, short cobby bodies, and straight legs. They make smart guards and companions.

Chows originally came from China, but are now largely bred here. They are square-built sturdy dogs, with dense coats, tails carried over the side, blunt-pointed ears, and rather short

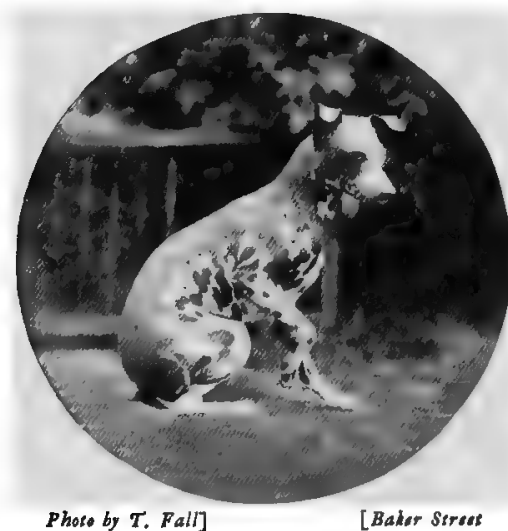

SA N D-D O G

A quaint picture of a quaint variety, quite hair less, and much the colour of Castile soap thick heads. They have a little of a large coarse Pomeranian, with something of an Eskimo about them, but are different from either, with a type of their own. The colour is usually some shade of red or black, often with a bluish tinge in it. One marked peculiarity is that the tongues of chows are blueblack in colour.

Pomeranians can be procured of any weight from 3 to 30 lbs., and of almost every shade of colour. At present brown of various shades is much in favour, but there are many beautiful whites, blacks, blues, sables, and others. They are very sharp and lively, and make charming pets and companions. Really good specimens command high prices. The illustration is of one of the best of his colour ever seen"Champion Pippin."

Pugs, both fawn and black, are old-fashioned favourites 
very quaint and peculiar in appearance. They should have square heads and muzzles, with small ears, large protruding eyes, short thick bodies, and tails tightly curled over the back. The illustration, "Duchess of Connaught," is of a well-known winner.

Maltese TerRiers are very beautiful when pure bred. They have a long straight coat of silky white hair nearly reaching the ground, black nose and eyes, and the tail curled over the back of their short cobby body. Their beauty well repays the trouble of keeping them in good condition. The illustration, from a photograph taken for this article, is that of the high-class dog "Santa Klaus."

Yorkshire Toy Terriers, with their steel-blue bodies and golden-tanned faces, legs, and lower parts, and long straight coats, require skilful attention to keep in order, but are very attractive as pets.

Toy Spaniels are very old members of the toy division, dating from or before the time of King Charles: KING Charles Spaniels being black and tan; PRINCE Charles SPAniels black, white, and tan; another strain, the BlenheIm,

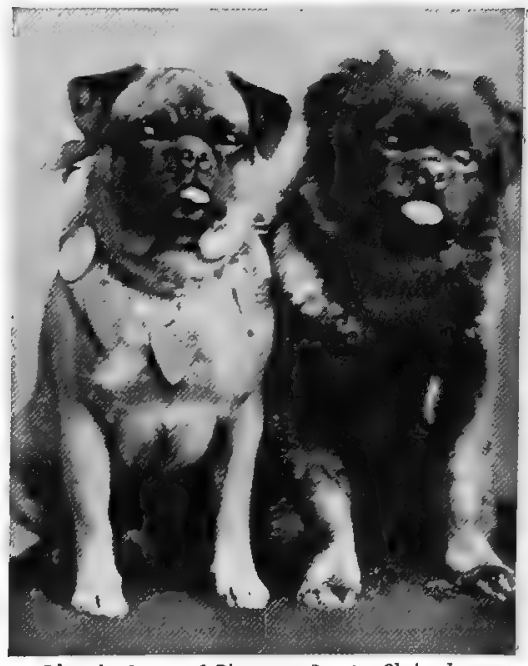

Photo by County of Gloucester Studio, Cheltenham PUG AND PEKINESE SPANIEL A typical portrait of two well-known winners in these popular varieties white, with shades of reddish-tan markings on the head and body, and a spot of same colour on forehead; and the RUBY, a rich coppery red all over. They should be small and stout in size and shape, without coarseness, long in the ear, with large full protruding eyes of dark colour, a short face, a straight coat, and not leggy.

JAPANESE SPANIELs carry heavy coats, usually black, or yellow, and white in colour, shorter in the ears, which are carried more forward than in the last-named, broader in the muzzle, with nearly flat faces, dark eyes, and bushy tails carried over the back. They have very short legs, and their hair nearly reaches the ground as they walk. When I kept them they were much larger in size, but they are often now produced under 6 lbs. in weight.

Pekin Spaniels, the last of the toy spaniels I need mention, come from China. They should have soft fluffy coats, tails inclined to turn over the back, short faces, broad muzzles, large lustrous eyes, and a grave, dignified expression. The colour is usually some shade of tawny fawn or drab, but I have seen them black and dark brown; whatever colour, it should be without white. The illustration, Mrs. Lindsay's “Tartan Plaid," was one of the early importations.

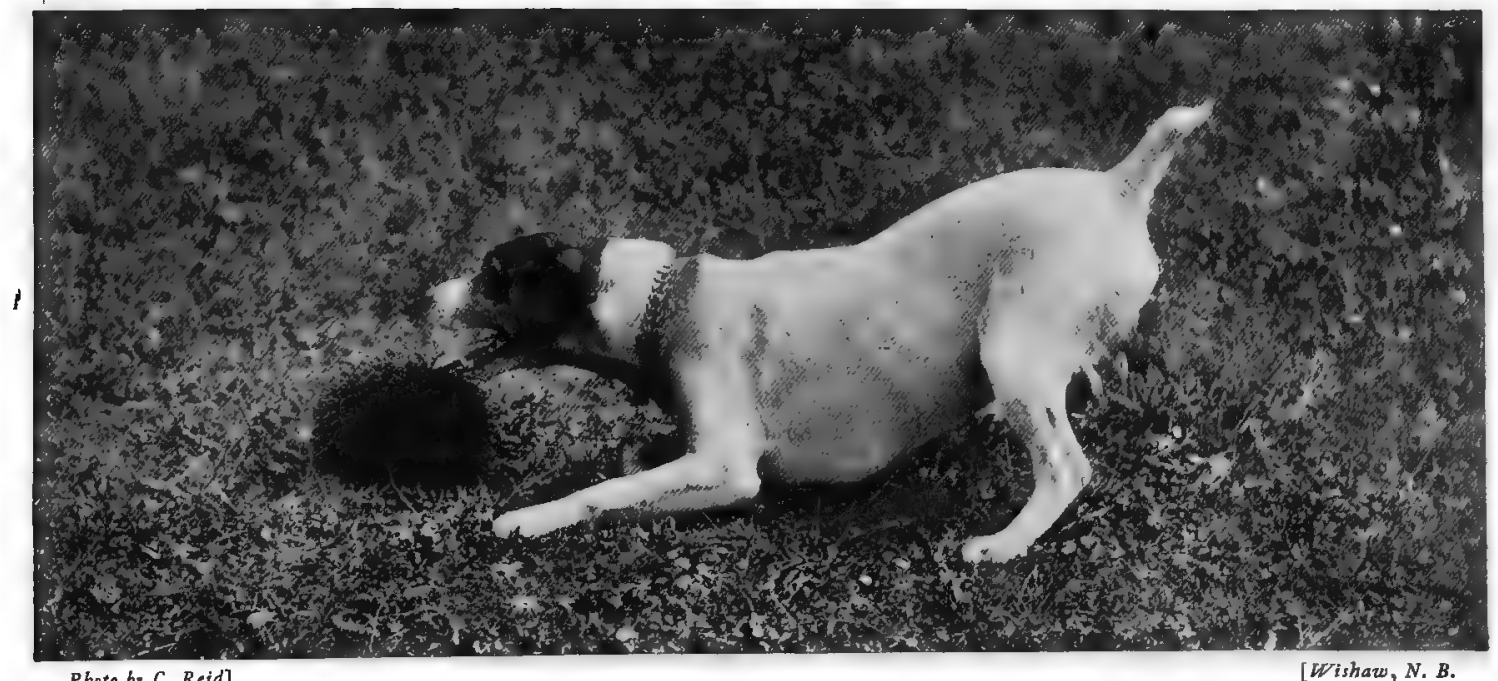

Pboto by C. Reid] 


\section{08 THE LIVING ANIMALS OF THE WORLD}

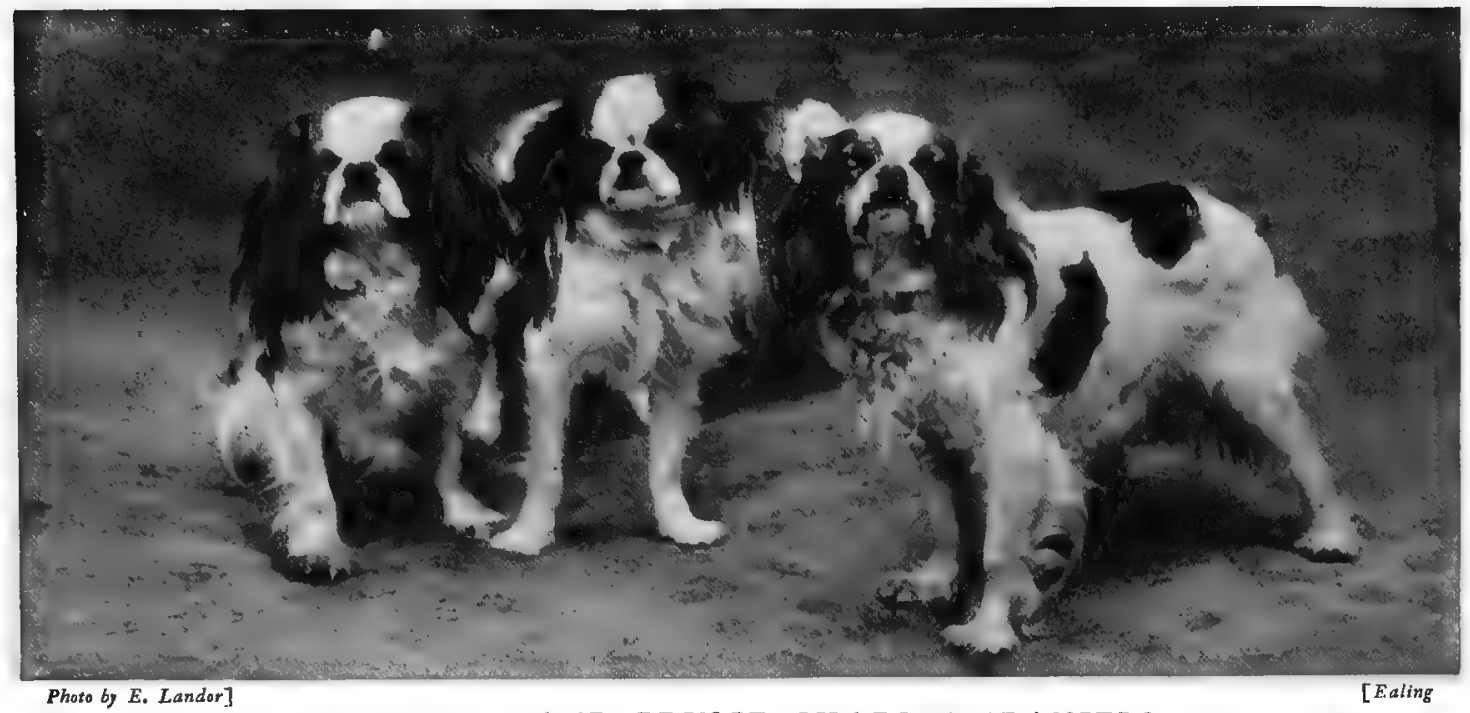

BLENHEIM AND PRINCE CHARLES SPANIELS

This litt'e group with serve to show the appearance of these charming littie pets

ItALIAn GReyhounds, another old-fashioned variety of toy dog, should not exceed i 2 lbs. in weight, but in my opinion are better if they are some pounds less. Much like miniature greyhounds in shape and build, they are elegant, graceful little creatures, very sensitive to cold. Shades of fawn, cream, or French gray are most common; but some are slate-blue, chestnut-red, and other tints. Of late years the breed has met with more encouragement, and there is less fear of its being allowed to die out.

Griffons Brusselors have been greatly taken up the last few years. They are something like Yorkshire toy terriers in size and shape, but with a shortish harsh coat, generally of some shade of reddish brown, very short face, small shining dark eyes, heavy under-jaw, short thick body, and an altogether comical appearance. Imported specimens, particularly before reaching maturity, are often difficult to rear.

The African SAND-DOG occasionally seen in this country (mostly at shows) is remarkable for being entirely hairless, except a few hairs of a bristly character on the top of the head and a slight tuft at the end of the tail; in colour, something in shape and terrier, and very susceptible to

Having been supplied with an will say a few words about this numbers at Constantinople and roam about unclaimed, and act as to divide the places they inhabit into leader, and resent any interference cases where they have made a delate at night; but they are rather a with a little firmness on the part of the descendants of the dogs so often probrium; and, among Eastern peonow the most insulting epithet that ancient times, the dog never seems hunting and pursuing game and guardian of their flocks, herds, and

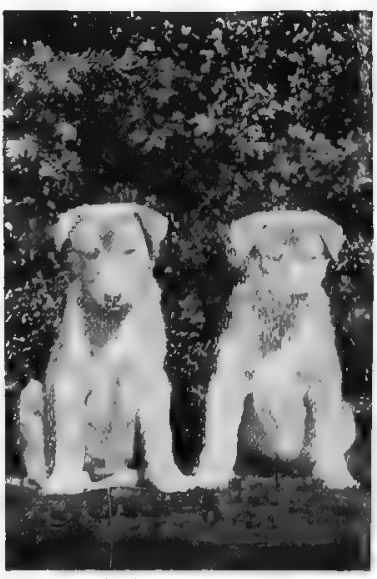
Photo by the Duchess of Bedford,
Woburn Abbey

PARIAH PUPPIES

This capital photograph of a variety seldom seen in this country will be very intertsting it is chiefly blue-black or mottled size like a coarse black-and-tan cold.

illustration of Pariah Puppies, I variety, which is seen in large other Eastern cities, where they amateur scavengers; they are said districts or beats, each with its own with their authority. I have known termined attack on travelers out cowardly race, and easily repulsed the attacked. Probably these are mentioned in Scripture with opples, to call a man "a dog" is even can be used. By the Jews, in to have been used, as with us, in wild animals, but merely as a sometimes dwellings. 


\section{CHAPTER VI}

\section{THE BEARS}

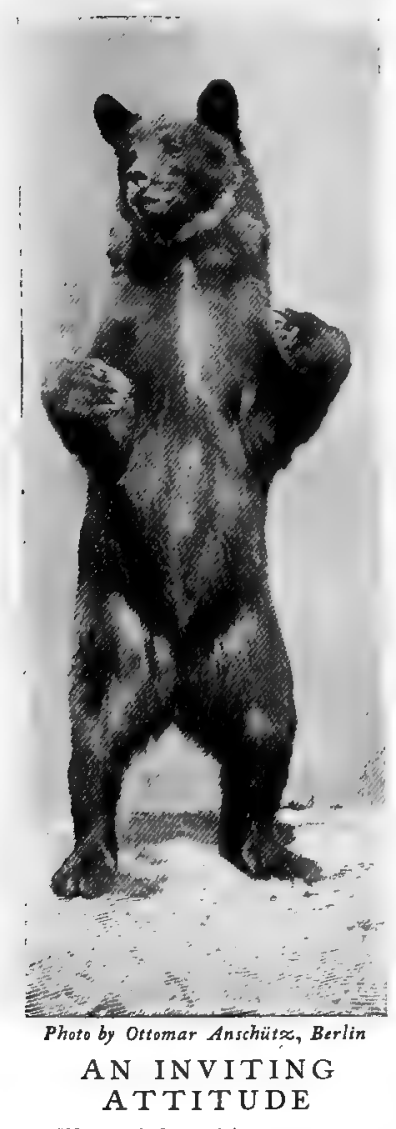

The upright position is not natural to the brown bear. It prefers to sit on its hams, and not to stand

$\mathrm{E}$

XCEPT the great cats, no creatures have longer held a place in human interest than the BEARS. Their size and formidable equipment of claws and teeth give the touch of fear which goes with admiration. On the other hand, they do not, as a rule, molest human beings, who see them employing their great strength on apparently insignificant objects with some amusement. Except one species, most bears are largely fruit and vegetable feeders. The sloth-bear of India sucks up ants and grubs with its funnel-like lips; the Malayan bear is a honey-eater by profession, scarcely touching other food when it can get the bees' store ; and only the great polar bear is entirely carnivorous. The grizzly bear of the Northern Rocky mountains is largely a flesh eater, consuming great quantities of putrid salmon in the Columbian rivers. But the ice-bear is ever on the quest for living or dead flesh ; it catches seals, devours young seafowl and eggs, and can actually kill and eat the gigantic walrus.

Every one will have noticed the deliberate flatfooted walk of the bears. This is due partly to the formation of the feet themselves. The whole sole is set flat upon the ground, and the impressions in a bear's track are not. unlike those of a man's footsteps. The claws are not capable of being retracted, like those of the Cats; consequently they are worn at the tips where the curve brings them in contact with the ground. Yet it is surprising what wounds these blunt but hard weapons will inflict on man-wounds resembling what might be caused by the use of a very large gardenrake. Against other animals protected by hair bears' claws are of little use. Dogs would never attack them so readily as they do were they armed with the talons of a leopard or tiger. The flesh-teeth in both jaws of the bear are

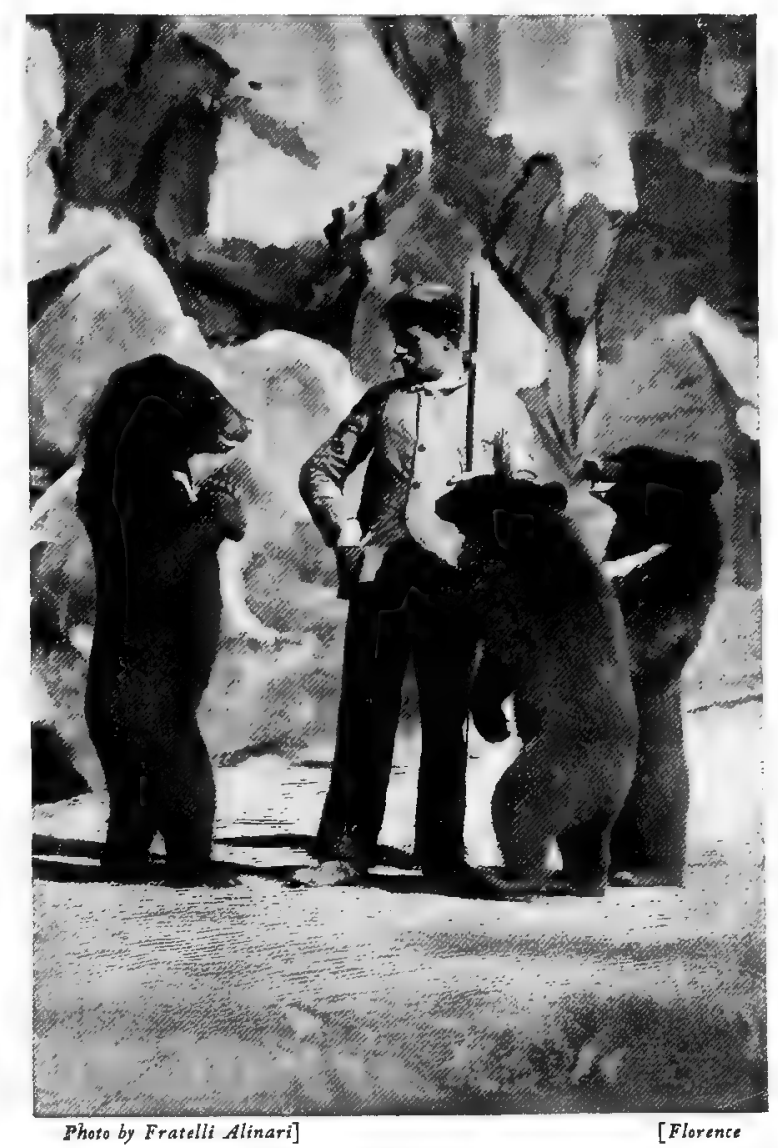

THREE PERFORMING BEARS

Those on the right and left are Himalayan black bears. The wohite collar is plainly seen 
unlike those of other carnivora. The teeth generally show that bears have a mixed diet. Bears appear to have descended from some dog-like ancestor, but to have been much modified.

Except the ice-bear, all the species are short and very bulky. It is said that a polar bear has been killed which weighed I,000 lbs. It is far the largest, and most formidable in some respects, of all the carnivora. The claws of the grizzly bear are sometimes 5 inches long over the outer curve. All bears can sit upright on their hams, and stand upright against a support like a tree. Some can stand upright with no aid at all. Except the grizzly bear, they can all climb, many of them very well. In the winter, if it be cold, they hibernate. In the spring, when the shoots of the early plants come up, they emerge, hungry and thin, to seek their food. Bears were formerly common in Britain, and were exported for the Roman amphitheatres. The prehistoric cave-bears were very large. Their re-

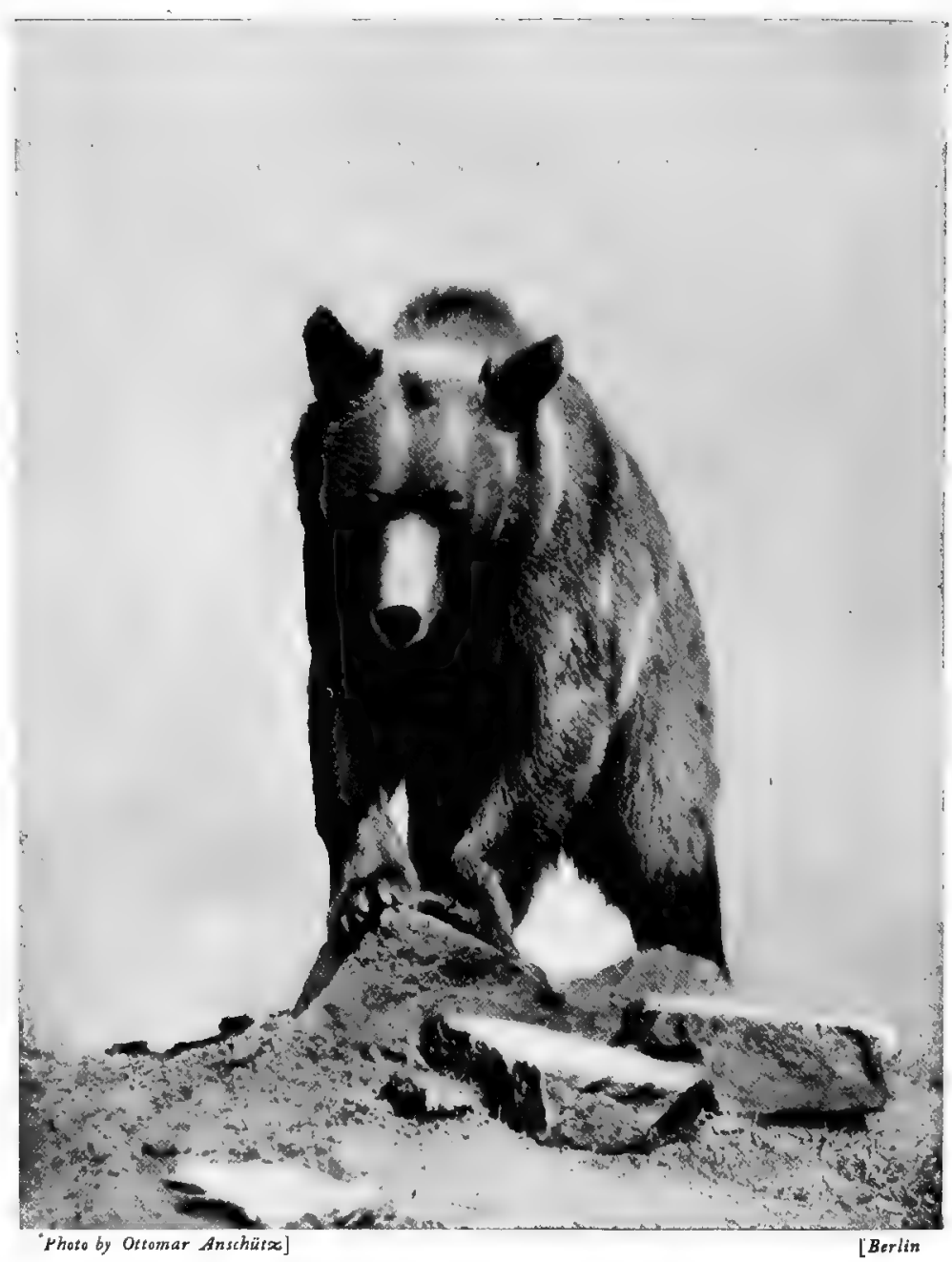

EUROPEAN BROWN BEAR

The specimen of the brown bear of Europe from which this picture was taken was an unusually light and active bear. Its flanks are almost flat

mains have been found in Devon, Derbyshire, and other counties. The species inhabiting Britain during the Roman period was the common brown bear of Europe.

\section{The Common Brown Bear.}

Only one species of bear is found in Europe south of the ice-line, though above it the white ice-bear inhabits Spitzbergen and the islands off the White Sea. This is the Brown BEAR, the emblem of Russia in all European caricature, and the hero of innumerable fragments of folklore and fable, from the tents of the Lapps to the nurseries of American children. Except the icebear, it is far the largest of European carnivora, but varies much in size. Russia is the main home of the brown bear, but it is found in Sweden and Norway, and right across Northern Asia. It is also common in the Carpathian Mountains, in the Caucasus, and in Mount Pindus in Greece. In the South it is found in Spain and the Pyrenees, and a few are left in the Alps. The dancing-bears commonly brought to England and America are caught in the Pyrenees. The "Queen's bear," so called because its owner was allowed to exhibit it at Windsor, was one of these. But lately dancingbears from Servia and Wallachia have also been seen about our roads and streets. In Russia the bear grows to a great size. Some have been killed of $800 \mathrm{lbs}$. in weight. The fur is magnificent in 
winter, and in great demand for rich Russians' sledge-rugs. The finest bear-skins of all are bought for the caps of the Grenadier and Coldstream Guards. In the Alps the bears occasionally visit a cow-shed in winter and kill a cow; but as a rule the only damage done by those in Europe is to the sheep on the hills in the far north of Norway. Tame brown bears are amusing creatures, but should never be trusted. They are always liable to turn savage, and the bite is almost as severe as that of a tiger. Men have had their heads completely crushed

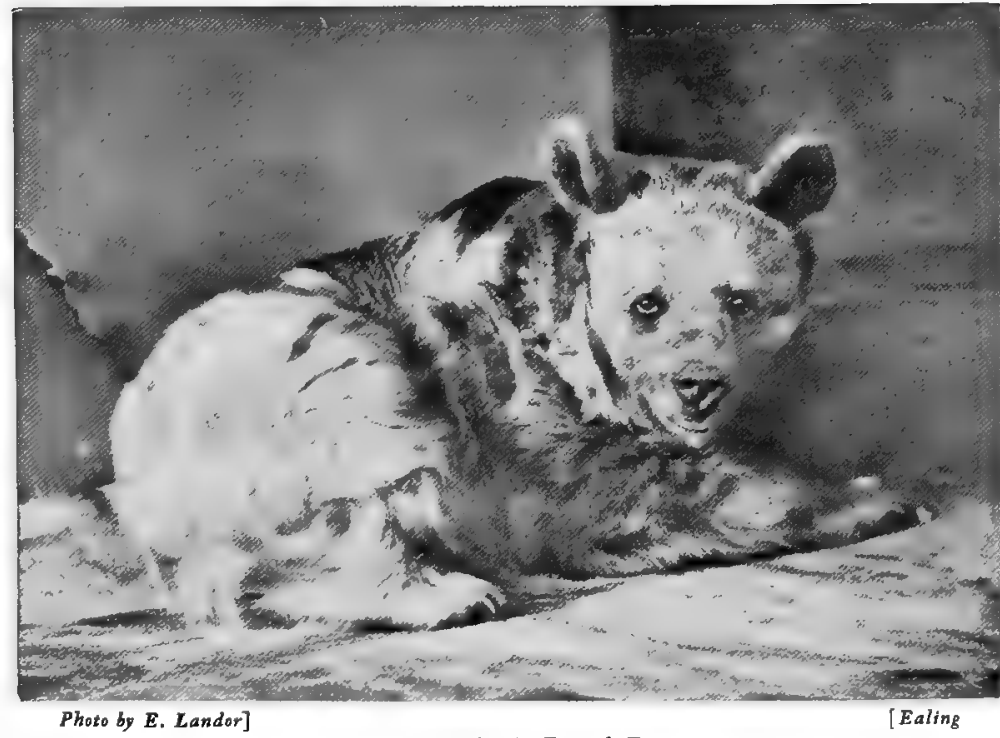

S Y R I A N B A R

This is the bear generally alluded to in the Old Testament in by the bite of one of these animals. In Russia bears are shot in the following manner. When the snow falls, the bears retire into the densest thickets, and there make a half-hut, half-burrow in the most tangled part to hibernate in. The bear is tracked, and then a ring made round the cover by beaters and peasants. The shooters follow the track and rouse the bear, which often charges them, and is forthwith shot. If it escapes, it is driven in by the beaters outside. High fees are paid to peasants who send information that a bear is harboured in this way. Sportsmen in Petrograd will go 300 or 400 miles to shoot one on receipt of a telegram.

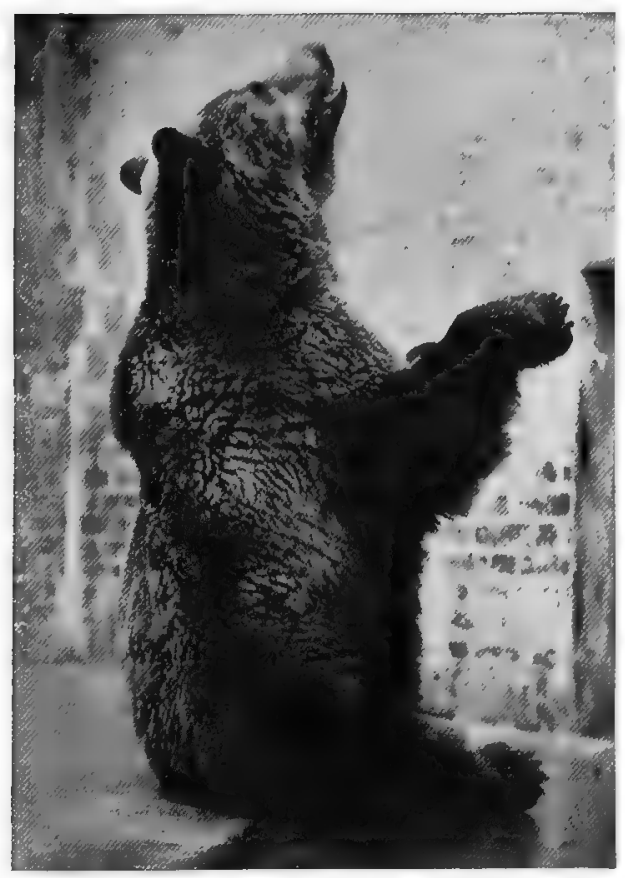

Photo by W. D. Dando?

[Regent's Park

LARGE RUSSIAN BROWN BEAR The picture shorws to what a size and strength the brown bear attains

A Siberian peasant who wished to do a little hunting on his own account had a lively adventure. The bear had the best of it, knocked him down, and so frightfully mangled his arm that he fainted. Bruin then buried him in orthodox bear fashion; and the man, when he came to, which he fortunately did before the bear came back, got up, and made his way to the village. There he was for a long time ill, and all through his sickness and delirium talked of nothing but shooting the bear. When he got well, he disappeared into the forest with his gun, and after a short absence returned with the bear's skin!

\section{The Syrian Bear.}

This bear, which figures in the story of Elisha, is a variety of the brown bear. It is found from the Caucasus to the mountains of Palestine, and is a smaller animal than the true brown bear, weighing about $300 \mathrm{lbs}$. The fur in summer is of a mixed rusty colour, with a whitish collar on the chest. It steals the grapes on Mount Horeb, and feeds upon ripe fruits, apples, chestnuts, corn, and the like. It is then ready to face the long winter sleep. 


\section{The Indian Sloth-BEar.}

Few people would believe that this awkward and ugly beast is so formidable as it is. It is the commonest Indian species, seldom eats flesh, prefers sucking up the contents of a white ants' nest to any other meal, and is not very large; from $200 \mathrm{lbs}$. to $300 \mathrm{lbs}$. is the weight of a male. But the skull and jaws are very strong, and the claws long and curved. As they are used almost like a pickaxe when the bear wishes to dig in the hardest soil, their effect upon the human body can be imagined.

Sir Samuel Baker says that there are more accidents to natives of India and Ceylon from this species than from any other animal.

Mr. Watts Jones writes an interesting account of his sensations while being bitten by one

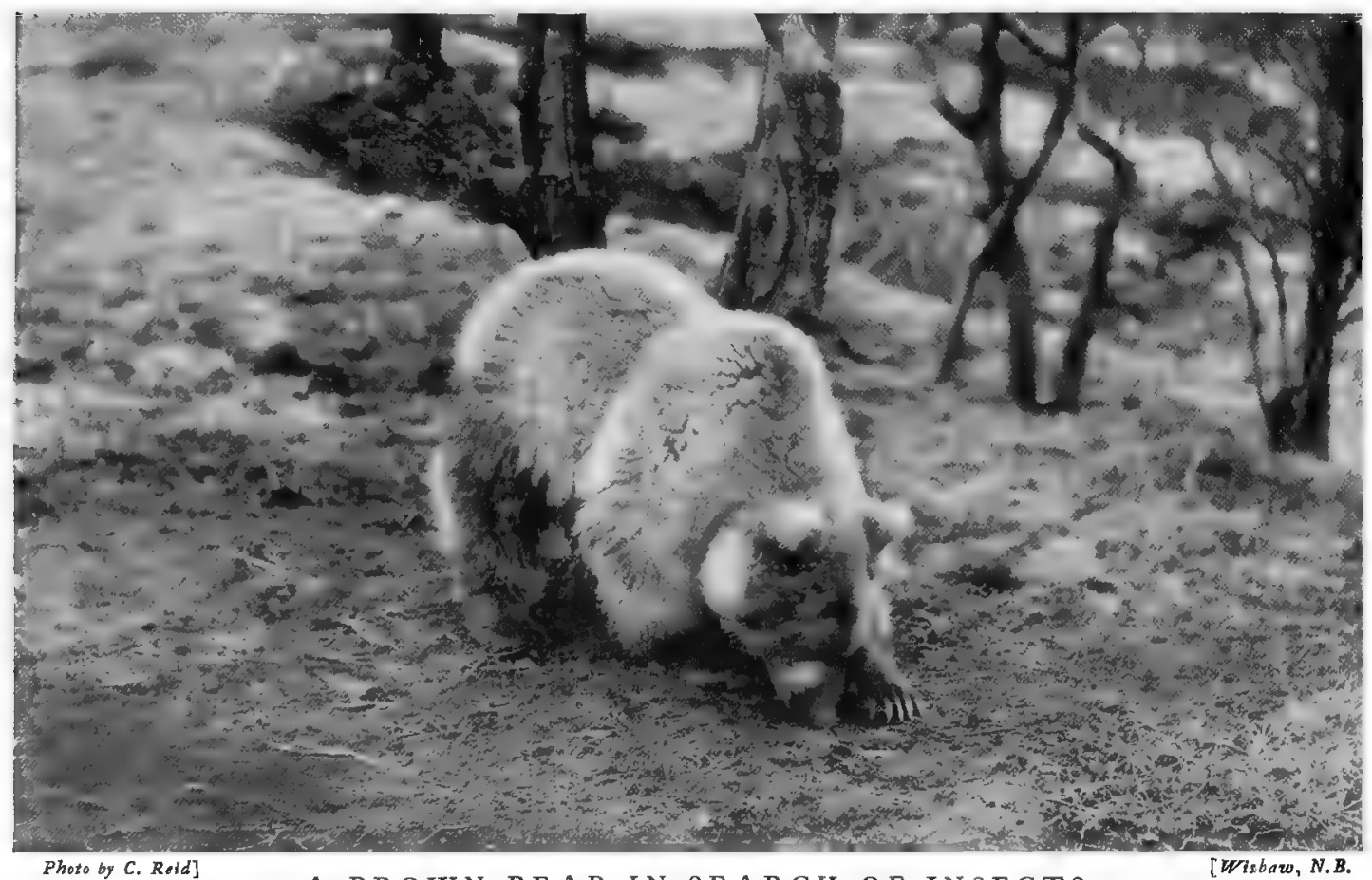

A BROWN BEAR IN SEARCH OF INSECTS

$[$ Wisbaw, N.B.

The photograph shows a bear feeding on insects, possibly large ants, which he licks up from the ground, after scratching them out with his claws

of these bears: "I was following up a bear which I had wounded, and rashly went to the mouth of a cave to which it had got. It charged. I shot, but failed to stop it. I do not know exactly what happened next, neither does my hunter who was with me ; but I believe, from the marks in the snow, that in his rush the bear knocked me over backwards-in fact, knocked me three or four feet away. When next I remembered anything, the bear's weight was on me, and he was biting my leg. He bit two or three times. I felt the flesh crush, but I felt no pain at all. It was rather like having a tooth out with gas. I felt no particular terror, though I thought the bear had got me; but in a hazy sort of way I wondered when he would kill me, and thought what a fool I was to get killed by a stupid beast like a bear. The shikari then very pluckily came up and fired a shot into the bear, and he left me. I felt the weight lift off me, and got up. I did not think I was much hurt. . . . The main wound was a flap of flesh torn out of the inside of my left thigh and left hanging. It was fairly deep, and I could see all the muscles working underneath when I lifted it up to clean the wound." This anecdote was sent to Mr. J. Crowther Hirst 


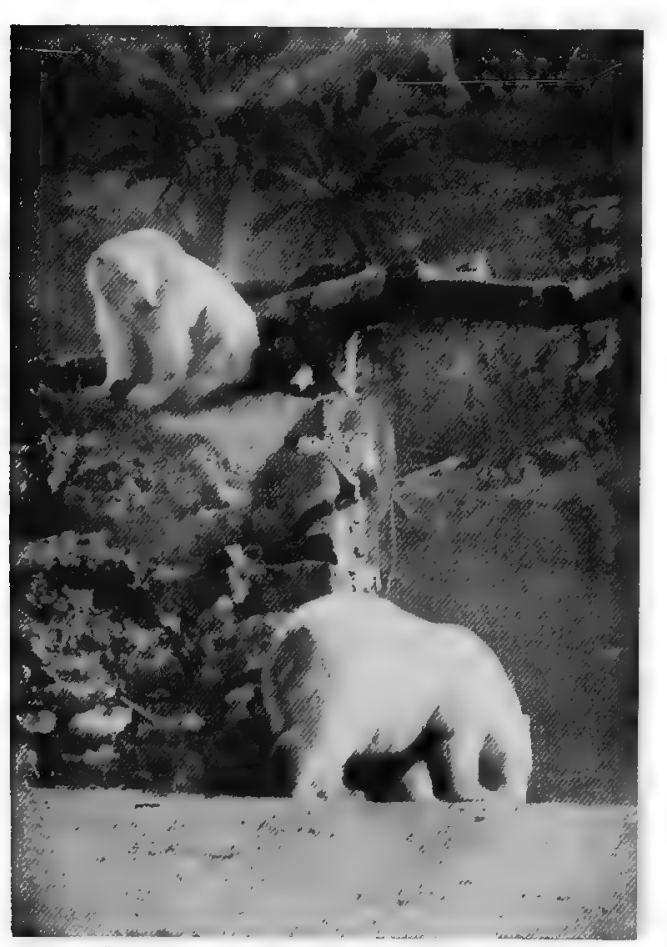

Photo by Fratell Alinari]

POLAR BEARS

Though Arctic animals, polar bears can endure great heat. During " "heat wave" at Hamburg, Herr C. Hagenbeck found two of his leopards suffering from heat apoplexy, but the polar bears were enjoying the sun to illustrate a theory of his, that the killing of wild animals by other animals is not a painfui one.

Rustem Pasha, once Turkish Ambassador in England, had an accident when brown bear shooting in Russia, and writes of it in the same sense: "When I met the accident alluded to, the bear injured both my hands, but did not tear off part of the arm or shoulder. In the moment of desperate struggle, the intense excitement and anger did, in fact, render me insensible to the feeling of actual pain as the bear gnawed my left hand, which was badly torn and perforated with holes, most of the bones being broken."

There is good reason to believe that when large carnivora, or beasts large in proportion to the size of their victims, strike and kill them with a great previous shock, the sense of pain is deadened. Not so if the person or animal is seized quietly. Then the pain is intense, though sometimes only momentary. A tigress seized Mr. J. Hansard, a forest officer in Ceylon, by the neck. In describing his sensations afterwards, he said: "The agony I felt was something frightful. My whole skull seemed as if it were being crushed to atoms in the jaws of the great brute. I certainly felt the most awful pain as she was biting my neck; but not afterwards, if I can remember." Sir Samuel Baker says he has twice seen the sloth-bear attack a howdah-elephant. Lord Edward St. Maur, son of the Duke of Somerset, was killed by one. Mr. Sanderson, the head of the Government Elephant-catching Department, used to hunt bears in the jungle with bull-terriers. Against these the bear was unable to make a good fight. They seized it by the nose; and as its claws were not sharp like those of the leopard, the bear could not get them off.

This bear seldom produces more than two or three young at a birth. The young cub is very ugly, but very strong, especially in the claws and legs. A six weeks' old cub has been turned upside-down in a basket, which was shaken violently, without dislodging the little animal clinging inside.

\section{The Isabelline Bear and Himalayan Black Bear.}

The former animal is a medium-sized variety of the brown bear. The coat in winter is of a beautiful silver-tipped cinnamon colour. The Himalayan Black BEar has a half-moon of white on its throat. The habits of both do not differ markedly from those of the brown bear of Europe.

Recently black bears have been most troublesome in Kashmir, attacking and killing and wounding the wood-cutters with no provocation. Dr. E. T. Vere, writing from Srinagar, says: " Every year we have about half a dozen patients who have been mauled by bears. Most of our people who are hurt are villagers or shepherds. Bears have been so shot at in Kashmir that, although not naturally very fierce, they have become truculent. When they attack men, they usually sit up and knock the victim over with a paw. They then make one or two bites at the arm or leg, and often finish up with a snap at the head. This is the most dangerous part of the attack. One of our fatal cases this year was a boy, the vault of whose skull was torn off and lacerated. Another man received a compound fracture of the cranium. A third had the bones 
of his face smashed and lacerated. He had an axe, but said, 'When the bear sat up, my courage failed me." "

\section{The Malayan Sun-bear.}

These small, smooth-coated bears have a yellow throat-patch like a mustard plaster, and are altogether the most amusing and comical of the tribe. They are almost as smooth as a pointer dog, and are devoted to all sweet substances which can be a substitute for honey, their main delicacy when wild. There are always a number of these bears at the Zoo incessantly begging for food. When one gets a piece of sugar, he cracks it into small pieces, sticks them on the back of his paw, and licks the mess until the paw is covered with sticky syrup, which he eats with great gusto. This bear is found in the Malay Peninsula, Borneo, Sumatra, and Java. It is only 4 feet high, or sometimes half a foot taller. It is more in the habit of walking upright than any other species. 


\section{CHAPTER VII.}

\section{THE SMALLER CARNIVORA.}

\section{The Coatis.}

$\mathrm{T}$

HE CoATrs are small arboreal creatures, with the habits of a raccoon and squirrel fairly proportioned. They are flesh-eaters, but active and playful. Their long piglike snouts give them an unpleasant appearance. They inhabit Mexico and Central and South America as far as Paraguay. Several specimens are generally to be seen at the Zoological Gardens. Their habits are much the same as those of the small tree climbing cats, but with something of the badger added. Insects and worms, as well as birds and small animals, form their food.

\section{The Pandas and Kinkajou.}

Among the small carnivorous mammals the BEAR-CAT, or PANDA, is a very interesting creature. Its colour is striking-a beautiful red-chestnut above, the lower surface jet-black, the tail long and ringed. The quality of the fur is fine also. It is found in the Eastern Himalaya, and is as large as a badger. The Great PANDA, from Eastern Tibet, is a much larger, short-tailed, black-and-white animal, once thought to be a bear. The KInkajou has a prehensile tail, and uses its paws as hands so readily that it was formerly placed among the lemurs. It is a native of Southern and intertropical America. Nocturnal, and living in the great forests, it is seldom

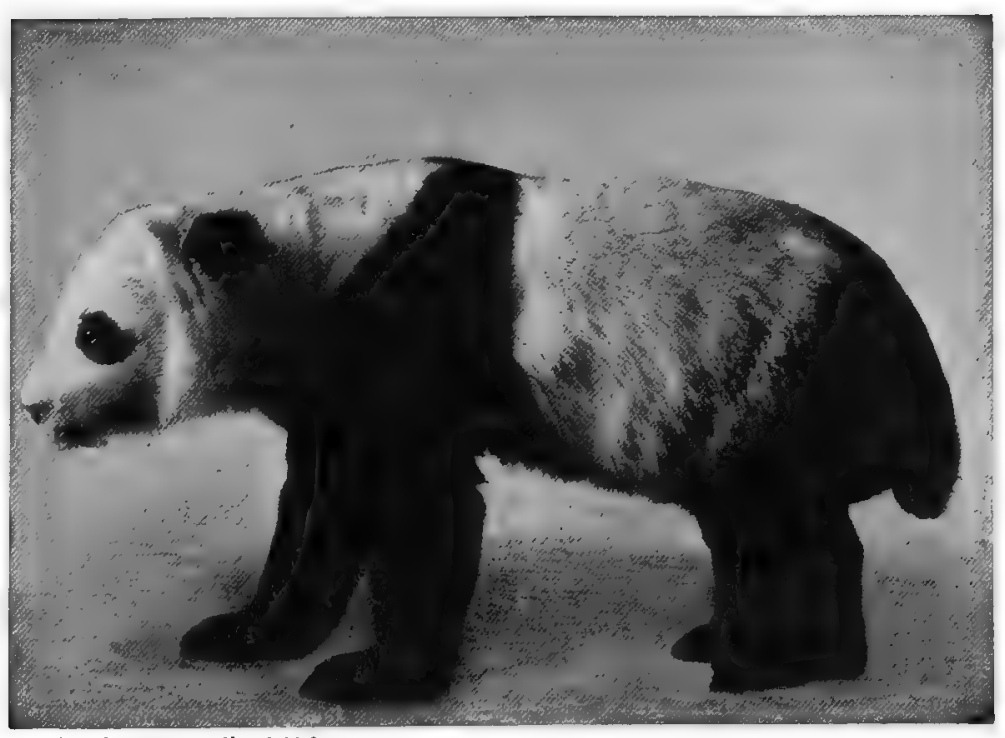

Photo by A. S, Rudland \& Sons

$$
\text { GREAT PANDA }
$$

This very rare animal is found on the high platean of Tibet seen by man. Its head is round and cat-like, its feet are the same, but with nonretractile claws, and it has a long, full tail. It has a long tongue, with which it can lick out insects from the crevices and holes of trees. Baron von Humboldt says that it attacks the nests of wild bees. It uses its tongue to draw objects of food towards it, even if they are not living. A pleasant description of this animal appeared in Charles Knight's "Museum of Animated Nature," published many years ago: "In its aspect there is something of gentleness and good-nature. 


\section{II6 THE LIVING ANIMALS OF THE WORLD}

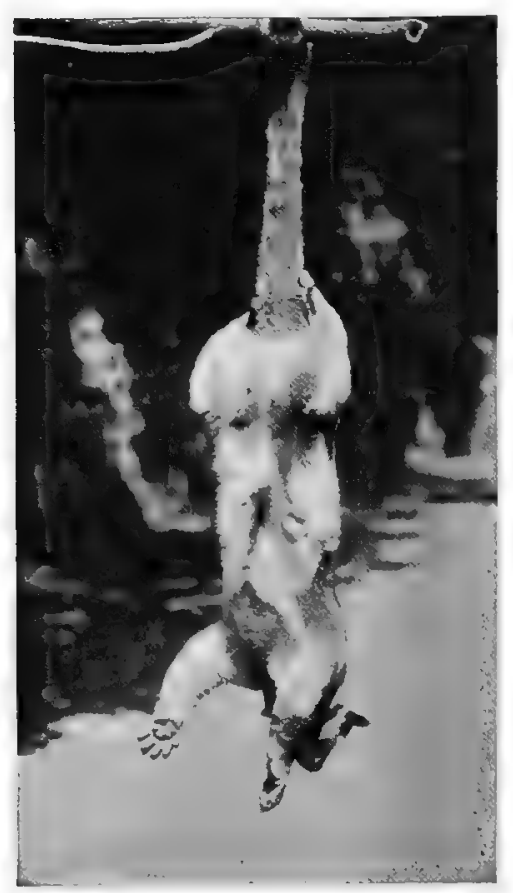

Photo oy scholastic Photo Co, Parson's Green K I N K A J O U

The kinkajou eats birds and eggs as well as honey and fruit. One kept in South America killed a whole brood of turkeys, and was partial to birds' eggs.
In captivity it is extremely playful, familiar, and fond of being noticed. One lived in the gardens of the Zoological Society for seven years. During the greater part of the morning it was asleep, rolled up in a ball in its cage. In the afternoon it would come out, traverse its cage, take food, and play with those to whom it was accustomed. Clinging to the top wires of its cage with its tail and hind paws, it would thus swing itself backwards and forwards. When thus hanging, it would bring its fore paws to the bars, as well as the hind pair, and in this manner would travel up and down its cage with the utmost address, every now and then thrusting out its long tongue between the wires, as if in quest of food, which, when offered to it, it would endeavour to draw in between the wires with this organ. It was very fond of being gently stroked and scratched, and when at play with any one it knew it would pretend to bite, seizing the hand or fingers with its teeth, as a dog will do when playing with its master. As the evening came on, it was full of animation, and exhibited in every movement the most surprising energy."

\section{THE OTTERS.}

As the badgers and ratels seem especially adapted to an underground and cave-making existence, so the OTTERs ali conform in structure to an aquatic life; yet, except the webbing of the space between the toes and the shortening and flattening of the head, there is very little obvious change in their structure to meet the very great difference in the conditions under which they live.

The Short-toed OtTer is a small Indian species. It has nails on its hands in place of claws. One kept at the Zoo was a most amusing and friendly little pet, which let itself be nursed like a kitten.

The Common OtTer is far the most attractive of the British carnivora. It is still fairly common all over Britain where fish exist. It is found on the Norfolk broads and rivers, all up the Thames, in Scotland, Devonshire, Wales, Cumberland, and Northumberland. It travels considerable distances from river to river, and sometimes gets into a preserved trout-pool or breeding-pond, and does much mischief. The beautiful youno, otters here figured are in $\mathrm{Mr}$. Percy Leigh Pemberton's collection of British mammals. Their owner made a large brick tank for them, where

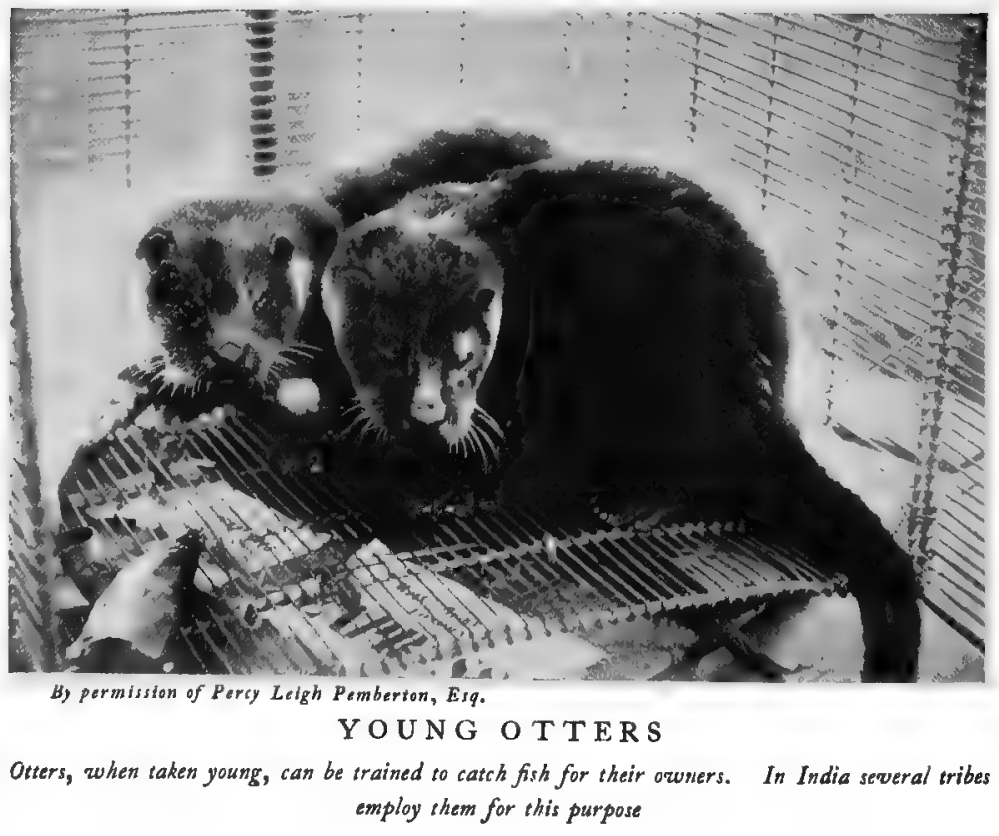


they were allowed to catch live fish. Once one of them seized a 4-1b. pike by the tail. The pike wriggled round and seized the otter's paw, but was soon placed hors de combat. The largest otter which the writer has seen was bolted by a ferret from a rabbitwarren on the edge of the Norfolk fen at Hockwold, and shot by the keeper, who was rabbiting.

English dog otters sometimes weigh as much as 26 lbs. They regularly hunt down the rivers by night, returning before morning to their holt, where they sleep by day. No fish stands a chance with them. They swim after the fish in, the open river, chase it under the bank, and then corner it, or seize it with a rush, just as the penguins catch gudgeon at the Zoo. Captain Salvin owned a famous tame otter which used to go for walks with him, and amuse itself by catching fish in the roadside ponds.

\section{THE BADGERS.}

The Badgers include several genera. The SAND-BADGERS of the East have a naked snout, small ears,

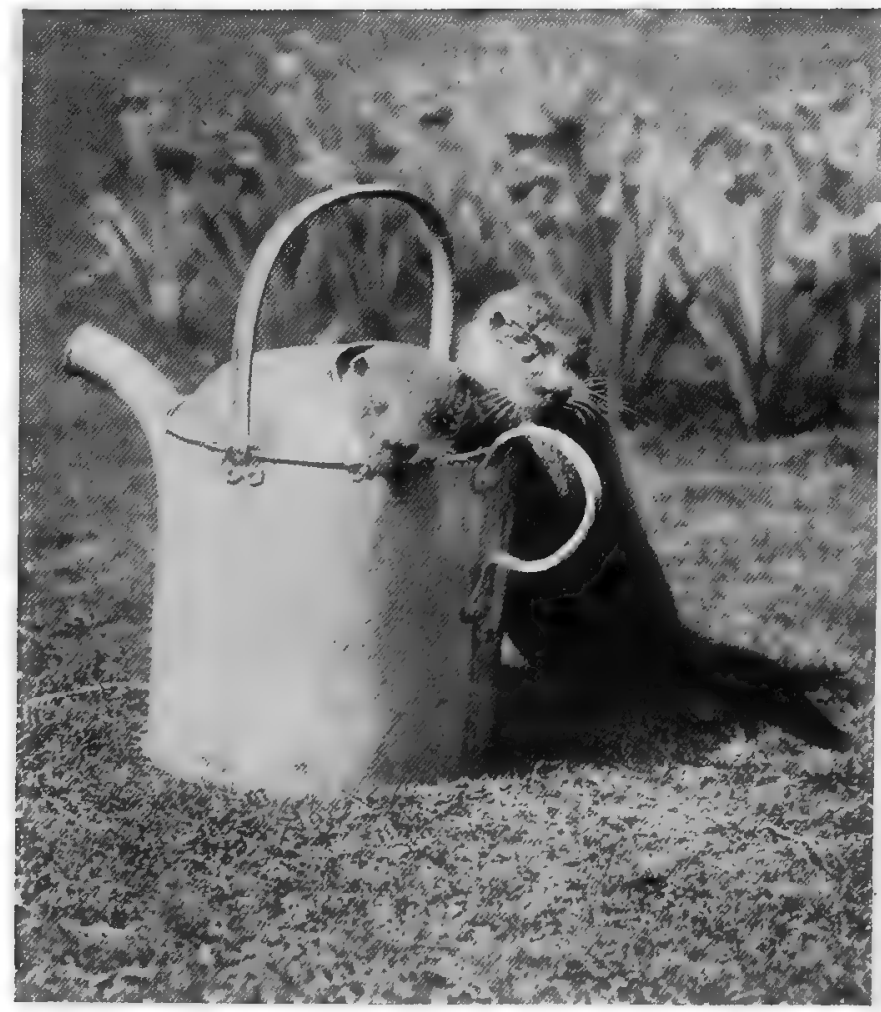

TWO TAME OTTERS

These two little otters were photographed by the Duchess of Bedford. "Alluding to the old signs of the zodiac and their fondness for the watering-pot, their porerait was called "Aquarius" and "The Trvins." and rough fur, with softer fur underneath. The Indian Badger is larger than that of Europe, while that of Java, Sumatra, and Borneo is smaller, and has a very short tail.

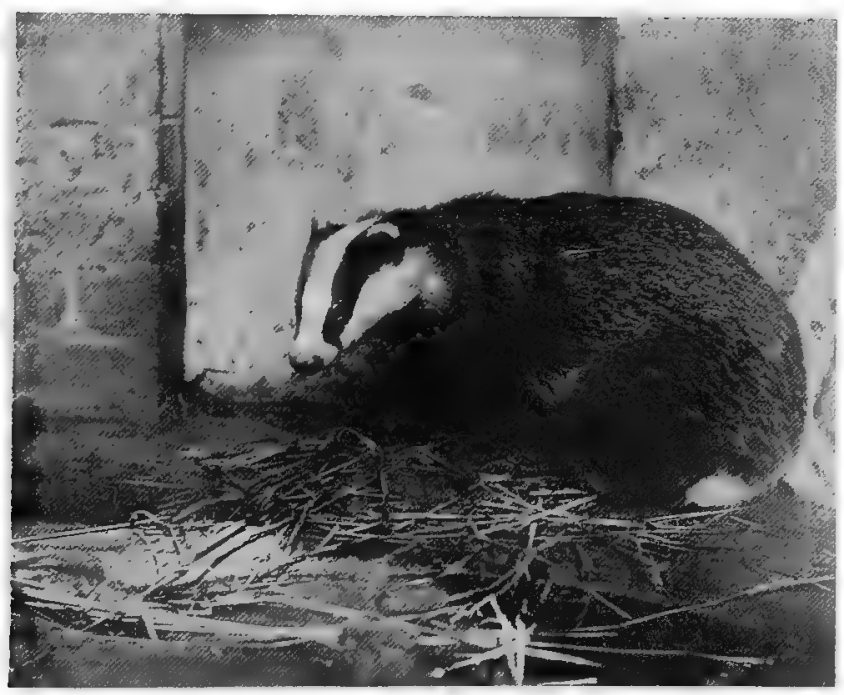

Photo by Scholastic Photo. Co.] EUROPEAN BADGER

Badgers can be readily kept in confinement, and are nat difficult to tame thoroughly

The FerRet-BADGERs from the East have elongated bodies and short tails. They are tree-climbers, and as omnivorous as the badger itself. The CAPE ZORILLA, with another species found in Egypt, is more nearly allied to the polecats, but is striped like a skunk.

The EURopean BADGER is still'fairly numerous. There is not a county in England where it is not found. A large colony has been established in Epping Forest, some fifty yards square of hillside being honeycombed with badgerearths. The European badger is found all over temperate Northern Europe and Asia; but being shy, wary, and mainly nocturnal, is seldom seen. At night it wanders about, and in August gets into the corn-fields, whence it is chased and caught by dogs. A Somer- 


\section{8 THE LIVING ANIMALS OF THE WORLD}

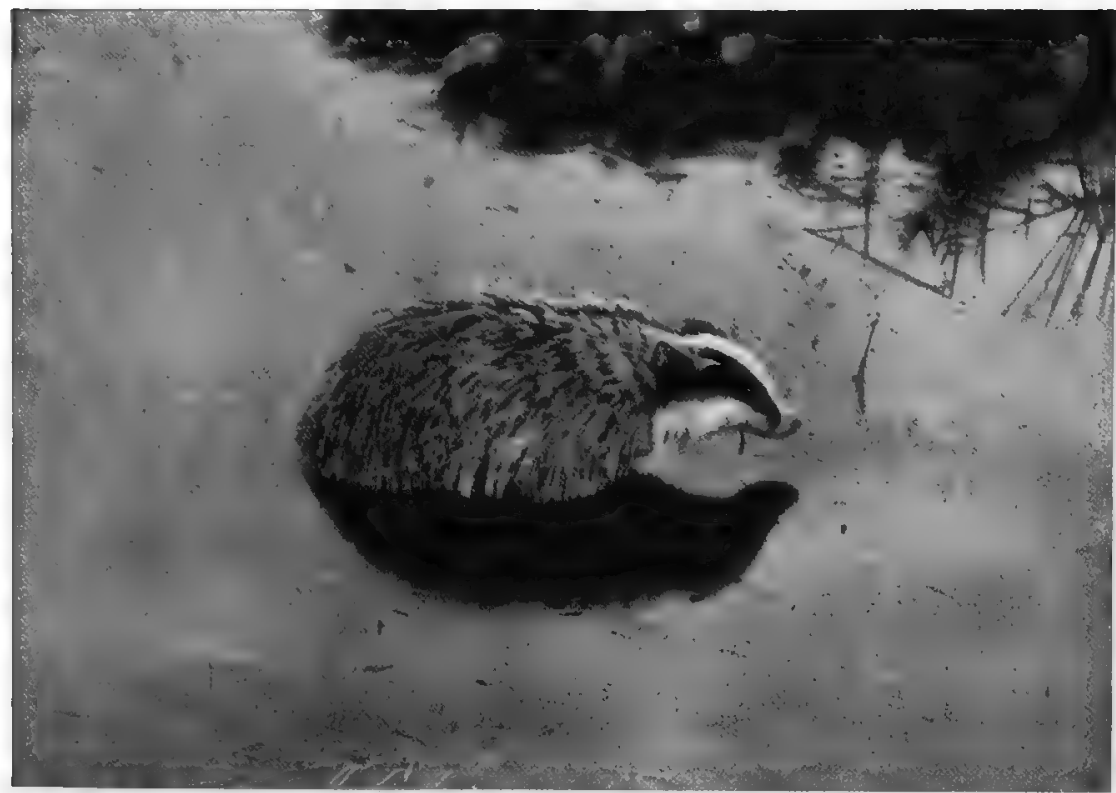

Photo by C. Reid]

A BADGER IN THE WATER

They are nocturnal animals

setshire farmer had a pointer and sheepdog which were adepts at this night catching of badgers. They would accompany their master along the roads, and the pointer instantly winded any badger which had crossed. Both dogs then bounded off, and soon their loud barking showed that they had found and "held up" the badger. The dogs' owner then came up, picked the badger up by its tail, and dropped it in a sack. The badger's "earth" is wonderfully deep and winding; in it the badger sleeps during the winter, and gives birth to its young, three or four of which are produced at a time. The end of March is the period of birth; but the cubs do not come out until June. In October they are full-grown. The badger carries in a great quantity of fern and grass as a bed for its cubs. Mr. Trevor-Battye writes: "I had a pair which were probably about six weeks old. They were called Gripper and Nancy. They would rest on my lap when feeding, and sit up and beg like dogs. Their hearing and power of scent were remarkable. The badgers were in a closed yard; but if any of the dogs came near, even following a path which ran at a distance of six or seven yards, they would instantly jump off my lap and disappear into a corner. The animals could walk and trot backwards with the greatest ease." I have never seen this noticed elsewhere, yet it is worth mentioning, because it is characteristic of the Weasel Family, not being shared, to my knowledge, by any other mammal-not, for instance, by the Bears.

Mr. A. E. Pease says of the badger: "It is easily domesticated, and if brought up by hand is found an interesting and charming companion. I had at one time two that I could do anything with, and which followed me so closely that they would

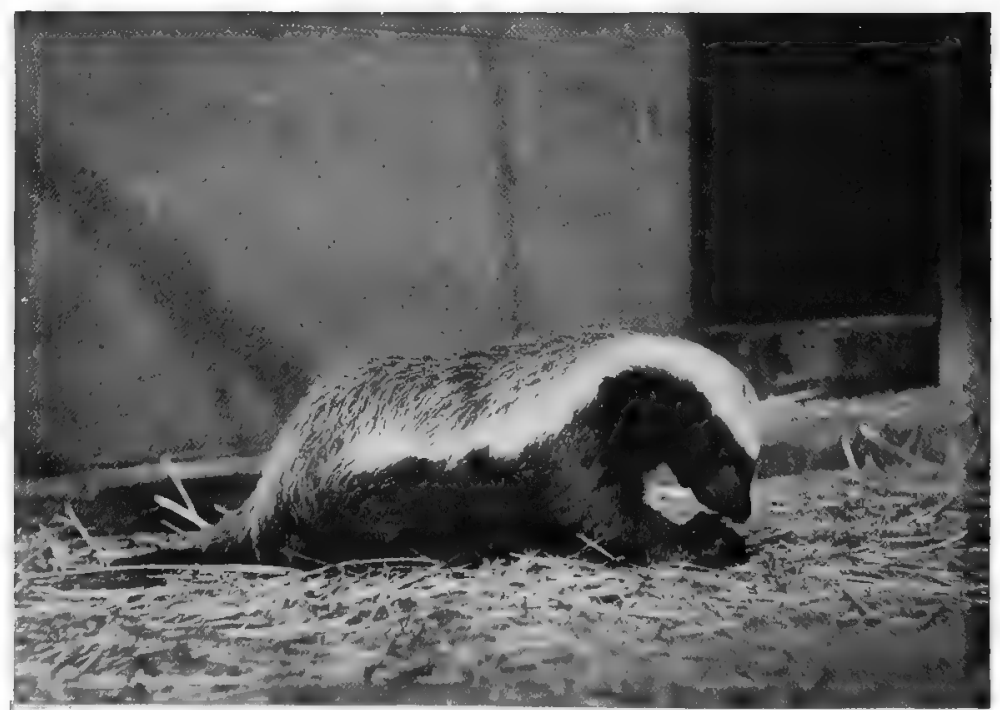

Photo by A. S. Rudland Son,

\section{R A T E L}

Ratels are curiously restless little animals, with a peculiar trot-like walk 
bump against my boots each step I took, and come and snuggle in under my coat when I sat down."

\section{The Ratels.}

As the mink is adapted for an aquatic diet, so the RATELs, a link between the Weasels and the Badgers, seem to have been specialised to live upon insects and honey as well as flesh. They are quaint creatures, with rounded iron-gray backs, and black bellies, noses, and feet. The African kind is found in Cape Colony and East Africa, and is believed to live largely on honey and bee-brood. The habits of the ratel are almost identical with those of the badger, except that it is less shy and very restless. A nearly similar species of ratel is found in Southern Asia from the Caspian to India.

The ratels are strictly nocturnal, and make their lair by day in hollow trees, though they are said not to climb. The skin is protected by thick, close hair, so that bees cannot sting through the fur. The skin is also very loose. If a dog bites it, the ratel can generally twist round and bite back. The African ratel is omnivorous. It eats snakes and birds. The body of a cobra has been found in the stomach of one.

\section{THE WEASEL TRIBE.}

\section{The Martens.}

There are two species of marten in Europe-the Beech- and the Pine-marten. The latter has a yellow throat, the former a white one. The fur is almost as fine as sable. All so-called Canadian sables are really martens. These animals are found throughout Northern Europe and Northern Asia, and also in Japan. It is a tree-loving animal, and feeds mainly on squirrels, which it pursues through the branches. It is also fond of fruit. Mr. Charles St. John discovered this in a curious way. He noticed that his raspberries were being stolen, so set a trap among the canes. Next day all he could see was a heap of newly gathered raspberry leaves where the trap was. Stooping down to move them, a marten sprang up and tried to defend itself. The poor beast had come to gather more raspberries, and had been caught. Unable to escape, it gathered the leaves near and concealed itself.

\section{The SABLE.}

This is so little different from the marten that some have thought it only a northern variety. That is not the case, as both are found in the same area, and no one who knows anything of form and colour could mistake the true sable's fur. This fur is so fine and even that each single hair tapers gradually to a point: that is why sable brushes for painting are so valutable; they always form a point when wet. The price of these brushes, which are of genuine sable fur, though made up from fragments of the worst coloured or damaged skins, varies yearly with the price of sable in the market.

\section{The Polecat.}

This is now probably the rarest of the European weasels. It is almost identically the same as the polecat-ferret, a cross-breed between it and the domesticated variety. It is an expert swimmer. Its habits are the same as those of the stoat, but it is slower in its movements. It catches fish, and can pick up food from the bottom of the water. Wild ones can be trained to work like ferrets. "They do not delay in the hole, but follow the rat out and catch it in a couple of bounds" (Trevor-Battye). The FERRET is a domesticated breed of polecat. It is identical in shape and habits, but unable to stand a cold climate. 


\section{CHAPTER VIII.}

MARINE CARNIVORA: THE SEALS, SEA-LION, AND WALRUS.

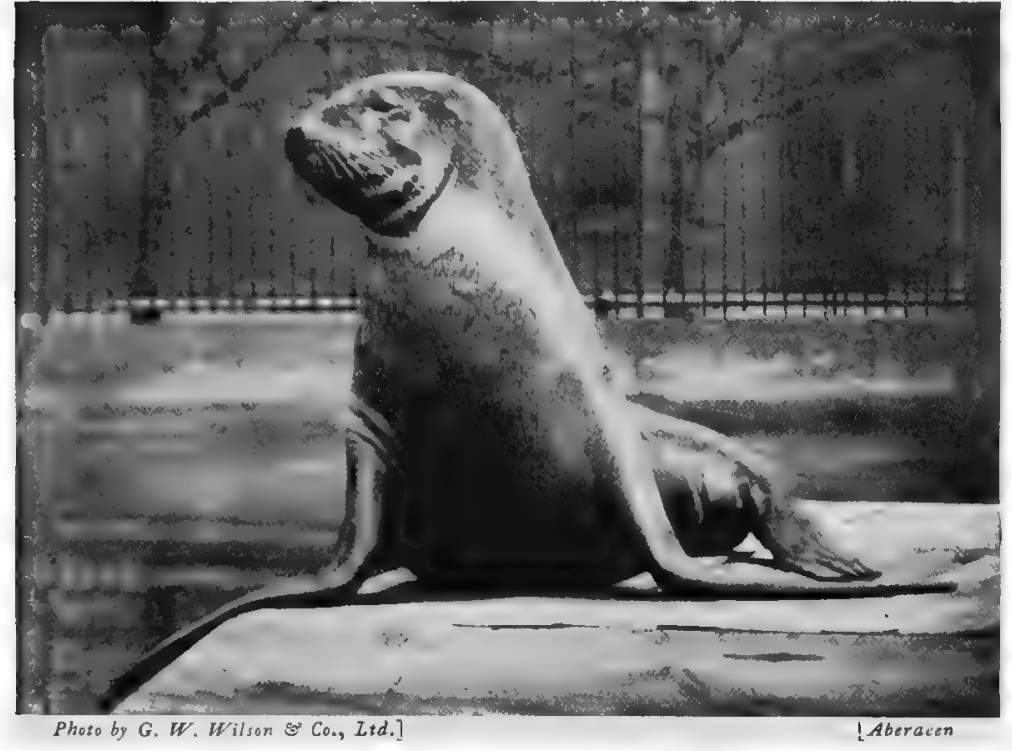

ST E L LER'S SEA-LION

The eared seal, or sea-lion, has the hind flippers divided, and is thus able to move with comparative ease on land

which is also turned to commercial uses by the sealers.

The Walnus stands by itself. It is a purely Arctic species, whereas fur-seals are found from Bering Sea to the Antarctic; and forms in some degree a connecting link between the eared seals and the true seals. Like the former, it turns the front flippers forwards and inwards when on land; but it resembles the true seals in having no external ears. The upper canine teeth are developed into enormous tusks of hard ivory.

The Common Seals are the most thoroughly aquatic. The hind flippers seem almost to have coalesced with the tail, and are always directed backwards in line with it. They have no under-fur. On land they can only use the front flippers to aid their progress.

Most seals are marine, though some are found in the land-locked sea of Lake Baikal, in Central Asia, and the true seals often come up rivers.

\section{The Eared Seals, or Sea-lions.}

These and the walrus have their hind limbs so far free that they can crawl on land and use their flippers for other purposes than swimming; they can comb their hair with them, and walk in an awkward way. They are divided into the fur-seals and hair-seals in the language of trade. The fur-seals are those from which ladies' sealskin jackets are made; the hair-seals are sought for their hides and oil. A demand has sprung up for the latter to make coats for automobilists to wear when riding at high speed in cold weather. The "porpoise-hide" boots are really made from the skin of the hair-seal.

Both hair-seals and fur-seals have in common the remarkable habit of assembling in large 
herds during the breeding-season, and of spenciing a long period on land after the young are born. The male seals reach the islands, or "rookeries," first, followed by the females. The latter give birth to their young almost as soon as they reach the rocks, and are then seized and gathered into harems by the strongest and oldest males. The sea-lions of Patagonia, equally with the fur-seals of Bering Sea and the Pribyloff Islands, never feed during the whole time which they spend on the rocks, often for a period of two months.

\section{The Fur-seals.}

The Northern Fur-SEAL is the only member of this group surviving in any number. These animals still annually resort to the Aleutian Islands, in the territory of Alaska, in great herds to produce their young, and to certain other islets off the coast of Japan. This northern fur-seal, from the fur of which the sealskin jackets are obtained, is, when full grown, between 6 and 7 feet long. The females are only 4 feet or $4 \frac{1}{2}$ feet in length. The shoulder of the male is gray, the rest of the body varying between reddish gray and deep black. The female is lighter in colour. Males of this species are not full grown till six years of age, but breed when four years old. The females produce young at three years of age. The male seals take possession of the females almost immediately after reaching the breeding grounds, each male collecting as many females as it can round it The pups keep with their mothers. This assemblage is surrounded by great numbers of young male or bachelor seals, which the old males prevent from annexing any of the females. The greatest of all these gathering-places are on the Pribyloff Islands and certain other islets in Bering Sea. By the end of May both male and female seals swim in flocks through Bering Straits, making for the islands. The islands themselves are leased to American merchants. But as those seals killed on the way are all just about to bring forth young, the waste and cruelty of this "pelagic sealing" will be easily understood. On the islands, or "rookeries," the males, mothers, and pups remain till August, when the pups take to the water. The male seals have remained for at least two months, incessantly fighting and watching, without taking any food. By that time they are quite exhausted, the fat which they laid up previously being all absorbed. The fur has not naturally either the colour or texture

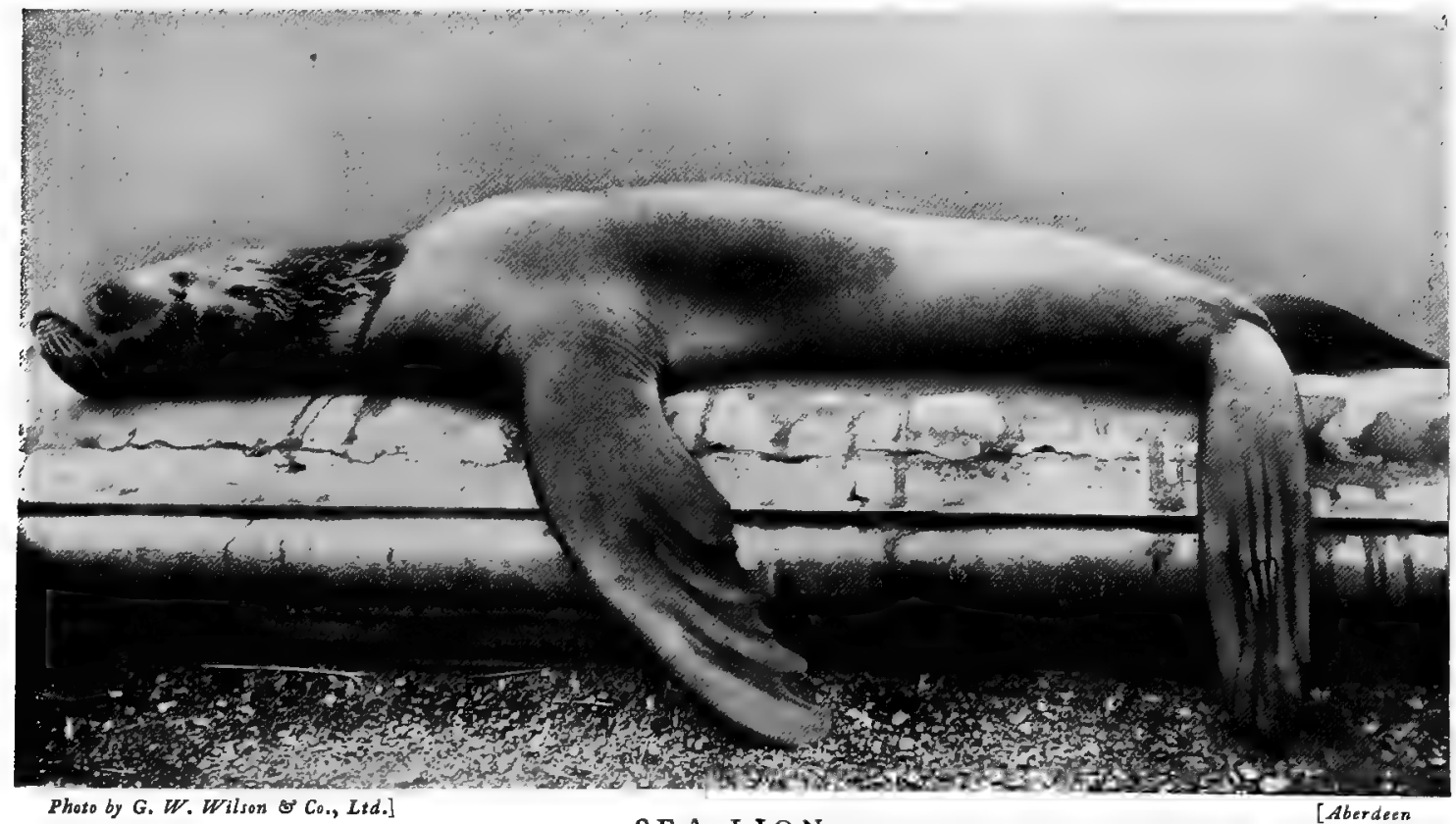

Photo by G. W. Wilson of Co., Ltd.]

This photograph shows the dry mane of the sea-lion, a rather uncommon sight, as it rarely remains lang enough out of the water for its fur to become absolutely dry 


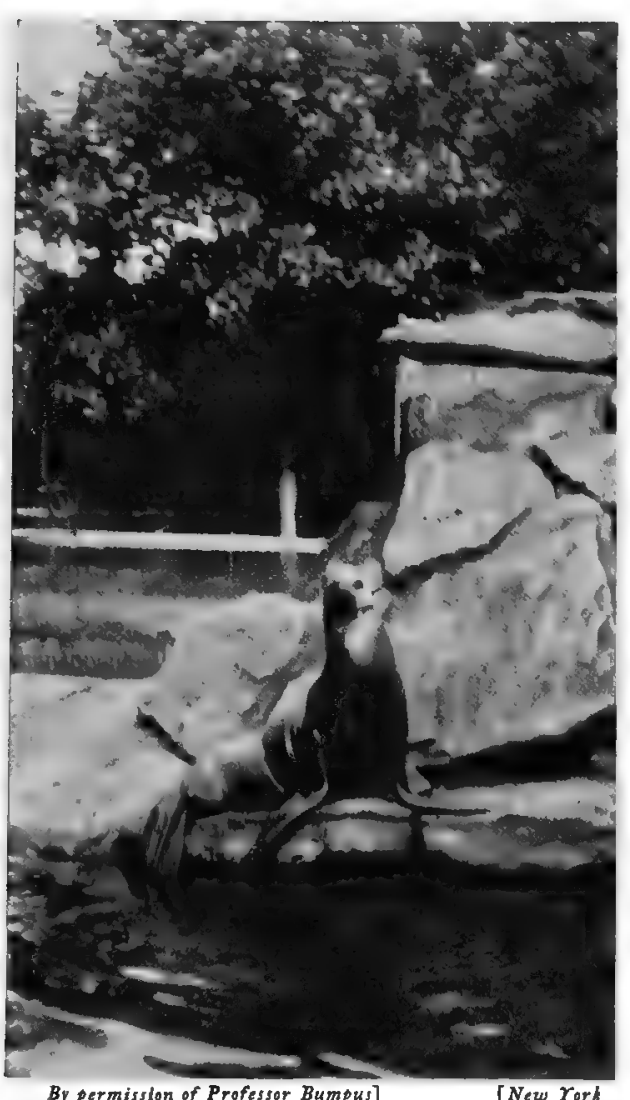

By permission of Professor Bumpus]

S E A - L I O N

All sea-lions are polygamous. The males guard their harems very jealously, and fight determinedly with any intruder which art gives it. The outer fur is long and coarse, and only the inner fur of the exquisite texture of the "made" skin. The former is removed, and the latter dyed to the rich brown colour which we see. The furseals are steadily diminishing, and each year's catch is smaller than that of the year before.

The Cape Fur-seal, Southern Fur-seal, and New Zealand FuR-SEAL are practically extinct for commercial purposes.

\section{The Hair-seals.}

Among these are the large so-called "sea-lions" of Patagonia and the North Pacific. We are familiar with their appearance, because for many years specimens have been kept at the Zoological Gardens. Their habits are much the same as those of the fur-seals. The principal species are, in the north, Steller's Sea-lion, and the Patagonian Sea-lion in the south. Those kept at the Zoological Gardens are usually of the latter species.

Steller's Sea-Lion is already on the road to extinction. When the annual catch of fur-seals reached 100,000 a year, the total number of these northern sea-lions was estimated at between 30,000 and 40,000. They repair every year to the Pribyloff Islands to breed, as the fur-seals do, but are shier and more entirely aquatic. The fur of the old males is tawny, and makes a kind of mane over the shoulders, whence its name. Off San Francisco there is a small rocky island, one of the ancient "rookeries" of these sea-lions, where they are carefully preserved by the United States Government as one of the sights of the bay. Another favourite haunt in old days was on the Farralone Islands, thirty miles from the bay.

Southwards, towards the Antarctic, on the desolate and uninhabited coasts and islets of the Far Southern Ocean, the most characteristic of the fauna still remaining are the sea-lions. Formerly they swarmed in great packs, crowding at the breeding-season the seaweed-covered rocks with their huge and unwieldy forms, and at other times cruising in uncouth and noisy companies in search of the fishes and squids, which they pursued like packs of ocean-wolves. In spring the sea-lions used to struggle on to the flat shore, where the equally aquatic tribes of penguins, which had lost the use of their wings, covered acre after acre of rock with their eggs and young. These the sea-lions devoured. When the men of the first exploring-ships visited the penguins' nurseries, all the ungainly birds began to hop inland, evidently taking the men for seals, and thinking it best to draw them as far from their native element as possible. But the eared seals can make good progress of a kind on land. When Captain Musgrave and his crew were cast away for twenty months on the Auckland Islands, they found their tracks on the top of a hill four miles from the water. Captain Musgrave also saw the mother seals teaching their puppies to swim; they were by no means inclined to do this, and were afraid of the water-fairly clear presumptive evidence that seals have only recently, so far as natural time is counted, taken to the aquatic life, and modified their form so profoundly as they have.

The Patagonian SEA-Lion is perhaps the most numerous species, though its numbers have 
been greatly reduced by whalers in search of skins and oil. The first sea-lion ever brought here was one of these. The Zoological Society did not import it; they found it in the possession of a Frenchman called Lecomte, who had taken it on the Patagonian coast, trained it, and brought it home, where he showed it in a caravan. Its training was long and difficult; it bit like a bull-dog, and Lecomte's limbs were scarred all over with its bites. In spite of this it was the cleverest performing animal ever seen up to that time in England. This sea-lion died from swallowing a fish-hook concealed in some fish with which it was fed. Lecomte was then sent out by the Zoological Society to obtain some more. With the greatest difficulty several were secured, but all died on the voyage to New York. Lecomte returned and obtained others, one of which he succeeded in bringing here. The cleverness of these animals-or rather their power of understanding what they are required to do, and their willingness to do it-probably exceeds that of any other animal, except the elephant and the dog. Why this is so is not easy to conjecture, except that the brain is more developed. They have been taught to fetch and carry on dry land like a retriever, in addition to the well-known tricks exhibited by those at the Zoo. One belonging to Barnum's Show caught strawberry-punnets on its nose when they were thrown to it, and waved a torch, which it held in its teeth and caught after tossing it into the air.

The sea-lions are much more powerfui animals than the fur-seals. The male of Steller's sealion attains a length of $\mathrm{IO}$ feet and a weight of $\mathrm{I}, 000 \mathrm{lbs}$. The Australian Sea-lion is even larger than that of the North Pacific. Some specimens are said to attain 2 feet in length. Captain Cook mentions seeing male Patagonian sea-lions 14 feet long and from 8 to io feet in circumference. Though none are now seen of such dimensions, skulls found on the beach show that anciently some of the sea-lions were larger than any now known.

It should be noted that all these creatures are carnivorous, yet the supply of food for them never seems to fail, as undoubtedly it would were the animals dependent for their food on land.

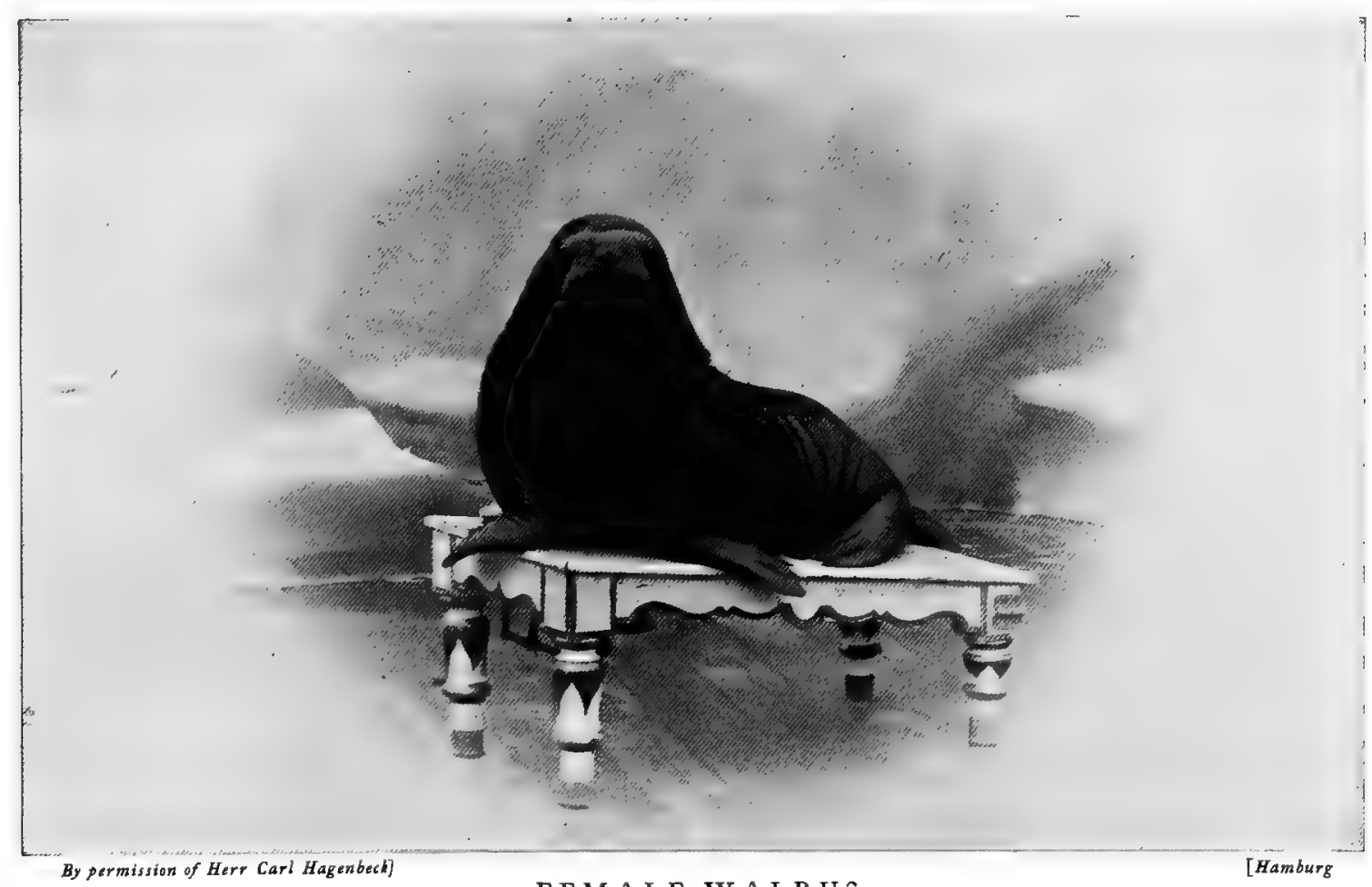

FEM ALE W ALRUS

This is a photograph of the only walrus which has ever been tamed and taught to perform tricks. It was taken when she was two years old and weighed 380 lbs. At that time she consumed 70 lbs. of boneless fish a day; a year later not less than roo lbs. satisfied her. She is now an inmate of the Roumanian Zoological Gardens 


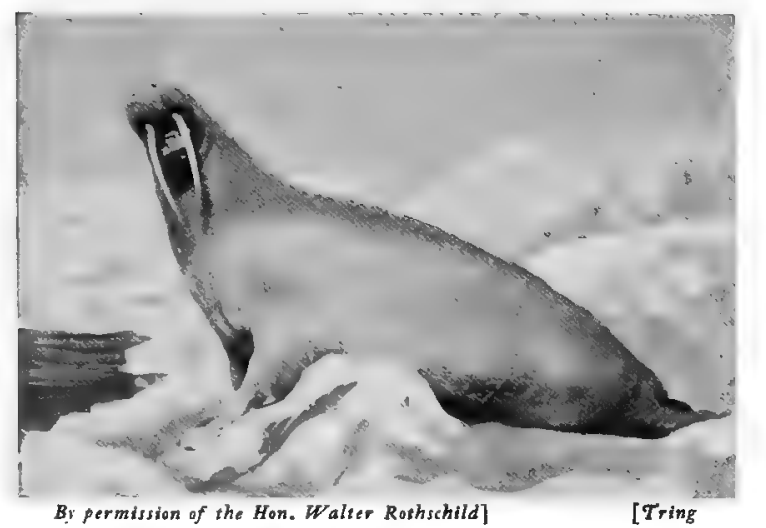

MALE W A LR US and after death are much walued for the ivory
The " "usks" of the walrus are put to many practical uses during life,

\section{The Walrus.}

The distinguishing features of the walrus have been mentioned in the introductory remarks to this chapter. It should be added that it has an external ear-passage, though no external ears, and very thick and bristly whiskers. It is practically confined to the Arctic Circle, though once its range extended to the British coasts (where its bones are found in the Suffolk Crag) and to Virginia. The skull of one was found in the peat at Ely-evidence that it once ascended rivers.

The walrus stands alone; it is a real monster of the deep. Strange and awful stories were told of it by some of the early voyagers to the Arctic Seas; but Captain Cook gave a very different account of his impressions of the walruses which he saw on the north coast of America: "They lie in herds of many hundreds on the ice, huddling over one another like swine. (They lie just like a lot of pigs in a yard.) They roar and bray so very loud, that in the night, or in foggy weather, they gave us notice of the vicinity of the ice before we could see.it. We never found the whole herd asleep, some being always on the watch These, on the approach of the boat, would awaken those next to them; and the alarm being thus gradually communicated, the whole herd would awake presently. But they were seldom in a hurry to get away, till after they had been once fired at; they then would tumble over one another into the sea in the utmost confusion They did not appear to us to be that dangerous animal which authors have described, not even when attacked. Vast numbers of them would follow us, and come close up to the boats; but the flash of the musket in the pan, or the bare pointing of it, would send them down in an instant. The female will defend her young to the last, and at the expense of her own life, whether in the water or upon the ice; nor will the young one quit the dam, though she be dead; so that if one be killed the other is certain prey." The long pendent tusks, bristly whiskers, small bloodshot eyes, and great size lent colour to the terrifying tales of the walrus. But more ancient voyagers than Captain Cook told the truth—that the "morses," as they called them, were harmless creatures, which often followed the ships from sheer curiosity. They sleep on the ice like elephantine pigs, and dive and rout on the sea-bottom for clams, cuttle-fish, and seaweeds. Probably the long tusks are used to rake up mussels and clams; they also help the walrus to climb on to the ice. A young walrus was kept for some time by the members of the JacksonHarmsworth Expedition, and was found to be an amusing pet. One kept on board a Dundee whaler used to sleep with an Eskimo dog, and got into the same kennel with it. It ate blubber and salt pork, but liked the sailors' pea soup better than anything else; it was most sociable, and could not bear to be alone-would tumble down the hatchway to seek the society of its beloved sailors, and scramble into the cabin if the door were open. When it fell ill and before it died, it seemed most grateful for any attention shown to it. The parent walrus shows the greatest courage in trying to defend the young one. Walruses are now scarce; but as the ivory is the only part of them of much present value, there is a chance that they may not be killed off entirely.

\section{The True Seals.}

The TRUe SeALs, with their greatly modified forms, heads set almost on to their shoulders, with no neck visible, have well-developed claws on all the toes, and in the typical species have double-rooted and small cheek teeth. The number of the incisors is variable. The Gray SEAL of the North Atlantic is a large species which visits the North British coasts and the Hebrides. 
One old male shot off the coast of Connemara weighed nearly $400 \mathrm{lbs}$., and was 8 feet long. It is found off Scandinavia and. eastwards to the coast of Greenland, and breeds off our coasts in October and November. This is the large seal occasionally shot up Scotch lochs. Its colour is yellowish gray, varied with blots and patches of dirty black and brown.

\section{The Common Seal.}

This seal is smaller than the preceding. It breeds on parts of the Welsh and Cornish coasts, and is found on both sides of the Atlantic and in the North Pacific. It assembles in small herds, and frequents lochs, estuaries, and river mouths. In the summer it is fond of following flounders and sea-trout up rivers. A few years ago one came up the Thames and was shot at Richmond. The young are born in June, and are grayish white. The adults are variously mottled with gray, brown, and black. The fondness of seals for music is proverbial. Macgillivray, the Scotch naturalist, said that in the Hebrides he could bring half a score of them within forty yards of him by a few notes on his flute, when they would swim about with their heads above water like so many black dogs. A seal was captured by the servants of a landowner near Clew Bay, on the west coast of Ireland, and kept. tame for four years. It became so attached to the house that, after being carried out to sea three times, it returned on each occasion. The cruel wretches who owned it then blinded it, out of curiosity to see whether it could find its way back sightless. The poor animal did so after eight days.

The common seal is still fairly numerous on the rocky western coasts of the British 'slands, though a few old seals, unable to forget their early habits, appear now and then in Morecambe Bay and in the Solway. It is not uncommon off the coasts of Caithness and Sutherland. It also frequents a sand-bank in the Dornoch Firth, though it has been much persecuted there. The common seal is gregarious, while the gray seal usually lives only in pairs, or at most in small companies. Two or three dozen like to lie closely packed on shore with all their heads turning seawards. The white hair of the young seals -which, as already said, are born in June-is shed in a day or two, when the young take to the water. With regard to their reputed musical proclivities, some experiments made at the Zoological Gardens did not bear out this belief; but there is much evidence that in a state of nature they will approach and listen to music. The common seal has a large brain capacity, and is a very intelligent creature. The upper parts of this seal are yellowish gray, spotted with black and brown, the under parts being silver-gray.

The Harp-seal is an Arctic or ice-seal which sometimes finds its way here. The young are born

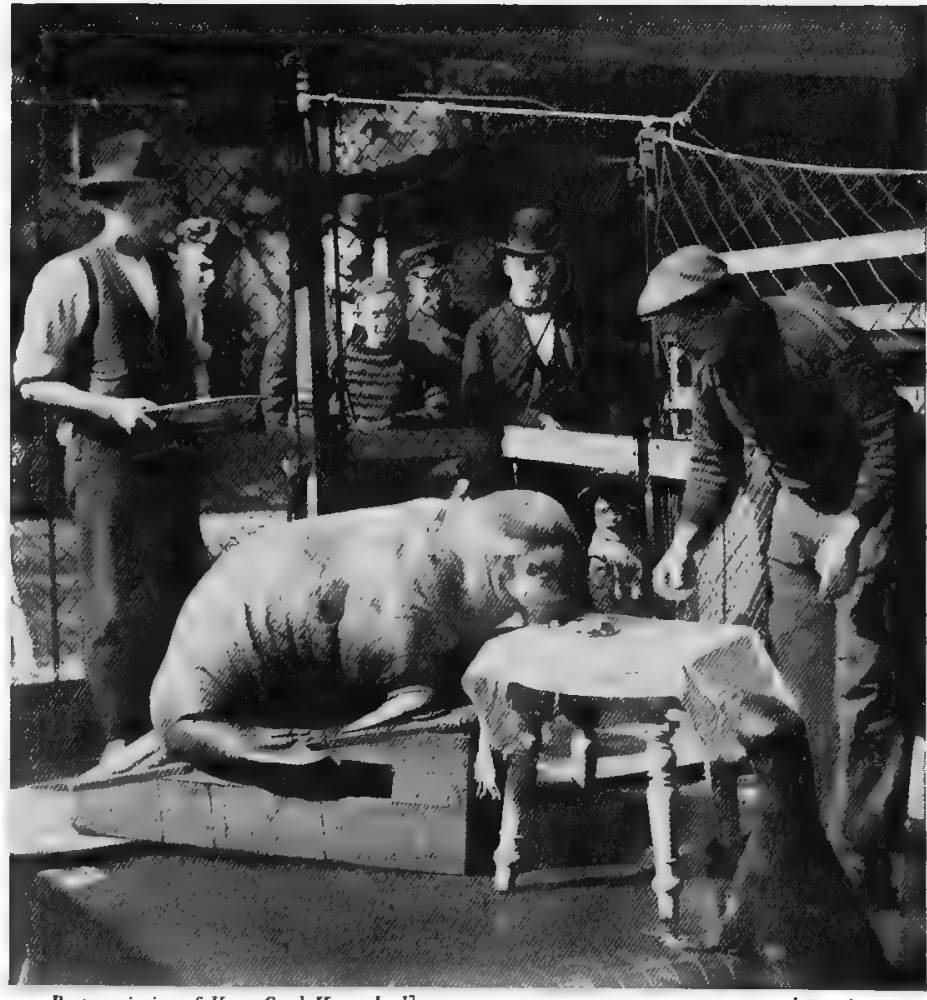

By permission of Herr Carl Hagenbeck]

W ALRUS AND SEA-LION

Another photograph of the walrus tamed by Herr Carl Hagenbeck. Notice the sea-lion in the right-hand corner, which also formed one of the same performing troupe 


\section{26 THE LIVING ANIMALS OF THE WORLD}

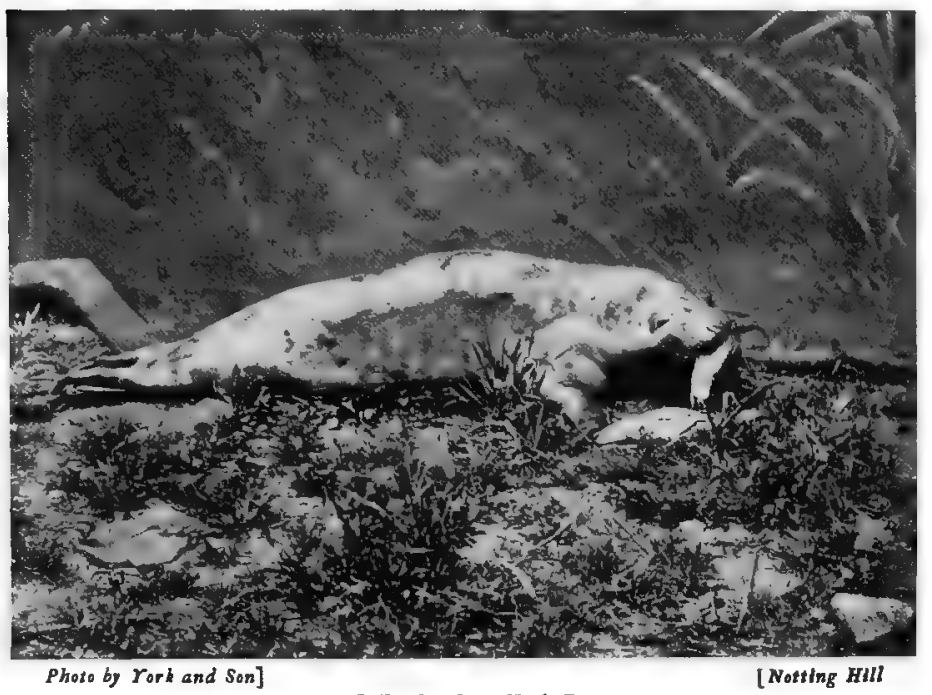

G R A Y S E A L

Seals are not so well adapted as sea-lions for getting about on the dry land, and, except for their habit of coming ashore to bask in the sun, are thoroughly aquatic on ice-floes. It is found in great herds in Davis Straits, on the coasts of Greenland and in the greater part of the frozen Arctic Ocean. It is the animal which the sealing-vessels which hunt seals for oil and "hair" - that is, the leather of the skins, not the fur-seek and destroy. In the old days they could be seen in tens of thousands blackening square miles of ice. They are still so numerous that in Danish Greenland more than 30,000 are taken each year. The Ringed SEAL is a small variety, not more than 3 or 4 feet in length, found in great numbers in the Far North. Its flesh is the main food of the

Eskimo, and its skin the clothing of the Greenlanders. The seals make breathing-holes in the ice. There the Eskimo waits with uplifted spear for hours at a time, until the seal comes up to breathe, when it is harpooned. The BLADDER-NOSED SEAL is a large spotted variety, with a curious bladder-like crest on the head and nose of the male. Unlike all other seals, it sometimes resists the hunters and attacks the Eskimo in their kayaks.

If any evidence were needed of the great destruction which the sealing and whaling industry causes, and has caused, among the large marine animals, the case of the ELEPHANT-SEALS ought to carry conviction. These are very large seals, the male of which has a projecting nose like a proboscis. They were formerly found both north and south of the Equator, their main haunts being on the coast of California, and on the islands of the South Pacific and Antarctic Ocean. They are gigantic compared with the common seals, some of the males being from I6 to 20 feet long. Cuttle-fish and seaweed are the principal food of this seal, which was formerly seen in astonishing numbers. The whaling-ships which hunted both these seals and spermwhales at the same time almost destroyed those which bred on the more accessible coasts, just as the earlier whalers entirely destroyed Steller's sea-cow, and their modern descendants destroyed the southern right-whales. The elephant-seal is now very scarce, and when one is killed the skin is regarded as something of a curiosity.

In the records of the voyage of the Challenger it is stated that there were still great numbers of the elephant-seals surviving near Heard Island, and not a few round the shores of Kerguelen Island. Professor Moseley states that on the windward shore of Heard Island " there is an extensive beach, called Long Beach. This was covered with thousands of sea-elephants in the breeding-season; but it is only accessible by land, and then only by crossing two glaciers. No boat can safely land on this shore; consequently men are stationed on the beach, and live there in huts. Their duty is constantly to drive the sea-elephants from this beach into the sea, which they do with whips made out of the hides of the seals themselves. The beasts thus ousted swim off, and often 'haul up,' as the term is, upon the accessible beach beyond. In very stormy weather, when they are driven into the sea, they are forced to betake themselves to the sheltered side of the island. 'Two or three old males, which are called 'beach-masters,' hold a beach for themselves and cover it with cows, but allow no other males to haul up. They fight furiously, and one man told me that he had seen an old male take a young one up in his teeth and throw him over, lifting him in the air. The males show fight when whipped, and are with 


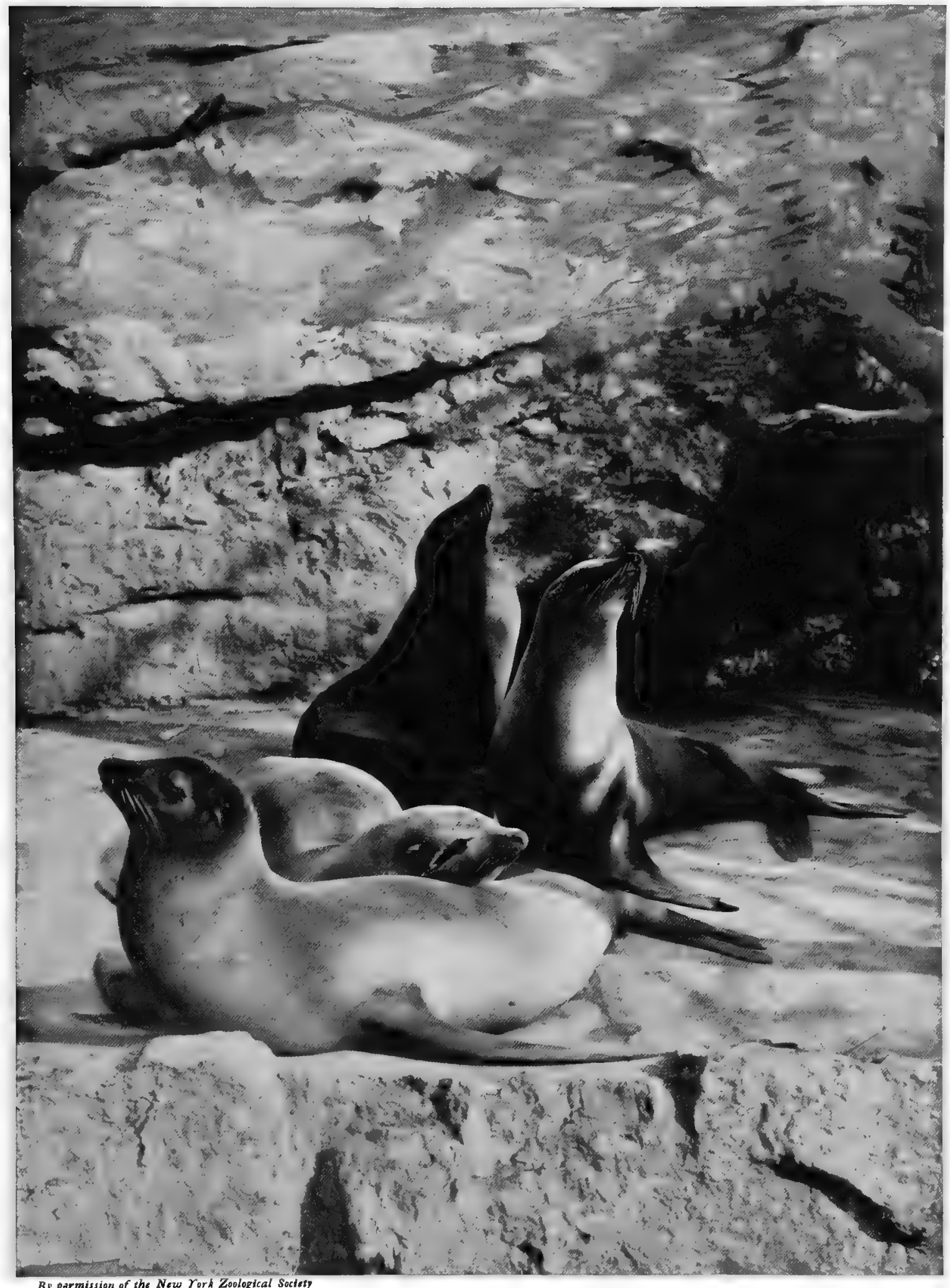

By parmission of the New York Zoological Socisty

CALIFORNIAN SEA-LIONS, OR EARED SEALS

Seal-herds form " rookeries" when on land at the breeding-season, during which time they undergo a compiete fast 
great difficulty driven into the sea. The females give birth to their young soon after their arrival. The new-born young ones are almost black, unlike the adults, which are of a light slatebrown. They are suckled by the female for some time, and then left to themselves, lying on the beach, where they seem to grow fat without further feeding. They are always allowed by the sealers to lie like this, ' in order to make more oil.' This account was corroborated by all the sealers I met, but I do not understand it. Probably the cows visit their offspring unobserved from time to time. Péron says that both parent elephant-seals stay with the young without taking any food at all till the latter are about six or seven weeks old, and that the old ones conduct the young to the water and carefully keep them company. The rapid increase in veight is in accordance with Péron's account. Goodridge gives a somewhat different story-namely, that after the females leave the young the old males and the pups proceed inland, as far as two miles sometimes, and stop without food for more than a month, during which time they lose fat. The male sea-elephants come ashore for the purpose of breeding about the middle of August, the females a little later."

Formerly the elephant-seals were found as far north as the Californian coast, where their capture was the main business of the sealing-traders. This species also formed the mainstay of the far southern sealers. As the elephant-seals were killed off, so the business became less and less profitable. It is to be hoped that the voyages of exploration to the Antarctic ice-fringe will not lead to the discovery of fresh sealing-grounds, for if this is the case there is little chance that any of the southern seals will escape entire destruction. Some form of close time has already been enforced in the pursuit of the hair-seals of Northern Europe; but it is very desirable that the species still found on our own coasts should also receive protection. Except when they paid visits to the fixed salmon-nets, they never did any harm; and fixed nets are now illegal. When a seal learned the use of the stake-nets, which these animals were very quick to understand, it would wait quietly till it saw a fish caught, and then swim up and carry it off before the fishermen could take it.

Two species-namely, the Common Seal and Gray Seal-still regularly visit our shores. The common seal breeds on our southwestern coasts, and the gray seal off the Hebrides. If the common seal were accorded a close time, its numbers would probably increase; and the spectacle of such interesting creatures visible on our coast could not fail to be of great interest. All the old legends of mermaids and wild men of the sea are based on the capture of seals. Perhaps the most ancient is one which records such a capture in the river near Orford Castle, in Suffolk, in the reign of Henry II. The ignorant soldiers were persuaded that it was a man, and tortured it

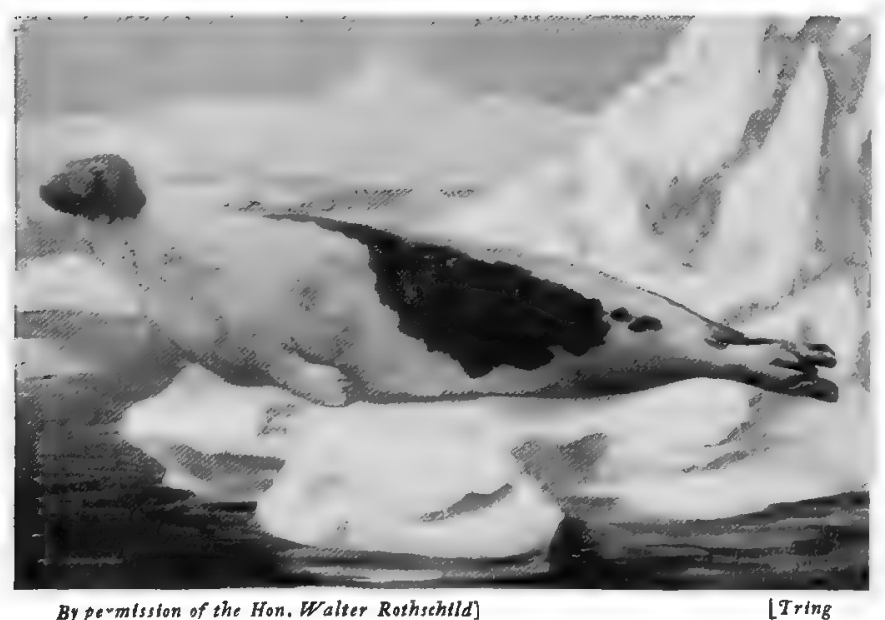

H A R P - S E A L

The harp-seal comes from Greenland to make it speak. 'They then took it to the church, and showed it the sacred emblems. As it " showed no reverence," they took it back to the castle, and fed it on fish. It was allowed to go into the river, but returned to its captors of its own accord. Later it swam away to the sea. The monk who recorded the story stated his conviction that this seal was an evil spirit which had got into the body of a drowned sailor. A gray seal was taken not many years ago in the creek leading up to the little town of Wells, in Norfolk. It was so tame that the fishermen caught it by throwing coats over it as it lay on the mud. 


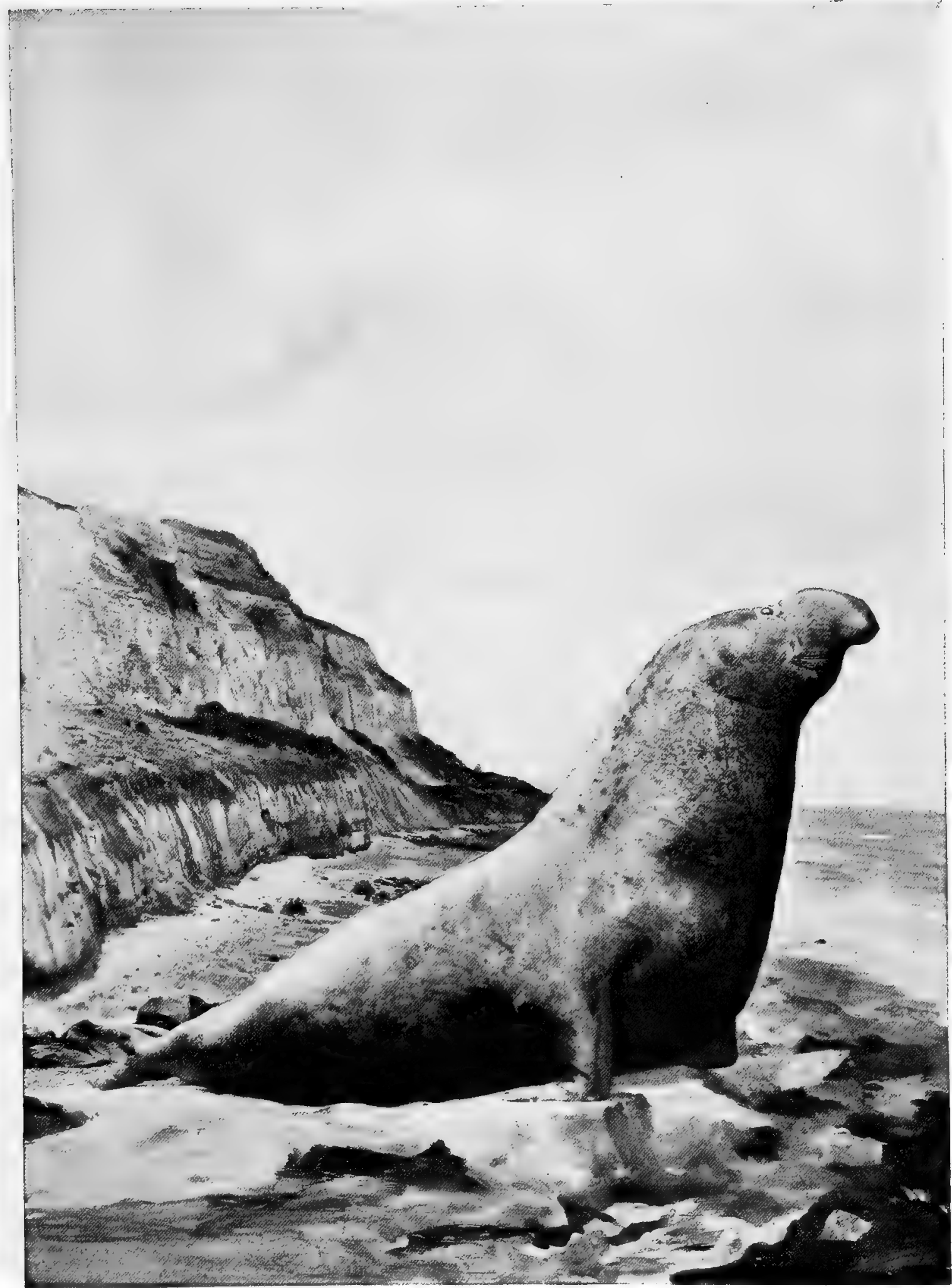

By permission of the Hon. Walter Rothschild]

SEA-ELEPH A T T

[Tring

These enormous seals (about zo feet in length) are becoming very scarce. When they come ashore, they are eastly upproached, though not :o casily killed. They are much valued for their oil. Note the trunk-like prolongation of the nose. which, wu ben the animal is excited. becomes sistended 


\section{CHAPTER IX.}

\section{THE RODENTS, OR GNAWING ANIMALS.}

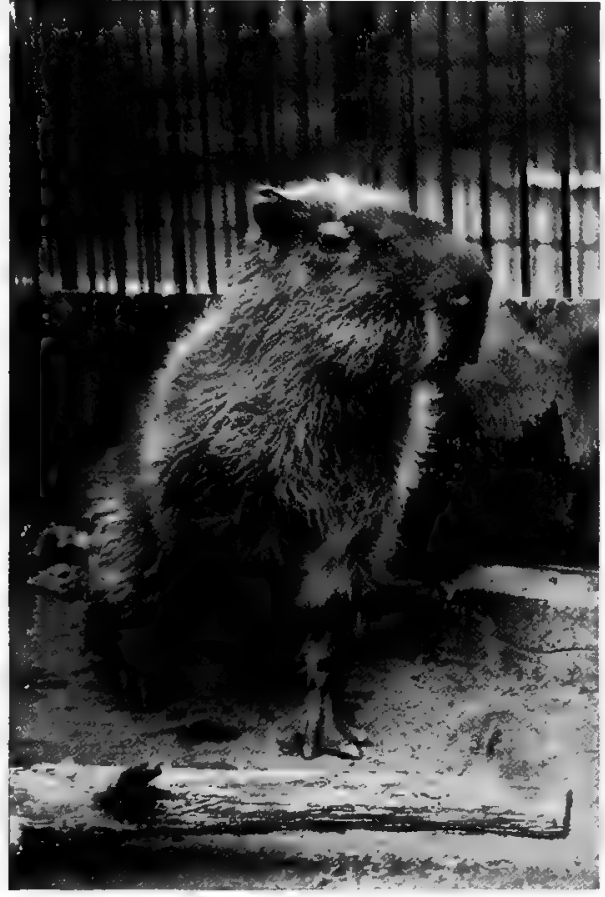

Photo by W. P. Dando]

C A P Y B A R A

This, the largest of the rodents, is found by the rivers of Souch America
WHE Rodents, or Gnawing Mammals, have all the same general type of teeth, from which the order receives its distinctive name. There are a very large number of families and of genera among the rodents, more than in any other order of mammals. All the rodents possess a pair of long chisel-shaped incisor teeth in each jaw. The ends of these teeth are worn into a sharp edge which cuts like a steel tool. In most rodents these are the only teeth in that part of the jaw, a wide gap intervening between them and the other teeth. The hares, rabbits, and calling-hares have a minute pair of teeth set just behind the large pair in the upper jaw. The grinding-teeth are set far back, and are never more than six in number, these being sometimes reduced to four. Rodents generally have five toes on the fore feet; in the hind feet there are in some cases only four, or even three. None of the species are of great size; the largest, the CAPYBARA, $z$ water-living animal of South America, is about the dimensions of a small pig. But the number of species of small rodents is prodigious, and their fecundity so great that they constantly increase in favourable seasons until they become a plague. Voles, lemming s, field-mice, and rabbits are constant sources of loss to agriculture in their seasons of extraordinary increase. Most rodents feed on vegetables, though rats and mice have developed carnivorous tastes. No rodents have canine teeth.

\section{The Squirrels.}

Those of the order of Gnawing A nimals which have only two incisors in each jaw, and no rudimentary teeth like those possessed by the hares, are called "Simple-toothed Rodents." Of these the family usually placed first in order is that of the Squirrels and their allies. The True Squirrels and Marmots have five molar teeth on each side of the upper jaw.

Squirrels are found in nearly every temperate part of the globe, from Norway to Japan, and in very great numbers in India and the tropics. Everywhere they are favourites;

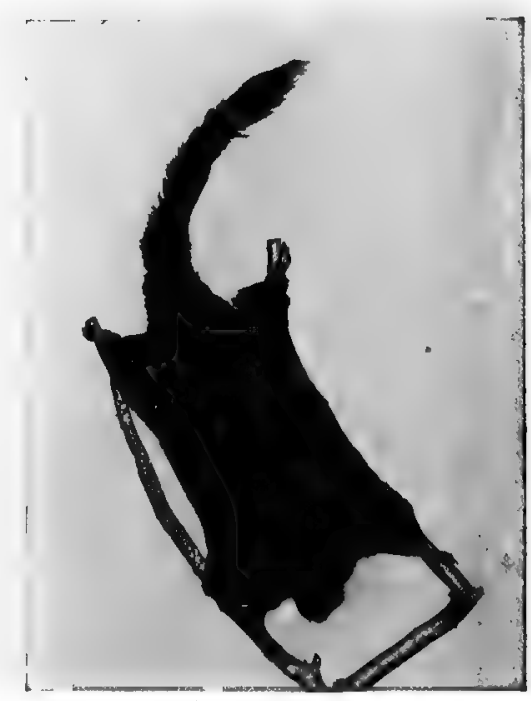

By permisston of Professor Bumpus, New York F L Y I N G - S QU I R R E L One of the small species of the group 
and though they do some mischief in highly cultivated countries, they are among the most harmless of creatures. Most of them live on wild nuts and the kernels of fruit; they suck eggs occasionally, and in Canada will come to the traps in extreme cold and eat the meat with which they are baited.

T.

\section{The Red Souirrel.}

This, the common squirrel here, is representative of the whole order. In old Scandinavian legends the squirrel is represented as the messenger of the gods, who carried the news of what was going on in the world to the other animals. Together with its close relations, it is the most graceful of all climbers of trees. With its long tail waving behind it, it races up or down the trunks and across the forests from branch to branch as easily as a horse gallops across a plain. It will descend the trunk head downwards as fast as it runs up. Squirrels pair for life, and are most affectionate little creatures, always playing or doing gymnastics together. far more sensible than the monkeys and apes; it is made of leaves, moss, and sticks. The sticks come first as a platform; then this is carpeted, and a roof put on. No one who has seen common squirrels at work house-building has ever described exactly how they do it; it is the best nest made by any mammal, thoroughly well fitted together and waterproof. In this nest the young squirrels are born in the month of June; that year they keep with the parents, and do not "set up for themselves" till the next spring. The red colour is very persistent in squirrels. One Chinese variety, black and red, has even bright red teeth. In cold countries the red squirrels make stores of food, but spend much of the winter asleep.

It is a great pity that in England no ones tries to tame the squirrels as they do in America; there they are the greatest ornament of the parks of cities, coming down to be fed as tamely as our sparrows. The writer has known one instance in which a lady induced wild squirrels to pay daily visits to her bedroom for food; they used to climb up the ivy and jump in at the open window. The great enemies of squirrels near houses are the cats, which kill all the young ones 


\section{I32 THE LIVING ANIMALS OF THE WORLD}

when they first come down from the trees. In a garden in the country a pair of squirrels had a family every summer for five years, but none ever survived the cats' persistent attacks. These squirrels were most amusing and improvident. They used to hide horse-chestnuts, small potatoes, kernels of stone fruit, bulbs of crocuses, and other treasures in all kinds of places, and then forget them. After deep snows they might be seen scampering about looking into every hole and crevice to see whether that happened to be the place where they had hidden something useful. Much of the store was buried among the roots of trees and bushes, and quite hidden when the snow fell.

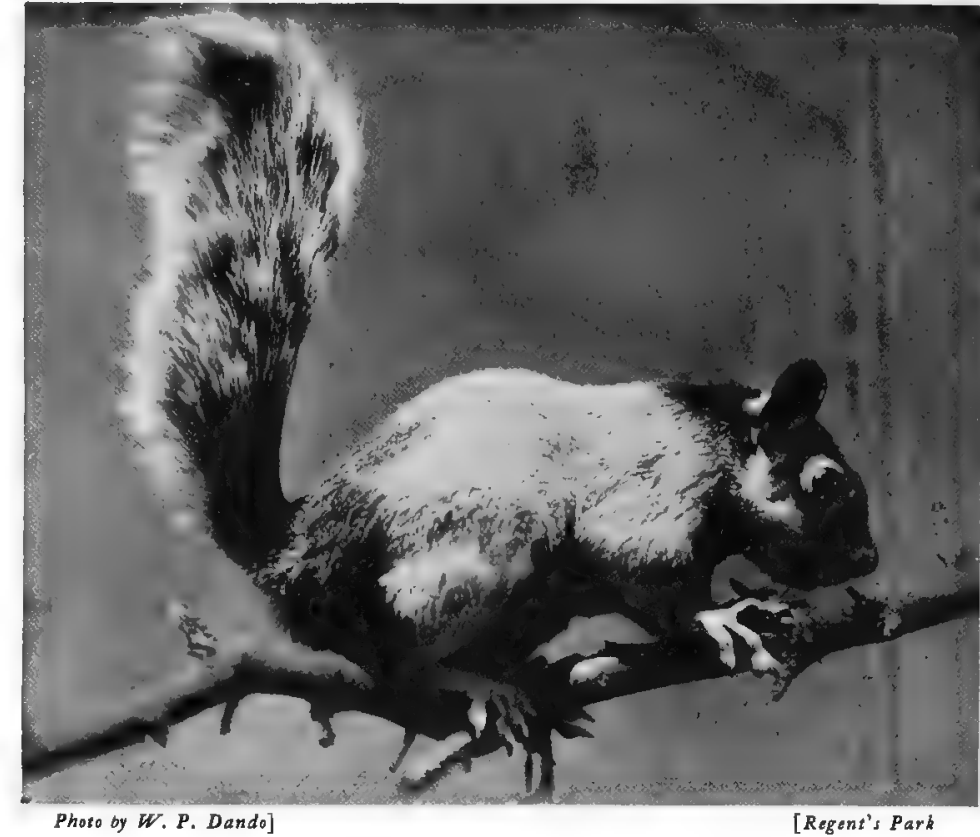

DORSAL SQUIRREL FROM CENTRAL AMERICA A most beautiful species. The main colour is red, but the back is French gray, and the tail French gray and red mingled.

\section{The Flying-Squirrels.}

One of the finest squirrels is the TAGUAN, a large squirrel of India, Ceylon, and the Malacca forests. It is a "flying-squirrel," with a body 2 feet long, and a bushy tail of the same length. Being nocturnal, it is not often seen; but when it leaps it unfolds a flap of skin on either side, which is stretched (like a sail) when the fore and hind limbs are extended in the act of leaping; it then forms a parachute. The colour of this squirrel is gray, brown, and pale chestnut. There are a number of different flying-squirrels in China, Formosa, and Japan, and in the forests of Central America. One small flying-squirrel, the Polatouche is found in Northeast Russia and Siberia. It flies from tree to tree with immense bounds, assisted by the "floats" on its sides. Though only six inches long, it can cover distances of 30 feet and more without diffi-

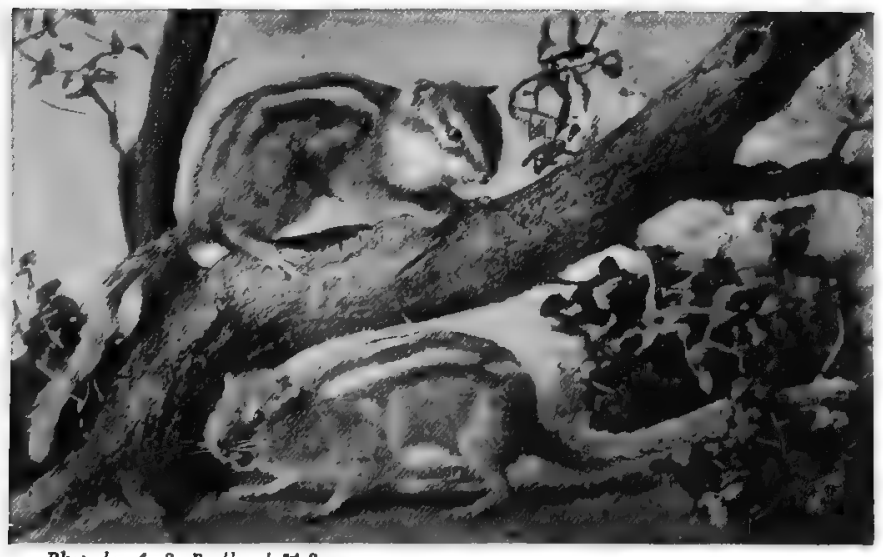

Phoso by A. S. Rudland Sons

A S I A T I C C H I P M U N K S

Small ground-squirrels wbicb store food for the wineer culty. Wherever there are birch forests this little squirrel is found.

In Africa, south of the Sahara, the place of the Oriental flyingsquirrel is taken by a separate family. They have a different arrangement of the parachute from that of the flyingsquirrels of India. This wide fold of skin is supported in the Asiatic squirrels by a cartilage extending from the wrist. In the South African flying-squirrels this support springs from the elbow, not from the wrist; they have also horny plates on the under-surface of the tail. Many of the tropical flying-squirrels 
are quite large animals, some being as large as a small cat.

Mr. W. H. Adams says of PEL's FLying-SQuirReL, a West African species: "These squirrels come out of their holes in the trees some hours after sunset, and return long before daybreak. They are only visible on bright moonlight nights. The natives say that they do not come out of their holes at all in stormy weather, or on very dark nights; they live on berries and fruits, being especially fond of the palm-oil nut, which they take to their nests to peel and eat. They pass from tree to tree with great rapidity, usually choosing to jump from a higher branch to a lower one, and then climbing up

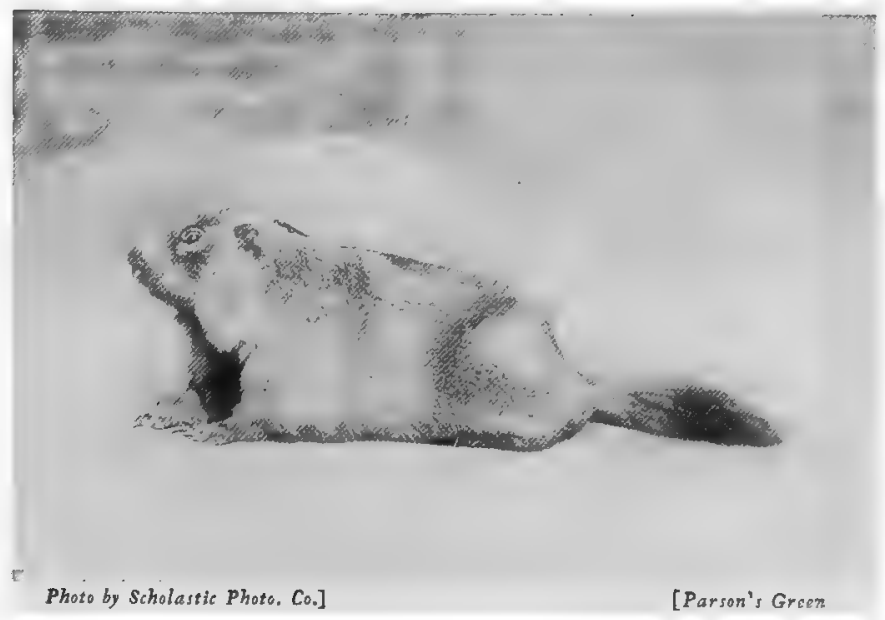

L ONG-TAILED MARMOT

The marmots live by preference on high and cold mountains just below the line of eternal snow in Europe. In Asia, where the snow-line is higher, they are found at altitudes of 12,000 feet again to make a fresh start. . . They litter about twice in a year, once in September. The young remain in the nest for about nine weeks, during which they are fed by the old ones on such food as shoots and kernels. They do not attempt to jump or 'fly' till the end of that period, extending the length of their jumps with their growth."

The Ethiopian SPIny Squirrels have coarse spiny fur; the little Indian Palm-squirrel is marked with longitudinal dark and light stripes on the back; others have light bands on their flanks.

The Alpine Marmor is a much larger species than the prairie-dog. It lives on the Alps just below the line of perpetual snow. From five to fifteen marmots combine in colonies, dig very deep holes, and, like the prairie-dogs, carefully line them with grass; they also store up dry grass for food. In autumn they grow very fat, and are then dug out of the burrows by the mountaineers for food. Young marmots used to be tamed and carried about by the Savoyard boys, but this practice is now rare. The monkey is probably more attractive to the public than the fat and sleepy marmot. Marmots are about the size of a rabbit, and have close iron-gray fur.

Tschudi, the naturalist of the Alps, says of the marmots that they are the only mammal which inhabits the region of the snows. No other warm-blooded quadrupeds live at such an altitude. In spring, when the lower snows melt, there are generally small pieces of short turf near their holes, as well as great rocks, precipices, and stones. Here they make their burrows, outside which they feed, with a sentinel always posted to warn them of the approach of the eagle or lammergeir. The young marmots, from four to six in number, are born in June. When they first appear at the mouth of the holes, they are bluish gray; later the fur gains a brownish tint. The burrows are usually at a height of not less than 7,000 or 8,000 feet. Winter comes on apace. By the end of autumn the ground is already covered with snow, and the marmots retire to sleep through the long winter. As they do not become torpid for some time, they require food when there is none accessible; this they store up in the form of dried grass, which they cut in August, and leave outside their burrows for a time to be turned into hay.

The Alpine Marmot is also found in the Carpathians and the Pyrenees. Another species, the BoBAC, ranges eastward from the German frontier across Poland, Russia, and the steppes of Asia to Kamchatka. In Ladak and Western Tibet a short-tailed species, the Himalayan MARMOT, is found, sometimes living at a height of nearly i7,00o feet. The Golden MARMOT is found in the Pamirs. 


\section{34 THE LIVING ANIMALS OF THE WORLD}

\section{The Dormice.}

There are a considerable number of animals, even here, which hibernate. Most of these feed largely on insect food, which in winter is unobtainable in any great quantity. Consequently the hedgehog and the badger, which live largely on snails and worms, go to sleep in the famine months. So does the sleepiest of all-the Dormouse. This alone would show that this little rodent probably feeds on insects very largely, for if it only ate nuts and berries it could easily store these, and find a good supply also in the winter woods. It has been recently proved that dormice are insectivorous, and will eat aphides, weevils, and caterpillars. But a dormouse hibernates for so long a time that one might imagine its vitality entirely lost; it sleeps for six months at a time, and becomes almost as cold as a dead animal, and breathes very slowly and almost imperceptibly. Mr. Trevor-Battye says that if warmed and made to awaken suddenly in

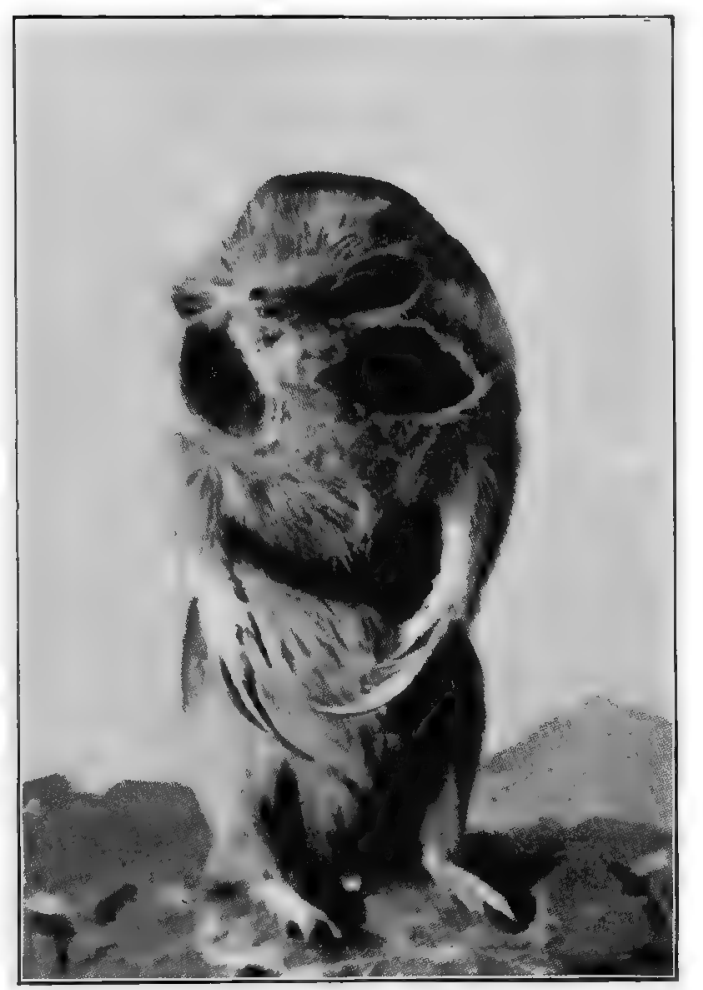

Photo by A. S. Rudland of Sons

$$
\text { P OCKET-G OPHER }
$$

The pocket-gophers are almost entirely subterranean. Their burrowing powvers are remarkable. The teeth as well as clazus are used to aid them the winter it would die in a minute or two, its heart beating very fast, "like a clock running down." Before their hibernation dormice grow very fat. There is a large species, found in Southern Europe, which the Romans used to eat when in this fat stage. In. winter dormice usually seek the nest of some small bird, and use it as a sleeping-place. They pull out and renew the lining, or add a roof themselves. Into the interior they carry a fresh supply of moss, and sleep there in great comfort. Their great ; sny at $i$ in time is $i$ : weascl. There are tiv main groups of the durmice, divided by naturalists in reference to the structure of their stomach. The South African Graphiures have short tufted tails. The hibernating habit is confined to the more northern species.

\section{The Mouse Tribe.}

This family, which includes the Mice, Rats, and Voles, contains more than a third of the number of the whole order of Rodents. Some are arboreal, others aquatic; but most are groundliving animals and burrowers. The number of known species has been estimated at 330. Among the most marked types are the WATER-MICE of Australia and New Guinea, and of the island of Luzon in the Philippines. The feet of the Australian species are webbed, though those of the Philippine form are not. The GerbiLs form another group, mainly inhabitants of desert districts. They have very large eyes, soft fur, and tails of various length and form in different species. They have greatly developed hind legs, and leap like jerboas, and are found in Southern Europe, Asia, and Africa. The Philippine Rats, large and long-haired, and the TREe-Mice of Africa south of the Sahara, form other groups. A very mischievous race of rodents is represented in Europe by the Hamsters, and in America by a closely allied group, the WhiteFOOTED Mice.

\section{The Hamsters.}

The HAMSTER is a well-known European species, and represents the group of pouched rats. 


\section{THE RODENTS, OR GNAWING ANIMALS I 35}

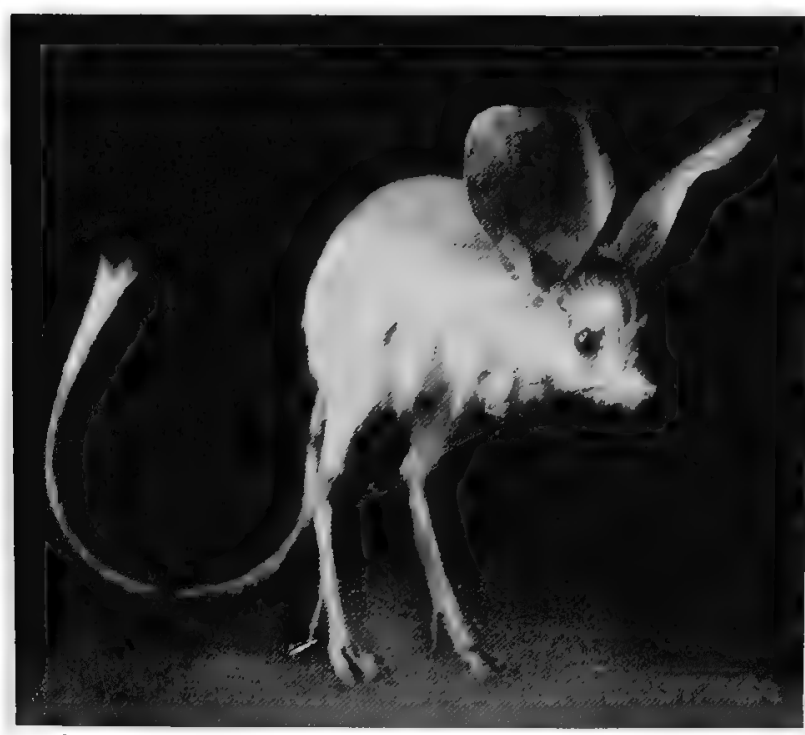

Photo Ly A. S. Rudland \& Sons

L O N - E A RED JERBOA

Tbese curious little animals are mainly desert creatures. They move by a series of leaps

These creatures have cheek-pouches to aid them in carrying food. In addition they are most voracious and inquisitive, so that the hamster is a type throughout Central Europe of selfishness and greed. We are sorry to add that John Bull occasionally appears in German cartoons as the "Land-hamster," or land-grabber. Hamsters are numerous from the Elbe to the Obi. They burrow and make cellars in the corn- and bean-fields, and convey thither as much as a bushel of grain. As soon as the young hamsters can shift for themselves, each moves off, makes a separate burrow, and begins to hoard beans and corn. As the litter sometimes contains eighteen young, the mischief done by the hamster is great. Its coloration is peculiar. The fur, which is so thick as to be used for the linings of coats, is a light yellowish brown above. A yellow spot marks each cheek. The lower surface of the body, the legs, and a band on the forehead are black, and the feet white. Thus the hamster reverses the usual natural order of colour in mammals, which tends to be dark on the back and light below. The animal is 10 inches long, and very courageous. Hamsters have been known to seize a horse by the nose which stepped on their burrow, and at all times they are ready to defend their home. Besides vegetables and corn, they destroy smaller animals. They spend the winter in a more or less torpid state in their burrows, but emerge early in spring. They then make their summer burrows and produce their young, which in a fortnight after birth are able to begin to make a burrow for themselves.

Among the South American members of the group to which the hamster belongs are the Fish-eating Rats, with webbed hind feet. The Rice-Rat, which is found from the United States to Ecuador, lives on the Texas prairies much as do the prairiemarmots, though its burrows are not so extensive, and often quite shallow. In these the rats make beds of dry grass.

The Voles.

The VolEs are allied to the preceding groups, but are marked externally by a shorter and heavier form than the typical rats and mice. Their ears are shorter, their noses blunter, their eyes smaller, and the tail generally shorter. They are found in great numbers at certain seasons, when

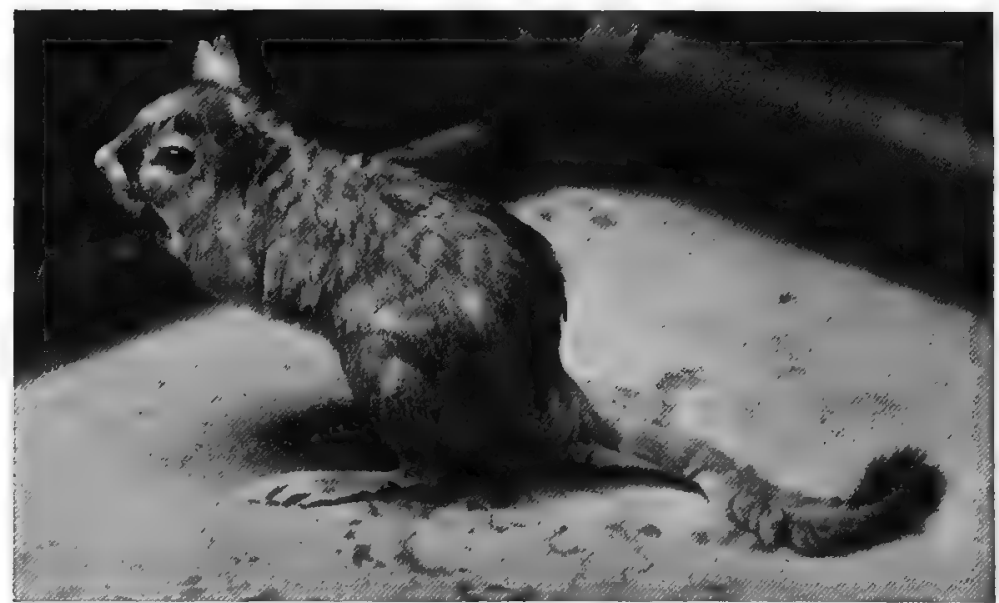

Photo by A. S. Rudland os Sons

C A P E J U M I N G - H A RE

Tbis animal is very common in Soutb Africa. The Boers call it tbe "Springbaas" 


\section{36 THE LIVING ANIMALS OF THE WORLD}

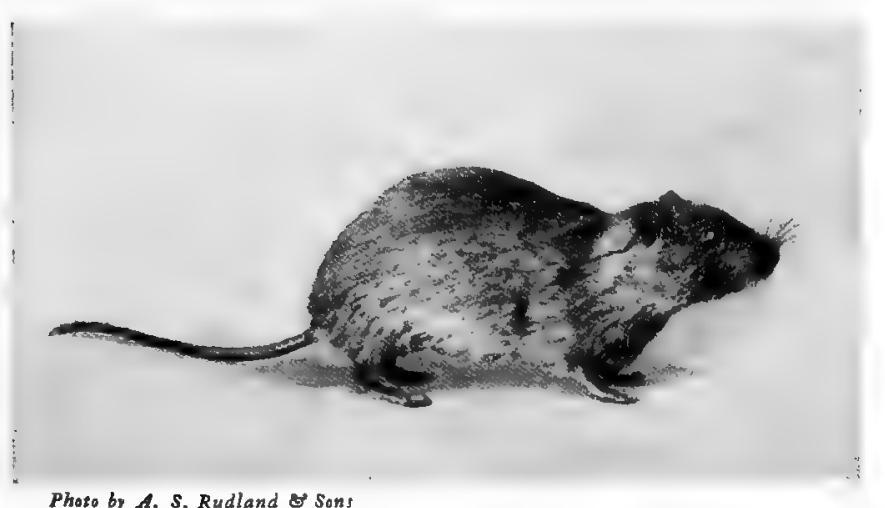

OCTODON T

The octodont, so called because they bave four molar teetb on eacb side of the jaw are a group of rodents found mainly in Soutb America

they often develop into a pest. The Short-TaIled Field-vole is responsible for much destruction of crops in Europe. One of the latest plagues of these animals took place in the Lowlands of Scotland, where these voles devoured all the higher pastures on the hills. Nearly at the same time a similar plague occurred in Turkish Epirus. When a special commissioner was sent to enquire into the remedies (if any existed) there in use, he found that the Turks were importing holy water from Mecca to sprinkle on the fields affected. The

Bank-vole is a small English species, replaced on the Continent by the Southern Field-vole.

The WATER-RAT belongs to the vole group. It is one of the most commonly seen of all American mammals-probably, except the rabbit, the most familiar. Although not entirely nocturnal, it prefers the darkness or twilight; but whenever the visitor to the waterside keeps still, the water-rats will allow him to watch them. The writer has had rather an extensive acquaintance with these cousins of the beavers, and, while watching them, has never ceased to be struck with their close resemblance to those creatures. At Holkham Lake, in Norfolk, he noticed a willow-bush, in which a number of twigs had been gnawed off; and then saw the missing sticks lying neatly peeled, just like "beaver-wood," in the water below. Waiting quietly, he noticed a water-rat climb into the bush, gnaw off a willow twig, descend with it to the edge of the water, and there, sitting on some crossed boughs, peel and eat the bark, just as a beaver does. By rivers a sound is often heard in the round reeds as of something tearing or biting them; it is made by the water-rats getting their supper. The rat cuts off three or four sedges and makes a rough platform. It then cuts down a piece of one of the large round reeds full of pith, and, holding it in its hands, seizes the bark with its teeth, and shreds it up the stem, peeling it from end to end. This exposes the white pith, which the rat then eats. Water-rats have been seen to swim out and pick up acacia blossoms floating on the water. When swimming under water, each hair is tipped by a little bubble, which makes the rat look like quicksilver. When it comes out, the rat shakes itself with a kind of shiver, throwing all the water off its coat. Though so good a swimmer, its feet are not webbed. It is found from Scotland to the Bering Sea, but not in Ireland.

In the Far North the Lemming takes the place of the voles. It is a very small, short-tailed creature, like a diminutive prairie-dog. Like the voles, lemmings have seasons of immoderate increase. They then migrate in enormous flocks, and are said never to stop till they reach the sea, into which they plunge. It is believed that they are following an inherited instinct, and that where there is now sea there once was land, over which they passed onwards.

The Musk-RAT inhabits the same waters as the beaver of North America. It makes a house, generally

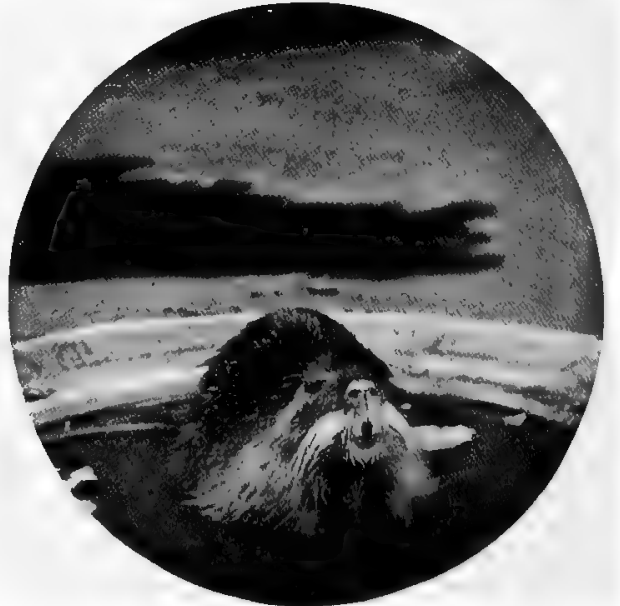

Photo by L. Medland, F.Z.S.]

C O Y P U

This is a large aquatic rodent, found on the Soutb American rivers. Its fur, called "nutria," forms a valuable export from Argentina 
of reeds piled in a mound, in the lakes and swamps. The body is only 12 inches long, but the fur is thick and close, and much used for lining coats and cloaks. The vast chains of rivers and lakes in Canada make that country the favourite home of the musk-rat. This creature lives upon roots of aquatic plants, freshwater-mussels, and stems of juicy herbs. Besides making the domed houses of grass, reeds, and mud, it also burrows in the banks of streams. There it makes rather an elaborate home, with numerous passages leading to the water. The odour of musk is very strong even in the skin. The tail is narrow and almost naked. This species is the largest of the vole group.

\section{The Typical Rats and Mice.}

These animals were originally an Old World group. Though the brown rat is now common in America, it is believed to have come originally from China.

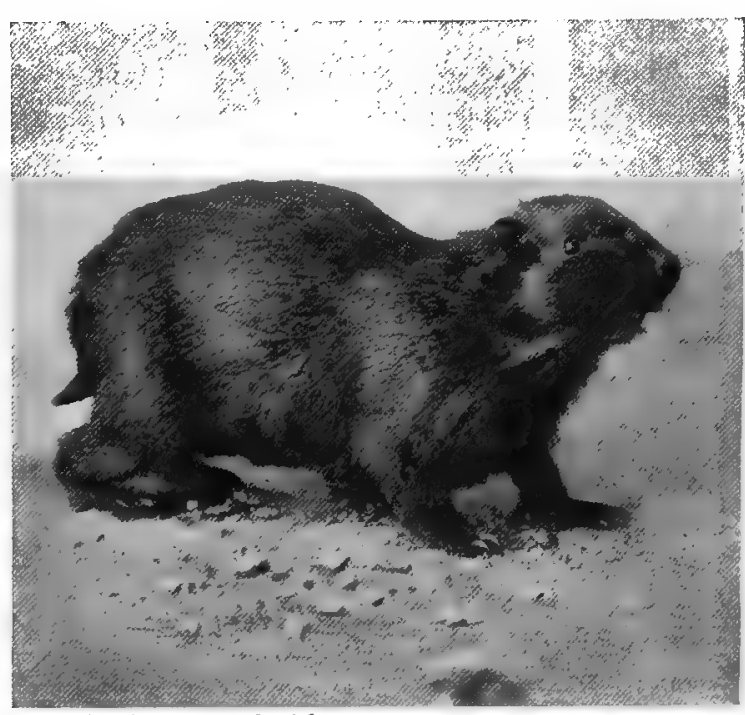

Photo by A. S. Rudland Eo Sons

SHORT-TAILED HUTIA

The butias are another group of octodons, found in tbe West India, Islands

A very large number of animals are now almost dependent on man and his belongings. Such creatures are said to be "commensalistic," or eaters at the same table. They are often very unwelcome guests, whether they are flies, sparrows, or cockroaches; but probably the least welcome of all are the rats and mice. The Brown RAT is the best known of any. It has come into worse repute than usual of late, because it is now certain that it harbours the plague-bacillus, and communicates the disease to man. Its habits and appearance need no description. The BLACK RAT is the older and smaller species indigenous in Europe, which the brown rat has almost extirpated from England. A few old houses still hold the black rat, and there are always a few wild ones at the Zoological Gardens which feed in the animals' houses. The BLAck-ANDwhite RAT (not the albino white rat) kept tame in this country is probably a domesticated form of the Alexandrine Rat of Egypt.

The House-mouse is now found in all parts of the world to which Europeans have access. In England its main home is in the corn-ricks. Were the farmers to thresh the grain, as is done in the United States, as soon as it is cut, mice would be far less common. Besides these parasitic mice, there are a host of field- and forest-mice in this and other countries. One of the best-known English species is the HARvest-mouse, which makes a globular nest of grass in the wheat-fields, attached to stems of corn or weeds. In this the young are born. In winter the mouse lives in holes in banks, and lays up a store of kernels and grain. The WooD-MOUSE is larger than the former, or than the House-mouse. It is yellowish brown in colour, lays up a great store of winter food, and is itself the favourite prey of the weasel.

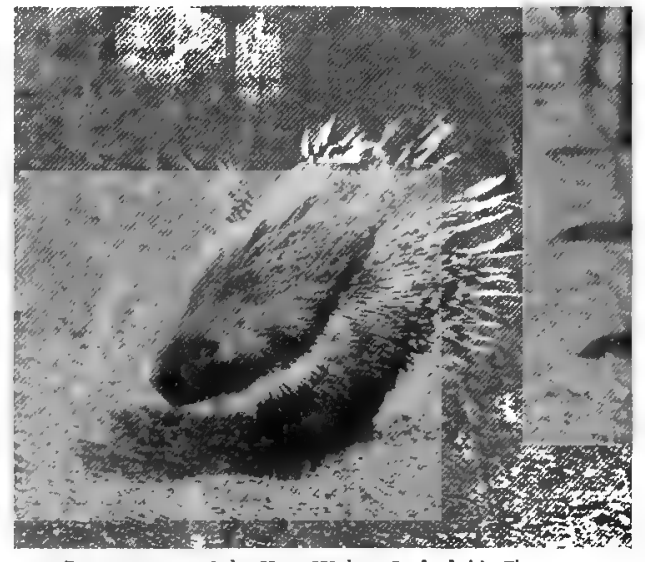

By permission of the Hon. Walter Rothschld, Tring

\section{PORCUPINE}

The common porcupine is found in North America, Italy. Spain, and North Africa 


\section{38 THE LIVING ANIMALS OF THE WORLD}

\section{The Bandicoot.}

A very mischievous class of rats is represented by the various species of BANDICOOT. They are found throughout Southern Asia as far as Ceylon, and in Kashmir and Turkestan. The BAndCOOT-RAT of India is a large and destructive species which is sometimes brought to the London docks in ships, but has not spread into the country.

\section{Other Murine Rodents.}

Among the numerous other rodents allied to the rat group are the MoLeRATS, with short mole-like bodies. The largest is the Great Mole-RAT, found in Southeastern Europe, Southwestern Asia, and Northeastern Africa. It is a sub-

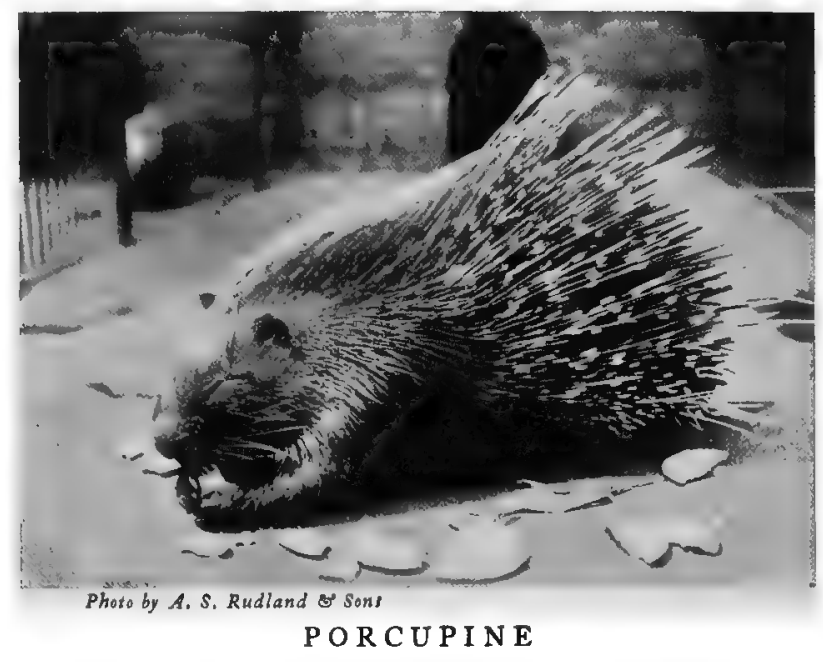

This phosograph showus the arrangement of the porcupine's defense of spines; but when frigheened it erects these, so as to form a complete protection to the body

terranean creature, burrowing for food like a mole. The BAMBOо-RATs have minute eyes, small external ears, and a short tail partly covered with hair. In Somaliland a small, almost naked SAND-RAT is found, which burrows in the sand of the desert, throwing up little. heaps like mole-hills.

\section{The Gophers.}

In North and Central America the Pocket-Gophens form a curious group of small rodents with cheek-pouches opening on the outside. They spend their entire existence underground, and are said to use their incisor teeth as picks to open the hard earth in their tunnels. They push the loosened soil out by pressing it with their chests and fore feet. When a gopher has eaten enough to satisfy the immediate calls of hunger, it stores all spare food away in the large cheek-pouches. When gophers desire to empty the pouches, they pass their feet along their cheeks from behind, and press the food forwards on to the ground.

\section{The Jerboas, Springhaas, and Jumping-mice.}

The hopping rodents have an immense range, from Southern Europe, through Africa,

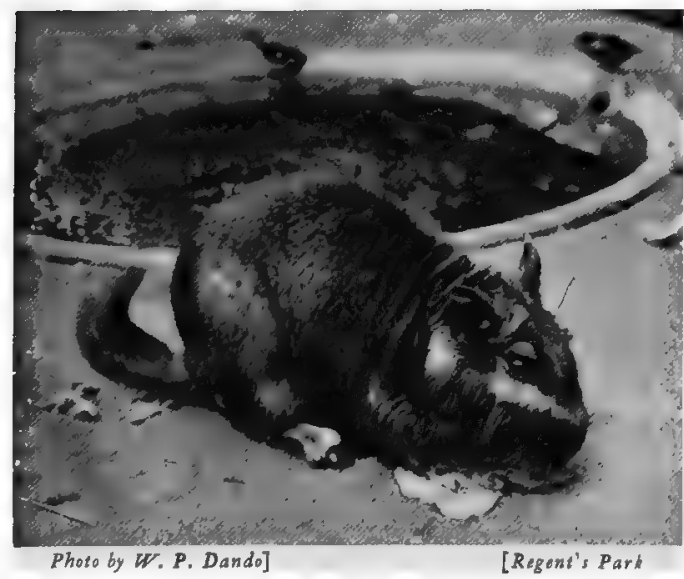

V I S C A C H A

The Viscacba forms colonies like tbose of the prairie-dogs. It is found on the pampas south of the La Plata
Arabia, India, and Ceylon, and even in the New World, where the American Jumping-mouse is found throughout the northern part of the continent. The latter is only 3 inches long. The true Jerboas are mainly found in Africa. All these, when excited, move like kangaroos. Their main home is the Central Asian steppe region, but they are found in Egypt, India, Syria, and Arabia. The hind legs are much elongated, the fore legs very small, and the body usually of a sandy colour. The American jumping-mouse, though a very small creature, can cover from 3 to 5 feet at each leap. It inhabits the beech and hard-wood forests. In winter it makes a globular nest about 6 inches under the surface of the ground.

The Care Jumping-hare forms a family by itself, with no near allies. It is of a tawny brown 


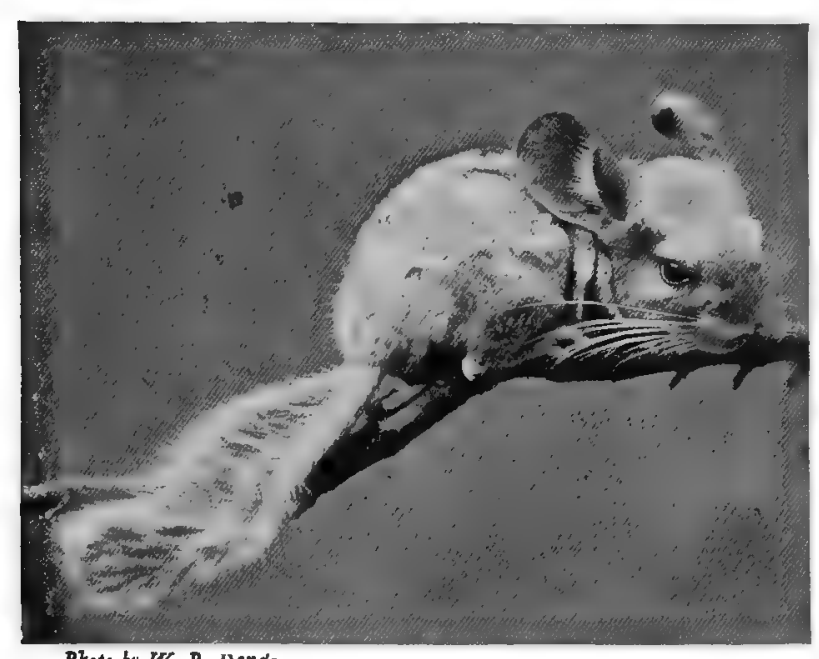

Photo by W. P. Dando

C H I N C H I L L A

A small rodent of the Andes, possessing very soft and valuable gray fur

colour, becoming almost pure white below. The tail is long, and carried upright as the animal leaps. The head and body are nearly 2 feet long, and the tail 20 inches. It is found both in the plains and mountains of South Africa, where it makes deep burrows, in which several families live. It is mainly nocturnal.

\section{The Octodone Family.}

America is the main home of this family of rodents, though there are several representatives in A frica. Their name is due to the fact that they have four molar teeth on each side of the jaw. The best-known species is the Coypu, or NuTRIA, of South America, an aquatic, furbearing animal. It is very plentiful in the large rivers of that continent, where its fur is a valuable commodity for export. When swimming, the female coypu carries its young on its back. The coypu is usually 20 inches long, with a tail two-thirds of the length of its head and body. The general colour is brown above and brownish yellow below. Coypus live in pairs in holes in the river-banks. In the Chonos Archipelago they frequent the seashore, and burrow near the beach.

The Hutia, another large octodont, is found in the West Indies. There are two species, both partly arboreal. The Tuco-Tucos, burrowing octodonts of the pampas and the far south of the American Continent, are rat-like animals, with large claws and very small eyes and ears.

\section{The Porcupines.}

These animals are either tree-climbers or ground-dwellers. The former are found in South America, though one, the Canadian Porcupine, is found in the North; the latter are European and Asiatic. In Africa they are also common. The Canadian porcupine passes nearly all its life in trees, feeding on the leaves; but it has not a prehensile tail. The Common Porcupine is abundant in Italy (where it is eaten by man), Greece, Spain, and Africa. It lives in burrows or among rocks. In India a very similar species is found. The head and shoulders of these ground-porcupines are not protected by the larger sharp spines which guard the rest of their bodies.

The tree-porcupines of the forests of Central America have long prehensile tails, and are very lightly built. The quills are short, the head rounded, and the appearance very different from that of the European or African species. The common porcupine of Europe and North Africa measures about 28 inches in length from the nose to the root of the tail. The head, neck, and shoulders are covered with short spines and hairs, and the

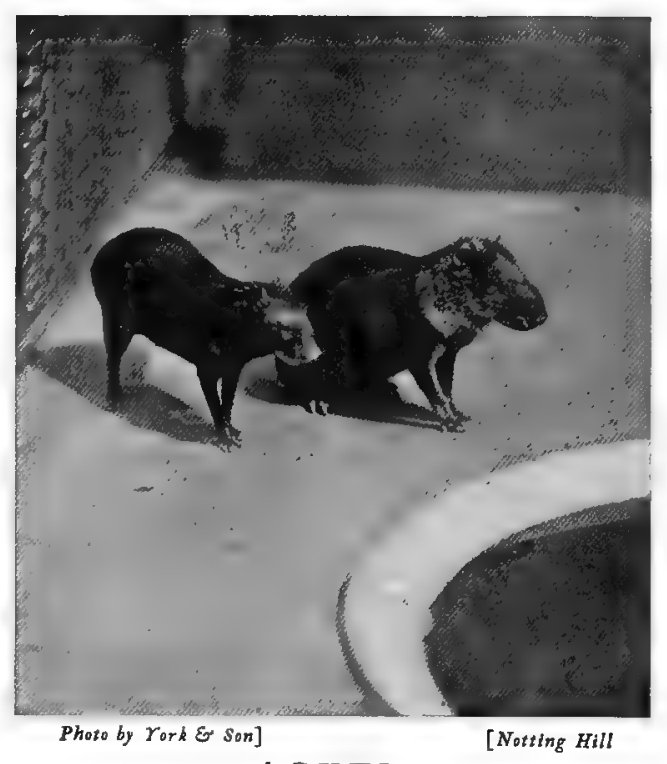

A G U T I S

The agutis are also a Soutb American group, found botb in the forests and on the plains 


\section{40 THE LIVING ANIMALS OF THE WORLD}

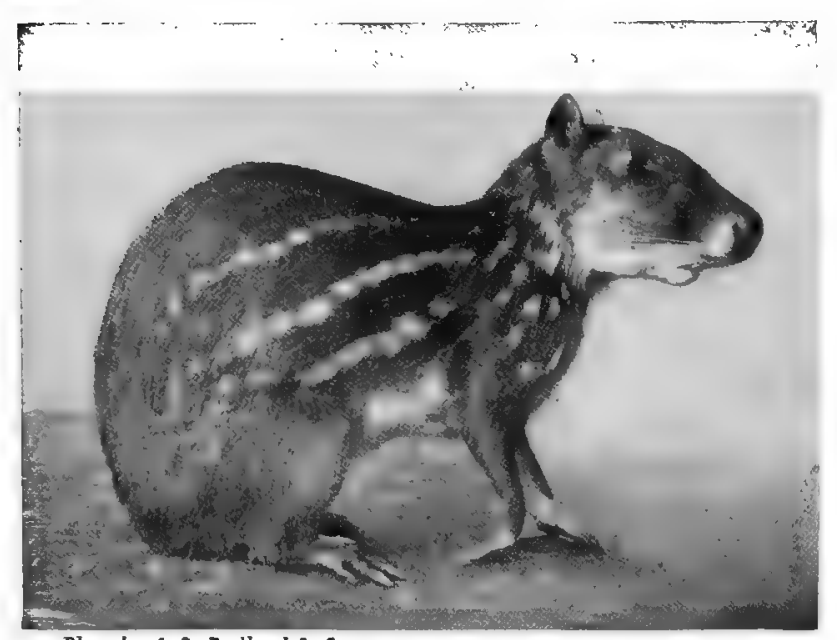

Photo by A. S. Rudland of Sons

$$
\text { PACA, OR SPOTTED CAVY }
$$

The pacas are among the larger rodents, found mainly in tbe nortbern part of tbe Soutb American region

shoulders and back by a crest of long spines, varying from 12 to 15 inches in length. The tail also carries spines

\section{Viscachas and Chinchillas.}

On the plains of La Plata the commonest large rodent is the VIscacha. It assembles in societies like the prairie-dogs, but is a much larger animal, from 18 inches to 2 feet long. Viscachas always set a sentinel to give warning of danger. They cut every kind of vegetable near and drag them to their holes; they also have a habit of picking up and collecting round the burrows any object which strikes them as curious. Articles lost by travelers, even whips or boots, may generally be found there. The viscacha belongs to the chinchilla family, but differs much from the beautiful creature of the high Andes from which chinchilla fur is taken. The Common ChinCHILla is about Io inches long, and the Short-TAILEd Chinchilla rather smaller. The exquisite fur is well known. Two other chinchillas are more like hares in appearance. All four creatures are found on the Andes.

\section{The Agutis and Pacas.}

South America also produces a family of rodents not unlike small pigs, but nearer to the mouse-deer in general appearance; they are called Agutis. Mainly forest animals, but living also in the plains, they feed on grass, leaves, and plants of all kinds; they are very swift in their movements, and have much the habits of the small South African bucks. The fur is long, oliveor chestnut-coloured, and thick.

The PACAS are allied to the agutis, but are stouter; they live either in burrows made by themselves, or in holes in the banks of rivers, or in old tree-roots. The pacas are spotted and rather ornamentally marked; they are found from Ecuador to Brazil and Paraguay.

\section{The Cavies.}

The Dinomys, a spotted rodent known by one example from Peru, has been thought to form a link between the pacas and the cavies, of which the guineapig is the most familiar and the aquatic capybara the largest. The original of our guinea-pig is believed to be the Restless CAVY, a small rodent common on the plains of La Plata. It is dark blackish, with yellowish-gray and white hairs of the domesticated species; and it is suggested that the original of the present name was "Guiana pig." This cavy lives in thickets rather than in forests or plains.

The Patagonian Cavy is a larger form, about twice the size of our hare. It burrows in the ground, and has a gray coat, with yellowish markings on the sides. It has been acclimatised successfully in France

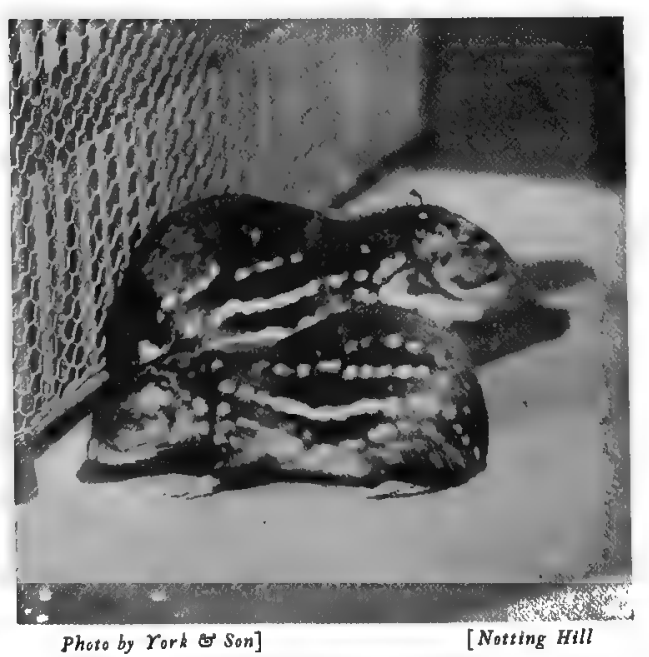

PACAS, OR SPOTTED CAVIES

This photograph, which represents young animals, shows in great perfection the linear arrangement of the stripes 


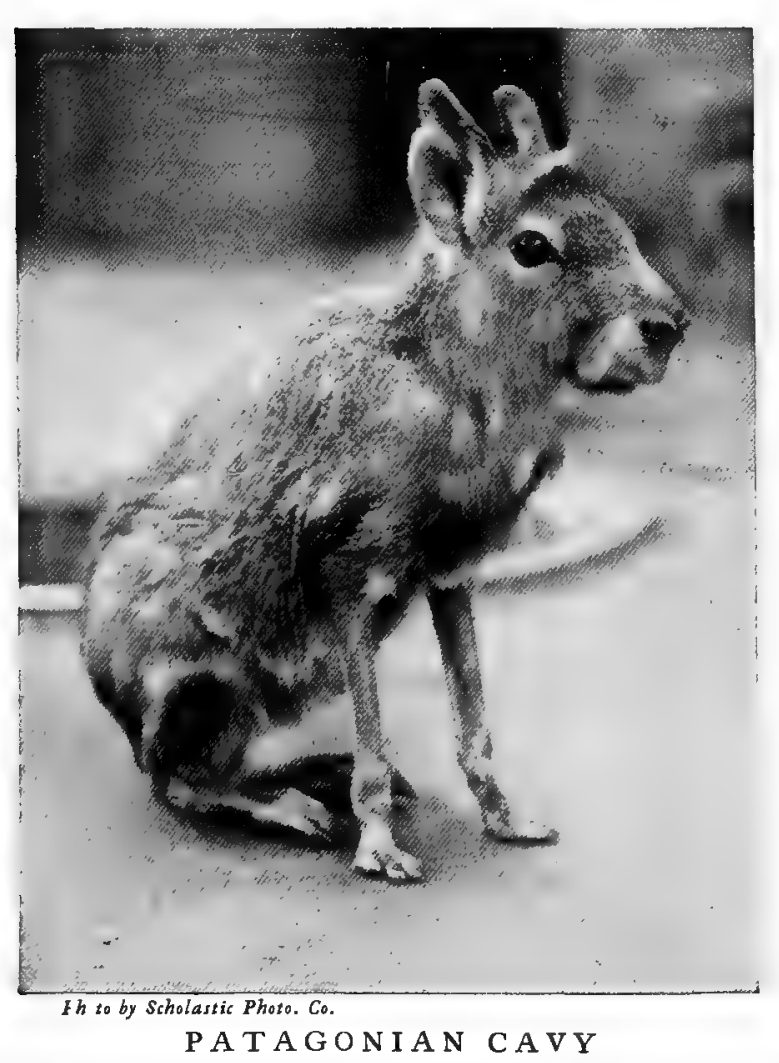

This large species of cavy has been acclimatised successfully both in England and in France

and England. The flesh is like that of the rabbit.

The CAPybara is the largest of all rodents. This species is, in fact, a gigantic water guineapig. It is found in all the great rivers of South America, from the Orinoco to the La Plata. It swims as well as a water-rat, though it is as large as a small pig. It feeds on weeds, waterplants, and grass. A capital photograph of this animal appears on page 146.

\section{Pikas, Hares, and Rabbits.}

The last two families of the Rodents have a small pair of rudimentary incisor teeth behind the large ones in the upper jaw. The Pikas, or Calling-hares, resemble the marmot tribe in general appearance. Their heads are short, their ears rounded, and, being tailless, they still less resemble the common hare; but their dentition marks them as allied. One species, about 9 inches long, is found in $\mathrm{Si}$ beria; and another, only 7 inches long, in the Rocky Mountains. The former has a habit of cutting grass and storing it in small stacks outside its hole for winter use; the Rocky Mountain species carries its hay into its burrows.

The HARES are a widely distributed group. They are found from the north of Scotland (where the gray mountain species turns white in winter) to the south of India, in South Africa, and across the continent of Asia to Japan. The Mountaln-HARE takes the place of the brown species in Scandinavia, Northern Russia, and Ireland; it is rather smaller, and has shorter ears and hind legs.

As early as 54 B.c., Cæasar, in his account of Britain, writes that the Common Hare was kept by the ancient Britons as a pet, but not eaten by them. It was protected by the Normans in the second list, or schedule, of animals reserved for sport. The first list included the Beasts of the Forest, the second the Beasts of the Chase, of which the hare was one of the first. The word "chase" has here a technical meaning. by which was understood an open park, or preserved area, midway in dignity between a forest and an enclosed park. "Hare parks" were also made, perhaps the most recent being that made at Bushey for the amusement of the sovereign

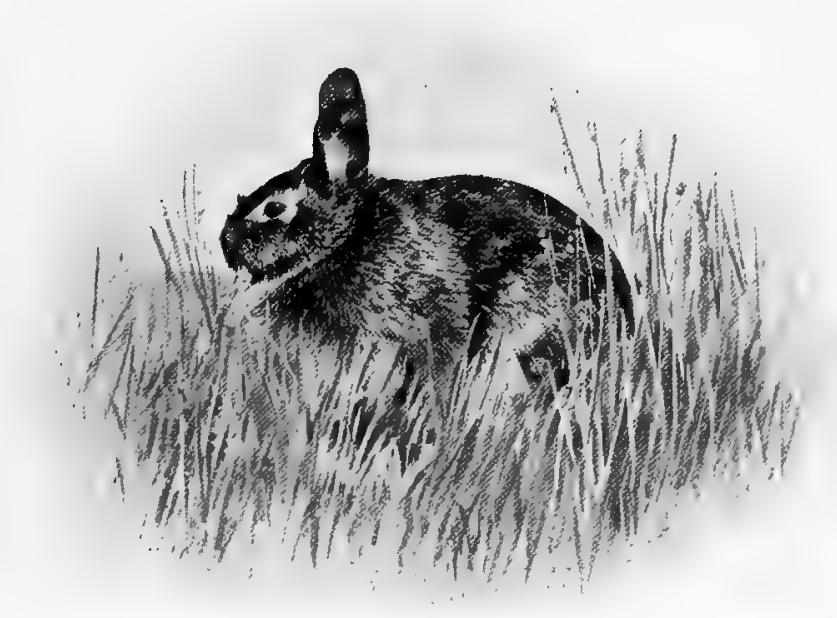

By permission of Professor Bumpus]

[New rork W O O D - H A R E

This is one of the forms intermediate between tbe bares and rabbits 


\section{42 THE LIVING ANIMALS OF THE WORLD}

when at Hampton Court Palace. The name is often found surviving elsewhere. Near one of the large country English seats a walled park of I,500 acres holds almost all the hares on the estate. If these parks and forest laws had not existed at an early date, it is probable that the hare would have become very scarce in this country.

Hares produce their leverets about the middle of April, though in mild seasons they are born much earlier. The number of the litter is from two to five. They are placed in a small hollow scraped out by the doe hare, but not in a burrow of any kind.

The instinct of concealment by remaining still is very highly developed in the hares and rabbits. They will often "squat" on the ground until picked up rather than take to flight. This seems almost a perverted instinct; yet hares often exhibit considerable courage and resource when escaping from their enemies. The following is an instance:-A hare was coursed by two

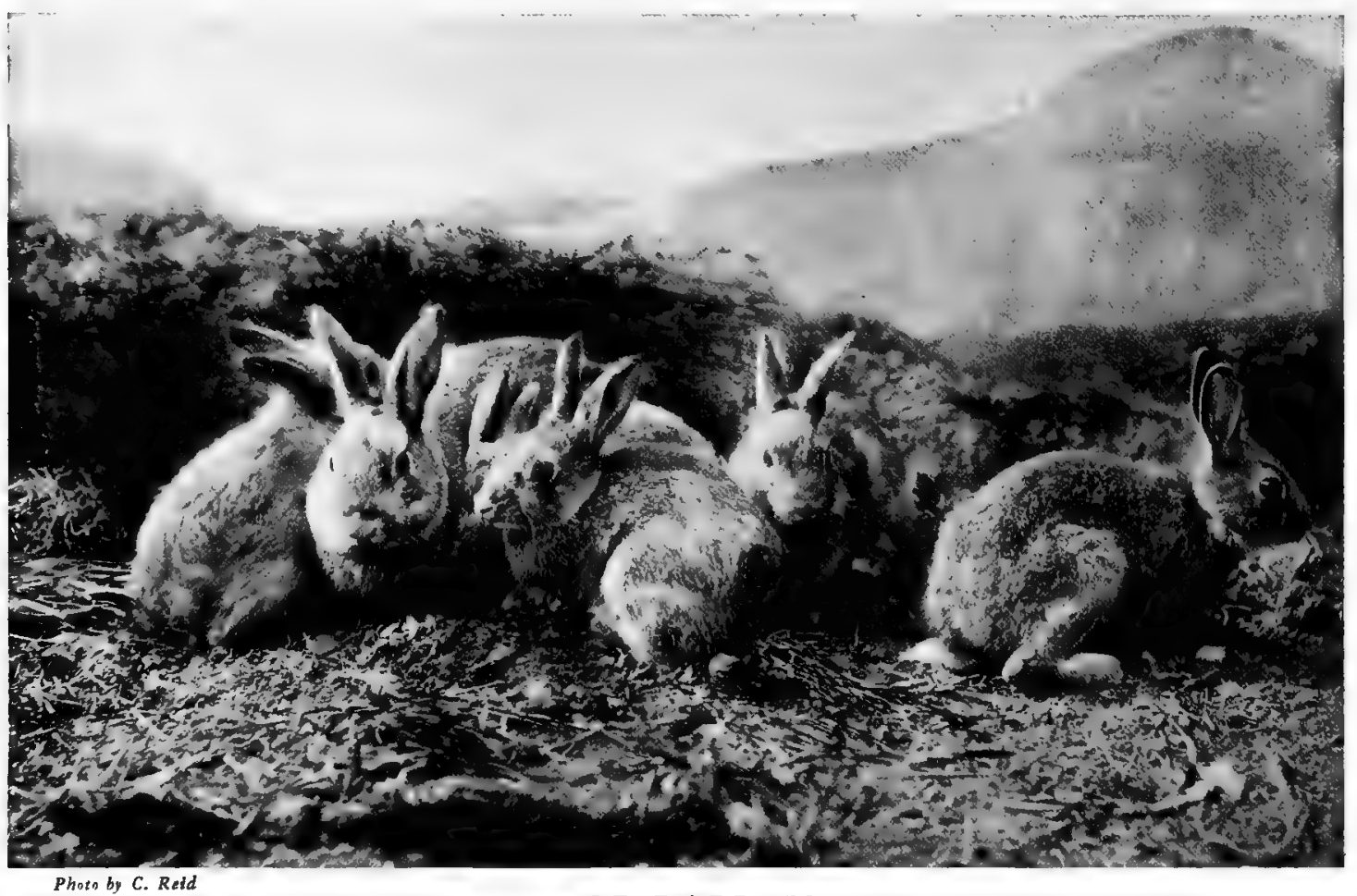

WILD RABBITS

young greyhounds on some marshes intersected by wide ditches of water. It first ran to the side of one of these ditches, and doubled at right angles on the brink. This caused the outer dog to lose its balance and to fall heavily into the deep and cold water. The hare then made straight for the line of walkers, and passed through them, with the other greyhound close behind it. The dog reached out and seized the hare by the fur of the back, throwing it down. The hare escaped, leaving a large patch of fur in the dog's jaws, doubled twice, and was again seized by the second dog, which had come up. It escaped from the jaws of the second pursuer, leapt two ditches 12 feet wide, and then sat for a moment behind a gate on a small bridge. This use of the only cover near caused the dogs to lose sight of it; they refused to jump the second drain; and the hare escaped.

The RABBIT is too well known to need description either of its habits or appearance. It originally came from the countries south of the Mediterranean, but is now common in Northern Europe, and has become a pest in Australia and New Zealand. The rabbit breeds when six months old, and has several litters in each year. 


\section{CHAPTER $\mathrm{X}$.}

THE BATS AND INSECT-EATING MAMMALS.

BY W. P. PYCRAFT, A.L.S., F.Z.S.

$\mathrm{T}$

HESE two groups are really closely allied; but the bats are generally considered apart, on account of their totally different mode of life. Originally, like their more commonplace relatives, they were dwellers upon the earth, or, more correctly, among the trees. By gradual modification of the fore limbs, and a corresponding development of folds of skin attached thereto, and to the body, they have acquired the power of flight. The cobego, to be mentioned presently, gives us a hint of how this may have come about.

The bats are the only members of the Mammalia which possess the power of true flight. The so-called flying-squirrels do not rightly deserve this title, for they have no wings. The wings of the bat have been formed by modification of the fore limbs, the finger-bones having become excessively lengthened, so as to serve as a support to a thin web of skin extending outwards from the body, much as the ribs of an umbrelia support the covering. The hand of the bat is therefore a quite unique organ.

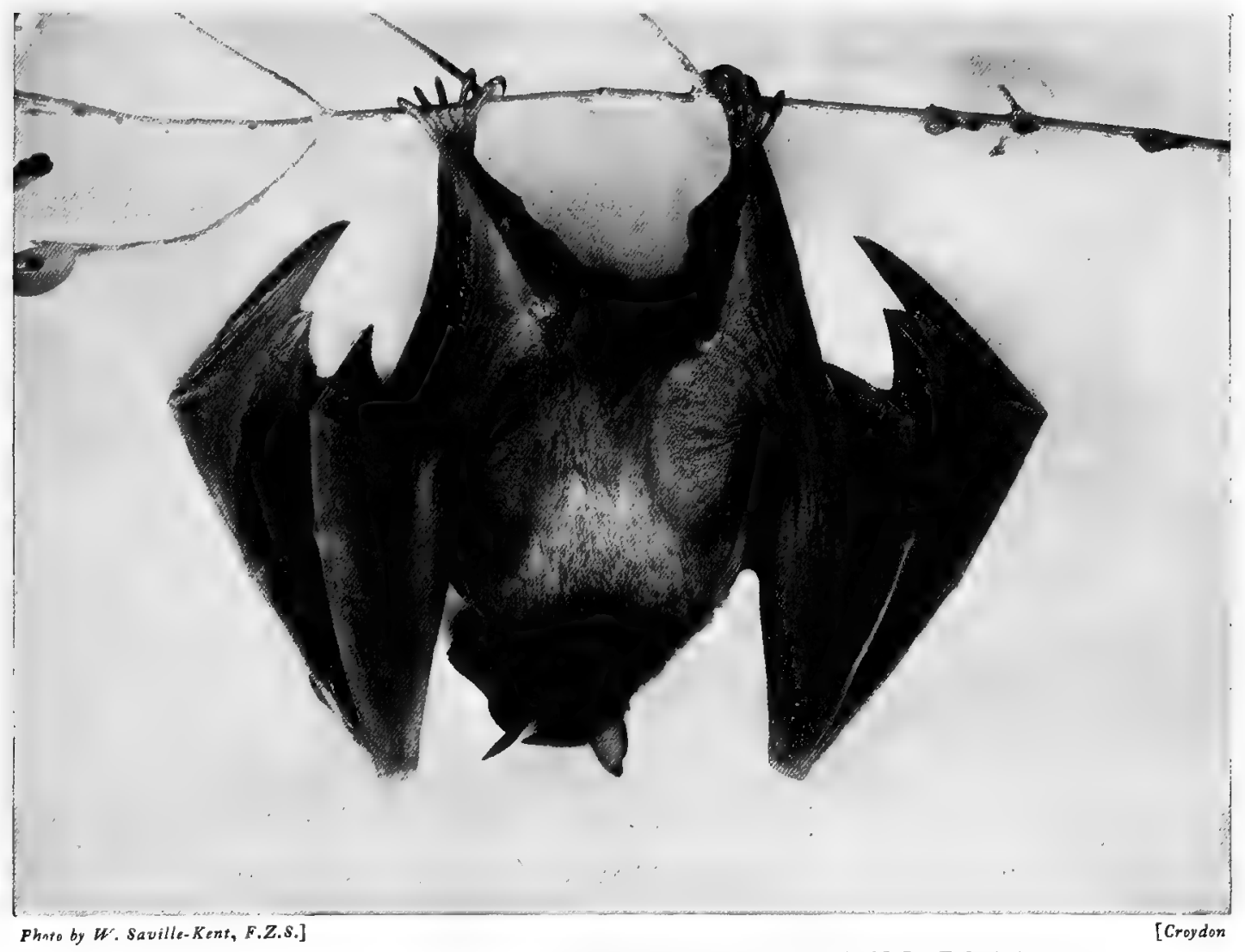

AUSTRALIAN FRUIT-BAT, OR "FLYING-FOX"

Tbis photograph sbows the "flying-fox" in its customary resting position. 


\section{44 THE LIVING ANIMALS OF THE WORLD}

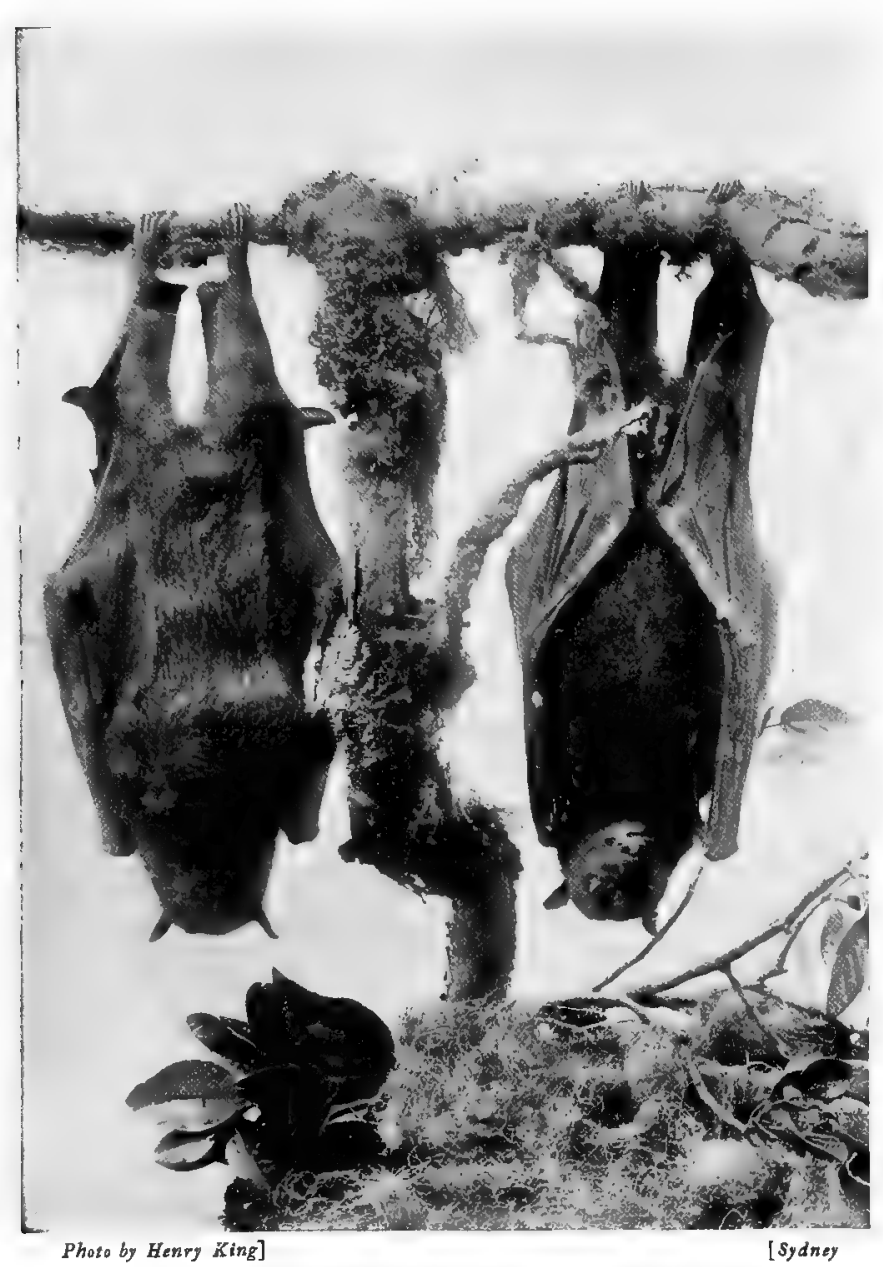

A USTRALIAN FR U I T-BATS

In tbeir roosting-places these bats bang all over the trees in enormous numbers, looking like great black fruits. Altbougb sbot in thousands, on account of the damage they do to fruit orcbards, their numbers do not appear to be reduced
The wing-membrane serves yet another purpose, for its sense of touch is exceedingly delicate, enabling eve 1 blind bats (for bats are not blind usually, as is popularly supposed) to avoid objects placed in their path. Some bats, however, appear to depend also in some slight degree upon hearing. The sense of touch is still further increased by the development of frills or leaf-like expansions of skin round the nose and mouth, and by the excessive development of the external ears. Delicate hairs fringing these membranes probably act like the "whiskers" of the cat.

Insect-eating bats inhabiting regions with a temperate climate must in winter, when food supplies cease, either hibernate or migrate to warmer regions. The majority hibernate; but two species at least of Canadian bats perform extensive migrations, it is supposed to escape the intense cold.

The power of flight has made the bats independent of the barriers which restrict the movements of terrestrial animals, and accordingly we find them all over the world, even as far north as the Arctic Circle. But certain groups of bats have an extremely restricted range. Thus the Fruit-bats occur only in the warmer regions of the Old World, the Vampires in America, whilst some of the more common insect eating forms are found everywhere. Those forms with a restricted distribution are, it should be noticed, all highly specialised-that is to say, they have all become in some way adapted to peculiar local conditions, and cannot subsist apart therefrom. It is the more lowly_less specialised_forms which have the widest geographical range. There are some spots, however, on the world's surface from which no bat has yet been recorded_-such are Ice. land, St. Helena, Kerguelen, and the Galapagos Islands.

\section{The Fruit-bats.}

These represent the giants of the bat world, the largest of them, the Kalong, or Malay Fox-Bat, measuring no less than 5 feet from tip to tip of the wing. The best known of the fruit-bats is the INDIAn Fox-BAT. Sir J. E. Tennent tells us that a favourite resort of theirs near Kandy, in

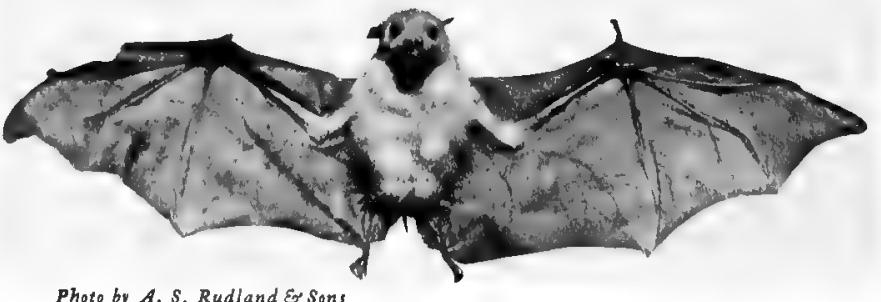

Photo by A. S. Rudland Eo Sons

T U B E-N OSED FR U I T - B A T

The tubular nostrils distinguish this and a species of insect-eating bat from all otber living mammals 


\section{THE BATS AND INSECT-EATING MAMMALS I 45}

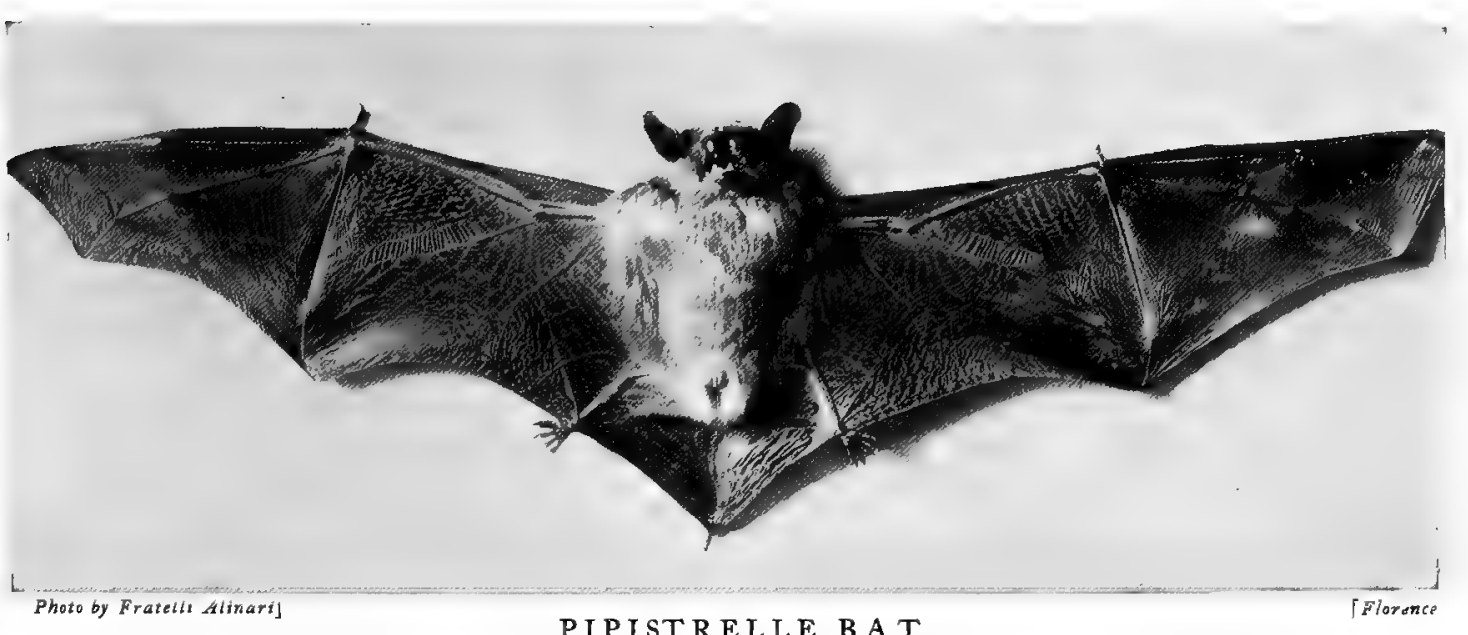

PIPISTRELLE BAT

This is one of the commonest bats. It is the first to appear in the spring, and the last to retire at the fall of the year

Ceylon, was some india-rubber-trees, "where they used to assemble in such prodigious numbers that large boughs would not infrequently give way beneath the accumulated weight of the flock." An observer in Calcutta relates that they occasionally travel in vast hordes, so great as to darken the sky. Whether they are performing some preconcerted migration or bent only on a foray to some distant feeding-ground is a matter for speculation. These hordes are quite distinct from the "long strings" which may be seen every evening in Calcutta on their way to neighbouring fruit-trees.

One of the most remarkable of this group is the TuBE-Nosed FRUIT-BAT, in which the nostrils are prolonged into a pair of relatively long tubes. Strangely enough, a group of insecteating bats has developed similar though smaller tubes. Except in these bats, such tubes are unknown among mammals. Their function is not known.

\section{INSECT-EATING BAIS.}

The vast majority of the bats comprising this group feed exclusively on insects. Some, however, have acquired the habit of fruit-eating, like the true fruit-bats; and a few have developed quite ogrelike habits, for they drink bloodindeed, they subsist upon nothing else. This they obtain from animals larger than themselves.

Many of the bats of this group have developed curious leaf-like expansions of skin around the nose and mouth, which are supposed to be endowed with a very delicate sense of touch. In some, as in the Flower-nosed Bat, the nose-leaf is excessively developed, forming a large rosette. The upper border of this rosette is furnished with three stalked balls, the function of which it is surmised is probably ornamental_from the bat's point of view. To our more æsthetic taste the whole effect is hideous.

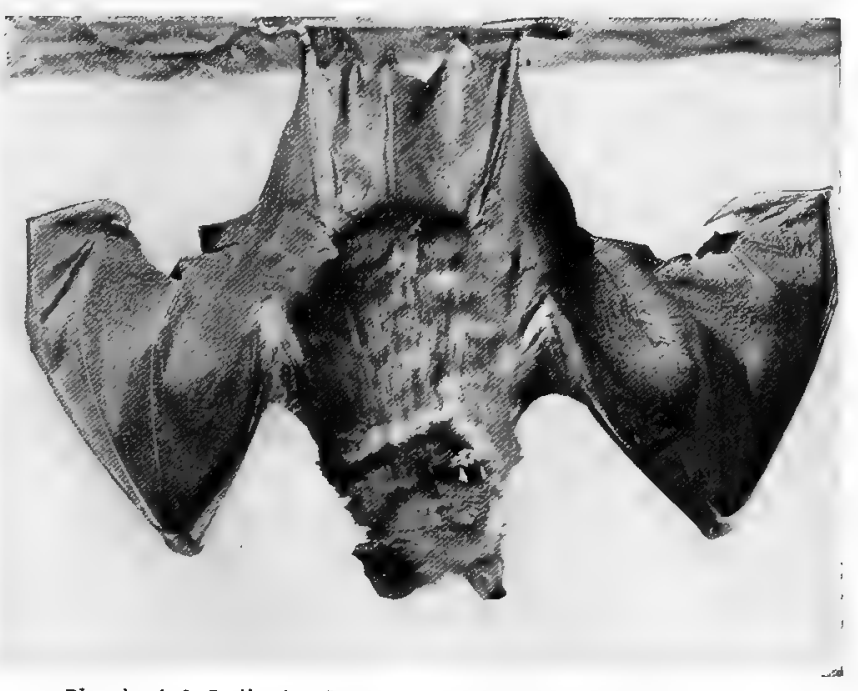

Photo by A. S. Rudland Sons

LE A F - N OSED B A T

The leaf-nosed are the most highly organised of all the bats. The remarkable leaf-like folds of skin around the nose or chin, as the case may be, serve as delicata organs of perception. There are numerous species of leaf-nosed bats 
Limited as is our space, we cannot pass over the Sucker-footed Bats. These are met with, strangely enough, in countries so far apart as Brazil and Madagascar. The suckers from which they derive their name, in the Brazilian species, are small circular, hollow disks, attached to the thumb and the sole of the foot, recalling the suckers of the cuttle-fish and brown waterbeetle. By their means the animal is enabled to climb over smooth vertical surfaces.

A white bat is a rarity in the bat world. We cannot therefore afford to pass without mention the fact that Centrai and South America possess two species of White BATs. This colour is probably developed for protection's sake, the bats being found nestling between the silvery leaves of a cocoanut-palm. Brilliant coloration, on the other hand, is by no means so rare. Welwitsch's BAT, for instance-a West African species-is remarkable for its gorgeous coloration, the colours being orange and black. An Indian species, known as the Pointed BAt, is said to be so brilliantly coloured as to resemble a gorgeous butterfly rather than a bat.

Ugliness is more common than beauty amongst the bats, and perhaps the ugliest of all the tribe is the NAKED BAT of the Malayan region. It is absolutely repulsive. The skin is naked, save for a collar of hair round the neck; whilst on the throat it gives rise to an enormous throat-pouch, which discharges an oily fluid of a peculiarly nauseating smell. On either side of the body is a deep pouch, in which the young are carried-a very necessary provision, for they would be quite unable to cling to the body of the parent, as do the young of fur-bearing bats, on account of the naked skin.

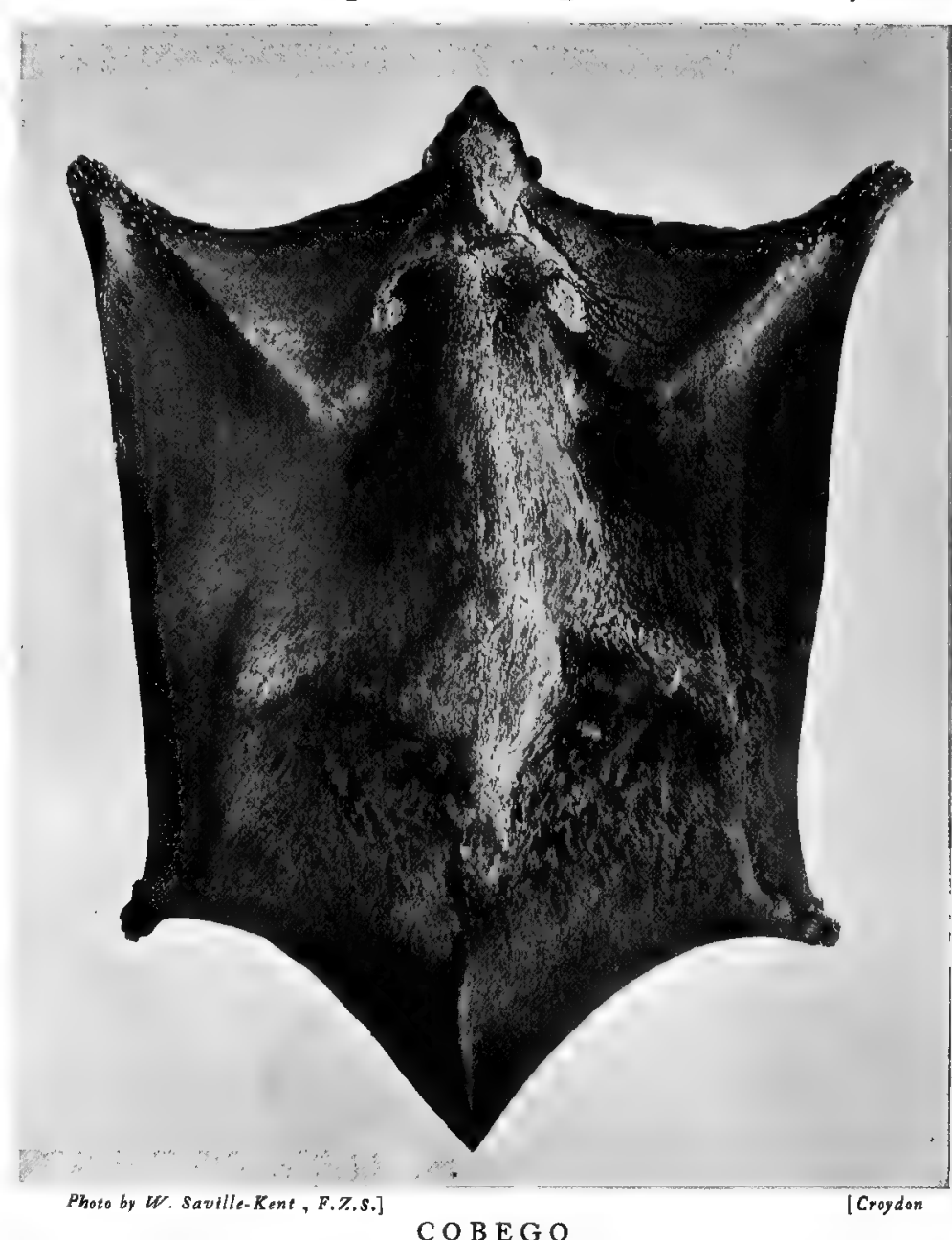

Back view of the cobego, with the limbs extended, showing the great stze of the flying-membranes, or parachute

Of the great group of the VAMPIRE-BATS we can only make mention of the blood-sucking species. These are natives of South America. It is to Dr. Darwin that we owe our first absolutely reliable information about these little animals. Before the account in his Journal, it was uncertain to which of the vampires belonged the unenviable distinction of being the blood-sucker. During the stay of the great naturalist in Chili one was actually caught by one of his servants, as evening was drawing on, biting the withers of a horse. In the morning the spot where the bite had been inflicted was plainly visible, from its swollen condition. These two species, it has beer stated, " are the only bats which subsist entirely on a diet of blood, yet it is possible that . . . some of the JAVELIN-BATS or their allies may on occasion vary their ordinary food with it." 


\section{THE BATS AND INSECT-EATING MAMMALS I 47}

The Insectivora, or Flightless Insect-eaters.

Some members of this group have departed from the traditional insect diet. Thus the cobego feeds upon leaves, a curious aquatic shrew-the Potamogale of West Africa-upon fish, and the moles upon worms.

The group has a very wide geographical distribution, but there are nevertheless large portions of the globe in which they are conspicuous by their absence. They are never found in Australia or South America. Madagascar, Africa, and the West India Islands produce the most

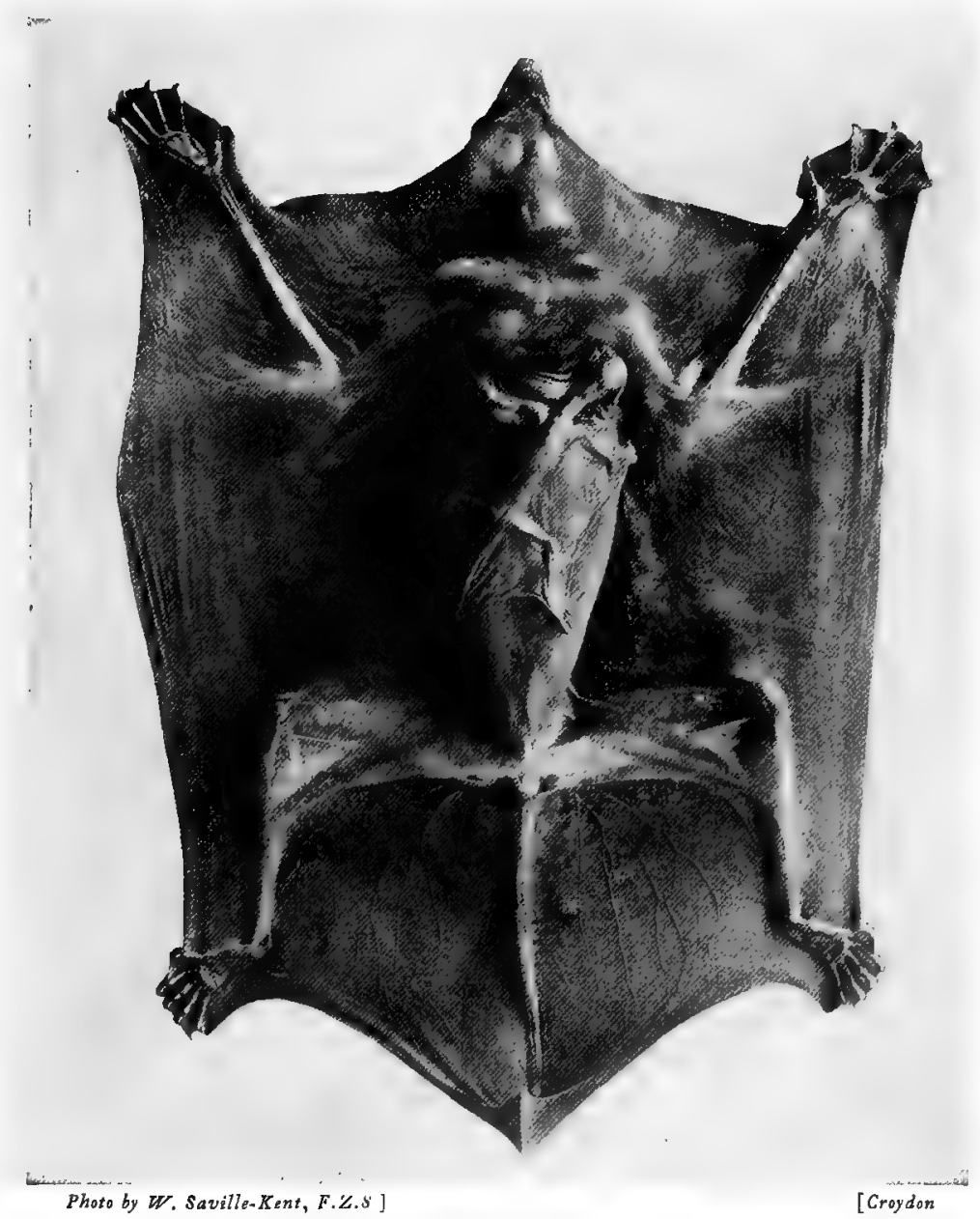

COB E G O

Vertical (front) view of the cobego, with newly born and naked young attacbed. Note the extension of the membrane between the toes of the fore feet of tbe adult remarkable forms.

\section{The Cobego.}

This is a peculiarly interesting animal, which lives in the forests of Sumatra, Borneo, the Malay Peninsula, and the Philippine Islands. It dwells among the trees, moving from one to another by taking flying leaps through the air, covering as much as seventy yards at a jump. Prodigious leaps like this would be quite impossible but for the fact that the animal, which is almost as large as a cat, is provided with a sort of parachute, formed by a broad web of skin stretched between the body on either side and the fore and hind limbs, and between the hind limbs and the tail.

\section{Shrews, Hedgehogs, ANd TENRECS.}

The variation in form presented by the members of this group is considerable. The most noteworthy examples of this variation are furnished by the pretty littlc squirrel-like TREE-SHREws of India and Borneo and neigh-

bouring lands, the mouse-like Jumping-Shrews of Africa, the Hedgehogs, the Tenrecs, the elegant little Mouse-Like Shrews of almost world-wide distribution, and the Water-shrews. Of these, hedgehogs and tenrecs have undergone the greatest transformation. By a curious modification of their original hairy covering they have developed a formidable armour of sharp spines. When alarmed, the former roll themselves up into a ball by the contraction of powerful muscles, and so present an almost impregnable armour to an enemy. Stoats and foxes, however, appear at least occasionally to succeed in overcoming this defense and making a meal of the vanquished.

'Tenrecs are found in Madagascar. The Common Tenrec is the largest of all insect-eaters, 


\section{48 THE LIVING ANIMALS OF THE WORLD}

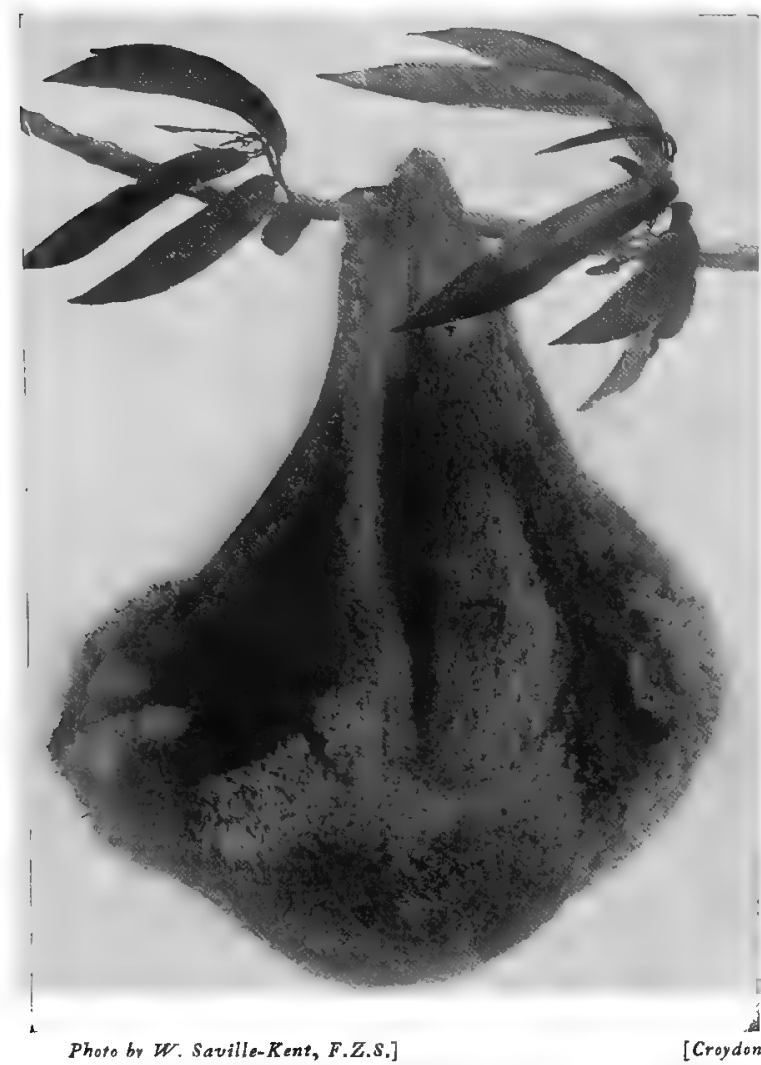

COBEGO ASLEEP

All four limbs are used in suspending itself when asleep, as in tine slotbs. In tbis position the cobego closely resembles, and is mistaken by its enemies for, the fruits of one of the native trees. It is a nocturnat animal and one of the most prolific, as many as twenty-one having been produced at birth. Of all living mammals it is the one most nearly allied to the Marsupials.

\section{The Moles.}

The Common Mole shows a most perfect adaptation to its underground mode of life. The general form of the animal is long, cylindrical, and pointed in front, whilst the legs are exceedingly short, the foot only in the fore limb projecting from the body. This foot is very broad and spade-like and immensely powerful, its use being to force a way -often with incredible speed--through the soft, yielding soil, and not to support the body, as in running or walking. The hind feet are weak, but resemble those of its allies the shrews, for instance. The eyes have become reduced to mere vestiges, very difficult to find. The fur has become so altered in structure that it will lie equally smooth whether brushed towards head or tail, so that it should not be damaged when the animal travels backwards in its burrow. External ears have been dispensed with.

Worms form the staple diet of the mole, but besides underground insects of all kinds are greedily devoured. This animal is one of the most voracious feeders, falling ravenously upon its prey. It has been said with truth that

so great is the ferocity displayed by the mole that if it could be magnified to the size of the lion it would be one of the most terrible of living creatures. That a constant supply of food is necessary to satiate its enormous appetite is shown by the fact that a mole will succumb to an abstinence of from ten to twelve hours. Moles fight among themselves furiously; and if two are confined together, the weaker will be attacked and devoured. They take readily to the water, and instances of moles observed in the act of crossing streams are numerous.

It is a curious fact, but the mole is unknown in Ireland; yet it ranges from England in the west through Asia to Japan.

Careful observation seems to have shown that with the common mole males are more numerous than females. Whether this is true of other species remains to be seen.

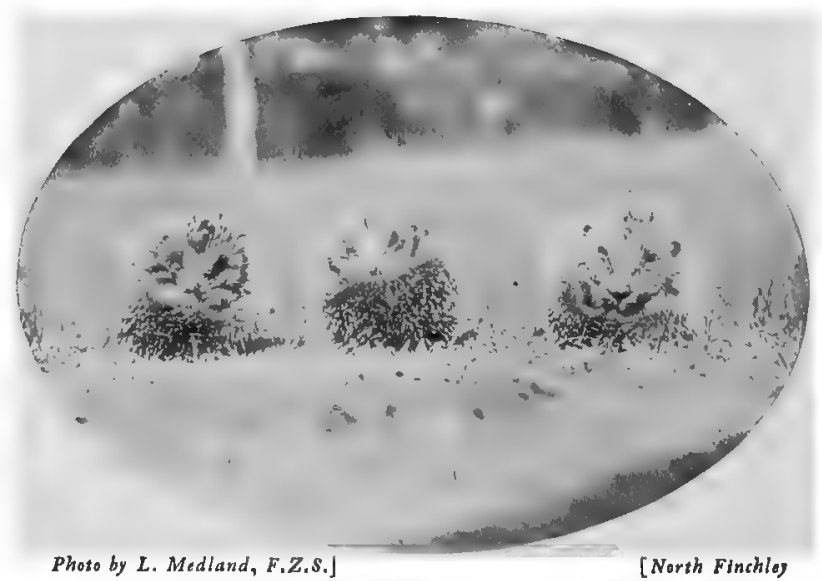

THREE B A B Y HEDGEHOGS

roung hedgelogs are born blind and naked. The spines on their first appearance are quite soft; they soon harden, and at the same time the porver to roll the body up into a ball is acquired 
The nearest allies of the moles are the curious aquatic DEsmans of Russia, and the SHREws. some of which are form, owing to ed a similar mode The Burrownot the only forms which have asshape, for allied to Tenrecs is a reknown as the The mole like of this animal is adaptation to a simThe fore limb of provided with huge used for digging is not broadened in the common rendering this un-

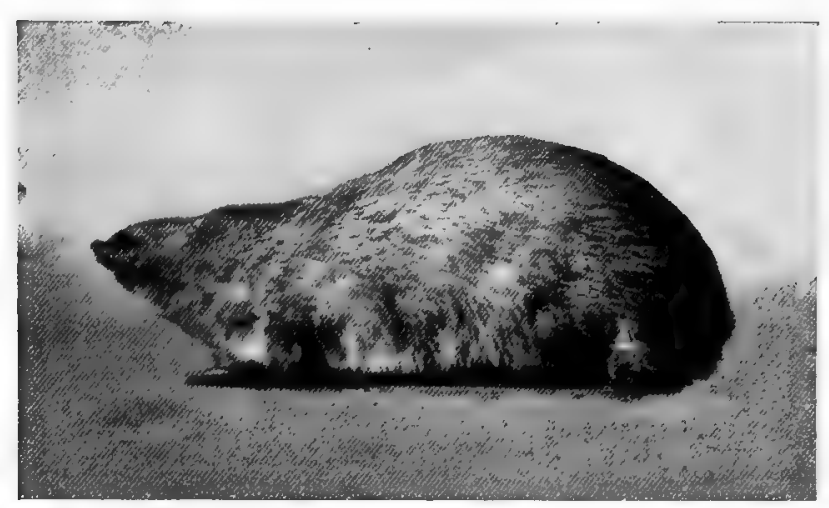

Photo by A. S. Rudland \& Sons

GOLDEN MOLE

This is found only in South Africa. The name is derived from the wonderful metallic lustre of the fur: the brilliancy of the hues is intensified by immersion in spirit quite mole-like in their having adoptof life.

ING Shrews are in the great group sumed a mole-like the hedge-hog-like markable animal Golden Mole. shape of the body another instance of ilar mode of life. the golden mole is claws, which are purposes; the hand out spade-like, as mole, the claws necessary. 


\section{CHAPTER XI.}

\section{THE ELEPHANT, TAPIR, HYRAX, AND RHINOCEROS.}

THE ELEPHANT.

BY F. C. SELOUS.

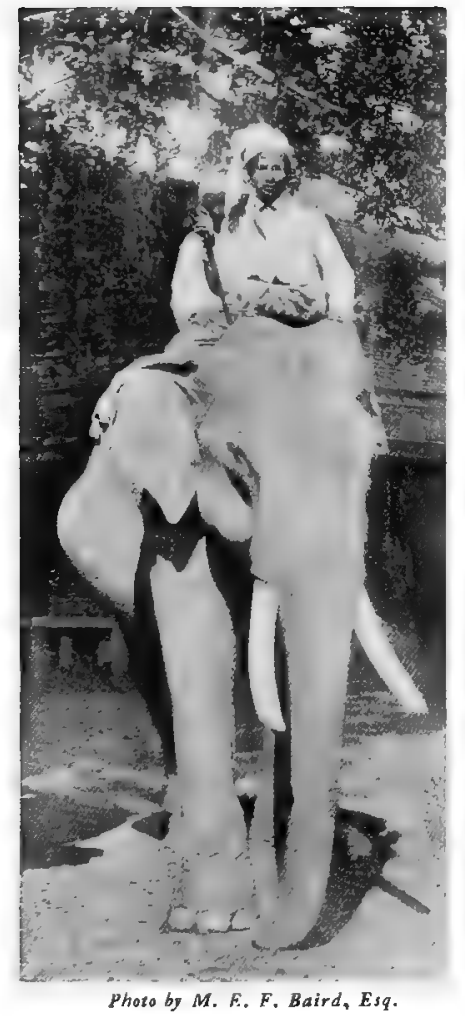

A FINE TUSKER

The male Indian elephant has smaller tusks than the African species

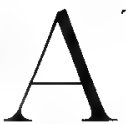

$T$ once the mightiest and most majestic of all terrestrial mammals, the elephant appeals to the imagination more forcibly than any other living animal, not only on account of its great sagacity and the strangeness and singularity of its outward appearance, but also because it is such an obvious link between the world of to-day and the dim and distant past of Pleiocene and Miocene times.

There are two existing species of elephant, the African and the Asiatic, the latter, from the structure of its molar teeth and the shape of its skull, appearing to be very nearly related to the MАммотн, which lived upon the earth in comparatively recent times-geologically speaking-and was undoubtedly contemporary with man in Europe during the Stone Age.

There are very considerable differences both in the external appearance and also in the habits of the two existing forms of elephant. In the African species the forehead is more convex and the eye relatively larger than in its Asiatic cousin; and whilst the ears of the latter are only of moderate size, those of the former are so large that they at once arrest the attention, and are one of that animal's most remarkable external characteristics. Both sexes of the African species, with few exceptions, carry well-developed tusks, but in the Asiatic form the tusks of the females are so small as scarcely to protrude beyond the jaws. In Asia, too, tuskless bull elephants are common, whilst males of the African species without tusks are extremely rare. The latter species has but three nails on the hind foot, the Asiatic elephant four. In the African species the middle of the back is hollowed, the shoulder being the highest point, whilst in the Asiatic elephant the back is arched, and the top of the shoulder lower than the highest part of the back. The extremity of the proboscis is also different in the two species, the African elephant being furnished with two nearly equal-sized prolongations, the one on the front, the other on the hinder margin, with which small objects can be grasped as with the finger and thumb of the human hand, whilst in the Asiatic species the finger-like process on the upper margin of the end of the trunk is considerably longer than that on the under-side. In external appearance the skin of the African elephant is darker in colour and rougher in texture than that of the Asiatic form. The molar teeth of the former animal are, too, of much coarser construction, with fewer and larger plates and thicker enamel than in the latter, which would naturally lead one to suppose that the 


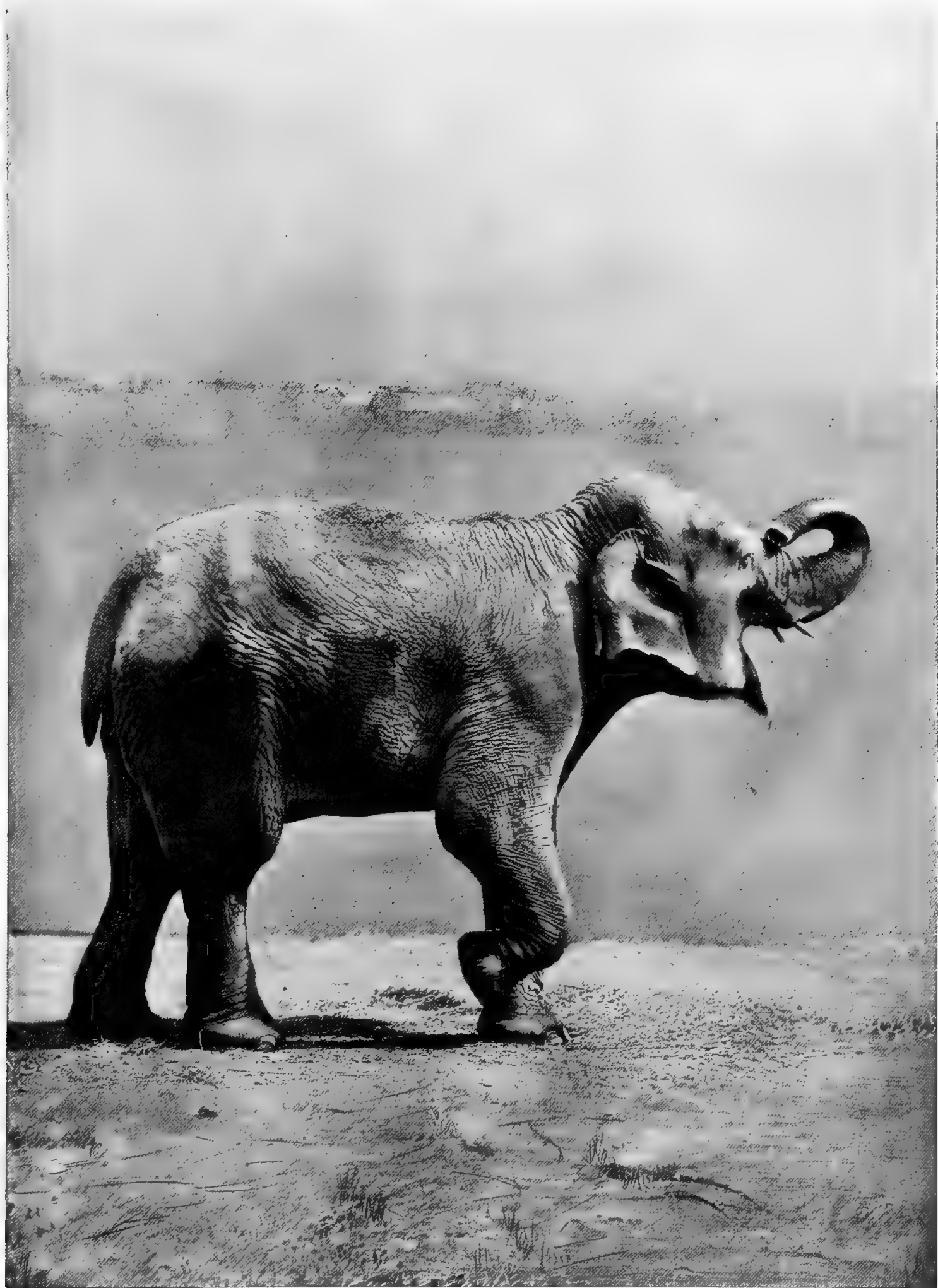

Phooo by Fratelli Alinari]

A YOUNG INDIAN ELEPHANT

This animal has been trained to "salute" by raising its trunk and foot. It has lost the end of its tarl 


\section{I52 THE LIVING ANIMALS OF THE WORLD}

African elephant is accustomed to eat coarser, harder food than the Asiatic species. This supposition is borne out by fact; for whilst the Asiatic elephant feeds mainly upon grass, the leaves and fruit of the wild plantain, and the young shoots of the bamboo, together with the leaves, twigs, and bark of certain trees, the African species never eats grass, and, although very fond of certain kinds of soft and succulent food, such as wild fruits and the inner bark of certain trees, is constantly engaged in chewing up the roots and branches of trees as thick as a man's wrist for the sake of the sap and bark, the woody portions being rejected after having been reduced to pulp. The Asiatic elephant appears to be far less tolerant of exposure to the heat of the sun than the African; and whilst the latter may often be found standing at rest or sleeping throughout the hottest hours of the day in long grass or scrubby bush of a height not sufficient to afford any protection from the sun to the whole of the upper portion of the head and body, the former, when in a wild state, is said to always seek the shade of the densest forests it can find during hot weather.

The Asiatic elephant often lies down when resting and sleeping. This is in marked contrast to the African species, which, if it ever does lie down at all, except to roll in mud or rub itself against an ant-heap, can only do so very rarely, since in all my experience, though I have seen some thousands of African elephants standing sleeping during the heat of the day, I have never yet seen one of these animals lying down, nor found the impress in the ground where one had been so lying.

When excited and charging, both species of elephant raise their heads and cock their ears, which in the African animal stand out at such a time like two sails, and, being each upwards of $31 / 2$ feet in breadth, cover, together with the animal's head, an expanse of fully 10 feet. The Asiatic elephant is said to remain mute whilst charging, and to hold its trunk tightly curled up between its tusks. The African elephant, on the other hand, usually accompanies a charge with a constant succession of short, sharp trumpeting screams. Sometimes, though rarely, however, animals of this species remain mute whilst charging, but they never, I believe, coil their trunks up under their throats. Often an African elephant will swing round for a charge with a loud scream and trunk held high in the air; but in my experience, when settling down to a chase, it drops its trunk and holds it pointing straight down in front of its chest.

In the southern portions of the African Continent the average standing height at the shoulder of full-grown bull elephants ranges from 10 feet to Io feet 6 inches, though individuals have doubtless been met with in those districts which have much exceeded these dimensions. In North Central Africa the average standing height appears to be some inches higher, approaching I I feet, and in those districts it is quite possible that individuals exist which exceed 12 feet in height. African cow elephants stand from 8 feet to 8 feet 6 inches at the shoulder. The Asiatic species is considerably smaller than the African, the average height of full-grown males not exceeding 9 feet, though certain individuals now and then attain to a much greater size, as is indicated by the fact that there is a mounted skelton of an Indian. elephant in the Museum at Cal-

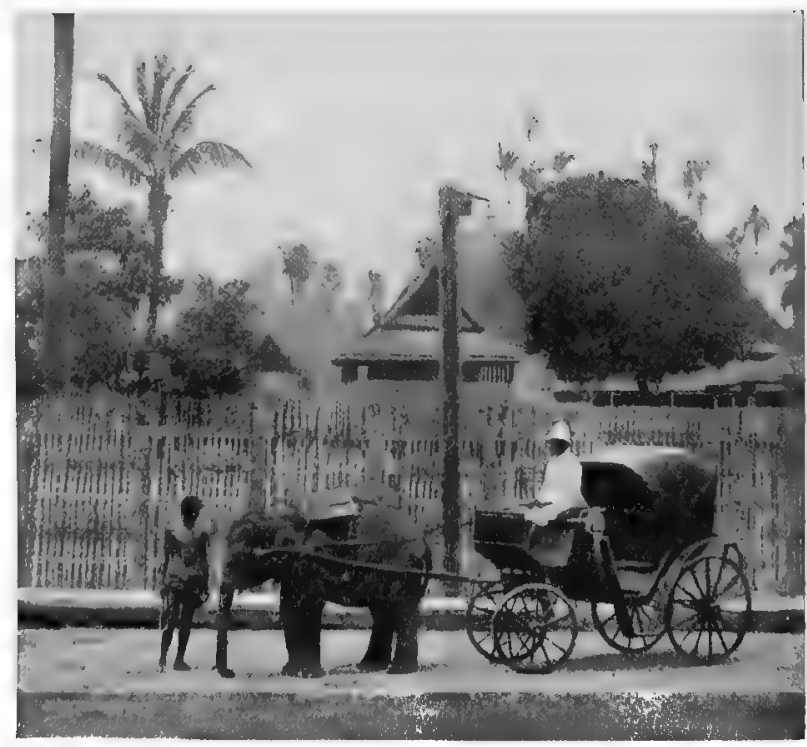

Photo by M. E. F. Batrd, Esq.

THE CHIEF OF CHIENGMAI'S CARRIAGE This victoria ruas drawn by a young Indian elephant 


\section{ELEPHANT, TAPIR, HYRAX, RHINOCEROS I 53}

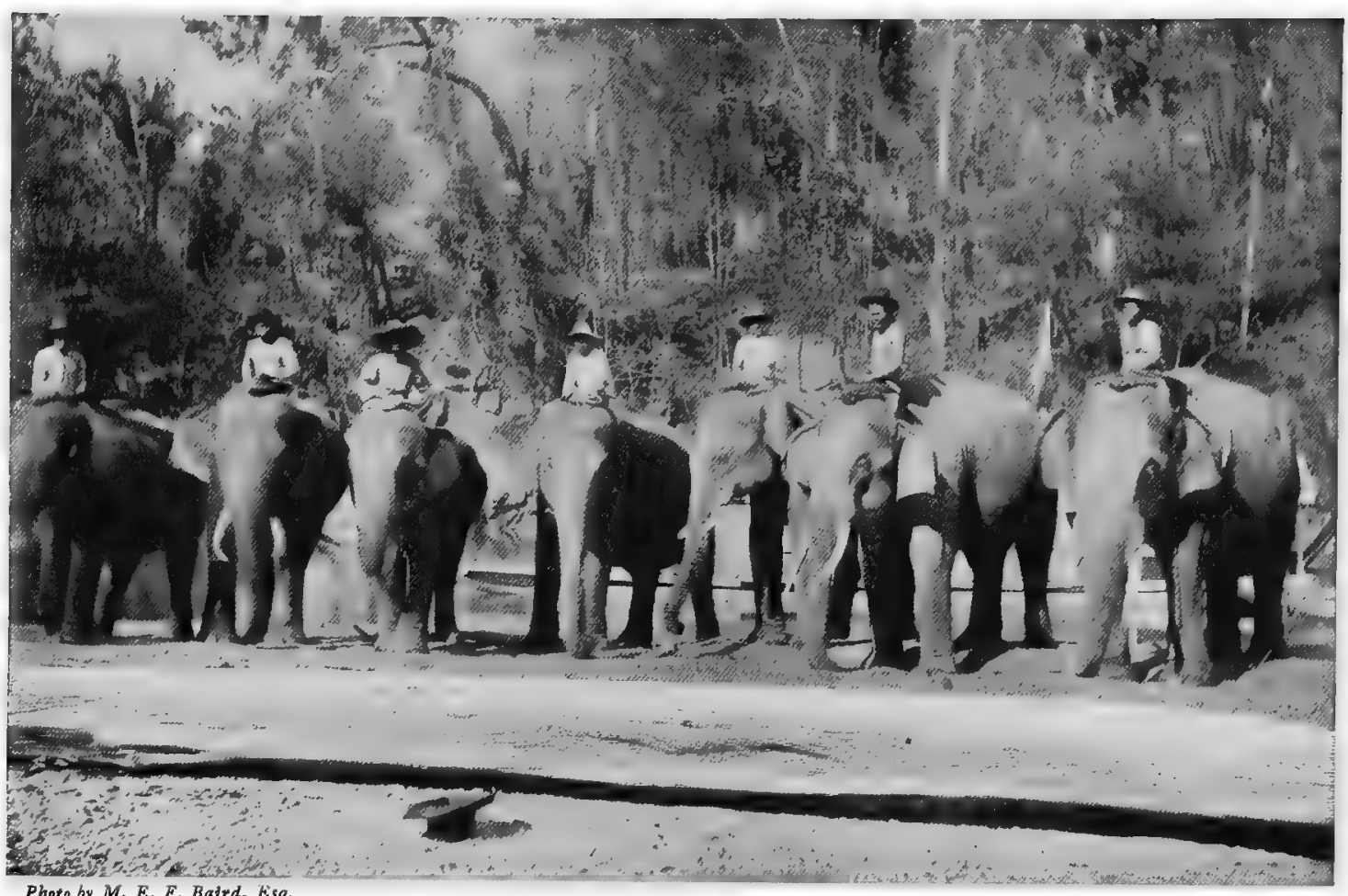

Photo by $M . E$. F. Baird, Esq.

T I M B E R - E L E P H A N T S

This pbotograpb was taken at Lakou, in Upper Siam. Notice tbe large teak log in the foreground

cutta which stands I I feet 3 inches at the shoulder. In the size of its tusks the African elephant far surpasses the Asiatic species. In India a pair of tusks measuring 5 feet in length and weighing $70 \mathrm{lbs}$. the pair would, I think, be considered large, though an elephant was killed by Sir Victor Brooke in the Garo Hills with a single tusk measuring 8 feet in length, 17 inches in circumference, and weighing $90 \mathrm{lbs}$, and a few tusks even exceeding these dimensions have been recorded. In Southern Africa the tusks of full-grown bull elephants usually weigh from 80 to I 20 lbs. the pair, and measure about 6 feet in length, with a circumference of from 16 to 18 inches; but these weights and measurements have often been much exceeded, and in my own experience I have known of two pairs of elephants' tusks having been obtained south of the Zambesi, each of which weighed slightly over $300 \mathrm{lbs}$, each tusk measuring upwards of 9 feet in length, whilst a single tusk brought from the neighbourhood of Lake Ngami in 1873 weighed 174 lbs. The average weight of cow-elephant tusks in Southern Africa is from 20 to 30 lbs. the pair, but I have seen the tusk of a cow elephant killed in Matabililand which weighed 39 lbs. and measured over 6 feet in length, whilst its fellow almost equaled it in size and weight. In North Central Africa, according to Sir Samuel Baker, the tusks of full-grown elephants average about I 40 lbs. the pair, and tusks weighing upwards of Ioo lbs. each are not at all uncommon, whilst many of a much greater size have been obtained.

Until quite recently a tusk in the possession of Sir E. G. Loder, which weighs I 84 lbs. and measures 9 feet 5 inches in length, with a circumference of $221 / 2$ inches, was supposed to be the largest in existence; but in 1899 two tusks were obtained near Kilimanjaro, in East Central Africa, both of which much exceed this weight. These enormous tusks were at first stated to be a pair taken from a single elephant; but though nearly equal in weight they are said to be differently shaped, and as their history is not yet fully known it is possible, though not probable, that they originally belonged to two different elephants. The larger of these two tusks has recently been purchased for the collection of the British Museum (Natural History), where it may now be 


\section{54 THE LIVING ANIMALS OF THE WORLD}

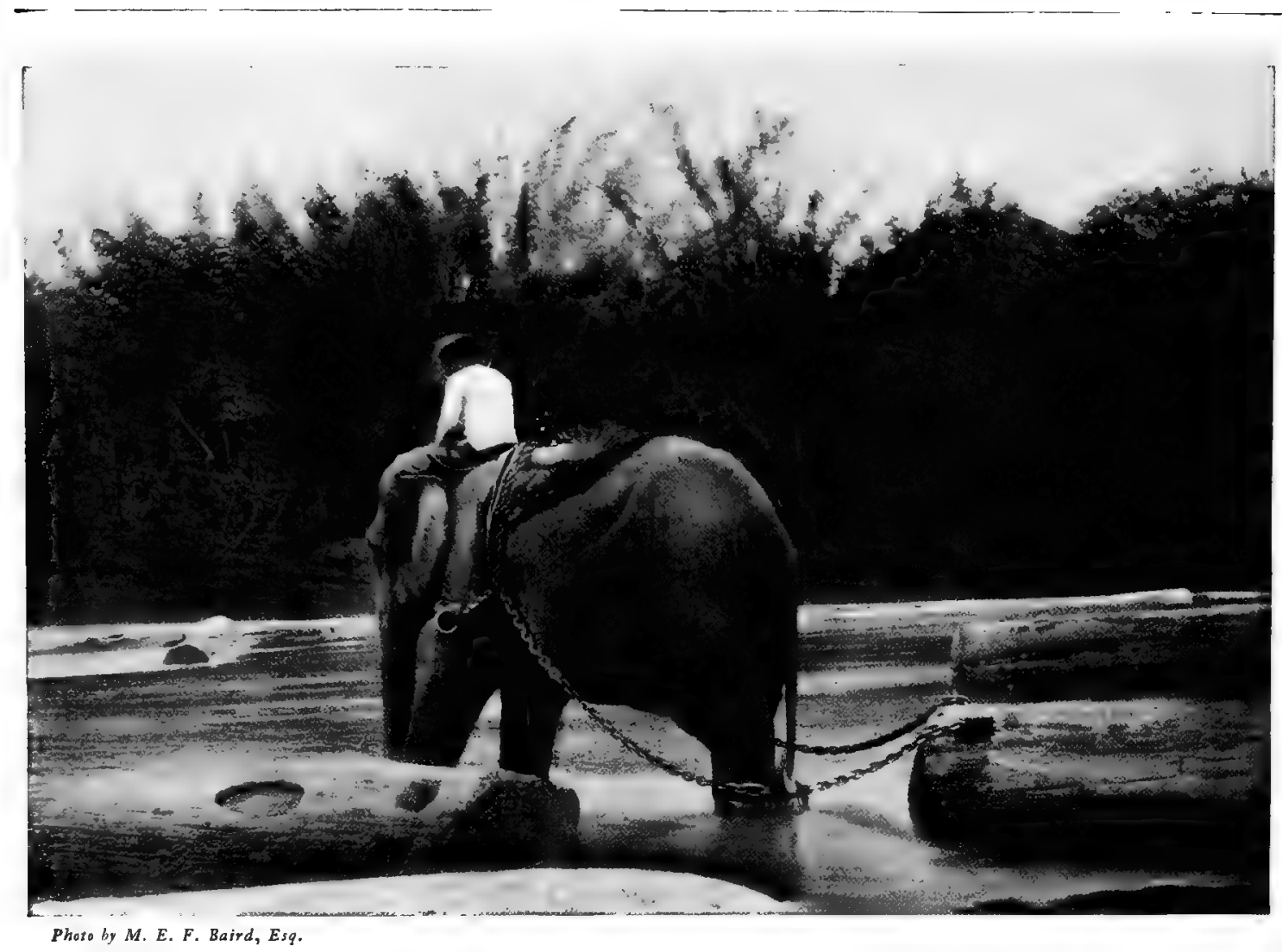

FEMALE INDIAN ELEPHANT DRAGGING TEAK

Tbe teak logs are floated down the Burmese rivers and dragged out by elepbants

seen. It weighs $228 \mathrm{lbs}$., measures 10 feet $2 \mathrm{~T} / 2$ inches on the outside curve, and $24 \mathrm{I} / 4$ in girth at the thickest part. The tusks of cow elephants are also considerably larger and heavier on the average in East Central and North Central Africa than in the southern portions of the continent.

At the present time the Asiatic elephant is found in a wild state in most of the forestcovered tracts of India, Ceylon, Assam, Burma, Siam, Cochin-China, Sumatra, and Borneo; whilst the African species, although it has been hunted out of large tracts of country in South and Southwestern Africa, still inhabits the greater part of the continent south of the Sahara, and in many districts of Central Africa appears to be extraordinarily abundant. In the Cape Colony two herds still exist under the protection of the Government.

As might be expected from the greater length of its legs, and consequent longer stride, the African elephant is admitted by those who have had experience of both species to be a more active animal than its Asiatic cousin. Speaking of the walking and running powers of the Indian elephant, that great authority Mr. Sanderson says that "the only pace of the elephant is the walk, capable of being increased to a fast shuffle of about fifteen miles an hour for very short distances. It can neither trot, canter, nor gallop. It does not move with the legs on the same side, but nearly so. A very good runner might keep out of an elephant's way on a smooth. piece of turf, but on the ground in which they are generally met with any attempt to escape by flight, unless supplemented by concealment, would be unavailing." This description exactly coincides with my own experience of the African elephant, except that I think that animals of the latter species, especially cows and young bulls, are capable of getting up a pace of at least twenty miles an hour, and keeping it up for from 100 to 200 yards, when charging. 


\section{ELEPHANT, TAPIR, HYRAX, RHINOCEROS I 55}

In disposition both African and Asiatic elephants are as a rule timid animals, and, excepting in the case of males of the latter species when suffering from sexual excitement, are always inclined to shun danger. I have never heard of male elephants of the African species becoming savage and aggressive at any season of the year; indeed, old bulls always appeared to me to be less inclined to charge than cows or young bulls. The eyesight of the elephant-of the African species at least_-is bad, and his hearing not particularly acute; but his olfactory nerves are probably more highly developed than in any other animal, and, aided by this exquisite sense of smell, he will avoid a human being if possible. But if elephants are attacked and wounded, they become savage and dangerous animals; and the charge of an African elephant, coming on with the great ears outspread, to the accompaniment of a quick succession of short, sharp trumpeting screams, besides being very sudden and rapid, is very disconcerting to the nerves of a man unaccustomed to such experiences. I remember the case of a young Englishman who was killed in Matabililand many years ago by the first elephant he had ever seen. This animal_-an old bull -had retired, after having been wounded, into a small but dense patch of thorn-bush, into which its pursuer thought it unadvisable to follow on horseback. He therefore left his horse, and advanced on foot towards the cluster of trees amongst which the elephant was concealed. The latter, having either seen or smelt the approaching enemy, at once charged out, screaming loudly; and the young hunter, instead of standing his ground and firing at the advancing monster, lost his presence of mind, and, turning, ran for his horse; but before he reached it he was overtaken and killed. It seemed to the friend who found his body (he was close at hand shooting another elephant at the time, and pieced the story together from the tracks of man, horse, and elephant) that the victim had first been struck in the back of the head by one of his pursuer's tusks-at any rate his skull had been smashed to pieces and emptied of its brains. Then the elephant had rushed upon him where he fell, and, after first having driven a tusk right through his chest and deep into the ground, had stamped him into a bloody pulp with his huge

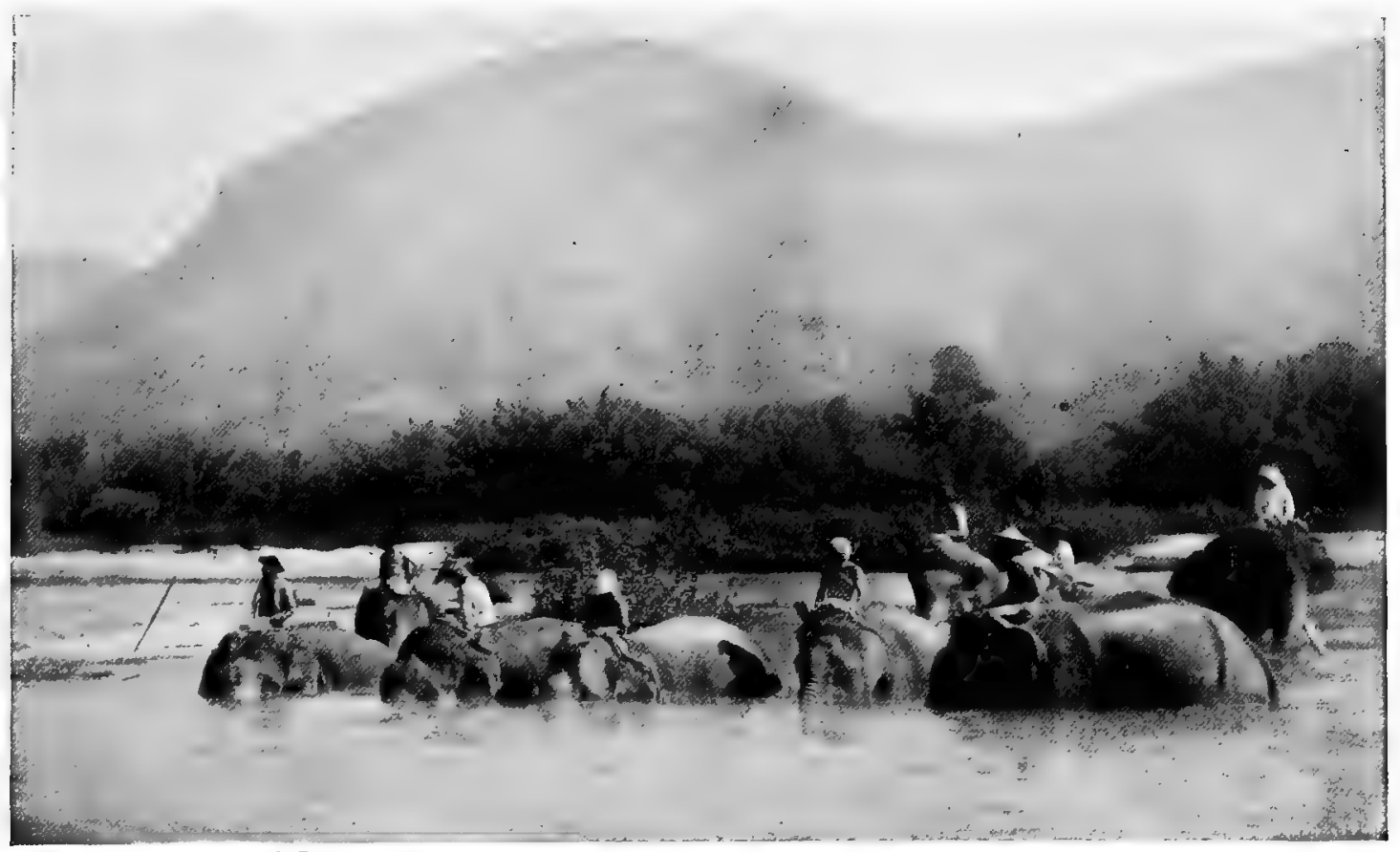

Photn bv M. E. F. Baird, Esq.

INDIAN ELEPHANTS BATHING

These animals lowe a bath, and will walk on the bottom of a deep river witb only their trunks raised above the wator 


\section{56 THE LIVING ANIMALS OF THE WORLD}

feet. A waggon was brought the same night, and the mangled body carried to the hunter's camp on the banks of the Ramokwebani, where it was buried.

The strength of the elephant is proverbial; and in India and Burma, where this animal has for ages past been trained in the service of man, this power is habitually made use of in moving and stacking large baulks of timber, or in dragging heavy guns through muddy ground or up steep ascents. In Africa the traveler is often astonished at the size of trees which have been uprooted and overturned by elephants. These trees, however, have no tap-root, and have not therefore a very firm hold in the ground, especially during the rainy season, when the ground is soft. At this time of year large trees are butted down by elephants, which push against their stems with the thick part of their trunks, and get them on the swing, until the roots become loosened and the trees are at last overturned. Small trees of 2 or 3 inches in diameter, as well as branches, they break off with their trunks. In 1878 a tuskless bull elephant-I met the same animal again in 1885 , and he is the only African bull elephant without tusks I have ever seenkilled a native hunter in Mashonaland. This man, a big powerful Zulu and a great friend of my own, was torn into three pieces. I imagine that, after having caught him, the elephant held the unfortunate man down with his foot or knee, and then, twisting his trunk round his body, tore him asunder-surely a terrible exhibition of strength.

The elephant is a very slow-going and long-lived animal, not arriving at maturity until upwards of thirty years of age; and since cases are'on record of elephants having lived for upwards of I 30 years in captivity in India, it is probable that in a wild state these animals, both in Asia and Africa, often attain to an age of 150 years. The female elephant produces, as a rule, but one calf at birth, the period of gestation lasting from eighteen to nearly twenty-two months. The mammæ of the cow elephant are placed between the fore legs, and the new-born calf sucks with its mouth, holding its trunk turned back over its head. I have seen elephant calves so engaged.

Although there is no reason to doubt that the African elephant is as intelligent as the Asiatic species, its domestication has never been attempted by the Negro or Bantu races of Africa. It is believed, however, that the African elephant was in ancient times domesticated by the Carthaginians, and used by them in their wars with the Romans. The opinion, too, is generally held that the elephants with whichHannibal crossed the Alps were of the African species, as well as those which, after the conquest of Carthage, were used in the Roman amphitheatres and military pageants. On the other hand, it is well to remember that the late $\mathrm{Mr}$. W. Cotton Oswell, who had had great experience both with African and Asiatic elephants, wrote as follows on this subject: "I believe some people suppose the Carthaginians tamed and used the African elephant they could hardly have had mahouts Indian fashion, for there is no marked depression in the nape of the neck for a seat, and the hemming of the ears when erected would have half smothered them. My knowledge does not allow me to raise any argument on this point; but might not the same market have been open to the dwellers at Carthage as was afterwards to

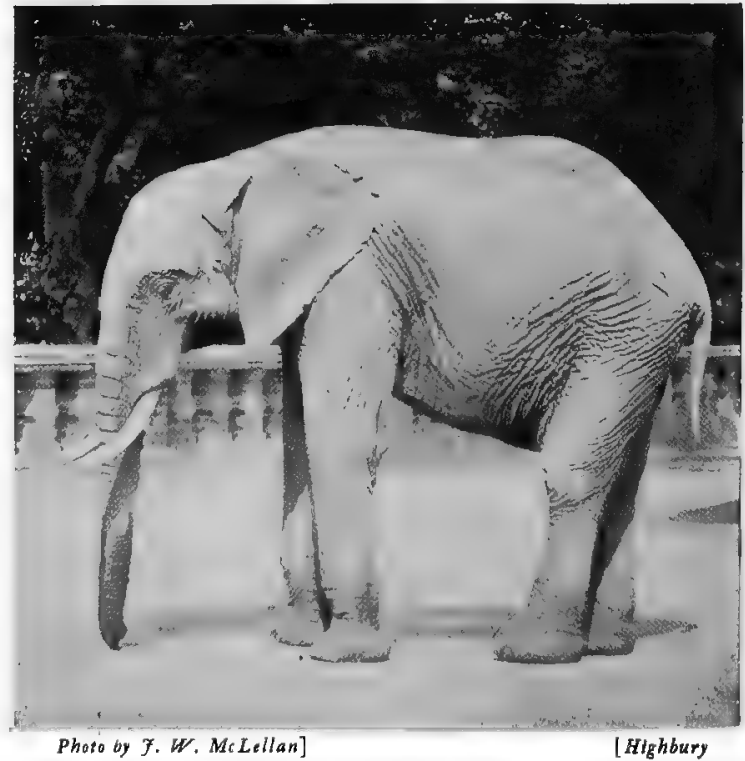

AFRICAN ELEPHANT

The difference in profile between this and the Indian species is noticeable. The forebead is receding and the ears mucb larger in the African species 
Mithridates, who, I suppose, drew his supply from India? I know in the representations of elephants on the medals of Faustina and of Septimus Severus the ears are African, though the bodies and heads are Indian; but these were struck nearly 400 years after Carthaginian times, when the whole known world had been ransacked by the Romans for beasts for their public shows; and I still think it possible that the Carthaginians-the great traders and colonisers of old-may have obtained elephants through some of their colonies from India."

An interesting example of the intelligence of these animals can be seen any day at the public Zoological Gardens. A large African elephant restores to his would-be entertainers all the biscuits, whole or broken, which strike the bars and fall alike out of his reach and theirs in the space between the barrier and his cage. He points his trunk at the biscuits, and

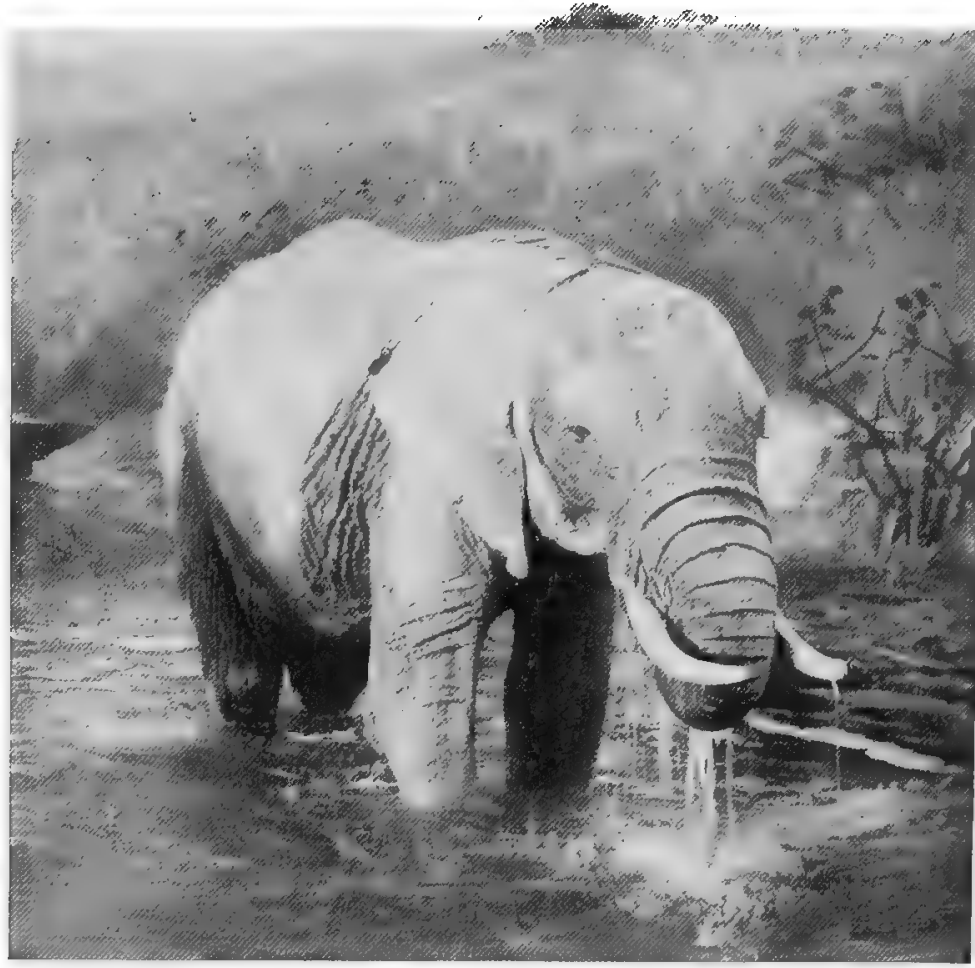

Photo by L. Medland, F.Z.S.]

[Nooth Finchley

MALE AFRICAN ELEPHANT DRINKING

Not the great size of the lusks and base of tbe trunk

blows them hard along the floor to the feet of the persons who have thrown them. He clearly knows what he is doing, because, if the biscuits do not travel far enough, he gives them a harder blow.

\section{TAPIRS AND HYRAX.}

BY W. P. PYCRAFT, A.L.S., F.Z.S.

TAPIRS are odd-looking creatures, and, strange as it may seem, are nevertheless related on the one hand to the rhinoceroses, and on the other to the horses. They are furthermore extremely interesting animals, because they have undergone less modification of form than any other members of the group to which they belong. This we know because fossil tapirs, belonging to a very remote period of the world's history, are practically indistinguishable from those now living.

The general form of the body may perhaps be described as pig-like; the head, too, suggests that animal. But the pig's snout is here produced into a short proboscis, or trunk. The feet are quite unlike those of the pig, and resemble those of the rhinoceros. The fore feet have each four and the hind feet three toes; these are all encased in large horse-like hoofs. The tail is reduced to a mere stump.

Tapirs are shy and inoffensive animals, living in the seclusion of dense forests in the neighbourhood of water, in which element they are quite at home; indeed, it is said that they wili frequently dive and walk along the bed of the river. They are also fond of wallowing in mud. 


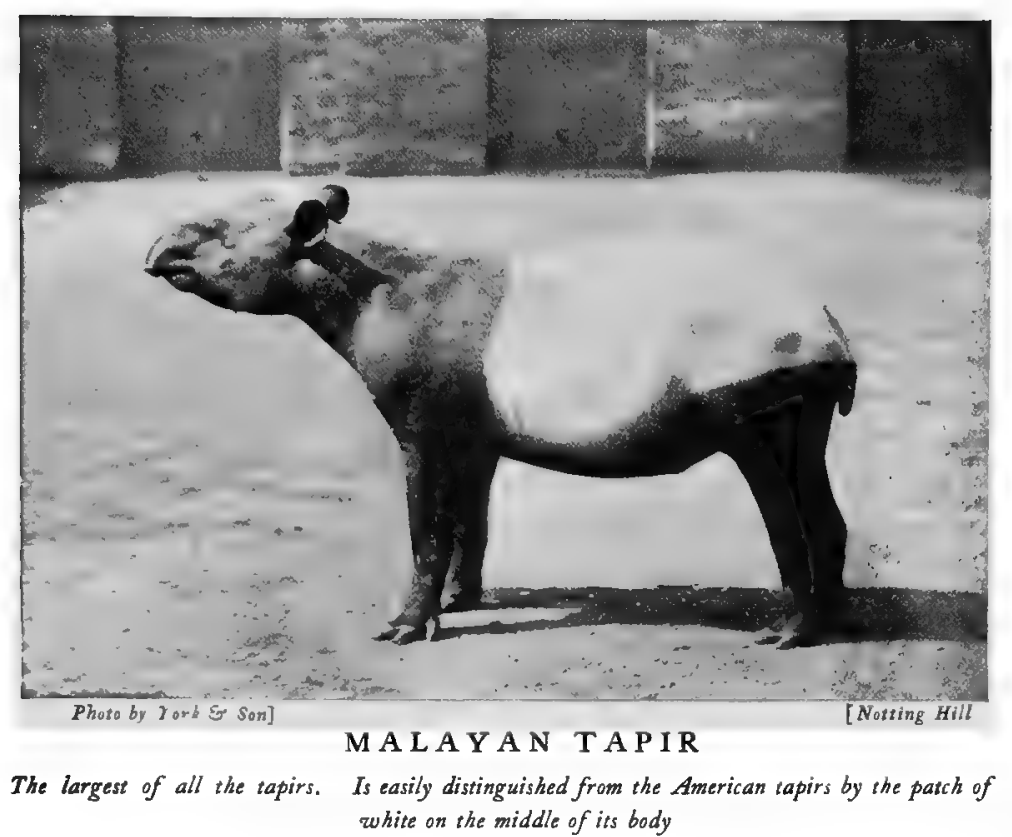

partly, it is believed, that they may encase themselves with it as a protection against the annoyance of flies. They feed on shoots of trees, bushes, leaves, and fallen fruits, foraging during the evening, and possibly far into the night.

Tapirs are hunted by the natives for the sake of their thick hides, which are cut into thongs for reins and bridles. The flesh also is esteemed by some. There are three methods of capture. In South America the lasso is used with occasional success. But when not foiled by undergrowth, the hunter often loses his victim by reason of the vio-

lence and force of its rush, which snaps the thong. The Gauchos intercept it with dogs on its way to the water, when it will fight furiously, and many dogs may be killed before its dispatch is accomplished. Others imitate its peculiar, shrill call, and shoot it on its approach in answer thereto. Captives are easily tamed, and may be seen walking about the streets in many South American towns. They wander into the forest by day, returning in the evening to be fed, and are said to display great affection. On account of their great strength, it has been suggested that such captives should be used as beasts of burden.

Except the Malayan TAPIR, which is black and white, tapirs are black or dark brown in colour, and but scantily clothed with hair; but the young, it is interesting to note, are spotted and striped with white or fawn-colour on a dark ground, a coloration recalling that of the wild pig.

There are five different species of tapir. Their geographical distribution is remarkable, four species being South American, and one belonging to the Malayan region. But far back in the world's history, as we know from fossils, tapirs roamed over the warm and temperate regions of Europe, and their remains have been found in China and the United States. Thus the intervening gaps existing to-day have been made by the extinction of these intermediate species.

By nature the tapir appears to be a harmless and inoffensive animal, flying even before the smallest dog. Occasionally, however, it displays great courage and ferocity, and this appears to be especially the case with females deprived of their young. At such times they will charge with great spirit, and knock down, trample on, and bite their victim after the fashion of wild swine.

Man alone excepted, the most deadly foe of the AMERICAN TAPIR is the jaguar, as is the tiger of the Malay species. The American tapir often gets rid of the jaguar by rushing at full speed into the dense jungle, thus sweeping its assailant from its back, the jaguar's claws finding but an insecure hold on its victim's thick hide. Tapirs are often found bearing scars all over the back, witnessing the terrible nature of the wounds received at such times.

That the tapir is a comparatively unknown animal is partly accounted for by the fact that it is but little sought after by the big-game hunter-who finds more excitement in pursuit of its larger relative the rhinoceros - and partly, perhaps, owing to its inhabiting regions comparatively. little visited by Europeans. Nevertheless, the tapir is an animal of quite peculiar interest, having undergone but little change during long ages, whilst its ally the horse has effected in the same time a complete transformation, not only in its general shape, but more especially in its teeth and 
feet. The gradual steps by which this transformation has been brought about we can trace through certain fossil forms, of which we can say little here.

Amongst these fossils occur remains of an animal bearing a very strong resemblance to the living tapir, but which, strangely enough, is not really so closely related thereto as to the horses. It does not, however, stand in the direct line of descent of these latter, but must be regarded as representing a collateral branch thereof. The occurrence of this distinct tapir-like animal is of great scientific interest.

The short, stout legs and spreading toes of the living tapirs, rhinoceroses, and ancestral horse are admirably adapted for plodding deliberately over soft and yielding ground, such as is afforded by reed-beds and banks of rivers, or the shady depths of forests. Speed in such surroundings is not necessary, food in plenty being always at hand, and escape from enemies being sought by concealment in thick herbage rather than flight. With a migration to drier and higher plains, the spreading foot has undergone a change. The short legs and numerous toes have given place to long ones, and of the several toes growth has taken place in one onlythe third; whilst the others have slowly dwindled, till eventually only traces of the second and fourth remain, as in the modern horse. Thus has a firmer support over hard, unyielding ground been brought about, and great speed gained. The animals with this type of foot (in which the third is the largest toe) are known as the Odd-toed Hoofed Animals. The pigs, sheep, deer, and oxen have gained an equally efficient foot, yet retaining four toes. Of these, the third and fourth are equal in size, and serve as a support to the body, whilst the second and fifth have now become functionless, and do not reach the ground. This type of foot characterises that group of the hoofed animals known as the Even-toed.

\section{The Hyrax.}

This is one of the most remarkable of living mammals, and one of the greatest puzzles to zoologists, having no near living relatives. 'Though bearing some resemblance to an earless rabbit, it really belongs to the hoofed animals, and amongst them comes perhaps somewhat nearer the rhinoceros than to any other animal. It is the Coney of the Bible. It inhabits the rocky districts of Syria and parts of Africa. It is a vegetable-feeder, and very wary. About a dozen species are known.

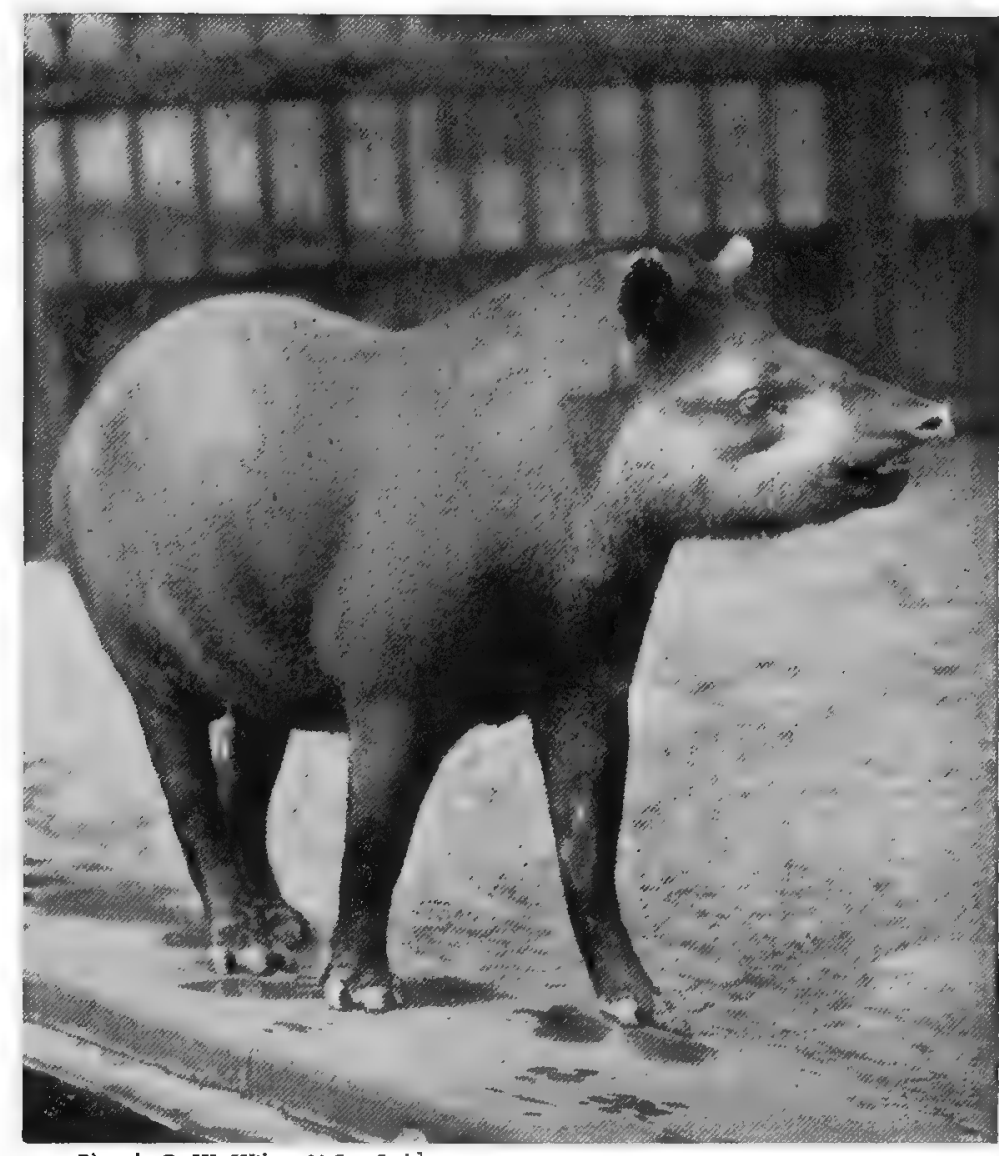

Photo by G.W. Wilson Eo Co., Ltd.]

COMMON AMERICAN TAPIR

This tapir inhabits tropical America. It is a nocturnal animal, frequenting the deptbs of shady forests in the neigbbourbood of water, to wbich it frequently resorts for the purpose of batbing, or as a refuge from pursuit 


\section{I60 THE LIVING ANIMALS OF THE WORLD}

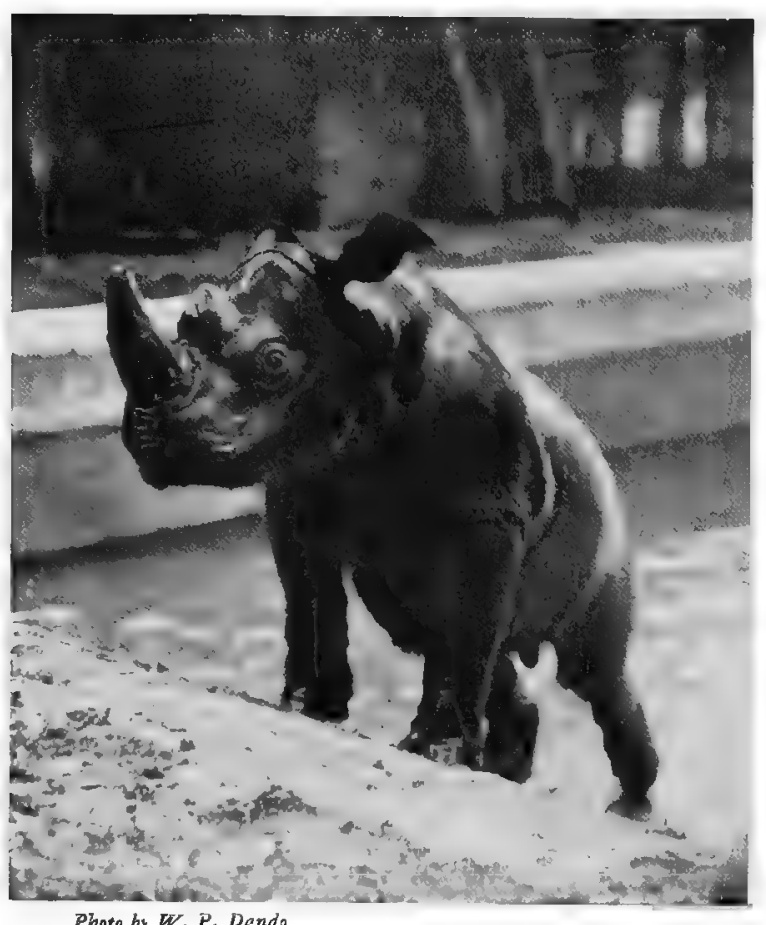

Photo by W. P. Dendo

H AIRY-EARED SUMATRAN RHINOCEROS

Tbis species is found in Eastern Bengal and in the Malay Peninsula and adjacent large islands

\section{THE RHINOCEROS.}

BY F. C. SELOUS.

OF the five existing species of RHINoCERos, three are found in Asia, whilst two are inhabitants of Africa.

Of the three Asiatic species, two, the INDIAN and the JAVAN, are one-horned, and have a single pair of broad incisor teeth in the upper jaw, and a pair of sharp-edged and pointed tusks in the lower, the nasal bones being long and narrow, and terminating in a point. In both these species the skin is hairless (except for tufts or fringes at the extremity of the tail and on the edges of the ears), and is arranged in shield-like folds over the body. The arrangement of these folds, however, differs somewhat in the two species, and the large round tubercles with which the skin of the great Indian rhinoceros is profusely studded are wanting in the Javan species.

The INDIAN RHINOCERos inhabits the Terai at the foot of the Himalaya from Bhutan to Nepal, and is said to be very abundant in Assam and the Bhutan Dooars. It frequents swampy ground, and lives amongst jungles and dense growths of reeds and grass, which attain a height sometimes of 20 feet, and cover vast areas of ground in the valley of the Brahmaputra and other rivers.

Owing to the nature of the country in which it lives, the Indian rhinoceros cannot often be hunted with much prospect of success, except.with the aid of elephants, which sagacious animals are not only employed to carry the hunters, but are also used to beat the great grass jungles in which the rhinoceroses lie hidden, and drive them towards the guns.

Despite its great size and strength, the Indian rhinoceros seems to be regarded as, in general, a timid and inoffensive animal, and even when wounded it seldom charges home. Elephants, however, appear to be as a rule nervous when in the near proximity of rhinoceroses, perhaps objecting to the smell of those animals. When the Indian rhinoceros does make good its charge against either man or elephant, it cuts and rips its enemy with its teeth, and makes little use of its horn as an offensive weapon.

The Indian rhinoceros is said to live principally, if not entirely, on grass and reeds. As a rule it is a solitary animal, but sometimes several are found living in a comparatively small extent of grass-covered plain.

Large males of this species will stand from 5 feet 9 inches to 6 feet at the shoulder, and they are enormously bulky. Both sexes carry well-developed horns, which, however, do not usually attain a length of upwards of $\mathrm{I} 2$ inches. There is a specimen in the British Museum measuring I9 inches, and it is believed that in very exceptional instances a length of 2 feet has been attained.

The Javan Rhinoceros, though it has been called the Lesser Indian Rhinoceros, is said by a late authority-Mr. C. E. M. Russell-to stand about the same height at the shoulder as the Indian species. It is found in the Sunderbunds of Eastern Bengal, and has been met with in the Sikhim Terai and in Assam, ranging eastwards through Burma and the Malay Peninsula to Sumatra, Java, and Borneo. 


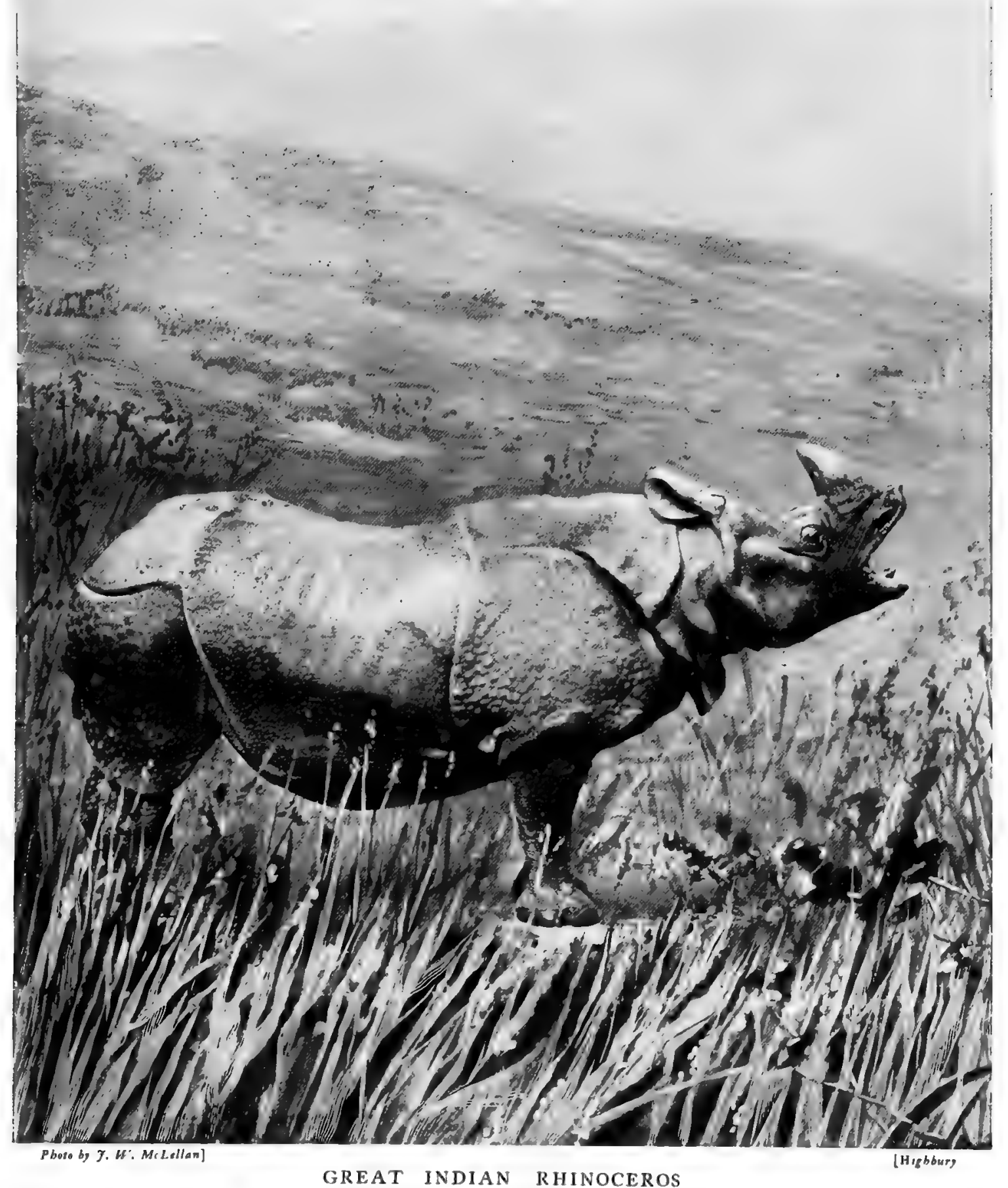

The largese land mammal of the East afuer the clephans 
But little appears to be known of the habits of this species of rhinoceros. Although it is found in the swampy grass-covered plains of the Sunderbunds, its more usual habitat seems to be hilly forest-covered country, and both in Burma and Java it ascends to a height of several thousand feet above sea-level. It feeds principally upon leaves and the young shoots of trees and bushes. In disposition it is timid and inoffensive. Only the male carries a horn, which, being very short, is a very poor trophy for a sports man.

The third Asiatic species of rhinoceros, known as the Sumatran, is the smallest of all living rhinoceroses. This species carries two horns, and its skin, which is very rough, is usually thinly covered with hair of a dark brown colour and of considerable length. The folds in the skin of the Sumatran rhinoceros are not nearly so well developed as in its single-horned relatives, and the one behind the shoulders is alone continued over the back. Although furnished with tusks in the lower jaw, the small pair of incisor teeth, which in the other two Asiatic rhinoceroses are always present in front of these tusks, are wanting in the Sumatran species.

The Sumatran rhinoceros is rare in Assam, but is found in Burma and the Malay Peninsula, as well as in Siam, Sumatra, and Burnes. The two horns of this species are placed at some

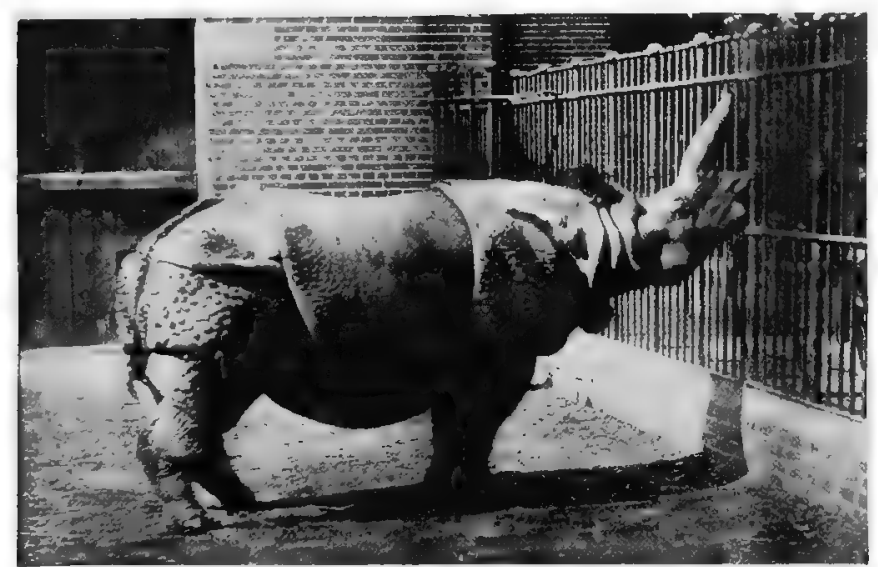

Photo by rork of Son]

[Notting Hill

GREAT INDIA N R H NOCEROS

This species inhabits the grass jungles of Northeastern India distance apart. Although they are as a rule very short, the front horn occasionally grows to a considerable length, sweeping backwards in a graceful curve.

In height adult males of the Sumatran species stand on the average from 4 feet to $4 \frac{1}{2}$ feet at the shoulder, and females sometimes not more than 3 feet 8 inches.

Like the Javan rhinoceros, the Sumatran species is by preference an inhabitant or hilly, forest-covered country, and browses on the leaves and shoots of trees and bushes. It is a timid and inoffensive animal, soon becoming tame in captivity. Its flesh is said to be much appreciated by the Dyaks of Borneo; and as its horns are of value for export to China, where they are used for medicinal purposes, it has of late years very much decreased in numbers in the province of Sarawak, but is more plentiful in Central and North Borneo. Living as it does in dense jungle, it is an animal which is seldom seen by European sportsmen, and its habits in a wild state have never been yet very closely studied.

Turning to the two species of rhinoceros which inhabit the continent of Africa, both are double-horned, and neither furnished with incisor teeth, the nasal bones being thick, rounded, and truncated in front. Both, too, are smooth-skinned and entirely hairless, except on the edge of the ears and extremity of the tail, which are fringed or tufted.

Of the two African species, the White or Square-mouthed Rhinoceros is the larger and the rarer. Until quite recently the range of this huge ungainly-looking animal, the biggest of all terrestrial mammals after the elephant, was supposed to be entirely confined to the southern portions of the African Continent; for although from time to time horns had found their way to Zanzibar which seemed referable to the square-mouthed rhinoceros, the fact of the existence of the white rhinoceros in any part of A frica north of the Zambesi remained in doubt until a female was shot in the year 1900, in the neighbourhood of Lado, on the Upper Nile, by Captain A. St. H. Gibbons, who brought its skin, skull, and horns to England. The fact, however, that the 


\section{ELEPHANT, TAPIR, HYRAX, RHINOCER OS I63}

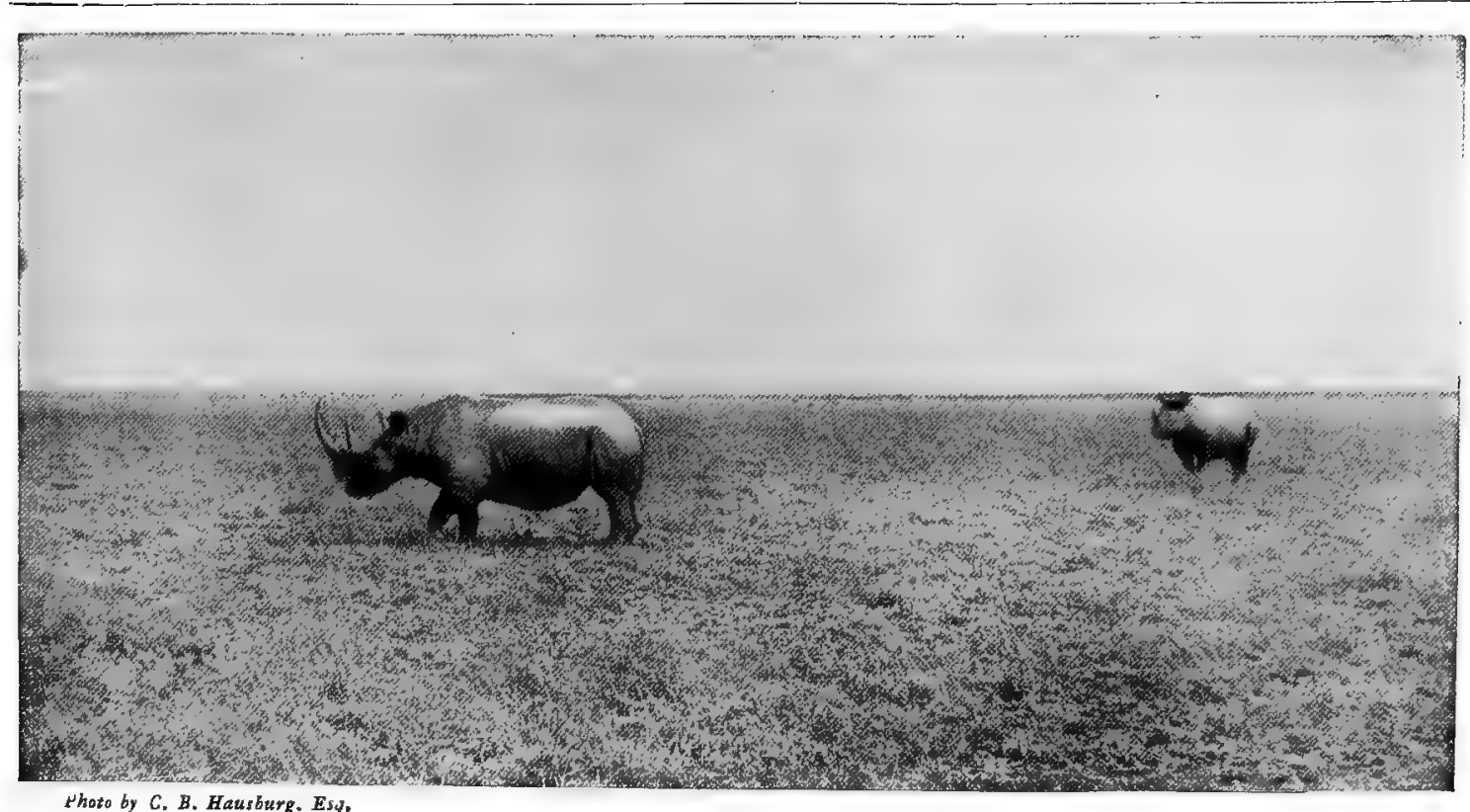

thoto by C. B. Hausburg. Esy.

BIACK AFRICAN RHINOCEROSES

A splendid snapshot of two black African rhinoceroses taken on the open veldt. They were afterwards shot by the party

white rhinoceros has never been encountered by any other traveler in Central Africa seems to show that the animal is either very rare in those districts, or that it has an exceedingly limited range.

In the early years of the nineteenth century the square-mouthed or white rhinoceros was found in large numbers over the whole of South Africa from the Orange River to the Zambesi, except in the waterless portions of the Kalahari Desert, or those parts of the country which are covered with rugged stony hills or dense jungle.

Speaking of his journey in 1837 through the western part of what is now the Transvaal Colony, Captain (afterwards Sir) Cornwallis Harris wrote: "On our way from the waggons to a hill not half a mile distant, we counted no less than twenty-two of the white species of rhinoceros, and were compelled in self-defense to slaughter four. On one occasion I was besieged in a bush by three at once, and had no little difficulty in beating off the assailants." Even so lately as thirty years ago the white rhinoceros was still to be met with in fair numbers in Ovampoland and other districts of Western South Africa, whilst it was quite plentiful in all the uninhabited parts of Eastern South Africa from Zululand to the Zambesi. In 1872 and 1873 , whilst elephant-hunting in the uninhabited parts of Matabililand, I encountered white rhinoceroses almost daily, and often saw several in one day. At the present time, however, unless it should prove to be numerous in some as yet unexplored districts of North Central Africa, this strange and interesting animal must be counted one of the rarest of existing mammals, and in Southern Africa I fear it must soon become extinct. A few still exist amongst the wild loquat groves of Northern Mashonaland, and there are also a few surviving in Zululand; but I fear that even with the most rigid protection

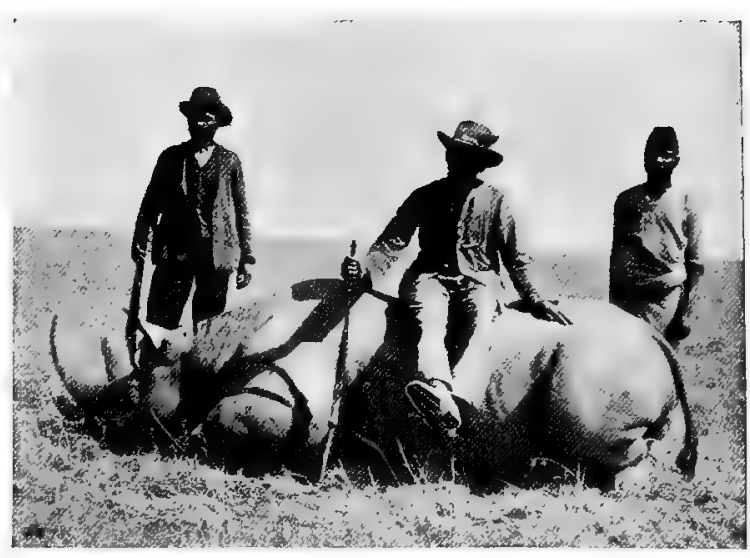

Photo by C. B. Hausburg, Eig.

ONE OF THESAMERHIN OCEROSES DEAD

This picture gives some idea of the size of the commonest surviving species 


\section{I64 THE LIVING ANIMALS OF THE WORLD}

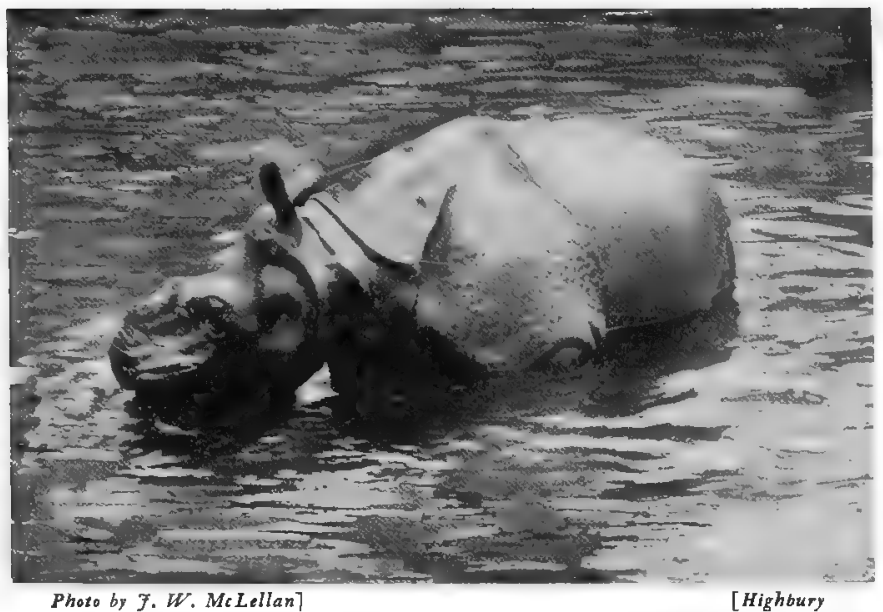

RHINOCEROS BATH ING

All the Asiatic species of rhinoceros are fond of bathing and wallorving in mud

they are too few in number to restock the country. They have a better chance, I think, of increasing in numbers in Zululand than in Mashonaland, in which latter country it is at present impossible to afford them any protection either from natives or Europeans.

A full-grown bull white rhinoceros stands from 6 feet 6 inches to 6 feet 9 inches at the shoulder, and is very massively built, with short, stout legs. The head is very much elongated, and the mouth square, like that of an ox. When white rhinoceroses were still plentiful, very considerable differences were observable in the length and shape of their horns. The anterior horns of full-grown bulls might measure from 18 inches to 40 inches in length; those of cows from 24 inches to 60 inches. The longest horn known-that of a cow-which was brought from South Africa by the wellknown hunter the late Roualeyn Gordon Cumming, measures $62 \mathrm{I} / 2$ inches over the curve. As a rule, the front horn of the white rhinoceros curved slightly backwards, but was often straight or bent slightly forwards, and sometimes curved strongly backwards. The posterior horn varied from a few inches to 2 feet in length.

The white rhinoceros lived in families, usually a bull, cow, and calf being found together; but there might be two or even three calves of different ages, and of which the youngest alone would be suckling, living with the father and mother. In the early South African spring (September and October), when the young green herbage was just sprouting after the first rains, two or three families of white rhinoceroses might be seen feeding in close proximity, presenting the appearance of a herd; but I fancy the several families of these animals had only been brought together for the sake of the young green grass. In Southern A frica the white rhinoceros lived entirely on grass, and I have never seen any evidence of their having eaten anything else. When either walking, trotting, or galloping, the white rhinoceros always carried its nose close to the ground. A calf always preceded its mother, and she appeared to guide it by holding the point of her horn on the little creature's rump; and in all changes of pace, no matter how sudden, this position was always maintained. The white rhinoceros was easily killed by a shot through the heart or through both lungs, but would travel very long distances, and probably, as a rule, ultimately recover from wounds in other parts of the body. They could travel at a great rate and for a considerable distance with a broken fore leg or shoulder, but if a hind leg were broken they were rendered almost immediately helpless. In disposition they were sluggish and inoffensive animals, lying asleep in the shade of trees or bushes during the heat of the day, and coming to the water to drink at night or often before sundown in parts of the country where they had not been much molested. When disturbed, white rhinoceroses would go off at a swift trot, but if chased on horseback would break into a gallop, which they were capable of maintaining for a considerable distance, and at a wonderful pace for so large and heavy an animal. The meat of the white rhinoceros was most excellent, the part in greatest favour amongst hunters being the hump on the back of the neck in front of the shoulder, which was cut off whole and roasted in the skin in a hole dug in the ground.

The colour of the so-called white rhinoceros is dark gray. The second species of African rhinoceros, which is also dark gray in colour, is known as the BLACK or PREHENSILE-LIPPED RhINoceros. 


\section{ELEPHANT, TAPIR, HYRAX, RHINOCEROS I 65}

Less than a hundred years ago the range of this fast-disappearing species extended from the northwestern districts of the Cape Colony to Abyssinia, and at that time it must have been plentiful over almost the whole of the intervening country. It never seems to have penetrated into the equatorial forest regions of West Central Africa, where the climate is probably too damp to suit its requirements ; for both species of A frican rhinoceros appear to like a dry climate, and not to object to very arid surroundings. At the same time they never wander many miles from a river or pool, and drink regularly every night, and in hot weather probably very often a second time in the early morning.

In Southern Africa the black rhinoceros appears to attain to a larger size than in the countries farther north. To the south of the Zambesi large bulls of this species will stand 5 feet 8 inches at the shoulder; whilst the height of an adult bull, as taken by Mr. F. Jackson at Naivasha, in East A frica, was 5 feet 5 inches; and Mr. A. H. Neumann gives the standing height of another adult bull shot by himself still farther north, near Lake Rudolph, as only 4 feet 9 inches.

It is now gener-

ally recognised that there is but one species of prehensile-lipped rhinoceros in Africa, though the horns, and especially the hinder one, differ in length and shape to such an extent that it was long thought that there were at least two distinct species, those with both horns of equal or nearly equal length having been distinguished from the more common form, with a comparatively short second horn, as the KeitloA, this being the name in the Sechuana dialect for a prehensile-lipped
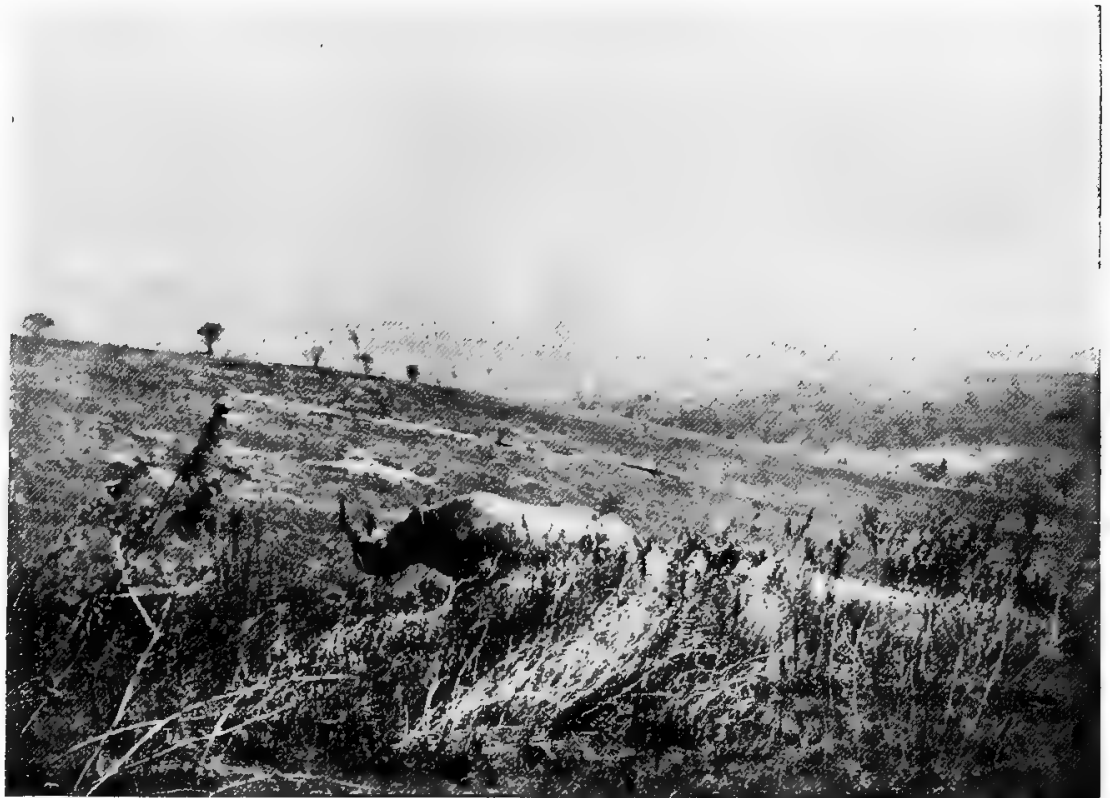

Photo by Norman B. Smith, Esq.

BLACK AFRICAN RHINOCEROS

Tbis pbotograpb, taken by a sportsman in Africa, sbows a charging rbinoceros just before it was sbot

rhinoceros with horns of equal length. Speaking on this subject, Mr. A. H. Neumann, who has had great experience with the black rhinoceros in East Africa, writes: "Length of horn is a purely fortuitous individual trait; and the extremely long horns (mostly of females) which have occasionally been obtained from traders on the east coast, and brought home, are merely exceptionally fine specimens, selected from among large numbers brought to the coast (the bulk of which, I am told, go to China to be ground up into medicine), and do not belong to any distinct species, nor come from any particular region. In proof of this contention I may mention that I have a 40-inch horn, the owner of which I myself shot at the northern base of the Jambeni Range (near Kenia), in a neighbourhood where I hunted a great deal and saw great numbers of rhinos, and shot a good many. The vast majority have quite short horns-under a foot-and anything over I 8 inches is uncommon, while a length of 30 inches or upwards is extremely rare." The black rhinoceros, I believe, never eats grass, but browses on the young shoots of trees and bushes, which are often quite leafless and seem excessively dry. In this way it chews up and swallows great quantities of dry-looking twigs, much of which passes through its stomach undigested. 


\section{66 THE LIVING ANIMALS OF THE WORLD}

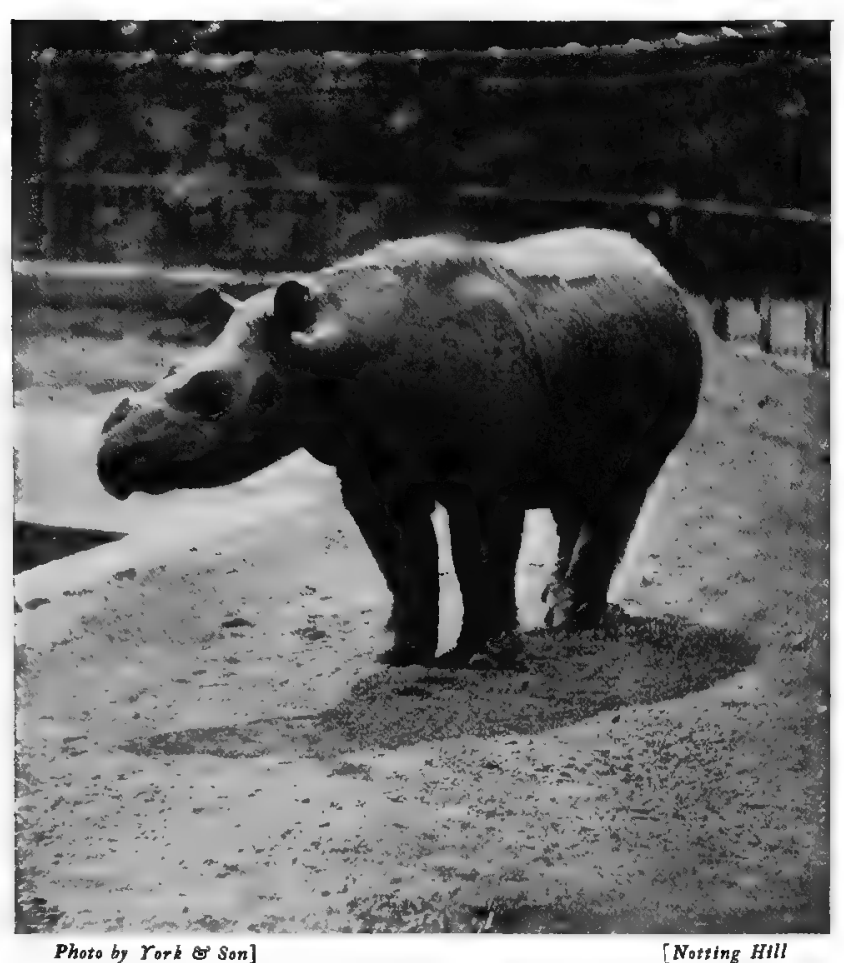

SUMATRAN RHINOCEROS

This species of rhinoceros is the smallest of the three Oriental forms. It has two horns snorting and puffing loudly; but as these animals always turned round and went off eventually without charging, I came to the conclusion that they were inquisitive and very short-sighted rather than vicious. When fired into, a black rhinoceros goes off at a gallop-his usual pace, when alarmed, being a-very fast trot-puffing and snorting loudly. He can gallop at a very great pace, considering his size and weight; but a South African shooting-pony can easily come up with him, or get away from him if pursued. In death a black rhinoceros will often sink down on its knees, and remain in that position, looking as if it were simply resting. When dying, it often gives vent to a pitiful squeal, the sound seeming very small and thin for so large a beast. The meat of the black rhinoceros is not ill-flavoured, and, if fat, very palatable; but as a rule these animals are very lean, and their flesh tough and coarse. The tongue, however, if well cooked, is alway; good; and the liver if first roasted under the ashes, and then, after being beaten up in a native wooden mortar, cooked with rice and fat, makes a dish which is good enough for a hungry man.

During the making of the Uganda Railway the engineers came upon something like a preserve of this species of rhinoceros, especially in the thick and waterless thorn jungle near the coast. The rhinoceros was almost the only animal, except the lion, which was able to penetrate the bush. As many as five of these animals were seen in one day when the line was being made; they did no injury to the coolies, other than by frightening them, and appeared to be stupid and by no means vigilant animals, perhaps because no other creature attacked them. The lion never meddles with a grown-up rhinoceros, though it might and probably does kill a calf occasionally, when the latter is no larger than a full-grown pig. The horns of some of these East African black rhinoceroses were of unusual length and thinness. 


\title{
CHAPTER XII。
}

\author{
THE HORSE TRIBE。
}

\section{ZEBRAS AND WILD ASSES。}

BY F. C. SELOUS.

\section{Zebras.}

7 C ZEBRAS have many points in common with the asses, from which latter group of animals they are principaily distinguished by their beautifully striped skins. Both asses and zebras carry short, erect manes, and in both the upper portion of the tail is free from long hair. In both groups there are naked callosities on the fore legs only, whilst the head is larger in proportion to the size of the animal, and the ears longer than in the horse. In Burchell's and Grevy's Zebras the hoof is intermediate between that of the horse and the ass; for although narrower than the hoof of the horse, it is broader and more rounded than that of the ass. In the TRUE ZEBRA, however, the hoof is thoroughly asinine in character, and the ears very long.

The True or Mountain Zebra appears never to have had a very extended range. It was once an inhabitant of all the mountainous regions of the Cape Colony as well as of the great Drakensberg Range, and fifty years ago was also found amongst the rugged hills of Great Namaqualand. The mountain-zebra is the smallest of the group, standing only from 12 to $12 \frac{1}{2}$ hands at the shoulder. It is a most beautiful animal, the whole of the head, body, and limbs, with the exception of the under-parts and the insides of the thighs, being striped. The groundcolour of the body is white, the stripes

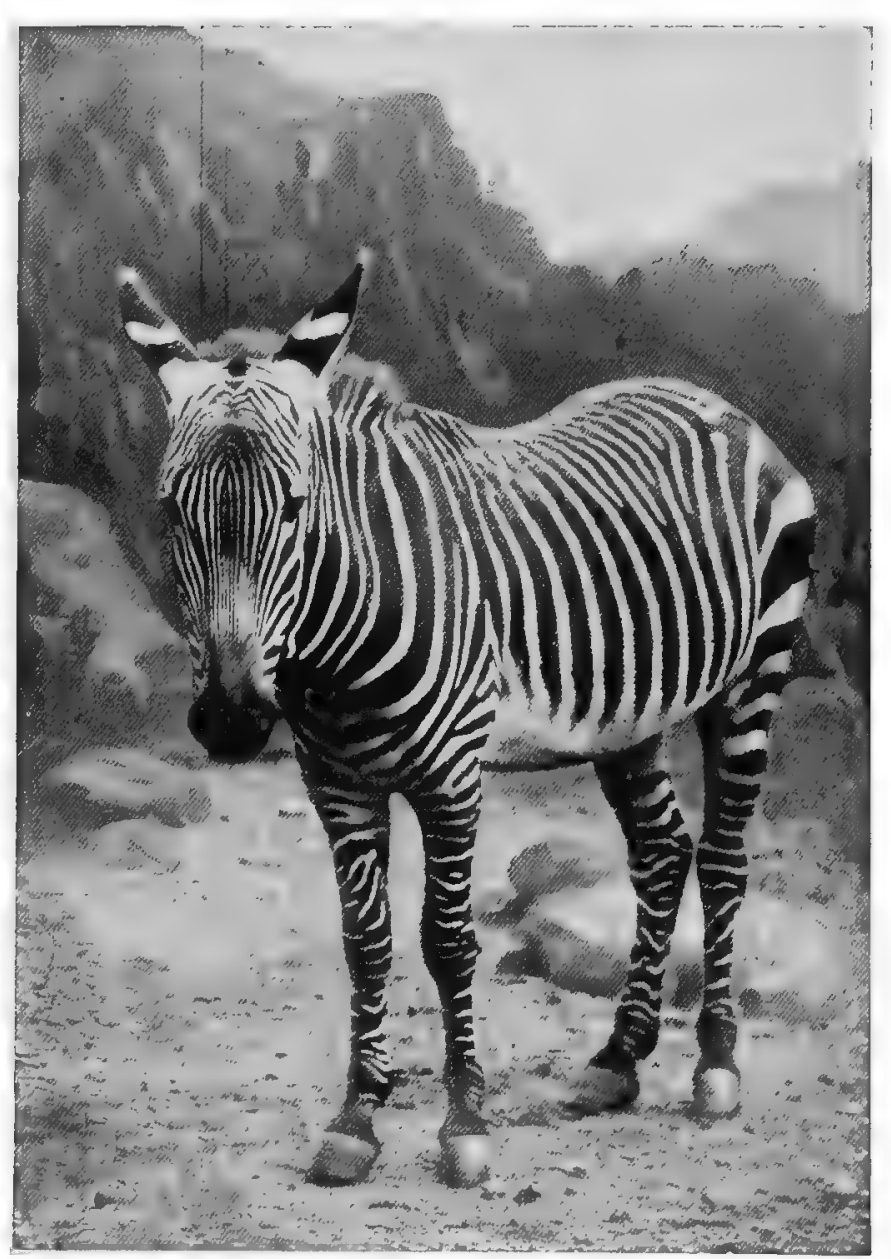

Photo by G. W. Wilson E Co., Ltd.

M OUNTA I N-ZEBRA

The true or mountain zebra is now becoming scarcer than formerly. At one time it was to be seen in great numbers on the mountains of Cape Colony 167 


\section{I68 THE LIVING ANIMALS OF THE WORLD}

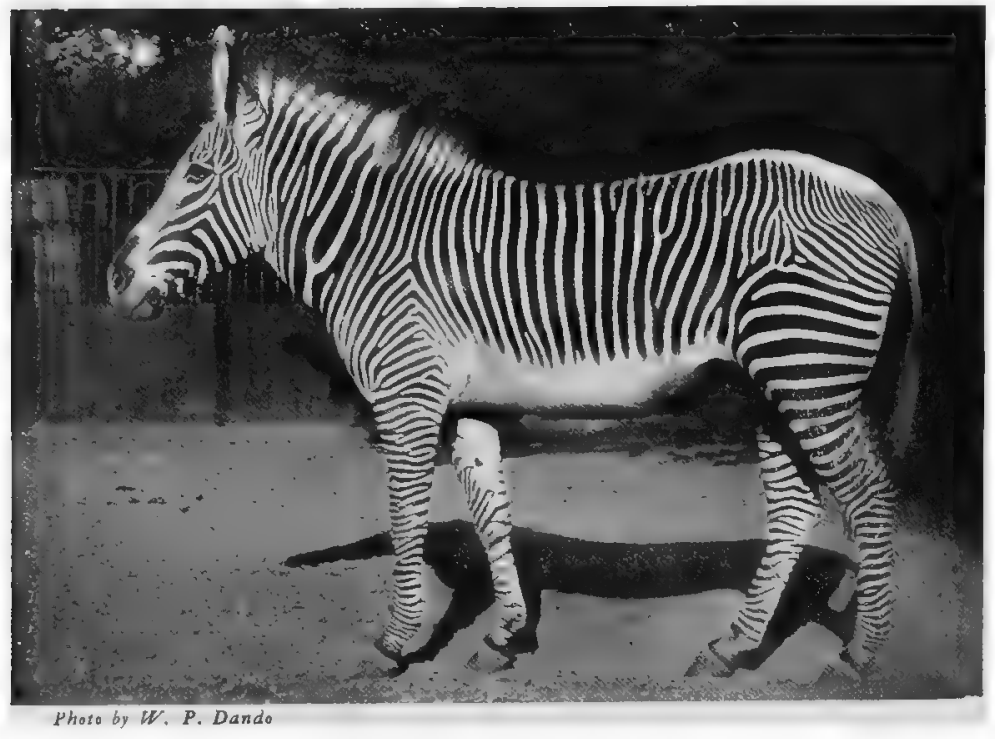

GREV Y'S ZEBRA

Tbis species of zebra come from the Galla country, and bas narrower and more numerous stripes tban the mountain-zebra being black and the muzzle bright brown. Both hind and fore legs are banded down to the hoofs. The stripes on the neck and body are narrower and more numerous than in Burchell's zebra, and on the hindquarters the median stripe, which runs down the centre of the back from the mane to the tail, is connected with the uppermost of the oblique longitudinal stripes by a series of short horizontal bars. The ears in this species are much larger than in Burchell's zebra.

The true zebra seems never to have been an inhabitant of the plains, like all its congeners, but to have

confined its range entirely to mountainous districts. Speaking on this point, Captain (afterwards Sir) Cornwallis Harris wrote upwards of sixty years ago: "This beautiful and wary animal never of its own free will descends into the plain, as erroneously asserted by all naturalists, and it therefore never herds with either of its congeners, the quagga and Burchell's zebra, whose habitat is equally limited to the open and level lowlands. Seeking the wildest and most sequestered spots, the haughty troops are exceedingly difficult of approach, as well on account of their watchful habits and extreme agility and fleetness of foot, as from the abrupt and inaccessible nature of their highland abode."

An allied species, of which examples have been obtained by Mr. G. W. Penrice, occurs in Benguela, Portuguese West Africa.

I once saw the carcase of a zebra stallion which had been sent by rail to the Cape Town Museum by a farmer living in the neighbourhood of the village of Worcester. This animal had come down from the mountains, and joined a troop of donkeys running on the farm. Its intrusion was, however, resented by a male donkey, which fought with and overpowered it, and, having seized it with its teeth by the back of the neck, held it fast until it was secured by the farmer and his men. The captured animal, however, refused food, and soon died, when its carcase was sent to the Cape Museum for preservation.

Grevy's ZeBra is the largest and perhaps the handsomest of all the zebras. This fine animal is an inhabitant of Eastern Africa, its range extending from the central portion of Somaliland southwards to the Tana River. It appears to be plentiful in the country between Mount Kenia and Lake Rudolph, but has not, I believe, been met with to the west of that lake. Full-grown specimens of Grevy's zebra will stand from $14 \mathrm{I} / 2$ to 15 hands at the shoulder, with a girth of body immediately behind the shoulders of nearly 5 feet. The arrangement of the stripes in this species differs considerably both from that of the mountain-zebra of the Cape Colony and also from Burchell's zebra. The body-stripes are very narrow, numerous, and deep black in colour, and are separated by equally narrow white bands. The longitudinal stripes on the haunches are also shorter and finer than in any other species of zebra, and on the top of the centre of the back from the neck to the tail. The belly and insides of the thighs are white, and the legs banded right down to the hoofs as in the mountain-zebra, and the ears are as large as in that species. 


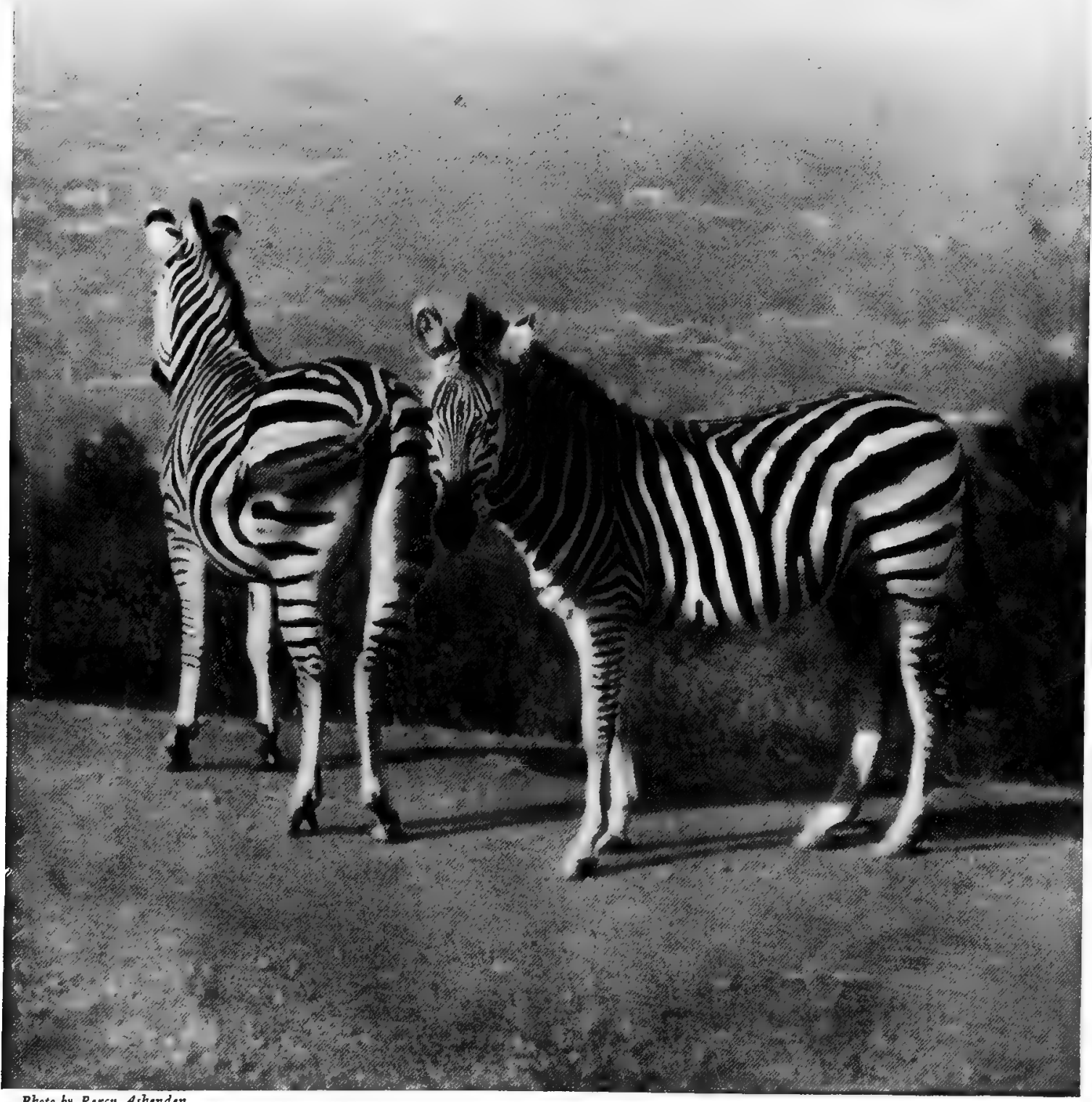

Photo by Percy Ashenden

BURCHELL'S ZEBRA AT HOME

This excellent photograph was taken in South Africa, and shows these animals in their native state I 69 


\section{70 THE LIVING ANIMALS OF THE WORLD}

Grevy's zebra is, as a rule, an inhabitant of open or thinly wooded country, and it appears to avoid anything in the nature of thick cover. In Central Somaliland Major Swayne met with it on low plateaux some 2,500 feet above sea-level, the sides of which fell in broken ravines to the river-valleys. This country is described as broken and hilly, and here Grevy's zebras were met with in small droves of about half a dozen. In the country between Mount Kenia and Lake Rudolph, Mr. A. H. Neumann frequently met with herds of Grevy's and Burchell's zebras consorting together. The contrast between the two species when thus seen side by side was very marked, the former animals looking like horses among a flock of ponies. Mr. Neumann never observed stallions of the two species fighting together, but on the other hand he states that the stallions of the larger species fight viciously amongst themselves for possession of the mares. Grevy's zebras seem never to collect in large herds, more than twenty, or at the outside thirty, being very seldom seen together.

Although this species is an inhabitant of arid plains and bare stony hills where the herbage

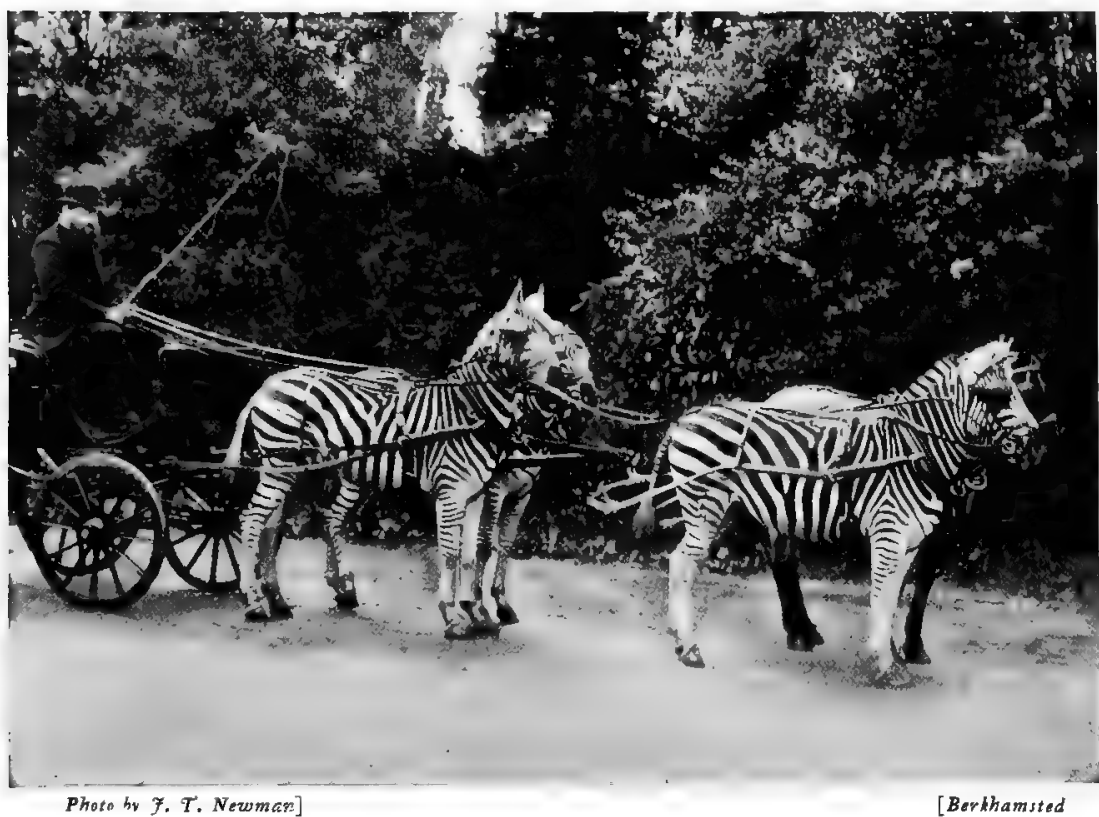

THE HON. WALTER ROTHSCHILD'S TEAM OF ZEBRAS

Mr. Rothschild was practically the first person to break in zebras to harness. At one time these animals were thought to be quite untamable is short, it requires to drink daily, and is never therefore found at any great distance from water.

The cry of Grevy's zebra is stated to be quite different from that of Burchell's. Mr. Neumann describes it as a very hoarse kind of grunt, varied by something approaching to a whistle, the grunts being long drawn out, and divided by the shrill whistling sound, as if the latter were made by drawing in the breath which had been expelled during the sustained grunt.

Like all other species of the genus to which they belong, Grevy's zebras, especially the mares when in foal, become very fat at certain seasons of the year, and their flesh is much appreciated both by natives and lions, the latter preying on them and their smaller congeners, Burchell's . zebras, in preference to any other animal, now that the rinderpest has almost exterminated the great herds of buffalo which once roamed in countless numbers all over East Central Africa.

Burchell's Zebra once inhabited the whole of Southwestern, Southeastern, Central, and Eastern Africa from the Orange River to Lake Rudolph; and though it has long ceased to exist in the more southerly portions of its range, it is still the most numerous and the best known of all the species of zebra.

The typical form of this species was first met with early last century by Dr. Burchell in Southern Bechuanaland. In this form the legs are white below the knees and hocks, and the body-stripes do not join the median stripe of the belly. In examples met with farther north the legs are striped down to the hoofs and the body-stripes join the belly-stripe. South of 
the Zambesi all forms of Burchell's zebra seem to have faint markings, known as shadowstripes, on the pale yellow ground-colour of the spaces between the broad black stripes. North of the Zambesi varieties are met with in which these shadow-stripes are wanting. As, however, the differences between all the various sub-species of Burchell's zebra are superficial and not structural, and as, moreover, the habits of these animals seem to be the same in every part of their widely extended range, I shall henceforth speak of them as one species.

Burchell's zebra is without the small horizontal bars on the hindquarters, which in the mountain-zebra connect the dorsal stripe with the uppermost of the broad longitudinal bands running across the flanks. Its ears, too, are smaller than in the latter species, and its mane fuller. In size Burchell's zebra is intermediate between the mountain-zebra and Grevy's zebra, standing from thirteen to thirteen and a half hands at the shoulder.

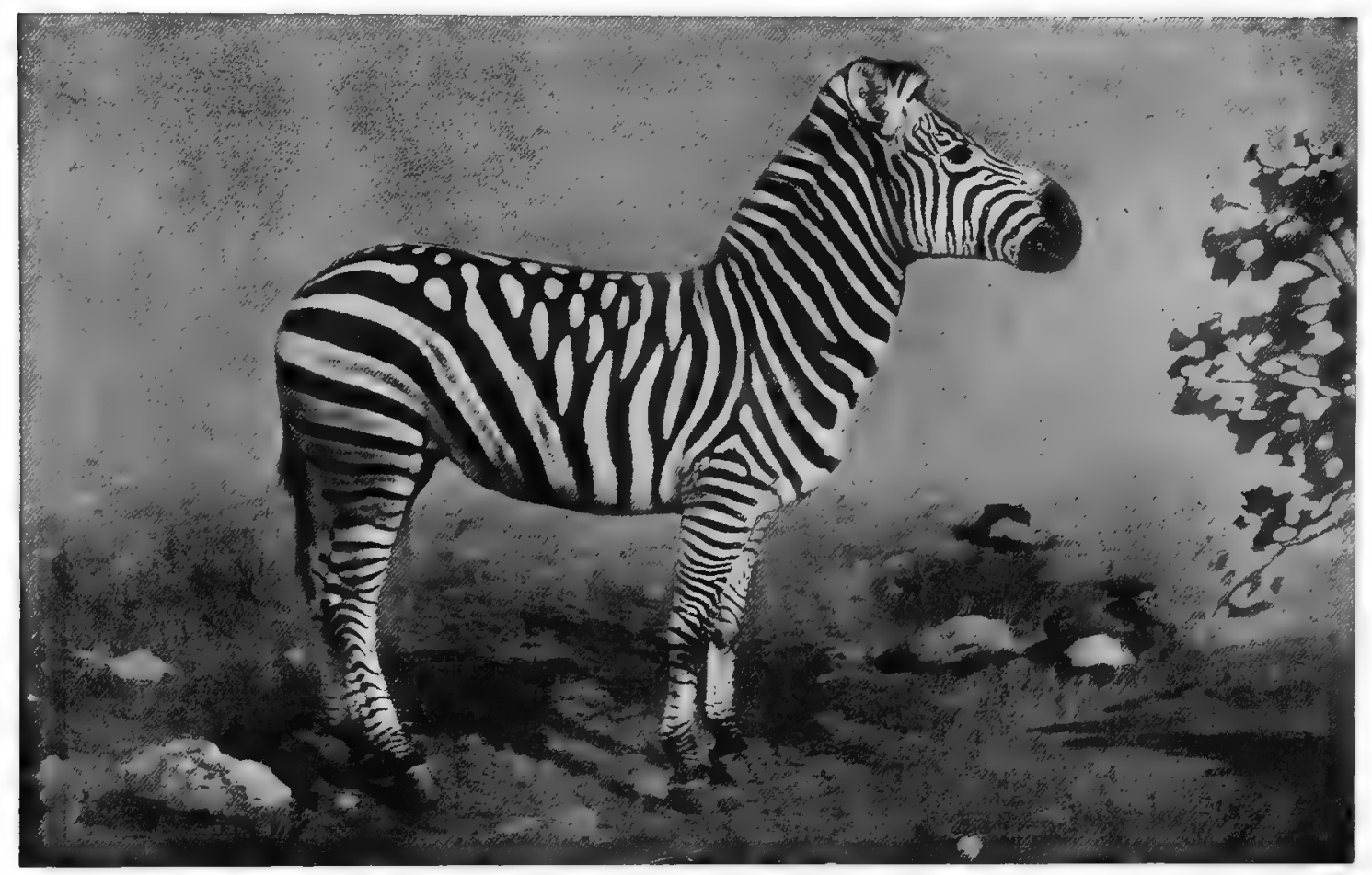

Bv permission of Mr. William Cross

BURCHELL'S ZEBRA, CHAPMAN'S VARIETY

Where they have not been shot down, Burchell's zebras often live in large herds of from fifty to over a hundred together. I have met with them almost at the level of the sea, as in the Pungwe district of South-east Africa, and all over the high plateaux of the interior up to a height of 5,000 feet above sea-level. They are partial to sparsely forested country intersected by open glades, but also frequent open plains entirely devoid of trees or bush, having been once numerous on the open downs of the Western Transvaal and Orange River Colony. They never live in dense jungle, but I have met with them frequently amongst broken rugged hills. Burchell's zebras are both fleet and enduring, but I have often galloped right amongst a herd of them when mounted on a fast horse, and in good ground. In broken, hilly, and stony ground, however, no horse can live with a Burchell's zebra. The hoofs of this species seem made for running in rocky ground, being deeply hollowed and as hard as iron.

I have always found the presence of Burchell's zebras a sure indication that water was not 


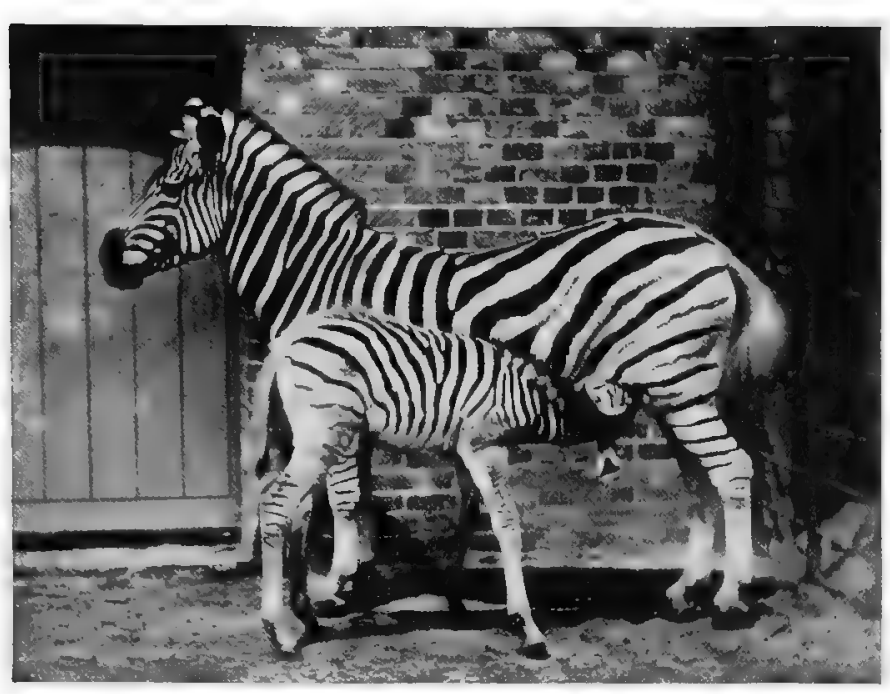

MARE AND FOAL OF BURCHELL'S ZEBRA

These animals breed regularly in captivity far distant, and it is my experience that these animals require to drink daily, and never wander more than a few miles away from the pool or river they frequent.

This species of zebra may often be seen in Southern Africa in company with other animals, such as buffaloes, blue wildebeests, elands, gemsbucks, roan and sassaby antelopes, and ostriches, and I have upon several occasions seen them come up to domestic cattle and horses. They are naturally not very wary, and in parts of the country where they have not been much molested are often very inquisitive, and will come trotting quite close up to a caravan, provided they do not get the scent of human beings. Foals of this species are easily caught, and become at once very tame and confiding; nor do I believe that adult Burchell's zebras are such vicious animals as is generally supposed, since I have seen several which were very quiet and well broken, whilst even the half-broken animals, which were at one time used on one of the coach-lines in the Transvaal, did not appear very vicious.

As with Grevy's zebra, the flesh of the species under consideration is much appreciated both by natives and lions. I have ofteri seen the fat on the quarters of the mares quite an inch thick. It is of a dark yellow colour, and too rich to suit the stomach of a European. The meat is rather sweet in taste, but if fried with bacon not at all unpalatable.

Professor Ewart has lately carried out a very interesting series of experiments on the hybridising of zebras and horses. The results were very satisfactory. The zebra cross proved to be very hardy creatures, capable of wintering in the open on the hills of Scotland. The scientific data obtained were of singular value, as showing the effect of crossbreeding on subsequent generations of foals of the same mother. It has long been believed that the influence of the first sire was seen in foals $\mathrm{cf}$ which other animals were subsequently the fathers. Thus, if a white mare threw a foal to a black stallion, it was considered that her subsequent progeny would occasionally be black, and instances were freely quoted to support this theory. The scientific name of "telegony" was given to this supposed influence of previous sires on futureoffspring. Professor Ewart's experiments, in which pony mares were first mated with a zebra and afterwards with horses, show that this theory of telegony is erroneous. The foals sired afterwards by ponies and horses showed no trace whatever of zebra stripes, but were normal pony foals, and not altered either in shape or disposition.

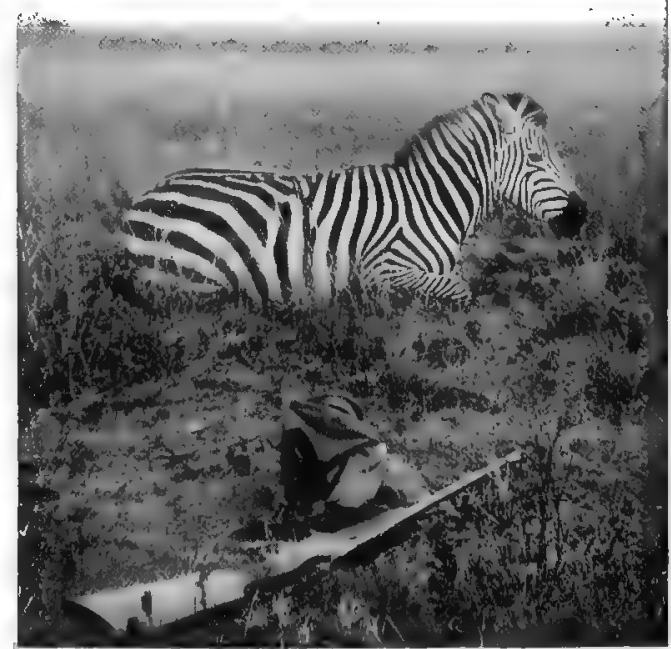

I'noto by Norman B. Snish, Esq.

BURCHELL'S ZEBRA

This species is occasionally domesticated and driven in South Africa, as it is not injured by the tsetse fyy 
The QUAGGA, which became extinct about thirty years ago, never had a very extended range, but in the early part of the last century it existed in great numbers on all the upland plains of the Cape Colony to the west of the Kei River, and in the open treeless country lying between the Orange and Vaal Rivers. North of the Vaal it appears to have been unknown.

The quagga seems to have been nearly allied to Burchell's zebra - especially to the most southerly form of that species but was much darker in general colour, being of a dark rufous brown on the neck and upperparts of the body, becoming lighter on the sides, and fading

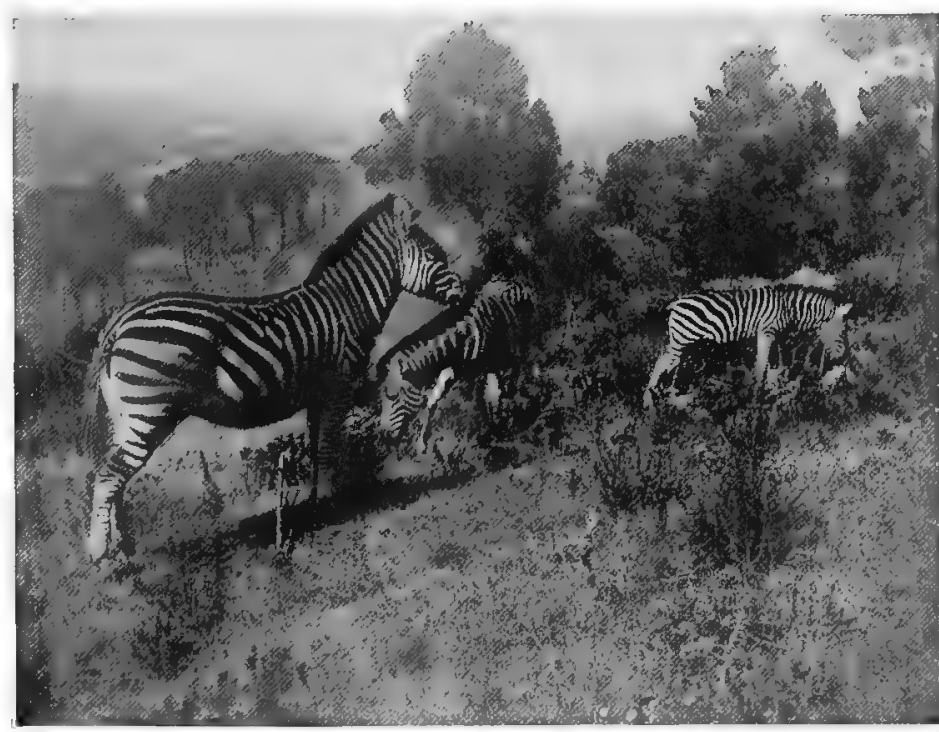

Phote by Percy Ashenden

ZEBRAS ON TABLE MOUNTAIN

Another South African photograph. Notice Cape Town in the far distance

off to white beneath and behind. Instead of being striped, too, over the whole body, it was only strongly banded on the head and neck, the dark brown stripes becoming fainter on the shoulders and dying away in spots and blotches. On the other hand, in size and build, in the appearance of its mane, ears, and tail, and in general habits, it seems to have nearly resembled its handsomer relative. The barking neigh "quā-hā-hā, quā-hā-hā" seems, too, to have been the same in both species. The word "quagga" is pronounced in South Africa "quā-hā," and is of Hottentot origin, being an imitation of the animal's neighing call. To-day Burchell's zebras are invariably called Quā-hās by both Boers and British colonists.

\section{Wild Asses}

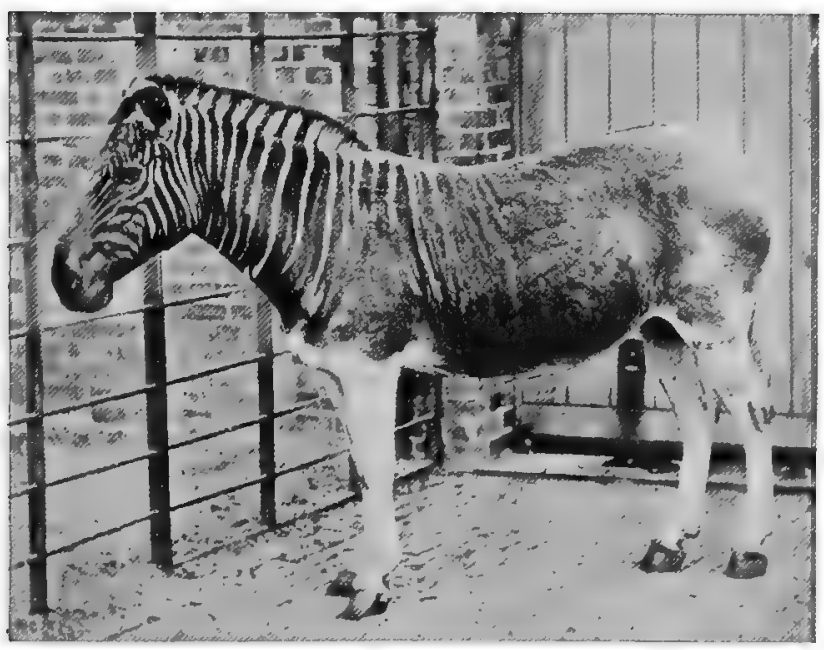

Photo by York os Son QUAGGA

This is, we believe, the only known photograph from life of this very rare animal. There will probably never be atrother, for the quagga is generally supposed to be extinct
The true asses are without stripes on the head, neck, and body, with the exception of a dark streak down the back from the mane to the tail, which is present in all members of the group, and in some cases a dark band across the shoulders and irregular markings on the legs.

In Africa the wild ass is only found in the desert regions of the north-eastern portion of that continent, being an inhabitant of Abyssinia, Somaliland, Gallaland, the Soudan, and the arid districts bordering the Red Sea. The form of wild ass found in Somaliland differs in some respects from its near relative of the Nubian Desert, in that it is of a paler colour, has the dorsal stripe but faintly marked, and is without a cross stripe over the shoulders, 
whilst on the other hand it has numerous markings both on the front and hind legs. Naturalists are, however, agreed that, although there may be certain small differences in the colour and markings of the wild asses found in different localities of Northern Africa, such variations are of no specific value, and only one species is recognised.

The AFRICAN WILD ASS is a fine animal, standing between $\mathrm{I} 3$ and 14 hands at the shoulder. It lives in small herds or families of four or five individuals, and is not found in mountainous districts, but frequents low stony hills and arid desert-wastes. It is as a general rule an alert animal and difficult to approach, and so fleet and enduring that, excepting in the case of foals and mares heavy in young, it cannot be overtaken even by a well-mounted horseman. Notwithstanding the scanty nature of the herbage in the districts they frequent, these desertbred asses are always in good condition. They travel long distances to water at night, but appear to require to drink regularly. Their flesh is eaten by the natives of the Soudan. The bray of the African wild ass is said to be indistinguishable from that of the domesticated animal, which latter is undoubtedly descended from the wild African breed.

In Asia three varieties of the wild ass are found, which were formerly believed to represent three distinct species; but since the points of difference between these varying forms do not appear to be of specific value, all the local races of the Asiatic wild ass are now considered to belong to one species.

These wild asses have a wide range, and are met with in the deserts of Asia from Syria to Persia and Western India, and northwards throughout the more arid portions of Central Asia.

In Tibet and Mongolia the wild ass inhabits the high mountain-plateaux, and lives at elevations of 14,000 feet and upwards above the sea. This local race, know as the KIANG, approaches in size to the African wild ass, standing 13 hands at the shoulder. It is dark reddish brown in colour, with a very narrow dorsal stripe. The ONAGER of Western India and Baluchistan is a smaller and lighter-coloured animal, with a broader stripe down the back. In parts of its range it is found at sea-level. In Persia and Syria a third local race of wild ass is found, which, however, differs from the two forms already enumerated in no essential particular.

Like their African congeners, the wild asses of Asia are inhabitants of the waste places of the earth, frequenting desert plains and wind-swept steppes. They are said to be so fleet and enduring that, except in the case of a mare heavy with foal, they cannot be overtaken

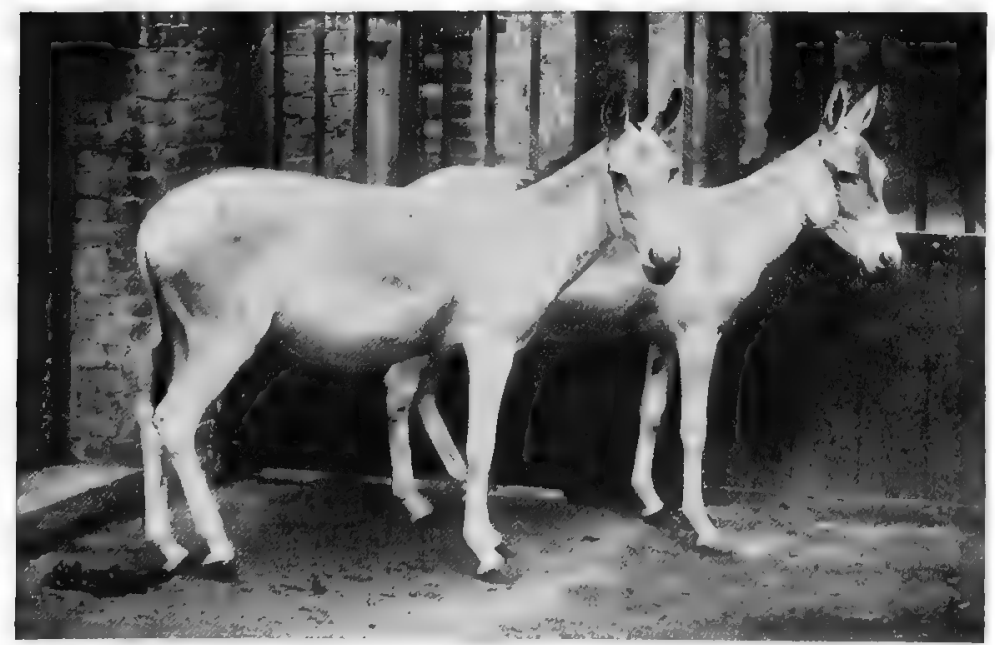

Photo by 7 . W. MCLallan

$$
\text { BALUCHI WILD ASS }
$$

This is one of the three leading variettes of the Asiatic wild ass. It is found in Western India and Baluchistan by a single horseman.

The wild asses of the desert plains of India and Persia are said to be very wary and difficult to approach, but the kiang of Tibet is always spoken of as a much more confiding animal, its curiosity being so great that it will frequently approach to within a short distance of any unfamiliar object, such as a sportsman engaged in stalking other game.

Asiatic wild asses usually live in small families of four or five, but sometımes congregate in herds. Their food consists of various grasses in the low-lying portions of their 


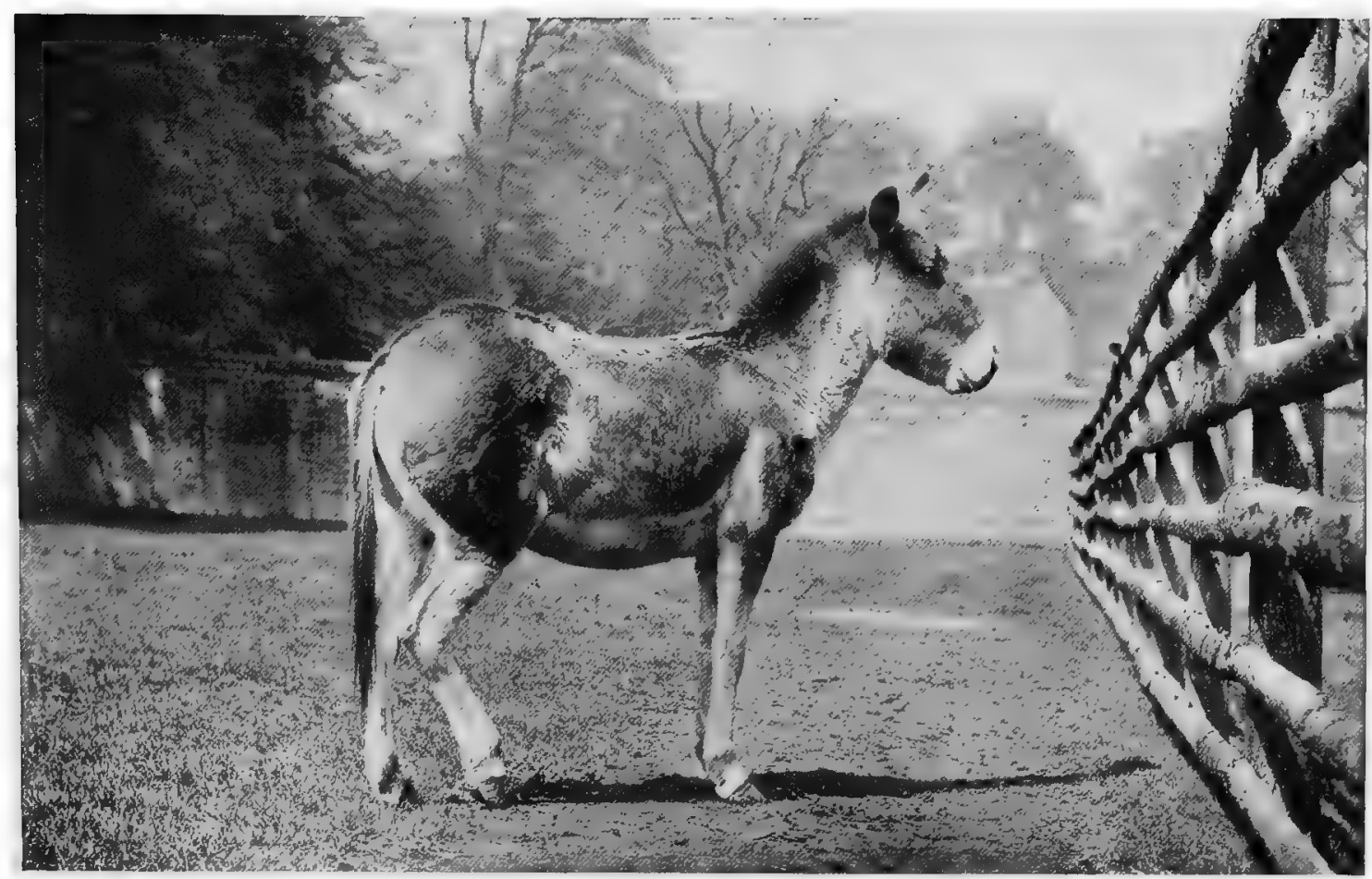

MALE KIANG

The kiang comes from the Tibetan highlands. It is the largest and most horse-like of the wild asses of Asia

range, but of woody plants on the high mountain-plateaux, where little else is to be obtained. Of wild asses in general the late Sir Samuel Baker once said: "Those who have seen donkeys only in their civilised state can have no conception of the wild or original animal; it is the perfection of activity and courage."

DOMESTICATED HORSE, ASSES, AND MULES

BY W. P. PYCRAFT, A.L.S., F.Z.S

\section{The Domesticated Horse}

LIKE the wild carnels, genuine wild horses are very generally believed to be extinct. The vast herds which occur to-day in a wild state in Europe, America, and Australia are to be regarded, say those who believe in the extinction theory, as descended from domesticated animals which have run wild. So far as the American and Australian horses are concerned, this is no doubt true; but of the European stocks it is by no means so certain. For Dr. Nehring - and he speaks with authority - assures us that the wild horses known as TARPANS, which occur on the steppes north of the Sea of Azoff, between the river Dnieper and the Caspian, are veritable wild horses, the last remaining members of enormous herds which occurred in Europe before the dawn of civilisation. These horses formed no small part of the food of the savage races of men then inhabiting this continent. This we know because of the quantities of their remains found in the caves of the south of France, for instance, associated with the remains of the men who hunted them. Further evidence of this we have in the shape of crude engravings on pieces of bone and deer horns, carved by the more artistic spirits amongst these early hunters. From these drawings we gather that the horse they hunted was small in size and heavy in build, with a large head and rough, shaggy mane and 


\section{76 THE LIVING ANIMALS OF THE WORLD}

tail - a horse, in fact, almost identical with the above-mentioned tarpan. But long before historic records begin these horses must have been domesticated; man discovered that they could be even more useful alive than dead, and from that time forth the horse became his inseparable companion. "Cæsar found the Ancient Britons and Germans using war-chariots drawn by horses."

But the stock of domestic horses drawn from this tarpan breed appears to have died out almıst. entirely, the majority of horses now existing being probably descendants of the native wild horses of Asia, the product of a still earlier domestication. In Egypt the horse, as a domestic animal, seems to have been preceded by the ass; but about I900 B.C. it begins to appear in the rôle of a war-horse, to draw chariots. Its use, indeed, until the Middle Ages was almost universally as a war-horse.

From the time of its domestication till to-day the history of the horse has been one of progress. The care and forethought of the breeder have produced many varieties, resulting in such extremes as the London Dray-horse, the Racer, and the Shetland Pony.

The coloration of our various breeds of horses is generally without any definite marking,. piebald and dappled being the nearest approach to a pattern. Occasionally, however, horses are

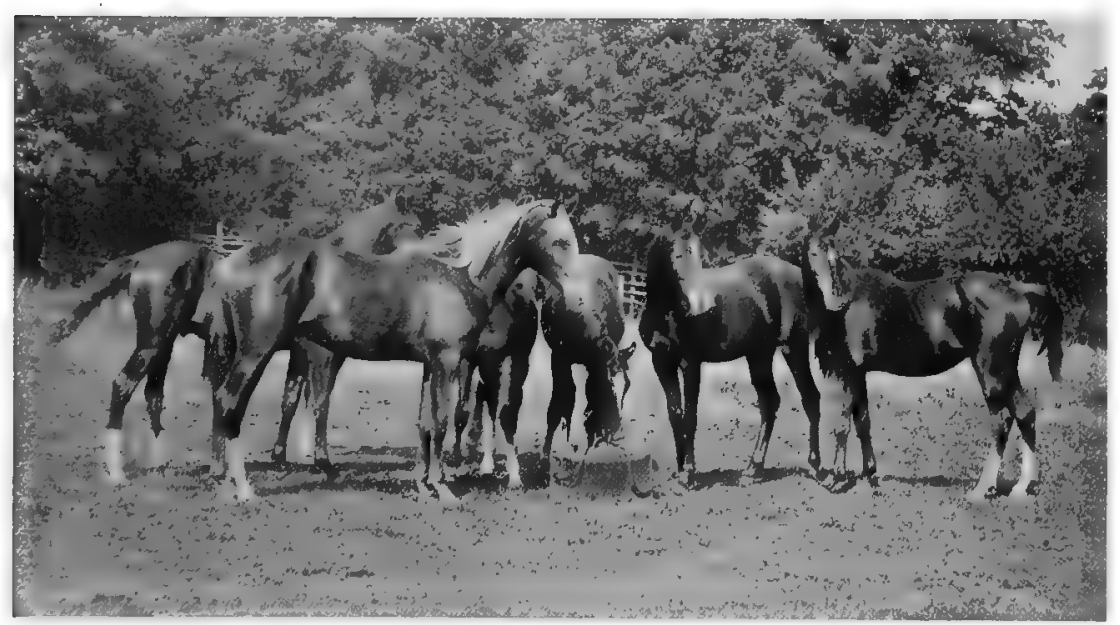

Photo by $T$. Fall

YEARLING ARAB COLTS

Note the colts examining the photographer's bag. They are very inquisitive creatures, but easily frightened found with a dark stripe along the back, and sometimes with dark stripes on the shoulders and legs. Darwin, discovering a number of horses so marked belonging to different breeds, came to the conclusion that probably all existing races of horses were descended from a "single dun-coloured, more or less striped primitive stock, to which [stock] our horses occasionally revert."

"If we were not so habituated to the sight of the horse," says the late Sir William Flower, "as hardly ever to consider its structure, we should greatly marvel at being told of a mammal so strangely constructed that it had but a single toe on each extremity, on the end of the nail of which it walked or galloped. Such a conformation is without parallel in the vertebrate series." By the aid of fossils we can trace out all the stages through which this wonderful foot has passed in arriving at its present state of perfection: we can see how it has become more and more beautifully adapted to fulfil the requirement demanded-a firm support to enable its owner to cover hard ground at great speed. The study of the structure of this foot, and a comparison with the intermediate forms, make it clear that this toe corresponds to the third finger or toe of the human hand or foot - according as we compare the fore or hind limbs and that its development was at the expense of the remaining toes, which gradually dwindled and disappeared, leaving in the living one-toed horse only traces of the second and fourth toes in the shape of a pair of splint-bones, one on either side of the excessively developed third toe.

The horses, it must be remarked, may be distinguished from the asses by the fact that the tail in the former is clothed with long hair throughout; in the latter long hair springs only from the sides and end, forming a tuft. Furthermore, the horses have a remarkable horny 


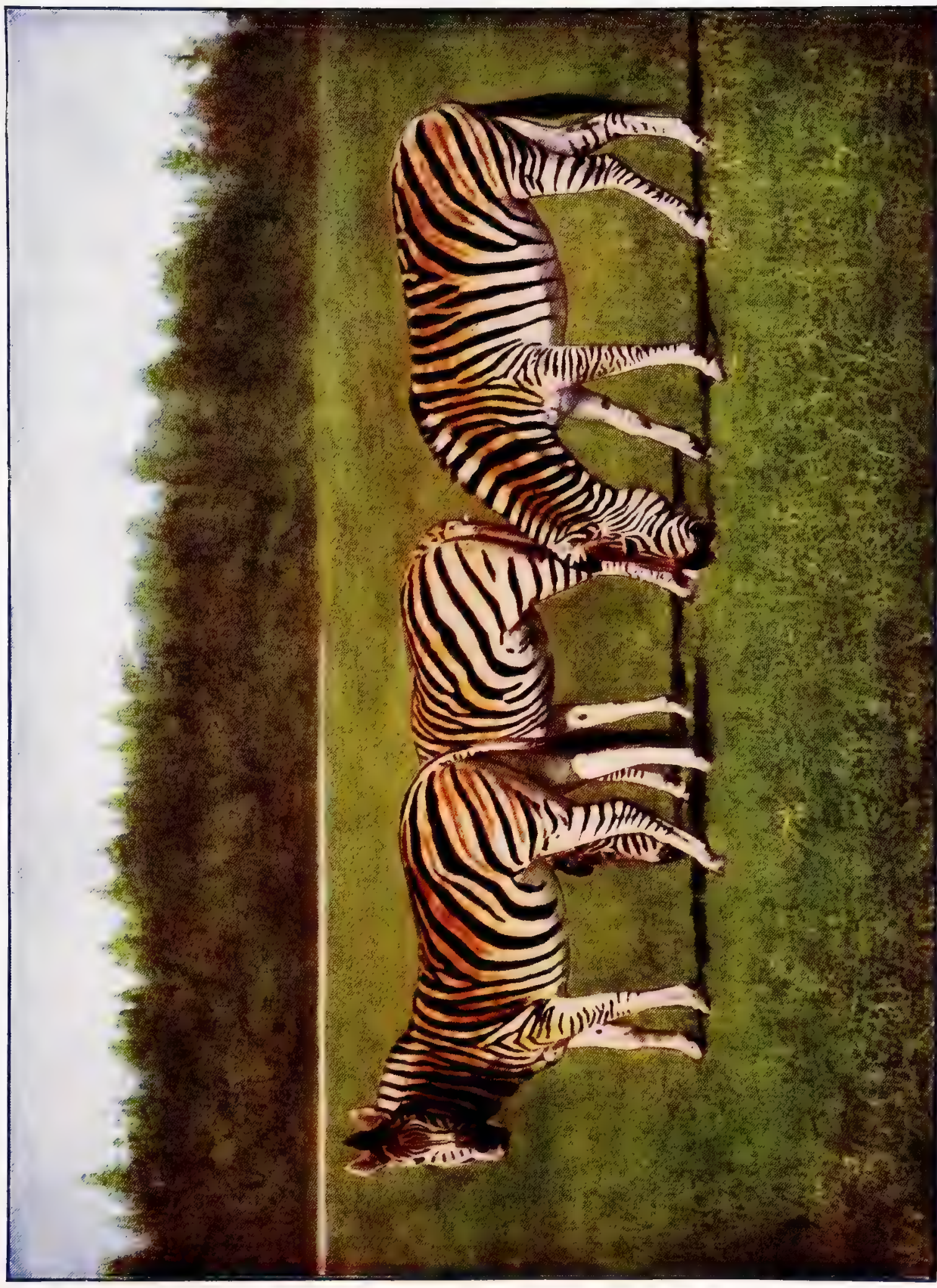

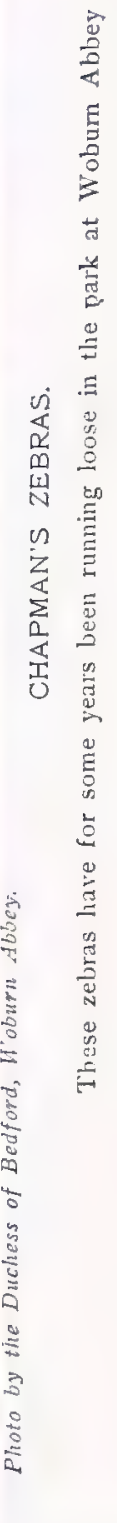





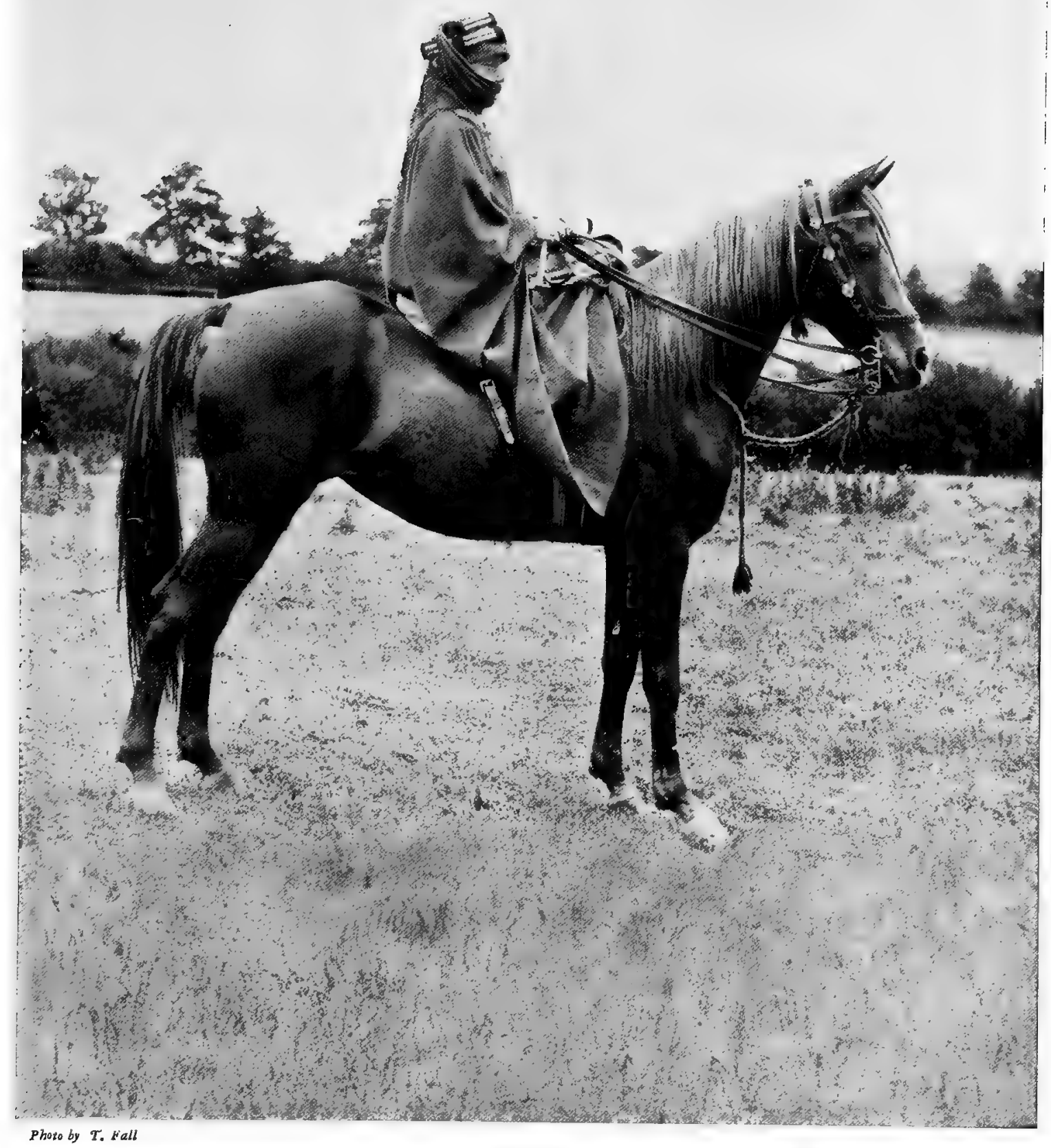

ARAB MARE

Nothing would induce this horse to stand still in order to be photographed; so as a last resource the rider put on her Arab costumt.

This acted like magir, for under its spell the animal at once became quiet 


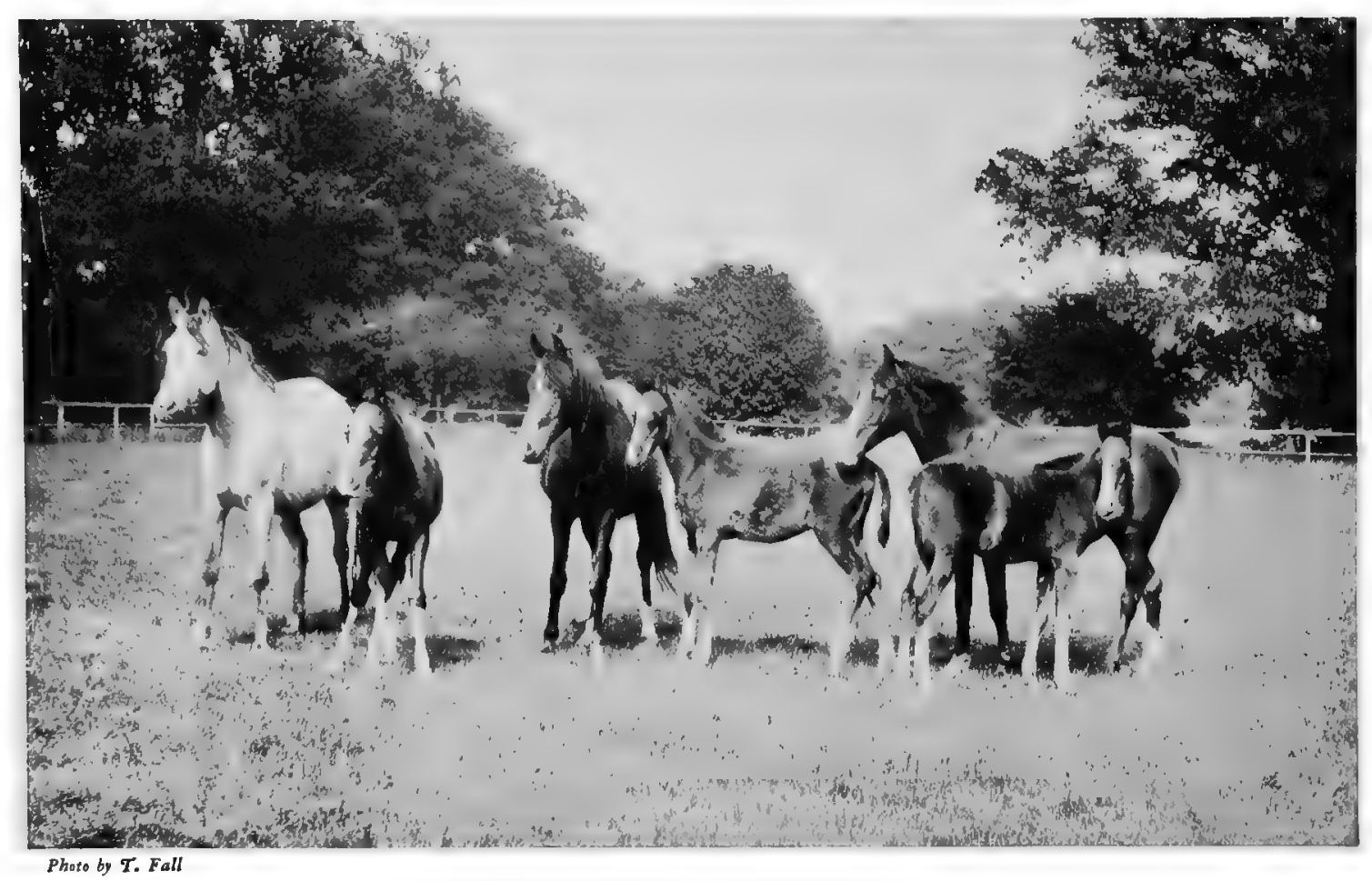

ARAB MARES AND FOALS

excrescence, resembling a huge black and flattened wart, on each hind leg just below the "hock," or heel-joint. This excrescence is commonly known as the "chestnut." Its function is unknown. A similar pair of "chestnuts" occurs on the inner side of the fore limb just above the wrist, or "knee," as it is generally called. The "chestnuts" of the fore limb occur also in the asses, but not those of the hind limb.

\section{The Arab Horse}

This magnificent and justly celebrated animal is chosen first for consideration because it is probably a direct descendant of an original wild breed - the Asiatic wild horse. How far back the domestication of this breed began will probably never be exactly known. Till the third century after Christ the Arabs were almost certainly camel-riders; but by the sixth century of our era we find them in possession of a breed of horses which they regarded with great reverence, and spoke of as an heritage from their forefathers. They were probably introduced from the Caucasus or Asia Minor. The Arab horse found its way into Europe, perhaps accompanied by an allied breed - the Barb - with the Arab invasion of Spain in the eighth and ninth centuries, leaving traces of its sojourn in the Andalusian and the French Limousin. But the great value of Arab blood was not appreciated till armour ceased to be used, the excessive weight of this demanding a horse of heavy build.

The Arab does not appear to have been introduced into England till the seventeenth century; but the result of that introduction, as we shall see presently, has been fraught with tremendous consequences. In its native land it appears to have been bred chiefly for the purposes of warfare. The success with which the breeders' judicious selection has been rewarded is plainly seen in the wonderful powers of endurance on long marches; so that, at the end of a raid, the animal is still fresh enough either for flight, if necessary, or for a final rush on a retreating enemy. Besides, Arabs possess great courage, and are frugal both in the matter of food and drink. 
As a race-horse, one enthusiast assures us, the Arab is superior to every other natural breed; he is beaten only by his own half-breed offspring - the English Race-horse. But this seems to be rather an overestimate.

The colour of the Arab varies; white is the most highly esteemed, but bay and chestnut are common, black being rare. Strange as it may seem, the white breed is never born white.

The great affection of the Arab for his horse is proverbial. The following story is certainly worth repeating: "The whole stock of an Arab of the desert consisted of a mare. The French Consul offered to purchase her, in order to send her to his sovereign, Louis XIV. The Arab would have rejected the proposal; but being miserably poor, with scarcely a rag to cover him, his wife and children starving, he was tempted greatly. At length he yielded. $\mathrm{He}$ brought the mare to the consul's

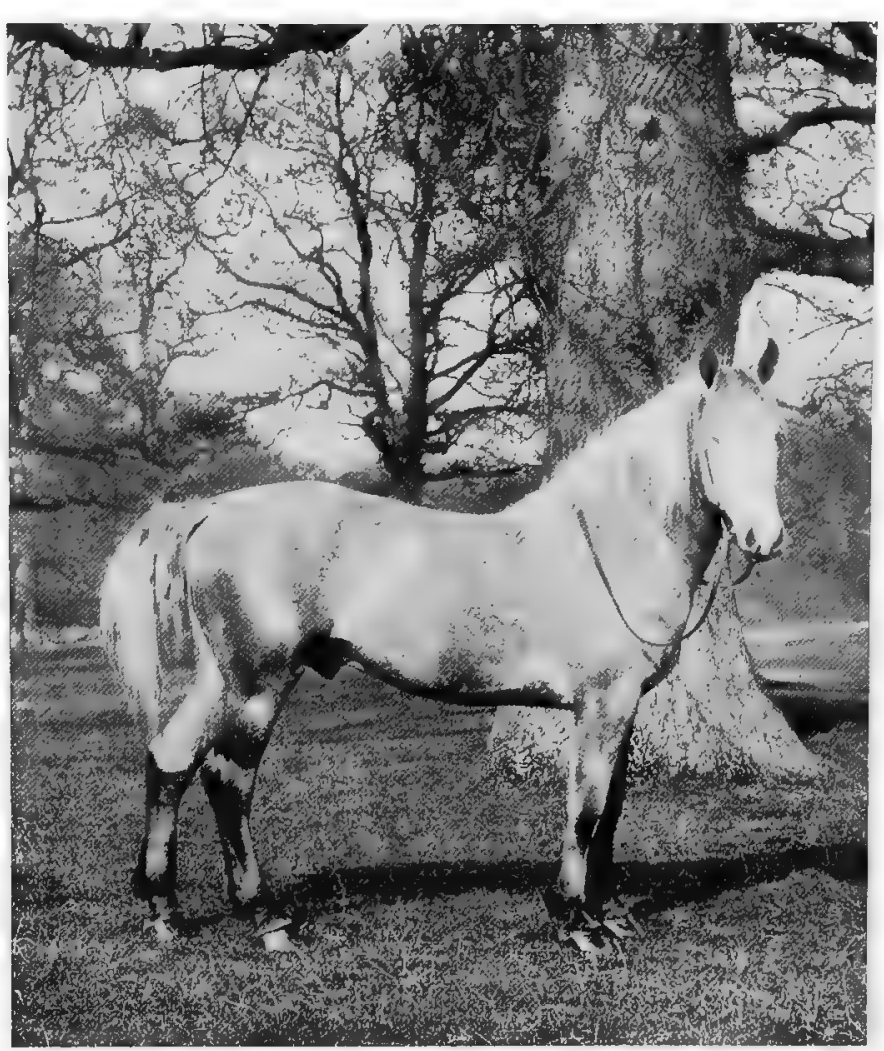

PERCHERON HORSE house, and stood leaning on her neck,

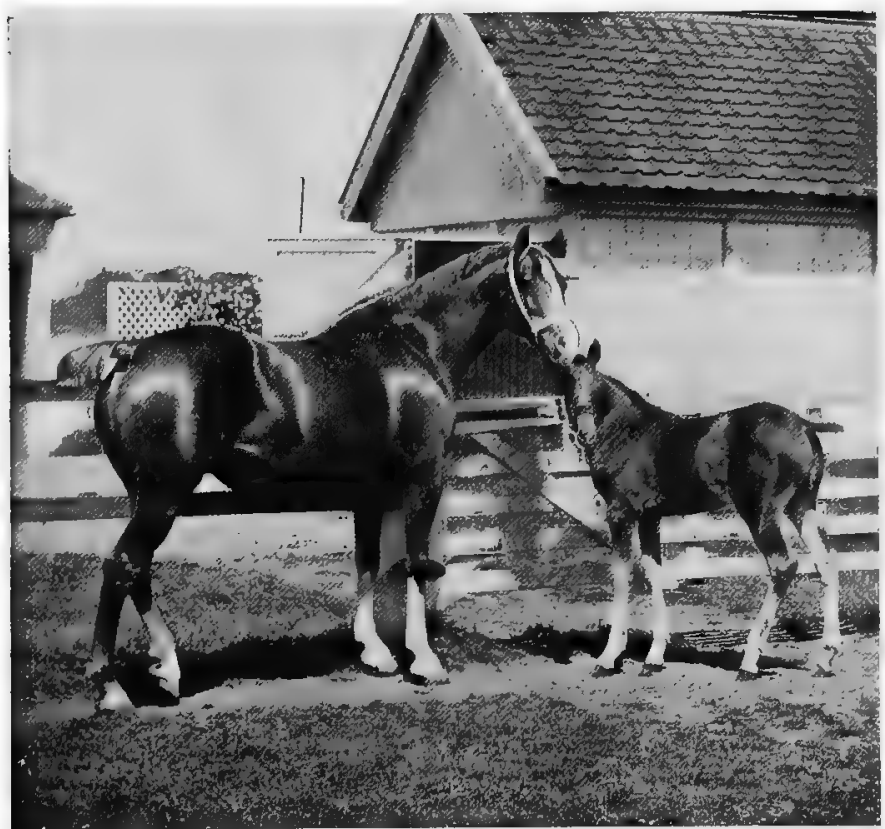

Photo by r. Fall
HACKNEY AND FOAL

A specimen of the English carriage-horse and looking, now at the gold, and now at the horse. The gold was good to look upon; it would make him rich for life. Turning at last to his favourite, he said: "To whom is it I am going to yield thee up? To Europeans, who will tie thee close, who will beat thee, who will make thee miserable. Return with me, my beauty, my jewel, and rejoice the hearts of my children.' At the last of these words he sprang upon her back, and was in a few moments out of sight."

\section{THE BARB}

This is an African breed, which, like the generality of African horses, is distinguished from those of Asia by its long limbs and small girth at the loins, thus resembling the foals of other breeds. It displays great powers of enduring hunger and 


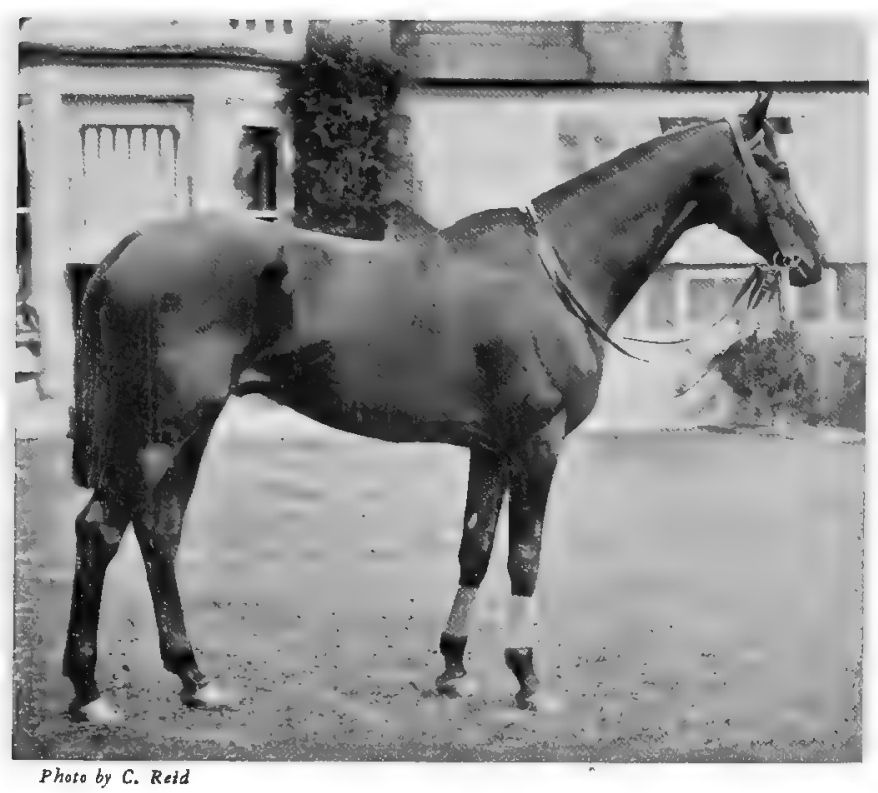

LADAS

$A$ perfect English thoroughbred. With this racer Lord Rosebery won the Derby
in 1894 thirst; and is fleet, with a high and graceful action. The barb takes its name from its native land Barbary. It is a larger breed than the Arab.

\section{Levant and Persian Horses}

These are very closely allied to the Arab, but generally of larger size; and in Southern Persia, at least, less delicately framed. The Turkoman horses are related to those of Northern Persia.

\section{The EngLish RaCE-HORSE}

This animal is the product of very careful selection and gradual improvement of an original native breed, extending over several centuries. Long since, so long ago as the reign of James I., it had reached a high degree of excellence.

Upon this native stock there has

been built up, by the infusion of Arab blood, the swiftest horse which the world has ever known - the BRITish THOROughBred. "Of this breed, it may be stated," says Mr. Allison, "that every such animal in the stud-book of the present day, in this country or any other, descends ... from one of three original Eastern sires - the Darley Arabian, the Byerley Turk, or the Godolphin Arabian." This is an extremely interesting fact, and constitutes a lasting monument to the enterprise and acumen of the British horse-breeder.

The Byerley Turk hailed from the Levant, and was introduced by Captain Byerley about I689. From the Byerley Turk came Herod, the most celebrated of his descendants, who has given rise to the Herod line, which to-day is but feebly represented.

The Godolphin Arabian, or the Godolphin Barb, was born about I 724 . From his grandson Matchem is derived the Matchem line, which is also to-day bordering on extinction.

The Darley Arabian carries us back to the reign of Queen Anne. Flying Childers and Bartlett's Childers are directly descended from him; and from the latter is descended Eclipse, the fastest horse which the turf has ever known. It is interesting to note that the descendants in the Eclipse line enormously outnumber those of the other two lines which we have considered. Of his descendants, one of the

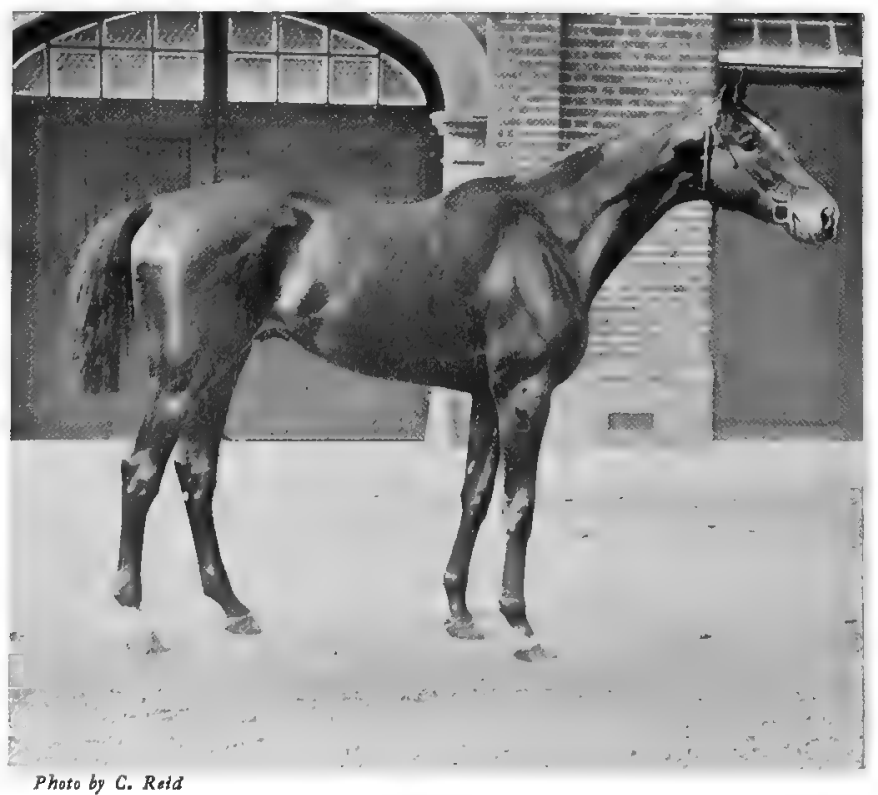

FLORIZEL II

One of King Edruard's racing-stud 
most illustrious is Stockwell, who has been described as the most extraordinary sire of all time, whose blood is coming more than ever to the front.

\section{The TrotTing-Horse}

This is an American breed. The trotting-horse is a combination of barb and Arab on an English stock. Most of the trotting- and pacing-horses of America may be traced to an English thoroughbred - Messenger - who was imported into America in I 780 . This horse became the founder of the greatest trotting family in the world. The speed attained by some of the fastest trotters is wonderful, a mile being covered in some three or four seconds over

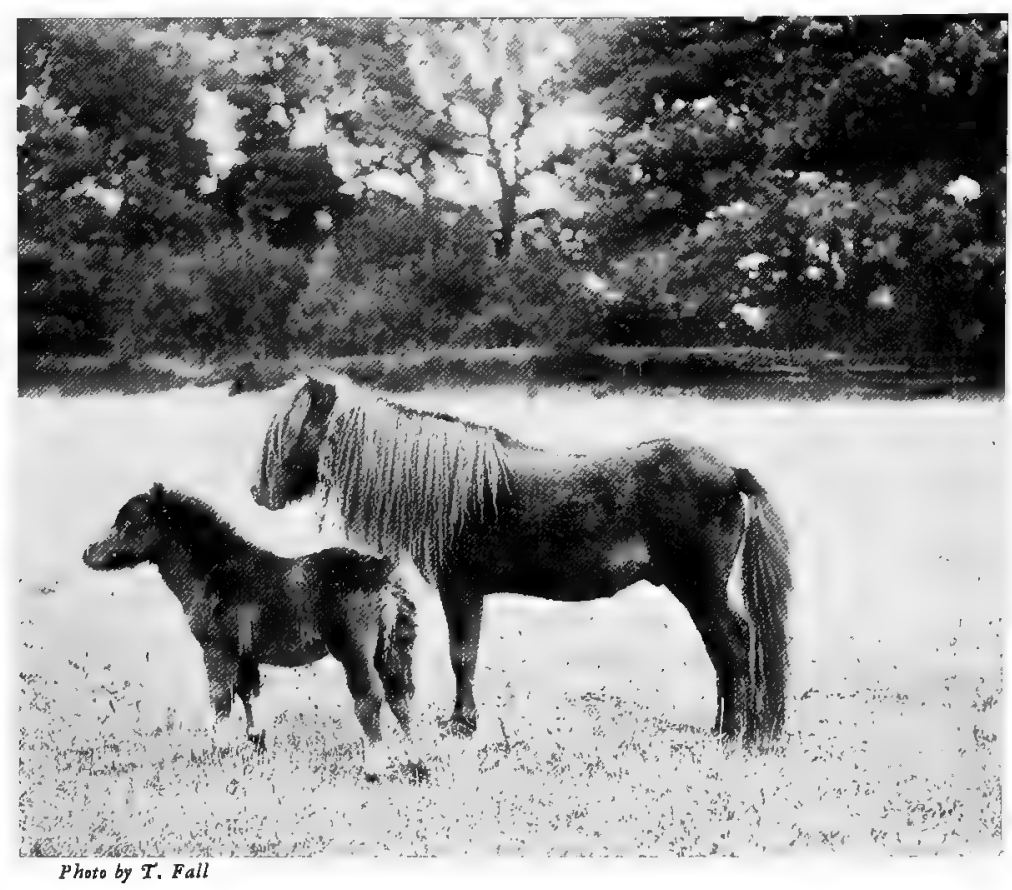

SHETLAND PONY AND FOAL two minutes.

Russia is the only European country with a distinct breed of trotter - the ORLOFF. This breed was made by crossing Arab and English horses with the native races. The Orloff

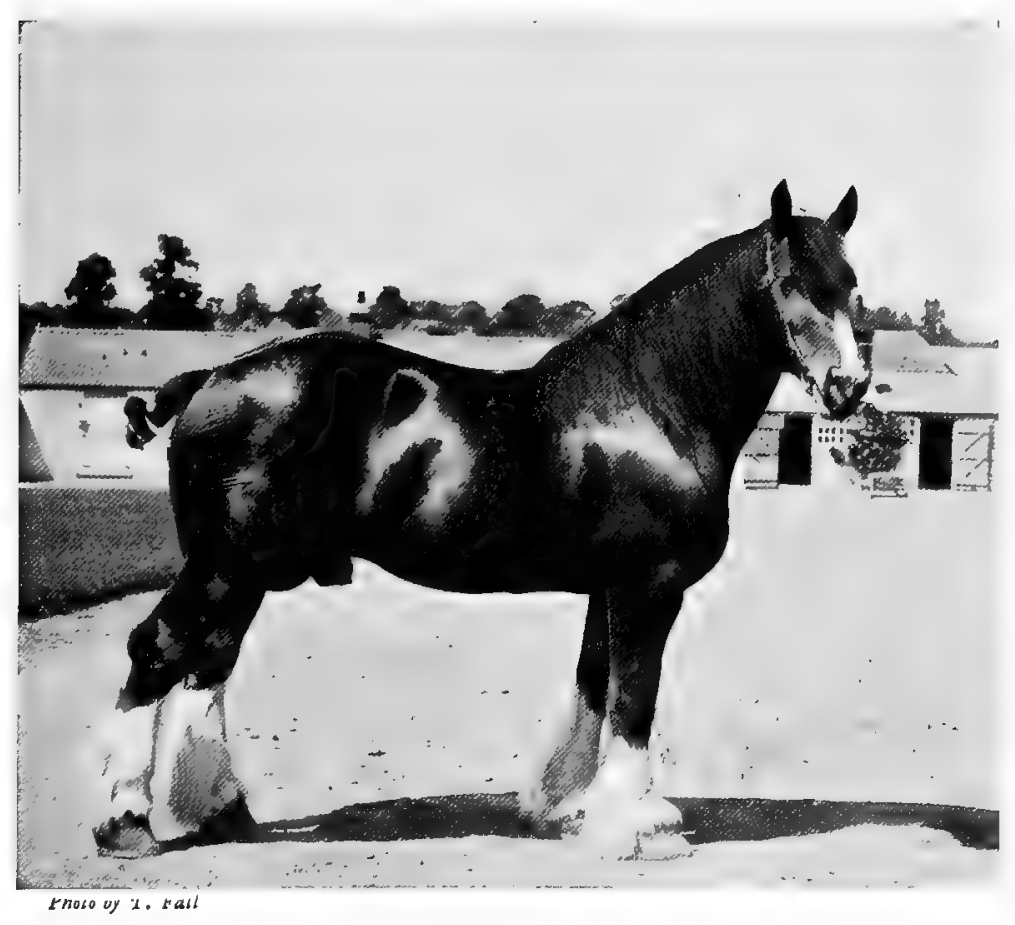

CHAMPION SHIRE STALLION

A celebrated cart horse has not the speed of the American horse, but has greater powers of endurance. The trotting-season in Russia is winter, the races taking place on the ice.

The PACER is not a distinct breed, but so called on account of its curious method of trotting. In trotting the left fore and right hind leg strike the ground at the same moment; in pacing the fore and hind leg of the same side move in unison. Some wild animals - as the giraffe - are pacers. "Many American horses," says Mr. Winans, " are able to move with either action, a set of lighter shoes often sufficing to convert a trotter into a pacer." Pacing is a swifter mode of motion than trotting. 


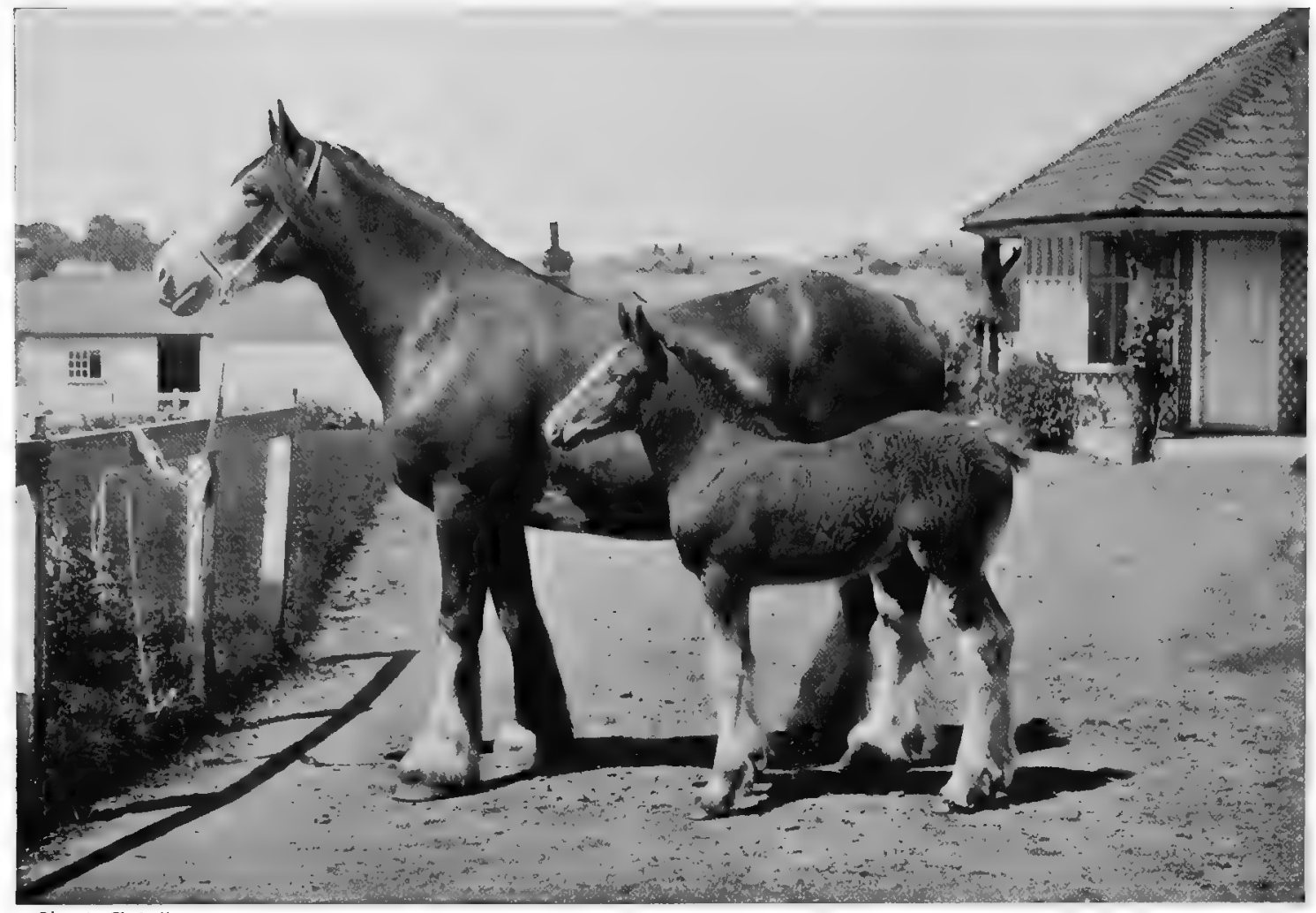

Phoro by T, tall

SHIRE MARE AND FOAL

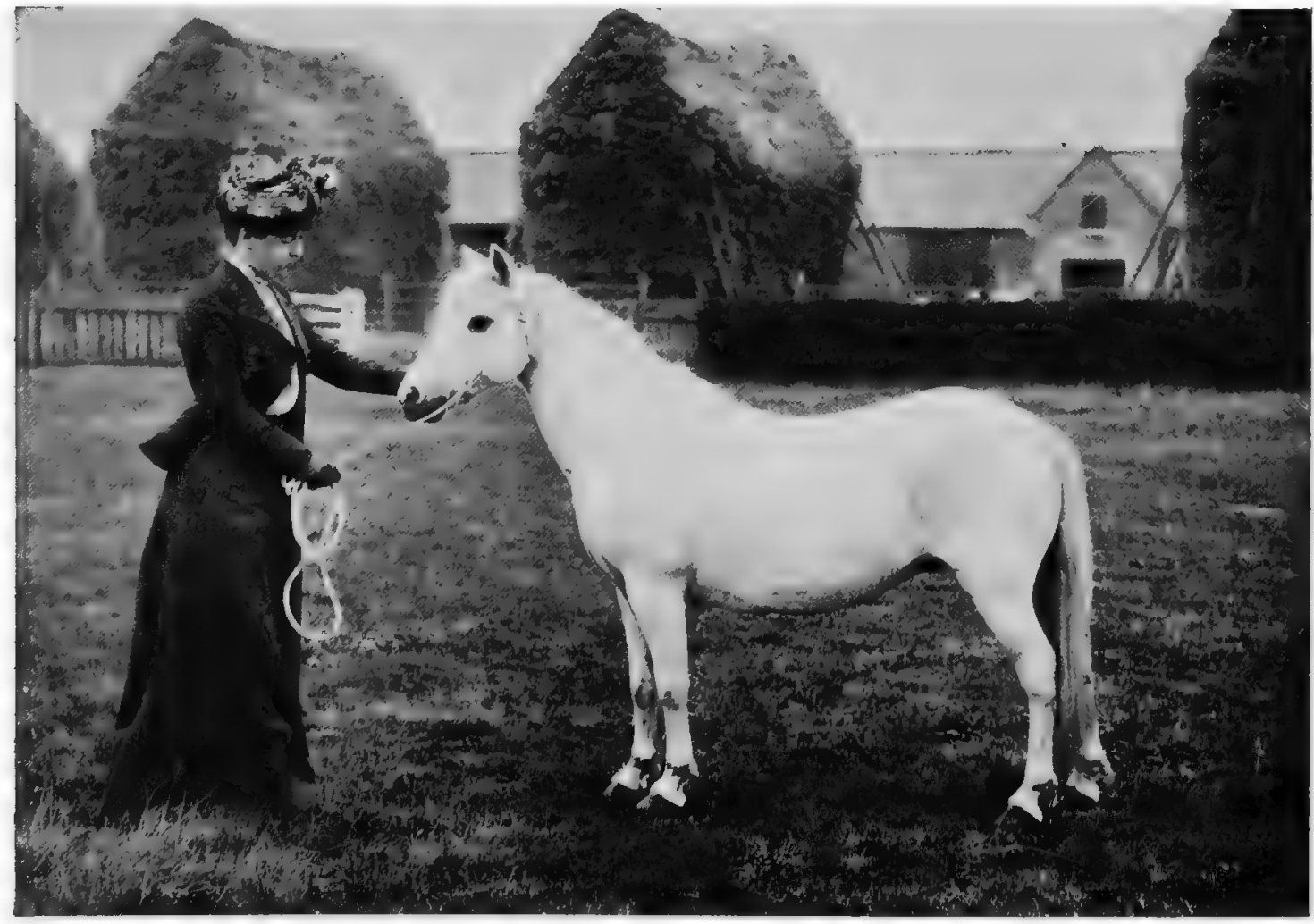

Photo by T. Fall

WELSH PONY

This photograph shows the Duchess of Newcastle with one of her white Welsh ponies 
The pacing record time stands at one mile in I minute $59 \frac{1}{2}$ seconds, as against the trotting record of one mile in 2 minutes $3 \frac{3}{4}$ seconds.

\section{The Hunter}

This also is not a distinct breed, as some suppose. Any good riding-horse may be used as a hunter. "Hunters" have been made by infusing the blood of the race-horse with native breeds. The chief requirements are a muscular neck and chest, with a rather short body, and shorter and stouter legs than the race-horse.

From the half-bred hunter we pass by insensible gradation to the ordinary saddle- and carriage-horses. The ideal carriage-horse, however, is more of a distinct breed than the hunter, and known as the CLEVELAND BAY. It has been produced by mingling the blood of the thoroughbred with that of a horse of stouter make than that of the hunter type.

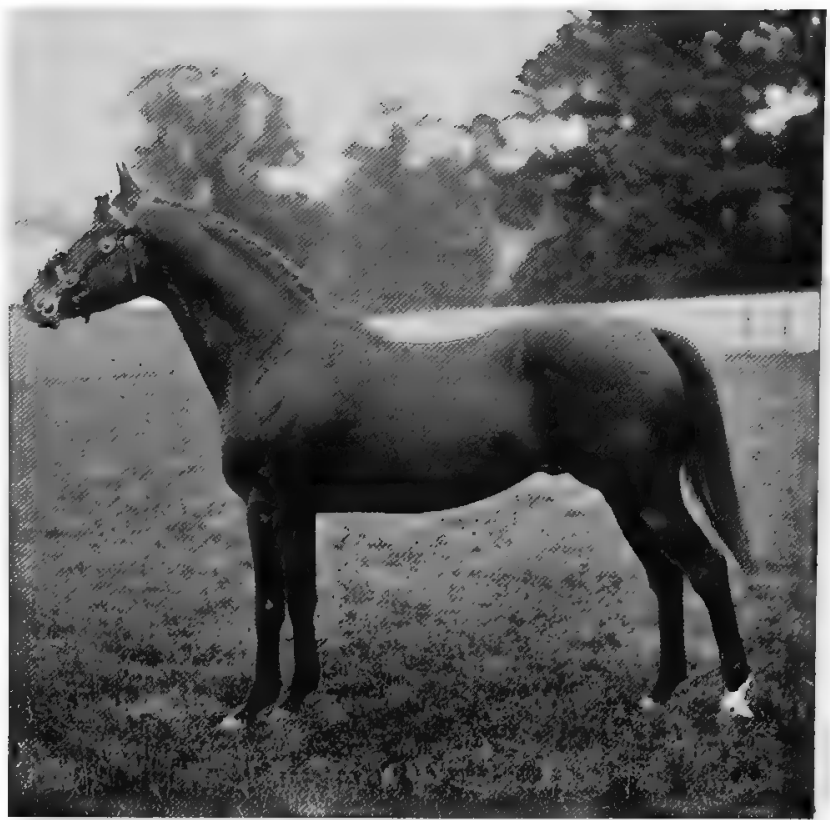

Photo by C. Reid

\section{POLO-PONY}

$V$ arious breeds of ponies are used in this game, but the most esteemed at the present day are the English-bred Newu Forest, Dartmoor, or Exmoor, or Welsh ponies.

The record broad jump for the hunter, we might mention in passing, is variously stated to be from 33 to 37 feet!

\section{The Shetland Pony}

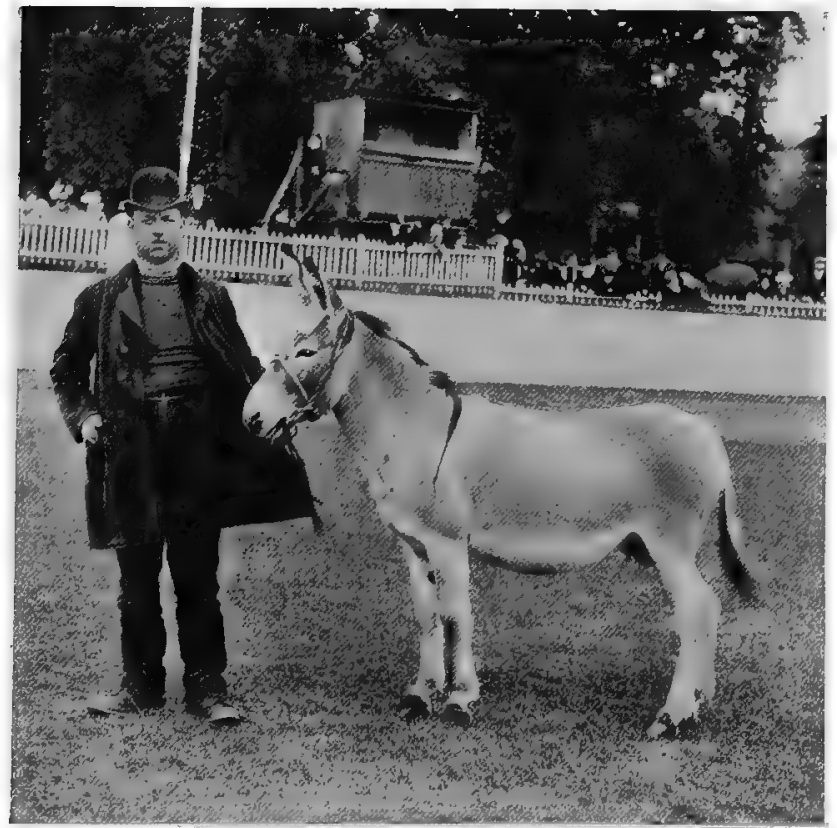

Phose by T. Fall
This is a native of the Shetland Islands, and remarkable for its small size, docility, and hardihood. It is allowed to run nearly wild, and made to forage almost entirely for itself. In the winter it grows a coat of great length, which, soon becoming matted, forms a most effective protection against cold and wet. The DARTMOOR, EXMOOR, and NEW FOREST are likewise small breeds, but lack the symmetry and beauty of the Shetland.

\section{CART-HORSES}

Under this head are included all the large, heavily built draught-horses. These are of European origin, and without intermixture of foreign - Asiatic or African-blood. In England the most important breeds are the BLACK or SHIRE Horse, the Clydesdale, and the SuFFOLK PUNCH. These are wonderful instances of the results of selective breeding 


\section{84 THE LIVING ANIMALS OF THE WORLD}

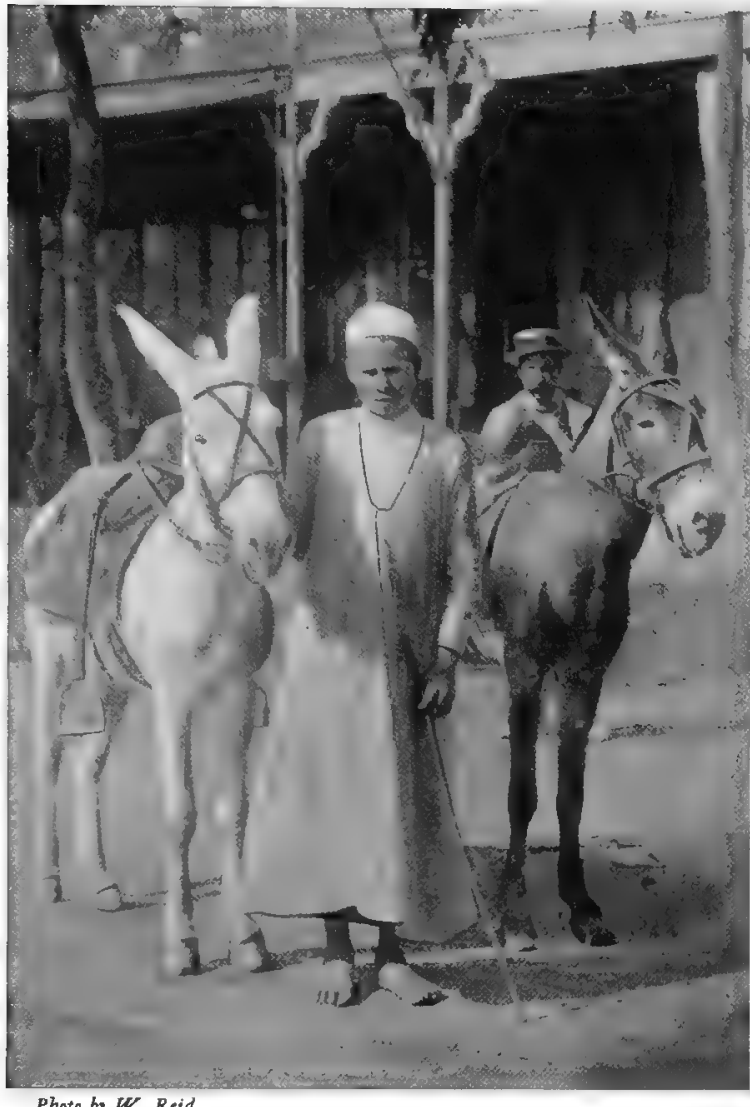

Photo by W. Reid

EGYPTIAN DONKEYS

The ass has long been known to the Egyptians, having been in use by them before the introduction of the horse towards a definite end - large size, accompanied by great physical strength and powers of endurance. To accomplish this, speed has had to be sacrificed.

\section{ASSES AND MULES Asses}

The Domestic Ass, so common to-day in these islands, is of African origin, and has, moreover, departed but little in either form or colour from the wild race. This is probably due to the fact that the ass has not been subjected in this country to that process of rigorous and careful selection that the horse has undergone.

We have no record of its first introduction to England, but it was certainly known in the reign of Ethelred, though it was a rare animal. Later it appears to have died out, and to have been reintroduced in the reign of Elizabeth; but it has never become popular. This is unfortunate; its sterling qualities have never been really appreciated there. Spain, Italy, and Malta have all succeeded in raising some fine breeds. The United States has, however, produced the finest of all in animals standing some I 5 or I 6 hands ( 5 feet or 5 feet 4 inches) high.

\section{MULES}

The term MULE, strictly speaking, should be reserved for the offspring of the male ass and' the mare: the offspring of the opposite cross is called the HinNy. Mules are valued on account of their great powers of endurance and their sure-footedness. The finest and handsomest are bred in Spain, the United States, and North-west India.

It is interesting to note that mules exhibit a strong tendency to revert to the dun-coloured and striped coloration believed to belong to the primitive horses. The spinal and shoulder stripes which sometimes appear in horses, and more frequently in asses, occur yet more frequently in mules. The legs of the mules appear particularly liable to revert to this striped coloration in the United States, it is said nine out of ten being so marked.

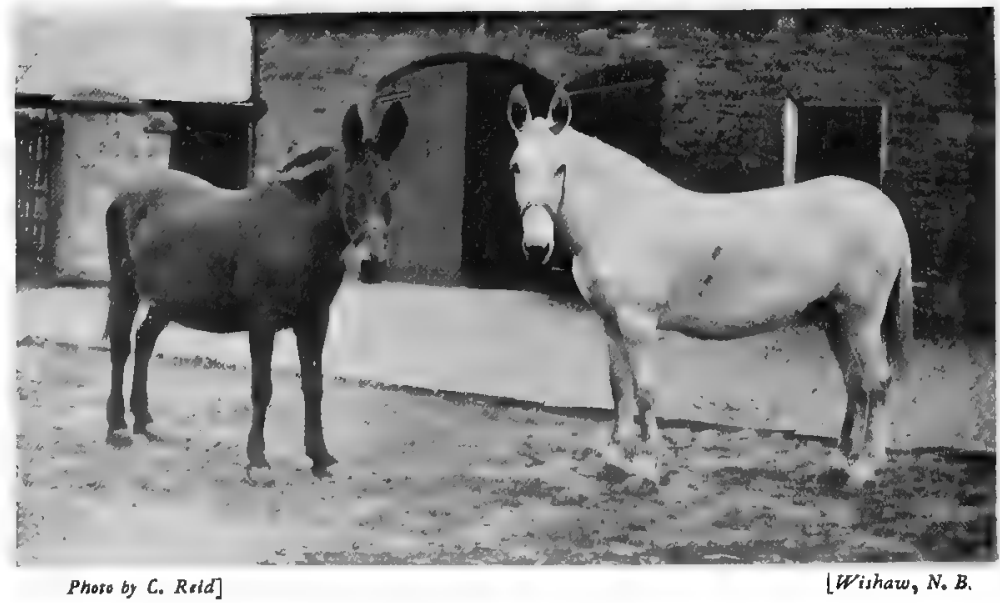

MULES 


\section{CHA P T E R X I I \\ THE HOLLOW HORNED RUMINANTS: OXEN, BISON BUFFALOES, AND MUSK-OX}

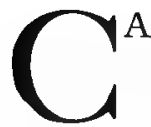

ATTLE, Deer, Camels, Pigs, Horses, Tapirs, Rhinoceroses, and Elephants differ greatly in structure from the orders already described. They are classed as the Ungulates, or Hoofed Mammals. In most of these, such as the Horse, Deer, and Oxen, the toes are contained within a solid hoof; in others, such as the Rhinoceros, they are protected by broad nails. Great differences exist in the feet of the various groups of Ungulates, caused by the degree in which the digits, or "toes," remain in use or not. Except in the Elephant, where there are five, the greatest number of "working" digits found in existing forms is four. In the Horse and its surviving allies the digits are reduced to one; in the Giraffes, to two.

The general process, as it can be learnt from the remains of the horse-like animals of the past, seems to have been as follows. One or more of the toes were developed in length and strength at the expense of the others, until, in the case of the Horse, only one toe remained, which was enclosed in a large and solid hoof, little splints on either side of the cannon-bone being left to hint where the second and fourth toes had once been. In the Oxen and Deer the third and fourth toes developed equally, at the expense of the others, and each gained a case or covering, which makes the two parts of the "cloven hoof" of these groups.

The first group of the order of Ungulates is represented by the Hollow-horned Ruminants. These have horns set on a core of bone, the horns themselves being hollow throughout. They " chew the cud," after receiving the food eaten into the first of four divisions in the stomach, whence it is brought up into the mouth, and then swallowed again for digestion. The Oxen, Sheep, and Goats have no popular name by which they are collectively distinguished, but their characteristics are sufficiently well known. The horns are never shed annually, as is the case with the Deer; and the hoofs are cloven. They have no incisor teeth in the upper jaw, acharacteristicalso shared by the Giraffes, the Prongbuck (or American antelope), and the Deer. The lower jaw has its full complement of incisor teeth.

The Oxen and the allied Bison, Yak, and Buffaloes are the bulkiest and most important to man of all ruminants. Some are found in nearly all inhabited parts of the Old World, and there is one North American species, now practically exterminated as a wild animal.

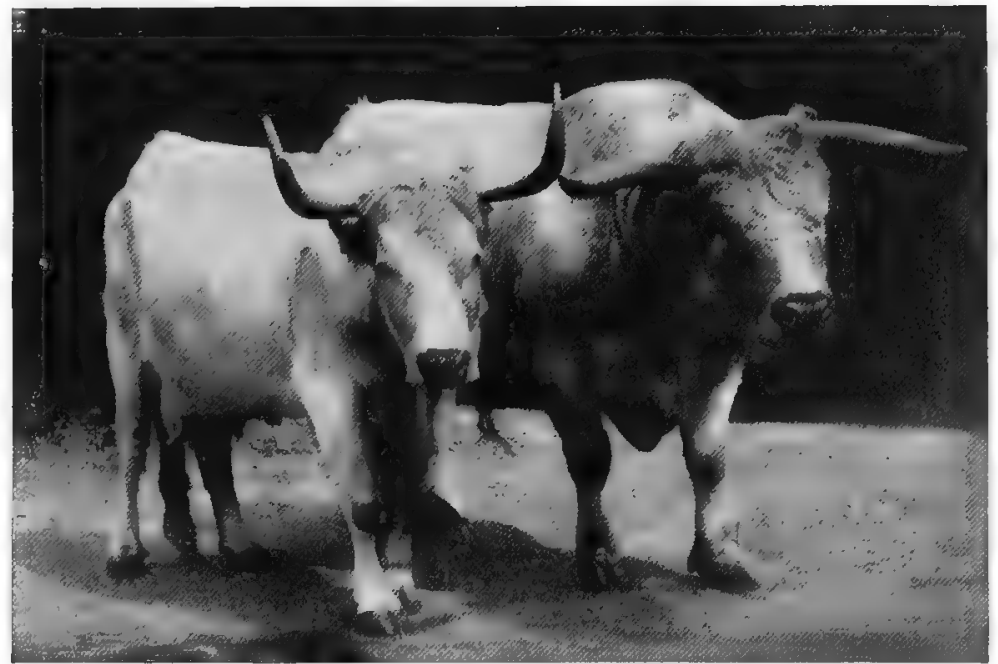

Photo by E. Lindor

ENGLISH PARK-CATTLE

This photograph represents two animals of different types. The bull is pure-bred; the cow is a 185 


\section{86 THE LIVING ANIMALS OF THE WORLD}

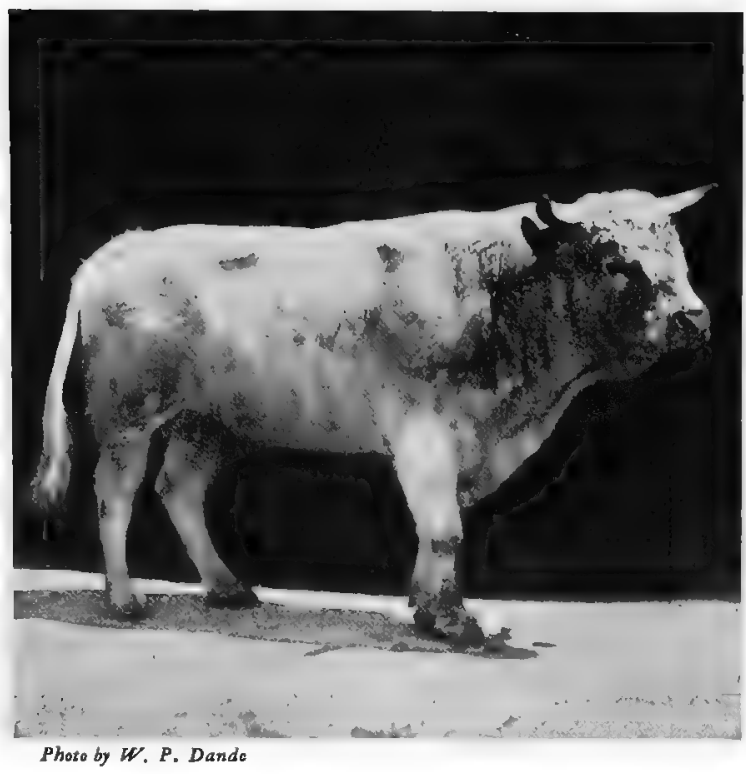

ENGLISH PARK BULL

The similarity in shape to the best-bred modern shorthorns is obvious

\section{BRITISH PARK-CATTLE, AND THE AUROCHS}

THE so-called "WiLd CATTLE" found in the parks of Chillingham and Chartley, as well as in Lord Leigh's park at Lyme, and in that of the Duke of Hamilton at Cadzow Castle, Scotland, are probably not the descendants of an indigenous wild race. It is not without reluctance that the belief in their wild descent has been abandoned. But the evidence seems fairly conclusive as to the antiquity of these white cattle, regarded as a primitive breed, and of the unlikelihood of their being survivors of a truly wild stock. They are almost identical in many points with the best breeds of modern cattle, and probably represent the finest type possessed by the ancient inhabitants of these islands. But they are far smaller than the original Wild OX, or Aurochs, the ancestor of our domestic breeds. The skulls of these large wild oxen, which still survived in the Black Forest in Cæsar's time, have been dug up in many parts of England, especially in the Thames Valley, and may be seen at the Natural History Museum. The remains of the extinct wild ox, the Bos urus of the Romans, show that, if not so large as an elephant, as Casar heard, its size was gigantic, reckoned by any modern cattle standard whatever. It probably stood 6 feet high at the shoulder, and there is every reason to believe that it was the progenitor of the modern race of domestic cattle in Europe. It seems certain that the Chartley Park herd did once run wild in Needwood Forest; but so do the Italian buffaloes in the Maremma, and the Spanish bulls on the plains of Andalusia. Those at Chartley have been kept in the park, which is very wild and remote, so long that they have gradually lost many of the attributes of domestication. This is even more marked in the case of Lord Tankervill's white cattle at Chillingham. An observant visitor to Chillingham lately noted that the bulls fight for the possession of the cows, and that one is occasionally killed in these combats. The cows still "stampede" with their calves when alarmed, and hide them for a week or ten days after they are born. The horns of the Chillingham cattle turn up; those of the bulls of the Chartley herd are straight or slightly inclined downwards. Crossbreds between the Chartley cattle and some other herds of reputed ancient descent may generally be seen at the London Zoological Gardens. They remain remarkably true to type.

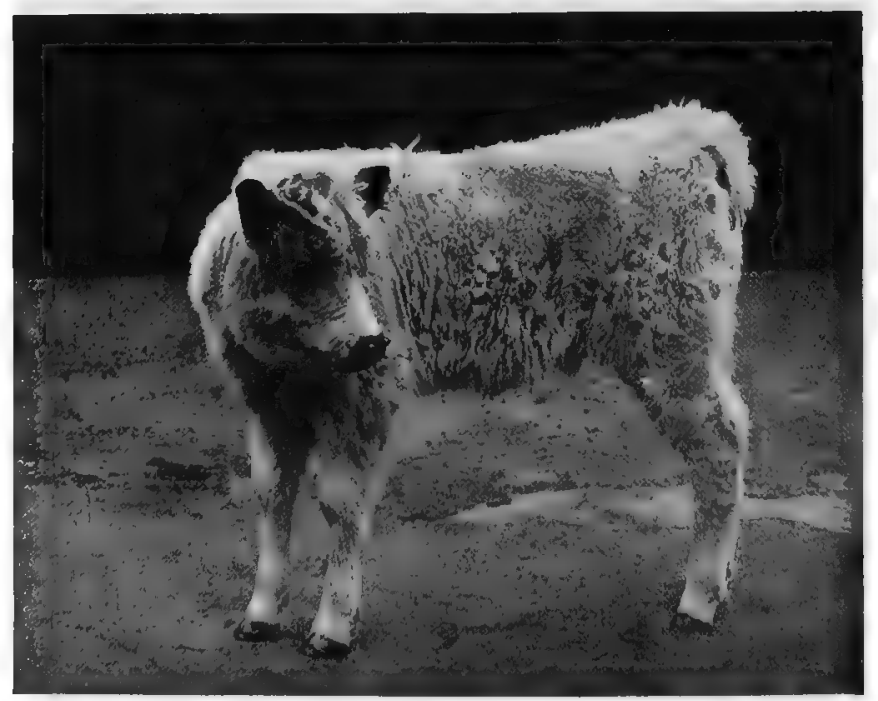

Phoso by $W, P$, Danco

CALF OF ENGLISH PARK-CATTLE

Though the stock is very old and inbred, the white park-cattle are still fairly prolific 
Formerly there were several other herds of ancient white cattle. One was at Gisburne, in Yorkshire; another at Chatelherault Park, in Lanarkshire; and records of herds at Bishop Auckland in Durham, Barnard Castle, Blair Athol,Burton Constable, Naworth Castle, and other ancient peaks are preserved. Probably all were of a breed highly prized in ancient days, which was allowed the run of the forests adjacent to the homes of their owners; then, as the forests were cleared, they were gradually taken up and enclosed in parks. Another theory is, that they were the

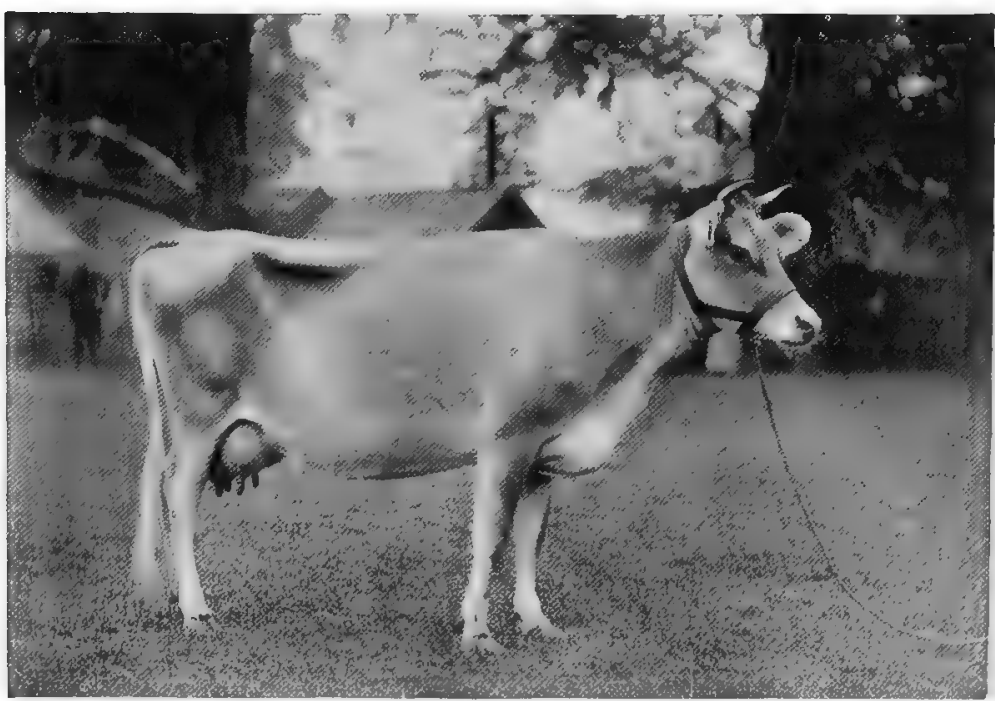

Photo by F. T. Newman

JERSEY COW

Though small in size, the $\mathcal{F}$ ersey cows produce more butter than any English breed white cattle of North-western Italy, imported by the first settlements of Italian monks after the conversion of the Saxons.

\section{SOME DOMESTICATED CATTLE}

THE various species of European domestic cattle have in most cases been brought to $\mathbf{a}$ degree of excellence even higher than that which might be expected from the long period of time in which their improvement lias been an object of solicitude to man. Of the foreign races, the dark red cattle of the Spanish Peninsula - animals which have been exported to the Canary Islands and Madeira with great success - are justly famous. The white oxen of Northeast Italy have been famous since the days of the Romans. The tall long-horned cattle of Hungary are excellent alike as beasts of draught and for beef. The black-and-white Dutch cows are, and have been, the mainstay of the dairy industry of Holland, and later of Denmark; while the small Brittany cows are perhaps the best butter-producers on the continent of Europe. But England and the Channel Islands may justly claim to rear the finest cattle of the

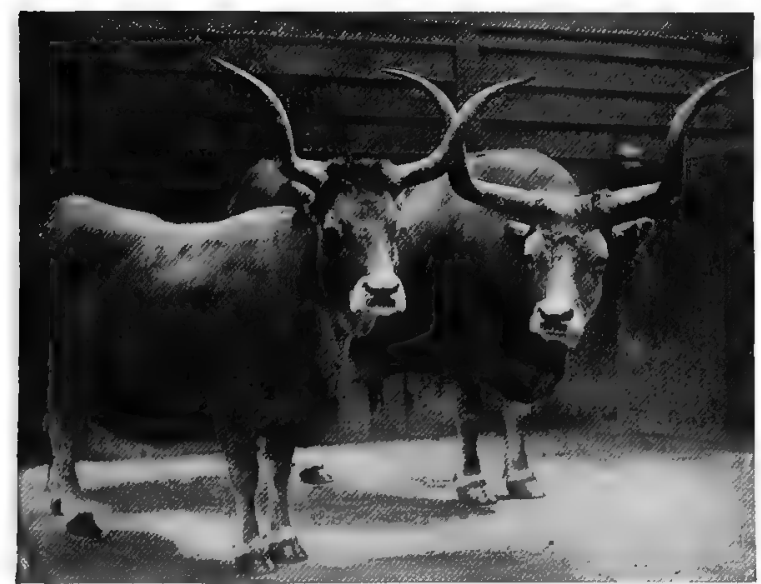

Photo by W. P. Dando

SPANISH CAT'TLE

These belong to the long-horned race of Southern and Easiern Europe. In the bulls the horns are shorter, and often turn downwards temperate parts of the world. The diminutive Jersey cows, now reared in all parts of the kingdom, surpass all the animals of Europe or America in the richness of their milk, while stock from the pedigree herds of various English breeds is eagerly sought by foreign and continental buyers on both sides of the Atlantic, and in New Zealand and Australia. These foreign strains need constant replenishing from the English herds, and the result is a golden harvest to the breeders in these islands.

The SHORTHORN was the first breed to be brought to perfection. Two main stocks one for producing beef, the other for the dairy - are recognised; they are the "allround breed" most in favour, and it is said that the improvement in this race alone has 
raised the value of average Irish store cattle $\$ 10$ per head during the last twenty years. The shorthorns are level-backed, large animals, maturing very quickly. The commonest colours are roan, white, red, and red-and-white. HEREFORD CATTLE are red, with white faces and long, upturned horns; they fatten quickly on good grass, and are in most demand for summer beef. Highland CATTLE have long horns, rough, shaggy coats, and bodies of moderate size and great symmetry; they are grazed on the mountains of the West Highlands mainly, and fattened in the south. The beef is of the finest quality. Sussex CATTLE are an "all red" variety, large, and formerly much used for draught and farm work. The DEvons are another red variety, very like the Sussex, yielding excellent and rich milk, and, when fattened, being little inferior to any breed as beef. The long-horned black WELSH CATTLE grow to a great size, as do the polled ANGus breed of Scotland. The polled or hornless cattle include the red Suffolks, a most valuable breed, hardy, and wonderful producers of milk. The cows often give milk every day of the year. The LONGHORN breed is almost disappearing, as the

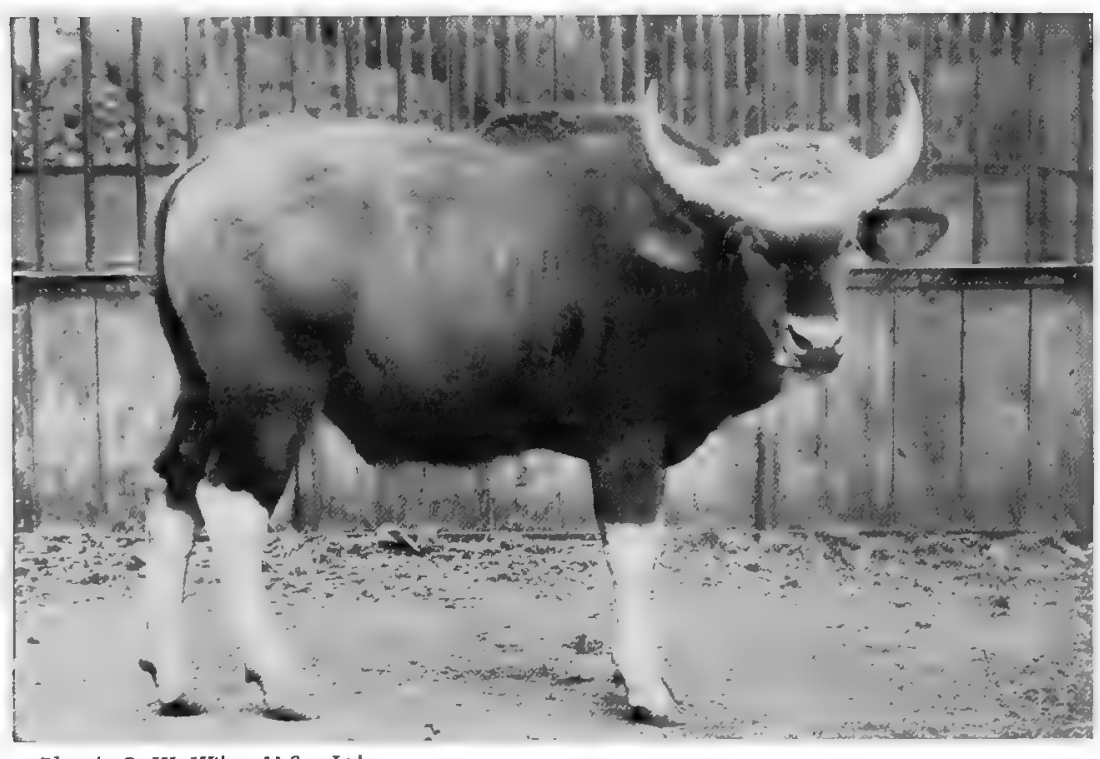

Photo by G. W. Whilson os Co, Lid.

YOUNG GAUR

The largest and handsomest of the wild oxen horns are a disadvantage both in the fields and when the animals are carried on board ship or in the train. The Humped Cattle of India and East A frica belong to a race different from European cattle, of which the parent stock is not known. They have a hump upon the withers, drooping ears (a sign of ancient domestication), and a very large dewlap. The coat is always exquisitely fine. They are of all sizes, from the tall Brahminee bull to dwarf breeds not larger than a Newfoundland dog. The commonest colours are cream, grey, mouse-colour, and white. They do not low, but grunt, and are by no means so fond of shade and water as European cattle.

\section{WILD OXEN}

THIS group consists of the GAUR of India; the GAYAL of Assam, which is possibly a domesticated form of the gaur, but rather smaller in size, with skull and horns different in character; and the BANTING, a lighter and more slender wild ox, of which different varieties are found in Burma, in Java (where it is kept in a half-domesticated condition), and in Manipur.

\section{THE GAUR}

The GAUR, the so-called INDIAN BISON, is probably the largest of all the wild bovine animals. It is found at the foot of the North-eastern Himalaya, in the Central Provinces of India, the forests of Madras and Mysore, and in parts of Burma and the Malay Peninsula, but not in Ceylon. Its range eastward is not accurately known. In habits the gaur is mainly a forest animal, retiring always at daybreak into the depths of the jungle. It sometimes attains a height of over 6 feet at the shoulder, and a length of 9 feet 6 inches 
from the nose to the tail. The colour of the full-grown gaur is dark brown, turning to black; the legs from above the knees and hocks to the hoofs are white, the hair being short and fine. Its horns are upturned, and tipped with black, with white hair covering the junction on the top of the skull. The cows are much smaller than the bulls, standing about 5 feet high at the shoulder. This species feeds both on grass and on the young shoots of trees and of bamboos. The calves are dropped in August and September. The pure-bred animal does not appear capable of domestication.

Hunting gaur by tracking in the jungle has long been a favourite sport of AngloIndians. General Douglas Hamilton says: "I have killed bulls measuring 6 feet at the shoulder, and the average height of the male is from 5 feet 8 inches to 5 feet Io inches. An old bull gaur is a magnificent

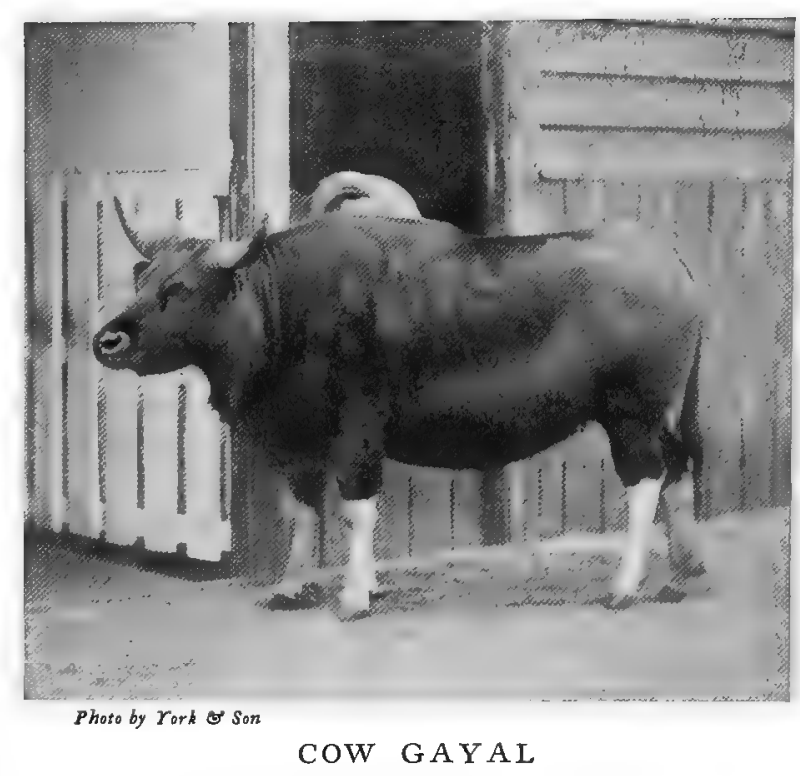

This animal is not at all dissimilar to the gaur. Its chief points of difference are in the horns and in the colour of its skin

animal. The normal colour is a brownish black, sometimes in very old specimens almost quite black. The white stockings reach from the hoof to above the knee, and are very conspicuous. When on the Anamalies, I had a grand fight with a big bull. I was out early, and came on the spoor of bison, and soon saw two, one a very large bull. To my disgust he lay down, and was completely covered by creepers and bushes. After a bit I attempted to move to get a better view; but there to my left was a cow bison staring at me. She at once gave the alarm, and I waited for the large bull to rise. This he did so quickly, and disappeared so suddenly, that I only got a snapshot. As I stopped to load, I saw a young calf squatting at the foot of a tree like a hare, intently watching me. I put the rifle down, crept up behind the tree, and suddenly threw myself on the little calf, and managed to get hold of its hind legs, but it got from under me. I managed, however, to tie its fore legs securely by means of some slender stems from the creepers. All this time it continued to bellow and to make a great row, and I fully expected to see the mother come charging down. I went back to the bungalow, and got some men to bring my little captive home. After breakfast I started again, and got on the track of the bison. . . . I saw some branches move, and on looking carefully perceived a large bull bison; but he was among the thick bushes, and I could not see his outline. I guessed as nearly as possible the position of the shoulder, and fired the big rifle at him. He gave a bound forward, and then stopped long enough for me to give him a shot with the other barrel. . . The next moment I saw the bull standing on the high ground above us. I fired again, and hit him well behind the shoulder. He dashed off, but only went fifty yards, and then stopped. I walked up, thinking to finish him, when he made a fearful rush at me. My man put the double rifle into my hands and then bolted, and I thought it prudent to retire and await my opportunity. But he only moved a few paces forward, and then stopped. Then began a regular siege of his position." The result of the siege was that the bison received four more bullets, charged and routed the hunter twice, and then walked off. It was shot twice more, charged again, and was finally killed by General Hamilton with his hunting-knife tied to a bamboo spear-pole.

Considering the size and tenacity of life of the gaur, it is rather wonderful that more accidents do not occur in the pursuit of this animal; but as it lives mainly in thick jungle, where large trees grow, the sportsman has more chance of getting out of sight of a wounded animal than when attacked by the Indian buffalo, which generally haunts jungles of high grass. 


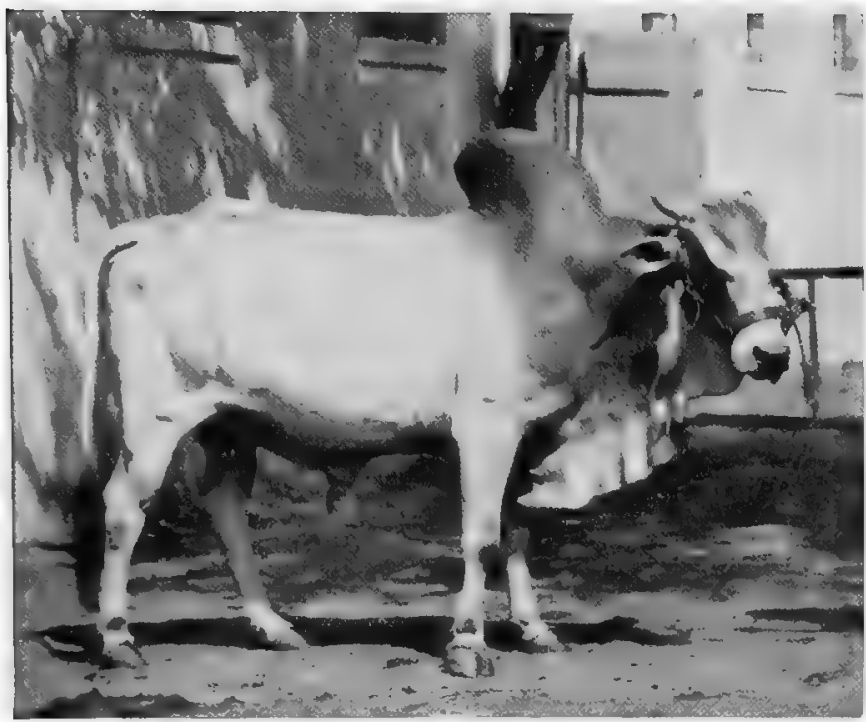

INDIAN HUMPED BULL

The hump and dewlap mark the Oriental cattle. The ears are often more drooping than in this specimen

\section{THE GAYAL}

The doubt whether this animal is found in a wild state has recently been considerably increased. It is well known in a semi-domesticated condition, in which it is kept by the tribes in and around the Assam Valley, where the wild gaur is also found. 'These herds roam during the day freely in the jungle, and return to be fed at the villages. It has been stated that wild gayal are enticed to join the tame herds by feeding them with balls of meal and salt; but these "wild" specimens may be only those which have belonged to or have descended from the domesticated herd. Gayal have been kept in England not only in the Zoological Gardens but in some parks, and crossed with English cattle.

The offspring furnished excellent beef, but were rather wild and intractable. The horns of the gayal are thicker and flatter than those of the gaur, and placed lower on the skull and farther apart. The domesticated gayal stands lower than the gaur, but is a very massive animal.

\section{THE BANTING}

The common wild ox of the Malay countries of Borneo, Java, Eastern Burma, and northwards, in Manipur resembles the European oxen rather more than does the gaur. In size the bulls sometimes reach 5 feet $9 \frac{1}{2}$ inches. The old bulls are black, the younger bulls chocolate red, and the cows a bright reddish brown. The rump is marked with a large white patch, and all have white stockings from above the knees and hocks down to the hoofs. The tail is considerably longer than in the gaur, coming well below the hocks. As might be expected from its distribution, the size of this animal and the shape of the horns vary considerably in the different districts which it inhabits. In Borneo the horns often curve forwards; in Java they spread outwards. In the latter island large herds of this species are kept in a state of domestication. When wild, banting live in small herds, and in Burma feed from early morning until ten o'clock, when they retire into the jungle for shelter. The Manipur race is smaller than that of Burma (of which the males are not black), and the bulls have not the white rump.

THE YAK

THE YAK is naturally an inhabitant of the very high plateaux and mountains of Tibet, where the climate is cold and the air excessively dry. Lower down on the Indian side of the Himalaya a smaller race is found domesticated, which is the only one able to stand the climate of India, or of Europe, where it is now kept in some parks as a curiosity. The tamed yaks are usually much smaller than the wild; these sometimes reach a weight of between I, 100 and 1,200 lbs. In form they are long and low, very massive, and with hair almost entirely black; this falls off along the sides into a long sweeping fringe. The tail is thickly tasselled with fine hair, and is employed by Indian princes for fly-flaps. The wild yak has large, massive black horns, curved upwards and forwards in the male. In Ladak and Chinese Tibet the yaks inhabit a desolate and barren country, in which their main food is a dry, 
coarse grass, on which they nevertheless contrive to keep themselves in condition, feeding in the mornings and evenings, and lying down by day to rest among the rocks.

\section{THE BISON}

THE BIsON form a marked group, differing from others of the Ox Tribe. They possess fourteen pairs of ribs, while the oxen have only thirteen (the yak has fourteen); and have very heavy, massive heads, broader and more convex foreheads than the oxen, longer spinal processes on the vertebrae of the front part of the back, and larger muscles to hold the ponderous head, causing a hump, which in the American bison is very marked. There are two living species of bison, one of which is found in Europe, the other in North America.

\section{The European Bison}

This is the most interesting survival of the primitive fauna of the Old World. It is still found wild, though protected, in a large forest in Lithuania, the property of the Czar of Russia, called the Forest of Bielowitza. A few are also left of the purely wild stock in the Caucasus. Those in Lithuania have been protected for several centuries, and the herd is numbered from time to time. In I857 there were I,898 of these bison left; in I 882 there were only 600 ; in 1889 the herd had sunk to 380 , but in 1892 it had risen to $49 \mathrm{I}$. The presence of the bison in the Caucasus had been almost forgotten till Mr. Littledale and Prince Demidoff gave accounts of hunting it there quite recently. The ZUBR, as it is called, only survives in some very inaccessible parts of the mountains, preserved by the Grand Duke Sergius Michaelovitch, in the Kouban district. There it exists as a really wild aninal. The dimensions of one recently shot were Io feet from the muzzle to the end of the last vertebra of the tail. The Grand Duke has to obtain special permission from the Czar to shoot one whenever he goes to the Caucasus.

This bison seems to have been an inhabitant of most of the forests of Europe and Northern Asia; its remains show that it existed in Britain, and it was plentiful in the Black Forest in the time of Cæsar. It is the largest of all European quadrupeds, measuring as much as 10 feet I inch from the nose to the root of the tail, and standing nearly 6 feet high at the shoulder. Prince Demidoff states his belief that it is found on the southern slopes of the Caucasus Range between the hills and the Black Sea. The weight of this bison reaches 1,700 lbs. It is now rare to see more than five or six together. Though the animal is so massive, its horns are rather small and slender, and curve upwards. The mane-which, like the rest of the coat, is of a uniform rich brown-is thick and curly, but not developed like that of the American bison.

\section{The Buffaloes.}

The Bufraloes are so far distinct from other species of wild cattle that it is said they will not interbreed with them; yet one species, the InDIAN BufFALO, has been domesticated for a long, though

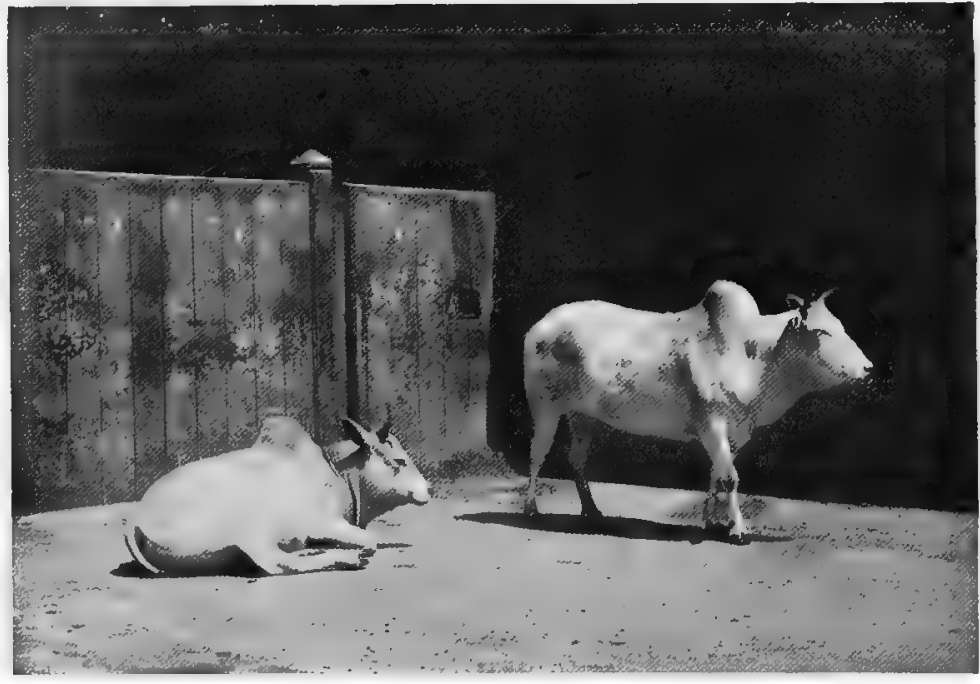

INDIAN HUMPED CATTLE

These are often called Zebu in Europe, but the origin of the name is unknown 


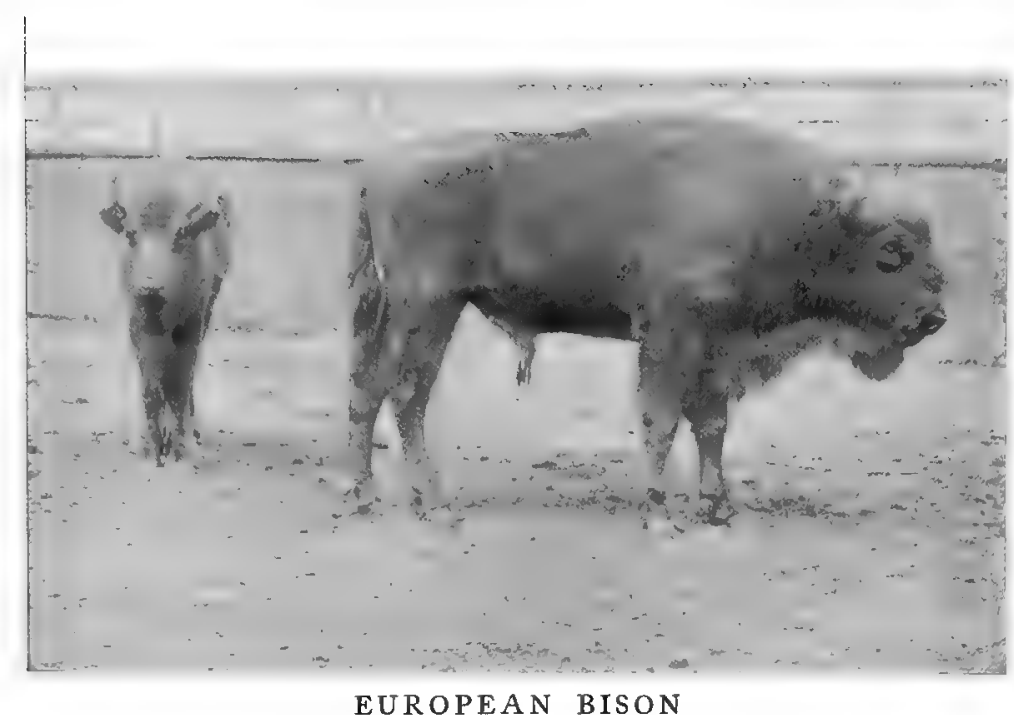

These wild animals of the Caucasus are very much scarcer than formcrly, and are in danger of becoming extinct

unknown period, and is among the most valuable of tame beasts of draught, as well as for dairy purposes. The various buffaloes usually have little hair, especially when old, and have flatter shoulders than the gaur, gayal, or bison. The pairs of ribs number thirteen.

\section{The African Buffalo}

Great differences in size and colour exist in the AFRICAN BUfFaloes. Whether they are separate species or not may be doubtful; but the small yellow CONGO BUFFALO, with upturned short horns, is a vastly different creature from the large black Cape Buffalo. There is also an Abyssinian or brown race of African buffalo, and another in Senegambia smaller than the former, and a reputed grey race near Lake Tchad. The Cape buffalo is a heavy, thickset animal, all black in colour, with large massive horns covering the skull, and nearly meeting in the middle line of the forehead. In height it varies from 4 feet Io inches to 5 feet at the shoulder. This species ranges from South Africa to the Congo on the west, and to the region of the Equator on the east of the continent. Firearms, and lately rinderpest, have greatly reduced the number of these creatures. They live and feed in herds, and, like the Indian species, are fond of the neighbourhood of water, in which they bathe, but are not so dependent on bathing and wallowing as the former.

Fully as formidable as the Indian buffalo, and much like it in habits, the African species is quite distinct. It has different horns, broad at the base and curled and tapering at the ends. Among the extreme measurements of the Indian buffalo's horns recorded is one of I 2 feet 2 inches from tip to tip along the curve. Those of the African buffalo are seldom more than 6 feet, measured in the same way. By far the greatest number of hunting accidents in Africa are caused by the buffalo. Sir Samuel Baker shot a buffalo bull one evening near the White Nile. His men actually danced upon the body, when the animal rose to its feet, and sent them flying into the river like so many frogs. It then disappeared in the thick vegetation. On the following day, supposing that it must have died during the night, thirty or forty men, armed with double-barrelled guns, went to look for it. The result was thus recorded by Sir Samuel Baker: "They had not been ashore for many minutes when I first heard a shot and then a regular volley. My people returned with the head of the buffalo and a large quantity of meat, but they aiso carried the body of my best man, who, when leading the way through the high reeds, following the traces of blood, actually stumbled upon the buffalo lying in the swamp, and the light guns failed to stop its charge. The crooked horn had caught him behind the ear, and, penctrating completely through the neck, had torn out the throat as though it had been cut. The savage beast had then knelt upon the body, and stamped it into the muddy ground, until it fell beneath the fire of thirty men."

The head and body of a male Cape buffalo are 9 feet long. It is stated that the parasite conveyed by the tsetse fly remains in the blood of the buffalo (which is not affected by it), and that this forms a reserve whence the fly, after sucking the blood of the buffalo, poisons other animals. 


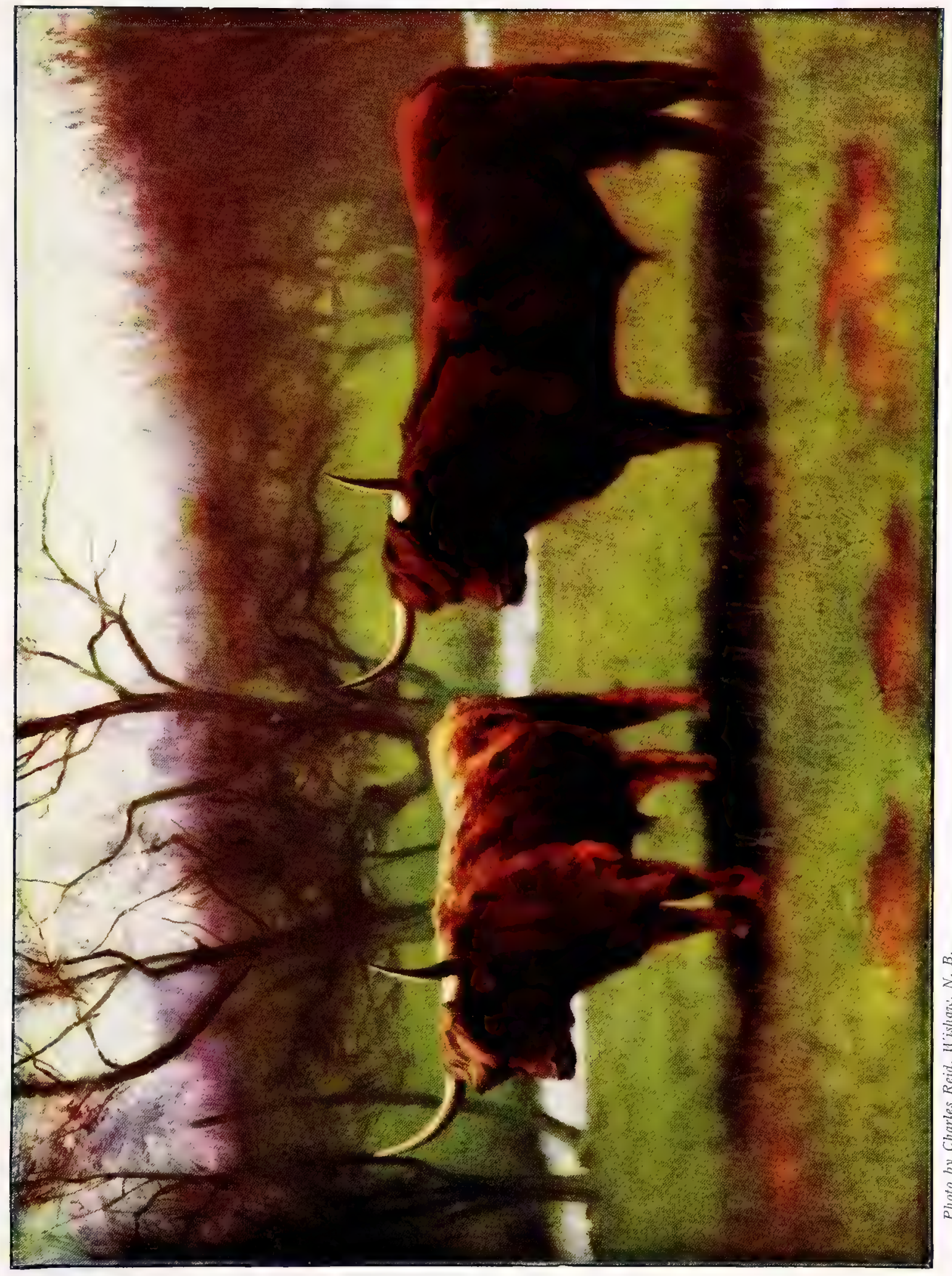

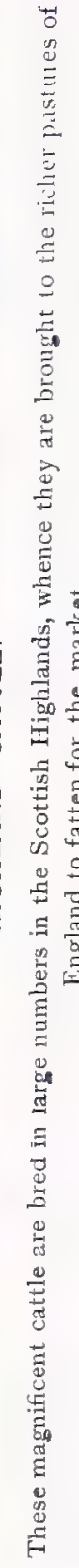





\section{The Congo Buffalo}

This is a very small race, the height at the shoulder being about 3 feet 6 inches. The shape of the horns varies, but they are wrinkled at the bases and flattened, and turn upwards, ending in thin, sharp tips. The hair is bright reddish yellow. It is entirely a West African species. Sir Samuel Baker records an instance in which his brother was nearly killed by a small West African buffalo, probably one of the species in question. It is said to be less gregarious than the Cape buffalo, and usually found in pairs.

\section{THE INDIAN OR WATER-BUFFALO}

Very great interest attaches to this animal, if only from the fact that it is evidently a species domesticated directly from the wild stock. It therefore deserves consideration both as a wild and as a domesticated animal. It is found wild in the swampy jungles at the foot of the Himalaya, in the Ganges Delta, and in the jungles of the Central Provinces; also, it is believed, in the jungles of West Assam. Like the African species, it is an animal of great size and strength, with short brown hair, white fetlocks, and immense long, narrow, flattened horns. It is almost aquatic by preference, passing many hours of each day wallowing in the water, or standing in any deep pool with only the tips of its nostrils and its horns out of the water. By general consent it is the most dangerous of Indian animals after the tiger. A buffalo bull when wounded will hunt for its enemy by scent as persistently as a dog hunting for a rabbit. A writer in Country Life lately gave an account of a duel between himself, armed with a small and light rifle, and a buffalo bull, in which the latter hunted him for more than an hour, each time being driven off by a shot from the light rifle, and each time returning to the search, until it was killed. Sir Samuel Baker, when he first went to Ceylon, found the buffaloes practically in possession of the meadows round a lake in the neighbourhood of his quarters, and waged a war of extermination against the bulls, which were very dangerous.

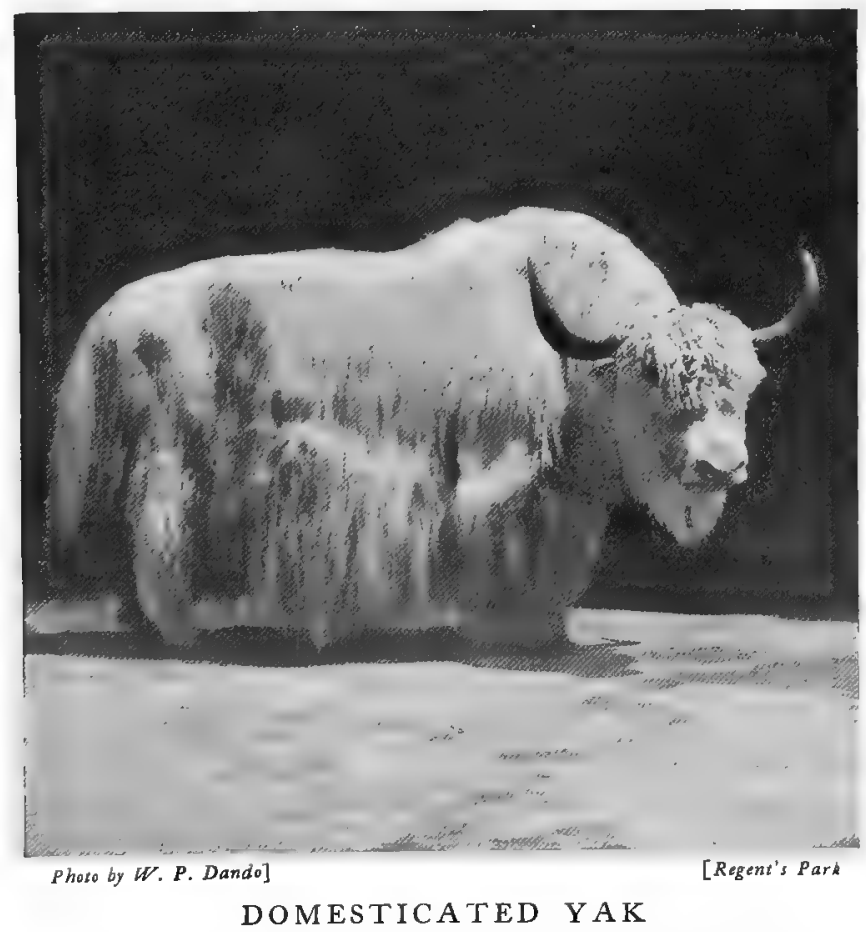

The wild bovine animal of the Central Asian plateau, tamed and domesticated 


\section{94 THE LIVING ANIMALS OF THE WORLD}

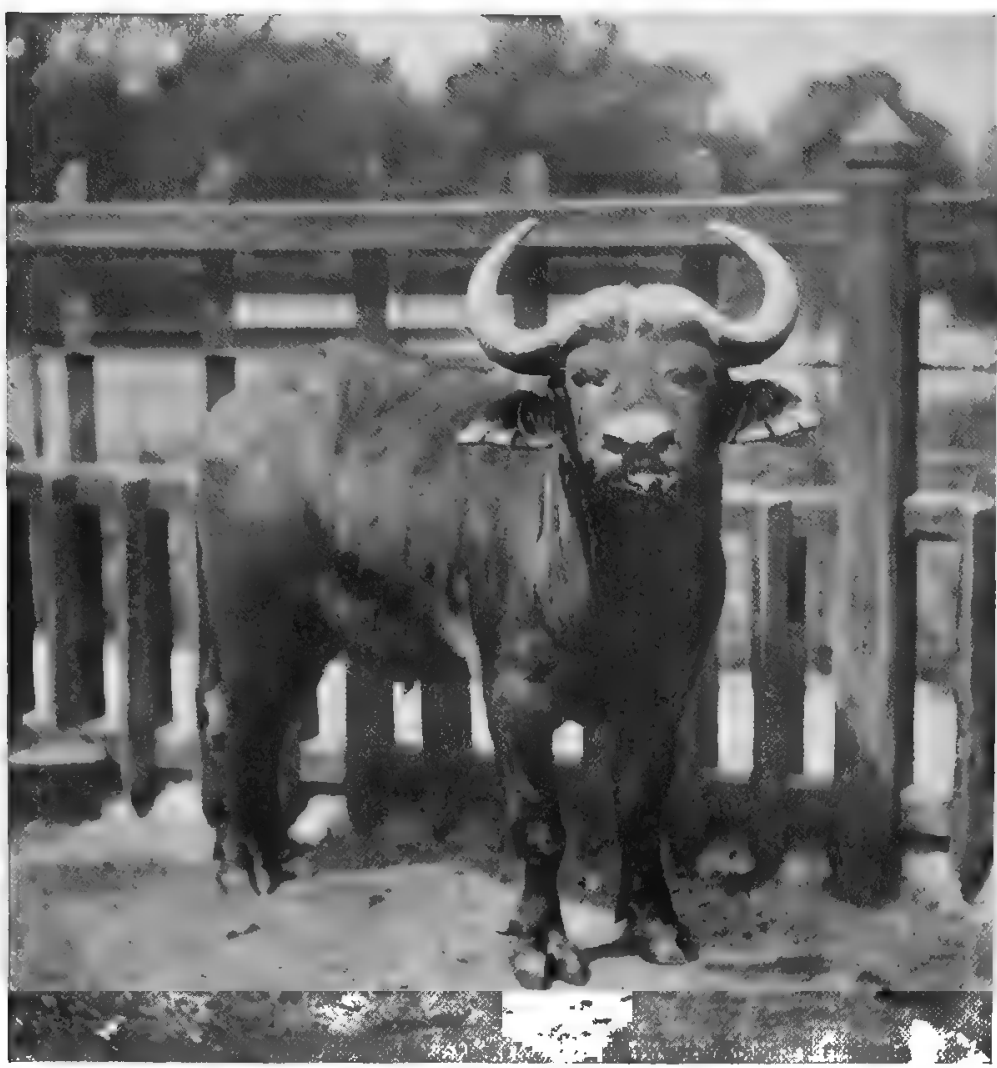

CAPE BUFFALO

Notice the striking difference depicted on this page betrveen the two species of buffalo-the Indian and the Cape

with its horns, but will kneel upon the lifeless form, and stamp it with its hoofs till the mutilated remains are beyond recognition."

The true Indian buffalo is usually shot from the back of an elephant. Hunting it on foot is dangerous in the extreme, for the buffalo can crash through obstacles which would prevent any man from making his way through them when escaping. When domesticated, the Indian buffalo loses most traces of its savageness; it is habitually managed by the children, who take the herds out to graze in the jungle, and drive them back, often riding on one of the bulls, at night. They dislike Europeans, and often show this by attacking them; but otherwise they are quite tame, and are docile when in harness or carrying burdens. The buffalo's milk is very rich, and makes a much larger per-
The buffaloes of Ceylon are the same as those of India, but the horns are inferior in size. "The charge of a buffalo is a serious matter," says Sir Samuel Baker. "Manyanimals charge when infuriated, but they can generally be turned aside by the stunning blow of a rifleshot, even if they be not mortally wounded. But a buffalo is a devil incarnate when it has once decided on the offensive; nothing will turn it. It must be actually stopped by death, sudden and instantaneous, as nothing else will stop it. If not killed, it will assuredly destroy its adversary. Thereisnocreature in existence so determined to stamp the life out of its opponents, and the intensity of its fury is unsurpassed when a wounded bull rushes forward upon its last desperate charge. Should it succeed in overthrowing its antagonist, it will not only gore the body
amp it with its hoofs till the

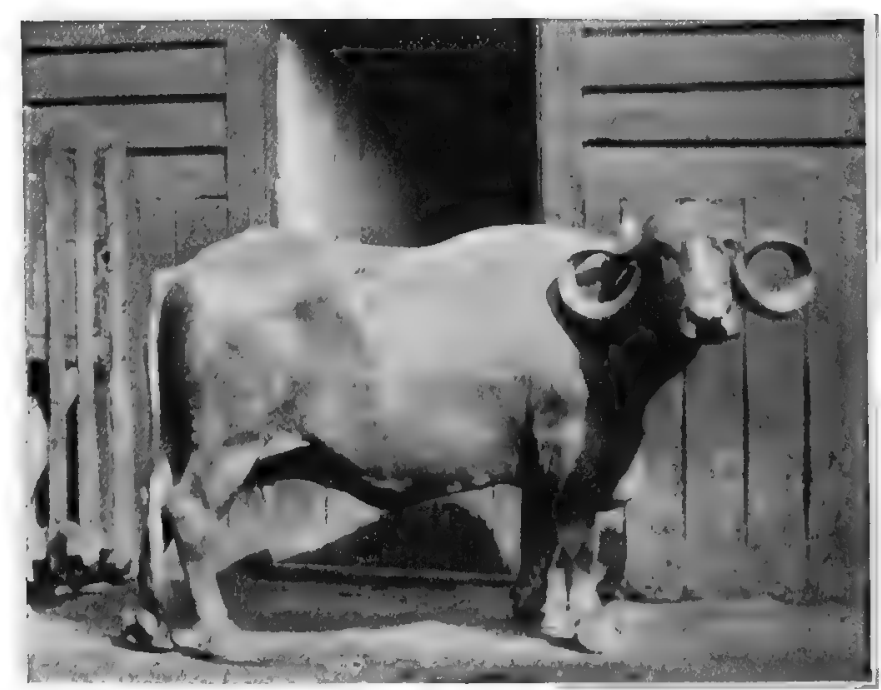

This animal is found as a wild and domesticated species in India. It is raluable as a beast of draught and for the dairy
DOMESTICATED INDIAN BUFFALO 
centage of butter than ordinary cow's milk. So useful is this mud-and water-loving animal in all swampy districts, that wherever rice is cultivated it is almost indispensable. The result is that the Indian buffalo has been transported, probably in comparatively modern times, to many distant quarters of the globe. When this was done is not known; but it is probable, for instance, that it was not known in Egypt in the days of the Pharaohs, for its form never appears in the paintings and sculptures. Now it is seen very far up the Nile, and plays an important part in Egyptian agriculture; it is also the general beast of burden and for the dairy in the Pontine Marshes of Italy. In Spain it was probably introduced by the Arabs, and is used to cultivate the marshy plains near the mouths of the rivers of Andalusia; it is also in use in the marshes of Hungary, in the Crimea, and across Western Asia to Afghanistan. We have thus the curious fact that a wild animal once confined to the jungles of the Indian Peninsula is now domesticated on two other continents. It has not been

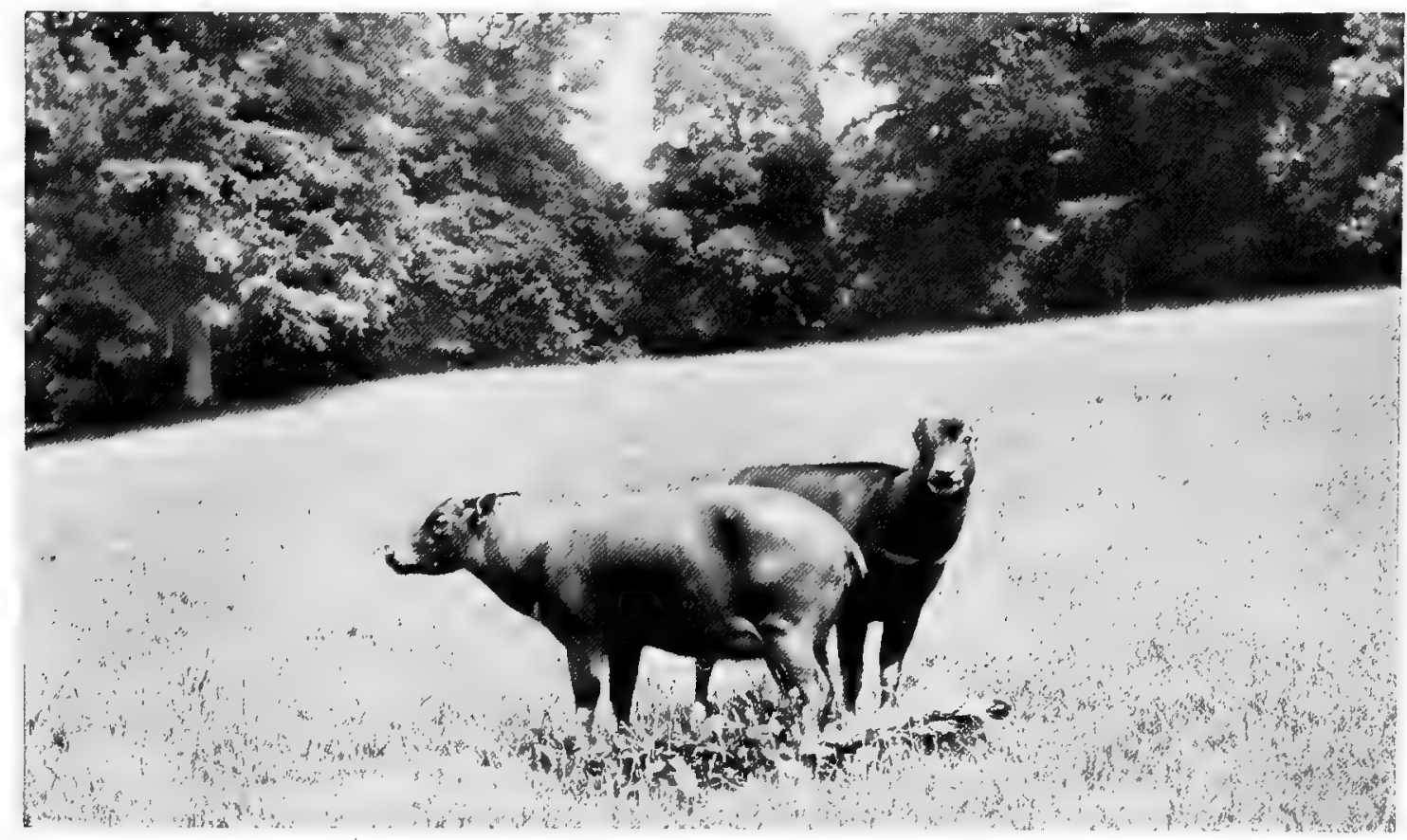

A PAIR OF ANOAS

The aroa is the smallest and most antelope-like member of the Ox Tribe

introduced into America yet, though it would be useful in the Mississippi swamps; but the Chinese have taken it to the Far East, and established it as their favourite beast of burden.

\section{The TAmaraU AND ANOA}

In the island of Mindoro, in the Philippines, a small black buffalo, with upright, slightly incurved horns, is found in the dense forests. The height at the shoulder is about 3 feet 6 inches; a few irregular marks of white are found on the fore legs, face, and occasionally the throat. It is called the TAMARAu by the natives, most of whom fear to attack it. Its habits are said to be much the same as those of the other buffaloes; but it is reputed to fight with the Indian buffaloes which have escaped and become semi-wild in the forests.

In Celebes a still smaller wild forest-buffalo is found, called the ANOA. It is only 3 feet 3 inches high at the shoulder, and has upright, almost straight horns. The general colour is brownish, tinged with yellow, that of the adults being very dark brown or black. Scarcely anything is known of its habits. 


\section{H A P T E R X I V}

\section{THE SHEEP AND GOATS}

\section{THE SHEEP}

$\longrightarrow$

HE sheep are represented at the present time by several wild species, one of which is found in Northern India east of the Indus, in the Punjab, and in Sind; one in North America; and another in North Africa. The rest inhabit the high ground of Europe and Asia as far south as the Himalaya. These mountains, with the adjacent plateaux of the Pamirs and the great ranges of Central Asia, form the main home of the group. Wild sheep are of various types, some so much like the goats that it is difficult to draw a hard-and-fast line between them; while others, especially the Curly-horned Argalis, Bighorns, Oorial, and Kamchatka Wild Sheep, are unmistakably ovine in type. The wild original of the domesticated breeds of sheep is unknown; but the extreme differences between various breeds of tame sheep - as, for instance, between the smooth-coated, drooping-eared breed of Nubia and the curly-horned, woolly sheep of Dorsetshire - must not be allowed to divert the attention from the considerable likeness of habit which still remains between other breeds and the wild species. Domesticated sheep which live on hills and mountains are still inclined to seek the highest ground at night. The rams fight as the wild rams do, and many of them display activity and powers of climbing and of finding a living on barren ground scarcely less remarkable than in the wild races. The apparent absence of wool in the latter does not indicate so great a difference as might be thought. The domesticated sheep have been bred by artificial selection for unnumbered ages in order to produce wool. It is said that in some of the wild breeds there is an under-fur which will "felt" like wool. Most of the species are shorttailed animals, but this is not the case with the Barbary wild sheep.

Wild sheep are mainly mountain-living animals or frequenters of high ground. They generally, although not always, frequent less rugged country than that affected by the wild goats, and some are found at quite low levels. The altitude at which other wild sheep are found is, however, very great; on the Pamirs it reaches 20,000 feet. Here the country is quite open.

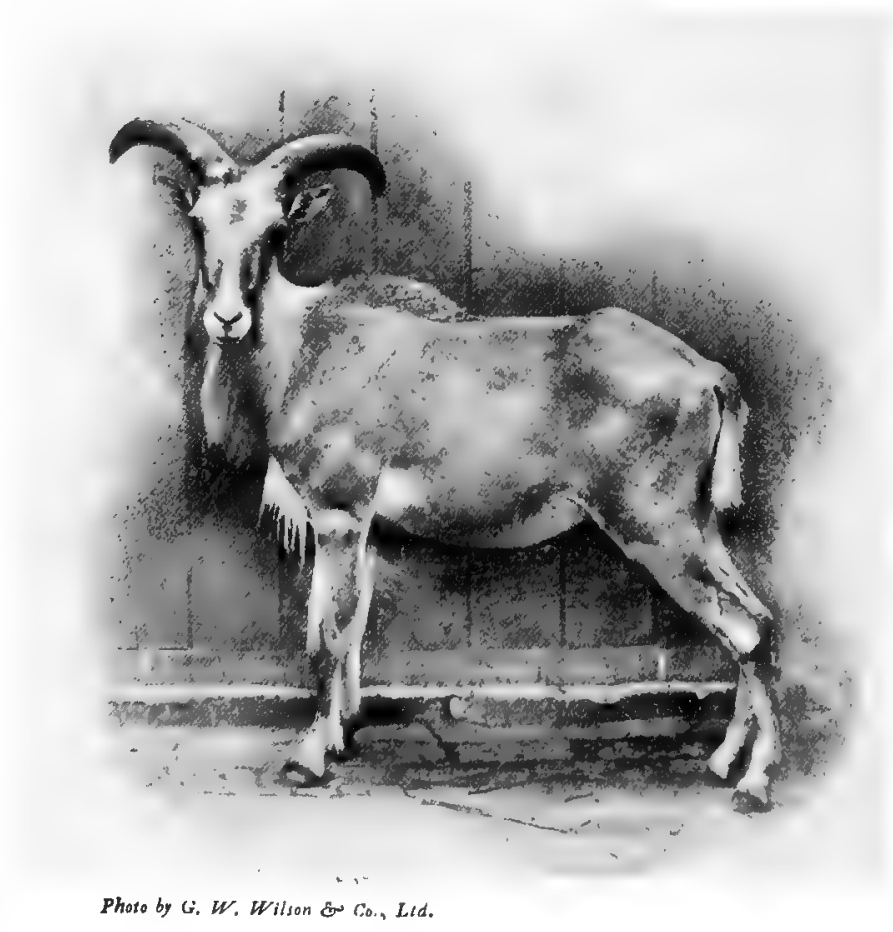

YOUNG BARBARY SHEEP

Note the length of the tail as compared with other wild sheep Ig6 


\section{THE LIVING ANIMALS OF THE WORLD I97}

\section{The European Moufflon}

The only wild sheep of Europe is the Moufflos, found in the mountains of Corsica and Sardinia. Its height at the shoulder is about 27 inches. In the rams the horns are strong; and curved into a spiral, forming almost a complete circle. The hair is close, and in winter has a woolly under-fur. In summer and autumn the coat is a bright red-brown on the neck, shoulders, and legs; the rump and under-parts are whitish, and the back and flanks marked with a white saddle. In winter the brown becomes darker and the white saddle broader. A rather larger moufflon is found on Mount Elburz in Persia, in Armenia, and in the Taurus Mountains. A smaller variety exists in Cyprus, where it has been preserved since the British occupation. The moufflon is a typical wild sheep. In Sardinia and Corsica are dense scrubby forests of tall heather, some 5 feet high. This maquia is practically impenetrable to hunters. When alarmed, the moufflon dash into it, and are safe. The maquia has preserved two very interesting survivals of antiquity - the moufflon, and the Corsican or Sardinian bandit. The Corsican bandit,

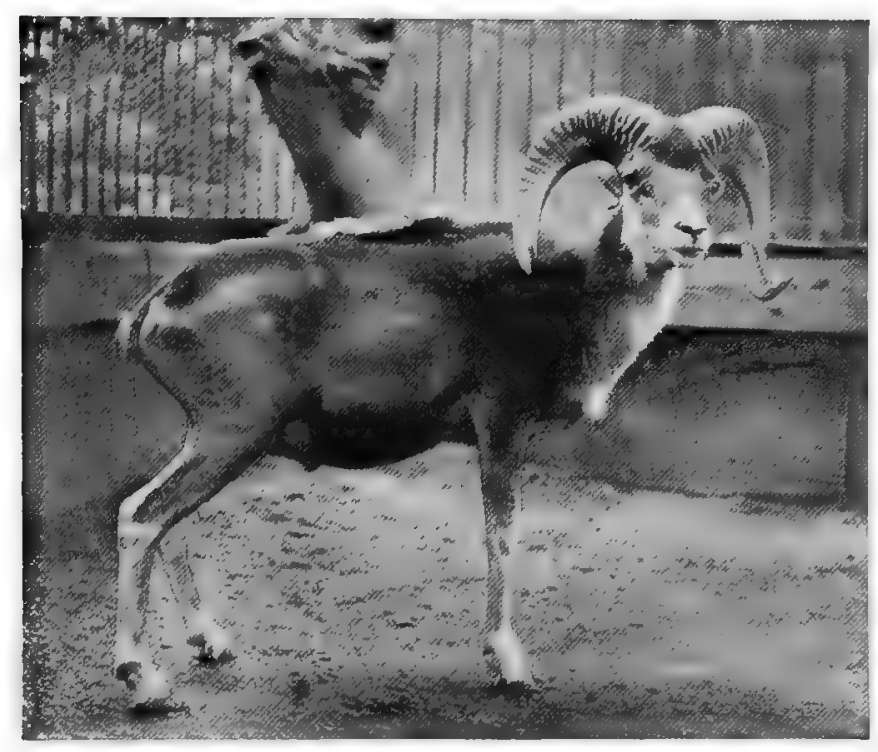

Photo by W. P. Dando

SIBERIAN ARGALI

One of the large wild sheep of Central Asia like the moufflon of the same island, is nearly extinct. In Sardinia both flourish. Many sportsmen have had their first taste of big-game shooting in the difficult pursuit of the moufflon on the Sardinian mountains. Some declare that the sport is so fascinating that they have seldom found much to equal it since. Mr. S. H. Whitbread, whose notes in "The Encyclopædia of Sport" are very full on this subject, deems that the best season to stalk moufflon is in October or November. The animals are then less disturbed by shepherds and dogs, and the moufflon are on the move and more easily seen during the day than in summer, when they feed at night and rest or sleep by day.

There is a small herd of moufflon running wild in one of the English parks. They have a specially built "mountain-top" of stone to make a

home of, but are free to feed where they like in the park. They produce lambs yearly. It is an interesting sight to see the quick rush of the little flock, when frightened, to their shelteringplace, led by an old white saddled ram.

\section{The ARgalis}

The ARGALIS are the largest of all living wild sheep. Some measure from 3 feet 9 inches to 4 feet at the shoulder. The horns are broad, corrugated, and curling in the male, and in the female short, erect, and curving backwards. The male TIBETAN ARGALI has a ruff on the throat. The usual colour is a stony grey, mingled with white in the summer in the case of the old males. The name is applied collectively to several wild sheep found in Northern and Central Asia. Whether these are only varieties or separate species it is difficult to say; but the following are some of the most marked forms.

The SIBERAIN ARGALI is the characteristic wild sheep of the rocky hills and mountains of Southern Siberia, the Altai Mountains, and Northern Mongolia. The horns curve so as to form more than a complete circle; the upper parts are tinged with grey, and the lower are white. 
The Tibetan ARgali is a little smaller in size, and has siightly smaller horns. The rams have also a large white ruff on the throat. These sheep descend in winter to the lower valleys of the Tibetan plateau, returning to the higher ground in spring. The lambs are born in May or June.

LitTLEDALE'S SHEEP is a smaller animal, found on the Sair Mountains in the Great Altai, on the northwestern border of Mongolia. It is darker in colour than the argali or Marco Polo's sheep, and has dark under-parts.

Writing of the argali of Southern Siberia, the naturalist $\mathrm{Brehm}$ says that when the Tartars want mutton an argali hunt is organised. The Tartar hunters advance on their horses at intervals of 200 or 300 yards, and when the sheep are started generally

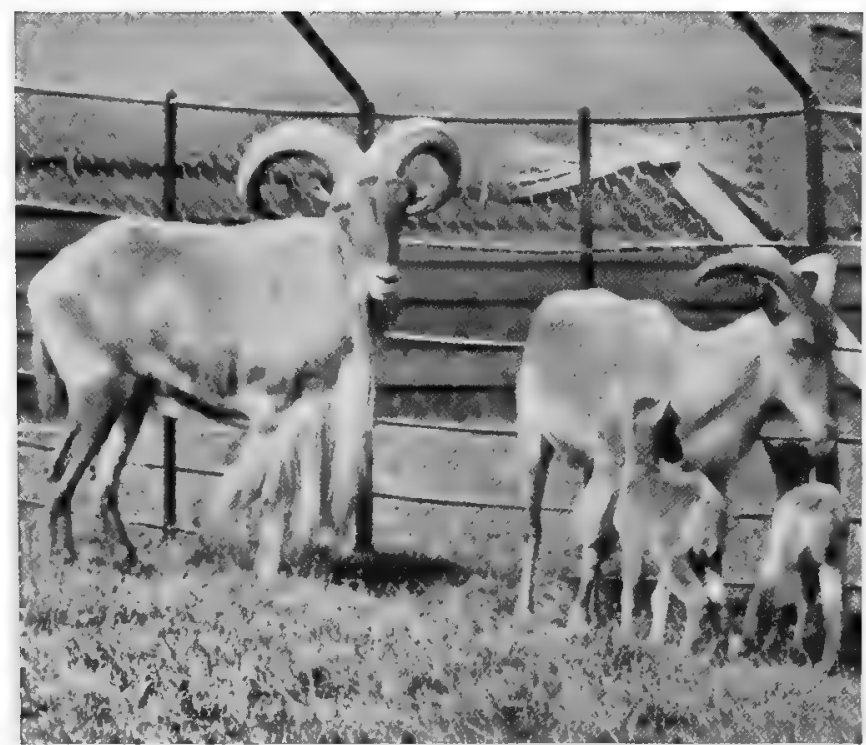

BARBARY SHEEP

These fine wild sheep are found in the Atlas and Aures Mountains of North Africa manage, by riding, shooting, coursing them with dogs, and shouting, to bewilder, shoot, or capture several.

On the high plateau of the Pamirs and the adjacent districts MARCo PoLo's SHeEP is found. The rams are only slightly less in size than the Siberian argali; the hair is longer than in that species, and the horns are thinner and more slender and extenc farther in an outward direction. An adult ram may weigh $300 \mathrm{lbs}$. The first description of this sheep was given by the old traveller whose name it now bears. He said that on the Pamir plateau wild

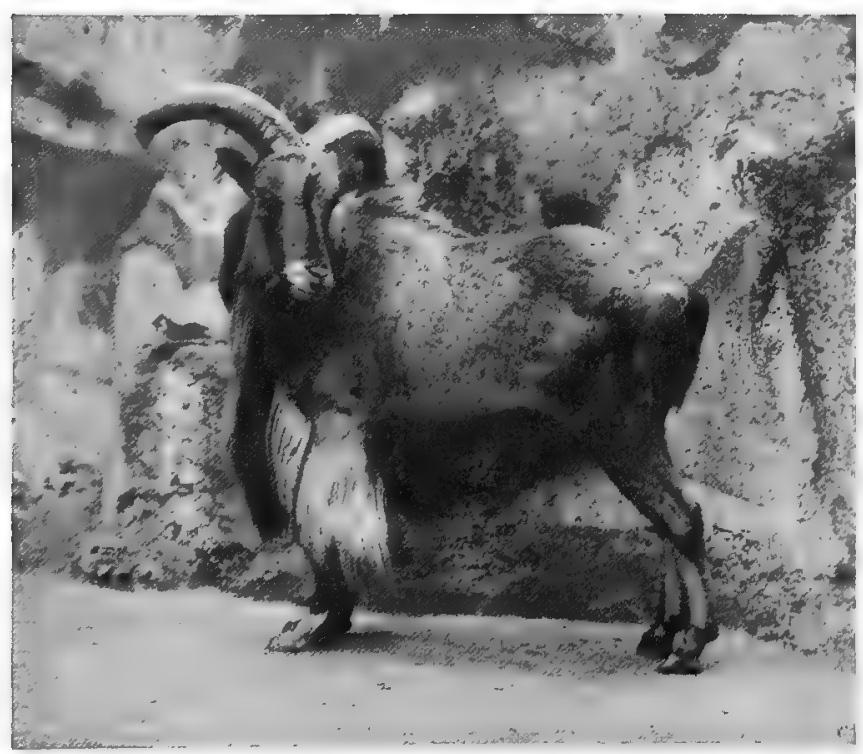

BARBARY SHEEP

This shows a fine ram, with a mane reaching almost to its hoof animals are met with in large numbers, particularly a sheep of great size, having horms three, four, and even six palms in length.

\section{The Oortal.}

The vast range of the Himalaya affords feeding-ground to other species of wild sheep and wild goat, so different in the shape of the horns that the variations of the ovine race under domestication need not be matter for wonder when so much variety is seen in nature.

The Oortal, or Sira, is found from North-west India to Persia. The horns make a half-curve backwards, and are flattened. The coat is of reddish-brown colour, with white on the belly, legs, and throat. This species is the only wild sheep found in India proper. 
The Barbary Sheep, Aoudad, OR ARUI

This is a large wild sheep of the North African highlands. The old rams have a very fine appearance, with a long flowing beard or mane, and large horns. These wild sheep, though somewhat goat-like in appearance, are typical of their race in general habits. They live in the Atlas Range, and in the splendid heights of the Aures Mountains, which lie at the back of Algeria and fringe the great Sahara Desert. In the isolated and burning rocks which jut up in the desert itself into single mountains they are also found, living on ground which seems absolutely destitute of water, grass, or vegetation. They live singly or in small families; but the rams keep mainly alone. Sometimes they lie in shallow caves during the heat of the day. These caves smell like a sheep-fold. More generally the sheep repose on some shelf of rock, where they exactly match the colour of the stone, and are invisible. The ground is among the most difficult in which any hunting is attempted, except perhaps in chamois stalking; but the pursuit seems to fascinate sportsmen.

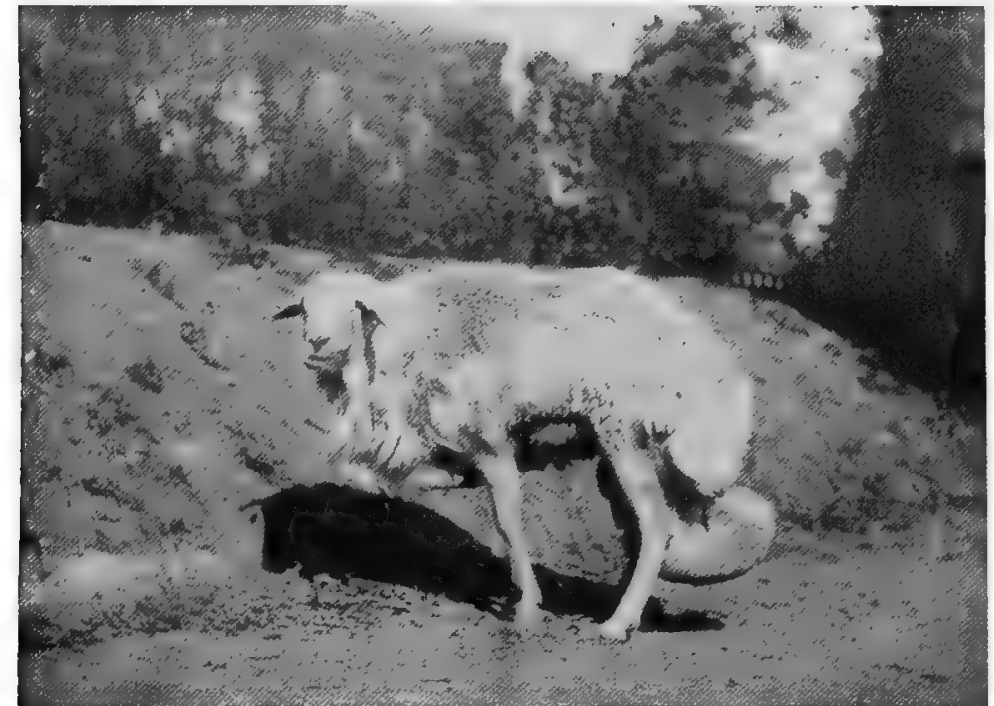

Photo by L. Medland, F.Z.S.]

FAT-TAILED SHEEP
[North Finchley
The fat tail of tbis sbeep was considered by Charles Darwin as due to degeneration

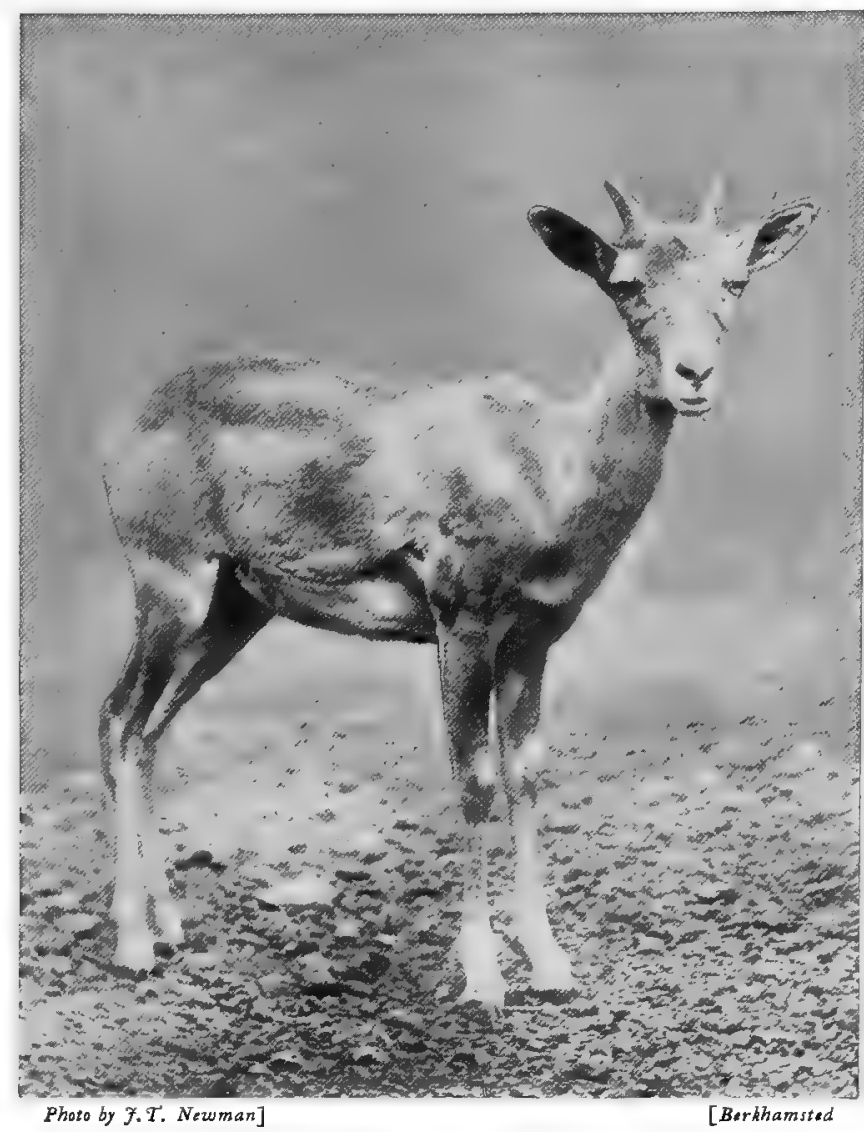

PUNJAB SHEEP

This is an example of one of the breeds which carry no woo whatever

Mr. A. E. Pease recently gave some sharming descriptions of the silence, the rugged rocks, and the astonishing views over the great orange Sahara Desert seen from the tops of these haunts of the Barbary shcep-mountains on the summits of which his Arab guides would prostrate themselves in evening prayer as the sun sank over the desert, and then, rising, once more resume the chase. The young lambs of the Barbary sheep are charming little creatures, more like reddish kids. They can follow the mother over the steepest ground at a great pace. When caught, as they sometimes are by the Arabs, they soon become tame. The 


\section{THE LIVING ANIMALS OF THE WORLD}

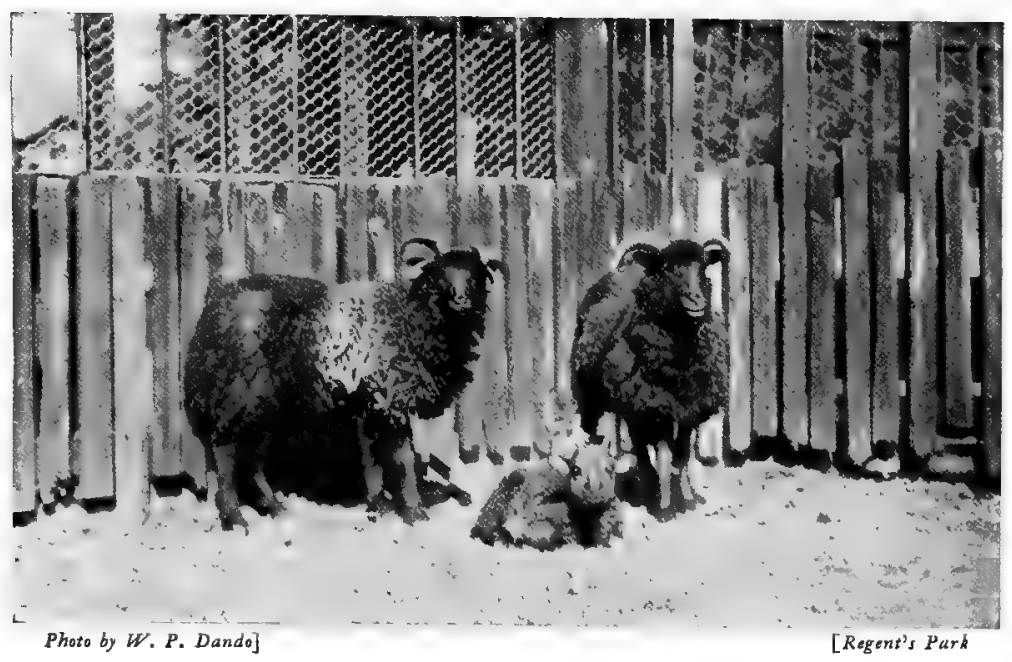

FOUR-HORNED SHEEP

There are several breeds of these sheep, some from China, some from Iceland, and others from South Africa

tail is longer than in other wild sheep, and in the males a large mane covers the chest.

The Burhal, or Blue SheeP

This species possibly indicates the transition-point from the sheep to the goats. It was pointed out by Mr. Brian Hodgson that it had certain features more like the goats than the sheep, and later other writers laid stress on structural differences of the same kind, both in skull and horns. It has not the disagreeable odour of the goats; but the black markings which separate the white of the belly

from the brown of the flanks, and run down the front of the legs, are like those seen on some goats. The horns rise in a curve outwards and downwards. The largest are only some 30 inches long.

Burhal are perhaps the commonest of all Asiatic wild sheep. They inhabit the whole length of the higher Himalayan Range, and are found over and round the Central Asian plateau as far north as Yarkand. The horns make two half-moons at right angles to the skull. Unlike some of the other wild sheep, burhal often climb the very highest ground of all. Much of the best burhal ground is above I 7,000 feet high, and, as Mr. Whitbread remarks, this alone makes the chase of such an animal difficult. As in the moufflon, the mutton is excellent. There is no difficulty whatever in taming these wild Himalayan sheep; those in the Zoological Gardens are practically domesticated.

\section{Domesticated SHeEP}

Under domestication sheep exhibit a wide variety of coat, shape, and size, very striking to the eye, and very important in regard to the produce of wool or mutton. The introduction of a particular breed, with long wool or short wool as the case may be, has often saved or altered for a time the economic condition of a colony or province. It was the introduction of the sheep which gave Australia first rank among the rich colonies of the world; and the discovery that the Cheviot breed would thrive on the Scotch hills made millions of acres remunerative which might otherwise have been very unproductive. But the only important change in the structure of the sheep in domestication is the lengthening of the tail. The carcase may be fat mutton or thin mutton, the wool long or short, fine or coarse; but the sheep itself remains true to type, and of much the same docile habits, under all the changes of the breeders.

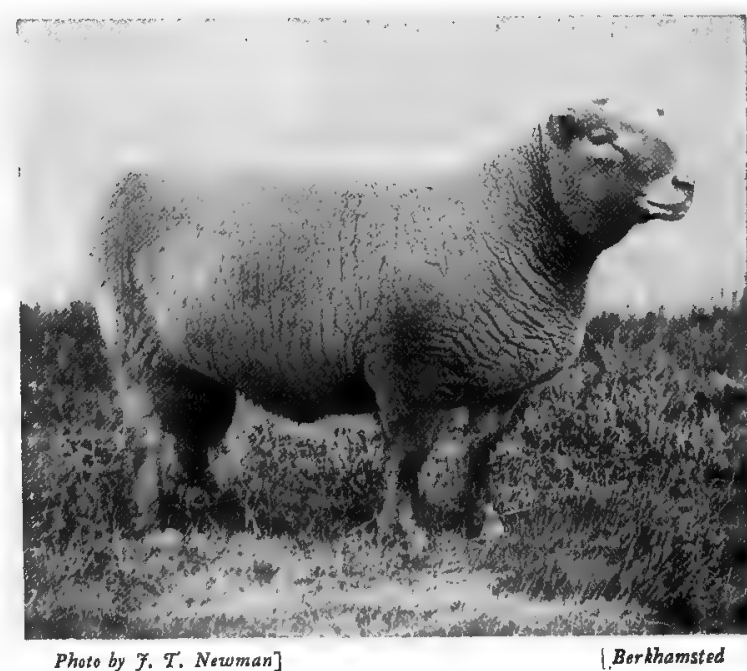

SOUTH DOWN SHEEP

The finest breed of dowun-sheep 
We may first say a word or two as to foreign breeds of sheep, especially those of the East. Some of these resemble the wild breeds in having smooth coats and almost no wool. The SoMALI SHEEP, for instance, yield no wool useful for felting or spinning. They have drooping ears and black heads. Some of the finest natural wool is developed by a white sheep in Tibet. The fur is usually sold as Tibetan lamb. The wool is exactly like white floss-silk. When cured by the Chinese, the leather is like white kid, with this flossy wool attached.

In India and Persia the sheep is sometimes used as a beast of burden. Mr. Lockwood Kipling, in his "Beast and Man in India," says: "Borax, asafœtida, and other commodities are brought into India on the backs of sheep in bags. The flocks are driven in large numbers from Tibet into British territory. One of the sensations of journeying in the hills of the 'interior,' as the farther recesses of the mountains are called by Anglo-Indians, is to come suddenly on such a drove, as it winds, with the multitudinous click of little feet, round the

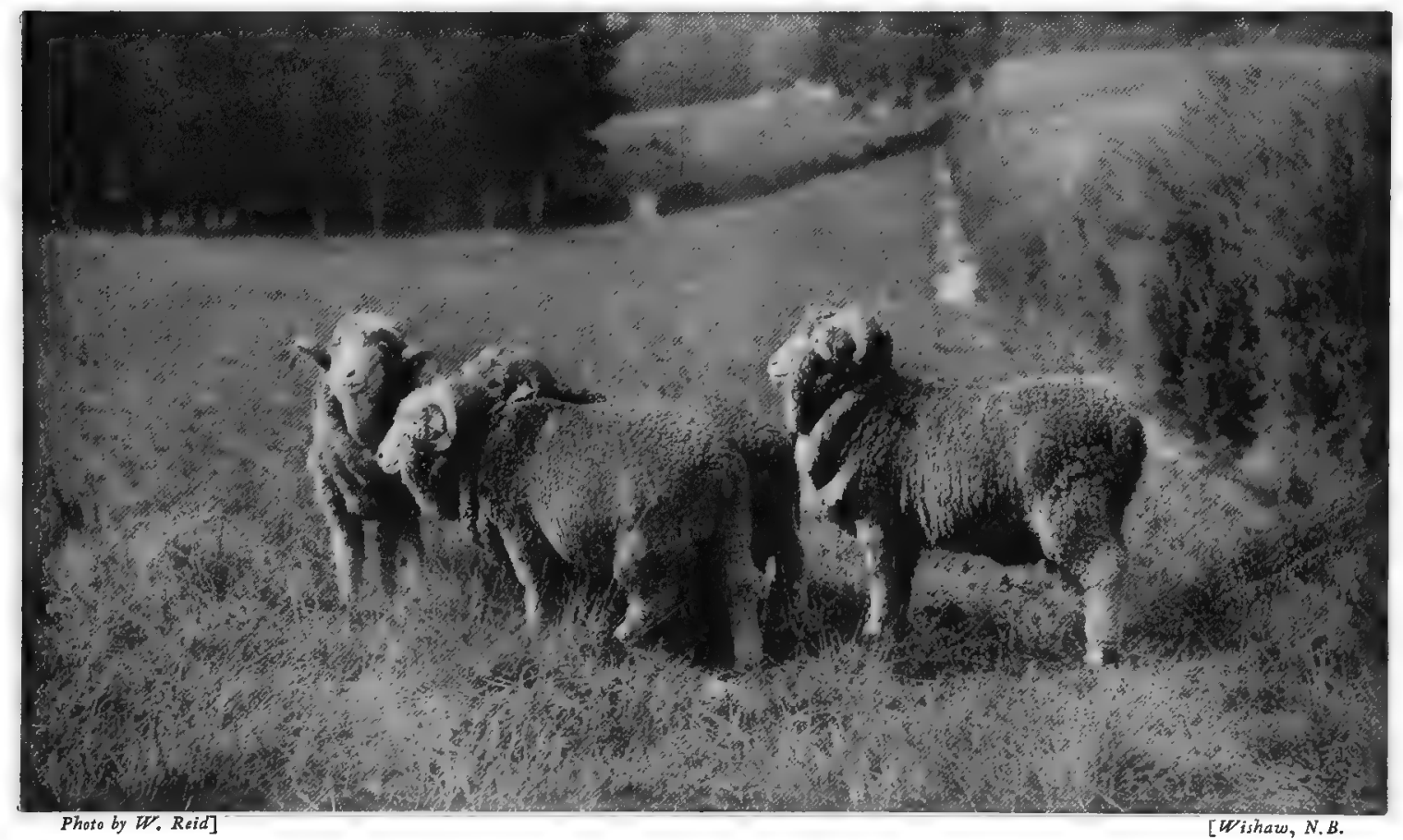

MERINO RAMS

The best zvool-producing sheep. Imported from Spain to Australia

shoulder of some Himalayan spur. The coarse hair bags scrape the cliffside from which the narrow path is built out or hollowed, and allow but scant roum for your pony, startled by the hurry and the quick-breathing rush of the creatures as they crowd and scuffle past. Only the picturesque shepherds return from these journeys. The carriers of the caravan (i.e. the sheep), feeding as they go, gather flesh in spite of their burdens, and provide most excellent mutton. ... In the towns of the plains rams are kept as fighting animals. A Mohammedan swell going out for a stroll with his fighting-ram makes a picture of foppery not easily surpassed by the sporting 'fancy' of the West. The ram is neatly clipped, with a judicious reservation of the salient tufts, tipped with saffron and mauve dye, and besides a large collar of blue beads it wears a necklace of hawk-bells."

The FAT-TAILED Sheep of Persia and Tartary exhibits a curious provision of nature. When food is plentiful, a quantity of fat accumulates on the tail and croup. As the pasture dries up and the animal finds little food, this store of fat is gradually absorbed. Another fat-tailed sheep is found from Syria and Egypt to the Cape. This has a long tail reaching to the 


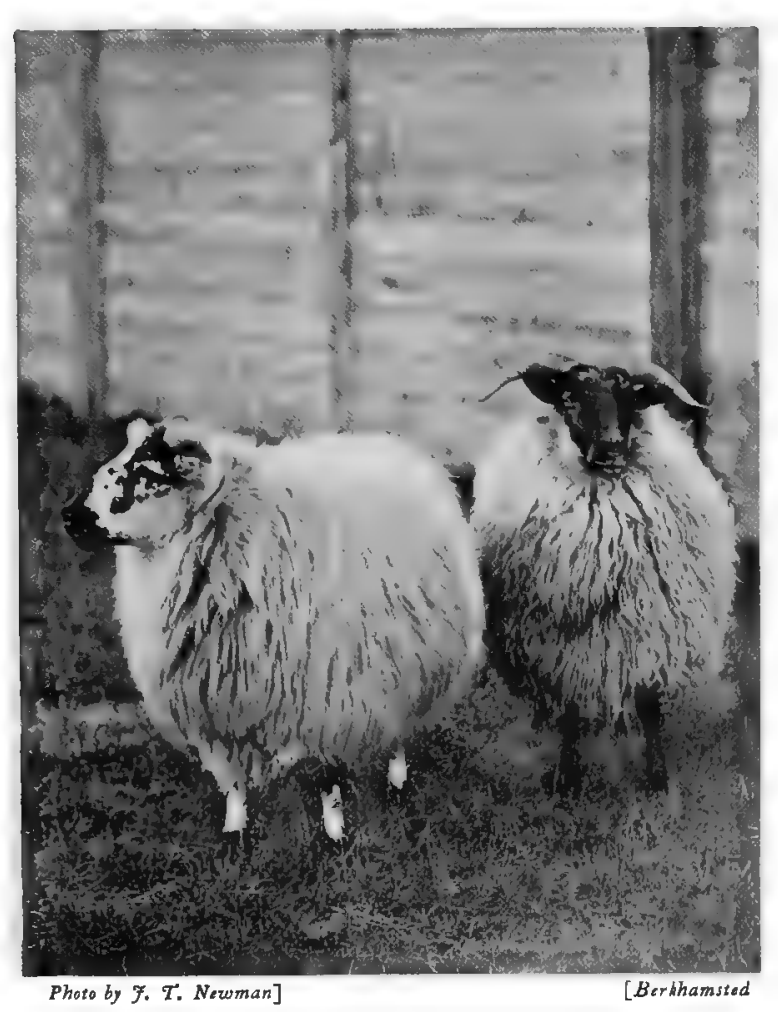

BLACK-FACED MOUNTAIN-SHEEP

The sheep of the high mountains and heather-moors

ground. In the Egyptian breed the tail is broad throughout; in the Syrian it narrows to a point. The ordinary weight of the Syrian sheep's tail is 15 lbs.; but in some well fattened examples it reaches 70 or 80 lbs. Ludolph saw in Egypt a sheep's tail of $8 \mathrm{o}$ lbs. weight. This overgrown tail is a great encumbrance to the animal. In order to lighten the burden, the shepherds fasten under it a small board, sometimes with wheels. attached, to make it easy to draw over the ground.

In Greece, Wallachia, and Western Asia. a fine breed of sheep, quite different from the English forms, is seen. It is called the Wallachian SheEP. When the Zoological Gardens were first founded here, some of these sheep were introduced and crossed with English breeds. The horns are tall spirals, as in the great kudu antelope. The body is large, and the fleece long and straight, and more like that of the long-haired goats. than curly wool.

There are now few countries in the world to which sheep have not been introduced. They were probably among theearliest animals to be domesticated. Certainly they are the first to be mentioned; for we learn that "Abel was a keeper of sheep," while Cain tilled the earth. The feud between the keeper of flocks and the grower of crops typified in this ancient quarrel still goes on wherever the wild mountain breeds of sheep are kept, for there is of necessity always danger that the wandering sheep may raid the plots of corn. In Spain a curious and ancient set of laws regulates the passage of the flocks to and from the mountain pastures through the corn-lands.

It is said that the name of the famous breed of Spanish sheep known as MERINos recalls their foreign origin from across the sea, and that they were originally imported into Spain from England. Whether that be so or not, it is certain that no one could recognise them now. The finest merino sheep, especially those bred in Australia, into which country they were imported some forty years ago, look as if covered with a dense growth of moss. The close wool grows not only on their backs, sides, and bellies, but on legs, forehead, and nose. There are believed to be ten millions of merino sheep in Spain, most of which are migratory. They are called "transhumantes," and are taken from the plains to the mountains and from the mountains to the plains yearly. These

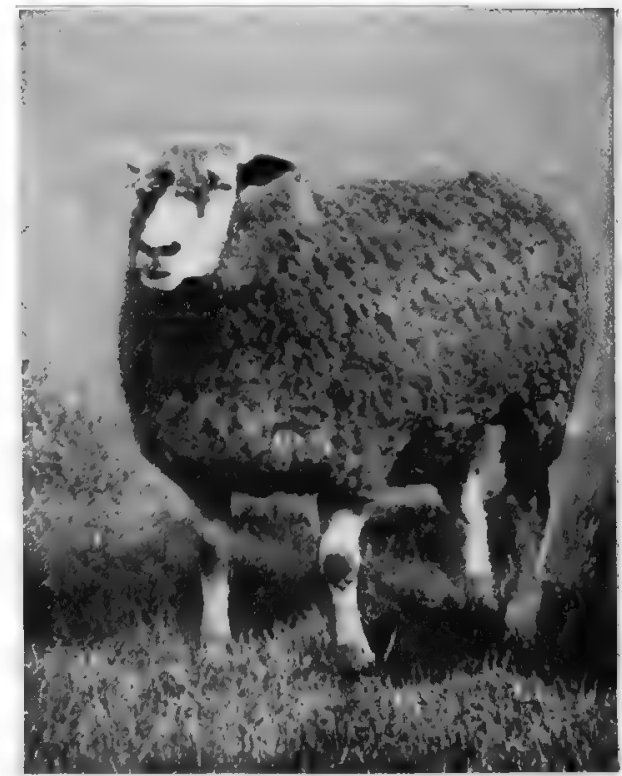

Photo by F. T. Newman]

[Berthamssed

LEICESTER EWE

$A$ heavy, long-woolled breed 
"transhumantes" are divided into flocks, each under a head shepherd, or " majoral." The flocks follow the shepherds, who lead the way, and direct the length and speed of the journey. A few wethers, trained to the business, follow the shepherds, and the rest come in due order. Powerful dogs accompany them as guards. This system of sheep migration is controlled by a tribunal termed the Mesta. It can be traced back to the middle of the fourteenth century. By it persons are prohibited from travelling along the course of the route pursued by the flocks so long as they are on the road. It also maintains the right for the flocks to graze on all the open or common land that lies in the way. Moreover, it claims a path ninety yards wide through all enclosed and cultivated country. The length of the journey is over 400 miles, which is accomplished in six or seven weeks. The system works greatly to the injury of local cultivators and stationary flocks, whose fields are injured by the migratory sheep.

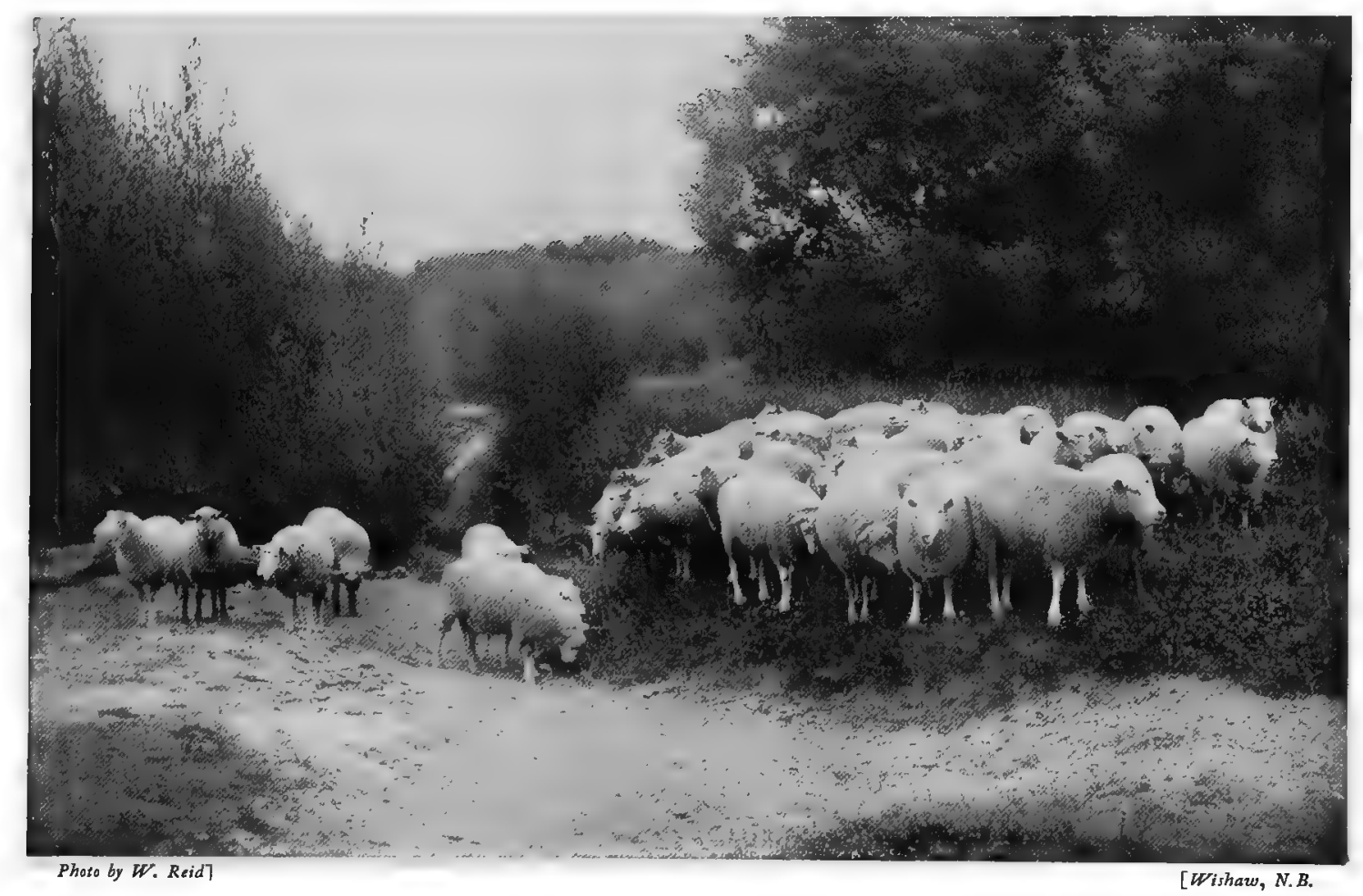

CROSS-BRED SHEEP

The class of sheep kept mainly on cultivated land in the North Midlands

\section{ENGLISH BREEDS OF SHEEP}

In England are reared the finest and most valuable sheep. This is evident from the prices paid for them by foreigners and breeders in our colonies. Except for merinos, no one comes to any other country but this when about to seek new blood for their flocks or to stock new lands. Recently I,O0O guineas were paid by a firm in Argentina for a single Lincoln ram.

Differences, well marked and of great importance, exist between our different breeds. Each suits its own district, and each is carefully improved and kept pure by herd-books, in which all pedigree animals are entered.

The "general utility sheep" in England is the South Down; in Scotland, the Border LEICESTER. The former is a small, fine sheep, with close wool, and yielding excellent mutton. It provides the meat sold in our best shops, and has largely stocked New Zealand. The original breed of England was possibly the COTSWOLD; it is a tall, long-woolled, white-fleeced 


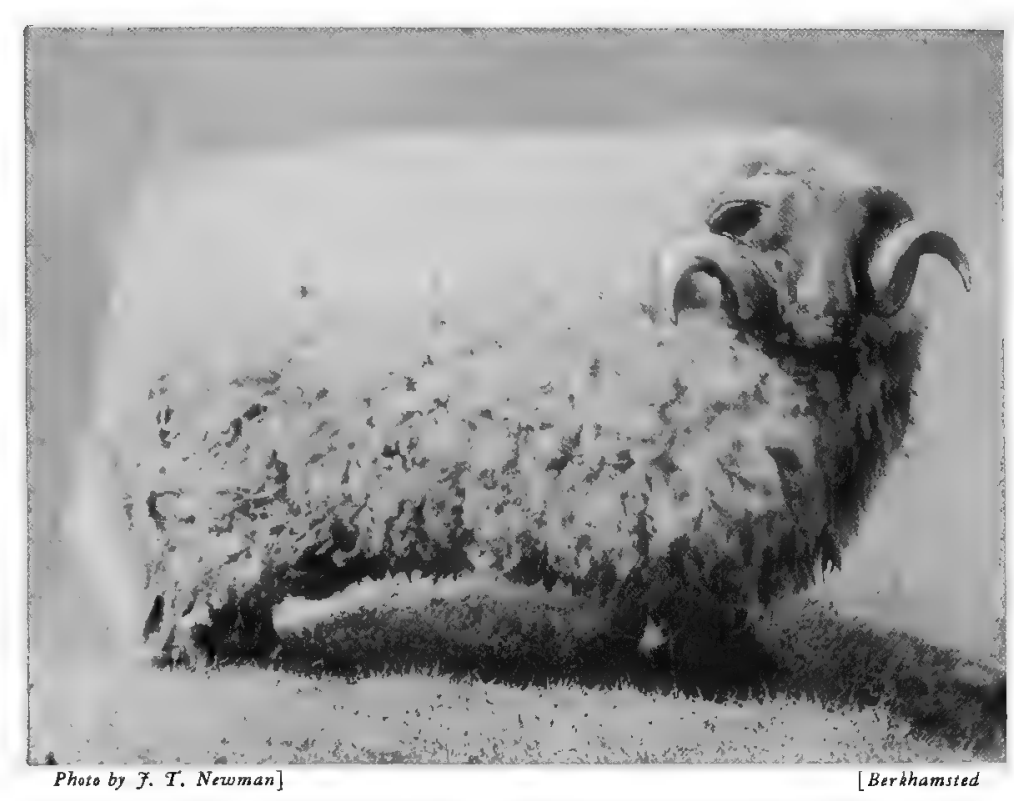

LONK RAM

This is a photograph of the largest sheep on record

sheep. Later a large heavy sheep, with long wool and a massive body, was bred in the Midlands, and called the LEICESTER LONG-WOOL. This sheep gives a great cut of wool, and much coarse mutton. The CHEviot SheEP, originally bred on the hills of that name, is now one of the mainstays of the Scotch mountain farmer. The Cheviots eat the grass on the high hillsides, while the BLACKFaced Highland SheEP live on the heather higher up. The SUfFolk, OxFord, HAMPSHIRE, and other "Down" sheep are larger breeds than the South Down. The Romney Marsh Sheep are a heavy long-woolled breed. The ExMOORS are small heather-sheep like those of Wales, and the SOA and ST. KILDA SinEEP, which are often four-horned, the smallest of all.

The maintenance of flocks is now almost an essential part of English agriculture on all chalk lands, which comprise a very large percentage of the southern counties. On the chalk downs the flocks are the great fertilisers of the soil. Every night the sheep are folded on the fields which are destined to produce corn in the following year. The manure so left on the soil ensures a good crop, with no expense for carting the fertiliser from the farmyard, as is the case with manure made by oxen kept in straw-yards.

On the South Downs, Oxfordshire Downs or Chiltern Hills, Salisbury Plain, and the Berkshire Downs the farms have been mainly carried on by the aid of the flocks. Where these are no longer kept the land reverts to grass, and the growing of corn ceases. On the coarse, new-sown grasses cattle take the place of sheep, and an inferior style of farming, like the ranches of South America, replaces the careful and highly skilled agriculture of Old England. In the far north of Scotland crossbred sheep are now reared and fed in winter on turnips, which will grow luxuriantly where the climate is too bleak and wet for wheat.

Formerly cattle were the main source of wealth to the owners of Highland estates. The sheep was only introduced after the Highlands were subdued subsequently to the rebellion in 1745 . It was found that the rough-coated heather-sheep throve on the wet and elevated hills. This led to their substitution for cattle, as wool was then dear. Sheep are now in their turn giving way to grouse and deer over much of the Central Highlands, as the price of wool has fallen.

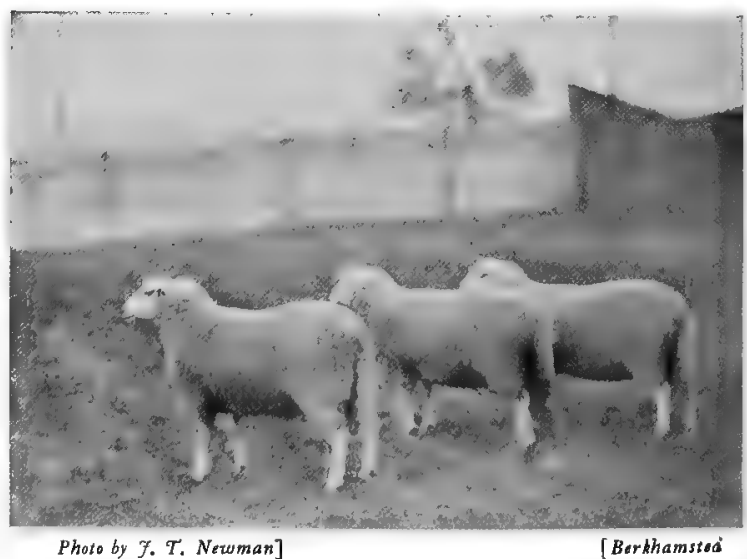

WELSH EWES

A small breed of bill-sbeep 
Though the dividing-line between the Sheep and Goats is very indistinct, some differences are of general application. The goats are distinguished by the unpleasant " hircine" odour of the males, and by beards on the chins of the same sex, by the absence of glands in the hind feet, which sheep possess, and by certain variations in the formation of the skull. The difference between the temperament of the sheep and goats is very curious and persistent, showing itself in a marked way, which affects their use in domestication to such a degree that the keeping of one or the other often marks the owners as possessors of different degrees of civilisation. Goats are restless, curious, adventurous, and so active that they cannot be kept in enclosed fields. For this reason they are not bred in any numbers in

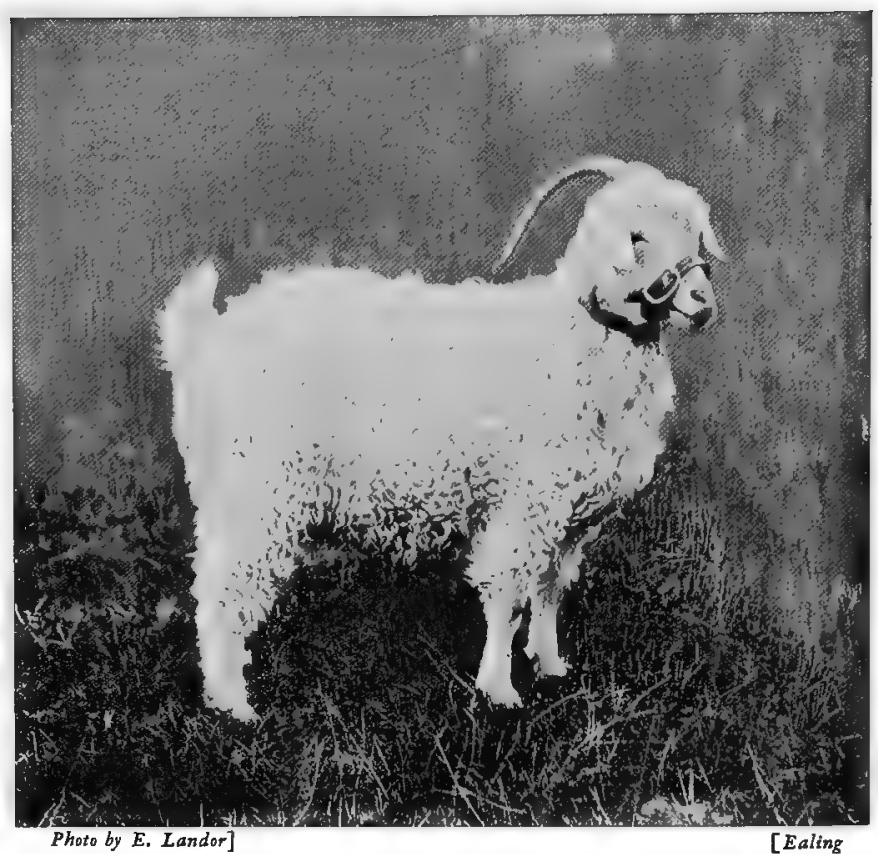

FEMALE ANGORA GOAT

The breed from whicb mobair is obtained lands where agriculture is practised on modern principles; they are too enterprising and too destructive. Consequently the goat is usually only seen in large flocks on mountain pastures and rocky, uncultivated ground, where the flocks are taken out to feed by the children.

On the high alps, in Greece, on the Apennines, and in Palestine the goat is a valuable domestic animal. The milk, butter, and cheese, and also the flesh of the kids, are in great esteem. But wherever the land is enclosed, and high cultivation attempted, the goat is banished,

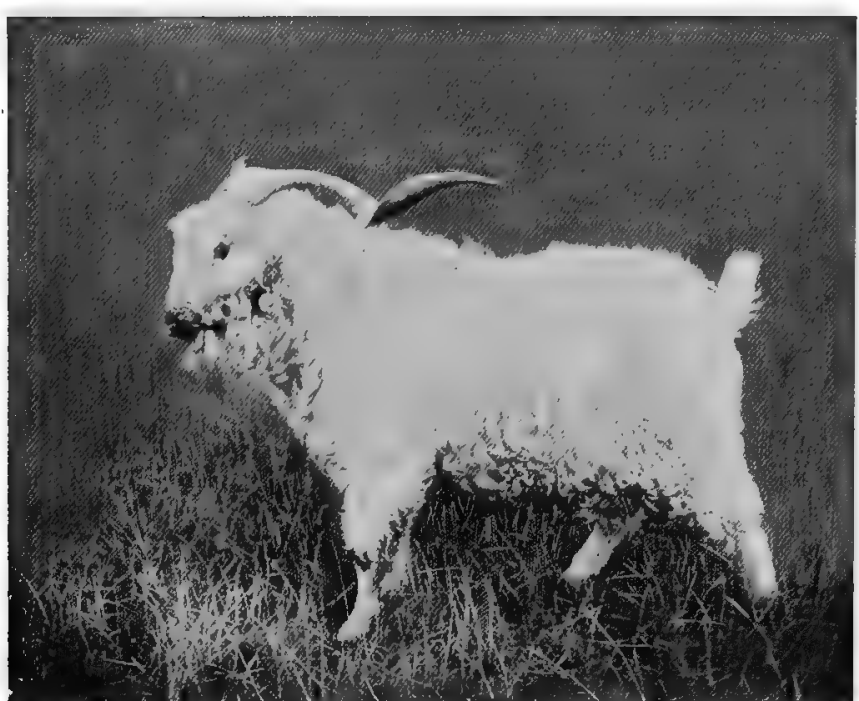

ANGORA RAM

[Ealing

Photo by E, Landor]

These goats were originally obtained from Turkey in Asia, and exported to Soutb I 4 and the more docile and controllable sheep takes its place. In Syria the goat is perhaps more docile and better understood as a dairy animal than elsewhere in the East. The flocks are driven into Damascus in the morning; and instead of a milk-cart calling, the flock itself goes round the city, and particular goats are milked before the doors of regular customers.

The EUROPEAN Goat is a very useful animal for providing milk to poor families in large towns. The following account of its present uses was recently published: "The sheep, while preserving its hardy habits in some districts, as on Exmoor, in Wales, and the Highlands, adapts itself to richer food, and acquires the habits as well as the digestion of domestication. The goat remains, as in old days, the 
enemy of trees, inquisitive, omnivorous, pugnacicus. It is unsuited for the settled life of the English farm. Rich pasture makes it ill, and a good clay soil, on which cattle grow fat, kills it. But it is far from being disqualified for the service of some forms of modern civilisation by the survival of primitive habits. Though it cannot live comfortably in the smiling pastures of the low country, it is perfectly willing to exchange the rocks of the mountain for a stable-yard in town. Its love for stony places is amply satisfied by the granite pavement of a 'mews,' and it has been ascertained that goats fed in stalls and allowed to wander in paved courts and yards live longer and enjoy better health than those tethered even on light pastures. In parts of New York the city goats are said to flourish on the paste-daubed paper of the advertisements, which they nibble from the hoardings. It is beyond doubt that these hardy creatures are exactly suited for living in large towns; an environment of bricks and mortar and paving-

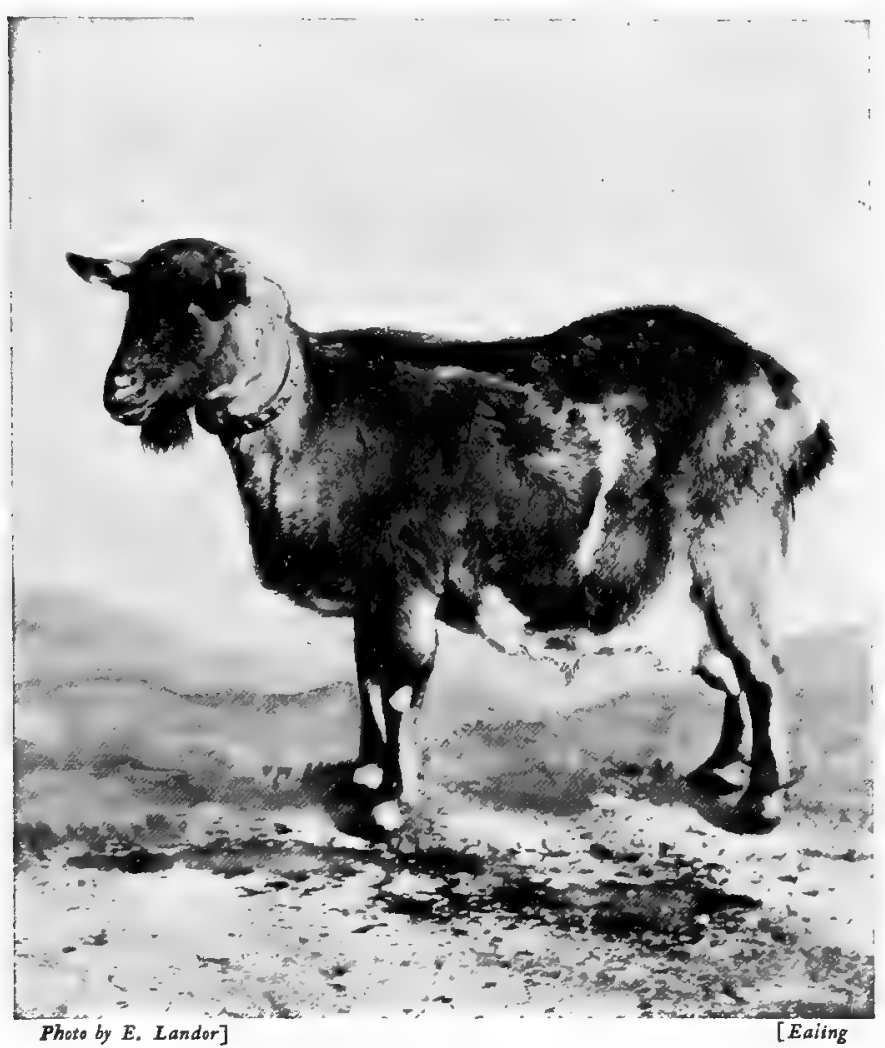

BRITISH GOAT stones suits them. Their spirits rise in proportion to what we should deem the depressing nature of their surroundings. They love to be tethered on a common, with scanty grass and a stock of furze-bushes to nibble. A deserted brick-field, with plenty of broken drain-tiles, rubbish-heaps, and weeds, pleases them still better. Almost any kind of food seems to suit them. Not even the pig has so varied a diet as the goat; it consumes and converts into milk not only great quantities of garden stuff which would otherwise be wasted, but also, thanks to its love for eating twigs and shoots, it enjoys the prunings and loppings of bushes and trees. In the Mont d'Or district of France the goats are fed on oatmeal porridge. With this diet, and plenty of salt, the animals are scarcely ever ill, and never suffer from tuberculosis; they will often give ten times their own weight of milk in a year."

The Kashmir shawls are made of the finest goats' hair. Most of this very soft hair is obtained from the under-fur of goats kept in Tibet, and by the Kirghiz in Central Asia. Only A much-neglected breed in this country. Note the shape of this animal

a small quantity, averaging $3 \mathrm{ozs}$., is produced yearly by each animal. The wool is purchased by middlemen, and taken to Kashmir for manufacture.

In India the goat reaches perhaps the highest point of domestication. The flocks are in charge of herd-boys, but the animals are so docile that they are regarded with no hostility by the cultivators of corn and cereals. Tame goats are also kept throughout Africa. The valuable ANGORA breed, from which "mohair" is obtained,'is now domesticated in South Africa and in Australia. In the former country it is a great commercial success. The animals were obtained with great difficulty, as the Turkish owners did not wish to sell their best-bred goats; but when once established at the Cape, it was found that they proved better producers of mohair than when in their native province of Angora. The "clip" from their descendants steadily improves. 
WILD GOATS

In the Caucasus, both east and west, in the Pyrenees, and on the South Spanish sierras three fine wild goats, with some features not unlike the burhal sheep, are found. They are called TUR by the Caucasian mountaineers. The species found in the East Caucasus differs from that of the west of the range, and both from that of Spain. The EAST CAUCASIAN TUR is a massive, heavy animal, all brown in colour (except on the fronts of the legs, which are blackish), and with horns springing from each side of the skull like halfcircles. The males are 38 inches high at the shoulder. The short beard and tail are blackish, and there is no white on the coat. The WEST CAUCASIAN TUR is much lighter in colour than that of the East Caucasus, and the horns point backwards, more like those of the ibex, though set on the skull at a different angle. The SPANISH TUR has the belly and inner sides of the legs white, and a blackish line along the flank, dividing the white from the brown; also a blackish chest, and some grey on the flank.

In the Caucasus the tur are found on the high crags above the snow-line in summer, whence they descend at night to feed on patches of upland grass; but the main home of the tur by day is above the snowline. The Spanish species modifies its habits according to the ground on which it lives. Mr. E. N. Buxton found it in dense scrub, while on the Andalusian sierras it frequents bare peaks Io,ooo feet high. In Spain tur are sometimes seen in flocks of from 100 to 150 each.

\section{The Persian Wild Goat}

The original of our domesticated goat is thought by some to be the

THE TUR

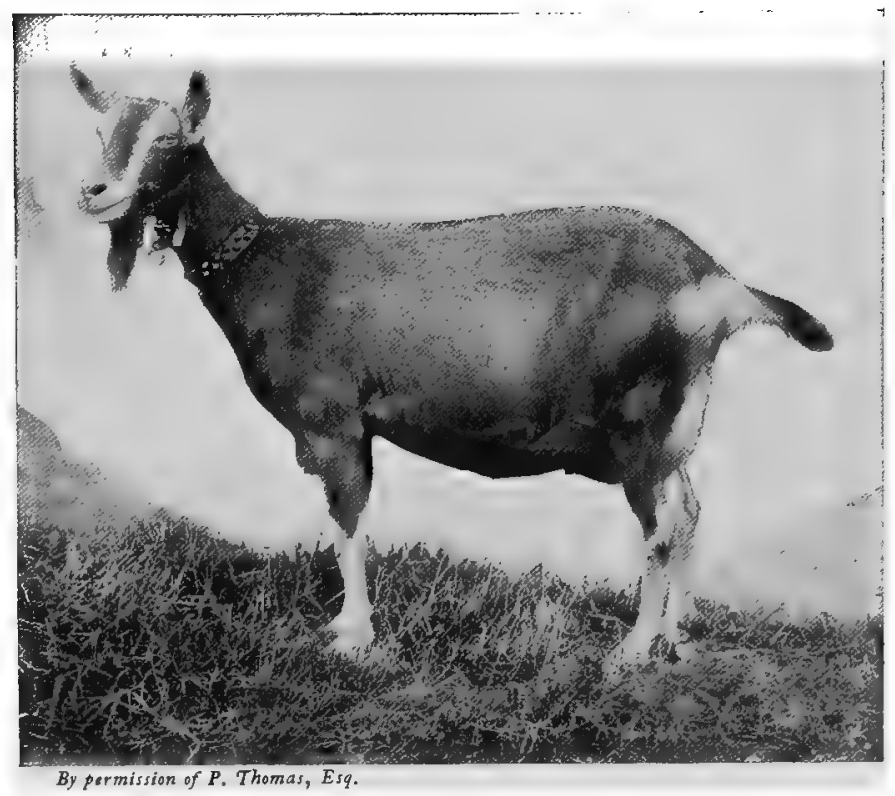

FEMALE TOGGENBURG GOAT

These goats are milk-goats par excellence; they remain in profit for at least ten months in the year. Each goat produces on an arverage from 1 IO to 120 gallons of milk during the year

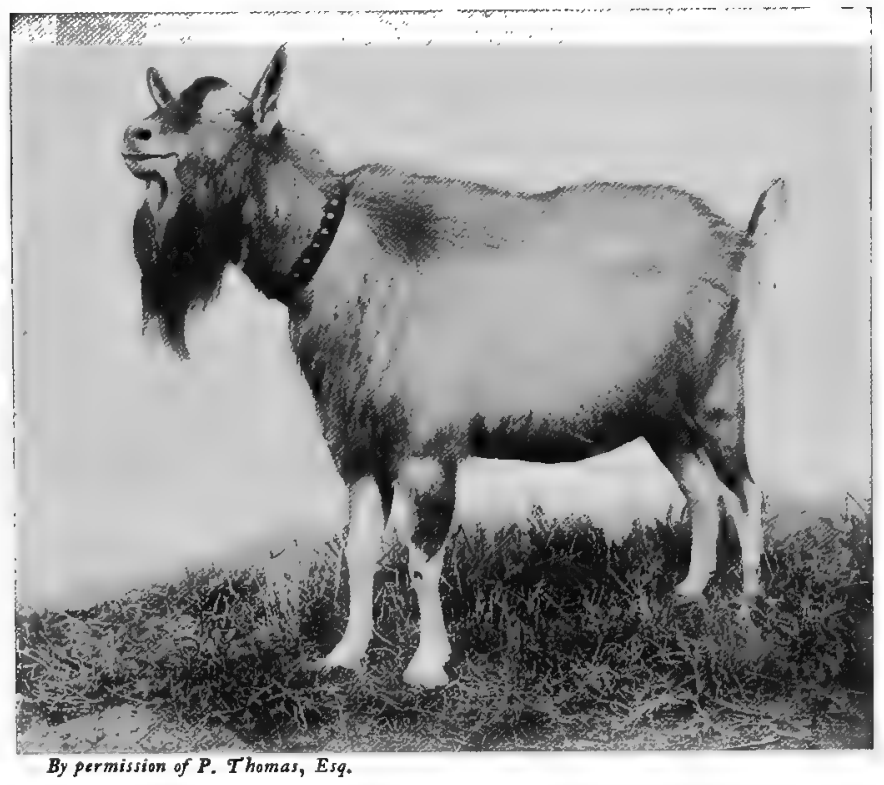

STUD TOGGENBURG GOAT

This breed originally came from Switzerland, but is now well known in England. The animals are fine in bone, have a leng, thin neck, with two tassellike appendages

PASANG, or PERsian Wild GoAT. It is a fine animal, with large scimitar-shaped horns, curving backwards, flattened laterally, and with knobs on the front edge at irregular intervals. It is more slender in build than the tur, light brown in general colour, marked with a black line 
along the nape and back, black tail, white belly, blackish shoulder-stripe, and a black line dividing the hinder part of the flank from the white belly. Formerly found in the islands of South-eastern Europe, it now inhabits parts of the Caucasus, the Armenian Highlands, Mount Ararat, and the Persian mountains as far east as Baluchistan. A smaller race is found in Sind. It lives in herds, sometimes of considerable size, and frequents not only the high ground, but the mountain forests and scrub, where such cover exists. The domesticated goat of Sweden is said to be certainly a descendant of this species.

\section{THE IBEX}

Of the IBEx, perhaps the best known of all the wild goats, several species, differing somewhat in size and in the form of their horns, are found in various parts of the Old World. Of these, the ARABIan Ibex inhabits the mountains of Southern Arabia, Palestine, and Sinai,

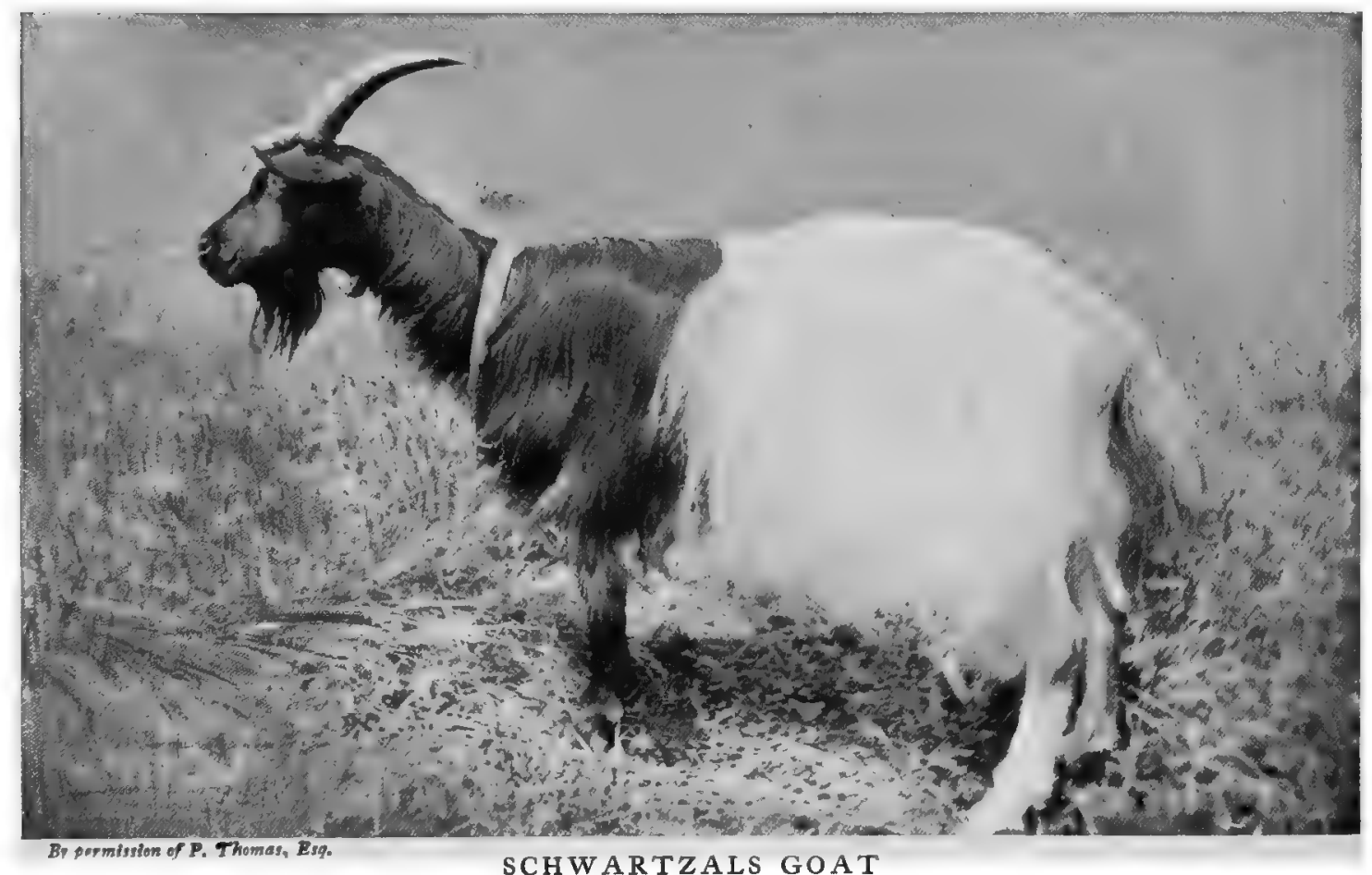

A large, long-haired breed, which derives its name from its peculiar colour, the fore part of the body being black and the hinder part white.
These goats are good milkers

Upper Egypt, and perhaps Morocco. The Abyssinian IBEx is found in the high mountains of the country from which it takes its name. The Alpine IBEx is now extinct in the Swiss Alps and Tyrol, but survives on the Piedmontese side of Monte Rosa. The AsIATIC IBEX is the finest of the group; its horns have been found to measure $54 \frac{3}{4}$ inches along the curve. This ibex inhabits the mountain-ranges of Central Asia, from the Altai to the Himalaya, and the Himalaya as far as the source of the Ganges.

The King of Italy is the great preserver of the ALPINE IBEX, and has succeeded where the nobles of the Tyrol have failed. The animals are shot by driving them, the drivers being expert mountaineers. The way in which the ibex come down the passes and over the precipices is simply astonishing. One writer lately saw them springing down perpendicular heights of 40 feet, or descending "chimneys " in the mountain-face by simply cannoning off with their feet from side to side. Young ibex can be tamed with ease, the only drawback to their maintenance being the impossibility of confining them. They will spring on to the roof of 
a house, and spend the day there by preference, though allowed the run of all the premises. The kids are generally two in number; they are born in June.

The ibex was long one of the chief objects of the Alpine hunter. The Emperor Maximilian had a preserve of them in the Tyrol mountains near the Aachen Sea; these he shot with a cross-bow when they were driven down the mountains. Sometimes they were forced across the lake. A picture in his private hunting-book shows the Emperor assisting to catch one in a net from a boat. $\mathrm{He}$ notes that he once shot an ibex at a distance of 200 yards with a cross-bow, after one of his companions had missed it with a gun, or " fire-tube." When away on an expedition in Holland, he wrote a letter to the wife of one of the most noted ibex-poachers on his domain, promising her a silk dress if she could induce her husband to let the animals alone. In the Himalaya the chief foes of the ibex are the snow-leopard and wild dog.

\section{The MarkHor}

The very fine Himalayan goat of this name differs from all other wild species. The horns are spiral, like those of the kudu

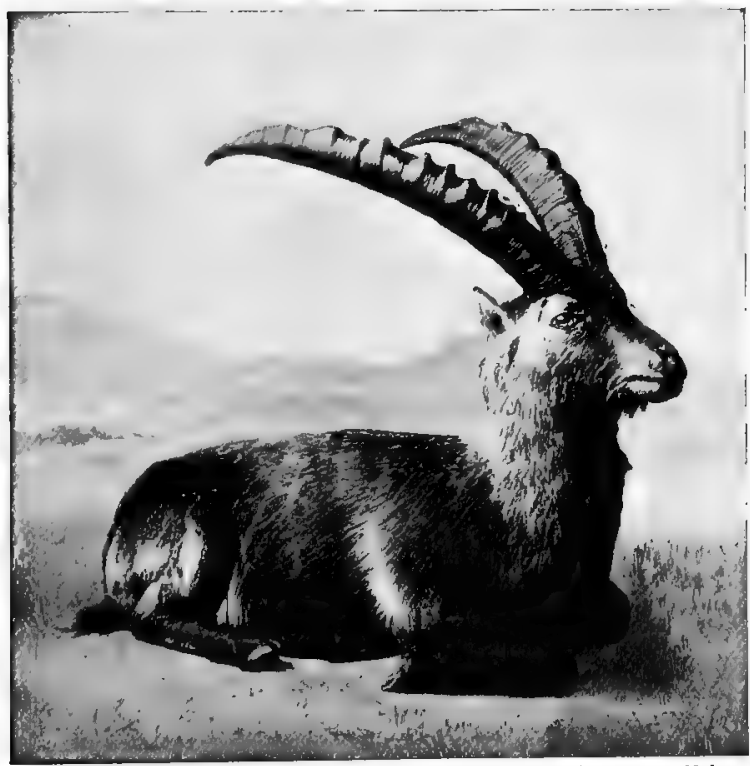

Photo by S. G. Payne, Aylesbury, by permission of the Hon. Walter Rothschild

YOUNG MALE ALPINE IBEX

The photograpb sbows the corrugated borns of the male

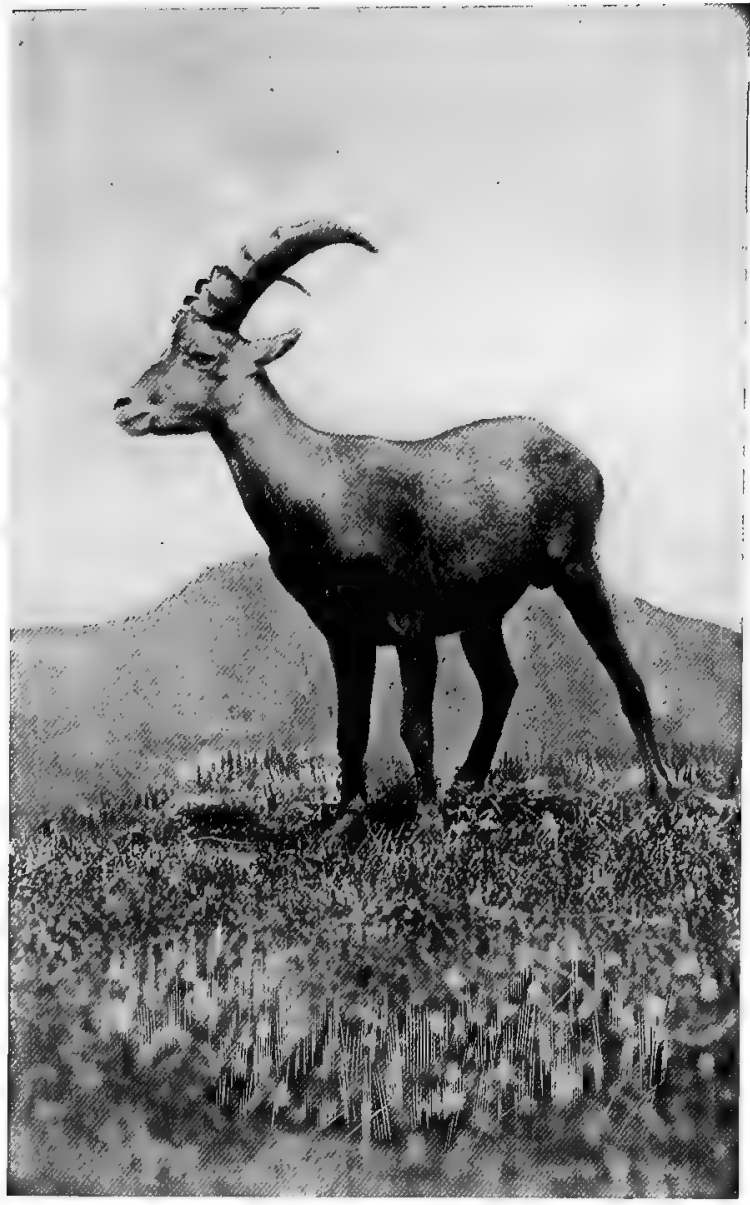

MALE ALPINE IBEX

The finest wild goat of Europe, formeriy common on the Swiss Alps, now only on a limited area on the Italian side

antelope and Wallachian sheep. It may well be called the king of the wild goats. A buck stands as much as $4 \mathrm{I}$ inches at the shoulder, and the maximum measurement of the horns is 63 inches, or over 5 feet! It has a long beard and mane, and stands very upright on its feet. Besides the Himalaya, it haunts the mountains on the Afghan frontier. The markhor keep along the line between the forest and snow, some of the most difficult ground in the hills. The horns are a much-prized trophy.

\section{THE TAHR}

The TAHR of the Himalaya is a very different-looking animal to the true goats, from which, among other characters, it is distinguished by the form and small size 


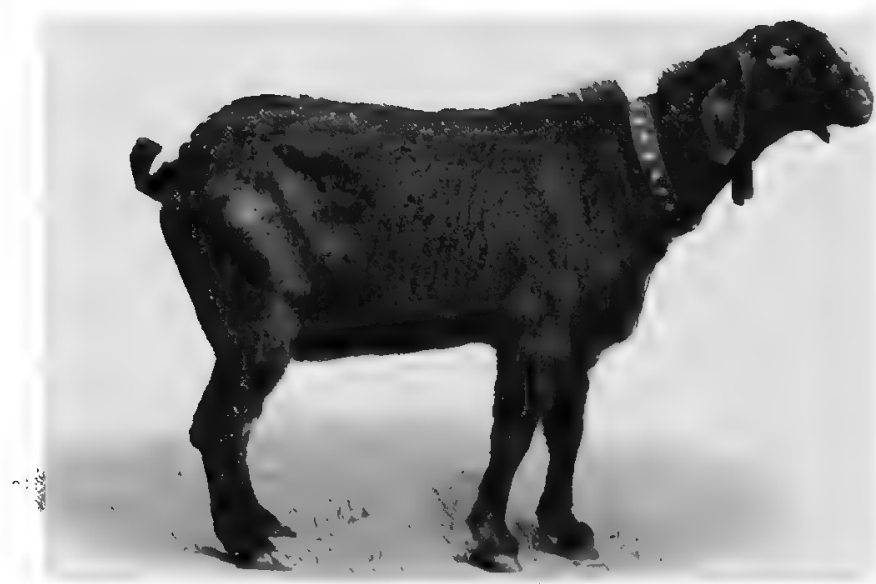

B) permission of P. Thomar, Esq.

\section{NUBIAN GOAT}

These goats come from Nubia and Upper Egypt. They are generally hornless and short-haired; the colour varies, being sometimes block, and sometimes tan and spotied.

to India for that object. A smaller kind is found in the mountains of Eastern Arabia, where very few, even sportsmen, have yet attempted to shoot them.

\section{The Nilgiri TAHr, or Nilgiri IBex}

Though not an ibex, the sportsmen of India early gave this name to the tahr of the Nilgiri and Anamalai Hills. The Himalayan species is covered with long, shaggy hair; the South Indian has short, smooth brown hair.

"The ibex," says Hawkeye, the Indian sportsman, of this animal, "is massively formed, with short legs, remarkably strong fetlocks, and a heavy carcase, short and well ribbed up, combining strength and agility wonderful to behold. Its habits are gregarious, and the does are seldom met with separate from the flock or herd, though males often are. The latter assume, as they grow old, a distinctive appearance. The hair on the back becomes lighter, almost white in some cases, causing a kind of saddle to appear; and from that time they become known to the shikaries as the saddle-backs of the herd, an object of ambition to the eyes of the true sportsman. It is a pleasant sight to watch a herd of ibex feeding undisturbed, the kids frisking here and there on pinnacles or ledges of rock and beetling cliffs where there seems scarcely safe hold for anything much larger than a grasshopper, the old mother looking calmly on. Then again, see the caution observed in taking up their resting or abiding-places for the day, where they may be warmed by the sun, listening to the war of many waters, chewing the cud of contentment, and giving themselves up to the full enjoyment of their nomadic life and its romantic haunts. Usually, before reposing, one of their number, generally an old doe, may be observed gazing intently below, apparently scanning every spot in the range of her vision, sometimes for half an hour or more, before she is satisfied that all is well, but, strange to say, seldom or never looking up to the rocks above. Then, being satisfied on the one side, she follows the same process on the other, and eventually lies down calmly, contented with the precautions she has taken. Should the sentinel be joined by another, or her kid come and lie by her, they always lie back to back, in such a manner as to keep a good look-out to either side. A solitary male goes through all this by himself, and wonderfully careful he is; but when with the herd he reposes in security, leaving it to the female to take precautions for their joint safety." 


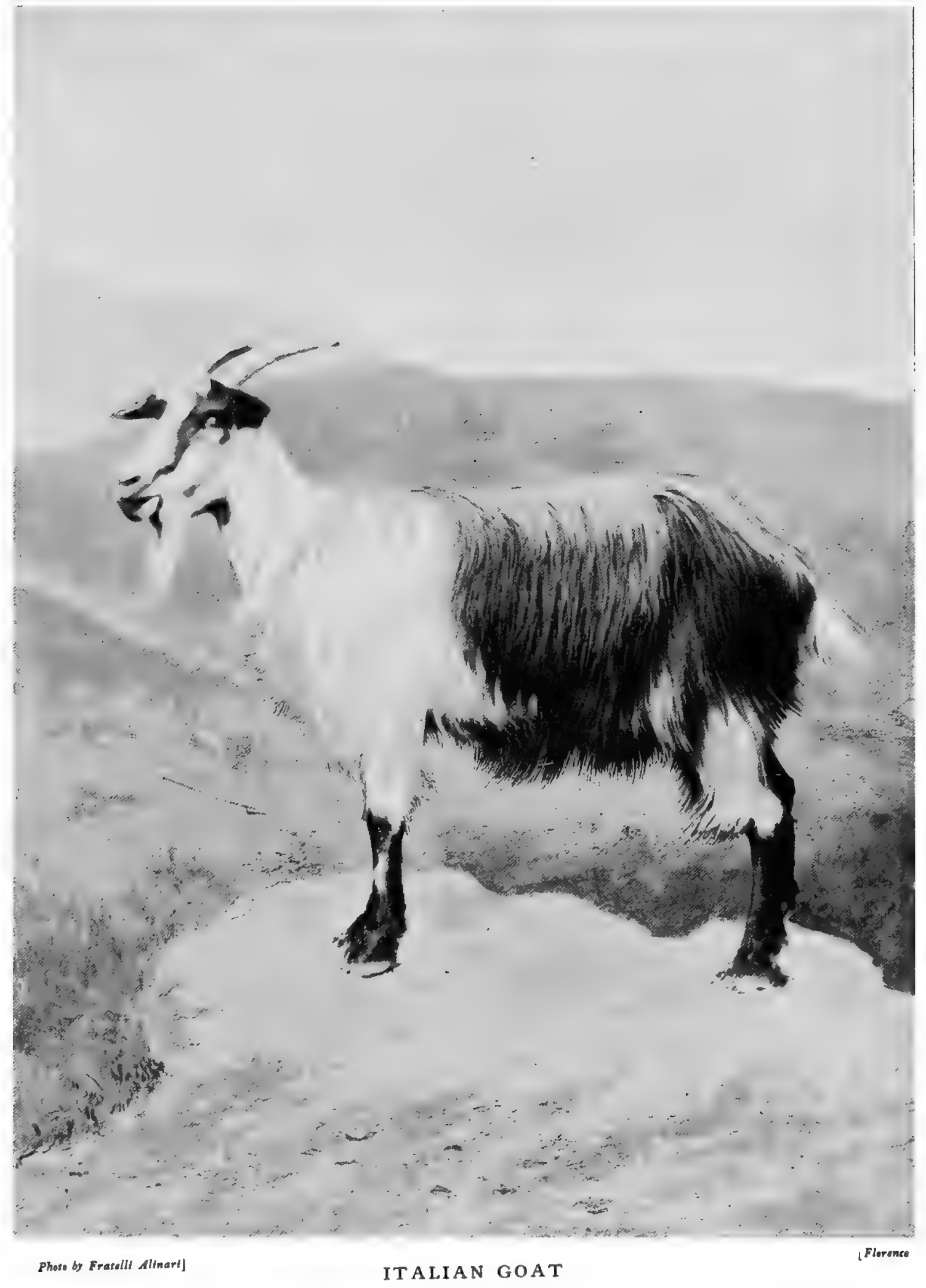

From the earliest Roman days shese goats have been the main form of livestock hept by the mountaineers of the Apennines 



\title{
CHAPTER XV
}

\author{
THE ANTELOPES
}

BY F, C. SELOUS

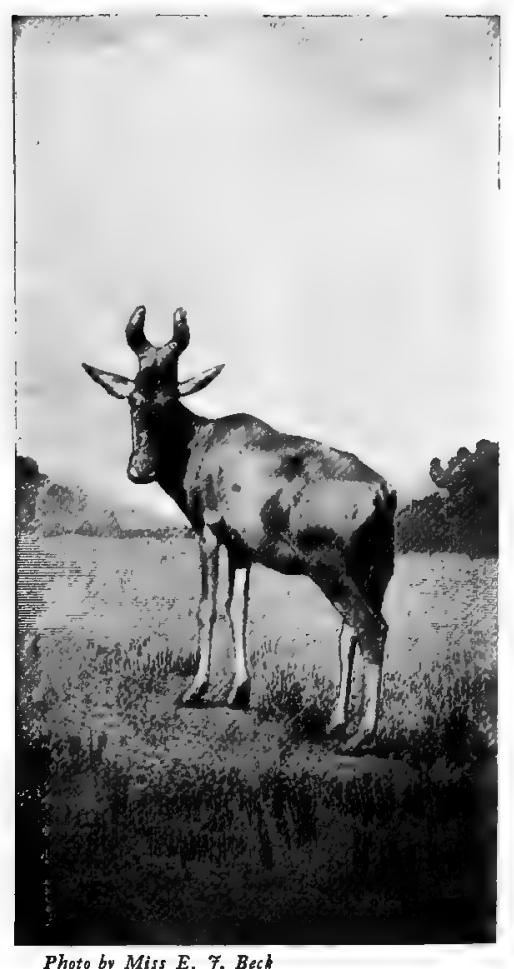

BUBALINE HARTEBEEST

A small species, found in Syria as well as in
7 HE True Antelopes (including the Gazelles) are strictly confined to the Old World, the Prongbuck of North America differing so much from all other living ruminants, in its horn growth and other particulars, that it is considered to be the sole representative of a distinct family.

\section{The Hartebeests}

With the exception of one species - the Bubal - which is found both in North Africa and Arabia, the HARTEBEESTS are entirely confined to the African Continent. They are animals of large size, standing from 43 to 48 inches at the shoulder, and are characterised by their long, narrow faces, high withers, and doubly curved horns, which are present in both sexes. Nine different species of this group are known to exist.

Although the ranges of these various species of hartebeest cover the greater part of the African Continent, it is noteworthy that each species keeps to its own ground, their several ranges but rarely overlapping.

All the hartebeests have a strong family resemblance, and are very similar in their habits. They are never found either in dense forests or in swampy or mountainous country, but are inhabitants of the arid deserts of Northern and South-western Africa, and of the open grassy plains and thinly forested regions of the high plateaux of the interior of that continent. They are extraordinarily fleet and enduring, and in my own experience I have never heard of one of these animals, of whatever species, having been overtaken or ridden to a standstill by a man on horseback. They are very inquisitive, and where they have not been molested will allow any unaccustomed object - such as a European in clothes to walk to within easy shot of them before running off. They soon gain experience, however; and in countries where they have been most persecuted hartebeests are the keenest-sighted and the most wary of all African game. They are very fond of climbing to the top of the large ant-heaps with which the plains of Africa are profusely studded, and from this point of vantage surveying the surrounding country. They live, I believe, entirely upon grass, and in the desert areas of their range seem able to subsist for long periods without drinking water. Their meat I have always thought very palatable. They are generally in fairly good condition, though they seldom carry much fat. Their fat, after being melted, becomes solid again immediately on cooling, and clogs on the teeth whilst being eaten. But very few African species, except the eland, ever become really fat; their life is too active, and the food-supply too uncertain, for them to put on flesh like European deer. 


\section{I 4 THE LIVING ANIMALS OF THE WORLD}

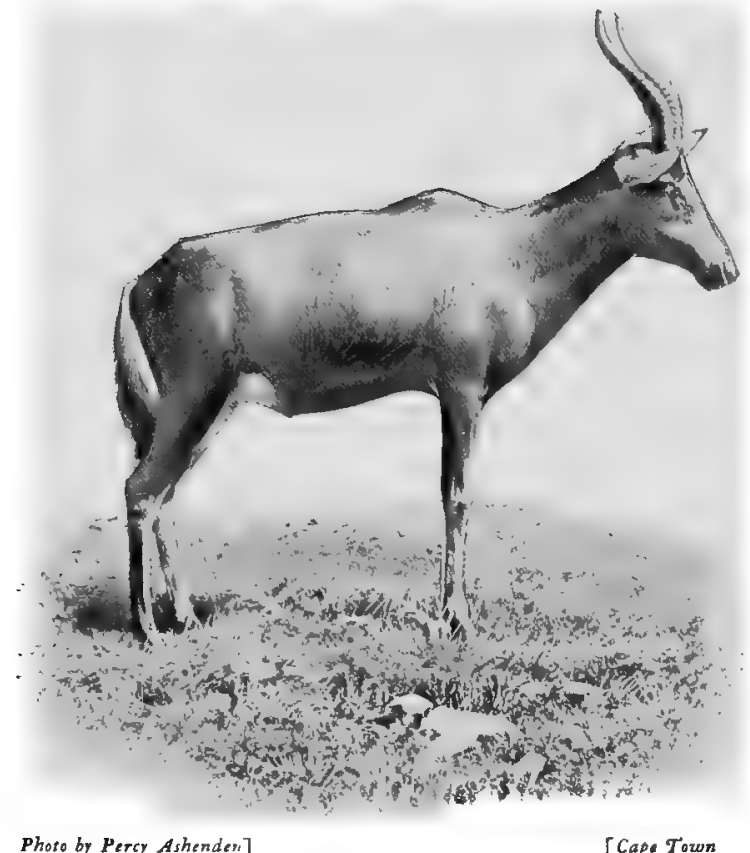

BLESBOK

A species formerly very numerous in South Africa, but now well-nigh exterminated

\section{BONTEBOK AND BLESBOK GROUP}

Nearly allied to the hartebeests are certain other antelopes of which it will be sufficient to mention but two species - viz. the BONTEBOK and the BlasBOK. These two antelopes, though doubtless distinct, since their points of difference are constant and unvarying, are nevertheless so much alike, and evidently so closely allied, that I look upon the former as a highly coloured and specialised race of the latter. The blesbok once had a far wider range than the bontebok, and ran in countless herds on the plains of the northern districts of the Cape Colony, the Orange River Colony, the Transvaal, Griqualand West, and British Bechuanaland, whilst the latter animal has always been confined to the sandy wastes in the neighbourhood of Cape Agulhas, the extreme southern point of Africa.

I think it, however, not improbable that ages ago the blesbok ranged right through Cape Colony to the sea-shore, and that subsequently the gradual desiccation

of the south-western portions of the country - which is still continuing - or several years of continuous drought, caused the withdrawal of the species northwards from the waterless parts of the country. Those, however, which had reached the neighbourhood of Cape Agulhas, where there is plenty of water, would have remained behind and formed an isolated race, which, being influenced by local conditions, would naturally in course of time have become differentiated from the parent stock. Be this as it may, the bontebok of to-day is nothing but a glorified blesbok, being slightly larger and more richly coloured than the latter animal. Its horns, too, are always black, whilst those of the blesbok are of a greenish hue. When they are in good condition, the coats of both these species of antelope, as well as of the SASSABY, another member of this group, show a beautiful satiny sheen, which plays over their purple-brown hides like shadows on sunlit water.

The few bonteboks which still survive are now all preserved on large enclosed farms; but their numbers are very small - less than 300 , it is believed. The farmers of Dutch descent now do their best to preserve rare species on their land.

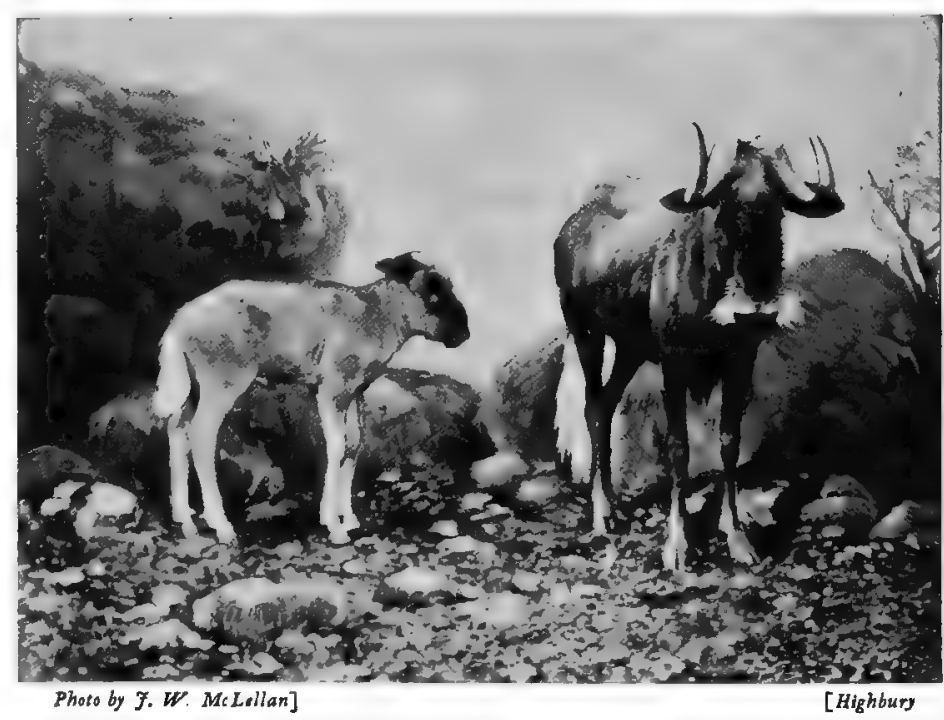

WHITE-TAILED GNU AND CALF

This "Wildebeest" is believed to be practically experminated as a wild animal 


\section{THE ANTELOPES}

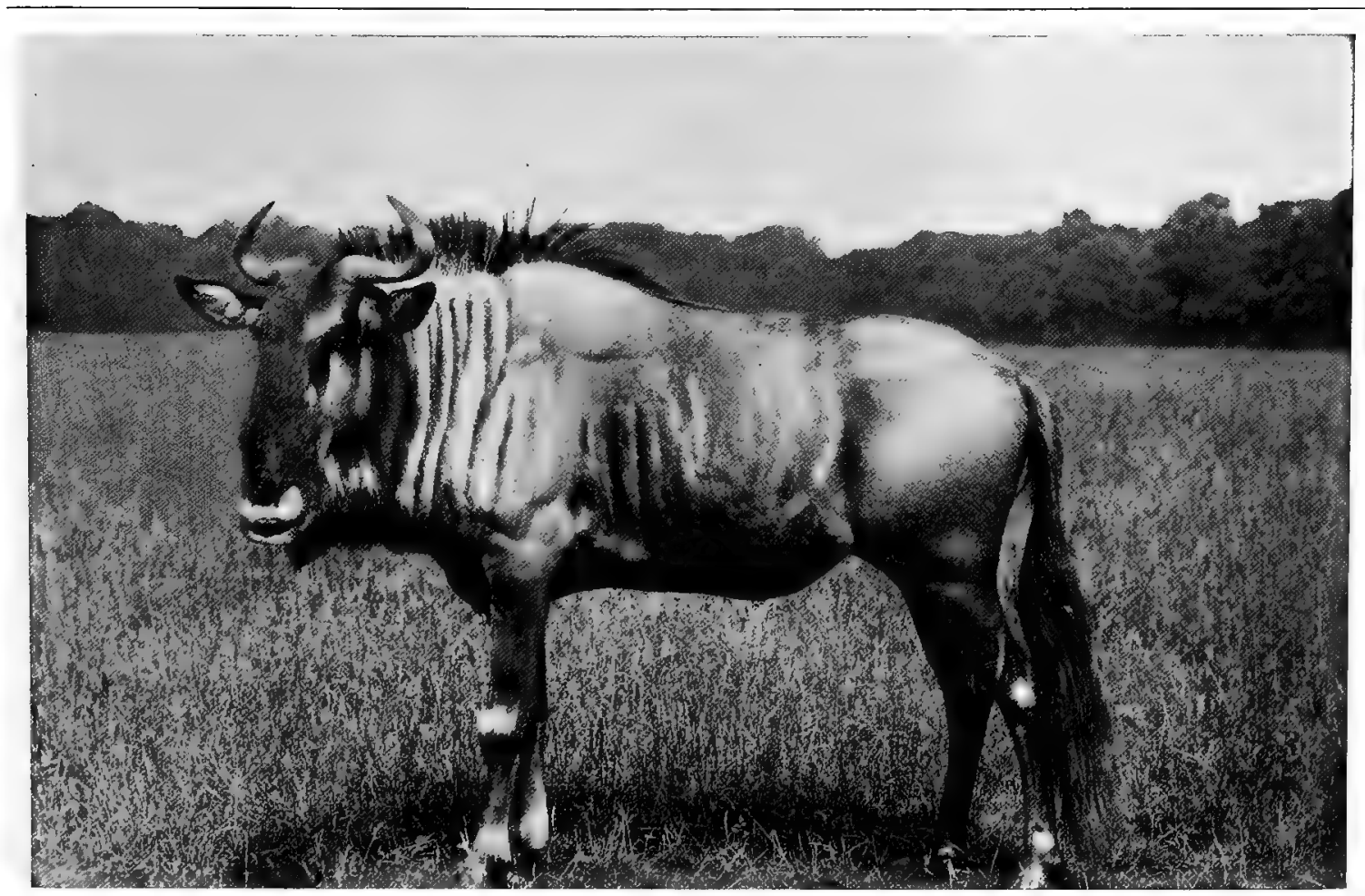

\section{A COW BRINDLED GNU}

This gnu, wbich is still found in great numbers in East Central Africa, indulges in the same curious antics as tbe wbite-tailed species

\section{THE GNuS}

These remarkable animals were once distributed throughout the greater part of Africa from the Cape to Abyssinia, and their range is even now very extensive, though what was once the most numerous and the most eccentric-looking species of the group has almost ceased to exist.

The gnus are of large size, and at first sight appear to have the head of a buffalo, the tail of a horse, and the limbs and hoofs of an antelope. Their heads are very massive, with broad muzzles and widely separated, hairy nostrils; their necks are maned, tails long and bushy, and both sexes carry horns. They are known as "wilde beeste," or "wild cattle," to the Dutch colonists of South Africa.

The White-TAiled GNU, or BlaCK WILDEBEEST, as it is more commonly called, was once found in great numbers on the karroos of Northern Cape Colony, and throughout the vast plains of the Orange River Colony, Transvaal, Griqualand West, and British Bechuanaland. Its range, in fact, was coequal with that of the blesbok. Even as lately as in 1875 and 1876 I personally saw very considerable herds of these quaint animals in the Orange River Colony and the Western Transvaal. When the present war broke out in 1899, there were only two herds of black wildebeest left alive. These animals numbered some 500 head altogether, and were protected by Dutch farmers. There

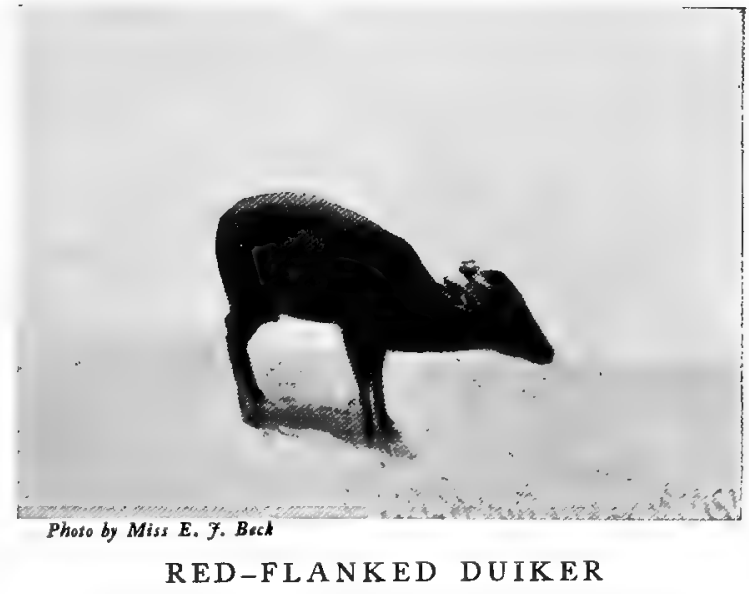

Tbe duikers are for tbe mot part diminutive and graceful antelopes, witb simple, spike-like borns 
are probably very few of them left to-day, and it is scarcely possible that this most interesting animal will long escape complete extinction.

Black wildebeests, before they had been much persecuted, were so inquisitive that, in the words of Gordon Cumming, they would "caper and gambol " round a hunter's waggon or any other unusual object, and sometimes approach to within a couple of hundred yards, when, whisking their long white tails, they would gallop off with loud snorts. They were always, however, very keen-sighted, and soon became extremely wary and almost impossible to approach on foot in the open plains they frequented, whilst their powers of endurance and fleetness of foot were such that they could only be overtaken by a well-mounted hunter. In spite of these advantages, however, the value of their skins, and the ever-increasing number of hunters, armed with long-range rifles, practically brought about the extermination of this species of gnu in a few decades.

The BRINDLED GNU is a larger animal than the last-named species, standing $4 \frac{1}{2}$ feet and upwards at the shoulder. This animal once ranged from the Vaal River northwards, throughout Eastern and Central Africa, to the north of Kilimanjaro, where its range overlaps that of a closely allied form, the WHITE-BEARDED GNU, which is only found in certain districts of Eastern Africa. In general habits these two varieties seem to be identical.

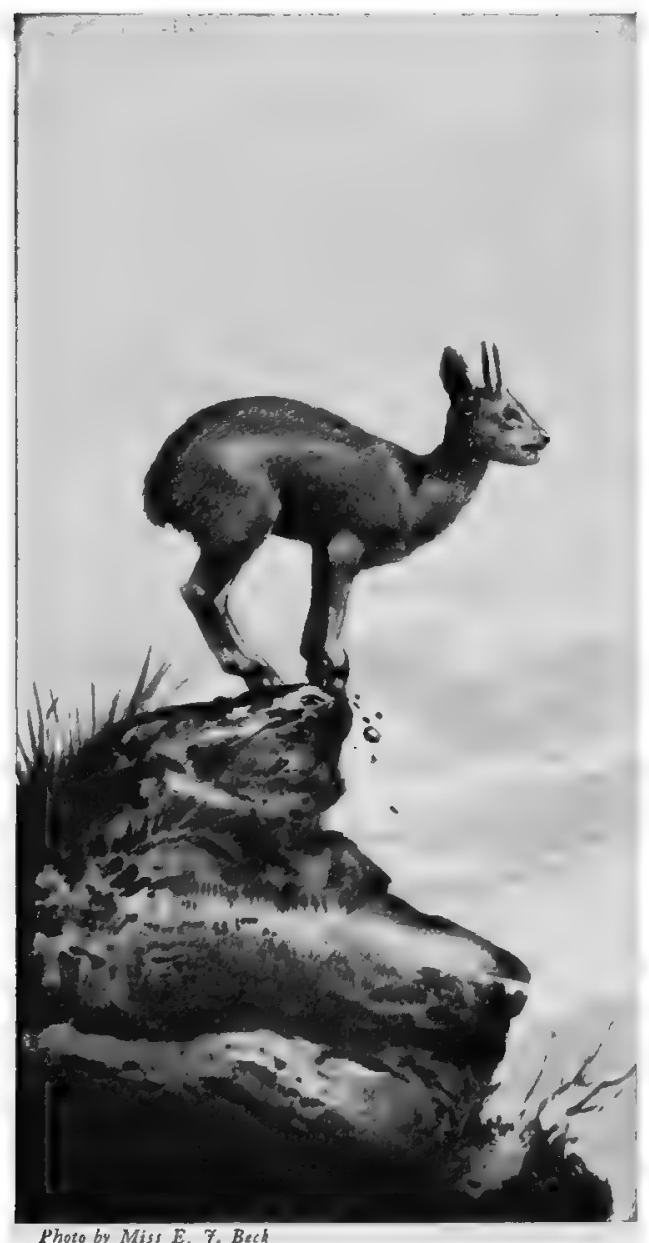

KLIPSPRINGER

The "cliff-jumper" is as active in its habits as a chamois, and is found in most of the mountain-ranges of Africa

In the interior of Southern Africa, both north and south of the Zambesi, I have met with very large numbers of BLUE WILDEBEESTS. They usually run in herds of from ten to twenty individuals, but towards the end of the dry season collect in droves of 200 or 300 . They are often found in company with zebras and sassaby antelopes. Their flesh resembles coarse beef, and, to my thinking, is not ill-flavoured.

\section{The Smaller Bucks}

In addition to the great number of antelopes of large size which inhabit the African Continent, there are also very many small species, the life history and habits of some of which are as yet but imperfectly known, since they are denizens of dense forests, and feed principally at night.

All these small African antelopes are divided into two sub-families. The first comprises the African DUIKERs and the Indian FOUR-HORNED ANTELOPE, and the second the DIK-DIKS, ORIBIS, KLIPSPRINGER, and certain other small bush-antelopes.

The African duikers are distributed throughout Africa south of the Sahara, and are represented by some twenty different species, the largest of which approaches a small donkey in size, whilst the smallest is not much larger than a hare.

The majority of these dainty little antelopes are inhabitants of the dense tangled forests of the coast-belts of Africa, and are therefore but seldom seen by travellers and sportsmen. One species of the group however, the COMMON DUIKER of South Africa, is a very well-known animal. This little antelope inhabits much more open country than most of its congeners, and has an enormous range, extending from Cape Agulhas to Somaliland, whilst 


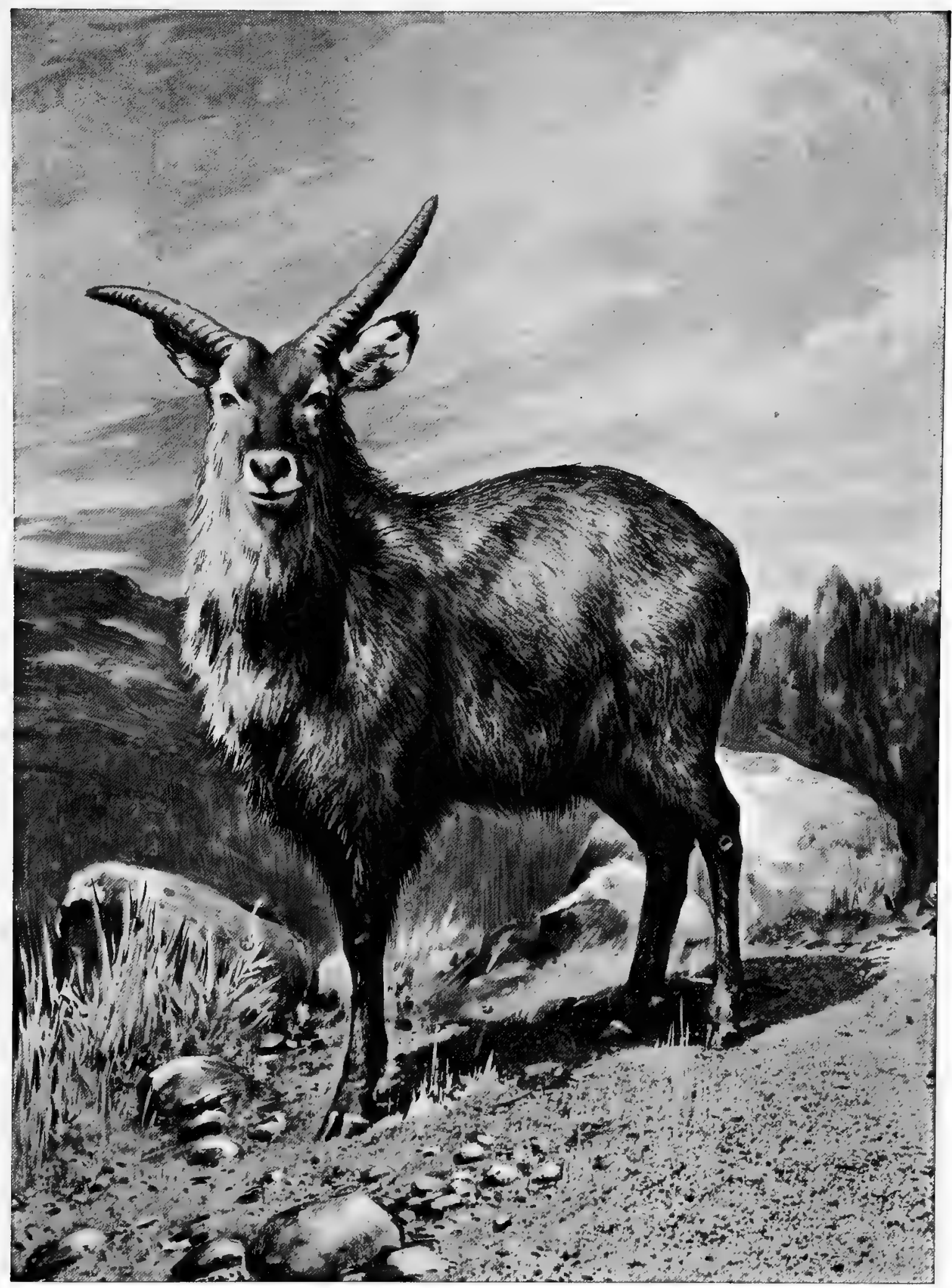

Photo by G. W. Wilson \& Co., Led.]

SING-SING WATERBUCK

The sing-sing and its relatives differ from the true waterbuck by the absence of the white elliptical ring on the rump 


\section{I 8 THE LIVING ANIMALS OF THE WORLD}

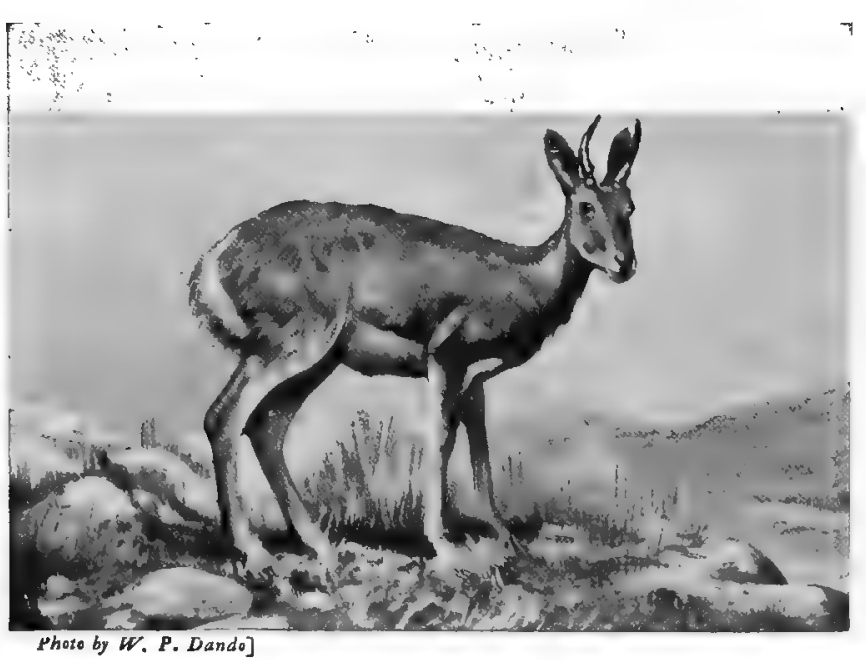

MOUNTAIN REEDBUCK

One of a group of small antelopes still common in many parts of Africa two very nearly allied forms are found in Senegal and Abyssinia respectively.

In most species of duikers both sexes are horned, but in the case of the common duiker it is very exceptional to find a female with horns, and in all my experience I have only known of three such cases.

The FOUR-HORNED ANTELOPE is the Indian representative of the African duikers, and is found along the foot of the Himalaya from the Punjab to Nepal, and in suitable localities throughout the peninsula of India. It frequents wooded hills, but avoids dense jungle. Like its nearest allies, the duikers, it is solitary in its habits, more than two of these antelopes seldom being seen together. The growth of four horns on the skull of this antelope and on certain breeds of domesticated sheep is a curious fact which has not roused as much comment as it deserves.

\section{THE KLIPSPRINGER}

Turning to the second sub-family, we may select the KLIPSPRINGER as the most characteristic . species to describe. This beautiful little animal, which is often called the African Chamois, is found in suitable localities from the Cape to Abyssinia. In the southern and northern portions of its range the klipspringer is an inhabitant only of rugged mountain-ranges, and ascends to a height of $9, \mathrm{COO}$ or 10,000 feet above sea-level. In the more central regions of its habitat, however, although it always lives amongst rocks, and thoroughly justifies its name of "rock-jumper," it is often found in regions where there are no high mountain-ranges. It used to be very common in Matabililand, both in the Matopo Hills and on the isolated granite kopjes which are so numerous in that country, and usually are not more than 200 or 300 feet in height. In Mashonaland I have found it living amongst granite rocks in the beds of the larger rivers, and actually on the same level as the surrounding country; whereas on Wedza, a great mountain-mass of slate and ironstone, which rises to a height of about 2,000 feet above the surrounding country, and to the top of which I once climbed, I did not see any klipspringers. The hoofs of this little animal are curiously different from those of any other African antelope, being remarkably short and small, with very deep hollows. This adaptation to its requirements enables the klipspringer to obtain a foothold on any small

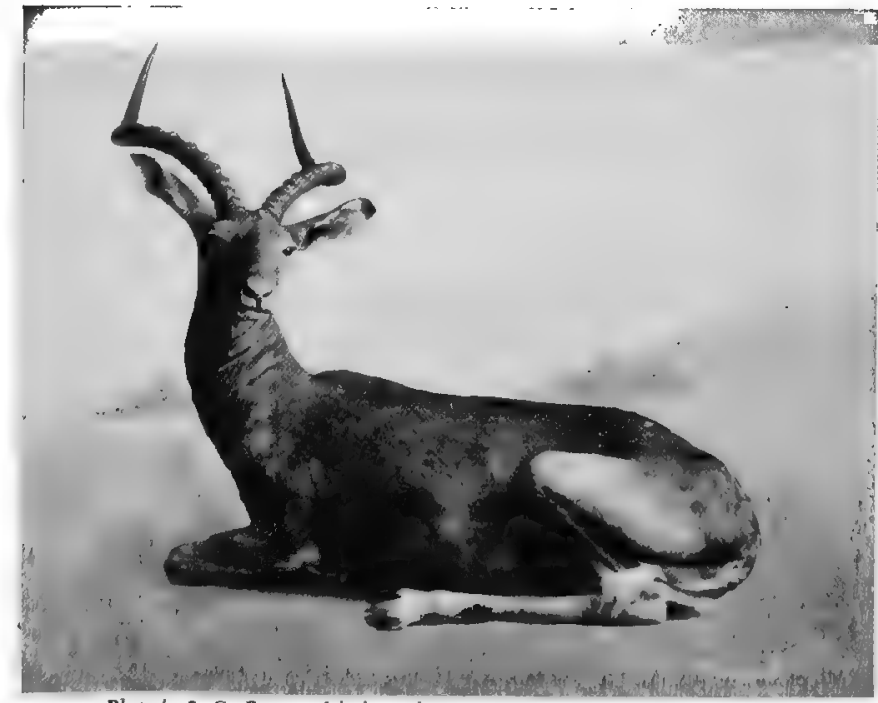

Phote by S. G. Payne, Aylesbury, by permission of the Hon. Waller Rothschld MALE IMPALA, OR PALLA

The beautifully curved borns of the male palla form some of the most graceful of tropbies 
projecting piece of rock, and to climb in a series of little jumps up the faces of cliffs which seem almost perpendicular.

In height the klipspringer stands about $I$ foot 9 inches at the shoulder. The males alone carry horns, which are straight and ringed at the base, and vary from 3 to 5 inches in length. The coat is of a greeny yellow-brown colour, with the hairs hollow and brittle. These little animals are usually met with singly, or in twos and threes together. When caught young, they become wonderfully tame, and make the most charming pets, being very playful and fond of jumping, with surprising ease and grace, from the floor of a room on to any elevated position, such as a table, mantelpiece, or window-sill.

\section{THE WATERBUCKS}

The largest animals in the first of three groups now to be considered are the WATERBUCKS, antelopes of stout and sturdy build, standing from 45 to 50 inches at the shoulder, and covered with long, coarse hair, especially on the neck, in both sexes. The males alone carry horns, which vary from 20 to 36 inches in length, and are strongly ringed in front for three-fourths of their length. They are sublyrate in shape, being first inclined backwards and then forwards at the tips. There are three well-marked species of waterbuck-viz. the COMMON WATERBUCK of South Africa, whose range extends from the Limpopo northwards, through Nyasaland to German and British East Africa, and to the Shebeyli River, in Somaliland ; the SING-SING of Senegal and Gambia; and the Defassa WATERBUCK of Western Abyssinia and the Nile Valley, south to Uganda and British and German East Africa. In habits all species of waterbuck are very similar. They live generally, though not invariably, in herds of from ten to twenty individuals, and in such small herds

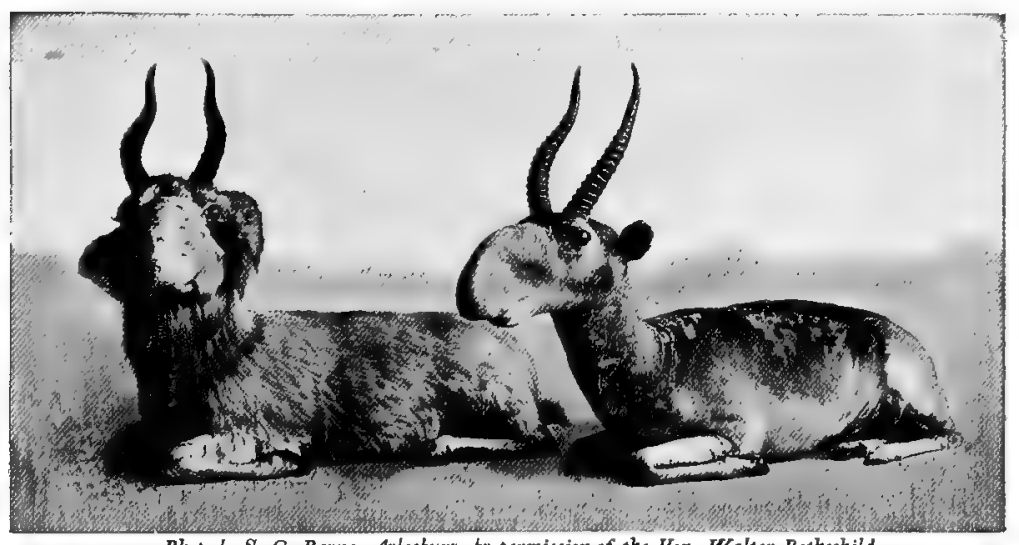

Photo by S. G. Payne, Aylesbury, by permission of the Hon. Walter Rothschild

MALE SAIGA ANTELOPES

These antelopes inhabit the East Russian steppes. The thick woolly coat turns nearly white in there is seldom more than one full-grown male present. In the interior of South Africa the waterbuck is often met with amongst steep stony hills and at a distance of more than a mile from the nearest river. Speaking generally, however, this antelope may be said to frequent the near neighbourhood of water, but to prefer dry to swampy ground. When chased by dogs it always makes for water, and will plunge fearlessly into broad, deep rivers, regardless of crocodiles, to which ravenous reptiles it sometimes falls a victim. In South Africa waterbuck vary much in colour even in the same district, some being reddish brown, whilst others are of a very dark grey. The flesh of the waterbuck is coarse, and sometimes rather strongly tasted, and when in good condition the fat is very hard.

The REEDBUCKS are similar in essential characters to the waterbucks, but are of smaller size, and have more bushy tails, and naked spots on the sides of the head beneath the ears.

Of this group the COMMON REEDBUCK of South Africa is the best known. This animal stands 3 feet at the withers, and is of a soft greyish fawn-colour, with a large fluffy tail, which is always thrown up when the animal runs, exposing the white under-surface. The males alone carry horns, which curve backwards and then forwards, and attain a length of from 12 to 16 inches. Reedbucks are met with singly or in twos and threes, and never congregate in herds. 
though I have seen as many as eight, belonging probably to three or four families, feeding in close proximity to one another on young green grass.

Another member of the reedbuck group is the RooI RHEBUCK of South Africa. 'This latter species, though a much smaller animal, is very similar to the common reedbuck in colour, shape, and general appearance; it is quite distinct in its habits and mode of life, as it lives in small herds of from four or five to fifteen head, amongst rugged stony hills, often far from water.

\section{THE BLACKBUCK OF INDiA}

This handsome species is found throughout India wherever there are open cultivated plains. The male stands about 32 inches at the shoulder, and when full grown is of a glossy black colour, with the exception of a chestnut-coloured patch at the back of the neck, and some markings of the same colour about the face. The belly and insides of the limbs are pure white, the line between the black and white being very clearly defined. The whole body and frame are very compact, strong, and beautifully proportioned, and the head is carried high. The males alone in shape, annulated almost to from 18 to 28 inches. Young coloured instead of black. met with in considerable cultivated tracts alternate with much damage to the natives' first execute a series of probefore finally settling down to prisingly fleet, and can seldom greyhounds, although they down without difficulty by are often called, hunting-

The Palla, which is Eastern Africa from Bechuanathe most graceful of animals. and is never found far from general bright reddish brown, alone carry horns, which are vary from 14 to upwards of finest specimens of the palla southerly and most northerly animals inhabiting the interand carrying shorter horns. in herds of from twenty to alarmed, they bound over

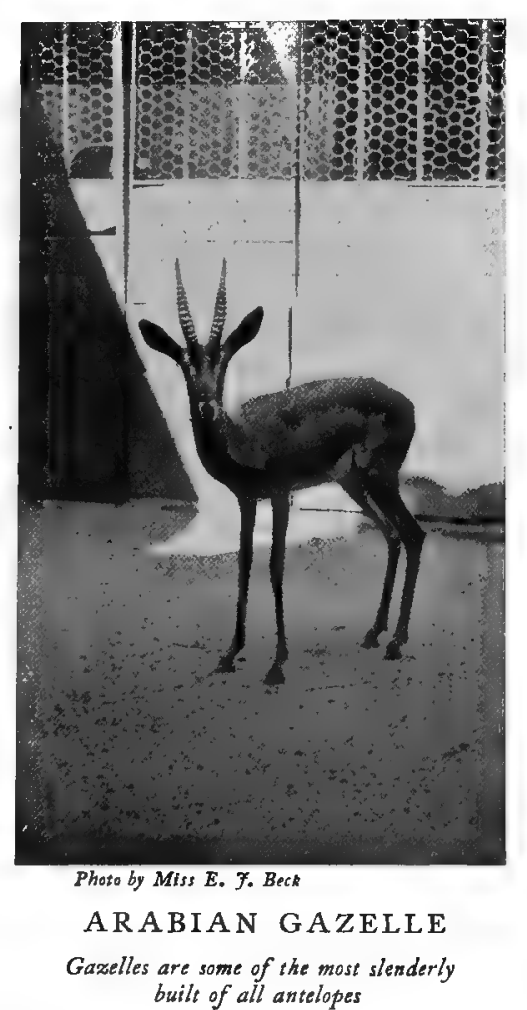
carry horns, which are spiral the tips, and vary in length bucks and does are fawnThese antelopes are usually herds on open plains in which waste land, and they often do crops. When alarmed, they digious bounds into the air a steady run. They are surbe overtaken by the fastest can be caught and pulled trained cheetas, or, as they leopards.

found in Southern and land to Kordofan, is one of It is a forest-loving species, water. Both sexes are of a with white bellies. The males very graceful in shape, and 20 inches in length. The are met with in the extreme portions of its range, the mediate districts being smaller Pallas are gregarious, living over one hundred. When bushes or any other obstacles with the utmost ease and grace, and appear to get over the ground at a high rate of speed. They are, however, very commonly run down and torn to pieces by wild dogs, which hunt in packs, and are very destructive to African game.

Of far less graceful appearance than the two preceding species is the SAIGA, which, though structurally closely allied to the gazelles, has been placed by naturalists in a genus by itself.

This curious-looking animal, which is chiefly remarkable for its large swollen-looking nose and light-coloured horns, is an inhabitant of the steppes of the South-eastern Europe and Western Asia. In height it stands about 30 inches at the withers, and is of a dull yellowish colour in summer, turning to nearly white in winter. The males alone carry horns, which are sometimes 13 or I 4 inches long, and of a peculiar colour which has been likened to pale amber, 
At the present day the saiga is only found in Europe on the plains between the Don and the Volga, but to the east of the Ural River its range extends over the Kirghiz Steppes and the high plains of all Western Siberia. Living in open country, and having the senses of hearing, sight, and scent all highly developed, the saiga is a difficult animal to approach, and can only be successfully stalked by an expert hunter. In summer it is usually met with in small, scattered bands, which, when driven southwards by snow and cold, are collected into considerable herds in the more southerly portions of its range. In very severe winters whole herds have been known to perish in snow-drifts, and in such inclement seasons large numbers are also: killed by the natives. The flesh of the saiga is said to resemble mutton, and is held in much esteem.

\section{THE Gazelles}

We now come to the Gazelles, among which are comprised many of the best known and most beautiful of the small or medium-sized antelopes. In the true gazelles both sexes generally carry horns. Indeed, this rule is universal in those of Africa and Arabia; and there

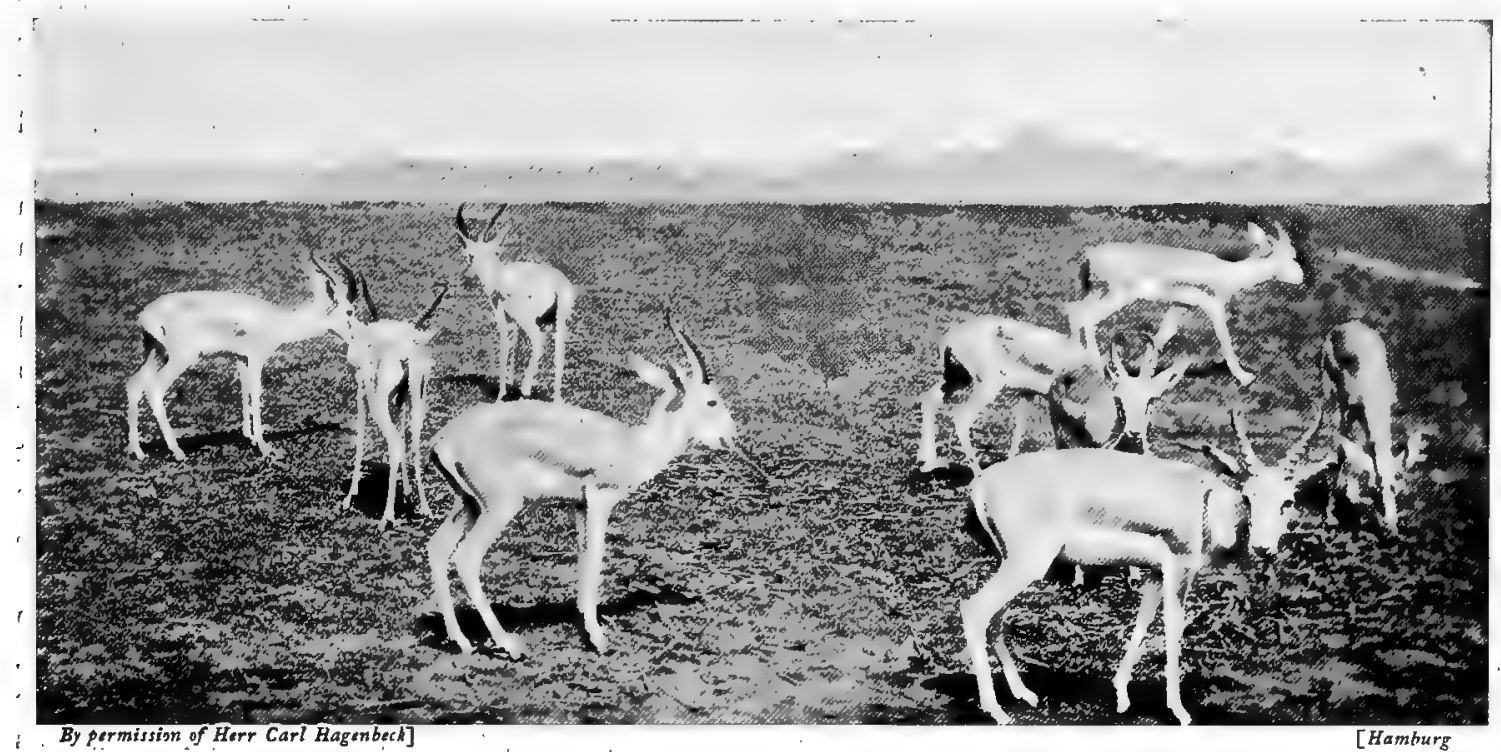

GOITRED GAZELLES FROM MESOPOTAMIA

These animals are inhabitants of rocky and desert ground. They are often kept tame by the zuandering Arabs

are only four species known - all Asiatic - in which the females are hornless: viz. the TIBETAN Gazelle, Prejevalski's Gazelle, the Mongolian Gazelle, and the Persian Gazelle.

The range of the various species belonging to this large group is very extensive, comprising the whole of Northern and Eastern Africa, Arabia, and Western and Central Asia, as well as Mongolia and India. The gazelles are inhabitants of the open plains and arid desert regions of the Old World, and, although sometimes met with in tracts' of country where there is a certain amount of scattered bush or open stunted forest, are never found in any kind of jungle or thick cover.

On the sandy plains of North-western Africa are found the RED-FRONTED GAZELLE of Senegal and Gambia; the little-known MHORR, GAZELLE of South-western Morocco; and the DAMA GAZELLE, a species which has been known to naturalists ever since the time of Buffon. A near ally of the last-named animal is the RED-NECKED GAZELLE of Dongola and Senaar. In North-eastern Africa are found the large and handsome SOEMMERRING'S GAZELLE; the ISABELla Gazelle, of the coastlands of the Red Sea; Heuglin's Gazflle; Pelzeln's Gazelle, of the maritime plains of Northern Somaliland; and SPEKE'S GAZELLE, of the interior of the same country; whilst farther south the group is represented by the large and beautiful GRANT's 


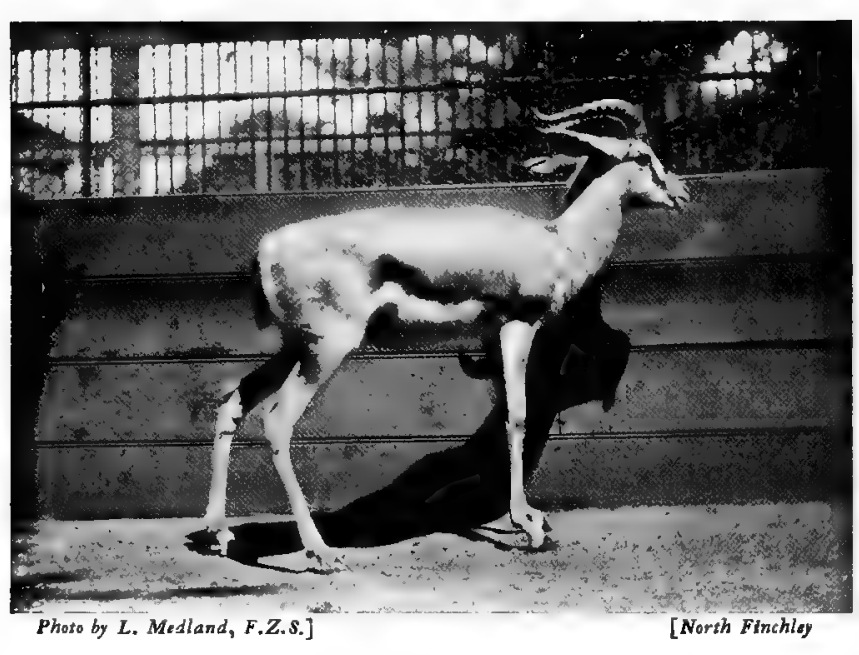

SPEKE'S GAZELLE

Found in the interior of Northern Somaliland
Gazelle, with its allies Peters's Gazelle and Thomson's Gazelle. The well-known DorCas Gazelle is an inhabitant of Morocco and Algeria, ranging through Egypt into Palestine and Syria; the MARICA GAzELLE, the Muscat Gazelle, and the Arabian GAZELLE inhabit the deserts of Arabia; the EDMI GAZELLE is found in the mountain-ranges of Morocco, Algeria, and Tunis; while LODER's GAzELLE inhabits the sandy tracts of the interior of Algeria and Tunis. In Asia, besides the four species of gazelle already enumerated in which the females are hornless, one other member of the group is met with. This is the INDIAN GAZELLE, a species very closely allied to the Arabian form.

Of the whole genus GRANT's GAzELLE is the most beautiful. This handsome animal, which was first discovered by the explorers Speke and Grant in I860, is an inhabitant of Eastern Africa, from the neighbourhood of Lake Rudolph southwards to Ugogo. In size the average height at the shoulder of males of this species is about 34 inches. The coat is close and short and of a general fawn colour, the rump and belly pure white, and the face marked with a rufous band from the horns to the nose and with streaks of white on each side. The upper surface of the tail is white, with a black and tufted tip. The horns, which are very elegant in shape, being first curved slightly forwards and then backwards, are much longer and more powerful than in any other gazelle, and attain a length of 30 inches in the males and 17 inches in the females.

Grant's gazelles, though they undoubtedly find their most congenial home in open country, have also been met with by recent travellers in bush-sprinkled wastes and stony, rugged hills. They are, however, never found in dense jungles or high mountains. They live in herds of from half a dozen to twenty or thirty individuals, though in certain localities as many as 200 have been seen together. They are fond of consorting with other game, such as Burchell's and Grevy's zebras, Coke's hartebeest, and the beisa oryx, and are often met with at long distances from the nearest water. They are keen-sighted and wary, and from the open character of the country in which they are usually encountered are often difficult to stalk. When in good condition, the meat of this gazelle is said to be excellent.

The nearest ally of the true gazelles is undoubtedly the SpRINGBuck of South Africa. Owing to the protection which it has received of late years, this graceful antelope is now a common animal in many parts of South Africa, and in the north-western portions of the Cape Colony still sometimes collects into prodigious herds, which travel through the country in dense masses, destroying every vestige of grass on the

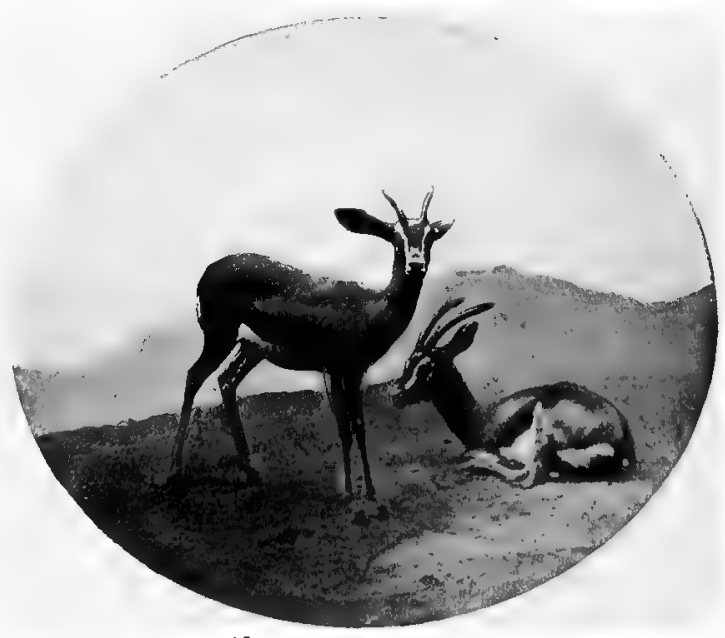

Photo by W. P. Dando]

GAZELLES FROM EGYPT 
line of their advance, and causing considerable anxiety to farmers, whose flocks of sheep and goats are sometimes swept away by the migrating springbucks. In former years the migration of these antelopes in countless thousands from the deserts of Namaqualand to the countries farther south was a common occurrence, an unerring instinct guiding the wandering herds to districts where rain had lately fallen and caused a new growth of green grass. The animals composing these migrating herds were called by the Dutch settlers of the Cape Colony "Trekbokken," or " travelling-bucks."

Two other antelopes, the DIBATAG and the GERENUK, are included in the present group; but both, whilst typically gazelline in certain respects, differ so much in other ways from all members of that group that each has been placed in a separate genus.

The DiBATAG is a very remarkablelooking antelope, only found in certain

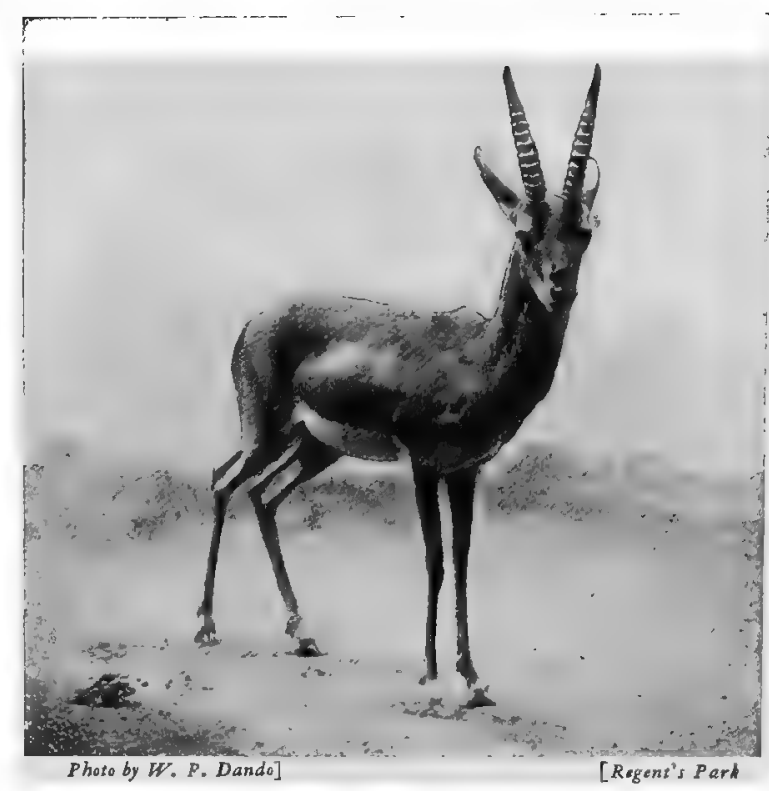

RED-FRONTED GAZELLE

Inhabits Dongola atd Senaar districts of Central Somaliland, where it was first discovered by Mr. T. W. H. Clarke in I89o. This species shows the face-markings of the gazelles, whilst the horns, which are only present in the males, much resemble in shape those of a reedbuck. They are rather short, attaining a length of only I I or I 2 inches, and their basal halves are strongly ringed in front. The neck of this antelope is singularly long and thin, and the tail, which is held curved forwards over the back when the animal is in motion, is also much elongated, and only tufted at the tip. The dibatag frequents sandy ground sparsely covered with low thorn-bushes,

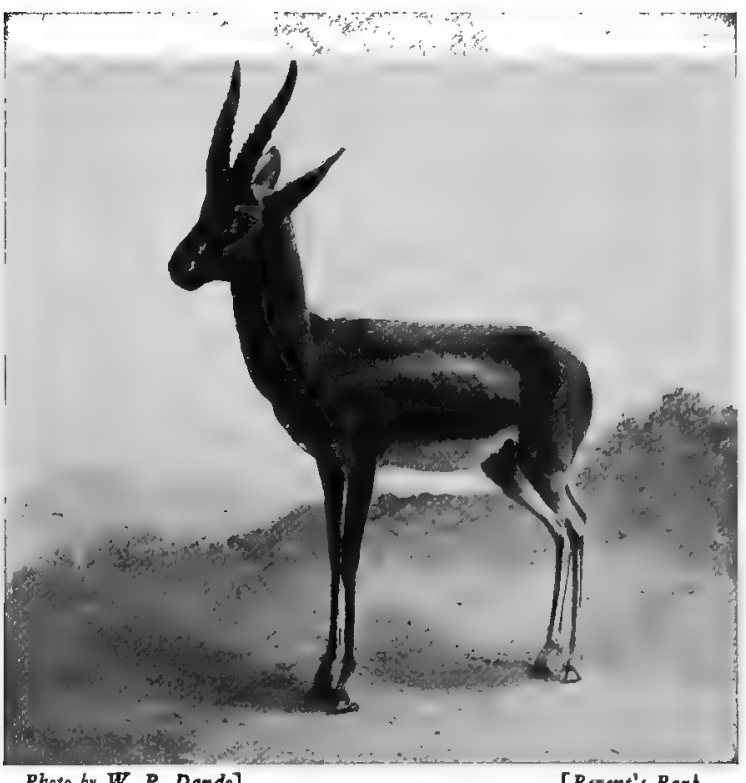

Photo by W. P. Dando] and lives in small families, being usually met with in twos or threes, whilst it is rare to find more than four or five consorting together.

The GERENUK, like the last-named animal, is an East African species, but has a more extended range, being found all over Somaliland, and thence southwards to the Tana Valley and the Kilimanjaro district of British East Africa. The most remarkable external characteristic of this species is the excessively long neck. The males alone carry horns, which attain an average length of I 2 or I 3 inches, and, though somewhat gazelle-like in shape, are more strongly crooked forwards at the points. The skull of this species is more dense and solid in structure than in the true gazelles, and the cheek-teeth are smaller in size.

Coming now to the Sable Antelope group, we find an assemblage of antelopes which are all of large size and handsome appearance, and in all of which both the

RED-FRONTED GAZELLE

Another view of the specimen shown above 


\section{THE LIVING ANIMALS OF THE WORLD}

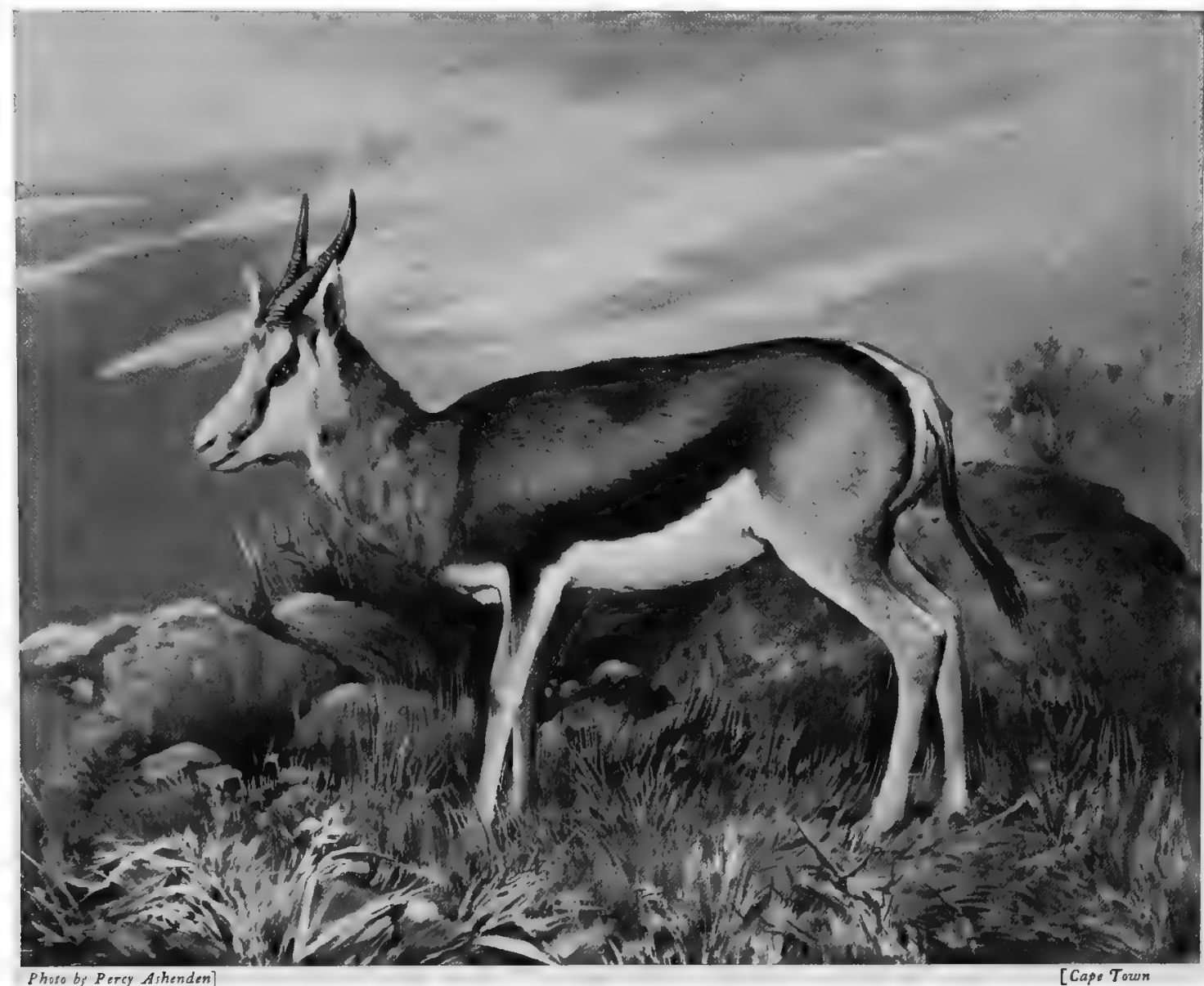

MALE SPRINGBUCK

Once the most numerous species in South Africa, where it is still not uncommon. Its migrations, or "treks," at certain seasons were one of the sights of the veldt

males and females are horned. With the single exception of the BEATRIX ORYx, which inhabits Arabia, all these antelopes are denizens of Africa. One species of the group, the BLUEBUCK, which appears to have been entirely confined to the mountainous districts of the Cape Peninsula, became extinct during the first decade of the last century. Little is known as to the life history of this animal, but it was undoubtedly nearly allied to the larger and more handsomely marked ROAN ANTELOPE. This latter animal once had a more extensive range than any other antelope, as it was found in almost every part of Africa south of the Sahara, with the exception of the Congo forest region. It has now been exterminated in the more southerly portions of the country, but from the Limpopo to the Upper Nile, and thence to the Niger, it is still to be found wherever the surroundings are suitable to its requirements.

A large bull roan antelope will stand 4 feet 9 inches at the withers. The general colour of the body differs in individuals, even in the same district, varying from a very light shade of brown to dark grey or red-roan. The front and sides of the face are jet-black in the adult male, and dark reddish brown in the female, with two long white tufts of hair under the eyes. The muzzle and extremity of the lower jaw are white. The hair on the under side of the neck is long and coarse, and a stiff mane about 3 inches in length runs from behind the ears to the withers. The ears are very long, and in the females and young males tufted. The horns are curved backwards, and in the male are very stout and strong, attaining 
a length of from 26 to 34 inches. In the female the horns are shorter and slighter, and not so strongly ringed.

Roan antelope are usually met with in small herds of from six to a dozen members, and never congregate in large numbers. I do not think I have ever counted as many as thirty together. I have found them fairly common in certain districts, but nowhere very plentiful. They frequent open plains and thinly forested country, and are never found far away from water. Bucks often become savage when wounded, and will sometimes charge viciously if approached incautiously. They can use their horns with great dexterity, and play havoc with a pack of dogs.

The SABLE ANTELOPE, though considerably smaller than the roan, is yet a handsomer animal. In colour the adult male, when in high condition, is jet-black all over with the exception of the white face-markings and the snow-white of the belly and insides of the thighs. The mane is longer and more bushy than in the roan antelope, and often hangs down on either side over the withers. The horns, too, are much finer, and, sweeping backwards in a bold curve, are commonly upwards of 42 inches long, and have been known to reach 50 inches. The striking colour, large size, and horns of this creature make it one of the most-prized trophies of the sportsman. The skin, when prepared and laid down as a rug in halls or dwelling-rooms, is far more handsome than that of any deer. The female of this species is usually of a rich red-brown in colour instead of black as in the male. South of the Zambesi, however, old cows become almost absolutely black. North of the Zambesi both male and female sable antelopes are dark red in colour rather than black. The horns in the female are slighter and less curved than in the male, and are also considerably shorter, as a rule not measuring over 30 inches in length.

The range of the sable antelope extends from the northern districts of the Transvaal to German East Africa. In the country between the Limpopo and the Central Zambesi it used to be a very common animal, especially in the northern districts of Mashonaland. It is partial to open forests intersected by grassy, wellwatered glades, and is never found on open plains entirely devoid of bush. It is usually met with in herds of from twelve to twenty individuals, but I have often seen as many as fifty, and once

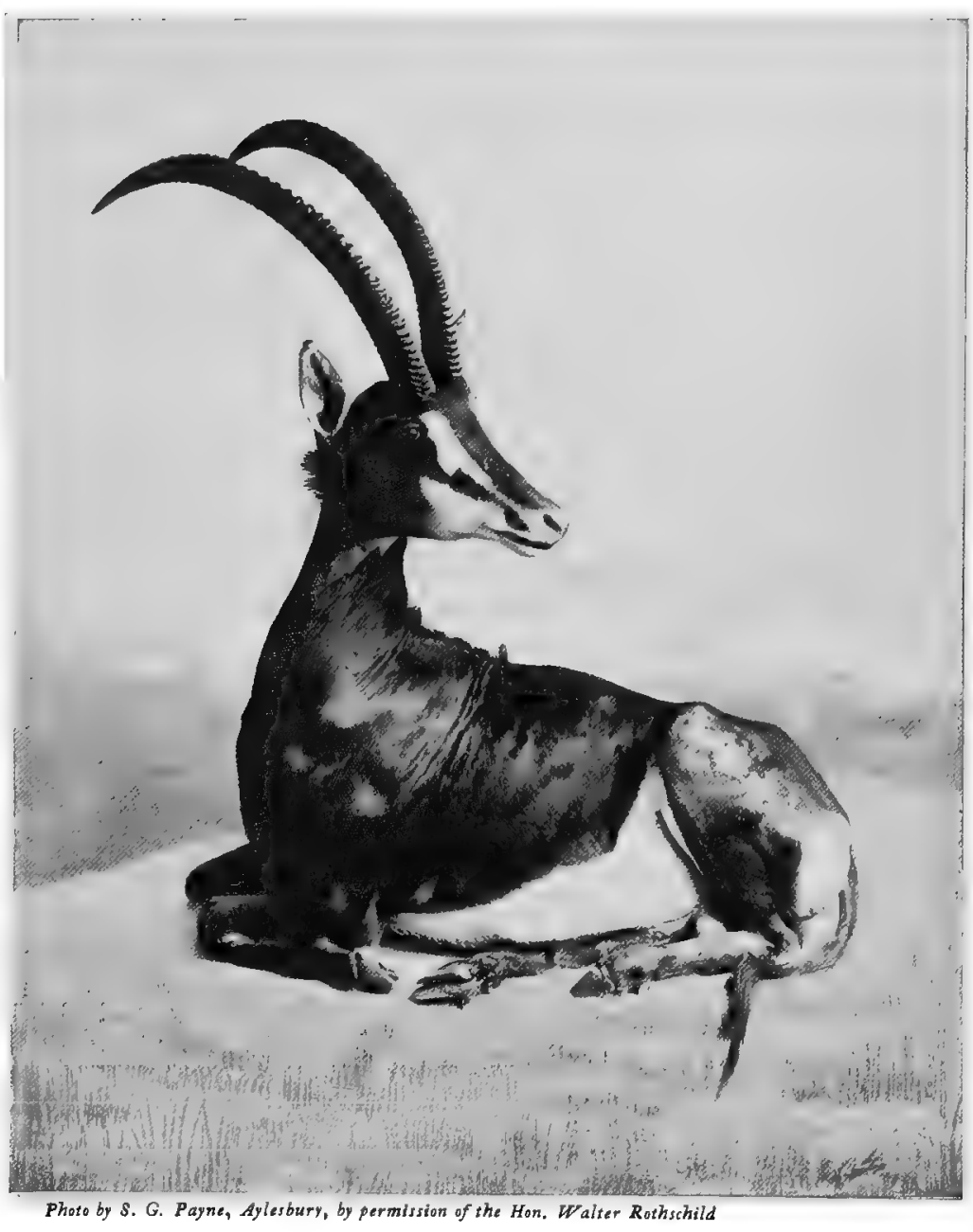

SABLE ANTELOPE

A near ally of the Roan Antelope, from which it is broadly distinguished by its striking coloratian - black and white 


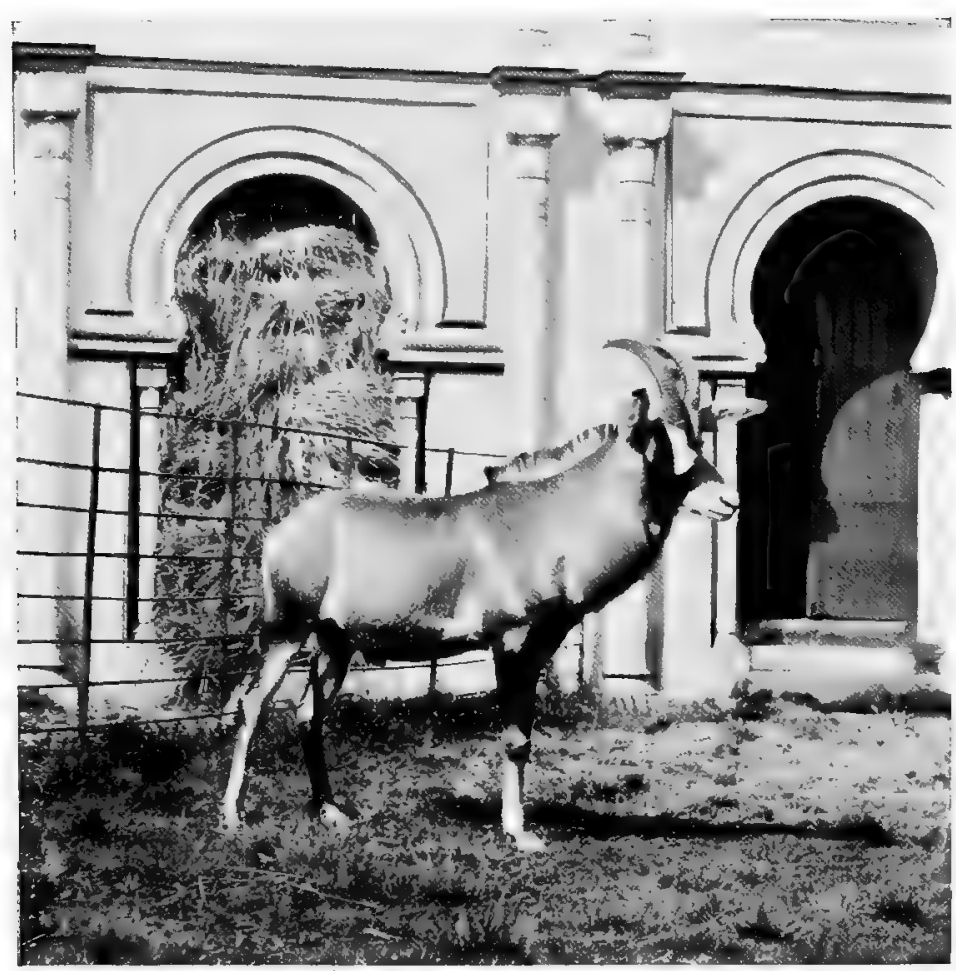

Photo by the Duchess of Bedford]

\section{ROAN ANTELOPE}

In common with the Sable Antelope and the Oryx group, both sexes of this species carry horns counted between seventy and eighty together. However large a herd of sable antelopes may be, it is very exceptional to find with it more than one fully adult male, from which fact I should judge that these animals are of a very jealous and pugnacious disposition. When wounded and brought to bay by dogs, a sable antelope defends itself with the utmost fury, using its long scimitar-shaped horns with most wonderful quickness and dexterity. If badly wounded it will lie down, otherwise it fights standing. Keeping its face to some of its foes, with a sideways twist of its head it will transfix and throw into the air any dog which attempts to attack it from behind. I have seen a wounded sable antelope, when lying down, drive one of its horns clean through a large dog deep into its own haunch, and I have

had four valuable hounds killed and four others grievously wounded by one of these animals in less than a minute. I once knew a native hunter who was stabbed through the kidneys and killed by a sable antelope cow.

The nearest allies of the sable and roan antelopes are the various species of the genus Oryx. In this group are included the WHITE Oryx, which inhabits the desert regions of the interior of Northern Africa from DongolatoSenegal ; the BEATRIX ORYX of Southern Arabia; the GEMSBUCK of Southwestern Africa; the BEISA, which is found in North-east Africa from Suakim southwards to the river Tana; and the TUFTED BEISA, which is

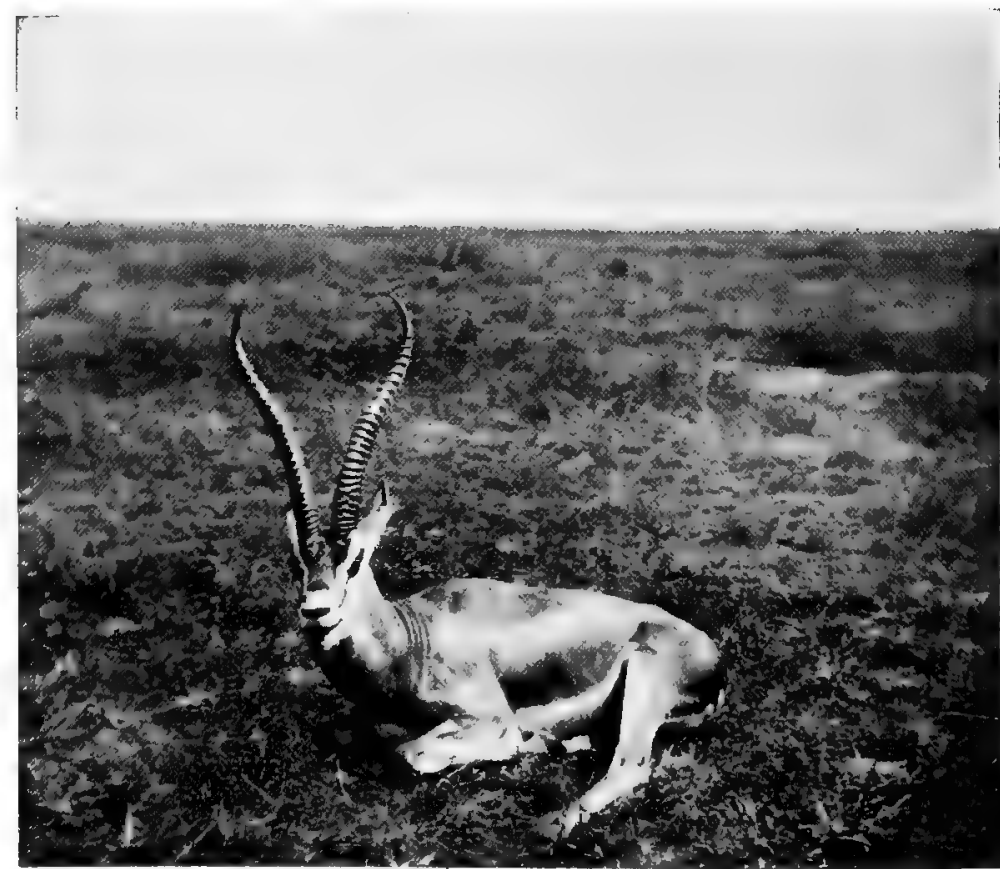

Phoso by Norman B Smith, Esq.]

MALE OF GRANT'S GAZELLE

This fine East African spectes is one of the handsomest of its kind 
very nearly related to the last-named species, whose place it takes south of the Tana River in certain districts of British and German East Africa. In general appearance there is a strong family resemblance between the different species of oryx. In all of them both sexes carry horns, which are considerably longer, though somewhat slighter, in the females than in the males. In the white oryx the horns are curved backwards; but in the other four species they are straight, or nearly so. In all the faces are conspicuously banded with black and white, and the tails long, with large dark terminal brushes. The two most desert-loving species, the white and the Beatrix oryx, are paler in general body-colour than the other three, and the latter animal is considerably smaller than any other member of the group, standing not more than 35 inches at the withers. The gemsbuck is the largest and undoubtedly the handsomest of the group, standing 4 feet at the shoulders; the horns of the females are often upwards of 40 inches long, and have been known to attain a length of 48 inches.

In habits all species of oryx seem to be very similar. They are denizens of the arid sunscorched plains of Africa, which are not necessarily devoid of all kind of vegetation, but are often covered with stunted bush, and carry a plentiful crop of coarse grass after rain. Oryx usually run in herds of from four or five to fifteen or twenty, though the beisa, the most abundant of the group, has been met with in troops numbering 400 or 500 head. All the oryx are shy and wary, and in the open country they usually frequent are difficult to approach on foot. If pursued on horseback, they run at a steady gallop, which they can ma intain for long distances, swinging their bushy black tails from side to side, and holding their heads in such a way that their long

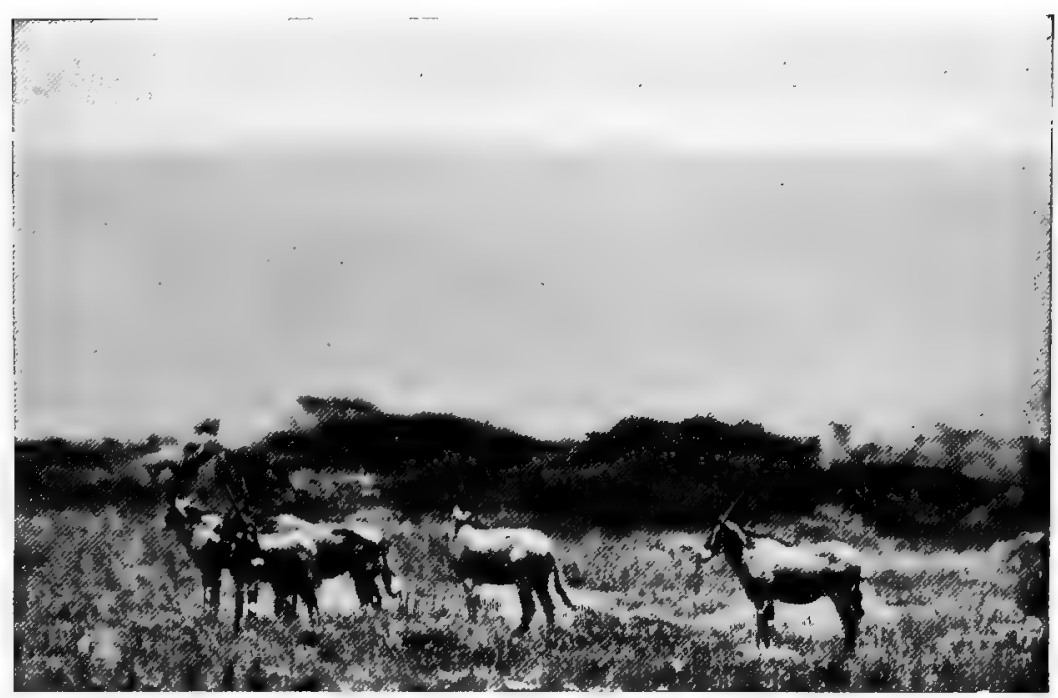

GROUP OF BEISA ORYX

This most interesting photograph, taken by Lord Delamere, showes a group of these fine antelopes on the East African plains straight horns are only sloped slightly backwards. Fleet and enduring, however, as oryx undoubtedly are, I am of opinion that in these respects the gemsbuck of South Africa, at any rate, is inferior to all other large antelopes living in the same country, with the single exception of the eland. I have often, when mounted on a fast horse, galloped right up to herds of gemsbuck, and on two occasions have run antelopes of this species to an absolute standstill. Oryx of all species should be approached with caution when badly wounded, as they are liable to make short rushes, and can use their horns with great effect.

Nearly related to the antelopes of the Oryx group in many essential characteristics, yet at once distinguishable by its spiral horns and broad reindeer-like feet, the desert-haunting ADDAX has been placed in a separate genus, of which it is the sole representative.

This remarkable animal stands about 38 inches in height at the withers, and varies in general colour at different seasons of the year, from brownish grey to a reddish hue. The forehead is covered with a thick growth of bushy black hair, beneath which there is a patch of white extending across the nose to under the eyes. The hindquarters, tail, and legs are white. The horns are spiral, and are present in both sexes. In the male they attain 


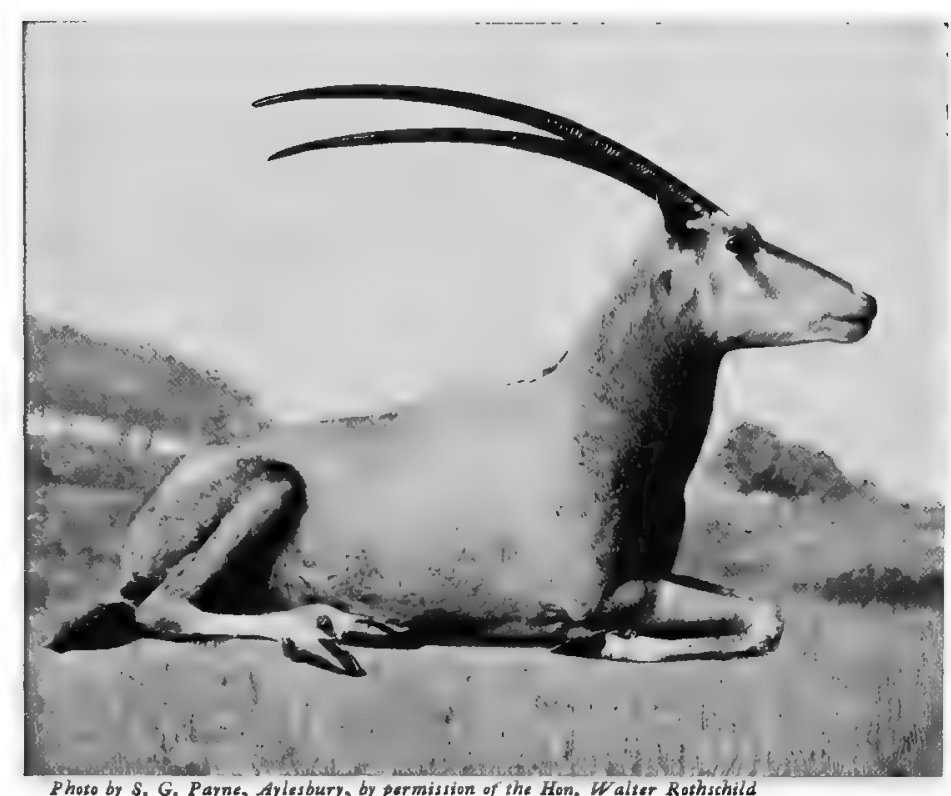

WHITE ORYX

Found in Northern Africa from Dongola to Senegal a length of about 28 inches in a straight line, and about 36 inches following the spiral. In the female they are thinner and less spirally curved. The addax is confined to the desert regions of Northern Africa from Dongola to Senegal, and the broad, rounded hoofs, so unlike those of any other antelope, would seem to show that it inhabits countries where the soil is deep, soft sand.

Very little is known of the life history or habits of this antelope. It is said to associate in pairs or small herds, and to be entirely independent of water, though it travels great distances over the desert in the track of thunder-storms for the sake of the young herbage which grows so quickly wherever rain falls in

those thirsty regions. It is killed in considerable numbers by the Arabs for the sake of its flesh and hide, and is either stalked or hunted on horseback, with the help of greyhounds, by Europeans.

The last of the sub-families into which modern naturalists have divided the antelopes of the world comprises some of the handsomest species of the whole group, and includes the largest of all antelopes, the Eland, as well as such small and beautifully marked creatures as the Harnessed Bushbucks.

With one exception - the Nilgai - all the members of this sub-family are denizens of the great African Continent.

The NILGaI, or BluE BULI, is an inhabitant of India, and is found throughout the greater portion of the peninsula, from the base of the Himalaya to the south of Mysore. It is an animal of large size, standing about 4 feet 6 inches at the shoulder. In general colour the male is of a dark iron-grey, the female tawny fawn. White spots on the cheeks and just above the hoofs on the fore and hind feet are the outward signs of its affinity to the African harnessed antelopes. The male alone carries horns, which are nearly straight and very small for the size of the animal, rarely exceeding 9 inches in length.

Passing now to the Harnessed Antelopes of Africa, our attention is first claimed by the BusHBUCKS. Excluding the Inyala and the Broad-

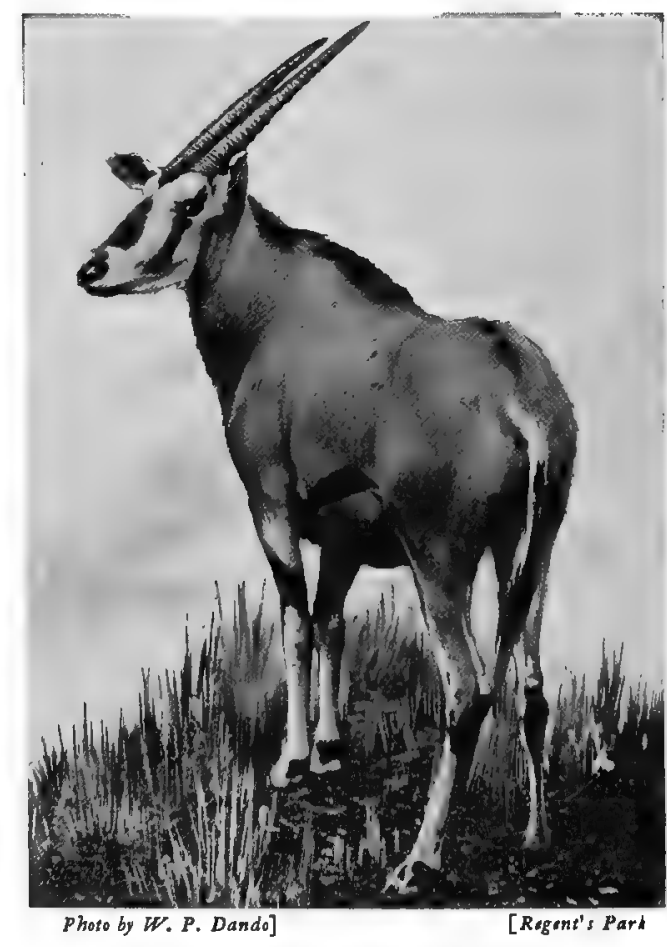

BEISA ORYX

The beisa is found in North-east Africa; by some it is believed to save suggested the original idea of the unicorn 
horned Antelope, we find several forms of the smaller bushbucks recognised by naturalists: viz. the HARNESSED ANTELOPE of the forest regions of Western Africa; the CAPE Bushbuck of South Africa ; CUMming's BusHBUCK of Eastern Africa; and the Decula Bushbuck of Abyssinia. The various forms of bushbuck vary in general colour from very dark brown to various shades of grey-brown, yellow-brown, and rich red. In all species the young are more or less striped and spotted; but whereas in some forms the adultanimals lose theirstripes and spots almost entirely, in others the adults are more richly marked than immature specimens. For my part, I am inclined to believe that, if largeseries of bushbuck-skins were collected from every district throughout Africa, it would be found that all the varieties of this animal at present accepted as distinct species would be found to grade into one another in such a way that only one true

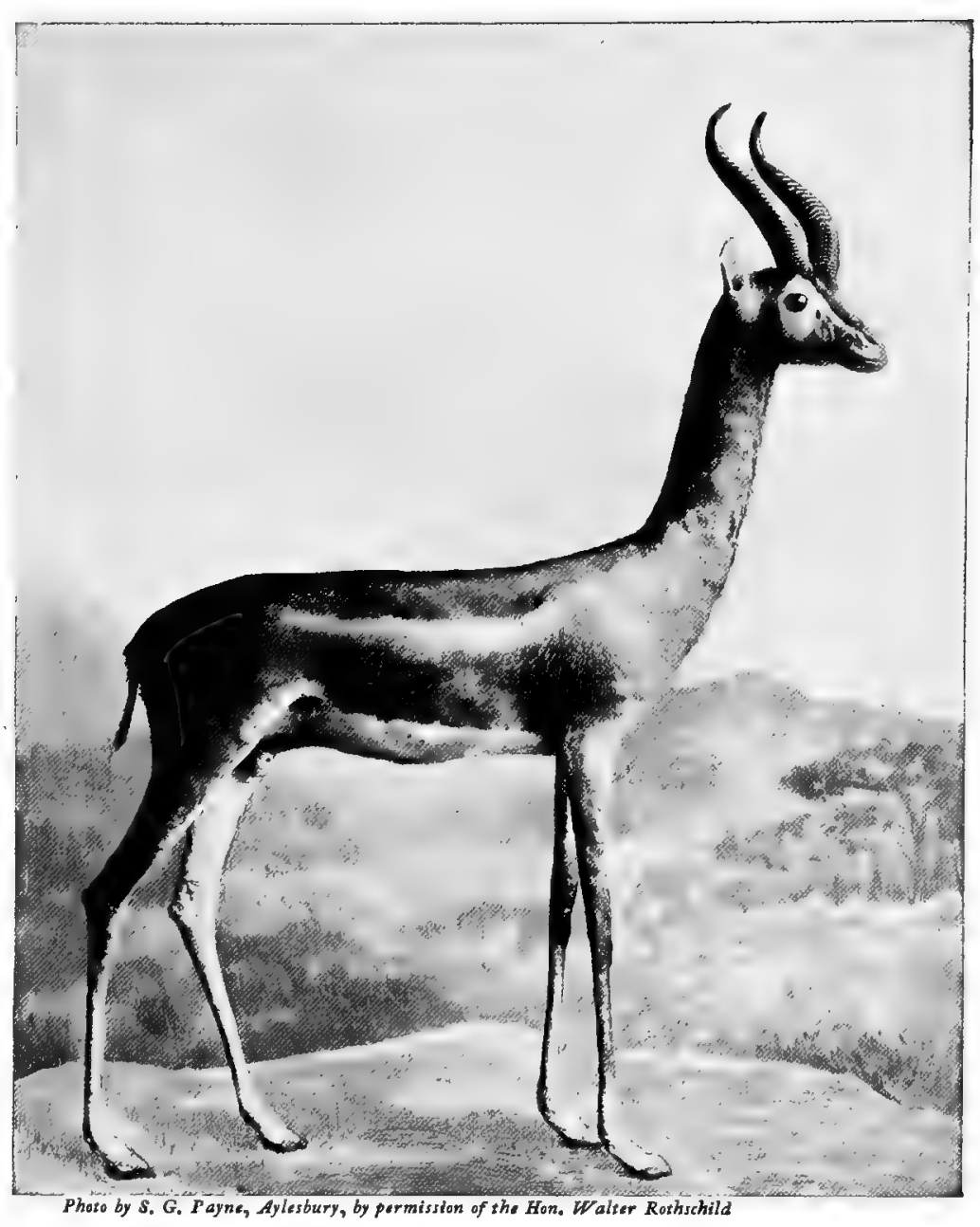

GERENUK

A gazelle-like antelope with long neck and legs, inhabiting North-east Africa species could be recognised.

The bushbucks vary in height at the shoulder from 28 inches to 33 inches, and only the males carry horns, which are nearly straight, with a close spiral twist, and measure in adult animals from 10 inches to 18 inches in length.

Bushbucks are not found in open country, but live in forest or thick bush near the bank of a river, stream, or lake, and are never met with far from water. They are very partial to wooded ravines amongst broken, mountainous country, provided such districts are well watered; and are very solitary in their habits, both males and females being usually found alone, though the latter are often accompanied by a kid or half-grown animal. They are shy and retiring, and should be looked for between daylight and sunrise, or late in the evening, as they are very nocturnal in their habits, and lie concealed in long grass or thick bush during the heat of the day. Their call resembles the bark of a dog, and may often be heard at nights.

The BROAD-HORNED ANTELOPE is only found in the forests of the West African coast range, from Liberia to Gaboon. The male of this species is a very handsome animal, standing about 43 inches at the withers, and is a bright chestnut-red in general colour, with a white spinal stripe extending from the withers to the root of the tail, and fourteen or fifteen white stripes on the shoulders, flanks, and hindquarters. The ears are large and rounded, and the horns very massive, and about 30 inches in length, measured over the single spiral twist. There are two or 


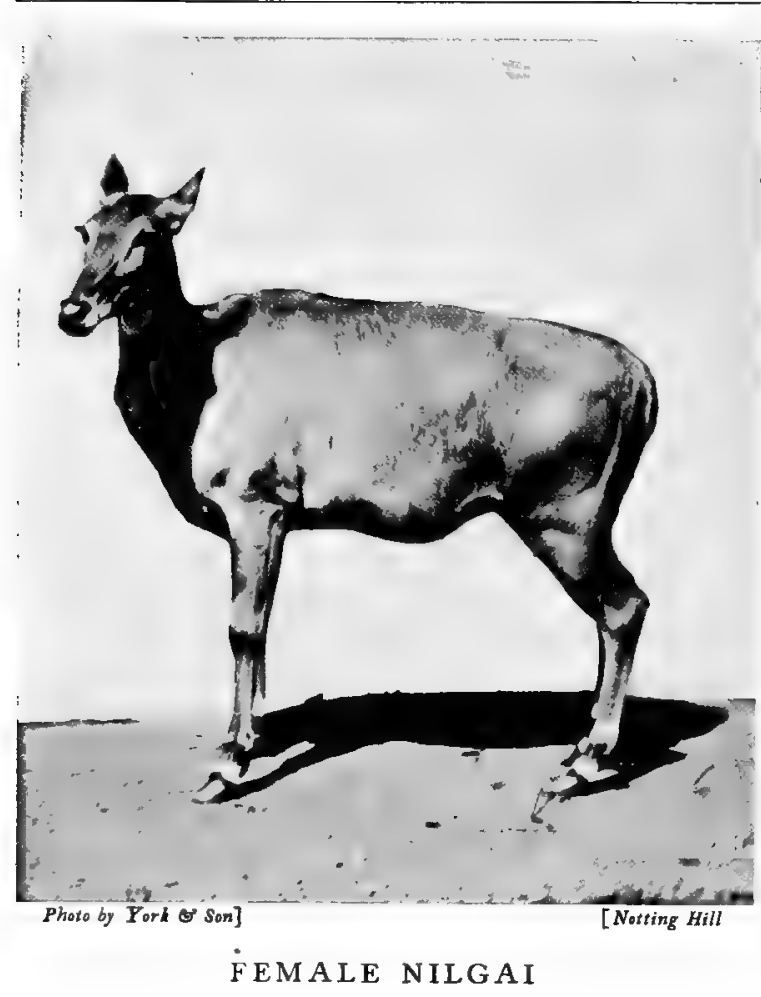

The largest of the antelopes of India, and a distant cousin of the Kudu

horns, which are only present in the male, attain a length of about 2 feet in a straight line, and 30 inches along their spiral curve. The standing height at the shoulder of males of this species is about 42 inches.

This most beautiful antelope has a very restricted range, being only found in a narrow belt of coastland extending from St. Lucia Bay to the Sabi River, in South-east Africa, and in a still smaller area in the neighbourhood of the Upper Shiri River, in British Central Africa.

Before the acquisition of firearms by the natives in South-east Africa, the inyala was very plentiful in Northern Zululand and Amatongaland, and was then to be met with in herds of from ten to twenty individuals; whilst the males, which at certain seasons of the year separated from the females, were in the habit of consorting together in bands of from five to eight. Constant persecution by the natives in Amatongaland and the countries farther north very much reduced the numbers of inyalas in those districts a long time ago; but in Zululand, where this animal has been strictly protected by the British authorities for the last twenty years, it was still plentiful up to I896, when the rinderpest swept over the country, and committed such sad three large white spots on the cheeks, and a broad white arrow-shaped mark across the nose below the eyes. The female is similar in coloration to the male, but smaller and hornless.

Little or nothing is known as to the habits of this very beautiful antelope. Du Chaillu, who met with it in the interior of Gaboon between 1856 and 1859 , says that it is "very shy, swift of foot, and exceedingly graceful in its motions"; but he does not tell us whether it lives in pairs like the bushbucks, or in small herds like some of its other near allies.

The INYALA is another bush-loving antelope closely allied to the bushbucks. In this species the general colour of the adult male is a deep dark grey, that of the female and young male bright yellow-red, and both sexes are beautifully striped with narrow white bands on the body and haunches. In the male long dark hair hangs from the throat, chest, and each side of the belly, and fringes the front of the thigh almost to the hock, and the back of it up to the root of the tail. The ears are large and rounded; and the .

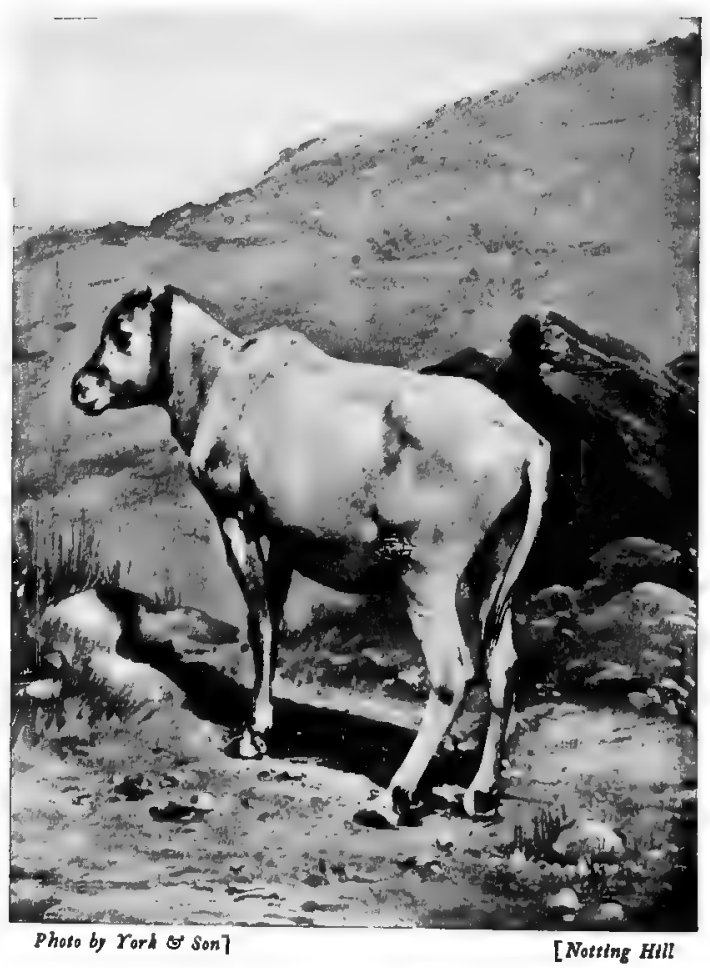

ADDAX

Unfortunately, the specimen from which this photograph was taken had lost its splendid spiral horns 


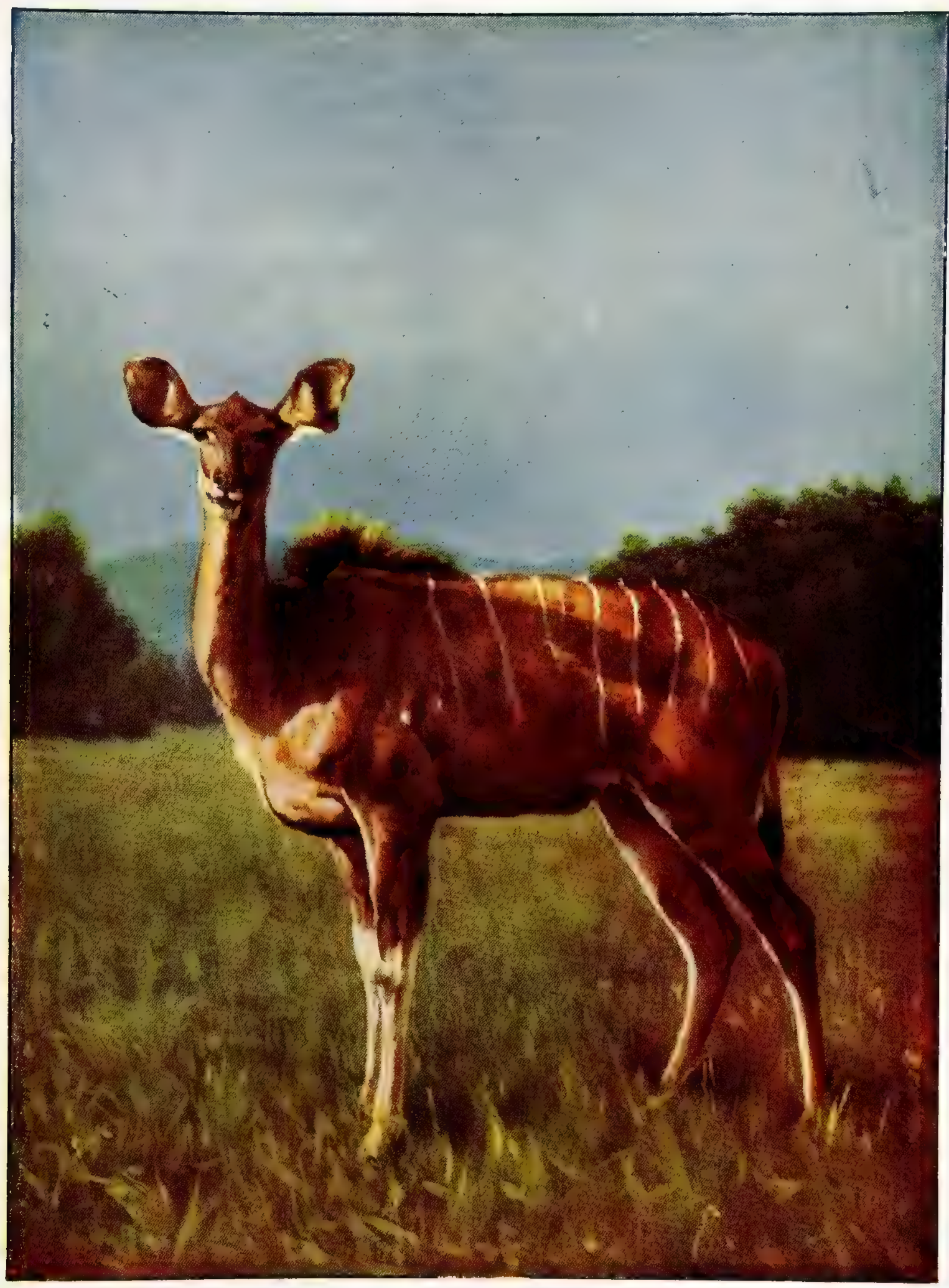

Photo by the Duchess of Bedford. Woburn Abbey.

FEMALE KUDU.

The Kudu is one of the handsomest of the African Antelopes, the corkscrew-like horns of the bucks forming some of the most striking of all sporting trophies. 

ravages amongst all the tragelaphine antelopes that it is to be feared the inyala can now no longer be found anywhere in any considerable numbers. Where I met with these antelopes some years ago, in the country to the south of Delagoa Bay, I found them living either alone or in pairs like bushbucks. They frequented dense thickets in the immediate neighbourhood of a river or lagoon, and I never saw one in anything like open country or far away from water. Their tracks showed me that at night they were accustomed to feed in open spaces in the bush, but they always retired to the jungle again at daylight, as they had become very wary and cunning through constant persecution at the hands of the natives.

Closely allied to the bush-antelopes of the present group are the swamp-haunting SitATUNGas. Three species of these have been described, - one from East Africa, named after Captain Speke; another from tropical West Africa; and a third from Lake Ngami and the Chobi River, named after the present writer.

There is very little difference between the adult males of these three species, except that in the West African form the coat is of a darker colour than in the other two. The main difference consists in the fact that, whereas the female of Selous' sitatunga is light brown in colour like the male, and the newly born young are very dark blackish brown (the colour of a mole), beautifully striped and spotted with pale yellow, the female and young of the other two forms are red in ground-colour, with white spots and stripes. However, personally I am of opinion that there is only one true species of sitatunga in all Africa, and that the differences between the various forms are superficial, and would be found to grade one into the other, if a sufficiently large series of skins of all ages and both sexes could be gathered together from all parts of the continent. In the Barotse Valley, on the Upper Zambesi, my friend Major R. T. Coryndon informs me that both red and brown female sitatungas are met with. On the Lower Chobi and Lake Ngami region

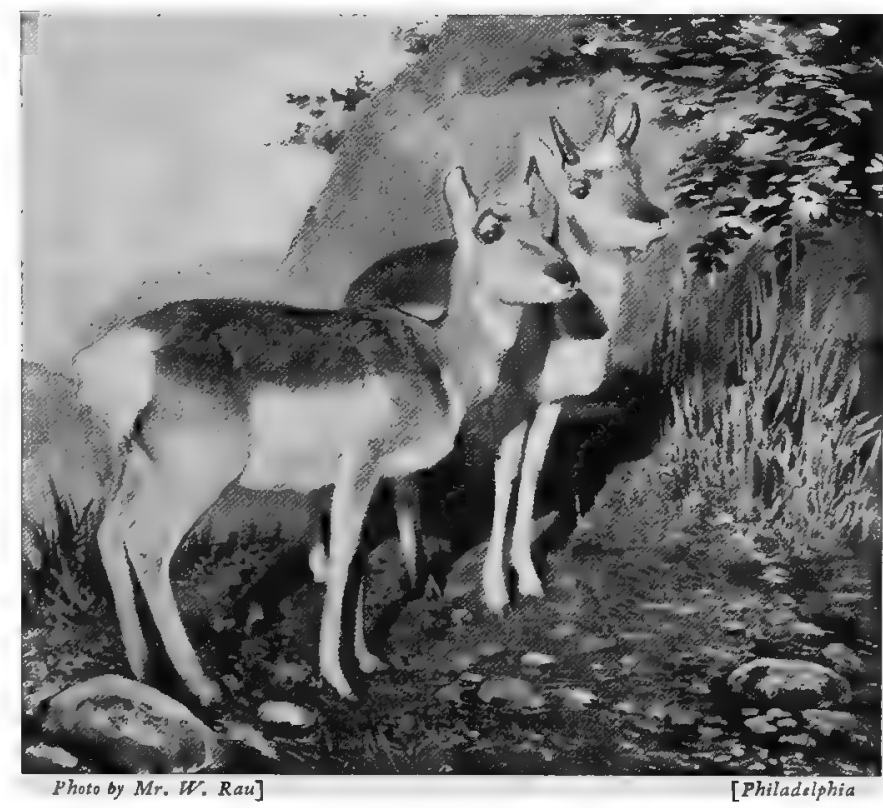

A PAIR OF YOUNG PRONGBUCKS

From the fact that the horns of the males are annually shed, the prongbuck is assigned to a group apart from the Antelopes the females are never red, but always of the same brown colour as the males, whilst on the Congo all the females are red.

The male sitatunga stands about 3 feet 6 inches at the shoulder, and varies in general colour in different localities from light to dark brown. The adult females are either red with a few faint stripes and spots, or light brown, only retaining very faint traces of any stripes or spots. The young are, both in tropical West and Central East Africa, red, striped, and spotted with white; but in South-west Africa dark blackish brown, with spots and stripes of yellowish white. The hoofs are excessively long, and the skin which covers the back of the pastern is hairless, and of a very thick and horny consistency. The males alone carry horns, which are of the same character as in the inyala, but more spiral and longer, having been known to attain a length of 28 inches in a straight line and 35 inches over the curve.

The sitatunga is an inhabitant of the extensive swamps which exist in many parts of the interior of Africa. It may be said to live in the water, as it passes its life in flooded beds of reeds and papyrus, into the muddy bottoms of which its long hoofs, when splayed out, prevent 


\section{THE LIVING ANIMALS OF THE WORLD}

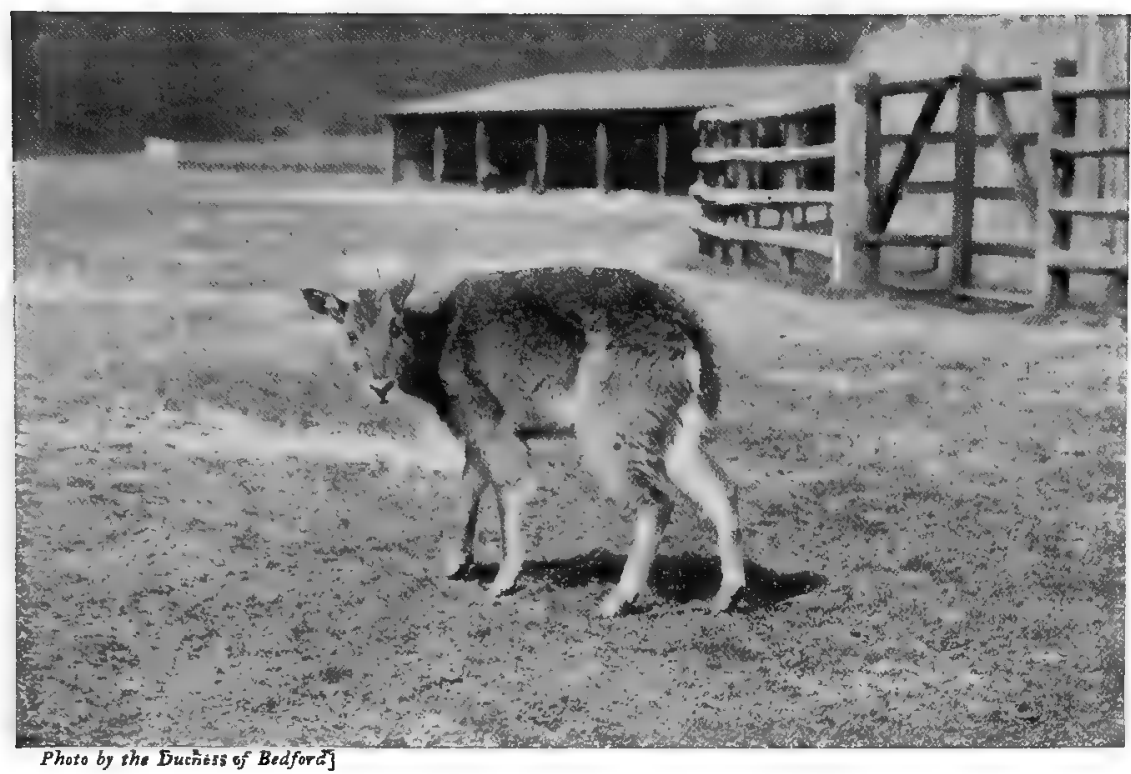

FEMALE GORAL

The goral is a Himalayan antelope, with someruhat the habits of a chamois it from sinking, When forced out into dry ground by heavy. floods, the formation of its feet so hinders it in running that it can be overtaken and speared by a native on foot. I was informed by the natives on the Chobi River that, when the floods enabled them to paddle their canoes throughthereed-beds, they often killed considerable numbers of the sitatungas. These animals, they said, when theysaw a canoe approaching, would often not attempt to

seek safety by flight, but would sink down in the water, submerging their whole bodies, and leaving only their nostrils above the surface, and in this position were easily speared.

The sitatunga is not gregarious, but is met with singly or in pairs. The hair is long, but soft and silky; and the skins are much sought after by the natives for blankets.

In addition to the bushbucks and sitatungas, two more very notable spiral-horned African antelopes remain to be mentioned - namely, the GREATER KUDU and the LESSER KUDU.

The GREATER KUDU is one of the most magnificent-looking of the whole family of antelopes; and is an animal of large size, an adult male standing 4 feet 9 inches and upwards at the withers. The general colour of this species is light brown to dark grey, the old males looking much darker than females or younger animals, because the scantiness of their coats shows the dark colour of the skin beneath. On each side of the body and hindquarters there are several white stripes, which varyin number from four to eight or nine. As in all this group of antelopes,

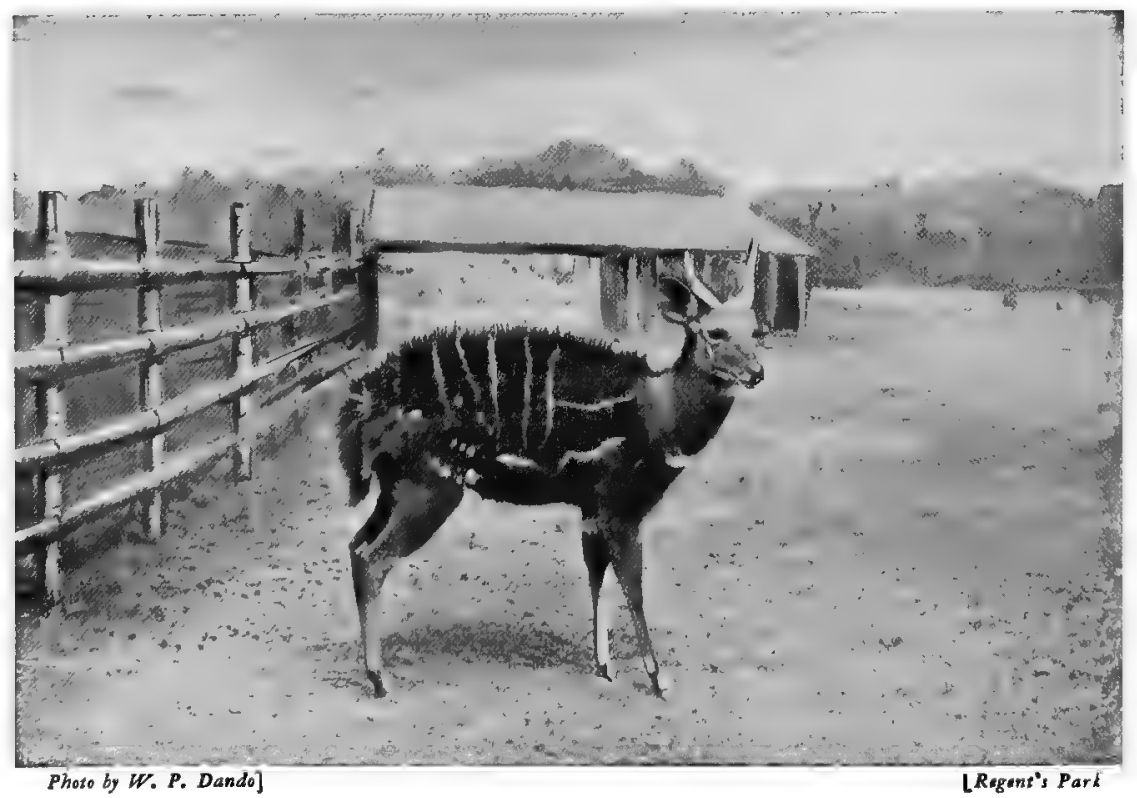

HARNESSED ANTELOPE

A very beautiful species, in which the ground-colour of the coat is a rich chestnut, while the spats and striper are pure white 
there are two or three cheek-spots, as well as an arrow-shaped white mark across the nose, below the eyes. In the male there is a slight mane on the back of the neck, and a fringe of long white and blackish-brown hair intermixed, extending from the throat to the chest. The ears are very large and rounded, and the male is adorned with magnificent spiral horns, which have been known to attain a length of 48 inches in a straight line from base to tip, and 64 inches over the curve.

The greater kudu once had a very wide range, which extended from the central portions of the Cape Colony to Angola on the west, and on the east throughout East Africa up to Abyssinia; but, with the single exception of the buffalo, no species of wild animal suffered more from the terrible scourge of rinderpest which recently swept over the continent than this lordly antelope, and it has almost ceased to exist in many districts of South and South Central Africa, where up to $\mathbf{I} 896$ it was still very numerous.

The greater kudu is a bush-loving antelope, and very partial to wooded hills, though it is also plentiful in the neighbourhood of rivers which flow through level tracts of country covered with forest and bush. In my own experience it is never found at any great distance from water. It eats leaves and wild fruits as well as grass, and lives in small herds or families, never, I believe, congregating in large numbers. In Southern Africa, at any rate, it was always exceptional to see more than twenty greater kudus together, and I have never seen more than thirty. At certain seasons of the year the males leave the females, and live alone or several together. I once saw nine magnificently horned kudus standing on the bank of the Chobi, and I have often seen four or five males of this species consorting together. As a rule the greater kudu is met with in hilly country or in bush so dense that a horse cannot gallop through it at full speed; but if met with in open ground, a good horse can overtake an old male without much difficulty. The females are much lighter and faster and cannot be overtaken in any kind of ground.

The greater kudu is one of the most timid and inoffensive of animals, and when attacked by dogs will not make the slightest attempt to defend itself either with its horns or by kicking.

The LEsser KUDU in general colour nearly resembles its larger relative, but is much smaller, the males only standing about 40 inches at the withers, and it lacks the long fringe of hair under the throat. The white stripes on the body and hindquarters are, however, more numerous - from eleven to fourteen; and the horns, which are only present in the males, are less divergent, and with the spiral curvature much closer than in the greater kudu.

The lesser kudu is an inhabitant of Somaliland and the maritime

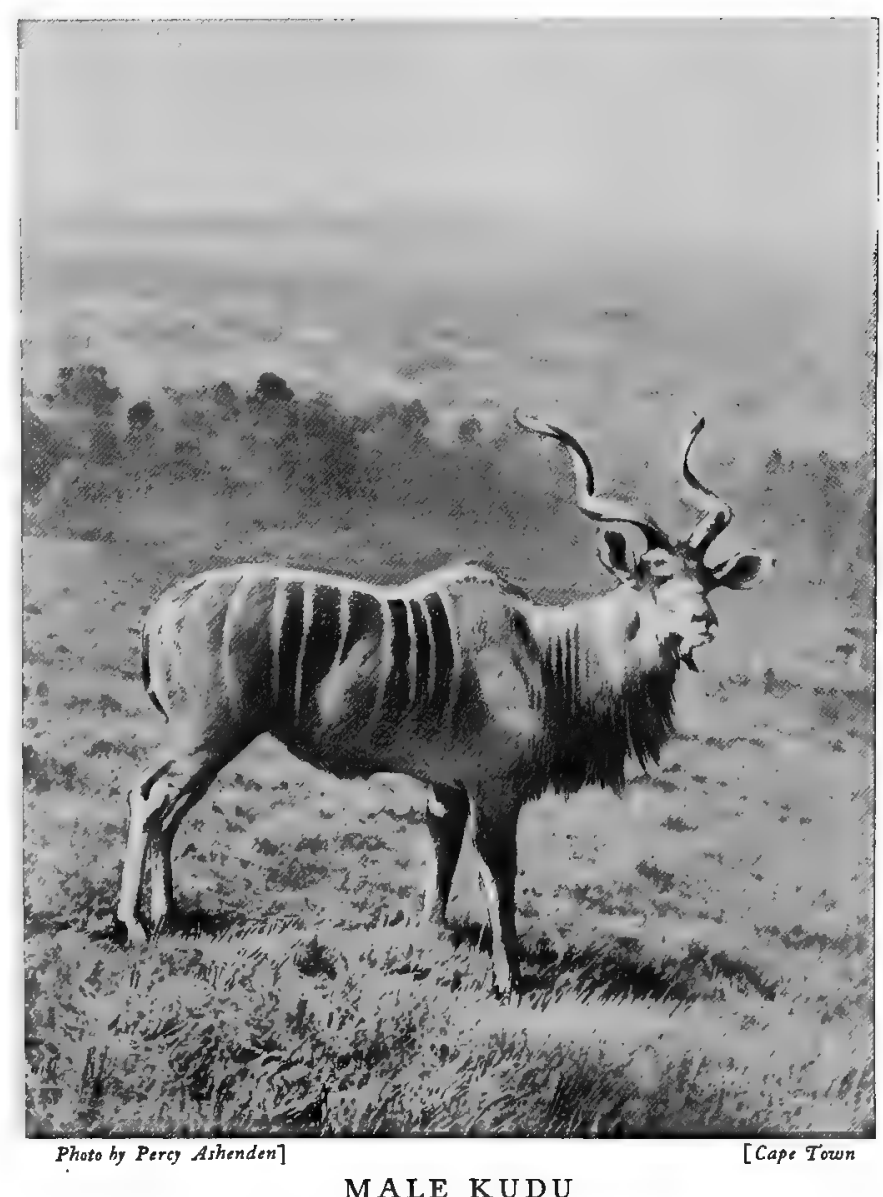

MALE KUDU

$A$ kudu bull stands about 5 feet or a little more at the withers, being in size oniy inferior to the eland. The horns form a corkscrew-like spira? 
districts of British East Africa. It frequents thick scrubby jungle, and is said to be exceedingly watchful and wary. It lives either in pairs or in small families, but never congregates in large herds. Like all the tragelaphine antelopes, this species is a leaf-eater, and feeds principally during the night, lying up in thick bush during the heat of the day.

There remains to be mentioned but one other group of antelopes, the ELANDS, large, heavily built animals, which belong to the present group, but differ from all species of kudu, sitatunga, and bushbuck, inasmuch as both sexes are horned. There are two forms of the COMMON ELAND—namely, the grey variety of South-western Africa, and the striped animal, which is found in the countries farther north and east. The two forms grade one into the other, and are absolutely identical in their habits and mode of life, the differences between them being merely superficial. To the south of the twenty-third parallel of south latitude all elands are of a uniform fawn colour, except the old animals, which look dark grey, from the fact that

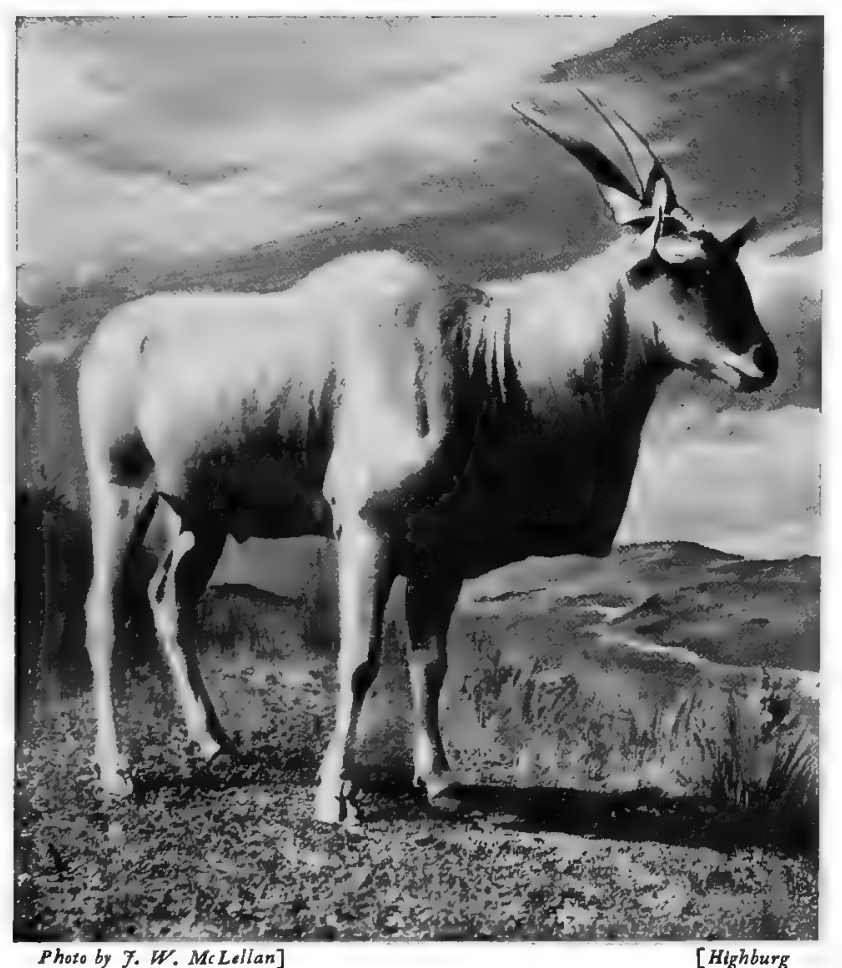

ELAND

A feature of the cland is the large "dervlap." Unlike the kudu, both sexes the scantiness of their coats allows the dark colour of the skin to show through the hair. Old males, when standing in the shade of a tree, appear to be of a deep blue-grey in colour, and are known to the colonists of South Africa as " blue bulls." In Rhodesia, South-east Africa, and the countries to the north of the Zambesi, all the elands are bright chestnut-red when young, with a black line down the centre of the back from the withers to the tail, broad black patches on the backs of the fore legs above the knees, and eight or nine white stripes on each side. When they grow old; the ruddiness of the ground-colour gradually fades, the black:markings on the fore legs die out, and the white stripes become indistinguishable at a short distance, the old sbulls looking deep blue-srey in general colour. 'Every intermediate stage of colouring between the unstriped and the highly coloured forms of eland is to be found in the district lying between the central portions of the Kalahari Desert and the Zambesi River. Old male elands south of the Zambesi develop a growth of long, bristly black hair on the forehead, which often hangs over their eyes and extends half-way down their noses. North of the Zambesi this growth of hair is not nearly so luxuriant.

I have carefully measured the standing height at the withers of many old male elands in the interior of South Africa, and found that it varied from 5 feet 8 inches to 5 feet 10 inches. The horns of bulls in their prime measure from 26 inches to 33 inches in length, but old bulls wear their horns down very much. The cows carry. longer, though thinner horns than the bulls.

The range of the eland once extended from Cape Agulhas to the White Nile, but it has become extinct in many districts of Southern Africa, and in almost every other portion of its range has, like all other tragelaphine antelopes, suffered so cruelly from the recent visitation of rinderpest that it has now become a scarce animal all over Africa.

During the rainy season elands are usually met with in small herds of from four or five 


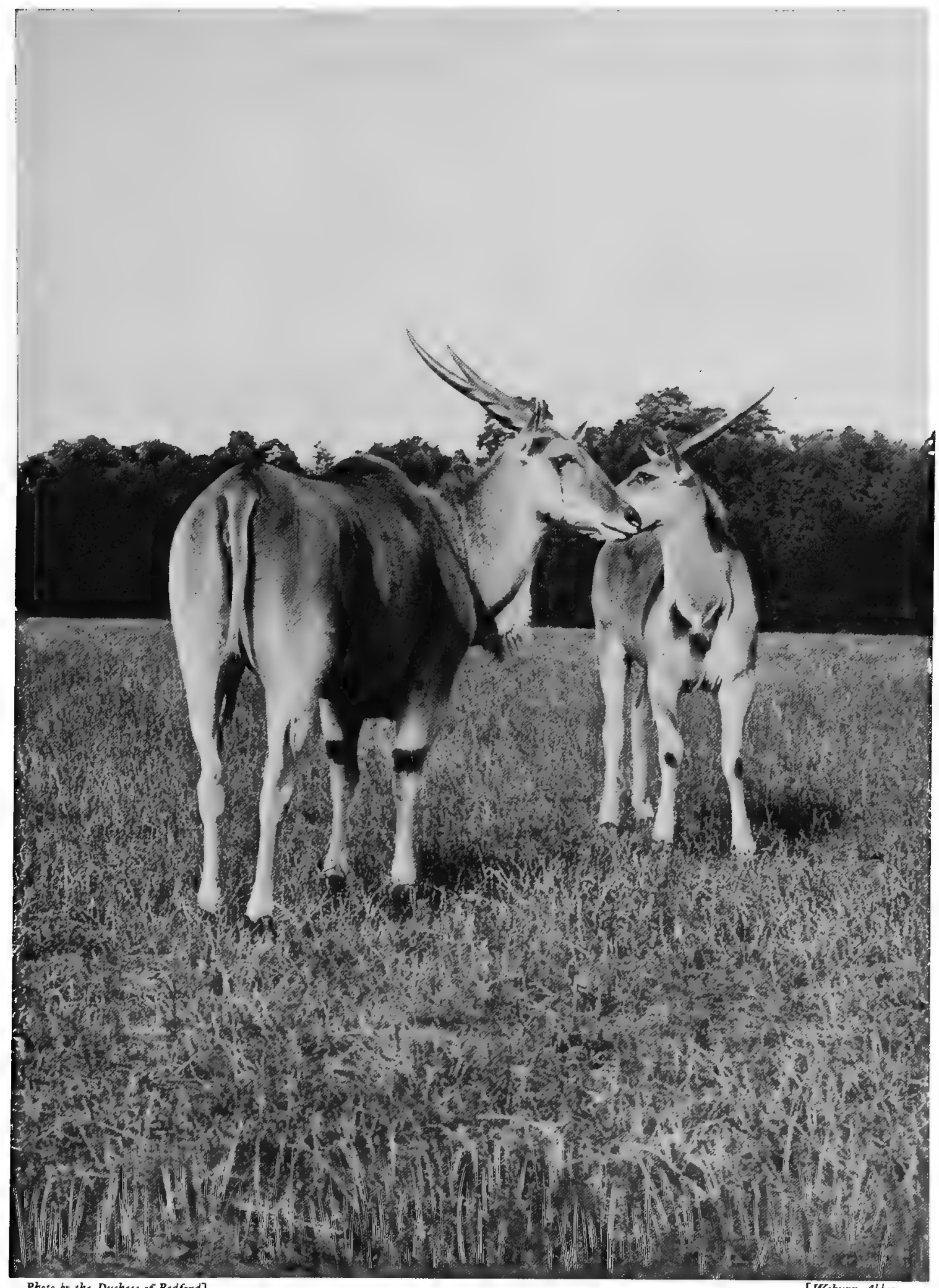

Photo by the Duchess of Bedford]

\section{ELAND COWS}

[Woburn Abbey

Female elands carry longer, although more slender horns than the bulls 
to ten individuals; but towards the end of the dry season they collect into large herds, and at such times I have often seen from fifty to over two hundred of these animals in one troop.

In my experience elands live for two-thirds of the year in forest or bush-covered country, or amongst rugged hills; and in such localities they are difficult to overtake on horseback; but in the middle of the dry season, as soon as they smell the smoke of the grass fires lighted by the natives on the open plateaux, they leave their retreats, and, collecting in herds, wander out on to the treeless plains in search of young grass. They then fall an easy prey to a mounted hunter, especially the heavy old bulls, which can be run to a standstill with ease by a very moderate horse.

The flesh of the eland is excellent when the animal is in good condition, as at such a time these animals become very fat, especially the old bulls, whose hearts become encased in a mass of fat which will often weigh $20 \mathrm{lbs}$. It is a mistake, however, to think that eland-meat is always good; for towards the end of the dry season, when there is little grass to be got, they feed extensively on the leaves of certain bushes, and their meat at such times. becomes very poor and tasteless.

Besides the common eland of Southern, Central, and Eastern Africa, another distinct species is met with in Senegal and the Gambia Colony. This is the DERBIAN Eland, about which animal our knowledge is still very slight, as I believe that it has never yet been shot nor its habits studied by a European traveler. A good many skulls and horns and a few skins have been obtained from natives, from which it appears that in general colour this species is of a rich reddish-fawn colour, becoming nearly white below, the middle of the belly being black. The neck is covered with long hair of a dark brown or black colour, blacker towards the shoulder than in front. A broad black stripe extends all down the centre of the back from the neck to the root of the tail, and there are large black patches on the backs and

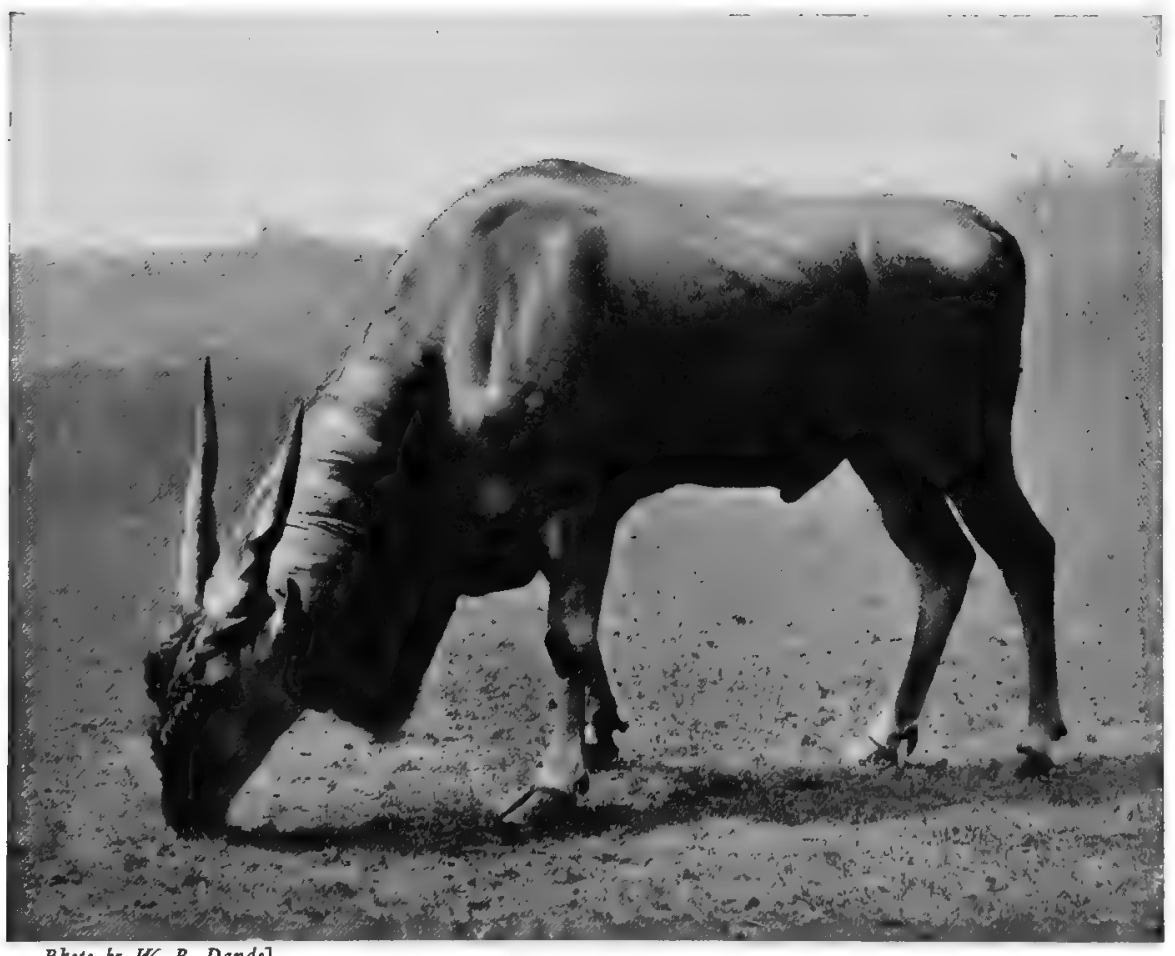

Photo by W. P. Dando]
BULL ELAND

The flesh of the eland is of better flavour than that of most other large game. If sheltered in winier, the species will thrive in English parks inner sides of the fore legs above the knees. On each side of the body and haunches there are thirteen or fourteen narrow white stripes. The horns are larger and more massive and divergent than in the common eland.

The Derbian eland is said to be a forest-loving animal, never of its own accord coming out into the plains. It lives in small herds, is very shy and not at all abundant, and browses on the leaves and young shoots of various trees and bushes. 


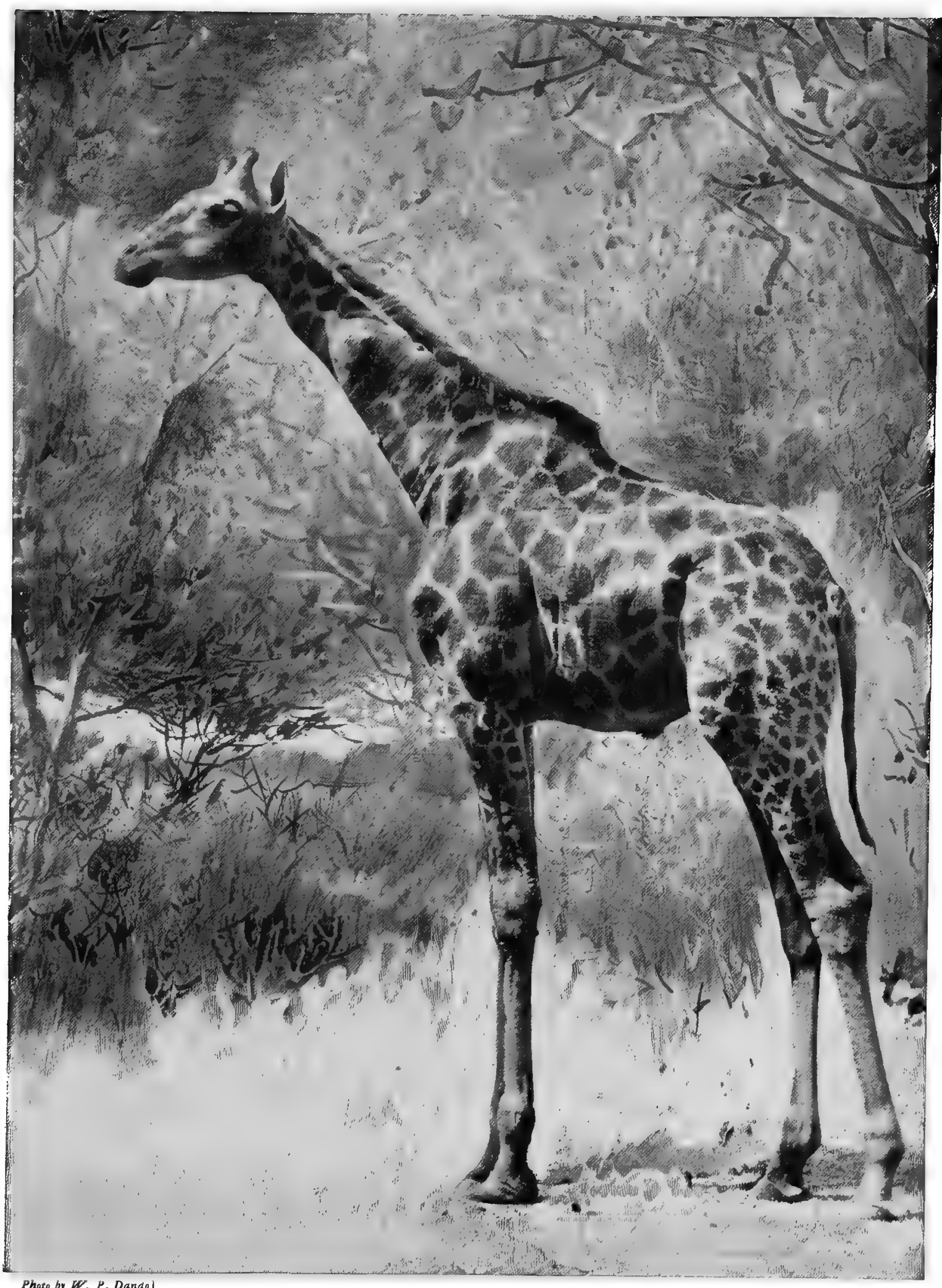




\section{H A P T E R X I}

\section{THE GIRAFFE AND OKAP,}

\section{THE GIRAFFE}

BY H. A. BRYDEN

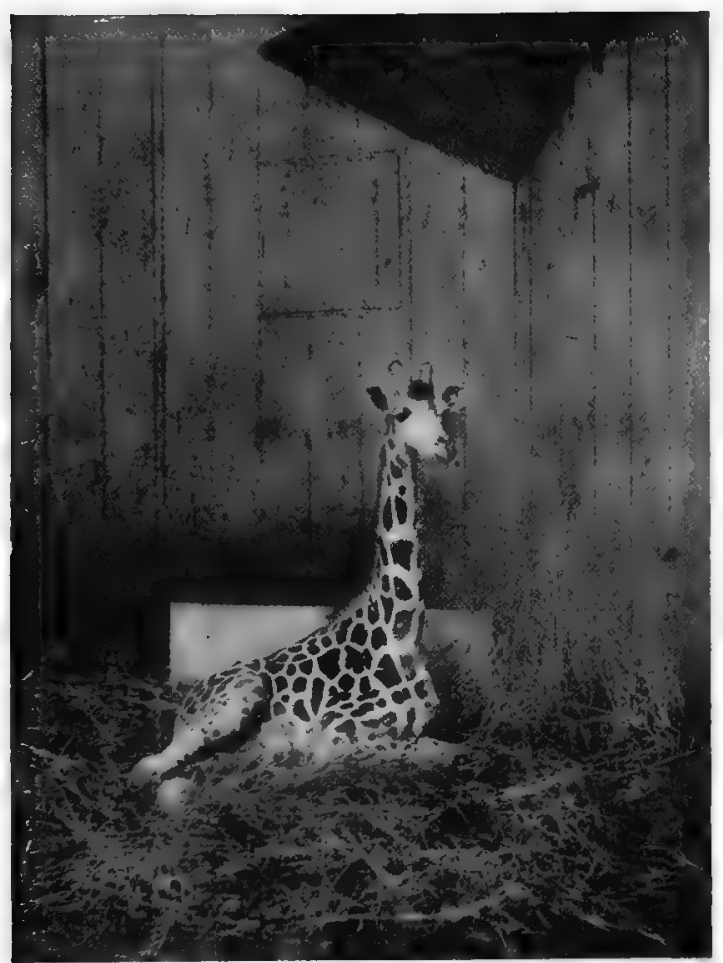

Phoro by Miss E. I Bech

SOUTHERN GIRAFFE LYING DOWN

This giraffe was a present to Queen Victoria; it only lived fourteen days after its arrival

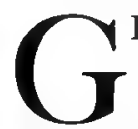

IRAFFES, which are found only in the continent of Africa, are the tallest of all living creatures. They belong to the Ruminants, or Cud-chewers, and naturalists are inclined to place them somewhere between the Deer Family and the Hollow-horned Ruminants, in which latter are to be found oxen, buffaloes, and antelopes. Rütimeyer, the Swiss naturalist, once clefined them as " a most fantastic form of deer," which is, perhaps, as good a definition of them as one is likely to hit upon. Fossil discoveries show that, in ages long remote, great giraffe-like creatures, some of them bearing horns or antlers, roamed widely in the south of Europe, Persia, India and even China.

Of living giraffes, two species have thus far been identificd, - the SOUTHERN or CAPE GIRAFFE, with a range extending from Bechuanaland and the Transvaal to British East Africa and the Soudan; and the Nubian or Northern Giraffe, found chiefly in East Africa, Somaliland, and the country between Abyssinia and the Nile. The southern giraffe, which, from its recent appearance in the Gardens of the Zoological Society, is now the more familiar of the two animals, has a creamy or yellowish-white ground-colour, marked by irregular blotches, which vary in colour, in animals of different ages, from lemon-fawn to orangetawny, and in older specimens to a very dark chestnut. Old bulls and occasionally old cows grow extremely dark with age, and at a distance appear almost black upon the back and shoulders. The northern giraffe is widely different, the coloration being usually a rich red-chestnut, darker with age, separated by a fine network of white lines, symmetrically arranged in polygonal patterns. At no great distance this giraffe, instead of having the blotchy or dappled appearance of the southern giraffe, looks almost entirely chestnut in colour. Again, the southern giraffe has only two horns, while the northern species usually develops a third, growing from the centre of the forehead. These horns, which are covered with hair in both species, and tufted black at the tips, are, in the youthful days of the animal, actually separable from the bones of the head. As the animal arrives at maturity, they become firmly 
united to the skull. A third race or sub-species of giraffe has been identified in Western Africa mainly from the skull and cannon-bones of a specimen shot in 1897 at the junction of the Binue and Niger Rivers; but very little is known abont this form. Other varieties or sub-species may yet be discovered in other parts of the Dark Continent. It is lacking in the giraffe's long neck.

The towering height of the giraffe is entirely attributable to the great length of the neck and limbs. A full-grown bull giraffe will certainly measure occasionally as much as 19 feet in height. I measured very carefully a specimen shot by my hunting friend, $\mathrm{Mr}$. W. Dove, in the forests of the North Kalahari, South Africa, which taped 18 feet I I $\frac{1}{2}$ inches. A fine cow, shot by myself in the same country, measured 16 feet 10 inches, and there is no reason to suppose that cow giraffes do not easily reach fully $\mathrm{I} 7$ feet in height. These animals feed almost entirely upon the leaves of acacia-trees, the foliage of the kameel-doorn, or giraffe-acacia, affording their most favourite food-supply. It is a most beautiful spectacle to see, as I have seen, a large troop of these dappled giants - creatures which, somehow, viewed in the wild state, always seem to me to belong to another epoch - quietly browsing, with upstretched necks and delicate heads, among the branches of the spreading mokala, as the Bechuanas call this tree.

The giraffe's upper lip is long and prehensile, and covered, no doubt as a protection against thorns, with a thick velvety coating of short hair. The tongue is long - some I 8 inches in length - and is employed for plucking down the tender leafage on which the giraffe feeds. The eyes of the giraffe are most beautiful - dark brown, shaded by long lashes, and peculiarly tender and melting in expression. Singularly enough, the animal is absolutely mute, and never, even in its death-agonies, utters a sound. The hoofs are large, elongate, nearly I 2 inclies in length in the case of old bulls, and look like those of gigantic cattle. There are no false hoofs, and the fetlock is round and smooth. The skin of a full-grown giraffe is extraordinarily tough and solid, attaining in the case of old males as much as an inch in thickness. From these animals most of the sjamboks, or colonial whips, in use all over South Africa, are now made; and it is a miserable fact to record that giraffes are now slaughtered by native and Boer hunters almost solely for the value of the hide, which is worth from $£_{3}$ to $£_{5}$ in the case of full-grown beasts. So perishes the giraffe from South Africa.

Giraffes live mainly in forest country, or country partially open and partially clothed with thin, park-like stretches of low acacia-trees. When pursued, they betake themselves to the densest part of the bush and timber, and, their thick hides being absolutely impervious to the frightful thorns with which all African jungle and forest seem to be provided, burst through every bushy obstacle with the greatest ease. They steer also in the most wonderful manner through the timber, ducking branches and evading tree-boles with marvellous facility. I shall never forget seeing my hunting comrade after his first chase in thick bush. We had ridden, as we always rode hunting, in our flannel shirts, coatless Attracted by his firing, I came up with my friend, who was sitting on the body of a huge old bull giraffe, which had' fallen dead in a grassy clearing. He was looking ruefully at the remains of his shirt, which hung about him, literally in rags and ribbons. Blood was streaming from innumerable wounds upon

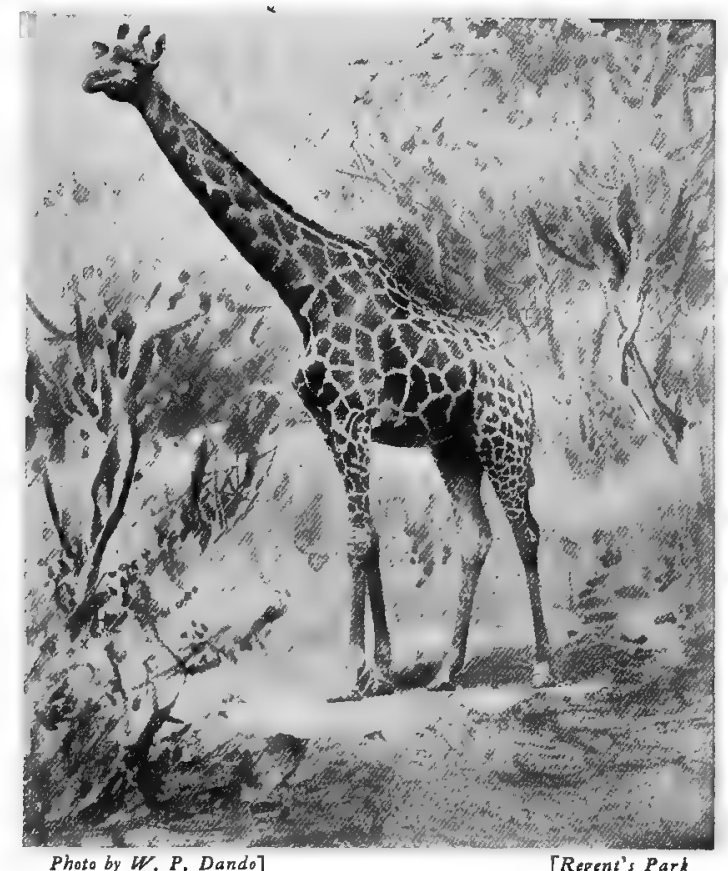

MALE SOUTHERN GIRAFFE

The coloration of these animals harmonises exactly with the dark ana light splashes of their surroundings 


\section{THE LIVING ANIMALS OF THE WORLD}

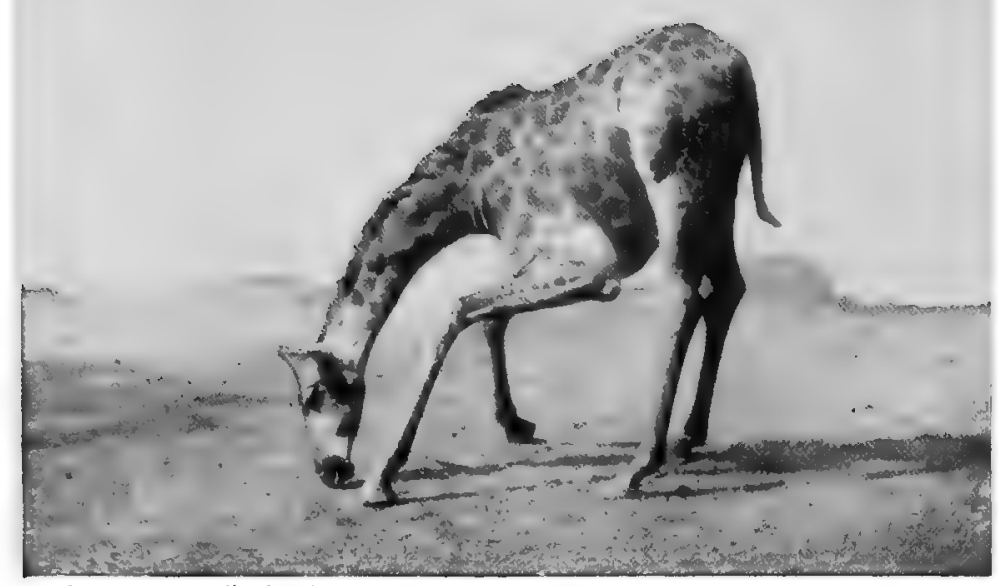

Photo oy $A$. S. Rudland of Sons

\section{A GIRAFFE GRAZING}

Grazing is evidently not the natural mode of feeding of these animals, which are essentially his chest, neck, and arms. Alwaysafter thatwe donned cord coats, when running giraffes in bush and forest country.

In regions where they have been little disturbed, giraffes no doubt wander across open plains, and are to be seen well away from the denser forests, feeding among scattered islets of acacias, easily exposed to the human eye. But in South Africa they are now seldom to be met with out of the forest region. Once, and once only, have I seen giraffes in the open. This was on the outskirts of the forest, and the great creatures had been tempted to a little knoll of mokala trees, rising like an islet from the sea of grass.

One's first impression of these creatures in the wild state is very deceptive. I well remember first setting eyes upon a troop of five or six. As they swung away from the leafage on which they were feeding, my friend and I cantered easily, thinking that we should soon come up with them. We were completely deceived. With those immense legs of theirs, the great creatures, going with their easy, shuffling, but marvellously swift walk, were simply striding away from us. Discovering our mistake, we rode hard, and the giraffes then broke into their strange, rocking gallop, and a headlong, desperate chase began, to be terminated by the death of a fine cow. Like the camel, the giraffe progresses by moving the two legs upon either side of the body simultaneously. At this strange, rocking gallop these animals move at a great pace, and a good Cape horse is needed to run into them. By far the best plan, if you are bent on shooting these animals, is to press your pony, so soon as you sight giraffes, to the top of its speed, and force the game beyond its natural paces in one desperate gallop of a couple of miles or so. If well mounted, your nag will take you right up to the heels of the tall beasts, and, firing from the saddle, you can, without great difficulty, bring down the game. The giraffe, unlike the antelopes of Africa, is not very tenacious of life, and a bullet planted near the root of the tail will, penetrating the short body, pierce a vital spot, and bring down the tall beast crashing to earth. Having tasted the delights of fox-hunting and many other forms of sport, I can testify that the run up to a good troop of giraffes is one of the most thrilling and exciting of all human experiences. There is nothing else quite like it in the wide range of sporting emotions. Having enjoyed this thrilling pleasure a few times, however, the humane hunter will stay his hand, and shoot only when meat, or perhaps an exceptionally fine specimen, is absolutely needed. Giraffes are, of course, utterly defenceless, and, save for their shy, wary habits and remote, waterless habitat, have nothing to shield them from the mounted hunter.

Giraffe-hunting on foot is a very different matter. In that case the giraffe has the better of it, and the stalker is placed at great disadvantage. These animals are in many places found in extremely waterless country, where even the mounted hunter has much trouble to reach them. Like elands and gemsbok and other desert-loving antelopes, they can exist for long periods - months together - without drinking. In the northern portions of the Kalahari Desert, where I have carefully observed their habits, as well as hunted them, it is an undoubted 


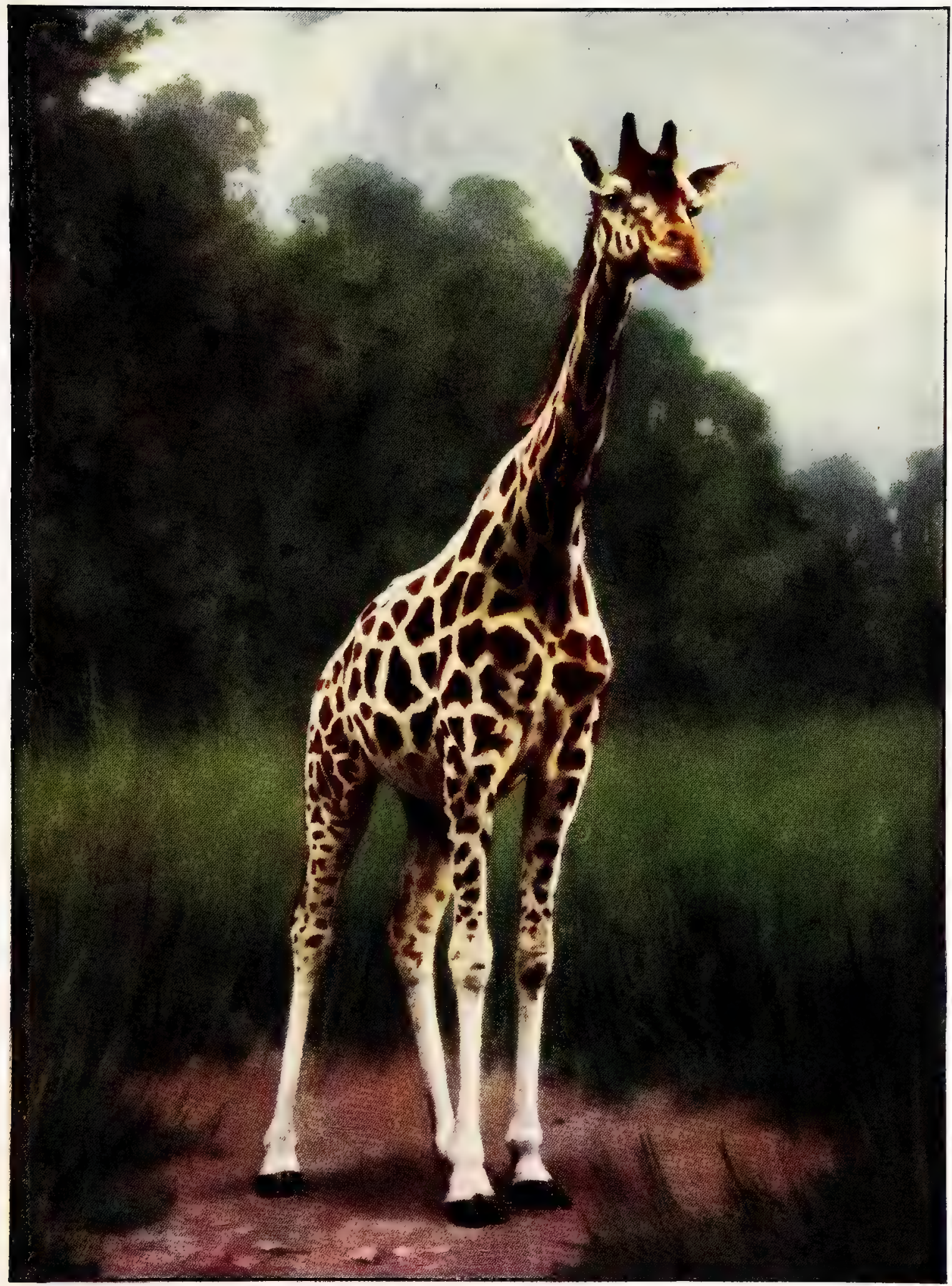

Photo by York \& Son.

\section{NORTHERN GIRAFFE.}

Two distinct types of Giraffe exist; the northern form, which has a large third horn, may be described as a chocolate-coloured animal marked with a network of fine buff lines; the southern form, in which the third hom is small, is fawn coloured with irregular brown blotches. 

fact that giraffes never touch water during the whole of the dry winter season - for several months on end. Gemsbok and elands in the same waterless tract of country are complete abstainers for the same period. The flesh of a giraffe cow, if fairly young, is excellent, tender, and well tasted, with a flavour of game-like veal. The marrow-bones also, roasted over a gentle wood fire, and sawn in half, afford delicious eating, quite one of the supreme delicacies of the African wilderness.

\section{THE OKAPI}

BY SIR HARRY JOHNSTON, K.C.B., F.Z.S,

READERS of "The Living Animals of the World" are in all probability readers of newspapers, and it would therefore be affectation on the part of the writer of these lines to assume that they have not heard more or less of the discovery which he was privileged to make of an entirely new ruminant of large size, dwelling in the forests bordering the Semliki River, in Central Africa, on the borderland between the Uganda Protectorate and the Congo Free State. The history of this discovery, stated briefly, is as follows:- In I882-83 I was the guest of $\mathrm{Mr}$. (now Sir Henry) Stanley on the River Congo at Stanley Pool. I was visiting the Congo at that time as an explorer in a very small way and a naturalist. Mr. Stanley, conversing with me on the possibility of African discoveries, told me then that he believed that all that was most wonderful in tropical Africa would be found to be concentrated in the region of the Blue Mountains, south of the Albert Nyanza. This feeling on Stanley's part doubtless was one of the reasons which urged him to go to the relief of Emin Pasha. His journey through the great Congo Forest towards the Blue Mountains of the Albert Nyanza resulted in his discovery of the greatest snow mountain-range of Africa, Ruwenzori, and the river Semliki, which is the Upper Albertine Nile; of Lake Albert Edward, from which it flows round the flanks of Ruwenzori; and, amongst other things, in more detailed information regarding the dwarf races of the Northern Congo forests than we

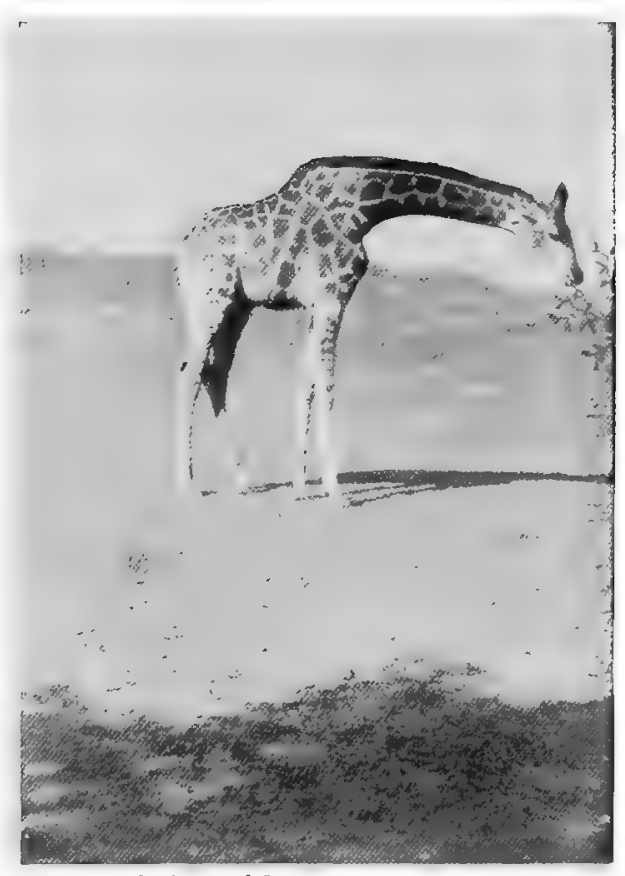

Photo by Charles Knight]

A GIRAFFE BROWSING

Here the posture is seen to be theroughly naturat had yet received. Stanley also was the first to draw the attention of the world to the dense and awful character of these mighty woods, and to hint at the mysteries and wonders in natural history which they possibly contained. The stress and trouble of his expedition prevented him and his companions from bestowing much attention on natural history; moreover, in these forests it is extremely difficult for persons who are passing hurriedly through the tangle to come into actual contact with the beasts that inhabit them. Sir Henry Stanley, discussing this subject with me since my return from Uganda, tells me that he believes that the okapi is only one amongst several strange new beasts which will be eventually discovered in these remarkable forests. He describes having seen a creature like a gigantic pig 6 feet in length, and certain antelopes unlike any known type. In regard to the okapi, the only hint of its existence which he obtained was the announcement that the dwarfs knew of the existence of a creature in their forests which greatly resembled an ass in appearance, and which they caught in pits. This tiny sentence in an appendix to his book "In Darkest Africa" attracted my attention some time before I went to Uganda. It seemed to me so extraordinary that any creature like a horse should inhabit a dense 


\section{THE LIVING ANIMALS OF THE WORLD}

forest, that I determined, if ever fate should lead me in that direction, I would make enquiries.

Soon after reac'ling the Uganda Protectorate at the end of 1899 , I came in contact with a large party of dwarfs who had been kidnapped by a too enterprising German impresario, who had decided to show them at the Paris Exhibition. As the Belgians objected to this procedure, I released the dwarfs from their kidnapper, and retained them with me for some months in Uganda, until I was able personally to escort them back to their homes in the Congo Forest. I had other reasons connected with my Government business for visiting the north-western part of the Congo Free State. As soon as I could make the dwarfs understand me by means of an interpreter, I questioned them regarding the existence of this horse-like creature in their forests. They at once understood what I meant; and pointing to a zebra-skin and a live mule, they informed me that the creature in question, which was called OKAPI, was like a mule with

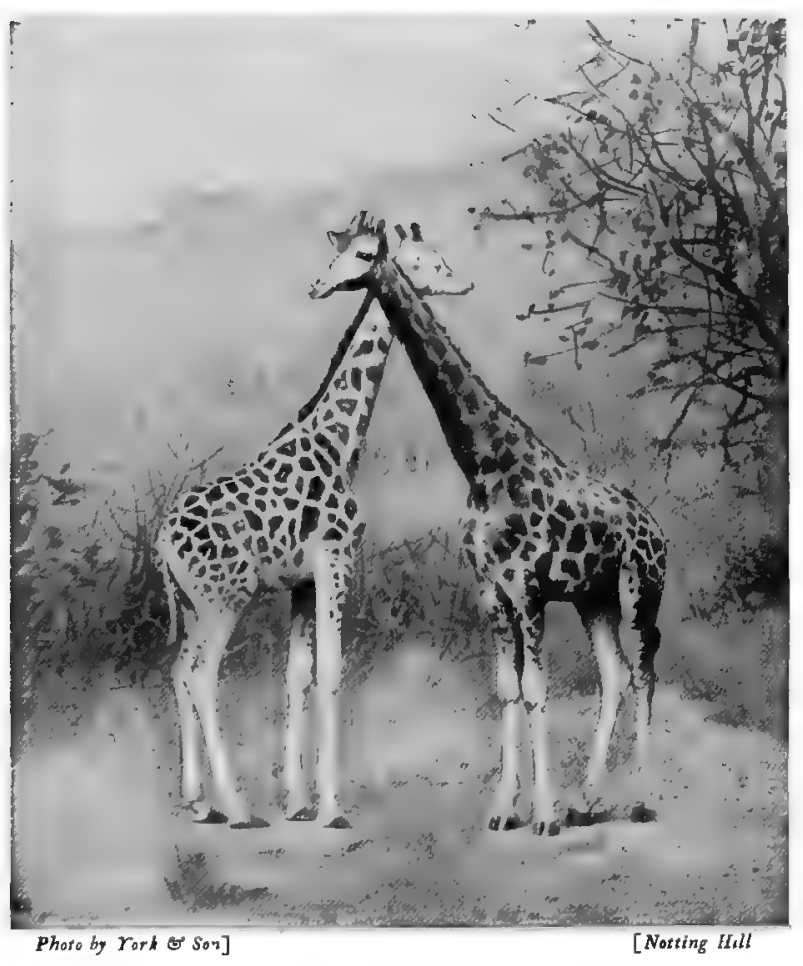

MALE AND FEMALE GIRAFFES

Giraffes are said to be very affecitonate animals zebra stripes on it. When I reached Fort Mbeni, in the Congo Free State, on the west bank of the river Semliki, I put questions to the Belgian officers stationed there. They all knew the okapi, at any rate, when dead. As a living animal they had none of them seen it, but their native soldiers were in the habit of hunting the animal in the forest and killing it with spears, and then bringing in the skin and the flesh for use in the fort. One of the officers declared there was even then a freshly obtained skin lying about in the precincts of the fort. On searching for this, however, it was discovered that the greater part of it had been thrown away, only the gaudier portions having been cut into strips by the soldiers to be made into bandoliers. These strips, together with similar ones obtained from natives in the forest, I sent to England, to Dr. P. L. Sclater, for his consideration. Furnished by the Belgian officers with guides, and taking with me all the dwarfs whom I had brought from Uganda, I entered the forest, and remained there for some days searching for the okapi. All this time I was convinced that I was on the track of a species of horse; and therefore when the natives showed the tracks of a cloven-footed animal like the eland, and told us these were the foot-prints of the okapi, I disbelieved them, and imagined that we were merely following a forest eland. We never saw the okapi; and as the life in the forest made the whole expedition extremely ill, and my time was required for official work elsewhere, I was obliged to give up this search. Meantime, I had elicited from the natives, whom I questioned closely, that the okapi was a creature without horns or any means of offence, the size of a large antelope or mule, which inhabited only the densest parts of the forest, and generally went about in pairs, male and female. It lived chiefly on leaves. The Belgian officers, seeing that I was disappointed at not obtaining a complete skin, offered to use their best efforts to obtain one for me, and send it on to Uganda after my departure.

This promise was eventually redeemed by Mr. Karl Eriksson, a Swedish officer in the Belgian service. Mr. Eriksson sent me a complete skin and two skulls. The skin and the 


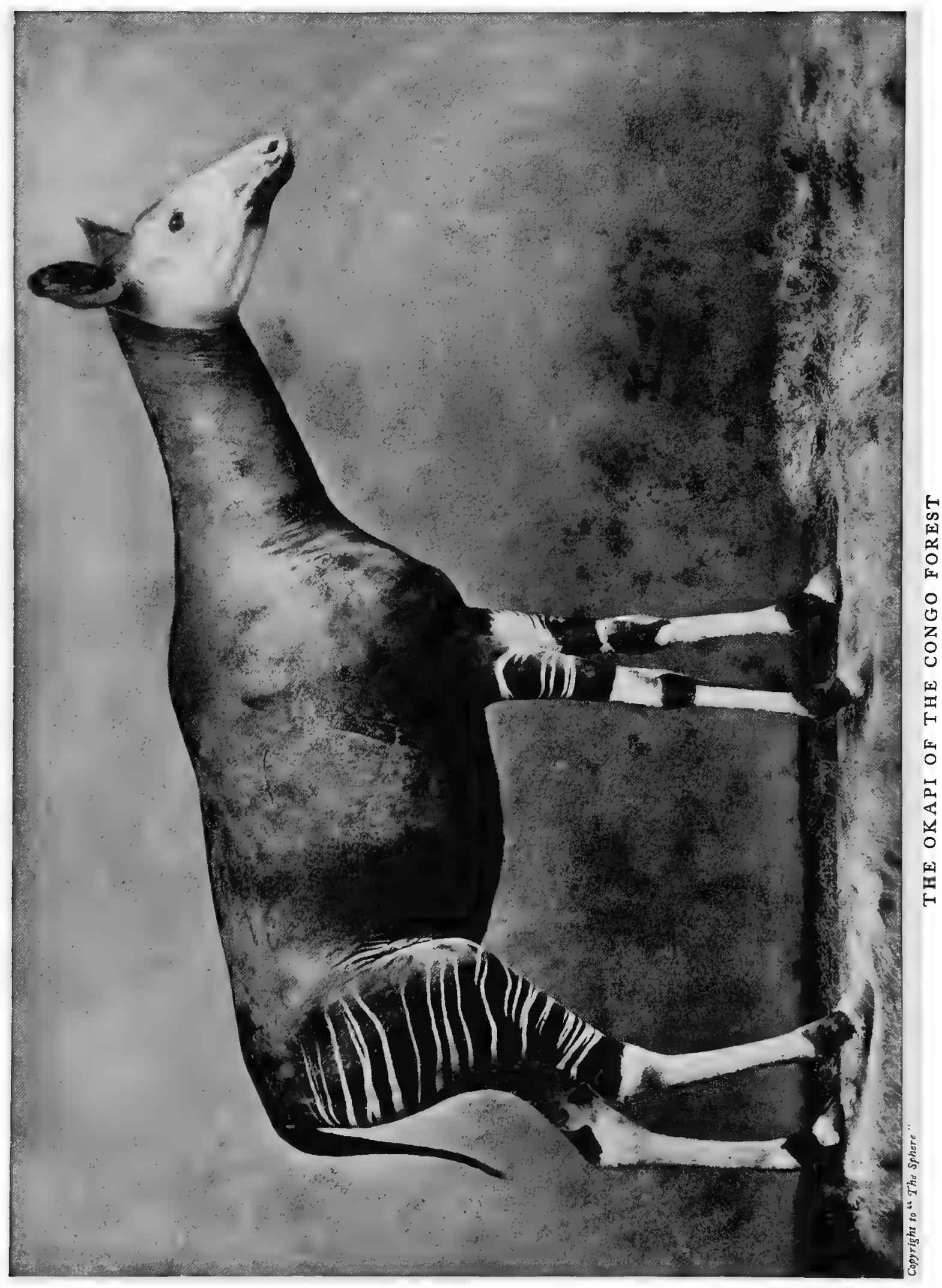




\section{THE LIVING ANIMALS OF THE WORLD}

bigger of the two skulls belonged to a young male. This is the skin which is now set up in the Natural History Museum at South Kensington, and of which a photographic illustration accompanies this notice. Upon receiving this skin, I saw at once what the okapi was - namely, a close relation of the giraffe. From the very small development of the horn-bosses, I believed that it was nearer allied to the helladotherium than to the living giraffe. In forwarding the specimens to Professor Ray Lankester, I therefore proposed that it should be called Helladotherium tigrimum. Professor Ray Lankester, having examined the specimens with a greater knowledge than I possessed, decided that the animal was rather more closely allied to the giraffe than to the helladotherium, but that it possessed sufficient peculiarities of its own to oblige hm to create for its reception a new genus, which he proposed to call Ocapia.

Meantime, the original strips of the skin (which apparently belonged to an older and

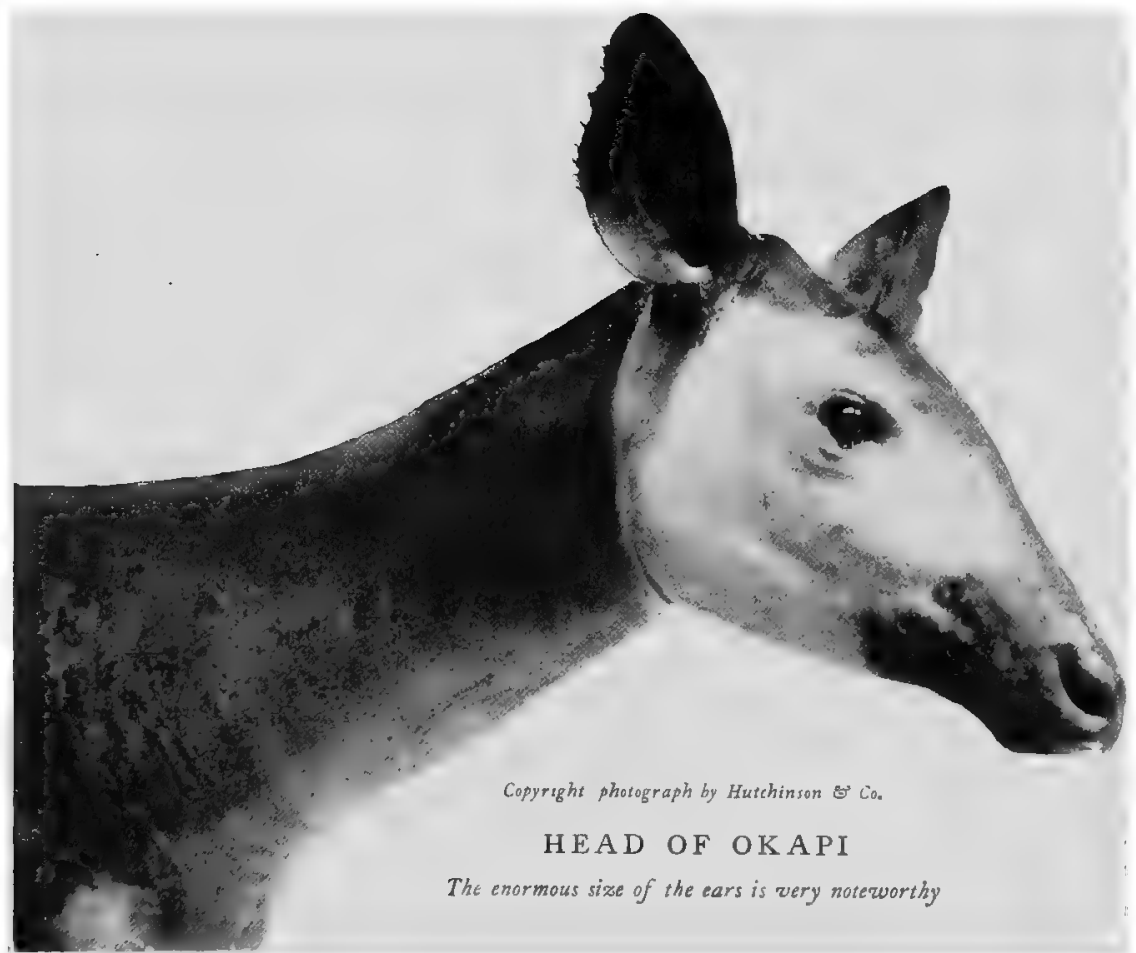
larger animal than the specimen mounted at South Kenisington) had been pronounced by experts to whom they were submitted to be the skin of an undiscovered species of horse, and this supposed new horse had been tentatively named by Dr. P. L. Sclater Equus jolmstoni. The full discovery obliged Professor Ray Lankester to set aside any idea of the okapi being allied to the horse, but he was good enough to attach Mr. Sclater's specific name of johnstoni to his newly founded genus of Ocapia.

$U_{p}$ to the time of writing this is all that is known of this extraordinary survival in the Congo Forest of the only living relation of the giraffe. We know by palæontological discoveries in Europe and in Asia that there existed a large family of ruminants which in their development and features were neither of the $\mathrm{Ox}$ group nor of the Deer, but in some respects occupied a position midway between these two branches of cloven-hoofed, horned, ruminating Ungulates. To this family the Giraffe, the Okapi, the Helladotherium, the Samotherium, the Sivatherium, and the Bramatherium belong. In all probability bony projections arose from the skulls of these creatures similar in some measure to the prominent bony cores of the horns of oxen. From the top, however, of these bony cores there would seem to have arisen anciently antlers, possibly deciduous like those of the prongbuck. In time creatures like the giraffe lost any need for such weapons of offence, and ceased to grow antlers; but the bony cores from which these antlers once proceeded still remained, and in the case of the giraffe remain to the present day. In the helladotherium and in the okapi these bony cores have dwindled to mere bumps. 


\section{C'H A P TER XVII}

\section{THE DEER TRIBE}

BY H. A. BRYDEN

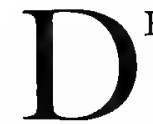

EER represent as a family the non-domesticated class of ruminants. Generally speaking, the males are distinguished by antlers, which are shed periodically, usually once a year, and again renewed. Comprising as it does some of the noblest mammals to be found on the face of the earth, this large and important tribe is to be found distributed over a large portion of the world's surface, from the Arctic North, the home of the wild reindeer, to Patagonia, in Southern South America. Deer are, however, not found in the continent of Africa south of the Sahara, nor in Madagascar or Australia. They are not indigenous to New Zealand; but the red deer, introduced there some years ago for purposes of sport, have thriven wonderfully well, and are now completely acclimatised.

From the earliest times deer, especially those species known as the true or typical deer, of which red deer may be said to be a type, have been animals of considerable importance to mankind. Their flesh has been always eagerly sought after; deer-skin is still, even in these days of high civilisation, useful for many purposes; and the antlers are almost equally in request.

It is more than probable that, in the vast and still littleexplored regions of Central, East, and Northern Asia, new species of deer remain to be discovered. At the present time there are known to exist, in various parts of the world, close on a hundred species and varieties. Within the space allotted to these animals it is, of course, manifestly impossible to notice all these in anything like detail. Many of the varieties or subspecies closely resemble one another, so much so that the differences between them are only apparent to the eyes of naturalists or acute observers.

\section{THE REINDEER}

REINDEER are distinguished from all other kinds of deer by the fact that antlers are borne by both males and females. The

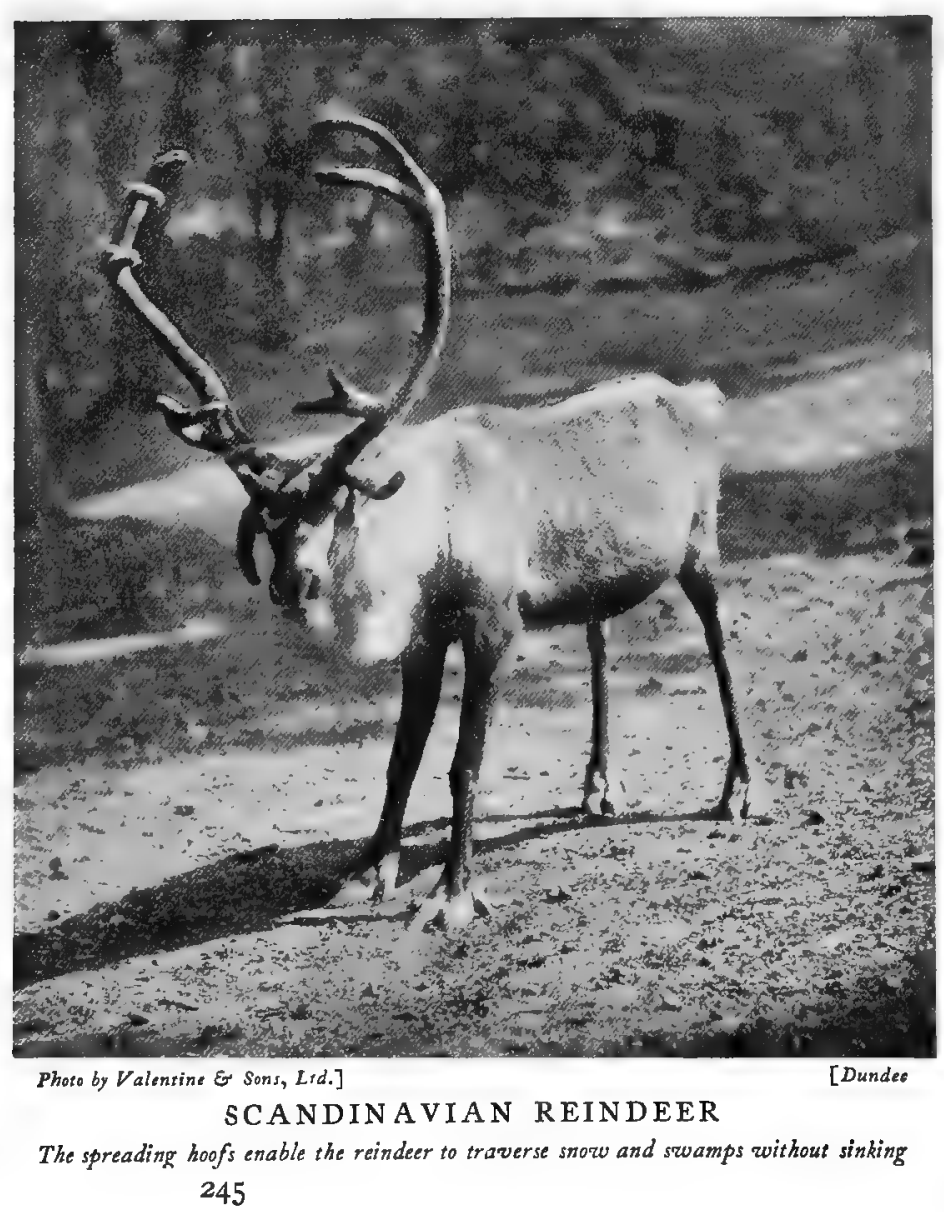




\section{THE LIVING ANIMALS OF THE WORLD}

antlers, as may be seen by the illustration, differ materially from those of the red deer, el. and other species; the brow-tines, especially, are often much palmated. These animals are heavily built, short-legged, and, as beseems dwellers in a snowy habitat, provided with round, short, and spreading hoofs. For ages reindeer have been domesticated by the Lapps of Scandinavia, the Samoyeds, and other primitive races of Northern Europe and Asia. Trained to harness, and drawing a sledge, they traverse long distances, while their milk, flesh, and

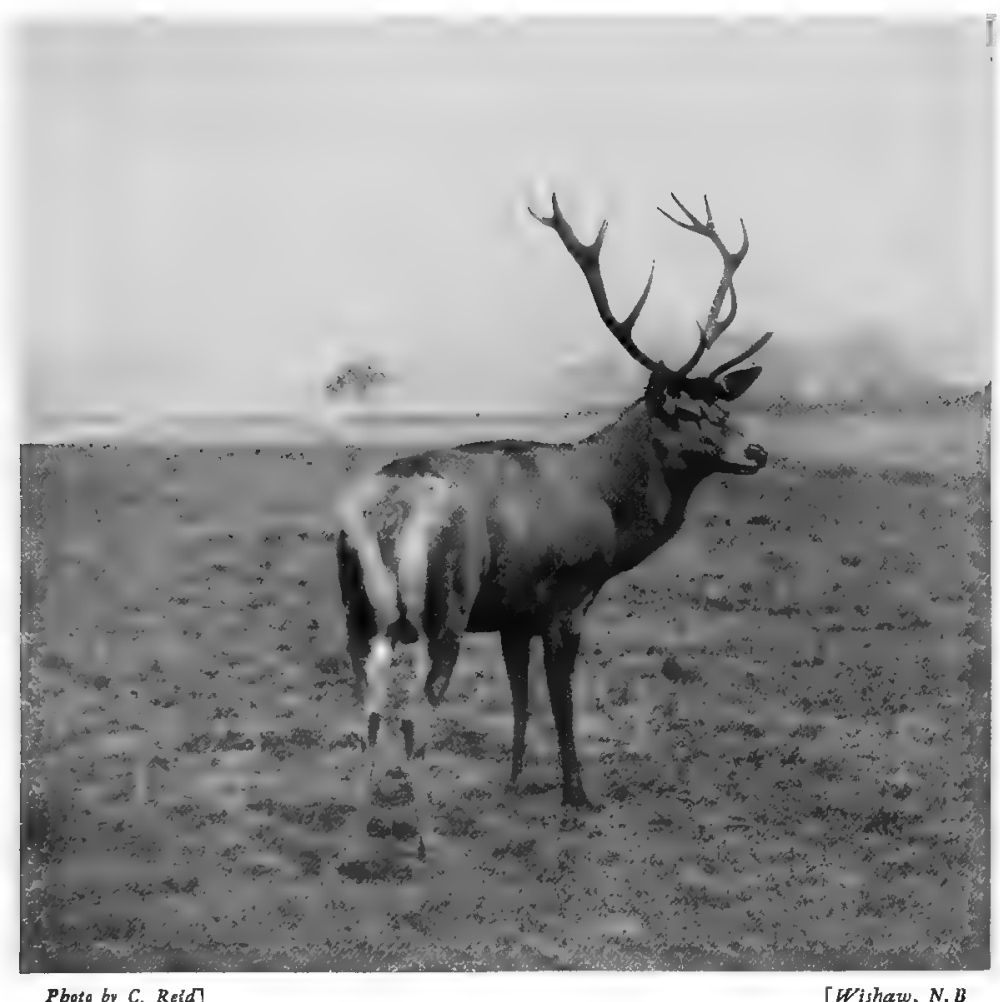

PARK RED DEER

The typical representative of the entire Deer Tribe hides are of great importance to the people who keep them. The Common or SCANDINAVIAN REINDEER ranges from Norway through Northern Europe into Asia, though how far eastward is not yet accurately determined. It is interesting to note that these animals were once denizens of Britain, and so lately as the twelfth century the Jarls of Orkney are believed to have been in the habit of crossing to the mainland for the purpose of hunting them in the wilds of Caithness. Wild reindeer are still to be found in the remoter parts of Norway, though,

from much persecution, they are becoming comparatively scarce in most parts of the country.

Mr. Abel Chapman, in his "Wild Norway," gives some excellent accounts of sport with these fine deer. Speaking of a good herd of twenty-one, discovered in Ryfylke, he says: "Most of the deer were lying down, but both the big stags stood upright in dreamy, inert postures. . . . I now fully realised what a truly magnificent animal I had before me. Both in body and horn he was a giant, and his coat was no less remarkable; the neck was pure white, and beneath it a shaggy mane hung down a foot in length. This white neck was set off by the dark head in front and the rich glossy brown of his robe behind. Besides this the contrasting black and white bars on flanks and stern were conspicuously clean-cut and defined, and the long and massive antlers showed a splendid recurved sweep, surmounted by branch-like tines, all clean." For three long, agonising hours the stalker watched this noble prize, and then one of those lucky chances which occasionally gladden the hunter's heart occurred, and the reindeer approached within a hundred yards. "Half-a-dozen forward steps, and his white neck and dark shoulder were beautifully exposed. Already, ere his head had appeared, the rifle had been shifted over, and now the foresight dwelt lovingly on a thrice-refined aim. The 450 bullet struck to an inch, just where the shaggy mane joined the brown shoulder. 


\section{The Red Deer.}

Mr. J. G. Millais, author of "British Deer and their Horns" and other works, himself a first-rate sportsman in many parts of the world, compares the style of shooting red deer in vogue forty or fifty years ago with that obtaining in the Highlands at the present day. "A stalker in Black Mount, Argyllshire," he says, "told me of a typical day's sport in which he took part some forty years ago. Fox Maule and Sir Edwin Landseer were the two rifles (they frequently stalked in pairs at that time), and, on the side of Clashven, Peter Robertson, the head forester, brought them within eighty yards of two exceptionally fine stags Maule fired and missed, as did also Sir Edwin as the stags moved away; then, on a signal from Robertson,

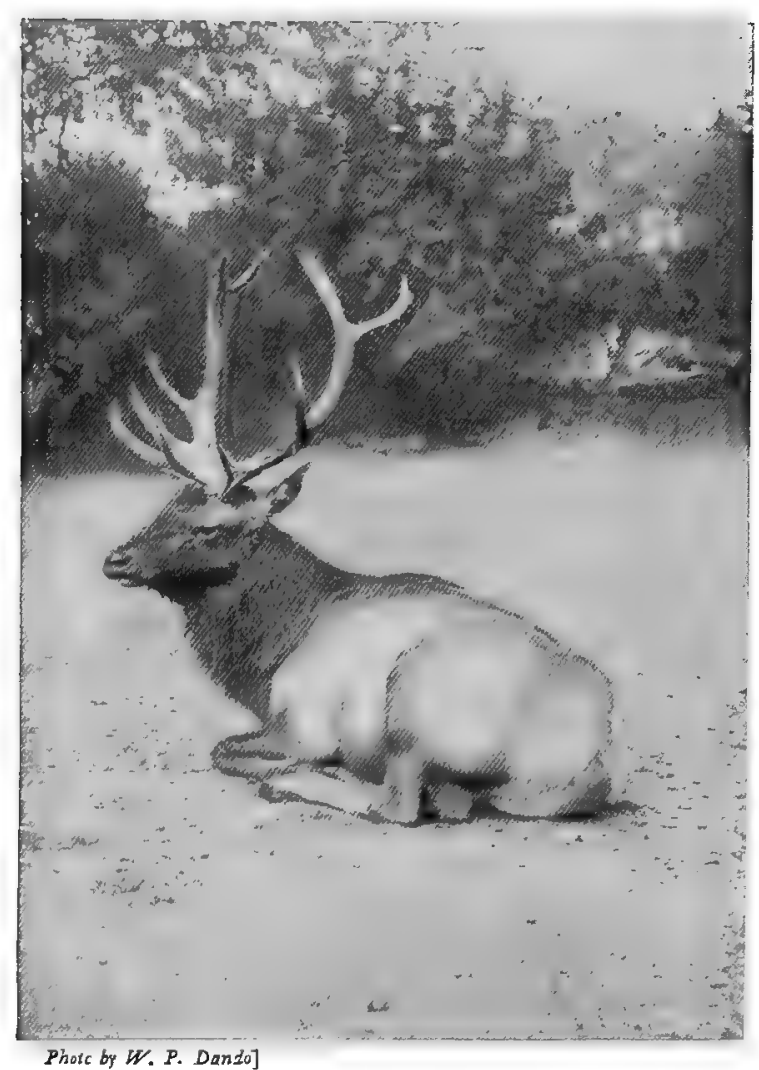

AN ASIATIC WAPITI

All the races of the wapiti are casily recognisable by the large fourth tine of the antlers and the short tail
Peter McColl, the gillie, slipped the hounds the two best ever owned by the late Marquis of Breadalbane, and whose portraits are still preserved in the famous picture of 'The Deer Drive ' - and away they went in hot pursuit of the deer. An end-on chase now ensued, the line taken being due east down the great glen towards Loch Dochart, and at last the stalkers were brought to a standstill, being fairly exhausted both in wind and limb. At this moment, however, four dark spots, like small rocks, standing out at the point of a little promontory in the lake, attracted their attention, and, on drawing nearer, they saw, to their surprise, each of the big stags being held at bay by a gallant hound. A couple of shots then settled the business, and so ended what was then considered a grand day's sport. No doubt it was most exciting to see the struggle of bone and sinew between two such noble quadrupeds, but it was not rifle-shooting. To-day the gallant but disturbing deer-hound has given place to the cunning and obedient collie, and the success of the stalker depends, for the most part, on the accuracy of his rifle and his skill in using it."

Here are a couple of sketches of modern stalking taken from Mr. Millais' own diary: -

"Wednesday, October 4th. - Started for the big corrie with $\mathrm{McColl}$, and saw nothing till we got to the Eagle Hill. On this were three stags and about twenty hinds, the property of a magnificent fellow carrying one of the best heads I have ever seen on Black Mount. For some time McColl thought he was just a bit too good to shoot, for the very best in this forest are generally left for stock purposes. Finding, however, that he was not Royal [a twelve-pointer], my companion agreed to a shot that is, if he got within shooting distance, which was not too likely, the Eagle Hill being one of those queer places where back eddies are carried down from almost every 'airt' from which the wind is blowing. Luck is apparently entirely my way this week, so far at any rate. The big stag was very 'kittle,' frequently roaring and keeping his hinds moving before him along the hillside, in the direction of another corrie running at right angles, the entrance to which, if reached, would checkmate us. A quick, stiff climb, and a dashing piece of stalking on the part of $\mathrm{McC}$ Coll, brought us in front of the herd only just in time, for I had hardly got 
into position when the first few hinds moved past a hundred yards below us. They were very uneasy and highly suspicious, but fortunately did not stop; and in another moment, to my joy, the big stag came slowly behind them, and offered a fair broadside in the very spot where I should have wished him to stand. The bullet took him through the ribs, certainly a trifle too far back, but he gave in at once, and rolled i 50 yards down the hill, fortunately without hurting his horns. A really fine Highland stag in his prime; weight, I6 stone $2 \mathrm{lbs}$, with a good wild head of ten points, and good cups on the top."

"Thursday, October 5th.-We negotiated the stiff climb, and McLeish, leaving me behind a rock on the summit, returned some distance to signal directions to the pony-man. He came back just as the stag returned roaring down the pass he had ascended; and as the mist was blotting out the landscape, I feared he would come right on to us without being seen, but, as luck would have it, he stopped and recommenced bellowing within seventy yards. I never heard a stag make such a row, but nothing of him could we see. It was most exciting, lying flat on a slab of rock, hoping devoutly that the mist would rise, if only for a few seconds. The tension had grown extreme, when there was a momentary lift in the gloom, and I made out the dim forms of the deer just as a big hind, which I had not noticed, 'bruached' loudly within twenty yards of us. The outline of the stag was barely visible when, after carefully aiming, I pressed the trigger, knowing that a moment later there would be no second chance. At the shot the deer at once disappeared, but I felt sure I had hit him, and, on following the tracks for some fifty yards, there he lay as dead as a door-nail. Weight, I3 stone 6 lbs.; a wild head of ten points; thin, and evidently that of a deer on the decline."

In England the wild red deer are hunted with stag-hounds on Exmoor, and first-rate sport is obtained on the great moorlands of Somerset and Devon. Durino the last fifty years the deer have much increased in numbrs, and no less than three packs-the Devon and Somerset, Sir John Heathcoat-Amory's, and Mr. Peter Ormrod's-are now engaged in hunting them. In the five years ending in 1892,276 deer were killed by the Devon and Somerset hounds.

Wild deer are much given to fighting during the mating season. This is evidenced by the number of pairs of dead deer formerly found with their antlers tightly interlocked. However, deer often make playful tests of strength by pushing each other with their antlers, and in this way also such casualties may have occurred.

The young of the red deer are in Europe usually dropped in June. The fawn is dexterously concealed by the hind amid the heather, and is left in concealment during the day. Scrope, a great authority on these animals, states that the hind induces her fawn to lie down by pressure of the nose: "It will never stir or lift up its head the whole of the day, unless you come right upon it, as I have often done; it lies like a dog, with its nose to its tail. The hind, however, although she often separates herself from the young fawn, does not lose sight of its welfare, but remains at a distance to windward, and goes to its succour in case of an attack of the wild cat or fox, or any other powerful vermin."

On the Continent far finer examples of red deer are to be found than in the British Isles, and the antlers and records of weights preserved at the Castle of Moritzburg in Saxony, and elsewhere, show that two hundred years ago the stags of Germany were far superior even to those of the present day, which are much heavier and afford finer trophies than do the Highland red deer. Even in Germany, however, marked deterioration has taken place during the last two centuries. A stag, for example, killed by the Elector of Saxony in 1646 weighed not less than 6I stone II lbs.; while from the Elector's records between I6II and I656 it appears that 59 stags exceeded 56 stone, 65 I exceeded 48 stone, 2.679 exceeded 40 stone, and 4,139 exceeded 32 stone. These figures are given by Mr. W. A. Baillie-Grohman, a distinguished sportsman, in a very interesting chapter contributed to the "Big Game Shooting" volumes of the Badminton Library.

This deterioration among the red deer of the forests of Central and Northern Europe is, however, not traceable among the red deer of the wild mountainous regions of Austria-Hungary 


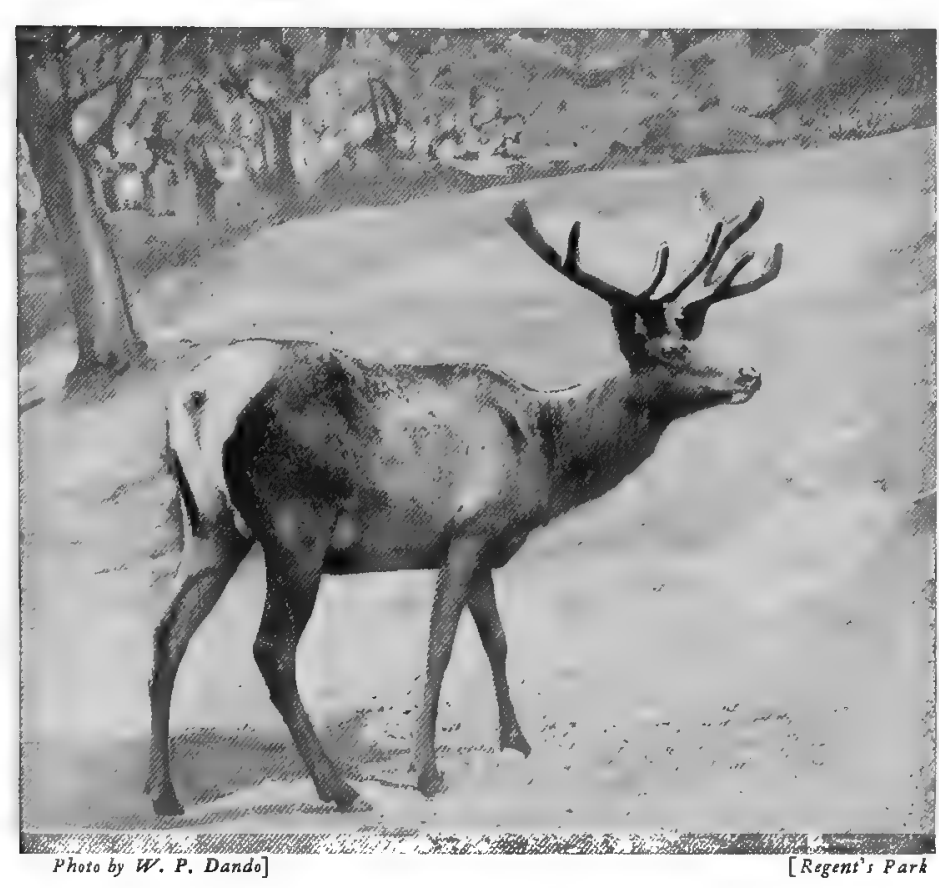

ALTAI WAPITI

This is one of several Asiatic forms of the wapiti

and South-eastern Europe. Here, at the present day, stags of enormous size and weight are still to be found. In the Carpathian Alps, for example, red deer stags are still to be shot scaling more than 40 stone (clean) in weight. Climate and feeding have, of course, much to do with the weight of stags and the size and beauty of their antlers. The Carpathian stags have enormous range, rich food, and, as Mr. BaillieGrohman points out, are suffered during the summer to "make undisturbed raids upon the rich agricultural valleys ... the feudal sway exercised by the great territorial magnates permitting the deer to trespass upon the crops with impunity, and thus grow to be the lustiest of their race."

In addition to the British Islands, the red deer of Europe is found on the Island of Hitteren, on the western coast of Norway, in the south of Sweden, and in Germany, Russia, France, Spain, Austria-Hungary, Turkey, and Greece.

In Corsica and Sardinia a local and smaller race is found, probably closely allied to the stag of North Africa. The BARBARY STAG is somewhat smaller than its first cousin of Europe, and carries antlers which usually lack the second, or bez, tine. The colour of this stag is "a dark sepia-brown, a little lighter and greyer on the back. Faint yellowish spots can occasionally be distinguished on the fur in the adults," says Sir Harry Johnston. The hinds are of the same colour as the stags, but lack the grey tint on the back. These fine deer are found in Algeria and Tunis, their habitat being chiefly in pine and cork forests. They are found also in parts of Morocco, near the frontiers of Algeria and Tunis, where their range extends from near the Mediterranean to the verge of the Sahara Desert. Formerly the Barbary stag was hunted by the Arabs on horseback by the aid of greyhounds. In Tunis, where it is protected by the French, it is now fairly abundant.

\section{The Maral and Kashmir Stag}

The CASPIAN RED DEER, or MARAL, is a magnificent sub-species, incomparably the finest representative of the red deer species. Standing about 4 feet 6 inches at the shoulder, a good stag will weigh as much as 40 stone clean, in exceptional specimens probably a good deal more. The range of this noble beast includes the Caspian provinces of North Persia, Transcaucasia, the Caucasus, and the Crimea. There can be little doubt that the great stags shot in the Galician Carpathians are Caspian red deer, and not the ordinary red deer of Western Europe. The red deer of Turkey is, too, no doubt referable to this sub-species.

Continuing our survey of typical deer, we come to the KASHMIR STAG, which is a magnificent beast, standing as much as 4 feet 4 inches at the shoulder, and carrying antlers approaching the red deer type, which measure in fine specimens from 45 to 48 inches. The Kashmir stag, often miscalled Barasingh by Indian sportsmen, makes its home in the forest regions of the north side of the Kashmir Valley, ranging chiefly on altitudes of from 5,000 to I2,000 feet. 
WAPITI.

WAPITI are giants of the red deer group, carrying large antiers and often attaining I,O0O 1bs. in weight. In America they are known as Elk.

In recent years it has been discovered that wapiti are also denizens of certain parts of Asia. At least two sub-species - the Altai Wapiti and the Manchurian Wapiti - have thus

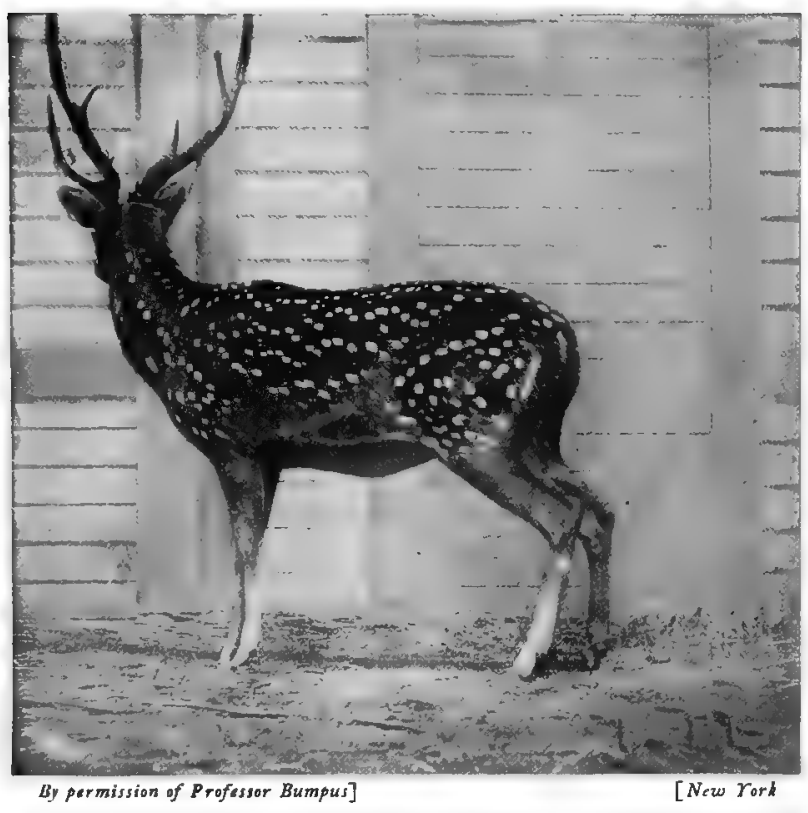

A SPOTTED ORIENTAL DEER

One of the numerous Philippine species far been identified. The former, sometimes known as the Thian-shan Stag, is found in the forests of the Altai and Thian-shan Mountains, west of the Mongolian Desert. Compared with its American congener, it is inferior in stature, has shorter legs, a longer body, and proportionately larger antlers, though none have yet approached those of the longest American specimens. These splendid stags, of which living specimens have been maintained by the Duke of Bedford at Woburn, are captured alive by the Altai natives, and kept in domestication for the sake of their antlers, which are sold in China for purposes of medicine at as much as the value of $\$ 50$ apiece.

The Manchurian Wapitu, or LueHDORF'S STAG, is a well-marked local race of the wapiti, which turns reddish in summer. It has received several names, and is well characterised by the form of its antlers. It has been kept alive in the Duke of Bedford's park at Woburn Abbey. It seems probable that the Siberian stags will eventually be referred to the wapiti group.

\section{BOKHARA DEER}

A fine deer from Russian Turkestan is at present known as the BOKHARA DEER. It is said to resemble the shou of Northern Bhutan more than any other species, and, standing about 4 feet at the shoulder, is of an ashen-grey colour, tinged with yellow. A living specimen has been exhibited at Moscow, and it is believed that specimens in the collection of the Duke of Bedford belong to this form.

\section{SIKAS}

The SIKAS, as typified by the JAPANESE DEER, are a group of deer of moderate size, distinguished from the preceding assemblage by antlers of simpler type, each antler having usually four points, and lacking the second, or bez, tine. The coat is spotted with white, and white markings appear about the tail. The tail is much longer than in the red deer group. The Japanese deer, found in Japan and North China, is a beautiful creature, somewhat smaller than the fallow deer of Europe, having a coat of brilliant chestnut, thickly spotted with white in curious longitudinal markings. This is the summer pelage; in winter the colour changes to dark brown, and the spots mostly disappear. When in the velvet, the antlers are of a bright chestnut-red, with black tips, and at this season the bucks look their handsomest. A good head measures from 25 to 3 I inches, and carries usually eight points.

The Manchurian Sika may be looked upon as a larger variety of the Japanese deer, with a somewhat darker coat. 
Another closely allied form is the Formosan SiKA, which bears a rather paler summer coat, and carries spots in its winter pelage. This deer is found on the mountains of the island from which it takes its name. The few antlers which have reached this country seem to indicate that in this respect this deer is inferior to the other sikas. The longest pair yet recorded measure not more than $19 \frac{3}{4}$ inches.

The Pekin SiKa, sometimes known as Dybowski's deer, is considerably larger in size than the rest of the group, standing well over 3 feet at the shoulder. The horns are large and rugged, and measure as much as 27 inches in length. The coat is thick and shaggy, and well adapted for life in a harsh climate. The habitat of this species is North-eastern Manchuria and the borders of Korea.

\section{FALLOW DEER}

FALLOW DEER are, perhaps, to English people, the most familiar of all the cervine race, forming as they do, in the semi-domesticated state, the adornments of many English parks. The flesh of this handsome deer furnishes the well-known venison of this country, and is perhaps the best-tasted of all deer-meat. A good fallow buck stands about 3 feet at the shoulder, and weighs (clean) about 150 lbs., though specimens have been shot weighing as much as $204 \mathrm{lbs}$.,

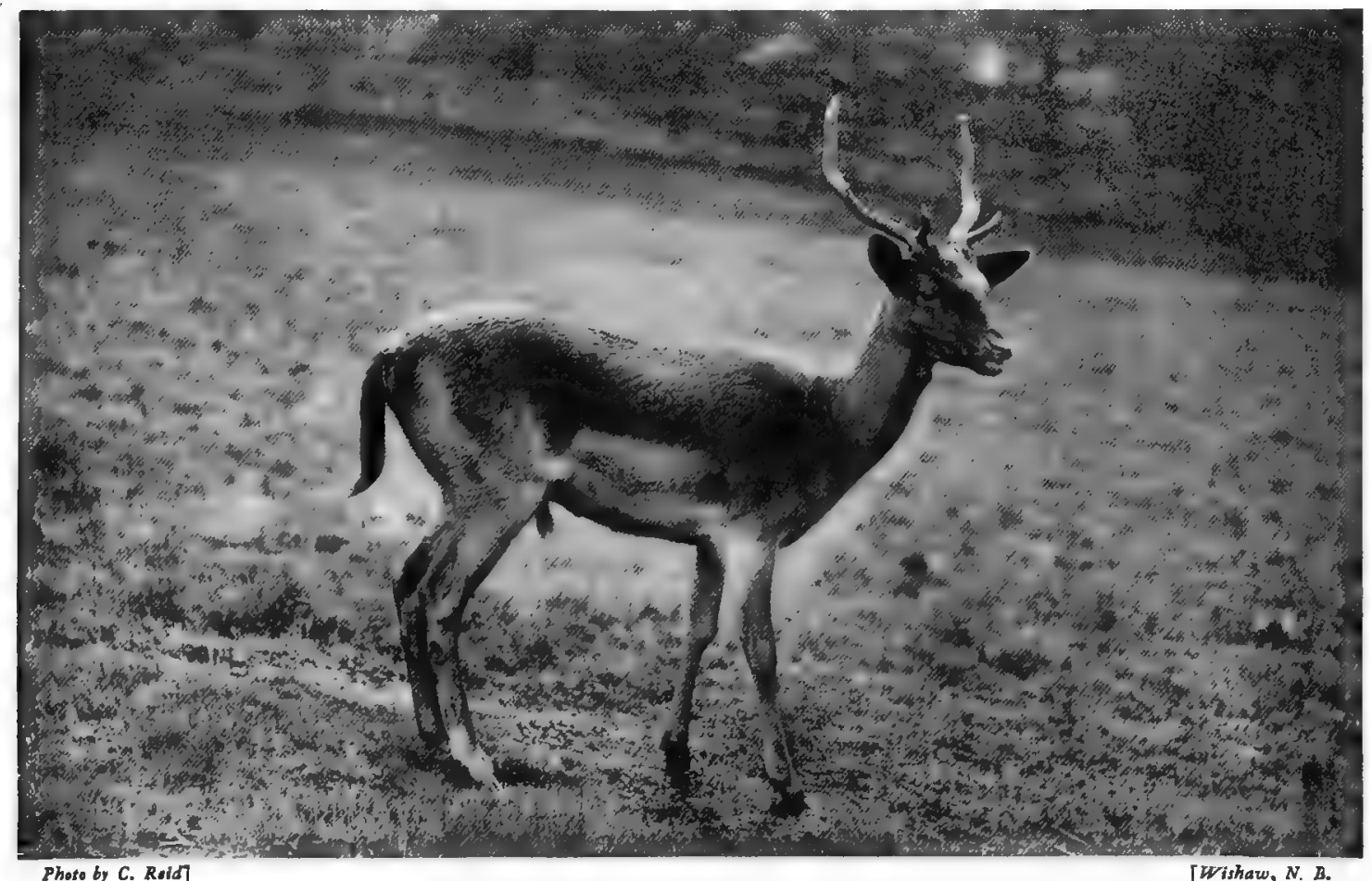

A YOUNG FALLOW BUCK OF THE BROWN BREED

The favourite park-deer of England

but this is exceptional. The horns are strongly palmated. Originally this deer was not indigenous to Britain, but is often said to have been introduced by the Romans from Eastern Europe.

The Common Fallow Deer is found in the wild state in Spain, Portugal, Greece, Austria, Rhades, Sardinia, Asia Minor, and North Palestine. It is doubtful whether, as has been stated, this deer ever existed in modern times in the wild state in North Africa. This is a highly gregarious species, delighting to move in considerable herds. In some parts of Scotland fallow deer have reverted completely to the wild state, and afford excellent sport. And even park- 


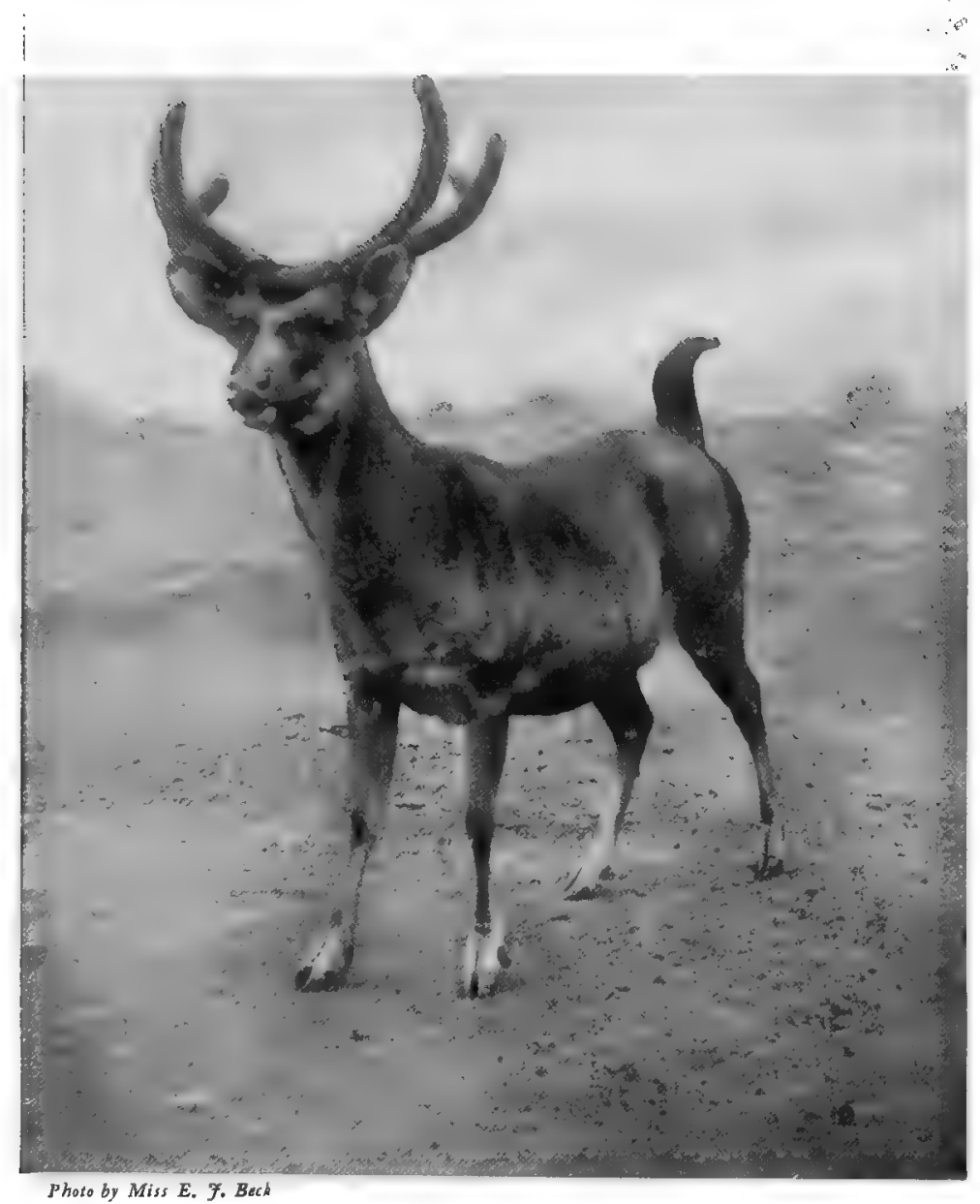

A SAMBAR STAG

The only Indian deer of which the faruns are unspotted

deer, once they are shot at, exhibit extraordinary wariness and cunning, so much so that curious tricks and disguises have often to be resorted to when a fat buck has to be shot for venison.

The beautiful MESOPOTAMIAN FALLOW DEER, found in the mountains of Luristan, in Mesopotamian Persia, is somewhat larger than the common species, while its coat is much more brightly coloured. The antlers bear little resemblance to those seen in the park-deer of this country, being far less palmated and spreading, and more vertical.

The enormous horns of the extinct deer once known as IRISH ELK are now considered by naturalists to be those of a gigantic species * of fallow deer. By the kindness of Mr. J. G. Millais, I am enabled to give the dimensions of a pair of antlers of one of these wonderful beasts from his museum. These antlers measure in spread, from tip to tip, 9 feet 4 inches; length round inside of right horn, 6 feet; round left horn, 5 feet 8 inches, a marvellous trophy, truly. This specimen was dug up in County Waterford. These colossal fallow deer, which roamed the wastes of Ireland in prehistoric times, must have afforded fairly exciting sport to the feebly armed human beings who then existed.

\section{The Sambar, or Rusine Deer}

SAMBAR may be shortly described as large deer, having rough, shaggy coats, and big, rugged antlers of simple type, usually displaying but three tines. They belong to the group known as Typical Deer, although they are but distantly connected with the red deer. The colour of the coat is usually dark umber-brown, marked with chestnut about the rump and under-parts. The well-known sambar of India stands as much as 5 feet 4 inches at the withers, and weighs, before being cleaned, some $600 \mathrm{lbs}$. The longest pair of antlers yet recorded (Rowland Ward's "Records of Big Game") measure 48 inches in length over the outer curve. Usually to be found among jungly, wooded hills and mountains in many parts of India and Ceylon, this fine stag affords first-rate sport, and is much sought after by shikaris. It is to be met with in small 
troops of from four to a dozen, or singly, while during the rutting-season the animals rove in more considerable herds. In jungle and thickly forested regions it is a hard matter to come up with the sambar on foot, and it is there usually shot from elephantback, by the aid of beaters. In more open hill country it affords good stalking. In Ceylon it is hunted with hounds, and yields in this way also capital sport. These animals seem to revel in heat, and love to shelter themselves in hot, stifling valleys; they drink only once in two or three days. It is a noticeable feature in connection with the antlers of the sambar that they are not invariably shed annually, as with most of the deer kind. In Ceylon, according to Sir Samuel Baker, they are shed "with great irregularity every third or fourth year."

Lieutenant-Colonel Reginald Heber Percy thus writes concerning the sambar, or sambur: "Compared with the Kashmir stag, red deer, or wapiti, he looks like an ugly,

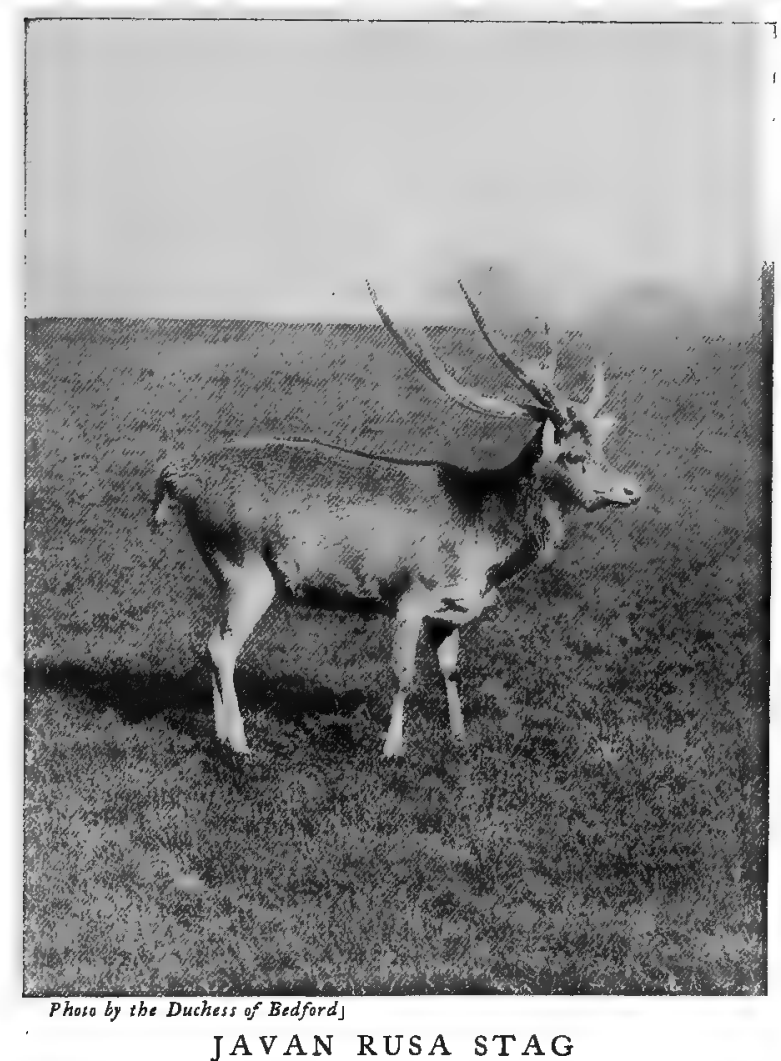

This deer is a near relative of the sambar, but has a somewnat different type of antler

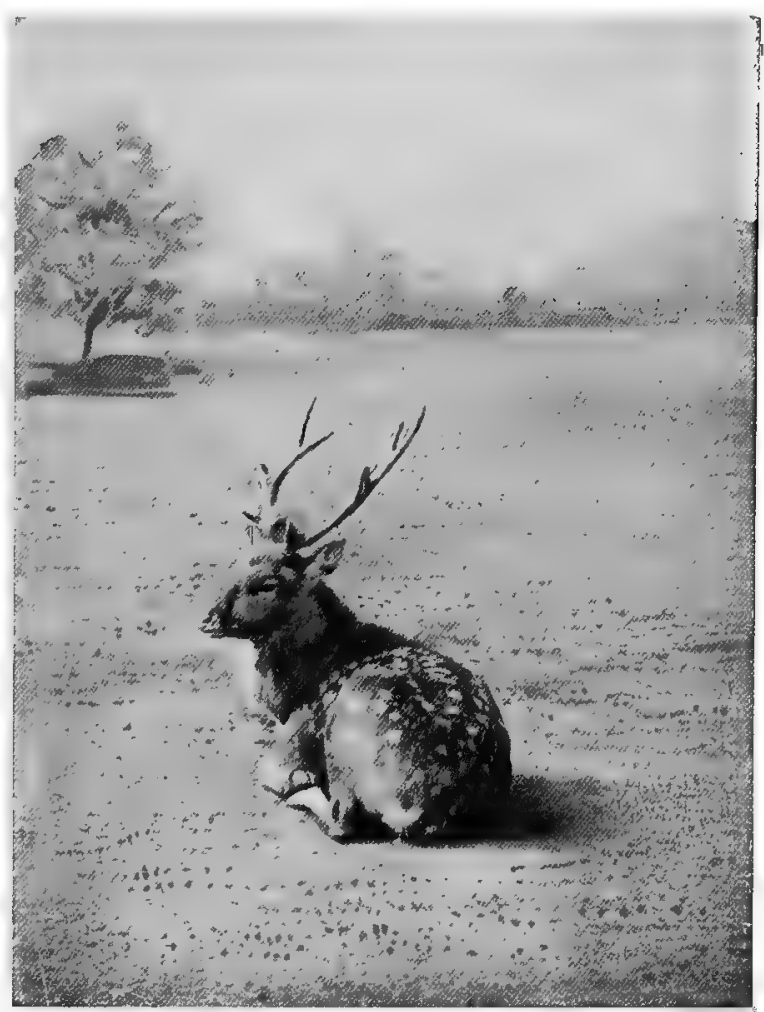

Photo by Miss E. F. Beck

\section{FORMOSAN SIKA STAG}

Like its Gapanese kindred, this deer is spotted only in summer

coarse, underbred brute. . . . As the sambur is almost entirely noct $\mathrm{mal}$ in its habits, it is most commonly shot in drives, and in many places it is almost impossible to obtain sambur otherwise; but where it can be managed, stalking is, of course, far better fun. The sportsman should be on his ground just before daylight, and work slowly through the forest at the edge of the feeding-grounds, taking the bottom of the hill if there are crops on the plain below, or, failing these, the edges of the open glades in the forest. Presently, if there are any sambur about, he will hear their trumpet-like call, and, creeping on, see two or three dark forms moving among the trees. In the grey of the morning it is often very hard to distinguish a stag from a hind, and the writer has on several occasions had to writ, after viewing the herd, till there was light enough to. pick his stag. Even in broad daylight it is difficult to judge the size of a stag's horns as he stands motionless in the deep gloom of the forest, and what little can be seen 


\section{THE LIVING ANIMALS OF THE WORLD}

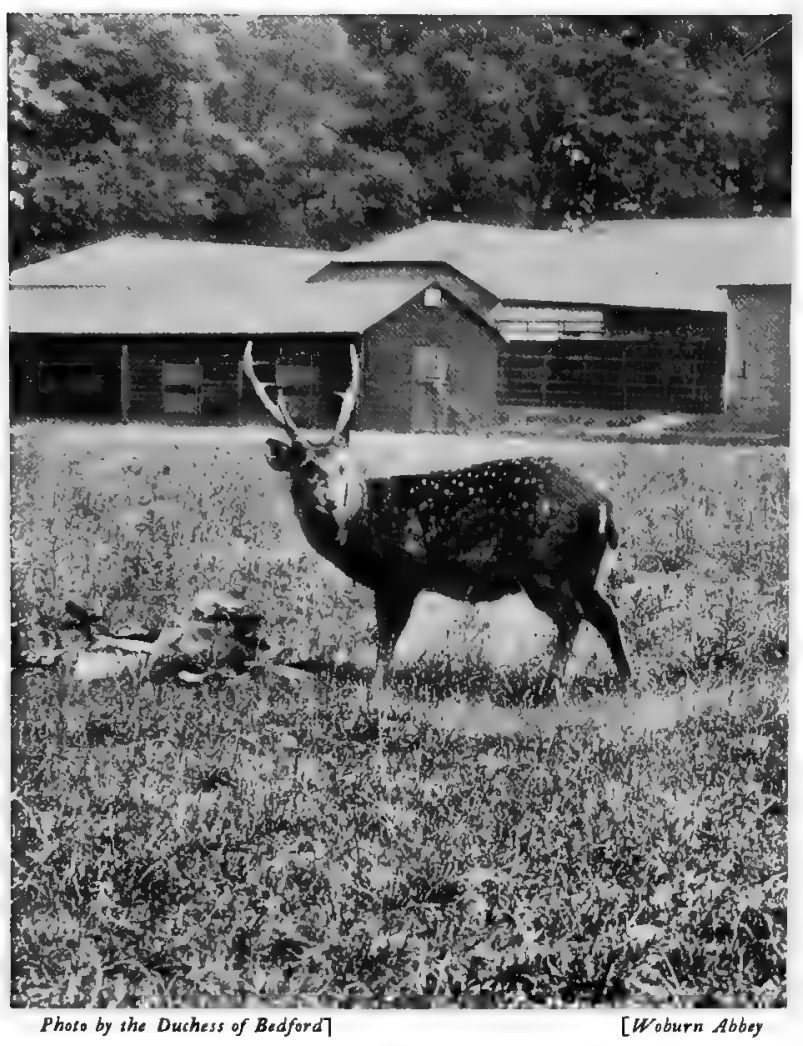

HOG-DEER

The smallest Indian representative of the sambar group

of them makes them look three times their real size - the beam is so massive and the tines so long. The stag, too, is such a big beast, standing nearly a hand taller than a barasingh, that if seen in the open he looks as big as the Irish elk. . . . All driving should be done during the heat of the day, when the animals are lying down; trying to drive when beasts are naturally on the move generally results in the game leaving the beat before the men are in their places. It may sound ridiculous for a man to get up a tree in a sambur drive, but he is far more likely to get an easy shot in this position, as the deer will neither see nor wind him; he commands more ground, and he runs no risk of heading back the wary old hind which often leads the herd, the chances being that if he is rightly posted the herd will come right under his tree. Another advantage is that, his fire being plunging, he can shoot all round without danger to the beaters. In some parts of the Himalaya native shikaris declare that they often shoot sambur by selecting a likely path and :mprovising a salt-lick, after the fashion of Laplanders when they want to catch their tame reindeer." The

flesh of this deer is coarse and only moderately good eating.

The Malayan Sambar, found from Assam, through Burma, to the Malay Peninsula, and in Siam, Hainan, Borneo, and perhaps Sumatra, is slightly less in size than its Indian prototype; the antlers vary somewhat, and are shorter and stouter. The longest antlers yet recorded measure $30_{3}^{\tau}$ inches over the outer curve; these come from Borneo.

The Formosan Sambar, sometimes called Swinhoe's Dcer, is, again, closely connected with the Malayan sambar, and may be looked upon as purely a local race. The antlers appear to run smaller, the best recorded examples only extending to I $9 \frac{3}{4}$ inches.

The Luzon Sambar (Philippines), a small sub-species, and the Szechuan Sambar (Northwest China), are also local races of the same species. This last seems thus far to occupy the most northerly habitat of this group.

The BaSilan Sambar (Philippines) is, like its congener of Luzon, a small sub-species, standing no more than from 24 to 26 inches at the shoulder, of slender build, and with the hindquarters higher than the withers. The best antlers yet recorded measure no more than I $5 \frac{1}{2}$ inches. It is interesting to note that as the island of Basilan is the smallest of the Philippines, so is this sambar by far the smallest of its group. Its restricted habitat has no doubt conduced, during long ages, to bring about this result.

The JAVAN SAMBAR, or RUSA, is a distinct species, found, as its name implies, in the island of Java. The antlers are somewhat slender, but are, next to those of the sambar of India, the longest of the group The best recorded pair measure $35 \frac{1}{2}$ inches, while another pair from Mauritius, where this animal has been introduced, measure half an inch longer. This sambar is smaller than the great sambar of India, and is about on a par with a good red deer.

The MolucCan Rusa, a sub-species somewhat smaller than the Javan deer, is found in 
Celebes and certain islands - Boru, Batchian, and Amboina - in the Moluccan group; while the TIMOR RUSA, a closely allied congener, is found on the islands of Timor, Semao, and Kambing. It is possible - nay, even probable - that the Malays may, in times gone by, have introduced certain of these rusine deer from one habitat to another. Such, at least, seems to be the presumption among naturalists.

Dr. Guillemard, in that charming book "The Cruise of the Marchesa" (p. 357), gives some interesting information concerning Moluccan sambar in the little-known island of Batchian. The inhabitants, "living for the most part in the hills, kill and smoke the deer, and bring the meat into the villages for sale. We were fortunate enough to assist at one of their hunts, in which no other weapon than the spear is used. The side of a large ravine, which had been partially cleared,' and presented a confused jumble of fallen trees and low brushwood, was assigned to us as our post, and, from the extensive view it commanded, we were able later in the day to watch one run almost from start to finish, although at first the sport appeared to be successful in every direction but our own. At length a stag broke covert about five hundred yards above us, and descended the slopes of the ravine, but shortly afterwards turned and made for the forest again. He was met by some of the hunters and driven back; but the dogs were now in full cry, and pressed him hard, the hunters meanwhile racing at their utmost speed above, in order to prevent his regaining the jungle. He now altered his direction, and turned down once more towards us; but the fallen trees were so thick that the dogs gained rapidly on him. He made one more effort for his life by doubling, but it was too late, and in another minute the dogs and hunters had fairly run him down."

Deer were probably the earliest animals of the chase. Their bones are found in the cavedwellings of prehistoric man, and some of the earliest efforts at drawing represent these animals.

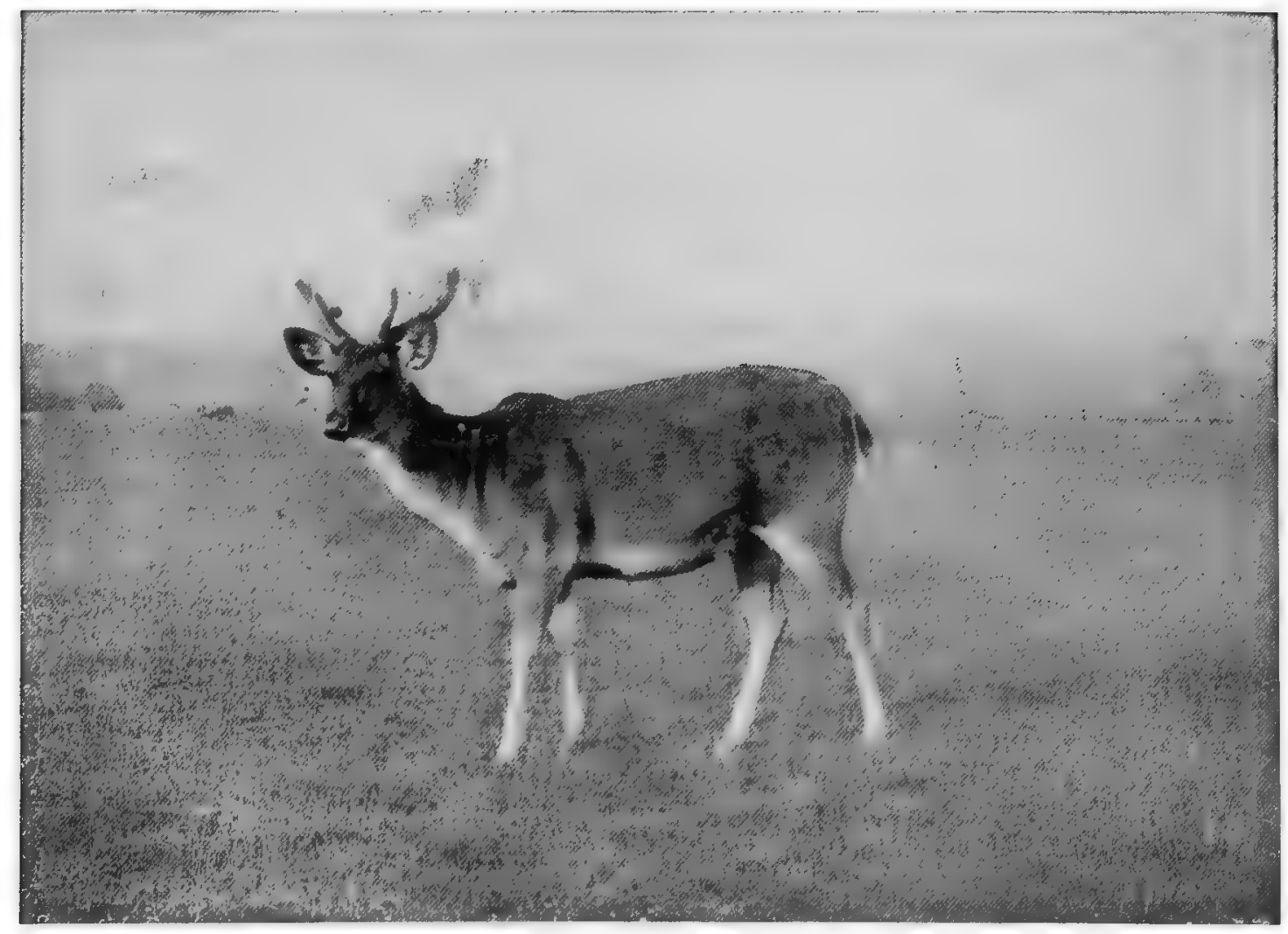

YOUNG MALE SWAMP-DEER

This species is the Barasingh of the natives of India. It is by no means addicted to swampy localities 


\section{THE LIVING ANIMALS OF THE WORLD}

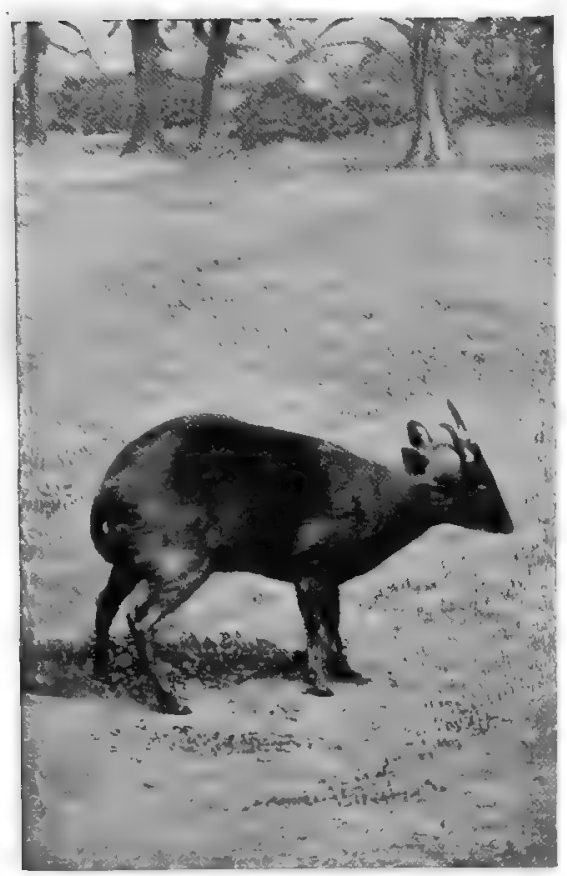

INDIAN MUNTJAC

Sometimes called the Barking-deer. The Indian species stands only 2 feet ligh

\section{OTher Typical DeER}

So numerous are the typical deer that they are not concluded even by the long list of animals already enumerated. We proceed now to glance briefly at the remainder of this important group.

The Philippine SPOTTED DeER, or Prince ALFRED'S DEER, is a small but extremely handsome species, found in the islands of Samar and Leyte. The height is under 30 inches; the colour very dark brown, spotted with white, the under-parts, chin, and upper portion of the legs also white.

Another small cervine from the Philippine group is the CALAMIANES DEER, a darkish brown beast, found in the island of that name.

The little BAVIAN DEER, another island-deer, from the Bavian group, between Borneo and Java, should also be mentioned. Very little is known of the habits of these three deer, and few specimens even of their skins and horns have reached Europe.

The HOG-DEER, allied to the last-named species, is an animal much better known, found as it is in many parts of India and Burma. This handsome little deer stands from 24 to 28 inches at the shoulder, and carries antlers which average from 10 to 15 inches, and reach. occasionally as much as $2 \mathrm{I}$ or 22 inches - one specimen is recorded measuring $23 \frac{1}{4}$ inches. It has a yellowish or reddish-brown coat, minutely speckled with white. The summer coat is paler and marked with white or palish-brown spots. This sturdy little deer is found usually in long grass, and affords excellent snap-shooting; it is also run into with dogs and speared by mounted sportsmen. Major FitzHerbert thus describes a chase of this kind: " $\mathrm{He}$ [the little stag] stood at bay, with head down and bristles raised like a miniature red deer of Landseer's, but broke away when I came up. Once he charged the bitch and knocked her over. He stood at bay two or three times, but I could never get a spear into him for fear of hurting the dogs. At last one time, as he was breaking bay, I came up, and he charged me with such force as to break one of his horns clean off against the spear. However, I struck him in the spine, and rolled him over." These little deer have quite extraordinary pluck, and have been known even to charge and wound a horse.

The Chital, or Indian SPOTted DEER, often called the Axis Deer, a very beautiful species, is the common jungle stag of India. Standingabout 3 feet or a little over, its lovely coat of bright reddish fawn is thickly spotted with white at all seasons of the year. The horns are somewhat of the sambar type, and measure as much as 36 or 38 inches in length in fine specimens. These cxquisite deer are often found in considerable herds, and are a forest-loving species.

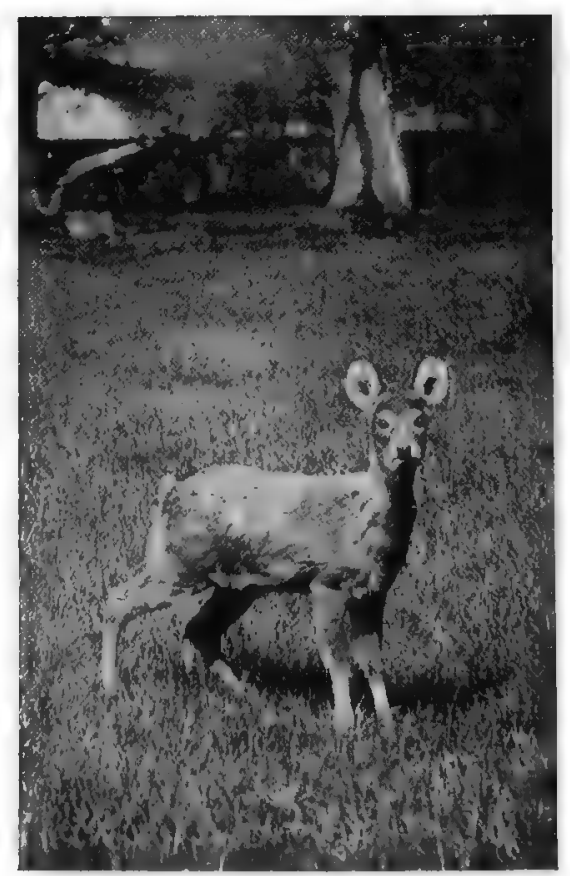

YOUNG MALE CHINESE W A TER--DEER .

One of the ferv deer which have no antiers 


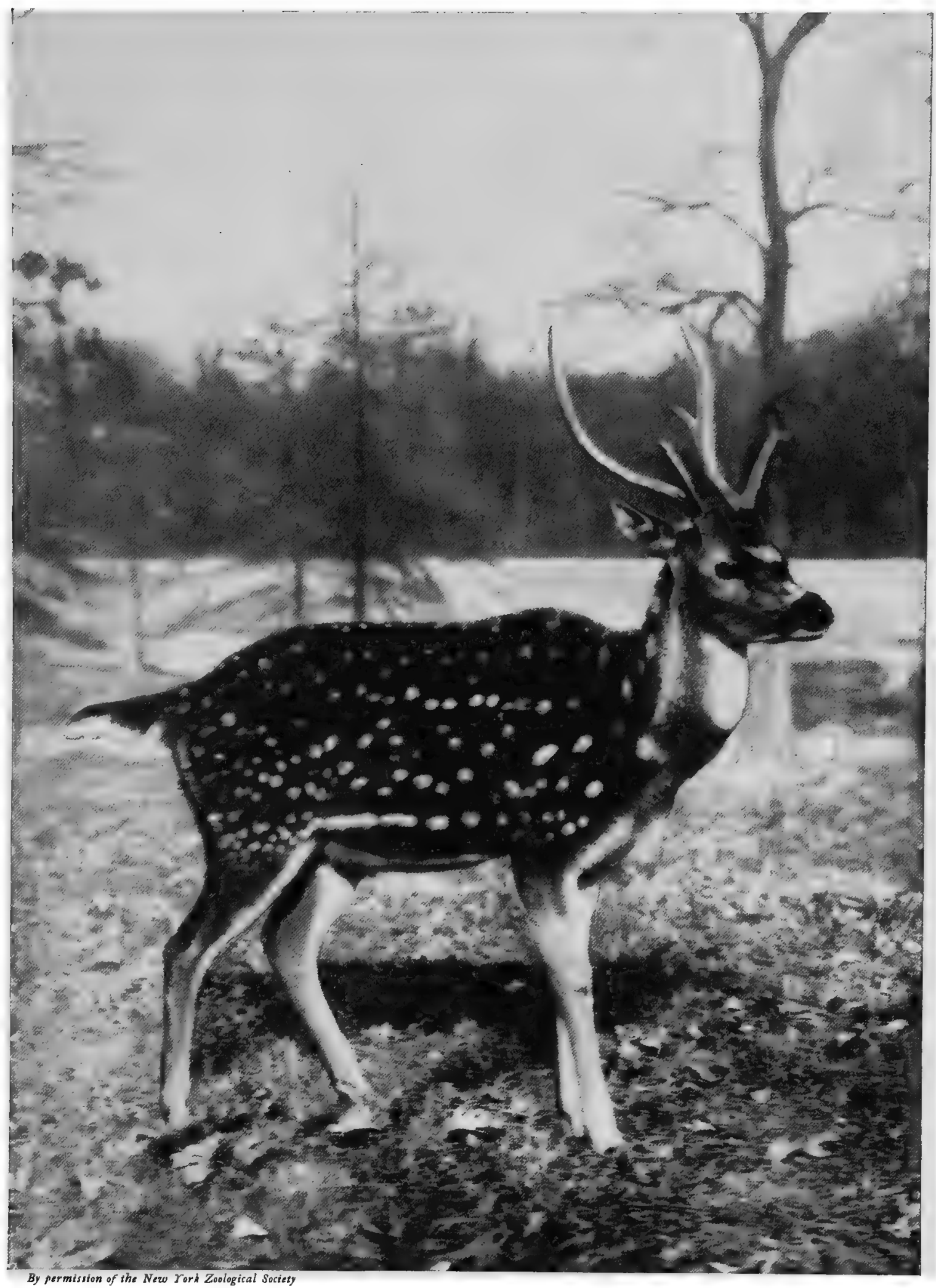

A STAG AXIS, OR INDIAN SPOTTED DEER

One of the most common animals in an Indian jungle scene 


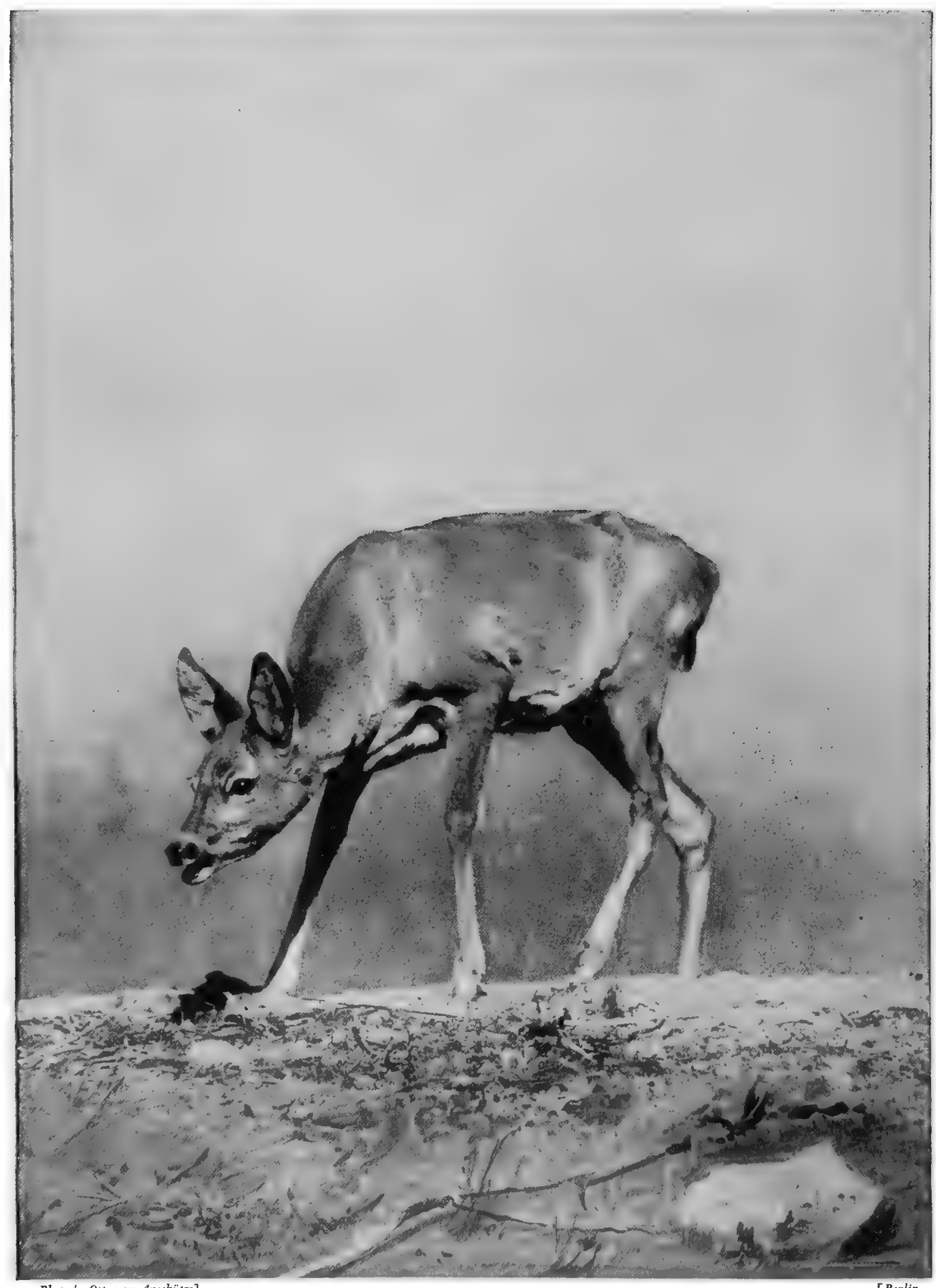

Photo by Ottomar Anschütz]

FEMALE EUROPEAN ROE DEER

[Berlin

Though common in the Scotch woods, these deer are rarely seen, keeping close in cover all day 
The SWAMP-DEER, the true Barasingh of India, as distinguished from the Kashmir stag, which is often loosely called Barasingh, is a plain-loving species, found in various parts of India, and characterised by handsome antlers, bearing as many as from Io to 16 points. This is a big, heavy deer, standing nearly 4 feet at the withers, and weighing as much as 560 lbs. The summer coat is light rufous, more or less spotted with white. The winter coat is yellowish brown. A near relative to this decr is SCHOMBURGK's DEER, found in Northern Siam. The antlers of this stag are most curiously forked and bifurcated.

The THAMIN, or ELd's DEER, sometimes called the Brow-antlered Deer, is another plains-deer, found chiefly from Manipur, through Burma, to the Malay Peninsula. It is a good-sized species, standing about 3 feet 9 inches at the shoulder, and weighing as much as 240 lbs. The large antlers are simple in type, the brow-tines curving down curiously over the forelread; the tail is

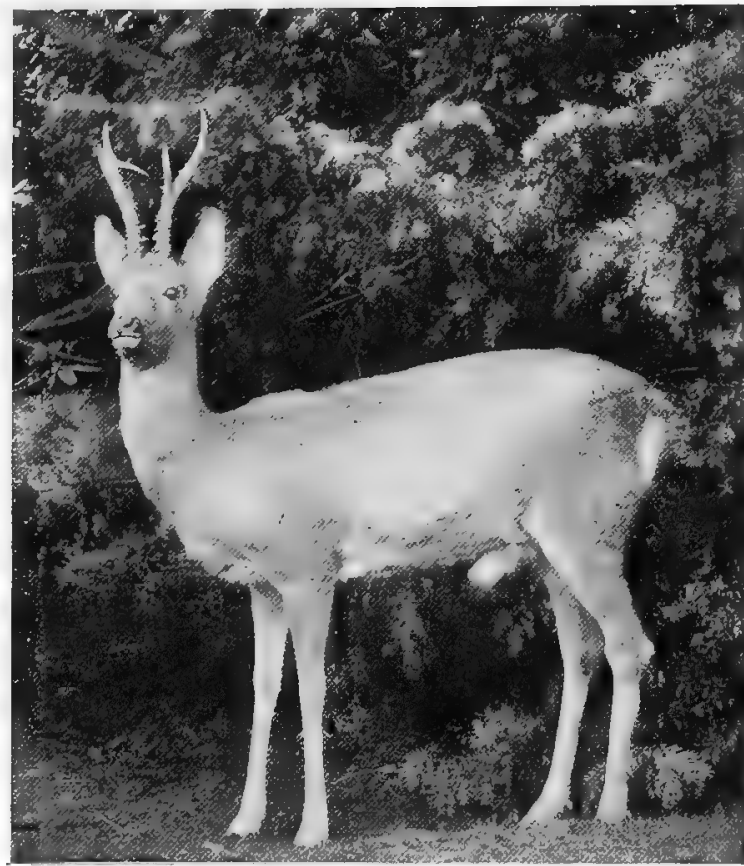

MALE SIBERIAN ROE.

$A$ very large species of roebuck, with more rugged antlers than the European roe sharp, and the neck provided with a mane, the young being spotted. A Siamese race of Eld's deer, found in Siam and Hainan, differs somewhat from the Burmese type.

\section{The Muntjacs}

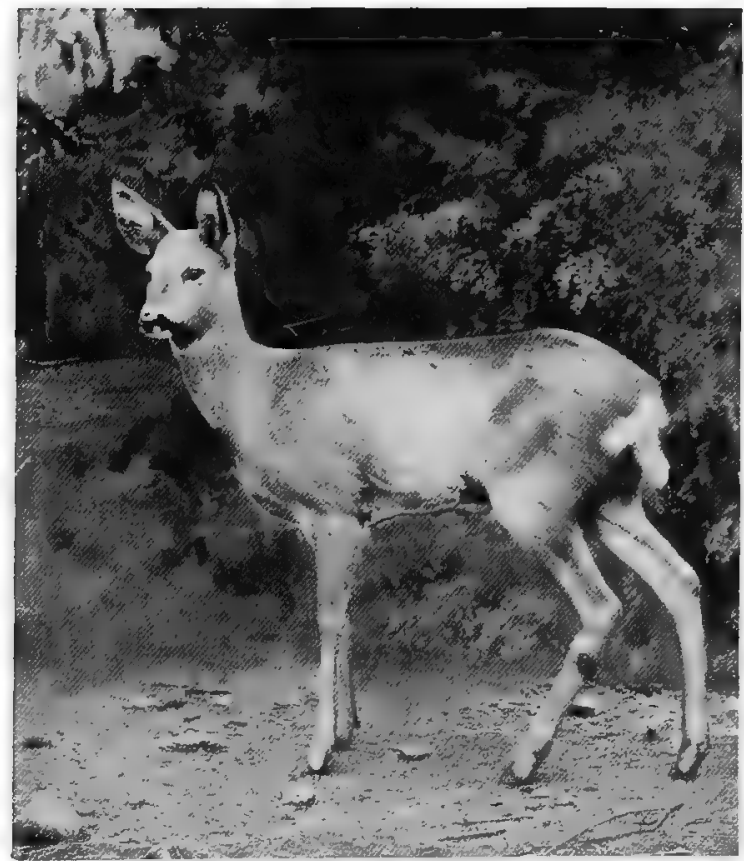

FEMALE SIBERIAN ROE

The absence of a tail, characteristic of all roes, is well shown

The MUNTJACS, or BARKING-DEER, are a group of small deer found in India, Burma, and the Malay region. The Indian MunTJAC stands about 2 feet in height, and weighs some $28 \mathrm{lbs}$. The antlers, which average 5 or 6 inches in length, bear two points brow-tine and beam; the lower portions, or pedicles, are curiously covered with hair, and the front of the face is ribbed or ridged in $V$ fashion. The general colour is a golden bay, the face and limbs brown, and the lower parts white. The buck has sharp tusks in the upper jaw, and, at a pinch, knows how to make use of them. A shy, stealthy little creature, the muntjac loves dense cover, and the sportsman usually obtains but a quick snapshot at this active and wary little deer as it flashes across him much as does a bolting rabbit scuttling across a narrow drive. Local Indian names for the barking-deer are Junglesheep, Red Hog-deer, and Rib-faced Deer. Other muntjacs, varying somewhat from the Indian form, are the HAIRI-FRONTED, the TEnasserim, the TiBetan, and the Chinese MunTJACS. 


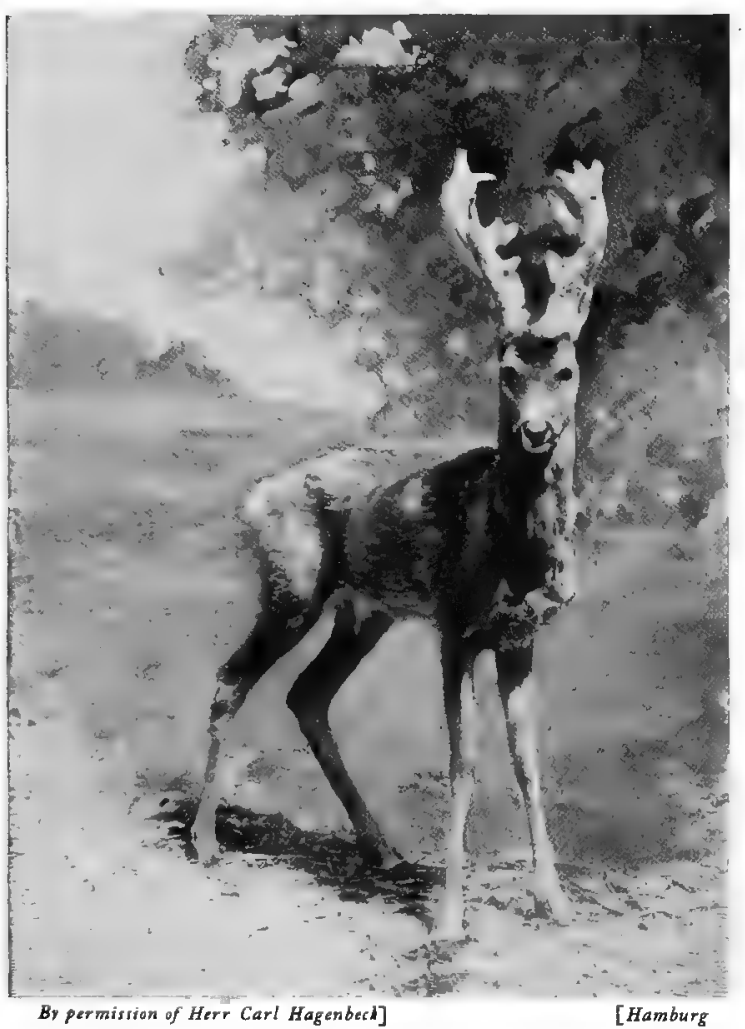

SIBERIAN ROEBUCK

Shows a magnificent pair of antlers

\section{Tufted Deer}

Near relatives of the odd little muntjacs are the TUFTED DEER, of which two species, the TIBETAN and MiCHIE's, are known to naturalists. The former, found in Eastern Tibet, is about the size of the Indian muntjac, and has a coat of dark chocolate-brown, curiously speckled on the face, neck, and fore parts; the frontal tuft is nearly black. The antlers of the bucks of both this and Michie's deer are extremely small, scarcely observable at a first glance. Both species have long curving tusks projecting from the upper jaw. Michie's tufted deer is of a greyish-black or iron-grey colour, the face and neck dark grey. This animal is found in the reed-beds bordering the Ningpo and other rivers in Eastern China.

\section{WATER-DEER}

The CHINEse WATER-DEER is another diminutive deer, standing no more than 20 inches at the shoulder. The body-colouring is pale rufous yellow, the head and the back " of the ears being darker in hue than the rest of the body. The males carry no antlers. This tiny deer is found in North-east China, and is well known on the islands of the Yangtse-kiang River. It loves thick cover, especially reeds and long grass. So apt is it at concealment, that in one park, where specimens are kept in a paddock of long tussocky grass, hours may be spent without catching a glimpse of it. When disturbed, it scurries off with short, quick leaps, very much after the manner of the hare. The males of the Chinese deer, like the muntjacs, carry long curved tusks in the upper jaw.

\section{ROE DEER}

The EuRopean RoE, one of the handsomest of all the smaller deer, is still happily found in many parts of Scotland. In England, where it had at one time beconse well-nigh extinct, it has been here and there reintroduced with some success. In Ireland it seems never to have been found. On the Continent its range is wide, extending from the south of Sweden, through France and Germany, to Italy, Greece, Turkey, Austria-Hungary, and Spain. Found in Southern Russia and the Caucasus, it makes its way eastward as far as North Palestine and Persia. The roe stands, in good adult specimens, 26 inches at the shoulder, and weigks about $60 \mathrm{lbs}$. The handsome and very characteristic horns measure in good specimens from 10 to 13 inches over the outer curve. The summer coat of this beautiful little deer is a bright rufous brown; in winter a darker and duller brown, with a notable white patch about the tail. The roe is always more or less a wood-loving creature. In winter, especially, it seldom cares to quit the shelter of the forest; in summer, however, the deer wander into more open localities. The fawns are born generally towards the end of May, and two young are usually produced. In. the rutting-season the males fight savagely with one another.

Mr. J. G. Millais gives an instance of a buck killed in one of these desperate battles, in which one antler of the victor, having penetrated the brain of the vanquished buck, had been 
broken clean off and remained embedded in the skull, firmly wclged between the ears and the antlers. "When wounded and brought to bay by a dog," says Mr. Millais, " a roebuck brings into play both head and fore legs in his defence, using his horns as described, and striking out with his legs, more as if to push off his antagonist than to cause a forcible blow, for he gives no shock, as a hind can. A doe, too, uses her fore legs and boxes with her head; and Mr. Steel, who has had wide experience in roe-shooting, tells me that he has seen a doe use her hind legs as well. The bark of the buck is loud, sharp, and deep in tone, not unlike what a single call might be from an old collie. At this season, too, the female gives an amorous call when she wishes the male to come to her. If he is within hearing, he puts his neck out straight and comes full speed to her. In Germany many roebucks are shot by alluring them in this manner, and calls exactly imitating her voice are made for the sportsman's use. One who has shot roe in this manner tells me it is most exciting sport, for the buck comes straight

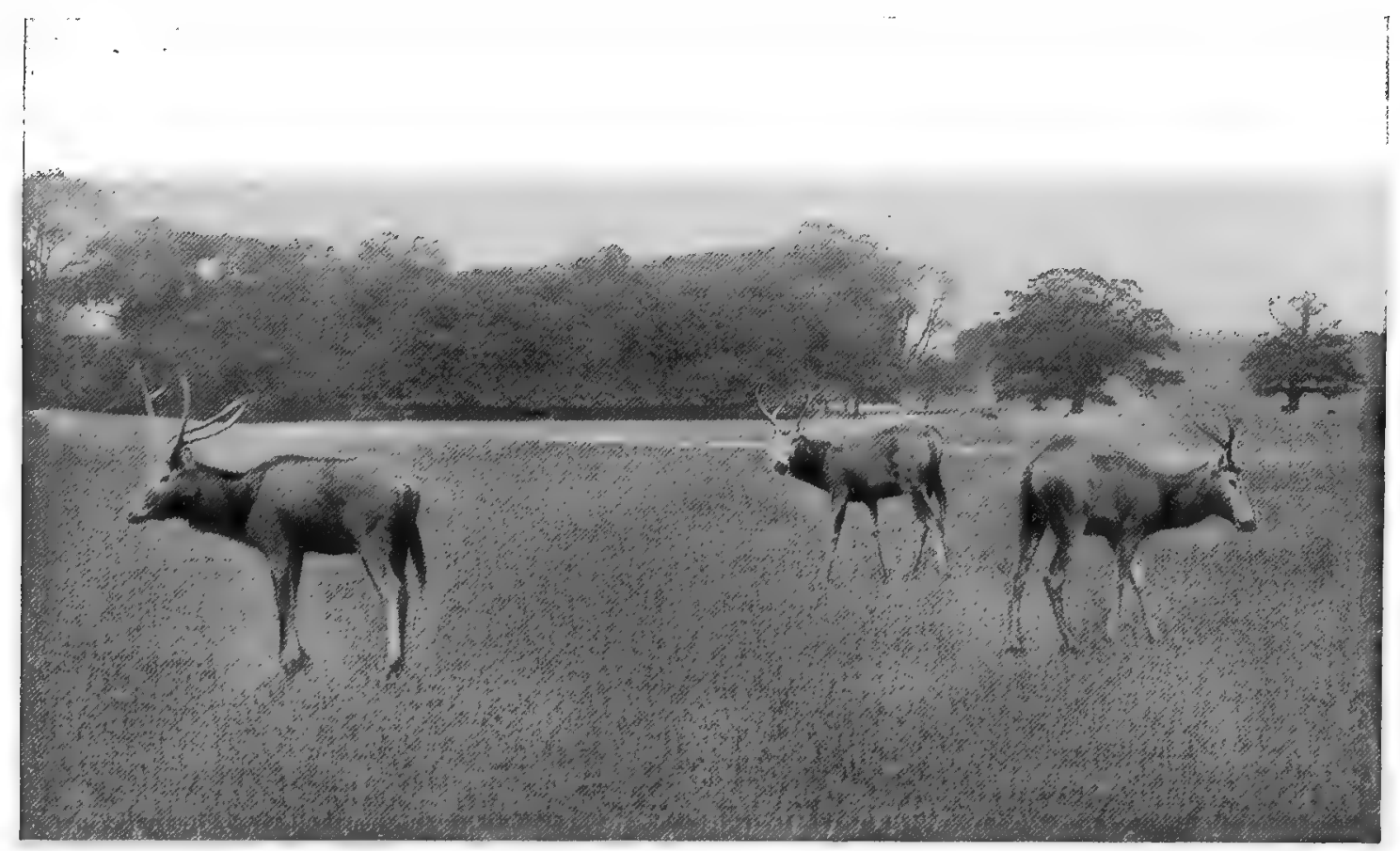

PERE DAVID'S DEER

Nineteen of these deer are in England; three are at Berlin. It is believed that these are the only deer of this species in exissence

for the sound at full speed, and will only stop startled for a second when he discovers the fraud, and as often as not he passes right on without giving a chance."

Roe have a curious trick of chasing one another in play, and certain roe-rings in the woods near Cawdor Castle, according to Mr. Millais, demonstrate the fact that for ages the deer have been in the habit of disporting themselves in these strange circles over the same pieces of ground. The fact is very singular. "These curious circles are most used in early summer; and Sutherland, the head keeper, tells me," says Mr. Millais, "that hardly a morning passes without there being one or two roe playing in the rings, and sometimes there is quite a party of them." Roe feed chiefly on grass; they will eat also rowan (mountain-ash) berries, of which they are especially fond, as well as turnips, grain, heather tops, and various other roots and plants. Certain fungi, to which they are partial, they take much pains to dig out with their sharp hoofs. "A ròebuck that I once kept," says Mr. Millais, "was a good Scotchman, though he had a beastly temper, for he liked nothing so much as oatmeal porridge." Roe make delightful pets, but the bucks are not to be trusted after the third year. One of these animals, supposed 
to be tame, has been known to kill a lad. In Scotland and on the Continent roe deer are usually killed by driving, and large bags are often made. Even within recent times, as many as sixty-five roebuclis and thirteen hinds have been shot during a day's driving. Shot-guns are employed for this kind of sport. Stalking the roe is not so much pursued in Scotland as it might be. It is a first-rate and most interesting form of sport, and in certain districts the rifle might very well be substituted for the shotgun. " Roe-stalking., say's Mr. Millais, "possesses many charms of its own.

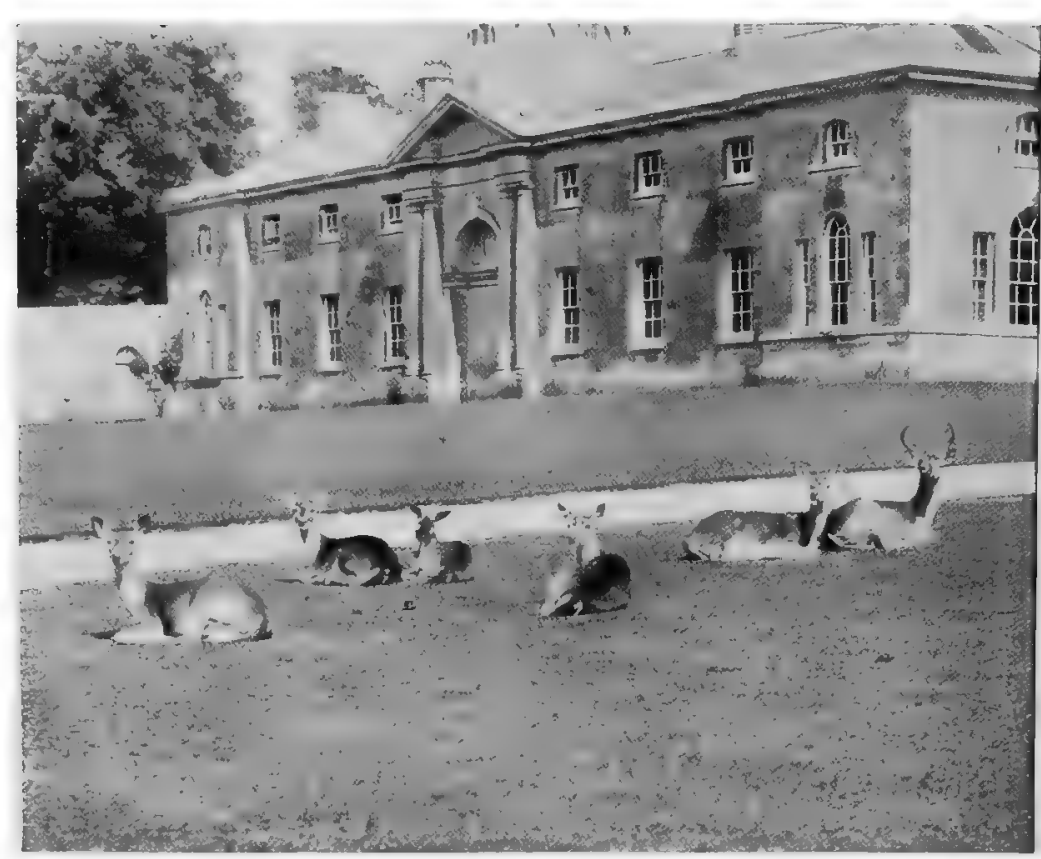

GROUP OF VIRGINIAN DEER (TWO BUCKS, FOUR DOES)

These are the common dear of the Eastern United States

In the first place, you can

enjoy it at a season when there is no other shooting going on; secondly, it takes you out in. the early morning, when all nature is full of life and beauty, and before the heat of the day commences; and, thirdly, where the chase of the animal is systematically conducted, as with red deer, the nature of the sport is everything that can be desired. I would therefore put forward a plea that tenants and owners of part-wood, part-forest lands in Argyll, Inverness, Ross, and Aberdeen should turn their attention to stalking the roe in preference to killing them during the usual winter wood-shoots." Roe deer are exceedingly abundant in the great forest regions of Germany and Austria-Hungary. In Austria alone, not including Hungary, during the year I 892, no less than 68, I I o of these beautiful little deer were shot on various estates.

The Siberian Roe, found from the mountains of the Altai and Turkestan to Siberia, is a somewhat larger species than its European cousin, measuring from 28 to 34 inches at the shoulder. The antlers are also larger, extending to as much as 16 and even 18 inches in measurement. As beseems its habitat, the coat of this species is also thicker and rougher than is the case with the European roe. Mr. Lydekker gives some interesting particulars regarding this animal: "When the snows of November fall, the roe themselves commence to collect in herds, which may number from 300 to 500 head, and soon after migrate southwards into Manchuria, whence they return about the end of March or beginning of April. On the Ussuri, which they must cross, they are at this season slaughtered in thousands by the hunters, without regard to age or sex."

One other species, the MANCHURIAN ROE, found chiefly in mountainous habitats, whence it never descends, should be noted. This is a smaller deer than the Siberian roe, and approximates in size and length of horn to the European race.

\section{PÈre DAVID's DeER}

This remarkable animal, which apparently bears little or no resemblance to any of the other deer of the Old World, has been placed by some naturalists between the roe deer and the American deer. Its habitat is North China, and, strangely enough, it seems to be unrecognised 
in the wild state, being apparently only known in China in the Imperial Park at Pekin. This deer approaches in size the red deer of Europe. The general colouring is greyish brown, white about the eyes, ears, rump, and under-parts; the horns, which lack the brow-tine, are very singular in shape, and measure as much as 32 inches in length; the tail is long, reaching to the hocks; the gait is "lolloping" and mule-like. This is a marsh-loving species, and at a certain park, where specimens are kept, "they may be seen wading far into the lakes and even swimming in the deeper water."

In South America are to be found several kinds of marsh-deer, of which the best known is the handsome MARSH-DEER, having its range from Brazil to the forest country of the Argentine Republic. Little is known of this and other South American deer of similar species. The marsh-deer is almost equal in size to the red deer of Scotland, but somewhat less stout of build; the colouring is bright chestnut in summer, brown in winter; the coat is long and coarse, as befits a swamp-loving creature; the antlers usually display ten points, and measure in fine specimens as much as 23 or 24 inches.

The Pampas-DeEr, a species closely allied to the marsh-deer, is of small size, standing about 2 feet 6 inches at the shoulder. The antlers, usually three-pointed, measure no more than from 12 to 14 inches in fine specimens. This deer is found from Brazil to Northern Patagonia.

The Peruvian and Chilian Guemals are small deer, found on the high Andes, and are somewhat inferior in size to the Virginian deer. The males carry simple antlers forming a single fork, and measuring about 9 inches. The coat, yellowish brown in hue, is coarse, thick; and brittle. The Chilian guemal is found also in most parts of Patagonia; unlike its congener of Peru, which delights in altitudes of from 14,000 to 16,000 feet, its habitat lies chiefly in deep valleys, thick forest, and even the adjacent plains, to which it resorts in winter.

The Brockets, of which seven species are found in South and Central America and Trinidad, are small deer, having spike-like antlers and tufted crowns. The largest is the RED Brocket, found in Guiana, Brazil, and Paraguay, which stands 27 inches at the shoulder. The body-colouring is brownish red. Like most of the group, this brocket is extremely shy; although fond of dense covert, it is found also on open campos. The Prgmy Brocket, a tiny dark brown deer, less than 19 inches in height, found in Central Brazil, is the smallest of these very small deer.

Two other diminutive deer, known as Pudus, closely allied to the brockets, are found in South America. These are the Chilian and Ecuador Pudus, of which the former is no more than $13 \frac{1}{2}$ inches in height, the latter about 14 or 15 inches. Little is known of the history and life habits of these charming little creatures, one of which, the Chilian species, has occasionally been seen in Zoological Gardens.

\section{THE MUSK-DEER.}

This brief account of the deer of the world closes with the Musk-DEEn, which differ from almost all others of their kind-the Chinese water-deer being the sole exception-in the absence of antlers. In place of these defensive and offensive weapons, nature has provided the musk-deer with long canine tusks, projecting downwards from the upper jaw. The musk, from which these curious deer take their name, is secreted during the rutting-season-in the male only-in a pouch or gland concained in the skin of the stomach.

The well-known Himalayan Musk-Deer, is a stout, heavily made deer for its size, measuring 20 inches at the shoulder, about 2 inches higher at the rump, and having a coat of coarse, brittle hair of a dark brown colour. This musk-deer, which is nowadays by no means common, is found in the forests of the Himalaya, Tibe乞. Siberia, and Western China, often at altitudes of about 8,0oo feet. These animals are extraordinary mountaineers, active, daring, and apparently quite unconscious of or indifferent to danger. 


\section{THE LIVING ANIMALS OF THE WORLD}

A WORD should be said upon the subject of the acclimatisation of various members of the Deer Tribe in countries which are distant from their native ground, but in which they are found to thrive and breed, some with greater and some with less success. Several of the illustrations in this chapter are taken from deer living in natural conditions at an English country seat in Bedfordshire. Others were photographed out of doors in zoological parks or private menageries. There is a considerable degree of transferability among deer, not only among those found in temper-

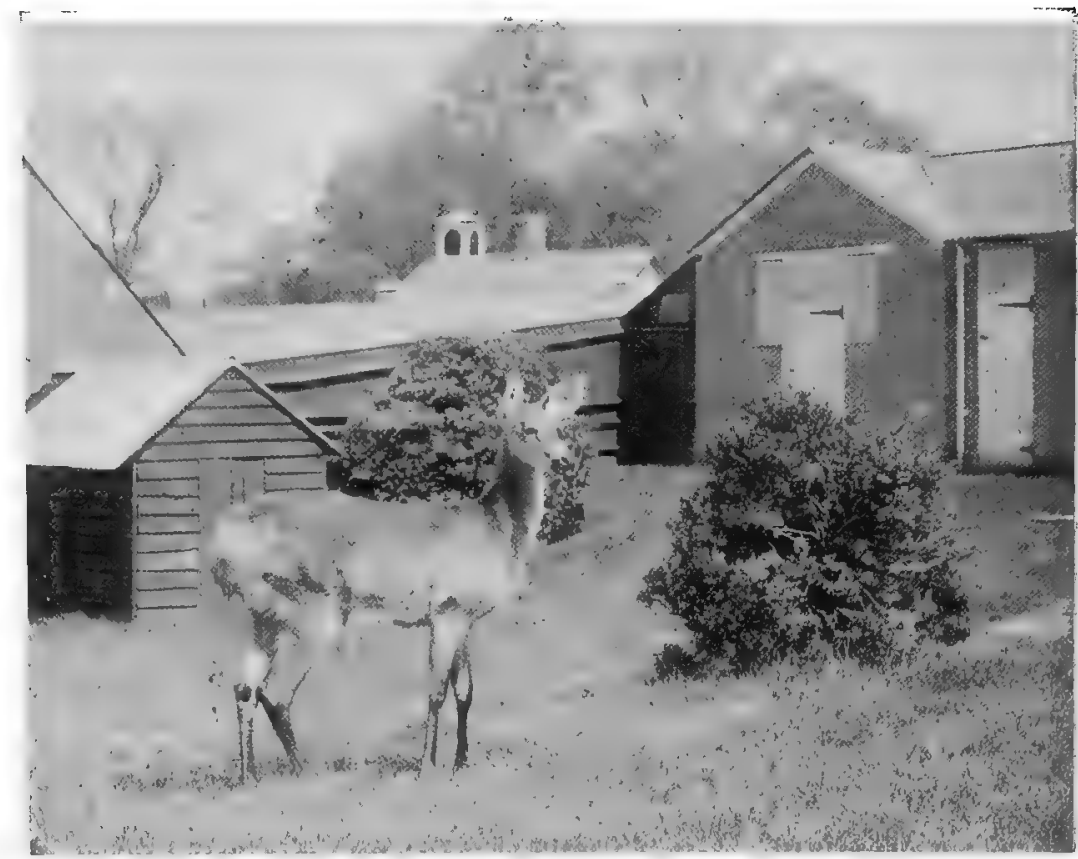

YOUNG MARSH-DEER

A zery clegant South American species. The main colour is a bright chestnut, with the lower part of the legs black. The insides of the ears are flled with white hair, looking like silver fligree

ate or northern regions, but also those which inhabit the tropical jungles of Southern India.

The Axis, or Chital Deer of India, is the most striking example. It lives in the hot jungles, where it is the usual food of the tiger. Yet it has been transferred to the forests of France and to English parks, and not only lives, but breeds and increases in numbers. In France and Germany herds of axis deer have been maintained long enough to observe a curious and noteworthy incident in acclimatisation. The axis deer breeds naturally in October, after the Indian rainy season. This habit, if persisted in in Europe, would expose the fawn to the rigours of the French or Engiish winter. Gradually and after some time the herds. become irregular in the time of reproduction, and later produce the fawns in Junc, at the time which is best suited to their survival. This is a real instance of acclimatisation.

The Japanese Deer, or Sika, was introduced into the park at Powerscourt by Viscount Powerscourt some thirty years ago. Now it is one of the commonest of recently introduced park-deer both in England and in France. The venison is excellent, and the herds are prolific. The stags are small, but very strong, and at Powerscourt always get the better of the red deer stags, and sometimes carry off their hinds. Wapiti Deer are kept in several English parks, but so far the Sambar has proved a failure. Hog-deer and Chinese Water-deer do very well both in England and France.

But it is in New Zealand that the best results have been obtained with imported deer. The English Red Deer, some of which were originally sent out by the Prince Consort, reinforced by some of the same species bred in Australia, have become indigenous. They grow far faster and to a larger size than those on the Scotch moors, and rival the great stags of the Carpathians. The antlers also increase in size at an abnormal rate. Licences are regularly issued to stalk and shoot these deer, which, like the brown trout and the pheasant, are now among the stock of established wild fauna. Moose and a few Sambar stags and herds have also been turned out in New Zealand. The latter are said to be doing well. 


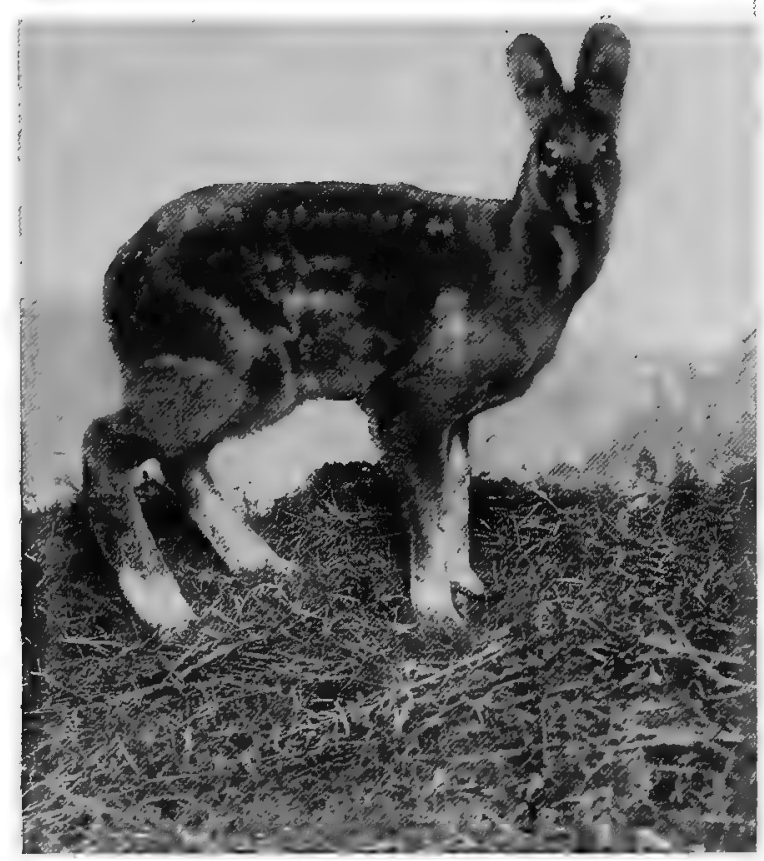

YOUNG HIMALAYAN MUSK-DEER

The male carries a pouch on the abdomen, from which the musk is obtained. There are no antlers

There is no particular reason why the deer of cold countries should not be interchanged; they seem to have the natural adaptability of oxen. But it is not a little surprising that the species from warm climates should flourish in damp and cold ones. The axis deer would be a real addition to the fauna of the great European forests, if it is found that it survives the winter snows without some form of artificial shelter. No one seems to have considered the advisability "of introducing the mule-deer into the Central European woods. It is a much finer animal than the fallow buck, and the venison is excellent. In these woods where fallow deer are preserved in a wild state, as on many of the German Emperor's sportingestates, the mule-deer would be a far more ornamental animal. Few people know what immense herds of red and fallow deer, as well as of wild boars, still exist, under careful preservation, in the forests of the great German, Austrian, and Russian princes, and in the royal forests of their respective countries.

When the Kaiser holds his great Court hunting-parties, to which the guests all come dressed in the uniform of the Order of

St. Hubert, as many as 200 deer are shot in a day. They are driven past the guns by beaters. After the day's sport is over all the antlers are wreathed with boughs of spruce fir, and the stags laid out like rabbits after an English battue.

It is rather surprising that only one species of deer has been entirely domesticated - viz. the Reindeer. Deer's meat is as highly prized as that of any other game, perhaps even more so. There is almost no part of the animal which is not useful. The horns are valuable for knife-handles, and always command a good price; they were prized even by prehistoric man, who converted them into pick-axes, and made spear-heads and daggers of them. The leather of the hide makes the softest and best of all hunting-garments: the American Indian or trapper always wears, or used to wear, a deer-skin shirt and deer-skin leggings, made as exquisitely soft as chamois leather by a process known to the squaws. At the present time all the best gloves are made of doe-skin; they are far the most costly of any gloves. Doe-skin breeches are also a luxurious garment to ride in. For ornamental rugs few skins beat those of the Dappled Deer, laid on the floor of some finely furnished hall or room.

Thus we have the curious spectacle of the wild men of the Far North, the Lapps and Ostiaks, taming and keeping in domestication great herds of deer, milking them, using them as beasts of draught, and feeding on their flesh, while far more civilised races in the South have not taken the trouble to do so. The reason is not easy to surmise, unless it be that the idea of making use of the Deer Tribe solely as beasts of the chase was so rooted in the European ruling races, and their kings and nobles, that the agriculturist never had a chance of trying to tame and use them for other purposes. It is certain that during the Middle Ages law and custom made any such attempt quite impossible. The deer were a valuable sporting asset, so hedged round with an atmosphere of feudal privilege, that to convert them into something useful to the common people would have been regarded as an insult to the powers that were. 


\section{CHAPTER XVIII}

\section{THE CAMEL TRIBE AND THE CHEVROTAINS \\ BY W. P. PYCRAFT, A.L.S., F.Z.S}

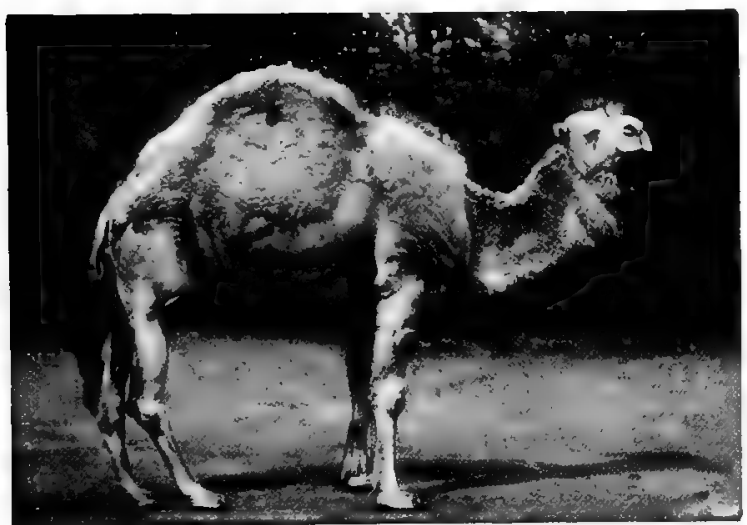

A WHITE CAMEL

A light sandy is the common colour, though wohite, grey, brown, and black occur; but black camels are held by the Arabs to be worthless
THE Camels and Llamas, constituting the present group, form a very distinct section of the great assemblage of animals known as the Ruminants, or Cud-chewers. The Camel Tribe are peculiar amongst the Ruminants in that they never possess horns, and in that the stomach is only divided into three instead of four compartments -- this division into compartments being intimately connected with the ruminating habit. Furthermore, the upper jaw bears cutting-teeth, or "front teeth," as they are popularly called: though the full set (three pairs) is only complete in the young, in the adult but one pair remains," the others being shed. The canine or "eye" teeth are also peculiar in their position,

those of the lower jaw being separated from the cutting-teeth by a very considerable gap.

In the structure of the feet the Camel Tribe are no less peculiar; indeed, it is on this character that the scientific name of the group is founded. Only two toes are present; these are of equal size, and, instead of being protected by hoofs, are provided with a hardened skin, covering a cushion-like pad, which expands when the weight of the body is thrown upon the foot, as in walking. This is an admirable adaptation for walking on soft and yielding sands. Hoofs are represented only by a pair of broad nails.

The three-chambered stomach is remarkable because the chamber known as the "paunch" lodges in its walls a large collection of "water-cells," in which can be stored as much as a gallon and a half of water. This faculty of storing water is invaluable to an animal which has often to subsist for days on absolutely waterless deserts.

Note the slit-like nostrils in the illustration of the Bactrian Camel on page 306. These can be closed at the will of the animal, a useful precaution against the entrance of sand during the violent sand-storms which often arise in the desert.

The True Camels are distinguished by the possession of a hump or humps: there are never more than two. It is in these humps that the camel was popularly supposed

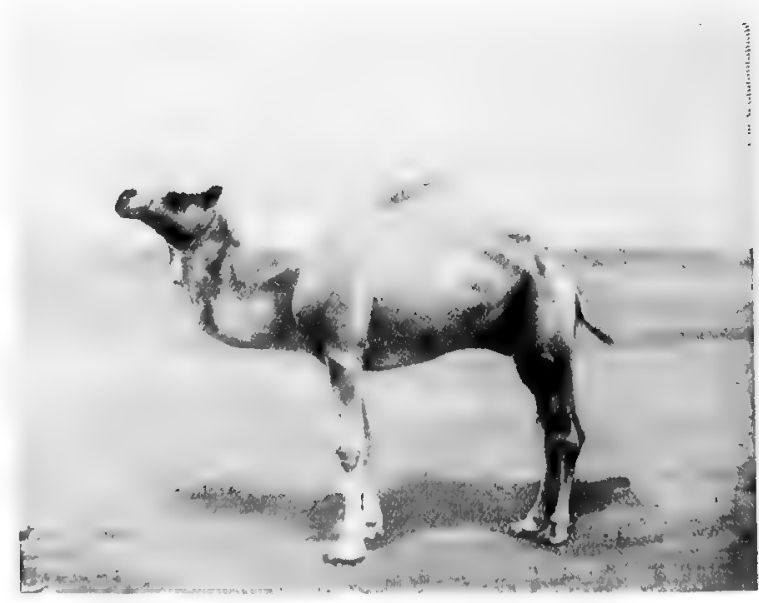

Photo by Charies Knight

ARABIAN CAMEL

This individual belongs to the heavy breed employed for carrying merchandise and baggage 


\section{THE CAMEL TRIBE AND THE CHEVROTAINS 267}

to store water; in reality they are huge masses of fat, serving as a reserve store of food. The accumulation of fat for this purpose is a common feature amongst the Mammalia. Most animals which hibernate, or lap up and sleep during the winter, store up fat; but, except in the camel, it is distributed more or less evenly over the body. With hard work or bad feeding the camel's hump dwindles almost to nothing. When on the eve of a long journey, the Arab looks anxiously to the state of this hump, for on the size of this depends the animal's condition and ability to undertake the march.

The Arabian camel as a wild animal has long since been extinct. Of the hordes of so-called wild camels which abound in the desert regions of Central Asia (Gobi Steppe), some are probably descendants of domesticated animals which have escaped from captivity, but others may be aboriginally wild. From the evidence of fossil camels, there seems little doubt that this animal originated in North America - one branch of the family (the Llamas) migrating into South America, and the other (the Camels) crossing Bering Sea into the Old World.

\section{The True Camel}

Before proceeding further, it may be well to refer to the confusion which exists in the use of the names Camel and Dromedary. The latter name seems popularly to be

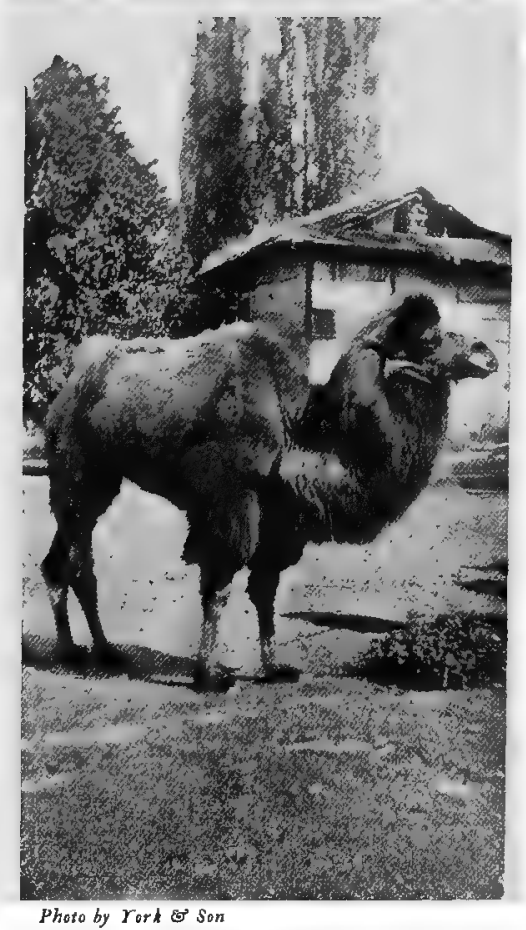

A CAMEL

$A$ half-breed between the Arabian and Bactrian species applied to the two-humped species, the name Camel being reserved for the one with a single hump. This is a mistake. The DROMEDARY is a swift breed of riding-camel of the onehumped species, and is so called to distinguish it from its slower brother, the Pack-camel, or

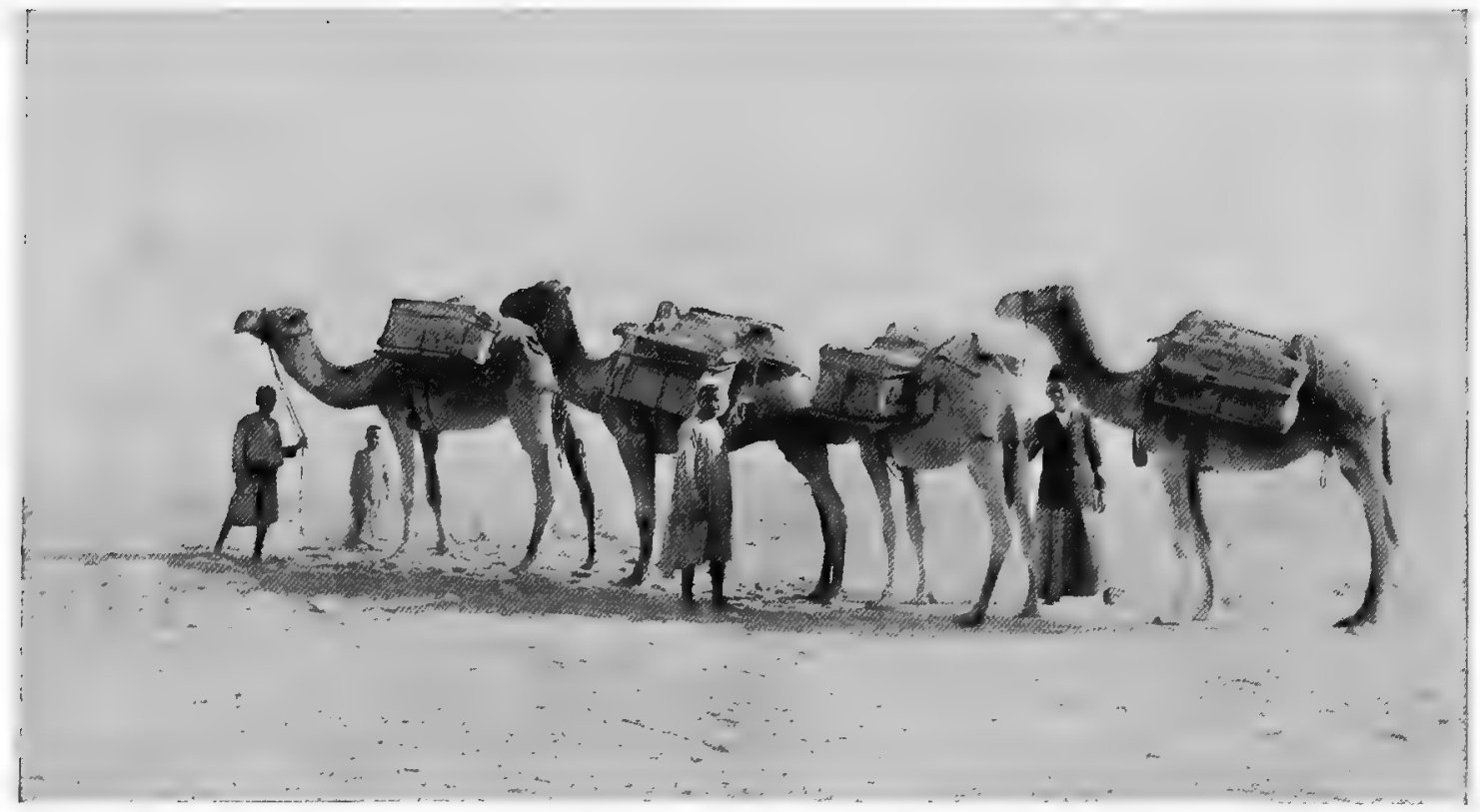

A STRING OF CAMELS NEAR PORT SAID

These are the typical desart camels of the East 
Baggage-camel. The pack-camel, it is interesting to note, has been introduced into Australia, where it has proved invaluable in crossing the vast waterless deserts, on account of its power to exist for long periods without drinking.

The True or ARabian Camel is found in a domesticated state in Africa and Asia, and, as we have just indicated, belongs to the one-humped species. It is a long-limbed, short-haired animal, standing as much as 7 feet high. As a wild animal it is extinct. Much mystery, indeed, surrounds the question of its origin. It

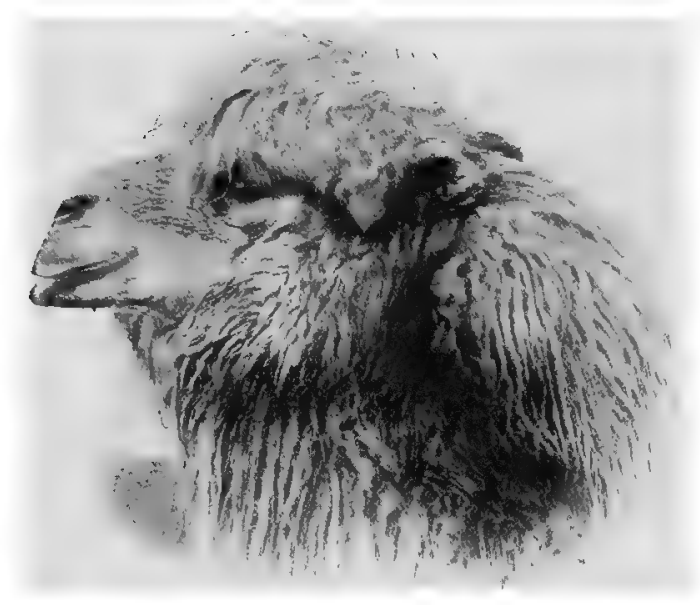

HEAD OF BACTRIAN CAMEL

The hair of this species is used to felt into material for tents. It is longest on the top of the head, neck, humps, and parts of the fore limbs

that the camel had treasured up the injury, for revenge, he kept a strict watch upon the animal. Time passed away; the camel, perceiving it was watched, was quiet and obedient, and the driver began to think the beating was forgotten, when one night, after the lapse of several months, the man was sleeping on a raised platform in the mill, whilst the camel, as is customary, was stabled in a corner. Happening to awake, the driver observed by the bright moonlight that, when all was quiet, the animal looked cautiously round, rose softly, and, stealing towards a spot where a bundle of clothes and a bernous, thrown carelessly on the ground, resembled a sleeping figure, cast itself with violence upon them, rolling with all its weight, and tearing them most viciously with its teeth. Satisfied that revenge was complete, the camel was returning to its corner, when the driver sat up and spoke. At the sound of his voice, perceiving the mistake it had made, the animal was so mortified at the failure and discovery of its scheme, that it dashed its head against the wall and died on the spot."

It is said that when camels pass a mounted man in a narrow path they will turn their heads suddenly round and endeavour to inflict a bite on the rider's arm or shoulder. This is naturally much dreaded, as a camel's bite is particularly severe.

Much care has been spent in the breeding of the camel. "In the Sahara Desert," says Canon Tristram, "the Tourareg is as careful in the selection of his breeding mahari (a fine race of the dromedary) as the Arab is in that of his horse. The pedigrees are handed down, and many a dromedary can boast a genealogy far longer than the descendants of the Darley Arabian" (page 202).

\section{The BaCtrian Camel}

This species is often called the Dromedary; but, as we have already remarked, this is an error. The dromedary is a swift breed of the Arabian camel. The BACTRIAN CAMEL may be 


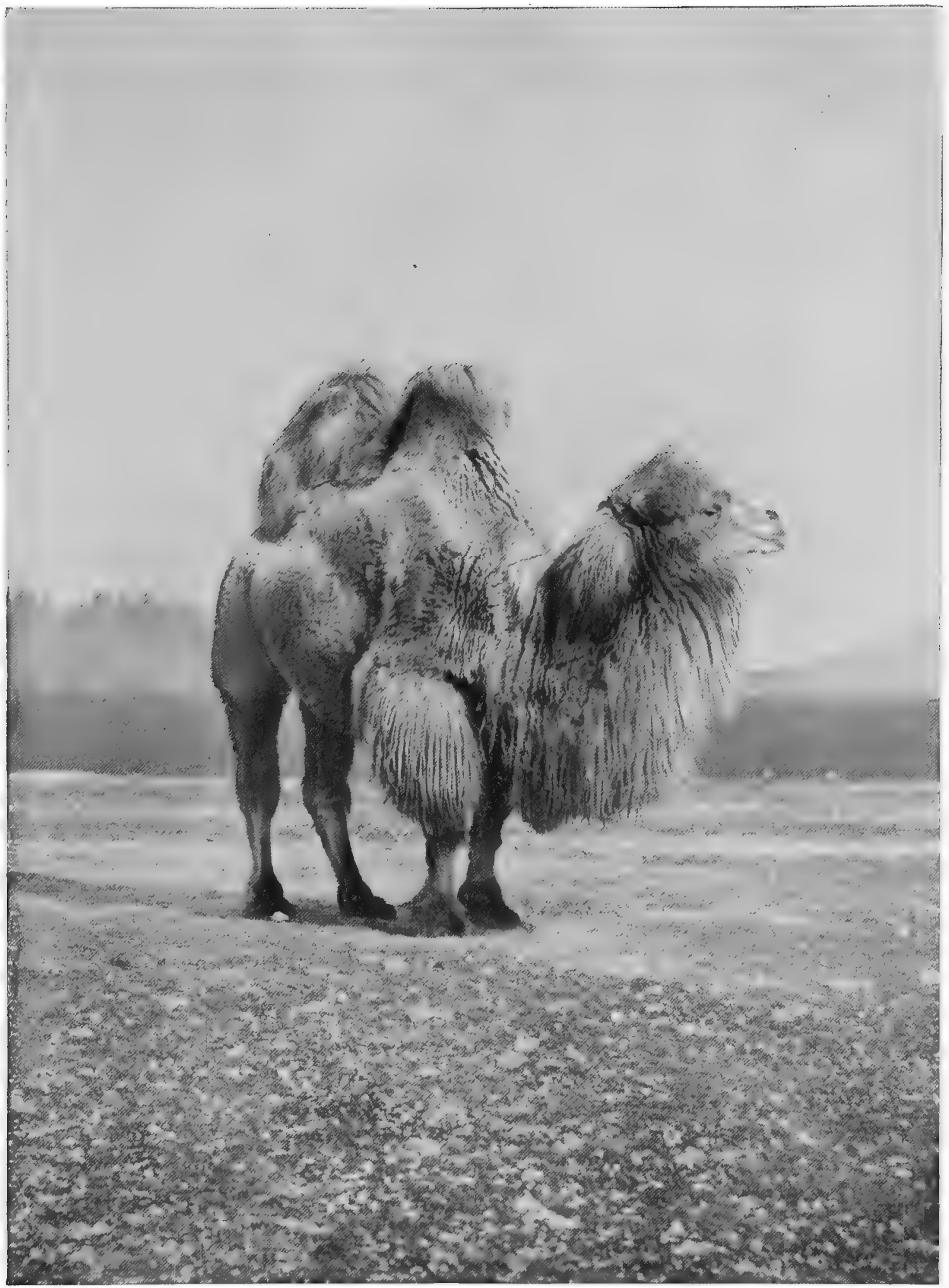

AN OLD MALE BACTRIAN CAMEL

This animal is a magnificent representative of the two-humped species, so widely distributed in Central Asta 


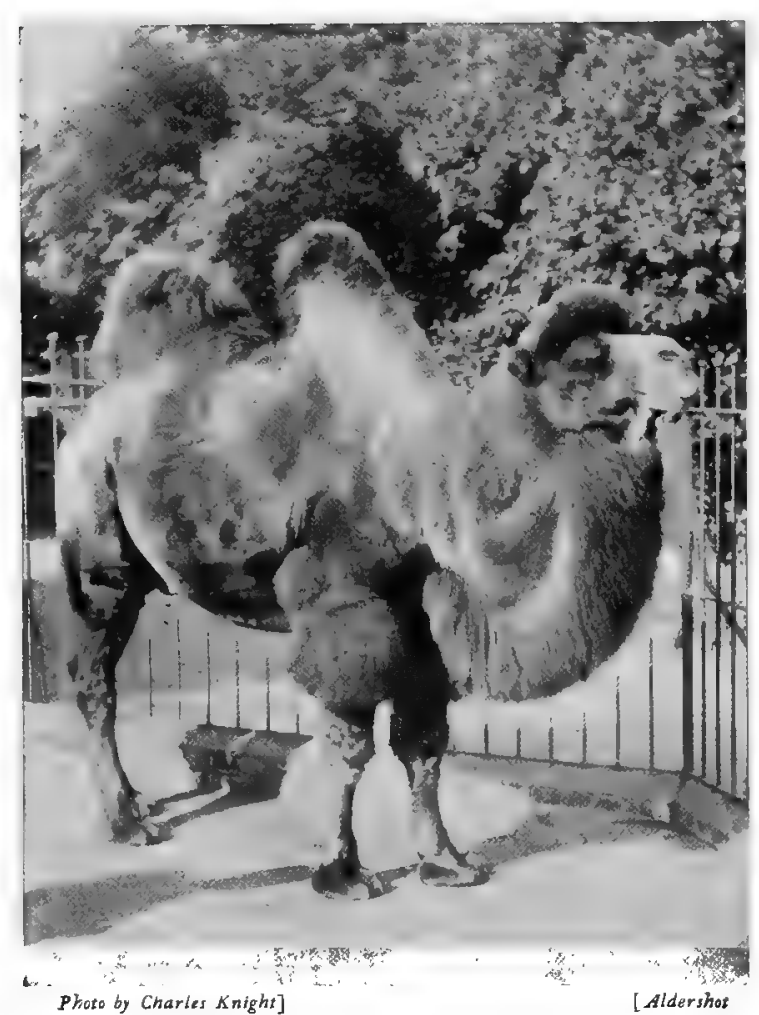

BACTRIAN CAMEL

The most useful transport animal of Central Asia

THE LLAMAS

THE LLAMAS are humpless camels, and confined to the western and southernmost parts of South America. Two wild and two domesticated species are known. The name Llama,itshould bementioned, properlybelongs to the domesticated animal of that name.

\section{The Vicuña}

This is the smaller of the two wild species. Vicuñas live in herds in the mountain-ranges of Peru, dwelling during the wet season high up amid rocks and precipices, near the region of perpetual snow. In the dry season they descend to the higher valleys. Their capture is a matter of great difficulty; for, apart from the inaccessible nature of their haunts, they are exceedingly shy and vigilant. They are clothed in a woolly coat of extremely delicate texture, much in demand for weaving purposes.

The baby vicuña, it is interesting to note, is able to run swittly directly after its birth, and possesses great powers of distinguished from its Arabian relative by the fact that it has two humps, is shorter in the leg and heavier, and has longer hair and stouter and harder feet. The shorter legs are distinctly advantageous, enabling the animal to get about with ease and safety over rocky and hilly ground.

The hordes of wild camels found in Turkestan, in the neighbourhood of Kashgar, are believed by Major C. S. Cumberland to be aescended from camels which escaped when the district known as Takla Makan was buried in a great sand-storm 200 years ago. From the fury of that storm it is said no human being escaped alive. Some camels apparently did, perhaps owing their survival to the power they possess of closing the nostrils, and thereby keeping out the sand.

The Bactrian camel lives upon the salt and bitter plants of the steppes, which are rejected by almost all other animals. It is further able to drink brackish water from the salt lakes by which it is surrounded. When pressed by hunger, it will even eat felt blankets, bones and skins of other animals, and fish!

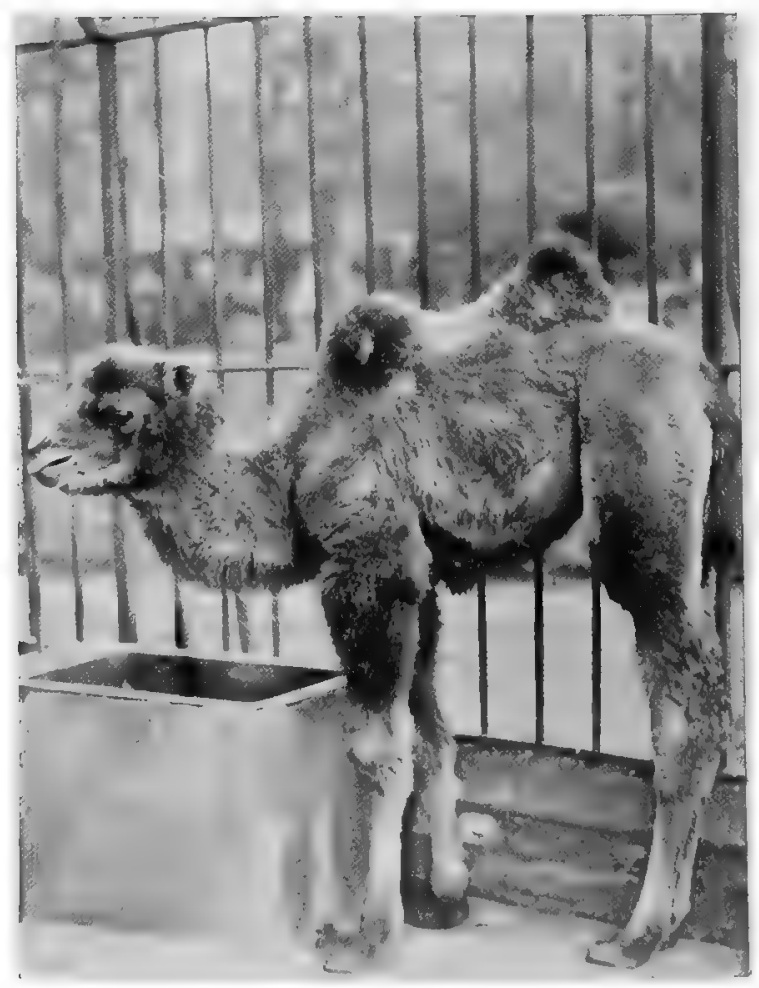

YOUNG BACTRIAN CAMEL

The two humps are just beginning to grow 
endurance. This is the more noteworthy since the young of the camel are exceedingly helpless.

Vicuñas are hunted by the Indians and captured by driving them into an enclosure of perhaps half a mile in diameter. This is hung round with bits of coloured rag, which, fluttering in the wind, appear to deter the captives from breaking through.

\section{The Guanaco}

This is larger than the vicuna, and is described as an elegant animal, being possessed of a long, slender, gracefully curved neck and fine legs. It ranges from the highlands of the Andes to the plains of Patagonia and the islands of Tierra del Fuego. As Mr. Darwin points out, the behaviour of guanaco when alarmed is very contradictory. At one time they will sound the danger-signal, and put themselves out of harm's way long before the enemy has perceived them; at another they exhibit the most extraordinary curiosity, and pay the deathpenalty in consequence. "That they are curious is certain; for if a person lies on the ground and plays strange antics, such as throwing up his feet in the air, they will almost always approach by degrees to reconnoitre him. It was an artifice that was repeatedly practised by our sportsmen with success, and it had, moreover, the advantage of allowing several shots to be fired, which were all taken as part of the performance. On the mountains of Tierra del Fuego, I have more than once seen a guanaco, on being approached, not only neigh and squeal, but prance and leap about in the most ridiculous manner, apparently in defiance, as a challenge. These animals are very easily domesticated, and I have seen some thus kept in Northern

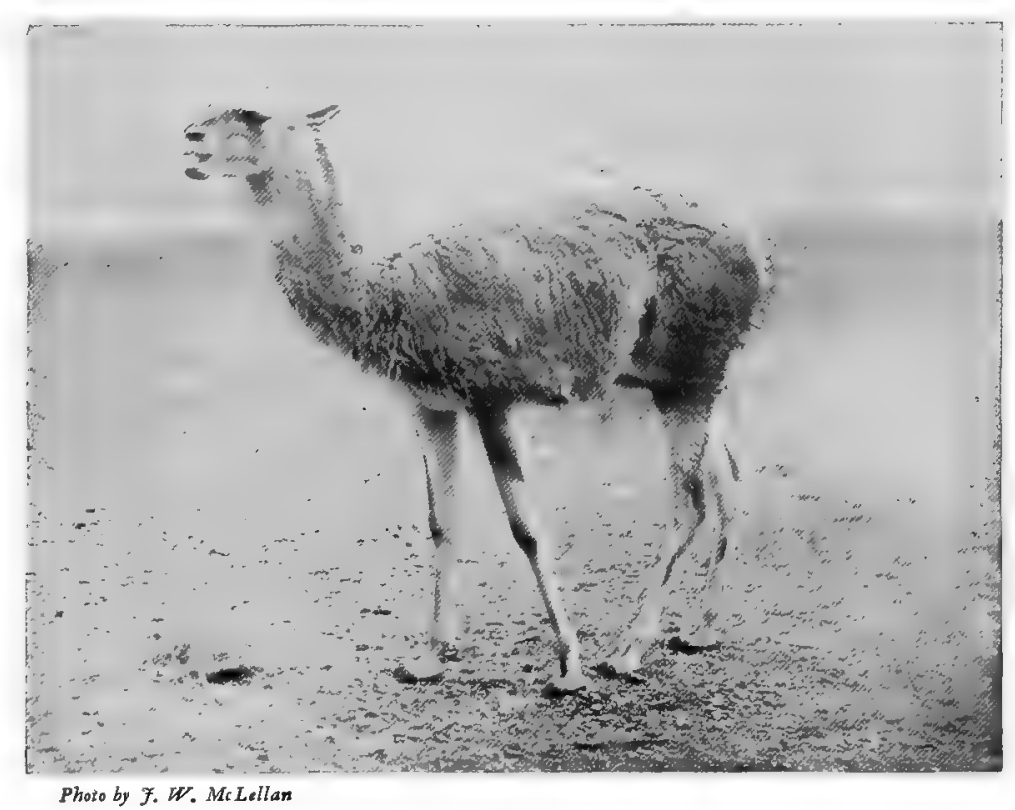

GUAN A CO

The wild original of the llama and alpaca

Patagonia near a house, though not under any restraint. They are in this state very bold, and readily attack a man by striking him from behind with both knees. The wild guanacos, however, have no idea of defence; even a single dog will secure one of these large animals till the huntsmen can come up. In many of their habits they are like sheep in a flock. Thus, when they see men approaching in several directions on horseback, they soon become bewildered, and know not which way to run. This greatly facilitates the Indian method of hunting, for they are thus easily driven to a central point, and are encompassed."

Guanacos readily take to the water, and have been frequently seen swimming from one island to another. Here again the llamas differ from the camels, for these can swim but little, if at all. Like the Bactrian camel, the guanaco can drink salt water with impunity.

One of the most remarkable traits of the guanaco is that which induces it, when it feels its end to be near, to seek out the dying-place of the tribe, and there breathe out its last. "The guanacos," says Mr. Darwin, "appear to have favourite spots for lying down to die. On the banks of the St. Cruz, in certain circumscribed places, which were generally bushy and all near the river, the ground was actually white with bones. On one such spot I counted 


\section{THE LIVING AN.IMALS OF THE WORLD}

between ten and twenty heads. . . . The animals in most cases must have crawled, before dying, beneath and amongst the bushes."

\section{The Llama}

This is the first of the two domesticated offshoots of the guanaco, the other being the Alpaca. The Llama is a larger beast than the guanaco, and variable in colour. The ancient Peruvians bred it as a beast of burden or for riding, and before the Spanish conquest kept it in enormous numbers. Soon after the Spanish conquest "it was not uncommon to meet droves of from 300 to 500 , or even I,000 llamas, each laden with silver ingots, and the whole in charge of a single native. . . Only the male llamas were used as beasts of burden, while the smaller females were kept for their milk and flesh. In traveling along the roads, the droves marched in single file, under the guidance of a leader; and such a line would traverse the highest passes of the Cordillera, and skirt the most stupendous precipices with perfect safety. . . . The Spanish conquerors of Peru spoke of llama-flesh as being fully equal to the best mutton, and they established shops in the towns for its regular sale. At the time of the conquest it is estimated that upwards of 300,000 llamas were employed in the transport of the product of the mines of Potosi alone."

\section{The AlpaCA}

This animal is bred solely for the sake of its wool, which is of great length and fineness. From it is made the well-known fabric which bears, in consequence, the name "alpaca."

The alpaca is kept in herds on the high grounds of Bolivia and South Peru, whence it is annually driven down to be sheared. The Incas dyed the wool - which is of two qualities, a fine and a coarse - with bright colours, and made it up into cloth or blankets, as the occasion served.

The earliest account of this animal is by Augustin de Zarate, the Treasurer-General of Peru in I544. He speaks of the beast as a sheep; but since he describes it as camel-iike in shape, though devoid of a hump, there can be no doubt that it is the llama he is describing.

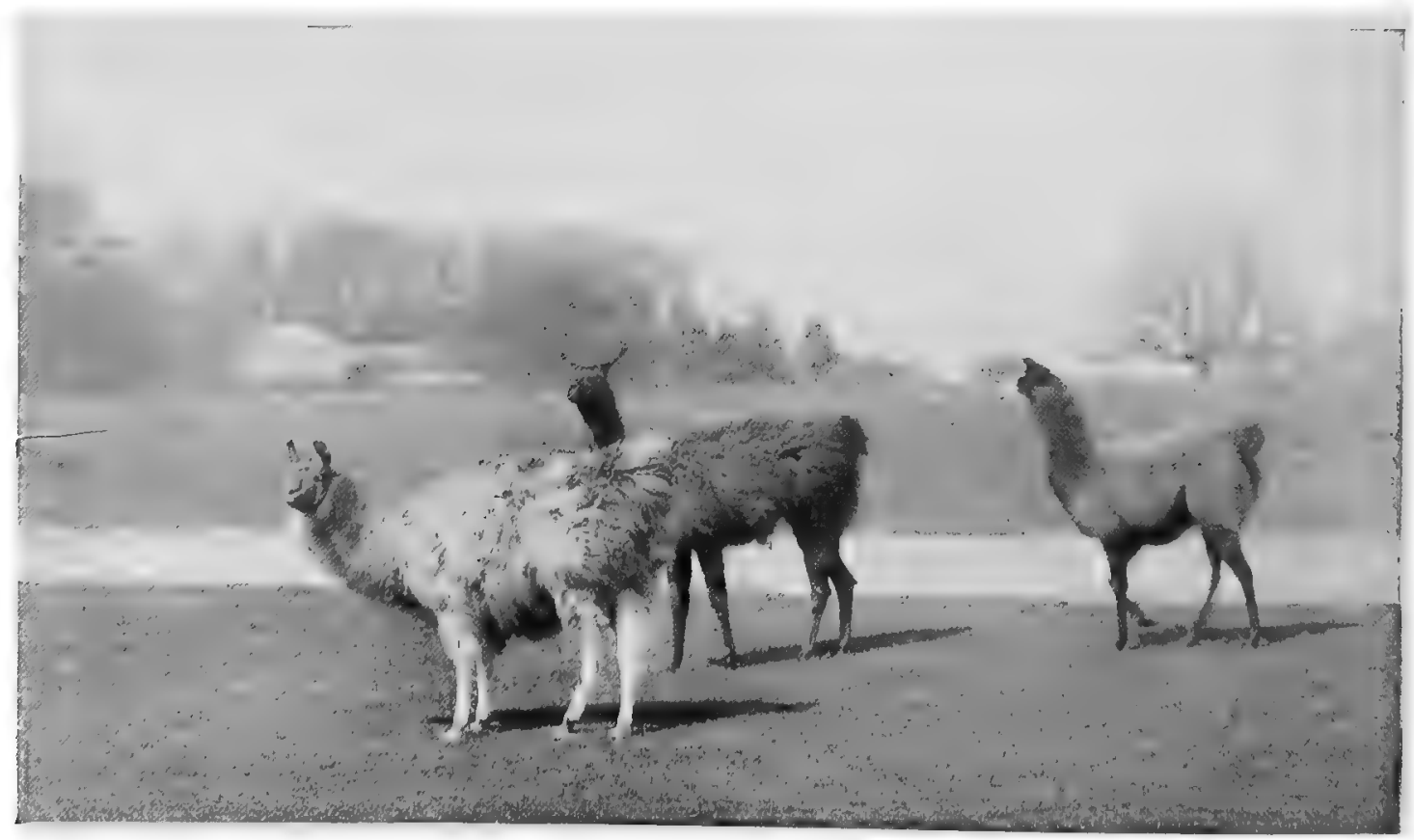

LL A M A S

Largely used as beasts of burden in Peru, where these and the alpaca were formerly the only domesticated ruminants 


\section{ThE CAMEL TRIBE AND THE CHEVROTAINS 273}

He says: "In places where there is no snow the natives want water, and to supply this they fill the skins of sheep with water, and make other living sheep carry them; for, it must be remarked, these sheep of Peru are large enough to serve as beasts of burden. They can carry about roo lbs. or more, and the Spaniards used to ride them, and they would go four or five leagues a day. When they are weary, they lie down on the ground; and as there are no means of making them get up, either by beating or assisting them, the load must of necessity be taken off. When there is a man on one of them, if the beast be tired and urged to go on, he turns his head round and discharges his saliva, which has an unpleasant odour, into the rider's face. These animals are of great use and profit to their masters, for their wool is very good and fine ... and the expense of their food is trifling, as a handful of maize suffices them, and they can go four or five days without water. Their flesh is as good as that of the fat sheep of Castile. There are now public shambles for the sale of their flesh in all parts of Peru, which was not the case when the Spaniards came first."

The particularly offensive habit of spitting in the face of people who may be obnoxious to it is

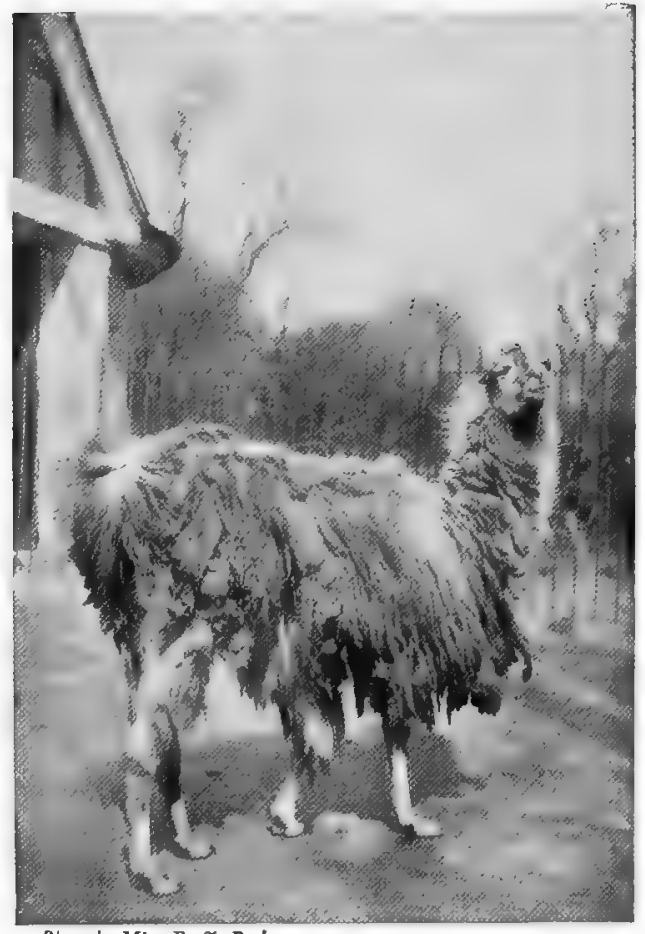

Photo by Miss E. F. Beck

L L A M A

The larger of the trwo domesticated forms descended from the guanaco well known to those who are in the habit of seeing much of this animal.

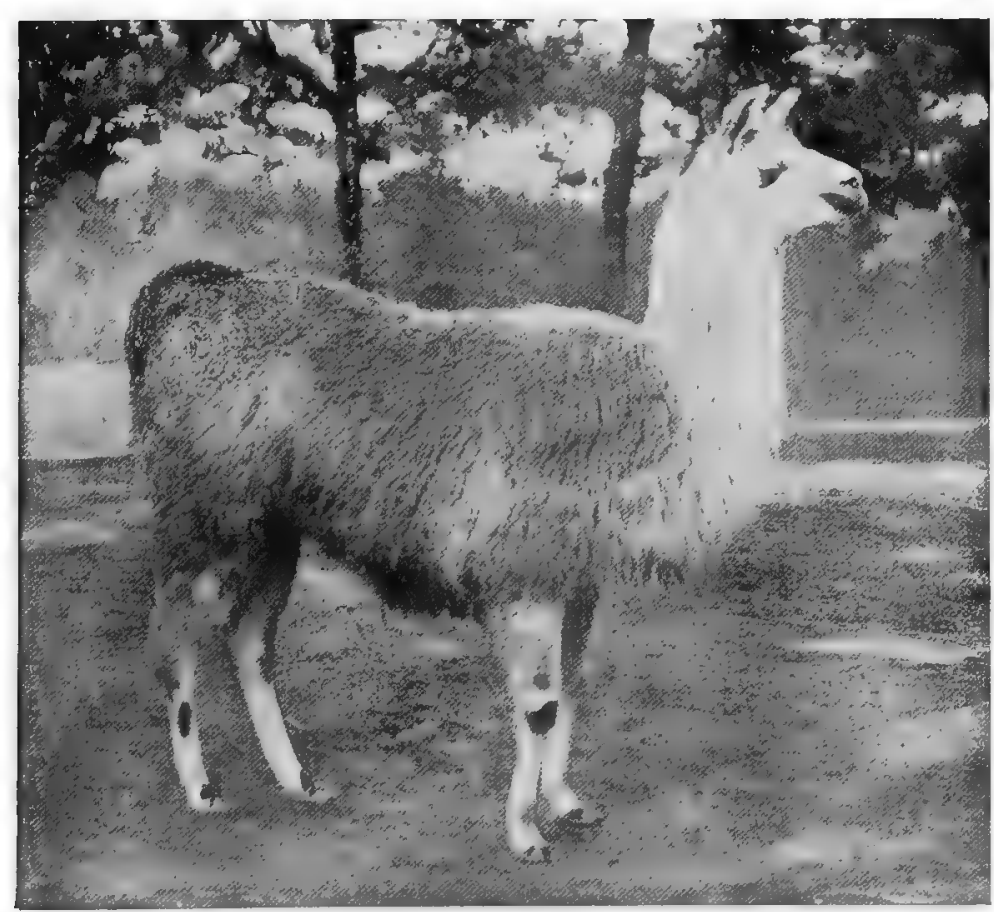

ALPACA

A domesticated form, bred solely for its wool, which is of a dark brown or black colour

\section{THE CHEVROTAINS}

MENTION must be made, before passing to the Pig Tribe, of the smallest of hoofed mammals, the Royal Antelope excepted-theCHEvrotaIns. These little animals are hornless, and intermediate in character between the Deer, Camels, and Pigs. The males have large canine teeth, like those of the Musk-deer, with which the Chevrotains have long been confounded. The range of these animals, of which there are five species known, extends from India and Ceylon, through the Malayan countries, as far east as the island of Palawan, in the Philippine group. One species, the largest of the group, occurs on the west coast of Africa. 


\title{
C H A P T E R X I X \\ THE PIG AND HIPPOPOTAMUS
}

\author{
THE PIG TRIBE
}

BY H. A. BRYDEN

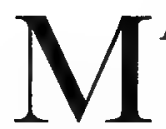

ANY species and varicties of swine are found in different parts of the world, most of them exhibiting strong traces of a general family resemblance, although widely sundered as to habitats and often markedly differing in outward appearance. All are omnivorous; all have the stomach simpler in type than in the Ruminants; and all have front or incisor teeth in the upper jaw. The two great families of swine proper are the Pigs and Peccaries.

There has been much discussion among scientists as to the early origin of the various breeds of domestic swine found in different parts of the world. There can be little doubt that, although selective breeding has produced extraordinary differences in outward appearance, even among the domestic pigs of our own islands, the origin of the numerous tame races is to be sought in the ancestry of the wild breeds of the countries in which they are found. Darwin has some very apposite remarks on the differences to be observed in domesticated swine. "The peculiar form of the skull and body in the most highly cultivated races is," " he observes, "not characteristic of any one race, but is common to all when improved up to

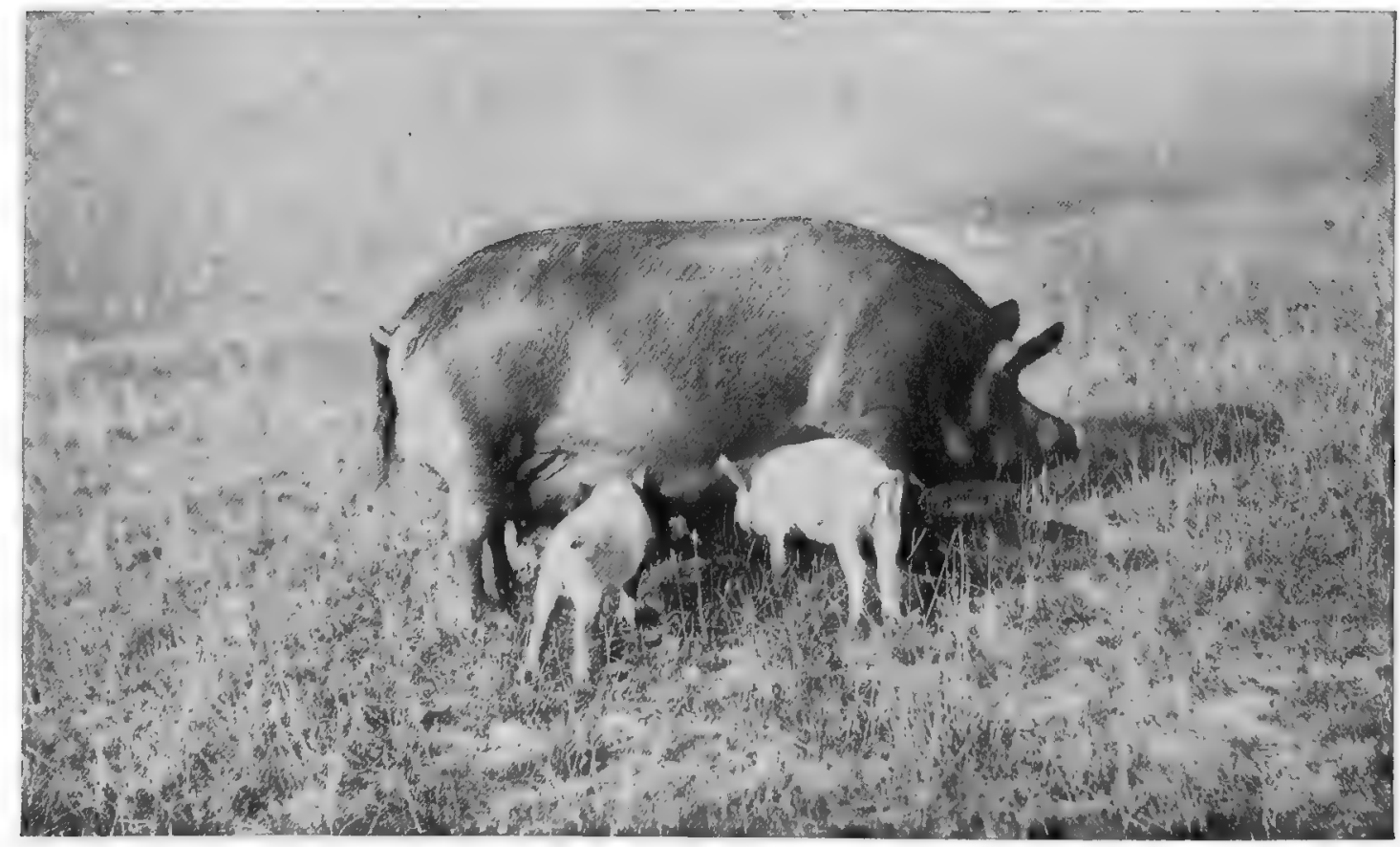

Photo by W. Reid

A DOMESTICATED SOW AND HER PROGENY

The absence of stripes and spots on the young is a feature in which they differ from those of nearly all wild swinc 


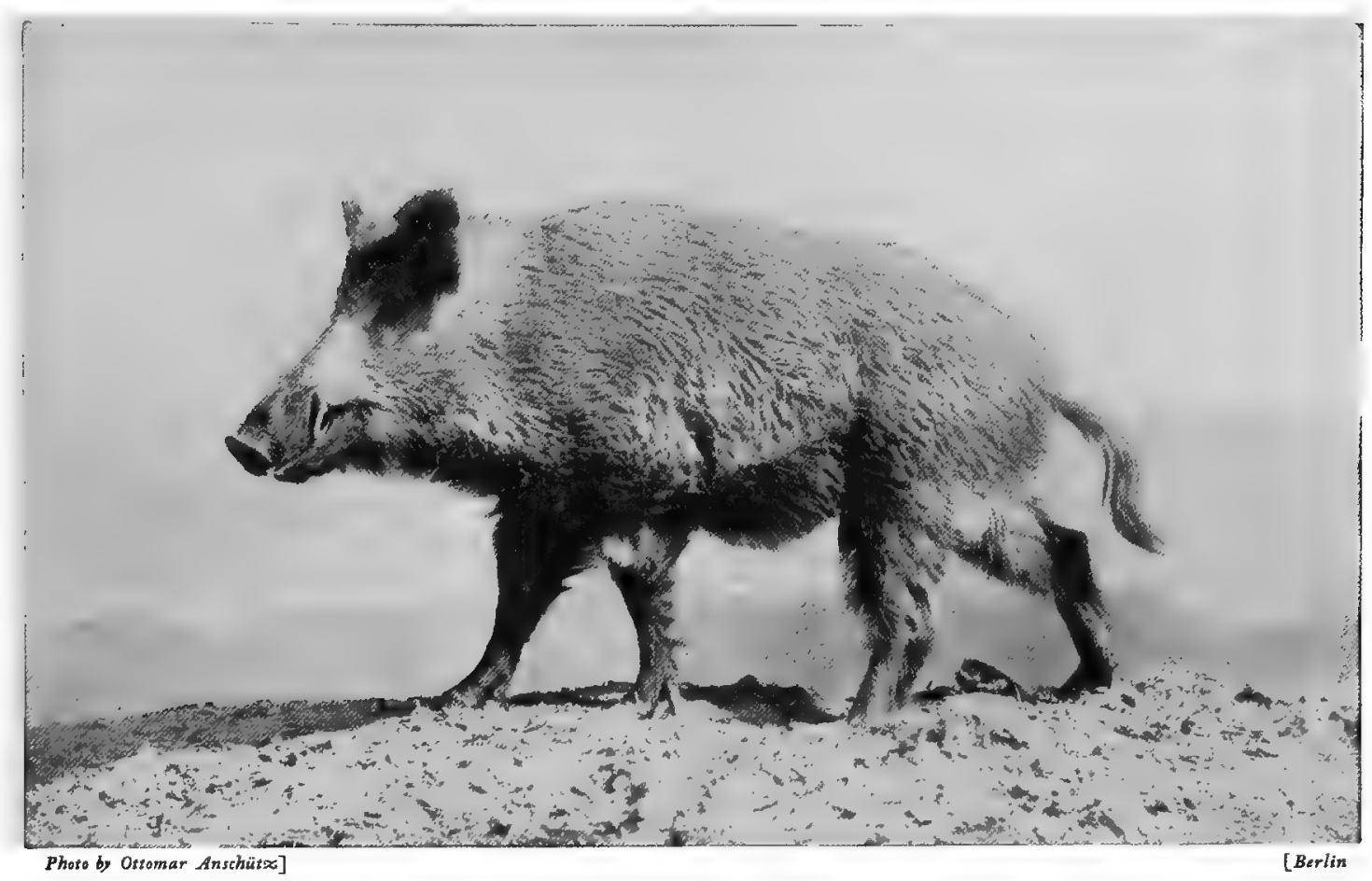

WILD BOAR

In its long, bristly hair and powerful lower tusks, the wild boar is a very different animal from its domesticated descendants

the same standard. Thus the large-bodied, long-eared English breed, with a convex back, and the small-bodied, short-eared Chinese breeds, with a concave back, when bred to the same state of perfection, nearly resemble each other in the form of the head and body. This result, it appears, is partly clue to similar causes of change acting on the several races, and partly to man breeding the pig for one sole purpose - namely, for the greatest amount of flesh and fat; so that selection has always tended towards one and the same end. With most domestic animals the result of selection has been divergence of character; here it has been convergence."

\section{The TRue Pigs}

True pigs are found only in the Old World, and even there in very widely different forms. Typical of these quadrupeds is the well-known WILD BOAR, found abundantly in many parts of Europe, North Africa, Asia Minor, and Central Asia. In the British Islands the wild boar must once have been extraordinarily plentiful, especially in Ireland, where its tame descendants still so greatly flourish. In the days of the Plantagenets wild swine fed and sheltered in the woodlands close to London. James I. hunted them near Windsor in I6I 7, and even down to the year 1683 these animals still had their haunts in the more secluded parts of England. Although now extinct in these Islands, the wild boar is to be found plentifully at the present day in France, Germany, Austria, Russia, and Spain, Greece, Albania, and other countries of the Mediterranean. In most parts of Europe the wild boar is shot during forest drives, but in the Caucasus and round the Black Sea the hardy peasants lie in wait for these animals by the fruit-trees on autumn nights or waylay them going to the water and shoot them single-handed. Many an old Cossack, writes Mr. Clive Phillipps-Wolley, bears the scars of some desperate encounter with these formidable foes. In Spain, where in the old days the boar was pursued by cavaliers with spear and pike, it is still, in the forests of Estremadura, followed with horse and hound, usually, says Mr. Abel Chapman, "during the stillness of a moonlight night, when the acorns are falling from the oaks in the magnificent Estremenian woods." 


\section{THE LIVING ANIMALS OF THE WORLD}

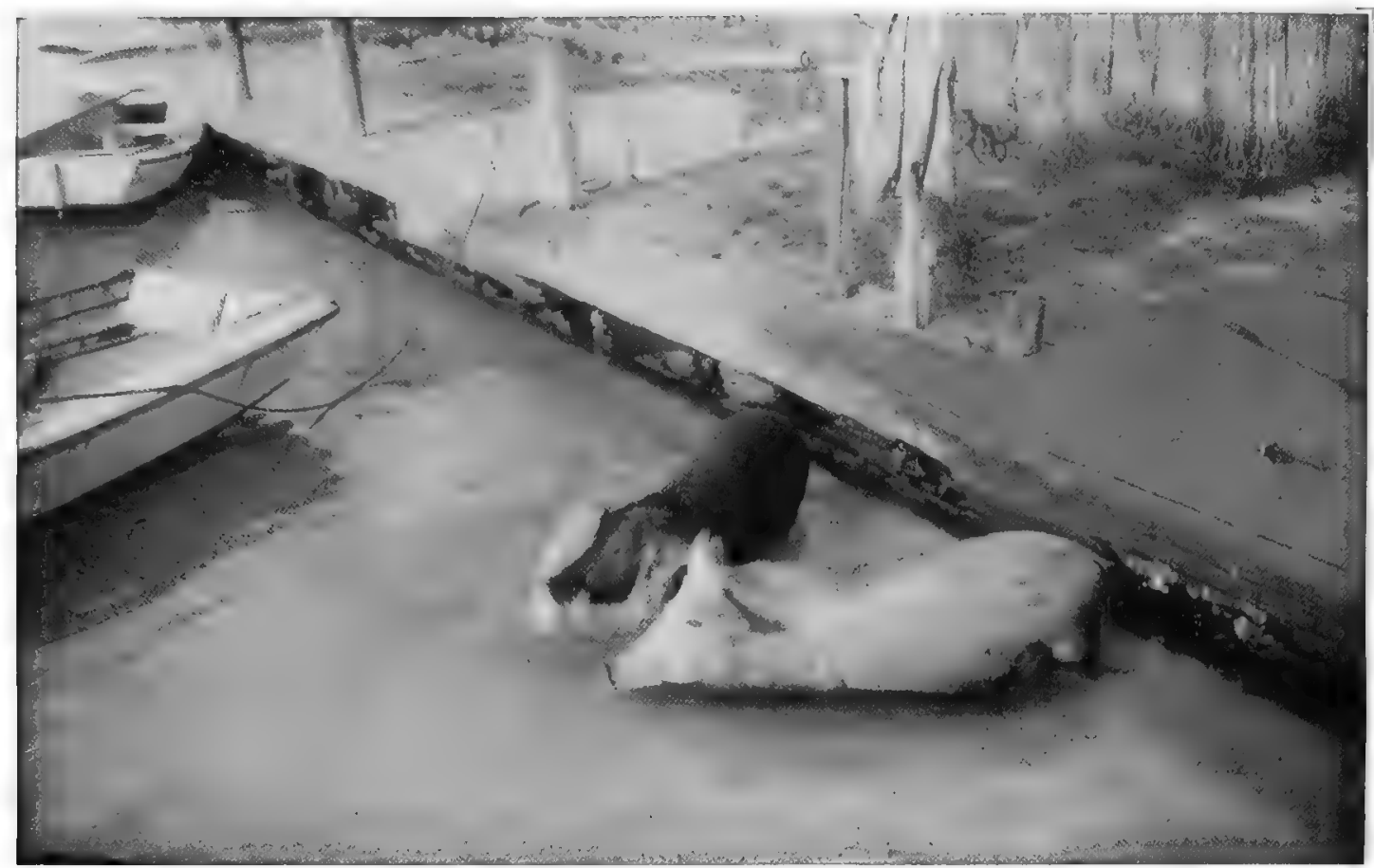

Phato by F. Turner-Turner, Esq.

DIVING-PIGS

Half-rild pigs, found in Florida, where they live on refuse fish. (See next page)

In India the wild boar of Europe and North Africa is replaced by a closely allied species (distinguished by a crest of long black bristles upon the neck and back), which furnishes some of the finest and most exciting sport in the world to mounted hunters armed with a sharp spear. There is not a pluckier or more fearless beast living than the boar; and as he carries long and extremely sharp tusks, and never scruples to use them, he is an exceedingly dangerous opponent when wounded and enraged. Severe and even fatal accidents have happened in the pursuit of this determined beast of chase. When at bay, the boar is absolutely reckless of life; and although pierced and mortally wounded by the spear, will yet force himself up the shaft, and with his dying effort inflict gaping wounds on the horse bearing his attacker. Indian shikaris, to illustrate the courage of the wild boar, say that he has the hardihood to drink at a river between two tigers; and Colonel R. Heber Percy mentions, in the Badmintan volumes on "Big Game Shooting," that "several cases are on record in which an old boar has beaten off a tiger, and some in which the latter has been killed by a boar. The boar's extraordinary activity and sharp tusks make him no mean adversary, and his short neck makes it difficult for a tiger to seize it and give it that fatal wrench with which he likes to polish off his victims." A wild boar will stand as much as 3 feet at the shoulder - some sportsmen affirm considerably more - and weigh more than 300 lbs. The finest boar's tusk known, is one mentioned in Rowland Ward's "Records of Big Game." This mieasures $1 \mathrm{I} \frac{1}{2}$ inches over the curve. It came from the Caucasus, and is in the possession of Colonel Veernhof.

It is worthy of note that, while the full-grown individuals of the various species of wild swine are uniformly coloured, their young are longitudinally striped and spotted. In India, besides the common boar, a tiny wild swine, known as the PYGMY HoG, is, found in the Bhutan Terai and the forests of Nepal and Sikhim. This pig, which is little bigger than a fox-terrier, runs in considerable troops, or sounders, and is said to attack intruders into its domain much in the same fearless' way in which the peccary of America defends its sanctuaries. The height of this diminutive species is given as from 8 to 10 inches - the weight at io lbs. 
Wild swine are nocturnal in their habits, frequenting moist and marshy country, loving the shade of forests, and making their lairs in tall grass, reed-beds, and similar covert. They go far afield for their food-supplies, and do a great deal of damage to crops in cultivated districts. The European wild sow produces from six to ten young, and at least two litters are usually brought forth in the year.

It is remarkable how quickly pigs, as well as other domesticated animals, revert to a semi-feral state of existence, and develop habits suited to a fresh environment. Mr. J. Turner-Turner sends us the following interesting note in connection with this trait: "DIVINGPIGS. - These pigs live in an almost wild condition on certain of the islands off Florida, and subsist chiefly upon the refuse fish cast away by the netsmen. To obtain this, the pigs dive under water, walking on the land at a depth of 5 feet below the surface."

Among other Asiatic wild swine are to be mentioned the Collared PIG, found in Java, Sumatra, and Borneo; the White-Whiskered Japanese Pig; the Papuan and

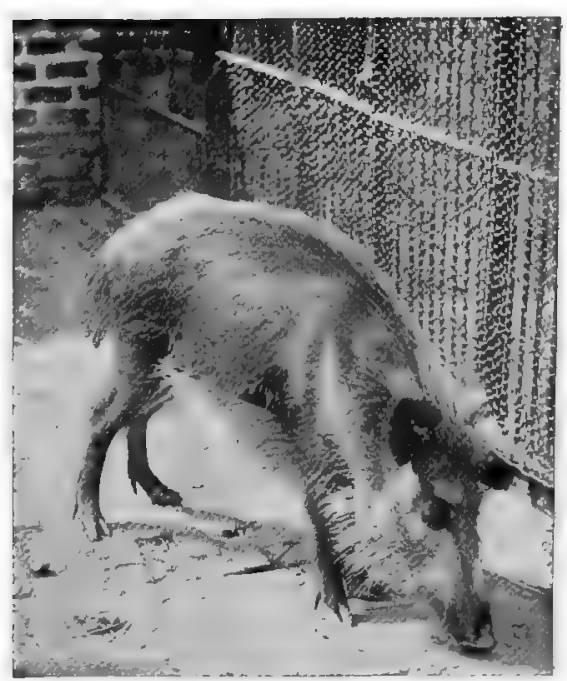

JAVAN WILD PIG

One of several nearly allied species inhabiting the Malay Islands

Formosan Pigs; the Warty Pig of Java and Borneo; the Ceram Pig; the Celebes Pig; and the BEARDED PIG of Borneo, a species distinguished by a quantity of long hair carried upon the cheeks. In the Andaman Islands a small, shaggy wild pig, standing about 20 inches at the shoulder, is found in the forests. Although distinguished from the well-known wild boar of India by certain peculiarities, there is a strong family resemblance to that well-known species in most of these various Asiatic species and races.

Among the many kinds of domesticated swine found in Asia, perhaps the strangest and most curious is the JAPANese MASKED PIG. This animal is described by Darwin as having " an extraordinary appearance, from its short head, broad forehead and nose, great fleshy ears, and deeply furrowed skin. Not only is the face furrowed, but thick folds of skin, which are

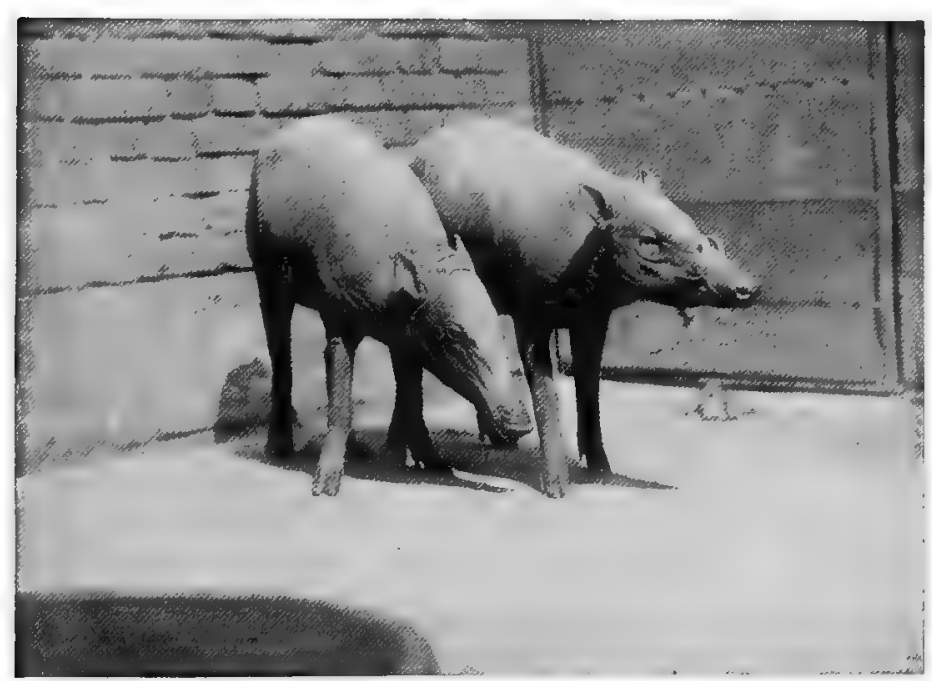

MALE AND FEMALE BABIRUSA

The chief characteristic of this pig is the peculiar and enormous development of the tusks in the male, the upper pair of which grow through the lips and curve backwards harder than the other parts, almost like the plates on the Indian rhinoceros, hang about the shoulders and rump. It is coloured black, with white feet, and breeds true. That it has long been domesticated there can be little doubt; and this might have been inferred even from the circumstance that its young are not longitudinally striped."

In Africa, besides the European wild boar, which there extends its range to Algeria and Morocco, a little known wild pig is the SENAaR BOAR, found in Senaar, Kordofan, and the Soudan region. In the late Dr. Gray's "Catalogue of Carnivora" this wild pig is described as having the fur dense and bristly, and 


\section{THE LIVING ANIMALS OF THE WORLD}

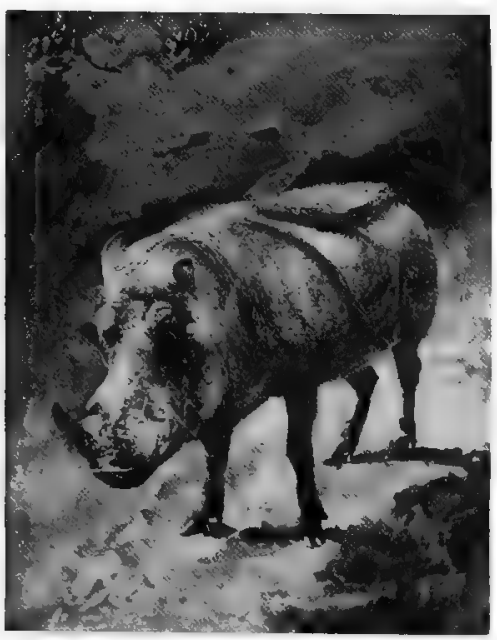

WART-HOG

Shows the great size of the head in proportion to the body

being in rolour dull olive-black, varied with yellow. Possibly this little-known swine may prove to be merely a sub-species of the common wild boar of Europe and North Africa. Now that the Soudan regions have once more been opened up to Europeans, we may expect shortly to hear more of this wild swine, as well as of other rare and interesting animals.

Still dealing with the true pigs, we come now to the BusH-PIGS of Africa and Madagascar. These differ somewhat from the typical wild boars of Europe and India in the structure of the teeth, the long pencilled ear-tufts, the elongated snout, and other characteristics. The tusks are considerably smaller, and seldom exceed 6 or 7 inches in length. The RED RIVER-HOG, or WEST AFRICAN BUSH-PIG, is decidedly the most striking of this group. Smaller than the bush-pig of South Africa, and seldom exceeding 2 feet in height at the shoulder, the colour of this animal is a brilliant reddish brown, with tints of yellow. Noticeable streaks of white are found round the eyes and on the cheeks. The ear-tufts, forehead, and limbs are blackish; more white markings are seen at the tips of the ear-tufts, along the thick mane, and round the margins of the ears. The under-parts are whitish grey in colour. This very handsome pig runs in considerable herds, and is found chiefly in forest and jungle near the banks of the various rivers in West Africa. Its range extends from Angola to Senegambia, and eastwards into the continent as far as Monbuttu.

The well-known BuSH-PIG OF SOUTH AFriCA, the BOSCH-VARK of the Boers, is a fine species, * having a wide range over much of the southern and south-eastern parts of the continent, extending as far north as Central Africa. In the Eastern Transvaal and Swaziland these animals attain their greatest size, an adult boar standing from 2 feet 4 inches to 2 feet 7 inches in height, and weighing as much as from I 50 to I $70 \mathrm{lbs}$. The usual colour is brownish red, the face and mane greyish; but in different specimens and at different ages great variations are to be noticed. Pale greyish brown or mottled brown are colours often to be found. These bush-pigs are formidable-looking creatures, with thick bristling manes, small deep-set eyes, and sharp if somewhat short tusks, which they know well how to use. Among the old fashioned Boers cured hams from these animals were, when they were more plentiful in Cape Colony, often to be found in up-country farmhouses. The bosch-vark is a beast of shy, nocturnal habit, and, loving as it does the shade and protection of dense covert and bush, is, unless carefully sought for, not often seen by sportsmen. The herds range usually from half a dozen to as many as twenty in number. When once encountered and set up at bay, this wild swine

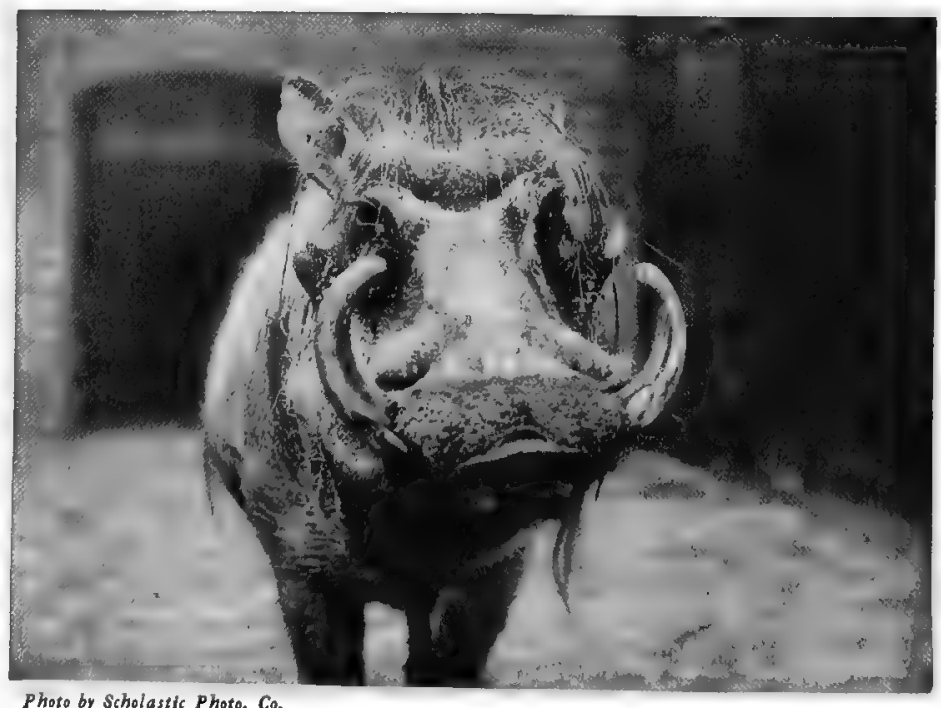

ELIAN'S WART-HOG

Displays the broad muzale and huge eusks, wuhich are nearly as large in the sorvs as in the bours 
will be found a most tough and courageous adversary, capable and willing to defend itself stoutly against all foes. "They are," says Mr. F. Vaughan Kirby, who has had much experience in hunting these animals, "expert swimmers and swift of foot, and can get over the roughest ground at a: great pace. There is no pluckier beast in Africa than a bush-pig, and even a leopard will hesitate before attacking a full-grown boar. Like all wild creatures, they have an instinctive dread of man, and will always make their escape from him if possible; but if surrounded or wounded and brought to bay, they appear to accept the situation with stolid imperturbability, and die fighting with rare pluck, against all odds, grim and silent to the last. . . . Face to face in the middle of a 'fast' bush, and only a Swazi 'stabbing-assegai' with which to kill him,... I have seen an old boar, after receiving nine thrusts from those terrible weapons, two of which were still fast in him, make a charge that scattered us like chaff, and in three consecutive lunges lame one of our number for life, and disembowel two of the finest 'pig-dogs' I ever hunted with. In such encounters a boar inflicts terrible wounds with his teeth, as well as with his tusks." Few men care to face a wart-hog on foot.

Another bush-pig is found in Madagascar, and is known as EDWARDs' BusHPIG. Its habits are very similar to those of its brethren in the neighbouring continent of Africa.

\section{The Babirusa}

Quitting the true pigs, we come now to perhaps the very strangest and most singular of all the great tribe of swine. This is the BABIRUSA, that curious and grotesque creature found in the island of Celebes, in the Malay Archipelago. The name Babirusa signifies " pigdeer." It is of course a misnomer, and the animal has no kinship whatever with the cervine race. The babi-

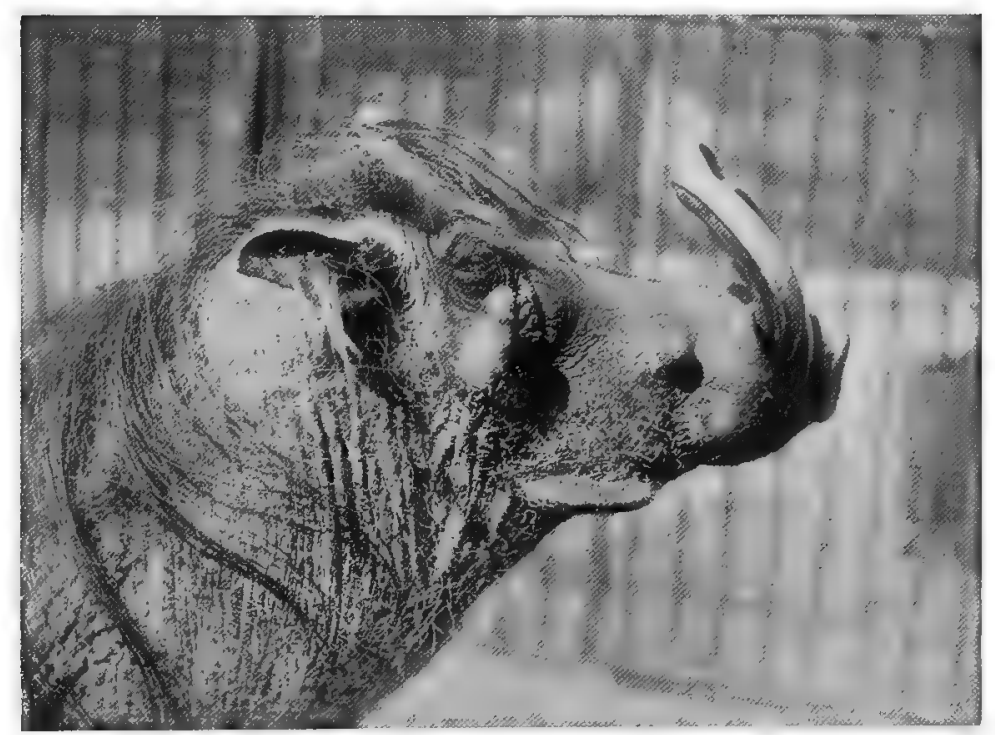

HEAD OF MALE WART-HOG

Profile showing the large conical warty growths on the side of the face so characteristze of these animals

rusa is a wild swine, having a dark slate-grey skin, very sparsely covered with hair along the ridge of the spine. This skin is very extraordinarily wrinkled. The ears are much smaller than is the case with other members of the swine group, while the tail is short, straight, and racks any semblance of tuft. The females have small tusks. In the boars the tusks are most singularly and abnormally developed. From the upper jaw, instead of curving from the side of the lips, the tusks grow from the centre of the muzzle, penetrate right through the skin, and curve backwards often till they touch the forehead. The lower tusks have also a strong curve, but are not so long as those of the upper jaw Although thus superabundantly provided with tushes, the babirusa is, as regards the rest of its teeth, less well off, having only thirty-four, as against the forty-four of the European wild boar. In their habits these singular pigs much resemble other wild swine, going in herds and frequenting forest, jungle, and the banks of rivers. They are excellent swimmers. The young are, unlike other wild swine in the infant state, unstriped. These animals are often found domesticated about the dwellings of native chiefs in Celebes. The weight of a good male is as much as I $28 \mathrm{lbs}$; height at shoulder, $27 \frac{1}{2}$ inches. The longest tusk recorded measures 17 inches 


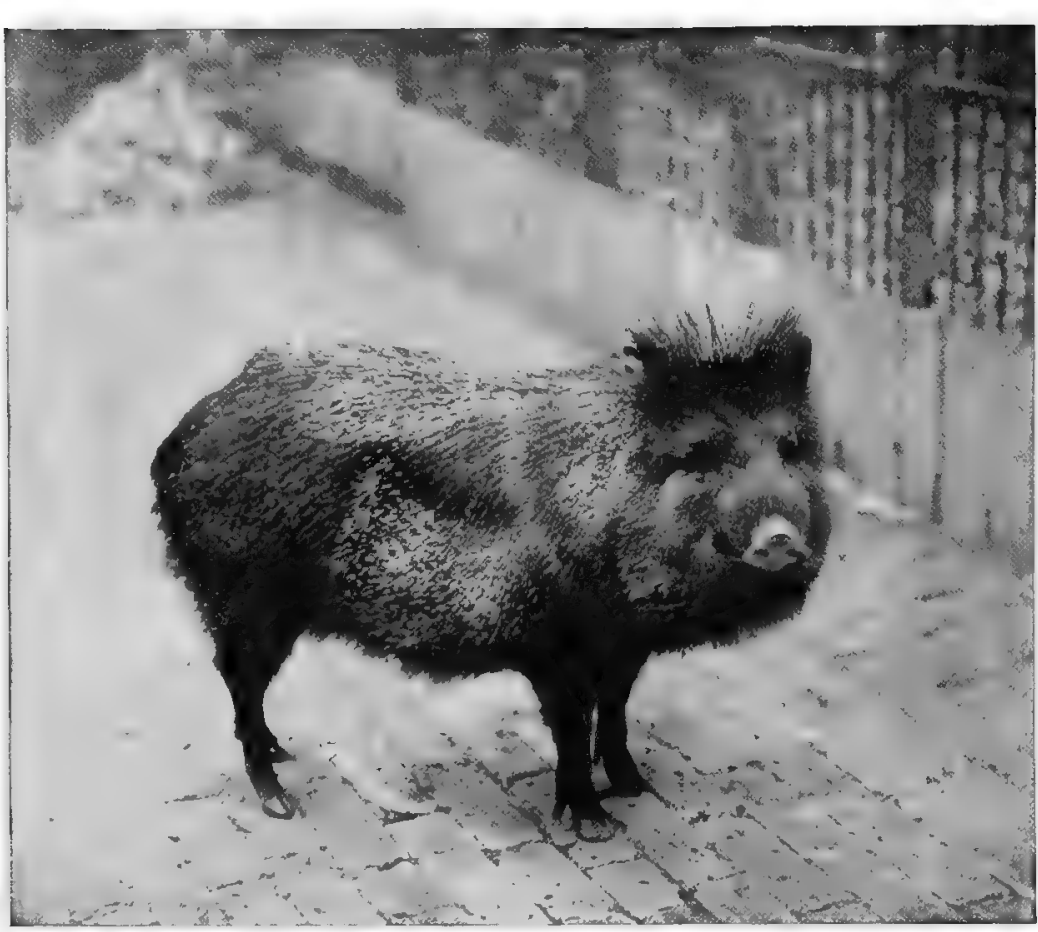

Phato by W. P. Dando

COLLARED PECCARY Peccaries are the American representatives of the Swine, and are cbaracterised by a large gland on
the back over the curve. These animals are driven into. nets and speared by the natives of Celebes, and afford excellent sport, the boars especially charging viciously at their assailants.

\section{THE WART-HOGS}

If the babirusa of the Malay Archipelago is a sufficiently bizarre-looking creature, the wart-hog of Africa yields to none of the wild pigs in sheer, downright hideousness of aspect. The WART-HOG OF SOUTH AFRICA, the VLAKTE-VARK (Pig of the Plains) of the Boers, has long been familiar to hunters and naturalists. Standing some 30 inches in height, this wild swine is distinguished by the disproportionate size of the head, extreme length,

breadth, and flatness of the front of the face and muzzle, smallish ears, huge tusks, and the strange wart-like protuberances from which it takes its name. Three of these wen-like growths are found on each side of the face. The tusks of the upper jaw, unlike the teeth of the true pigs, are much larger than those protruding from the lower jaw. The lower tusks seldom exceed 6 inches in length; those of the upper jaw occasionally reach as much as 20 inches over the curve. A pair from North-east Africa (Annesley Bay, on the Abyssinian littoral) measure respectively 27 and 26 inches - truly gigantic trophies. The skin of this wild hog is nearly naked, except upon the neck and back, where a long, coarse mane of dark bristly hair is to be observed. Wart-hogs, as their Dutch name implies, in the days when game was plentiful, were often found in open country, on the broad grass-plains and karroos. At the present day they are less often seen in the open. They run in small family parties, usually two or three sows and their litters. The old boars, throughout a great part of the year, prefer a more solitary existence. These animals, when pursued, usually betake themselves to an open earth, not of their own making, and, slewing round sharply just as they enter, make their way in hind end first. They afford no great sport to the hunter, and are usually secured with a rifle-bullet. The flesh is fairly good eating, especially that of a young and tender specimen. Speaking generally, wart-hogs are nothing like such fierce and determined opponents as the wild boars of Europe and India, or even the bush-pig. They will, however, charge occasionally, and have been known to attack and rip up a horse. A northern species. - Elian's WART-HOG - is found in Abyssinia, Somaliland, and other parts of East Africa, where - especially in Abyssinia - it roams the mountains and their vicinity, occasionally to a height of 9,000 or 10,000 feet. There is little difference between. this and the southern form. Wart-hogs produce usually three or four young, and the sow makes her litter in a disused burrow. Unlike those of the majority of wild swine, the young of the wart-hog are uniformly coloured, having no white stripes or spots. 


\section{THe PECCARIES}

Peculiar to the American Continent, the PECCARIEs differ considerably from the wild swine of the Old World. They are of small size; the dentition is not the same, the stomach is more complicated in structure, and the hind feet have three instead of four toes. In general appearance peccaries are not unlike small dark-coloured pigs, well covered with bristles, and having, as well as a prominent mane, a deep fringe of hair beneath the throat. They are essentially forest-loving animals, roaming over large tracts of country and making considerable migrations in search of food. Two species have been distinctly identified by naturalists - the Collared Peccary, and the White-Lipped PecCary. Of these, the former species is found from Texas, in North America, as far south as the Rio Negro, in Patagonia. The habitat of the white-lipped peccary is more circumscribed, and the animal is seldom found except in that part of South and Central America lying between British Honduras and Paraguay. No members of the Pig Family are fiercer or more tenacious of their sanctuaries than the whitelipped peccary, which roams the dense forests of Brazil and Paraguay in large herds. A human being, attacked and surrounded by a herd of these savage little creatures, would indeed stand but a poor chance of his life, and many a hunter and traveler has been compelled to seek refuge in a tree and sustain some hours of siege. Of the two species, the white-lipped peccary is somewhat the larger, standing from $I_{5}$ to $I \frac{1}{2}$ inches in height. The collared. peccary averages from $13 \frac{1}{2}$ to $15 \frac{1}{2}$ inches. The flesh of these wild swine is not in much repute, and unless the back-gland is at once cut out a freshly killed specimen will become quickly spoiled as a human food-supply. Young peccaries appear to be easily tamed, fierce as is their nature in the wild state. In contrast with the abundant litters of other pigs, wild and domesticated, only one offspring is ordinarily produced at birth. In fighting, the peccary does not rip like the wild boar, but inflicts savage and severe bites.

"Untrained dogs," says President Roosevelt, "even those of a large size, will speedily be killed by a single peccary, and if they venture to attack a herd will be literally torn into shreds. A big trained dog, however, can, single-handed, kill a peccary, and I have known the feat performed several times."

Azara, the eminent Spanish naturalist of the end of the eighteenth century, had considerable experience of the peccaries of Central and Southern America, where the Indians are much addicted to taming wild animals, and keep both the peccary and the tapir in a state of semi-domestication. The peccary he found to be domesticated more easily than might be expected. Though so fierce in its wild state, it soon becomes troublesome from its familiarity.

Mr. Schomburgk, the explorer of Central America, whose travels were so constantly quoted during the Venezuelan arbitration, saw much of the white-lipped species in the forests. He found the animals in large troops under the leadership of an old boar. When attacked, they were ready to surround man, dog, or jaguar; and if there were no means of escape, the enemy was certain to be cut to pieces. He himself had a narrow escape from an infuriated herd, the leader of which he shot in the act of rushing at him. As the herd approached the sound was like that of a whirlwind through the bushes.

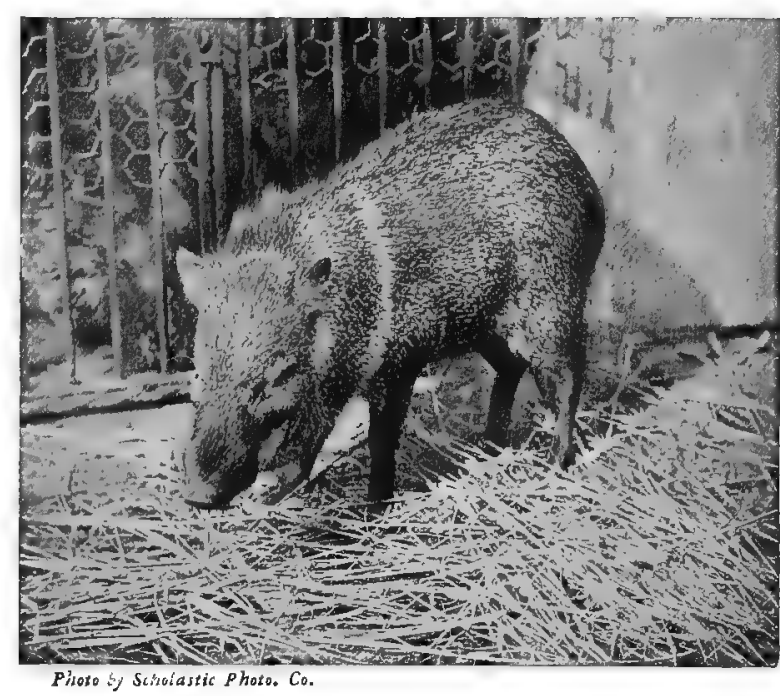

A YOUNG COLLARED PECCARY

In this specimen the white collar from wohich the species takes its name is very clearly displayed 


\section{THE LIVING ANIMALS OF THE WORLD}

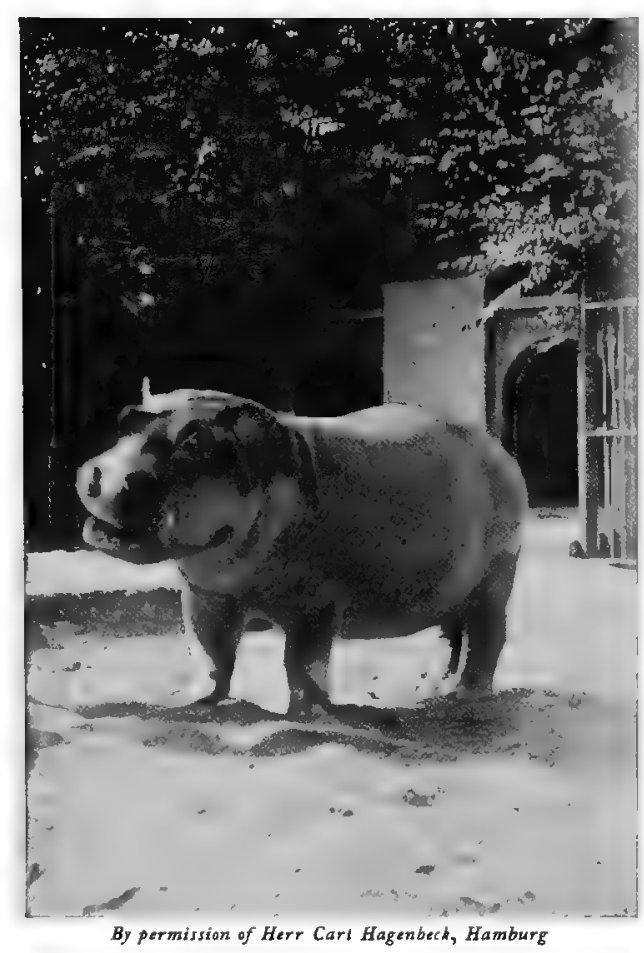

A THREE-YEAR-OLD HIPPOPOTAMUS

In this specimen the great lower tusks are not yet developed

\section{THE HIPPOPOTAMUS}

BY F, C. SELOUS

Two species of the Hippopotamus Family exist on the earth to-day, both of which are inhabitants of Africa, and are not found in any other country; but the remains of many extinct forms of this genus which have been discovered in various parts of Europe and Asia show that in Pleistocene and Pliocene times these strange and uncouth animals must have been widely distributed throughout the greater part of the Old World. The fossil remains of the large form of hippopotamus which once frequented the lakes and rivers of England and Western Europe cannot be distinguished from the bones of the common African species of to-day, which latter is possibly the only animal in the world which has undergone no change in form or structure since the prehistoric savages of the Thames Valley threw stone-headed spears at their enemies.

The Common Hippopotamus, though it has long been banished from the Lower Nile, and has more recently been practically exterminated in the British colonies south of the Limpopo, was once an inhabitant of every lake and river throughout the entire A frican Continent from the delta of the Nile to the neighbourhood of Cape Town. Now it is not found below

Khartum, on the Nile; but in Southern Africa a few hippopotamuses are said still to exist in the lower reaches of the Orange River. When Van Riebeck first landed at the Cape, in I652, he found some of these animals in the swamp now occupied by Church Square, in the centre of Cape Town, and the last in the district was only killed in the Berg River, about seventy miles north of that city, as recently as I874. This animal, which had been protected for some years, was at last shot, as it had become very savage, and was in the habit of attacking any one who approached it. In my own experience I have met with the hippopotamus in all the large rivers of Africa where I have travelled, such as the Zambesi, Kafukwe, Chobi, Sabi, Limpopo, and Usutu, and also in most of the many large streams which take their. rise on the plateau of Matabililand and Mashonaland, and flow north, south, and east into the Zambesi, the Limpopo, or the Sabi. I have also seen them in the sea, at the mouth of the Quillimani River, and have heard from natives that they will travel by sea from the mouth of one river to another.

Hippopotamuses live either in families of a few individuals or in herds that may number from twenty to thirty members. Old bulls are often met with alone, and cows when about to calve will sometimes leave their companions and live for a time in seclusion, returning, however, to the herd soon after the birth of their calves. Although, owing to the shortness of its legs, a hippopotamus bull does not stand very high at the shoulder - about 4 feet 8 inches being the average height - yet its body is of enormous bulk. A male which died some years ago in the Zoological Gardens of London measured 2 feet in length from the nose to the root of the tail, and weighed 4 tons; and these dimensions are probably often exceeded in a wild state.

The huge mouth of the hippopotamus (see Coloured Plate), which the animal is fond of opening to its widest extent, is furnished with very large canine and incisor teeth, which are kept sharp by constantly grinding one against another, and thus enable their possessor 


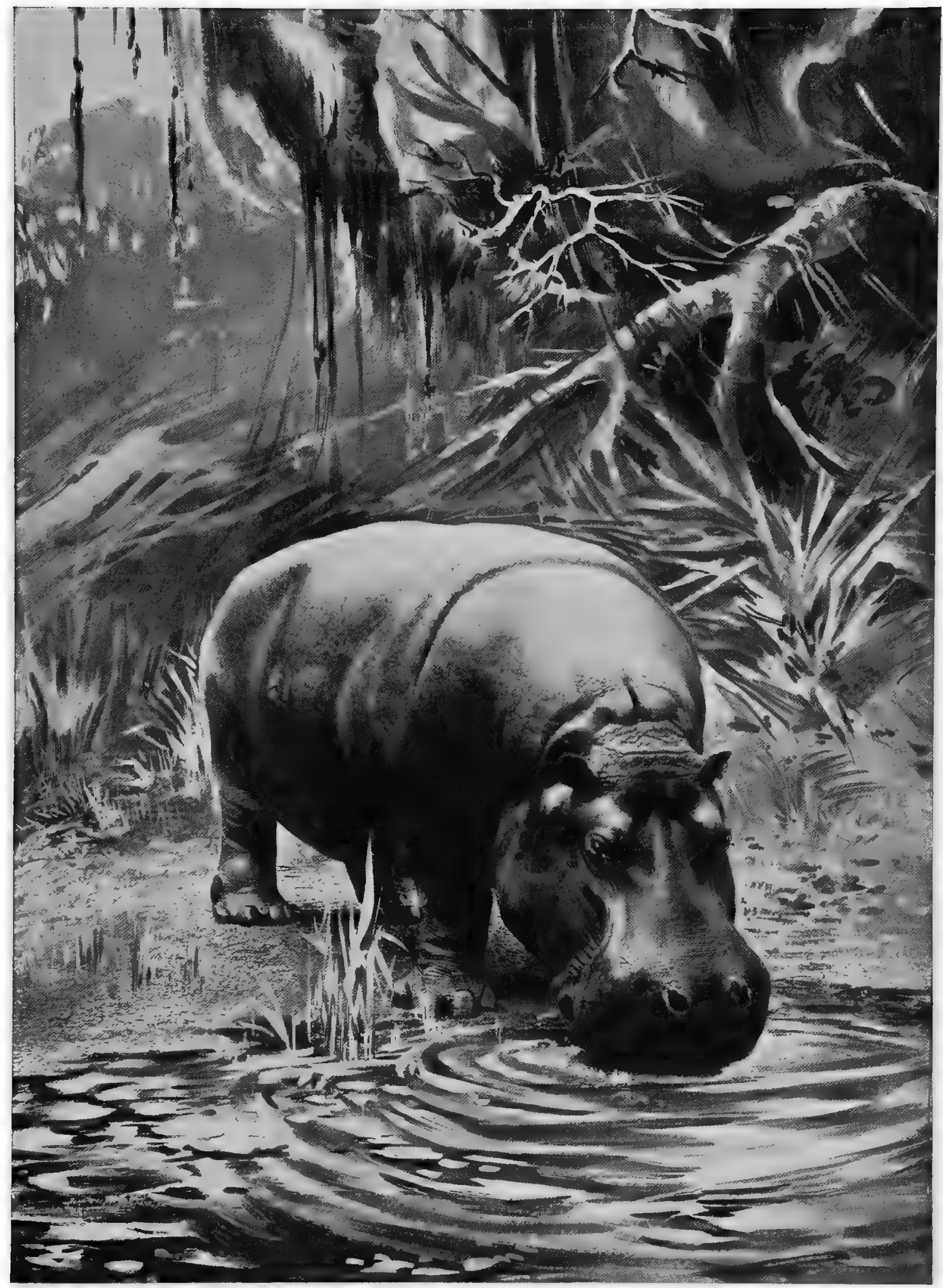

Photo by f. W. Mc Lellat

HIPPOPOTAMUS DRINKING

The enormous breadth of the muxzle, as well as the small nostrils, which can be closed at will, are clearly displayed in this posture 
to rapidly cut down great quantities of the coarse grass and reeds upon which these animals exclusively feed when living in uninhabited countries. When, however, their haunts are in the neighbourhood of native villages, they often commit great havoc in the corn-fields of the inhabitants, trampling down as much as they eat; and it was their fondness for sugar cane which brought about the destruction of the last herd of hippopotamuses surviving in Natal.

The lower canine teeth or tusks of the hippopotamus grow to a great size, and in bulls may weigh from $4 \mathrm{lbs}$. to $7 \mathrm{lbs}$. each. They are curved in shape, and when extracted from the jaw form a complete half-circle, and have been known to measure upwards of 30 inches over the curve. In life, however, not more than a third of their length protrudes beyond the gums.

During the daytime hippopotamuses are seldom met with out of the water. They lie and doze all day long in the deep pools of the rivers they frequent, with only their eyes, ears, and nostrils above the surface, or else bask in the sun on the tail of a sandbank, looking like so many gigantic pigs with their bodies only partially submerged. Sometimes they will lie and sleep entirely out of water amongst reeds. I have seen them feeding in the reed-beds of the great swamps of the Chobi just at sundown, but as a rule they do not leave the water until after dark. At night

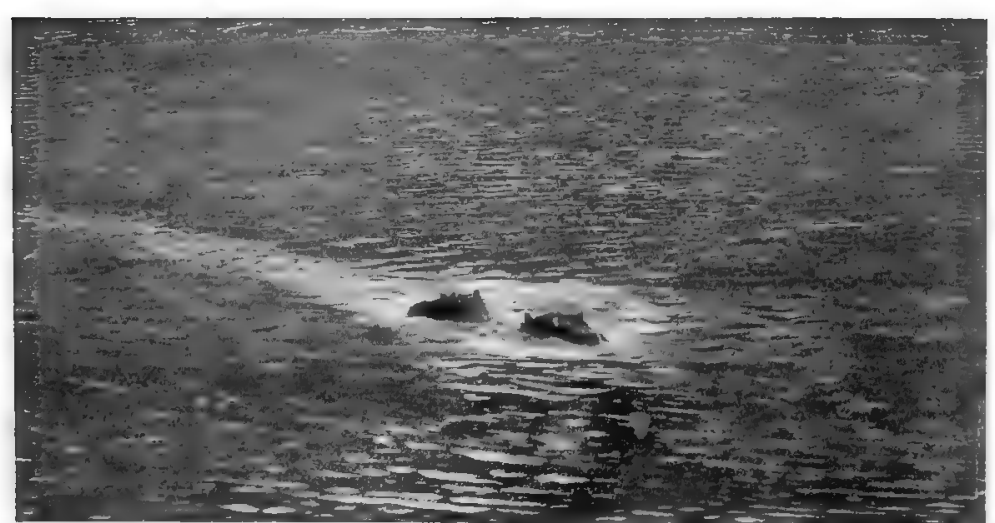

HIPPOPOTAMUSES BATHING

$A$ hippofotumus stays under water for about $21 / 2$ minutes at a time, and then just shows part of its head above water while it draws a fresh breath they often wander far afield, especially in the rainy season, in search of suitable food; and after having been fired at and frightened, I have known a herd of hippopotamuses to travel at least fiveand-twenty miles along the" course of a river during the ensuing night, in order to reach a larger and deeper pool than the one in which they had been molested.

Although the hippopotamus is thoroughly at home in the hottest parts of Africa, and appears to thrive in the tepid waters of all the rivers which flow through the malarious coast regions of the tropical portions of that continent, it is also found at a considerable altitude above the sea, and in quite small streams where the temperature of the water during the winter months cannot be many degrees above freezing-point. I have personally met with hippopotamuses in the Manyami River, not far from the present town of Salisbury, in Mashonaland. The country there has an altitude of about 5,000 feet above sea-level; and the water was so cold on the last occasion on which I came across the animals in question - July, I887 - that, if a basinful was left out during the night, ice quite an eighth of an inch in thickness would be formed over it before morning. There was, however, never any ice on the river itself. During the rainy season, when the grass and reeds are green and succulent, hippopotamuses become enormously fat, especially in the higher and colder portions of their range, and retain a good deal of their fat right through . the driest season of the year. Old bulls are usually very lean; but I have seen cows the greater part of whose carcasses, after the skin had been stripped off, was covered with a layer of fat from $I$ inch to 2 inches in thickness. The meat of these animals is dark red in colour, and more like beef than pork. To my mind, that of a young animal is most excellent in flavour, and far preferable to that of a lean antelope. The fat, when prepared, is as good as the best lard, from which, indeed, it is hardly distinguishable. The skin of the 


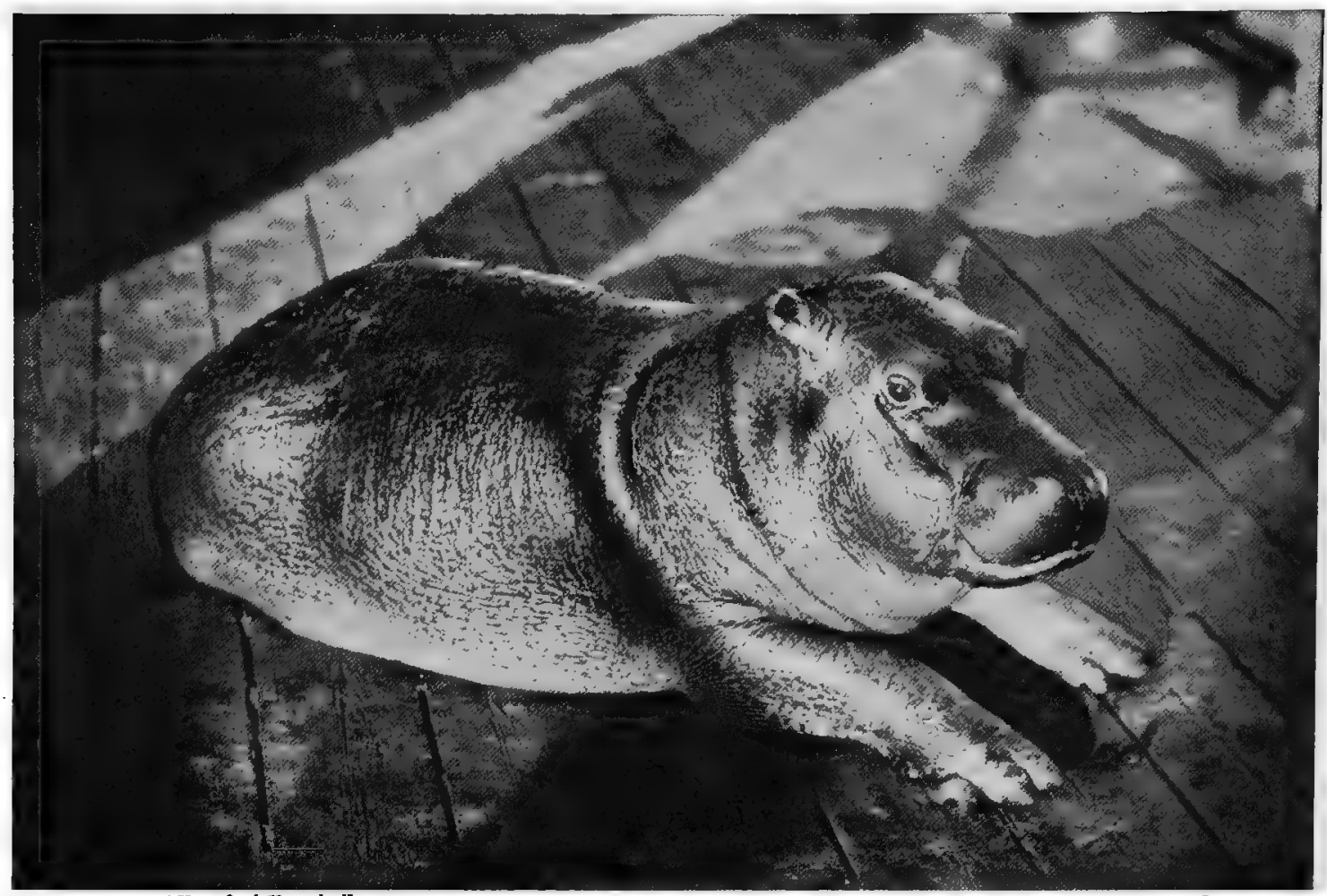

By permission of Herr Carl Hagenbsck]

BABY HIPPOPOTAMUS, AGED SIX MONTHS

The flesh of a young hippopotamus is said to have an excellent flavour. Natives often follow shooting expeditions in order to secure some

hippopotamus is smooth and hairless, and in adult animals quite $I \frac{1}{2}$ inch in thickness on the upper parts of the body.

Hippopotamuses are said to be capable of remaining under water for ten or twelve minutes. Should, however, a herd of these animals be watched but not fired at from the bank of a river in which they are passing the day, they will all sink below the surface of the water as soon as they become aware of and more or less alarmed by the presence of the intruder, but each member of the herd will come up to breathe at intervals of from one to two minutes. I have seen hippopotamuses so tame and unsuspicious of danger that they allowed me - the first human being probably with any kind of hat or clothes on him that they had ever seen - to take up a position within fifty yards of them on the edge of the deep rock-bound pool in which they were resting without showing any signs of alarm. They simply stared at me in an inquisitive sort of way, raising their heads higher out of the water, and constantly twitching their little rounded ears; and it was not until a number of natives came up and began to talk loudly that they took alarm, and, sinking out of sight, retreated to the farther end of the pool. I once took the length of time with my watch for more than an hour that a hippopotamus which I was trying to shoot remained under water. This animal, a cow with a new-born calf, had made an attack upon one of my canoes. It first came up under the canoe, tilting one end of it into the air and almost filling it with water. Then it made a rush at the half-swamped craft, and, laying its huge head over it, pressed it down under the water and sank it. There were four natives in the canoe at the time of the attack, all of whom swam safely to an island in the river - the Zambesi. After the accident - which caused me a good deal of loss and inconvenience - I tried to shoot this unprovoked aggressor, but unsuccessfully, as the river was too broad to allow me to get anything but a long shot at her. The shortest time she remained under water during the seventy minutes I was paying attention 
to her was forty seconds, and the longest four minutes and twenty seconds - the usual time being from two to two and a half minutes. She always remained a long time under water after having been fired at.

The capsizing of canoes by these animals is quite a common occurrence on most African rivers, and the great pains the natives will take in certain districts to give these animals a wide berth seem to prove that they have good reason to dread them. Solitary bulls and cows with young calves are the most feared. Such animals will sometimes, I have been assured by the natives, tear out the side of a canoe with their teeth, and even crunch up some of its occupants whilst they are trying to save themselves by swimming. Sipopo, a chief of the Barotse tribe, who was deposed by his nephew Mona Wena in 1876, was said to have been attacked and killed by a hippopotamus whilst lying wounded amongst the reeds on the southern bank of the Zambesi, but I cannot vouch for the truth of the story.

Bull hippopotamuses must be rather quarrelsome, as I have shot several whose hides were

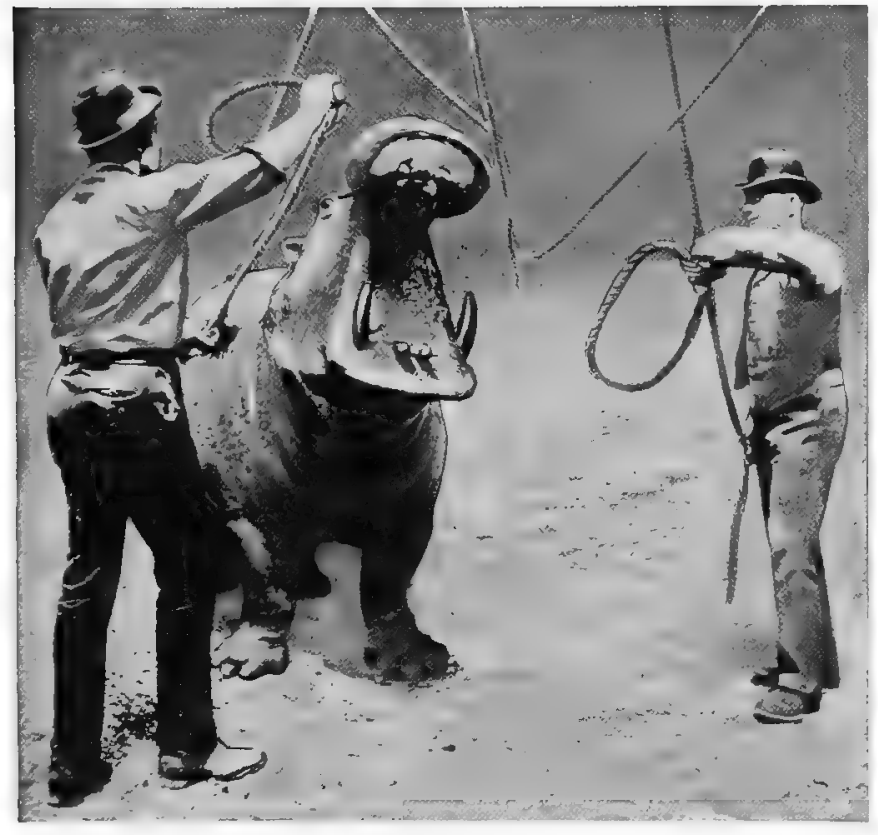

No. I

DENTAL OPERATIONS ON A HIPPOPOTAMUS

This and the next two photographs probably constitute the most remarkable series of animal photographs ever seen. No. I shows a hippopotamus about to be trapped, preparatory to having its teeth attended to of the water with such a furious rush that not only half the body of the dead animal it had attacked was exposed, but the whole of its own head and shoulders came above the water. A bullet through the brain killed it instantly, and it sank to the bottom of the pool, still holding its companion's hind leg fast in its jaws.

When a hippopotamus is killed in the water, the carcase sinks to the bottom, and in the cold water of the rivers of Mashonaland will not rise to the surface till six hours after death. In the warmer water of the Lower Zambesi a dead hippopotamus will come up in about half that time. When it rises, the carcase comes up like a submerged cork, with a rush as it were, and then settles down, only a small piece of the side showing above the surface. As decomposition sets in, it becomes more and more swollen, and shows higher and higher above the water. When the body of a dead hippopotamus has been taken by the wind or current to the wrong side of a river, I have often climbed on to it and paddled it with a stout stick rigit across the river to a spot nearer camp. A dead hippopotamus is not the easiest or the 
pleasantest thing to sit on in deep water with crocodiles about, especially in a wind, as it is very much like sitting on a floating barrel, and unless the balance is exactly maintained one is bound to roll off.

Although it is often necessary for an African traveler to shoot one or more of them in order to obtain a supply of meat for his native followers, there is not much sport attached to the killing of these animals. The modern small-bore rifles, with their low trajectory and great penetration, render their destruction very easy when they are encountered in small lakes or narrow rivers, though in larger sheets of water, where they must be approached and shot from rickety canoes, it is by no means a simple matter to kill hippopotamuses, especially after they have grown shy and wary through persecution. As these animals are almost invariably killed by Europeans in the daytime, and are therefore encountered in the

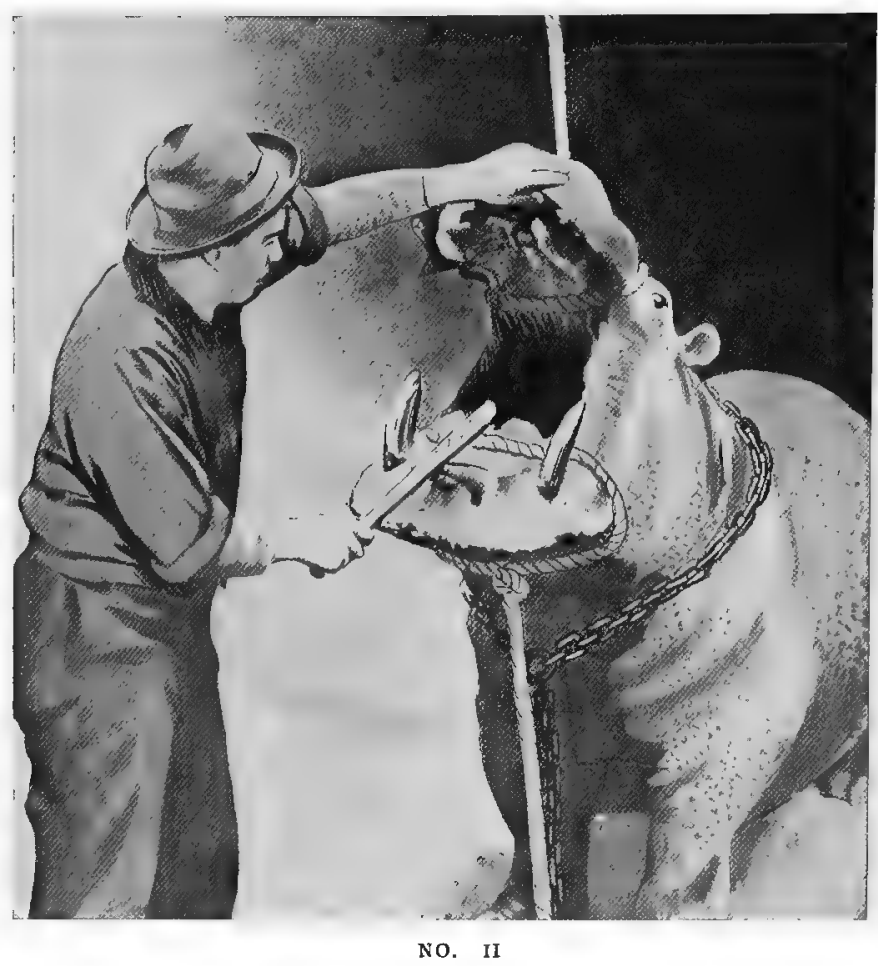

DENTAL OPERATIONS ON A HIPPOPOTAMUS This showes the process of filing one of the lower tusks water, they are usually shot through the brain as they raise their heads above the surface to breathe. By the natives hippopotamuses are killed in various ways. They are sometimes attacked first with harpoons, to which long lines are attached, with a float at the end to mark the position of the wounded animal, and then followed up in canoes and finally speared to

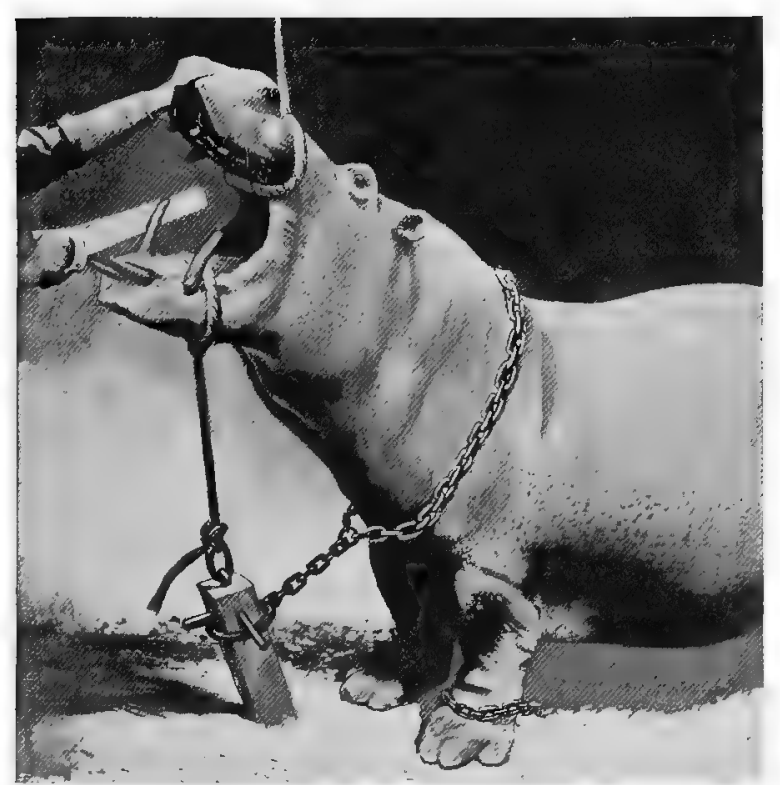

No. III

DENTAL OPERATIONS ON A HIPPOPOTAMUS Sawing off one of the lower tusks death. Sometimes they are caught in huge pitfalls, or killed by the fall of a spear-head fixed in a heavy block of wood, which is released from its position when a line, attached to the weight and then pegged across a hippopotamus's path a few inches above the ground, is suddenly pulled by the feet of one of these animals striking against it. A frieñd of mine once had a horse killed under him by a similar trap set for buffaloes. His horse's feet struck the line attached to the heavily weighted spear-head, and down it came, just missing his head and entering his horse's back close behind the saddle. Where the natives have guns - mostly old muzzleloading weapons of large bore - they often shoot hippopotamuses at close quarters when they are feeding at night. The most destructive native method, however, of killing these monsters with which I am acquainted is one which used to be practised by the natives of Northern Mashonaland - namely, fencing in 


\section{THE IIVING ANIMALS OF THE WORLD}

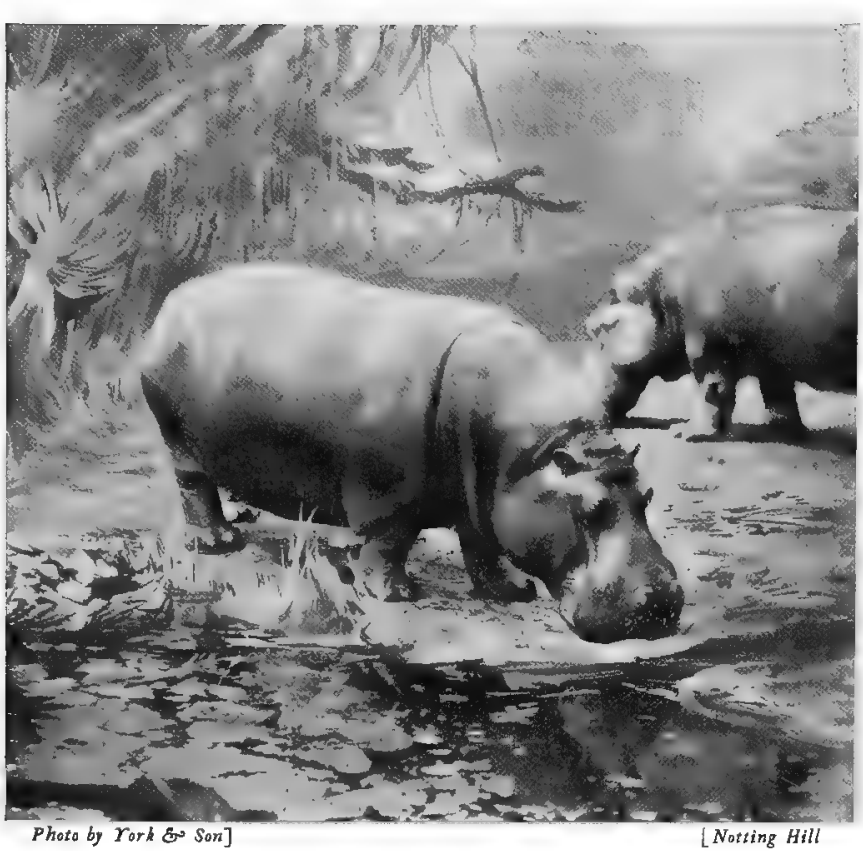

FEMALE HIPPOPOTAMUSES

Exhibits a very characteristic uttitude of the animal a herd of these animals and starving them to death. As there is a very rapid fall in the country through which all the rivers run to the Zambesi from the northern slope of Mashonaland, these streams consist of a series of deep, still pools (called "sea-cow holes" by the old hunters), from a hundred yards to more than a mile in length, connected with one another by shallow, swift-flowing water, often running in several small stroams over the bed of the river. A herd of hippopotanuses having been found resting for the day in one of the smaller pools, all the natives in the district, men, women, and children, would collect ana build strong fences across the shallows at each end. At night large fires would be kept blazing all round the pool and tom-toms beaten incessantly, in order to prevent the imprisoned animals from escaping. Day after day the fences would be

strengthened, and platforms sometimes built to command naturally weak places, and from these points of vantage the poor animals were speared when in their desperation they tried to leave the pool. Gradually the whole herd would be speared or starved to death.

Once, in August, I880, I came upon a native tribe engaged in starving to death a herd of hippopotamuses in a pool of the Umniati River, in Northern Mashonaland. When I came on the scene, there were ten hippopotamuses still alive in the pool. Eight of these appeared to be standing on a sandbank in the middle of the river, as more than half their bodies were above the water. They were all huddled up together, their heads resting on each other's bodies. Two others were swimming about, each with a heavily shafted assegai sticking in its back. Besides these ten still living hippopotamuses two dead ones were being cut up on the side of the pool, and many more must already have been

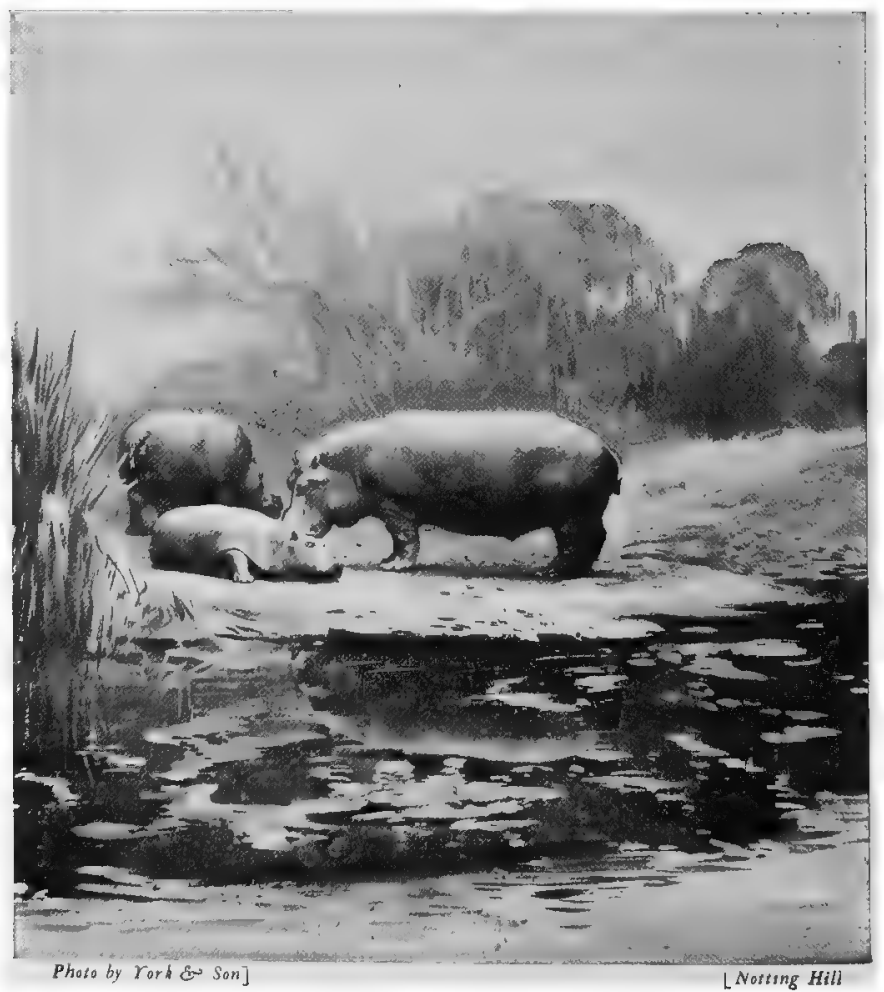

A HIPPOPOTAMUS FAMILY-FATHER, MO'IHER, AND YOUNG

Hippopotamuses are very sociable animals, and are often to be met with in large 


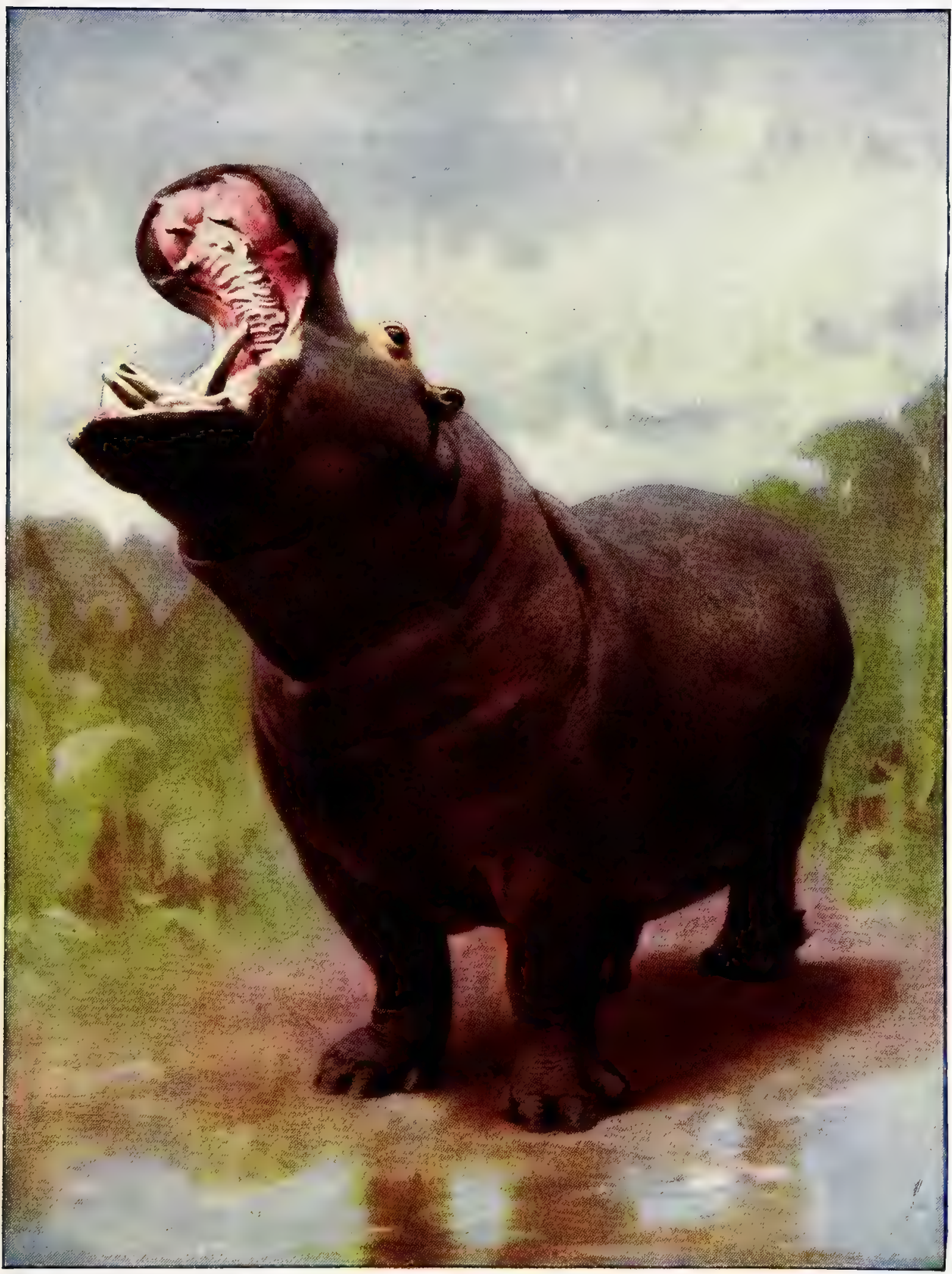

Photo by J. W. McLellan

A. HIPPOPOTAMUS GAPING.

The position of the animal displays the enormous capacity, and likewise the powerful lower tusks: the shortness of the limbs is also well exhibited. 



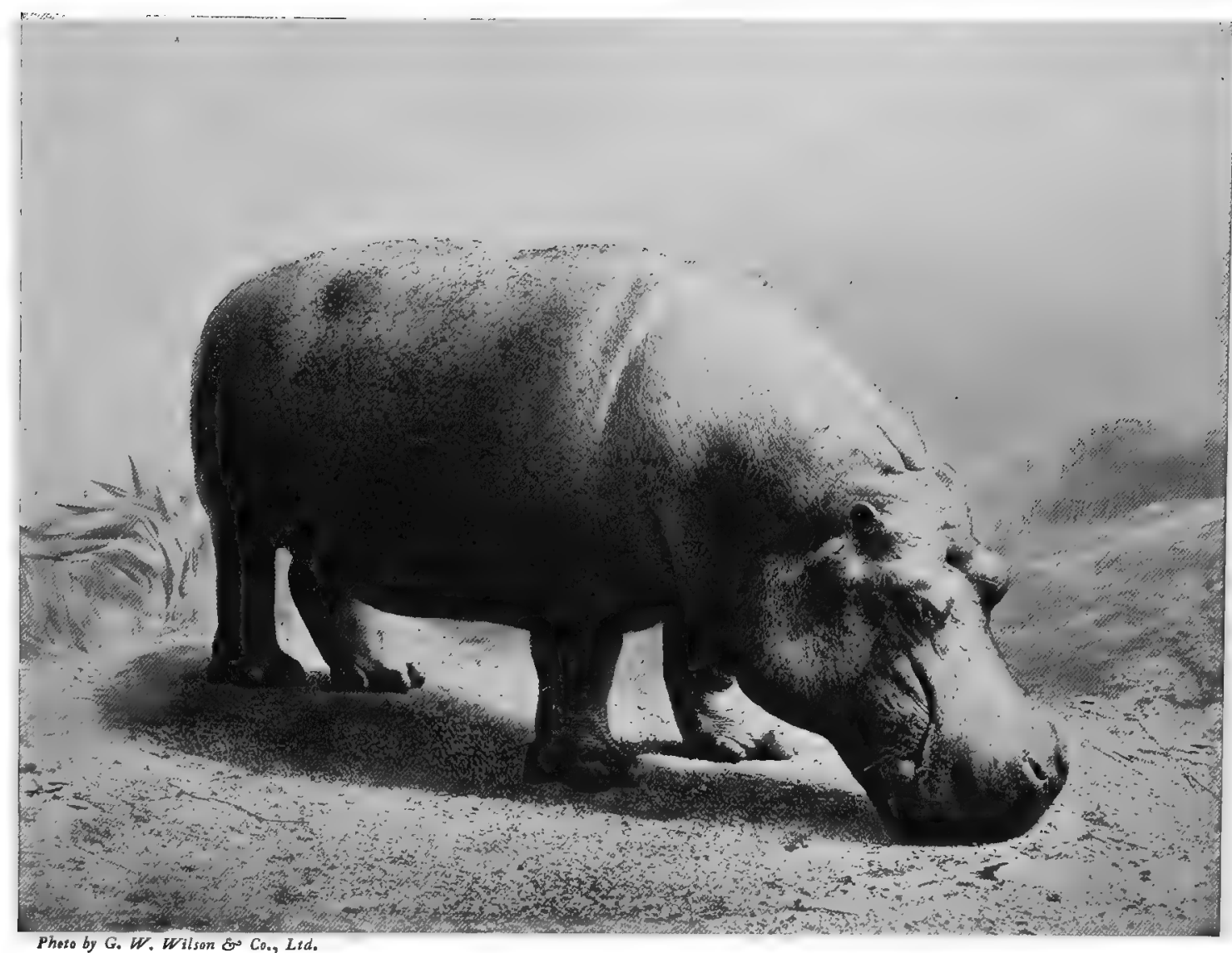

H IPPOPOTAMUS

The skin of the hippopotamus is often as much as an inch and a half in thickness on the upper parts of the body

killed, as all round the pool festoons of meat were hanging on poles to dry, and a large number of natives had been living for some time on nothing but hippopotamus-meat. Altogether I imagine that a herd of at least twenty animals must have been destroyed. Much as one must regret such a wholesale slaughter, it must be remembered that this great killing was the work of hungry savages, who at any rate utilised every scrap of the meat thus obtained, and much of the skin as well, for food; and such an incident is far less reprehensible - indeed, stands on quite a different plane as regards moral guilt - to the wanton destruction of a large number of hippopotamuses in the Umzingwani River, near Bulawayo, within a few months of the conquest of Matabililand by the Chartered Company's forces in I893 These animals had been protected for many years by Lo Bengula and his father Umziligazi before him; but no sooner were the Matabili conquered and their country thrown open to white men than certain unscrupulous persons destroyed all but a very few of these half-tame animals, for the sake of the few paltry pieces of money their hides were worth!

Gradually, as the world grows older, more civilised, and, to my thinking, less and less interesting, the range of the hippopotamus, like that of all other large animals, must become more and more circumscribed; but now that all Africa has been parcelled out amongst the white races of Western Europe, if the indiscriminate killing of hippopotamuses by either white men or natives can be controlled, and the constant and cruel custom of firing at the heads of these animals from the decks of river-steamers all over Africa be put a stop to, I believe that this most interesting mammal, owing to the nature of its habitat, and the vast extent of the rivers, swamps, and lakes in which it still exists in considerable numbers, will long outlive all other pachydermatous animals. Hideous, uncouth, and unnecessary as the hippopotamus 


\section{THE LIVING ANIMALS OF THE WORLD}

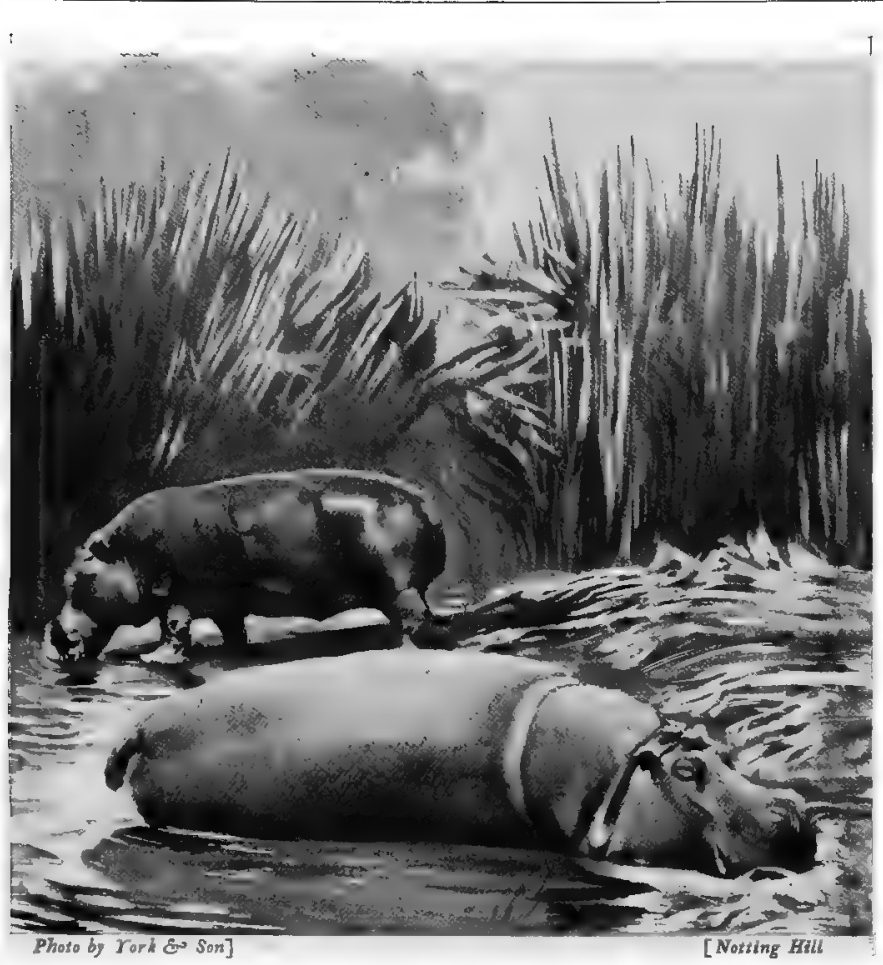

MALE AND FEMALE HIPPOPOTAMUSES

$A$ hippopotamus is almost inseparable from the water; it never goes farther away than possible from a river or lake may seem when viewed from behind the bars of its den in a zoological garden, it is nevertheless true that, when these animals have been banished from an African river by the progress of civilisation, that river has lost one of its highest charms and greatest ornaments.

The Pygmy or Liberian HipPOPOTAMUS is confined to Upper Guinea, and, compared with its only existing relative, is a very small animal, not standing more than 2 feet 6 inches in height, and measuring less than 6 feet in length. In weight a full-grown specimen will scale about 400 lbs. But little is known of the habits of this rare animal, specimens of which, I believe, have never been obtained, except by the German naturalists Herrn Büttikofer and Jentink. When alive, the colour of the skin of the pygmy hippopotamus is said to be of a greenish black, changing on the under-parts to yellowish green. The surface of the skin is very shiny. This species,

unlike its giant relative, does not congregate in herds, nor pass its days in rivers or lakes, but lives in pairs in marshes or shady forests. It sleeps during the day, and at night wanders over a great extent of country, eating grass, wild fruits, and the young shoots of trees. Its flesh is said to be very succulent and much esteemed by the natives.

A hippopotamus, apparently of the same species as that now found in Africa, formerly inhabited the Thames Valley. Great quantities of fossil remains of another species are also found in the island of Sicily. The bones found in England are mainly in the river gravel and brick earth of the south and midland districts of England. This seems to show that at the time when the animal existed our rivers must have been open all the year, and not ice-bound, for it is certain that no hippopotamus could live in a river which froze in winter. Yet among the remains of these animals are also found those of quite arctic species like the Musk-ox and the Reindeer, together with those of the Saiga Antelope, an inhabitant of the cold plateau of Tibet. The problem is: How could these creatures, one a dweller in warm rivers and the others inhabitants of cold arctic or sub-arctic regions, have existed together, apparently on the same area of ground? The answer, which does not seem to have occurred to naturalists who have discussed the question, seems to be plain enough. Any one who knows the conditions of the great rift valleys of Central Africa has the key to the solution of the puzzle. There was probably a very great difference in the vertical plane. Deep in the rift was probably a warm river, while above it may have been mountains from 10,000 to 20,000 feet high, with snow on the summits and glaciers in their valleys. On these cold and arctic heights the reindeer and the musk-ox would find congenial homes. Thousands of feet below, in the hot and narrow valley, the hippopotamus would revel in a warm and steamy climate. This is what actually occurs in the rift valleys of Central Africa, where the hippopotamus swims in rivers that are at no great distance from snow-covered and icecapped mountains. 


\title{
C H A P T E R X X
}

\author{
THE DUGONG, MANATEES, WHALES, PORPOISES, AND DOLPHINS \\ BY F. G, AFLALO, F. Z. S.
}

\section{The Dugong and Manatees}

7 HESE curious creatures, which seem to have been the basis of much of the old mermaid legend, have puzzled many eminent naturalists. Before they were placed in an order by themselves, Linnæus had classed them with the Walrus, Cuvier with the Whales, and another French zoologist with the Elephants. They are popularly regarded as the cows of the sea-pastures. Their habits justify this. I have often watched dugongs on the Queensland coast browsing on the long grasses, of which they tear up tussocks with sidelong twists of the head, coming to the surface to breathe at short intervals.

Omitting the extinct Rhytina, otherwise known as Steller's Sea-cow, which was exterminated in the Bering Strait not very long after civilised man had first learnt of its existence, we have to consider two distinct groups, or genera, of these sirenians. The DUGONG is the representative of the first, and the two MANATEES belong to the other.

The dugong is found on the coasts of Northern Australia, in many parts of the Indian Ocean (particularly off Ceylon), and in the Red Sea. It is easily distinguished, by even superficial observation, from the manatees. Its tail is slightly forked, somewhat like that of the whales: the tail of manatees, on the other hand, is rounded. The dugong's flippers, to which we also find a superficial resemblance in those of the whale, show no traces of external nails: in those of the manatees, which show projecting nails, there is a considerable power of free movement (the hands being, in fact, used in manipulating the food), which is not the

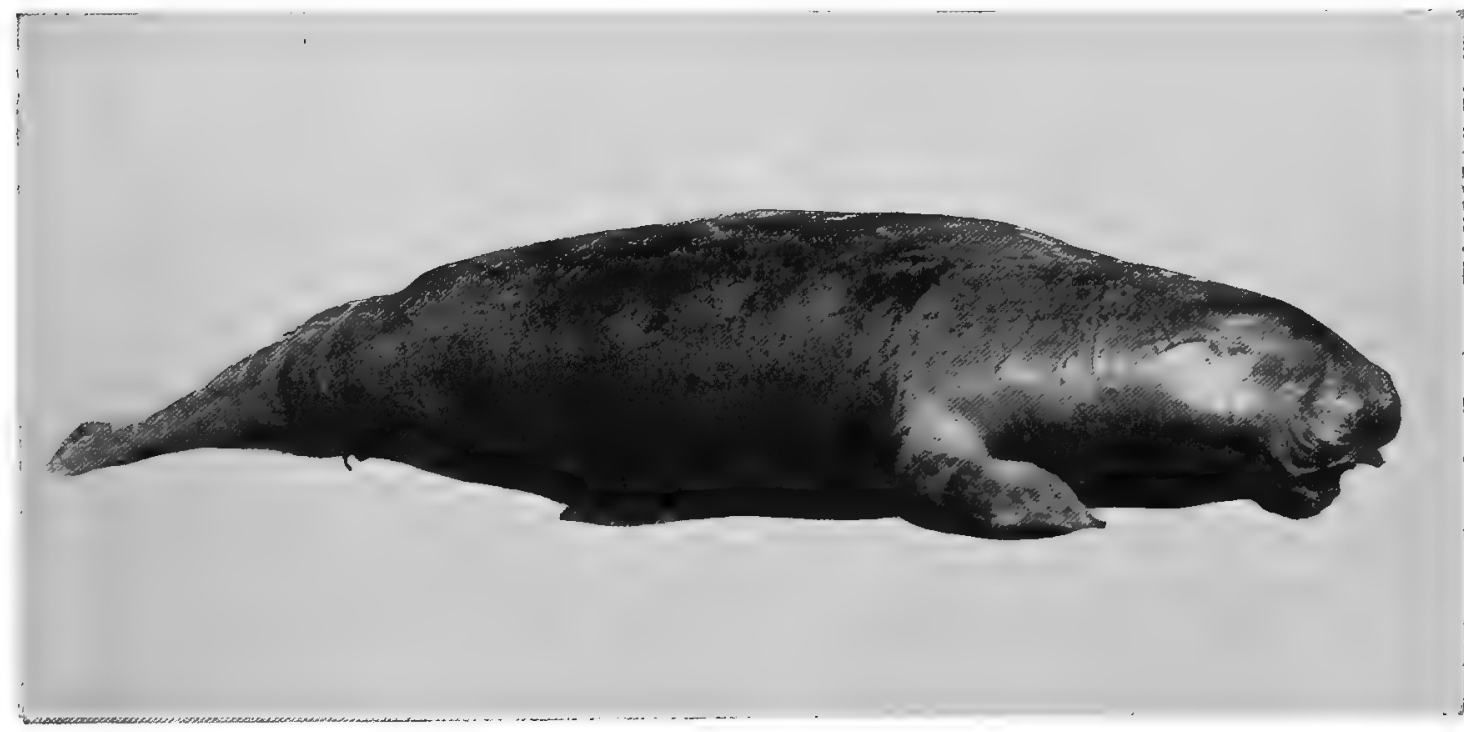

photo by $A$. S. Rudlana \&o Sons

\section{DUGONG}

A vegetable-feeding sea-mammal from the Indian Ocean and North Australian waters 


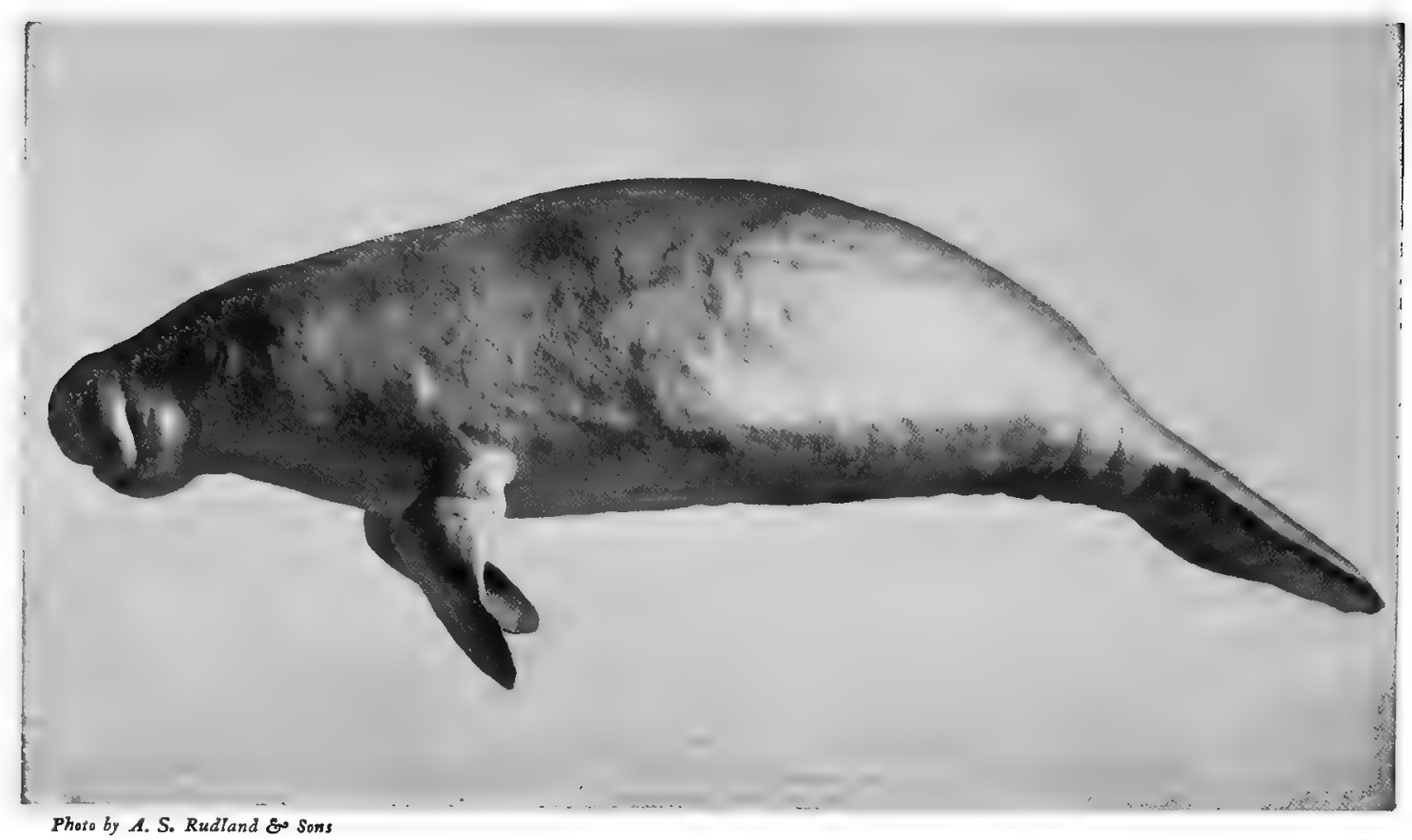

AMERICAN MANATEF,

Found in the Amazons River. The Manatees differ remarkably from the Dugong in the number and structure of their teeth

case in the limbs of the whale. The body of the dugong is almost smooth, though there are bristles in the region of the mouth: that of the manatees is studded with short hairs. The male dugong has two large tusks: in neither sex of the manatees are such tusks developed. Finally, a more detailed examination of the skeletons would reveal the fact that, whereas the dugong has the usual seven bones in the neck, that of the manatees has only six.

When we come to the Whales, we shall encounter that very characteristic covering known as "blubber"; and, though it is present in smaller quantity, these sirenians have blubber as well. Complex stomachs they also have, like the whales, only in their case both the nature of the food and the structure of the teeth point clearly to a ruminating habit, which, for reasons that will be given in the right place, seems inadmissible in the whales. In both dugong and manatees the mouth is furnished with singular horny plates, the precise use of which does not appear to have been satisfactorily determined; and the upper lip of the manatee is cleft in two hairy pads that work laterally. This enables the animal to draw the grass into its mouth without using the lower lip at all.

In their mode of life the dugong and manatees differ as widely almost as in their appearance; for the former is a creature of open coasts, whereas the manatees hug riverestuaries and even travel many miles up the rivers. Of both it has been said that they leave the water at night, and the manatees have even been accused of plundering crops near the banks. The few, however, which have been under observation in captivity have always been manifestly uncomfortable whenever, by accident or otherwise, the water of their tank was run off, so that there is not sufficient reason for believing this assertion.

This group of animals cannot be regarded as possessing any high commercial value, though both natives and white men eat their flesh, and the afore-mentioned rhytina was, in fact, exterminated solely for the sake of its meat. There is also a limited use for the bones as ivory, and the leather is employed on a small scale, - a German writer has, in fact, been at great pains to prove that the Tabernacle, which was 300 cubits long, was roofed with dugong* skin, and the Red Sea is certainly well within the animal's range. 


\section{The Whales, Porpoises, and Dolphins}

Although anatomists have good reason for suspecting that all the members of the Whale Tribe are directly descended from river-dwelling forms, if not indeed, more remotely, from some land animal, there is something appropriate in the fact of the vast ocean, which covers something like three-quarters of the earth's surface, producing the mightiest creatures which have ever lived. There should also be some little satisfaction for ourselves in the thought that, their fish-like form notwithstanding, these enormous beings really belong to the highest, or mammalian, class of animal life.

One striking feature all these many-sized cetaceans have in common, and that is their similarity of form. Though they may vary in length from 70 to $7 \mathrm{feet}$, their outline shows a remarkable uniformity. Important internal and even external differences there may be. A whale may be toothed or toothless; a dolphin may be beaked or round-headed; either may be with or without a slight ridge on the back or a distinct dorsal fin; but no cetacean could well be mistaken for an animal of any other order. It is as well to appreciate as clearly as possible this close general resemblance between the largest whale and the smallest dolphin, as the similarity is one of some interest; and we may estimate it at its proper worth if we bear in mind that two species of cetaceans, outwardly alike, may not, perhaps, be more closely allied than such divergent ruminant types as the elephant, the giraffe, and the gazelle.

Reference has already been made to the fact that the whales are true mammals, and we must now clearly set before us the justification for scparating them from the Fishes - to which any one with a superficial knowledge of their habits and appearance would unhesitatingly assign them and raising them to the company of other mammals. Let us first separate them from the Fishes. The vast majority of fishes, with some familiar exceptions like the conger-eel, are covered with scales: whales have no scales. The tail of fishes, often forked like that of whales, is set vertically: in whales the tail is set laterally, and for this a good reason will presently be shown. Fishes have anal fins: whales not only have no anal fins, but their so-called pectoral fins differ radically from the fins of fishes. Fishes breathe with the aid of gills: whales have

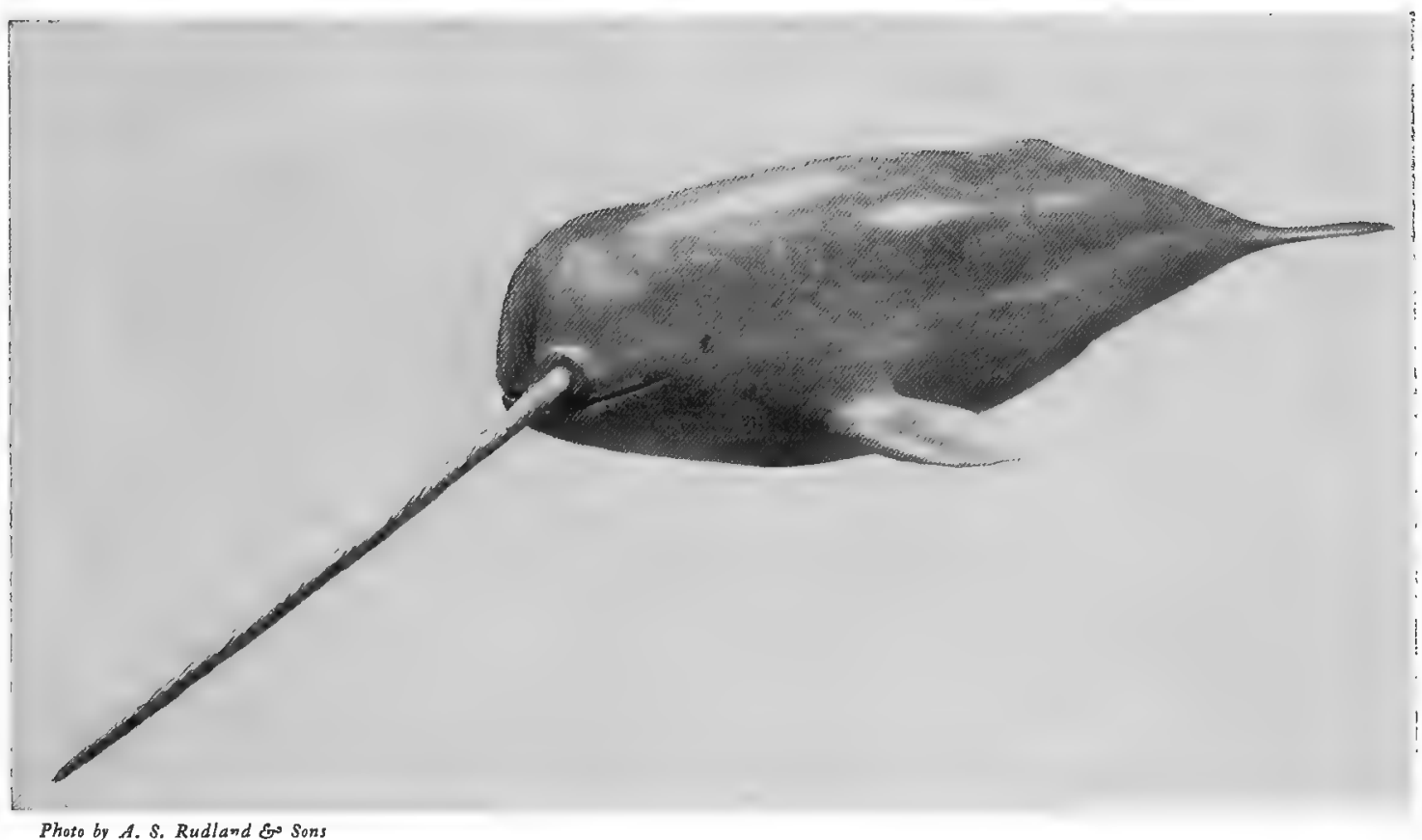

Photo by A. S. Rudland EN Sons 
no gills. Fishes, in the vast majority of cases, reproduce their young by spawning, the eggs being left to hatch out either in gravel-beds or among the water-plants, lying on the bottom (as in the case of the herring), or floating near the surface (as in that of the plaice): whales do not lay eggs, but bear the young alive. This brings us to the simple points of resemblance between them and other mammals. When the young whale is born, it is nourished on its mother's milk. This alone would constitute its claim to a place among the highest class. Whales breathe atmospheric air by means of lungs. Hair is peculiarly the covering of mammals, just as scales are characteristic of fishes and feathers of birds. Many whales, it is true, have no

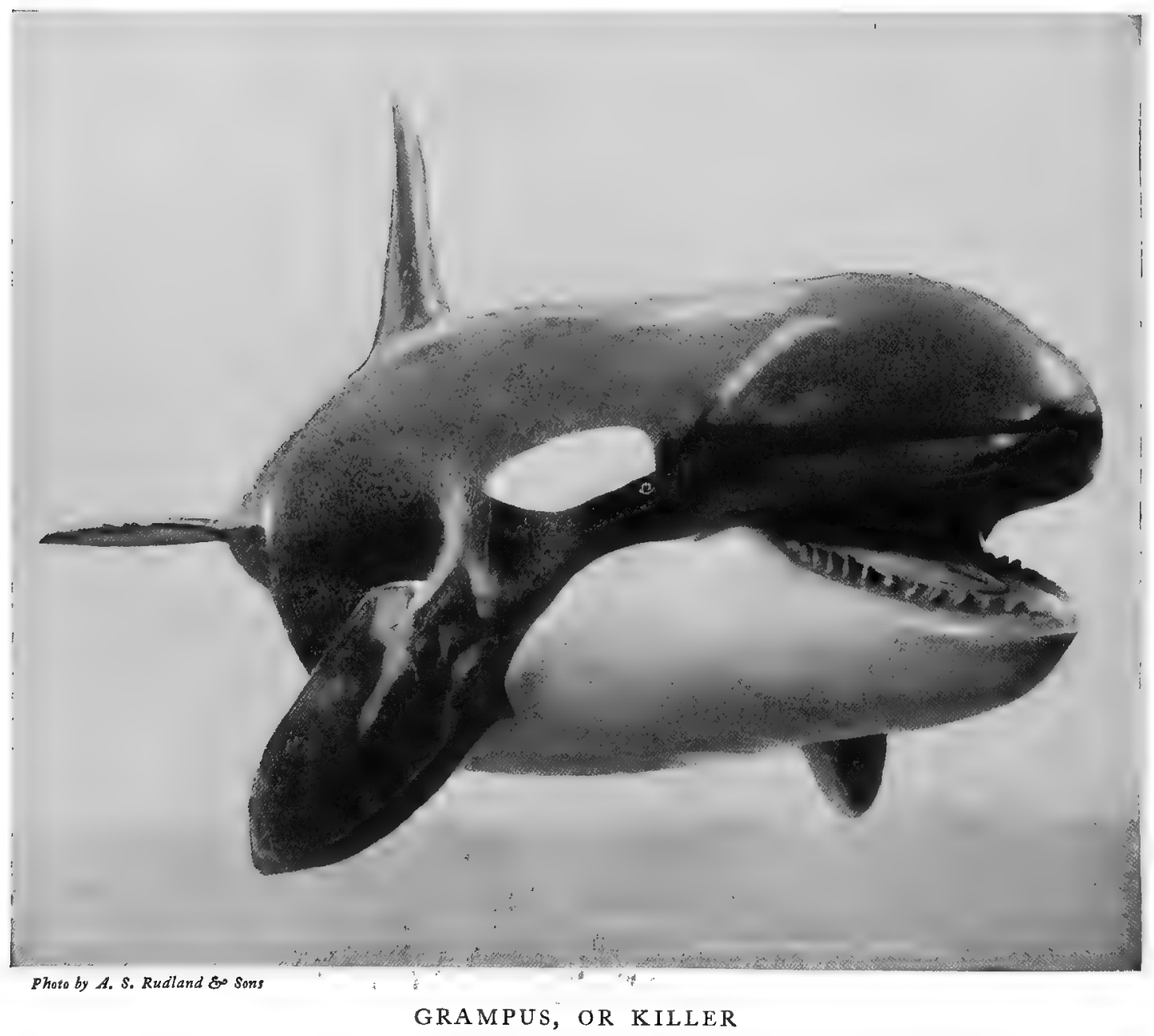

A carnivorous cetacean with large teeth, often found in the North Sea

hair; but others, if only in the embryonic stage, have traces of this characteristic mammalian covering. It must, moreover, be remembered that in some other orders of mammals the amount of hair varies considerably - as, for instance, between the camel and rhinoceros.

Having, then, shown that whales are mammals, we must now determine the chief features of the more typical members of the order. The extremities of whales are characteristic: a large head, occupying in some species as much as one-third of the total length; and the afore-mentioned forked, or lobed, tail set laterally. The flippers, which bear only a slight resemblance to the pectoral fins in fishes, are in reality hands encased in swimminggloves. In some whales these hands are five-fingered, in others the fingers number only four, 
but many of the fingers contain more bones than the fingers of man. In some whales we find a dorsal fin, and this, as also the flippers, acts as a balancer. In no whale or porpoise is there any external trace of hind limbs, but the skeleton of some kinds shows in varying stages of degradation a rudimentary bone answering to this description. Perhaps, however, the most distinctive feature of whales is the blow-hole, situated, like the nostrils of the hippopotamus, on the upper surface of the head, and similarly enabling the animal to breathe the air without exposing much of its head above the surface of the water. The blow-hole (or blow-holes, for whalebone-whales have two) may be said to take the place of nostrils as regards the breathing, though perhaps no sense of smell is included in its functions. In the Sperm-whale, or Cachalot, there is a single $\boldsymbol{\omega}$-shaped blow-hole near the end of the snout. The well-known spouting of whales is merely the breathing out of warm vapour, which, on coming in contact with the colder air - and it should be remembered that most whaling is carried on in the neighbourhood of icebergs - condenses in a cloud above the animal's head. I have seen many a sperm-whale spout, and the cloud of spray, often mixed with a varying volume of water if the whale commences to blow before its blow-hole is clear of the surface, drifts forward over the forehead. This is due to the forward position of the blow-hole. I never to my knowledge saw a whalebone-whale spouting, but its double jet is said to ascend vertically over its back, and this would in like manner be accounted for by the more posterior position of the blow-holes. Having filled its lungs, which are long and of simple structure, with fresh air, in enormous draughts that fill the great cavities of its chest, the whale sinks to the depths. There, in ordinary circumstances, it will lie for a quarter of an hour or more, but the pain of the harpoon and the knowledge that there is danger at the surface may keep it below for as much as an hour. When it has to breathe again, a few powerful strokes from the laterally set tail suffice to bring it quickly to the surface. This is not the place for a detailed anatomy of the whale, but no one can fail to notice with admiration such parts of its equipment for the battle of life as the structure of its windpipe, which enables it to breathe with comfort with its mouth full of water, the complicated network of blood-vessels that ensures the slow and thorough utilising of all the oxygen in its lungs while it remains at the bottom, and the elastic cushion of blubber that makes this gigantic animal indifferent to extremes of pressure and temperature. Thanks mainly to its coat of blubber, the whale exists with equal comfort at the surface or hundreds of fathoms below it; in the arctic or in tropical seas.

It is not perhaps in keeping with the plan of this work that we should consider in detail the soft parts of the whale's inside. One or two parts of its feeding and digestive mechanism may, however, offer some points of passing interest. The complex stomach, which is divided into chambers, like that of the ruminants already described, has suggested that the latter function

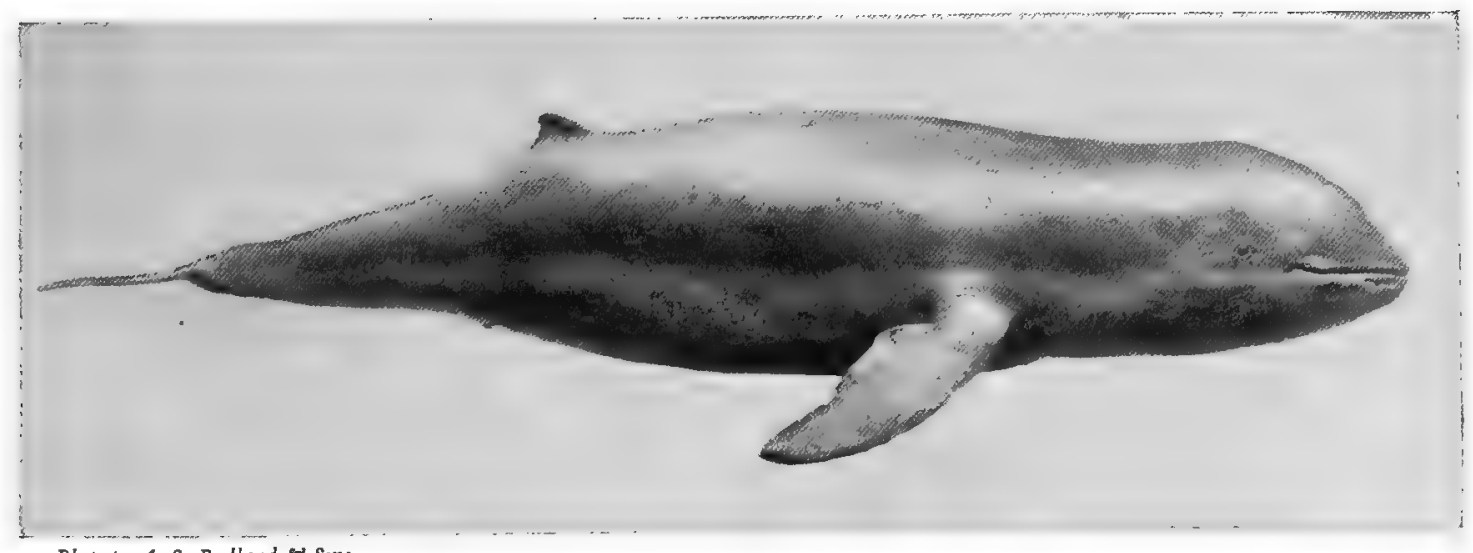

Photo by A. S. Rudland of Sons

SHORT-BEAKED RIVER-DOLPHIN

In this type the head is produced into a beak, supported in the upper jaw by a mass of ivory-like bone 
may in a modified process be performed by whales. It is, however, evident that the teeth of toothed whales are in no way adapted to the act of mastication, which is inseparable from any conception of ruminating, while the toothless whales have as complicated a stomach as the rest. Mr. Beddard, writing on the subject in his interesting "Book of Whales," takes the more reasonable view that the first chamber of the stomach of whales should be regarded rather as a storehouse in which the food is crushed and softened. The teeth of whales, the survival of which in the adult animal offers the simplest basis of its classification under one or other of the two existing groups, or sub-orders, are essentially different from the teeth of many other kinds of mammals. It cannot, perhaps, be insisted that the distinctive terms employed for these two categories of whales are wholly satisfactory. For instance, the so-called "toothless" whales have distinct teeth before birth, thus claiming descent from toothed kinds. On the other hand, the so-called " toothed" whales are by no means uniformly equipped in this respect, some of the porpoises having as many as twenty-six teeth, distributed over both jaws, while the bottlenoses have no more than two, or at most four, and these in the lower jaw only. Only the lower jaw, in fact, of the great sperm-whale bears teeth that are of any use, though there are smaller and functionless teeth in the gums of the upper. The teeth of whales, by the way, are not differentiated like our canines and molars, but are all of one character. Although, in "toothless" whales, the fœtal teeth disappear with the

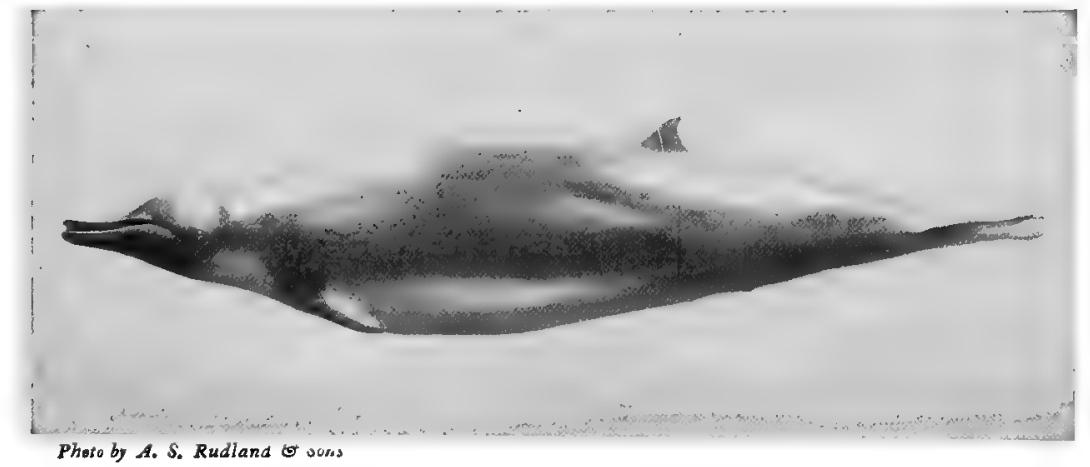

SOWERBY'S BEAKED WHALE

One of the rarest of whales. It probably inhabits the open seas coming of the baleen, or whalebone, the latter must not, in either structure or uses, be thought to take their place. The plates of whalebone act rather as a hairy strainer. Unless we seek a possible analogy at the other end of the mammalian scale, in the Australian duckbill, the feeding of the whalebone-whales is unique. They gulp in the water, full of plankton, swimming openmouthed through the streaks of that substance. Then the huge jaws are closed, and the massive tongue is moved slowly, so as to drive the water from the angles of the mouth through the straining-plates of baleen, the food remaining stranded on these and on the tongue. The size and number of the baleen-plates appear to vary in a degree not yet definitely established; but there may, in a large whale, be as many as between 300 and 400 on either side of the cavernous mouth, and they may measure as much as Io or 12 feet in length and 7 or 8 fect in width.

An enumeration of such whales and porpoises and dolphins as have at one time or other been stranded on the shores of the British Isles may serve as an epitome of the whole order. Only one interesting group, in fact - the River-dolphins of the Ganges and Amazons is unrepresented in the list. Whales, either exhausted or dead, are periodically thrown up on our coasts, even on the less-exposed portions - one of the most recent examples in the writer's memory being that of a large specimen, over 60 feet long, stranded on the sands near Boscombe, in Hampshire, and the skeleton of which at present adorns Boscombe Pier. It was one of the rorquals, or finbacks, probably of the species called after Rudolphi; but the skeleton is imperfect, though its owner, Dr. Spencer Simpson, appears to have preserved some details of its earlier appearance. It should be remembered that many of the following can only be regarded as "British" with considerable latitude, the records of their visits being in 
some cases as rare as those of the rustic bunting and red-necked nightjar among birds, or of the derkio and spotted dragonet among fishes.

British zoologists, however, usually include the following:-WHALEBONE-WHALES : Southern Right-whale; Humpback; Finbacks, or Rorquals。 Toothed Whales : Sperm-whale, or Cachalot ; Narwhal; Beluga, or White Whale; Grampuses; Beaked Whale; Broad-fronted Whale ; Cuvier's Whale; Sowerby's Whale; Pilot-whale; Porpoise; Dolphin; White-sided Dolphin ; White-beaked Dolphin; Bottlenose.

A selection may therefore be made of five of the most representative of these species - the Southern Whale, the Cachalot, the Narwhal, the Porpoise, and the Dolphin.

The SOUTHERN WHALE, which, in common with the closely allied polar species, whalingcrews call "right," seeing that all other kinds are, from their point of view, "wrong," is probably the only right-whale which has ever found its way to our shores. Some writers include the Greenland Right-whale, but their authority for this is doubtful. It is said to grow to a length of at any rate 70 feet, though 55 feet would perhaps be more common for even large specimens. In colour it is said to be dark above, with a varying amount of white or grey on the flippers and under-surface. The head and mouth are very large, occupying in some cases one-third of the total length, and the baleen-plates measure as much as 8 or ro feet in length and, 5 or 6 feet in width. The species has no back-fin, but there is a protuberance on the snout, known technically as the "bonnet." This whale appears to give birth to its single calf some time in the spring months, and the mother shows great affection for her offspring. The HUMPBACK is distinguished from the right-whales externally by its longer flippers and the prominence on its back, and internally by the fluted skin of the throat. The FINNERS, or RoRQUALs, have a distinct back-fin. They feed on fishes and cuttles, and I have more than once known a rorqual, which looked fully 50 feet long (comparing it roughly with my 24-foot boat), to swim slowly round and round my lugger, down on the Cornish coast, puffing and hissing like a torpedo-boat on its trial trip, rounding up the pilchards in a mass, and every now and then dashing through them open mouthed with a terrific roar, after several of which helpings it would sink out of sight and not again put in an appearance.

The SPERM-Whale, or CACHALOT, may serve as our type of the toothed whales. It attains to the same great dimensions as the largest of the whalebone group. A more active

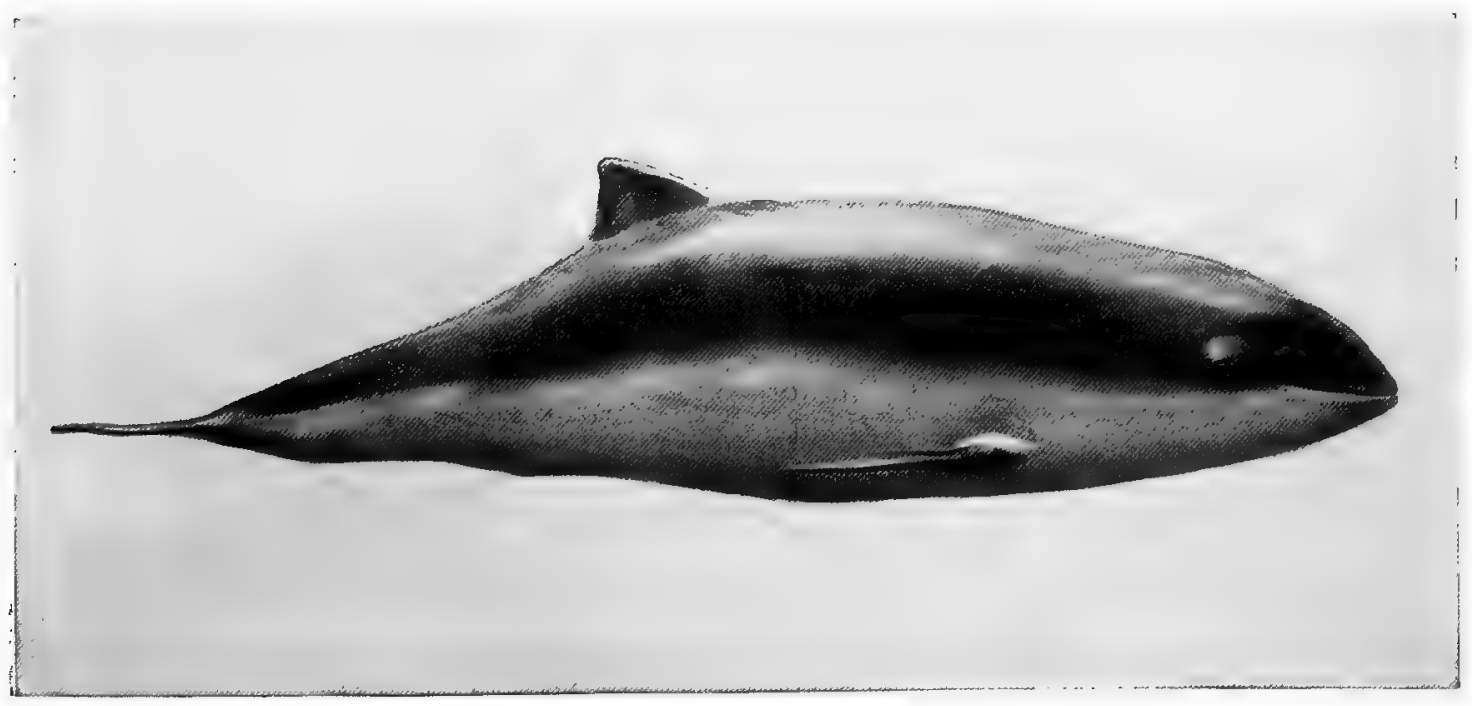

Pboto by A. S. Rudland E' Sons

From 4 to 5 feet long. It lives in "schools," or companies, and pursues the herrings and mackerel 
animal for its size could scarcely be conceived; and I have seen one, in the Indian Ocean, fling itself three or four times in succession out of water like a salmon, striking the surface each time as it fell back with a report like that of a gun. No one appears to have explained whether performances of this sort are due to mere playfulness, or, as seems more probable, to the attacks of parasites or such larger enemies as sharks or "killers." I have also seen four thresher-sharks leaping out of water, and falling with a loud blow on the whale's back; but the victim lay quite still in this case, and may in fact have been worn out before we came upon the scene. I wish to add that I took the word of the skipper, himself an old whaling-captain, for their identity as threshers. The dazzling sun shone full on them, and on the sea between, and it was impossible, even with the ship's telescope, to recognise them
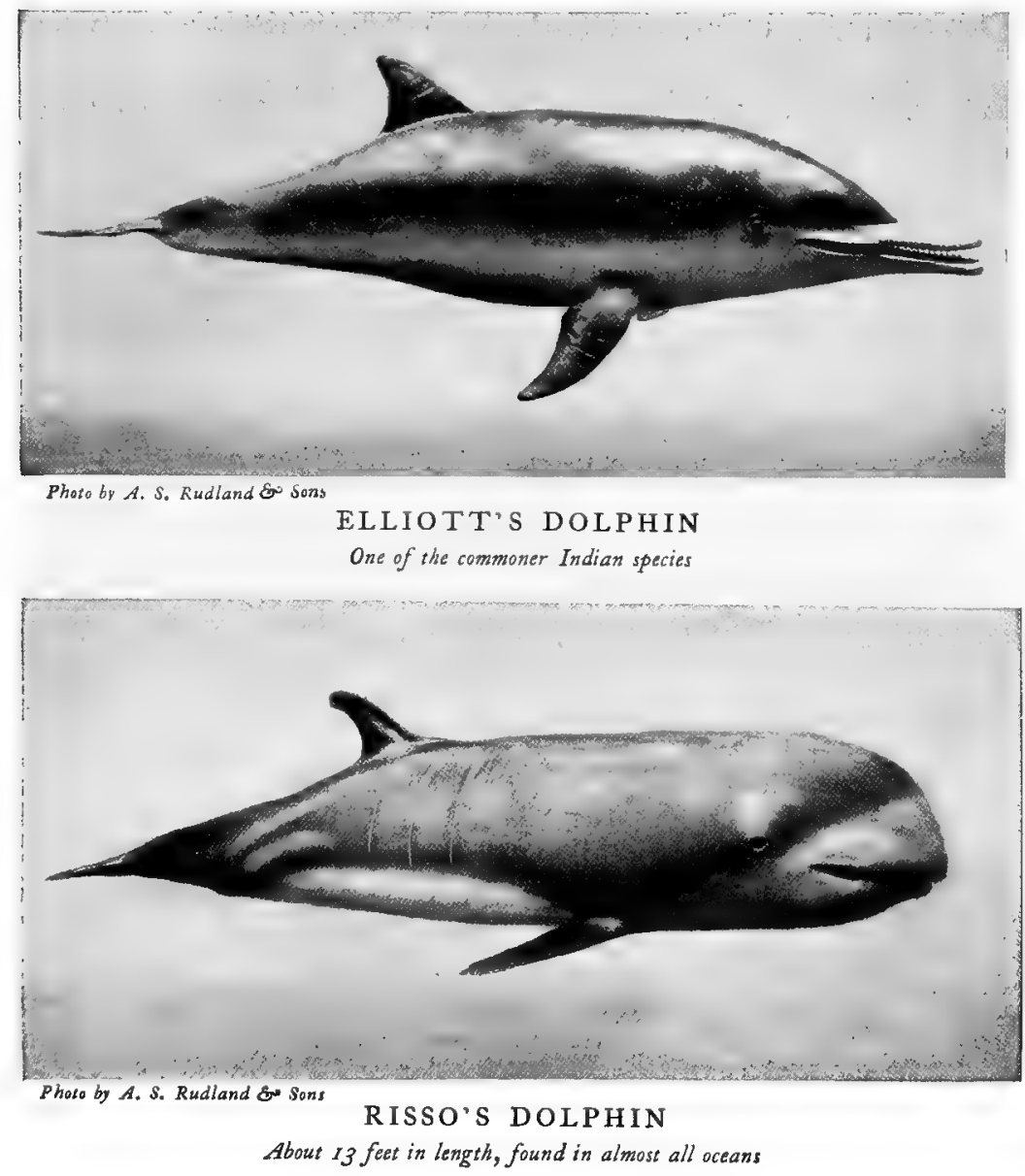
with any accuracy. The cachalot has a very different profile from what any one who had seen only its skull in a museum would be led to. expect, for the spermcavity in the forehead is not indicated in the bones. The structure of the head enables the animal to drop the lower jaw almost at right angles to the upper; and $\mathrm{Mr}$. Frank Bullen quotes, in his fascinating "Cruise of the Cachalot," the current belief that it does so to attract its prey by the whiteness of its teeth and palate. Although both fishes and cephalopods are very curious, even to their own destruction, it is doubtful. whether the whale could not catch its food more rapidly by swimming open-mouthed through the acres of floating squid: encountered all over the warmer waters of the ocean.

The NARWHAL, an arctic type, may be distinguished from all other cetaceans by the singlespiral tusk in the left side of the head of the male. Sometimes the right tusk grows as. well, and either may attain a length of as much as 8 feet; but in the female both teeth remain undeveloped.

The COMMON PORPOISE of our own seas, distinguished by its rounded head from the equally common beaked dolphin, is too familiar to need much description. It grows to a length of 5 or 6 feet, and is dark in colour on the back and white beneath. Its conspicuous back-fin is always recognisable when it gambols with a herd of its fellows; and a line of these sea-pigs, a mile or so in length, is no uncommon sight, their presence inshore being indicative on some parts of the coast of the coming of east wind. The porpoise, which has, 
like many of its group, teeth in either jaw, is a voracious feeder, preying in estuaries on salmon and flounders, and on more open parts of the coast on pilchards and mackerel. It is occasionally a serious nuisance in the Mediterranean sardinefisheries, and I have known of the fishermen of Collioure, in the Gulf of Lyons, appealing to the French Government to send a gunboat from Toulon that might steam after the marauders and frighten them away. One of the most

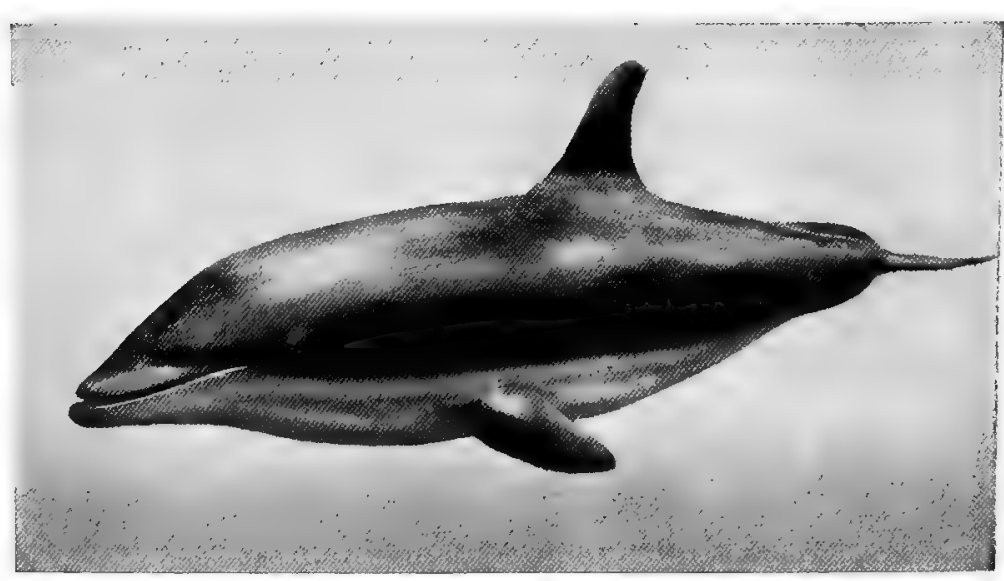

Photo by A, S, Rudland o Sons

BOTTLE-NOSED DOLPHIN

From 8 to 9 feet long, found from the Mediterranean to the North Sed remarkable cases of a feeding porpoise that I can recall was that of one which played with a conger-eel in a Cornish harbour as a cat might play with a mouse, blowing the fish 20 or 30 feet through the air, and swimming after it so rapidly as to catch it again almost as it touched the water.

The Dolphin, which is in some seasons as common in the British Channel as the more familiar porpoise, is distinguished by its small head and long beak, the lower jaw always carrying more teeth than the upper. It feeds on pilchards and mackerel, and, like the porpoises, gambols, particularly after an east wind, with its fellows close inshore. There are many other marine mammals somewhat loosely bracketed as dolphins. RISSO'S DOLPHIN, for instance, a rare visitor to our coasts, has a striped skin, and its jaws are without teeth, which distinguish it from the commion dolphin and most of the others. It cannot therefore feed on fishes, and most probably eats squid and cuttle-fish. The BOTTLE-NOSED DOLPHIN, a species occurring in the greatest numbers on the Atlantic coast of North America, is regularly hunted for its oil. HEAvyside's Dolphin, which hails from South African waters, is a smaller kind, chiefly remarkable for the curious distribution of black and white on its back and sides.

A word must, in conclusion, be said on the economic value of the whales. Fortunately, as they are getting rarer, substitutes for their once invaluable products are being from time to time discovered, and much of the regret at their extermination by wasteful slaughter is sentimental and not economic. For whalebone it is not probable that a perfect substitute will ever be found. It therefore maintains a high price, though the former highest market value of over $\$ 10,000$ per ton has fallen to something nearer the half. The sperm-oil from the sperm-whale,

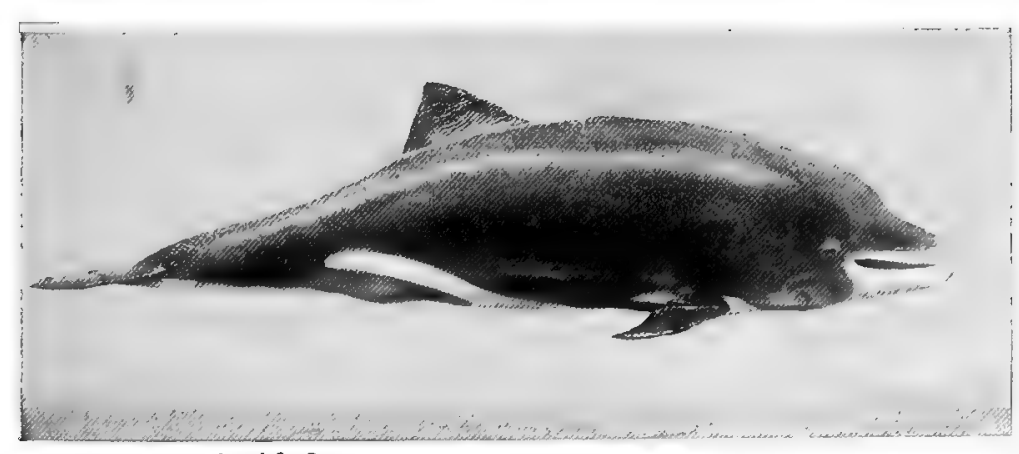

Photo by A. S. Rudiand है Sons

HEAVYSIDE"S DOLPHIN

A small, peculiarly coloured species from the Cape and the train oil from that of the right-whales, the spermaceti out of the cachalot's forehead and the ambergris secreted in its stomach, are the other valuable products. Ambergris is a greyish, fatty secretion, caused by the irritation set up in the whale's inside by the undigested beaks of cuttle-fish. Its market price is about $\$ 25$ per ounce. A lump of 240 lbs. sold for nearly $\$ 100,000$. 


\section{H A P T E R X X I}

\section{THE SLOTHS, ANT-EATERS, AND ARMADILLOS}

BI* W. P. PYCRAFT, A, L. S., F. Z. S.

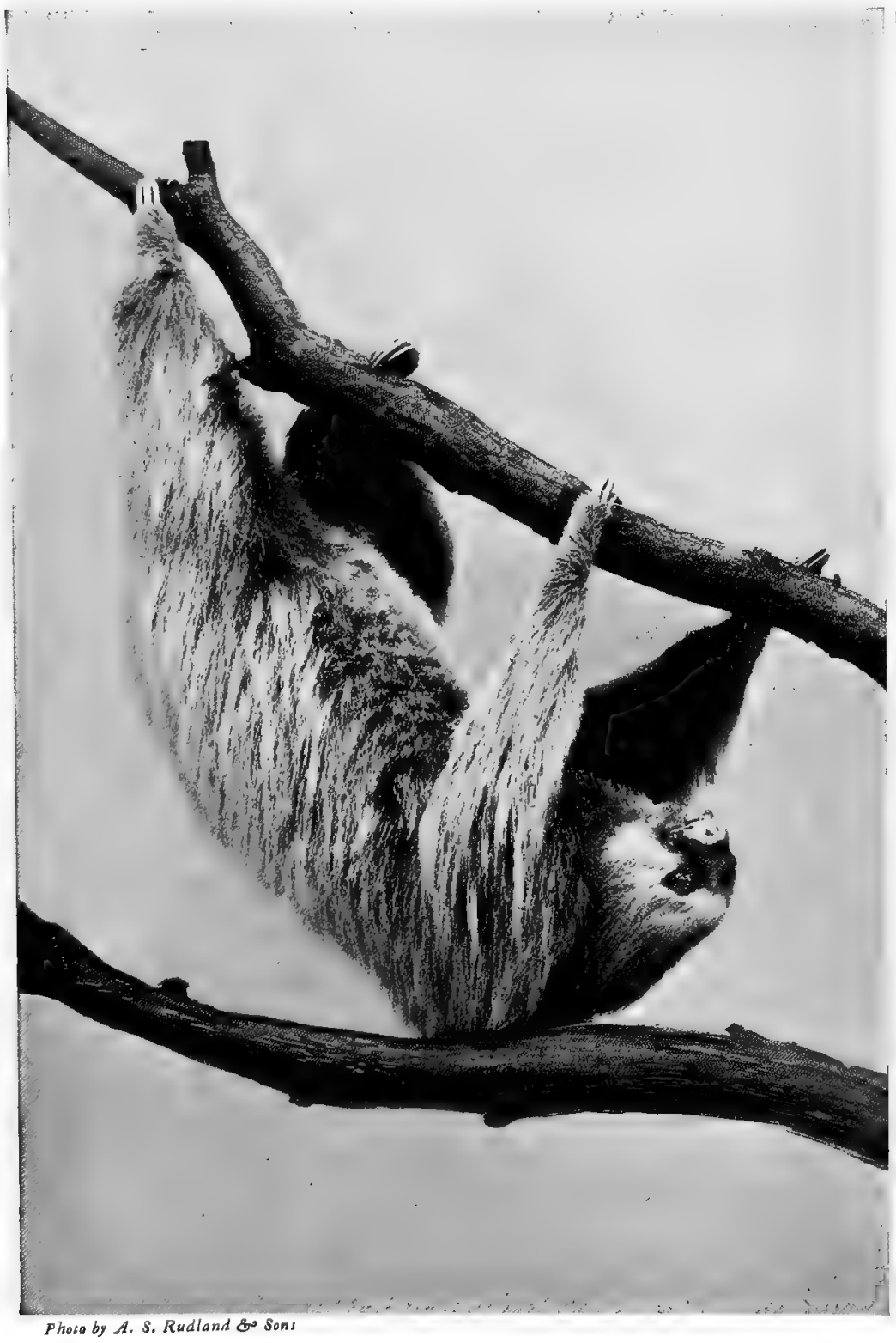

NORTHERN TWO-TOED SLOTH (COSTA RICA)

This is also known as Hoffmann's Sloth. The appellation " two-toed" refers to the fore limb only. The hind foot has three toes

hideous. The mode of life of the sloth is certainly remarkable for almost its whole is passed among the highest trees of the densest South American forests, and passed, too, in
THE very remarkable assemblage of animals we are now about to consider includes many diverse forms, bracketed together group; and this on account of the peculiarities of the structure and distribution of the teeth, which are never present in the front of the jaw, and may be absent altogether. Of the five groups recognised, three occur in the New and two in the Old World. All have undergone vely considerable modification of form and structure, and in every case this modification has tended to rencer themmoreperfectlyadapted to an arboreal or terrestrial existence. Flyingor aquatic types are wanting. Whilst one great group the Sloths - is entirely vegetarian, the others feed either on flesh or insects.

\section{The Sioths}

In the matter of personal appearance Nature has not been kind to the Sloth, though it is certainly true that there are many uglier animals - not including those, such as some of the Monkey Tribe and certain of the Swine, which are positively almost its whole existence 300 to constitute one great 
a perfectly topsy-turvy manner, inasmuch as it moves from bough to bough with its legs up in the air and its back towards the ground. It walks and sleeps suspended beneath the boughs instead of balanced above them, securely holding itself by means of powerful hooked claws on the fore and hind feet. This method of locomotion, so remarkable in a mammal, coupled with the deliberate fashion in which it moves, and the air of sadness expressed in its quaint physiognomy - large-eyed, snub-nosed, and earless - on which there seems to dwell an ever-present air of resignation, led the great Buffon to believe that the sloth was a creature afflicted of God for some hidden reason man could not fathom! His sympathy was as certainly wasted as his hasty conclusion was unjustified. There can be no doubt but that the life led by the sloth is at least as blissful as that of its more lively neighbours - the spider monkeys, for instance. Walking beneath the boughs comes as natural to the sloth as walking on the ceiling to the fly.

The sloth sleeps, as we have already remarked, suspended from a bough. During this time the feet are drawn close together, and the head raised up and placed between the fore legs, as in the cobego, which we depictcd asleep on page $\mathrm{I} 7 \mathrm{O}$, as our readers will remember. In the sleeping position the sloth bears a striking resemblance to the stump of a lichen-covered bough, just as the cobego resembles a fruit. Thus is protection from enemies gained. The resemblance to lichen is further aided by the fact that the long, coarse hair with which the sloth is clothed becomes encrusted with a peculiar green alga - a lowly form of vegetable growth whichlodges in certain grooves or flutings peculiar to the hair of this animal. Such a method of protection is unique amongst the Mammalia. As the sloths sleep by day

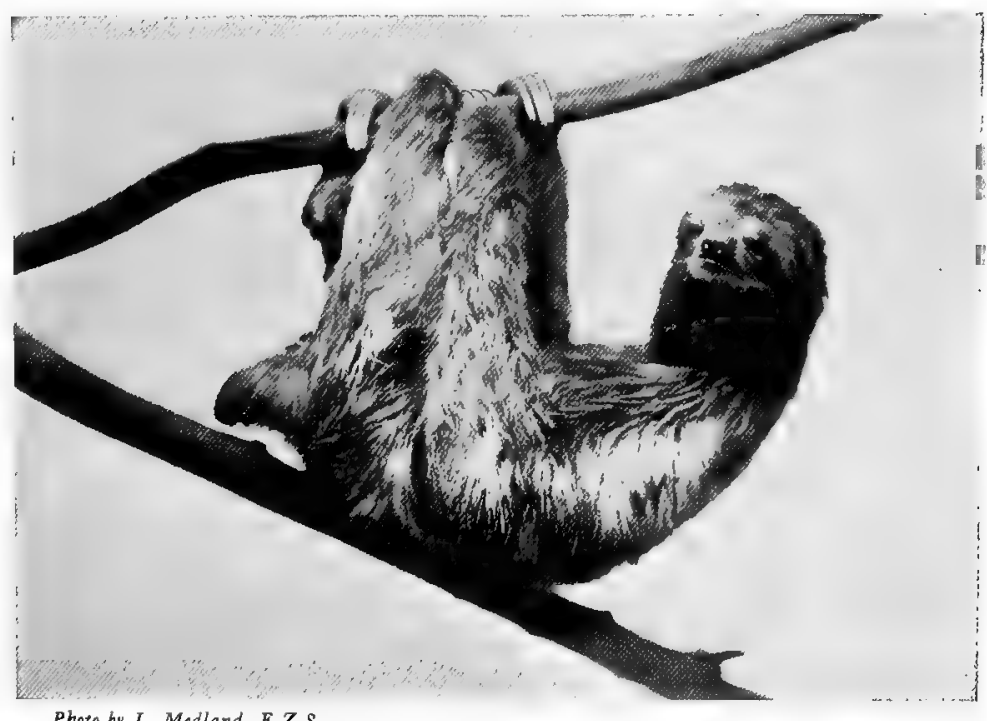

Photo by L. Medland, F.Z.S.

THREE-TOED SLOTH

A remarkable peculiarity about the three-toed sloths is the fact that they have no less than nine vertebre in the neck, instead of seven, as is usual among mamals

and feed by night, the usefulness of such a method of concealment is beyond question.

The strange form of locomotion of the sloths renders separate fingers and toes unnecessary, and so the fingers and toes have come to be enclosed in a common fold of skin, extending down to the base of the claws.

The sloths stand out in strong contrast to the volatile spider monkeys, with whom they share the forest; these have added a fifth limb in the shape of a prehensile tail, by which they may suspend themselves at will. The sloths, on the contrary, have no tail; they move deliberately, and do not require it. The monkeys move by prodigious leaps, taken not seldom by gathering impetus by swinging on their tails.

The great naturalist Bates writes of the sloth: "It is a strange sight to watch this uncouth creature, fit production of these silent shades, lazily moving from branch to branch. Every movement betrays, not indolence exactly, but extreme caution. He never loses his hold from one branch without first securing himself to the next.... After watching the animal for about half an hour, I gave him a charge of shot; he fell with a terrific crash, but caught a bough in his descent with his powerful claws, and remained suspended. Our Indian lad 


\section{THE LIVING ANIMALS OF THE WORLD}

tried to climb the tree, but was driven back by swarms of stinging ants; the poor little fellow slid down in a sad predicament, and plunged headlong into the brook to free himself."

On another occasion the same writer tells us he "saw a sloth swimming across a river at a place where it was 300 yards broad. I believe it is not generally known that this animal takes to the water. Our men caught the beast, cooked and ate him."

In past ages gigantic ground-sloths roamed over South America. The largest of these, the Megatherium, rivalled the elephant in size. Descendants of these giants appear to have lingered on till comparatively recent times, as witness the wonderful discovery by Moreno, made during the year of 1900, in a cave in Patagonia. This was nothing less than a skull and a large piece of the hide of one of these monsters in a wonderful state of preservation, showing indeed undoubted traces of blood and sinew. That the hide was removed by human hands there can be no doubt, for it was rolled up and turned inside-out. Immediately after this discovery was announced, an expedition was dispatched from England to hunt, not so much for more remains, but for the animal itself. Time will show whether these efforts will prove successful.

\section{The Ant-eaters}

Unlike as the ant-eaters are to the sloths, they are nevertheless very closely related thereto. This unlikeness at the present day is so great that, were it not for "missing-links" in the shape of fossils, we should probably never have discovered the relationship. The head of the typical ant-eaters has been drawn out into a long tubular muzzle, at the end of which is a tiny mouth just big enough to permit the exit of a long worm-like tongue, covered with a sticky saliva. This tongue is thrust out with great rapidity amongst the hosts of ants and termites and their larvæ, on which they prey. These victims are captured by breaking open their nests. At once all the active inhabitants swarm up to the breach, and are instantaneously swept away by the remorseless tongue. The jaws of the ant-eaters are entirely toothless, and the eyes ard ears are very small.

The largest species of ant-eater is about 4 feet long. It lives entirely upon the ground. Generally speaking, it is a harmless creature; but at times, when cornered, it will fight

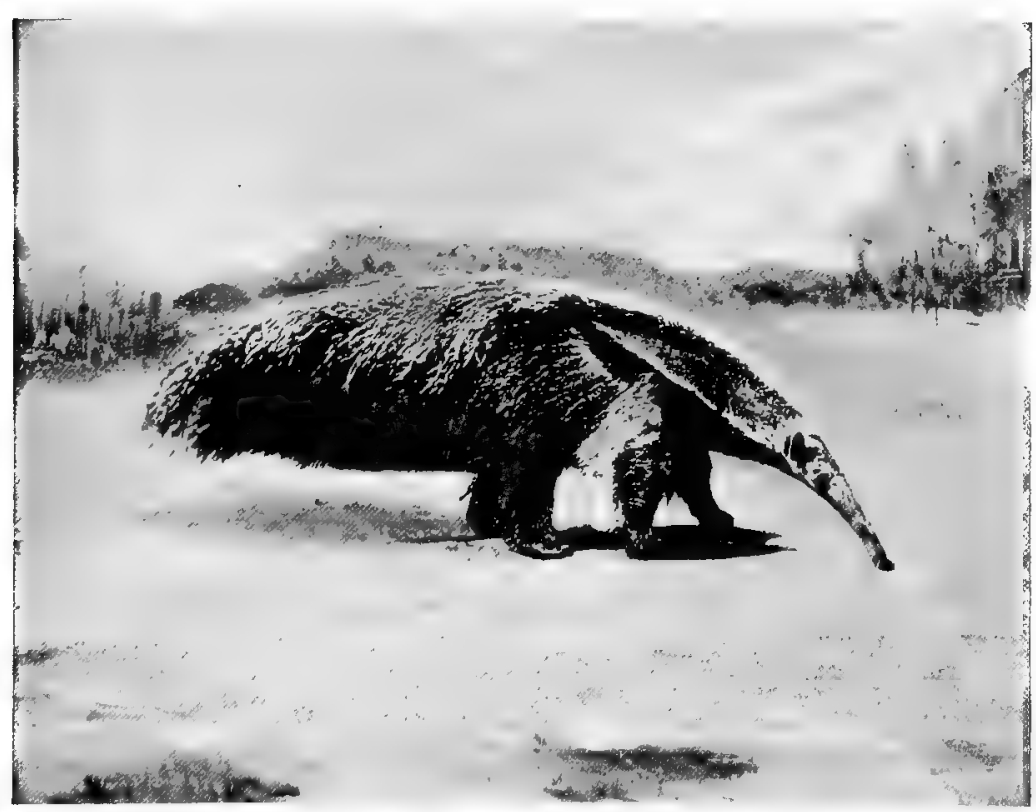

THE GREAT ANT-EATER

In walkng the ant-eater turns its toes inzvards, so that the claws turn upwards and inwards, the weight of the body being borne by a horny pad on the fifth toe, and the balls of the third and faurth toes furiously, sitting up on its hind legs and hugging its foe in its powerful arms. Bates, the travelernaturaist, relates an instance in which a dog used in hunting the GREAT ANT-EATER was caught in its grip and kilied. The tail of this large species is covered with very long hair, forming an immense brush. The claw on the third toe of each fore limb is of great size, and used for breaking open ants' and other insects' nests.

But besides the great ground ant-eater there are some tree-haunting species. These have a shorter muzzle, and short hair on the tail, which is used, as with the spider monkeys, as a 


\section{SLOTHS, ANT-EATERS, AND ARMADILLOS 303}

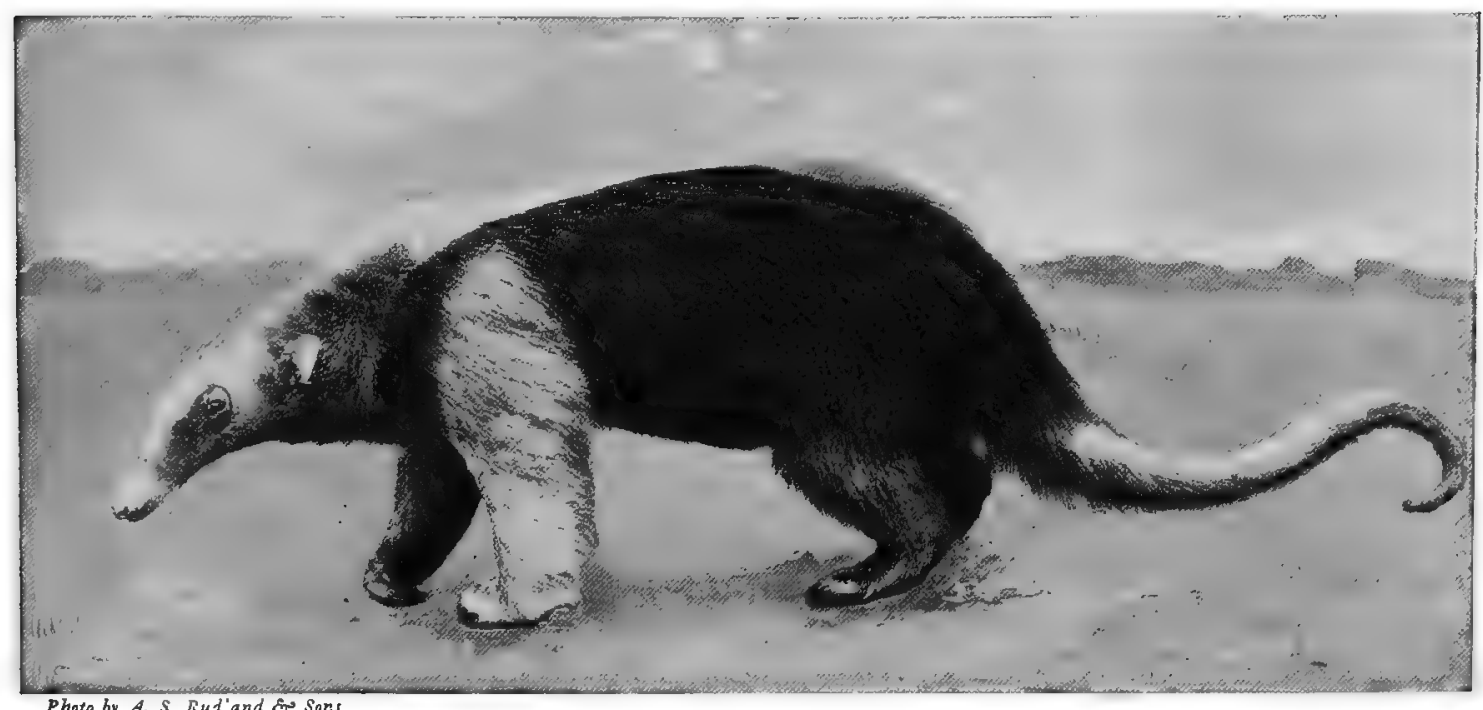

Photo by A. S. Rud' and Es Sons

TAMANDUA ANT-EATER

This species, which is a smaller animal than the Great Ant-eater, lives almost entirely in the trees, instead of on the ground

fifth limb. Curled round the bough of a tree, its owner is free to swing himself out on to another branch.

The smallest of the tree-dwelling species is not larger than a rat, and is a native of the hottest parts of the forests of South and Central America. The muzzle in this species is quite short, not long and tubular, as in the larger species. It is a very rare animal, or is at least very seldom seen, a fact perhaps due to its small size. It is known as the TwO-TOED ANTEATER, only the secund and third fingers of the fore feet bearing claws.

Von Sack, in his "Narrative of a Voyage to Surinam," tells us that the natives of Surinam call this little animal "Kissing-hand" - "as the inhabitants pretend that it will never eat, at least when caught, but that it only licks its paws, in the same manner as the bear; that all trials to make it eat have proved in vain, and that it soon dies in confinement. When I got the first, I sent to the forest for a nest of ants; and during the interim I put into its cage some eggs, honey, milk, and meat; but it refused to touch any of them At last the ants' nest arrived, but the animal did not pay the slightest attention to it either. By the shape of its fore paws, which resemble nippers, I thought that this little creature might perhaps live on the nymphæ of wasps, etc. I therefore brought it a wasps' nest, and then it pulled out with its nippers the nymphæ from the nest, and began to eat them with the greatest eagerness, sitting in the posture of a squirrel. I showed this phenomenon to many of the inhabitants, who all assured me that it was the first time they had ever known that species of animal take any nourishment."

\section{The ARMAdillos}

Readers of this book will doubtless have noticed long ere this how manifold are the devices for the purpose of defence adopted by the Mammalia. The ARMADILLOs have certainly selected the most complete, having encased themselves in an impenetrable bony armour as perfect as the coat of mail of the warrior of the Middle Ages. Concerning this and the variations thereon adopted by the different members of the group we shall speak presently.

Armadillos are mostly confined to South America, and occur both in the open pampas and the shady depths of the forest. They live in burrows, which they dig with incredible speed. These burrows are generally found in the vicinity of the nests of ants and termites, which form their staple diet. One species, however, at least feeds apparently with equal relish upon vegetable matter, eggs, young birds, mice, snakes, and carrion. 
The bony armour is disposed over the crown of the head, back, and flanks. It is made up of numerous small, bony plates, buried deep in the skin, and each overlaid by a horny scale. The tail is protected by bony rings. The plates covering the shoulders and those directly over the hindquarters fuse into a solid mass, thus forming chambers into which the limbs can be withdrawn. In the region of the body, between these two shields, the plates are arranged in rows encircling the body, thus permitting the animal to roll itself up as occasion may require. Hairs grow out between the plates, and in some cases give the animal quite a furry appearance.

Speaking of the burrowing powers of the armadillo, Darwin, in his most fascinating "Voyage of the Beagle," tells us that "the instant one was perceived, it was necessary, in order to catch it, almost to tumble off one's horse; for in soft soil the animal burrowed so quickly that its hinder quarters would almost disappear before one could alight. It seems almost a pity to kill such nice little animals; for as a Gaucho said, while sharpening his knife on the back of one, 'Son tan mansos' (They are so quiet)." As a rule, armadillos are regarded as animals loving dry, sandy wastes; nevertheless, they are said to be able to swim both well and swiftly. The flesh of the armadillo is apparently by no means unpalatable.

\section{The Pichiciago}

One of the most remarkable of the armadillos is the Pichiciago, or FatRy Armadillo. It is a tiny creature of some 5 inches long, found in the sandy wastes of the western part of the Argentine Republic. The horny covering of the bony plates is pinkish colour, and the hair is
silky in texture and snow-white. But it is not on this 17 account that the fairy armadillo is remarkable: its claim to notoriety rests on the peculiar arrangement of the a bony plates constituting the armour. These bony plates 1. 3 are small and thin, and covered, as in other species, with

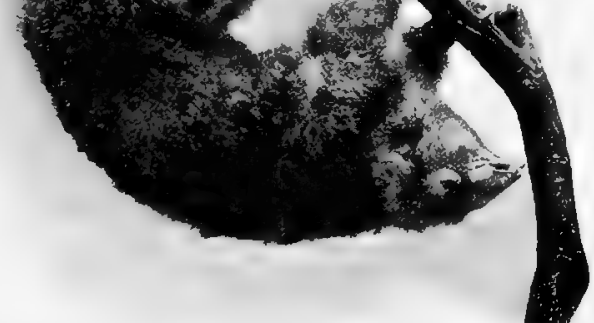

Phoso by A. S. Kudland so suns

TWO-TOED ANT-EATER

A.though the fore feet have four toes, only the second and third bear claws; hence the name "Tzuo-toed" Ant-eater a horny coat; but instead of being embedded in the skin, they are attached only along the middle of the back, and project freely over the body on either side, leaving a space between the shield and the body. The hinder end of the body is specially protected by a nearly circular vertical shield, firmly fixed to the hip-girdle. This shield, it is said, is used as a plug to fill up its burrow with.

\section{The Peludo}

Armadillos of the normal type, wherein the body armour is embedded in the skin, are represented by numerous species. Of one, known as the PELudo, Mr. Hudson has given us some interesting details. "It feeds," he tells us, "not only upon insects, but also upon vegetable matter, eggs, young birds, and carrion. Its method of capturing mice was certainly ingenious. It hunted by smell, and when nearing its prey became greatly agitated. The exact spot discovered, the body was raised slowly to a sitting posture, and then flung suddenly forwards, so that the mouse or nest of mice was imprisoned beneath, and promptly dispatched." "Still more remarkable," says Mr. Lydekker, " is the manner in which a peludo has been observed to kill a snake, by rushing upon it and proceeding to saw the unfortunate reptile in pieces by pressing upon it closely with the jagged edges of its armour, and at the same time moving its body backwards and forwards. The struggles of the snake were all in vain, as its fangs could make no impression upon the panoply of its assailant, and eventually the reptile slowly dropped and died, to be soon afterwards devoured by the armadillo, which commenced the meal by seizing the snake's tail in its mouth, and gradually eating forwards." 


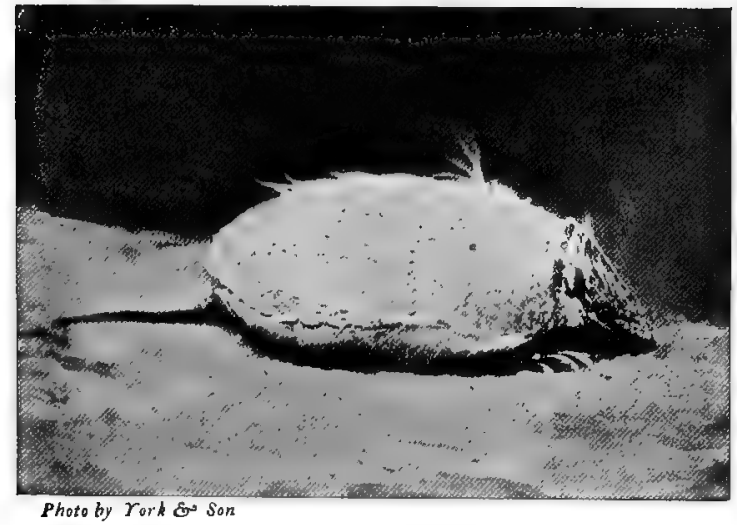

WEASEL-HEADED ARMADILLO

The weasel-headed armadillos have from six to eight movable bands in the bony armour in which they are encased

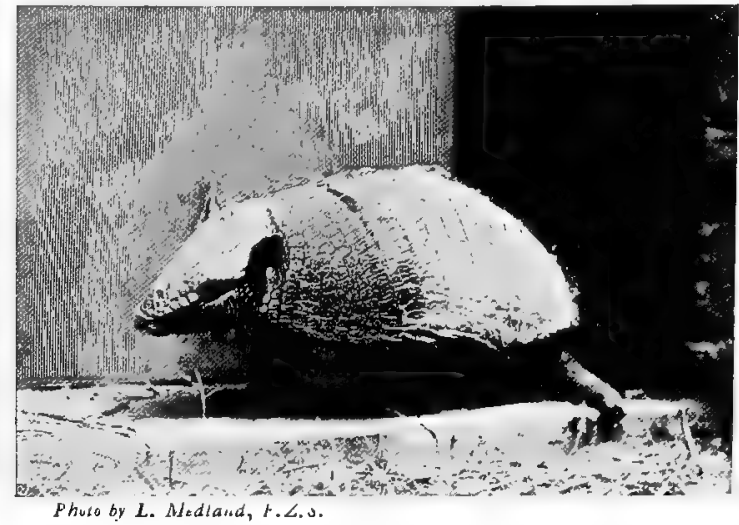

HAIRY-RUMPED ARMADILLO

This species, like the Peba Armadillo, varies its diet with carrion

\section{The Pangolins}

The PANGolins, or SCALY ANT-EATERS, are perhaps even more curious creatures than the armadillos. They have been likened in appearance to animated spruce fir-cones, to which indeed they bear a strange resemblance. This resemblance is due to the wonderful armature of the skin, which takes the form of large overlapping, pointed, horny plates or scales. The pangolins are confined to the Old World, occurring in South Africa and South-eastern Asia. Like the American Ant-eaters, teeth are wanting, and the tongue is long and worm-like, being employed in the capture of insects, as in the New World ant-eaters.

The scales of the MANIS are formed by the fusion together of fine hairs. Like the spines of the hedgehog and porcupine, they serve the purpose of offensive defence; for when the manis rolls itself up, these pointed scales project at right angles to the body, and offer a formidable resistance to any enemy whatsoever. They also serve to break the force of a fall, which, indeed, is often voluntary; for should the animal wish to descend from the branch of a tree, it will often take a short cut to the ground by deliberately dropping, the force of the fall being entirely broken by the elastic scales.

In climbing, the tail is of the greatest service, its under-surface being clothed with pointed scales, which serve as so many climbing-hooks. The grasp of a tree-trunk gained by the hind legs and tail is so secure that the body can be moved to a horizontal position with ease. In a specimen kept in captivity by Mr. Fraser, this horizontal movement was a form of exercise which appeared to afford the grcatcst pleasure.

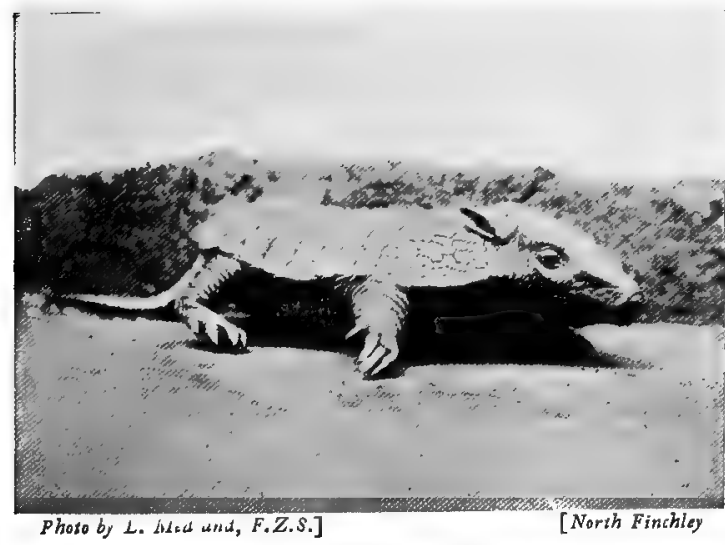

PEBA ARMADILLO

This species lives largely upon carrion, which it buries in its burrow till wanted

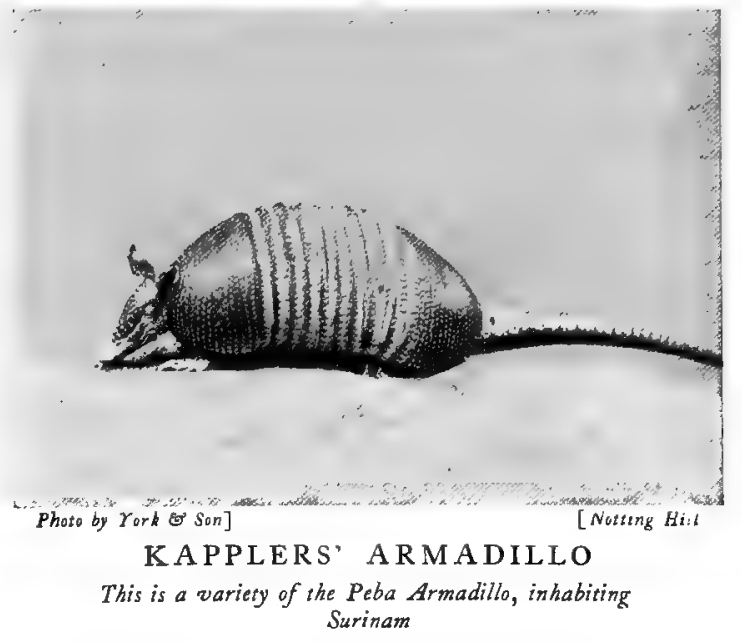




\section{THE AARD-VARK}

The custom of naming newly discovered animals after well-known forms to which they are supposed to bear some resemblance, physically or otherwise, is a common one. The animal now under consideration shows this once more, having originally received the name of AARD-VARK (Earth-pig) from the Boers of the Cape. The aard-vark is a most decidedly ugly animal, and justifies its name in several particulars. It is hunted for the sake of its hide, which is of great thickness and resembles that of the pig, but is sparsely covered with hairs, the general shape of its body being not unlike that of a long-headed, short-legged, heavy-tailed pig. The whole animal is about 6 feet long. In a wild state, or even in captivity, it is but rarely seen, since it is a night-feeder, and passes the day in sleep deep down in a burrow. This burrow it digs for itself with the aid of powerful claws borne on the fore feet. It lives principally on ants and termites, breaking down their nests, and remorselessly sweeping up the frightened occupants with a long, sticky tongue, as soon as they rush to the seat of the disturbance which has broken up the harmony and order of their community. At one time it was believed that the aard-vark was a close ally of the pangolin, but later researches have disproved this, and have furthermore thrown doubt upon the probability of its relationship with any of the members of this group of mammals at all.

There are two species of this animal - the CAPE AARD-VARK of South and South-east Africa, and the ETHIOpian AARD-VARK of North-east Africa.

Where the nest-building ants are most common, there will the aard-vark - or Innagus, as the Boers sometimes call it - be most plentiful. The nests of these ants are huge structures of from 3 to 7 feet high, and often occupy vast areas of ground, extending as far as the eye can reach. They are substantially built, and swarm with occupants, and consequently are quite worth raiding. But the aard-vark has become much less common since a price has been set upon its skin. The powers of digging of these animals are so great that they can completely bury their large bodies in a few minutes, even when the ground has been baked by the sun into something like adamantine hardness. In excavating their burrows, the ground is thrown out by the fore feet, in huge lumps, through or rather between the hind legs. Shy and suspicious, the least unusual sound will send them scuttling to earth, for their sense of hearing is very keen. They seem to change their minds somewhat frequently, when engaged in digging out a new burrow; for half-excavated burrows in the side of ant-hills are very commonly met with. A fully grown aard-vark is about 6 feet long - generally rather more. Although this animal is frequently kept in captivity, it is but rarely seen by visitors; owing to its nocturnal habits, of which we have already spoken.

The teeth of the aard-vark are sufficiently remarkable to justify notice here. Only the crushing teeth are represented - that is to say, the front or cutting teetk. are conspicuous by their absence. These crushing teeth number from eight to ten in the upper and eight in the lower jaw, on each side; but in the adult fewer would be found, the number being reduced to five in each side of the jaws - that is to say, there are but twenty all told. In

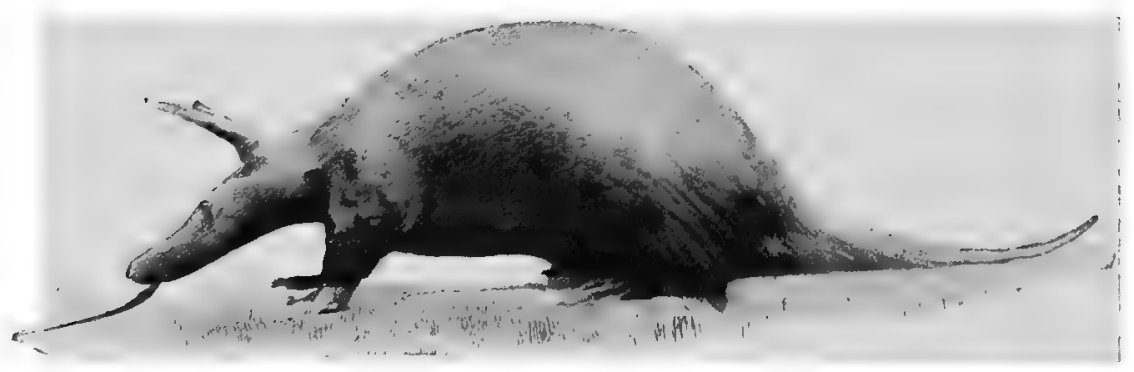

By permission of the Hon. Walter Rotbscbild

$$
\text { CAPE AARD-VARK }
$$

The ants upon which the aard-vark largely subsists appear to be very fattening, and impart a delicate flavour to the flesh, especially' to the hams, which are greatly esteemed structure these teeth are quite remarkable, differing entirely from those of all other $\mathrm{m}$ a $\mathrm{mmals}$, and resem bling those of some fishes; furthermore, they have no "roots," but instead grow continually throughout life, which "rooted" teeth do not. 


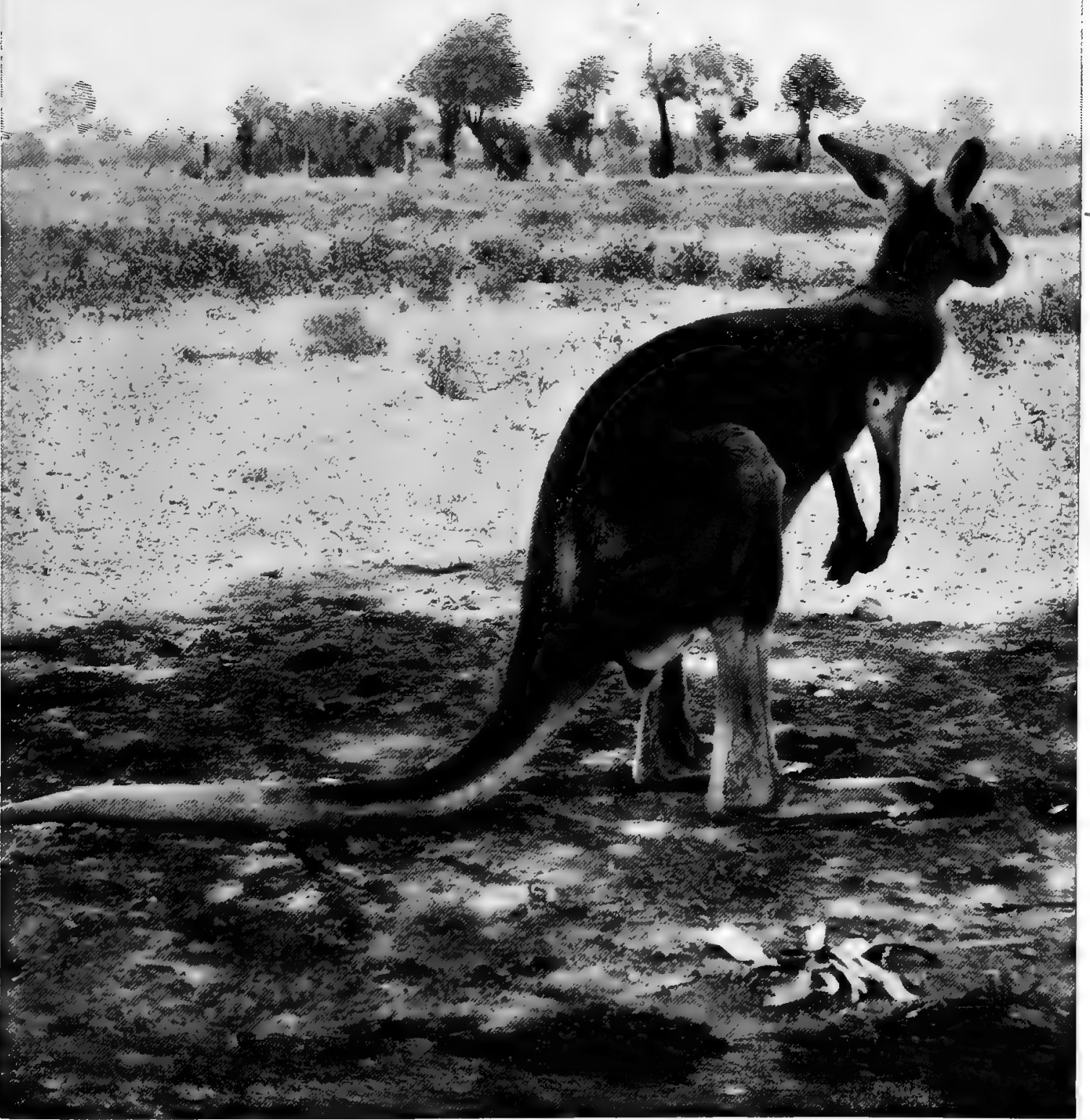

Phoso by Billington]

THE GREAT GREY KANGAROO

The massive hind limbs and tail of the animal constztute, in its characteristic resting pose, a most efficient supporting tripod 


\title{
CHAPTER XXII
}

\author{
MARSUPIALS AND MONOTREMES
}

BY W. SAVILLE-KENT, F.L.S., F.Z.S.

\section{MARSUPIALS}

$\mathrm{W}$

ITH the order of the Pouched Mammals we arrive - with the exception of the Echidna and Platypus, next described - at the most simply organised representatives of the Mammalian Class. In the two forms above named, egg-production, after the manner of birds and reptiles, constitutes the only method of propagation. Although among marsupials so rudimentary a method of reproduction is not met with, the young are brought into the world in a far more embryonic condition than occurs among any of the mammalian groups previously enumerated. There is, as a matter of fact,'an entire absence of that vascular or blood connection betwixt the parent and young previous to birth, known as placentation, common to all the higher mammals, though certain of the more generalised forms have been recently found to possess a rudiment of such development. In correlation with their abnormally premature birth, it may be observed that a special provision commonly exists for the early nurture of the infant marsupials. In such a form as the Kangaroo, for example, the young one is placed, through the instrumentality of its parent's lips, in contact with the food-supplying teat, and to which for some considerable period it then becomes inseparably attached. Special muscles exist in connection with the parent's mammary glands for controlling the supply of milk to the young animal, while the respiratory organs of the little creature are temporarily modified in order to ensure unimpeded respiration. The fact of the young in their early life being commonly found thus inseparably adhering to the parent's nipple has given rise to the fallacious but still very widely prevalent idea among the Australian settlers that the embryo marsupial is ushered into the world as a direct outgrowth from the mammary region.

At the present day, with the exception of the small group of the American Opossums and the Selvas, the entire assemblage of marsupials, comprising some 36 genera and 150 species, are, singularly to relate, exclusively found in Australia, New Guinea, and the few neighbouring islands recognised by systematic zoologists as pertaining to the Australasian region. What is more, this region of Australasia produces, with some few insignificant exceptions, chiefly rodents, no other indigenous mammals.

It is interesting to note that within the limits of this isolated

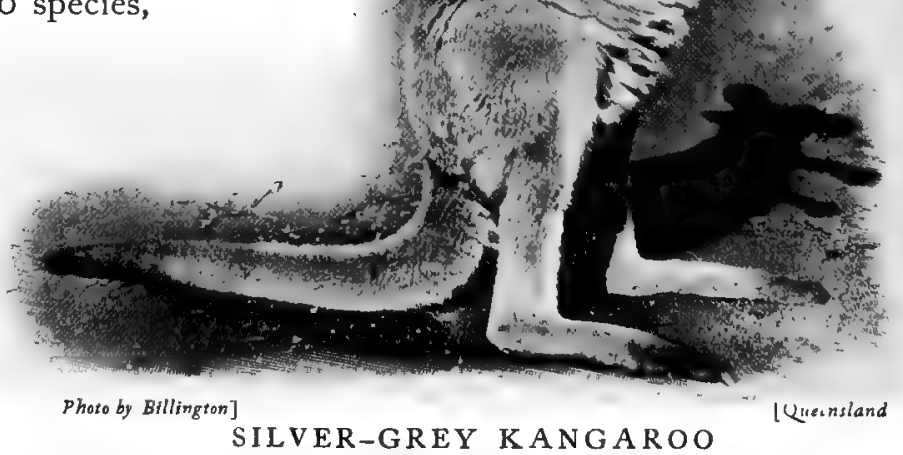

SILVER-GREY KANGAROO

In general form the kangaroos are so like one another that one figure would almost serve 308 for all 


\section{MARSUPIALS AND MONOTREMES}

and anciently founded marsupial order we have an epitome, as it were, of many of the more important groups of an equivalent classificatory value that are included among the higher mammalia previously described. In this relationship we find in the so-called Tasmanian Wolf, the Tasmanian Devil, and the "Native Cats" carnivorous and eminently predatory forms whose habits and general conformation are immediately comparable to those of the typical Carnivora. The Bandicoots, Banded Ant-eater, and Phascogales recall in a similar manner the higher Insectivora. In the tree-frequenting Opossums and Phalangers the external likeness and conformity in habits to the arboreal rodents is notably apparent, several of the species, moreover, possessing a parachute-like flying-membrane essentially identical with that which is found in the typical Flying-squirrels. An example in which the groundfrequenting or burrowing rodents are closely approached is furnished by the Australian. Wombat, an animal which 'may be appropriately likened to an 'overgrown and lethargic Marmot. In this form, moreover, the rodent-like character of the dentition is especially noteworthy. The higher grass-eating

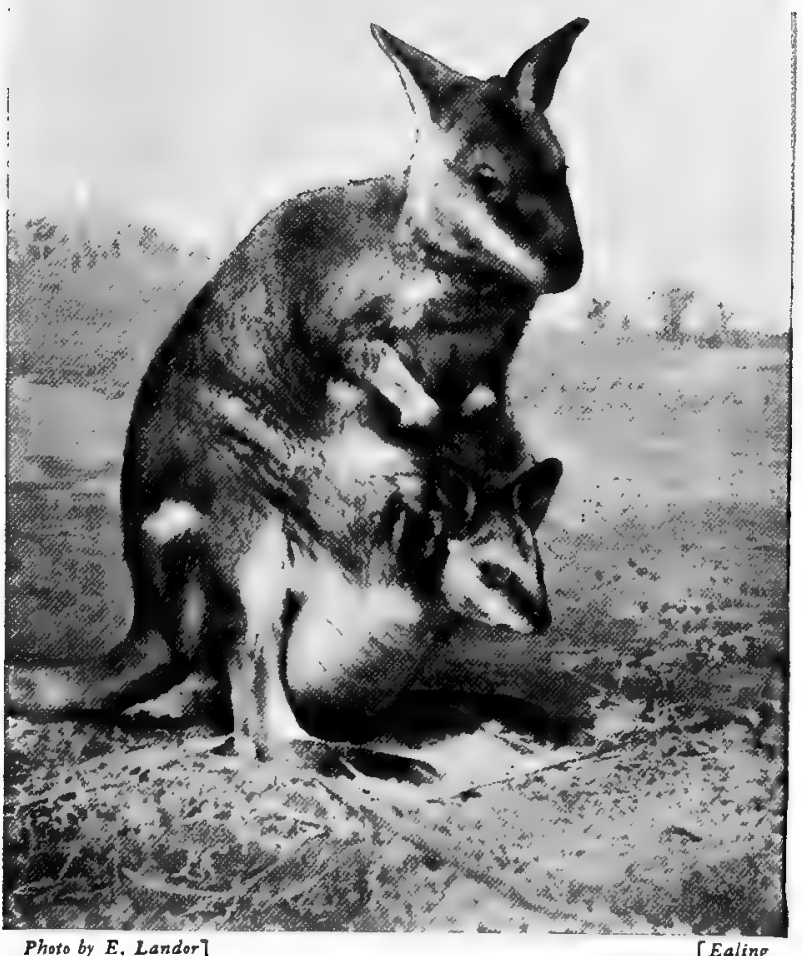

BLACK-STRIPED WALLABY

Female with half-growen young in her pouch

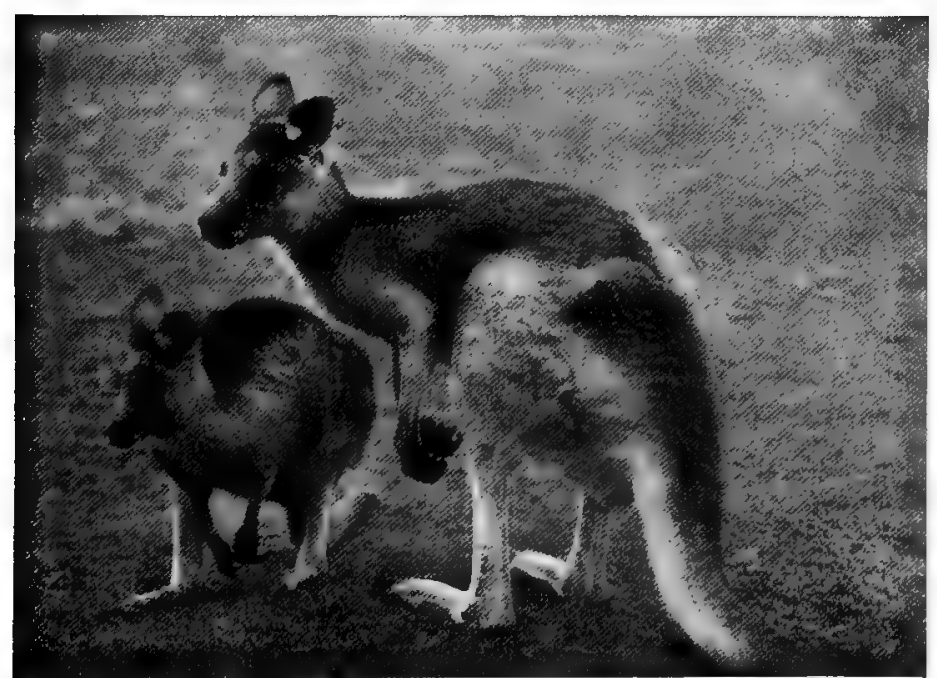

Photo by F. T. Nezuman]

BENNETT'S WALLABY AND THE GREAT GREY KA N G A R O

mhis photograph illustrates the relative sizes of these two species mammals find their counterparts in the family group of the Kangaroos, in which, in addition to their essentially herbivorous habits, the contour of the head and neck, together with the expressive eyes and large expanding ears, are wonderfully suggestive of the various members of the Deer Family. The Cuscuses of New Guinea and the adjacent islands, both in form and habits, somewhat resemble their geographical neighbours, the Lorises, belonging to the Lemur Tribe, compared with which higher mammals, however, they possess the advantage of an eminently serviceable prehensile tail. The Australian 


\section{IO THE LIVING ANIMALS OF THE WORLD}

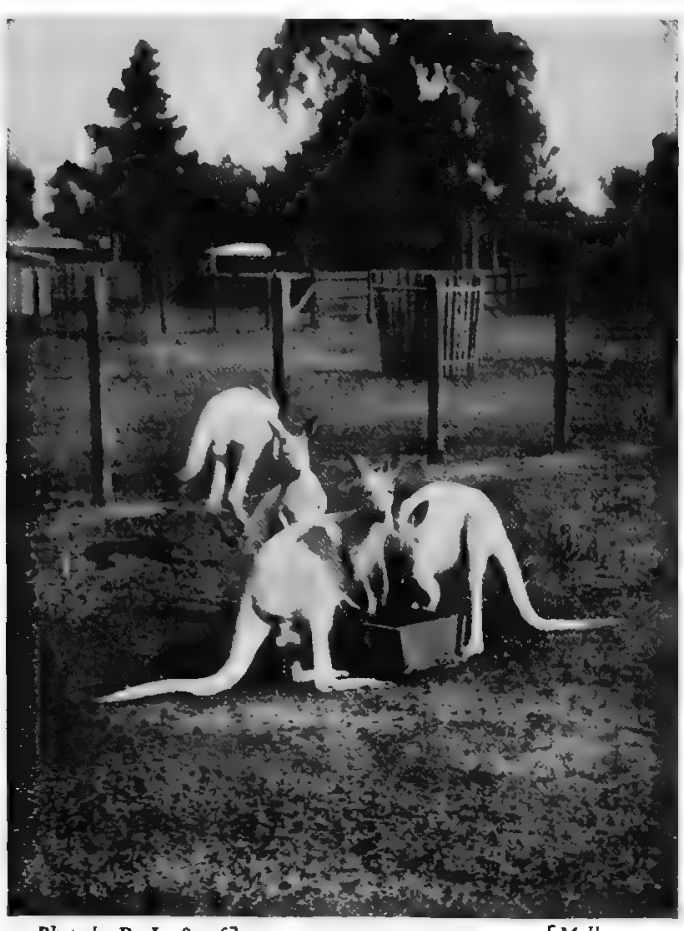

Photo by $D, L E$ Souef ]

[Melbourne

ALBINO RED KANGAROOS

Albino kangaroos and other Australian animals have been observed to be the product of special, narrowly limited locations

Koala, or so-called " Native Bear," has been commonly compared by zoologists with the Edentate Sloths; while in the most recently discovered marsupial, the Pouched Mole, we have a counterpart, in both form and habits, of the familiar European species. Finally, in the small American section of the Marsupialia, we meet with a type - the so-called Yapock, or Wateropossum - in which the resemblances to an Otter, in both aspect and its aquatic habits, are so marked that the animal was originally regarded as a species only of the Otter Tribe.

The character of the marsupium, or pouch, differs materially among the various members of their order. It presents its most conspicuous and normal development in such animals as the Kangaroos, Wallabies, and the Australian Opossums or Phalangers. In the Tasmanian Wolf and the Bandicoots the pouch opens backwards. In such forms as the Phascogale, or Pouched Mouse, the pouch is reduced to a few rudimentary skin-folds, while in the Banded Anteater its position is occupied by a mere patch of longer hairs, to which the helpless young ones cling. On the same lucus a non lucenato principle there is no trace of a pouch in the Koala, nor in those smaller species of the American Opossums which habitually carry their young upon their back. Even in these pouchless marsupials, however, the peculiar marsupial bones are invariably present, and in all other essential details their accord with the marsupial type of organisation and development is fully maintained.

\section{The Kangaroos}

The typical and most familiar member of the Marsupial Order is the KANGAROo - the heraldic mammal of that vast island-continent in the South Seas, whose phenomenal advance by leaps and bounds, from what scarcely a century since was represented by but a fcw isolated settlements, has been aptly likened to the characteristic progression of this animal. Of kangaroos proper there are some twenty-four known species distributed throughout the length and breadth of Australia, extending southwards to Tasmania, and to the north as far as New Guinea and a few other adjacent islands.

In point of size the GREAT GREY Kangaroo and the RED or WOOLLy species run each other very closely. A full-grown male of either species will weigh as much as $200 \mathrm{lbs}$, and measure a little over 5 feet from the tip of the nose to the base of the tail, this latter important member monopolising another 4 or $4 \frac{1}{2}$ feet. The red or woolly species more especially affects the rocky districts of South and East Australia, while the great grey kind is essentially a plain-dweller and widely distributed throughout the grassy plains of the entiro Australian Continent and also Tasmania. It is to the big males of this species that the titles of "Boomer," "Forester," and "Old Man Kangaroos" are commonly applied by the settlers, and the species with which the popular and exciting sport of a kangaroo hunt - the Antipodean substitute for fox-hunting - is associated. The pace and staying power of an old man kangaroo are something phenomenal. Fox-hounds would have no chance with it; consequently a breed of rough-haired greyhounds, known as kangaroo-dogs, are specially trained for this sport. 


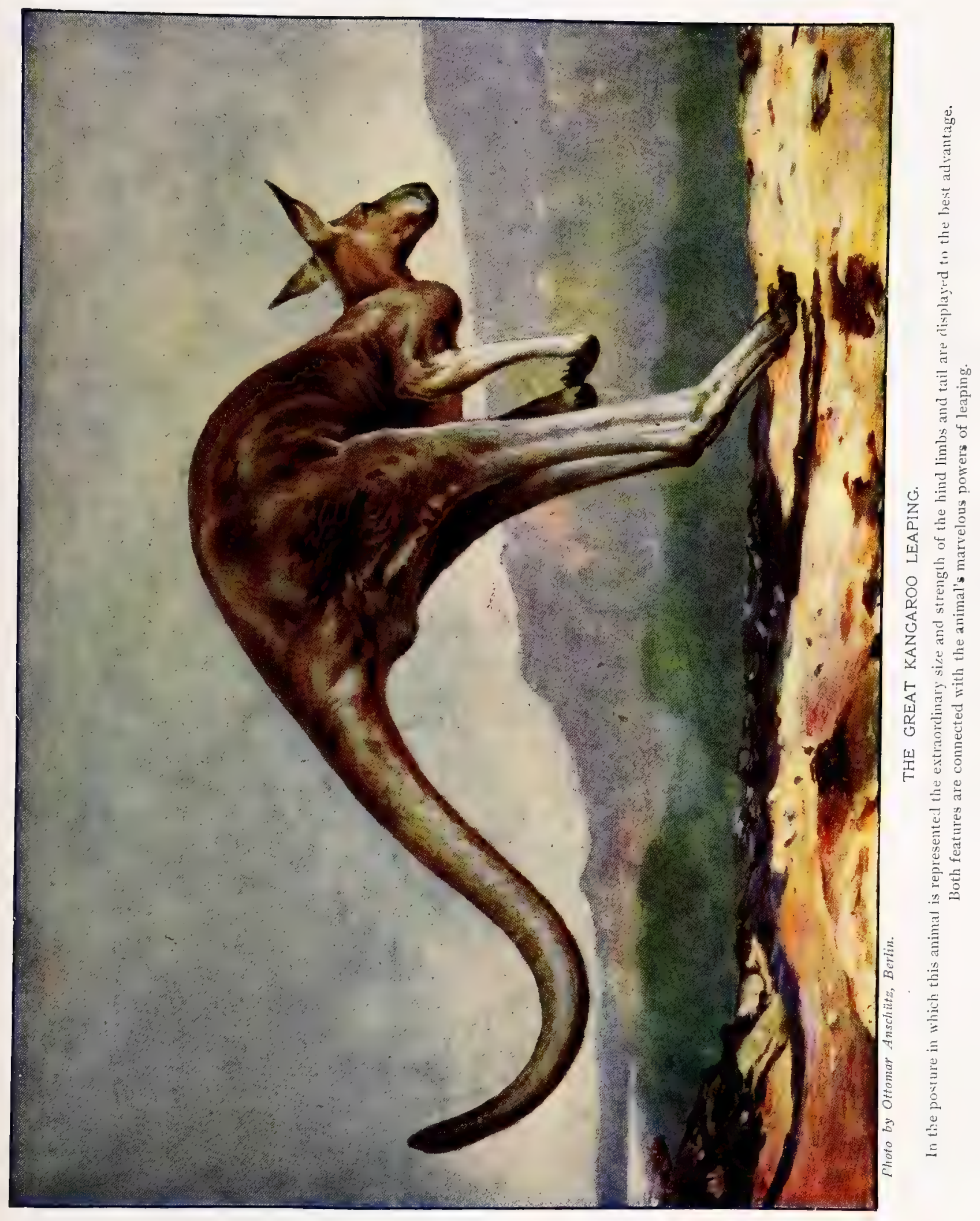



A run of eighteen miles, with a swim of two in the sea at the finish, and all within the space of two brief crowded hours, is one of the interesting records chronicled. The quarry, when brought to bay, is, moreover, a by no means despicable foe. Erect on its haunches, with its back against a tree, the dogs approach it at their peril, as, with a stroke of its powerful spur-armed hind foot, it will with facility disembowel or otherwise fatally maim its assailant. Another favourite refuge of the hunted "boomer" is a shailow water-hole, wherein, wading waist-deep, it calmly awaits its pursuers' onslaught. On the dogs swimming out to the attack, it will seize them with its hand-like fore paws, thrust them under water, and, if their rescue is not speedily effected, literally drown them. Even man, without the aid of firearms, is liable to be worsted in an encounter under these conditions, as is evidenced in the following anecdote.

A newly arrived settler from the old country, or more precisely from the sister island, ignorant of the strength and prowess of the wily marsupial, essayed his maiden kangaroo hunt with only a single dog as company. A fine grey boomer was in due course started, and after an exciting chase was cornered in a water-hole. The dog, rushing after it, was promptly seized and ducked; and Pat, irate at the threatened drowning of his companion, fired, but missed his quarry, and thereupon jumped into the water-hole, with the intention, as he afterwards avowed, "to bate the brains out of the baste" with the butt-end of his gun. The kangaroo, however, very soon turned the tables upon Pat. Before he had time to realise the seriousness of the situation he found himself lifted off his feet, and soused and hustled with such vigour that both Pat and his dog most narrowly escaped a watery grave. A couple of neighbours, by good luck passing that way, observed the turmoil, and came to the rescue.

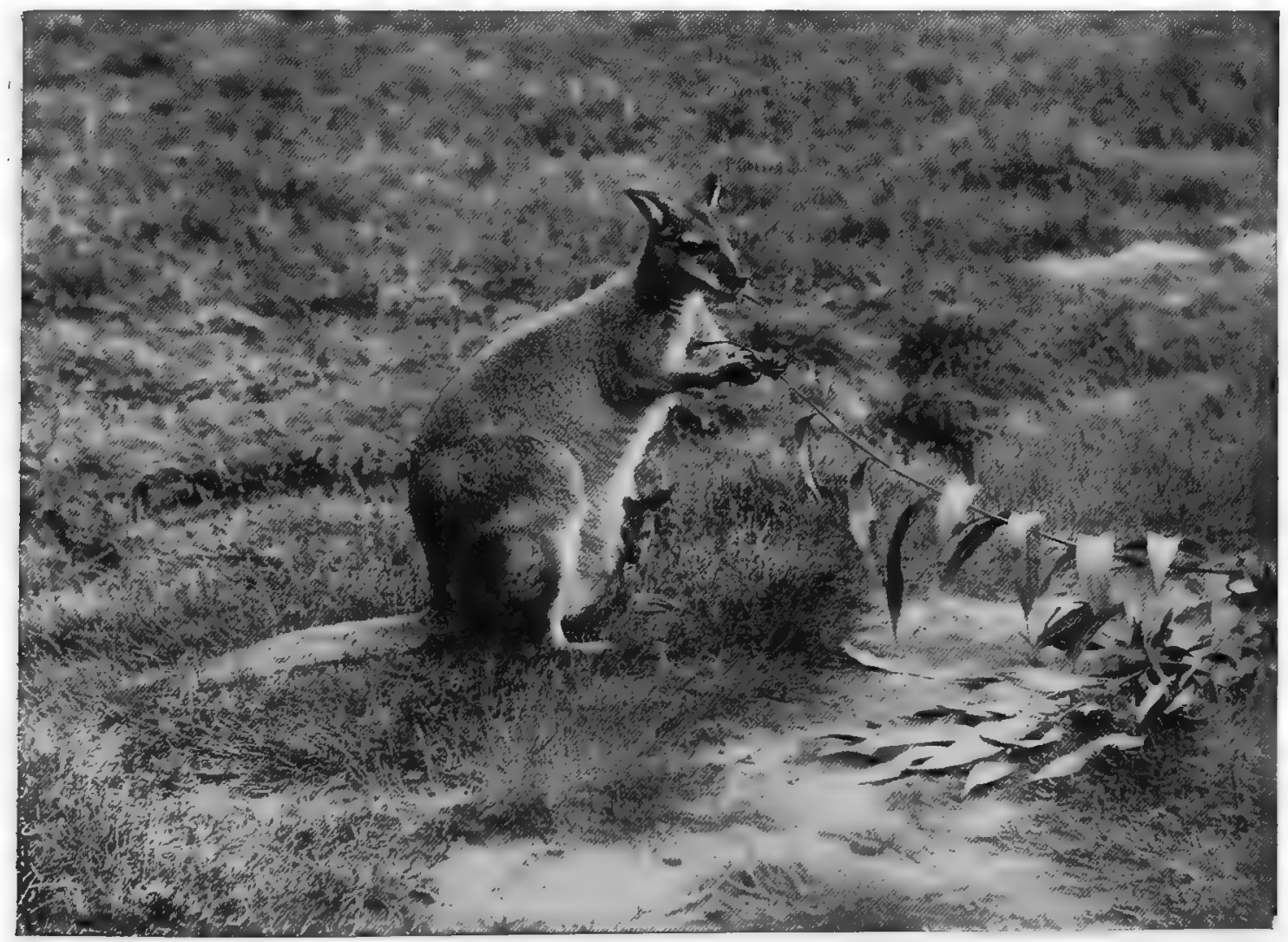

Pboso by W. Reid

TASMANIAN W ALLABY

Has softer and thicker fur than its relative of the Australian mainland 
Between them they beat off and killed the kangaroo, and dragged Pat to land in a halfdrowned and almost insensible condition. Pat recovered, and vowed "niver to meddle with such big bastes" again.

The doe kangaroos, while of smaller size and possessing much less staying power than their mates, can nevertheless afford a good run for horses and dogs, and are commonly known as "flyers." When carrying a youngster, or "Joey," in her pouch, and hard pressed by the dogs, it is a common thing for the parent to abstract her offspring from the pouch with her fore paws, and to throw it aside into the bush. The instinct of self-preservation only, by the discharge of hampering impedimenta, is usually ascribed to this act; but it is an open question whether the maternal one of securing a chance of escape for her young, while feeling powerless to accomplish it for herself, does not more often represent the actual condition of the case.

In proportion to the size of its body the kangaroo yields but a limited amount of meat that is esteemed for food. The tail represents the most highly appreciated portion, since from it can be compounded a soup not only equal to ordinary ox-tail, but by gourmands considered

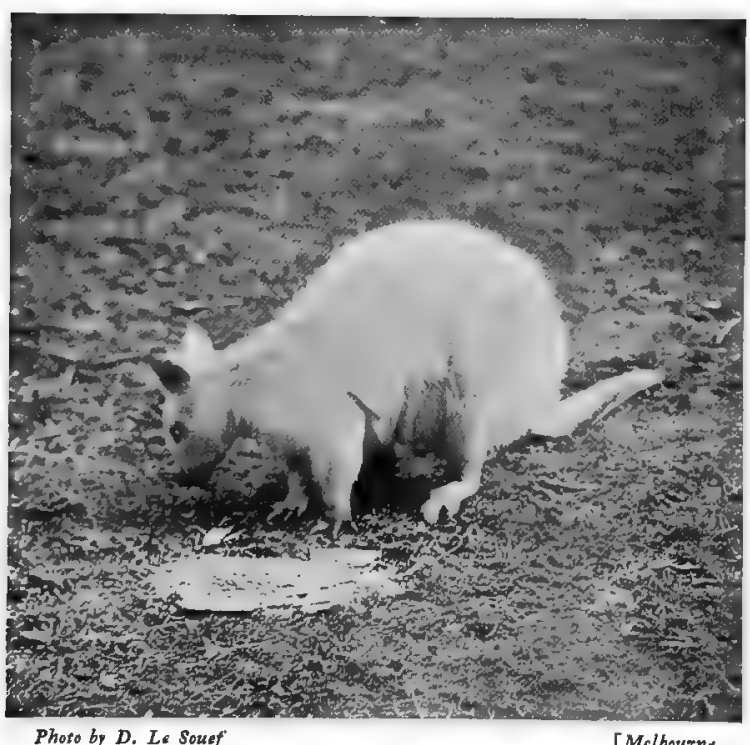

Photo by $D$. Le Sounf

ALBINO RED-BELLIED WALLABY

Many of the Marsupials, including Kangaroos and the Opposum-like Phalangers, exhibit a tendency to albinism so superior that its conservation and export have proved a successful trade enterprise. The loins also are much esteemed for the table, but the hind limbs are hard and coarse, and only appreciated by the native when rations are abnormally short. "Steamer," composed of kangaroo-flesh mixed with slices of ham, represented a standing and very popular dish with the earlier Australian settlers; but with the rapid disappearance of the animal before the advance of colonisation this one time common concoction possesses at the present day a greater traditional than actual reputation.

The hunting of the kangaroo is conclucted on several distinct lines, the method of its pursuit being varied, according to whether the animal is required for the primary object of food, for the commercial value of its skin, as a matter of pure sport, or to accomplish its wholesale destruction in consequence of its encroachments on the pasturage required for sheep- and cattle-grazing.

The greatest measure of healthy excitement in hunting the kangaroo, from the standpoint $f$ pure sport, is no doubt to be obtained when running the marsupial down with horse and hounds in congenial company, as referred to on a previous page. The stalking of the animal single-handed on horseback or on foot, much after the manner of the deer, has also its enthusiastic votaries, and calls into play the greatest amount of patience and savoir-faire on the part of the sportsman It has been affirmed by a Queensland writer, "To kill kangaroos with a stalking-horse requires the practice of a lifetime, and few 'new chums' have the patience to learn it. It is, in fact, only stockmen, black-fellows, and natives of the bush who can by this method expect to make kangaroo-shooting pay." The horse which is successfully employed by experienced bushmen for stalking purposes is specially trained to its work, and, walking apparently unconcernedly in the direction of the selected quarry, brings the gunners, if they are experts in the art of keeping themselves well concealed, within easy range. In this manner two or three kangaroos are not infrequently shot in the same stalk, the animals having a tendency, on hearing the report of the gun, but not locating the direction from which 


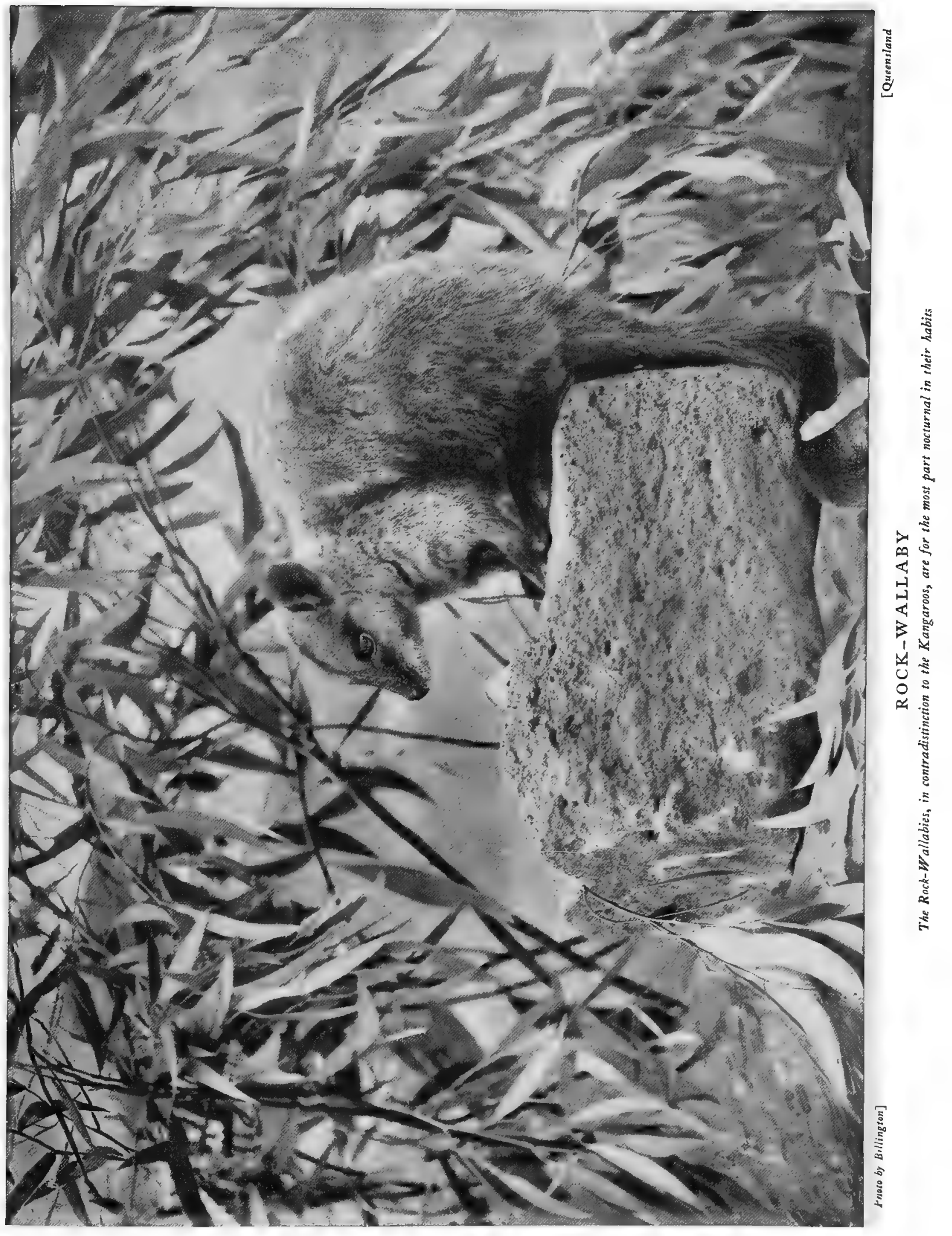




\section{I 4 THE LIVING ANIMALS OF THE WORLD}

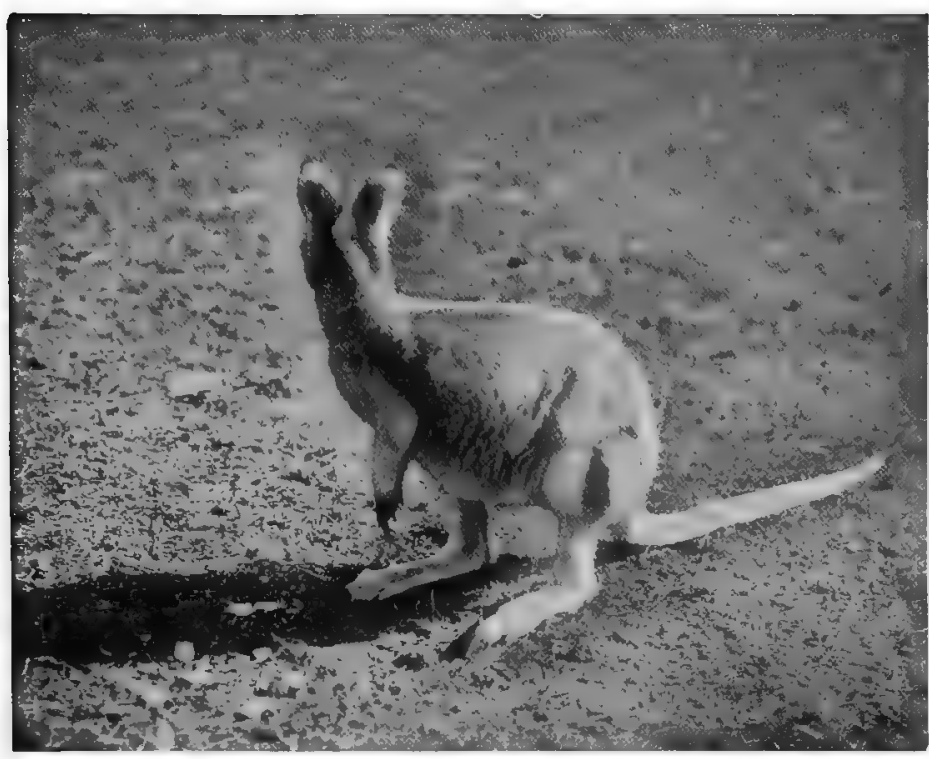

Phote by D. LE Soute]

PARRY'S WALLABY

In attitude of listening

it was discharged, to rush about in an aimless manner, and, as frequently happens, in the immediate direction of the hidden sportsman. In the good old times it is recorded that an experienced hand might kill as many as. seventy or eighty kangaroos in a day by this stalking method. The marsupials are at the present date, however, so severely decimated that even in the most favourable settled districts a bag of from twelve to twenty head must be regarded as exceptional. Stalking the kangaroo on foot without the horse's aid is more strongly recommended to those to whom an occasional shot is considered sufficiently remunerative. Taking full advantage of intervening bushes and other indigenous cover, an approach to within a hundred yards or so of the quarry may be usually accomplished, though not quite so easily, perhaps, as might be at first anticipated. It is the habit of the kangaroo to sit "up waist-high in the midst of the sun-bleached grass, which corresponds so closely in colour with its own hide that unless the animal is silhouetted against the sky-line it readily escapes detection.

The conditions under which the kangaroo is obtained for the main purpose of supplying the human commissariat is perhaps most aptly illustrated in connection with its chase as. prosecuted by the Australian aborigines. In Tasmania and the Southern Australian States the primeval man is either extinct or more rare than the kangaroo. In the extreme north and far northwest, however, he still poses as "the lord of creation," and conducts his hunting expeditions on a lordly scale. The food-supply of the Australian native is essentially precarious. Long intervals of "short commons" are interspersed with brief periods of over-abundance, in which he indulges his appetite to its fullest bent. A kangaroo drive on native lines represents to the Australian mind one of these

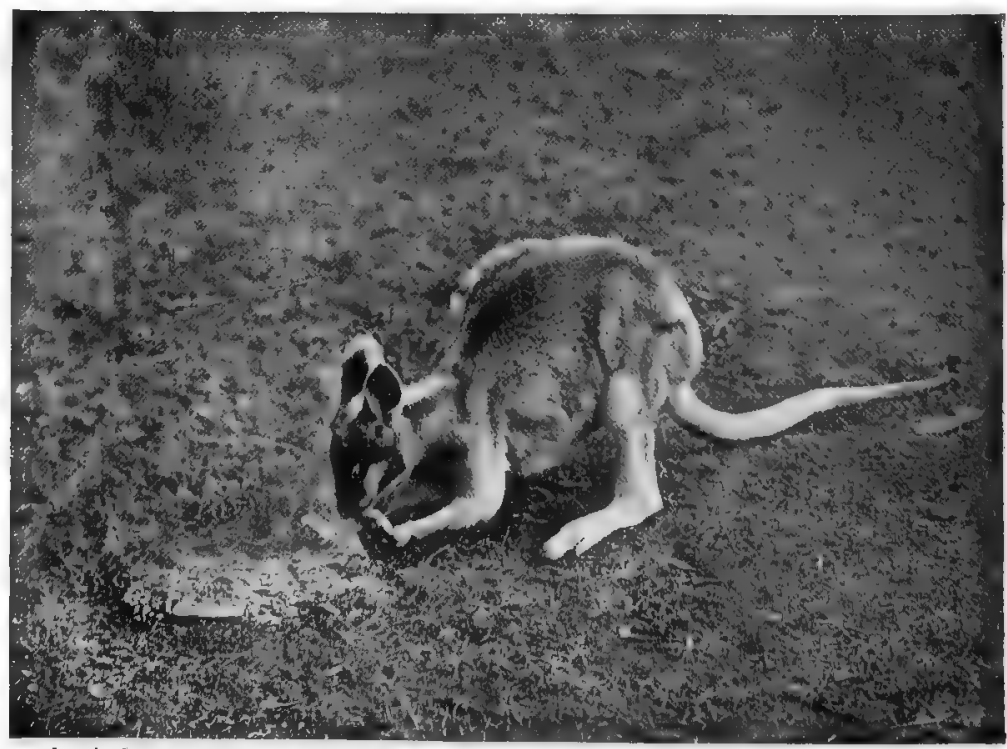

Photo by D. Le Souef]

PARRY'S WALLAB

Charecteristic feeding atritude 
last-named superlatively memorable occasions. The entire tribe, men, women, and all capable youths, participate in the sport. Fires are lit by one section of the tribe, according to the direction of the wind, encircling a vast area of the country, while the other section posts itself in detachments in advantageous positions to intercept the terrified marsupials as they fly in the presumed direction of safety to escape the devouring element. Spears and waddies and boomerangs, in the hands of the expert natives, speedily accomplish a scene of carnage, and the after feast that follows may perhaps be best left to the imagination of the reader. The encroachments of neighbouring natives on the happy hunting-grounds that time and custom have conceded to be the sole monopoly of any one particular tribe is most strenuously resented, and constitute one of the commonest sources of their well-nigh perpetual inter-tribal battles.

A kangaroo battue, as carried into practice by European settlers in those few remaining districts where the animal is sufficiently abundant to constitute a pest by its wholesale consumption of the much-prized pasturage, is far more deadly in its results to the unfortunate marsupials. Existing sheep-fences, supplemented by a large suitably enclosed yard, are first specially prepared for the reception of the expected victims. All the settlers, stockmen, and farm hands from the country round are pressed into service, and assemble on horseback or on foot at the appointed rendezvous at break of day. A widely spreading cordon of beaters being told off, a systematic drive is then commenced, which results in all the animals being driven towards and collected within the enclosed yard. The culminating scene is one of wholesale slaughter with club and gun. From these battues none of the unfortunate animals escape, as they are so closely hemmed in.

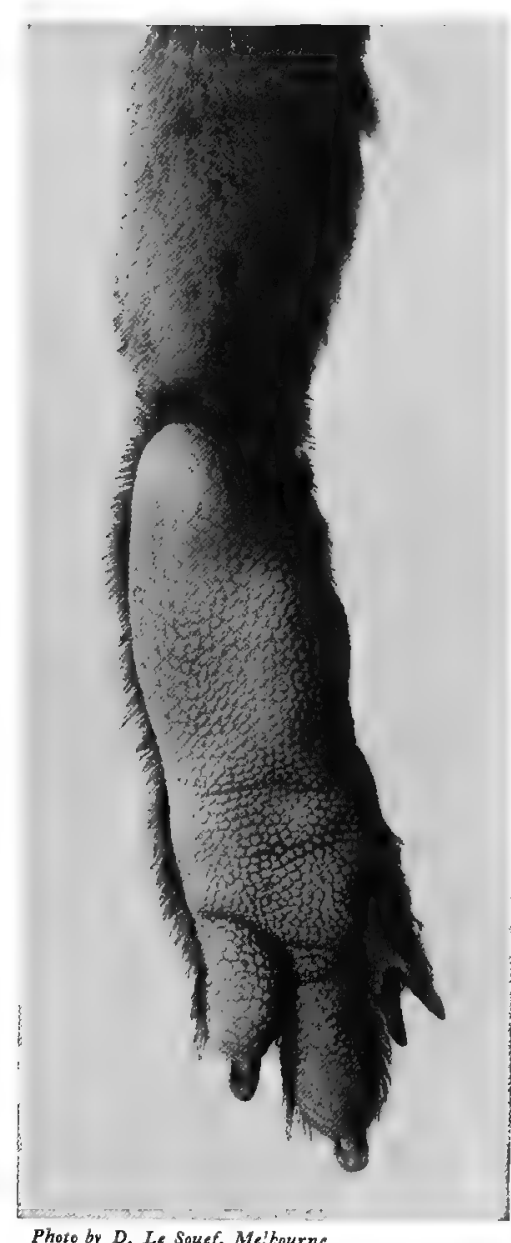

Photo by D. Le Sousf, Me!bourne

FOOT OF TREE-KANGAROO

Underside, shozving peculiar skin-corrugations and the united second and third toes

The first record of the existence of the kangaroo, coupled with its characteristic name, is found associated, it is interesting to observe, with the history of one of the earlier voyages of Captain Cook. The neighbourhood of Cooktown, in Queensland, claims the honour of supplying the first example of the animal which was brought to Europe and astonished the zoologists of that time by the singularity of its form and reported habits. Captain Cook happened in July, I770 - to be laying up his ship, the Encieavour, for repairs, after narrowly escaping total wreck on the neighbouring Great Barrier Reef, in the estuary of the river subsequently coupled with his ship's name. Foraging parties, dispatched with the object of securing, if possible, fresh meat or game for the replenishment of the ship's well-nigh exhausted larder, returned with reports of a strange creature, of which they subsequently secured specimens. Skins were preserved and brought to England, but it was some little time before the zoological position and affinities of the creature were correctly allocated. By some naturalists it was regarded as representing a huge species of Jerboa, its near relationship to the previously known American Opossums being, however, eventually substantiated. The closer acquaintanceship with the peculiar fauna of Australia that followed upon Captain Cook's memorable voyage of discovery along the coast-line of that island-continent soon familiarised naturalists with many other of the allied species of which the kangaroo constitutes the leading representative. 


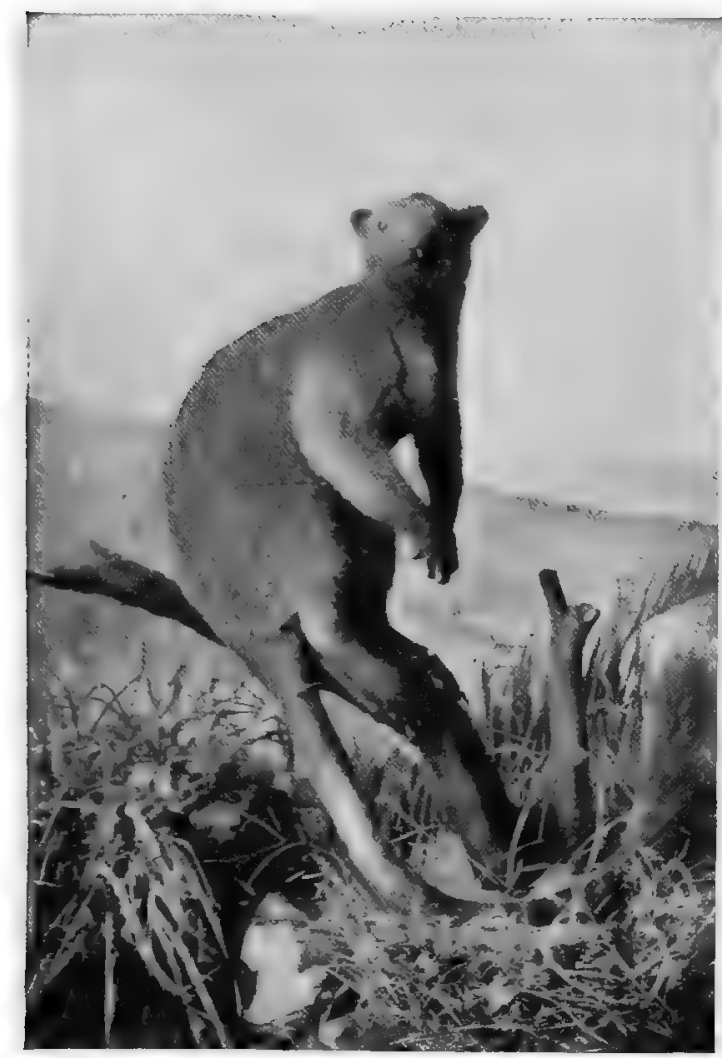

Photo by W. Saville-Kent, F.Z.S.

\section{BROWN TREE-KANGAROO}

This species represents the group in North Queensland
Some considerable amount of obscurity is associated with the prime origin of the animal's almost world-wide title of "Kangaroo." It is most commonly accepted as representing the native name for the creature in that Queens-. land district from whence it was first reported by Captain Cook. No later investigations and enquiries have, however, in any way established. the correctness of this hypothesis, those explorers who have made a special study of the dialects and habits of the aboriginal in habitants. entirely failing to elicit anything even remotely coinciding with the name in question. It has, in fact, been reluctantly concluded by one of the most experienced Queensland authorities on these matters that the name originated: as a mere miscomprehension of the informationi elicited from the natives. Verbal communication with the native tribes under the most favourable circumstances is liable to a vast amount of misunderstanding, and where other than linguistic experts are present it frequently happens that much mongrel or "pidgin English" gets mixed up with the native terms. Assuming this to have been the case in the present instance, it has been suggested that the name of Kangaroo, or "Kanguroo," as it was originally spelt, implied some form of negation of the knowledge which the enquiring white man was seeking to elicit, or, maybe, partly even a phonetic and parrot-like repetition of the constantly recurring query that was doubtless current among the "hindy men" of the Endeavour's commission, such as "Can you" tell me this or that concerning the many unfamiliar objects that greeted the eyes of the new arrivals in this strange land. The writer retains a vivid recollection of a closely analogous manner in which the rural inhabitants of Vigo Bay, on the Spanish coast, appropriated a common phrase used by the crew of the yacht with whom he landed there. Having evidently noted that the two words "I say" prefaced the majority of Jack-tar's speeches, this catch-phrase was adopted and applied by them as a greeting and as a reply to almost every interrogation in dumb-show or otherwise that was addressed to them. An unknown animal submitted to these rustic Solons would doubtless have been dubbed the "I say"; and had the land been a new one - say, somewhere in the South Seas - that name would probably have stuck to it. Applying this interpretation to the kangaroo, and bearing in mind the fondness of the Australian native to duplicate his name-words or syllables - e. g. wagga wagga, debil-debil, and so forth - the "Kang-you-you" or a closely resembling phonetic expression would present itself to the native mind as a much more correct rendering of the simpler "Can you" or "Kang you" which he had picked up as a catch-phrase from the Endeavour's crew. In the absence, at all events, of any more rational interpretation of the mystery, this one would seem to merit consideration.

While the kangaroo is being speedily dethroned from the dominant position it originally occupied in the indigenous Australian fauna, praiseworthy and highly successful attempts have been made to acclimatise this marsupial in one of the English Parks, Woburn Abbey, and elsewhere, where troops of these graceful creatures may be seen under conditions of happiness and liberty scarcely inferior to those by which they are environed in their native "bush." 
Of smaller members of the Kangaroo Family, there are some thirty distinct forms, popularly known in Australia as Wallabies, WaLlaroos, Paddy-melons, Potoroos, Kangaroo-hares, KANGAROO-RATS, etc. The wallabies, which represent the most important group with regard to their larger size and economic utility, number some fourteen or fifteen species, and are distinguished, with relation more especially to thcir habitats or peculiar structure, as ROCK-, BRLsiITAIL, and SpUr-Tail Wallabies, etc. Among the rock-wallabies the yellow footed species from South Australia is undoubtedly one of the handsomest as well as the largest member of its group, the uniform grey characteristic of the majority of its members being in this instance represented by an elegantly striped and banded form, in which the several tints of brown, yellow, black, and white are pleasingly interblended. The successful stalking of rockwallabies in their native fastnesses entails no mean amount of patience and agility. Although these animals are so abundant in favoured localities as to make hard-beaten tracks to and fro betwixt their rock-dwellings and their pasturegrounds, one may traverse the country in broad daylight without catching a glimpse of a single individual. One species, about the size of a large rabbit, is very plentiful among the socky bastion-like hills that border the Ord River, which flows into Cambridge Gulf, in Western Australia. Efforts to stalk examples in broad daylight proved fruitless; but by sallying out a little before daybreak, so as to arrive at their feeding-grounds while the light was still dim, the writer succeeded in securing several specimens. Many of these rock-wallabies are notable for the length, fine texture, and pleasing tints of their fur, their skins on such account being highly esteemed for the composition of carriage-rugs and other furry articles.

Of the larger brush or scrub varieties, the

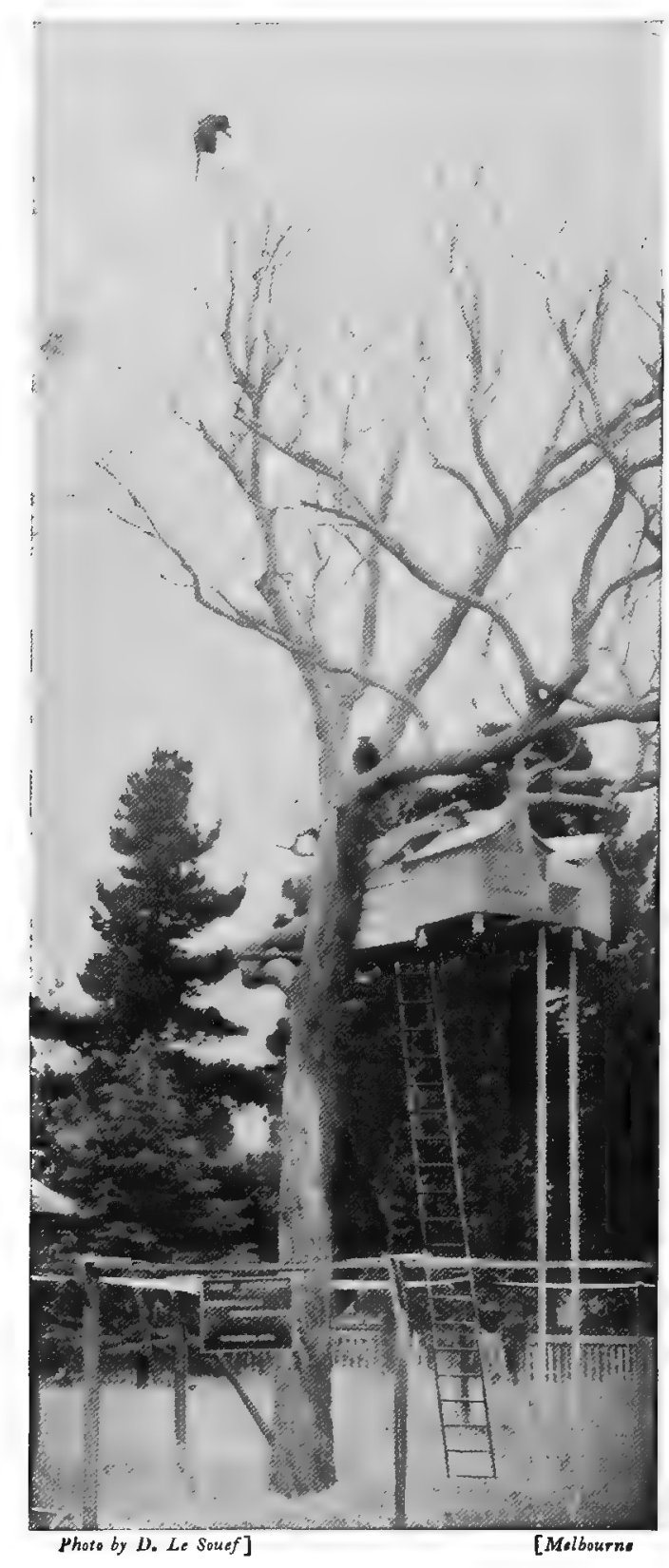

TREE-KANGAROOS

Examples acclimatised in the Melbourne, Zoological Gardens species known as the BLACK WALLABY is the most familiar form. It is particularly abundant in the Southern Australian States, and also in Tasmania. Its flesh is excellent eating, and, dressed and served up in the orthodox manner of jugged hare, can scarcely be distinguished from that toothsome dish. Some of the smaller species, such as the hare- and rat.kangaroos or potoroos, are, as their names denote, of no larger dimensions than the familiar rodents from which they are popularly named. Several of these smaller species, including notably the potoroo, or kangaroo-rat of New South Wales, are addicted to paying marked attention to the settlers' gardens, and, being to a large extent root-feeders, have acquired a special predi 


\section{I 8 THE LIVING ANIMALS OF THE WORLD}

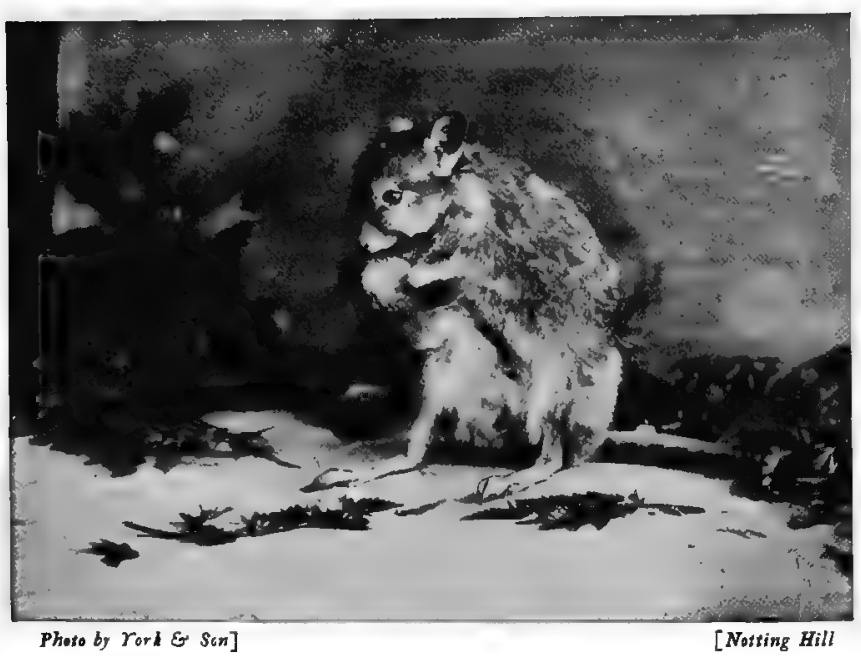

GAIMARD'S RAT-KANGAROO

A species named afrer the French naturalist, Gaimard lection for the newly planted or more fully matured potato crops.

The most abnormal group of the Kangaroo Family is undoubtedly that of the TREE-KANGAROOS, formerly supposed to have been limited in its distribution to the island of New Guinea, but which has within recent years been found to be represented by one or more species in Northern Queensland. At the Melbourne Zoo they have been found, except in the coldest weather, to thrive well in the open a moderate-sized tree, with a small fenced-in enclosure around it, being admirably suited to their requirements, at the same time providing a most instructive exhibition of their peculiar forms and idiosyncrasies.

Seen at its best, however, the tree-kangaroo, or "boongarry," as it is known amongst the Queensland natives, is a most clumsy, melancholy-looking beast, which has apparently found itself "up a tree," not as the outcome of its personal predilections, but owing to the force majeure of untoward pressure in the form either of relentlessly persecuting enemies or the failure of its normal terrestrial commissariat. Compared with the graceful and superlatively agile tree-frequenting phalangers, between whom and the ordinary kangaroos it has been sometimes, but erroneously, regarded as representing a connecting-link, the boongarry presents a most ungainly contrast. Its climbing powers are of the slowest and most awkward description, the whole of its energies being concentrated on its endeavour to preserve its balance and to retain a tight hold upon the branches of the trees it frequents, and to which it clings with such tenacity with its long sharp claws that it can with difficulty be detached. In its wild state, moreover, these claws can be very effectively used as weapons of defence; and hence the natives, with whom the animal is highly esteemed as an article of food, are careful to give it its quietus with their clubs or waddies before venturing to handle it. The tree-kangaroos inhabit the densest parts of the forests or "scrubs" of New Guinea and tropical Queensland, and appear to confine their movements chiefly to the trees of moderate size, or the lower branches only of the taller ones.

The species which constitutes the most natural known connecting-link between the typical Kangaroos and the family of the Phalangers, next described, is the FIVE-TOED Rat-Kangaroo, or Potoroo. As its name implies, it is a small creature of rat-like aspect and dimensions, and possesses, like a rat, a long, cylindrical, naked, scaly tail. It is the structure of the feet, however, that constitutes the important distinction. In place of the four toes only to the hind limbs it possesses the full complement of five, and the first toe, moreover, is set farther back, and is opposable for grasping purposes. This animal is from Queensland.

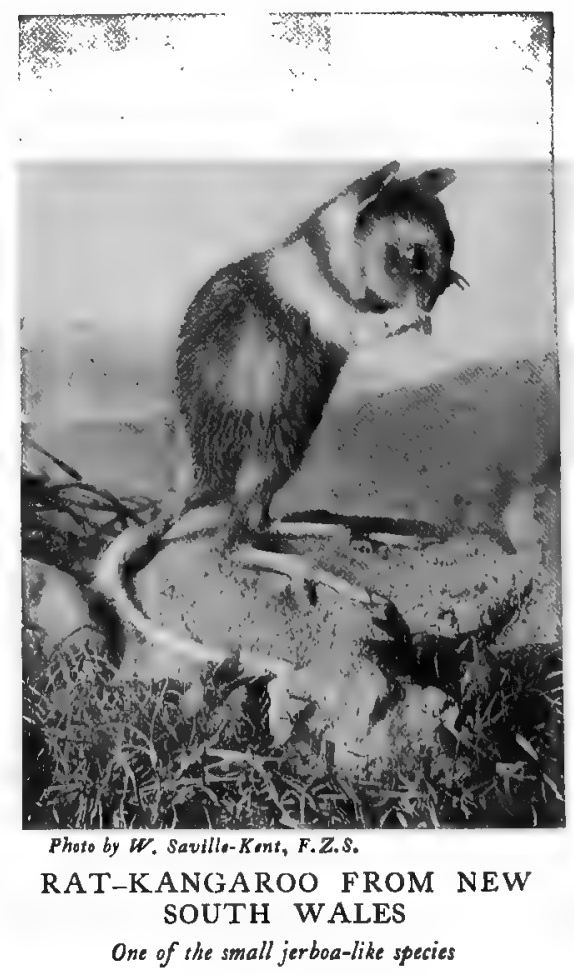




\section{The Phalangers}

The Phalanger Family of Marsupials, which next invites attention, is constituted of animals especially adapted to lead an arboreal life, though among themselves they exhibit very considerable structural variations. The species usually placed at the head of this group is the essentially droll and in many respects abnormal form known as the KOALA, or AUSTRALIAN Native BEar. Its little podgy tailless body, short thick-set head, and round tufted ears lend some countenance perhaps to the ursine analogy; but there the likeness ends.

The koala is limited in its distribution to the southeastern region of the Australian Continent, and is there found inhabiting the loftiest gumtrees, on the leaves and flowers of which it almost exclusively feeds. Compared with the opossum and squirrel-like phalangers, the koala is a very slow and sedentary little animal, remaining stationary in and browsing upon the leaves of the same gum-tree

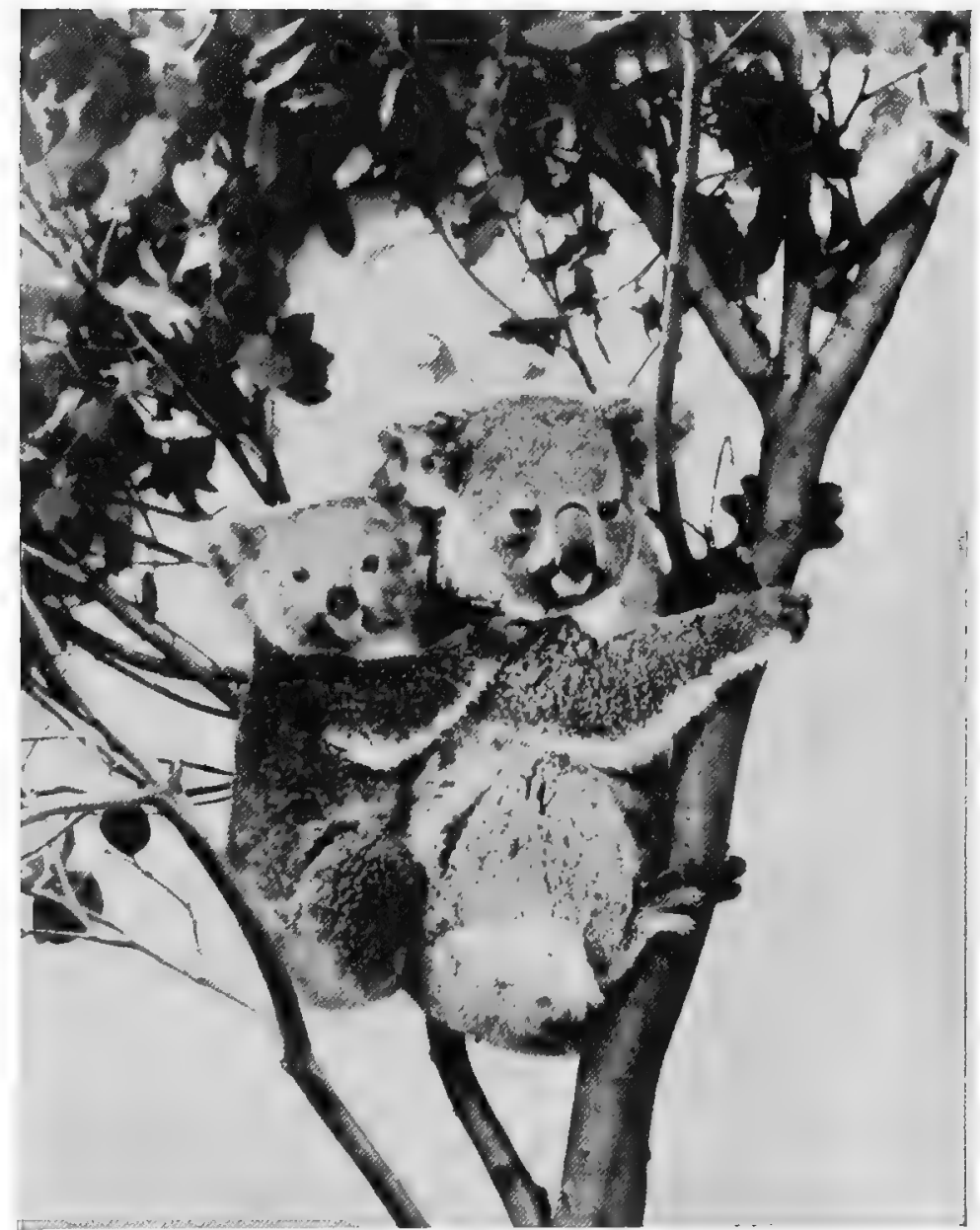

Photo by W. Saville-Kent, F Z.S.

KOALA, OR AUSTRALIAN NATIVE BEAR AND CUB An excellent illustration of the way in which the female koalas carry their young securely perched on their backs

for days or even weeks at a stretch. Taking advantage of this home-staying propensity, examples are established, with full liberty to wander at will among the large gum trees, in the Melbourne Zoological Gardens, and have never abused the confidence reposed in them by surreptitiously absconding. The young koalas in particular make the most droll and delightful of houschold pets, speedily becoming attached to and following their owners about the premises, or contentedly settling down to the possession of an allotted corner of the verandah, in which an improvised perch has been erected and a constant supply of its favourite gum-leaves is daily assured. One such example, kept in Brisbane, Queensland, furnished the writer with the material for the photograph on this page; also of another one that illustrated in an interesting manner the very singular attitude assumed by the animal when asleep. Instead of creeping into the hollow trunk or spout of a gum or other tree, as the opossums and other phalangers are wont to do, the little "bear" simply sticks tight to his supporting branch, and, tucking in his head and ears and limbs, converts himself into an apparently homogeneous rounded mass of fur or moss, and, thus disguised, peacefully sleeps. Seen at some little distance, in fact, none but a trained eye could distinguish this sleeping bear from one of the round woody excrescences or bunches of mistletoe-like parasitic growths that are of common occurrence on the trees in every gum forest. In this way the little creature secures immunity from the 


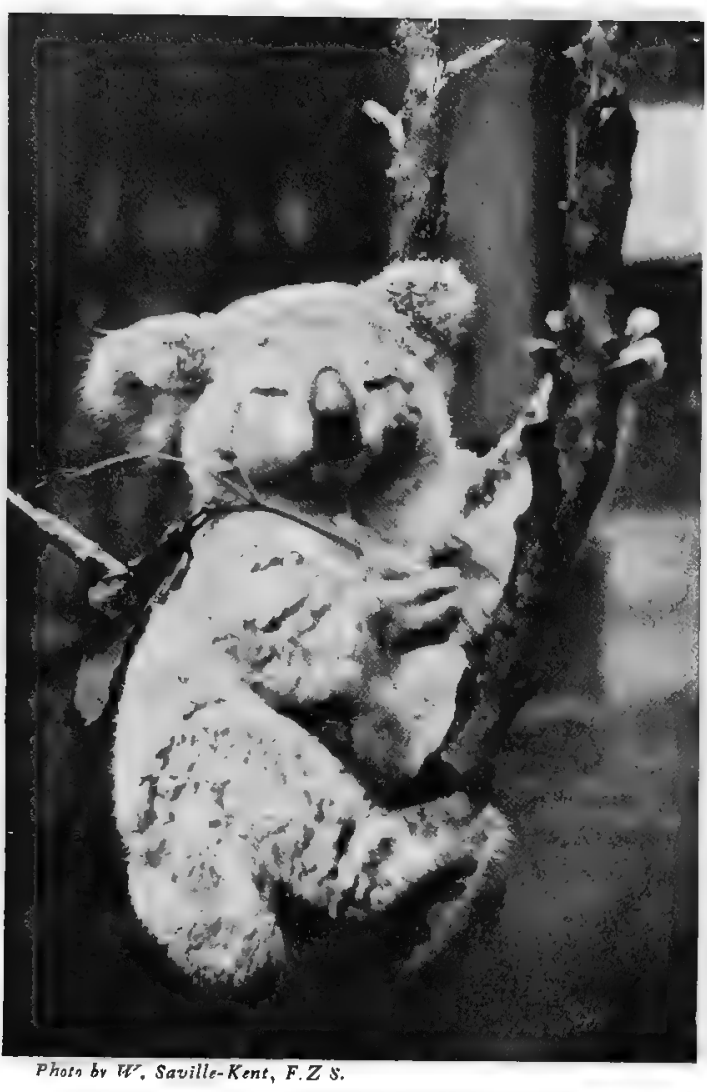

KOALA, OR AUSTRALIAN NATIVE BEAR

The koala has no tail, and is a stout, clumsily built animal, about 32 inches in length, with thick woolly fur of a greyish colour attacks of enemies by mimiching the characteristic peculiarities of its environment, as obtains so generally among insects and other of the lower orders of animated nature. A closely analogous sleeping attitude, itmay be mentioned, is assumed by one of the African lemurs or pottos, which have been dealt with in a previous chapter.

Although in captivity the koala takes kindly to a mixed diet in which bread-and-milk and fruit may form substantial elements, it can rarely be induccd to altogether dispense with its customary gum-leaf regimen, and it is this circumstance that mainly accounts for its rarity in European menageries. Time and again, however, this interesting animal has put in an appearance at the Regrent's Park; but in spite of Kew Gardens and other sources being laid under contribution for a supply of gum-tree leaves, its sojourn there has been but brief. As a matter of fact, the common or blue gum-tree, which is alone cultivated and available in any quantity in this country, and which is indigenous to Tasmania, is not the spccies on which the koala is accustomed to fced. Of gum-trees there are some hundred species, every one differing in the peculiarity of its aromatic scent and flavour, and having its special clientèle among the ranks of leafbrowsing animals. So far as the writer's observations extended, it was the big Queensland "white" and "swamp" gums that were especially patronised by the Australian bears, and these are not grown in England.

Although at first sight, and normally so far as the younger individuals are concerned, the koala would appear to represent the most perfect embodiment of peace and goodwill among mammals, he is accredited at a maturer age, when crossed in love or goaded to resentment by some other cause, to give way to fits of ungovernable rage. These temporary lapses are, however, very transient, and our little friend soon recovers his customary bland placidity. While it is being threshed out, nevertheless, the "burden of song" delivered by rival claimants for a partner's favours is a remarkable phenomenon. The circumstance that the vocal duet is commonly executed high up among the branches of the loftiest gums no doubt adds very considerably to both the timbre of the "music" and the distance to which it is carried. The old-time phrase of "making the welkin ring" would undoubtedly have been applied with alacrity and singular appropriateness by the poets of the departed century to the love-song of the koala, had they been privileged to hear it.

Among the examples of the koala which have been in residence at the Zoo, one of

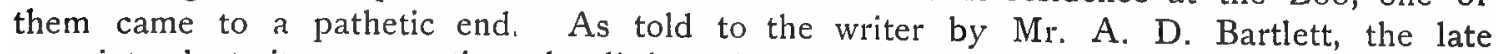
superintendent, it appears that the little animal, on exhibition in the gardens during the day, was brought into the house at night, and allowed the run of a room which, among other furniture, included a large swing looking-glass. One morning the little creature was found crushed to death beneath the mirror, upon which it had apparently climbed and over balanced. The information that the animal was a female evoked the suspicion that personal vanity and 


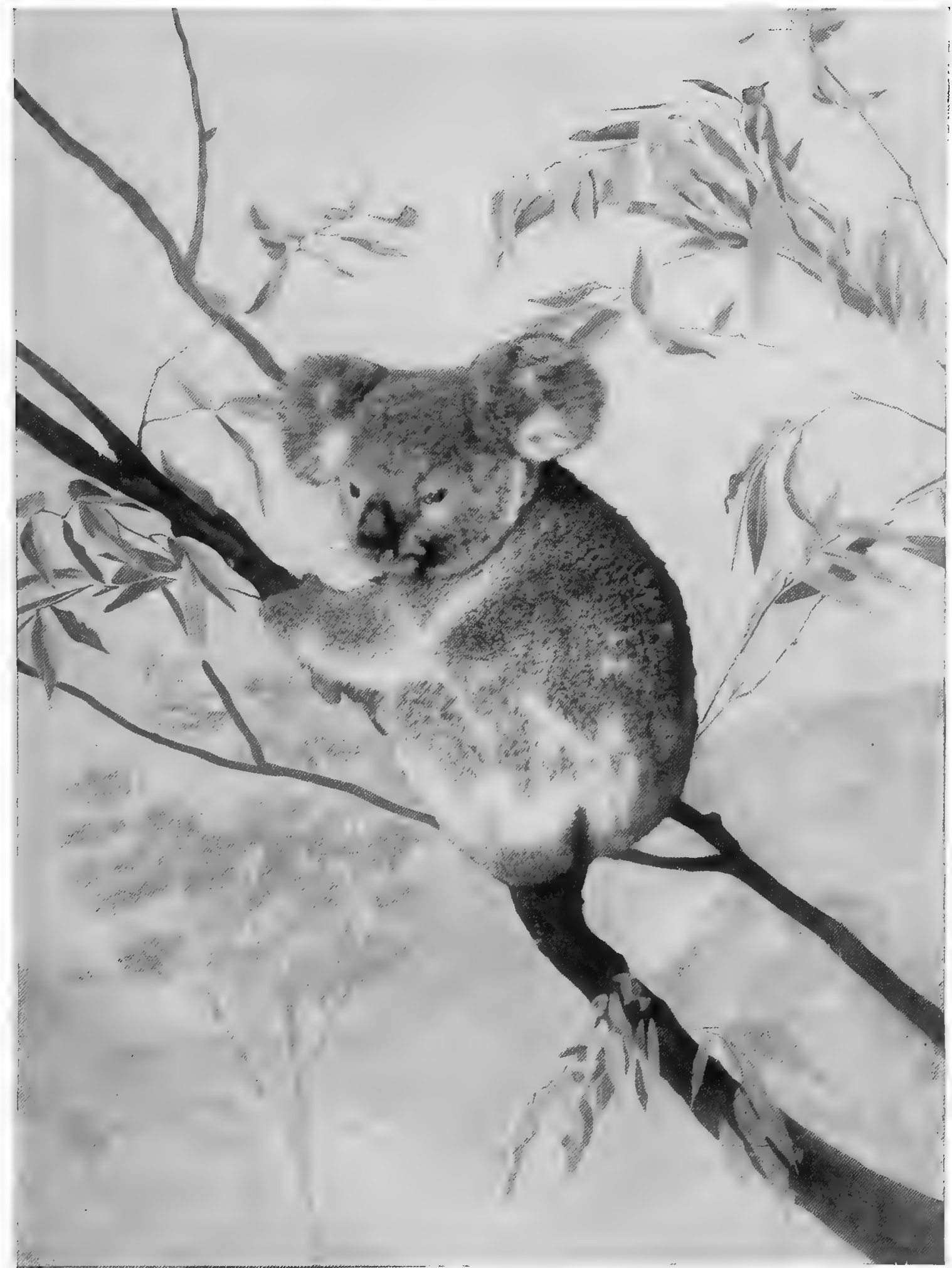

Photo by W. Saville-Kent, F.Z.S.

KOALA, OR AUSTRALIAN NATIVE BEAR

These animals make a peculiarly plaintive cry when molested in any way by human beings 
the admiration of its own image in the glass had some share in compassing its untimely end. Possibly, however, it hailed in the reflection the welcome advent of a companion to share its lone banishment from the land of the gum-tree, and in its efforts to greet it thus came to grief.

The female koala produces but one cub at a time. At an early period after its birth this is transferred to its mother's back, and is thus transported until its dimensions are about one-half of those of its parent. The pair as shown in the illustration on page 355 presents, under these conditions, an cssentially grotesque aspect.

It is a noteworthy circumstance that, compared with the male, the female koala is but rarely to be observed wandering abroad during broad daylight. As with the typical phalangers food is consumed chiefly at night or during the brief Australian twilight hours. While the male at certain periods, more especially the months of March and April, is much in evidence in daytime to both the senses of sight and hearing, as attested to on a previous page, the female spends the whole or greater portion of the day clinging as an inert sleeping mass to a convenient branch. "Bear"-shooting in Australia, as might be anticipated from the description here given of the animal's habits and temperament, affords but sorry sport. It may further be remarked that those who have shot at and only disabled one of these inoffensive little creatures are scarcely likely to repeat the experiment. The cry of a wounded koala has been aptly compared to that of a distressed child, but still more pathetic. When fatally shot, it also more frequently than otherwise clings tenaciously back-downwards, like the South American sloths, to the supporting tree-branch, and is thus frequently irrecoverable. With the nonsentimental Australian furrier the koala's pelt of soft, crisp, ashy-grey fur is unfortunately in considerable demand, being made up mostly, with the quaint round head and tufted ears intact, into, it must be confessed, singularly attractive and warm rugs.

The correspondence of the koala in form and habits to the sloths among the higher mammalia has been previously mentioned. The parallelism might be pursued in yet another direction. In earlier times the small tree-inhabiting South American sloths were supplemented

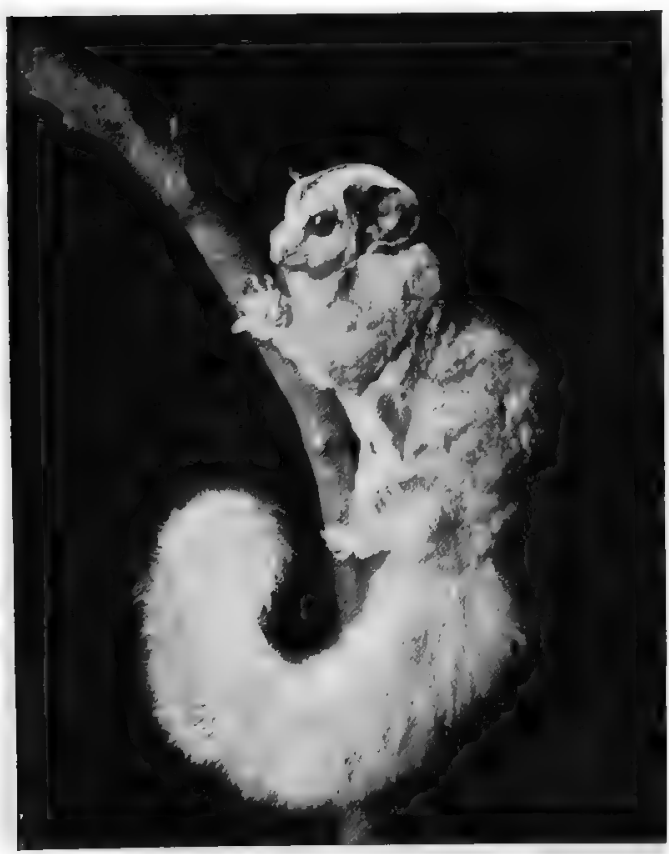

Photo by W. Saville-Kene, F.Z.S.

SQUIRREL-LIKE FLYING-PHALANGER OF VICTORIA

This animal has soft grey fur like that of the chinchilla by ground-frequenting species, such as the Megatherium, which were of comparatively titanic proportions. The epoch of the accredited existence of these huge ground-sloths was so comparatively recent - the later tertiaries - that it is even yet not regarded as altogether improbable that some existing representative of the race may yet be discovered in the fastnesses of the South American forests, and thus claim a niche in the pages of a subsequent edition of "Living Animals." In a like manner the little sloth-like tree-frequenting "Australian Bear" had his primeval ground-dwelling colossi, and there is yet a lurking hope among enthusiastic zoologists that some surviving scion of the little koala's doughty forebears may yet turn up in the practically unexplored Central Australian wildernesses. Some such anticipations, as a matter of fact, stimulated the hopes and aspirations of the participators in one of the latest of these exploring expeditions, which, while not successful in this instance in obtaining so great a prize, secured for science that most interesting and previously unknown marsupial mammal the Pouched Mole. 


\section{The Typical Phalangers}

The typical Phalangers, or Opossums, as they are familiarly known throughout Australia, include a very considerable number of representatives, ranging in size from that of a small mouse to that of a full-grown cat. All are essentially arboreal in their habits, feeding principally on the leaves and flowers of the various gums. They are for the most part strictly nocturnal in their habits, and make their homes and retiringplaces during the day in the hollow trunks and limbs that are of such abundant occurrence in the periodically fire-swept Australian forests. Almost all the larger species are notable for the length, thickness, and exquisitely fine texture of their fur, a circumstance for which they are consequently laid under heavy penalties for the sake of their pelts. The island colony of Tasmania, in the extreme south, with its colder climate, as might be anticipated, produces the finest qualities of these furs, that of the BLACK or SоOту OPOSSUM, which is peculiar to the island, being most highly prized. The length and furry character of their in many instances prehensile tails also form a conspicuous feature of this group. Nature, in fact, apparently distributed caudal material so over-liberally among these marsupials that the little koala had to make shift without.

The group of the Phalanger Family

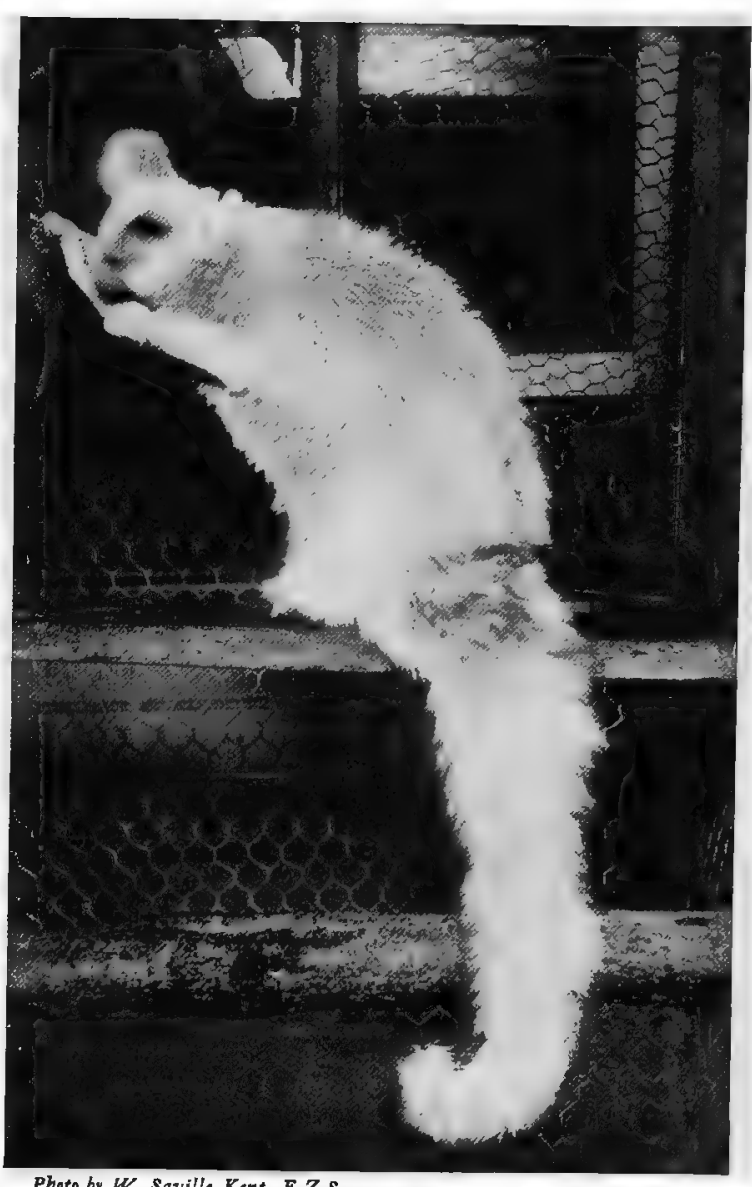

Phato by W. Saville-Kent, F.Z.S.

LARGER FLYING-PHALANGER

$A$ nearly pure white example

popularly known as FLYING-SQUIRRELS, or more correctly as FLYING-PHALANGERS, is almost universally admitted to include some of the most beautiful of living mammals. In external structure, so far as their peculiar so-called "flying" mechanism is concerned, these animals coincide in a remarkable manner with the true flying-squirrels, belonging to the Rodent Order, indigenous to the Asiatic and American Continents. In neither instance is there flight, in the true sense of the term, similar to that of birds and bats, but the fore and hind limbs are connected by a parachute-like membrane, which, outstretched when the animal leaps from tree to tree, buoys it up and enables its owner to traverse, in a straight and gradually descending line only, very considerable distances.

The smaller squirrel-like form common to the south-eastern districts of Australia, and on account of its predilection for sweets commonly known as the SUGAR-SQUIRREL, makes a most charming little pet. For the most part addicted to sleep, and impatient at being disturbed during the day, towards sundown it wakes up, and is full of frolic. One such example was the writer's traveling companion for a considerable interval in Western Australia. While remaining packed conveniently away in a small box throughout the day, it was accustomed to enjoy the liberty of whatever apartment its owner occupied in the evening and throughout the night, returning of its own accord to its sleeping-box with the approach of dawn. On one exceptional occasion, however, Master Tiny, as this individual was named, was missing in the morning from his accustomed crib, and a prolonged search and examination of every 
corner and article of furniture that could afford shelter failed to recover him. That the little creature was lost through some one having unwittingly left the door of the apartment open, permitting its escape, was the only and much deplored conclusion that could be arrived at. Towards evening, however, there was a slight rustle close at hand, and Master Tiny was discovered emerging, like Minerva from the head of Jupiter, from the top of one of the old-fashioned china dogs that decorated the hotel room mantelpiece. The ornament, seemingly intact from the front, had the back of the head battered in. Through the resulting crevice the little animal had managed to squeeze itself, having come to the conclusion, doubtless, that this newly chosen retreat more nearly resembled the cavernous shelter of its native trec-spout than its accustomed artificially constructed box. This singular domicile Master Tiny was permitted to monopolise for the remainder of his sojourn at that hostelry. One of the favourite diversions of this little phalanger during the evenings was to climb up the curtain and cornice of the room he occupicd, and thence hurl himself through the air with outspread parachute to the writer at the opposite end. The apartment, happening to be the commercial room of the hotel, some thirty feet in length, gave him good scope for exercising his characteristic flying leaps. The attitude invariably maintained during these flights is aptly illustrated in the accompanying photograph; the body is never poised with the head inclined downwards, as is commonly depicted in artists' fancy sketches of the animal contained in popular natural histories. A friend of the writer's in Tasmania, who kept one of these flying-phalangers as a household pet, was accustomed to leave a crevice of the window open at night, so that the little fellow could go in and out as it liked. After the manner of most pets, however, a day arrived upon which its box was found vacant, a marauding cat or other disaster having apparently compassed its untimely end.

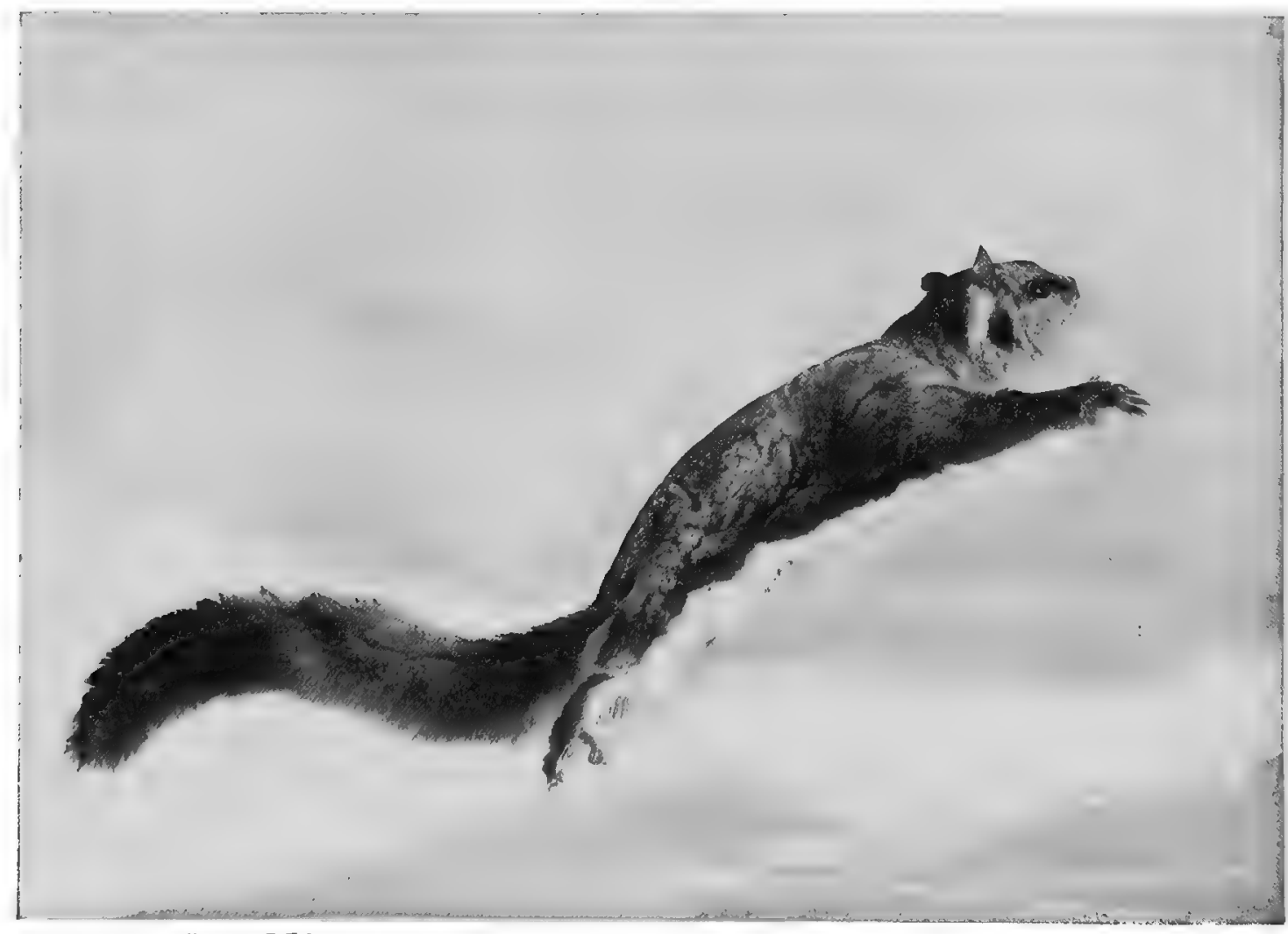

Phoso by W. Saville-Kent, F.Z.S.

LESSER FLYING-PHALANGER

Illustrating postion maintained during its remarkable fying leaps 
The larger flyingphalanger, the dimensions of our domestic tabby, and with fur as long and as soft as the Persian variety, is less frequently domesticated. It has, in fact, an evil reputation for scratching, biting, and general untamableness. One that was kept for some little time by the late Dr. Bennett, of Sydney, and brought to England, never entirely lost its innate savagery. On the voyage from Australia it Decame sufficiently tame as to be allowed occasionally to run about on the deck, and was so far amiable as to lay on its back and permit itself to be tickled. On attempting to handle it, however, " it displayed its usual savage disposition, digging its sharp claws and teeth into the hands of its captor." The writer was fortunate in being the recipient in Queensland of a couple of these large phalangers which were exceptions to the usual rule. These specimens-a mother and its young male offspring -also varied in colour from normal examples, which are usually dark slate or blackish brown above and whitish underneath. The mother in this instance was

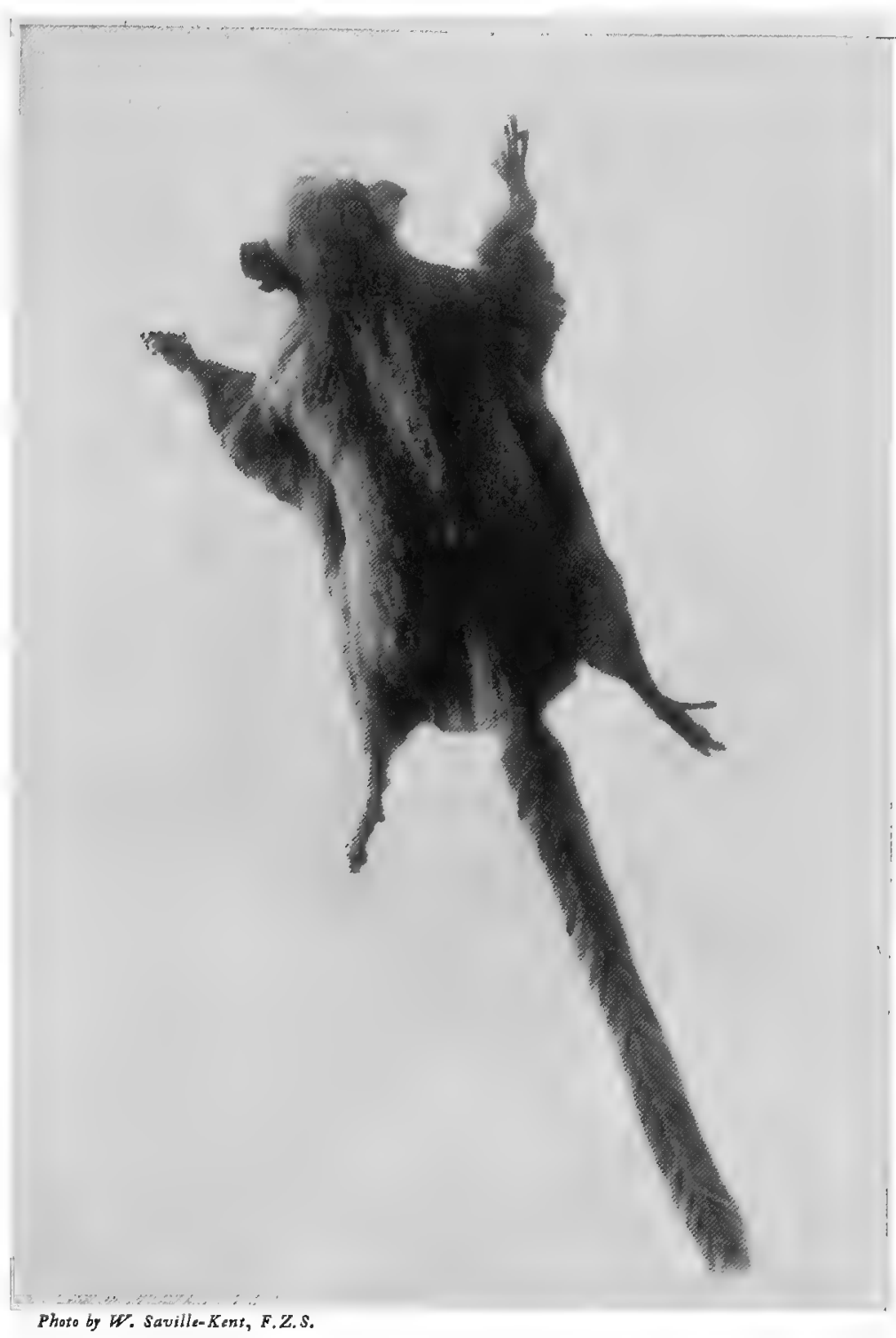

PYGMY FLYING-PHALANGER

A life-size photograph. The hairs of the tail in this animal are arranged in two parallel lines, like the vanes of a bird's feather

a beautiful cream-white throughout; and her young one, while dark chinchilla-grey upon the back, limbs, and tail, had white ears and breast. Both were very friendly, and would of their own accord climb over their owner's person, seeking in his pockets for hidden lumps of sugar and other acceptable dainties. As with the smaller squirrel-like forms, they slept throughout the greater portion of the day, waking to activity and making excursions in search of their food as soon as the sun went down. The tail of this species of phalanger is abnormally long and furry, but not prehensile. It was observed of them that when feeding leisurely on the gum-tree leaves this appendage was permitted to hang or rest loosely, but that when walking along the branches they would very frequently coil this member into a tight spiral coil, like a watch-spring or the proboscis of a butterfly, against their hindquarters. This phenomenon is apparently unique among mammals. Although generally seeking the darker retreat of their box for their long daylight sleep, the female, more particularly, would frequently simply curl herself 


\section{THE LIVING ANIMALS OF THE WORLD}

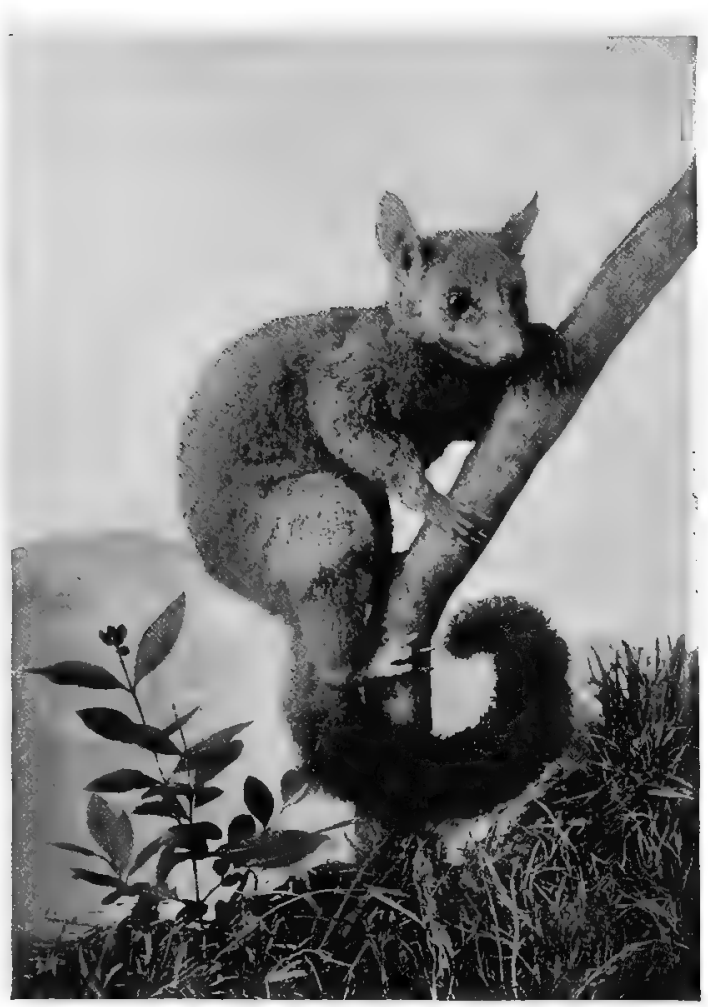

Photo by WV. Saville-Kent, F.Z.S.

COMMON GREY OPOSSUM, OR PHALANGER

The fur of this species is in great demand for the manufacture of carriage-rugr up into a furry white ball in one corner of the cage, the head, limbs, or other features being at such times altogether indistinguishable. The aid of the magnesium flash-light was successfully called into service to secure the photographic likeness of this animal, here reproduced, which was taken while it was enjoying its evening meal.

As previously mentioned, some representatives of the flying-phalanger group are no larger than mice, and are furnished in a similar manner with a parachute-like membrane that enables them to take abnormally long flying leaps, or as it were to sail horizontally through the air. The Pygmy Flying-PHALANGer, whose length of body does not exceed $2 \frac{1}{2}$ inches, is one of the most interesting. The tail in this form is also adapted for aerial flotation, the long hairs that grow upon this appendage being arranged in two parallel lines like the vanes of a feather. Its distribution is limited to the south and eastern districts of the Australian Continent. There are also a number of mouse- and squirrel-like phalangers destitute of the flying-membrane, which in this respect very closely resemble in external aspect more typical members of the Rodent Order. One form in particular, the Striped Phalanger of New Guinea, decorated with broad longitudinal black and white stripes, is singularly suggestive of some of the variously striped American squirrels. This interesting island of New Guinea also produces a little PyGMY PHALANGER with a feather-like tail which, except for the absence of a parachute or flyingmembrane, is the very counterpart of the Australian kind. Another species, which in shape, size, and more especially with reference to its long, pointed snout, closely resembles a shrewmouse, is found in Western Australia. The tail of this species, known as the LONG-SNOUTED PHALANGER, is highly prehensile; and it is also provided with a long, slender, protrusile tongue, with which it abstracts the honey from Banksias and other flowers, upon which it customarily feeds.

The two large phalangers knorvn as the BLACK and GREY or VULPINE OPOSSUMS, which are chiefly laid under contribution for the Australian fur supplies, are provided with prehensile tails, the under side of the extremity of which grasps the supporting fulcrum and is devoid of hair. The adaptation of the tail for use as a fifth hand - as in the New World monkeys is, however, much more conspicuously manifested in what are known to the colonists as the Ring-TAiled Opossums, and to zoologists as Crescent-Toothen Phalangers. In these the tail tapers to a fine point, and the hair throughout the terminal third of this appendage is so fine and short that it at first sight presents the appearance of being entirely naked. This terminal third of the tail, moreover, in the greater number of species, contrasts with the remaining portion by being white in hue. It occasionally happens, however, that individuals occur which are entirely white. One such which came into the writer's possession was obtained from the Bruni Islands, in the Derwent Estuary, Tasmania, and afterwards became a great pet with the young people at Government House, Hobart. It is an interesting circumstance that the Bruni Islands were noted for the production of albino animals of various descriptions, white kangaroos and white emus having also been obtained from this locality. Probably some peculiarity of the soil, and its action on the vegetable food the animals 


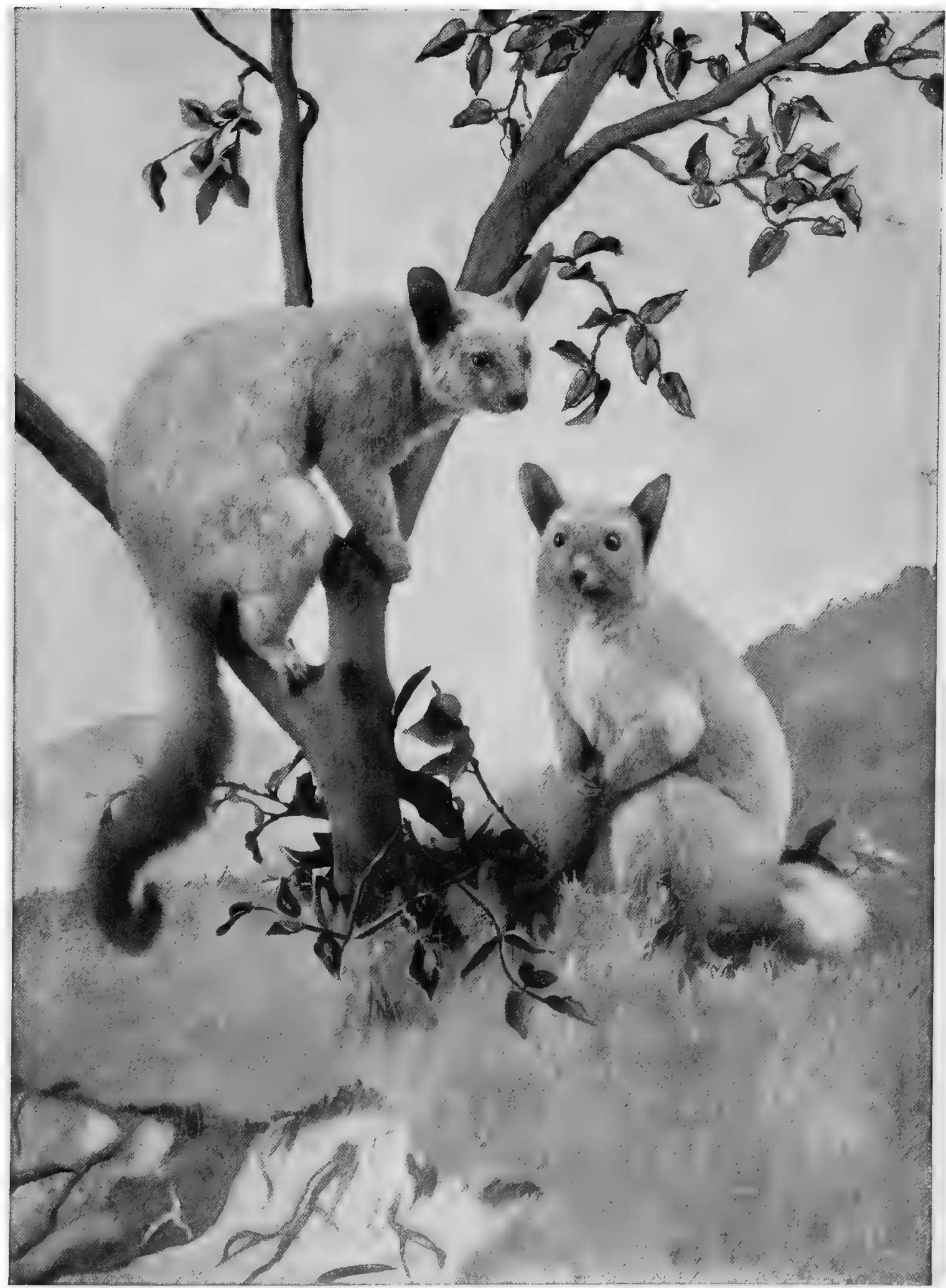

Photo oy Henry King]

AUSTRALIAN GREY OPOSSUM, OR PHALANGER

On account of its "foxy" appearance, this species is also known as the Vulpine Phalanger 


\section{THE LIVING ANIMALS OF THE WORLD}

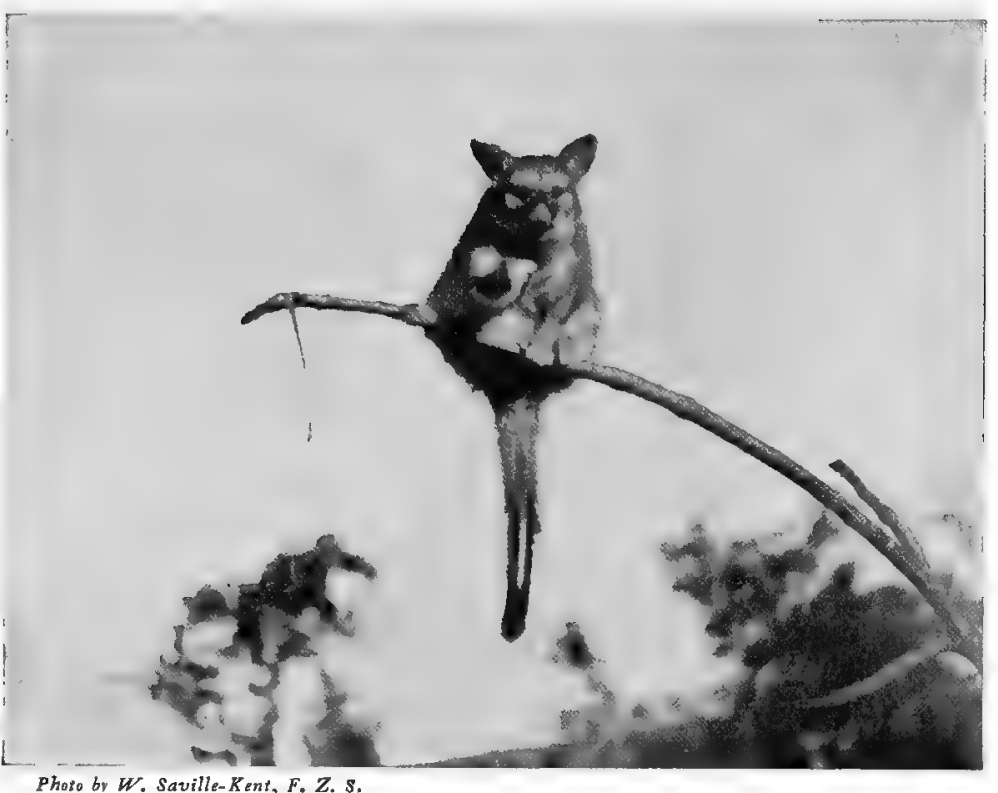

FRONT VIEW OF GREY OPOSSUM, OR PHALANGER

Displays the bare under-surface of the prehensile tail consumed, played an important part in the unusally frequent occurrence of this phenomenon.

The ring-tailed opossums differ essentially from the common opossum or phalanger and its allies in their life habits. While these latter habitually take up their abode and bring forth their young in hollow trees, the ringtailed species construct a regular nest of interlaced sticks, leaves, grass, or any other available material for their domicile. The structure much resembles the nest, or "drey," of our own familiar squirrel, and may be perched high up among the tree branches or within only a few feet from the

ground among the scrub thickets. In New Guinea a variety of these ring-tailed phalangers occurs, not found in Australia, which has no white tip to its tail, and the ears are very short and wide. The group as represented by this species leads to the consideration of the so-called Cuscuses or typical phalangers indigenous to New Guinea and North Queensland, though but rarely seen there, which, as an exception to the Marsupial Tribe, are distributed among the Indo-Malay Islands as far westward as Celebes. In the cuscuses the tail is altogether naked, and pre-eminently prehensile throughout almost its entire terminal moiety; the ears are round and, proportionately, exceedingly small; while the fur is very short, thick, and woolly. Compared with the opossums or phalangers, the cuscuses are very dull and sluggish in their movements, creeping slowly among the branches of the trees to browse on the fruit and leaves which constitute their principal diet. Like the opossums, however, or even to a greater extent, they vary this vegetarian regimen with insects or an occasionally captured bird.

\section{The Cuscuses}

The familiar SpotTed Cuscus of New Guinea is the most ornate marsupial mammal. The males, more especially, are as variegated in colour as a tortoiseshell cat, their tints, moreover, closely corresponding in hue with those of the feline. No two individuals, however, are precisely alike in this respect. Usually the ground-colour of the

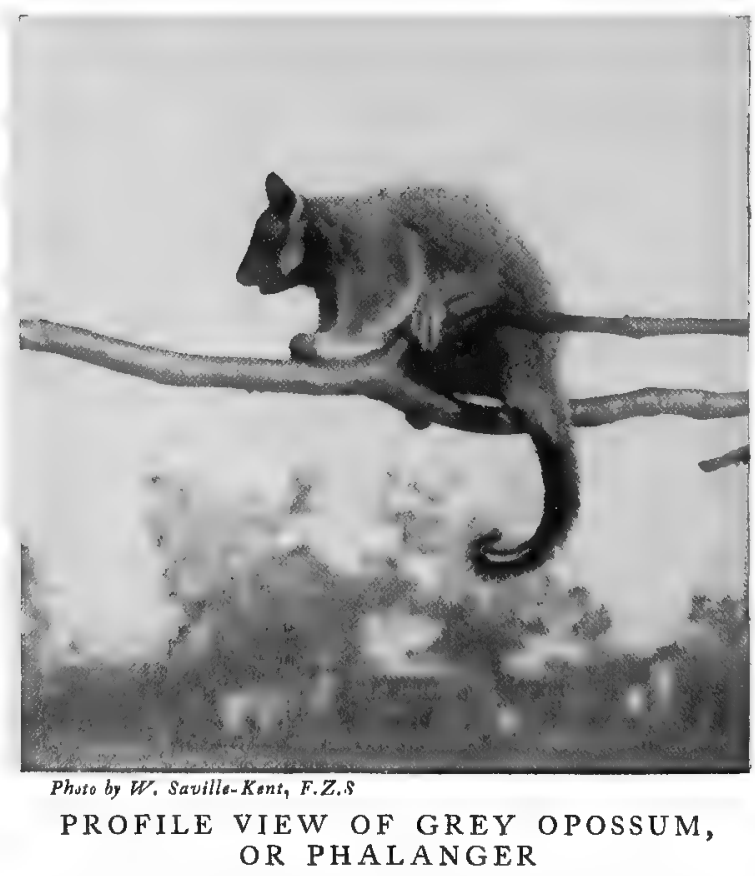

The opossums are usually shot by moonlight, as seen silhouetted against 
back is a dirty or creamy white, interspersed with various-shaped blotches of nut-brown or black ; the chin, breast, and under-parts are a purer white, and the limbs grey or reddish brown, or, as shown in the photograph over-leaf, mottled like the body. The BLACK Cuscus of Celebes is, as its name denotes, a much more sombrelooking animal, and is also the largest species, its dimensions equalling or exceeding those of a large cat. The uniformly tinted GREY CUSCUS of Timor, Amboina, and other of the Indo-Malay Islands is very similar in size and aspect, excepting for the half-naked tail, to the common ringtailed phalanger. All the cuscuses are of rare occurrence in even their most favoured habitats. On one occasion the writer came across an example of the grey species in the scrub forest of Thursday Island, Torres Straits. In this instance, however, it is doubtful if the animal was not an escaped pet brought over from the neighbouring coast of New Guinea.

Much interesting information concerning different varieties of the cuscus is contained in Dr. Alfred Wallace's interesting work "The Malay Archipelago." An anecdote of one which was brought to this naturalist during his residence in the Aru Islands - the headquarters of the great bird of paradise - is thus related: "Just as we had cleared away and packed up for the night, a strange beast was brought, which had been shot by the natives. It resembled in size and in its white woolly covering a small fat lamb, but had short legs, hand-like feet with large claws, and a long prehensile tail. It was a Spotted Cuscus, one of the curious marsupial animals of the Papuan region, and I was very desirous to obtain the skin. The owners, however, said they wanted to eat it; and though I offered them a good price, and promised to give them all the meat, there was great hesitation. Suspecting the reason, I offered, though it was night, to set to work immediately, and get out the body for them, to which they agreed. The creature was much hacked about, and the two hind feet almost cut off, but it was the largest and finest 


\section{THE LIVING ANIMALS OF THE WORLD}

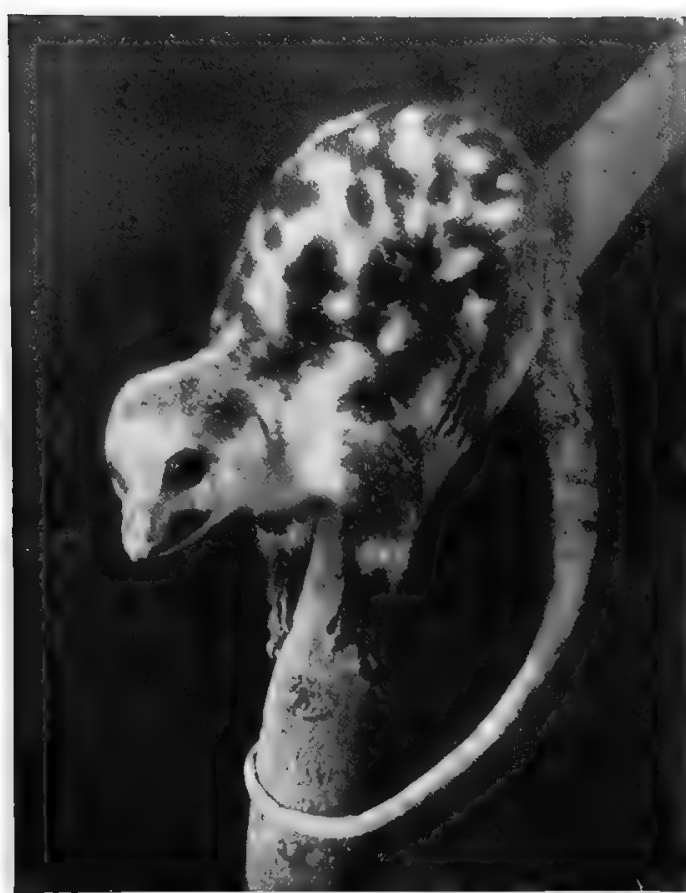

Photo by W. Saville-Kent, F.Z.S.]

[Crojdon

SPOTTED CUSCUS

The cuscuses are sleepy animals, with soft, woolly fur, which in this species is curiously variegated in colour

specimen of the kind I had seen; and after an hour's hard work I handed over the body to the owners, who inmediately cut it up and roasted it for supper."

The remarkable tenacity of life possessed by the cuscus is fully attested to by Dr. Wallace. He says: "They move about slowly, and are most difficult to kill, owing to the thickness of their skins and tenacity of life. A heavy charge of shot will often lodge in the skin and do them no harm, and even breaking the spine or piercing the brain will not kill them for some hours. The natives everywhere eat their flesh; and as their motions are so slow, easily catch them by climbing; so that it is wonderful that they have not been exterminated. It may be, however, that their dense woolly fur protects them from birds of prey, and the islands they live in are too thinly inhabited for man to be able to exterminate them."

One of the most notable circumstances respecting the cuscus is the fact that it is one of the few marsupials whose geographical distribution extends so far east in the Malay Archipelago as to be found associated with many of the higher mammalia which are altogether unrepresented in Australia or New Guinea. The Moluccas, including notably the islands of Silolo, Ceram, Boru, and many smaller ones, for example, produce no less than three species of cuscus, and are also the home of a species of baboon, a civetcat, a deer, and that remarkable pig the babirusa. One other marsupial, a little flyingphalanger, is likewise a denizen of these islands. It has been suggested by Dr. Wallace that none of the foregoing higher mammals are possibly indigenous to the Moluccas. The baboon, he remarks, is only found in the island of Batchian, and seems to be much out of place there. It probably originated from some individuals which escaped from confinement, these and similar animals being often kept as pets by the Malay inhabitants and carried about in their praus. The civet-cat, which is more common in the Philippines and throughout the Indo-Malay region, is also carried about in cages from one island to another, and not infrequently liberated after the civet has been abstracted from them. The deer, which is likewise tamed and petted, its flesh also being much. esteemed for food, might very naturally have been brought by the Malays from Java with the express object of its acclimatisation. The babirusa, whose headquarters are in the island of Celebes, is only found in Boru, its nearest neighbour in the Moluccan group. Dr. Wallace anticipates that these two islands were in former times more closely connected by land, and that under such conditions the babirusa may have swum across the intervening channel. Should these several hypotheses be correct, the Molucca Islands must not be regarded, from a zoological standpoint, as an essentially Australasian or marsupial-producing region.

\section{THE WOMBATS}

The Wombat Family, claiming the next position in the marsupial galaxy, constitutes the very antithesis to the light and graceful arboreal phalangers. There are but three known species, one of these inhabiting Tasmania and the adjacent islands, while the other two are peculiar to the southern region of the Australian Continent. In forms and gait their thick-set tailless bodies suggest a cross between a small bear and a capybara, and as "bears" and "badgers" 
they are familiarly known by the Australian colonists. The badger simile is perhaps the most pertinently applied with reference to their habit of excavating huge earth-burrows as dwellingplaces, and out of which they customarily emerge only at night to feed. The TASMANIAN Wомват, at all events, is essentially gregarious in its habits. In the neighbourhood of Swansea, on the east coast, it is, or was, particularly abundant, forming regular warrens among a light undergrowth of vegetation, through which traveling on horseback is a distinctly risky proceeding. The temperament of the wombat is peculiarly placid; and hence, as it might be anticipated, they are essentially long-lived. One, Charlie by name, which has been domiciled at the Zoo for the past thirty years, is still hale and hearty, and evidently disinclined yet awhile to immolate himself on the altar of fame as a much-needed successor to the antique effigy which has for so long represented his species in the British Natural History Museum. Waiting for dead men's shoes is a proverbially tedious task, and for a coveted wombat's skin evidently more so.

The tough hide, with its thick, harsh fur, of the Tasmanian wombat, or "badger," as it is locally dubbed, is somewhat highly prized in the land of its birth. For floor-and door-mats and rugs the pelt is practically indestructible; and as such, though scarcely a thing of beauty, the special pride of the thrifty housewife. This animal is also not infrequently made a household pet, and will waddle as complacently as an over-fed poodle around the premises after its owner. The wombat, like the large majority of the marsupial animals, is for the most part nocturnal in habits, and a strict vegetarian.

The wombats present several interestingly distinct structural peculiarities. In the first place, their teeth, which are twenty-four in number, all grow uninterruptedly throughout life, and are consequently devoid of roots. The incisor teeth are represented by but a single pair in each jaw, and, having enamel only on their front surfaces, wear away in a chisel-like form, as in the beavers and other rodents. Superficially in both form and habits, as well as in the character of their dentition, the wombats may in fact be aptly likened to some unwieldy representative of the Rodent Order. Another structural peculiarity of the wombat is that it is the proud possessor of two more pairs of ribs than any other marsupial.

Of the three known species, the COMmon Wombat of the South and Eastern Australian States is the largest, attaining to a length of as much as 3 feet. The colour of this form is subject to considerable variation, being sometimes yellow, yellow more or less mixed with black, or completely black. Albinism, as in the kangaroos and phalangers, is of apparently rare occurrence. The hair, while coarse, is less so than in the Tasmanian species. What is known as the HAIRY-NOSED WOMBAT, inhabiting South Australia, is intermediate in size between the common and the Tasmanianvarieties;

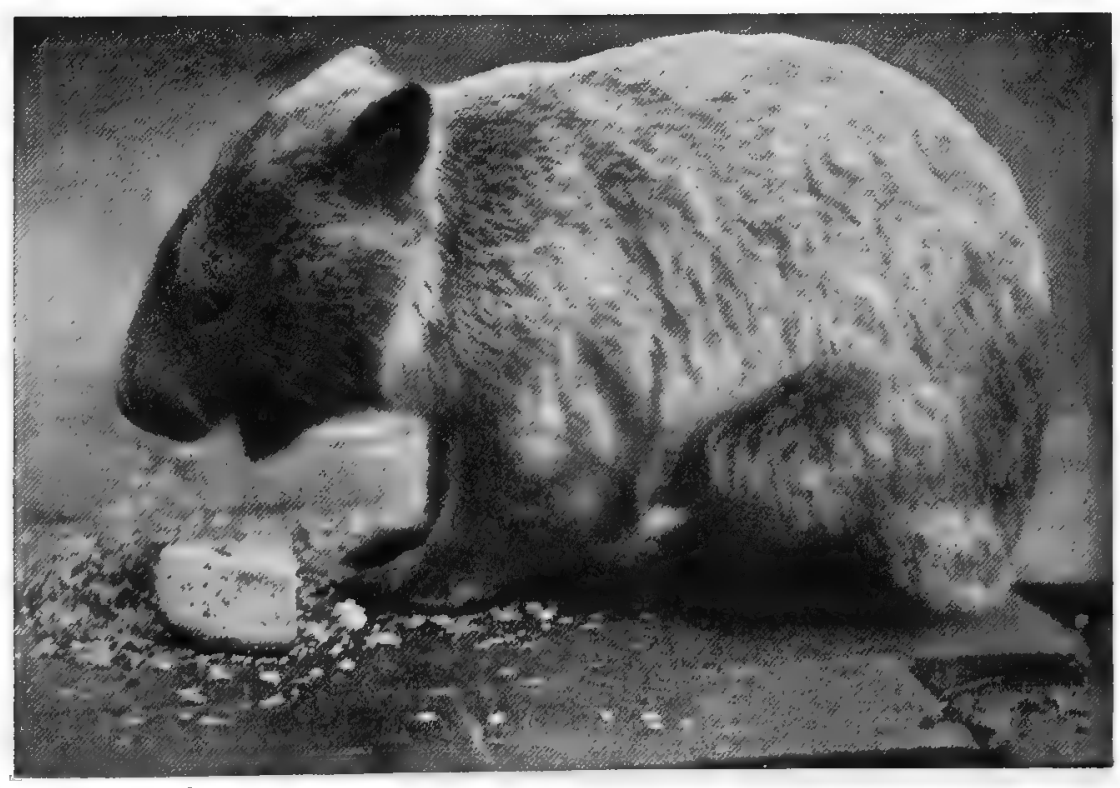

Photo by E. Zandor

A burrowing animal about the size of a small pig 
its most distinctive features are the soft and silky character of its brownish hair, and its longer and more pointed ears. The coarseness of the hair of the Tasmanian species has been previously referred to; in colour it is most usually a dark greyish brown, while the ears are small and rounded.

The flesh of the wombat is somewhat esteemed for food, being regarded by some as equal to pork, and much resembling it in flavour. The predilection of tame specimens for milk is very strong, and it has been recorded of one animal that it was not only in the habit of seeking out the milk-pans and pushing off the covers in order to drink the contents, but afterwards of taking a bath in what was left.

A remarkable habit has been accredited to the wombat which invites scientific investigation. It is said to be capable of sustaining life for an abnormally long period

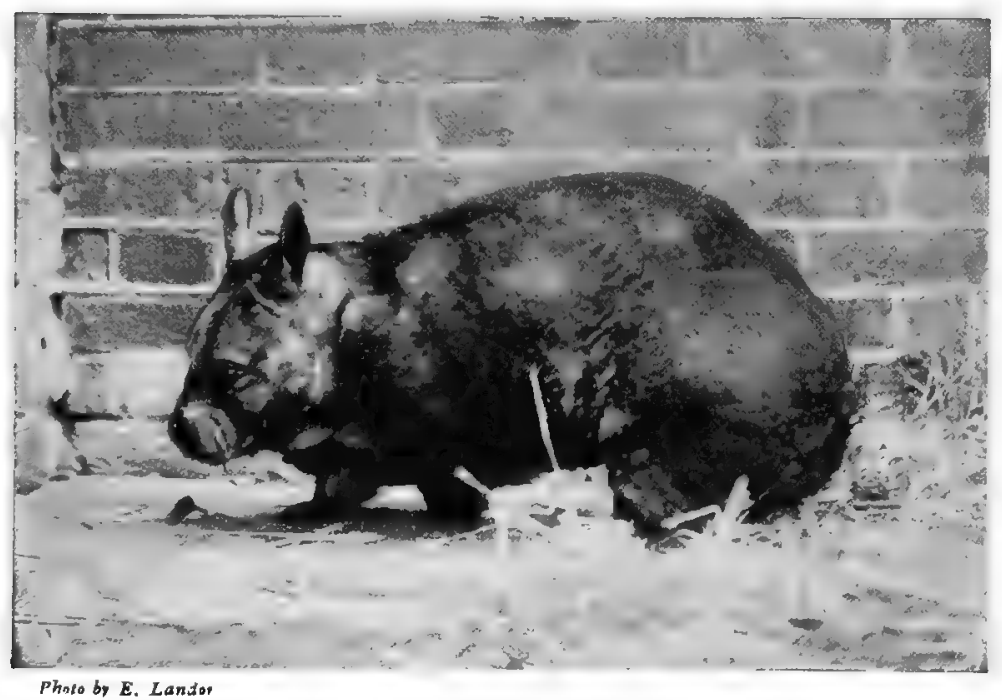

HAIRY-NOSED WOMBAT

A form peculiar to South Australia under water, and that when in the course of its travels it meets with a pond or river it does not attempt to swim, but, deliberately entering the water, walks along the bottom, and so emerges on the opposite bank.

The animals of Australia living in not very remote geological times included a near ally of the wombat which equalled a tapir in dimensions.

\section{The Bandicoots}

The Australian BANDIcooTs-not to be confounded with their namesake of India, which is a big rat - constitute a very distinct little family group. They number in all some eight or nine species, distributed throughout the length and breadth of Australia and Tasmania, and found also in New Guinea. The largest member is about the size of a rabbit; and as its general shape, long ears, and soft silky hair impart some slight resemblance to that rodent, it is commonly known as the RABBIT-BANDICOOT. With the above-enumerated points, however, the likeness ceases - its possession of a moderately long tail, pointed snout, and feet modified on a plan closely resembling those of the kangaroo's indicating its essentially distinct nature. In a second variety, having somewhat the same external contour, but smaller in size, the fore limbs are very short, and the feet so modified that only two toes are visible externally. With reference to this peculiar feature, it is known as the PIG-FOOTED BANDICOOT. In a third kind of similar dimensions, with harsh brown fur, the ears are comparatively short, and the snout is so abnormally prolonged that it has been appropriately named the LONG-NOSED BANDICOOT. Superficially, in point of fact, this and other allied species so closely resemble certain of the long-snouted insectivorous mammals, such as the Ienrec and Solenodon, that they might be excusably mistaken by the non-scientific for members of the same group. The bandicoots are chiefly nocturnal, and at all events incorrigible "sun-downers," turning up for their meals when the evening shadows fall, and taking a heavy and unwelcome toll of the farmers' potatoes, beets, or other root crops. Like the wombat, already described, they are earth-burrowers. Some of them, however, construct nests above-ground in long coarse grass or low tangled shrubs, which are so ingeniously built in accord with their environment as to readily escape detection. 


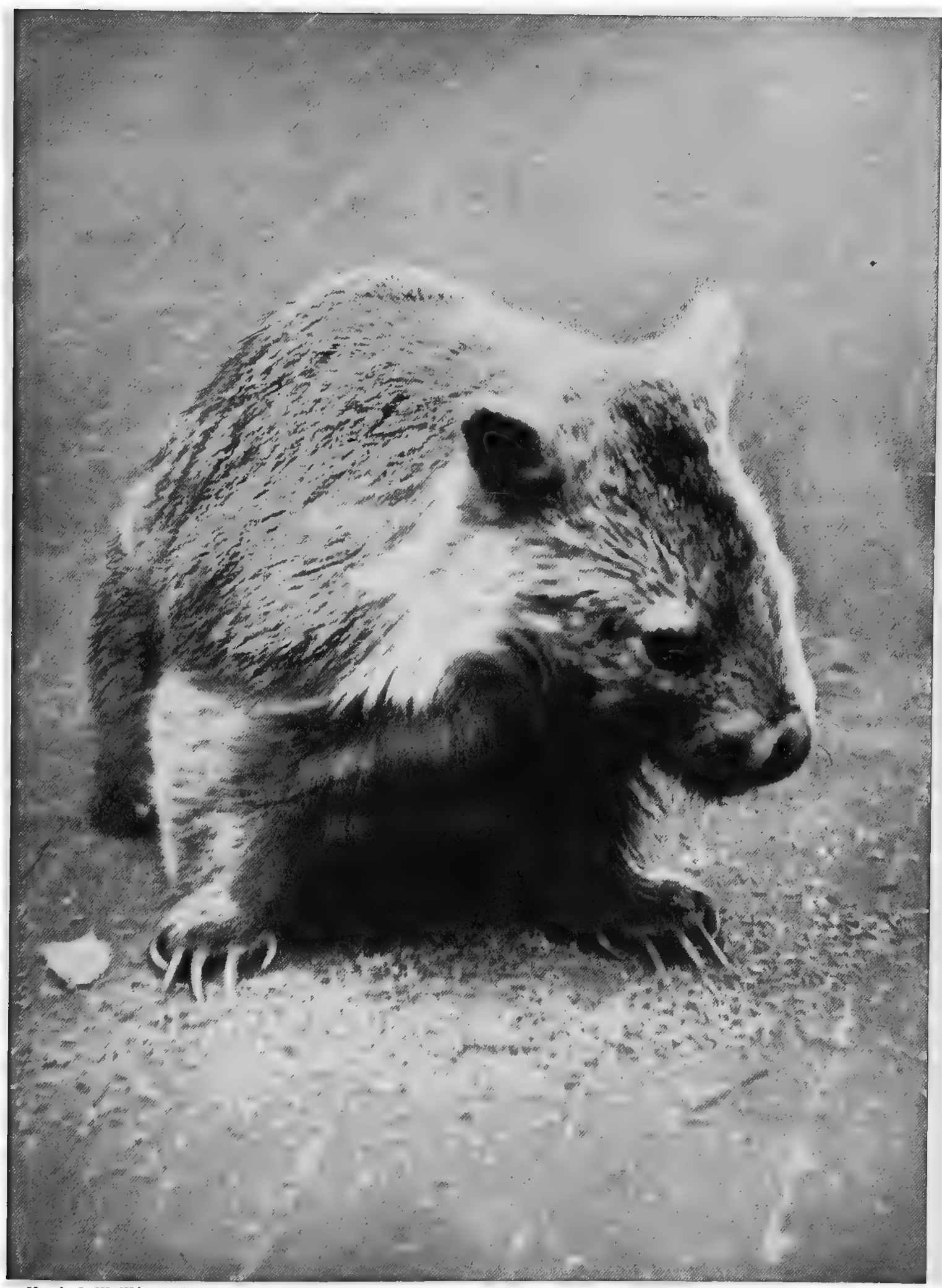

Phoro by G. W Wilson E Co., Lid.

COMMON WOMBAT

The Wombats may be said to hold the place occupied in other parts of the world by the Badgers 


\section{THE LIVING ANIMALS OF THE WORLD}

Insects and worms, in addition to a main diet of vegetable matter, contribute to the bandicoot's somewhat heterogeneous menu.

The wood- and root-boring larvæ of a moth which infests the Australian wattle- or acaciatrees are a very favourite food with several of the species, and it is worthy of remark that the bandicoots are not alone in displaying a penchant for this delicacy. Under the title of "bardies" they are collected and highly esteemed for food by the natives of Western Australia, who eat them either cooked or raw. These larvæ are, moreover, acceptable to many European palates, and the writer has witnessed little faggot-like bundles of them brought round by the natives to the hotels at Geraldton, Western Australia, for sale or barter to chance customers. It may be observed in this connection that the analogous wood-boring larvæ of the goat-moth, which were kept and specially fattened for the occasion, constituted one of the dainty dishes of the luxurious Romans.

One of the commonest species found in Tasmania is known as the BANDED or STRIPEDBACKED BANDICOOT, being so named on account of the characteristic markings of its fur. The general ground-colour of the coat is an almost equal admixture of black and yellow hairs, the black tint, however, prevailing on the back, and the lighter one on the sides. The hindquarters are, however, variegated by the presence of some three or four broad transverse stripes that are almost entirely black, while the intervening spaces are a light whitish yellow. A few shorter stripes are sometimes continued as far as the root of the tail, this appendage also having a dark line running along its upper surface. The head is of a somewhat lighter tint than the remainder of the body, while the breast, abdomen, and feet are white, slightly tinged with grey. The transversely striped pattern of ornamentation of the hindquarters of this bandicoot is of interest with relation to the circumstance that a similarly located banded variegation of the fur occurs also in the Tasmanian wolf, or thylacine, and in the banded ant-eater, described in a following section. As a colour-pattern it would appear to be quite peculiar to these marsupials, no such restriction of the markings occurring among the higher or placental mammals. In the South African suricate, a member of the Ichneumon Tribe, in which the nearest approach to this dorsal banding is met with, the stripes are equally developed as far forward as the base of the neck.

Both the banded and other species of bandicoots are extremely swift and active in their movements, and are at the same time noted for the singularity of their gait. This consists of a half-running and half-jumping action, induced by the peculiar structure of their feet and greater length of the hind legs, which are modified on a plan intermediate between that of the kangaroos and the dasyures, or native cats. The back of the animal while running being

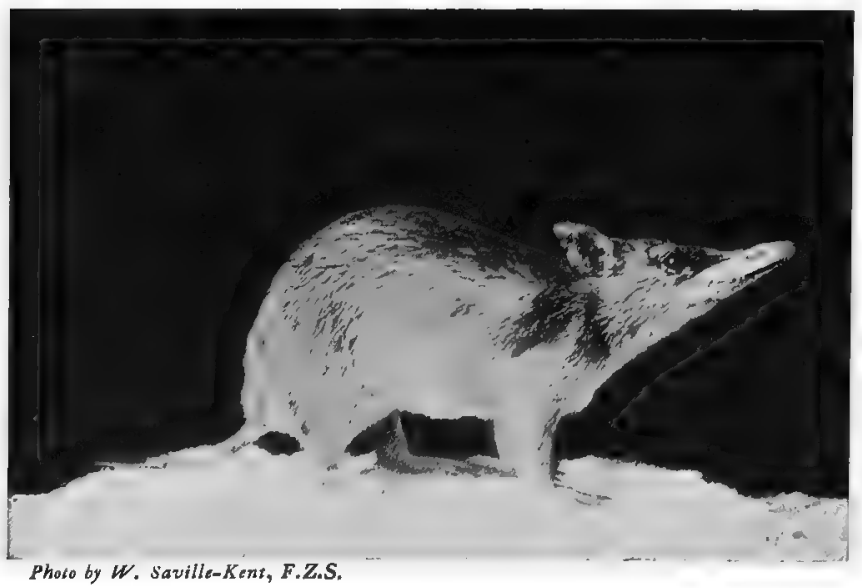

LONG-NOSED AUSTRALIAN BANDICOOT

Bandicoots, although larger, have somerwhat the appearance of shrews highly arched, adds to the grotesqueness of its appearance. Like the native cats, the pouch in the bandicoots opens backwards; it is furnished with eight teats, but not more than two young are usually produced at a birth.

The striped-backed bandicoot is not infrequently adopted as a household pet, in spite of its notorious garden depredations. When thus domesticated, it appears to be capable of developing a strong attachment for its owner. One that was owned by friends of the writer especially attached itself to the lady of the house. It was acquired when quite young, having escaped from the pouch of an adult 
female which the dogs had killed, and being then about the size of a mouse. It speedily learned to lap milk, and throve on a diet of bread and raw potato. As it grew larger it was allowed the run of the house, and also of the garden, but habitually returned to the sleeping-quarters selected by itself, and represented by the woolly depths of its mistress's work-basket. In this haven of rest it slept all day, scolding and snapping at any intruding hand. Towards dusk it would waken up and bustle about in a most energetic manner, with the air, in fact, of having an immense amount of business to transact within the very shortest limits of time. Its first dart was always towards a corner where a supper of bread-and-milk

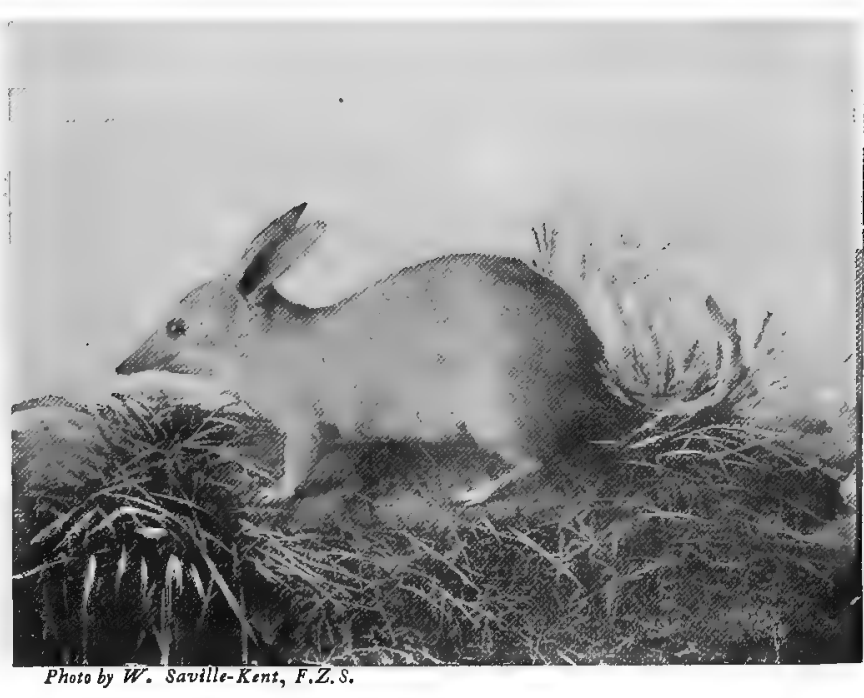

RABBIT-BANDICOOT

The largest of the bandicoots; about the size of a rabbit and potato was usually placed. This meal discussed, its evening's occupation commenced of scampering, around the room and over every accessible article of furniture. Nor was it shy; of climbing up and resting for a few seconds on the shoulders of its human friends, being always, however, in too great a hurry to prolong the visit. Finally, as with all pets, "Coota," as he was familiarly named, came to an untimely end - not a cat, however, on this occasion, but, if rumour whispers true, through over-indulgence in a too liberally furnished meal of custard pudding.

The flesh of this and other species of bandicoots is esteemed for food both by the natives and the white settlers in Australia. It is noteworthy of the banded variety, more especially, that the skin adheres so tightly to the flesh that its removal is a matter of some considerable difficulty. When full grown, this species measures as much as 18 inches in total length, and is little inferior to a rabbit with regard to the amount of good meat it provides for the larder.

\section{The Pouched Mole}

A still more essentially insectivorous marsupial is represented by the little mammal discovered only a few years since in the wild sandy wastes of Central Australia. In form and habits it so nearly resembles the familiar European mole that the title of the PoUCHED MoLE has been very suitably given to it. At the same time, with regard to its remarkable organisation, it constitutes the sole representative of its peculiar family group. The first suspicions of the existence of this singular little animal were raised by the observation of peculiar sinuous three-lined tracks at irregular intervals on the surface of the sandy regions it inhabits.

After a long quest, with the aid of the aborigines, the first specimen was discovered reposing under a tuft of coarse porcupine-grass. A further investigation elicited the fact that its burrowing proclivities were much less pronounced than those of the ordinary moles, the little creature progressing alternately over the surface of the sand, and then ploughing its way, for several feet or yards, two or three inches only beneath the surface. All efforts to preserve examples of this marsupial alive for longer periods than three or four days proved abortive; for though the remains of ants and other insects were found within its viscera, it refused to feed upon the living supplies that were provided for it. In fact, the animal itself apparently ran the greater risk of being eaten. 


\section{THE LIVING ANIMALS OF THE WORLD}

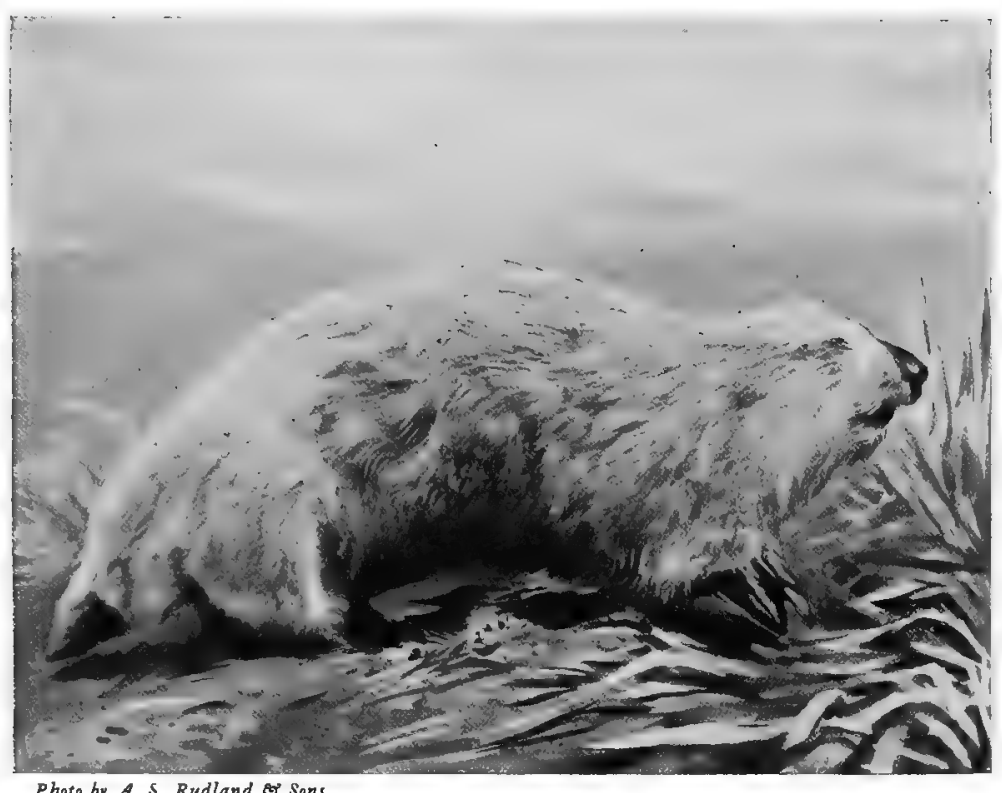

POUCHED MOLE

This animal is of a pale golden-red colour, and about 5 inches long. It spends most of its time burrowing, which it can do with great rapidity, in the sand of the Australian deserts in search of insects
Thecolour of thepouched mole is for the most part light fawn, varying in parts to golden yellow. One of its most conspicuous features, as illustrated in the accompanying photographs, is the abnormal size of the third and fourth toes of the fore limbs, their peculiar scoop-like character proving of eminent service to the animal in its customary sand-burrowing habits.

\section{The TaSManian Wolf}

The remaining family of the Australian marsupials constitutes a parallel to the carnivorous order of the higher mammalia, all its members being more or less flesheaters, and having their

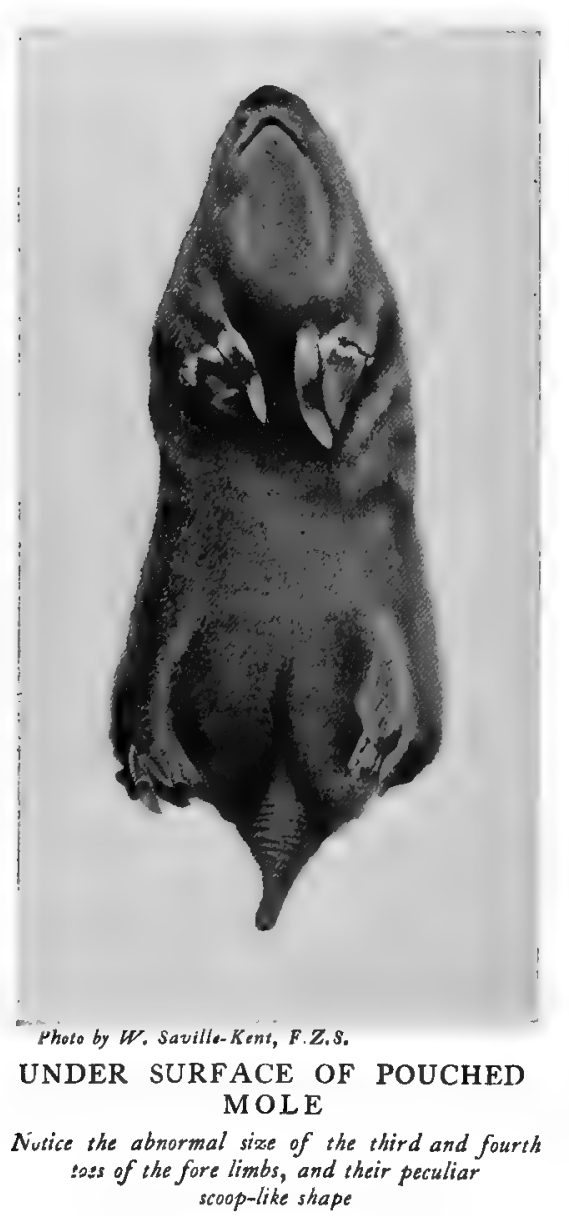
dentition modified with relation to such habits. One of these (the TASMANIAN WOLF, or TIGER of the colonists, better known to zoologists as the THYLACINE) is an animal of considerable size. Its dimensions equal those of a wolf or mastiff, with which the contour of its body and more especially that of the head very nearly correspond. In common with the true dogs, the thylacine hunts its prey by scent. This is well attested to by the following incident, as related by eye-witnesses. While camping out among the hills in Tasmania their attention was attracted very early one morning by a brush-kangaroo hopping past their fire in an evidently highly excited state. Some ten minutes later up cantered a she thylacine with her nose down exactly on the track, evidently following the scent, and in another quarter of an hour her two cubs came by also in the precise track. While not very swift, the Tasmanian "tigers" possess immense staying power, and will keep up a long, steady canter for many hours on end. Accustomed in its primitive state to run down and prey upon the kangaroos, wallabies, and other weaker marsupial mammals indigenous to the regions it inhabits, the Tasmanian wolf speedily acquired a predilection for the imported flocks of the settlers, and proved almost as destructive to them as its Old World namesake. To check its ravages, a price was put upon its head by the Tasmanian Government; and this measure, in conjunction with the rapid advances towards the complete settlement of the country which have been accomplished within later years, has compassed this animal's extermination in all but the wildest and 
most inaccessible mountain districts. The colour-markings of this animal are somewhat striking, the grey-brown tints which characterise the ground-hues of the body and limbs being varied by a series of dark bands traversing the buttocks, these being widest in this region, and continued forwards to the middle of the back. A somewhat similar cross-stripe pattern of ornamentation occurs in the relatively small member of the same family described later on as the Banded Ant-eater.

Examples of the Tasmanian wolf have frequently been on view at the Regent's Park Gardens, a very fine young male specimen being at present located in the marsupial section. Within a few weeks of its arrival it was on excellent terms with its keeper, though, owing to its somewhat imperfect sense of vision during the daytime, it was apt to snap somewhat promiscuously at those attempting to cultivate its close acquaintanceship. That a bite from its formidable teeth is not to be lightly risked will be made abundantly apparent by a glance at the successful yawning pose photograph secured of

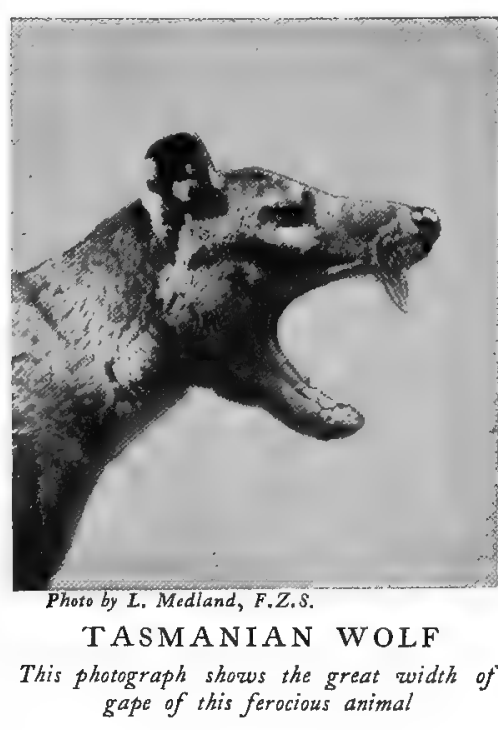
this example by Mr. Medland, and here reproduced. Although the thylacine is at the present time entirely limited in its distribution to Tasmania, it occurs in the fossil state on the Australian mainland; while, singularly to relate, the remains of a closely allied form have within recent years been unearthed in Patagonia. This circumstance, taken in conjunction with the fact that many other fossil types with Australian and New Zealand affinities have been discovered in the same South American strata, has strengthened the supposition maintained by many zoologists that in bygone ages a vast Antarctic continent, spreading through the areas now occupied by the Southern Indian and Pacific Oceans, temporarily united the now distinct lands of South America and Australasia.

\section{The Tasmanian Devil}

Next in size to the thylacine, but possessing a more

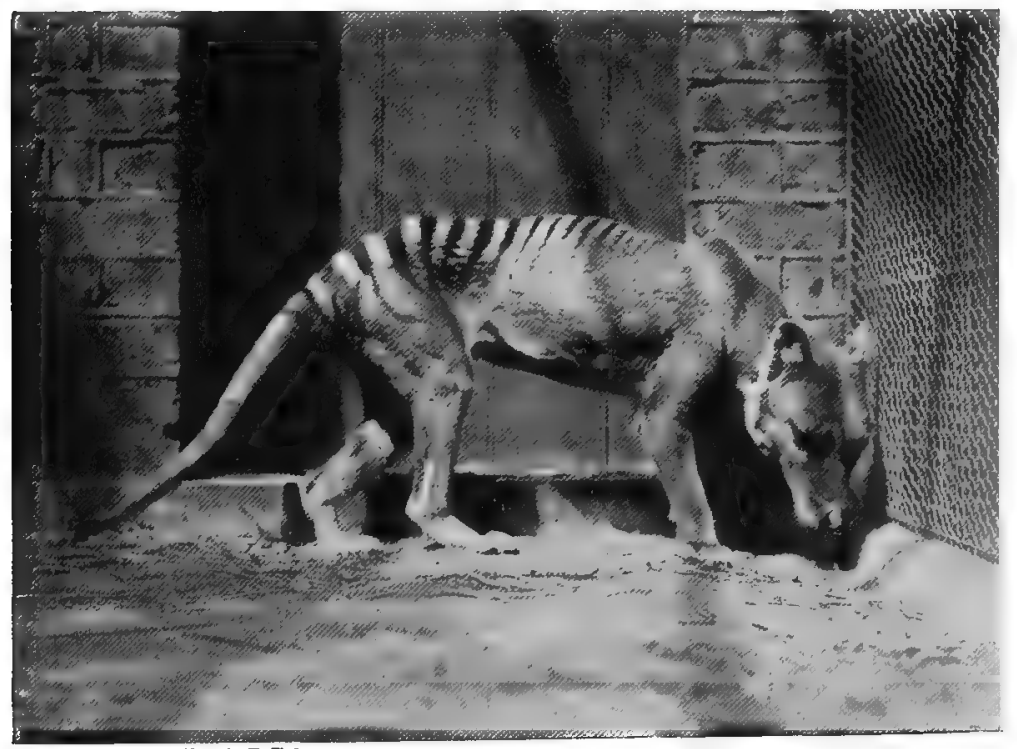

Phato by L. Medland, F.Z.S.

TASMANIAN WOLF

In this photograph are shown nearly all the chief characteristic points of the Tasmanian roolf unenviable notoriety for the uncompromising sulkiness and savagery of its disposition, is the animal which, in virtue of the aforesaid qualities, is known by the title of the TASMANIAN DEVIL. In shape and dimensions this marsupial carnivore somewhat resembles a badger; but the head is abnormally large, the masseter muscles which control the action of the powerful jaws monopolising a very considerable share of the face area. The limbs are short and also very powerful, the front paws being well adapted to its burrowing habits. There is some slight variation in the colours of this marsupial Apollyon; and, as the 


\section{THE LIVING ANIMALS OF THE WORLD}

i

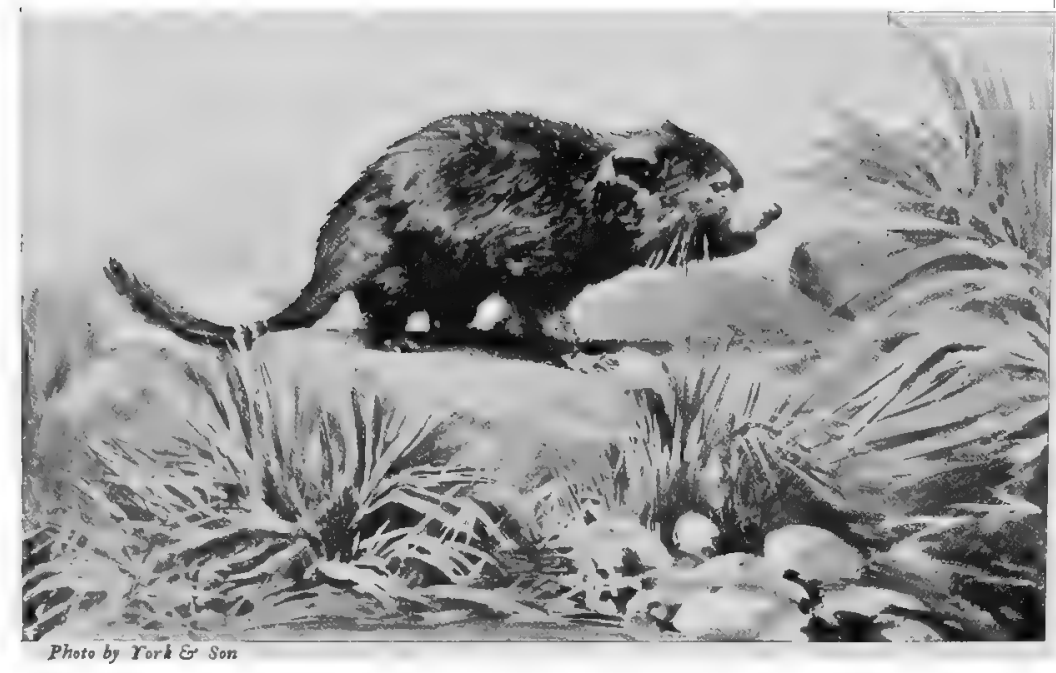

TASMANIAN DEVIL

A small, but stout and pozverful animal, very destructive, and absolutely untamable aphorism runs concerning his sable namesake, he is not always so black as he is painted. More or less or in fact mostly black he always is, but there is usually a redeeming thread or patch of white upon his coat. This may take the form of a small star-like spot only on the front of its chest, which not infrequently extends to a narrow crescent-shaped band or line continued round the neck almost to the shoulders. One or more supplementary spots of white may also be developed upon the flanks and hindquarters.

The destructive propensities of the Tasmanian devil, wherein the farmers' sheep and poultry are concerned, are in no way inferior to those of the Tasmanian wolf, and in consequence of their former much greater abundance the havoc these animals committed was the more serious. Placed, like the last-named type, under Government ban, these native devils have, in comparison with the earlier days of colonisation, very considerably ceased from troubling, and with the ever-progressing march of settlement and civilisation will probably be altogether exterminated at a no.very distant date. A bag of no less than 150 of these marauders, in the course of one winter, was recorded from an upland sheep-station some twenty or thirty years ago. In common with the thylacine, it has been observed that the Tasmanian devil has a marked predilection for prowling along the seashore in search apparently of crabs, fish, or any acceptable flotsam and jetsam that may be cast up by the waves.

Examples of this most unamiable of mammals were brought in alive on several occasions to the Hobart Museum during the writer's residence in Tasmania, but in all cases obstinately resisted every attempt towards the establishment of a friendly footing. Their ultimate relegation to the specimen-cases was, under the circumstances, unattended by any very poignant manifestations of regret. A fact brought into prominent notice during subsequent post-mortem investigations was the extraordinary extent to which these animals are infested with vermin. Possibly this circumstance is to a considerable extent accountable for the creature's unconquerable irritability. The experiment as to whether a course of disinfecting treatment, by baths or otherwise, would not conduce towards the taming of this native devil, where all other applied methods have failed, would at all events be worth the trial. The bath pure and simple is a wonderful soporific for unruly tempers. As most schoolboys know, a pail of water, from which the patient is withdrawn when a watery grave is apparently inevitable, is an unfailing specific for the taming of mice and other "small deer." The writer's experience with a villainously savage cat which one night fell incontinently into an uncovered cistern, and was rescued by him at almost the last gasp, will not be readily forgotten. That cat, though still a vixen to the ordinary members of the household, forthwith attached itself affectionately to its rescuer, and would sit for hours awaiting his arrival on the doorstep when the business of the day was over. Other fierce creatures, including the Tasmanian devil, would possibly prove amenable to the judicious application of the "water cure." 


\section{The Native Cats}

The animals common in Tasmania and throughout the greater portion of the Australian Continent, and familiarly known as Spotted or NATive CaTs, and to zoologists as Dasyures, enjoy also an unenviable reputation for their depredations among the settlers' hen-roosts. To look at, these native cats are the most mild-mannered and inoffensive of creatures. Actually, however, they possess the most bloodthirsty proclivities, and may be aptly compared in their habits to the stoats, weasels, polecats, and other Old World carnivora. There are some five known species, the largest being equal to an ordinary cat in size, and the smaller ones about half these dimensions. All of them are distinguished by their spotted pattern of ornamentation, such spots being white or nearly so, and more or less abundantly sprinkled over a darker background which varies from light grey to chocolate-brown. In the commonest form, represented in the accompanying photograph, the ears and the under surface of the body are also often white. No two individuals, however, are to be found precisely alike in the pattern of their

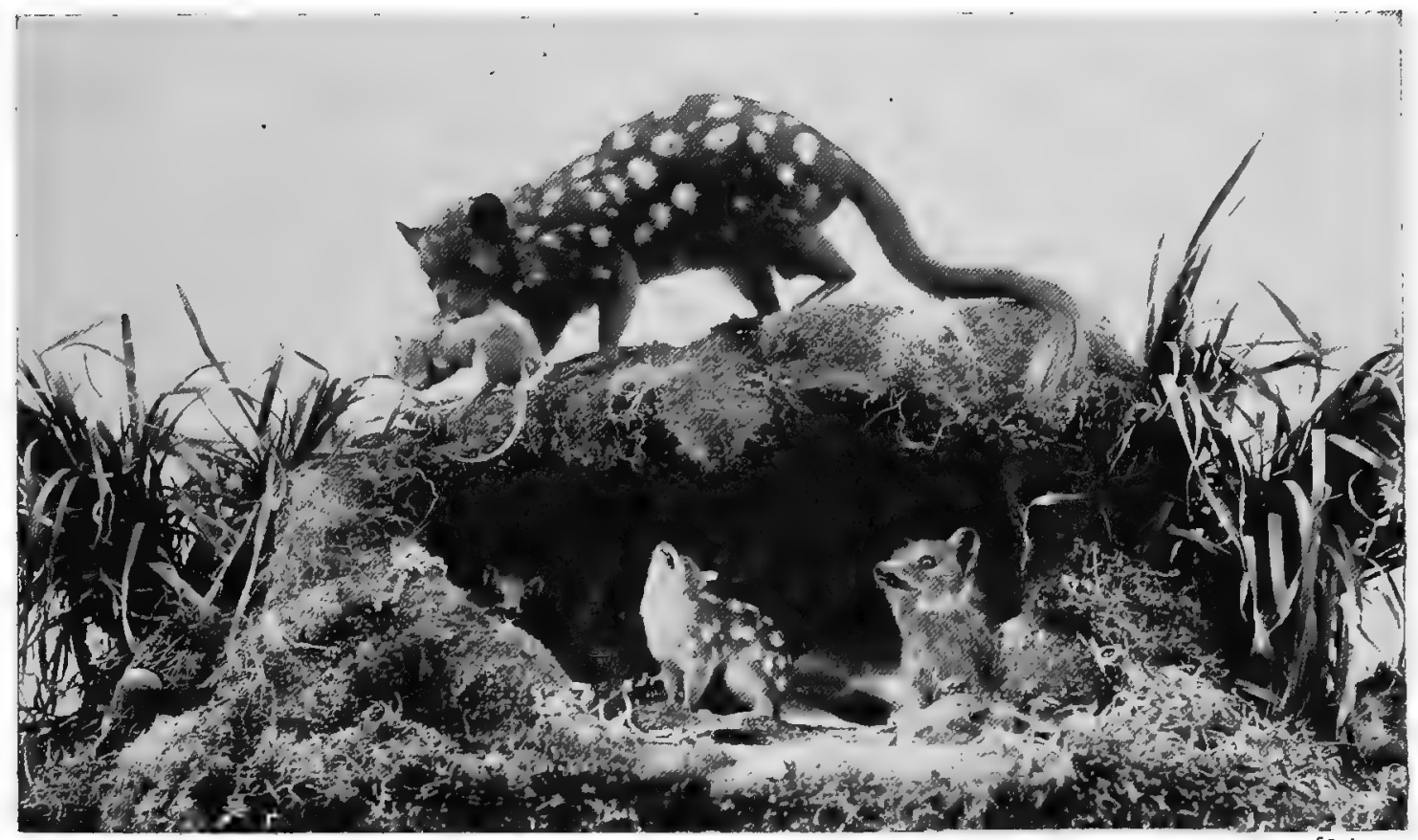

By permission of S. Sinclair, Esq.]

SPOTTED DASYURES, OR AUSTRALIAN NATIVE CATS

This species is rather smaller than an ordinary-sized cat. All the dasyures are arboreal in their habits, and very destructive to birds

markings. The dasyures differ from the two preceding types, the Tasmanian wolf and the devil, in being essentially arboreal in their habits, living by day and breeding, as the majority of the Australian opossums, in the hollow gum-tree trunks, from which they emerge at nightfall to seek their food. This, in their native state, when hen-roosts are not accessible, consists mainly of birds and such smaller marsupial forms as they can readily overpower.

\section{The Pouched Mice}

The so-called PoucheD MICE represent a group of smaller-sized carnivorous mammals which have much in common with the dasyures, but are devoid of their spotted ornamentation. None of them exceed a rat in size. They number about twelve or fourteen known species, and are distributed throughout the greater part of Australia and New Guinea, and extend thence to the Aru Islands. They are said not to occur in the extreme north of the Australian Continent. The writer, however, obtained an example of the brush-tailed species, 


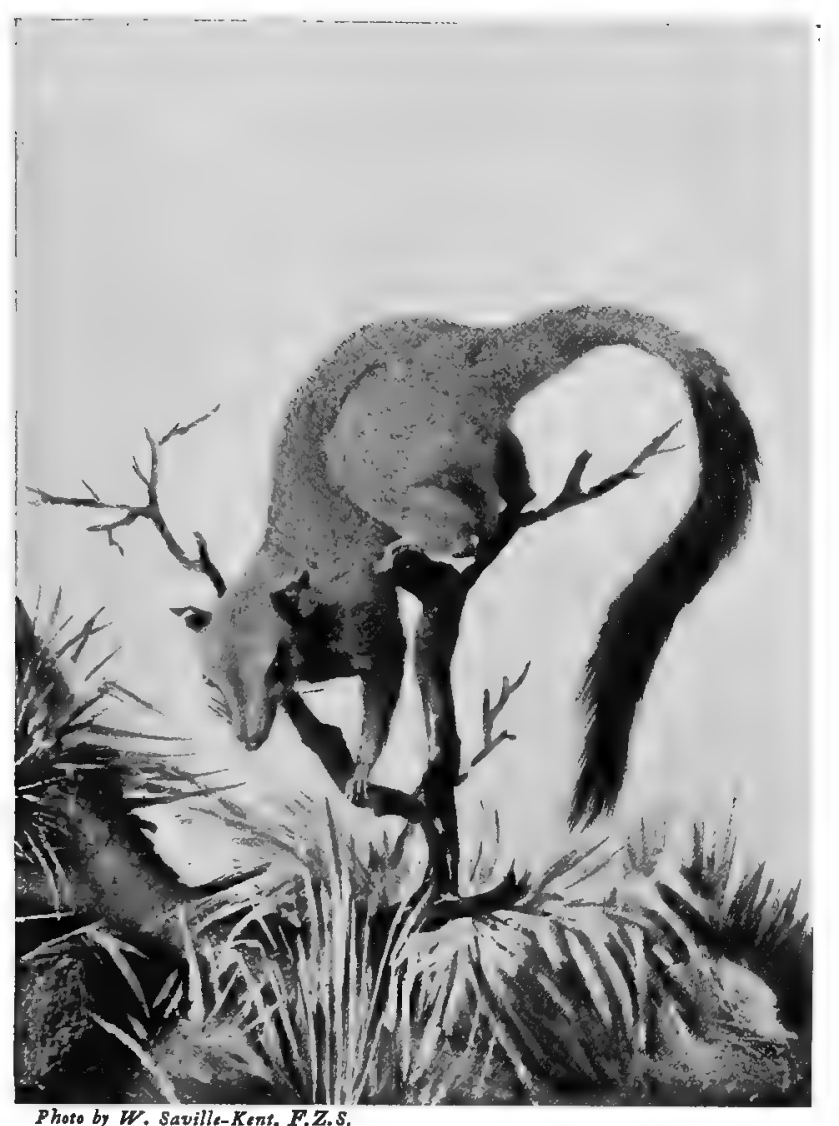

BRUSH-TAILED POUCHED MOUSE, OR PHASCOGALE

$A$ slender and graceful animal, the largest of the thirteen known species, and about the size of an ordinary cat

here illustrated, from the neighbourhood of Broome, in the farthest north or Kimberley district of Western Australia. This specimen, which was caught alive in a rat trap, exhibited astonishingly potent gnawing powers, almost succeeding one night in eating its way through the wooden box in which it was temporarily confined. The habits of this species are omnivorous, and chiefly akin to those of the ordinary rats, it being accustomed to prowl round the out-buildings at night, picking up any unconsidered trifles in the way of food that may be left unprotected.

Many of the smaller members of this tribe are no larger than mice; and in one form, known as the JERBOA Pouched MOUse, inhabitingQueensland and New South Wales, the hind limbs are abnormally prolonged, and the animal progresses by leaps and bounds, after the fashion of the true jerboas, or its nearer relatives, the ordinary kangarogs and rat-kangaroos.

\section{The Banded Ant-Eater}

One of the most interesting from the zoologist's standpoint, and the last on our list of the Australian marsupials, is the little creature, limited in its habitat to Western Australia, locally known as the SQUIRREL. The BANDED ANT-EATER, with reference to its striped ornamentation and ant-eating habits, is the name by which it is usually chronicled in natural history works. In size and shape, except for its more pointed snout, its squirrellike aspect is certainly somewhat striking. Like the true ant-eaters of the Edentate Mammalian Order, it, however, possesses a long protrusile tongue, with which it is accustomed in a similar manner to lick up the ants which constitute its main food-supply.

The most interesting biological peculiarity of this animal is the abnormal development of its teeth. These number as many as from fifty-two to fifty-six, and exceed the dental formula of any other known existing marsupial. The usual colour of this interesting little animal is a warm chestnut-brown, banded transversely over the back with white, these stripes being widest and most conspicuous over the hindquarters. This somewhat paradoxical marsupial possesses no pouch, the young, when first born and attached to the nipples in the manner characteristic of ordinary marsupials, being covered over and concealed among the longer hairs that clothe the abdominal region. In the dasyures, or native cats, previously described, the pouch exists only in a rudimentary condition, its function being fulfilled by merely a few skin-folds ; while in the "tiger" and native devil the pouch, contrary to that of the kangaroos, opens backwards.

In disposition the banded ant-eater presents a marked contrast to that of many of the preceding types. Caught in its native habitat, it does not attempt to bite, and soon becomes reconciled to captivity. The peculiar nature of its diet, however, militates against its being easily transported over-sea from the Antipodes. 


\section{The Selva.}

South America has one other marsupial-the Selva-an animal which, while possessing the dimensions and much of the aspect of an ordinary rat, is remarkable as differing so materially in the character of its teeth and other structural points that it cannot be referred to any existing marsupial family. On the other hand, this type is found to coincide in the above particulars with species hitherto only known in the fossil state, and excavated from the same tertiary deposits in Patagonia which have been productive of the distant ally of the Tasmanian wolf. It is yet hoped by zoologists that the discovery of other interesting and possibly some supposed extinct mammals may reward the thorough exploration of the vast South American forests. The capture in the flesh of some form allied to the huge ground-sloths, such as the Mylodon and Megatherium, is, however, now considered to be quite beyond the pale of possibility.

\section{Monotremes, or Egg-laying Mammals.}

With this group or order of the Mammalian Class we arrive, as it were, on the borderland between the more typical Mammals and Reptiles. In the last group, that of the Marsupials, it was observed that the young were brought into the world at an abnormally early and helpless phase of their existence, and usually consigned, until able to see and walk, to a variously modified protective pouch. With the Monotremes a yet lower rung in the evolutional ladder is reached, and we find that the young are brought into the outer world as eggs, these being in the one case deposited in a nest or burrow, and in the other carried about by the parent in a rudimentary sort of pouch until they are hatched.

The living representatives of this singular mammalian order are but few in number, being restricted, in point of fact, to only two distinctly differentiated family types-the Echidna or Porcupine Ant-eater, and the Platypus. These monotremes, moreover, like the majority of the existing marsupials, are limited in their distribution to the Australasian region. The single species of the Platypus is only found in Tasmania and the southern and eastern districts of the Australian Continent, while the Echidna numbers some three recognised species, two of which belong to Australia and Tasmania and the third to New Guinea.

\section{The Echidna.}

The Echidna, Porcupine Ant-eater, or "Porcupine," as it is commonly called by the Australian colonists, would seem at first sight to represent an animal in which the characters of the hedgehog and the common porcupine are interblended, the innumerable spines being longer than those of the former, but less in length than those of the last-named animal. The head, with no externally visible ears and remarkable elongated beak-like snout, however, at once proclaims it to be altogether distinct from these. The animal has no teeth, and the tiny mouth at the termination of the beak-like snout simply constitutes an aperture for the extrusion of the worm-like glutinous tongue, wherewith, after the manner of the true ant-eaters, it licks up the inhabitants of the ants' nests upon which it feeds. For tearing down the ants' nests and obtaining its customary food, as also for its inveterate burrowing propensity, the feet, and more especially the front ones, are provided with strong, blunt, and very powerful claws. The male aninal is in addition armed on the hind feet with a peculiar supplementary spur, which is, however, still more conspicuously developed in the platypus.

Three distinct species of the echidna are recognized by zoologists. The one peculiar to the cooler climate of Tasmania is remarkable for its more slender spines, the much greater abundance of the long bristle-like hairs, and the thickness of the seal-brown under-fur, as compared with the typical Australian form. In North-west New Guinea the largest and most aberrant form is met with. Normally it has only three toes in place of five to each foot, the spines are very long and thick, the body is deeper and more compressed, and the animal stands comparatively high upon its feet. 
The writer, during his residence in Tasmania, had several examples of the local species as domestic pets. For the first few days they were very shy and untractable, burrowing into the earth and seeking to escape, or presenting an impenetrable cheval de frise of sharppointed spines to the hands that sought to caress them. After a short interval, however, the creatures became entirely reconciled to human society and the small amount of restraint to which they were subjected. They would follow their owner about the garden, or, flattening their bodies and spreading out their limbs to the greatest extent, lie basking in the sun close to where he might be seated. They also apparently appreciated being carried, slung across their owner's arm after the manner of a lap dog. Living in the near vicinity of unreclaimed bush-land, it was found possible to keep these echidnas well supplied with their customary food; they were, in fact, permitted to forage on their own account. Liberated amidst their normal surroundings, they would walk leisurely from one ant-hill to another, tearing down the side of it with their powerful front claws, and appropriating its living contents with the greatest relish. It was observed, however, in this connection that the echidna paid attention entirely to the succulent white larvæ and pupal phases of the insects with which the inner chambers of the ant-hills are customarily crowded, and that adult ants, as they abounded in the tracts near at hand or elsewhere, were altogether neglected. In addition to this natural food these animals were supplied daily with a saucer of either well-softened bread or porridge and milk, for which they evinced a decided appreciation, assimilating this food dexterously, though somewhat slowly, with the aid of their long protrusile tongues. Allowed to wander about the house, they displayed a most inquisitive turn of mind, peering into every crevice, and climbing upon every accessible article of furniture.

The echidna usually produces only one egg at a time; it is relatively small, not larger than a sparrow's egg, but equally and obtusely rounded at both extremities, and with a white leathery shell like that of a reptile. For some time previous to hatching, this egg is carried in a-skin-fold or rudimentary pouch in the parent's abdomen, much similar to that possessed by many of the marsupials. The young one is also retained in this pouch for some weeks after escaping from the egg. When finally leaving the pouch, it is between three and four inches in length, and the spines are in an altogether rudimentary condition.

Examples of the Australian echidna have on several occasions been "in residence" at the Zoo; while the Hon. Walter Rothschild has been fortunate in keeping living specimens of both this and the very rare three-toed New Guinea variety in his admirably appointed menagerie at Tring

\section{The Platypus}

The egg-laying mammal known as the DuCk-BILled Platypus differs very essentially from the echidna both in aspect and habits. It is adapted especially for an amphibious life, and for feeding on molluscs, worms, and insects, which it abstracts from the muddy bed or banks of the rivers that it frequents. The somewhat depressed ovate body is covered with short dense fur much resembling in colour and texture that of an otter. The tail is short and flattened like that of a beaver, but in place of being naked and scaly, as in that aninal, is covered, on the upper surface more

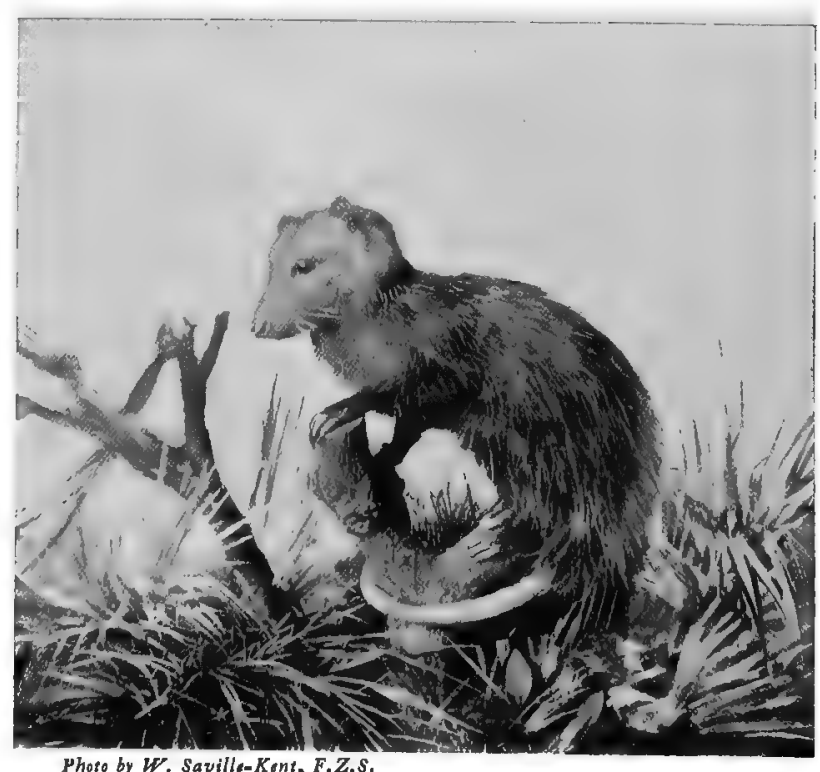

Photo by W. Saville-Kent, F.Z.S.

COMMON OR VIRGINIAN OPOSSUM

The only marsupial animal found north of Mexico 
particularly, with long, coarse, bristle-like hairs that intercross one another in all directions. Neither is this tail used, as with the beaver, as a mason's trowel, it being simply subservient as a steer-oar. The feet are all four distinctly webbed, the membranes of the front feet in particular projecting to some distance beyond the extremities of the claws, and so communicating to these members a singular resemblance to the feet of a duck. The head of the platypus tapers off from the body without any conspicuous neck, and terminates in a most remarkable duck-like beak, having at its base a supplementary membranous ferrule-like structure which would seem to serve the purpose of limiting the distance into which the beak of the animal is thrust into the mud during the quest for its accustomed food, and at the same time protecting the creature's eyes. The mouth of the adult platypus contains no teeth, simply a few horny plates; but, singularly to relate, rudimentary teeth exist temporarily in the young animals. These provisional teeth, moreover, correspond in a marked manner with those of some ancient types of mammals which occur as fossils in the tertiary deposits of North America. The platypus, with relation to the obliteration of its teeth in the adult state, is regarded as a very exceptionally modified form and not as the immediate prototype of the ordinary mammals.

The platypus is found in Tasmania and in the south and eastern districts of Australia only, being altogether unknown in the west and north. Being especially shy and retiring, and to a large extent nocturnal in its habits, it is not frequently seen even in districts where it may be rather abundant. The animal excavates burrows of so great a length as from thirty to fifty feet in the river-banks that it frequents, and at the extreme end of these burrows it constructs a loose nest of weeds and root-fibres, which it uses as its retreat, and also for the production of its eggs and young. There are invariably two entrances to these burrows, the one being under water, and the other usually opening into a tangle of brushwood at some little distance from the water's edge. As many as from one to four eggs and young may be produced at a time, but two is the more general number. From the first it would appear that the eggs and young are deposited and nursed in the nest, not being retained or carried about in a pouch, as observed of the echidna.

The late Dr. George Bennett, of Sydney, New South Wales, has probably placed on record the most detailed account of the ways and life-habits of these remarkable animals, though it did not fall to him to solve the much-vexed question as to whether or not they were oviparous. This discovery, as applied also to the like phenomenon in the case of the echidna, was the outcome within quite recent years of the researches of $\mathrm{Mr}$. Caldwell. After much indefatigable

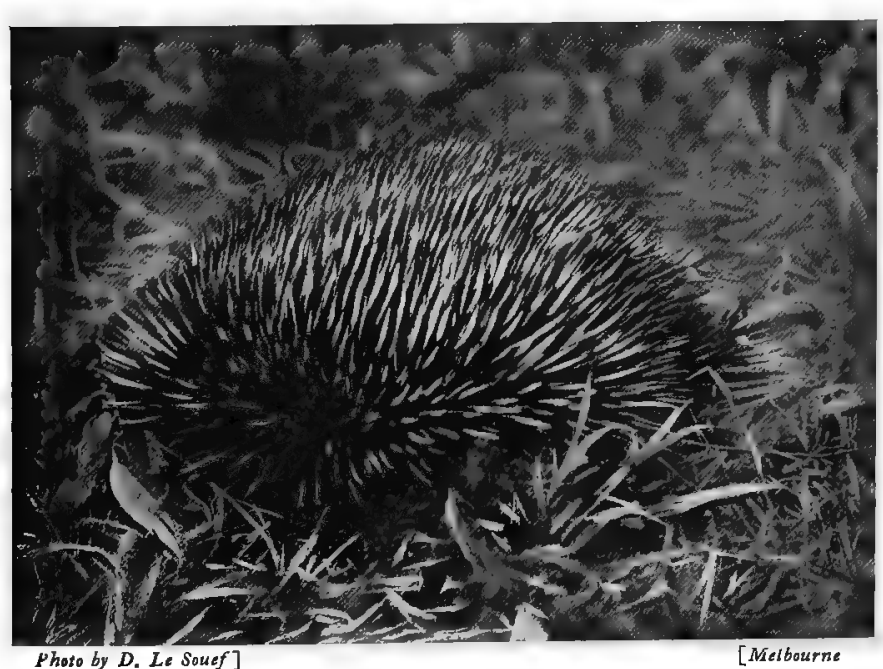

ECHIDNA, OR ANT-EATING PORCUPINE

The female echidna can carry two eggs in her powch, which in due course are hatched by the heat of her body exploration, in which he was ably assisted by the natives, Dr. Bennett obtained from the extremity of an exceptionally long burrow a mother and pair of half-grown young. The young ones survived several weeks, and proved most droll and interesting pets. In playful habits they much resembled puppies, chasing and rolling one another over, and pretending to bite with their toothless bills. They were also much addicted to climbing every scalable article of furniture, including even a tall book-case, which they would negotiate by "swarming" up behind it as a sweep climbs a chimney, with their backs to the wall and their feet against the back of the bookcase. The sleeping and waking hours 


\section{THE LIVING ANIMALS OF THE WORLD}

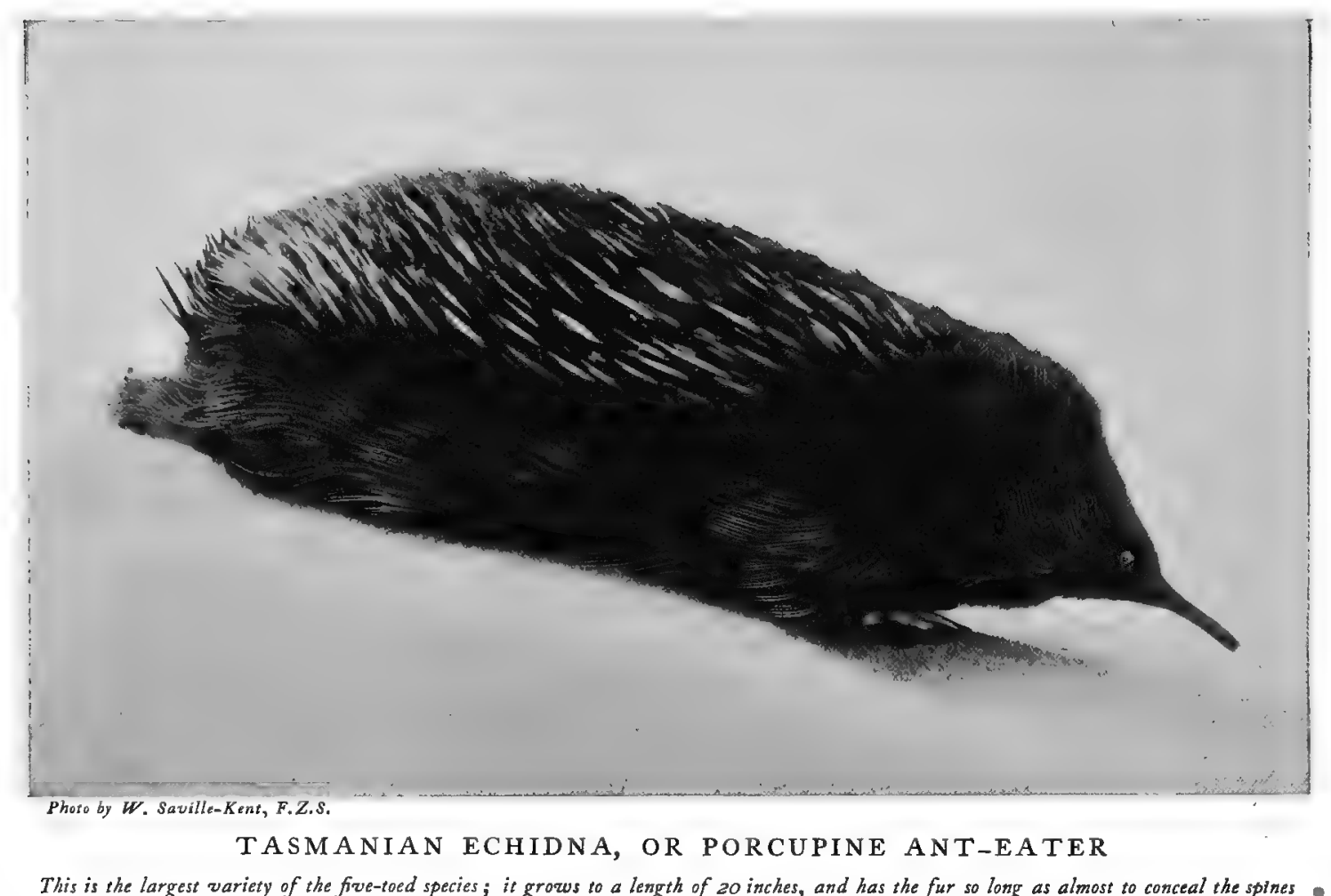

that both these and other examples kept were observed to be very irregular; for while usually most lively and disposed to ramble after it grew dusk, they would at other times come out of their own accord in the daytime, or perhaps one would ramble about while the other slept. When going to sleep, they would roll themselves up in a perfect ball, the head, tail, and limbs being closely folded over the abdomen.

The food question appears to have presented almost insurmountable difficulties so far against the permanent acclimatisation of these interesting animals in any of our European zoological gardens. At the Melbourne Zoo some considerable success was obtained by fencing off a small pond abounding with insects and well-established water-plants for their reception, and in this instance they had also the advantage of being brought speedily and within a few hours of their capture to their new home. For their long voyage to Europe the provision of an adequate quantity of living insects or other aquatic organisms is a by no means easy task. They have, however, been known to thrive on broken-up river-mussels for the space of two or three weeks, and would probably have done so for a longer period. This material might easily be stored for their use on board ship.

An incident concerning the natural predilections of the platypus that fell within the writer's observation in Tasmania might also be utilised in their experimental transportation. At the trout- and salmon-rearing establishment on the river Plenty-of which the writer was at the time superintendent-the platypuses proved to be most destructive to the spawn both deposited in the hatching-boxes and upon the natural spawning-beds, or " redds," and they had in consequence to be systematically destroyed. This being the case, it is probable that they would be found to thrive well on a diet consisting to a large extent of the preserved roes or spawn of any easily procurable fish-such as the Murray perch and cod-and of which adequate supplies might with facility be stored aboard ship. The admixture in all cases of a certain amount of sand or mud with their provided pabulum would appear to be essential for digestive purposes, such material being always found in considerable quantities in their stomachs when dissected. 
A distinguishing feature which the male platypus shares in common with the echidna is the peculiar spur developed on its hind foot. It is in this case, however, much larger and sharper, and has been accredited with aggressive functions and poisonous properties. There can be little doubt, however, that they are normally used by the animal only as clasping or retaining instruments during intercourse with the female at the breeding-season. At the same time, undoubted cases of persons receiving severe wounds from these animals' spurs have been placed on record. One such that fell within the writer's cognisance happened on the Murray River, on the Victorian and New South Wales boundary. A young fisher-lad, on taking up his nets, found a half-drowned platypus entangled in them, and, whilst disengaging it, it convulsively

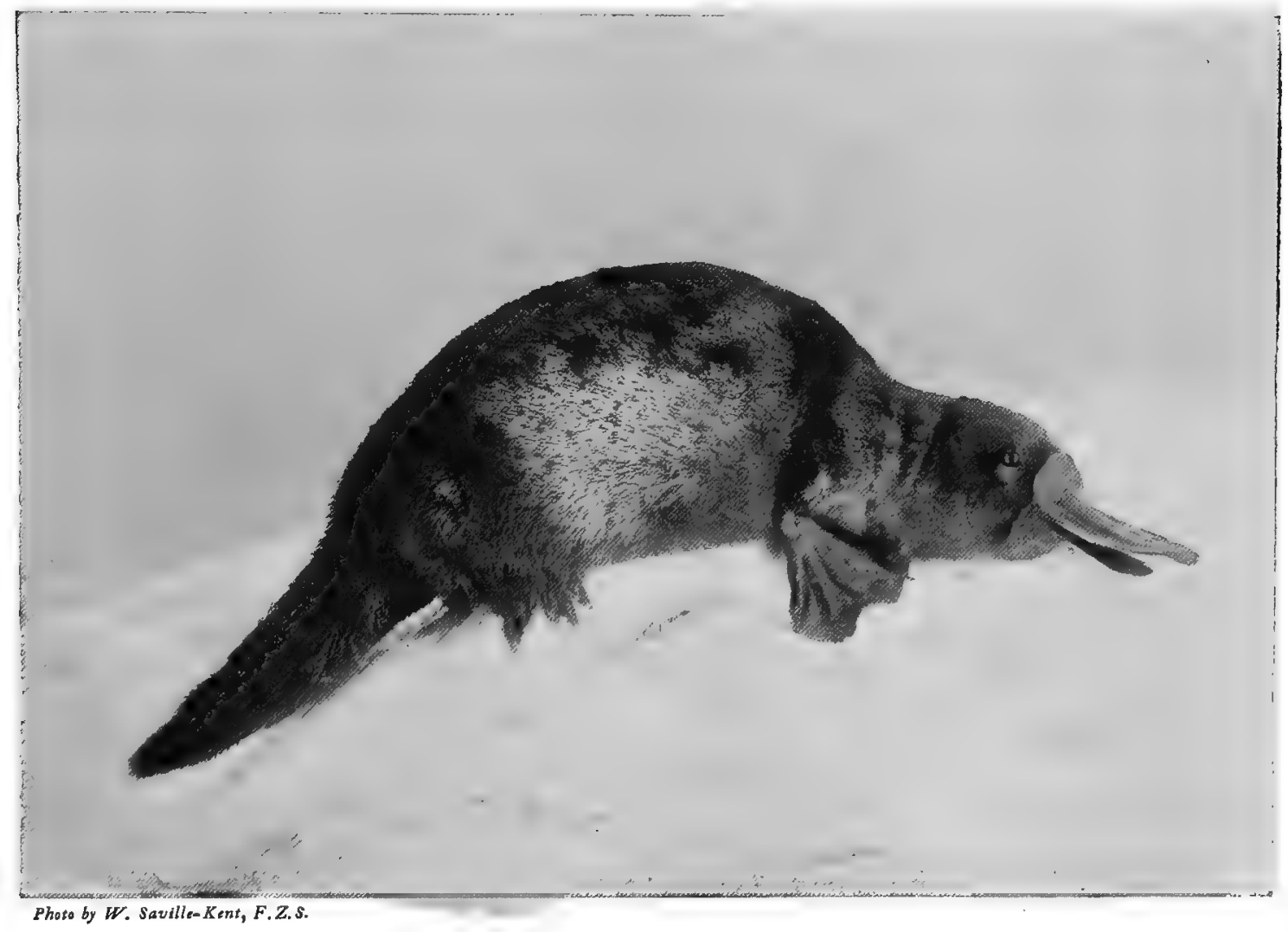

DUCK-BILLED PLATYPUS

This curious egg-laying mammal, the only representative of its family, is mainly nocturnal in habits

gripped his hand between the two spurs, the points penetrating deeply into the flesh on either side. The result was a festering wound that refused to heal for many months, and for such time entirely deprived the lad of his use of that hand.

The fur of the platypus, dressed so as to remove the outer and longer series of hairs, nearly resembles that of the fur-seal in both colour and texture, and as a rare local product is highly prized for the manufacture of carriage-rugs and other articles.

WITH the egg-laying Echidna and Platypus we terminate the Mammalian Series, and they pave the way to the typical egg-laying animals which follow. 

IN DEX 



\section{IN DEX}

\section{MAMMALS OF OTHER LANDS}

\section{A}

Aard-vark, Cape, 306; Ethiopian, 306

Aard-wolf, 82

Abyssinian Cat, 73

Abyssinian Ibex, 208

Addax Antelope, 227, 230

Ælian's Wart-hog, 278

African Civet, 75

Agutis, 139, 140

Airedale Terriers, 104

Alexandrine Rat, 137

Alpaca, 272, 273

Alpine Ibex, 208

Alpine Marmot, 133

Altai Wapiti, 249

American Jumping-mouse, 138

Angora Goat, 205

Angus Cattle, 188

Anoa, 195

Ant-eater, 300, 302; Banded, 337, 340 ; Great, 302 ; Porcupine, 341 ; Scaly, 305; Tamandua, 303; Two-toed, 303, 304

Antelope, Addax, 227, 230; Broadhorned, 229; Harnessed, 228, 229, 232; Indian Four-horned, 216; Inyala, 230; Roan, 224; Sable, 225; Saiga, 219, 220; True, 213

Anubis Baboon, 17

Aoudad, 199

Ape, Barbary, 14, 15

Apes, Man-like,

Arab Horse, 178

Arab Mares, 177, 178

Arabian Gazelle, 220, 222

Argali, Siberian, 197; Tibetan, 197 , 198

Armadillo, 300, 303; Fairy, 304; Hairy-rumped, 305 ; Kapplers', 305; Peba, 305; Weasel-headed, 305

Arui, 199

Asiatic Ibex, 208

Ass, Domestic, 184

Asses, Wild, 173

Aurochs, 186

Australian Fruit-bat, 143, 144

Australian Native Bear, 319, 320, 321

Axis Deer, 256, 257, 264

Aye-aye, 27, 32

Azara's Dog, 94
B

Babirusa, 277, 279, 330

Baboon, 15; Anubis, 17; Arabian, 17; Common, 17; Gelada, 13

Bactrian Camel, 266, 268, 269, 270

Badget, 117; European, 117; Indian, 117

Baggage-camel, 268

Bamboo-rats, 138

Bandar Monkey, 14

Banded Ant-eater, 340

Bandicoot, 138; Australian, 332;

Banded, 334; Long-nosed, 332 ,

334; Pig-footed, 332 ; Rabbit-,

332, 335; Striped-backed, 334

Bank-vole, 136

Banting, 188, 190

Barb, 178, 179

Barbary Ape, 14

Barbary Sheep, 196, 198, 199

Barbary Stag, 249

Barking-deer, 259

Basilan Sambar, 254

Basset-hounds, 100

Bat, Australian Fruit, 143, 144; Indian Fox-, 144; Javelin, 146; Kalong, 144; Leaf-nosed, 145 ; Malay Fox-, 144; Naked, 146; Pipistrelle, 145; Pointed, 146; Sucker-footed, 146; Tube-nosed Fruit-, 144; Vampire, 146; Welwitsch's, 146: White, 146

Bavian Deer, 256

Bay Cat, 56

Beagles, 97

Bear, 109; Australian Native, 319 . Himalayan Black, 113; Isabelline, 113; Malayan Sun-, 114; Performing, 109; Russian Brown, 111; Syrian, 111

Bear-cat, 76, 115

Bearded Pig, 277

Beatrice Oryx, 224

Bedlington Terriers, 114

Beech-marten, 119

Beisa Oryx, 226

Beluga, 297

Bennett's Civet, 76

Bennett's Wallaby, 309

Binturong, 76, 79

Bison, European, 191; Indian, 188

Black-and-tan English Terriers, 104

Blackbuck, 220
Black-faced Mountain-sheep, 202

Black Horse, 183

Black Rhinoceros, 164

Black Wildebeest, 215

Blenheim Toy Spaniels, 107, 108

Blesbok, 214

Blood-hound, 97, 100

Bluebuck, 224

Blue Bull, 228

Blue Sheep, 200

Blue Wildebeests, 216

Boar, Senaar, 277; Wild, 275

Bokhara Deer, 250

Bonnet Macaque, 14, 17

Bontebok, 214

Border Leicester Sheep, 203

Borzoi, 97

Bosch-vark, 278

Bottle-nosed Dolphin, 297, 299

Brindled Gnu, 215, 216

British Goat, 206

Broad-horned Antelope, 229

Brocket, 263

Brown Bear, European, 110

Brown Rat, 137

Bubaline Hartebeests, 213

Buffalo, 191; African, 192; Cape, 192, 194; 'Congo, 192, 193; Indian, 193, 194; Water-, 193

Bull-dogs, 101, 103

Bull-terriers, 104

Burchell's Zebra, 167, 169, 170, 171,172

Burhal, 200

Burme e Civet, 75

Bushback, Cape, 229; Cumming's, 229; Decula, 229

Bush-pig, Edwards', 279; South African, 278; West African, 278

Butterfly-dog, 105

Cachalot, 297

Calamianes Deer, 256

Calling-hares, 141

Camel, Arabian, 266, 268; Bactrian, 268, 269, 270; Baggage-, 268;-Pack-, 267; True, 266, 267, 268

Camel Tribe, 266

Canadian Lynx, 63, 64

Cape Aard-vark, 306

Cape Buffalo, 192, 194 
Cape Bushbuck, 229

Cape Giraffe, 239

Cape Hunting-dog, 92, 94

Cape Jumping-hare, 135, 138

Cape Zorilla, 117

Capuchin Monkeys, 20, 22, 23

Capybara, 130, 141

Caracal, 62

Cart-horses, 183

Caspian Red Deer, 249

Cat, Bay, 56; Black, 70; Blue, 71; Blue Long-haired, 69, 72; Blue Persian, 69, 72; Bun Shorthaired, 73; Bunny, 73; Domestic, 68; Egyptian Fettered, 57 ; Eyra, 56; Fishing-, 54; Geoffray's, 54; Golden. 55; Jungle-, 57; Kaffir, 56, 57; Lemur, 29; Long-haired Chinchilla, 73. Long-haired Orange, 71 ; Longhaired Tabby, 69; Mackerelmarked Tabby, 69; Manx, 73; Marbled, 54; Mottled, 54; Musical, 70; Non-retractile-clawed, 66; Orange Tabby, 69; Pallas', 56; Rusty-spotted, 56; Shorthaired Tabby, 71; Siamese, 72; Siamese Royal, 73; Silver Persian, 69, 72; Silver Tabby, 70; Smoke and Blue Long-haired, 69; Smoke Long-haired, 69, 73; Smoke Persian, 69; Ticked Short-haired, 73; Tortoise Shell, 68; White, 70; White Longhaired, 68; White Short-haired, 68

Cat Tribe, 53

Cattle, Angus, 188; Brittany, 187 ; Devon, 188; Domesticated, 187; Dutch, 187 ; English Park-, 185, 186; Hereford, 188; Humped, $188,190,191$; Jersey, 187 ; Longhorn, 188; Shorthorn, 187; Spanish, 187; Sussex, 188; Welsh, 188

Cavy, Restless, 140; Patagonian, 140,141

Celebes Pig, 277

Ceram Pig, 277

Chacma, 15, 20, 21

Chaus, African, 57

Cheeta, 49, 65, 67; A hooded, 66

Cherrotains, 266, 273

Chilian Guemal, 263

Chilian Pudu, 263

Chimpanzee, Bald, 1; True, 1

Chinchilla, 139, 140; Short-tailed, 140

Chinese Muntjac, 259

Chipmunks, Asiatic, 132

Chirogales, 30

Chital Deer, 256, 264

Chows, 106

Civet, African, 75, 76; Bennett's, 76 ; Burmese, 75; Indian, 75; Javan, 75; Large Indian, 74; Malabar, 75 ; Sumatran, 76

Cleveland Bay, 183

Clumber Spaniels, 100

Clydesdale, 183

Coatis, 115

Cobego, 143, 146, 147, 148

Cockers, 100

Collared Peccary, 280

Collared Pig, 277

Collies, Rough, 102

Collies, Smooth, 102
Coney, 159

Congo Buffalo, 192, 193

Coquerel's Lemur, 29, 30

Cotswold Sheep, 203

Coypu, 136, 139

Cumming's Bushbuck, 229

Cuscus, Black, 329; Grey, 329;

Spotted, 328, 330

Cusimanses, 78

Cuvier's Whale, 297

\section{D}

Dachshunds, 100, 101

Dalmatians, 102, 103

Dama Gazelle, 221

Dandie Dinmont Terriers, 106

Danes, Great, 100, 101

Dartmoor Pony, 183

Dasyures, 339

Decula Bushbuck, 229

Deer, Axis, 256, 257, 264 ; Barking-, 259; Bavian, 256; Bokhara, 250; Brow-antlered, 259; Calamianes, 256; Chinese Water-, 256, 260; Chital, 256, 264; Dybowski's, 251 ; Eld's, 259 ; Fallow, 251; Himalayan Musk-, 263, 265; Hog-, 256; Indian Spotted, 256; Japanese, 250, 264 ; Marsh-, 263, 264; Michie's Tufted, 260 : Pampas-, 263; Père David's, 261, 262; Philippine Spotted, 256; Prince Alfred's, 256; Red, 247, 264 ; Rib-faced, 259; Roe, 259, 260; Rusine, 252; Schomburgk's, 259; Spotted, 250; Swinhoe's, 254; Thamin, 259; Tibetan Tufted, 260; Typical, 252, 256

Deer Tribe, 245

Defassa Waterbuck, 219

Derbian Eland, 236

Desmans, 149

Devon Cattle, 188

Diana Monkey, 12, 15

Dibatag, 223

Dik-diks, 216

Dingo, 92, 93, 94

Dinoneys, 140

Diving-pigs, 276, 277

Dog, Azara's, 94; Domestic, 97 ; Sand-, 106, 108; Wild, 92

Dog Family, 83

Dolphin, 297; Bottle-nosed, 297 299 ; Elliott's, 298; Heavyside's, 299: Risso's, 298, 299; Shortbeaked River-, 295; Whitebeaked, 297; White-sided, 297

Donkey, 183; Egyptian, 184

Dorcas Gazelle, 222

Dormice, 134

Dorsal Squirrel, 132

Drill, 18, 22

Dromedary, 267, 268

Dugong, 291

Duikers, 216; Common, 216; Redflanked, 215

Dybowski's Deer, 251

\section{E}

Eared Seais, 120

Echidna, 341, 342, 343, 344; Ecuador Pudu, 263

Edmi Gazelle, 222

Egyptian Fettered Cat, 57

Egyptian Mongoose, 78
Eland, Common, 234; Derbian, 236

Eld's Deer, 259

Elephant, 150; African, 150, 156, 157; Asiatic, 150; Female Indian, dragging teak, 154; Timber-, 153; Young Indian, 151, 152

Elephant-seals, 126

Elk, Irish, 252

Elliott's Dolphin, 298

Entellus Monkey, 10

Eryocks (Chimpanzee), 1

Ethiopian Aard-vark, 306

Ethiopian Spring Squirrels, 133

European Badger, 117

European Bison, 191

European Goat, 205

European Lynx, 64

European Roe Deer, 258, 260

Exmoor Pony, 183

Eyra Cat, 56

\section{F}

Fairy Armadillo, 304

Fallow Deer, Common, 251 ; Mesopotamian, 252

Fat-tailed Sheep, 199, 201

Fennec, 96; Common, 96

Ferret, 119

Ferret-badger, 117

Field-vole, Short-tailed, 136

Finback, Whales, 297

Fish-eating Rats, 135

Fishing-cat, 53

Florizel II., The Race-horse, 180 .

Flower-nosed Bat, 145

Flying-fox, Australian, 143

Flying-phalangers, 323

Flying-squirrels, 130, 323

Formosan Macaque, 14

Formosan Pig. 277

Formosan Sambar, 254

Formosan Sika, 251, 253

Fossa, 27, 74

Four-horned Antelope, 216

Four-horned Sheep, 200

Fox, Common, 95; Leicestershire. 96; Mountain-, 96; Silver, 96

Fox-bat, Indian, 144; Malay, 144

Fox-hound, 97

Fruit-bat, Australian, 143, 144; Tube-nosed, 144

Fur-seal, 121; Cape, 122; New Zealand, 122; Northern, 121 . Southern, 122

Gaimard's Rat-kangaroo, 318

Galago, Garnett's, 30; Maholi, 30

Garnett's Galago, 30

Gaur, 188

Gaya1, 188, 189, 190

Gaze-hounds, 97

Gazelle, Arabian, 220, 222; Dama 221; Dorcas, 222; Edmi, 222 Goitred, 221 ; Grant's, 221, 222; Heuglin's, 221; Indian, 222 ; Isabella, 221; Loder's, 222; Marica, 222; Mhorr, 221; Mongolian, 221; Muscat, 222; Pelzeln's 221 ; Persian, 221 ; Peters', 222 ; Red-fronted, 221, 223; Rednecked, 221 ; Soemmerring's, 221; Speke's, 221, 222; Thomson's, 222 
Gelada Baboon, 13

Gemsbuck, 226

Genet, Common, 75, 77

Geoffray's Cat, 54

Gerbils, 134

Gerenuk, 223, 229

Gibbon, 8; Agile, 9; Silvery, 9; White-handed 8,9

Giraffe, Northern, 239; Nubian, 238; Southern, 237, 238, 239

Gnawing Mammals; 130

Gnu, Brindled, 215, 216; Whitebearded, 216; White-tailed, 21:

Goat, 205; Angora, 205; British. 206 ; European. 205 ; Italian, 211 ; Schwartzals, 208; Toggenburg, 207; Wild, 207

Golden Cat, 55

Golden Marmot, 133

Golden Mole, 149

Gordon Setters, 98

Gorilla, 4

Grampus, 294, 297

Grant's Gazelle, 222, 226

Graphiures, 134

Great Danes, 100, 101

Grevy's Zebra, 167, 168

Greyhound, 97, 98; Italian, 108

Griffons Brusselois, 108

Grivet Monkey, 14, 17

Guanaco, 271

Guemal, Chilian, 263; Peruvian, 263

Guenons, 12

Guereza, 12; Mantled, 14

\section{$\mathbf{H}$}

Hackney, 179

Hair-seals, 122

Hamsters, 134

Hardwicke's Hemigale, 76

Hare, Cape Jumping-, 135 ; Common, 141 ; Mountain-. 141

Hare-kangaroo, 317

Hare-skin Monkey, 26

Harp-seal, 125, 128

Harriers, 97

Hartebeests, 213; Bubaline, 213

Harvest-mouse, 137

Heavyside's Dolphin, 299

Hedgehogs, 147, 148

Hemigale, Hardwicke's, 76

Hereford Cattle, 188

Heuglin's Gazelle, 221

Himalayan Black Bear, 113

Himalayan Marmot, 133

Hinny, 184

Hippopotamus, Baby, 285; Common, 282, 289 ; Dental operations on a, 286, 287; Liberian, 290; Pygmy, 290

Hippopotamus drinking, 283

Hippopotamuses bathing, 284

Hog-deer, 254, 256; Red, 259

Hog, Pygmy, 276

Hollow-horned Ruminants, 185

Horse, Domesticated, 175; Levant, 180; London Dray-, 176; Persian, 180

Horse Tribe, 167

House-mouse, 137

Howler Monkeys, 22, 23

Hulock, 9

Humpback Whale, 297

Humped Cattle, 188, 190, 191

Hunter, 183
Hunting-leopard, 66

Hutia, 137, 139

Hyæna, Brown, 81 ; Laughing-, 81 ; Spotted, 81 ; Striped, 82

Hyrax, 159

\section{I}

Ibex, 208; Abyssinian, 208; A1pine, 208, 209; Arabian, 208; Asiatic, 208; Nilgiri, 210

Impala, 218

Indian Bison, 188

Indian Civet, 75

Indian Mongoose, 77

Indian Muntjac, 259

Indian Sloth-bear, 112

Indian Spotted Deer, 256, 257

Indri, Black, 29; Black-and-white, 28; Woolly, 29

Insectivora, 147

Inyala Antelope, 230

Irish Elk, 252

Irish Setters, 98

Irish Terriers, 104

Irish Wolf-hounds, 97

Isabella Gazelle, 221

Isabelline Bear, 113

Italian Goat, 211

Italian Greyhounds, 108

\section{$\mathrm{J}$}

Jackal, Black-backed, 90; Indian, 90; North African, 90; Sidestriped, 90; Striped, 90; Turkish, 91

Jaguar, 50

Japanese Deer, 250, 264

Japanese Macaque, 14

Japanese Masked Pig, 277

Japanese Spaniels, 107

Javan Civet, 75

Javan Sambar, 254

Javelin-bats, 146

Jenny, the Chimpanzee, 2

Jerboa, Long-eared, 135; Pouched Mouse, 340 ; 'True, 138

Jersey Cow, 187

Jumping-shrews, 147

Jungle-cat, 57

Jungle-sheep, 259

\section{K.}

Kaffir Cat, 56, 57

Kaffir Mongoose, 78

Kalong, 144

Kangaroo, 310; Albino Red, 310 . Great Grey, 307, 309, 310; Brown Tree-, 316; Rat-, 317, 318; Si1ver-grey, 308; Tree-, 315, 317, 318; Woolly, 310

Kapplers' Armadillo, 305

Kashmir Stag, 249

Keitloa, 165

Kiang, 174, 175

Killer, 294

King Charles Spaniels, 107

Kinkajou, 115, 116

Klipspringer, 216, 218

Koala, 319, 320, 321

Kudu, Greater, 232, 233; Lesser, 232,233

\section{L}

Ladas, The English Thoroughbred, 180

Lagothrix, 26

Langur, 10; Cross-bearing, 11; Himalayan, 11

Leaf-nosed Bat, 145

Leicester Ewe, 202

Leicester Long-wool Sheep, 204

Lemming, 136

Lemur, Black, 29; Cat (Lemur Catta), 29; Coquerel's, 29, 30 ; Crowned, 29; Dwarf, 28; Gentle, 29 ; Grey, 29; Mouse, 29; Ringtailed, 28; Ruffed, 29; Slow, 31; Sportive, 29; True, 29

Leopard, 47; Black, 46; Clouded. 54; Hunting-, 66; Snow, 48; -puma Hybrid, 46

Leopard-cat, 54

Liberian Hippopotamus, 290

Linsang, Nepalese, 76

Lion, A performing, 36; African, 33; -tiger Hybrid, 38

Lion Marmoset, 24

Lioness, Algerian, 35

Littledale's Sheep, 198

Llamas, $270,272,273$

Loder's Gazelle, 222

London Dray-horse, 176

Longhorn Cattle, 188

Long-wool (Leicester) Sheep, 204

Loris, Slender, 31; Slow, 31

Luehdorf's Stag, 250

Luzon Sambar, 254

Lynx, 62 ; Canadian, 63, 64 ; Common, 63; European, 64; Mediterranean, 63; Northern, 63; Red, 63, 64; Siberian, 64; Spanish, 63

\section{M}

Macaque, Bonnet, 14; Chinese, 17: Common, 14; Formosan, 14; Japanese, 14

Mahari Dromedary, 268

Maholi, Galago, 30

Makis, 28

Malabar Civet, 75

Malay Fox-bat, 144

Malayan Sambar, 254

Malayan Sun-bear, 114

Maltese Toy Terriers, 105, 107

Mammals, Egg-laying, 341

Mammoth, 150

Manatees, 291, 292

Manchurian Roe, 262

Manchurian Sika, 250

Manchurian Wapiti, 250

Mandrill, 18, 22

Mangabey, 14; Grey-cheeked, 17 ; Sooty, 16

Manis, 305

Manx Cat, 72

Maral, 249

Marco Polo's Sheep, 198

Margot, 14

Marica Gazelle, 222

Marine Carnivora, 120

Marknor, 209

Marmoset, Black-eared, 26; Lion, 24; Pinché, 24

Marmot, Alpine, 133; Golden, 133; Himalayan, 133

Marsh-deer, 263, 264 
Marsupials, 308

Marten, Beech-, 119; Pine-, 119

Mastiffs, 101, 104

Mediterranean Lynx, 63

Meerkat, 78, 80; Slender-tailed, 79

Merino Sheep, 201, 202

Mhorr Gazelle, 221

Mias-kassu (orang-utan), 6

Mias-pappan (orang-utan), 6

Mias-rambi (orang-utan), 6

Mice, White-footed, 134

Michie's Tufted Deer, 260

Mole, 148; Common, 148; Golden, 149; Pouched, 322, 335, 336

Mole-rats, 138

Moluccan Rusa, 254

Mona Monkey, 14

Mongolian Gazelle, 221

Mongoose, Egyptian, 78; Indian, 77 ; Kaffir, 78

Monkey, Bandar, 14; Diana, 12 ; Dog-shaped, 10; Entellus, 10; Green, 14; Grivet, 17; Hareskin, 26; Mona, 14; Patas, 24; Pig-tailed, 19, 27; Proboscis, 10; Rhesus, 14, 16; Sacred, 10; Snub-nosed, 12, 18; Spider, 22, 23; Squirrel, 24; Tcheli, 14: Wanderoo, 24; White-bearded Wanderoo, 12; Woolly, 26

Monotremes, 308, 341

Moose, 264

Moufflon, European, 197

Mountain-cat, 64

Mountain-fox, 96

Mountain-reedbuck, 218

Mountain-zebra, 167

Mouse, House-, 137

Mouse Lemur, 29

Mouse Tribe, 134

Mules, 184

Muntjac, Chinese, 259; Hairyfronted, 259; Indian, 259; Tenasserim, 259; Tibetan, 259

Muscat Gazelle, 222

Musk-deer, Himalayan, 263, 265

Musk-rat, 136

\section{N}

Naked Bat, 146

Narwhal, 293, 297, 298

Native Cats, Australian, 339

New Forest Pony, 183

New foundlands, 101, 102

Nilgai, 228, 230

Nilgiri Ibex, 210

Nilgiri Tahr, 210

Nubian Giraffe, 238

Nubian Goat, 210

Nutria, 139

Ocelot, 53

Octodont, 136

Odd-toed Hoofed Animals, 159

Okapi, 241, 243, 244

Old English Sheep-dogs, 102, 107

Old English Terriers, 104

Onager, 174

Oorial, 198

Opossum, 308, 323; Black, 323,

326; Common Grey, 326, 327,

328; Ring-tailed, 326, 329; Sooty,

323; Virginia, 342; Vulpine, 326

Orang-utan, 5

Orang-utans, Baby, at play, 8
Oribis, 216

Orloff, 181

Oryx, Beatrice, 224-226; Beisa, 226, 228; Tufted Beisa, 226; White, 226, 228

Otter, 116; Common, 116; Shorttoed, 116

Oukari, Scarlet-faced, 24

Ounce, 48

Oxen, Italian White, 187; Wild, 186,188

Paca, 140

Pacer, 181

Pack-camel, 267

Paddy-melons, 317

Palla, 218, 220

Pallas' Cat, 56

Palm-civet, 76; Masked, 78; Twospotted, 78

Pampas-cat, 56

Pampas-deer, 263

Panda, 115; Great, 115

Pangolins, 305

Papuan Pig, 277

Pariah Puppies, 108

Park-cattle, English, 185, 186

Parry's Wallaby, 314

Pasang, 207

Patas Monkey, 24

Peba Armadillo, 305

Peccary, Collared, 280, 281; Whitelipped, 281

Pekin Sika, 251

Pekin Spaniels, 107

Pel's Flying-squirrel, 153

Peludo, 304

Pelzeln's Gazelle, 221

Percheron, 179

Père David's Deer, 261, 262

Persian Gazelle, 221

Peruvian Guemal, 263

Peter's Gazelle, 222

Phalanger, 319; Crescent-toothed, 326; Flying-, 323; Larger Flying-, 323; Lesser Flying-, 324; Long-snouted, 326; Pygmy, 326; Pygmy Flying-, 325, 326; Squirrel - like Flying-, 322 ; Striped, 326; Typical, 323

Phascogali, 340

Philippine Rats, 134

Philippine Spotted Deer, 256

Pig, Bearded, 277; Celebes, 277 ; Ceram, 277; Collared, 277; Diving-, 276, 277; Formosan, 277; Japanese Masked, 277; Papuan, 277; True, 275; White-whiskered Japanese, 277; Warty, 277

Pig-tailed Monkey, 19, 27

Pig Tribe, 274

Pikas, 141

Pilot-whale, 297

Pinché Marmoset, 24

Pine-marten, 119

Pipistrelle Bat, 145

Platypus, 341, 342; Duck-billed, 342-345

Pocket-gopher, 134, 138

Pointers, 97, 105

Polatouche, 132

Polecat, 119

Polecat-ferret, 119

Polo-pony, 183

Pomeranians, 105, 106

Pongo (Gorilla), 1, 4
Pony, Dartmoor, 183; Exmoor, 183; New Forest, 183; Polo-, 183; Shetland, 183; Welsh, 182, 183

Poodles, 103; Corded, 103, 105; Curly, 103; Fluffy, 103

Porcupine, 137; Canadian, 139

Porpoise, Common, 297, 298

Potoroos, 317, 318

Pottos, 31

Pouched Mice, 339

Pouched Mole, 322, 335

Pouched Mouse, Jerboa, 340

Prejevalski's Gazelle, 221

Prehensile-lipped Rhinoceros, 164

Prince Alfred's Deer, 256

Prince Charles Spaniels, 107, 108

Proboscis Monkey, 10

Prongbuck, 231

Pudu, Chilian, 263; Ecuador, 263

Pugs, 106

Puma, 50, 51

Punjab Sheep, 199

Pygmy Hippopotamus, 290

Pygmy Hog, 276

Quagga, 173

Rabbit, 142

$\mathbf{R}$

Rabbit-bandicoot, 332, 335

Raccoon-dog, 94

Race-horse, English, 179, 180

Rasse, 75

Rat, Alexandrine, 137; Bamboo138; Black - and - white, 137; Brown, 137; Fish-eating, 135; Philippine, 134; Rice-, 135

Ratel, 118, 119

Red Deer, 247, 264; Caspian, 249; Park, 246

Red Dogs of the Deccan, 94

Reedbuck, Common, 219; Mountain-, 218

Reindeer, 246; Scandinavian, 245

Retrievers, 98, 99

Rhesus Monkey, 14, 16

Rhinoceros, 160; bathing, 164 ; Black African, 163, 165; Great Indian, 161, 162; Hairy-eared Sumatran, 160, 162, 166; Indian, 160; Javan, 160; Prehensilelipped, 164, 165; Squaremouthed, 162; White, 162

Rice-rat, 135

Ring-tailed Lemur, 28

Risso's Dolphin, 298

River-dolphin, Short-beaked, 295

River-hog, Red, 278

Roan Antelope, 224, 226

Rodents, 130

Roe, Manchurian, 262; Siberian, 259, 262

Roebuck, Siberian, 260

Rorquals, 297

Ruby Toy Spaniels, 107

Rusa, 254; Moluccan. 254; Stag. Javan, 253; Timor, 255

Rusine Deer, 252

Russian Wolf-hound, 97

\section{s}

Sable, 119

Sable Antelope, 225

Saiga Antelope, 219, 220 
Saint Bernard, 101; Smoothcoated, 100

Saki, White-headed, 24

Sally, the Chimpanzee, 2, 3, 4

Sambar, Basilan, 254; Formosan, 254 ; Javan, 254; Luzon, 254 ; Malayan, 254; Stag, 252; Szechuan, 254

Sand-dog, 106, 108

Sand-rat, 138

Sassaby, 214

Schipperkes, 106

Schomburgk's Deer, 259

Schwartzals Goat, 208

Scottish Deer-hounds, 97

Scottish Terriers, 104, 105

Sea-elephant, 129

Sea-lion, 120, 122; Australian, 123; Californian, 127; Patagonian, 122

Seal, Bladder-nosed, 126; Common, 120, 125, 128; Elephant, 126; Grey, 124, 126, 128; Harp-, 126, 128; True, 124

Selvas, 308, 341

Senaar Boar, 277

Serval, $56,58,59$

Setter, 98; English, 100; Gordon, 98; Irish, 98

Sha, 198

Sheep, Barbary, 196, 198, 199 ; Black-faced Mountain-, 202; Blue, 200; Border Leicester, 203; Cotswold, 203; Domesticated, 200; Fat-tailed, 199, 201; Four-horned, 200; Leicester, 202; Littledale's, 198; Marco Polo's, 198; Merino, 201, 202; Somali, 201; South Down, 200, 203; Wallachian, 202; Welsh, 204; Wild, 196

Sheep-dogs, Old English, 102

Shetland Pony, 176, 181, 183

Shire Horse, 183

Shire Mare, 182

Shire Stallion, 181

Shorthorn Cattle. 187

Shrew, 147; Burrowing, 149; Mouse-like, 147; Tree-, 147; Water-. 147

Siamang, 8

Siamese Cat, 72

Siberian Argali, 197

Siberian Lynx, 64

Siberian Roe, 259, 262

Siberian Roebuck, 260

Sifaka. Diademed, 28

Sika, Formosan, 251, 253; Manchurian, 250; Pekin, 251

Silver Fox, 96

Sing-sing Waterbuck, 217, 219

Sitatungas, 231

Skye, Drop-eared, 106; Prickeared, 106

Skye Terriers, 105, 106

Sloth, 300; Northern Two-toed, 300; Three-toed, 301

Sloth-bear, Indian, 112

Soemmerring's Gazelle, 221

Soko (Chimpanzee), 3

Somali Sheep, 201

South Down Sheep, 200, 203

Southern Field-vole, 136

Southern Giraffe, 237, 238, 239

Sow, Domesticated, 274

Sowerby's Beaked Whale, 296, 297
Spaniel, 98; Black, 100; Clumber, 100; Cocker, 100; Japanese, 107 ; Pekin, 107; Sussex, 100

Spanish Lynx, 63

Spanish Tur, 207

Speke's Gazelle, 221, 222

Sperm-whale, 297

Spider Monkeys, 22, 23

Spotted Cats, 339

Spotted Cavy, 140

Springbuck, 222, 224

Square-mouthed Rhinoceros, 162

Squirrel, 130; Dorsal, 132; Ethiopian Spiny, 133; Flying-, 130, 131, 132, 323; Indian Palm-, 133; Red, 131; Sugar-, 323

Squirrel Monkeys, 24, 25

Stag, Barbary, 249; Kashmir, 249; Luehdorf's, 250

Stag-hound, 97

Steller's Sea-lion, 120, 122

Strand-wolf, 81

Sucker-footed Bats, 146

Suffolk Punch, 183

Sugar-squirrel, 323

Sumatran Civet, 76

Sun-bear, Malayan, 114

Suricates, 78

Sussex Spaniels, 100

Swamp-deer, 255, 259

Swine, 274

Swinhoe's Deer, 254

Syrian Bear, 111, 114

Szechuan Sambar, 254

\section{$\mathbf{T}$}

Tabby, Short-haired, 71

Taguan, 132

Tahr, 209; Nilgiri, 210

Tamandua Ant-eater, 303

Tamarau, 195

Tapirs, 157, 158; American, 158, 159; Malayan, 158

Tarpans, 175

Tarsier, 31, 32

Tasmanian Devil, 337, 338

Tasmanian Tiger, 336

Tasmanian Wallaby, 311

Tasmanian Wolf, 336, 337

Tcheli Monkey, 14

Tenasserim Muntjac, 259

Tenrecs, 147; Common, 147

Terrier, Airdale, 104; Bedlington, 104: Bull-, 104: 'Fox-, 107 ; Irish, 104; Old English, 104; Scottish, 104, 105; Skye, 105 106; Welsh, 104

Thamin Deer, 259

Thomson's Gazelle, 222

Thoroughbred, British, 180

Thylucine, 336

Tibetan Argali, 197, 198

Tibetan Gazelle, 221

Tibetan Muntjac, 259

Tibetan Tiger-cat, 54

Tibetan Tufted Deer, 260

Tiger, Royal Bengal, 42

Tiger-cat, Indian, 56; Tibetan, 54

Tigress, 41

Timber-elephants, 153

Timor Rusa, 255

Toddy-cats, 76

Toggenburg Goat, 207

Toothed Whales, 297
Toy Spaniels, 107

Toy Terriers, Yorkshire, 107

Transhumantes, 202

Tree-kangaroo, 315, 317, 318

Tree-mice, 134

Tree-shrews, 147

Trotting-horse, 181

Tube-nosed Fruit-bat, 144

Tuco-tucos, 139

Tufted Beisa Oryx, 226

Tur, 207; East Caucasian, 207; Spanish, 207

U

Ungulates, 185

Vampire-bats, 146

Vicuña, 270

Virginian Deer, 262

Viscacha, 138,140

Vlakte-vark, 280

Vole, 135; Bank-, 136; Shorttailed Field-, 136; Southern Field-, 136

Waita, 23

W

Wallaby, Albino Red-bellied, 312; Bennett's, 309; Black, 317' Black-striped, 309; Brush-tail, 317; Parry's, 314; Rock, 313; Spur-tail, 317; Tasmanian, 311

Wallachian Sheep, 202

Wallaroos, 317

Walrus, 120, 123, 124

Wanderoo Monkey, Great, 12; White-bearded, 12

Wapiti, 250, 264; Altai, 249; Asiatic, 247; Manchurian, 250

Wart-hog, 278, 279; Elian's, 278 280; South African, 280

Warty Pig, 277

Waterbuck, 219; Common, 219; Defassa, 219; Sing-sing, 217, 219

Water-buffalo, 193

Water-deer, Chinese, 256, 260

Water-mice, 134

Water-rat, 136

Water-shrews, 147

Weasel Lemur, 29

Weasel Tribe, 119

Welsh Pony, 182

Welsh Sheep, 204

Welsh Terriers, 104

Welwitsch's Bat, 146

West African Bush-pig, 278

West Caucasian Tur, 207

Whale, Beaked, 297; Broadfronted, 297; Cuvier's, 297; Southern Right-, 297; Toothed, 297; Whalebone-, 297; White, 297

Whalebone-whales, 297

Whiffets, 97

White-bearded Gnu, 216

White English Terriers, 104

White-footed Mice, 134

White-lipped Peccary, 281

White Rhinoceros, 162 
Marsupials, 308

Marten, Beech-, 119; Pine-, 119

Mastiffs, 101, 104

Mediterranean Lynx, 63

Meerkat, 78, 80; Slender-tailed, 79

Merino Sheep, 201, 202

Mhorr Gazelle, 221

Mias-kassu (orang-utan), 6

Mias-pappan (orang-utan), 6

Mias-rambi (orang-utan), 6

Mice, White-footed, 134

Michie's Tufted Deer, 260

Mole, 148; Common, 148; Golden, 149; Pouched, 322, 335, 336

Mole-rats, 138

Moluccan Rusa, 254

Mona Monkey, 14

Mongolian Gazelle, 221

Mongoose, Egyptian, 78; Indian, 77; Kaffir, 78

Monkey, Bandar, 14; Diana, 12; Dog-shaped, 10; Entellus, 10; Green, 14; Grivet, 17; Hareskin, 26; Mona, 14; Patas, 24 ; Pig-tailed, 19, 27; Proboscis, 10; Rhesus, 14, 16; Sacred, 10; Snub-nosed, 12, 18; Spider, 22, 23; Squirrel, 24; Tcheli, 14; Wanderoo, 24; White-bearded Wanderoo, 12; Woolly, 26

Monotremes, 308, 341

Moose, 264

Moufflon, European, 197

Mountain-cat, 64

Mountain-fox, 96

Mountain-reedbuck, 218

Mountain-zebra, 167

Mouse, House-, 137

Mouse Lemur, 29

Mouse Tribe, 134

Mules, 184

Muntjac, Chinese, 259; Hairyfronted, 259; Indian, 259; Tenasserim, 259; Tibetan, 259

Muscat Gazelle, 222

Musk-deer, Himalayan, 263, 265

Musk-rat, 136

\section{$\mathbf{N}$}

Naked Bat, 146

Narwhal, 293, 297, 298

Native Cats, Australian, 339

New Forest Pony, 183

New foundlands, 101, 102

Nilgai, 228, 230

Nilgiri Ibex, 210

Nilgiri Tahr, 210

Nubian Giraffe, 238

Nubian Goat, 210

Nutria, 139

Ocelot, 53

Octodont, 136

Odd-toed Hoofed Animals, 159

Okapi, 241, 243, 244

Old English Sheep-dogs, 102, 107

Old English Terriers, 104

Onager, 174

Oorial, 198

Opossum, 308, 323; Black, 323 ,

326; Common Grey, 326, 327,

328; Ring-tailed, 326, 329; Sooty,

323; Virginia, 342; Vulpine, 326

Orang-utan, 5

Orang-utans, Baby, at play, 8
Oribis, 216

Orloff, 181

Oryx, Beatrice, 224-226; Beisa, 226, 228; Tufted Beisa, 226; White, 226, 228

Otter, 116; Common, 116; Shorttoed, 116

Oukari, Scarlet-faced, 24

Ounce, 48

Oxen, Italian White, 187; Wild, 186,188

\section{$\mathbf{P}$}

Paca, 140

Pacer, 181

Pack-camel, 267

Paddy-melons, 317

Palla, 218, 220

Pallas' Cat, 56

Palm-civet, 76; Masked, 78; Twospotted, 78

Pampas-cat, 56

Pampas-deer, 263

Panda, 115; Great, 115

Pangolins, 305

Papuan Pig, 277

Pariah Puppies, 108

Park-cattle, English, 185, 186

Parry's Wallaby, 314

Pasang, 207

Patas Monkey, 24

Peba Armadillo, 305

Peccary, Collared, 280, 281; Whitelipped, 281

Pekin Sika, 251

Pekin Spaniels, 107

Pel's Flying-squirrel, 153

Peludo, 304

Pelzeln's Gazelle, 221

Percheron, 179

Père David's Deer, 261, 262

Persian Gazelle, 221

Peruvian Guemal, 263

Peter's Gazelle, 222

Phalanger, 319; Crescent-toothed, 326; Flying-, 323; Larger Flying-, 323; Lesser Flying-, 324; Long-snouted, 326; Pygmy, 326; Pygmy Flying-, 325, 326; Squirrel - like Flying-, 322; Striped, 326; Typical, 323

Phascogali, 340

Philippine Rats, 134

Philippine Spotted Deer, 256

Pig, Bearded, 277 ; Celebes, 277 ; Ceram, 277; Collared, 277; Diving-, 276, 277; Formosan, 277; Japanese Masked, 277; Papuan, 277; True, 275; White-whiskered Japanese, 277; Warty, 277

Pig-tailed Monkey, 19, 27

Pig Tribe, 274

Pikas, 141

Pilot-whale, 297

Pinché Marmoset, 24

Pine-marten, 119

Pipistrelle Bat, 145

Platypus, 341, 342; Duck-billed, 342-345

Pocket-gopher, 134, 138

Pointers, 97, 105

Polatouche, 132

Polecat, 119

Polecat-ferret, 119

Polo-pony, 183

Pomeranians, 105, 106

Pongo (Gorilla), 1, 4
Pony, Dartmoor, 183; Exmoor, 183; New Forest, 183; Polo-, 183 ; Shetland, 183; Welsh, 182, 183

Poodles, 103; Corded, 103, 105; Curly, 103; Fluffy, 103

Porcupine, 137; Canadian, 139

Porpoise, Common, 297, 298

Potoroos, 317, 318

Pottos, 31

Pouched Mice, 339

Pouched Mole, 322, 335

Pouched Mouse, Jerboa, 340

Prejevalski's Gazelle, 221

Prehensile-lipped Rhinoceros, 164

Prince Alfred's Deer, 256

Prince Charles Spaniels, 107, 108

Proboscis Monkey, 10

Prongbuck, 231

Pudu, Chilian, 263; Ecuador, 263

Pugs, 106

Puma, 50, 51

Punjab Sheep, 199

Pygmy Hippopotamus, 290

Pygmy Hog, 276

Quagga, 173

Rabbit, 142

$\mathbf{R}$

Rabbit-bandicoot, 332, 335

Raccoon-dog, 94

Race-horse, English, 179, 180

Rasse, 75

Rat, Alexandrine, 137 ; Bamboo 138; Black - and - white, 137; Brown, 137; Fish-eating, 135; Philippine, 134; Rice-, 135

Ratel, 118, 119

Red Deer, 247, 264; Caspian, 249; Park, 246

Red Dogs of the Deccan, 94

Reedbuck, Common, 219; Mountain-, 218

Reindeer, 246; Scandinavian, 245

Retrievers, 98, 99

Rhesus Monkey, 14, 16

Rhinoceros, 160; bathing, 164 ; Black African, 163, 165; Great Indian, 161, 162; Hairy-eared Sumatran, 160, 162, 166; Indian, 160; Javan, 160; Prehensilelipped, 164, 165; Squaremouthed, 162; White, 162

Rice-rat, 135

Ring-tailed Lemur, 28

Risso's Dolphin, 298

River-dolphin, Short-beaked, 295

River-hog, Red, 278

Roan Antelope, 224, 226

Rodents, 130

Roe, Manchurian, 262; Siberian, 259,262

Roebuck, Siberian, 260

Rorquals, 297

Ruby Toy Spaniels, 107

Rusa, 254; Moluccan,. 254; Stag, Javan, 253; Timor, 255

Rusine Deer, 252

Russian Wolf-hound, 97

\section{$\mathbf{S}$}

Sable, 119

Sable Antelope, 225

Saiga Antelope, 219, 220 
Saint Bernard, 101; Smoothcoated, 100

Saki, White-headed, 24

Sally, the Chimpanzee, 2, 3, 4

Sambar, Basilan, 254; Formosan, 254; Javan, 254; Luzon, 254; Malayan, 254; Stag, 252; Szechuan, 254

Sand-dog, 106, 108

Sand-rat, 138

Sassaby, 214

Schipperkes, 106

Schomburgk's Deer, 259

Schwartzals Goat, 208

Scottish Deer-hounds, 97

Scottish Terriers, 104, 105

Sea-elephant, 129

Sea-lion, 120, 122; Australian, 123; Californian, 127; Patagonian, 122

Seal, Bladder-nosed, 126; Common, $120,125,128$; Elephant, 126; Grey, 124, 126, 128; Harp-, 126,128 ; True, 124

Selvas, 308, 341

Senaar Boar, 277

Serval, 56, 58, 59

Setter, 98; English, 100; Gordon, 98; Irish, 98

Sha, 198

Sheep, Barbary, 196, 198, 199; Black-faced Mountain-, 202; Blue, 200; Border Leicester, 203; Cotswold, 203; Domesticated, 200; Fat-tailed, 199, 201 ; Four-horned, 200; Leicester, 202; Littledale's, 198; Marco Polo's, 198; Merino, 201, 202 ; Somali, 201; South Down, 200, 203; Wallachian, 202; Welsh, 204; Wild, 196

Sheep-dogs, Old English, 102

Shetland Pony, 176, 181, 183

Shire Horse, 183

Shire Mare, 182

Shire Stallion, 181

Shorthorn Cattle. 187

Shrew, 147; Burrowing, 149 ; Mouse-like, 147; Tree-, 147; Water-, 147

Siamang, 8

Siamese Cat, 72

Siberian Argali, 197

Siberian Lynx, 64

Siberian Roe, 259, 262

Siberian Roebuck, 260

Sifaka, Diademed, 28

Sika, Formosan, 251, 253 ; Manchurian, 250; Pekin, 251

Silver Fox, 96

Sing-sing Waterbuck, 217, 219

Sitatungas, 231

Skye, Drop-eared, 106; Prickeared, 106

Skye Terriers, 105, 106

Sloth, 300; Northern Two-toed, 300; Three-toed, 301

Sloth-bear, Indian, 112

Soemmerring's Gazelle, 221

Soko (Chimpanzee), 3

Somali Sheep, 201

South Down Sheep, 200, 203

Southern Field-vole, 136

Southern Giraffe, 237, 238, 239

Sow, Domesticated, 274

Sowerby's Beaked Whale, 296, 297
Spaniel, 98; Black, 100; Clumber, 100; Cocker, 100; Japanese, 107 ;

Pekin, 107; Sussex, 100

Spanish Lynx, 63

Spanish Tur, 207

Speke's Gazelle, 221, 222

Sperm-whale, 297

Spider Monkeys, 22, 23

Spotted Cats, 339

Spotted Cavy, 140

Springbuck, 222, 224

Square-mouthed Rhinoceros, 162

Squirrel, 130; Dorsal, 132; Ethiopian Spiny, 133; Flying-, 130, 131, 132, 323; Indian Palm-, 133; Red, 131; Sugar-, 323

Squirrel Monkeys, 24, 25

Stag, Barbary, 249; Kashmir, 249; Luehdorf's, 250

Stag-hound, 97

Steller's Sea-lion, 120, 122

Strand-wolf, 81

Sucker-footed Bats, 146

Suffolk Punch, 183

Sugar-squirrel, 323

Sumatran Civet, 76

Sun-bear, Malayan, 114

Suricates, 78

Sussex Spaniels, 100

Swamp-deer, 255, 259

Swine, 274

Swinhoe's Deer, 254

Syrian Bear, 111, 114

Szechuan Sambar, 254

\section{$T$}

Tabby, Short-haired, 71

Taguan, 132

Tahr, 209; Nilgiri, 210

Tamandua Ant-eater, 303

Tamarau, 195

Tapirs, 157, 158; American, 158 159; Malayan, 158

Tarpans, 175

Tarsier, 31, 32

Tasmanian Devil, 337, 338

Tasmanian Tiger, 336

Tasmanian Wallaby, 311

Tasmanian Wolf, 336, 337

Tcheli Monkey, 14

Tenasserim Muntjac, 259

Tenrecs, 147 ; Common, 147

Terrier, Airdale, 104; Bedlington, 104; Bull-, 104 ; Fox-, 107 ; Irish, 104; Old English, 104; Scottish, 104, 105; Skye, 105, 106; Welsh, 104

Thamin Deer, 259

Thomson's Gazelle, 222

Thoroughbred, British, 180

Thylucine, 336

Tibetan Árgali, 197, 198

Tibetan Gazelle, 221

Tibetan Muntjac, 259

Tibetan Tiger-cat, 54

Tibetan Tufted Deer, 260

Tiger, Royal Bengal, 42

Tiger-cat, Indian, 56; Tibetan, 54

Tigress, 41

Timber-elephants, 153

Timor Rusa, 255

Toddy-cats, 76

Toggenburg Goat, 207

Toothed Whales, 297
Toy Spaniels, 107

Toy Terriers, Yorkshire, 107

Transhumantes, 202

Tree-kangaroo, $315,317,318$

Tree-mice, 134

Tree-shrews, 147

Trotting-horse, 181

Tube-nosed Fruit-bat, 144

Tuco-tucos, 139

Tufted Beisa Oryx, 226

Tur, 207; East Caucasian, 207; Spanish, 207

Ungulates, 185

Vampire-bats, 146

Vicuña, 270

Virginian Deer, 262

Viscacha, 138,140

Vlakte-vark, 280

Vole, 135; Bank-, 136; Shorttailed Field-, 136; Southern Field-, 136

Waita, 23

Wallaby, Albino Red-bellied, 312; Bennett's, 309; Black, 317. Black-striped, 309; Brush-tail. 317 ; Parry's, 314; Rock, 313; Spur-tail, 317; Tasmanian, 311

Wallachian Sheep, 202

Wallaroos, 317

Walrus, $120,123,124$

Wanderoo Monkey, Great, 12 ; White-bearded, 12

Wapiti, 250, 264; Altai, 249 Asiatic, 247; Manchurian, 250

Wart-hog, 278, 279; Alian's, 278 280; South African, 280

Warty Pig, 277

Waterbuck, 219; Common, 219 : Defassa, 219; Sing-sing, 217 . 219

Water-buffalo, 193

Water-deer, Chinese, 256, 260

Water-mice, 134

Water-rat, 136

Water-shrews, 147

Weasel Lemur, 29

Weasel Tribe, 119

Welsh Pony, 182

Welsh Sheep, 204

Welsh Terriers, 104

Welwitsch's Bat, 146

West African Bush-pig, 278

West Caucasian Tur, 207

Whale, Beaked, 297; Broadfronted, 297; Cuvier's, 297 Southern Right-, 297; Toothed 297; Whalebone-, 297; White 297

Whalebone-whales, 297

Whiffets, 97

White-bearded Gnu, 216

White English Terriers, 104

White-footed Mice, 134

White-lipped Peccary, 281

White Rhinoceros, 162 
White Whale, 297

White-whiskered Japanese Pig, 277

Wild Ass, 173; African, Asiatic, 174; Baluchi, 174

Wild Boar, 275

Wild Cat, Black-footed, 56; Common, 60; European, 61; Scotch, 62

Wild Cattle, 186

Wild Dog, 92, 94

Wild Goats, 207; Persian, 207

Wild Oxen, 186,188
Wild Sheep, 196

Wildebeest, Black, 215; Blue, 216

Wolf, Carpathian, 87; Indiaı, 88 ; Maned, 91; Northern, 84; Russian, 86, 89; White, 85

Wolf-hound, Irish, 97; Russian, 97

Wombat, 330; Common, 331, 333 . Hairy-nosed, 331, 332; Tasmanian, 331

Wood-hare, 141

Wood-mouse, 137

Woolly Monkey, 26

\section{Y}

Yak, 190, 193

Yorkshire Toy Terriers, 107

\section{Z}

Zebra, 167; Burchell's, 167, 169 170,171 , 172; Grevy's, 167, 168; Mountain-, 167; Team of, 170; True, 167

Zebu, 191

Zorilla, Cape, 117

Zubr, 191 



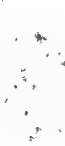

, . 

1 (

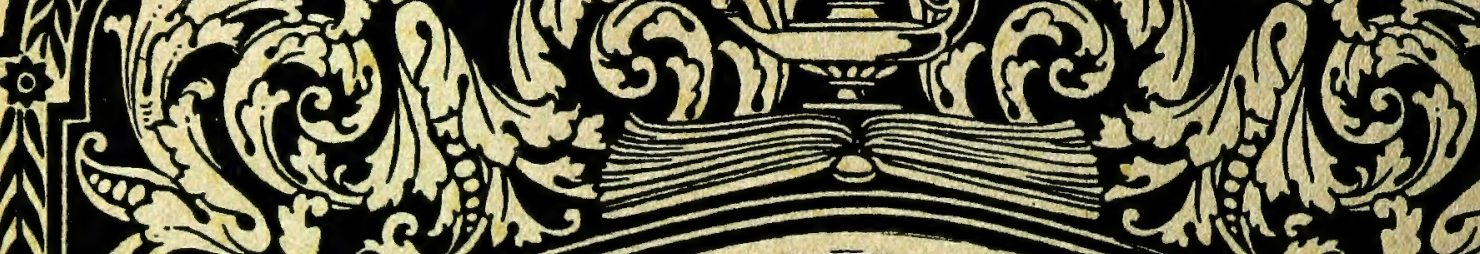

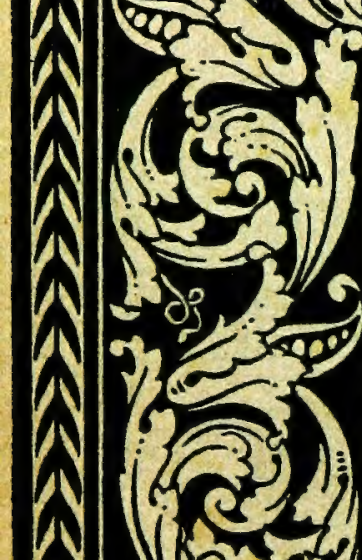

1

(2)

cor

हर
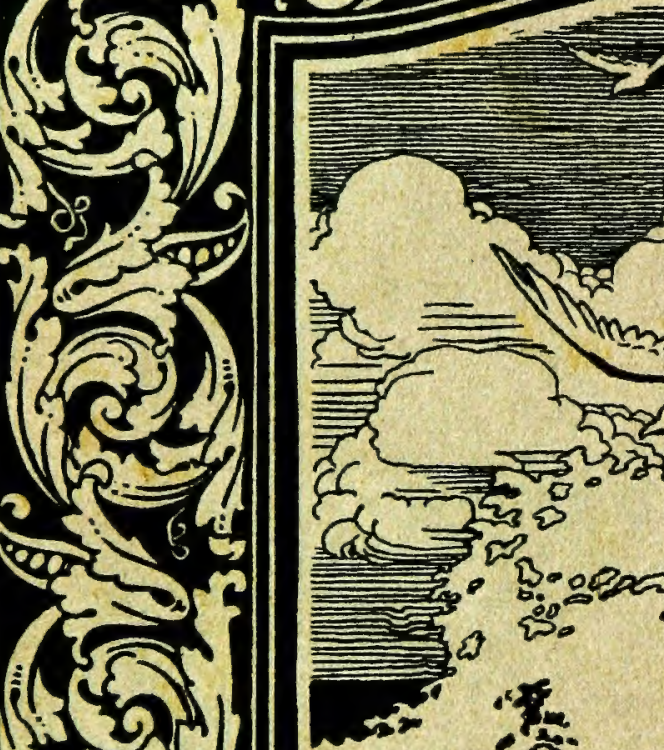

10
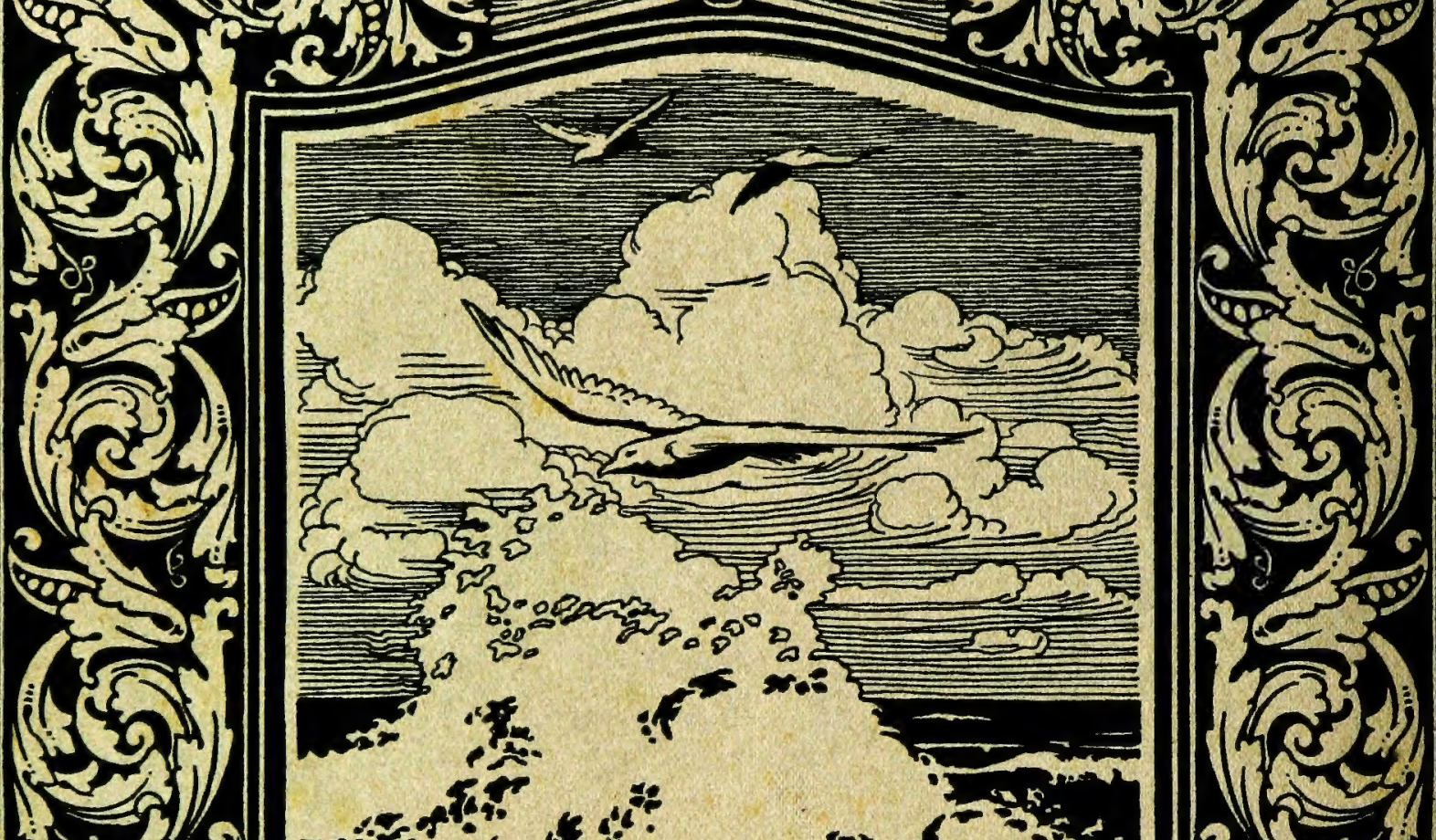

is

10

$(2)$

$16: 2$

cos: -16

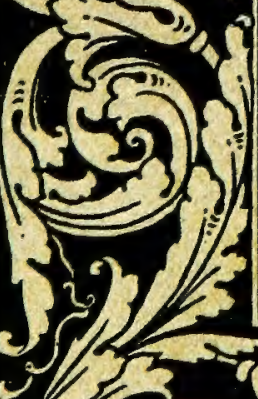

-

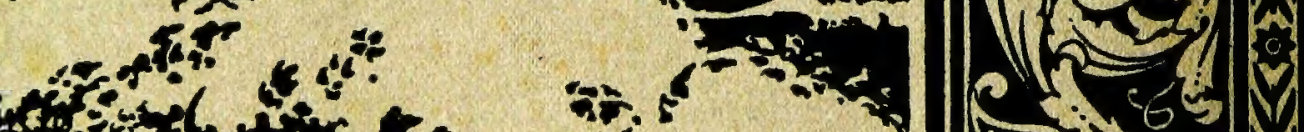
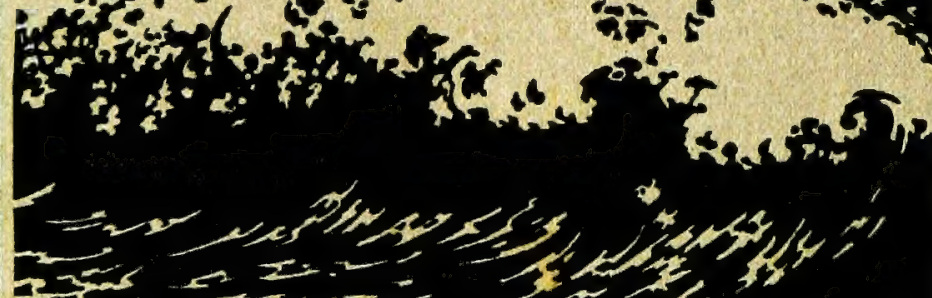

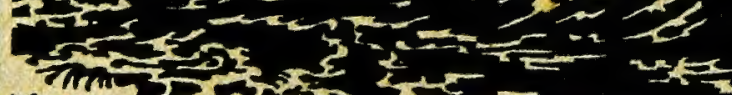

-

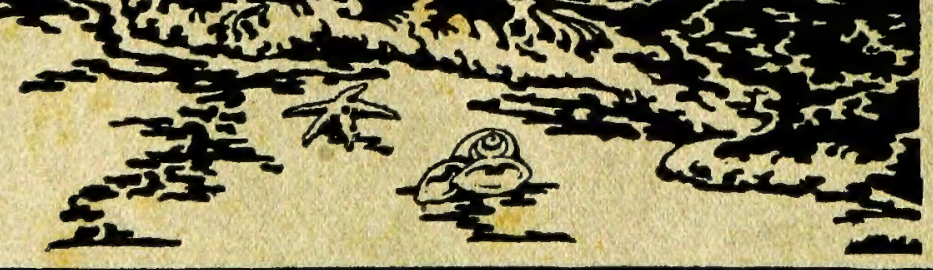

6) 5 (5) 50

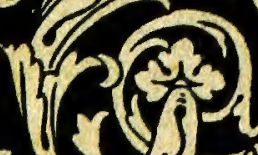

$3(2)-6013$

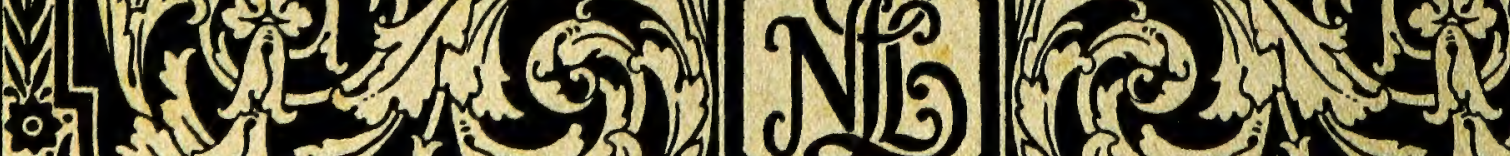

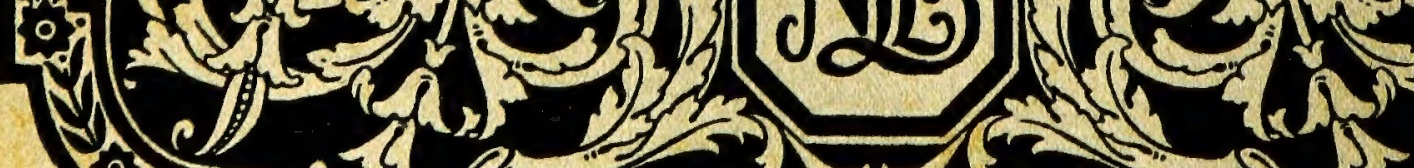

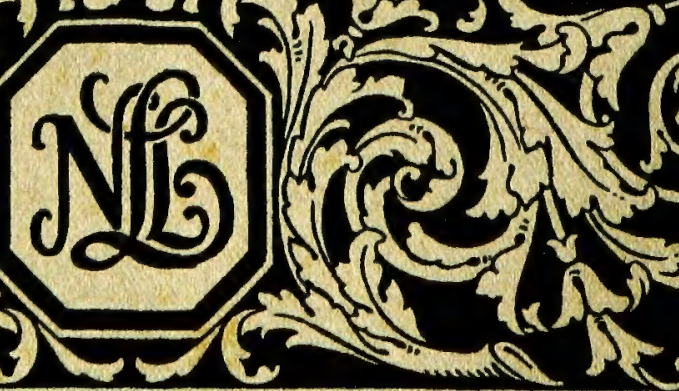




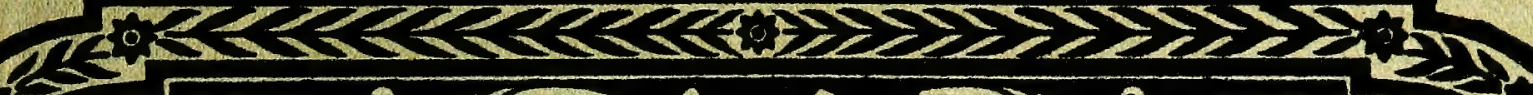

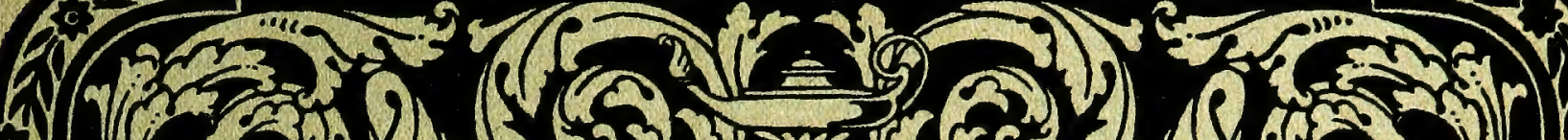

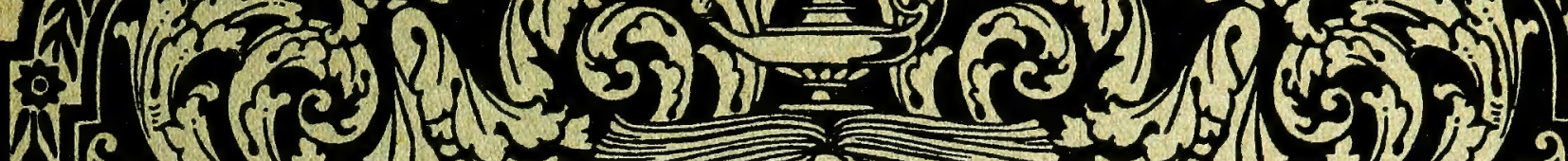

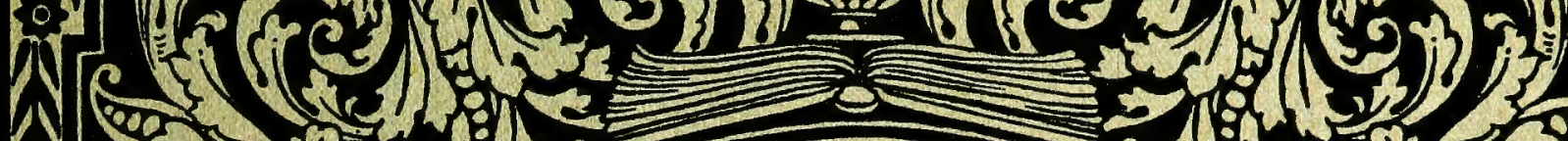

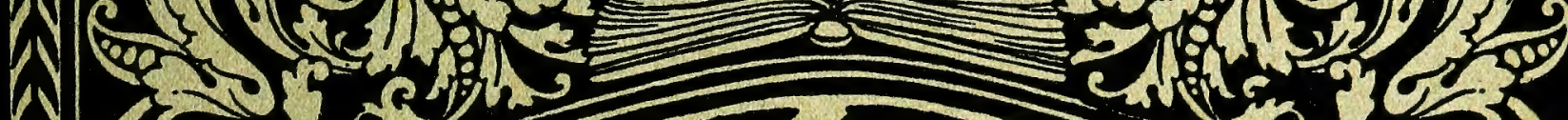
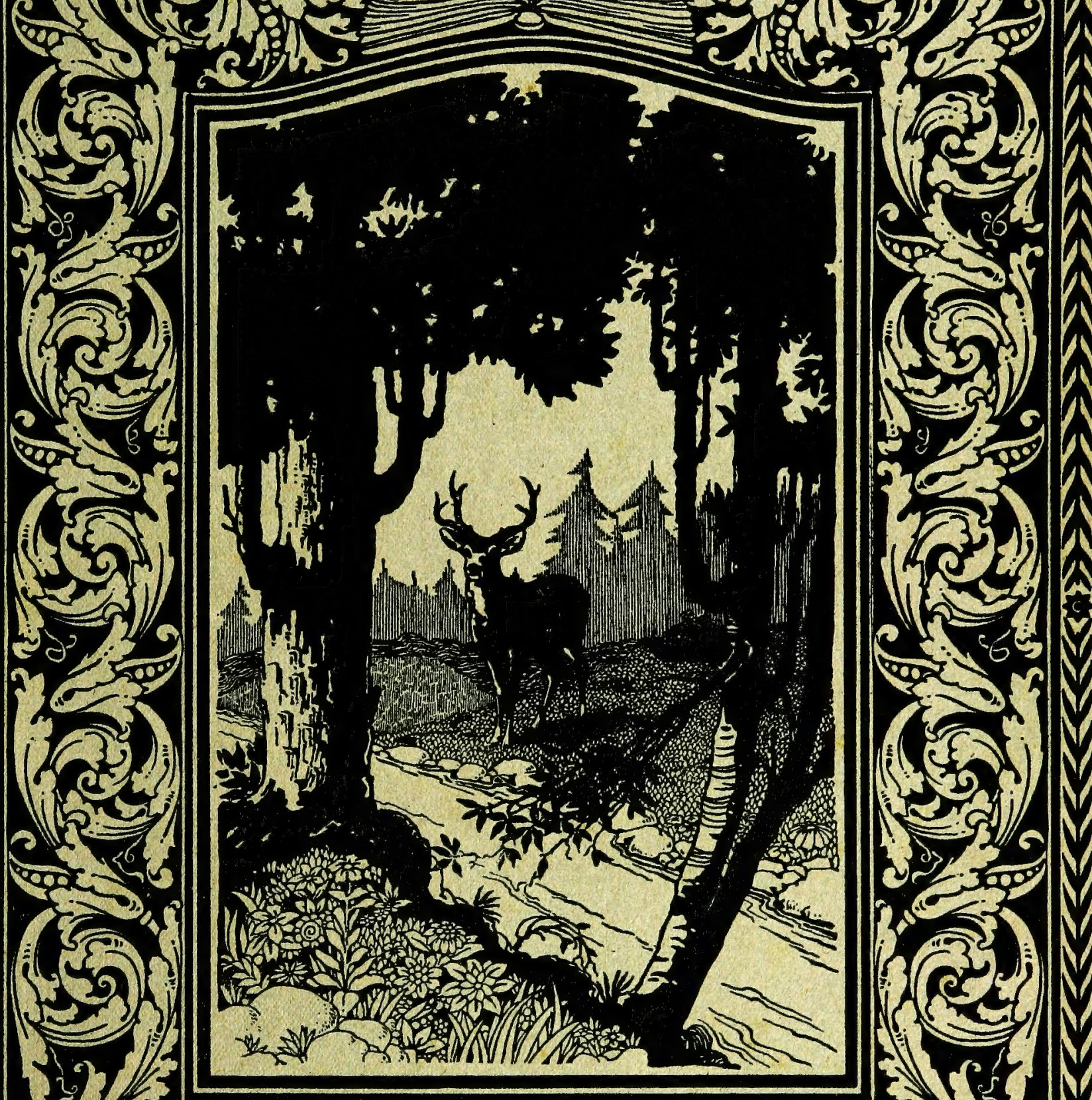

3 
